\title{
Wind and Seismic Effects
}

Proceedings of the 28th Joint Meeting

\section{NIST SP 904}

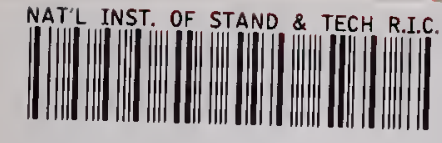

A I1】05 043053
NIST

PUBLICATIONS
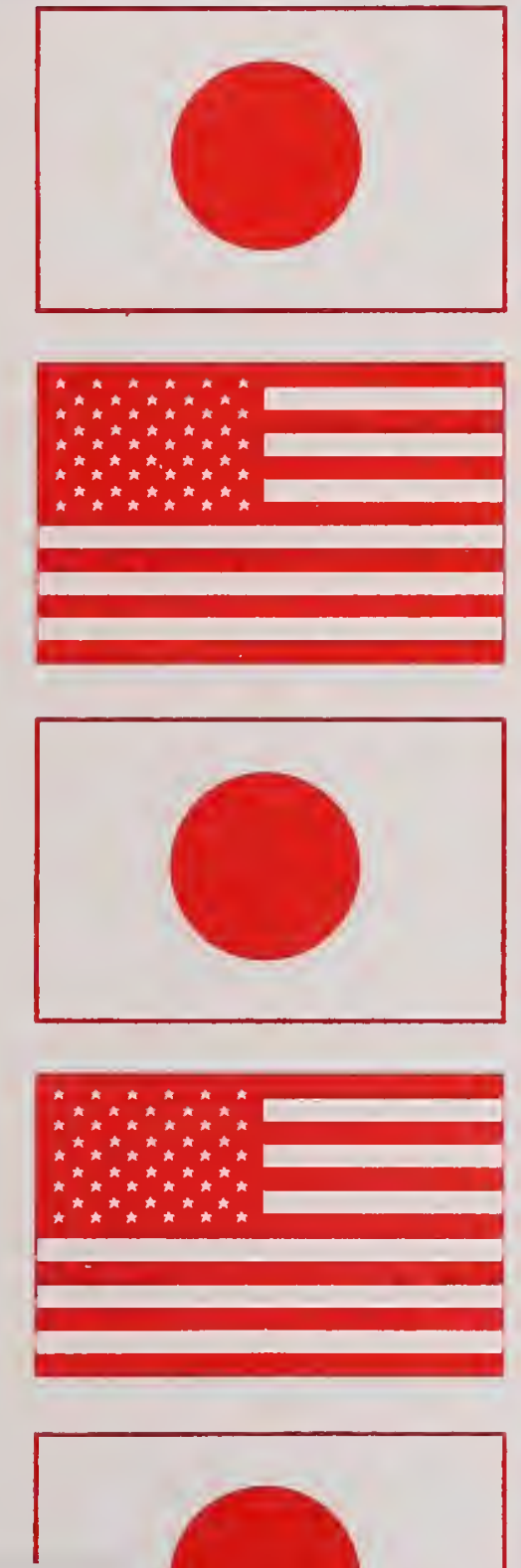

QC

100
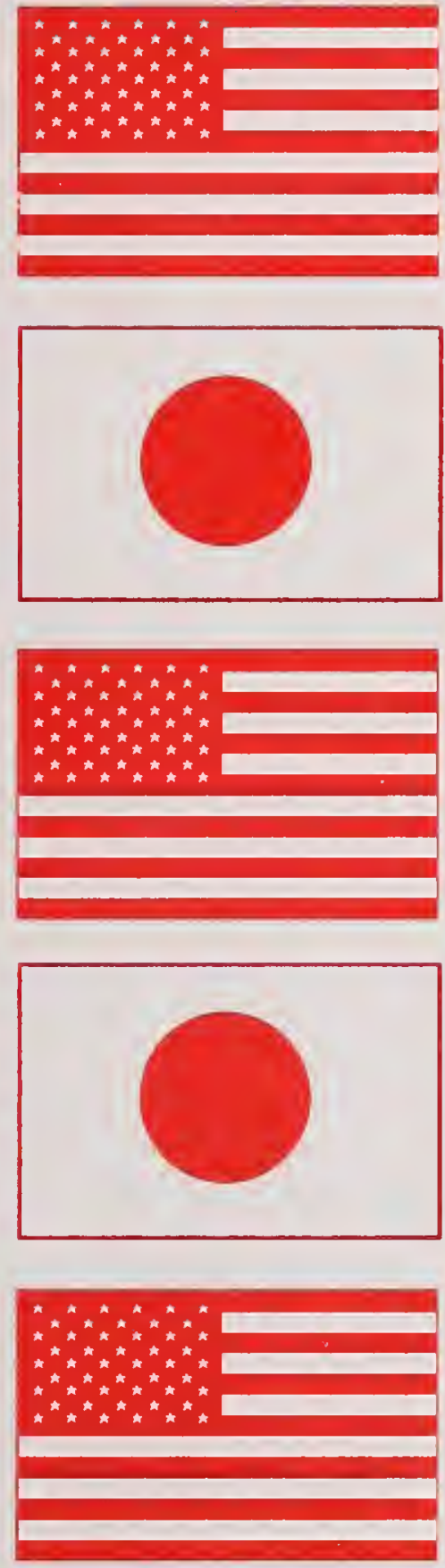
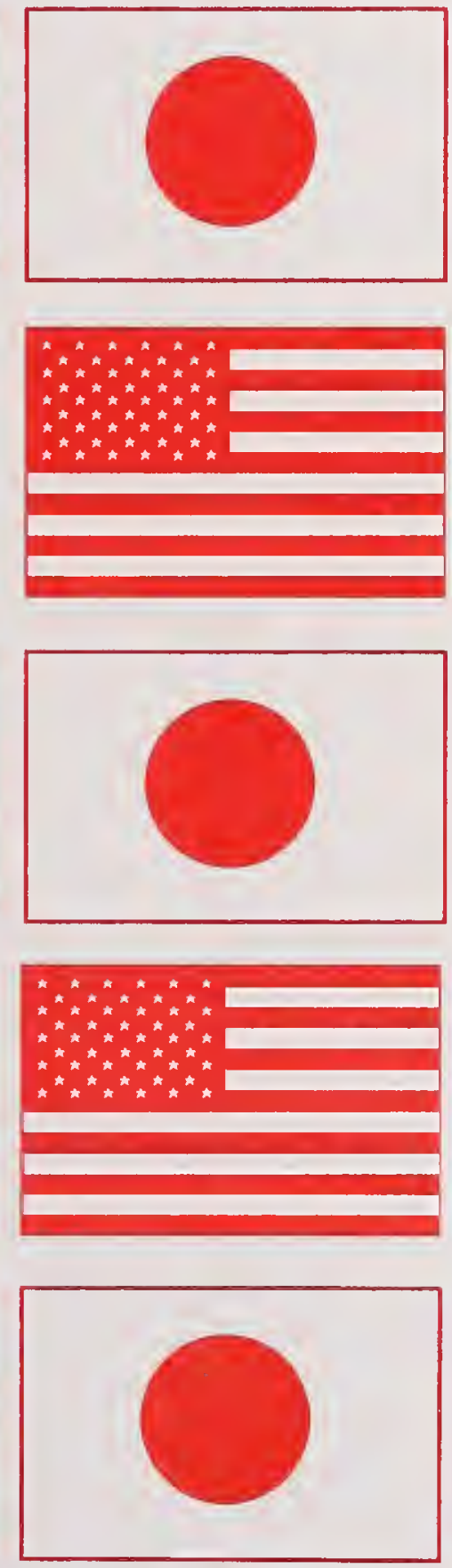
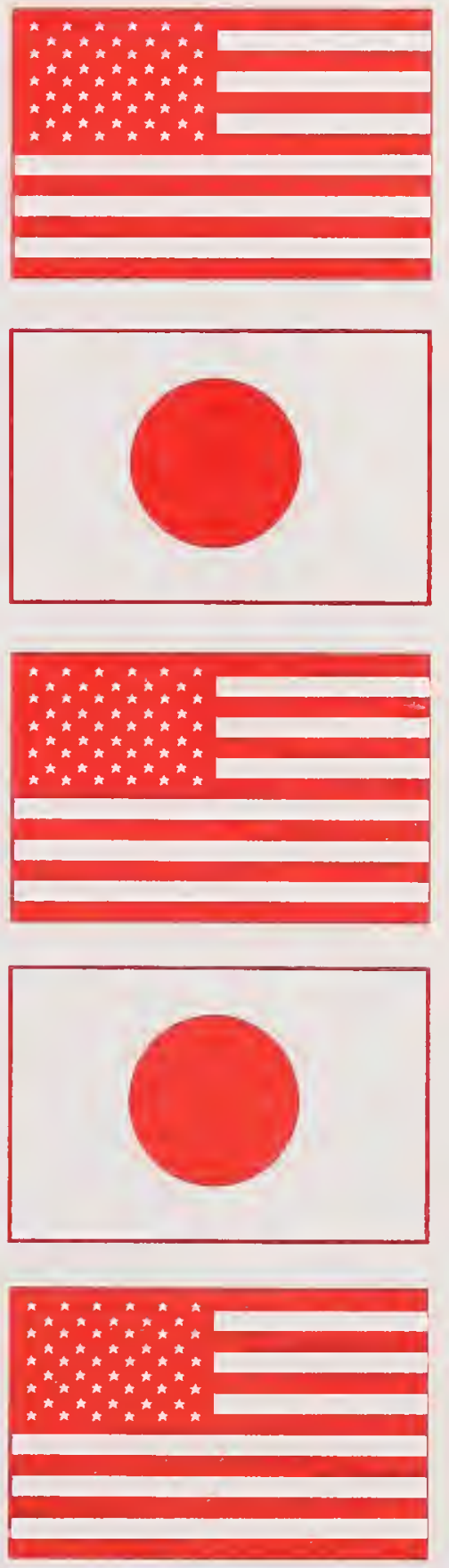

.457

N0.904

1996

U.S. DEPARTMENT OF COMMERCE

Technology Administration

National Institute of Standards and Technology 


\section{$T$}

he National Institute of Standards and Technology was established in 1988 by Congress to "assist industry in the development of technology . . . needed to improve product quality, to modernize manufacturing processes, to ensure product reliability .... and to facilitate rapid commercialization ... of products based on new scientific discoveries."

NIST, originally founded as the National Bureau of Standards in 1901, works to strengthen U.S. industry's competitiveness; advance science and engineering; and improve public health, safety, and the environment. One of the agency's basic functions is to develop, maintain, and retain custody of the national standards of measurement, and provide the means and methods for comparing standards used in science, engineering, manufacturing, commerce, industry, and education with the standards adopted or recognized by the Federal Government.

As an agency of the U.S. Commerce Department's Technology Administration, NIST conducts basic and applied research in the physical sciences and engineering, and develops measurement techniques, test methods, standards, and related services. The Institute does generic and precompetitive work on new and advanced technologies. NIST's research facilities are located at Gaithersburg, MD 20899, and at Boulder, CO 80303. For more information contact the Public Inquiries Desk, 301-975-3058. 


\section{Wind and Seismic Effects}

NIST SP 904

PROCEEDINGS OF

THE 28TH JOINT

MEETING OF

THE U.S.-JAPAN

COOPERATIVE PROGRAM

IN NATURAL RESOURCES

PANEL ON WIND AND

SEISMIC EFFECTS

Issued August 1996

Noel J. Raufaste, EDITOR

Building and Fire Research Laboaratory National Institute of Standards and Technology

Gaithersburg, MD 20899-0001

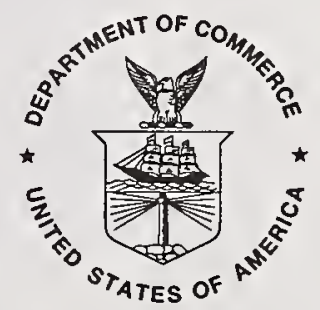

U.S. DEPARTMENT OF COMMERCE

Michael Kantor, Secretary

TECHNOLOGY ADMINISTRATION

Mary L. Good, Under Secretary for Technology

National Institute of Standards and Technology

Arati Prabhakar, Director 
National Institute of Standards and Technology Special Publication 904 Natl. Inst. Stand. Technol. Spec. Publ. 904, 613 pages (Aug. 1996)

CODEN: NSPUE2

\section{U.S. GOVERNMENT PRINTING OFFICE}

WASHINGTON: 1996

For sale by the Superintendent of Documents, U.S. Government Printing Office, Washington, DC $20402-9325$ 


\section{PREFACE}

This publication contains the Proceedings of the 28th Joint Meeting of the U.S.-Japan Panel on Wind and Seismic Effects. The meeting was held at the National Institute of Standards and Technology in Gaithersburg, Maryland during 14-17 May 1996. Forty-six papers were written, 21 by U.S. members and 25 by Japanese members. Thirty-four papers were presented orally; 16 by the U.S.-side and 18 by the Japan-side. The papers were organized into five themes: Wind Engineering; Earthquake Engineering; Storm Surge and Tsunamis; Summary of Joint Cooperative Research Programs; and Report of Task Committee Workshops conducted during the past year. Also, eight papers were presented at two mini-symposia during the technical site visit segment of the Joint Panel Meeting, four from each side. The papers were presented at the University of Minnesota, Minneapolis and at the Oregon Department of Geology and Mineral Industries, Portland. The Japan-side papers are included in these proceedings in the section, Japan-side Papers Presented at Mini-Symposia.

\section{BACKGROUND}

Responding to the need for improved engineering and scientific practices through exchange of technical data and information, research personnel, and research equipment, the United States and Japan in $196 \mathrm{l}$ created the U.S.-Japan Cooperative Science Program. Three collateral programs comprise the Cooperative Science Program. The U.S.-Japan Cooperative Program in Natural Resources (UJNR), one of the three, was created in January 1964. The objective of UJNR is to exchange information on research results and exchange scientists and engineers in the area of natural resources for the benefit of both countries. UJNR is composed of 16 Panels each responsible for specific technical subjects.

The Panel on Wind and Seismic Effects was established in 1969. Nineteen U.S. and seven Japanese agencies participate with representatives of private sector organizations to develop and exchange technologies aimed at reducing damages from high winds, earthquakes, storm surge, and tsunamis. This work is produced through collaboration between U.S. and Japanese member researchers working in 11 task committees. Each committee focuses on specific technical issues, e.g., earthquake strong motion data. The Panel provides the vehicle to exchange technical data and information on design and construction of civil engineering lifelines, buildings, and water front structures, and to exchange high wind and seismic measurement records. Annual meetings alternate between Japan and the United States (odd numbered years in Japan; even numbered years in the United States). These one-week technical meetings provide the forum to discuss ongoing research and research results; oneweek technical study tours follow the meetings.

The National Institute of Standards and Technology (NIST) provides the U.S.-side chair and secretariat. The Public Works Research Institute (PWRI), Japan, provides the Japan Side chair and secretariat. 
Cooperative research is done through formal Panel Programs. In 1981, cooperative research in Large-Scale Testing was started under the auspices of the Panel. Also, in 1981, joint research on Reinforced Concrete Structures was initiated. Full-scale testing was performed at the Building Research Institute (BRI), one of the six Japanese members' organizations, with supporting tests in Japan and in the United States Two years later, a joint research program on Steel Structures was initiated. Full-scale testing again was led by BRI with supporting tests in the United States and Japan. The U.S.-Japan coordinated program for Masonry Building Research was started in 1985. A U.S.-Japan coordinated program on Precast Seismic Structural Systems was initiated in 1991. A joint program on Seismic Performance of Composite and Hybrid Structures was initiated in 1993. In 1994, a joint program was started on Physical and Numerical Simulation of Structural Damages Due to Liquefaction and Development of Countermeasure Techniques.

Task Committee meetings, exchanges of data and information through technical presentations at annual Panel meetings, exchanges of guest researchers, visits to respective research laboratories and informal interactions between Panel meetings, joint workshops and seminars, and joint cooperative research programs all contribute to the development and effective delivery of knowledge that has influenced design and construction practices in both countries. Guest research exchanges have advanced the state of technology in areas of steel, concrete, and masonry structures under seismic forces; developed techniques to analyze risks from liquefaction; modeled water seepage in dam foundations; performed comparative analyses of seismic design of U.S. and Japanese bridges.

Direct communication between counterpart country organizations is the cornerstone of the Panel. Effective information exchanges and exchanges of personnel and equipment have strengthened domestic programs of both countries. There are opportunities for experts in various technical fields to get to know their foreign counterparts, conduct informal exchanges, bring their respcctivc views to the frontiers of knowledge, and advance knowledge of their specialties.

The Panel's activities rcsulted in improved building and bridge standards and codes and design and construction practices in hydraulic structures in both countries, for example:

- created and exchanged digitized earthquake records used as the basis of design and research for Japan and the United States;

- transferred earthquakc engineering information and strong-motion measurement techniqucs for use by scismically active countries, e.g., Australia, Canada, Italy, Mexico, Peru, Taiwan, Turkey, and North Africa;

- produced data that advanced retrofit techniques for bridge structures;

- developed field test data for use in aerodynamic retrofit of bridge structures;

- produced full-scale test data that advanced seismic design standards for buildings;

- advanced teclınology for repairing and strengthening reinforced concrete, steel, and masonry structures;

- improved in-situ measurement methods for soil liquefaction and stability under seismic 
loads;

- created a database comparing Japanese and U.S. standard penetration tests to improve prediction of soil liquefaction;

- created a database on storm surge and tsunamis and verified mathematical models of tsınami and storm surge warning systems;

- established a library resource of current research on wind and earthquake engineering and on storm surge and tsunamis;

- published proceedings of Panel meetings, Task Committee Workshops, and special publications such as List of Panel Publications and translated two-volume series on earthquake resistant construction using base isolation systems;

gained better knowledge of both countries' research, design, and construction capabilities from in-depth visits to the host country's laboratories and building and public work projects. Results of such visits contribute to creation of new Task Committees, agendas for Joint Panel meetings and task committee workshops, special visits of U.S.-Japan researchers, and joint collaborative research.

\section{HIGHLIGHTS OF THE TECHNICAL SITE VISITS}

Eight technical sites were visited at four geographic locations during the 28th Joint Panel Meeting.

\section{Washington, DC}

\section{Ronald Reagan Federal Triangle Building}

This $298000 \mathrm{~m}^{2}$ Federal office building, on 4.5 hectares of land in central Washington, DC, completes Congress' 1972 plan to redevelop the Federal Triangle; and the periphery of Pennsylvania Avenue, Constitution Avenue, and 14th Street. The building's main function is to serve as a trade center.

Congress created the Pennsylvania Avenue Development Corporation (PADC) in 1972, along with the General Services Administration (GSA), to provide oversight to all construction within the Federal Triangle. In the Winter of 1995, U.S. budget cuts forced elimination of PADC's role one-year before it scheduled close-down. Congress assigned GSA's National Capital Region with full responsibility to manage the completion of this $\$ 720$ million project through 1997 when GSA will take ownership of the building and begin repaying the construction loan from rent collected by GSA tenants. While this facility is a Federal building, it was not funded by appropriations. Loans were secured from the Federal Financing Bank.

Site construction started in 1991; more than $840000 \mathrm{~m}^{3}$ of earth was excavated. Since the water level is about $4 \mathrm{~m}$ below strect level, a $1 \mathrm{~m}$ thick perimeter slurry wall was constructed down to bed rock about $27 \mathrm{~m}$ below street level. The wall is anchored into rock stratums. The water level could not be drawn down because neighboring buildings are on timber piles. Over $191000 \mathrm{~m}^{3}$ concrete was used for this cast-in-place trade center. About 33700 metric tons 
of epoxy coated reinforcing rods were used and more than 1730 metric tons of structural steel. Below grade concrete girders, some $4 \mathrm{~m}$ deep and $24 \mathrm{~m}$ long, transfer loads onto the $9 \mathrm{~m}$ by 18 $\mathrm{m}$ grids for the $33400 \mathrm{~m}^{2}$ parking. The building's facade is faced with $6650 \mathrm{~m}^{3}$ of Indiana limestone.

The height of the building conforms to Washington, DC Fine Arts Commission's $33.5 \mathrm{~m}$ height limitation (not to exceed the height of the U.S. Capitol) and design (conforms to the neoclassical style of its 1920's and 1930's-era neighbors). However, its interior is contemporary with a half-cone-shaped atrium, curved wall mirrors, large auditorium, and $37000 \mathrm{~m}^{2}$ space for exhibitions, restaurants, and private-sector trade-related offices.

\section{Smithsonian Quadrangle Museums}

The delegation visited the underground $34000 \mathrm{~m}^{2}$ museum designed for the Smithsonian Institution to house its vast art collection from Japan and Africa. Opened in 1987, the Quadrangle Museums comprise the National Museum of African Art and the Arthur M. Sackler Gallery and an education center, the S. Dillion Rippley Center. To satisfy Washington, DC Commission of Fine Art's concerns about constructing a new museum on this site, the Smithsonian lnstitution proposed and received approval to construct the African and Asian art museums below ground. Only five percent of its volume would be above ground. This design permitted unimpeded visibility of the original Smithsonian Institution Building, known as the Renwick "Castle" (1855), from Independence Avenue. The layout, to hold this vast collection, involved three levels of viewing space below grade. It was designed to local seismic code. A 20 m slurry wall was constructed along with 27 dewatering wells. Since a high water table was present, a $2.6 \mathrm{~m}$ double slab was constructed as ballast to prevent upheaving and a double wall construction to reduce moisture migration into the museum spaces further. Soil $1 \mathrm{~m}$ to $2 \mathrm{~m}$ thick was placed on the roofs for construction of a public garden. An underground passage connects to an adjourning art museum -- the Freer Gallery.

\section{Miami, FL}

\section{The National Hurricane Center, National Oceanic and Atmospheric Administration}

The National Hurricane Center (NHC), maintains a continuous watch on tropical storms over the Atlantic, Caribbean, and Gulf of Mexico from 15 May through 30 November. The Center prepares and distributes hurricane watches and wamings for the public, and prepares and distributes marine and military advisories for other users. NHC coordinates with Hurricane Warning Offices, Weather Service Forecast Offices, and Weather Service Offices when a tropical storm threatens the United States. The Center prepares and distributes probabilities of hurricane/tropical storm conditions for 45 locations along the East and Gulf coasts.

NHC conducts R\&D to improve tropical storm forecasting and concentrates on transferring theoretical advances to operational forecasting. Within NHC is the Aerial Reconnaissance Coordination All Hurricanes Unit that schedules aerial reconnaissance requirements and assigns flying units to meet these requirements. Data from the reconnaissance aircraft is down- 
linked from satellites and provided to the hurricane specialist for forecasting and waming.

Tropical storm position estimates are issued between 2-hourly intermediate advisories whenever a storm with a well-defined radar center is within 200 nautical miles of land-based radar in the United States. These estimates give the center location in map coordinates and distance and direction from a well-known point.

NHC is improving its ability to: forecast a storm strike at a landfall because evacuation of people costs about $\$ 1$ million per $1.6 \mathrm{~km}$ (not including costs of closing down businesses) and to develop better prediction and 3-D models. Forecasting predictions have improved at the rate of about 1 percent a year over the last 20-years (from 120 to 100 nautical miles out). Since more than 50 million people live along the east U.S. coast to Texas, NHC places high priority toward improving forecasting accuracy.

HRC's Hurricane Research Division (HRD) is concerned with tropical meteorology using radar and instrumented aircraft. HRD produces real-time surface wind analysis for major storms giving forecasters better data. HRD is improving future real-time surface wind analysis and storm surge modeling and developing products for emergency management officials for post storm search and rescue cfforts, damages assessments, and recovery efforts. HRD's staff total 30 persons who are operating with $\$ 4$ million budget.

\section{Homestead, FL}

\section{Habitat for Humanity}

Following the 1992 Hurricane Andrew, a 18 hectare site known as Jordan Commons, Homestead, Florida was selected as the site for 187 dwelling units that replace housing destroyed by the Hurricane. Jordan Commons is one of many self-help, sweat-equity housing projects established throughout the United States under the auspices of Habitat for Humanity. Here, qualified families are required to donate 400 hours of their time toward the construction of their homes. Forty units will be constructed using all steel frames. The other homes are constructed of reinforced masonry blocks -- the traditional building material in southern Florida. All units will be fully insulated and equipped with solar water heating systems. Each unit cost $\$ 75,000$ paid over 20 years or 30 years, interest free. This community features a sustainable environment. All construction materials are recycled.

The project site was selected by HUD which has teamed with the National Association of Home Builders Rescarch Center (NAHBRC) to provide the technical assistance in construction code approval and buildcr education. Assembly of cold formed steel members is performed onsite. The American Iron and Steel Institute (AISI) donated the steel for framing and produced a training manual for owncrs and contractors who are constructing the houses. NAHBRC provides quality control methods through use of their research facility and seminars and oneweek, hands-on, stecl framing construction training for carpenters, builders, and new owners of these residences. 
Building codes have been revised as a result of damages sustained from the 1992 Hurricane. Building codes now require low rise buildings to resist lateral wind velocity of $52 \mathrm{~m} / \mathrm{s}$ and wind borne missiles traveling at $15 \mathrm{~m} / \mathrm{s}$.

Since the use of cold formed steel for frame construction is not explicit in the building code, prototype housing will be evaluated for performance and cost. NAHBRC developed performance criteria of the steel framing and recommended lateral bracing to meet local building codes. The residences' exterior walls are $16 \mathrm{~mm}$, 4-ply plywood; all windows require functional shutters. The steel exterior $\mathrm{C}$-shaped wall studs are $1.1 \mathrm{~mm}$ (43 mils) thick. Headers and beams are $1.4 \mathrm{~mm}$ ( 58 mils) thick. The exterior wall studs are about 30 percent thicker than minimum code requirements.

\section{Minneapolis, Minnesota}

\section{St. Anthony Falls Hydraulic Laboratory, University of Minnesota} The Laboratory is part of the Department of Civil and Mineral Engineering, University of Minnesota. Its focus is on fluid mechanics, waters resources engineering, and aerodynamics and wind engineering. Their principal facilities include a glass walled flume to study pressure fluctuations in hydraulic-jump spillways and turbidity currents; $76 \mathrm{~m}$ multipurpose river channel used to study navigation conditions and develop geometries for water facilities and structures; and the 7.5:1 contraction boundary Layer Wind Tunnel high-speed test section measures $1.7 \mathrm{~m}$ by $1.8 \mathrm{~m}$ in cross section by $16 \mathrm{~m}$ long, with velocities up to $45 \mathrm{~m} / \mathrm{s}$. Its lowspeed test section measures $2.4 \mathrm{~m}$ by $2.4 \mathrm{~m}$ by $18 \mathrm{~m}$ long, with velocities up to $19 \mathrm{~m} / \mathrm{s}$, in the return leg of the tunncl. The wind tunnel is available under contract. Recent past studies include the flow of wind around buildings and determination of the peak and fluctuation pressures on buildings.

The Hydraulic Laboratory's budget supports seven staff and graduate students. The budget varies between $\$ 1-2$ million annually with a typical project costing about $\$ 150,000$. The budget for the wind tmnel is about $\$ 250,000$.

During this visit, the delegation conducted a mini-symposium featuring four papers, two by wind tunnel graduate students:

- Review of On-going Research on Effect of Turbulence on Mean and Fluctuation Pressures of Buildings and

- Wind Tunnel Simwlation of Atmospheric Boundary Layers

and two from the Japan-side:

- New Evaluation Teclnique of Wind Loads on External Building Elements by Hisashi Okada, of BRI and

- Wind Tunnel Study on Long-Span Bridges Conducted at the Large Boundary Layer Wind Tunnel by Hiroshi Sato of PWRI.

Discussions followed cach paper. Professor Farell, our host, discussed his research on wind loading around circular cylinders including cooling towers and distributed related papers. 


\section{Eden Prairie, Minnesota}

\section{MTS Systems Corporation}

MTS was founded in 1962 as the Mechanical Testing and Simulation Company to perform aerospace stress simulations and matcrial performance testing for transport and experimental aircraft. Today MTS is:

o developing vehicle testing and software control technology to replicate test track conditions in the laboratory,

- performing civil enginecring testing including simulations of material testing systems for rock, soils, and concretc, and

- developing actuators and controls for large scale test facilities.

Eight percent of its revenue from the approximate $\$ 150$ million sales is put back in to research. MTS's enginecring and management data are available through its internal web site.

Following a tour of the facilitics, the delegation learned about MTS's future direction of dynamic testing using large-scale structural test facilities. Currently MTS is developing Japan's Public Works Research Institute's shake table to replicate the loading from the Hyogoken Nanbu (Kobe) Earthquake. Also, they provided the major components for Japan's Science and Technology Agency's National Rescarch Institute for Earth Scicnce and Disaster Prevention large shake table. MTS said its future is in producing modular multi-span portable shake tables such as the $2-45$ ton $14 \mathrm{~m}$ by $14 \mathrm{~m}$ tables being designed for the University of Nevada under FEMA sponsorship. MTS, in collaboration with MIT, is studying a large scale seismic simulator for the Idaho National Enginecring Laboratory. Work is underway to perform in-situ, artificial earthquake tests for highway bridges using SRI/MTS' RESCUE Technique (Repeatable Earthquake Shaking by Controlled Underground Explosives).

\section{Portland Oregon}

\section{CORPS Portland Earthquake Engineering District}

The delegation visited the CORPS Portland District Offices and on another day the CORPS' Bonneville Dam, located about $60 \mathrm{~km}$ east of Portland that spans the Columbia River separating Oregon and Washington States. Staff from the Structural and Architecture Design Section presented a comprehensive and lively revicw of the Districts' responsibilities about seismic design and construction and provided a set of the latest CORPS earthquake related design manuals:

- Dam Safety. The District manages 21 multipurpose hydroelectric power dams; provides dam safety and evaluation, emergency action plans, and dam safety training programs. The District enacted scismic studies of dam safety programs in 1990 and in 1994 established more stringent requirements based on new findings of Oregon's earthquake ground motion. Scismic evaluations must be done for all projects in Zone 2 and greater. Dynamic response stress analysis is required in seismic Zone 2 or greater when the sitespecific peak ground motion is $0.15 \mathrm{~g}$ or greatcr. During the early 1990 's, seismic risk of northem Oregon has been changed from Zone 2 to Zone 3. The District is reevaluating the maximum credible earthquake values considering new earthquake sources and 
evaluating critical structures to assure that they meet project safety requirements. There is consideration of using GPS to monitor dams' performance.

Ground Motion Studies. District staff is mapping fault zones and estimating earthquake damage along non-known faults where earthquakes are envisioned to occur. Based on new knowledge, the District staffs are revising project design criteria guidelines to ensure uniform revisions are made to highways, bridges, dams, and buildings. Seismic Analysis of Embankment Dams. Based on recent data, the District Office has revised its dam safety evaluation guidelines for liquification potential and embankment deformations. The design procedures used for embankment dams are in the engineering manual, Stability of Eartl and Rockfill Dams that uses a static analysis with an additional horizontal force (calculated based on the seismic coefficient for the region). These analyses are based on Simplified Procedures for Evaluating Soil Liquification Potential and Rationalizing the Seismic Coefficient Method.

Seismic Technical Center. The Center conducts seminars on lifeline safety and training, determines the vulnerability of Army facilities against earthquakes, develops databases on civil works' facilities and cost estimates to remedy the damaged facilities, develops recommendations to revise the CORPS' Energency Manual on Evaluating Lifelines, and develops seismic information bulletins and the CORPS' Engineering Manual. The Center is collaborating with the Air Force in its development of an Air Force Lifelines Assessment Manual. The staff participates in the Interagency Committee on Seismic safety in Construction and in civil and military seismic oversight groups. Bonneville Seismic Rehabilitation. The original dam, powerhouse, and lock were constructed during 1933 to 1937; a second powerhouse was constructed between 1974 and 1981. Result from the District's latest dam safety assurance evaluation shows the dam is adequate for current stability requirements. Now, there is a reassessment underway of the reinforced downstream piles for the original powerhouse. Initial analysis showed the up stream end and intermediate pilasters would be stressed beyond yield under the more stringent earthquake requirements. The main intake piers at the intake roof and the intake roof itself were determined to be areas of vulnerability under the more stringent requirements. The District will perform further strength evaluation based on consideration on nonelastic energy dissipation behavior, response modification factors and ductility of concrete structures. In addition, a 2-D and 3-D localized models of up stream and down stream wall-roof system will be done.

\section{Portland Oregon}

\section{Oregon Department of Geology and Mineral Industries (DGMI)}

The Department's mission concerning natural disaster reduction includes: providing a costeffective source of geological information for State citizens and using that information to create partnerships for reducing life loss and property damage from geologic hazards; serving as experts on the state's geologic processes; and serving as the State's entry point to recommend geologic hazards safety legislation. Before 1975, there were no seismic requirements for constructing buildings in Oregon. Based on findings from various seismic vulnerability and zonation studies of the carly and mid-1980's greater attention has been given to better 
designing against seismic loads. Seismic records show the Portland Greater Metropolitan Area experienced 5-10 reasonably large carthquakes during the past 100 years. As instrumentation improved, greater number of seismic records were detected. Before 1993, Oregon was designated a Zone 2 level of risk; now North Oregon is designated, Zone 3. Recent studies revealed a large earthcyuake could result in $\$ 127$ billion of damages to buildings in Portland. About 50 percent of the State's buildings were constructed before seismic design criteria were available. The costs to rehabilitate these buildings are estimated at $\$ 16$ billion; too costly for the State to fund. DGMI has identified the highest risk unreinforced masonry buildings. The estimated cost to retrofit these buildings is $\$ 2$ billion. A recent Department report

recommends: develop a State wide seismic standard; create an inventory of buildings; increase State seismic engineering expertise; identify financial incentives that will speed seismic retrofit alterations; and stress education to achieve public support for raising the needed money to realize seismic retrofit. A Dcpartment Task Force is performing a triage of the most important actions based on available funding. Their schedule of actions includes: a 5-year plan to perform an inventory of State buildings; a 15-year plan to complete the necessary rehabilitation of triaged buildings; and a 75-100 year plan where all buildings will either have been retrofitted or were constructed during the 21 st century.

A mini-symposium was held featuring four papers; two from the Japan-side include:

- A Seisulic Retrofitting Metlod for Reinforced Concrete Bridge Piers by Hisanori Otsuka, Jun-ichi Hoshikuma and Kazuhiro Nagaya of PWRI and

- Experimental Study ou the Bearing Capacity of Cast-In-Place Concrete Piles Damaged by the Hanslin Eartliquake by Hiroyuki Nakajima, Hidenao Hayashi and Kenji Kosa of the Hanshin Expressway Public Corporation.

DGMI presented two papers:

- Eartliquake Risk inl Oregon by Matthew Mabey from DGMI and

- Discussion of the Draft Report Prepared by DGMI's Seismic Rehabilitation Task Force by David Bugni of DGMI.

Following discussion, the delegation visited three unreinforced masonry buildings undergoing seismic retrofit:

Pioneer Federal Courthousc. This historic building is being proposed for retrofit with base isolation. Three types are under consideration: high damping rubber; lead rubber; and friction pendulum. Shear wave velocities tests were performed in a $100 \mathrm{~m}$ hole to characterize the soil conditions around the building and to develop base isolation specifications. The basement floor will be replaced to permit installation of 50-70 base isolators. The estimated cost for this job is $\$ 13$ million.

Multnomah County Library. This partially reinforced 1912 building was constructed of clay tile infills (inside) and its exterior is of masonry infills. The building experienced high uplift loads in the basement causing walls to buckle. The building has a stiff diaphragm pans in place and reinforced concretc beams. A conventional seismic retrofit program commenced in 
1994 consisting of retrofitting the foundation using pin piles to tie it to the earth. The estimated retrofit cost is expected at $\$ 25$ million.

Multnomah Hotel. This 1910 abandoned building was one of Portland's finest hotels. The Eshape building, in cross-section, is constructed of lightly reinforced concrete frames and infill masonry walls. Embassy Suites Hotel Corporation purchased the building and is retrofitting it for seismic safety. Thirty- $12 \mathrm{~m}$ pin piles were installed to tie the foundation to the ground. Shear walls were installed from its basement to the top of the building. They are tied into existing columns; three in the E-W direction and four in the N-S direction. Gunite was used to face the walls. Drag bars were installed on the third floor to transfer the tension loads to the shear walls. Struts were installed between the wings and the gunite faced shear walls for structural stability. The cost of this retrofit is $\$ 20$ million; $\$ 1.5$ million for the structural retrofit.

Noel J. Raufaste, Secretary-General

U.S.-side Panel on Wind and Seismic Effects 


\begin{abstract}
This publication is the Proceedings of the 28th Joint Meeting of the U.S.-Japan Panel on Wind and Seismic Effects. The meeting was held at the National Institute of Standards and Technology, Gaithersburg, Maryland, during 14-17 May 1996. The Proceedings include the program, list of members, panel resolutions, task committee reports, and the 46 technical papers written for this joint meeting.

The papers were presented within five themes: 1. Storm Surge and Tsunamis, 2. Earthquake Engineering, 3. Joint Cooperative Research Program, 4. Wind Engineering, and 5. Summaries of Task Committee Workshop Reports (oral presentations only).

KEYWORDS: Bridges; building technology; concrete; design criteria; disaster reduction; earthquakes; geotechnical engineering; ground failures; lifelines; liquefaction; masonry; repair and retrofit; risk assessment; seismic; standards; storm surge; structural engineering; tsunamis; and wind loads.
\end{abstract}





\section{CONTENTS}

PREFACE $\ldots \ldots \ldots \ldots \ldots \ldots \ldots \ldots \ldots \ldots \ldots \ldots \ldots \ldots \ldots \ldots \ldots \ldots \ldots \ldots \ldots \ldots \ldots \ldots \ldots \ldots \ldots \ldots \ldots \ldots$

ABSTRACT $\ldots \ldots \ldots \ldots \ldots \ldots \ldots \ldots \ldots \ldots \ldots \ldots \ldots \ldots \ldots \ldots \ldots \ldots \ldots \ldots \ldots \ldots \ldots \ldots \ldots$

AGENDA FOR 28TH JOINT PANEL MEETING $\ldots \ldots \ldots \ldots \ldots \ldots \ldots \ldots \ldots \ldots \ldots \ldots \ldots$

LIST OF PANEL MEMBERS $\ldots \ldots \ldots \ldots \ldots \ldots \ldots \ldots \ldots \ldots \ldots \ldots \ldots \ldots \ldots \ldots \ldots \ldots \ldots \ldots$ xxvii

LIST OF TASK COMMITTEE MEMBERS $\ldots \ldots \ldots \ldots \ldots \ldots \ldots \ldots \ldots \ldots \ldots \ldots \ldots \ldots \ldots$ Ivii

RESOLUTIONS $\ldots \ldots \ldots \ldots \ldots \ldots \ldots \ldots \ldots \ldots \ldots \ldots \ldots \ldots \ldots \ldots \ldots \ldots \ldots \ldots \ldots \ldots \ldots \ldots \ldots \ldots \ldots \ldots$

THEME I: Storm Surge and Tsunamis

U.S. Operational Storm Surge Forecast Models ....................... 3

Wilson A. Shaffer and Jye Chen

Long-term Shoreline Change in Japan $\ldots \ldots \ldots \ldots \ldots \ldots \ldots \ldots \ldots \ldots \ldots \ldots \ldots \ldots$

Shigenobu Tanaka

Assessment of Hurricane Opal Impact on East Pass Florida with Airborne Lidar . . . . . . 23

William E. Roper

THEME II: Earthquake Engineering

Mitigation of Lateral Flow of Liquefied Ground .................... 39

Ikuo Towhata, Yoshihiro Kogai, Kei Amimoto, and Hendri Gusti Putra

Evaluation of Liquefaction Potential Using the CPT .................. 53

Richard S. Olsen, Joseph P. Koester, and Mary E. Hynes

Estimation of Effects of Liquefaction-Induced Ground Flow on Bridge Foundations . . . . 69

Keiichi Tamura, Yoshio Ninomiya, and Tadashi Hamada

Preliminary Guidelines for Liquefaction Assessment Using Shear Wave Velocity . . . . . . 77

Ronald D. Andrus and Kenneth H. Stokoe, II

Damage Investigation of Steel Buildings in Specific Areas Observed from the 1995

Hyogoken-Nanbu Earthquake ............................ 85

Midorikawa Mitsumasa, Hasegawa Takashi, Mukai Akiyoshi, Nishiyama Isao,

Fukuta Toshibumi, and Yamanouchi Hiroyuki

An Integrated Program to Improve the Performance of Steel Moment Resisting

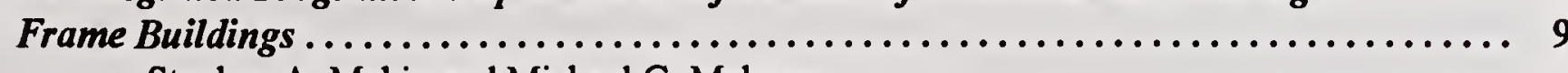

Stephen A. Mahin and Michael G. Mahoney 
Recent Developments in Strong-Motion Attenuation Relationships

William B. Joyner and David M. Boore

Topographical Effect in the Evaluation of Design Ground Motion

I. Okawa, T. Kashima, and S. Koyama

Preliminary Estimates of Ground-Motion Amplification for the Northridge and

Hyogo-ken Nanbu Earthquakes of January 17, 1994 and 1995 .................

Roger D. Borcherdt

Damage to Communication Tunnels Caused by Liquefaction and Other Phenomenon

During the Hanshin-Awaji Earthquake and Future Countermeasures ..............

Yuzo Yamaguchi and Masayuki Tsuchiya

Effect of Load Path on Damage to Concrete Bridge Piers ......................

Andrew W. Taylor, Ashraf El-Bahy, William Stone, and Sashi Kunnath

Guide Specifications for Reconstruction and Repair of Highway Bridges Which

Suffered Damage Due to the Hyogo-ken Nanbu Earthquake ....................

Kazuhiko Kawashima, Kazuhiro Nishikawa, Masanori Nakano, Shigeki Unjoh,

Yoshitomi Kimura, and Jun-ichi Hoshikuma

Comparison of U.S. and Japanese Highway Bridge Column Seismic Design ...........

W. Phillip Yen, James D. Cooper, Hisanori Otsuka, and Toru Terayama

Residual Displacement Response Spectrum and its Application to Reinforced

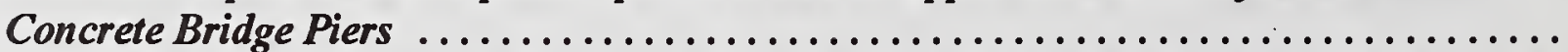

Kazuhiko Kawashima, Gregory A. MacRae, Jyun-ichi Hoshikuma, and Kazuhiro Nagaya

Analysis of Damaged Foundations of Highway Bridges in the 1995 Hyogo-ken

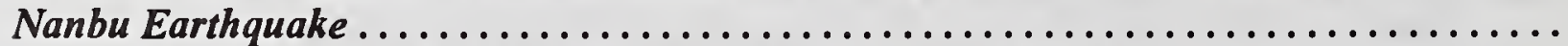

Michio Okahara, Masanori Nakano, and Yoshitomi Kimura

Evaluation of Fault Rupture Geometry on Design Ground Motions ..............

D.R.H. O'Connell, and J.P. Ake

Damage to Port Facilities of KOBE Port by the 1995 Hyogo-ken Nanbu Earthquake

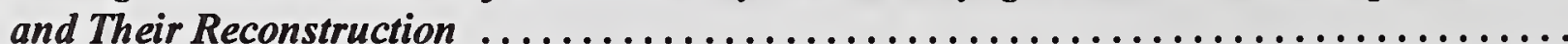

Tatsuo Uwabe, Ken Oikawa, Tatsuo Wako, and Takahiro Sugano

Major Factors of Damages of Reinforced Concrete Buildings due to the 1995

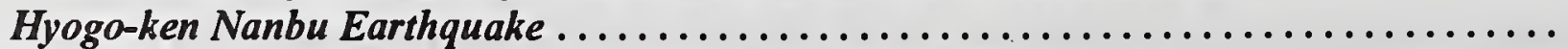

H. Hiraishi, T. Kaminosono, M. Teshigawara, and S. Nakata

Push Over Laboratory Testing of Unreinforced Masonry Infills

Ghassan Al-Chaar, Steve Sweeney, and Parmalee Brady

Designs and Techniques for the Restoration of the Earthquake-Damaged

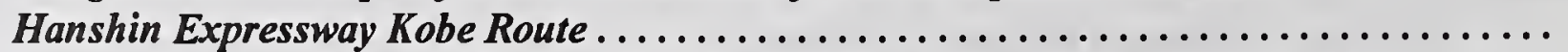

Hisamori Ohtsuka, Hiroyuki Nakajima, Hidenao Hayashi, and Kenji Kosa 
Action and Concept on Performance-Based Design and Engineering System

in Japan ............................................. 285

Hiroyuki Yamanouchi, Hisashi Okada, and Yuji Ohashi

Composites for Construction

John B. Scalzi

Arrangement of Kyoshin Net

Keiichi Ohtani, Shigeo Kinoshita, and Hiroyuki Fujiwara

Seismic Stability for Sliding of Rockfill Dams

Tadahiko Sakamoto, Tadahiko Fujisawa, Akira Nakamura, and Tomoya Iwashita

THEME III: Summary of Joint Cooperative Research Programs

U.S.-Japan Cooperative Earthquake Research Program on Composite and Hybrid

Structures - Research Progress and Current Status ......................

Subhash C. Goel and Isao Nishiyama

Design of Large-Scale Liquefaction Experiment System .

K. Ishihara, T. Kagawa, N. Ogawa, C. Minowa, K. Sakai, and A. Abe

THEME IV: Wind Engineering

Influence of Vent Configurations on Bridge Response to Wind Harold R. Bosch

Aerodynamic Characteristics of Slotted Box Girders

Hiroshi Sato and Katsuya Ogihara

Wind Engineering Research in the United States Ahsan Kareem and Eleanore Sabadell

Estimation of Relevant Internal Pressure and Wind Loads on Cladding H. Okada and L. Kong

Descriptive Epidemiology of Wind-Related Mortality 381 Josephine Malilay, Annemarie Wasley, and Leslie A. Fiedler

\section{JAPAN-side PAPERS PRESENTED AT MINI-SYMPOSIA}

New Evaluation Technique of Wind Loads on Building External Elements

H. Okada and L. Kong

Wind Tunnel Studies on Long-Span Bridges Conducted at the Large Boundary

Layer Wind Tunnel in Tsukuba

Hiroshi Sato 
A Seismic Retrofitting Method for Reinforced Concrete Bridge Piers and Their

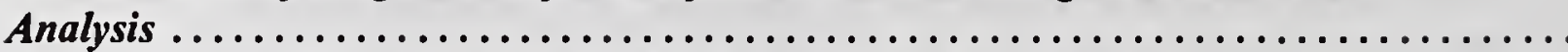

Hisanori Otuska, Jun-ichi Hoshikuma, and Kazuhiro Nagaya

Experimental Study on the Bearing Capacity of Cast-in-Place Concrete Piles

Damaged by the Hanshin Earthquake.

Hiroyuki Nakajima, Kidenao Hayashi, and Kenji Kosa

\section{MANUSCRIPTS AUTHORED FOR PANEL MEETING BUT NOT PRESENTED ORALLY}

Analyses of Liquefaction in the 1995 Hyogo-ken Nanbu Earthquake ..............

Osamu Matsuo, Takao Shimazu, and Tatsuya Tsutsumi

Photogrammetric Measurement of Three Dimensional Ground Surface

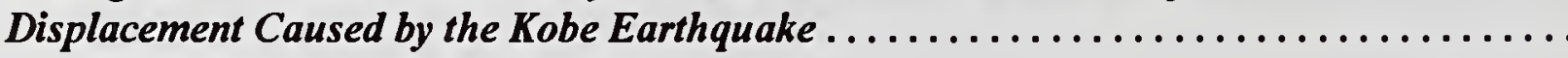

Hiroshi Murakami and Minoru Hoshino

A Real Time System for Forecasting Storm Surges Caused by the Typhoons

Tatsuo Konishi

Windborne Debris in Hurricanes and Typhoons Joseph E. Minor

Liquefaction Potential of Coarse Foundation Materials: Lost Creek Dam Ronald A. Oaks

U.S. Guidelines for the Seismic Rehabilitation of Buildings

Christopher Rojahn and Ugo Morelli

Northridge Earthquake Responses of Base-Isolated (USC) and Conventionally

Designed (Olive View) Hospital Buildings .

Mehmet K. Celebi

Recent U.S. Experience in Design and Testing of Beam-to-Column Connections

for Moment-Resisting Steel Frames

Ferdinand LoRay Schwartz 


\section{AGENDA \\ 28th TECHNICAL PANEL MEETING on \\ WIND AND SEISMIC EFFECTS \\ 14-17 May 1996}

\section{Tuesday 14 May}

\section{OPENING CEREMONIES}

(Lecture Room B, Administration Building)

Call to order by Noel RAUFASTE, Secretary-General US-side Panel

Opening remarks by Dr. Robert HEBNER, Deputy Director, National Institute of Standards and Technology

Remarks by Akihiro FUJITA, Counsellor for Science and Technology, Embassy of Japan

Remarks by Richard N. WRIGHT, Chairman US-Side, Panel on Wind and Seismic Effects, Director, Building and Fire Research Laboratory

Remarks by Tadahiko SAKAMOTO, Chairman Japan-Side, Panel on Wind and Seismic Effects, Director-General, Public Works Research Institute

Introduction of U.S. Members by U.S. Panel Chairman

Introduction of Japan Members by Japan Panel Chairman

Elect Joint Meeting Chairman

Adopt Agenda

Adjourn

\section{Group Photograph}

1130 Lunch: Hosted by Dr. Robert HEBNER, Deputy Director, National Institute of Standards and Technology 


\section{THEME - STORM SURGE AND TSUNAMIS}

\section{5-1405 Technical Session - STORM SURGE AND TSUNAMIS}

Chairman: Mr. Tadahiko SAKAMOTO

1245 U.S. Operational Storm Surge Forecast Models, Wilson A. SHAFFER and Jye CHEN, NOAA

1305 Long-term Shoreline Change in Japan, Shigenobu TANAKA, PWRI

1325 Assessment of Hurricane Opal Impact on East Pass Florida with Airborne Lidar, William ROPER, CORPS

1345 Discussion

1405 Break

\section{TASK COMMITTEE MEETINGS}

1425-1700 Task Committee Meetings

T/C B Testing and Evaluation Procedures for Building Systems Mr. K. Ohtani (Japanside Chair) and H.S. Lew (U.S.-side Chair)

T/C C Design Evaluation and Improvement of Structures Dr. Hirashi (Japan-side Chair) and Dr. Ken Chong (U.S.-side Chair)

T/C D Dam Earthquake Engineering Dr. Okahara (Japan-side Acting Chair) and Dr. William Roper (U.S.-side Chair)

T/C E Design for Wind and Wind Hazard Mitigation Drs. Okada and Sato (Japanside Co-Chairs) Drs. Nora Sabadel and Andrew Taylor (U.S.-side Co-Chairs)

T/C F Disaster Prevention Methods for Lifeline Systems Dr. Otsuka (Japan-side Acting Chair) and Dr. Riley Chung (U.S.-side Chair)

T/C K Wind and Earthquake Engineering for Offshore and Coastal Facilities Dr. Sugano (Japan-side Acting Chair) and Dr. Charles Smith (U.S.-side Chair) 
Wednesday 15 May

\section{THEME - EARTHQUAKE ENGINEERING}

0830-1130 Technical Session - Earthquake Engineering Part 1

Chairman: Dr. Richard WRIGHT

0830 Mitigation of Lateral Flow of Liquefied Ground, Ikuo TOWHATA, Univ. of Tokyo, Yoshihiro KOGAI, Fudo Construction Co., Kei AMIMOTO, Univ. of Tokyo, and Hendri GUSTI-PUTRA, Andalas Univ., Indonesia

0850 Evaluation of Liquefaction Potential Using the CPT, Richard OLSEN, Joseph KOESTER, and Mary Ellen HYNES, WES

0910 Estimation of Effects of Liquefaction-induced Lateral Spreading on Bridge Foundations, Keiichi TAMURA, Yoshio NINOMIYA, Tadashi HAMADA, PWRI

0930 Preliminary Guidelines for Liquefaction Assessment Using Shear Wave Velocity, Ronald ANDRUS, NIST and Kenneth Stokoe, University of Texas

0950 Discussion

1010 Break

1030 Damage Investigation of Steel Buildings in Specific Areas Observed from the 1995 Hyogoken Nanbu Earthquake, Mitsumasa MIDORIKAWA, Takashi HASAGAWA, Yoshiaki MUKAI, Isao NISHIYAMA, Toshifumi FUKUTA, Hiroyuki YAMANOUCHI, BRI

1050 An Integrated Program to Improve the Performance of Steel Moment Resisting Frame Buildings, Stephen MAHIN, Univ of Calif Berkeley and Michael MAHONEY, FEMA

1110 Discussion

1130 Adjourn for Lunch

1135 Lunch: Hosted by Dr. William ANDERSON, Director, Hazard Mitigation Section, Civil and Mechanical Systems Division, National Science Foundation 
1245-1425 Technical Session - Earthquake Engineering (Continued)

Chairman: Dr. Richard WRIGHT

1245 Recent Developments in Strong-Motion Attenuation Relationships, William B. JOYNER and David M. BOORE, USGS

1305 Topographical Effect in the Evaluation of Design Earthquake Motion, Izuru OKAWA, Toshihide KASHIMA, Shin KOYAMA, BRI

1325 Preliminary Estimates of Ground-Motion Amplification for the Northridge and Hyogo-ken Nambu Earthquakes of January 17, 1994 and 1995, Roger BORCHERDT, USGS

1345 Damage to Communication Tunnels Caused by Liquefaction and Other Phenomenon during the Hanshin-Awaji Earthquake and future Countermeasures, yuzo YAMAGUCHI and Masayuki TSUCHIYA, NTT

1405 Discussion

1425 Break

\section{TASK COMMITTEE MEETINGS}

1440-1700 Task Committee Meetings

T/C A Strong-motion Data and Applications Dr. Sugano (Japan-side Acting Chair and Dr. Roger Borcherdt (U.S.-side Chair)

T/C G Structural Control and Intelligent Material Systems Dr. Otsuka (Japan-side Chair) and Dr. Shi-Chi Liu (U.S.-side Chair)

T/C H Soil Behavior and Stability During Earthquakes Dr. Tamura (Japan-side Chair) and Dr. A.G. Franklin, U.S.-side Chair)

T/C I Storm Surge and Tsunamis Dr. Okahara (Japan-side Acting Chair) and Dr. Blackford (U.S.-side Chair)

T/C J Wind and Earthquake Engineering for Transportation Systems Dr. Sato (Japanside Acting Chair) and Mr. JamesCooper (U.S.-side Chair)

1700 Conclusion of Day 2 


\section{Thursday 16 May}

\section{THEME - EARTHQUAKE ENGINEERING - PART II}

\section{5-1135 Technical Session - Earthquake Engineering-Part II}

Chairman: Mr. Tadahiko SAKAMOTO

0815 Effect of Load Path on Damage to Concrete Bridge Piers, Andrew TAYLOR, NIST, Ashraf EL-BAHY, Univ. of Central Florida, William STONE, NIST, and Safshi KUNNATH, Univ. of Central Florida

0835 Guide Specifications for Reconstruction and Repair of Highway Bridges Which Suffered Damage due to the Hyogo-ken Nanbu Earthquake, Kazuhiko KAWASHIMA, Tokyo Institute of Technology, Kazuhiro NISHIKAWA, Masanori NAKANO, Shigaki UNJOH, Yoshitomi KIMURA, and Jun-ichi HOSHIKUMA, PWRI

0855 Comparison of U.S. and Japanese Highway Bridge Column Seismic Design, Philip YEN and James Cooper, FHWA, and Hisanori OTSUKA and Toru Terayama, PWRI

0915 Residual Displacement Response Spectrum and its Application to Reinforced Concrete Bridge Piers, Kazuhiko KAWASHIMA, Tokyo Institute of Technology, Gregory A. MACRAE, Univ. of Wash., Jun-ichi HOSHIKUMA and Kazuhiro NAGAYA, PWRI

0935 Discussion

0955 Break

1015 Analysis of Damaged Foundations of Highway Bridge in the Hyogoken Nanbu Earthquake, Michio OKAHARA, Masanori NAKANO, Yoshitomi KIMURA, PWRI

1035 Evaluation of Fault Geometry on Design Ground Motions, Jon P. AKE and D.R.H. O'CONNELL, BUREC

1055 Damage to Port Facilities of Kobe Port by the 1995 Hyogo-ken Nanbu Earthquake and their Reconstruction, Tatsuo UWABE, PHRI, Ken OlKAWA, Port Construction Bureau, and Tatsuo WAKO, and Takahiro SUGANO, PHRI

1115 Discussion

1135 Adjourn for lunch

1135 Lunch: Hosted by Richard KRIMM, Acting Associate Director, Mitigation Directorate, Federal Emergency Management Agency 
1235-1620 Technical Session - Earthquake Engineering (Continued)

Chairman: Mr. Tadahiko SAKAMOTO

1300 Major Factors of Damages of Reinforced Concrete Building due to the 1995 Hyogo-ken Nanbu Earthquake, Hisahiro HIRAISHI, Takashi KAMINOSONO, Masaomi TESHIGAWARA and S. NAKATA, BRI

1320 Pushover laboratory testing of unreinforced Masonry Infills, Steven Sweeney, Pamalee Brady, and Ghassan Al-Chaar, CERL

1340 Design and Techniques for the Restoration of the Earthquake Damaged Hanshin Expressway Kobe Route, Hisanori OHTSUKA, PWRI, and Hiroyuki NAKAJIMA, Hidenao HAYASHI, and Kenji KOSA, Hanshin Expressway Public Corporation

1400 Action and Concept on Performance-Based Design and Engineering System in Japan, Hiroyuki YAMANOUCHl, Hisashi OKADA, Yuji OHASHI, BRI

1420 Discussion

1440 Break

1500 Composites for Construction, Jack SCALZI, NSF

1520 Arrangement for Kyoshin-net, Keiichi OHTANI, Shigeo KINOSHITA, Hiroyuki HUJIWARA, NRIESDP

1540 Seismic Stability for Sliding of Rockfill Dams, Tadahiko SAKAMOTO, Tadahiko FUJISAWA, Akira NAKAMURA, Tomoya IWASHITA, PWRI

1600 Discussion

1620 Break

\section{THEME - SUMMARY JOINT COOPERATIVE RESEARCH PROGRAMS}

\section{Chairman: Mr. Tadahiko SAKAMOTO}

\section{0-1740 Technical Session - Joint Cooperative Research Programs}

1640 U.S.-Japan Cooperative Earthquake Research Program on Composite and Hybrid Structures - Research Progress and Current Status, Subhash C. GOEL, University of Michigan and Isao NISHIYAMA, BRI

1700 Design of Large-scale Liquefaction Experiment System, Kenji ISHIHARA, Science Univ. of Tokyo, Takaaki KAGAWA, Wayne Univ, Nobuyuki OGAWA, NIED, Chikahiro MINOWA, NIED, K. SAKAI, Kiso-Jiban Consultants Co., and A. ABE, Tolyo Soil Research Co.

1720 Discussions

1740 Conclusion of Day 3 
Friday 17 May

\title{
THEME - WIND ENGINEERING
}

\author{
Chairman: Dr. Richard WRIGHT
}

\section{5-1030 Technical Session - Wind Engineering}

0815 Influence of Vent Configurations on Bridge Response to Wind, Harold $\mathrm{BOSCH}$, FHWA

0835 Aerodyanic Characteristics of Slotted Box Girders, Hiroshi SATO, Katsuya OGIHARA, PWRI

0855 Discussion

0910 Wind Engineering Research in the United States, Ahsan KAREEM, Notre Dame University and Eleanore SABADELL, NSF

0930 Estimation of Relevant Internal Pressure and Wind Loads on Cladding, Hisashi OKADA, Linze KONG, BRI

0950 Descriptive Epidemiology of Wind-related Mortality, Josephine MALILAY, Annemarie WASLEY, and Leslie A. FIEDLER, CDC

1010 Discussion

1030 Break

\section{THEME - SUMMARY RECENT PANEL WORISHOPS}

Chairman: Dr. Richard WRIGHT

1045-1140 Workshop Reports

1045 T/C "A" Strong Motion Data, Site Response to Strong Earthquake Mo-

tions, 16-17 January 1996, Yokosuka.

1055 T/C "F" Disaster Prevention Methods for Lifeline Systems, 6th Workshop on Earthquake Disaster Prevention for Lifeline Systems, 1819 July 1995, Osaka.

1105 T/C "I" Storm Surge and Tsunamis, 4th Workshop on Storm Surge and Tsunamis, Hawaii, l April 1996.

1115 T/C "J" Wind and Earthquake Engineering for Transportation Systems, 10th Workshop on Bridge Engineering, 30-31 May 1995, Tsukuba.

1125 Discussion

1140 Adjourn for Lunch

1140 Lunch: Hosted by Dr. Walter HAYS, Deputy for Research Applications, United States Geological Survey (Courtyard) 


\section{TASIK COMMITTEE REPORTS AND RESOLUTIONS}

1245-1445 Report of Task Committees

Chairman: Dr. Richard WRIGHT

$\mathrm{T} / \mathrm{CA}$

$\mathrm{T} / \mathrm{C} \mathrm{B}$

$\mathrm{T} / \mathrm{C} C$

$\mathrm{T} / \mathrm{C} \mathrm{D}$

$\mathrm{T} / \mathrm{C} E$

$\mathrm{T} / \mathrm{C} \mathrm{F}$

$\mathrm{T} / \mathrm{C} \mathrm{G}$

$\mathrm{T} / \mathrm{C} \mathrm{H}$

$\mathrm{T} / \mathrm{CI}$

$\mathrm{T} / \mathrm{C} \mathrm{J}$

$\mathrm{T} / \mathrm{C} \mathrm{K}$

1445-1500 Break

1500-1600 Adoption of Final Resolutions

1600-1610 Break

\section{CLOSING CEREMONIES}

1610 Call to Order by Noel J. RAUFASTE, Secretary-General, U.S.-Side Panel Closing Remarks by Tadahiko SAKAMOTO, Chairman Japan-Side Panel Closing Remarks by Richard N. WRIGHT, Chairman U.S.-Side Panel

\section{Conclusion of 28th Joint Panel Technical Sessions}


LIST OF PANEL MEMBERS 



\section{UNITED STATES-SIDE PANEL ON WIND AND SEISMIC EFFECTS MEMBERSHIP LIST 1996}

Dr. Richard N. Wright

Chairman

Director, Building and Fire Research Laboratory

National Institute of Standards and Technology

U.S. Department of Commerce

Gaithersburg, MD 20899

301-975-5900 FAX: 301-975-4032

e-mail:rwright@nist.gov

Mr. Noel J. Raufaste

Secretary-General

Head, Cooperative Research Programs

Building and Fire Research Laboratory

National Institute of Standards and Technology

U.S. Department of Commerce

Gaithersburg, MD 20899

301-975-5905

FAX: 301-975-4032

e-mail:nraufaste@nist.gov

Mr. Kharaiti L. Abrol

Principal Structural Engineering Consultant (088)

Room 475

Department of Veterans Affairs

810 Vermont Avenue, NW

Washington, DC 20420

202-565-5579

FAX: 202-565-5478

Dr. John Ake

Geophysicist

Seismotectonics and Geophysics Section

Code D-8330

P.O. Box 25007

Bureau of Reclamation

U.S. Department of the Interior

Denver, CO 80225

303-236-4195 x276 FAX: 303-236-9127

e-mail:jake@seismo.usbr.gov 
Mr. Charles E. Anderson

Seismic Safety Coordinator

P.O. Box 25007 (D-8110)

Bureau of Reclamation

U.S. Department of the Interior

Denver, CO 80225

303-236-3999 x534 FAX: 303-236-9099

e-mail:canderson@do.usbr.gov

Dr. Celso S. Barrientos

Supervisory Physical Scientist

National Environmental Satelite Data

Information Service - Code E/RA28

National Oceanic and Atmospheric Administration

U.S. Department of Commerce

5200 Auth Road

Camp Springs, MD 20746

301-763-8102 FAX: 301-763-8020

e-mail:cbarrientos@nesdis.noaa.gov

Dr. Eddie N. Bernard

Director, Pacific Marine Environmental Laboratory

National Oceanic and Atmospheric Administration

U.S. Department of Commerce

7600 Sand Point Way, NE

BIN C15700/Building 3

Seattle, WA $98115-0070$

206-526-6800

FAX: 206-526-6815

e-mail:bernard@pmel.noaa.gov

Mr. Mike Blackford

Director, Pacific Tsunami Warning Center

National Oceanic and Atmospheric Administration

U.S. Department of Commerce

91270 Fort Weaver Road

Ewa Beach, HI 96706-2928

808-689-8207 FAX: 808-689-4543

e-mail:mike@ptwc.noaa.gov

Dr. David M. Boore

U.S. Geological Survey

345 Middlefield Road MS 977

Menlo Park, CA 94025

415-329-5616

FAX: $415-329-5163$

e-mail:boore@samoa.wr.usgs.gov 
Dr. Roger D. Borcherdt

Branch of Seismology

U.S. Geological Survey

U.S. Department of the Interior

345 Middlefield Road, MS 977

Menlo Park, CA 94025

415-329-5619 FAX: 415-329-5163

e-mail:borcherdt@samoa.wr.usgs.gov

Mr. H. Lee Butler

Chief, Research Division

Coastal Engineering Research Center

U.S. Army Engineer Waterways Experiment Station

Office CEWES-CR

3909 Halls Ferry Road

Vicksburg, MS 39180-6199

601-634-2405 FAX: 601-634-4314

Mr. Harish Chander

U.S. Dept. Of Energy (EH-31),

CXXI, Room 2016 (GTN)

19901 Germantown Road

Germantown, MD 20874-1290

301-903-6681 FAX: 903-8693

e-mail:harish.chander@hq.doe.gov

Dr. Ken P. Chong

Program Director, Mechanical \& Structural Systems

National Science Foundation

4201 Wilson Boulevard - Room 545

Arlington, VA 22230

703-306-1361 FAX: 703-306-0291

e-mail:Kchong@NSF.gov

Dr. Riley Chung

Group Leader, Earthquake Engineering

Structures Division

Building and Fire Research Laboratory

National Institute of Standards and Technology

U.S. Department of Commerce

Gaithersburg, MD 20899

301-975-6056 FAX: 301-869-6275

e-mail:rchung@enh.nist.gov 
Mr. James D. Cooper

Chief, Structures Division, HNR-10

Federal Highway Administration

U.S. Department of Transportation

6300 Georgetown Pike

McLean, VA 22101

703-285-2060 FAX: 703-285-2766

e-mail:jcooper@cais.com

Dr. A.G. Franklin

Chief, Earthquake Engineering \& Geophysics Division

CEWES-GH Geotechnical Laboratory

U.S. Army Engineer Waterways Experiment Station

3909 Halls Ferry Road

Vicksburg, MS 39180-6199

601-634-2658 FAX: 601-634-4134

e-mail:FRANKLA@EX1.wes.army.mil

Mr. William Freeborn

Housing and Urban Development

Room 8132

451 Seventh Street, SW

Washington, DC 20410

202-708-4370 FAX: 202-619-8360

E-mail:William_E._Freeborne@HUD.GOV

Mr. James H. Gates

Caltrans - Structures

P. O. Box 94287

Sacramento, CA 94274

916-227-8773 FAX: 916-227-8174

Mr. Peter E. Gurvin

Director, Building Design and Engineering Division

Foreign Building Operations

Building SA-6, Room 335

U.S. Department of State

Washington, DC 20520

703-875-6117 FAX: 703-875-6204 
Dr. Walter W. Hays

Deputy for Research Applications

Office of Earthquake, Volcanoes and Engineering

905 National Center

U.S. Geological Survey

U.S. Department of the Interior

Reston, VA 22092

703-648-6711 FAX: 703-648-6717

e-mail:whays@usgs.gov

Mr. Larry C. Hultengren

Senior Structural Engineer

Office of Civil/Structural Engineering

Foreign Building Operations

Building SA-6, Room 346

U.S. Department of State

Washington, DC 20520

703-875-6194 FAX: 703-875-6204

Dr. William B. Joyner

Geophysicist

Branch of Seismology

U.S. Geological Survey

U.S. Department of the Interior

345 Middlefield Road, MS 977

Menlo Park, CA 94025

415-329-5640 FAX: 415-329-5163

e-mail:joyner@samoa.wr.usgs.gov

Mr. Roger M. Kenneally

Structural Engineer

Structural and Seismic Engineering Branch

Mail Stop T10-L1

U.S. Nuclear Regulatory Commission

Washington, DC 20555

301-415-6303 FAX: 301-415-5074

e-mail:rmk@nrc.gov

Dr. George Lee

Director

National Center for Earthquake Engineering Research

State University of New York at Buffalo

Red Jacket Quadrangle

Buffalo, NY 14261

716-645-3391 FAX: 716-645-3399 
Dr. H.S. Lew

Chief, Structures Division

Building and Fire Research Laboratory

National Institute of Standards and Technology

U.S. Department of Commerce

Gaithersburg, MD 20899

301.975-6061

FAX: 301-869-6275

e-mail:hsl@nist.gov

Dr. Shih-Chi Liu

Program Director, Structural Systems

Division of Biological and Critical Systems

National Science Foundation

4201 Wilson Boulevard - Room 545

Arlington, VA 22230

703-306-1362 FAX: 703-306-0291

e-mail:cliu@nsf.gov

Dr. Francis G. McLean

Value Engineering Program Manager

Code D-8170

P.O. Box 25007

Bureau of Reclamation

U.S. Department of the Interior

Denver, CO 80225

303-236-9120 x236 FAX: 303-236-6737

e-mail:fmclean@do.usbr.gov

Dr. Josephine Malilay

Diaster Assessment and Epidemiology Section

National Center for Environmental Health

F-46 Center for Disease Control and Prevention

4770 Buford Highway, NE

Atlanta, GA 30341

770-488-7350

FAX: 770-488-7335

Dr. Raymond E. Meyer

Senior Program Manager

Office of Foreign Disaster Assistance

SA14/Room 1705

USAID/Washington, D.C. 20523-1443

703-875-1522

FAX: 703-875-1708 
Mr. Ugo Morelli

Policy Manager

Federal Emergency Management Agency

500 C Street, SW

Washington, DC 20472

202-646-2810 FAX: 202-646-2577

Mr. Howard D. Nickerson

Earthquake Engineering and Weapons Specialist

Naval Facilities Engineering Command

Hoffman Building \#2, Room 12S63, Code 04B2

200 Stovall Street

Alexandria, VA 22332

202-433-8599 FAX: 202-433-8777

Dr. William E. Roper

Assistant Director

Research and Development (Civil Works)

U.S. Army Corps of Engineers

20 Massachusetts Avenue, N.W.

Washington, DC 20314-1000

202-761-0257 or 1845 FAX: 202-761-0907

email:Bill.Roper@inet.hq.USACE.army.mil

Dr. J. Eleonora Sabadell

Director, Natural and Technological Hazards Mitigation Program

Directorate of Engineering

National Science Foundation

4201 Wilson Boulevard - Room 545-03

Arlington, VA 22230

703-306-1361

FAX: 703-306-0291

e-mail:esabadel@nsf.gov

Dr. Charles E. Smith

Research Program Manager

Offshore Minerals Management

Technology Assessment and Research Branch

Minerals Management Service

U.S. Department of the Interior

381 Elden Street, MS 4800

Herndon, VA 22070-4817

703-787-1559 FAX: 703-787-1555

e-mail:smithc@smtp.mms.gov 
Mr. Stanley Strickland

Chief, Air Base Systems Branch

Stop 37, WL/FIVC/OL, Bldg. 1120

139 Barnes Drive, STE 2

Tyndall AFB, FL 2403-6001

904-283-3709

FAX: 904-283-3722

Dr. Andrew Taylor

Research Structural Engineer

Structures Division

Bldg. 226, Room B-158

Building and Fire Research Laboratory

National Institute of Standards and Technology

Gaithersburg, MD 20899-1000

301.975-6078

FAX: 301-869-6275

e-mail:ataylor@enh.nist.gov 


\section{ALTERNATE MEMBERS}

Dr. Clifford J. Astill

Program Director

Division of Biological and Critical Systems

National Science Foundation

4201 Wilson Boulevard - Room 545

Arlington, VA 22230

703-306-1361 FAX: 703-306-0291

Dr. Mehmet K. Celebi

Research Civil Engineer

Branch of Earthquake and Geomagnetic Information

U.S. Geological Survey

U.S. Department of the Interior

345 Middlefield Road, MS 977

Menlo Park, CA 94025

415-329-5623 FAX: 415-329-5163

Mr. Michael Changery

Chief, Global Analysis Branch

National Climatic Data Center

National Oceanic and Atmospheric Administration

U. S. Department of Commerce

Federal Building

Ashville, NC 28801

704-271-4765

FAX: 704-271-4246

Dr. C.Y. Chen

Senior Civi//Geotechnical Engineer

Office of Foreign Buildings

Department of State

Code SA-6, Rm. 347

Washington, DC 20520

703-875-6207 FAX: 703-875-6204

Mr. Vincent P. Chiarito

Research Structural Engineer

Structural Mechanics Division

Structures Laboratory

U.S. Army Engineer Waterways Experiment Station 3909 Halls Ferry Road

Vicksburg, MS 39180-6199

601-634-2714 FAX: 601-634-3412 
Dr. James F. Costello

Senior Structural Engineer

Structural and Geological Engineering Branch

Office of Nuclear Regulatory Research

U.S. Nuclear Regulatory Commission

Mail Stop T10-L1

Washington, DC 20555

301-415-6009 FAX: 301-415-5074

Mr. Lucian G. Guthrie, P.E.

Structures Branch, Eng. Div.

U.S. Army Corps of Engrs.

UQUSACE (CECW-ED)

Washington, D.C. 20314-1000

202-761-8673 FAX: 202-761-4716

e-mail:civil_works.eng1_postguthrie(Lucian Guthrie)

Dr. Robert L. Hall

Chief, Structural Analysis Group

U.S. Army Engineer Waterways Experiment Station

3909 Halls Ferry Road

Vicksburg, MS 39180-6199

601-634-2567 FAX: 601-634-3412

Dr. James R. Houston

Director, Coastal Engineering Research Center

U.S. Army Engineer Waterways Experiment Station/WESCV-Z

3909 Halls Ferry Road

Vicksburg, MS 39180-6199

601-634-2000 FAX: 601-634-2055

e-mail:houston@coafs l.wes.army.mil

Mr. James Lander

Geophysicist

Cooperative Institute for Research in

Environmental Sciences

University of Colorado

Campus Box 449, Room 152 RL3

3100 Marine Street

Boulder, CO 80309

303-497-6446 FAX: 303-497-6513 
Mr. Tingley K. Lew

Research Structural Engineer

Structures Division

Naval Facilities Engineering Service Center - Code C62

1110 23rd Ave.

Port Hueneme, CA 93043-4370

805-982-1234 FAX: 805-982-1418

Mr. Michael Mahoney

Physical Scientist

Federal Emergency Management Agency

500 C Street, SW

Washington, DC 20472

202-646-2794

FAX: 202-646-4387

Dr. Erdal Safak

Research Structural Engineer

U.S. Geological Survey

Box 25046, MS 966

Denver Federal Center

Denver, CO 80225

303-273-8593

FAX: $303-273-8600$

Dr. John B. Scalzi

Program Director, Structures and Building Systems

National Science Foundation

4201 Wilson Blvd. - Room 545

Arlington, VA 22230

703-306-1361

FAX: 703-306-0291

E-mail:jscalzi@nsf.gov 


\section{JAPAN-SIDE PANEL ON WIND AND SEISMIC EFFECTS MEMBERSHIP LIST}

\section{Steering Committee Membership List}

Mr. Tadahiko Sakamoto

Chairman, Japan-side

Panel on Wind and Seismic Effects, UJNR

Director-General

Public Works Research Institute

Ministry of Construction

1, Asahi, Tsukuba-shi,

Ibaraki-ken 305

TEL: 0298-64-2821

FAX: 0298-64-2148

e-mail: tsakamo@pwri.go.jp

Dr. Michio Okahara

Secretary-General, Japan-side

Panel on Wind and Seismic Effects, UJNR

Research Coordinator for Advanced Technology

Public Works Research Institute

Ministry of Construction

I, Asahi, Tsukuba-shi,

Ibaraki-ken 305

TEL: 0298-64-3725

FAX: 0298-64-4344

e-mail: okahara@pwri.go.jp

Mr. Naotoshi Baba

Director, Road Disaster Prevention Section

Road Bureau

Ministry of Construction

2-1-3,Kasumigaseki,Chiyoda-ku,

Tokyo 100

TEL: 03-5251-1896

FAX: 03-5251-1949 
Mr. Kunio Enoshima

Senior Assistant for Disaster Prevention

Planning Division

Administration Department

Japan Meteorological Agency

1-3-4,Ohtemachi,Chiyoda-ku

Tokyo 100

TEL: 03-3212-8341

FAX: 03-32 12-2453

Mr. Tadahiko Fujisawa

Director, Dam Department

Public Works Research Institute

Ministry of Construction

1, Asahi, Tsukuba-shi,

Ibaraki-ken 305

TEL: 0298-64-2832

FAX: 0298-64-0164

e-mail: fujisawa@pwri.go.jp

Mr. Takeshi Hashimoto

Director,Earthquake Disaster Countermeasures Division

Prevention Bureau

National Land Agency

1-2-2, Kasumigaseki, Chiyoda-ku,

Tokyo 100

TEL: 03-3593-3311

FAX: 03-3501-5199

Dr. Hisahiro Hiraishi

Structural Engineering Department

Building Research Institute

Ministry of Construction

1,Tatehara,Tsukuba-shi,

Ibaraki-ken 305

TEL: 0298-64-6639

FAX: 0298-64-6773 
Dr. Susumu Iai

Chief, Geotechnical Earthquake

Engineering Laboratory

Port and Harbour Research Institute

Ministry of Transport

3-1-1,Nagase,Yokosuka -shi

Kanagawa-ken 239

TEL: 0468-44-5028

FAX: 0468-44-4095

Dr. Takamasa Inatomi

Director, Structural Engineering Division

Port and Harbour Research Institute

Ministry of Transport

3-1-1,Nagase, Yokosuka-shi,

Kanagawa-ken 239

TEL: 0468-44-5027

FAX: 0468-44-0839

Dr. Toshio Iwasaki

President, Civil Engineering Research Laboratory

Kyodo Building 5F, 3-3-4,Kanda,

Kaji-cho, Chiyoda-ku,

Tokyo 101

TEL: 03-3254-9481

FAX: 03-3254-9448

Mr. Takashi Kaminosono

Head, Construction Techniques Division

Building Research Institute

Ministry of Construction

1,Tatehara, Tsukuba-shi,

Ibaraki-ken 305

TEL: 0298-64-2151

FAX: 0298-64-2989

e-mail: kamino@kenken.go.jp

Dr. Kazuhiko Kawashima

Professor, Department of Civil Engineering Tokyo Institute of Technology

2-12-1,O-okayama,Meguro-ku,

Tokyo 152, Japan

TEL: 03-5734-2922

FAX: 03-3729-0728 
Dr. Yasuyuki Koga

Director, Earthquake Disaster

Prevention Department

Public Works Research Institute

Ministry of Construction

1,Asahi,Tsukuba-shi,

Ibaraki-ken 305

TEL: 0298-64-2829

FAX: 0298-64-0598

e-mail: koga@pwri.go.jp

Dr. Hiroshi Kofune

Director, Hydraulic Engineering Division

Port and Harbour Research Institute

Ministry of Transport

3-1-1, Nagase, Yokosuka-shi

Kanagawa-ken 239

TEL: 0468-44-5009

FAX: 0468-41-3888

Mr. Kiyoshi Mimura

Director,Geographic Department

Geographical Survey Institute

Ministry of Construction

1, Kitasato, Tsukuba-shi

Ibaraki-ken 305

TEL: 0298-64-1 111

FAX: 0298-64-1804

Dr. Chikahiro Minowa

Cooperative Research Officer

National Research Institute for

Earth Science and Disaster Prevention

Science and Technology Agency

3-1, Tennodai, Tsukuba-shi,

Ibaraki-ken,305

TEL: 0298-51-1611

FAX: 0298-51-5658

e-mail: minowa@geo.bosai.go.jp 
Mr. Eishi Mochizuki

Director, Seismology and Volcanology

Research Department

Meteorological Research Institute

Japan Meteorological Agency

1-1, Nagamine, Tsukuba-shi

Ibaraki-ken 305

TEL: 0298-53-8675

FAX: 0298-51-3730

e-mail: emochizu@mri-jma.go.jp

Mr. Akihito Nakahama

Director, Disaster Prevention Office

Coast Construction and Disaster Prevention Division

Ports and Harbour Bureau, MOT

2-1-3, Kasumigaseki, Chiyoda-ku,

Tokyo 100

TEL: 03-3580-4452

FAX: 03-5511-8280

Mr. Akira Nakamura

Head, Fill Type Dam Division

Dam Department

Public Works Research Institute

Ministry of Construction

1, Asahi, Tsukuba-shi,

Ibaraki-ken 305

TEL: 0298-64-2413

FAX: 0298-64-0164

e-mail: nakamura@pwri.go.jp

Dr. Tadahiko Nakao

Director, River Department

Public Works Research Institute

Ministry of Construction

1, Asahi, Tsukuba-shi,

Ibaraki-ken 305

TEL: 0298-64-2830

FAX: 0298-64-1168 
Dr. Shinsuke Nakata

Director, Production Department

Building Research Institute

Ministry of Construction

1, Tatehara, Tsukuba-shi,

Ibaraki-ken 305

TEL: 0298-64-1111

FAX: 0298-64-2989

Dr. Nobuyuki Narita

Professor, Tokyo Metropolitan University

17-15, Yawata-6, Ichikawa-shi,

Chiba-ken 272

TEL: 0473-35-0324

FAX: 0473-35-0324

Dr. Isao Nishiyama

Research Planning and Information

Department Coordination for International Research Cooperation

Building Research Institute

Ministry of Construction

1, Tatehara,Tsukuba-shi,

Ibaraki-ken 305

TEL: 0298-64-2151

FAX: 0298-64-2989

e-mail: isao@kenken.go.jp

Dr. Setsuo Noda

Director- General

Port and Harbour Research Institute

Ministry of Transport

3-1-1,Nagase, Yokosuka-shi,

Kanagawa-ken 239

TEL: 0468-44-5000

FAX: 0468-42-9265

Dr. Shigeyuki Noto

Director, Structures Division

Civil Engineering Research Institute

Hokkaido Development Agency

1-3, Hiragishi, Toyohira-ku, Sapporo-shi, Hokkaido 062

TEL: 011-841-1111

FAX: 011-820-2714

e-mail: noto@hdbceri.go.jp 
Dr. Tsuneo Okada

Professor, University of Tokyo

7-22-1, Roppongi, Minato-ku,

Tokyo 106

TEL: 03-3402-6231

FAX: 03-3402-1908

e-mail: okada@kappa.iis.u-tokyo.ac.jp

Dr. Masao Okamoto

Director, Disaster Prevention Investigation Section

River Bureau

Ministry of Construction

2-1-3, Kasumigaseki, chiyoda-ku,

Tokyo 100

TEL: 03-5251-1884

FAX: 03-5251-1946

Mr. Keiichi Ohtani

Director, Disaster Prevention Research Division

National Research Institute for Earth Science and Disaster Prevention

Science and Technology Agency

3-1, Tennodai, Tsukuba-shi,

Ibaraki-ken,305

TEL: 0298-51-1611

FAX: 0298-51-1622

Dr. Hisanori Ohtsuka

Head, Earthquake Engineering Division

Earthquake Disaster Prevention Department

Public Works Research Institute

Ministry of Construction

1, Asahi, Tsukuba-shi,

Ibaraki-ken 305

TEL: 0298-64-2932

FAX: 0298-64-0598

e-mail: otsuka@pwri.go.jp

Mr. Shin Ohtsuka

Director, Typhoon Research Division

Meteorological Research Institute

Japan Meteorological Agency

Ministry of Transport

1-1, Nagamine, Tsukuba-shi

Ibaraki-ken 305

TEL: 0298-53-8552

FAX: 0298-53-8545 
Mr. Hiroshi Sasaki

Director, Building Guidance Division

Building Disaster Prevention Section

Housing Bureau

Ministry of Construction

2-1-3,Kasumigaseki,Chiyoda-ku,

Tokyo 100

TEL: 03-3580-4311

FAX: 03-3580-7050

Dr. Hiroshi Sato

Head, Structure Division

Structure and Bridge Department

Public Works Research Institute

Ministry of Construction

I,Asahi,Tsukuba-shi,

Ibaraki-ken 305

TEL: 0298-64-2874

FAX: 0298-64-0565

e-mail: hsato@pwri.go.jp

Dr. Keiichi Tamura

Head, Ground Vibration Division

Earthquake Disaster Prevention Department

Public Works Research Institute

Ministry of Construction

1, Asahi, Tsukuba-shi,

Ibaraki-ken 305

TEL: 0298-64-2926

FAX: 0298-64-0598

Mr. Shigenobu Tanaka

Head, Coastal Engineering Division

River Department

Public Works Research Institute

Ministry of Construction

1, Asahi, Tsukuba-shi,

Ibaraki-ken 305

TEL: 0298-64-2327

FAX: 0298-64-1168

e-mail: stanaka@pwri.go.jp 
Dr. Tetsushi Uehara

Director, Office of Disaster Prevention

Research Policy Division

Research and Development Bureau

1-2-2, Kasumigaseki Chiyoda-ku

Tokyo 100

TEL: 03-3581-5271

FAX: 03-3595-0980

Dr. Tatsuo Uwabe

Chief, Earthquake Disaster Prevention Laboratory

Structural Engineering Division

Port and Harbour Research Institute

Ministry of Transport

3-1-1, Nagase, Yokosuka-shi,

Kanagawa-ken 239

TEL: 0468-44-5030

FAX: 0468-44-0839

Dr. Makoto Watabe

Professor, Faculty of Environmental Information,

Keio University

5322, Endo, Fujisawa-shi,

Kanagawa-ken 252

TEL: 0466-47-5111

FAX: 0466-47-5041

Mr. Asao Yamakawa

Director, International Affairs Division

Economic Affairs Bureau

Ministry of Construction

2-1-3, Kasumigaseki, Chiyoda-ku,

Tokyo 100

TEL: 03-5251-1836

FAX: 03-3502-3955

Dr. Hiroyuki Yamanouchi

Director, Structural Engineering Department

Building Research Institute

Ministry of Construction

1,Tatehara, Tsukuba-shi,

Ibaraki-ken 305.

TEL: 0298-64-2151

FAX: 0298-64-6773

e-mail: yamanoch@kenken.go.jp 
Dr. Koichi Yokoyama

Director, Structure and Bridge Department

Public Works Research Institute

Ministry of Construction

1, Asahi, Tsukuba-shi,

Ibaraki-ken 305

TEL: 0298-64-2835

FAX: 0298-64-0565

e-mail: yokoyama@pwri.go.jp

\section{Secretaries Committee Membership List}

Dr. Michio Okahara

Secretary-General,Japan-side

Panel on Wind and Seismic Effects, UJNR

Research Coordinator for Advanced Technology

Public Works Research Institute

Ministry of Construction

1, Asahi, Tsukuba-shi,

Ibaraki-ken 305

TEL: 0298-64-3725

FAX: 0298-64-4344

e-mail: okahara@pwri.go.jp

Mr. Takekazu Akagiri

Head, Planning Division

Geographic Department Geographical Survey Institute

1, Kitasato, Tsukuba-shi,

Ibaraki-ken 305

TEL: 0298-64-1111

FAX: 0298-64-1804

Dr. Hisahiro Hiraishi

Structural Engineering Department

Building Research Institute

Ministry of Construction

1, Tatehara, Tsukuba-shi,

Ibaraki-ken 305

TEL: 0298-64-6639

FAX: 0298-64-6773 
Mr. Koichi Honda

Director, Research Planning and Coordination

Section Administration Division

Civil Engineering Research Institute of

Hokkaido Development Bureau

1-3, Hiragishi, Toyohira-ku, Sapporo-shi,

Hokkaido 062

TEL: 011-841-1111

FAX: 011-824-1226

Dr. Susumu Iai

Chief, Geotechnical Earthquake

Engineering Laboratory

Port and Harbour Research Institute

Ministry of Transport

3-1-1, Nagase, Yokosuka-shi

Kanagawa-ken 239

TEL: 0468-44-5028

FAX: 0468-44-4095

Dr. Kazuhiko Kawashima

Professor, Department of Civil Engineering

Tokyo Institute of Technology

2-12-1, O-okayama, Meguro-ku,

Tokyo 152, Japan

TEL: 03-5734-2922

FAX: 03-3729-0728

e-mail: kawashima@cv.titech.ac.jp

Dr. Yasuyuki Koga

Director, Earthquake Disaster

Prevention Department

Public Works Research Institute

Ministry of Construction

1, Asahi, Tsukuba-shi,

Ibaraki-ken 305

TEL: 0298-64-2829

FAX: 0298-64-0598

e-mail: koga@pwri.go.jp 
Mr. Osamu Matsuo

Head, Soil Dynamics Division

Earthquake Disaster Prevention Department

Public Works Research Institute

Ministry of Construction

1, Asahi, Tsukuba-shi,

Ibaraki-ken 305, Japan

TEL: 0298-64-2933

FAX: 0298-64-2576

Dr. Chikahiro Minowa

Cooperative Research Officer

National Research Institute for Earth Science and Disaster Prevention

Science and Technology Agency

3-1, Tennodai, Tsukuba-shi,

Ibaraki-ken, 305, Japan

TEL: 0298-51-1611

FAX: 0298-51-5658

e-mail: minowa@geo.bosai.go.jp

Mr. Akira Nakamura

Head, Fill Type Dam Division

Dam Department

Public Works Research Institute

Ministry of Construction

1, Asahi, Tsukuba-shi,

Ibaraki-ken 305

TEL: 0298-64-2413

FAX: 0298-64-0164

e-mail: nakamura@pwri.go.jp

Mr. Masanori Nakano

Head, Foundation Engineering Division

Structure and Bridge Department

Public Works Research Institute

Ministry of Construction

1, Asahi, Tsukuba-shi,

Ibaraki-ken 305, Japan

TEL: 0298-64-2873

FAX: 0298-64-0565 
Mr. Kazuhiro Nishikawa

Head, Bridge Division

Structure and Bridge Department

Public Works Research Institute

Ministry of Construction

1, Asahi, Tsukuba-shi,

Ibaraki-ken 305, Japan

TEL: 0298-64-2905

FAX: 0298-64-0565

e-mail: knisika@pwri.go.jp

Dr. Nobuyuki Ogawa

Head, Earthquake Engineering Laboratory

National Research Institute for Earth Science and Disaster Prevention

Science and Technology Agency

3-1, Tennodai, Tsukuba-shi,

Ibaraki-ken 305

TEL: 0298-51-1611

FAX: 0298-51-8512

e-mail: ogawa@geo.bosai.go.jp

Dr. Hisashi Okada

Head of Aerodynamic Division

Structural Engineering Department

Building Research Institute

Ministry of Construction

1, Tatehara, Tsukuba-shi,

Ibaraki-ken 305

TEL: 0298-64-6641

FAX: 0298-64-6773

e-mail: okada@kenken.go.jp

Mr. Masami Okada

Head, The First Research Laboratory,

Seismology and Volcanology Research Department

Meteorological Research Institute

Japan Meteorological Agency,

Ministry of Transport

1-1, Nagamine, Tsukuba-shi,

Ibaraki-ken 305

TEL: 0298-53-8677

FAX: 0298-51-3730

e-mail:mokada@mri-jma.go.jp 
Dr. Izuru Okawa

Head, Geotechnical Engineering Division

Structural Engineering Department

Building Research Institute

Ministry of Construction

1,Tatehara, Tsukuba-shi,

Ibaraki-ken 305

TEL: 0298-64-6642

FAX: 0298-64-6773

e-mail: okawa@kenken.go.jp

Mr. Keiichi Ohtani

Director, Disaster Prevention Research Division

National Research Institute for Earth Science and Disaster Prevention

Science and Technology Agency

3-1,Tennodai, Tsukuba-shi,

Ibaraki-ken, 305

TEL: 0298-51-1611

FAX: 0298-51-1622

Dr. Hisanori Ohtsuka

Head, Earthquake Engineering Division

Earthquake Disaster Prevention Department

Public Works Research Institute

Ministry of Construction

1,Asahi,Tsukuba-shi,

Ibaraki-ken 305

TEL: 0298-64-2932

FAX: 0298-64-0598

e-mail: otsuka@pwri.go.jp

Dr. Hiroshi Sato

Head, Structure Division

Structure and Bridge Department

Public Works Research Institute

Ministry of Construction

1, Asahi, Tsukuba-shi,

Ibaraki-ken 305

TEL: 0298-64-2874

FAX: 0298-64-0565

e-mail: hsato@pwri.go.jp 
Mr. Masashi Satou

Head, Structures Section

Structures Division

Civil Engineering Research Institute

Hokkaido Development Bureau

1-3, Hiragishi, Toyohira-ku

Sapporo-shi, Hokkaido,062

TEL: 011-841-1111

FAX: 011-820-2714

Dr. Keiichi Tamura

Head, Ground Vibration Division

Earthquake Disaster Prevention Department

Public Works Research Institute

Ministry of Construction

1,Asahi, Tsukuba-shi,

Ibaraki-ken 305

TEL: 0298-64-2926

FAX: 0298-64-0598

Mr. Shigenobu Tanaka

Head, Coastal Engineering Division

River Department

Public Works Research Institute

Ministry of Construction

1,Asahi, Tsukuba-shi,

Ibaraki-ken 305

TEL: 0298-64-2327

FAX: 0298-64-1168

e-mail: stanaka@pwri.go.jp

Dr. Tatsuo Uwabe

Chief, Earthquake Disaster Prevention Laboratory, Structural Engineering

Division

Port and Harbour Research Institute

Ministry of Transport

3-1-1, Nagase, Yokosuka-shi,

Kanagawa-ken 239, Japan

TEL: 0468-44-5030

FAX: 0468-44-0839

Dr. Hiroyuki Yamanouchi

Director, Structural Engineering Department

Building Research Institute

Ministry of Construction

1, Tatehara, Tsukuba-shi, 
Ibaraki-ken 305

TEL: 0298-64-2151

FAX: 0298-64-6773

e-mail: yamanoch@kenken.go.jo

Dr. Koichi Yokoyama

Director, Structure and Bridge Department

Public Works Research Institute

Ministry of Construction

1, Asahi, Tsukuba-shi,

Ibaraki-ken 305

TEL: 0298-64-2835

FAX: 0298-64-0565 



\section{LIST OF TASIK COMMITTEE MEMBERS}

$\underline{\text { Task Committee }}$
A. Strong-Motion Data and Applications

$\underline{\text { US Side }}$

$$
\begin{aligned}
& \text { R.D. Borcherdt* } \\
& \text { C.J. Astill } \\
& \text { M.K. Celebi } \\
& \text { A.G. Franklin } \\
& \text { W.B. Joyner } \\
& \text { F.G. McLean } \\
& \text { C.S. Barrientos } \\
& \text { T.K. Lew } \\
& \text { E. Safak } \\
& \text { +J. Kimball } \\
& \text { +J. Hunt } \\
& \text { W. Freeborn } \\
& \text { J. Ake } \\
& \text { H. Meyers }
\end{aligned}
$$

H.S. Lew*

V.P. Chiarito

J.E. Sabadell

C.E. Smith

K. Abrol

+ S. Sweeney

+ A. Bieniawski

W. Freeborn
C. Evaluation and Improvement K.P. Chong* of Structures

\author{
+ J.O. Jirsa \\ H.S. Lew \\ T.K. Lew \\ H.D. Nickerson \\ +D.H. Oh \\ +M.A. Phipps \\ J.B. Scalzi \\ $+\mathrm{S}$. Woodson \\ + S.A. Asar \\ M.K. Celebi \\ K.L. Abrol \\ R.L. Hall \\ + A. Bieniawski
}

Lapanese Side

S. Iai*

K. Tamura

R. Honda

Y. Yamanouchi

I. Okawa

K. Mimura

K. Otani

+ M. Miyata

+ Y. Ichii

E. Mochizuki

M. Sato
K. Ohtani*

O. Matsuo

S. Nakata

I. Nishiyama

T. Kaminosono

$+T$. Fukuda

+A. Tanaka

$+S$. Morino

+ H. Noguchi

+ A. Wada

H. Hiraishi*

Y. Fujishiro

H. Okada

I. Nishiyama

T. Kaminosono

$+\mathrm{M}$. Teshigawara

+A. Mukai

$+\mathrm{H}$. Fukuyama

$+\mathrm{S}$. Kotani

$+\mathrm{H}$. Kuwamura

$+F$. Watanabe

+ M. Nakajima

+ H. Shiobara

+ J. Kanda 
+K. Mutreja

P. Brady

D. Ellsworth

W. Freeborn

D. Earthquake Engineering for Dams
W.E. Roper*

R.L. Hall

L.G. Guthrie

$+R$. Davidson

+ M.E. Hynes

A.G. Franklin

$+R$. Navidi

$+\mathrm{L}$. Von Thun

+ W. Allerton

F.G. McLean

$+\mathrm{T}$. Kabeyazawa

+ A. Wada

+ B. Tsuji

+ Y. Matsus

H. Yoshida*

+ T. Koga

T. Fujisawa

+ Y. Kato

+I. Nagayama

$+\mathrm{K}$. Watanabe

+ Y. Niitaka

$+\mathrm{T}$. Sasaki

$+\mathrm{M}$. Toyota

+ Y. Yamaguchi

$+\mathrm{T}$. Iwashita

+ J. Kashiwai

+Y. Nakamura

+ ). Tamura

+ Y. One

+ H. Watanabe

+T. Omachi

$+\mathrm{T}$. Kawakami

+ Y. Iida

+K. Yoshikawa

$+\mathrm{H}$. Nishida

A. Taylor*

E. Sabadell*

R.M. Chung*

C.J. Astill

M.K. Celebi

J.D. Cooper

+G. Al-Chaar

T.K. Lew

J.B. Scalzi

+J.S. Spencer

$+\mathrm{S}$. Wu

$+\mathrm{S}$. Sommer
H. Sato*

H. Okada*

K. Yokoyama*

K. Tamura

H. Otsuka

O. Matsuo

+ S. Tanaka

+M. Kaneko

+J. Hoshikuma

+Y. Kumaki

N. Ogawa

$T$. Uwabe

+Y. Kajiya

$+\mathrm{T}$. Katayama

+ H. Kameda

+ S. Takada

$+\mathrm{T}$. Sato

+ J. Toma 
$+\mathrm{K}$. Honda

+ H. Suzuki

+ K. Shimamura

+ Y. Taguchi

G. Structural Control and Intelligent Material Systems

H. Soil Behavior and Stability During Earthquakes
S.C. Liu*

V.P. Chiarito

K.P. Chong

$+J$.R. Hayes

L.C. Hultengren

G. Lee
H. Otsuka*

+ S. Unjo

Y. Yamanouchi

H. Okada

$+\mathrm{H}$. Fukuyama

+ H. Fujitani

$+N$. Inoue

C. Minowa

M. Sato

K. Kawashima

+ Y. Fujino

+ H. Iemura

$+Y$. Inoue

$+\mathrm{T}$. Ishimaru

$+\mathrm{K}$. Yoshida

$+\mathrm{K}$. Asano

+A. Nishitani

+ A. Ogawa

+ K. Ymazaki

+ H. Nakajima

$+\mathrm{T}$. Moritani

+ Y. Goto

+ Y. Makiguchi

+ S. Okamoto

A.G. Franklin*

C.J. Astill

R.D. Borcherdt

C.Y. Chen

F.G. McLean

C.E. Smith

R.M. Chung
K. Tamura*

K. Yokoyama

M. Nakano

H. Yoshida

O. Matsuo

$+\mathrm{T}$. Hamada

+ M. Iiba

C. Minowa

S. Iai

+ K. Zen

$T$. Sugano

+ J. Nishikawa

$+\mathrm{S}$. Yasuda

+ I. Towata

+ J. Koseki

+ H. Suzuki 
+ Y. Yamaguchi

+ J. Toma

I. Storm Surge and Tsunami

J. Wind and Earthquake Engineering for Transportation Systems
M. Blackford*

C.J. Astill

C.S. Barrientos

E.N. Bernard

H.L. Butler

J. Lander

W.E. Roper

A.M. Hittelman

J.D. Cooper*

A.G. Franklin

J.H. Gates

J.B. Scalzi

H.S. Lew

$+P$. Yen

+ H.R. Bosch
S. Tanaka*

+ S. Sato

+ S. Iwasaki

R. Kojima

+ N. Nagai

M. Okada

$+\mathrm{T}$. Konishi

$+\mathrm{T}$. Sasajima

+ N. Syudo

+Y. Kawada

+T. Yamashita

+T. Goto

+A. Nakayama

+K. Satake

Y. Fujishiro*

M. Nakano

+ Y. Kimura

$+\mathrm{M}$. Ishida

H. Sato

$+\mathrm{K}$. Ogihara

K. Nishikawa

+J. Murakoshi

K. Tamura

$+\mathrm{R}$. Honda

H. Otsuka

+ S. Unjo

K. Yokoyama

$\mathrm{T}$. Inatomi

+ S. Tanaka

M. Sato

+ Y. Fujino

K. Kawashima

+A. Ogawa

+K. Yamazaki

+ H. Nakajima

+ H. Akiyama

+T. Moritani 
K. Wind and Earthquake Engineering C.E. Smith* for Offshore and Coastal Facilities C.S. Barrientos

W.E. Roper

J.E. Sabadell

+M.C. Miller

M.K. Celebi
T. Uwabe*

M. Nakan

T. Inatomi

T. Sugano

S. Iai

+ A. Nozu

M. Okada

+ H. Shiojiri

+ M. Kazama

$+\mathrm{H}$. Tuchida

+ Y. Yoshida

\begin{tabular}{ll}
\hline$*$ & Chairman \\
$+\quad$ TC Members (not Panel Members)
\end{tabular} 

RESOLUTIONS 



\section{RESOLUTIONS OF THE TWENTY-EIGHTH JOINT MEETING U.S.-JAPAN PANEL ON WIND AND SEISMIC EFFECTS (UJNR) National Institute of Standards and Technology May 14-17, 1996}

The following resolutions are hereby adopted:

1. The Twenty-Eighth Joint Panel Meeting provided the forum to exchange valuable technical information that was beneficial to both countries. In view of the importance of cooperative programs on the subject of wind and seismic effects, the continuation of Joint Panel Meetings is considered essential.

2. The following activities have been conducted since the Twenty-Seventh Joint Meeting:

a. Technology Exchanges. Technical experts, technical documents, research reports, and proceedings for workshops have been exchanged. These exchanges contributed to the development of research programs and enhanced ongoing research in both countries.

b. Task Committee Workshops. The Panel held four workshops with technical site visits:

1. Task Committee (A) Workshop on Site Response to Strong Earthquake Motions, 16-17 January 1996, Yokosuka.

2. Task Committee (F) 6th Workshop on Earthquake Disaster Prevention for Lifeline Systems, 18-19 July 1995, Osaka.

3. Task Committee (I) 4th Workshop on Storn Surge and Tsunamis, 1-3 April 1996, Hawaii.

4. Task Committee (J), 11 th Bridge Engineering Workshop, 30-31 May 1995, Tsukuba.

3. The Panel will continue to seek methods to contribute to the IDNDR such as exchanging Proceedings of Joint Panel Meetings and of Task Committee Workshops with their respective country's National Committees for the IDNDR.

4. Japanese and U.S. members continued analysis of the most probable causes of failures from the 17 January 1995 Hyogo-ken-Nanbu Earthquake and the 17 January 1994 Northridge Earthquake. The Japan-side discussed its analysis of the Hyogo-ken-Nanbu Earthquake at the 28th Joint Panel Meeting. These deliberations presented important data and information about the reasons for building and infrastructure damages. The Panel recognizes the importance of using these findings in its ongoing work and of the need to continue performing future joint post-disaster investigations to improve scientific knowledge, engineering, and construction practices.

5. The Panel recognizes the importance of providing earthquake science and technology expertise to the U.S.-Japan Earthquake Disaster Mitigation Partnership of the April 17, 1996 Agreement, U.S.Japan Common Agenda. The Panel will provide technical 
leadership and participation in appropriate research projects aimed at realizing the objectives of the priority themes for joint collaborations. Appropriate Task Committees will respond to the Partnership in planning their work.

6. The Panel approved the Task Committee reports presented during the 28th Joint Panel Meeting. Each report included objectives, scope of work, accomplishments, future plans, and other information.

7. The Panel endorsed the following six proposed Task Committee Workshops during the coming year:
a. $\quad$ Task Committee (B), Workshop on Load Path and Test Observation
Requirements for Quasi-Dynamic and Shake Testing, planned before the 29 th Joint Panel Meeting
b. Task Committees ( $\quad \& G$ ), 2nd Workshop on Structural Control and Intelligent Material Systems, planned for November 1996, College Park, MD, USA
c. Task Committee (D), 1st Workshop on State-of-the-Art Review of U.S.-Japan Research on Earthquake Engineering for Dams, proposed for 19-22 November 1996, WES, Vicksburg, MS USA
d. Task Committees ( $\mathrm{G} \& \mathrm{~J})$ ), 4th Workshop on Earthquake Protective Systems for Bridges, December 1996, Japan
e. Task Committee (J), 12th Bridge Engineering Workshop, 26 October - 3 November 1996, USA.
f. Task Committee (J), 3rd Workshop on Seismic Retrofit of Bridges, December 1996, Japan

In addition, three Task Committees plan to conduct Workshops in 1997, following the 29th Joint Panel meeting:
a. Task Committee (E), 1st Workshop on Design for Wind and Wind Hazard Mitigation, October or November 1997, USA.
b. Task Committee (F), 7th Joint Workshop on Disaster Prevention for Lifeline Systems, proposed for June or July 1997, Seattle
c. Task Committee (K) 3rd Workshop on Wind and Earthquake Engineering for Offshore and Coastal Facilities, July 1997, Japan

Scheduling for the Workshops will be performed by the U.S. and Japan Chairmen of the respective Task Committees with concurrence of the Joint Panel Chairmen. Both sides' Secretaries- General shall be kept informed of the planning. Results of each activity conducted before the 29th Joint Meeting shall be presented at the 29th Joint Panel Meeting.

8. The Panel recognizes the importance of continuing its joint research programs on Composite and Hybrid Structures and on Soil Liquefaction and Countermeasures.

9. The Panel approved creation of the Task Committee on Design for Wind and Wind Hazard Mitigation (T/C "E"). 
10. The Panel published its third issue, Wind and Seismic Effects Newsletter, Winter 1996. The newsletter featured the Hyogo-ken Nanbu Earthquake and the 27th Joint Panel Meeting and summarized damage investigations, workshops and review of two U.S.-side Panel Agencies and one Japan-side Panel Agency. The Panel endorses continuation of publishing Panel news as reported in the newsletter. The U.S.-side will publish the fourth newsletter during the fall of 1996. The Panel encourages both sides to use the electronic media as much as possible in communicating Panel findings and summaries of activities. Therefore, the Panel has endorsed creation of a Home Page on the Internet. NIST will create and maintain the Panel's Home Page. In addition, future Panel newsletters will be made available through the Panel's Home Page on the Internet.

11. The Panel recognizes the importance of continued exchange of personnel, technical information, research results, and recorded data that lead to mitigating losses from strong winds and earthquakes. The Panel also recognizes the importance of using available large-scale testing facilities and other complementary capabilities in both countries. Thus, these activities should be continued, strengthened, and expanded. The Panel will provide official endorsement to facilitate these exchanges.

12. The Twenty-Ninth Joint Panel Meeting of the UJNR Panel on Wind and Seismic Effects will be held at the Public Works Research Institute, Japan in May 1997. Specific dates, program, and itinerary will be proposed by the Japan-side with concurrence of the U.S.-side Panel. 

STORM SURGE AND TSUNAMIS 



\title{
U.S. Operational Storm Surge Forecast Models
}

\author{
by
}

Wilson A. Shaffer" and Jye Chen"

\section{INTRODUCTION}

Historically, hurricane-related deaths have mostly been caused by drowning due to coastal flooding. The 1900 hurricane that struck Galveston, Texas caused the deaths of 10,000 to 12,000 people. (This is the greatest natural disaster to befall the U.S.) Galveston Island was overwashed by a storm surge, with waves riding above the surge. Virtually every building on the island was destroyed. But even in those early days of meteorology, there was a warning issued. Dr. Isaac Kline headed the weather office in Galveston. By observing the swell striking the coast in the morning, he correctly foretold the approach of the hurricane. He spent much of the day riding along the coast, warning residents of the great storm. Many were saved through his actions.

Weather observations and forecasts matured considerably since that devastating 1900 hurricane. We now use satellites, doppler radar, and aircraft reconnaissance to observe storms from their inception. We run sophisticated numerical models of the atmosphere which give a computer forecast of where a storm is going, as well as a hint of its future intensity. Forecasters at our National Hurricane Center combine all of this information to make forecasts of a storm's track and intensity out to 72 hours. This information is disseminated through various electronic means to inform the emergency management community and the public.

Unfortunately, hurricane forecasting is not an exact science. Track errors have improved over the past two decades, but is currently at $182 \mathrm{~km}$ $(100 \mathrm{nmi})$ for the average 24 hour forecast. As a result or lack of forecast skill, a relatively large area of the coastline must be warned and evacuated. Typically, 24 hours before landfall is the time when emergency managers must make an evacuation decision. Implicit in the track error is timing error. Using typical forward hurricane speeds, we see that a storm can make its landfall either 6 hours before or 6 hours after its projected time. Along our East Coast, this means that the storm could come at either high tide or low tide.

Another important forecast parameter is the strength, or intensity, of a hurricane. Today, we have only marginal "skill" in forecasting the intensity of a storm. We know, for example, that most hurricanes intensify as they go over warmer water and die out after land falling. However, there are exceptions to even these generalities. Hurricane Alicia (Galveston 1983) was intensifying as it passed over Houston, Texas. Hurricane Andrew (Miami 1992) seemed to loose strength over the Gulf Stream, then intensified as it struck Miami.

\section{STORM SURGE MODELING}

The NWS's Techniques Development Laboratory has developed two numerical models to forecast storm surges: the Special Program to List the Amplitudes of Surges from Hurricanes (SPLASH) (Jelesnianski, 1972) and the Sea, Lake, and Overland Surges from Hurricanes (SLOSH) (Jelesnianski et. al., 1992) models. SPLASH treated surges only up to a smoothed

\footnotetext{
* Techniques Development Laboratory, Office of Systems

Development, National Weather Service, NOAA, Silver Spring, in l?
} 
coastline. SLOSH considers overland flooding, flow up rivers, through sub-grid cuts, and along barriers. The SPLASH model, because of its limitations, is no longer used by the NWS.

The original goal of TDL's modeling effort was to produce a model that could be run in real-time to estimate the surge before a hurricane makes landfall. If a hurricane such as Camille was about to make landfall near Pass Christian, Mississippi, the NWS would run the SLOSH model to compute the possible flooding the hurricane would cause. Because of the uncertainty in forecasting the landfall location, several runs would be needed to capture the possible scenarios of the storm making landfall, all within the error limitations of the forecast.

Such computer runs are time-consuming. Only a limited number of SLOSH runs can be prepared, run, and analyzed as a storm approaches. When the next forecast package is issued containing a change in the hurricane's track or characteristics, a new set of runs would need to be prepared and run. This would continue for every forecast package up to the landfall time. Clearly, this process would be time consuming and difficult. Can you imagine the number of computer runs that would be made for a storm like Donna (1960) as it skirts the U.S.'s East Coast?

\section{MODEL INPUT AND VALIDATION}

The model was developed and tested extensively against observations from past hurricanes. Only parameters that could reasonably be forecast by NHC were incorporated as input to SLOSH. The hurricane was described numerically by its track, intensity, and size. The required track begins well before landfall and extends well beyond landfall. This assures that the storm's impact is correctly forecast numerically. The intensity of the storm is described in the model as the pressure drop from the ambient pressure outside the storm to the lowest pressure at the center of the storm. The outer ambient pressure can be obtained as the pressure of the first anticyclonic isobar from a weather map. In a forecast, the value of $1012 \mathrm{mb}$ is usually chosen. Aircraft reconnaissance measurements of central pressure are used to determine the central pressure of the storm. The storm's size is parameterized through the radius of maximum wind, as measured by reconnaissance aircraft.

The SLOSH model has been tested extensively (Jarvinen and Lawrence, 1985), with computed surge levels compared to observed high water marks and tide gage observations. In general, we claim that the observed and forecast surge levels vary by about $+/-20 \%$. However, the reader should keep in mind that these comparisons are done after the hurricane, when the track, size, and intensity are known. For such comparisons, the model is run with the same type of input as it is under true forecast conditions.

Not only are the maximum surge values compared, but we also compare the tide gage record, when possible, to the time-history generated by the model. Wind speed and direction are also compared whenever we have corresponding forecasts and observational data. Some of these comparisons are given in Jelesnianski, 1992. More recently, we compared the SLOSH wind field with the analyzed winds of Powell et. al., 1995. For most "well behaved" storms, the computed and the analyzed fields compare quite well. Hurricane Emily (1993) proved to be quite anomalous; SLOSH parametric winds and analyzed winds differed considerably.

\section{EVACUATION STUDIES}

The time required to complete an evacuation along the coastline were poorly understood before the 1980's. Most evacuations took place when the NWS issued a formal "hurricane warning", roughly 18 hours before landfall. Some coastal areas clearly needed more time to complete an evacuation. People living on the southern Florida Keys have approximately 100 miles to drive simply to get off the Keys, then another $\mathbf{3 0}$ miles to get to the Miami area. The city of New Orleans, Louisiana and its 
surrounding areas have a population of over a million persons. Much more time would be needed for an evacuation than the 18 hour warning period. Clearly, more information related to evacuations was needed by the NHC.

The NHC undertook several pilot studies to assist emergency management in assessing their risk due to storm surge. Instead of waiting for a hurricane to threaten, the NWS could run its SLOSH model during a convenient time to assess the potential flooding a hurricane of a given category would generate.

This methodology has expanded to simulation study in which they examine a full range of hurricane categories and land falling directions. For a typical stretch of coastline, NHC runs the SLOSH model for hurricanes making landfall from 10 different directions. Approximately a dozen runs will be made for each direction, with the landfall changed by approximately $15 \mathrm{~km}$ for successive model runs. Also, all five of the Saffir-Simpson hurricane categories are simulated for areas south of Cape Hatteras, NC. To the north, category 5 storms are considered extremely unlikely.

No one could be expected to assimilate such a large number of model runs and the overwhelming amount of flooding information generated by each run. Composites are formed which grousp together all storms of an individual direction. These Maximum Envelopes of Water (MEOW's) are formed as the highest surge forecast at each model gridpoint from the hurricanes of the chosen track direction.

Further compositing is done to depict each SaffirSimpson category's potential threat. These composites, called the Maximum Of the MEOW's, or MOM's, are formed by taking the highest value at each gridpoint for MEOW's of a given category.

\section{FORECASTER/EMERGENCY MANAGEMENT AIDS}

A computer graphics program has been written by TDL to aid NWS forecasters and emergency managers in their response to the hurricane threat. This program allows the user to view either MEOW's or MOM's for a given basin. The user can also inquire to find the projected surge heights at any location, as well as to window or zoom in to a given geographic area. This program has been distributed to NWS offices and to emergency managers trained at the NWS/FEMA workshop on hurricanes and evacuation planning.

In addition, there are several useful computer programs available that aid emergency managers in interpreting $\mathrm{NHC}$ products and in making the appropriate evacuation decisions.

\section{FORECASTS DURING HURRICANE OPAL, 1995}

Throughout the lifetime of hurricane Opal, 1995 from its formation over the Yucatan Peninsula, during its threat to the U.S. Gulf Coast, and as it died over the continental U.S., forecasts were continually being issued by NHC. Aircraft reconnaissance was flown during most of this period to gather information on the storm's intensity and movement. Satellite estimates of the storm's intensity and location were also being made.

Emergency management officials made preparations at various times to respond to the storm's increasing threat to their local jurisdictions. Approximately three days before the hurricane was projected to make landfall, emergency management began their preliminary actions. Personnel were called and alerted of the storm. Checkouts of operating procedures were conducted. Fuel tanks of emergency generators were topped off. Police and fire departments were put on alert.

As the hurricane came closer to the U.S., addition actions had to be taken. At approximately 24 hours before landfall, a go/no go decision on evacuation needs to be made. Studies have 
shown (J. Baker, personnel communication) that it takes 4-6 hours from the time that the emergency manager makes his decision to gather the county officials or city management officials to make the final decision.

Emergency management officials must keep in mind that the hurricane is an extensive phenomenon, not simply a point on a map. When we concentrate only on the eye position, we all have a tendency to think of that point as the storm and calculate our distance to the storm accordingly. In reality, gale force winds may extend outward from this center over $200 \mathrm{~km}$. Most emergency managers have chosen to have their evacuation completed by the time gale force winds reach the coastline, or when water rises to an elevation that would flood evacuation routes. In the vast majority of cases, the gale force winds will arrive first. If the hurricane is moving with a forward speed of $20 \mathrm{~km} / \mathrm{sec}$, the gale force winds would arrive approximately 10 hours before the hurricane's eye made landfall. Disaster could result from not taking such a "pre-landfall" hazards time into account.

\section{REFERENCES}

Houston, S. H., W. A. Shaffer, M. D. Powell, and J. Chen, "Comparisons of SLOSH parametric and HRD analyzed surface wind fields in recent hurricanes", Preprints, 21 st Conf. on Hurricanes and Tropical Meteorology, Miami, Florida.

Amer. Meteor. Soc., Boston, Massachusetts, 1995

Jarvinen, B. J. and M. B. Lawrence, "An evaluation of the SLOSH storm-surge model", Bull. Amer. Meteor. Soc., 66, 1408-1411 1985.

Jelesnianski, C. P., 1972: SPLASH (Special program to list the amplitudes of surges from hurricanes): I. Landfall storms, NOAA Technical Memorandum, NWS TDL-46, National Oceanic and Atmospheric Administration, U.S. Department of Commerce, 33pp.

Jelesnianski, C. P., J. Chen, and W. A. Shaffer, SLOSH, Sea, lake, and overland surges from hurricanes, NOAA Technical Report, NWS-48, National Oceanic and Atmospheric Administration, U.S. Department of Commerce, $71 \mathrm{pp}, 1992$. 


\title{
Long-term Shoreline Change in Japan
}

\author{
Shigenobu TANAKA*
}

\section{ABSTRACT}

Damages due to beach erosion have increased in recent years in Japan. Changes in the coastline of whole Japan were investigated by comparison of topographical maps. It results in that a net loss was 5,059 ha in 70 year period before 1978 and 2,395 ha in 15 year period after 1978. An annual net loss rate had been 72 ha per year before 1978 while it grew 160 ha per year after 1978. Erosion was severe along Hokkaido and the Japan Sea coast in both former period and latter one. A comparison of the erosion rates and crustal movements shows that the crustal subsidence in Hokkaido was favorable to the severe erosion while the crustal slight uplift on the Japan Sea coast did not support the erosion. Primary cause of long-term and overall erosion was considered to be a net offshore sand drift.

KEYWORDS: Beach Erosion, Comparison of Topographical Maps, Crustal Movement, Offshore Sand Drift

\section{INTRODUCTION}

Japan is an island country, and its people have deeply related to the ocean since ancient times. Geographically speaking, Japan is an arc-shaped chain of islands located in the northwestern, monsoon region of the Pacific Ocean. Compared to other places in the world, Japan is very susceptible to the harsh effects of waves. In addition, it has also suffered damage from countless tidal waves, or tsunami, because it is situated in the circum-Pacific earthquake region.

The land area of Japan is $378,000 \mathrm{~km}^{2}$ and the length of the coastline is as long as 34,500 $\mathrm{km}$. Compared with other countries, the coast length in relation to the land area of the country is quite long. Therefore, it is easy to under- stand the deep relation between the country and the surrounding ocean. The people of Japan have lived near the sea since the beginning of agricultural culture, and the use of coastal regions has grown along with the development of civilization. However, at the same time, lives and property have been lost countless times due to the destructive energy of the ocean. Then protection from coastal disasters has increased in importance along with expanded use of the ocean.

In recent years, instances of damages due to coastal erosion have gained frequent attention in the mass media. Such treatments of the subject seem to suggest that the cause of the problem lies in the development of river basins since the period of Japan's high economic growth. Actually, however, coastal erosion was a problem in some regions before the beginning of the high economic growth, and the problems involved are very complex. So far, the followings have been considered to be the causes of coastal erosion: the construction of large-scale structures on the coast, decreases in the supply of sediment from rivers and seacliffs, ground subsidence, and the influence of ocean waves and currents. However, it is still impossible to identify these precisely at present.

Though there is an accumulation of shoreline evolution of coasts data in which erosion is severe, data of the same preciseness with regard to tendencies and amounts of erosion is not available for the country as a whole. Changes in the shoreline between two points of time can be investigated through the following methods: comparison of topographical maps, comparison of aerial photographs, sounding measurements, etc. However, the easiest method of investigating the entire

\footnotetext{
* Head, Seacoast Division

Public Works Research Institute

1, Asahi, Tsukuba, Ibaraki, 305, Japan
} 
country with the same precision is the use of topographical maps. Regarding sandy beach shorelines, Koike (1977) used maps to investigate the 70 year period following 1890 , and Tanaka, et al. $(1973,1974)$ used aerial photographs to investigate major changes in the shoreline in the 20 year period following the World War II.

Since these reports were of more than a decade ago and damages around the whole country due to coastal erosion have increased recently, there is a need to grasp the situation of coastal erosion for the whole country. For this purpose, the newest maps as of 1992 were compared with those of 1978 to determine the situation of erosion since 1978. In addition, by comparing these results with the situation prior to 1978 , it was also possible to investigate trends in the erosion situation.

\section{NATIONWIDE SURVEY OF THE CUR- RENT SITUATION OF COASTAL ERO- SION}

\subsection{Method of the Survey}

In this study, all of the maps were on a scale of 50,000:1 of the Geographical Survey Institute. The newest maps as of 1978 (hereafter re- ferred to as second edition maps) were compared with those available in 1992 (hereafter referred to as current maps). In all, there were 607 maps that covered the whole country. Also, I compared the earliest, or, first edition maps with the second edition maps, focusing mainly on sandy beach shorelines. Although, in this comparison only 386 maps were used, it was possible to investigate nearly the entire country and to compare differences between the erosion from the Meiji Era to 1978 and that from 1978 to 1992 .

In Fig. 1, the areas covered by Koike, or in his compilation of the material taken from Tanaka, et al., are shown along with those of the present survey. From Fig. 1, it can be seen that the present survey covers a larger area than these earlier studies. It should be noted, however, that the legend for that from 1978 to 1992 is not shown, since the entire country was covered in this study.

The first edition maps were published between 1887 and 1934, and the average date of publication is 1905 . On the other hand, second edition maps were published between 1957 and 1978 , with the average year being 1973 . The current maps were published between 1976 and 1992, with the average of 1986.

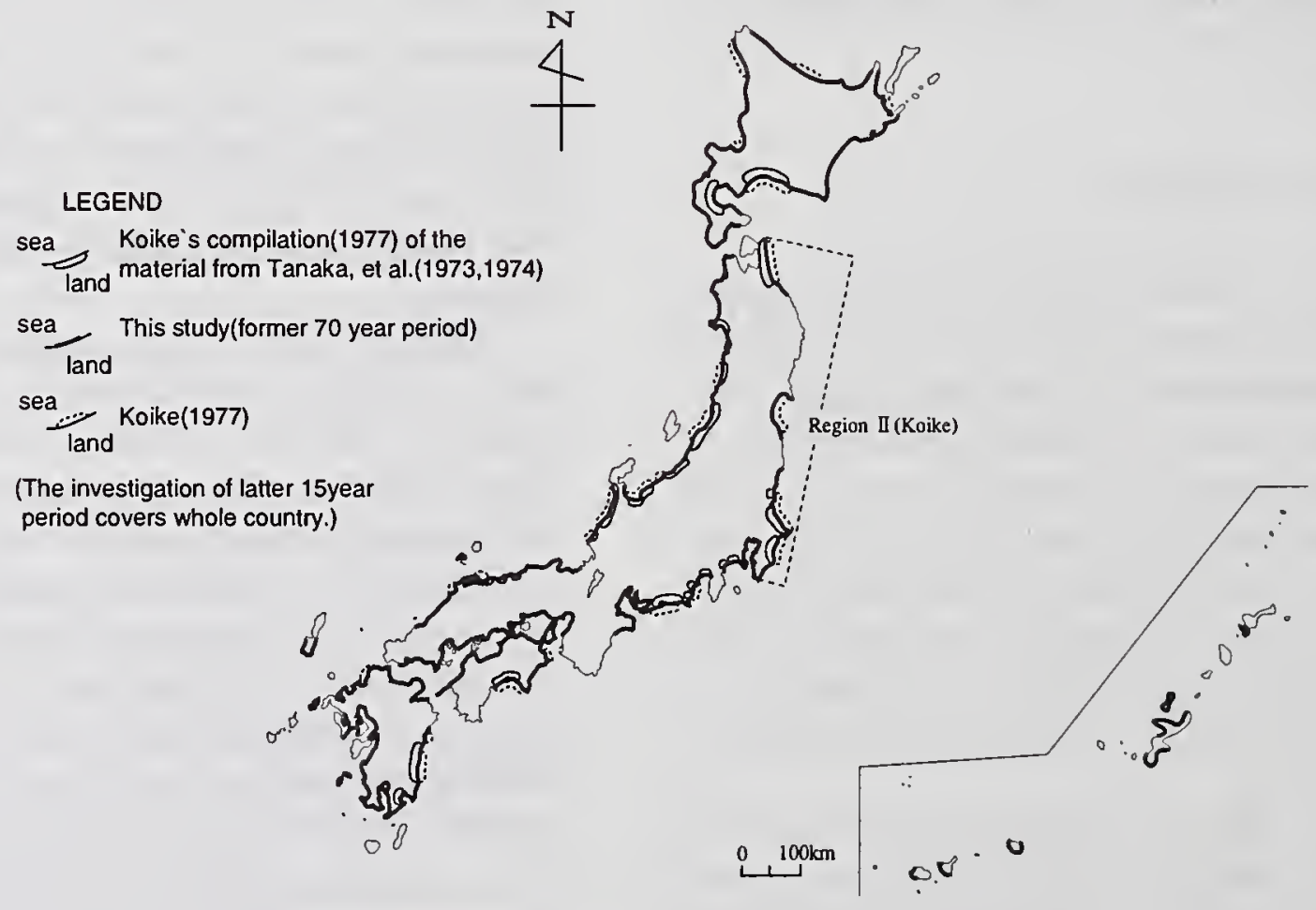

Fig. 1 Extention of Investigation Area 
Table 1 Shoreline Change in Area

\begin{tabular}{|c|c|c|c|c|c|c|}
\hline & \multicolumn{3}{|c|}{$1905-1978$} & \multicolumn{3}{|c|}{$1978-1992$} \\
\hline & Erosion & Accretion & Net Loss & Erosion & Accretion & Net Loss \\
\hline Total * & 12,539 & 7,480 & 5,059 & 4,605 & 2,210 & 2,395 \\
\hline Hokkaido & 4,534 & 1,869 & 2,665 & 1,921 & 631 & 1,290 \\
\hline Aomori & 676 & 60 & 616 & 182 & 94 & 88 \\
\hline Akita & 447 & 123 & 324 & 153 & 43 & 110 \\
\hline Yamagata & 84 & 53 & 31 & 65 & 43 & 22 \\
\hline Iwate & 21 & 13 & 8 & 8 & 9 & -1 \\
\hline Miyagi & 68 & 292 & -224 & 79 & 52 & 27 \\
\hline Niigata & 847 & 444 & 403 & 221 & 121 & 100 \\
\hline Fukushima & 259 & 68 & 191 & 65 & 73 & -8 \\
\hline Ibaraki & 300 & 306 & -6 & 114 & 176 & -62 \\
\hline Chiba & 315 & 658 & -343 & 249 & 127 & 122 \\
\hline Tokyo & 0 & 0 & 0 & 36 & 79 & -43 \\
\hline Kanagawa & 62 & 127 & -65 & 37 & 26 & 11 \\
\hline Shizuoka & 327 & 867 & -540 & 21 & 43 & -22 \\
\hline Toyama & 305 & 36 & 269 & 26 & 16 & 10 \\
\hline Ishikawa & 384 & 31 & 353 & 38 & 26 & 12 \\
\hline Fukui & 56 & 28 & 28 & 100 & 19 & 81 \\
\hline Aichi & 298 & 198 & 100 & 40 & 25 & 15 \\
\hline Mie & 196 & 200 & -4 & 51 & 26 & 25 \\
\hline Wakayama & 38 & 20 & 18 & 16 & 20 & -4 \\
\hline Kyoto & 49 & 9 & 40 & 10 & 12 & -2 \\
\hline Osaka & 20 & 17 & 3 & 1 & 17 & -16 \\
\hline Hyogo & 635 & 148 & 487 & 36 & 89 & -53 \\
\hline Tottori & 137 & 346 & -209 & 106 & 42 & 64 \\
\hline Shimane & 51 & 118 & -67 & 89 & 19 & 70 \\
\hline Okayama & 165 & 105 & 60 & 31 & 5 & 26 \\
\hline Hiroshima & 40 & 30 & 10 & 79 & 3 & 76 \\
\hline Yamaguchi & 191 & 37 & 154 & 55 & 10 & 45 \\
\hline Ehime & 296 & 97 & 199 & 53 & 24 & 29 \\
\hline Kagawa & 61 & 102 & -41 & 21 & 20 & 1 \\
\hline Tokushima & 233 & 157 & 76 & 28 & 11 & 17 \\
\hline Kochi & 114 & 123 & -9 & 78 & 75 & 3 \\
\hline Fukuoka & 189 & 64 & 125 & 3 & 10 & -7 \\
\hline Saga & 39 & 1 & 38 & 3 & 1 & 2 \\
\hline Nagasaki & 85 & 3 & 82 & 134 & 22 & 112 \\
\hline Kumamoto & 17 & 1 & 16 & 7 & 3 & 4 \\
\hline Oita & 356 & 97 & 259 & 90 & 8 & 82 \\
\hline Miyazaki & 170 & 366 & -196 & 95 & 46 & 49 \\
\hline Kagosima & 474 & 266 & 208 & 264 & 144 & 120 \\
\hline Okinawa & 341 & 332 & 9 & 1,117 & 597 & 520 \\
\hline
\end{tabular}

*Total does not include Okinawa pref.

As to the intervals between publication of first and second edition maps, its average was 67.5 years and its maximum interval was 74 years. So, I regarded these intervals as a 70 year period up to 1978. Similarly, as to the intervals between publication of second edition 
and current maps, its average was 14.6 years and its maximum was 18 years. So, I regarded these intervals as a 15 year period from 1978.

The method of measurement was as follows. First, the old maps and new ones were compared precisely and a drawing for measurement was made by sketching coastlines that had changed. Areas of coastal change are roughly divided into cases of erosion, sediment accumulation, reclamation, dredging, and estuaries. In this study, however, cases of estuaries, or river mouths, were excluded since there are significant seasonal and temporary fluctuations in the amount of sediment due to flood discharge from river. Also, cases of reclamation and dredging were excluded. A digitizer was used to measure the areas as well as lengths and widths of changed parts.

Resolution of the equipment used was 0.1 $\mathrm{mm}$. But there were errors due to such things as the widths of lines in the drawings (0.2-0.3 $\mathrm{mm}$ ), readings of the maps and orientation, consequently, overall preciseness of measurements was equivalent to measuring the shoreline changes of about $20 \mathrm{~m}$ in cross-shore direc- tion. Also, precision for area was approximately one hectare.

\subsection{Results and Considerations}

(1) Coastal Areas which Changed due to Erosion and Sedimentation

There are 39 prefectures with seacoast in Japan. Figure 2 shows each location of prefecture. The areas of erosion, sedimentation and net loss of land are shown in Table 1 for each prefecture. There are data of former 70 year period and of last 15 years. Though the results regarding Okinawa Prefecture are also shown in the table, these were disregarded in calculating the total since there were regions that diverge greatly from the actual situation. In the 70 year period, the area of erosion for the whole country was 12,539 ha. In contrast to this, the area of sedimentation was only 7,480 ha. This indicates a net loss of 5,059 ha. In the 15 year period, in contrast to the area of erosion for the entire country that was 4,605 ha, the area of accretion was 2,210 ha. This indicates a net loss of 2,395 ha. In both periods, erosion exceeded sedimentation and the tendency toward erosion

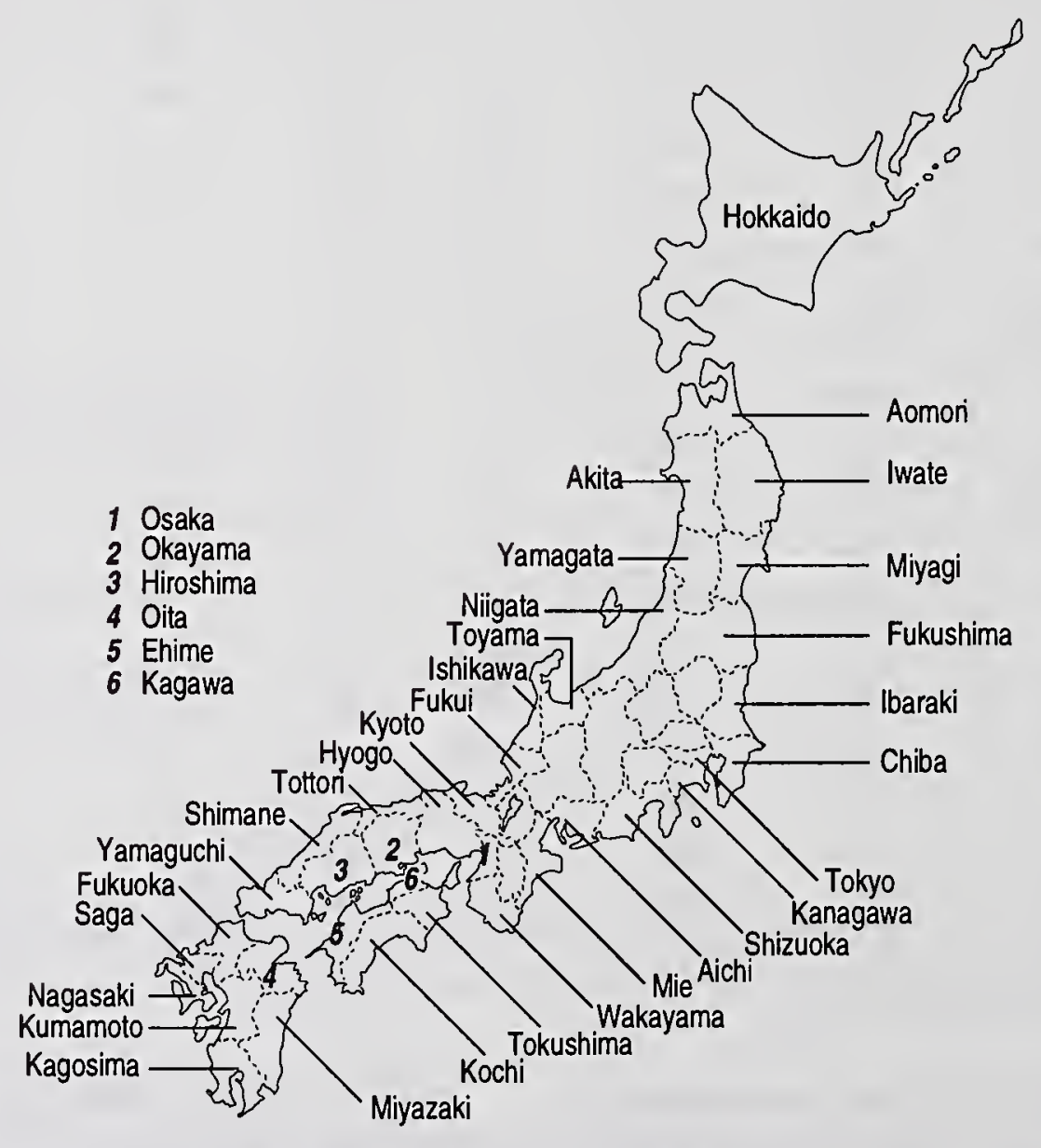

Fig. 2 Location of Prefecture 
Table 2 Shoreline Change Considering Extention of Sandy Coast

\begin{tabular}{|c|c|c|c|c|c|c|c|}
\hline & \multirow{2}{*}{$\begin{array}{c}\text { Sandy Beach } \\
\text { Length } \\
(\mathrm{km})\end{array}$} & \multicolumn{3}{|c|}{1905 - 1978} & \multicolumn{3}{|c|}{1978 - 1992} \\
\hline & & $\begin{array}{l}\text { Erosion } \\
\text { (m) }\end{array}$ & $\begin{array}{l}\text { Accretion } \\
\text { (m) }\end{array}$ & $\begin{array}{c}\text { Net Loss } \\
\text { (m) }\end{array}$ & $\begin{array}{c}\text { Erosion } \\
(\mathrm{m})\end{array}$ & $\begin{array}{c}\text { Accretion } \\
\text { (m) }\end{array}$ & $\begin{array}{c}\text { Net Loss } \\
\text { (m) }\end{array}$ \\
\hline Total * & $9,499.1$ & 13.2 & 7.9 & 5.3 & 4.8 & 2.3 & 2.5 \\
\hline Hokkaido & $1,993.1$ & 22.7 & 9.4 & 13.4 & 9.6 & 3.2 & 6.5 \\
\hline Aomori & 366.7 & 18.4 & 1.6 & 16.8 & 5.0 & 2.6 & 2.4 \\
\hline Akita & 146.7 & 30.5 & 8.4 & 22.1 & 10.4 & 2.9 & 7.5 \\
\hline Yamagata & 49.3 & 17.0 & 10.7 & 6.3 & 13.2 & 8.7 & 4.5 \\
\hline Iwate & 100.6 & 2.1 & 1.3 & 0.8 & 0.8 & 0.9 & -0.1 \\
\hline Miyagi & 167.6 & 4.1 & 17.4 & -13.4 & 4.7 & 3.1 & 1.6 \\
\hline Niigata & 290.1 & 29.2 & 15.3 & 13.9 & 7.6 & 4.2 & 3.4 \\
\hline Fukushima & 114.7 & 22.6 & 5.9 & 16.6 & 5.7 & 6.4 & -0.7 \\
\hline Ibaraki & 123.3 & 24.3 & 24.8 & -0.5 & 9.2 & 14.3 & -5.0 \\
\hline Chiba & 138.9 & 22.7 & 47.4 & -24.7 & 17.9 & 9.1 & 8.8 \\
\hline Tokyo & 113.8 & 0.0 & 0.0 & 0.0 & 3.2 & 6.9 & -3.8 \\
\hline Kanagawa & 89.9 & 6.9 & 14.1 & -7.2 & 4.1 & 2.9 & 1.2 \\
\hline Shizuoka & 227.0 & 14.4 & 38.2 & -23.8 & 0.9 & 1.9 & -1.0 \\
\hline Toyama & 65.7 & 46.4 & 5.5 & 40.9 & 4.0 & 2.4 & 1.5 \\
\hline Ishikawa & 188.8 & 20.3 & 1.6 & 18.7 & 2.0 & 1.4 & 0.6 \\
\hline Fukui & 135.3 & 4.1 & 2.1 & 2.1 & 7.4 & 1.4 & 6.0 \\
\hline Aichi & 111.7 & 26.7 & 17.7 & 9.0 & 3.6 & 2.2 & 1.3 \\
\hline Mie & 426.4 & 4.6 & 4.7 & -0.1 & 1.2 & 0.6 & 0.6 \\
\hline Wakayama & 135.0 & 2.8 & 1.5 & 1.3 & 1.2 & 1.5 & -0.3 \\
\hline Kyoto & 81.8 & 6.0 & 1.1 & 4.9 & 1.2 & 1.5 & -0.2 \\
\hline Osaka & 21.5 & 9.3 & 7.9 & 1.4 & 0.5 & 7.9 & -7.4 \\
\hline Hyogo & 202.6 & 31.4 & 7.3 & 24.0 & 1.8 & 4.4 & -2.6 \\
\hline Tottori & 93.1 & 14.7 & 37.2 & -22.5 & 11.4 & 4.5 & 6.9 \\
\hline Shimane & 269.5 & 1.9 & 4.4 & -2.5 & 3.3 & 0.7 & 2.6 \\
\hline Okayama & 157.5 & 10.5 & 6.7 & 3.8 & 2.0 & 0.3 & 1.7 \\
\hline Hiroshima & 187.3 & 2.1 & 1.6 & 0.5 & 4.2 & 0.2 & 4.1 \\
\hline Yamaguchi & 414.5 & 4.6 & 0.9 & 3.7 & 1.3 & 0.2 & 1.1 \\
\hline Ehime & 303.3 & 9.8 & 3.2 & 6.6 & 1.7 & 0.8 & 1.0 \\
\hline Kagawa & 196.4 & 3.1 & 5.2 & -2.1 & 1.1 & 1.0 & 0.1 \\
\hline Tokushima & 115.3 & 20.2 & 13.6 & 6.6 & 2.4 & 1.0 & 1.5 \\
\hline Kochi & 180.0 & 6.3 & 6.8 & -0.5 & 4.3 & 4.2 & 0.2 \\
\hline Fukuoka & 189.7 & 10.0 & 3.4 & 6.6 & 0.2 & 0.5 & -0.4 \\
\hline Saga & 54.6 & 7.1 & 0.2 & 7.0 & 0.5 & 0.2 & 0.4 \\
\hline Nagasaki & 787.1 & 1.1 & 0.0 & 1.0 & 1.7 & 0.3 & 1.4 \\
\hline Kumamoto & 141.8 & 1.2 & 0.1 & 1.1 & 0.5 & 0.2 & 0.3 \\
\hline Oita & 190.8 & 18.7 & 5.1 & 13.6 & 4.7 & 0.4 & 4.3 \\
\hline Miyazaki & 173.0 & 9.8 & 21.2 & -11.3 & 5.5 & 2.7 & 2.8 \\
\hline Kagosima & 754.8 & 6.3 & 3.5 & 2.8 & 3.5 & 1.9 & 1.6 \\
\hline Okinawa & 732.9 & 4.7 & 4.5 & 0.1 & 15.2 & 8.1 & 7.1 \\
\hline
\end{tabular}

*Total does not include Okinawa pref. 
Table 3 Shoreline Change in Length for 1978 - 1992

\begin{tabular}{|c|c|c|c|c|c|c|}
\hline & \multicolumn{3}{|c|}{ Changed Length } & \multicolumn{3}{|c|}{ Proportion to Sandy Beach } \\
\hline & $\begin{array}{r}\text { Erosion } \\
(\mathrm{km}) \\
\end{array}$ & $\begin{array}{c}\text { Accretion } \\
(\mathrm{km})\end{array}$ & $\begin{array}{r}\text { Total } \\
(\mathrm{km}) \\
\end{array}$ & $\begin{array}{c}\text { Erosion } \\
(\%)\end{array}$ & $\begin{array}{c}\text { Accretion } \\
(\%)\end{array}$ & $\begin{array}{c}\text { Total } \\
(\%) \\
\end{array}$ \\
\hline Total * & $1,320.4$ & 640.0 & $1,960.4$ & 13.9 & 6.7 & 20.6 \\
\hline Hokkaido & 521.7 & 198.8 & 720.5 & 26.2 & 10.0 & 36.2 \\
\hline Aomori & 64.5 & 26.6 & 91.1 & 17.6 & 7.3 & 24.8 \\
\hline Akita & 38.9 & 12.5 & 51.4 & 26.5 & 8.5 & 35.0 \\
\hline Yamagata & 16.0 & 14.2 & 30.2 & 32.4 & 28.8 & 61.2 \\
\hline Iwate & 3.1 & 2.9 & 6.0 & 3.1 & 2.9 & 6.0 \\
\hline Miyagi & 27.2 & 16.3 & 43.5 & 16.2 & 9.7 & 26.0 \\
\hline Niigata & 56.2 & 37.0 & 93.2 & 19.4 & 12.8 & 32.1 \\
\hline Fukushima & 19.3 & 18.0 & 37.3 & 16.8 & 15.7 & 32.5 \\
\hline Ibaraki & 25.7 & 26.1 & 51.8 & 20.8 & 21.2 & 42.0 \\
\hline Chiba & 53.5 & 32.8 & 86.3 & 38.5 & 23.6 & 62.1 \\
\hline Tokyo & 7.9 & 14.3 & 22.2 & 6.9 & 12.6 & 19.5 \\
\hline Kanagawa & 14.8 & 10.8 & 25.6 & 16.5 & 12.0 & 28.5 \\
\hline Shizuoka & 7.7 & 9.2 & 16.9 & 3.4 & 4.1 & 7.4 \\
\hline Toyama & 8.7 & 5.6 & 14.3 & 13.2 & 8.5 & 21.8 \\
\hline Ishikawa & 15.2 & 8.0 & 23.2 & 8.1 & 4.2 & 12.3 \\
\hline Fukui & 31.1 & 7.3 & 38.4 & 23.0 & 5.4 & 28.4 \\
\hline Aichi & 11.3 & 8.2 & 19.5 & 10.1 & 7.3 & 17.5 \\
\hline Mie & 14.8 & 9.7 & 24.5 & 3.5 & 2.3 & 5.7 \\
\hline Wakayama & 4.6 & 4.9 & 9.5 & 3.4 & 3.6 & 7.0 \\
\hline Kyoto & 4.9 & 4.3 & 9.2 & 6.0 & 5.3 & 11.2 \\
\hline Osaka & 0.2 & 5.9 & 6.1 & 0.9 & 27.4 & 28.3 \\
\hline Hyogo & 13.0 & 25.4 & 38.4 & 6.4 & 12.5 & 19.0 \\
\hline Tottori & 34.6 & 13.1 & 47.7 & 37.2 & 14.1 & 51.2 \\
\hline Shimane & 26.8 & 5.4 & 32.2 & 9.9 & 2.0 & 11.9 \\
\hline Okayama & 13.6 & 2.9 & 16.5 & 8.6 & 1.8 & 10.5 \\
\hline Hiroshima & 25.4 & 1.0 & 26.4 & 13.6 & 0.5 & 14.1 \\
\hline Yamaguchi & 14.9 & 4.1 & 19.0 & 3.6 & 1.0 & 4.6 \\
\hline Ehime & 21.3 & 10.3 & 31.6 & 7.0 & 3.4 & 10.4 \\
\hline Kagawa & 9.1 & 6.3 & 15.4 & 4.6 & 3.2 & 7.8 \\
\hline Tokushima & 9.8 & 4.2 & 14.0 & 8.5 & 3.6 & 12.1 \\
\hline Kochi & 26.3 & 20.4 & 46.7 & 14.6 & 11.3 & 25.9 \\
\hline Fukuoka & 1.2 & 3.4 & 4.6 & 0.6 & 1.8 & 2.4 \\
\hline Saga & 0.9 & 0.3 & 1.2 & 1.6 & 0.5 & 2.2 \\
\hline Nagasaki & 43.4 & 8.9 & 52.3 & 5.5 & 1.1 & 6.6 \\
\hline Kumamoto & 2.6 & 0.7 & 3.3 & 1.8 & 0.5 & 2.3 \\
\hline Oita & 32.9 & 3.7 & 36.6 & 17.2 & 1.9 & 19.2 \\
\hline Miyazaki & 26.0 & 11.3 & 37.3 & 15.0 & 6.5 & 21.6 \\
\hline Kagosima & 71.3 & 45.2 & 116.5 & 9.4 & 6.0 & 15.4 \\
\hline Okinawa & 250.8 & 131.7 & 382.5 & 34.2 & 18.0 & 52.2 \\
\hline
\end{tabular}

*Total does not include Okinawa pref.

continues. The annual average loss was $72 \mathrm{ha}$ year in the 70 year period, while it was $160 \mathrm{ha} /$ year in the 15 year period. It can be seen from these figures that the rate of loss of national land area is increasing extremely.

Looking at prefectures separately, Hokkaido 
shows the greatest erosion for both periods, making up $2 / 5$ of the figure for the entire country. Though Hokkaido also had the most sedimentation, since this was not as much as the erosion, the amount of net loss area was large. In fact, its net loss is more than half of that for the country.

\section{(2) Average Cross-shore Change}

Each prefecture has different length of coast, and there are also differences in the lengths of sandy coasts. For this reason, comparisons of the extensions of sandy coasts were attempted. Table 2 shows the results of dividing the changed areas in Table 1 by lengths of sandy coasts that is based on a survey of Geographical Survey Institute in 1975 to get the average cross-shore change. During the 70 year period, there was an average net retreat of 5.3 $\mathrm{m}$. During the 15 year period, there was an average net retreat of $2.5 \mathrm{~m}$. In other words, sandy coasts receded an average of $1 \mathrm{~m}$ over a 6 year period in the 15 year period. Also, during the 70 year period, prefectures with over $10 \mathrm{~m}$ of sedimentation were Miyagi, Chiba, Shizuoka, Tottori, and Miyazaki ; but during the 15 year period, with the exception of Shizuoka Prefecture, all of these switched to net retreat due to erosion. Even in the case of Shizuoka Prefecture, the average amount of sedimentation decreased from $23.8 \mathrm{~m}$ to $1 \mathrm{~m}$; and it is thought that erosion will eclipse sedimentation in the future. During the 15 year period, the prefectures with large average net retreat included Chiba, Akita, Tottori, Hokkaido, and Fukui.

(3) Shoreline Length which Changed due to Erosion and Sedimentation

Table 3 shows shoreline length changed due to erosion and sedimentation, and the proportions of these two processes in sandy coastal extension in the 15 year period. The total length of erosion was $1,320 \mathrm{~km}$ while the sedimentation was only $640 \mathrm{~km}$, and an advance to retreat ratio becomes 0.48 . The erosion area of 4,605 ha and sedimentation area of 2,210 ha also gives almost the same ratio. Calculation with the areas and the lengths show average widths to be $34.9 \mathrm{~m}$ for erosion areas and $34.5 \mathrm{~m}$ for areas of sedimentation. In addition, $13.9 \%$ of all sandy coast in Japan are subject to erosion, while sedimentation is apparent in $6.7 \%$. In other words, in the last 15 years, about $20 \%$ of sandy coastal areas have experienced erosion or sedimentation of $20 \mathrm{~m}$ or more. Prefectures with eroded sandy shoreline exceeding $20 \%$ include Hokkaido, Akita, Yamagata, Ibaraki, Chiba, Fukui and Tottori. Furthermore, in Yamagata, Chiba and Tottori prefectures, the length of coastline changes of $20 \mathrm{~m}$ or more caused by erosion or sedimentation exceeded half of their sandy coast.

\section{(4) Rates of Beach Erosion}

According to Koike, the ratio advanced coastlines to from 1890 to 1965 is 1.24 . The ratio for the 20 years following the World War II is 1.05. According to the present study, the ratio and erosion for the 70 year period, which nearly corresponds with the earlier period just cited above, is 0.57 , while for the 15 year period it is 0.48 . Though the results of both studies correspond in showing the tendency towards increased erosion, there is a wide discrepancy in the numbers. The principal reason for this is that Koike only measured coastline changes of more than $50 \mathrm{~m}$ in width for those coastlines that had sandy coast more than 500 $\mathrm{m}$ wide and more than $5 \mathrm{~km}$ long. For instance, the advance/retreat ratio for Koike's Region II(see Fig. 1) is $84 \mathrm{~km} / 36 \mathrm{~km}=2.33$. In the present study, however, the ratio for the total of the Shimokita-Hachinohe Coast, the Sendai Bay Coast and the Kashima-nada Coast is $116 \mathrm{~km} / 122 \mathrm{~km}=0.95$. There are large defference between the Koike's and present study. But, when the area west of the Shiriyazaki Cape, which is north top of the Region II, is excluded and only areas with more than $50 \mathrm{~m}$ of change in width are collected, the result is $96 \mathrm{~km} / 50 \mathrm{~km}=1.92$. This latter figure is closer to Koike's. This discussion leads us to consider that the shoreline in areas of the type which Koike investigated where there is a very long and wide coast, is somewhat in favor of accretion .

As can be gleaned from the information obtained by comparing topographical maps as described above, it can be seen that there are obvious topographical changes in Japan. In particular, erosion greatly exceeds sedimentation, and 
Advance/Retreat ratio

$>1.0$ Sedimentation

$=1.0$ No Net Loss

$<1.0$ Erosion

(1)

Land uplift is taken as
positive (shaded area)
Unit : mm/year
(after Kato)

1905-1978 $\quad 0.53$

1978-1992 0.39
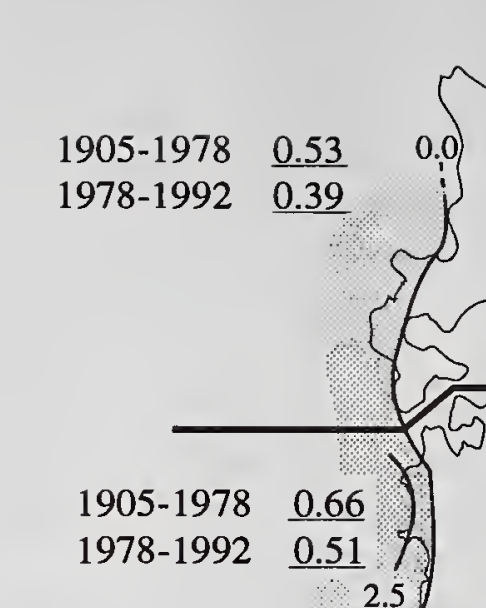

1978-1992

1905-1978
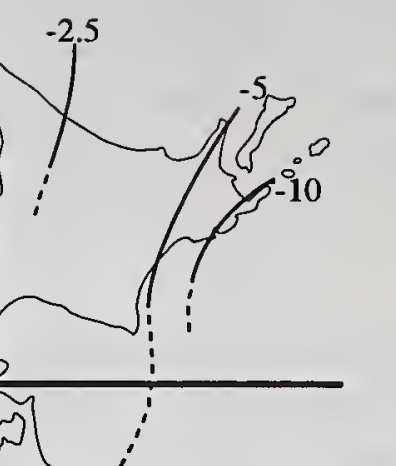

Japan Sea

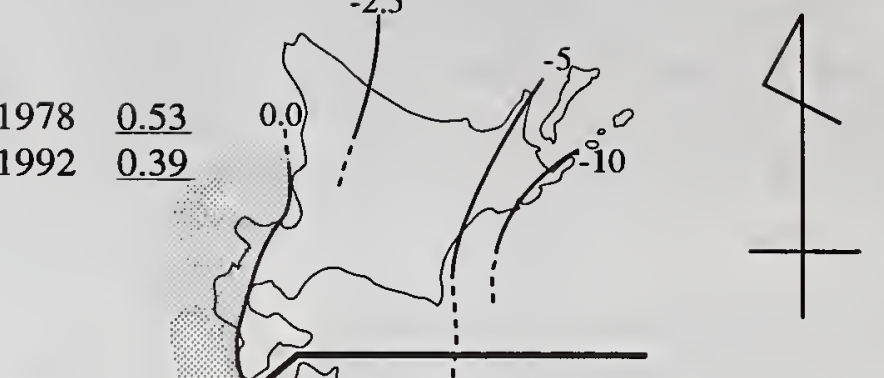

1905-1978 $\quad \underline{0.59}$

\section{8-1992}

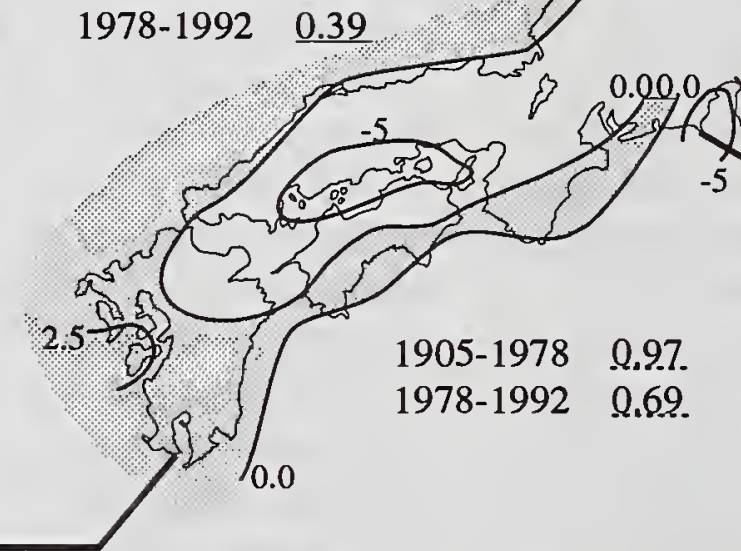

1905-1978 0.97.

Pacific Ocean

\begin{tabular}{cc}
$1905-1978$ & 0.84 \\
$1978-1992$ & 0.75 \\
\hline
\end{tabular}

\begin{tabular}{cc}
$1905-1978$ & 0.84 \\
$1978-1992$ & 0.75 \\
\hline
\end{tabular}

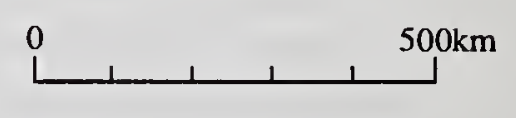

Fig. 3 Vertical Crustal Movements at the Coast (1951-1982) and Advance/Retreat Ratio

is in fact becoming worse.

\section{COMPARISON WITH EROSION AND CRUSTAL MOVEMENT}

Figure 3 shows advance/retreat length ratios for large blocks of coast. In this figure, upper is the one for the 70 year period and lower is for the 15 year period. In all blocks and both periods the ratio is less than 1.0 , that is, erosion has exceeded accretion and there has been a net loss. Further, in any blocks, the ratios became lower. This tendency shows that beach erosion in Japan has become severer. Looking at blocks separately, erosion is severe in Hokkaido and the coast along the Japan Sea.

Figure 3 also shows vertical crustal movements in Japan as deduced from tidal records for the period 1951 - 1982 after Kato, et al.(1983). Shaded area indicates crustal uplift. It can be found that there had been rapid subsid- ence in northeast part of Japan. This fact agrees well with the severe erosion in north part of Japan. In other part, there is no good agreement between vertical crustal movements and beach erosion. Especially, on the Japan Sea coasts, though the vertical crustal movement was positive, the beach erosion was rather severe. In addition, in the areas facing the Japan Sea, because the economic growth of them has been not so high compared to the Pacific Ocean side, there are few large-scale structures on the coast nor so much development in river basins. After all, it is concluded that the vertical crustal movement might be one of the causes of severe erosion of Japan, however, it is not the major one and the mechanism of erosion is still uncertain.

\section{TYPICAL EXAMPLES OF EROSION}

Let us look at examples of coastal erosion 


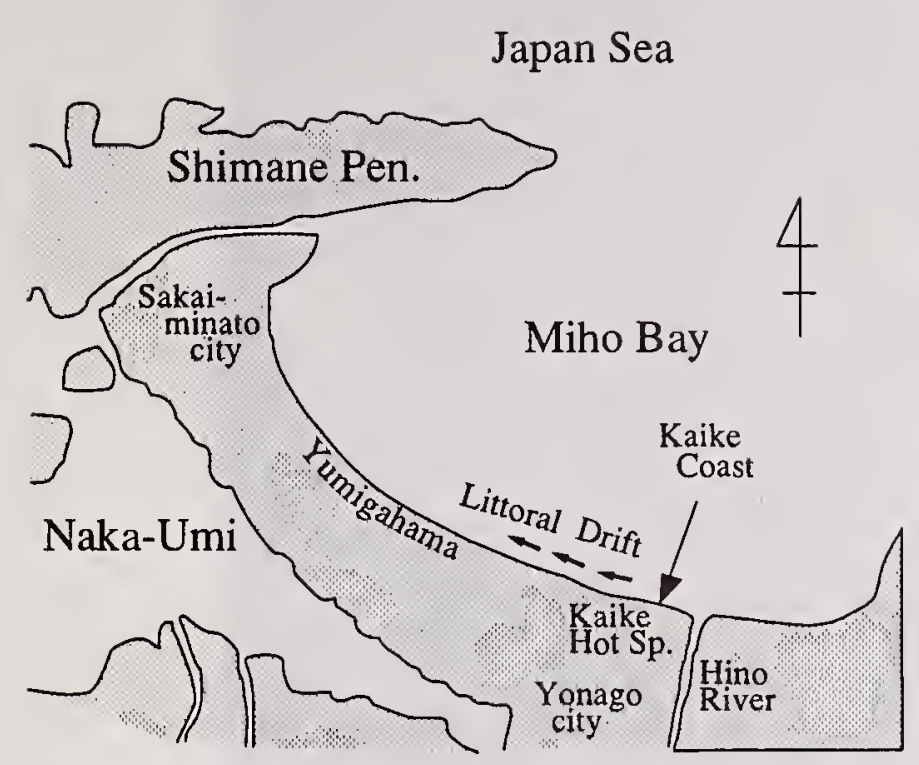

Fig. 4 Location of Kaike Coast and its major causes. As stated previously, coastal erosion is a result of the complex interactions of many factors. Careful examination is, therefore, required in considering possible countermeasures.

\subsection{Erosion from Old Days \\ (1) Kaike Coast}

Kaike coast is located in the midwest part of the Japan Sea coast. There are Kaike hot spring and Yonago city behind it. Between Yonago City and Sakaiminato City in Tottori Prefecture, there is an arc-shaped coastline lined with white sand and pine trees by the name of "Yumigahama", which means arc-shaped beach in Japanese.(see Fig. 4) It is considered that Kaike beach had been formed from the discharged sediment from Hino River whose upstream basin had been famous for iron production from iron sand. As the iron production caused a lot of sediment discharge into the Hino River(see Photo 1), the shoreline of Kaike beach progressed, for example, $180 \mathrm{~m}$ in 30 years from 1868. However, as the iron production

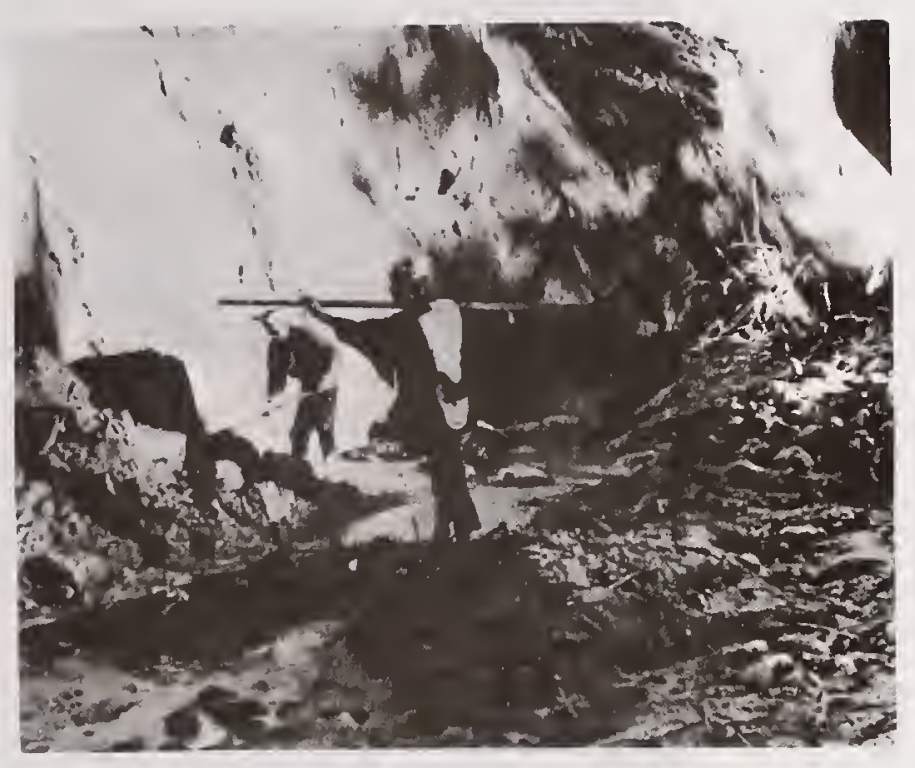

\section{Photo 1 Digging Decomposed Granite for Separation of Iron Sand}

declined around 1920 due to modernization, the beach began to suffer from erosion. In particular, about $300 \mathrm{~m}$ of sandy beach has been eroded away due to wave action at the front beach of Kaike hot springs, with losses both of hot spring wells as well as of hotels (see Photo $2)$. In view of countermeasures against erosion, this coast was one of the first coasts in Japan at which many countermeasures carried out. First, jetties were constructed in 1947. Once the beach was restored, but in a few years it became unsuccessful. Next, seawall was applied. However, erosion could not be stopped.

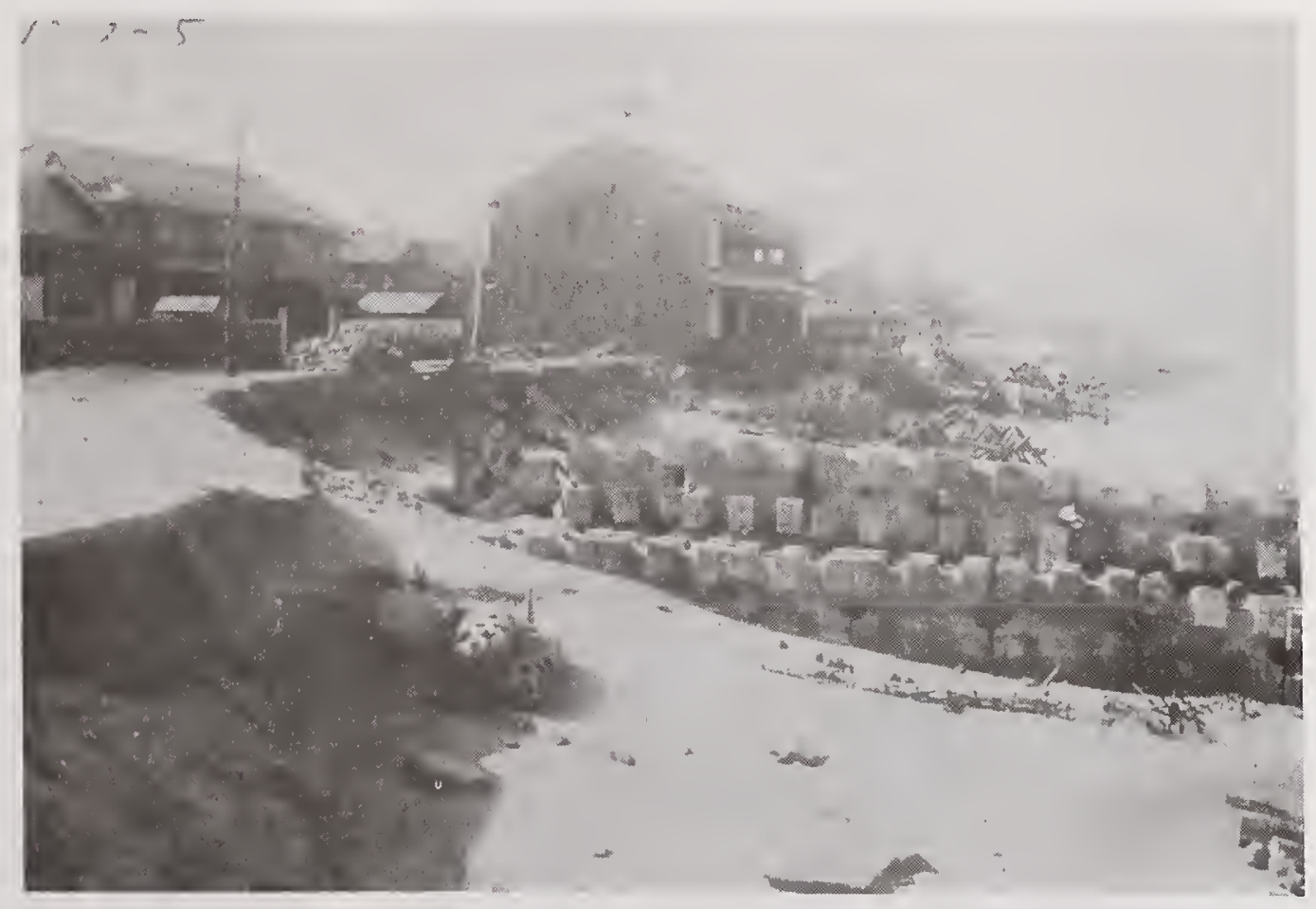

Photo 2 Hotel is about to Collapse 


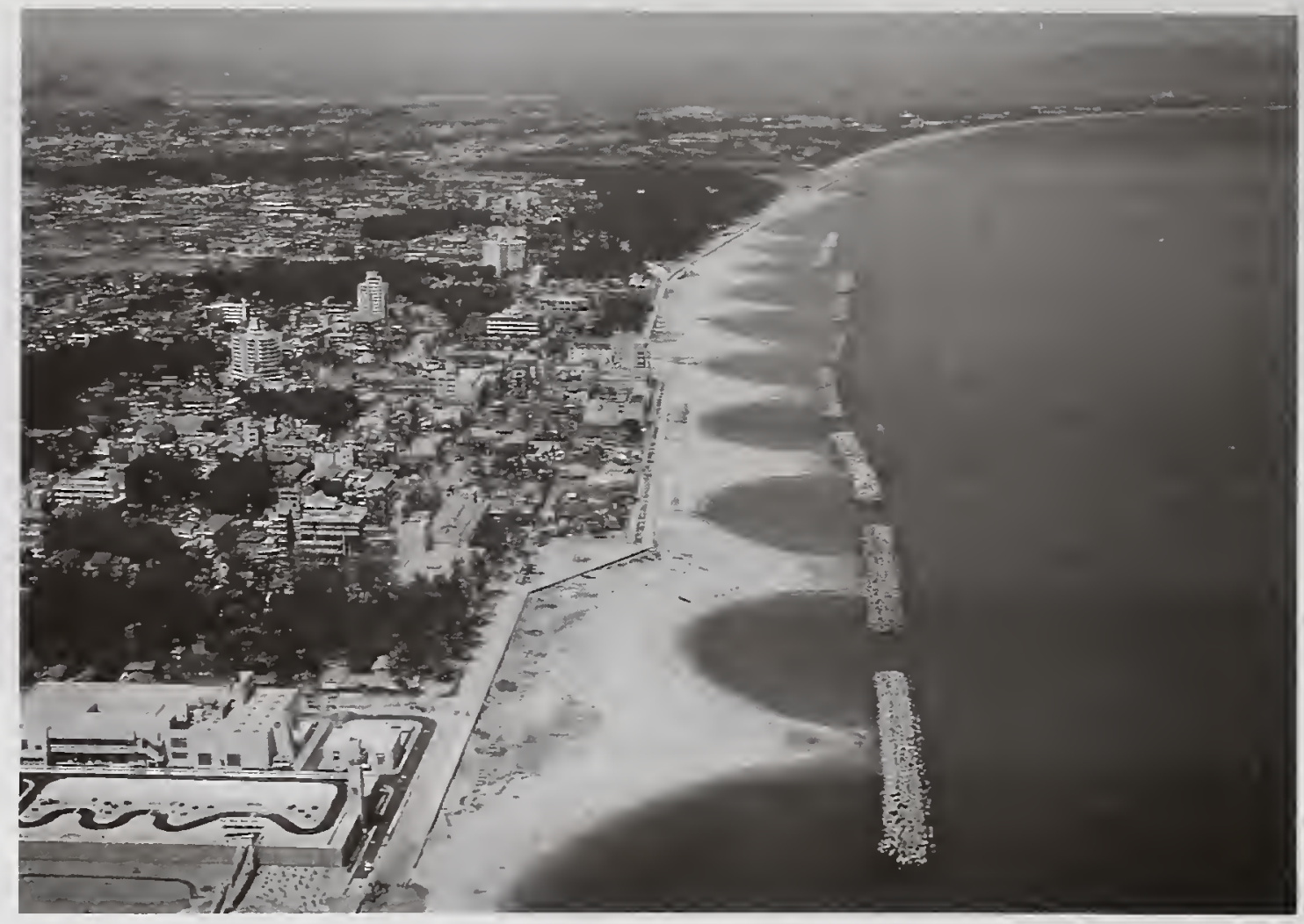

Photo 3 Detached Breakwaters and "Tombolo" at Kaike Beach
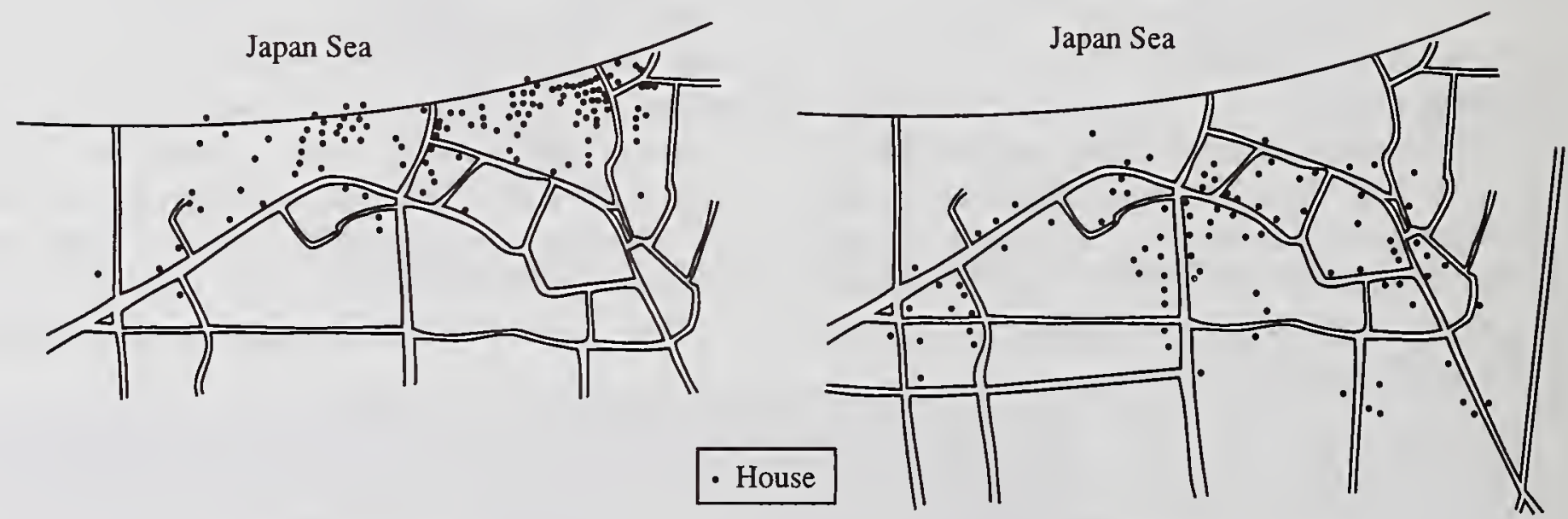

Before moving

After moving(1977)

Fig. 5 Houses Moved Inland due to Erosion at Shimoniikawa Coast

Finally, detached breakwater was introduced since 1971, then tombolo formed behind the detached breakwater, and beach erosion stopped (see Photo 3).

\section{(2) Shimoniikawa Coast}

The Shimoniikawa coast is situated near the mouth of the Kurobe River which runs through the eastern part of Toyama Prefecture. In this region, villages are located along the arc of the fan-shaped delta of the Kurobe River at which underground water is plentiful. In this coast, erosion has been a serious problem since an- cient days due to sand and gravel moving in a westerly direction, and there are records that villages have had to relocate inland several times(see Fig. 5). Further, swells peculiar to Toyama Bay are exceptionally huge, and coastal disasters have occurred repeatedly in conjunction with erosion. Still more, the slope of the seabed is very steep, and there is no place for coastal sand to accumulate on the coast. Judging by above fact, it is thought that sediment is swept away to the deep ocean. So far, seawall was completed but detached breakwater has been carried out mainly near villages as 


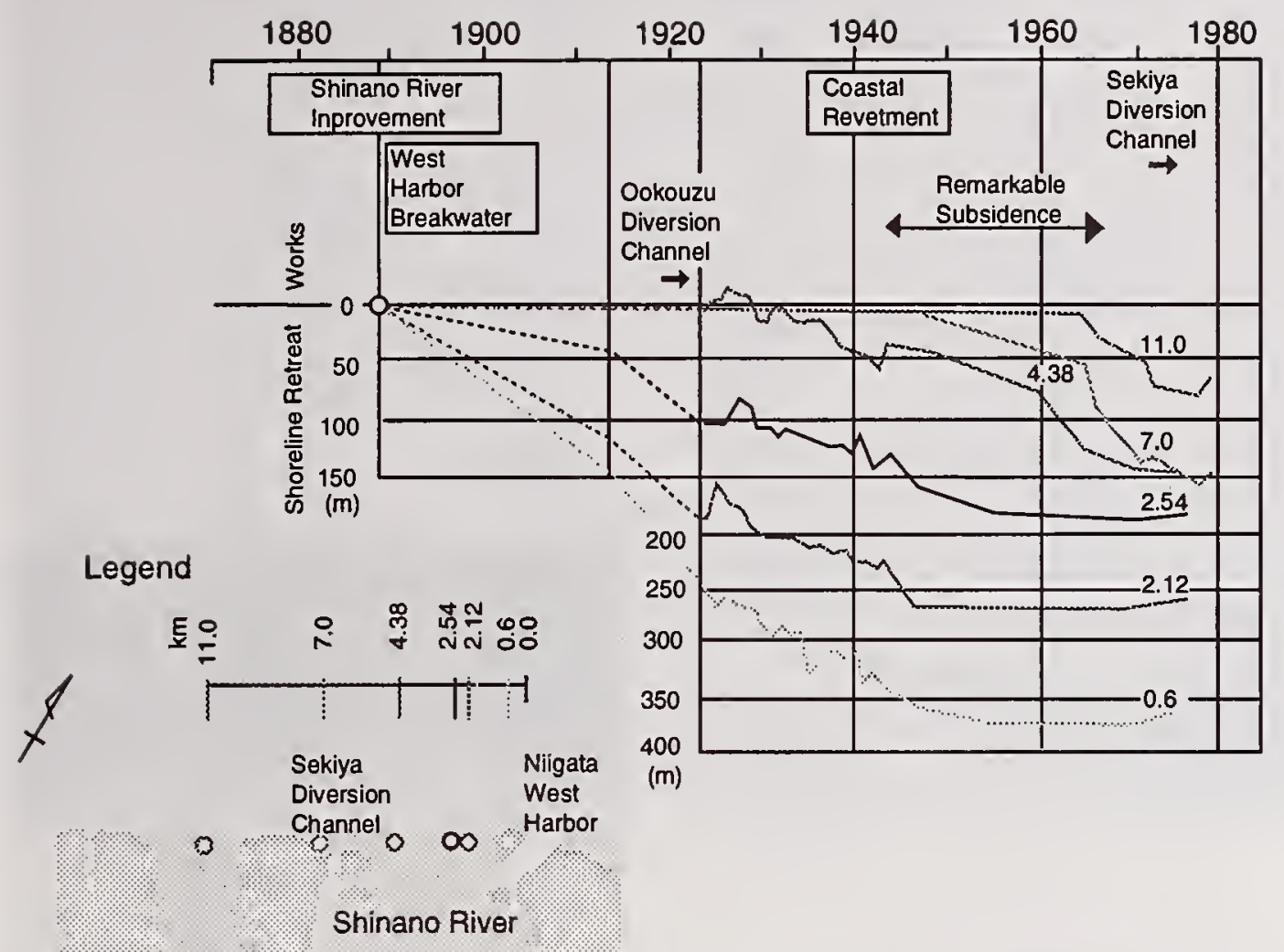

Fig. 6 Erosion and Major Causes in Niigata Coast

an emergent measure against erosion and high wave.

\section{(3) Niigata Coast}

Niigata is located in the central part of the Japan Sea coast. The Niigata Plain is one of the biggest alluvial lowlands in Japan and has several sand dune ridges. The Shinano River, which is the longest river in Japan, and the Agano River run into the sea at Niigata city. It is said that Niigata coast has been eroded since 1890 's. Figure 6 shows the erosion history of this coast. A meteorological observatory was constructed $100 \mathrm{~m}$ landward from the shoreline in 1928, but it was collapsed in the water in 1949 (see Photo 4). Major causes of the beach erosion have been thought to be 1)interruption of sand drift in a westerly direction due to the construction of breakwater of Niigata West Harbor, 2)reduction in the amount of sediment discharge from the Shinano River due to the operation of Ookouzu flood channel and 3) ground subsidence due to extraction of ground water for natural gas. For the countermeasure, seawall was constructed first. The beach could not be restored enough untill the detached breakwater was introduced. In stead of detached breakwaters, however, artificial reef method has been recently applied because Niigata city, the major city along the Japan Sea, is famous for sunset scenery.

4.2 Problem of Coastal Structure Interrupting Littoral Sand Drift

The Shimokita-Hachinohe Coast is located in the north Pacific coast of Honshu Island. In

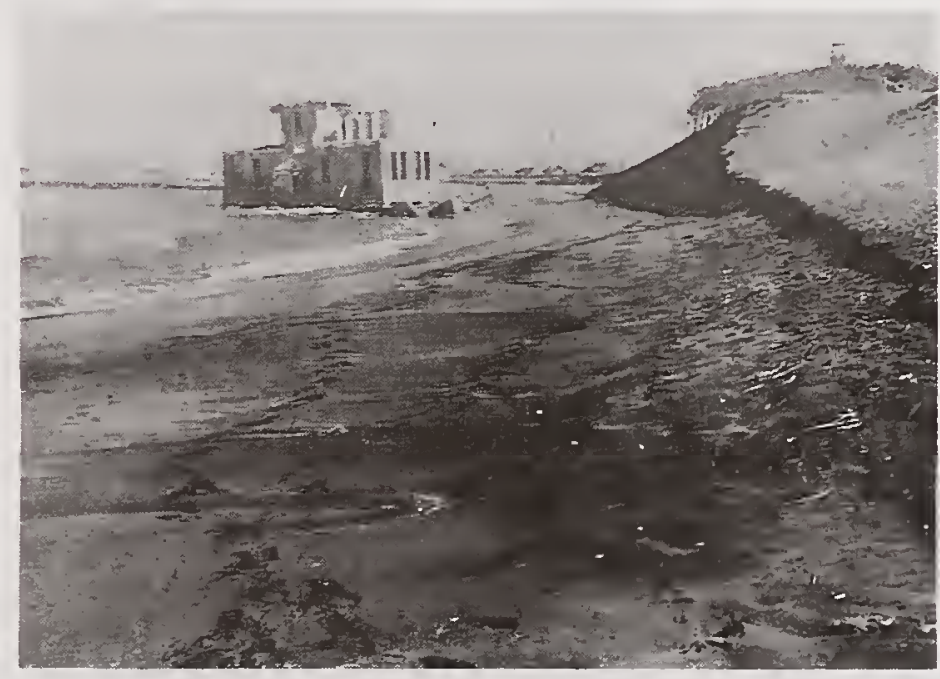

Photo 4 Collapsed Meteorological Observatory at Niigata Coast 


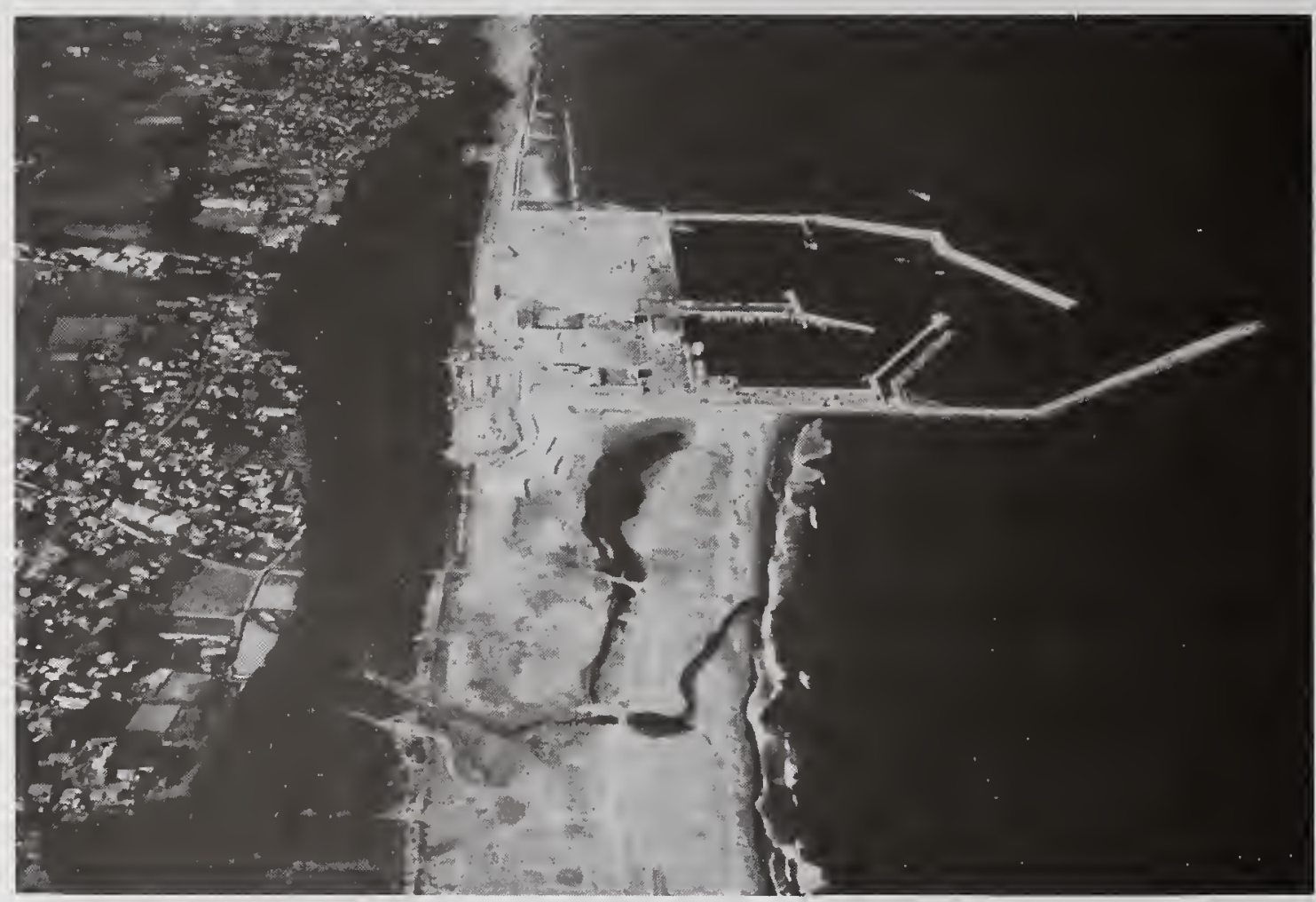

Photo 5 Severe Erosion and Sedimentation around Misawa Fishery Port

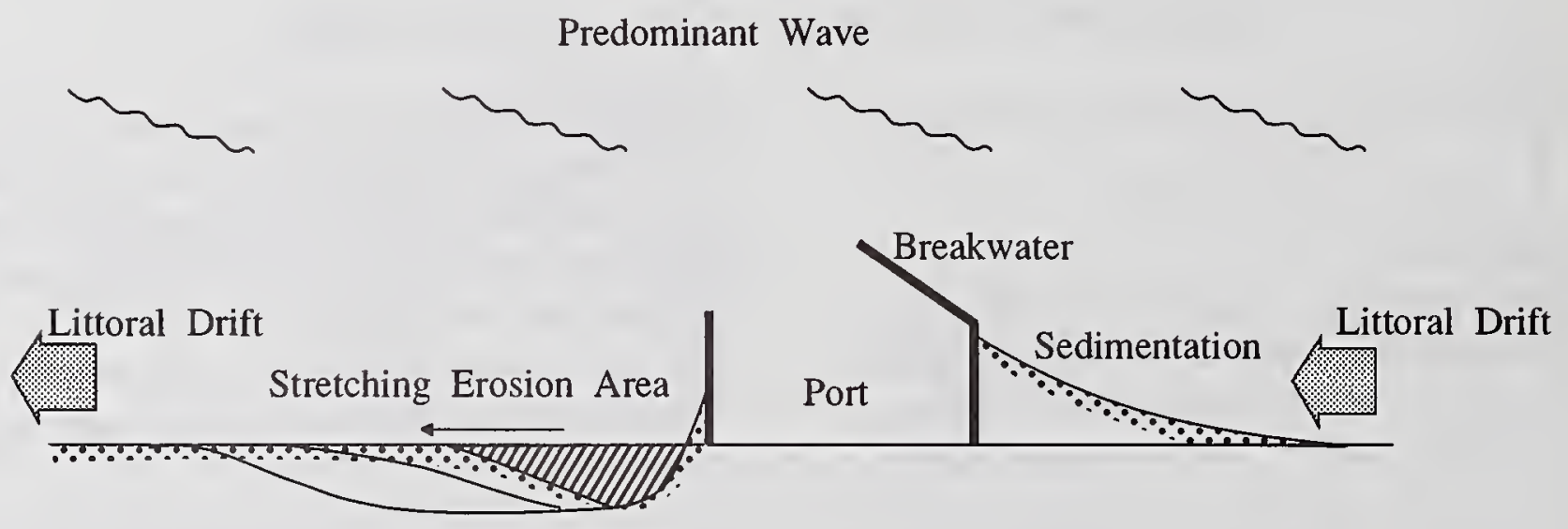

Fig. 7 Beach Changes around the Port Interrupting Littoral Drift

this area, a northerly littoral drift is predominant. In Photo 5, while large advance of the shoreline can be seen on the southern side, there is severe erosion on the northern side. Though seawalls and wave dissipating works have been built, the area of erosion is gradually expanding to the north direction. In 1987, sediment stretching $3 \mathrm{~km}$ in length and $150 \mathrm{~m}$ in width accumulated on the southern side of the breakwater. On the other hand, on the northern side there was erosion for $6 \mathrm{~km}$. Uda (1991) shows a diagram shown in Fig. 7 for this kind of situation.
4.3 Erosion near the Lee of Large Offshore Structure

The Oarai Beach is situated on the northern end of the Kashima-nada coast, which is located in the central Pacific coast. There is Oarai harbor next to the beach, and in conjunction with expansion of the harbor, large-scale breakwaters have been built. As a result, however, erosion problems have developed (see Photo 6). Uda (1991) also shows a diagram shown in Fig. 8 for this kind of situation. Because waves behind the breakwater become smaller, a difference in wave height occurs between in the lee side of the offshore breakwater 


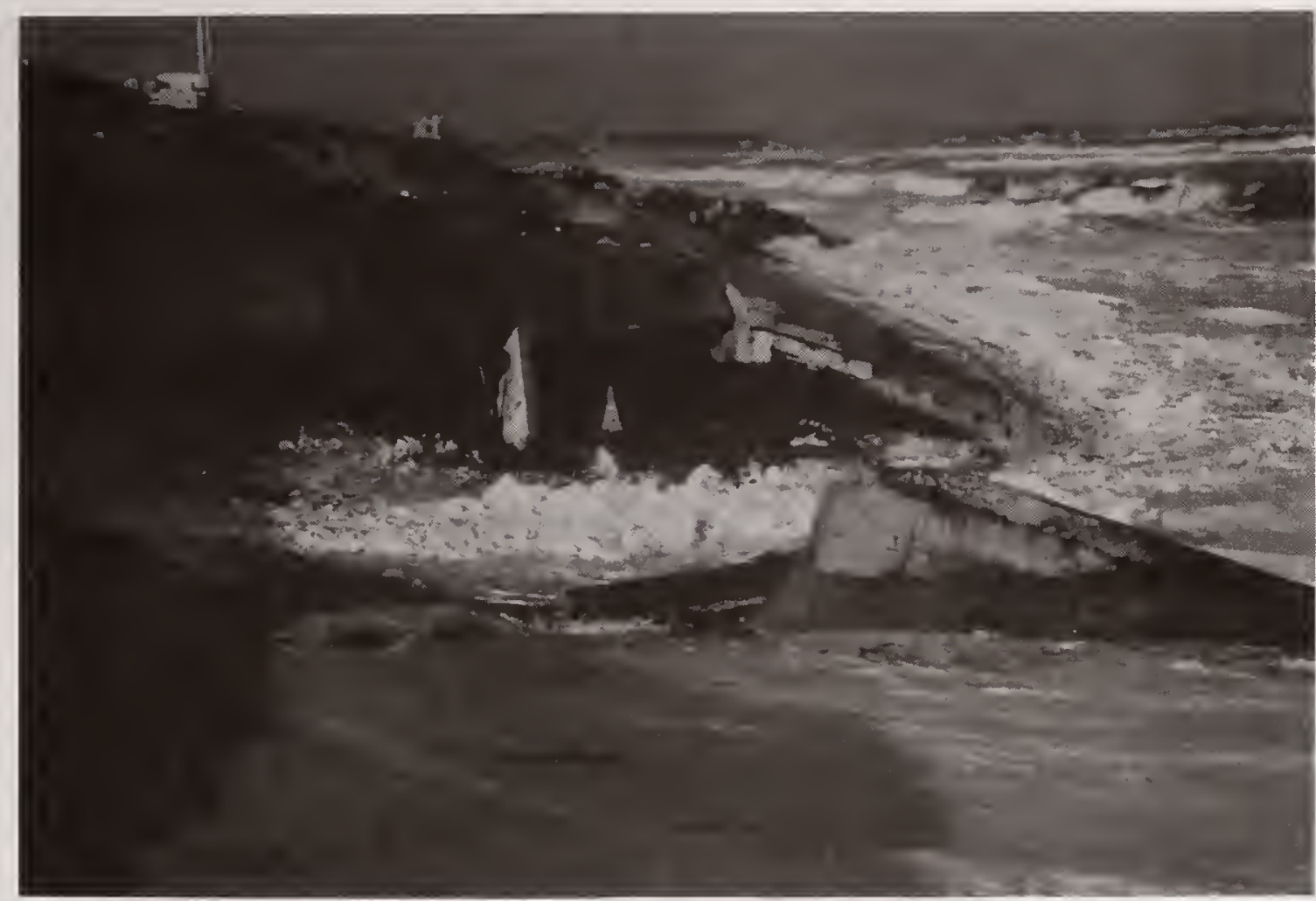

Photo 6 Seawall Damage by Erosion at Oarai Beach

and out of it. This condition develops a circulating current that flows toward inside of the harbor near the beach. This current causes littoral drift into the harbor. On the other hand, in the area out of the lee of offshore breakwater, because littoral drift is induced by incident waves, the direction of littoral drift is out of harbor for this wave condition. Therefore, Erosion occurs in the area where the tip of the breakwater is projected upon the shore in the direction of the predominant waves, and this area stretches in both directions along the shore. On the harbor side, however, as an effect of the

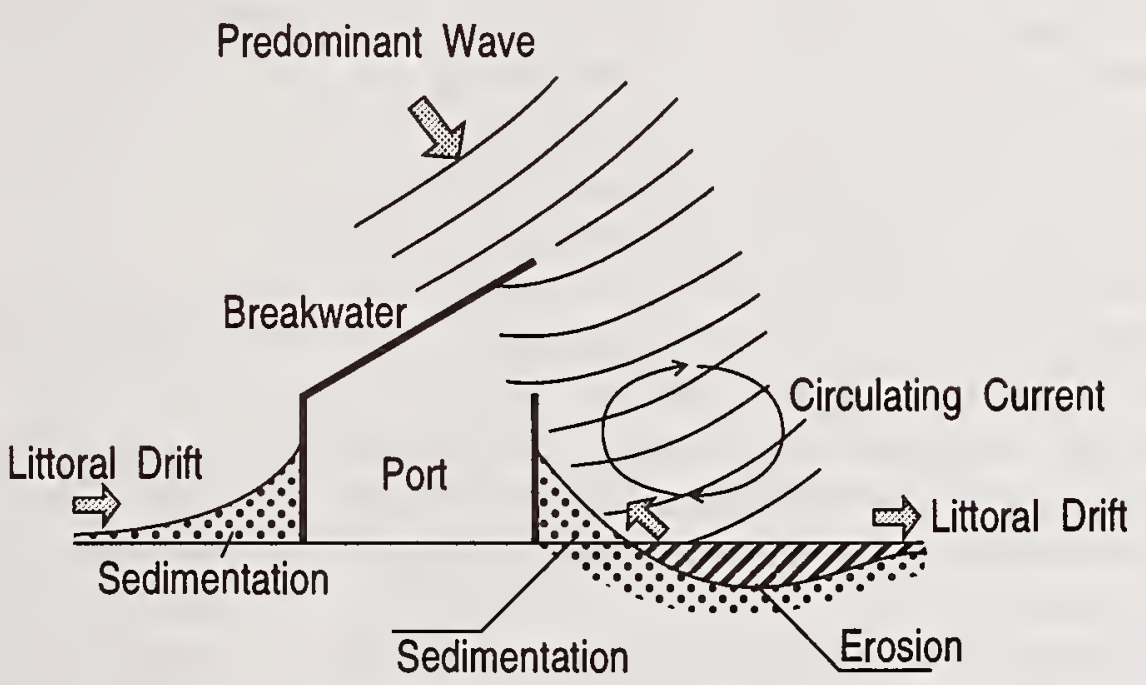

Fig. 8 Beach Changes in the Lee of Offshore Breakwater circulating current and calming of wave, sand accumulates in the harbor and near the breakwater (see Photo 7).

\section{CAUSES OF EROSION}

As noted previously, though coastal erosion is a phenomenon that has been observed since long ago, its causes are complex and have not yet been clarified. In this regard, let us consider the movement of sand on the coast. 
amounts coming in and going out are balanced, there is no change in the amount of sand within the system; but when the amount going out exceeds the amount supplied, then there is a net loss in the system and erosion occurs.

It is supposed that the effect of the imbalance of $B_{1}$ and $B_{2}$ is small in Japan.

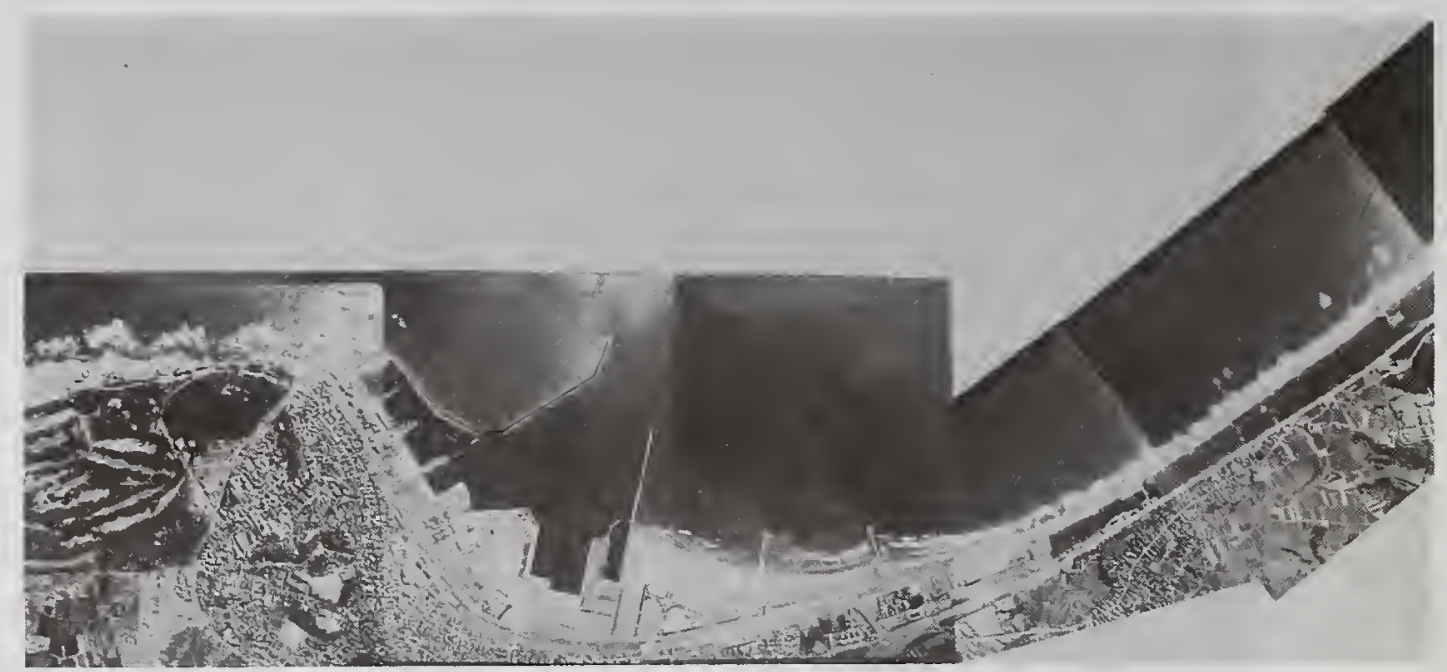

Photo 7 Beach Changes in the Lee of Oarai Harbor

From the macro scale point of view the sand moved due to littoral drift $\mathrm{L}_{1}$ and $\mathrm{L}_{2}$ will remain nearshore. Th erosion and sedimentation like section 4.2 and 4.3 by the imbalance of $\mathrm{L}_{1}$ and $\mathrm{L}_{2}$ is therefore considered to be diminished as a whole while there are local severe erosion and sedimentation. Further, in spite of the sediment discharge from river, there were coasts that suffered from erosion from early days as Shimoniikawa coast. And the net loss of national land has been increased quickly. Additionally, the crustal movement could not give enough explanation of erosion all over Japan. These

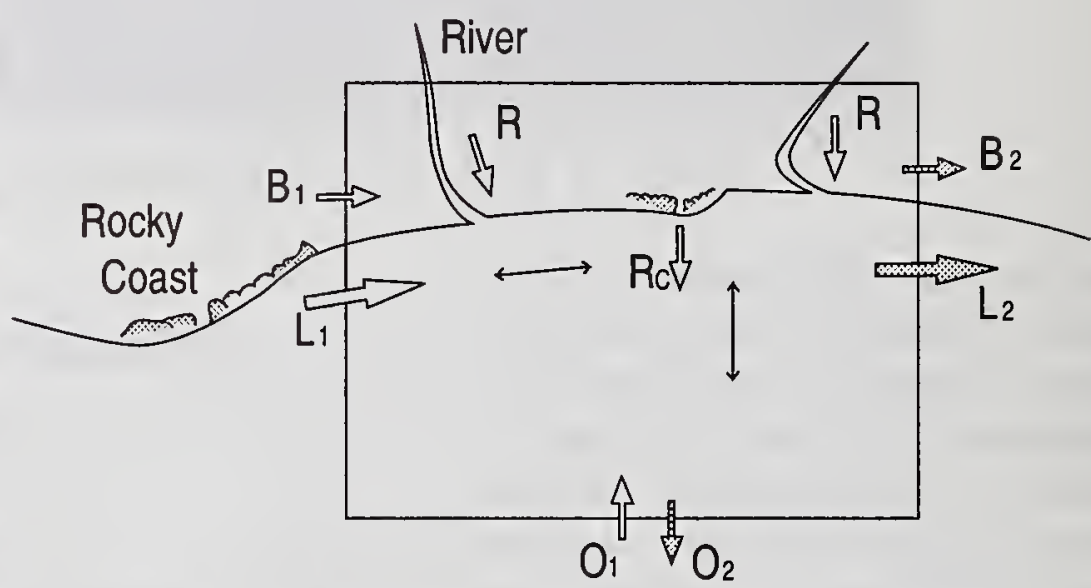
facts imply that there has been the imbalance of $\mathrm{O}_{1}$ and $\mathrm{O}_{2}$, that is, a net offshore sand drift, and this has played important role in sand budget of littoral zone.

Therefore it must be noted that the hydraulic mechanism in shallow water under waves and currents should be investigated further in order to understand the mechanism of the net offshore sand drift and to cope with it.

\section{CONCLUSION}

In Japan, beach erosions have become severe in recent years. Investigation by comparison of topographical maps shows that a net loss was 5,059 ha in 70 year period before 1978 but 2,395 ha in 15 year period after 1978 . It indicates that an annual net loss rate had been 72 ha per year before 1978 while it grew 160 ha per year after 1978 . The length ratio of the sedi-

mentation to erosion for the 70 year period is 0.57 , while for the 15 year period it is 0.48 . While Japanese high economic growth began around 1960, beach erosion was severe here and there long before that. Further, although the river basin facing to the Pacific Ocean was developed higher than that of the Japan Sea, the Japan Sea coast has suffered from severer erosion than that of the Pacific Ocean coast. Erosion was severe in Hokkaido and along the Japan Sea in both former period and latter one. A comparison of the erosion rates and crustal movements shows that the crustal movement could not give a good explanation to the overall characteristic of erosion. And considerations from a macro scale point of view imply that the net offshore drift is suspected of the cause of net losses found in topographical maps. All these results suggest the necessity of further investigation on hydraulic mechanism in shallow 
water.

\section{REFERENCES}

Kato, T. \& K. Tsumura, 1983. Vertical Crustal Movements in Japan as Deduced from Tidal Records (1951-August, 1982), Report of the Coordinating Committee for Earthquake Prediction, 29, 368-380 (in Japanese).

Koike, K., 1977. The Recent Change of Sandy Shorelines in Japan, Komazawa Geography, 13, 1-16.

Tanaka, N., H. Ozasa \& A. Ogasawara, 1973. Note of the Investigations on Change of Shoreline, Part 1 -- the Investigation on Shoreline Change on the Basis of Aerial Photographs --, Technical note of Port \&Harbor Res. Inst., 163, 1-95(in Japanese).

Tanaka, N., H. Ozasa, 1974. Note of the Investigations on Change of Shoreline, Part 2 -- the Investigation on Shoreline Change on the Basis of Aerial Photographs --, Technical note of Port \&Harbor Res. Inst., 192, 1-106(in Japanese).

Uda, T., 1991. Beach Erosion in Japan and its Classification, Coastal Sediments '91, ASCE, 1856-1870. 



\title{
ASSESSMENT OF HURRICANE OPAL IMPACT ON EAST PASS, FLORIDA WITH AIRBORNE LIDAR ${ }^{1}$
}

\author{
William E. Roper \\ Director, Civil Works Research and Development \\ U.S. Army Corps of Engineers \\ Washington, DC
}

\begin{abstract}
Advances in remote sensing technology are providing a number of practical tools for application to Corps of Engineer Civil Works field projects and new directions in research programs. Hydrographic survey operations using the jointly developed U.S./Canadian Scanning Hydrographic Operational Airborne LIDAR Survey (SHOALS) is faster and less costly than traditional methods. It is particularly useful to rapidly assess bottom changes following major storm or tsumani events. Its operating and system performance characteristics are summarized. As part of the rapid assessment response to hurricane Opal's passage through East Pass, Florida the SHOALS system was used to describe bottom changes and navigation channel impacts. Hurricane Opal's track and characters are presented along with the results of the SHOALS survey and evaluation of storm induced bathymetric changes in the area of East Pass.
\end{abstract}

\subsection{INTRODUCTION}

The Corps of Engineers is involved in virtually all navigation dredging operations performed in the United States. The Corps dredging mission entails maintenance and improvement of 25,000 miles of commercially navigable channels serving 400 ports, including 130 of the nation's 150 largest cities. Connecting waterways and inlets to the nation's ports and harbors handle about 2 billion tons of commerce each year. Emergency dredging is often needed following major storms at coastal inlets due to sediment relocation induced by storm surge, wave action, and ebb flushing currents.

The Corps dredges an average of 250 to 300 million cu yd of sedimentary material at a current expenditure level of about $\$ 500$ million per year in order to maintain and operate the nation's existing navigation system. Dredging is the single most costly item in the Corps' Civil Works Operations and maintenance program.

\section{Coastal and navigation dredging} projects almost always require hydrographic survey. This information is essential in the planning, design, construction, operation and maintenance of projects. During the 1980s research programs were initiated to

${ }^{1}$ Presented at the United States - Japan Natural Resources Program Workshop, Two Great Tsunamis, University of Hawaii at Hilo, April 1- 5, 1996. 
explore opportunities to decrease cost, improve response time, and enhance product quality in areas of hydrographic surveying, and subbottom geology (Roper, 1995). This paper presents the results of one of those research programs and its application for rapidly assessing storm induced damage from Hurricane Opal to East Pass, Florida.

\subsection{AIRBORNE LIDAR BATHYMETRY}

In the 1980s, the U.S. Army Corps of Engineers begin investigating technologies that could augment existing survey capabilities at comparable cost and provide fast, accurate surveys. In March 1988, the Corps began a cost-shared program with the Canadian government to design, construct and field verify an airborne LIDAR (LIght Detection And Ranging) hydrographic surveying system. The Scanning Hydrographic Operations Airborne LIDAR Survey (SHOALS) development program was implemented through a Memorandum of Understanding under the U.S./Canadian Defense Development Sharing Program. Optech, Inc. of Toronto, Canada, under contract was responsible for development of the SHOALS system.

The SHOALS system provides the capability for high spatial density utilizing state-of-the-art LIDAR technology consisting of a scanning laser transmitter/receiver that produces 200 soundings per second. SHOALS operates from a helicopter and includes a separate ground based data processing system. It is a highly mobile system capable of rapidly covering large areas. This unique capability produces a more comprehensive measurement of inlets and the adjacent near shore bathymetry. Output from SHOALS is an accurate $\mathrm{X}, \mathrm{Y}$, and $\mathrm{Z}$ (position/depth) from each laser (Lillycrop, Parson, etal, 1994) sounding that is easily formatted for most data analysis software tools such as Geographic Information Systems (GIS), volumetric computations, or other contouring and mapping systems.

The development approach began in 1988 with a conceptual design, followed by detailed design, construction, laboratory testing, field testing, and operational use.

\subsection{LIDAR BATHYMETRY TECHNOLOGY}

The system operates by emitting laser pulses that travel from an airborne platform to the water surface where most of the laser energy is back scattered to the airborne receiver as illustrated in Figure 1. The remaining energy at the water's surface propagates through the water column and reflects off the sea bottom back to the airborne detector. The time difference between the surface return and the bottom return corresponds to water depth.

As the light travels through the water column and reflects off the sea bottom it undergoes scattering, absorption, and refraction, which attenuate the return energy and limit the maximum depth of penetration or depth of bottom detection. The maximum depth the system is able to detect is related to a complex interaction of bottom radiance, incident sun angle and intensity, and water turbidity. As a rule-of-thumb, the SHOALS system is capable of sensing bottom to depths equal to two or three times 
the Secchi depth. A Secchi depth is calculated using an oceanographers tool, a black and white Secchi disk, that is lowered by a line down into the water column. The point where the Secchi disk is no longer visible is the Secchi depth. Thus, if a Secchi depth was measured to be $5 \mathrm{~m}$ then the maximum depth of bottom detection would be between $10 \mathrm{~m}$ and $15 \mathrm{~m}$ depending on the composition of the suspended material in the water column.

\subsection{THE SHOALS SYSTEM}

SHOALS is comprised of two separate systems: the airborne system and ground based data processing system. The airborne system operates from a Bell 212 helicopter and performs the task of primary data acquisition. The ground based data processing system provides the data postprocessing to calculate position and depth for each laser pulse. This design permits SHOALS to be highly mobile system capable of producing a 4 meter sounding grid under normal operating conditions, however, the scan pattern and survey speed can be modified to obtain even higher or lower sounding densities. The SHOALS system performance specifications are presented in Table 1.

\subsubsection{Airborne System}

The airborne system is divided into three subsystems (Lillycrop and Banic, 1993); Transceiver (TRS), Airborne Positioning and Auxiliary Sensors (APASS), and Acquisition, Control and Display (ACDS). These combined with the groundbased Data Processing System comprise the SHOALS system.
The transceiver subsystem consists of the laser, scanner, and receiver. The function of the TRS is to transmit laser pulses in a defined scan pattern and receive back scattered energy from these pulses to produce laser depth soundings and aircraft altitude information. The laser is $200 \mathrm{~Hz}$ $\mathrm{Nd}$ :YAG operating in the infrared and green frequencies. Returned laser energy is detected using several optic sensors providing the ability to discriminate between surface, bottom, and land returns.

The Aircraft Positioning and Auxiliary Sensors functions are to collect information from the Global Positioning System (GPS), inertial reference system (IRS), and video imagery system. Differential GPS is used for horizontal positioning and the IRS provides information about aircraft attitude, including roll, pitch, heading, and vertical acceleration. Included as an auxiliary sensor is a video camera to record a video image of the areas being surveyed.

Central to the SHOALS system is the ACDS, which provides and operator interface and monitors and controls the airborne system. The ACDS provides five functions: data collection, operator interface, pilot guidance, airborne depth processing, and system integrity. The data collection function acquires and manages all data as it flows through the system and records it on high density magnetic tape at a rate of over 300 kbytes per second. The operator interface allows human interaction between the operator and the system with access to all elements of the airborne system. The pilot guidance function provides aid to the pilot in 
navigating to the survey site and along each survey line. The airborne depth processing function calculates and displays preliminary water depth in real time, providing a means for data quality checking during the survey mission.

The last and perhaps most important function is system integrity. This function serves as the airborne system coordinator which continually monitors and interrogates communications between the various system components. Without precise (billionths of seconds) component communications timing the system could not functions as a unit (Parson, Lillycrop, etal 1995).

\subsubsection{Data Processing System}

The airborne system acquires a tremendous volume of raw data during a single mission. The Data Processing System (DPS) is the hardware and software required to post-process the LIDAR data. Its main functions are to 1) import airborne data stored on high density data tape; 2) perform quality control checks on initial depths and horizontal positions; 3 ) provide display and edit capabilities; 4) calculate depth and position (XYZ) values for each sounding; and 5) output final positions and depths for each sounding.

The interface between the airborne system and DPS is via the high density tape containing the raw data acquired during the survey mission. All of the data types (GPS, IRS, and LIDAR returns, etc) are collected at varying rates and recorded in asynchronous format. The primary task of DPS is to transfer the raw data from the survey and store it in a data base which requires some degree of preprocessing so that the information can be synchronized into a complete data set.

The DPS possesses a fully automated capability to post-process the data and update the database with corrected depth and horizontal positions within the accuracies presented in

Table 1. The software accomplishes this by identifying the surface and bottom returns from the airborne data. Depths are determined by computing the differences between the arrival times of the surface and bottom returns and applying corrections for depth biases associated with light propagation, water level fluctuations, and various inherent system characteristics (Guenther and Thomas 1984a and Guenther and Thomas 1984b). Sophisticated modeling algorithms are used to predict and apply corrections associated with these biases (Guenther, 1985). Surface are modeled and removed so that depths can be referenced to a common mean water surface. Determining a mean water surface and isolating the aircraft's vertical fluctuation allows for an accurate estimation of the aircraft height above the mean water level. Applying tides then produces a depth reference to a known water level datum such as mean low water.

A manual processing capability allows hydrographers to evaluate anomalous data by providing display and edit functions of sounding data and system parameters. Video imagery of the survey area permits visual scrutiny of the area to aid the hydrographer in deciding whether to exclude suspect data from further processing. Output from the DPS is an accurate digital 
data set of XYZ (positions/depths) for each laser sounding that is compatible with most GIS and other contouring and mapping systems.

\subsection{APPLICATIONS OF SHOALS}

Since accepting the SHOALS system in March of 1994 and following successful field trials in Sarasota, Florida, it has been used at project sites in the eastern U.S. and at --project sites on the western U.S. These project locations and sponsors are shown in Table 2.

The SHOALS System has consistently provided bathymetric soundings at a normal density of four meters and surveying rates of $9 \mathrm{Km}^{2} / \mathrm{hr}$ with digitized results produced within a day. The system provides detailed inlet bathymetry which can reveal features not produced by other survey methods. It can also be used to evaluate near shore sediment change behavior as a result of seasonal change and storm events.

\subsection{PLANNED SHOALS ENHANCEMENTS}

Over the last year our field experience with the SHOALS system has identified four areas for potential enhancement of its capability. As a result additional applied research will be focused on:

1) Three-dimensional positioning of SHOALS using kinematic Global Positioning System (KGPS). If SHOALS can be positioned accurately with KGPS then depth calculations would no longer require tide measurements.

2) Improved data procession time. The original specification was to process one hour of airborne survey data in seven hours, a ratio of $1: 7$. We have been working to accelerate this performance specification and currently we are at 1:2.

3) Shallow water measurement capability. The original performance specification was for SHOALS to be able to measure a minimum depth of 1.7 meters. However, with enhanced signal processing we can now measure at zero water depth and profile the near beach area. We are currently testing the accuracy of this new capability and will have it permanently implemented in the depth calculation algorithm by late 1996 .

4) Sensor fusion. We are currently evaluating other remote sensors that can be added to the SHOALS platform to collect useful data for managing coastal projects. One such sensor is a hyperspectral sensor that when fused with SHOALS depth data can be used to accurately classify sea bottom type such as seagrass, sand, mud, silt, rock, and coral, in optically clear water.

\subsection{HURRICANE OPAL}

Hurricane Opal achieved hurricane status on September 27, 1995 with sustained winds of $75 \mathrm{mph}$ just off the east coast of the Yucatan Peninsula of Mexico as shown in Figure 2. Opal made landfall early on September 28th and moved in a zig-zag path across the Yucatan Peninsula for three days until it reentered the Gulf late on September 30 th. It gathered strength over the warm gulf waters for the next four days. Initially Opal moved west across the gulf and then turned sharply northeast and headed directly toward the western panhandle of Florida. Opal made landfall at 1700 central daylight 
time (CDT) on October 4, 1995 on the western Florida panhandle in the area of Destin, Florida. Satellite imagery of Opal just prior to landfall in Figure 3 show a compact classic hurricane form with heavy rain bands and a well defined eye. The eye passed west of East Pass making direct landfall on Santa Rosa island near the town of Mary Esther. Hurricane Opal generated winds up to $67 \mathrm{~m} / \mathrm{sec}$ (150 mph or 130 knots), classifying it as a great hurricane (Category 4 on the Saffir-Simpson Scale). The following statistics summarize this storm:

Minimum Barometric Pressure
$916 \mathrm{MB}$
Maximum Wind Speed
$67 \mathrm{~m} / \mathrm{sec}$
Maximum Storm Surge
$14.6 \mathrm{ft}(4.45 \mathrm{~m})(\mathrm{MLW})$

During the storm, a 14- $\mathrm{ft}$ surge pushed a tremendous amount of water through the inlet and across Santa Rosa Island into Choctawhatchee Bay. The elevated bay, augmented by fresh water runoff from the Choctawhatchee River basin, drained out to sea through East Pass. Considering the height of the surge, it is likely that there were tremendous currents in the inlet and between the jetties as the ebb jet escape out to the Gulf.

\section{Most of the coastal damage from} Opal was caused by storm surge rather than from wind. Three surge effects can be seen in an aerial photograph of East Pass taken just after landfall (Figure 4): First, a narrow over wash fan projects into East Pass near the west end of the highway bridge. This part of Santa Rosa Island was low and provided little resistance to over wash. Second, almost half of the west jetty was over washed, with sand being carried from Santa Rosa Island into the channel. Third, Norriego point was breached just to the northwest of the condominiums. Mobile District engineers, who conducted a postOpal reconnaissance, estimated that bout 80 percent of the above-water portion of the point was removed (Mr. L. Robinson, USAE District, Mobile, unpublished reconnaissance report).

\subsection{SHOALS SURVEY AT EAST PASS}

On October 10, 1995, just one week after Opal, the SHOALS system was used to survey East Pass. The survey was completed in just over one hour covering about one square mile and recording nearly 200,000 individual depth readings (Morang, Irish, and Pope, 1996). The results are shown in Figure 5. Each grey band represents a 1000 meter swath width form a SHOALS scan along the flight line. Converging jetties mark the mouth of the inlet. The state plane coordinates are in feet and north is to the top.

The SHOALS generated results were compared with project channel requirements to determine changed dredging requirements. There was also an evaluation of risk to project structure, particularly the jetties, as a result storm induced changes within the inlet system. This analysis included a comparison of the SHOALS data with a 1990 survey (Morang, Irish, and Pope 1996). A graphic display of the differences is shown in Figure 6. This clearly shows a significant growth in the scour hole at the tip of the west jetty. If it continues to deepen 
the stability of the jetty tip maybe at risk. There was also an accumulation of sediment north of the spur jetty.

\subsection{SUMMARY}

SHOALS is a rapid, accurate survey tool for accessing post storm changes in bathymetry. This can assist in post storm recovery planning and better allocation of recovery assets, and lead to an improved understanding of sediment dynamics of inlet and coastal systems. The SHOALS system is moving toward full deployment for Corps of Engineer projects. For the last nine coastal inlet surveys conducted there was a savings of $\$ 300 \mathrm{~K}$ over traditional methods and a better product produced. When fully deployed savings in the range of over $\$ 3$ million is expected annually at Corps of Engineers projects. Through cooperative project applications for NOAA, Navy, Coast Guard and others the savings to the Federal government could be significantly greater. Planned improvement will further expand SHOALS capability, accuracy, and timeliness.

\subsection{REFERENCES}

1. Guenther, G.C., Airborne Laser Hydrography, System Design and Performance Factors, National Ocean Service, Rockville, MD, p 385, 1985.

2. Guenther, G.C., and Thomas, R.W.L., "Propagation-Induced Depth Measurement Biases and Peak Bottom Return Power Relationships for Airborne Laser Hydrography, "NOAA Technical Report NOS 1062, National Oceanic and Atmospheric Administration, U.S.
Department of Commerce, Washington, DC, p. 121, 1984a.

3. Guenther, G.C., and Thomas, R.W.L., "Effectives of Propagation-Induced Pulse Stretching in Airborne Laser Hydrography," In Proceedings SPIE Ocean Optics, Vol. 489, pp. 286-297, 1984 b.

4. Lillycrop, W.J., and Banic, J.R., "Advancements in the U.S. Army Corps of Engineers Hydrographic Survey Capabilities: The SHOALS System," Marine Geodesy, Volume 15, 1993.

5. Lillycrop, W.J., Parson, L.E., Estep, L.L., Laroque, P.E., Guenther, G.C., Reed, M.D., and Truitt, C. L., "Field test results of the U.S. Army Corps of Engineers airborne LIDAR Hydrographic survey system," In Proceedings U.S. Army Corps of Engineers 1994 Training Symposium, Surveying and Mapping Remote Sensing/GIS, New Orleans, LA, pp SM:2A 1-5, 1994.

6. Morang, A., Irish, J.L., and Pope J., "Hurricane Opal Morphodynamic Impacts on East Pass, Florida: Preliminary Findings," U. S. Army Engineer Waterways Experiment Station, Vicksburg, MS, 1996.

7. Parson, L.E., Lillycrop, W.J., Klein, C.J., Ives, C.P., Orlando, S.P., "LIDAR

Bathymetric Applications for Surveying Florida Bay," Journal of Coastal Research, 1995.

8. Roper, W.E., "New Applications of Remote Sensing Technology in Coastal Engineering," Third Thematic Conference on Remote Sensing for Marine and Coastal Environments, Seattle, WA., 1995 


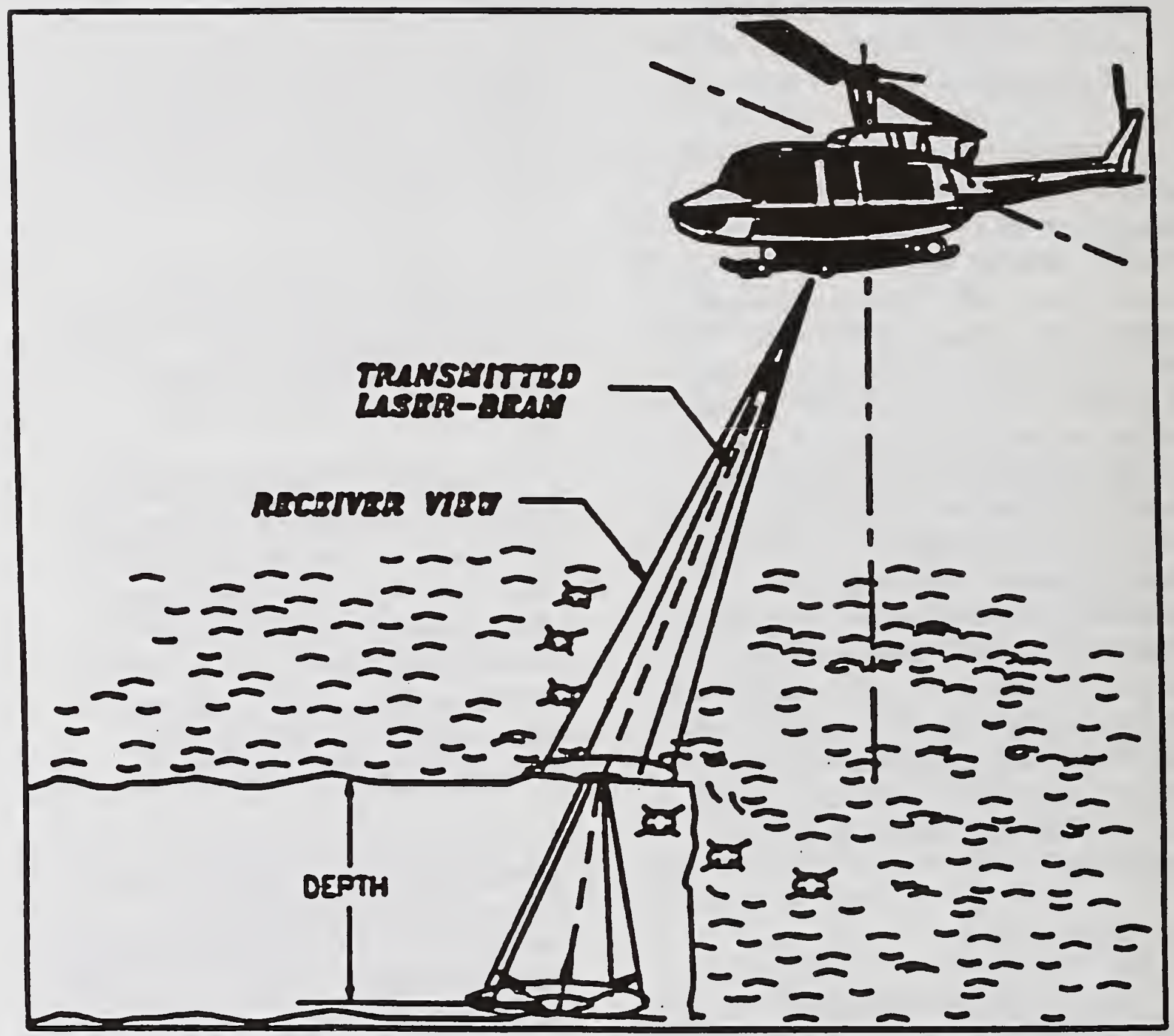

Figure 1. LIDAR Operating Principle 


\begin{tabular}{|c|c|}
\hline Maximum Depth & $\begin{array}{l}\mathrm{K}^{\prime} \mathrm{d}>3 \text { day } \\
\mathrm{Kd}>4 \text { night }\end{array}$ \\
\hline Minimum Depth & 0.9 meters \\
\hline Vertical Accuracy & $+/-30 \mathrm{~cm}$ \\
\hline Horizontal Accuracy & $+/-6$ meters \\
\hline Sounding Density & $3-15$ meters \\
\hline Operating Altitude & $200-1000 m$ \\
\hline Scan Swath Width & $1 / 2$ aircraft altitude \\
\hline Operating Speed & $0-50 \mathrm{~m} / \mathrm{sec}$ \\
\hline Operating Temperature & $5-40 \mathrm{C}$ \\
\hline Data Processing & $2 \mathrm{hrs}$ of processing for $1 \mathrm{hr}$ of data \\
\hline Aircraft & Bell 212 \\
\hline System Mob/Demob & $8 \mathrm{hrs}$ to install $/ 6 \mathrm{hrs}$ to demob \\
\hline $\begin{array}{l}1 / \text { where } \mathrm{K} \text { is the diffuse } \\
\text { attenuation coefficient of water } \\
\text { and } \mathrm{d} \text { is depth. In clear water the } \\
\text { maximum depth is } 40 \mathrm{~m} \text {. }\end{array}$ & \\
\hline
\end{tabular}


T able 2. Projects Surveyed by the SHOA IIS

Systent through March 1996

\begin{tabular}{|c|c|}
\hline Sponsor & Project \\
\hline U.S. Navy & Elgin AFB, FL and Gulf of California, CA \\
\hline $\begin{array}{l}\text { National Oceanic and } \\
\text { Atmospheric Administration } \\
\text { (NOAA) }\end{array}$ & Tampa Harbor, Florida Bay, FL \\
\hline $\begin{array}{l}\text { Corps of Engineers } \\
\text { Waterways Experiment Station }\end{array}$ & $\begin{array}{l}\text { Longboat Key Beach, New Pass, Palm Beach Harbor, } \\
\text { Palm Beach IWW, Vero Beach, Ponce de Leon Inlet, } \\
\text { Canaveral Harbor, St.Augustine Inlet, FL }\end{array}$ \\
\hline Jacksonville District & $\begin{array}{l}\text { Estero Island, Gasparilla Island, Key Biscayne, Miami } \\
\text { Beach, St. Lucie Inlet, Ft. Pierce Inlet, Hamlets Cove, } \\
\text { East Pass, Jupiter Beach, Sarasota Pass, FL }\end{array}$ \\
\hline New York Harbor & $\begin{array}{l}\text { Morches Inlet, Shinnecock Inlet, Long Island Beach, } \\
\text { NY }\end{array}$ \\
\hline Philadelphia District & $\begin{array}{l}\text { Hereford Inlet, Great Egg Harbor Island, Barnegate Inlet, } \\
\text { NJ }\end{array}$ \\
\hline New England District & Nantucket Beach, Martha's Vineyard Beach, MA \\
\hline New Orleans District & $\begin{array}{l}\text { Mississippi River Ship Channel oulets to the Gulf of } \\
\text { Mexico, LA }\end{array}$ \\
\hline Mobile District & Mobile Bay Navigation Channel, AL \\
\hline Galveston District & $\begin{array}{l}\text { Galveston Beach, Gulf Intercoastal Waterway, Houston } \\
\text { Ship Channel, TX }\end{array}$ \\
\hline Los Angeles District & Oceanside Inlet, Los Angeles/Long Beach Harbor, CA \\
\hline
\end{tabular}




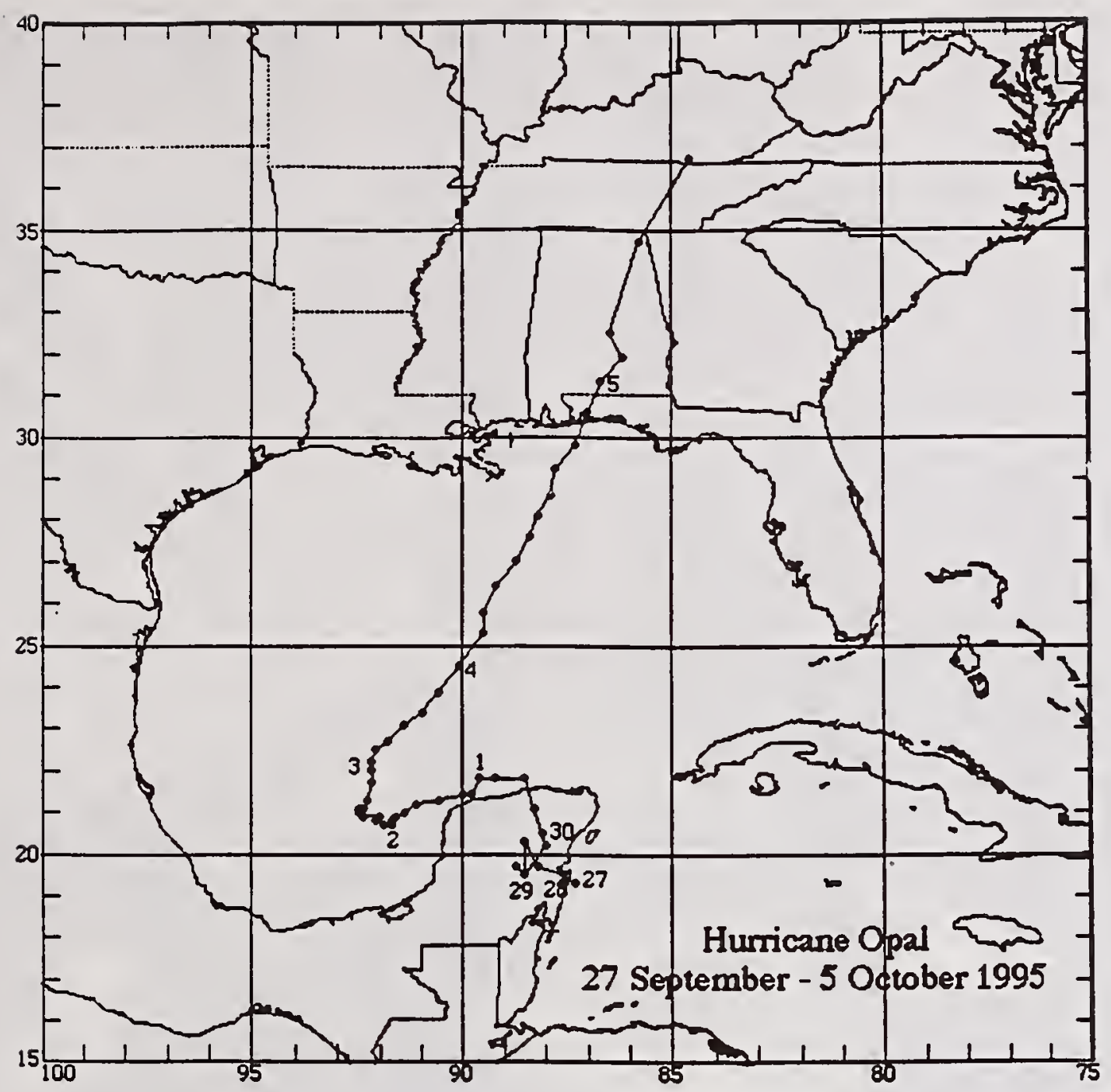

Figure 2: Path of Hurricane Opal

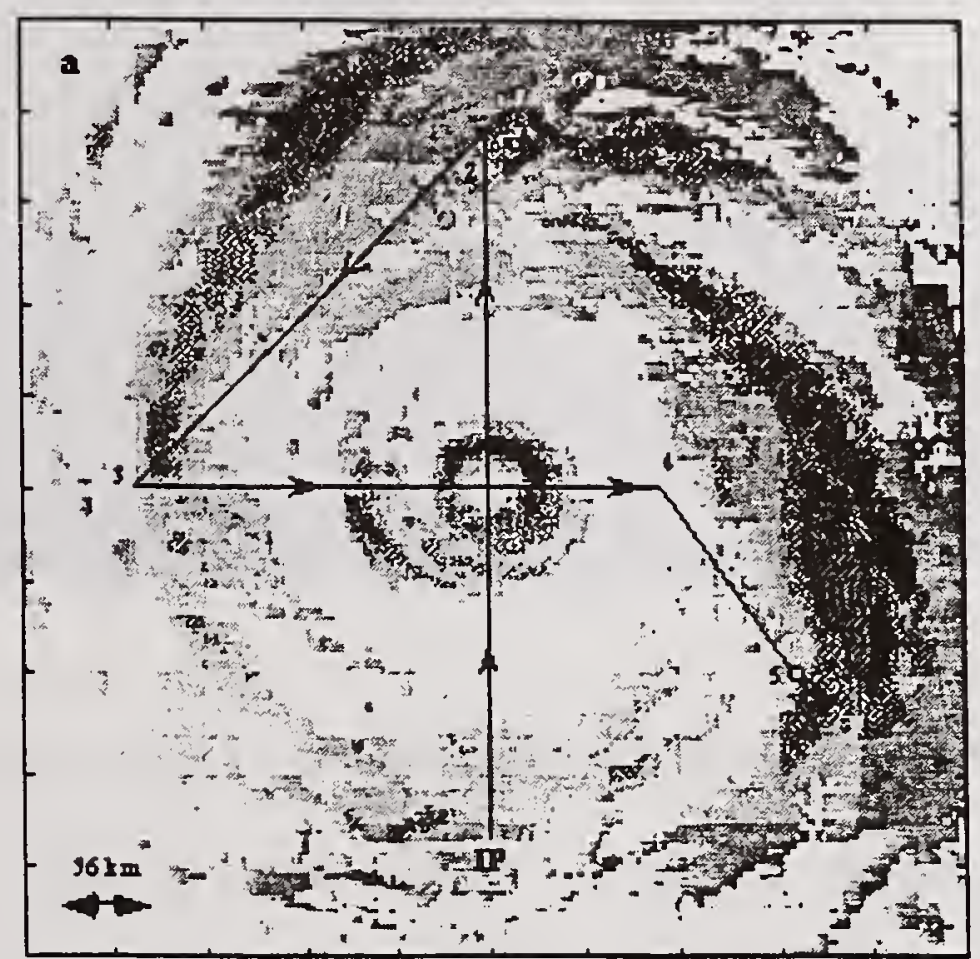

Figure 3. Imagery of Opal just prior to landfall 


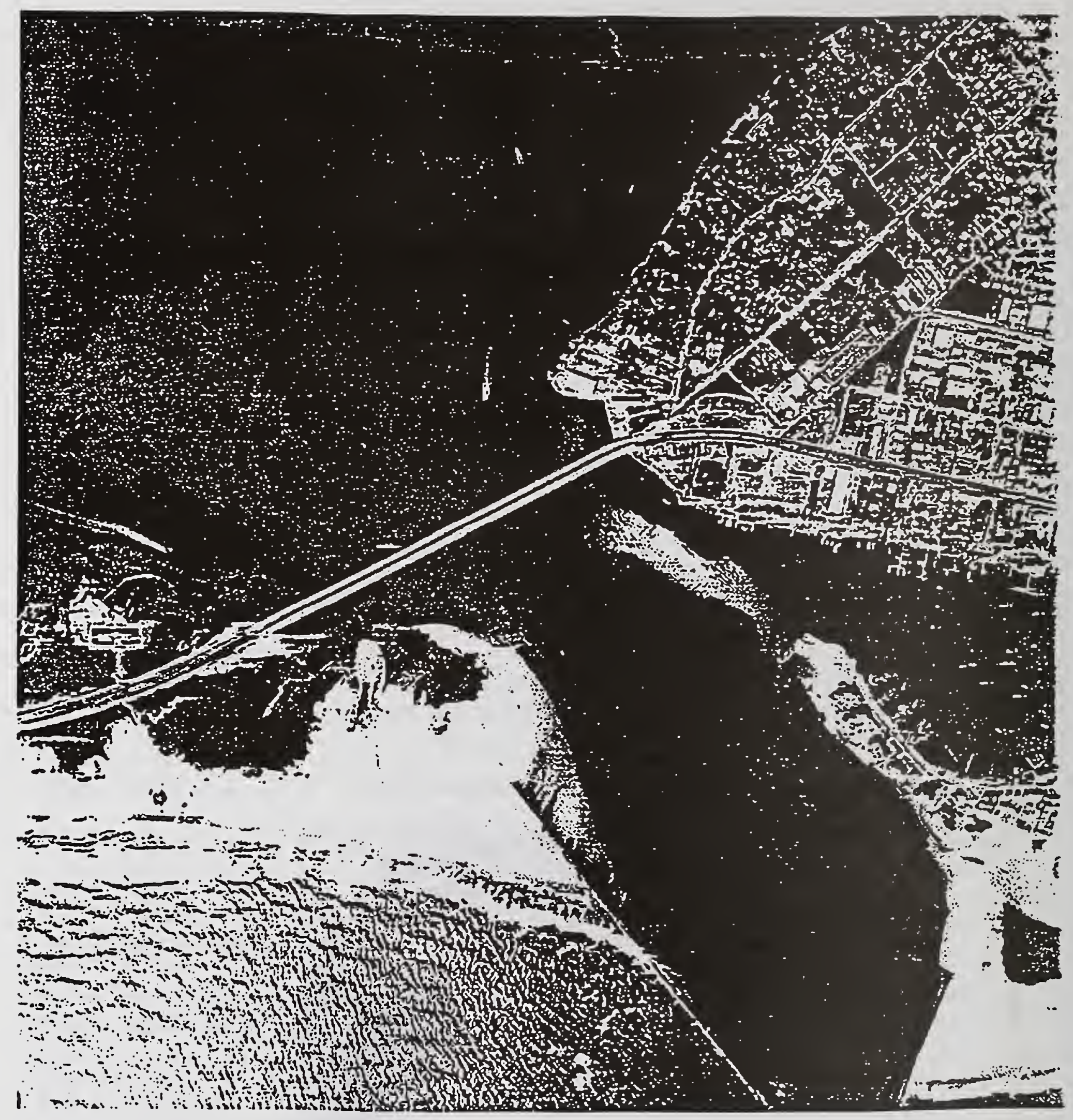

Figure 4. Aerial photograph of East Pass after Hurricane Opal (north is to the top) 


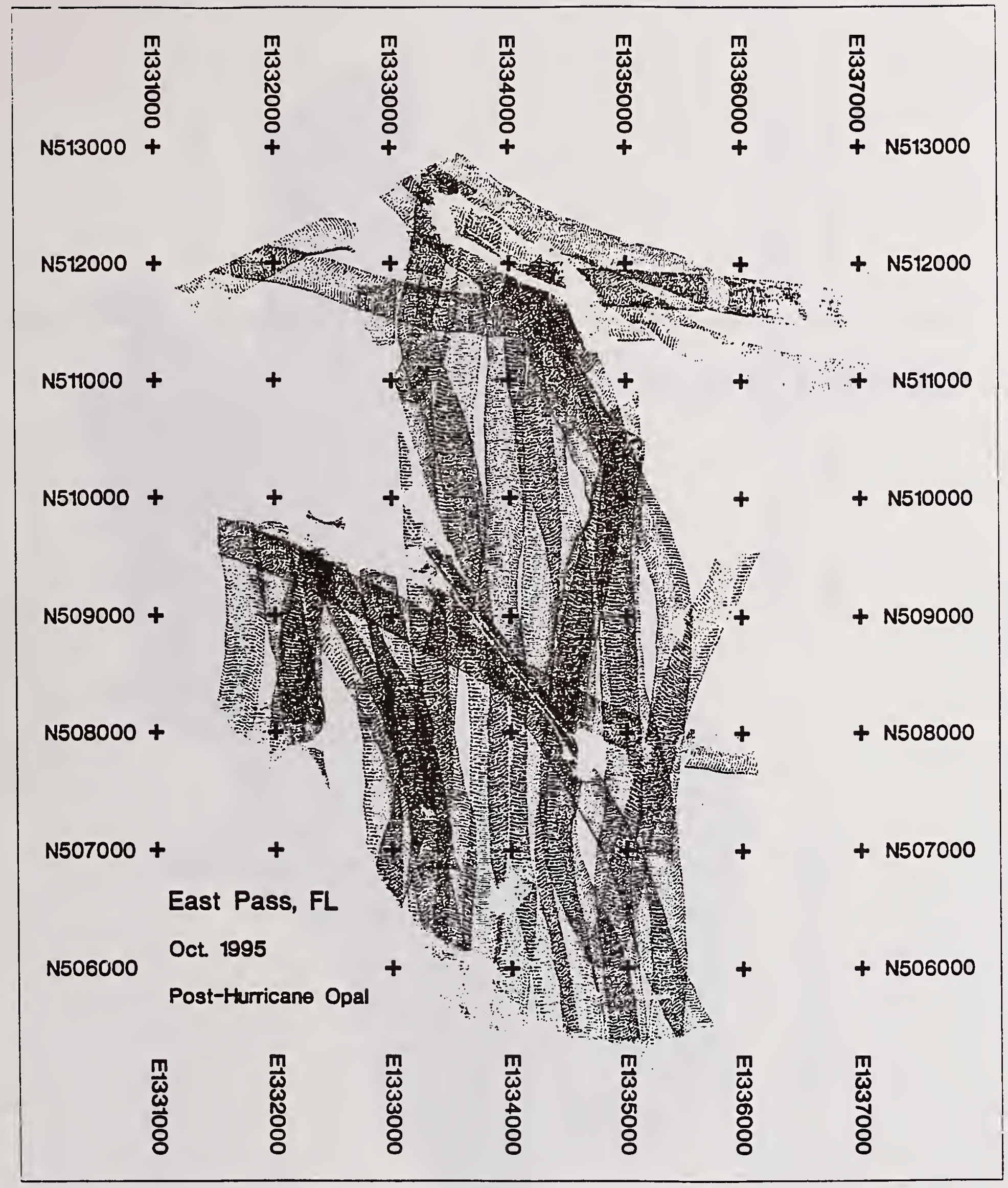

Figure 5. SHOALS survey of East Pass, Florida 


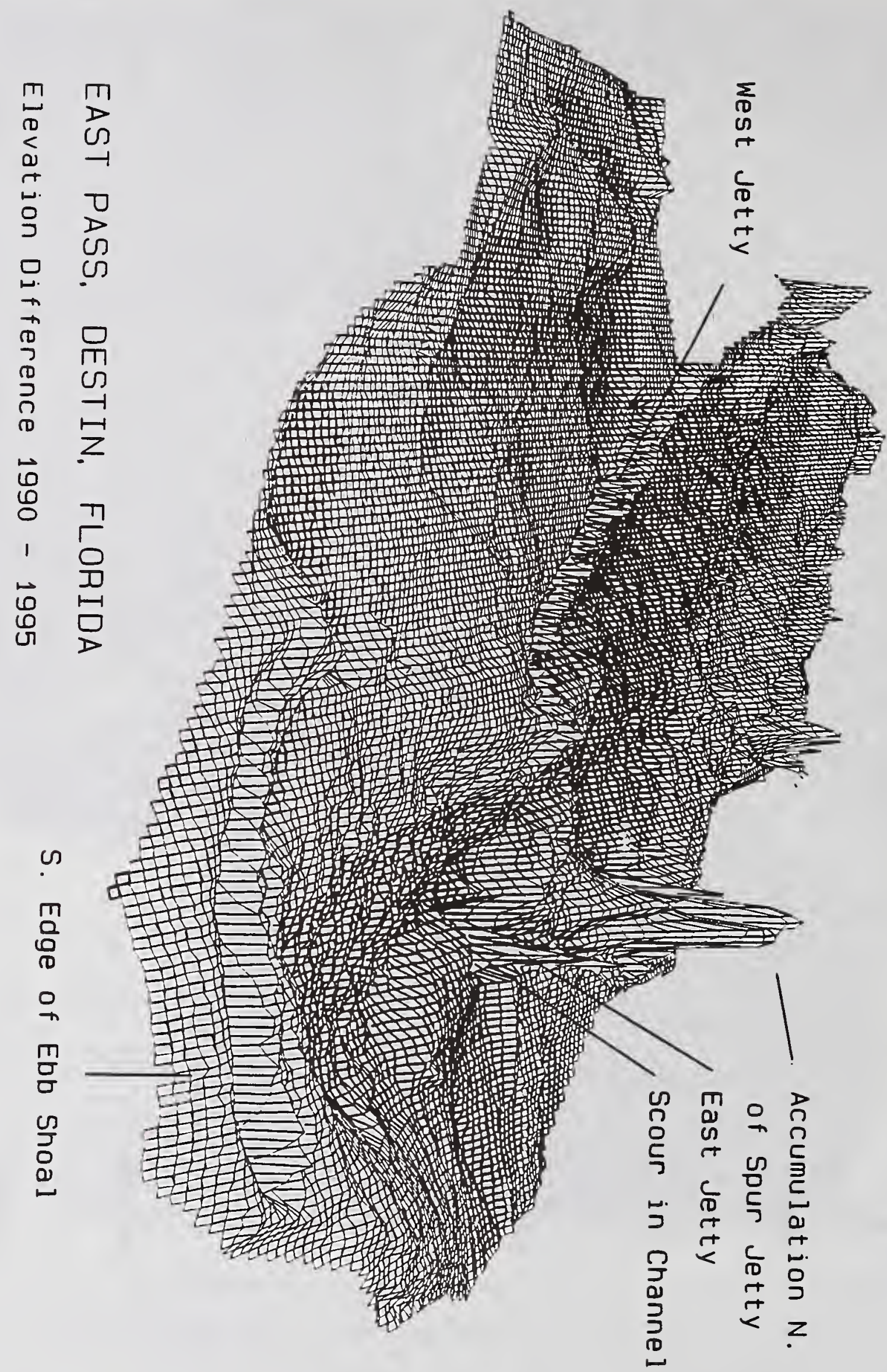

Figure 6. Sea floor elevation changes between 1990 and 1995 at East Pass 
EARTHQUAKE ENGINEERING 

by

\author{
Ikuo Towhata* \\ Yoshihiro Kogai** \\ Kei Amimoto*** \\ and \\ Hendri Gusti Putra+
}

\begin{abstract}
The lateral displacement of liquefied subsoil during earthquakes is one of the causes of damages to such facilities as river dikes and lifeline networks. The present study aims at developing measures which mitigates this lateral ground movement. A wall made of sheet piles or compacted sand is installed in a model deposit of sand and is shaken dynamically. The observed behavior of a wall showed its capability to prevent the lateral ground displacement. A theoretical study on such a wall was conducted simultaneously in order to calculate the reduced displacement of liquefied ground as well as the bending moment and shear force in walls. Finally, a example analysis was conducted to make sure the efficiency of the walls in mitigating the lateral ground displacement. Both experimentally and analytically, a sheet-pile wall and a wall of compacted sand exhibited a good mitigation of the ground movement.
\end{abstract}

KEYWORDS: earthquake, liquefaction, flow, shaking table tests, sand.

\section{INTRODUCTION}

The present text is concerned about mitigation of lateral displacement of liquefied subsoil induced by earthquakes. Although an overall densification is the ultimate measure to prevent laieral movement caused by liquefaction, there is a situation in which it is not feasible. For example, existing facilities in a developed area do not allow a compaction work under their foundations. A financial restriction could be another reason why a compaction is not possible. As long as the displacement is not so significant, a limited extent of liquefaction may be tolerated. In this respect, alternative mea- sures are investigated in this study by which a lateral flow of liquefied subsoil can be mitigated.

\section{METHOD OF SHAKING TABLE TEST}

A series of shaking table tests were carried out in order to study the effects of embedded walls which reduce the lateral flow of liquefied sandy slopes. The studied walls were of two types; a sheet-pile wall and a wall of a compacted sand.

Loose deposits of Toyoura sand were made in a container which measured $100 \mathrm{~cm}$ in length and $20 \mathrm{~cm}$ in width. The thickness of model deposits was variable in the horizontal direction, making the surface (Fig.1) gradient $15 \%$.

The stress-strain behavior of liquefied sand undergoing lateral flow is characterized by a peak strength followed by softening and a residual state. This behavior can be reproduced under a low confining pressure as occurs in shaking table tests by making the density of sand much lower than in situ. Hence, in the present study, the void ratio of sand was about 1.05 , making the relative density around $-20 \%$. This low density was attained by first placing wet sand in a container, and then submerging it under water. The base shaking was generated in the longitudinal direction of the model deposits. The amplitude of acceleration was 200 to 300 gals while the frequency was $4 \mathrm{~Hz}$.

* Professor of Civil Engineering, University of Tokyo, Tokyo, Japan

** Research Engineer, Fudo Construction Company

*** Former student, University of Tokyo

+ Andalas University, Sumatera, Indonesia 


\section{OBSERVED DISPLACEMENT}

Fig.1 illustrates the ultimate configuration of a control case in which no mitigation was installed. This model deposit liquefied upon shaking and flew laterally until the surface became level. No further movement occurred after this configuration because the level surface was associated with the minimum potential energy. The grid of colored sand in Fig.1 demonstrates the subsurface deformation. The horizontal displacement is zero at the bottom, while taking the maximum near the surface.

The second test was run on a model with a sheet-pile wall. A model of a sheet pile was made of an aluminum plate with a thickness of $0.5,0.8$, or $1.0 \mathrm{~mm}$. The ultimate deformation of a model in Fig. 2 was observed when the thickness of a sheet-pile was $0.8 \mathrm{~mm}$. It is seen in Fig. 3 that the elevation of the ground surface is different between the front and the rear sides of the wall. This difference induced a differential lateral earth pressure along the wall, resulting in distortion of the wall. It should be noted that the installedwall could not completely prevent the soil displacement, although the displacement was made remarkably smaller in Fig. 2 than in the control case of Fig.1 where no mitigative measure was taken. The ground surface on both sides of the wall was level in the ultimate stage, because the minimum potential energy is attained when the surface was level.

Fig. 3 indicates the ultimate displacement when the central part of the model was compacted to make the void ratio ranging from 0.75 to 0.79 . This void ratio is equivalent with a relative density of 50 to $60 \%$. The lateral movement of sand was prevented by this compacted sand wall, generating a difference in elevation of the ground surface on the front and the rear sides of the wall. The ground surface became level after flow. It should be noted again that the displacement in this figure is smaller than what was seen in Fig.1 without a remedial measure. Nevertheless, there was still some displacement in both sides of the wall. Finally, it is demonstrated in all figures that the ground surface subsided near the upper end while uplift was the case near the bottom of the slope.

\section{EFFECTS OF WALL SIZE ON OB- SERVED DISPLACEMENT}

Similar to the bending deformation of a cantilever beam, the differential earth pressure between the front and the rear faces of the wall induces bending of a sheet-pile wall. It is easily speculated that the bending stiffness of a sheet pile has a substantial influence on the deformation of the wall. This is demonstrated in Fig. 4 where the time history of the lateral displacement at the ground surface adjacent to a sheet-pile wall is compared for a family of the wall thickness. A thicker wall has a greater stiffness, making the displacement smaller. It is interesting that the thicker wall completes its displacement at earlier times than thinner ones do. Similarly, a thicker sheet pile reduces the subsidence of the ground surface near the upper end of a slope; see Fig.5.

The effects of the size of a compacted sandy wall on the magnitude of ground flow were similarly studied. The width of the compacted domain was varied from $0 \mathrm{~cm}$, which is the case without mitigation, up to $15 \mathrm{~cm}$. Fig. $6 \mathrm{dem}$ onstrates that the lateral displacement at the ground surface near the compacted area decreased as the range of compaction increased. Fig.7 reveals that the subsidence decreased simultaneously.

\section{THEORY FOR STRUCTURAL ANALY - SIS ON MITIGATIVE MEASURES}

It was demonstrated in the preceding sections that both a sheet-pile wall and a compacted sandy wall can reduce the lateral displacement of liquefied ground. It is, however, left unknown how to predict the reduced ground displacement as well as the bending moment, shear force, shear strain and others in these mitigative walls. Since the deflection of those walls is caused by the difference of earth pressure between the front and the rear faces of the walls, it is essential to calculate this earth pressure difference in the prediciton of displacement.

Figs. 1 to 3 indicated that the elevation of the ground surface became different after the lateral flow, producing the earth pressure difference. It is therefore important to calculate the displacement of ground movement induced by liquefaction. 


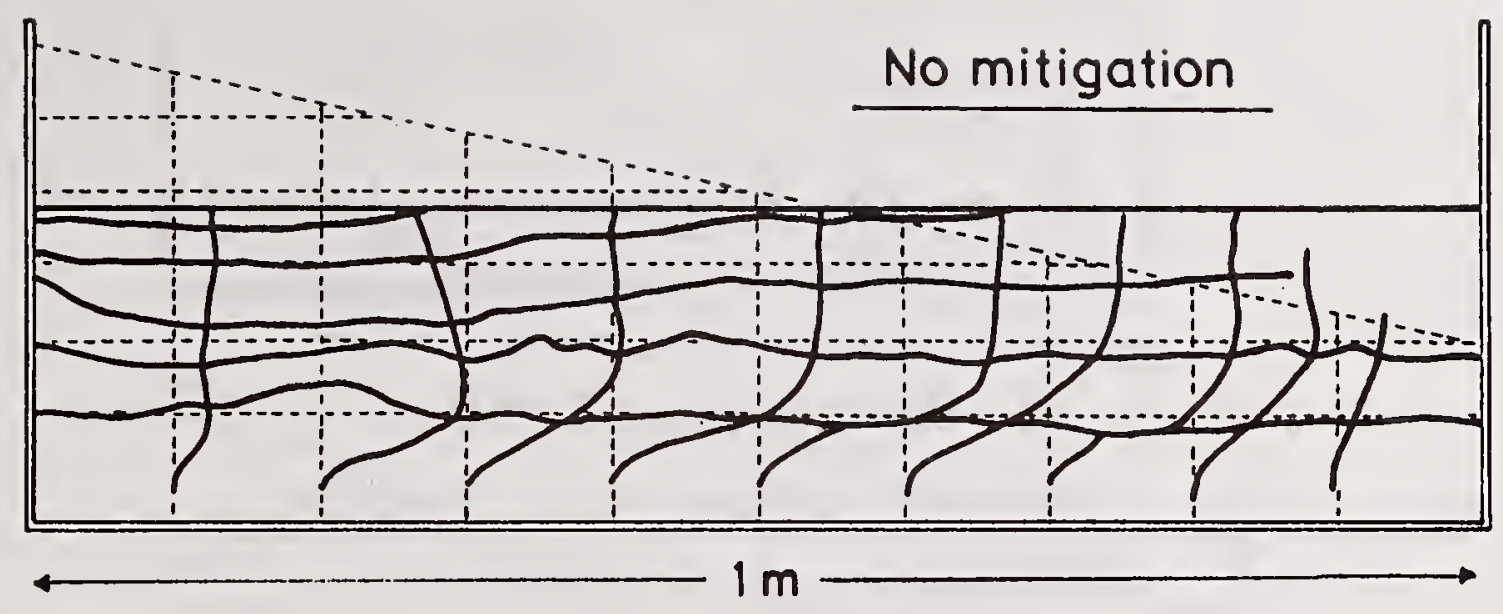

Fig.1 Ultimate deformation of control case without mitigation.

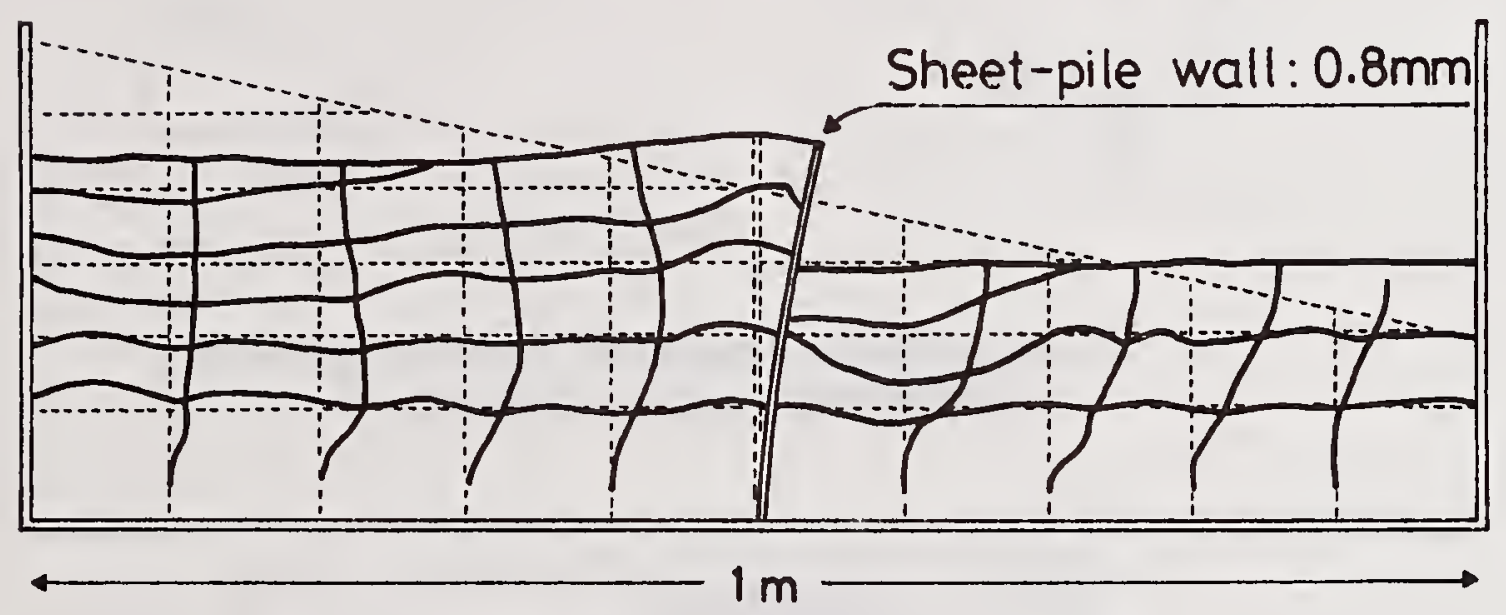

Fig.2 Ultimate deformation reduced by a sheet-pile wall.

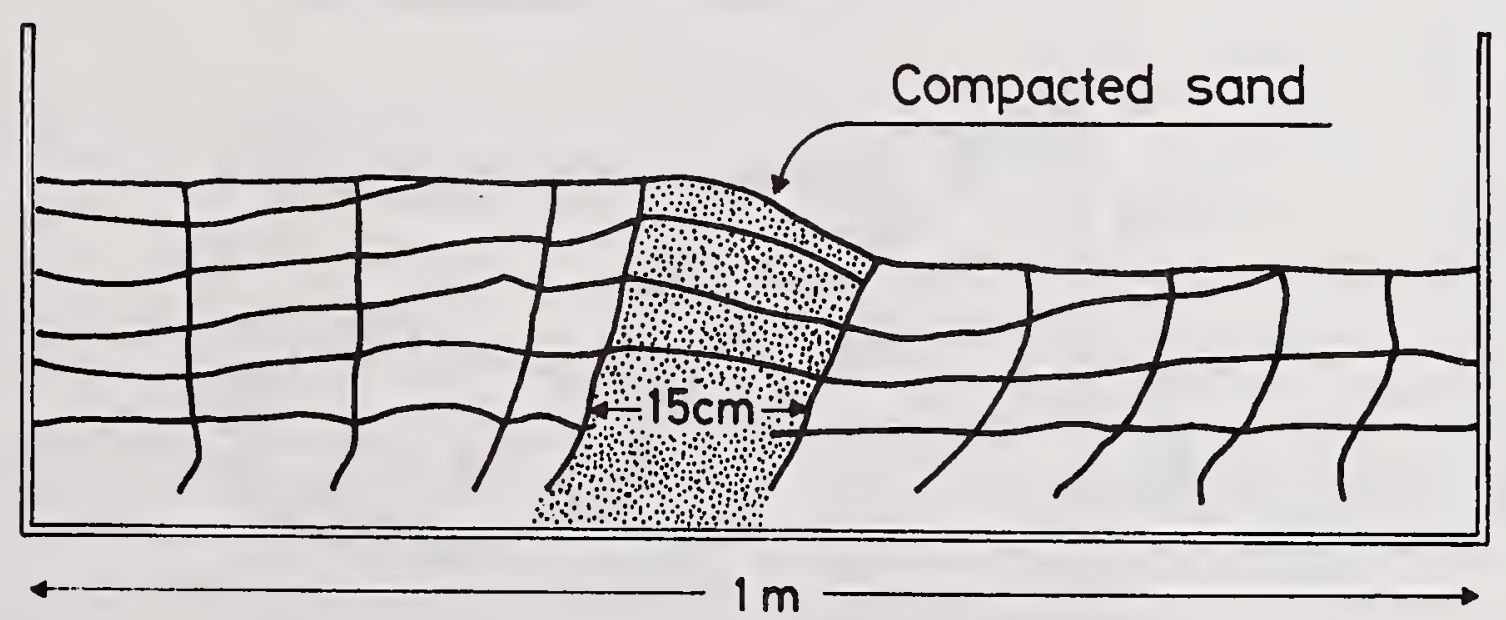

Fig.3 Ultimate deformation reduced by compacted sand wall. 


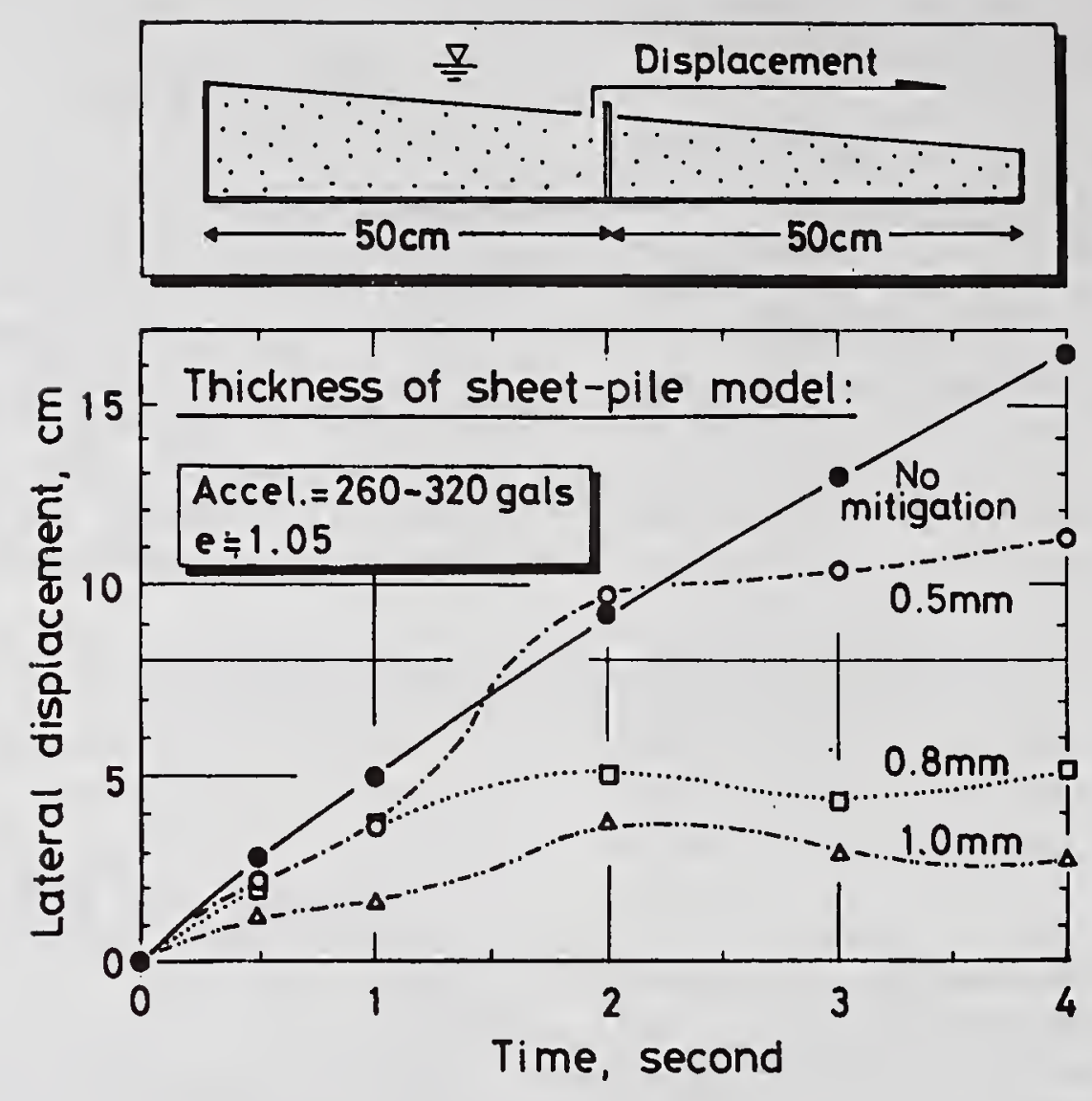

Fig. 4 Effects of sheet-pile thickness on lateral displacement of ground surface.
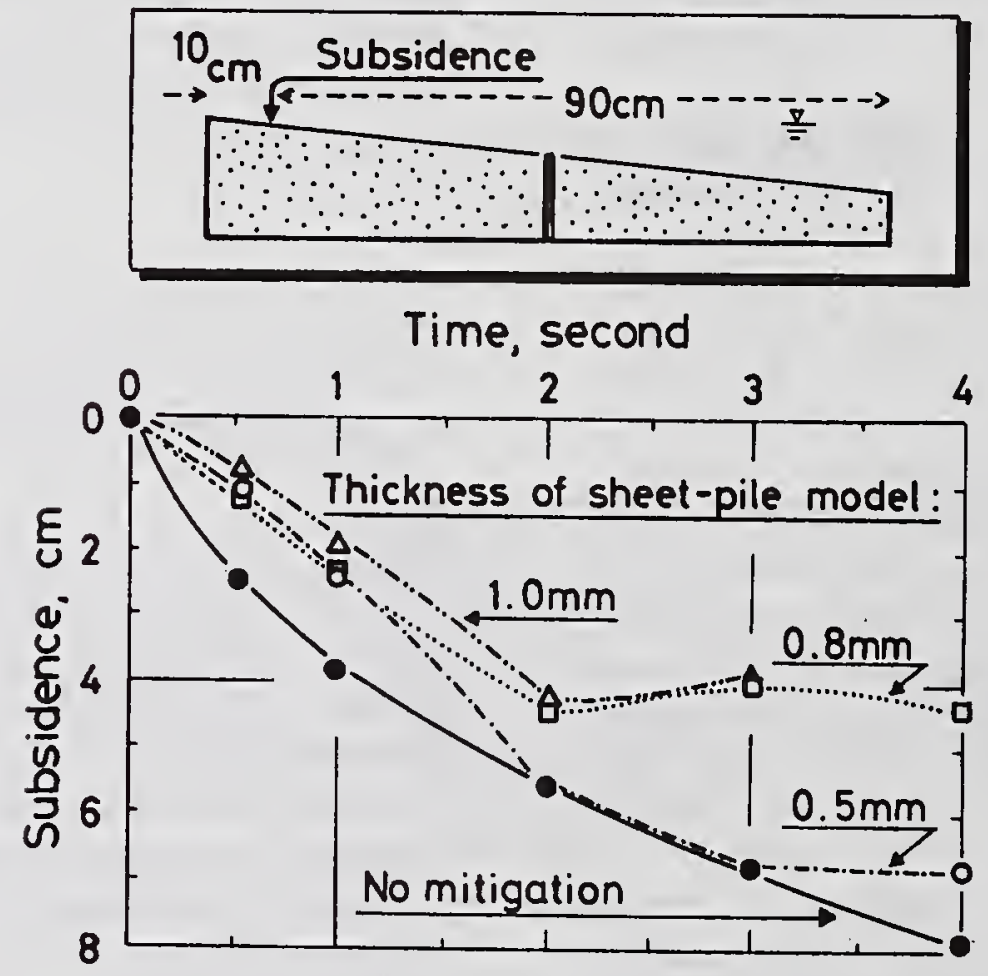

Fig.5 Effects of sheet-pile thickness on subsidence of ground surface (at $10 \mathrm{~cm}$ from upper end). 


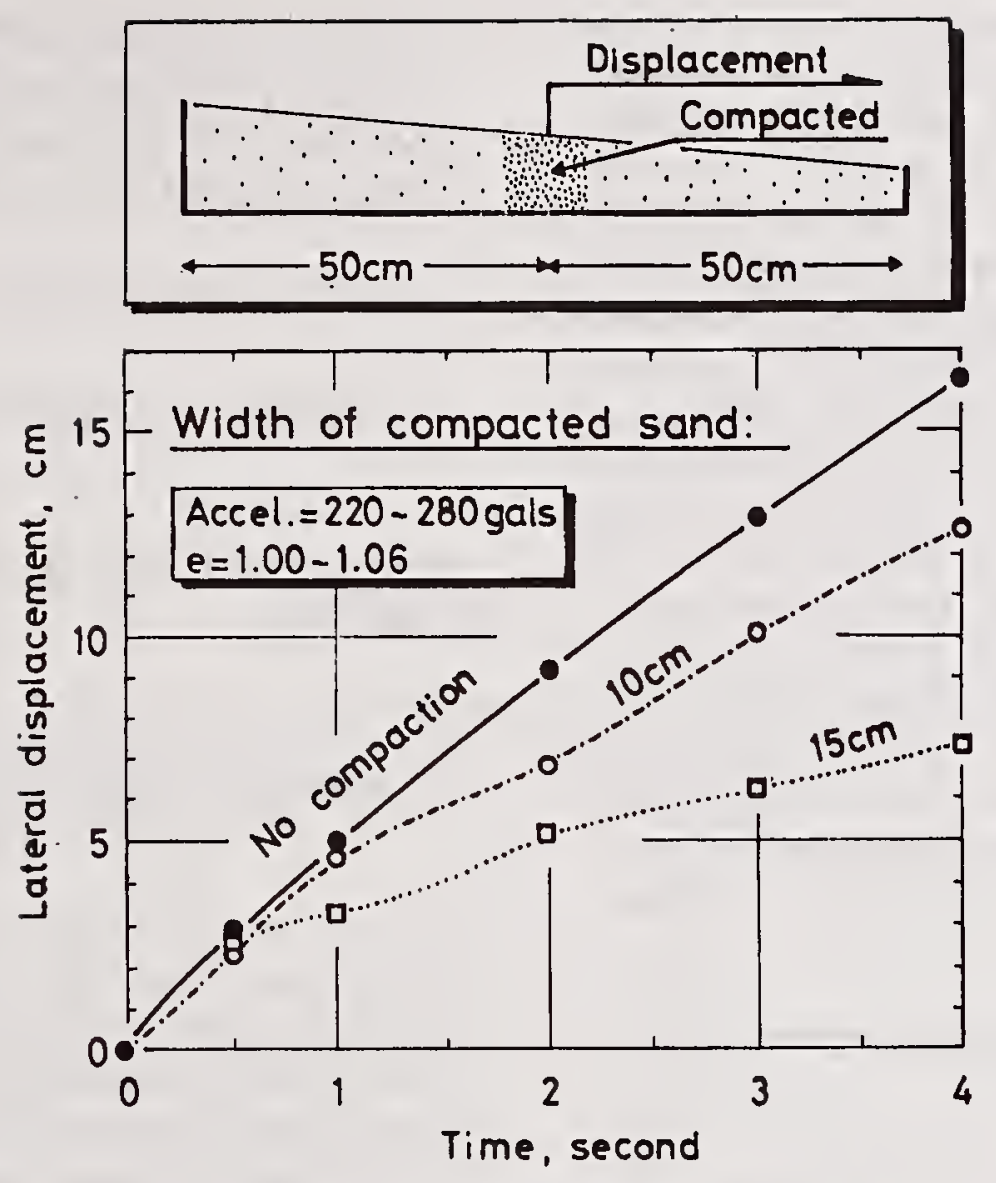

Fig.6 Effects of width of compacted soil on lateral displacement of ground surface.
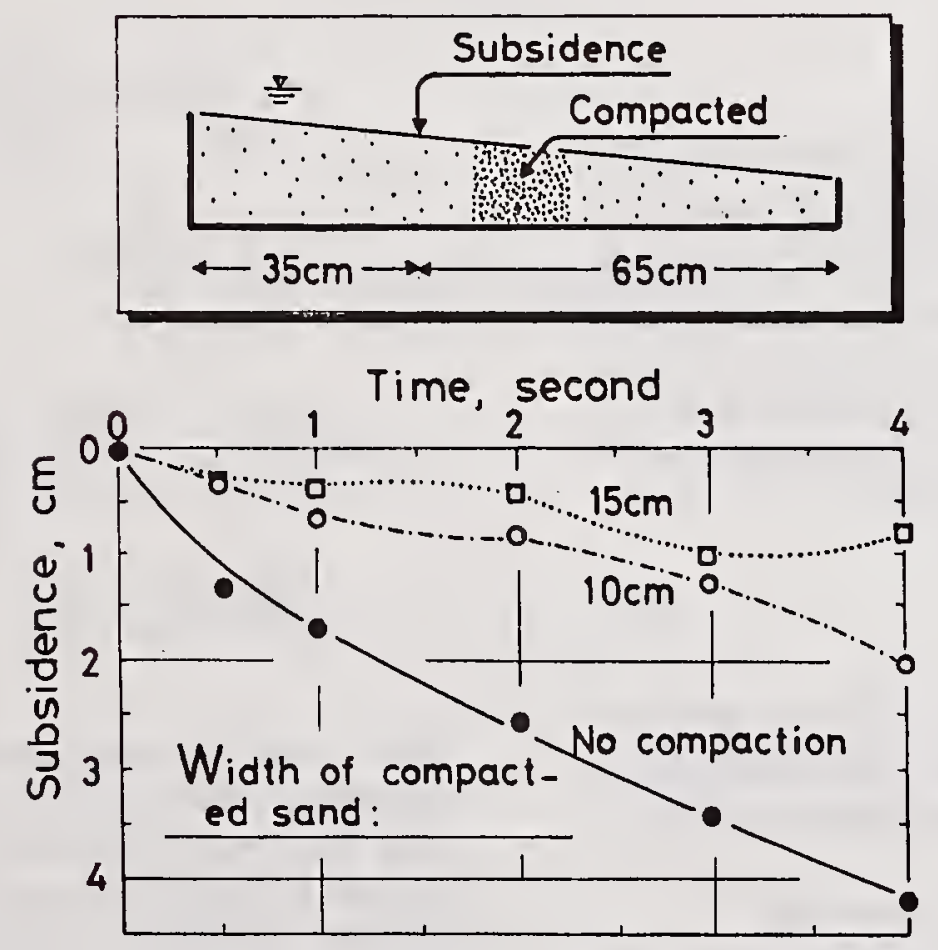

Fig.7 Effects of width of compacted soil on subsidence of ground surface (at $35 \mathrm{~cm}$ from upper end). 
Towhata et al. (1992) developed a closed-form solution of a flow displacement of ground caused by liquefaction by using the principle of the minimum potential energy. Towhata (1995) further developed this solution in order to deal with such an irregular topography as shown in Fig.8. It is seen in this figure that the analyzed subsoil is composed of a surface unliquefied crust, a liquefied sandy layer, and a stable base. The surface crust is modeled as an elastic column which moves together with the liquefied layer. The liquefied sand is modeled as a viscous and constant-volume liquid. Previous model tests indicated that this liquefied layer develops a sinusoidal mode of lateral displacement (Fig.9). It was shown by previous model tests as well that the lateral displacement is continuous at the interface between the liquefied layer and the surface crust; i.e., no slip at this interface.

The solution for an irregular topography is composed of a nodal equation;

$$
\begin{gathered}
{\left[\frac{4 \gamma H}{\pi^{2}}\left(H \frac{d F}{d x}+b F\right)+\frac{2 y H^{2}}{\pi}+E T \frac{d F}{d x}+\frac{2 P H}{\pi}\right.} \\
\left.-\frac{4 \gamma H^{2}}{\pi^{2}}\right]_{x^{-}}^{x^{+}}=0
\end{gathered}
$$

where $\mathrm{H}$ and $\mathrm{P}$ denote the thickness of the liquefied layer and the weight of the surface crust per unit area, while $\gamma$ the unit weight of the liquefied sand, E the elastic modulus of the surface crust, $T$ the thickness of the crust. $F$ is the lateral displacement at the surface and $\mathrm{x}$ is the horizontal coordinate. The variation of $\mathrm{H}$ with $\mathrm{x}$ coordinate is expressed as

$$
H=H_{o}+b x
$$

Finally, $\mathrm{x}^{+}$and $\mathrm{x}^{-}$in Eq. 1 stand for the positive and negative sides of a node. This equation is associated with the minimum potential energy.

\section{Nodal equation for a sheet-pile wall}

A nodal equation for a sheet-pile wall is going to be developed in what follows by using the principle of the minimum potential energy. A sheet-pile wall is modeled by a cantilever elastic beam in which the bending stiffness is denoted as $E_{p} I_{p}$ and the lateral deflection by $\rho$. The bottom of the wall at the unliquefied base is fixed while the top is a free end (Fig.10);

$$
\begin{array}{r}
\rho=0 \text { and } d \rho / d z=0 \text { at } z=B \\
d^{2} \rho / d z^{2}=0 \text { and } d^{3} \rho / d z^{3}=0 \\
\text { at } z=B+H
\end{array}
$$

The strain energy stored in the sheet pile is obtained by

$$
\text { Strain energy }=\int_{\mathrm{B}}^{\mathrm{B}+\mathrm{H}} \frac{E_{p} I p}{2}\left(\frac{d^{2} \rho}{d z^{2}}\right)^{2} d z
$$

This is added to the analytical expression of the potential energy of a liquefied ground (Towhata, 1995) and the total energy is made minimum by searching for a closed-form solution of displacement; $F$ (variational principle of mathematics). Consequently,

$$
\begin{gathered}
\left.E_{p} I_{p} \frac{d^{4} \rho}{d z^{4}}=\frac{\pi}{2 H}\right\}\left[E T \frac{d F}{d x}\right]_{x}^{x^{+}}+\left[\frac{2 P H}{\pi}+\frac{2}{\pi}\right. \\
\left.\times\left(1-\frac{2}{\pi}\right) H^{2}+\frac{4 \gamma H}{\pi^{2}}\left(H \frac{d F}{d x}+b F\right)\right]_{x}^{-} \\
\int_{B}^{B+H} \rho d z-\frac{2 F H}{\pi}=0 \\
{\left[E T \frac{d F}{d x}\right]_{x}^{x^{+}}+\left[\frac{2 P H}{\pi}+\frac{2}{\pi}\left(1-\frac{2}{\pi}\right) H^{2}+\frac{4 y H}{\pi^{2}}\right.} \\
\left.\times \frac{4 y H}{\pi^{2}}\left(H \frac{d F}{d x}+b F\right)\right]_{x}^{-}-\frac{80 E_{p} p_{p}}{\pi^{2} H^{3}} F=0
\end{gathered}
$$

Eq.5 gives the earth pressure difference which is shown to be constant in the vertical direction. The different elevation of the ground surface between two sides produces a different overburden after flow which, since the liquefied sand is liquid, is equal to a net earth pressure. Eq.6 is the volume compatibility between the wall deflection and the soil movement. 


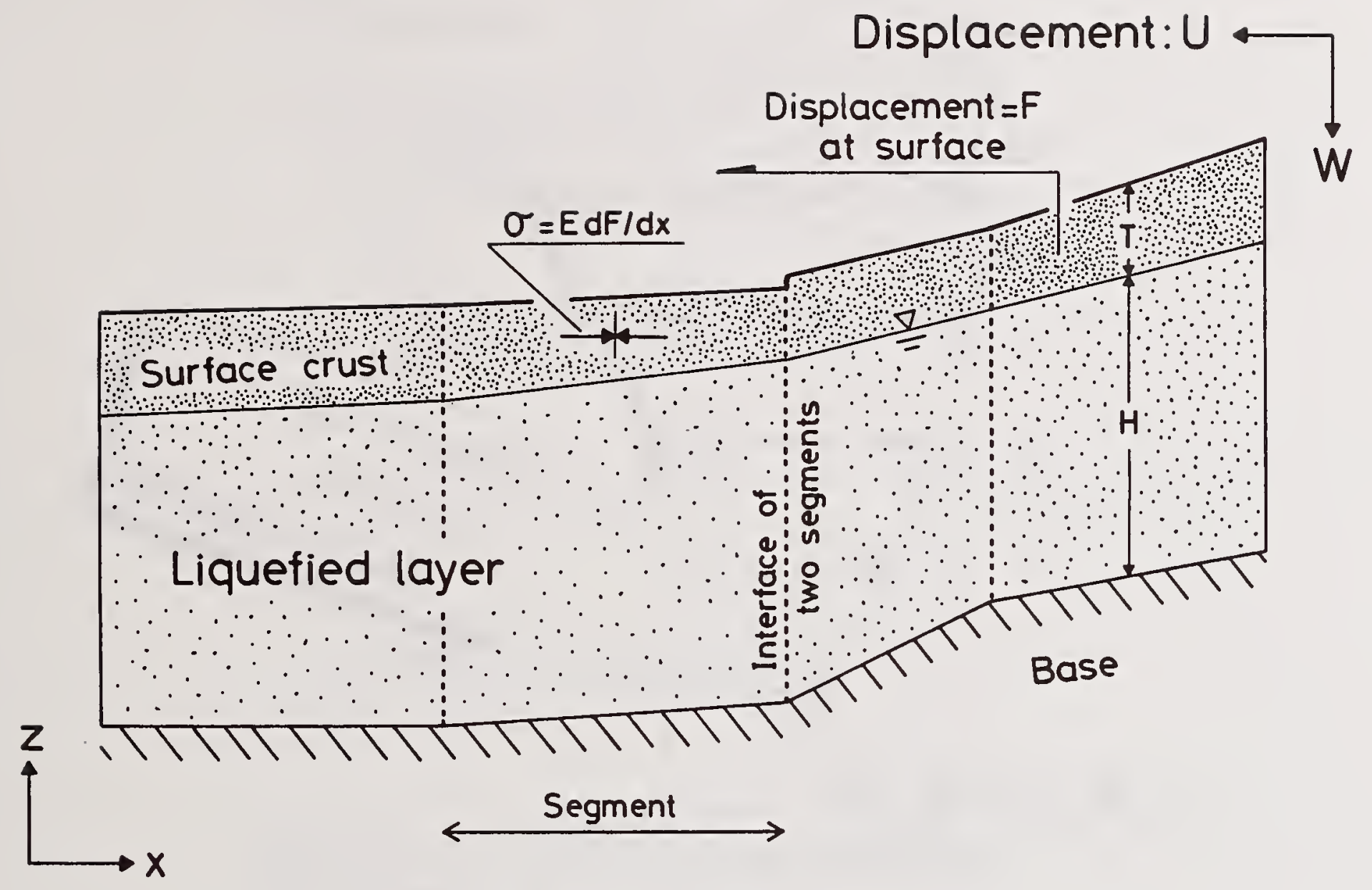

Fig.8 Irregular topography. 


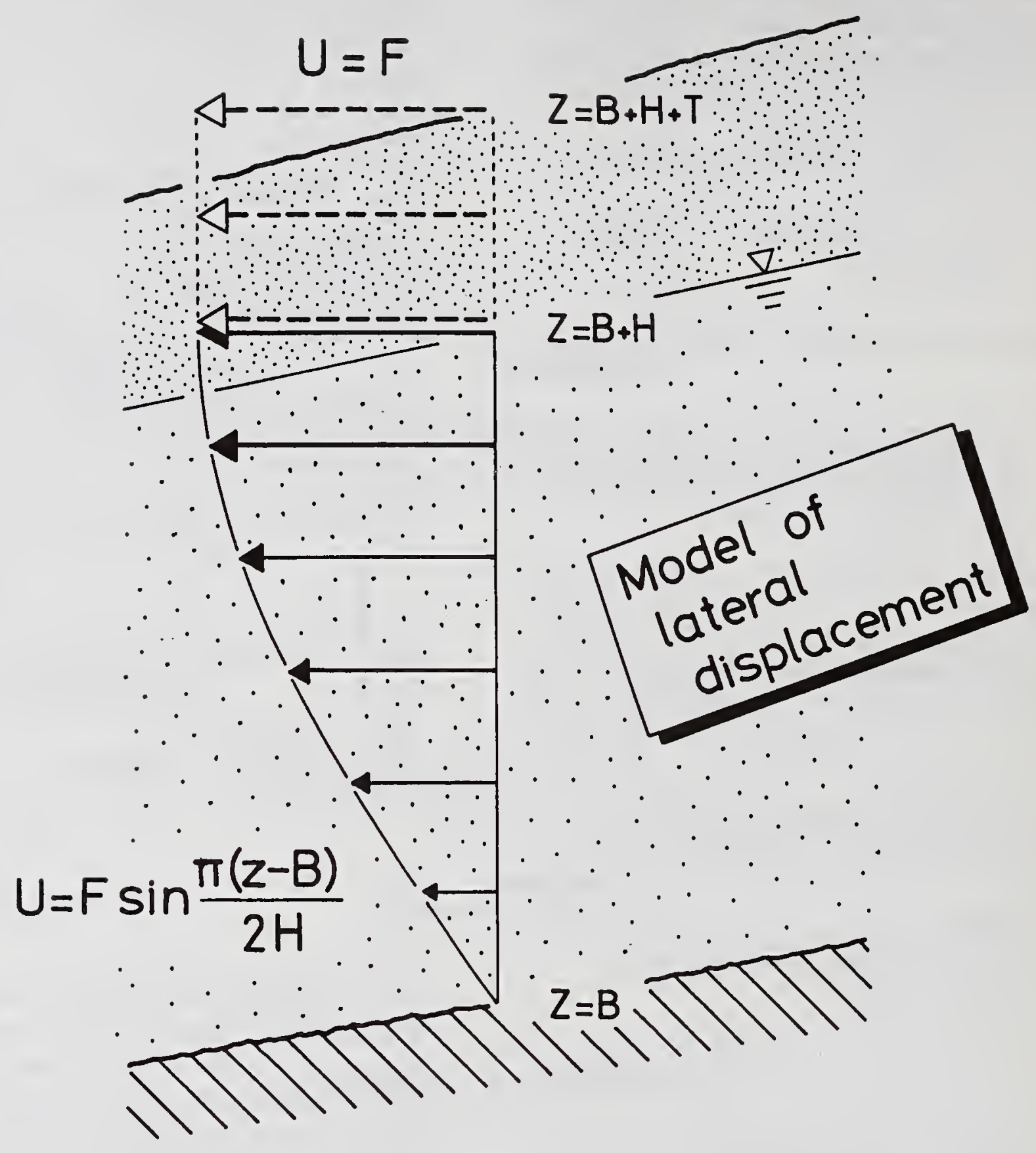

Fig.9 Sinusoidal distribution of lateral displacement. 


\section{Mitigation of lateral flow of liquefied subsoil}

(1) Sheetpile wall

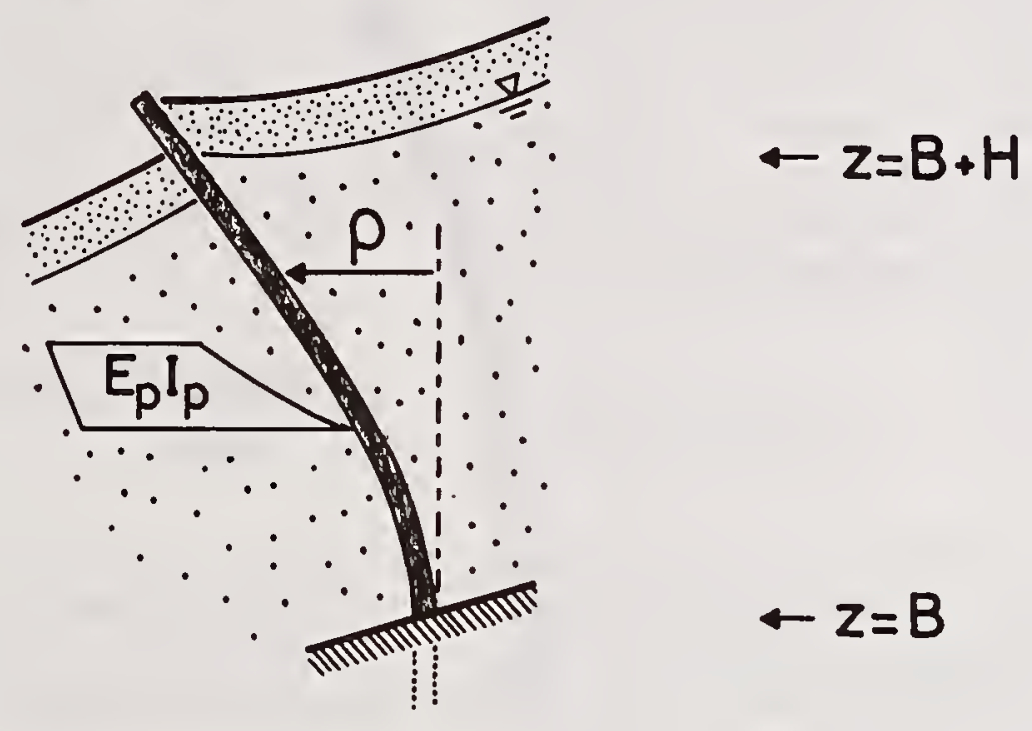

Fig.10 Model of a sheet-pile wall.

(2) Wall of elastic unliquefied soil

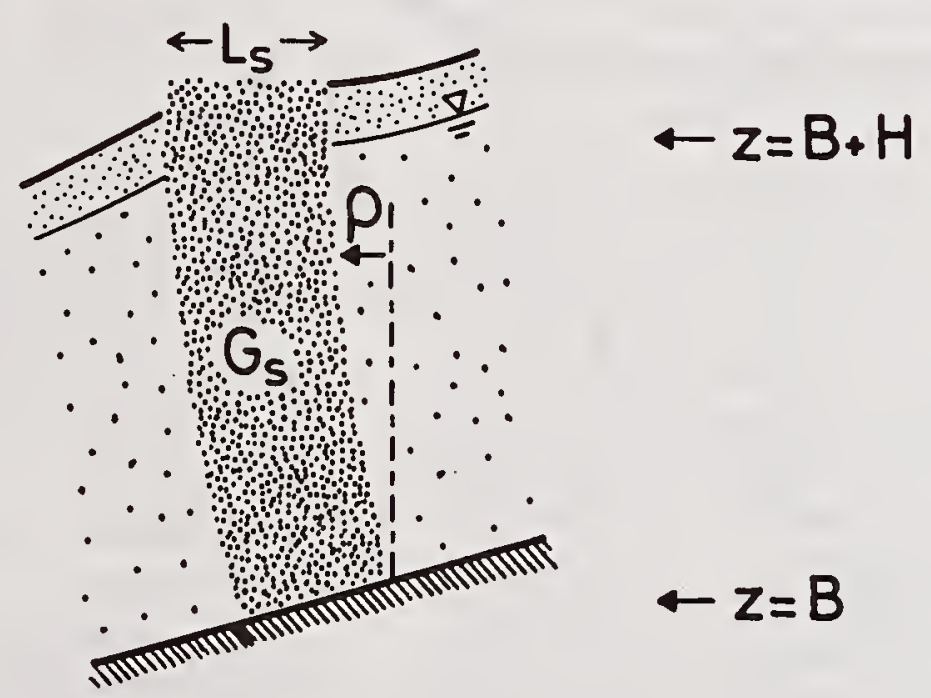

Fig.11 Model of a elastic wall of compacted sand. 


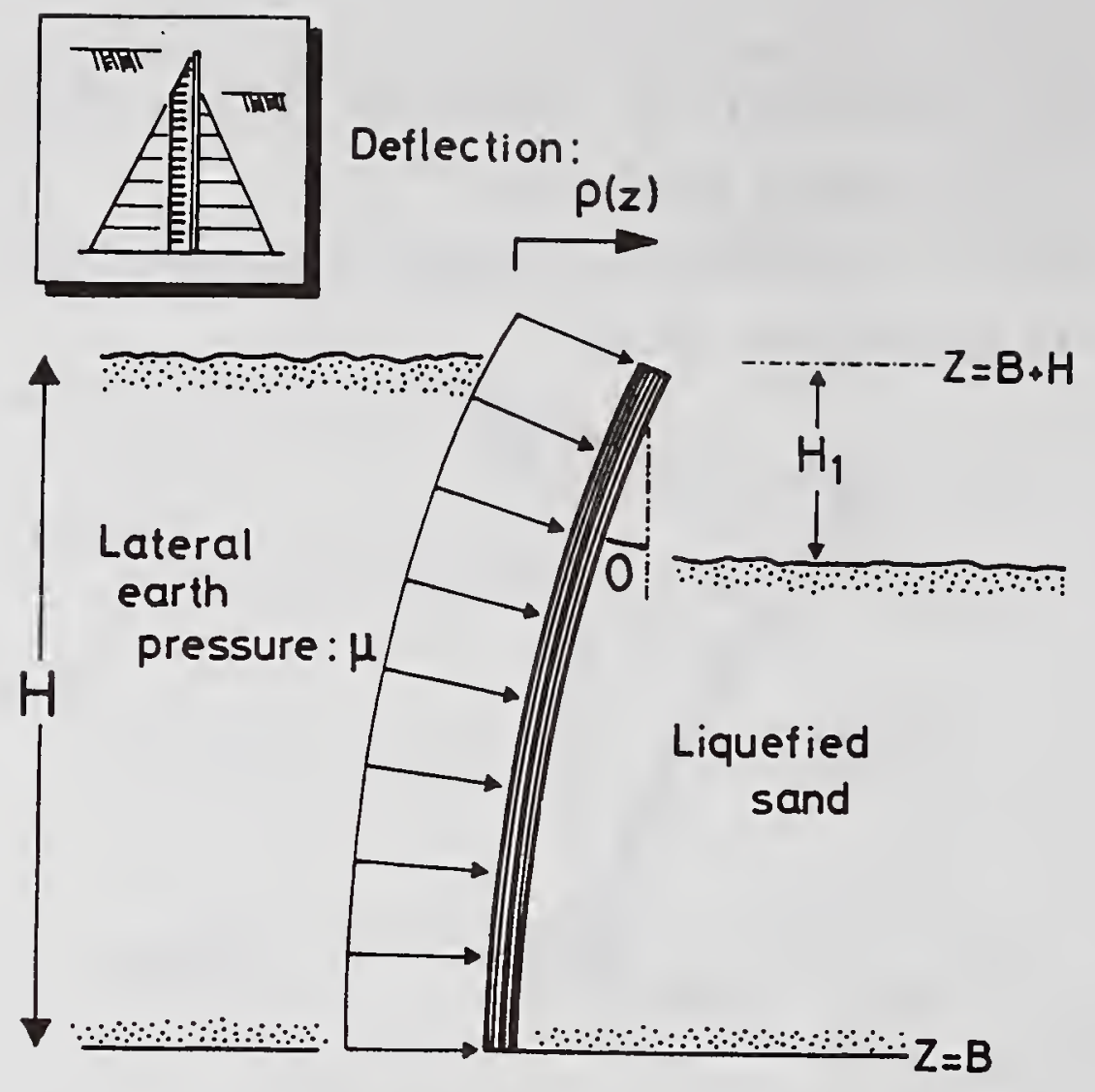

Fig.12 Bending of shet pile undergoing large distortion.

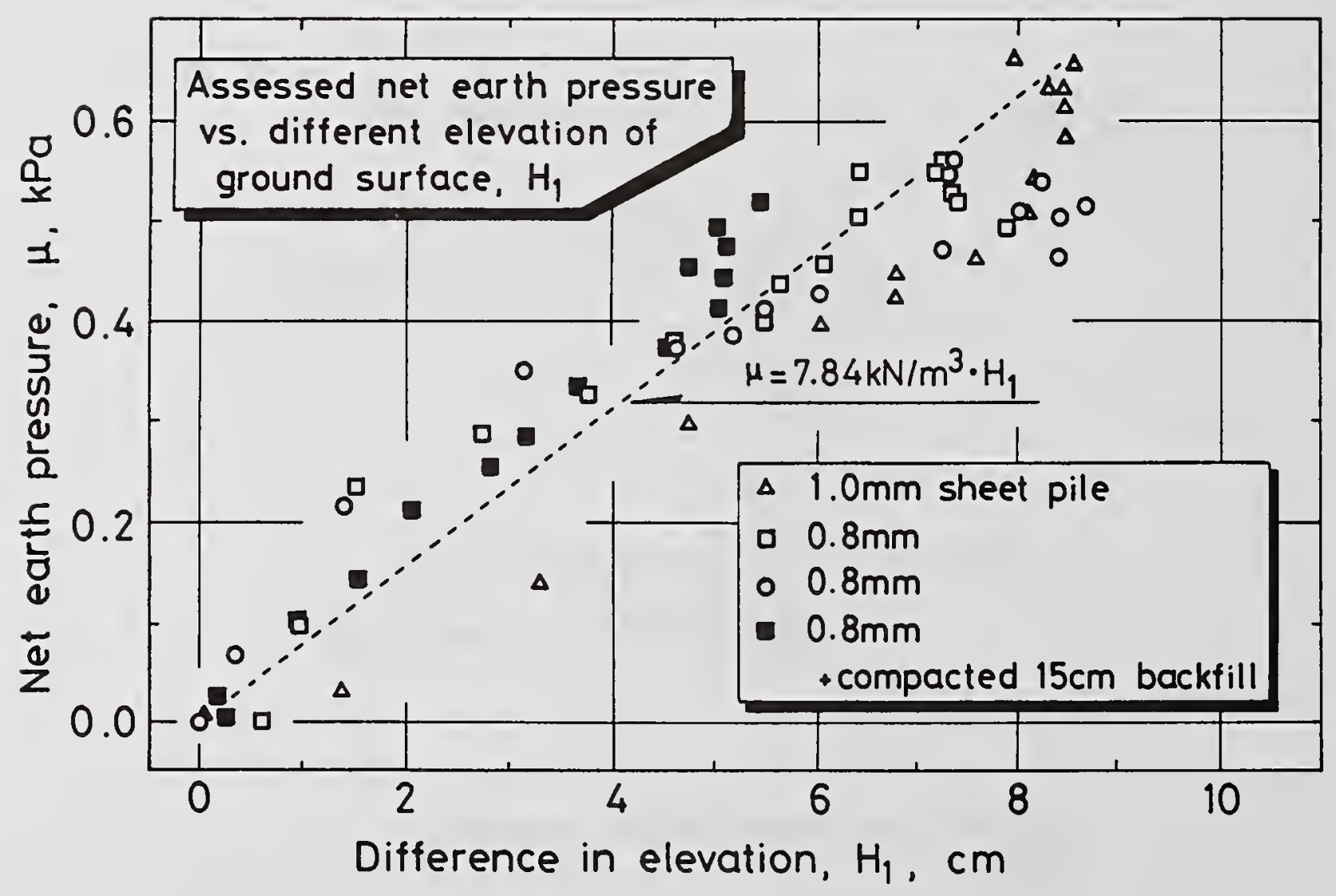

Fig.13 Relationship between assesed lateral pressure and elevation difference. 
pressure in the vertical direction (Eq.6),

$$
\mu=-\frac{2(\text { Bending moment })}{(\mathrm{B}+\mathrm{H}-\mathrm{z})^{2}+\{\rho(B+H)-\rho(z)\}^{2}}
$$

A compacted soil column is modeled by an elastic body which is of a shear modulus of $G_{s}$ and width of $\mathrm{L}_{\mathrm{s}}$ (Fig.11). The strain energy was calculated on this wall and, eventually, a nodal equation was derived as

$$
\begin{gathered}
{\left[E T \frac{d F}{d x}\right]_{x}^{x^{+}}+\left[\frac{2 P H}{\pi}+\frac{2}{\pi}\left(1-\frac{2}{\pi}\right) \gamma H^{2}+\frac{4 \gamma H}{\pi^{2}}\right.} \\
\left.\times\left(H \frac{d F}{d x}+b F\right)\right]_{x}-\frac{12 L_{S} G_{S}}{\pi^{2} H} F=0
\end{gathered}
$$

\section{OBSERVED EARTH PRESSURE DIF- FERENCE}

Eq.6 suggested theoretically that the earth pressure difference exerted on a sheet-pile wall is constant in the vertical direction and is produced by the different elevation of the ground surface around the wall.

To study the earth pressure experimentally, sheet-pile walls employed in model tests were equipped with strain gauges which made it possible to monitor the bending moment and eventually the lateral earth pressure exerted on walls. When this earth pressure was studied, a care was taken of the large deformation of the sheet pile which increased the bending moment along the wall. Fig. 12 illustrates the bending of a sheet pile due to lateral pressure. When the distortion is significant, the lateral pressure comes to have a vertical component near the top of the wall and makes an additional bending moment near the bottom. The bending moment is calculated below by considering the horizontal and vertical components of the normal earth pressure;

$$
\begin{gathered}
\text { Bending moment }=-\int_{z}^{H} \mu \cos \theta(\eta-z) d \eta \\
-\int_{z}^{H} \sin \theta\{\rho(\eta)-\rho(z)\} d \eta
\end{gathered}
$$

where $\mu$ denotes the lateral earth pressure which is normal to the face of the pile, $\theta$ is the angle of rotation, and $\eta$ is a local vertical coordinate. Considering $\theta$ to be reasonably small, $\cos \theta \approx 1$ and $\sin \theta \approx \tan \theta \approx d \rho / d \eta$. By further considering a uniform distribution of the earth

Fig. 13 compares the earth pressure assessed experimentally by using Eq.12 against the elevation difference at the ground surface. The bending moment at the bottom of a wall $(z=B)$ was used. It is interesting that the earth pressure difference is reasonably equal to the elevation difference times the unit weight of liquefied sand. Hence, the liquefied sand around the wall appears to behave as a liquid.

\section{EXAMPLE ANALYSIS ON MITIGATIVE MEASURES}

An example calculation was performed on the mitigative effects of walls installed in a liquefiable subsoil. Fig. 14 illustrates a modeled situation in which an embankment rests on a level liquefiable deposit. Zero displacement is assumed on both lateral ends of the model. The analysis of Case 1 has no mitigative measure. Case 2 has a berm as a counter weight over a $200 \mathrm{~m}$ interval. Case 3 has a sheet pile wall in addition at the foot of the embankment. This wall penetrates into the unliquefied base and its bending stiffness is $E_{p} I_{p}=35300 \mathrm{kNm} / \mathrm{m}$. Case 4 has one more sheet-pile wall at the end of the berm.

When the state of shaking and flow is maintained for a sufficiently long period of time, the lateral movement of the subsoil continues until the minimum potential energy is attained. The ultimate displacement at this minimum-energy state is indicated in Fig. 15. Although Case 1 without mitigation appears to have less significant displacement than others, it actually has the largest displacement of the embankment $(x>300 \mathrm{~m})$. The counter weight in Case 2 reduces the displacement of the embankment to $75 \%$, while an additional displacement is generated in the berm itself. The sheet-pile walls in Case 3 and Case 4 made the displacement negligible.

The ultimate displacement in Fig. 15 did not clearly indicate the efficiency of a counter weight. Actually, a berm decelerates the lateral ground movement by increasing the total mass of the moving soil. Since liquefied sand be- 


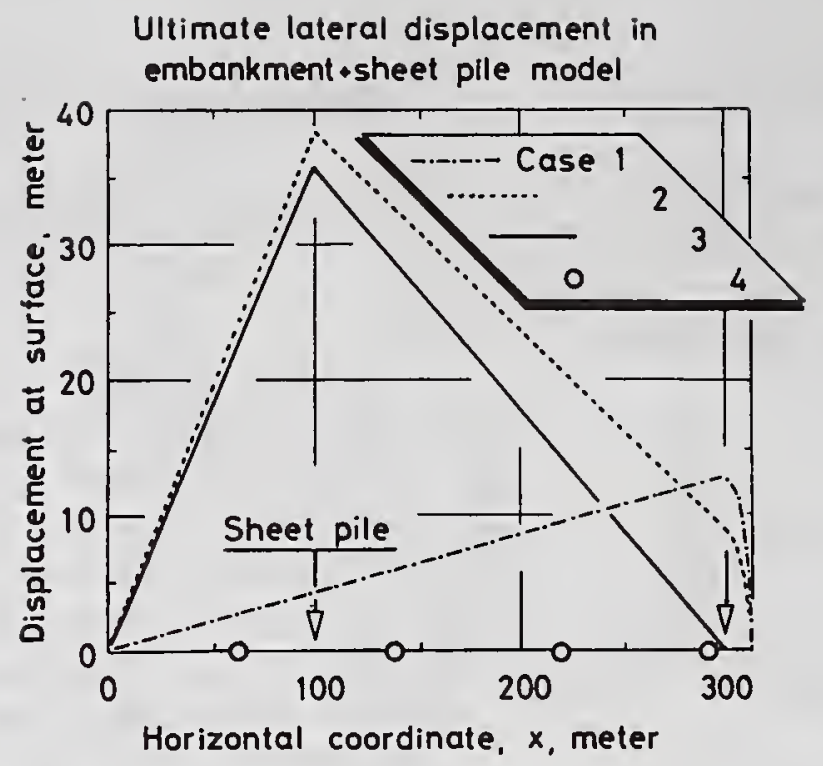

Fig.15 Ultimate displacement in model subsoil.

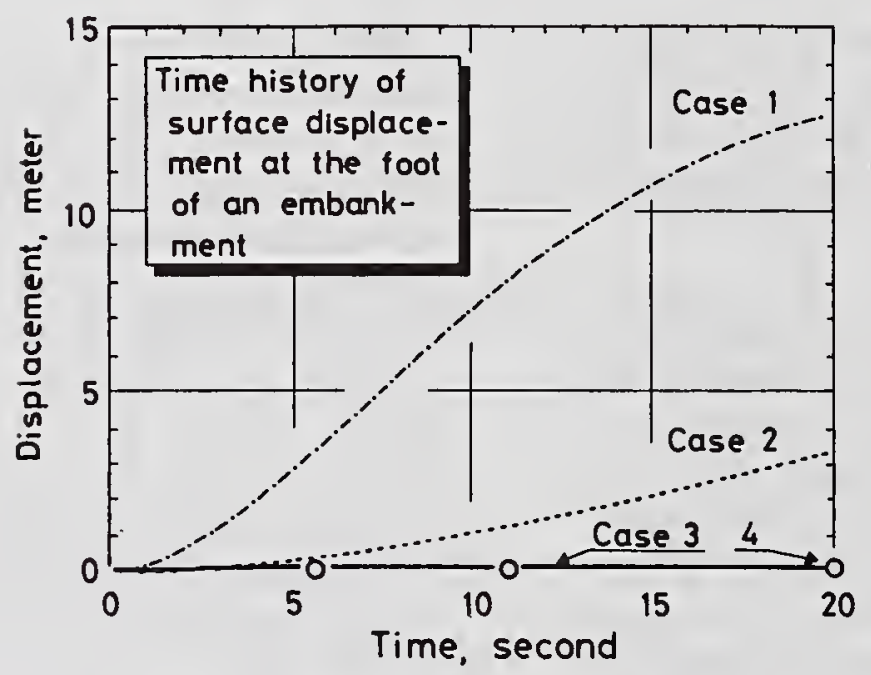

Fig.16 Calcualted time history of lateral displacement.

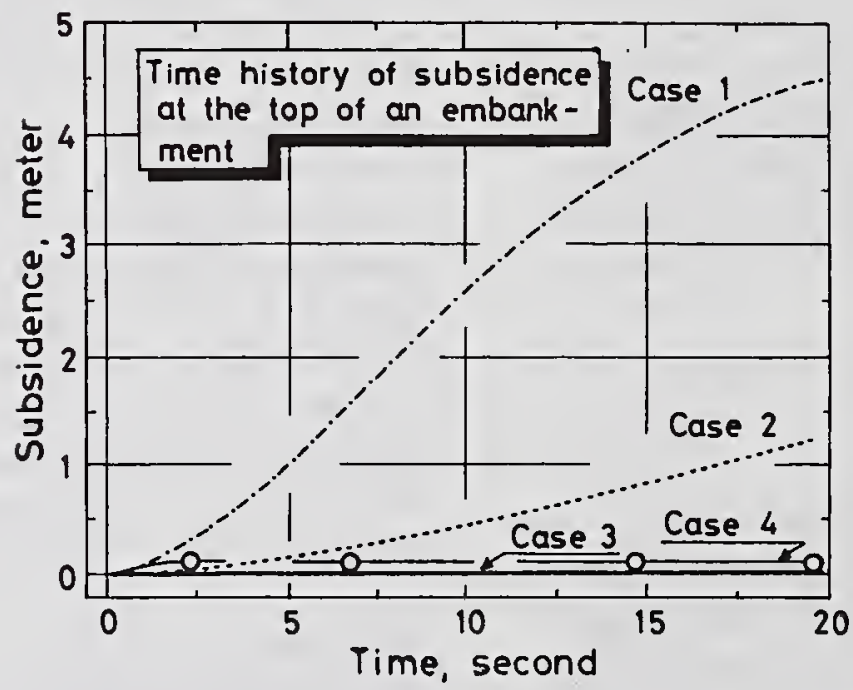

Fig. 17 Calcualted time history of subsidence of embankment. 
comes unlikely to flow further at the end of shaking, due to regained shear strength (Towhata, 1995), the ground flow stops then. Therefore, it is important to pay attention not only to the ultimate displacement as in Fig. 15 but the development of flow with time.

Figs.16 and 17 demonstrate the time history of lateral displacement at the foot of the embankment as well as the time history of the subsidence of the embankment. It is interesting that Case 2 with a berm has a remarkably smaller displacement than Case 1. Case 3 and Case 4 with sheet-pile walls are of even smaller displacement. Thus, it seems that a berm and sheetpile walls are very efficient measures to mitigate the lateral displacement of liquefied subsoil.

\section{CONCLUSION}

An experimental study was made of the mitigation of lateral flow due to liquefaction by using such subsurface walls as sheet piles and compacted sand. These measures prevent the lateral movement of ground when it is subjected to a differential earth pressure and distorts later- ally. A structural analysis on these wall together with a counter-weight berm was made possible by using a principle of minimum potential energy. Example analyses revealed the efficiency of these measures.

\section{ACKNOWLEDGMENT}

Model tests on sheet-pile walls and a compacted soil wall were conducted with a financial support provided by the Association for the Development of Earthquake Prediction in Tokyo. This aid is deeply appreciated by the authors.

\section{REFERENCES}

Towhata,I., Sasaki,Y., Tokida,K., Matsumoto,H., Tamari,Y., and Yamada,K. (1992): "Prediction of Permanent Displacement of Liquefied Ground by Means of Minimum Energy Principle," Soils and Foundations, Vol.32, No.3, pp.97-116.

I.Towhata (1995): "Liquefaction and Associated Phenomenon," Theme lecture, IS-Tokyo '95, Tokyo. 



\title{
Evaluation of Liquefaction Potential using the CPT
}

by

\author{
Richard S. Olsen*, Joseph P. Koester* and Mary E. Hynes*
}

\begin{abstract}
Prediction of liquefaction resistance using in situ test data has progressed, over the last 15 years, from techniques based on the Standard Penetration Test (SPT) to the Cone Penetrometer Test (CPT). Current CPT-based techniques for prediction of liquefaction resistance typicaliy only rely on correlations to the cone tip (or end-bearing) resistance. This paper presents an improved technique for prediction of liquefaction resistance which uses both of the primary CPT measurements (cone and sleeve friction resistances).
\end{abstract}

KEYWORDS: CPT, Liquefaction, Normalization, Sands, Silt correction, Silts, SPT

\section{INTRODUCTION}

This paper will describe an updated technique for estimating liquefaction resistance that uses both Cone Penetration Test (CPT) measurements (i.e., cone and sleeve friction resistances). This technique was originally developed in 1982 (Olsen, 1984) and improved in 1988 (Olsen, 1988) and 1995 (Olsen \& Koester, 1995). All other CPT-based techniques use only the cone resistance to estimate liquefaction resistance (Seed \& De Alba, 1985, Robertson \& Campanella, 1985, Ishihara, 1985).

CPT sleeve friction resistance is employed in the current approach because it is an index of high strain behavior. If a soil has an unstable structure, the passage of soil around the cone tip will disturb the initial soil structure; the sleeve will measure the effect of high strain. The cone resistance is an index of soil structure strength and the sleeve friction resistance is an index of high strain strength.

\section{LIQUEFACTION DEFINED}

The classic definition of liquefaction involves breakage of the grain-to-grain contacts in a loose, saturated honeycomb sand (due to the earthquake shearing action) and the temporary suspension of sand grains in water. The consequence of liquefaction was originally defined as "flow failure," but over the last 20 years a given strain level (e.g., 10 percent double amplitude cyclic strain, or 5 percent strain potential) has been used as a failure criterion. Loose to medium dense sands can experience liquefaction, however, loose sands exhibit more strain potential than do medium dense sands. Loose sands that liquefy can cause large slope movements, whereas medium dense sands might deform only slightly.

In the 1960 's, liquefaction resistance was typically determined using expensive cyclic triaxial laboratory tests. However, undisturbed sampling of sand is very difficult (e.g., loose sands densify and dense sands may dilate during sampling). Also, natural in situ variability is more complex than can be generalized with a few tests on undisturbed soil samples. For these reasons, the late Professor H. Bolton Seed began to emphasize the SPT for liquefaction resistance determination in the early 1970 's.

\section{NORMALIZATION OF PARAMETERS}

Normalization of parameters is important for CPTand SPT-based liquefaction resistance determination techniques because it corrects for numerous trend effects. This section describes stress normalization to determine equivalent CPT and SPT measurements at a vertical effective stress of one atmospheric pressure $(\mathrm{atm})(\approx 100 \mathrm{kPa}$ or $\approx 1$ ton $/ \mathrm{ft}^{2}$ ).

\footnotetext{
*Earthquake Engineering \& Seismology Branch, Geotechnical Laboratory, USAE Waterways Experiment Station, Vicksburg, MS 39180
} 
of one atmospheric pressure $(\mathrm{atm})(\approx 100 \mathrm{kPa}$ or $\approx 1$ ton $/ \mathrm{ft}^{2}$ ).

\subsection{CPT normalization}

Recent research has significantly impro red our understanding of the exponent relationship of cone resistance with vertical effective stress (Olsen, 1994). It is now known that CPT measurements (actually all geotechnical properties) are exponentially influenced by vertical effective stress. The difference between an exponentially based sand strength and linear based sand strength (i.e., $\sigma_{v} \tan \phi$ ) decreases with increased $\sigma_{v}$ level. Normalized cone and sleeve friction resistances are described below:

$$
\begin{aligned}
& q_{c l e}=\frac{q_{c}}{\left(\sigma_{v}^{\prime}\right)^{c}} \\
& f_{s l e}=\frac{f_{s}}{\left(\sigma_{v}^{\prime}\right)^{s}} \\
& R_{f}=\left(\frac{f_{s}}{q_{c}}\right)_{100}
\end{aligned}
$$

where

$$
\begin{array}{ll}
\sigma_{v}^{\prime}= & \text { Vertical effective stress (atm) } \\
q_{c l e}= & \text { Normalized cone resistance (using a } \\
& \text { variable exponent) } \\
q_{c}= & \text { Measured cone resistance (atm) } \\
c= & \text { Cone resistance stress exponent } \\
f_{\text {s1e }}= & \text { Normalized sleeve friction } \\
f_{s}= & \text { Measured sleeve resistance (atm) } \\
s= & \text { Sleeve stress exponent } \\
& \text { (approximately equal to c) } \\
\mathbf{R}_{\mathbf{f}}= & \text { Friction ratio }
\end{array}
$$

The normalized cone resistance, $\mathrm{q}_{\mathrm{cle}}$, has a " 1 " subscript to represent normalization to one atmosphere vertical effective pressure (approximately $100 \mathrm{kPa}$ or 1 ton $/ \mathrm{ft}^{2}$ (tsf)); the "e" subscript signifies that a variable stress exponent was used for normalization. The CPT stress exponent, c, can be determined using the CPT soil characterization chart in Figure 1. Alternatively, for depths between 4 and 10 meters, the stress exponent can be roughly estimated as 0.6 for sand and 1.0 for clay.

\subsection{SPT normalization}

The normalized Standard Penetration Test (SPT) blow count $\left(\mathrm{N}_{1}\right)_{60}$ is defined as:

$$
\left(N_{1}\right)_{60}=N_{60} \cdot C_{N}=N_{60} \frac{1}{\left(\sigma_{v}^{\prime}\right)^{n}}
$$

where

$$
\begin{aligned}
\mathrm{N}_{60}= & \begin{array}{l}
\text { Measured SPT blowcount (blows per } \\
\text { foot) adjusted to correspond to a } \\
\text { driving energy equivalent to } 60 \% \text { of } \\
\text { theoretical maximum free-fall } \\
\text { hammer energy }
\end{array} \\
\left(N_{1}\right)_{60}= & \text { Normalized SPT }\left(\mathrm{N}_{60} \text { at } \sigma_{v}^{\prime}=1 \mathrm{~atm}\right) \\
\mathrm{C}_{\mathrm{N}}= & \text { SPT normalization factor } \\
\mathrm{n}_{1}= & \text { stress exponent for the SPT } \\
\sigma_{v}= & \text { vertical effective stress (atm units) }
\end{aligned}
$$

The field-measured SPT blow count $(\mathbb{N})$ must be converted to an equivalent $\mathrm{N}_{60}$ either based on an understanding of the hammer type or field SPT energy measurements. The stress exponent, $n$, in Equation 4 was originally established based on SPT chamber tests in the laboratory at varying chamber confining stresses (Marcuson \& Bieganousky, 1977, Gibbs \& Holtz, 1957). These tests were performed using a short drill rod and a constant 2 meters depth of drilling mud. The constant borehole fluid pressure (due to the constant 2 meter column of drill mud) reduced the overall confining stress surrounding the SPT sampler at high chamber stresses (Olsen, 1994). This borehole fluid influence results in calculated stress exponents, $\mathrm{n}$, which are too low compared to field stress conditions. New evidence (Olsen, 1994) indicates that the SPT stress exponent, $n$, is closer in value to the CPT determined stress exponent value, $\mathrm{c}$. 
4 HISTORICAL FIELD-BASED

TECHNIQUES FOR PREDICTION OF LIQUEFACTION RESISTANCE

The industry standard for field occurrence-based liquefaction resistance prediction for the last 25+ years has been the SPT technique (Seed and Idriss, 1971, Seed \& De Alba, 1986). The SPT-based liquefaction technique still provides a good estimate of liquefaction resistance. This section will describe current SPT and CPT techniques for estimating liquefaction resistance stress ratio (Cyclic Stress Ratio, or CSR).

\subsection{SPT liquefaction technique}

Professor H. B. Seed developed the classic relationship between the normalized SPT blow count $\left(\mathrm{N}_{1}\right)_{60}$ and the CSR causing liquefaction in the field as shown in Figure 2. Increasing fines content (i.e., silts in sand) generally increases liquefaction resistance (in all but very loose sands). One means of accounting for fines content influence on liquefaction resistance is to determine an equivalent clean sand SPT blow count $\left(\mathrm{N}_{1 \mathrm{c}}\right)_{60}$ using the percent passing the \#200 sieve as shown in Figure 3 and using Equation 5.

$$
\left(N_{1 c}\right)_{60}=\left(N_{1}\right)_{60}+\Delta N_{l i q}
$$

where

$$
\begin{array}{ll}
\left(\mathrm{N}_{1 \mathrm{c}}\right)_{60}= & \begin{array}{l}
\text { Silt-corrected clean sand } \\
\text { normalized SPT blow count }
\end{array} \\
\Delta N_{l i q}= & \text { Silt correction for blow count } \\
\left(\mathrm{N}_{1}\right)_{60}= & \text { Normalized SPT blow count }
\end{array}
$$

\subsection{CPT liquefaction techniques}

Most historical CPT techniques for estimating liquefaction resistance only rely on the cone resistance measurement. The classic cone resistance-based CPT liquefaction technique is summarized in Figure 4 (Seed \& De Alba, 1986).

The only CPT-based liquefaction resistance prediction technique using both cone and sleeve friction CPT measurements was developed by Olsen $(1984,1988,1995)$. Contours of liquefaction resistance CSR shown in Figure 5
(Olsen, 1988) were established on a CPT soil characterization chart based on: 1) cyclic laboratory test results and 2) trends of CPT-predicted SPT equivalent clean sand blow counts. The unique feature of this CPT-based technique is that soil index tests are not required to predict liquefaction resistance. Other techniques require soil gradation tests to determine percent passing the $\# 200$ sieve or $D_{50}$ to estimate the liquefaction resistance.

\section{UPDATED CPT TECHNIQUE FOR PREDICTION OF LIQUEFACTION RESISTANCE}

The proposed CPT-based technique for prediction of liquefaction resistance is an improvement on the method depicted in Figure 5. Three principle steps involved in the development and application of the technique are described in the next three sections.

\subsection{Correlating cyclic laboratory results to} normalized CPT data

Cyclic laboratory triaxial and simple shear strengths from nine projects were correlated to normalized CPT parameters from nearby CPT soundings. The cyclic laboratory strengths (obtained using a failure criterion of 5\% strain) were converted to normalized CSR proportionate at 15 equivalent uniform load cycles (appropriate for a magnitude 7.5 earthquake) and adjusted to an equivalent vertical effective stress of $1 \mathrm{~atm}$. Normalized CPT parameters $\left(q_{c l e}\right.$ and $\left.R_{f}\right)$ were determined from nearby CPT soundings for each corresponding laboratory data value. These $q_{c l e}$ and $R_{f}$ values were located on the CPT soil characterization chart and the corresponding normalized laboratory CSR values were reported at each point as shown in Figure 6. Circles bound each CSR value in recognition of the fact that no sand layer is uniform; the laboratory liquefaction CSR should fall somewhere within the circles. The trend of these laboratory values indicates that normalized liquefaction resistance increases with friction ratio, at least within the soil mixture (i.e., sand mixtures and silt mixtures) and clay classification zones. 


\subsection{Equivalent strain-based cyclic strength of clay}

Clays have the potential for straining during earthquakes. Figure 6 contains results of several laboratory cyclic tests on clay (three test results located in the clay zone are marked with " $A$ "). These tests show that normally consolidated clays may potentially develop $5 \%$ cyclic strain if cyclic shear stress approaches the static strength. A static undrained strength $\mathrm{c} / \mathrm{p}$ ratio (undrained strength divided by consolidation vertical effective stress) for normally consolidated clay is typically equal to 0.3 (Olsen, 1995). An earthquake induced CSR of 0.26 when compared to the clay $\mathrm{c} / \mathrm{p}$ ratio of 0.3 represents an induced shear stress of $80 \%$ and normally consolidated clays will deform at these stress levels. Normally consolidated soft clays should therefore be expected to have equivalent liquefaction resistance CSR between 0.25 and 0.30 as is reflected in Figure 6.

\subsection{Establishing CPT-predicted equivalent clean} sand SPT blow count

Figure 7 shows the concept used to construct equivalent clean SPT blow count contours on the CPT soil characterization chart. Trends of liquefaction resistance can be estimated if trends of equivalent clean sand SPT blow counts are known. The first step required is to plot contours of CPT-predicted normalized SPT blow count $\left(\mathrm{N}_{1}\right)_{60}$ (illustrated with solid lines in Figure 7 (Olsen, 1994)). These $\left(\mathrm{N}_{1}\right)_{60}$ contours have corresponding equivalent clean sand liquefaction resistance ratios (i.e., cyclic stress ratio, CSR) also shown in Figure 7. The silt correction for blow count $\left(\Delta N_{l i q}\right)$ becomes larger with increased fines content (and/or decreasing $\mathrm{D}_{50}$ ). CPT-based soil classification can be used to estimate the fines content for the purpose of estimating $\Delta N_{\text {liq }}$ as shown in Figure 7. The silt corrected blow count, $\left(\mathrm{N}_{1 \mathrm{c}}\right)_{60}$, contours, which equals $\mathrm{N}_{1}+\Delta \mathrm{N}_{\text {liq }}$, are illustrated with dashed lines in Figure 7 and bend away from the $\left(\mathrm{N}_{1}\right)_{60}$ contours within the silty sand portion of the chart and have larger values of CSR (than underlying $\left(\mathrm{N}_{1}\right)_{60}$ contours).

The concepts illustrated in Figure 7 to determine the equivalent clean sand SPT blowcounts $\left(\mathrm{N}_{1 \mathrm{c}}\right)_{60}$ were implemented in Figure 6. These $\left(\mathrm{N}_{1 \mathrm{c}}\right)_{60}$ contours (dashed lines) in Figure 6 bend into the region of the chart where normalized laboratory CSR's are available. The CSR contours agree with the laboratory CSR data points in the soil mixture zone. The CSR contours were established based only on laboratory CSR within the clayey soil mixture and clay zone.

5.4 Final CPT correlation for prediction of liquefaction resistance

The final CPT chart for estimation of liquefaction resistance CSR is shown in Figure 8, based on the discussion in sections 5.1 through 5.3. These SPT-based CSR and laboratory cyclic test-based CSR trends match within the "Sand mixtures" zone of the CPT soil characterization chart. These CSR contours were extended down into the soil mixture and clay region of the chart using trends from the cyclic laboratory test results. These contours improve the 1988 version (Olsen, 1988) as a result of improved understanding of stress effects, availability of more laboratory cyclic data, and better CPT-based soil classification.

\section{COMPARISON OF CPT-BASED APPROACHES}

This section will compare the differences between the "cone resistance only"-based liquefaction evaluation approach and the updated liquefaction technique using both CPT measurements. These two techniques will also be compared using a unique plotting procedure.

6.1 CPT liquefaction resistance prediction technique comparison

The updated CPT liquefaction technique shows that as friction ratio increases, the predicted liquefaction resistance also increases (for a given $\mathrm{q}_{\mathrm{cle}}$ value). However, cone resistance-based techniques (i.e., Seed technique) infer a constant liquefaction resistance for all friction ratio levels. The cone resistance-based techniques, therefore, must use soil indices (such as percent passing \#200 sieve or $\mathrm{D}_{50}$ ) to approximate the soil type effects. As stated earlier, sleeve friction resistance is an index of the soil structure sensitivity and as such is an important contribution for prediction of liquefaction resistance. 
6.2 Plotting the improved CPT based liquefaction technique onto the Seed CPT liquefaction chart

The CSR contours on the $q_{c 1}$ to $R_{f}$ liquefaction resistance correlation chart in Figure 8 can be replotted as $R_{f}$ contours on a CSR to $q_{c 1}$ chart with the results shown in Figure 9. An example can illustrate how this chart-to-chart transformation occurs. The $R_{f}=0.5 \%$ contour (shown at the bottom of Figure 10) was established using a vertical projection of the $R_{f}=0.5 \%$ in the chart at the top of Figure 10, upward through the CSR contours. The intersection of the CSR contours with $R_{f}$ at the top chart provides the $q_{c 1}$ and CSR values to establish the $R_{f}$ line in the lower chart of Figure 10.

Also shown in Figure 9 is the technique developed by Seed and De Alba (1986) so that these two techniques can be compared. Seed's technique uses contours of soil indices to determine liquefaction resistance whereas the Olsen technique uses contours of friction ratio $\left(R_{f}\right)$ (which is the ratio of the two CPT strength-based measurements). In general, increasing friction ratio (for a given cone resistance level) indicates a higher lateral stress condition or higher large-strain strength. In either case, the Olsen technique shows a higher liquefaction resistance with increased friction ratio for a given normalized cone resistance. While these two different sets of contours are not parallel (in Figure 9), the Olsen technique was designed to predict liquefaction resistances equal to the SPT liquefaction technique.

The Olsen technique does not require nearby soil borings (for soil index determination), but confirmation SPT blow counts and related soil indices will always be required for technique confirmation. However, this technique does have the potential for reducing the number of required borings and soil samples for a project.

CPT-based soil classification lines (from Figure 1) were superimposed onto Figure 9 with the results shown in Figure 11. Also shown is Seed's contour for $10 \%$ fines content sand. The Olsen and Seed contours representing $10 \%$ fines content cross at two points and are relatively close considering the technical independence of the approaches.
Examples using the Olsen and Seed techniques are shown in Figure 12. Low fines content sands (i.e., fines $<5 \%$ ) generally have friction ratios of 0.3 to $0.5 \%$ and medium dense sands have normalized cone resistances of approximately 90 atm $(900 \mathrm{kPa})$. This typical medium dense sand corresponds to a point on the chart representing a CSR of approximately 0.19 using the Olsen technique. This point on the chart also falls between the $D_{50}=0.4$ and $0.8 \mathrm{~mm}$ contours for the Seed technique. The $\mathrm{D}_{50}=0.4$ to $0.8 \mathrm{~mm}$ contours represents low fines content (i.e., $<5 \%$ fines) sand.

\section{CONCLUSIONS}

An improved CPT-based technique for estimating liquefaction resistance is presented. This technique uses both cone and sleeve friction measurements. It allows a more refined prediction of liquefaction resistance compared to techniques that use only the cone resistance.

\section{ACKNOWLEDGMENT}

The data presented herein, unless otherwise noted, were obtained from various projects at Waterways Experiment Station of the United Stated Army Corps of Engineers. Permission was granted by the Chief of Engineers to publish this information.

\section{REFERENCES}

1 Ishihara, K. (1985) Stability of Natural Deposits During Earthquakes, Proceedings, 11th International Conference on Soil Mechanics and Foundation Engineering (ICSMFE), San Francisco, Vol. 1, 321-376

2 Olsen, R. S. and Koester, J. P. (1995). Prediction of Liquefaction Resistance using the CPT, Proceedings, International Symposium on Cone Penetration Testing CPT '95, Linkoping, Sweden, Oct. 1995

3 Olsen, R. S. and Mitchell, J. K. (1995). CPT Stress Normalization and Prediction of Soil Classification, Proceedings, International Symposium on Cone Penetration Testing CPT '95, Linkoping, Sweden, Oct. 1995 
4 Olsen, R. S.(1995). Prediction of Clay Strength using the combination of Cone and Sleeve Resistance, Proceedings, International Symposium on Cone Penetration Testing CPT '95, Linkoping, Sweden, Oct. 1995

5 Olsen, R. S. (1994). Normalization and Prediction of Geotechnical Properties using the Cone Penetrometer Test (CPT), Technical Report GL-94-29. U.S. Army Engineer Waterways Experiment Station, Vicksburg, MS. August 1994

6 Olsen, R. S. (1994). Normalization and Prediction of Geotechnical Properties using the Cone Penetrometer Test (CPT), Ph.D. Dissertation, University of California, Berkeley, CA.

7 Olsen, R. S. (1988). Using the CPT for Dynamic Response Characterization, Proceedings, Earthquake Engineering and Soil Dynamics II Conference, 1988, ASCE.

8 Olsen, R. S., (1984). Liquefaction Analysis using the Cone Penetrometer Test, Proceedings, Eighth World Conference on Earthquake Engineering, San Francisco.

9 Robertson, P. K. and Campanella, R. G. (1985) Liquefaction Potential of Sands using the CPT, ASCE Journal of Geotechnical Engineering, Vol. 111, No. 3, 384-402

10 Seed, H. B. and De Alba, P. (1986) Use of SPT and CPT Tests for Evaluating the Liquefaction Resistance of Sands, Proceedings, In Situ 86 Specialty Conference, Blacksburg, VA, Geotechnical Special Publication No. 6

11 Seed, H. B., Idriss, I. M. and Arango, T. (1983). Evaluation of Liquefaction Potential Using Field Performance Data, Journal of Geotechnical Engineering Division, ASCE, Vol. 109, No. 3, March 1983, pp. 458-492.
12 Seed, H. B. and Idriss I. M. (1971) Simplified Procedure for Evaluating Soil Liquefaction Potential, ASCE Geotechnical Journal, Vol 97, SM9, 1249-1275 


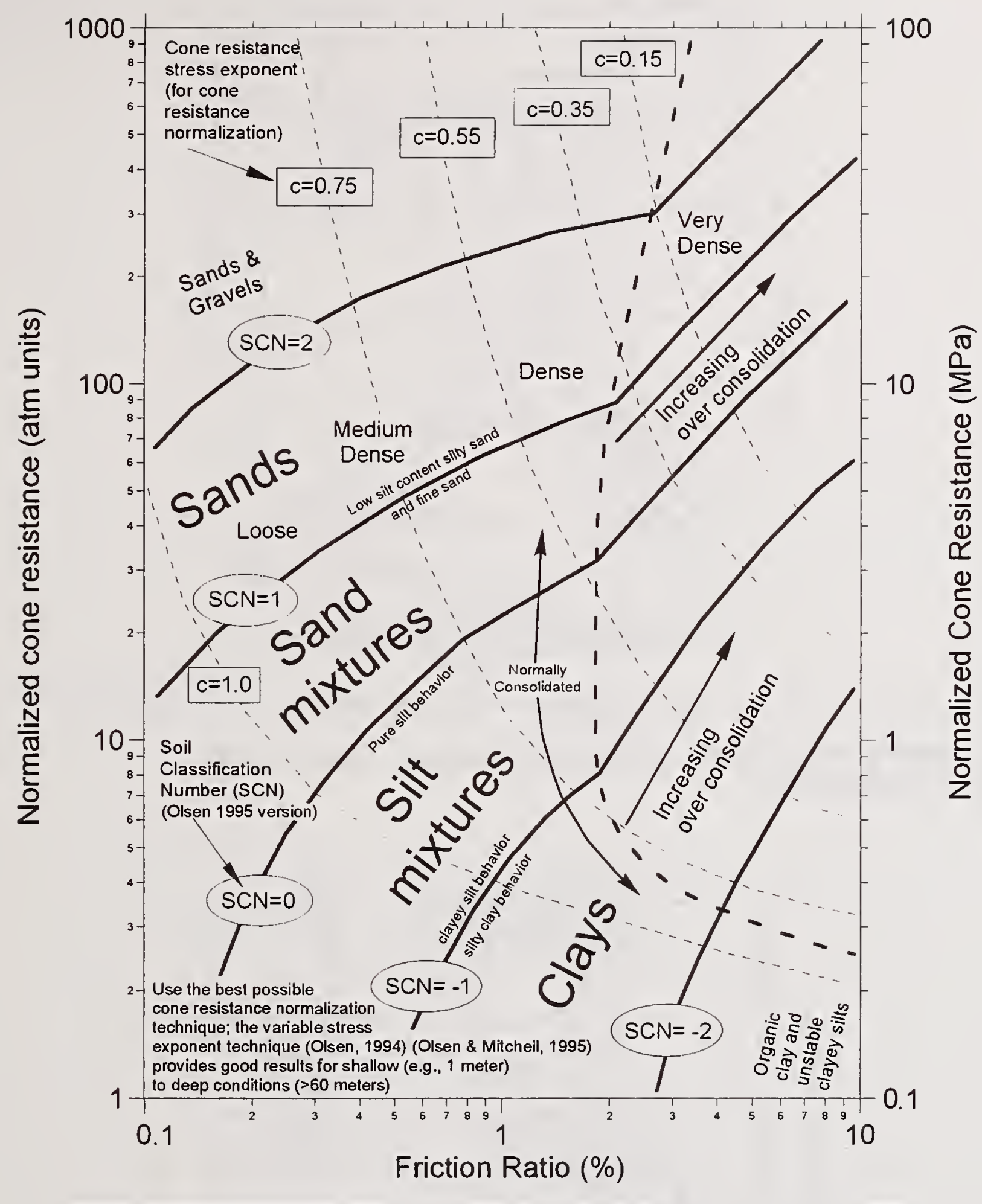

Use the best available technique for cone resistance normalization

Linear normalization

is adequate for

hand calculations

(Olsen and Douglas, 1981)

(Douglas, Olsen \& Martin, 1981)

$$
q_{c 1 L}=\frac{q_{c}}{\bar{\sigma}_{v}}
$$

Constant stress exponent Variable stress exponent is the most normalization (for sands) advanced stress normalization technique, is adequate for many situations (Robertson, $1988,1989,1994)$ required for shallow and deep situations and soil mixtures (Olsen, 1984, 1988, 1994) (Olsen and Mitchell, 1995)

$$
q_{c 1 s}=\frac{q_{c}}{\left(\overline{q_{j}}\right)^{0.6}} \quad q_{c 1 e}=\frac{q_{c}}{\left(\bar{\sigma}_{v}\right)^{c}}
$$

Figure 1. CPT soil characterization chart having SCN and stress exponent contours (Olsen \& Mitchell, 1995) 


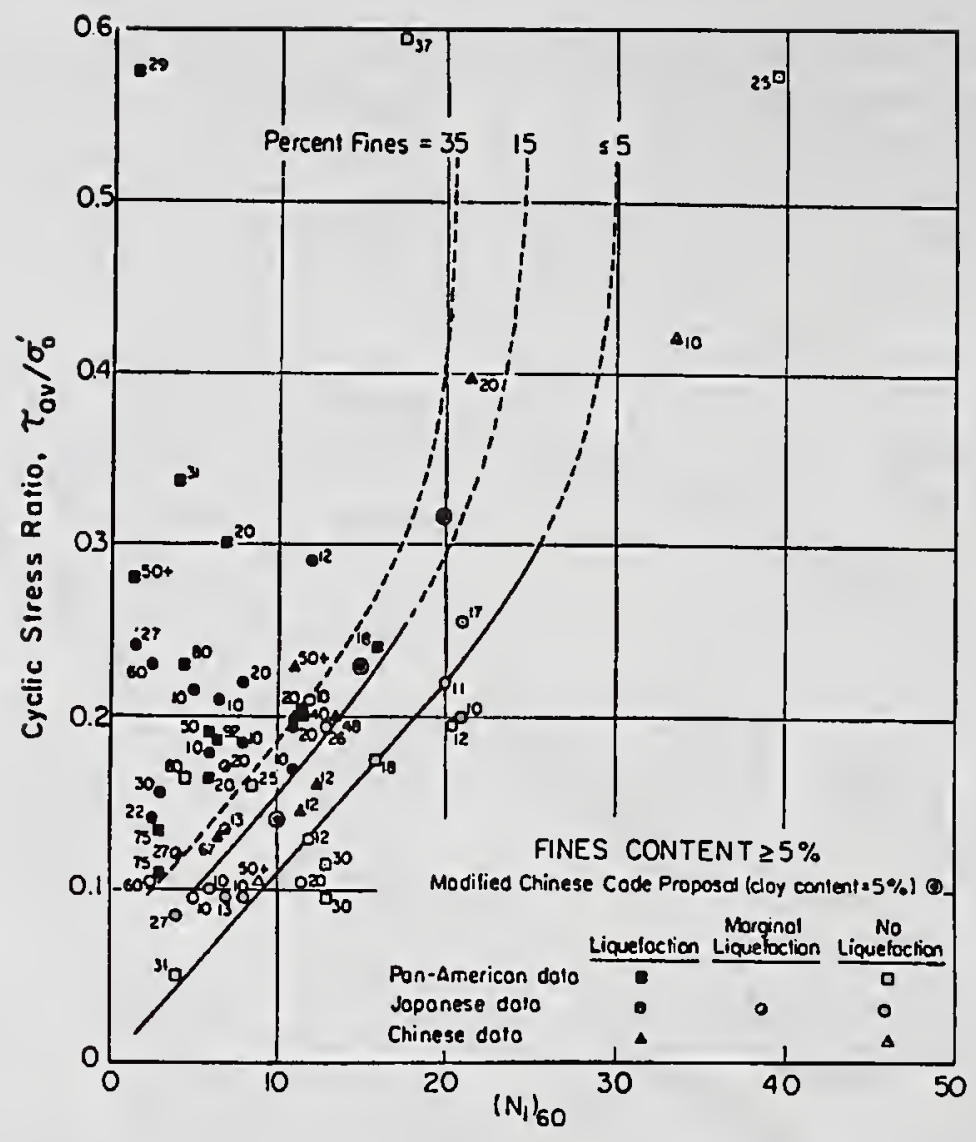

Figure 2. Seed technique for estimating liquefaction resistance based on the SPT (Seed, Idriss \& Arango, 1983)

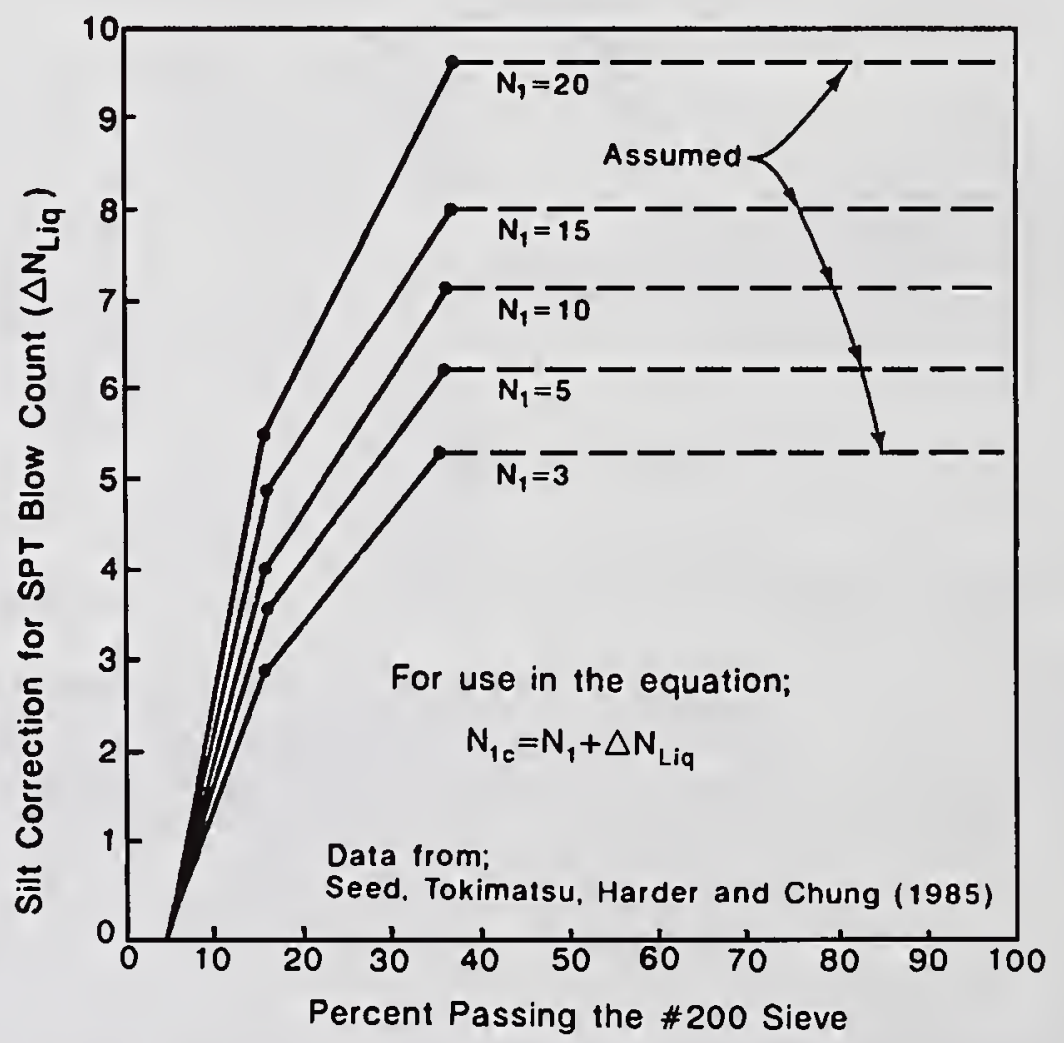

Figure 3. SPT silt correction blow count $\left(\Delta N_{\text {liq }}\right)$ to fines content (Olsen, 1988) 


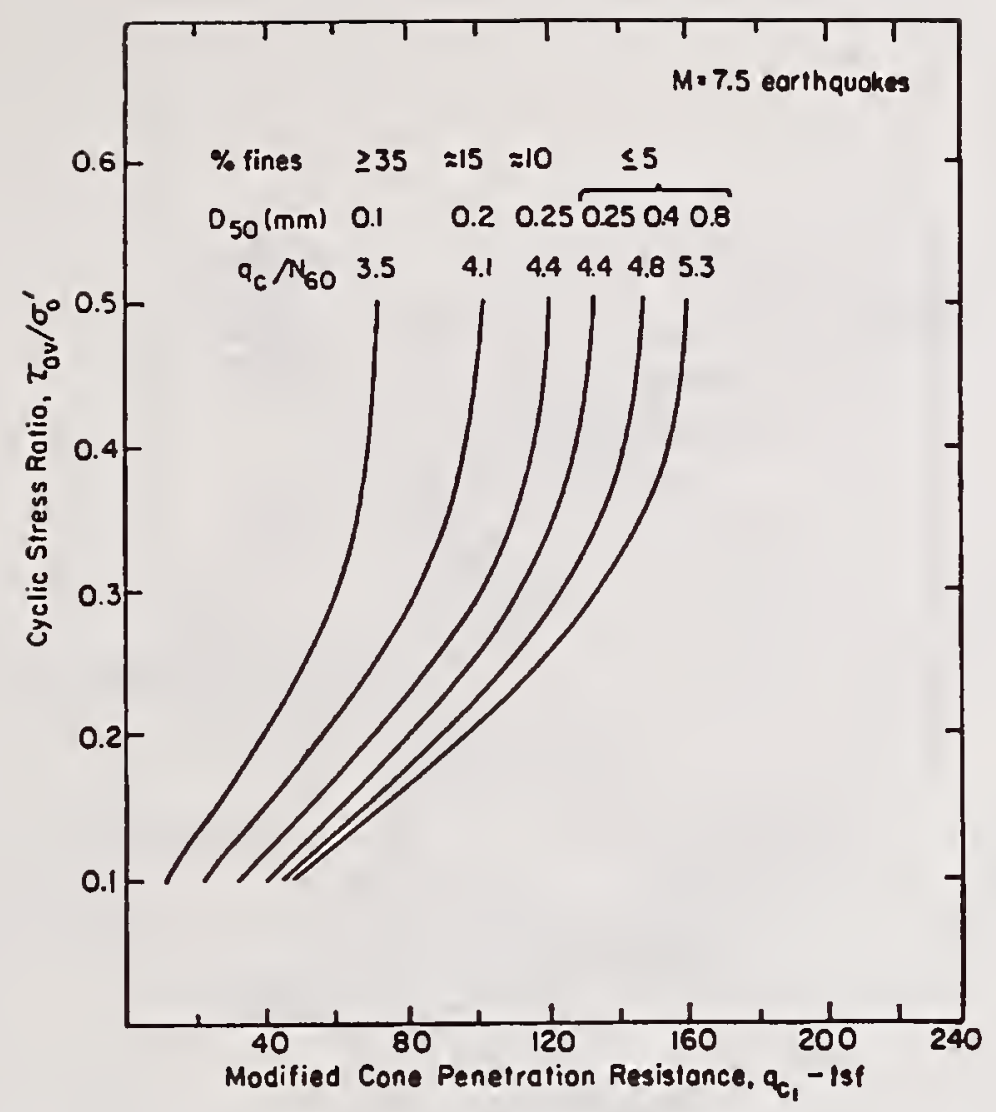

Figure 4. Seed technique for CPT-based prediction of liquefaction resistance (Seed \& De Alba, 1986)

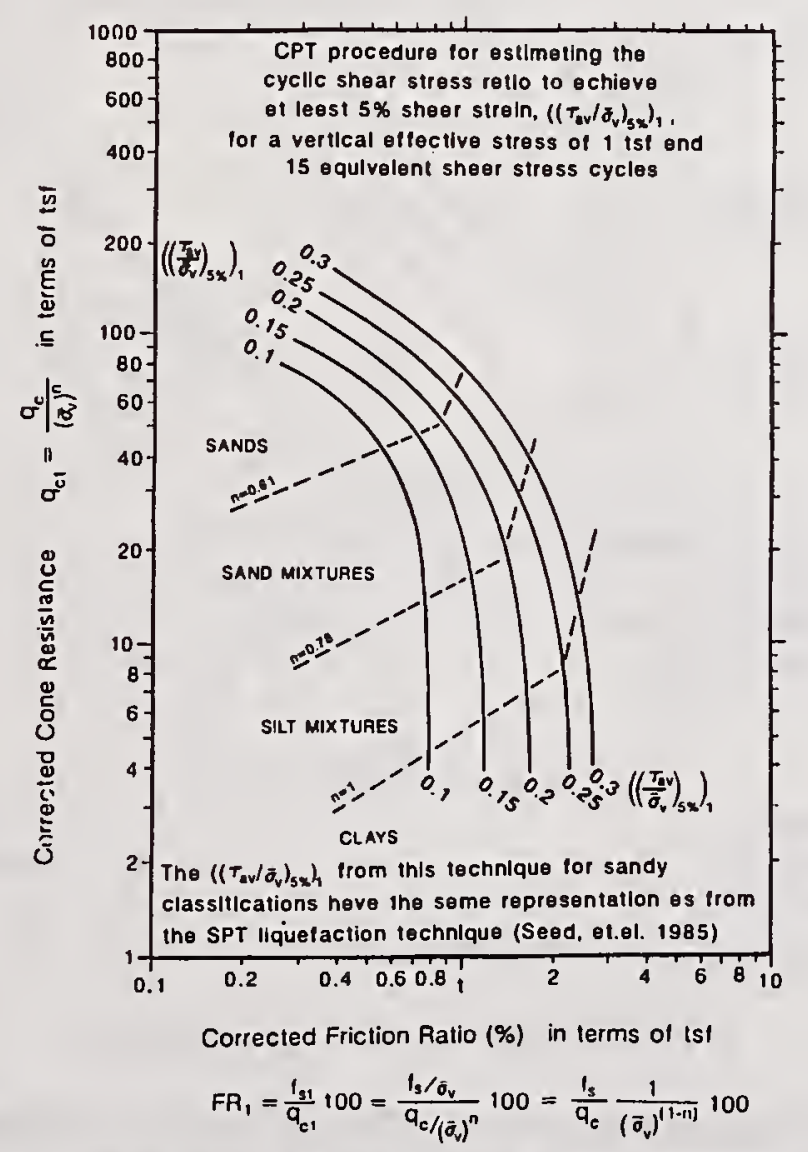

Figure 5. CPT prediction of liquefaction resistance using both CPT measurements (Olsen, 1988) 


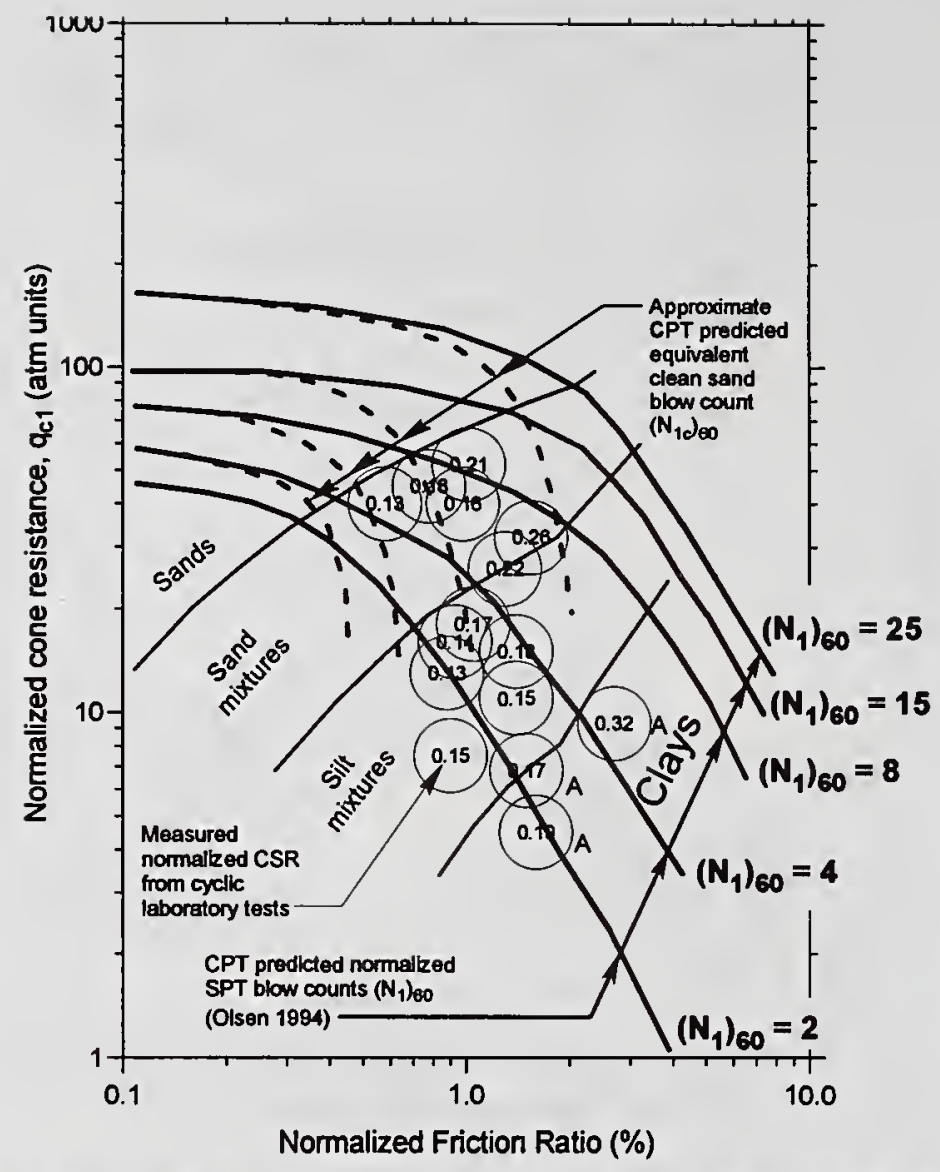

Figure 6. The components for determining the CPT liquefaction technique using CPT predicted SPT blow contours and cyclic laboratory test results

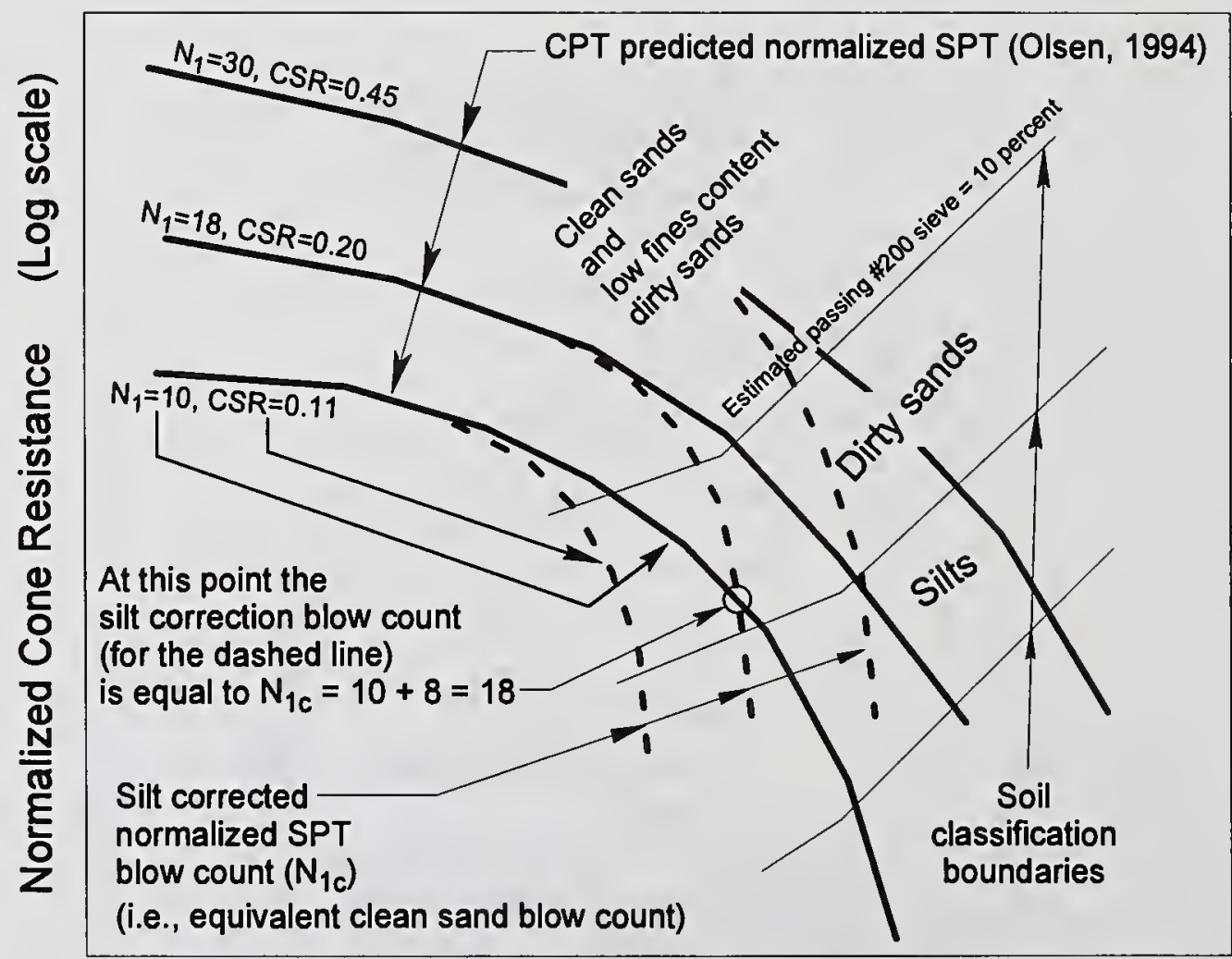

\section{Friction Ratio (\%) (Log scale)}

Figure 7. Illustration showing how to construct the CPT predicted equivalent clean sand SPT blow count (Olsen, 1988, 1984) 


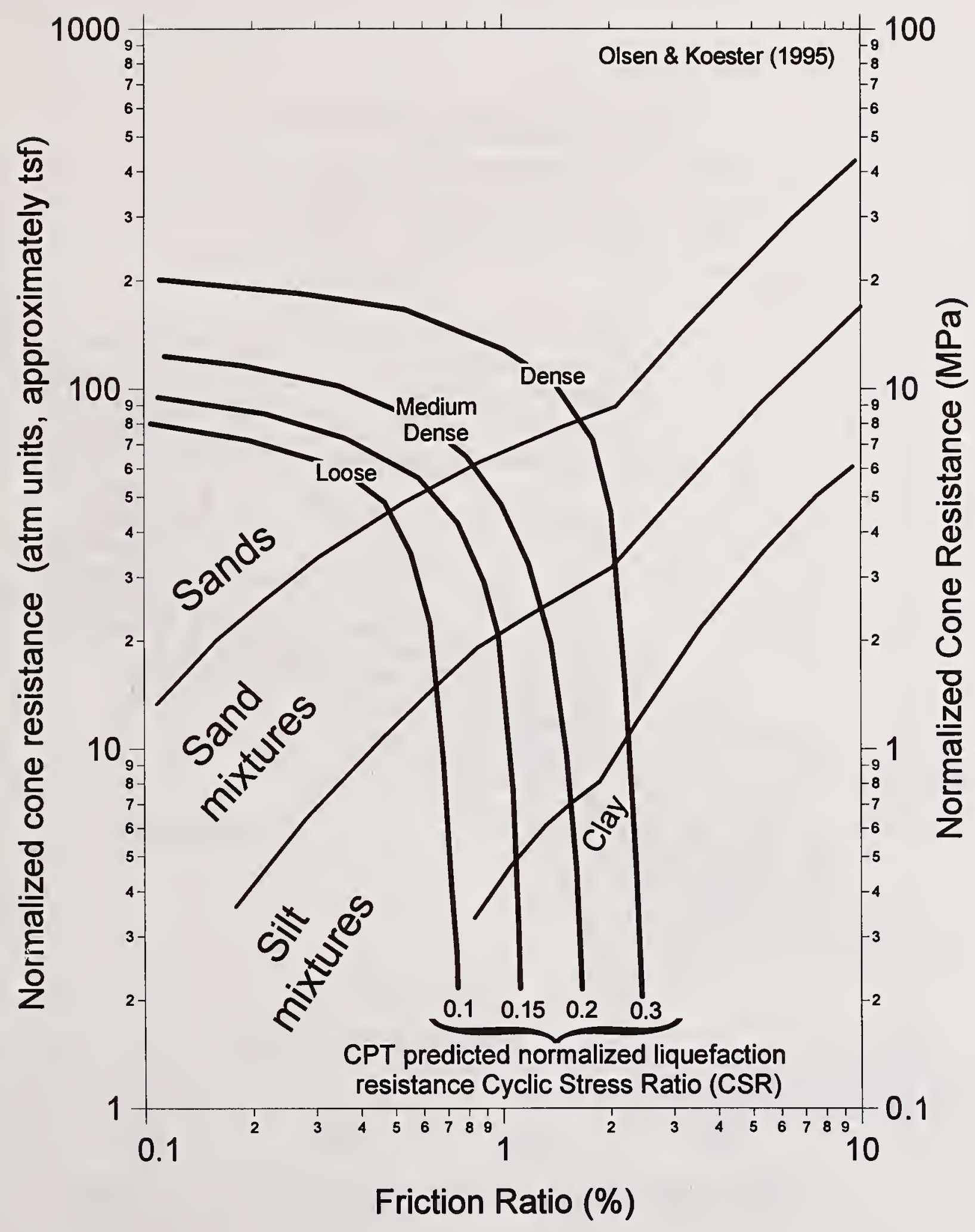

Figure 8. Final relationship for prediction of liquefaction resistance cyclic stress ratio (CSR) using both CPT measurements 


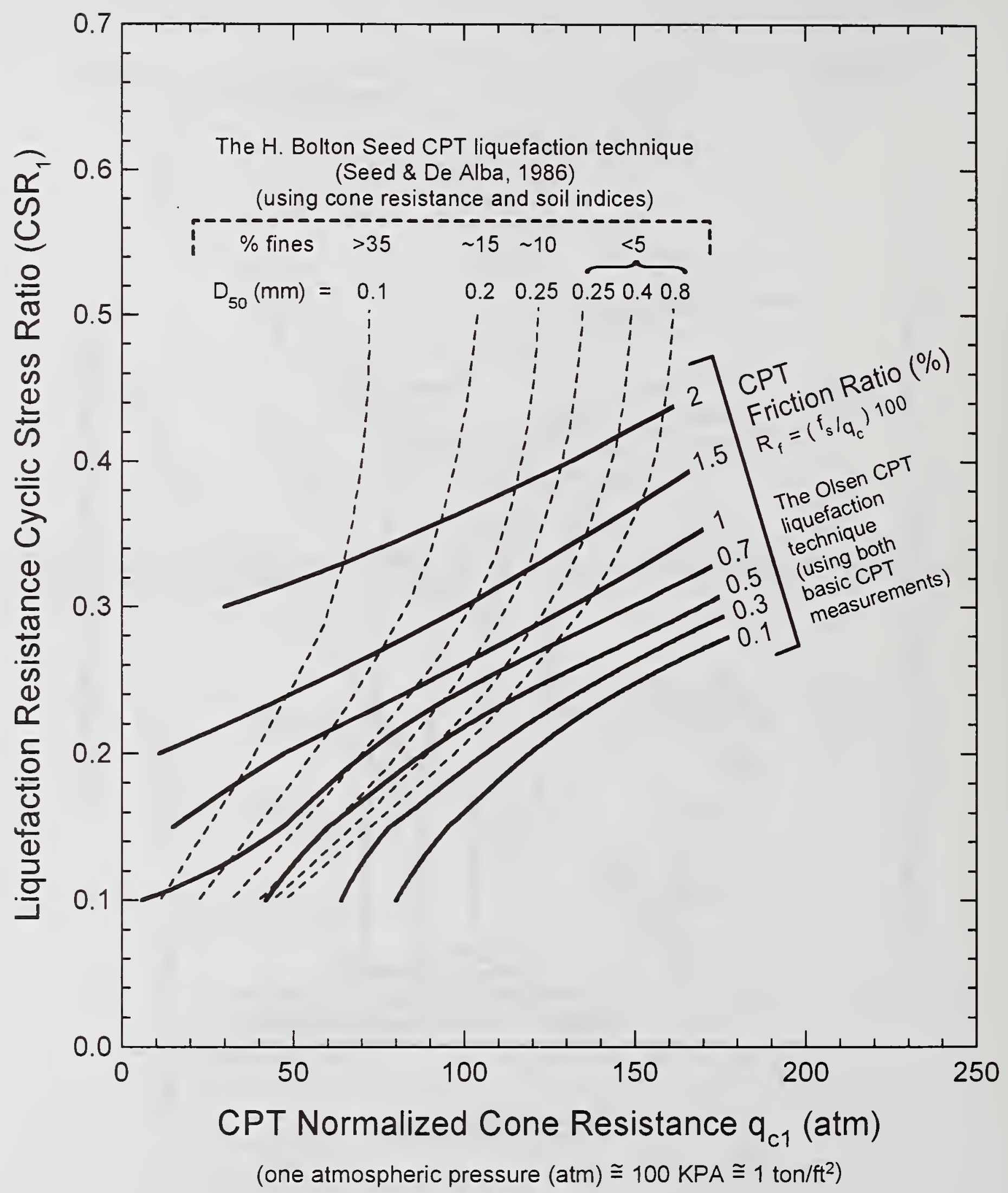

Figure 9. Determining liquefaction resistance based on the CPT normalized cone resistance and friction ratio (from Olsen \& Koester, 1995) and with comparison to the Seed \& De Alba (1986) technique (the latter based on normalized cone resistance and soil indices from soil samples). 


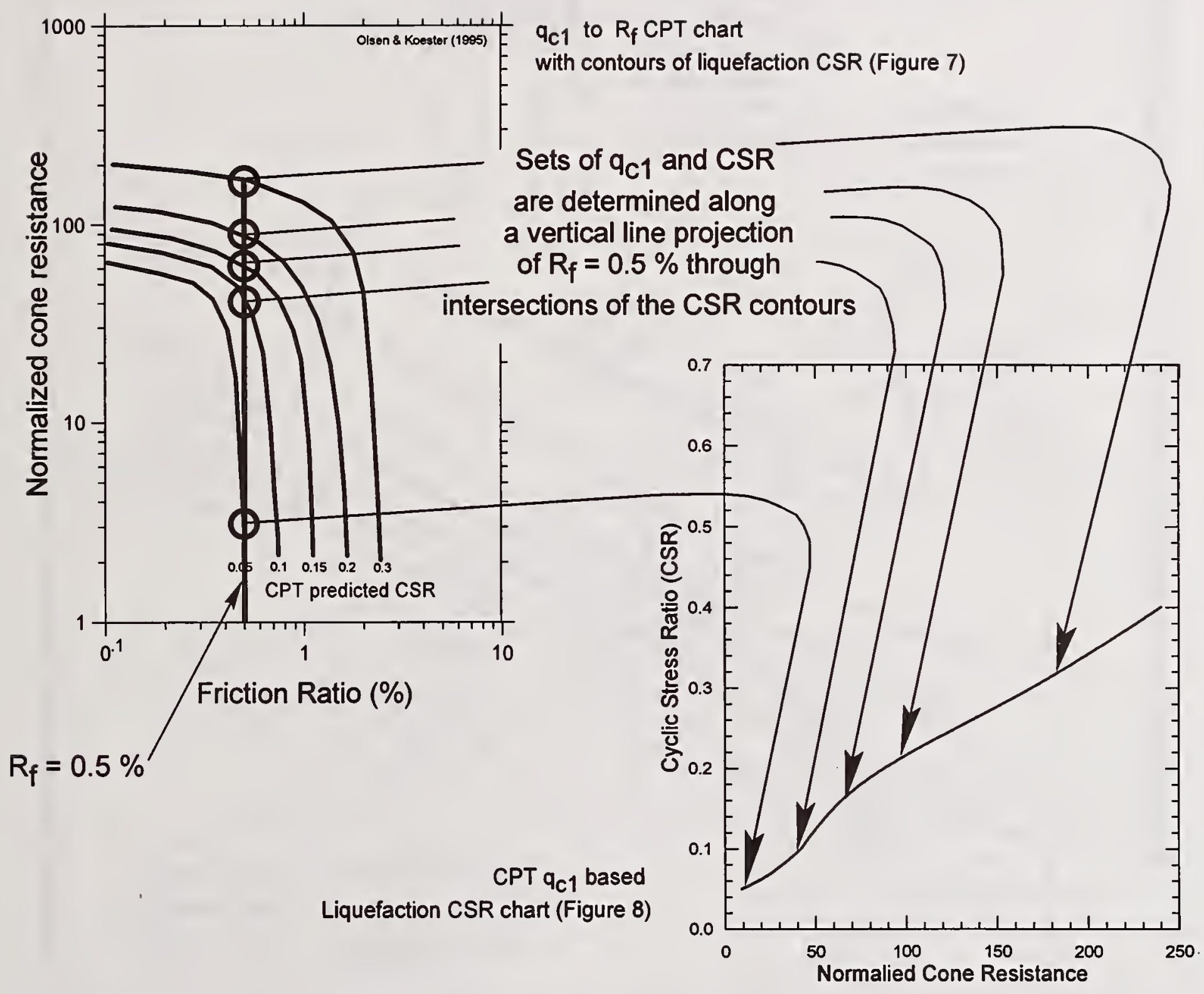

Figure 10. Illustration of the conversion of CSR contours on the $q_{c 1}$ versus $R_{f}$ chart to the $R_{f}=0.5 \%$ contour on the CSR versus $q_{c 1}$ chart 


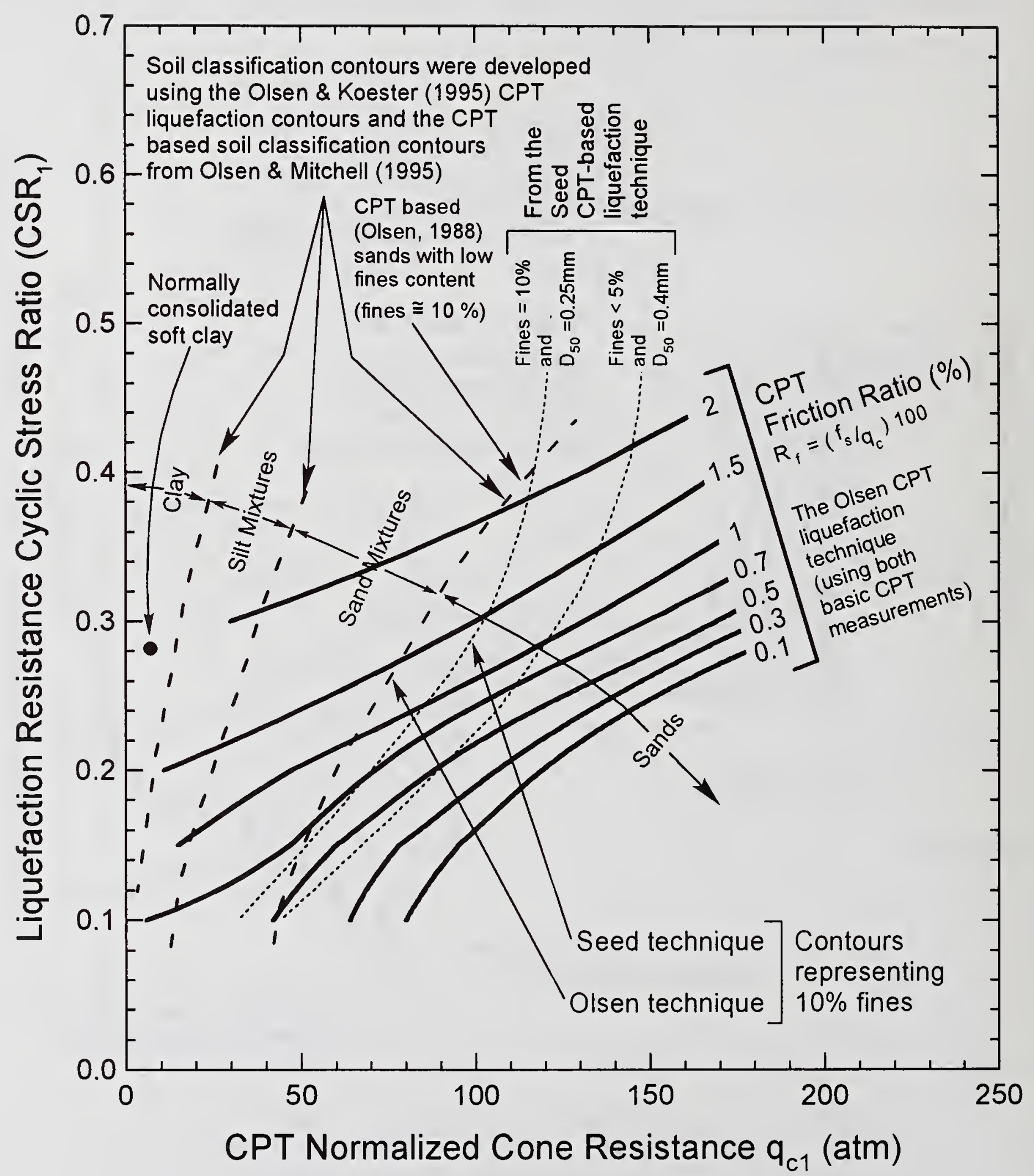

(one atmospheric pressure $(\mathrm{atm}) \cong 100 \mathrm{KPA} \cong 1$ ton $/ \mathrm{ft}^{2}$ )

Figure 11. Superposition of the CPT soil classification lines on the CSR versus $q_{c 1}$ chart based on contours of friction ratio. Note the comparison between $10 \%$ fine content sands contours for the Olsen and Seed techniques. 


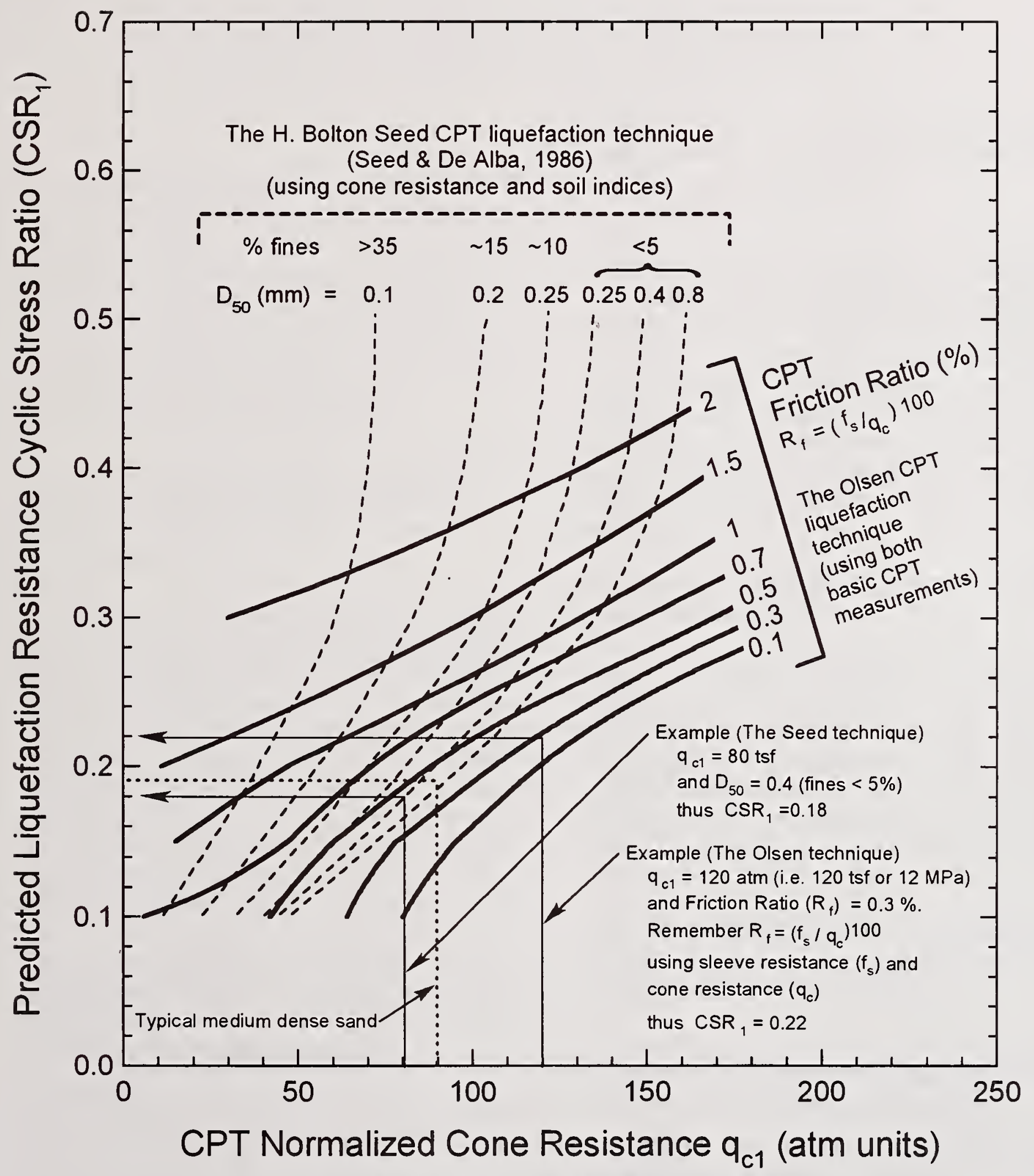

(one atmospheric pressure $(\mathrm{atm}) \cong 100 \mathrm{kPa} \cong 1$ ton/ $/ \mathrm{ft}^{2}$ )

Figure 12. Example determination of normalized liquefaction resistance CSR using the Olsen and Seed CPT-based techniques 



\title{
ESTIMATION OF EFFECTS OF LIQUEFACTION-INDUCED GROUND FLOW ON BRIDGE FOUNDATIONS
}

\author{
by \\ Keiichi Tamura ${ }^{1)}$, Yoshio Ninomiya ${ }^{2)}$ and Tadashi Hamada ${ }^{3)}$
}

\begin{abstract}
The Hyogo-ken Nanbu Earthquake of January 1995 caused liquefaction in wide area. Especially, the liquefaction induced the ground flow with the movement of sea walls along the waterfront, and this ground flow caused large deformation of bridge foundations. This paper summarizes a feature of the liquefaction-induced ground flow and the results of analysis on the ground movement and the ground flow force acted on a bridge foundation.
\end{abstract}

KEYWORDS: Bridge Foundation, Ground Flow, Hyogo-ken Nanbu Earthquake, Liquefaction

\section{INTRODUCTION}

The Hyogo-ken Nanbu Earthquake of January 1995 caused widespread liquefaction in the reclaimed land. Furthermore, the liquefaction induced the ground flow with the movement of sea walls, and this ground flow caused large deformation of bridge foundations. In Japan, the liquefaction-induced ground flow has been recognized since the Niigata earthquake of 1964 from an engineering point of view, however it was the first time that the ground flow caused the extensive damage to the newly constructed highway bridges.

This paper presents a feature of the liquefaction-induced ground flow and an estimation of the ground movement and the force acted on a bridge foundation by the ground flow.

\section{OUTLINE OF LIQUEFACTION-INDUCED GROUND FLOW}

Where the soft ground underwent liquefaction, the resulting decrease of bearing capacity of the ground and the ground subsidence caused various damage. Besides that, near the water's edge, the liquefaction caused the movement of sea walls and ground flow, which resulted in the damage to the structures behind sea walls. Photos 1 and 2 show the examples of damage caused by ground flow.

Photo 1 shows damage to a parking lot on the north shore of Uozakihama. This photo shows that the sea wall shifted out into the watercourse followed by the subsidence and movement of the ground behind it. Photo 2 was taken on the north shore of Port Island. In Photo 2, it appears that the quaywall in the foreground moved to the watercourse and the quaywall in the background did not move, however, the quaywall in the background also moved about $30 \mathrm{~cm}$, which was clarified by the survey of bridge location.

\section{GROUND MOVEMENT BASED ON AERIAL PHOTOGRAMMETRY}

It may be possible to judge the occurrence of ground flow by the movement of sea walls near watercourses as seen in Photos 1 and 2, however, it is difficult to make judgments of this kind for locations further from watercourses. Even close to a watercourse, it is impossible to quantitatively estimate the amount of movement of the ground simply by inspecting the damage to structures.

The aerial photogrammetry was employed to estimate the amount of ground displacement. An outline of the procedure is as follows:

1) Head, Ground Vibration Division, Public Works Research Institute, Ministry of Construction

2) Deputy Head, Structures Division, Civil Engineering Research Institute, Hokkaido Development Bureau

3) Research Engineer, Ground Vibration Division, Public Works Research Institute, Ministry of Construction 
Step 1. Selection of the Target Points

The target points selected for aerial photogrammetry are points such as lane markers of roads that have not been dislodged before and after the earthquake by factors other than the ground flow.

Step 2. Photographic Inspection of Coordinates of the Target Points Before the Earthquake

Step 3. Photographic Inspection of the Coordinates of the Target Points After the Earthquake

Step 4. Calculation of the Movement Vector

The difference between the coordinates of a target point measured in steps 2 and 3 is defined as the movement vector.

In order to study the effect of ground flow on bridge foundations, the target points were set along the Route 5, Bay Shore Line of the Hanshin Expressway, and separate survey was performed to find movement vectors of the expressway bridge piers. The movement vectors of the bridge piers were found in the same manner as the case of ground movement vector. The as-built drawings and the GPS measurements were used to obtain bridge pier coordinates before and after the earthquake, respectively. The difference in the coordinates of each target point before and after the earthquake may be composed of three constituents: displacement caused by ground flow, displacement caused by diastrophism, and measurement error. The movement vector found in this study excluded the diastrophism.

Figures 1 and 2 show the results of estimating the movement vector of the ground and bridge piers. Figure 1 shows the area near the north shore of Rokko Island. The quaywall in the east-west direction ( $\left.A-A^{\prime}\right)$ and the quaywall in the north-south direction (B-B') moved to the north and the west, respectively, and the ground behind the walls moved north-west direction. Directly at the edge of the watercourse, the ground moved more than $2 \mathrm{~m}$, and a bridge pier moved approximately $0.9 \mathrm{~m}$. The maximum ground displacement in this area was about $3 \mathrm{~m}$. The amount of ground movement and bridge pier generally decreases as the distance from the watercourse increases.

Figure 2 shows the area near the south shore line of Uozakihama, which lies opposite to the north shore of Rokko Island. At this area, the southward movement of the east-west quaywall $\left(\mathrm{C}-\mathrm{C}^{\prime}\right)$ was accompanied by the southward movement of the ground and bridge piers behind this quaywall.

Similar phenomena occurred on other artificial islands, however, no superstructure on the Hanshin Expressway felt down under the effects of ground flow.

\section{ESTIMATION OF GROUND FLOW FORCE BY BACK ANALYSIS}

As an example of back analysis of ground flow force, the case of Shin-Syukugawa Bridge on Route 5, Hanshin Expressway is here presented.

As Figure 3 shows, Shin-Syukugawa Bridge is a 3-span continuous steel slab Gerber box girder bridge crossing a watercourse. The bridge was completed in 1993. The pier P-134, which was analyzed in this study, was a 4-column steel rigid frame pier and was supported by cast-in-place concrete piles with diameter of $1.5 \mathrm{~m}$ and $34 \mathrm{~m}$ long. The foundation was constructed in the reclaimed soil and was supported by a diluvial layer.

Extensive liquefaction occurred around the bridge, and the $\mathrm{P}-131$ and $\mathrm{P}-134$ moved approximately $0.5 \mathrm{~m}$ and $1 \mathrm{~m}$ toward the waterway with the movement of sea walls, respectively. The longitudinal component of the movement of $\mathrm{P}-134$ was $0.7 \mathrm{~m}$. On the piers $\mathrm{P}-131$ and $\mathrm{P}-134$, all the bearing supports were destroyed and the girder felt down from the supports, however, it remained on the piers.

As shown in Figure 4, the foundation was so idealized that a rigid footing is supported by piles that are supported by soils, considering nonlinear properties of pile bodies and the ground. Figure 5 shows an analytical model of Shin-Syukugawa Bridge. The second layer from the surface was considered to be liquefied. At first, we assumed that the first layer on the liquefied layer acted lateral force on the foundation with the ground flow, and 
calculated the relationship between the lateral force and displacement, which is indicated by a fine line in Figure 6. Based on this assumption, the maximum lateral force is limited to the passive earth pressure of the non-liquefied layer, which was estimated as approximately 3,200 $\mathrm{tf}$, however, even if this maximum load was considered, the amount of residual displacement of the bridge pier could not be accounted.

Then, in addition to the passive earth pressure of the non-liquefied layer, we assumed that some portion of overburden pressure of liquefied layer also acted on the foundation, and the thick line in Figure 6 was obtained. This overburden pressure corresponds to the pressure acting on piles when slurry goes through between piles in the liquefied layer. As seen from Figure 6, the movement of P-134 may be accountable by considering that the passive earth pressure of non-liquefied layer and a portion of overburden pressure of liquefied layer acted on the foundation. From the five cases of back analysis, the contribution ratio of overburden pressure was estimated as 0.2 .

\section{CONCLUSIONS}

An outline of the liquefaction-induced ground flow was presented. The ground movement caused by the ground flow was estimated by comparing aerial photos taken before and after the earthquake, and the maximum movement was found to be approximately $3 \mathrm{~m}$. The ground flow force acted on a bridge foundation was estimated by back analysis using a nonlinear foundation model. From the analysis of this study, the ground flow force may be estimated as the sum of the passive earth pressure of the non-liquefied layer and $20 \%$ of the overburden pressure of the liquefied layer.

\section{REFERENCES}

1) Committee for Investigation on the Damage of Highway Bridges by the Hyogo-ken Nanbu Earthquake, 1995: Report on the Damage of Highway Bridges by the Hyogo-ken Nanbu Earthquake, 1995 (in Japanese)

2) Hamada M., Isoyama R. and Wakamatsu K.: The 1995 Hyogoken-Nanbu (Kobe) Earthquake,
Liquefaction, Ground Displacement and Soil condition in Hanshin Area, Association for Development of Earthquake Prediction, 1995

3) Japan Road Association: Reference for Applying the Guide Specifications for Reconstruction and Repair of Highway Bridges Suffered Damage from the Hyogo-ken Nanbu Earthquake of 1995, 1995 


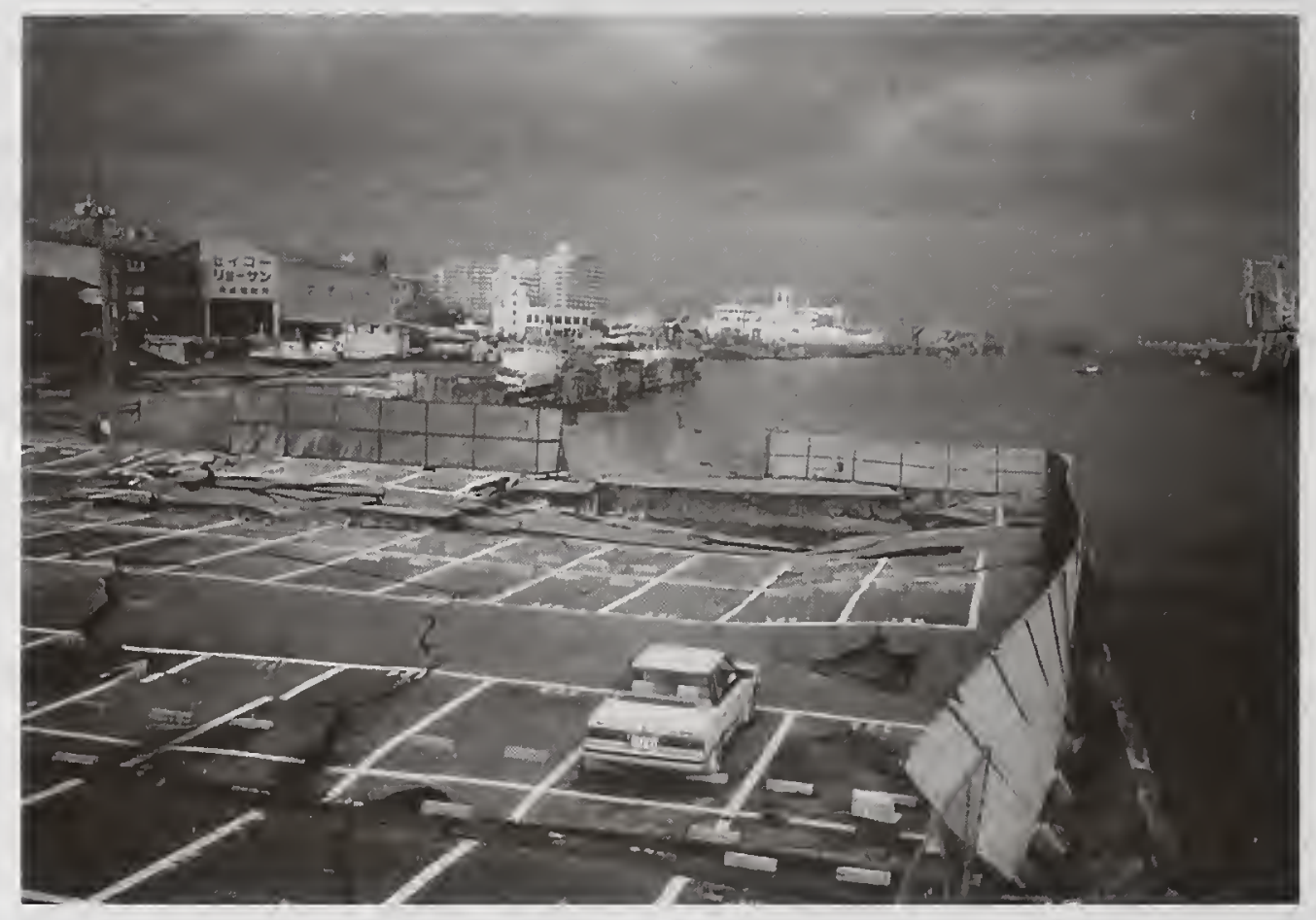

Photo 1 Damage to a Parking Lot at Uozakihama

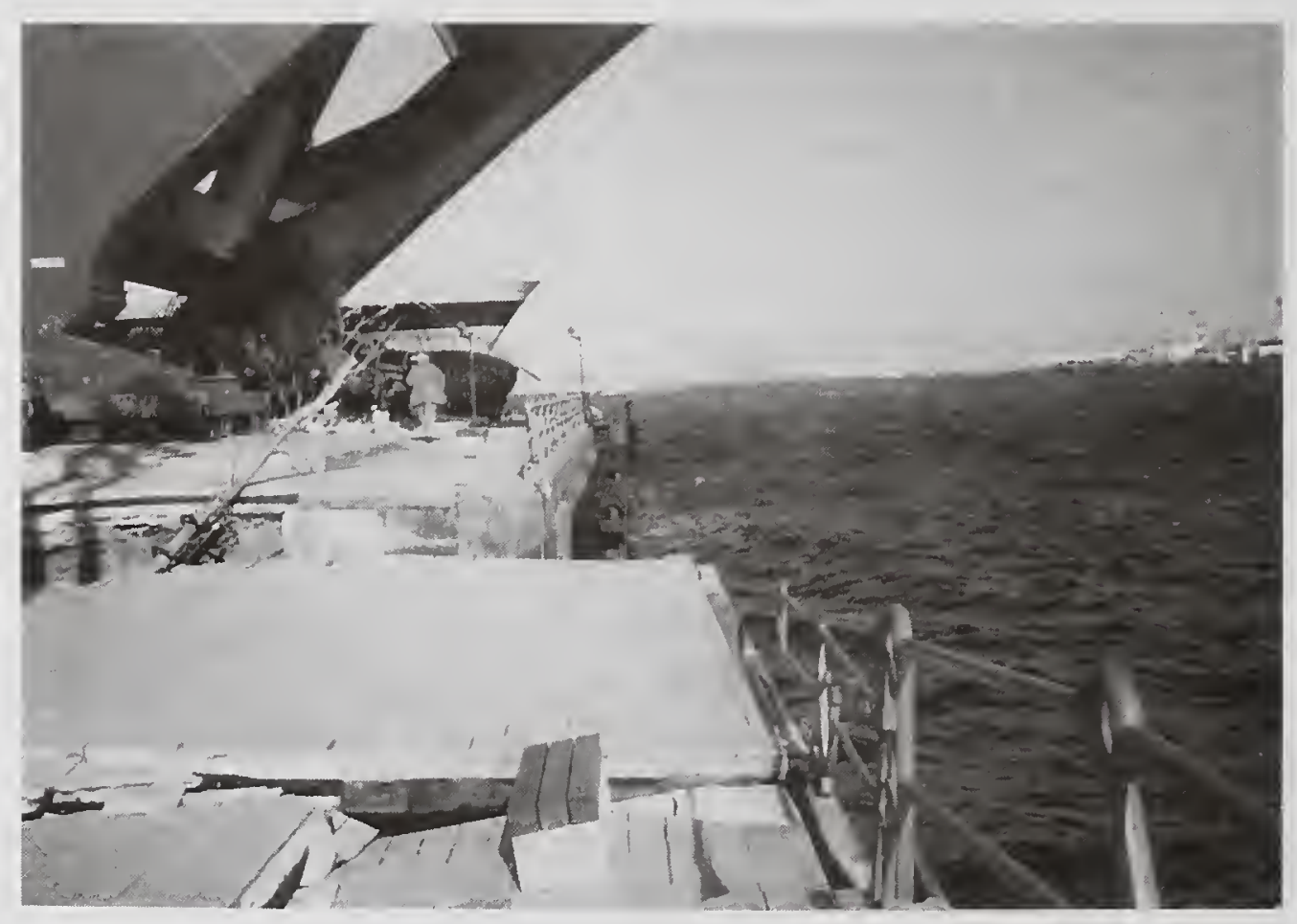

Photo 2 Damage to the North Shore of Port Island 


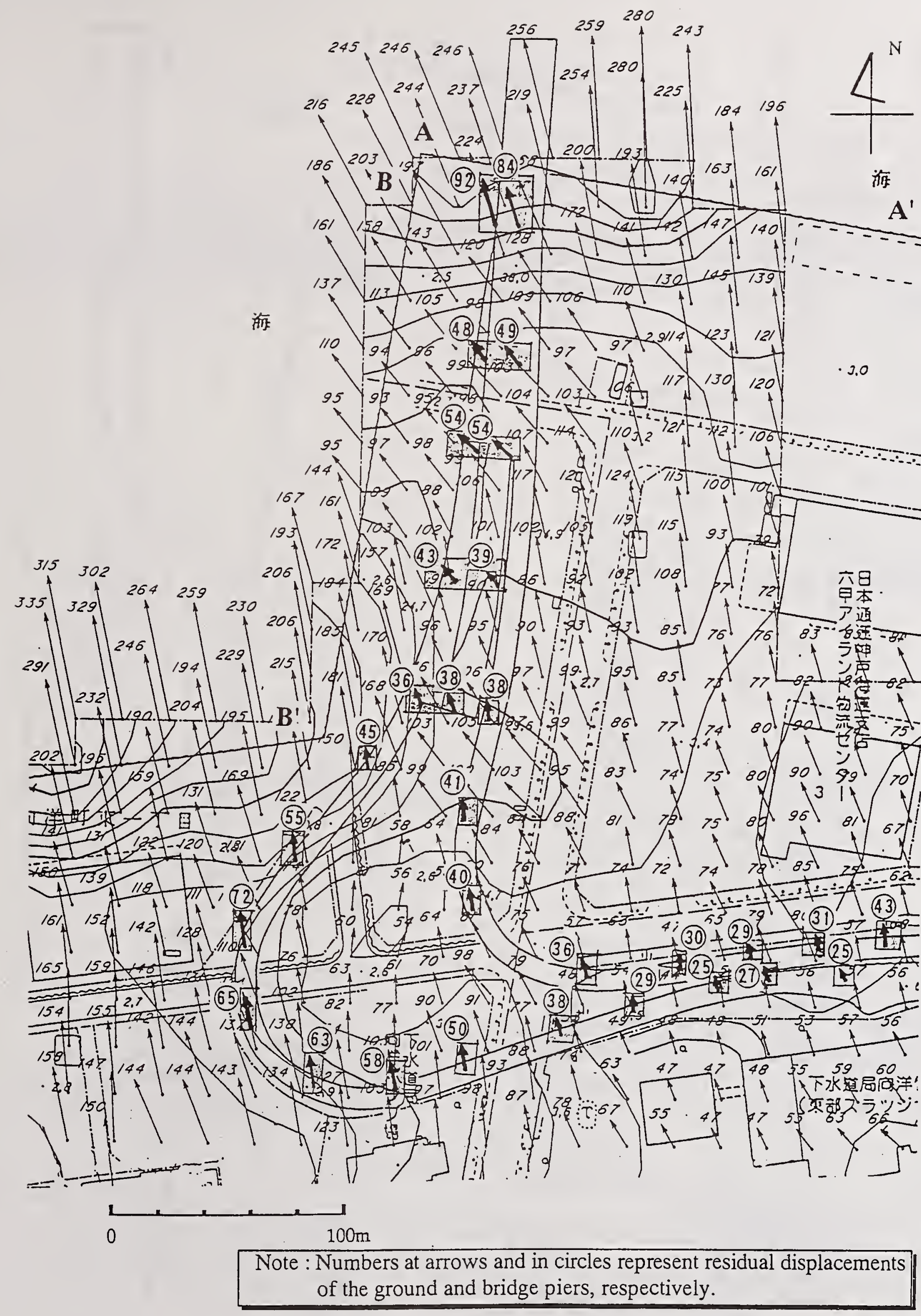

Figure 1 Residual Displacements of the Ground and Bridge Piers at Rokko Island 


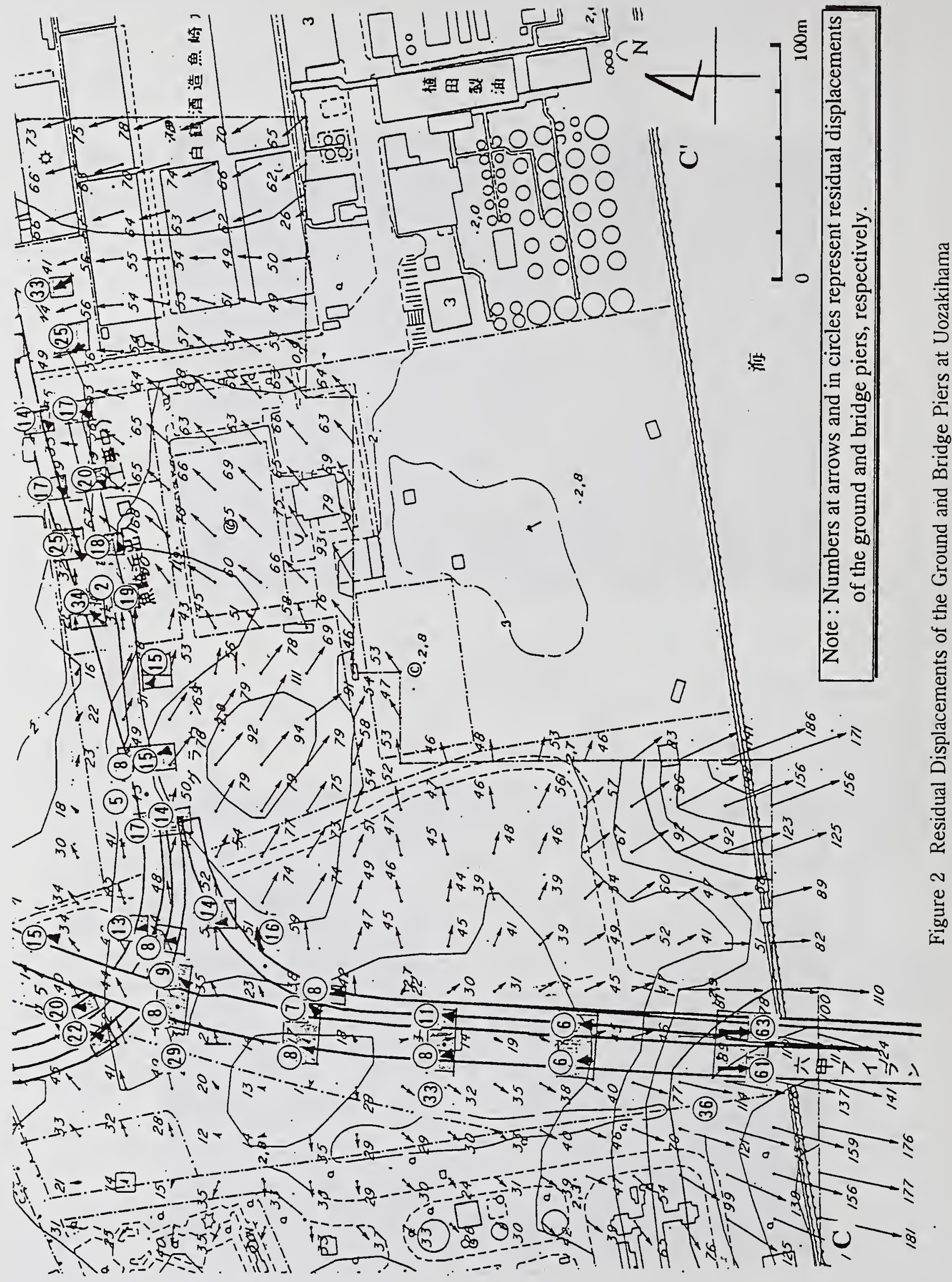




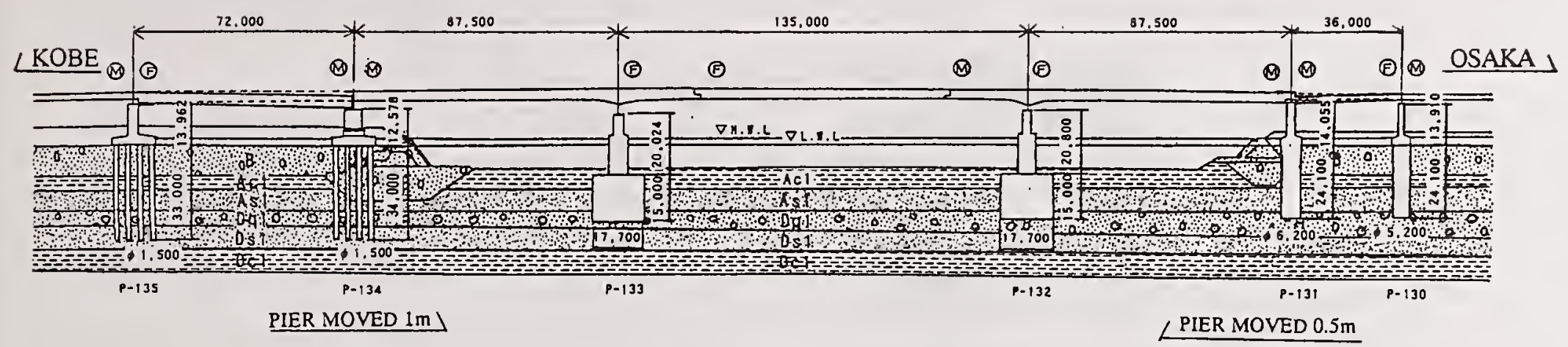

Figure 3 General View of Shin-Syukugawa Bridge
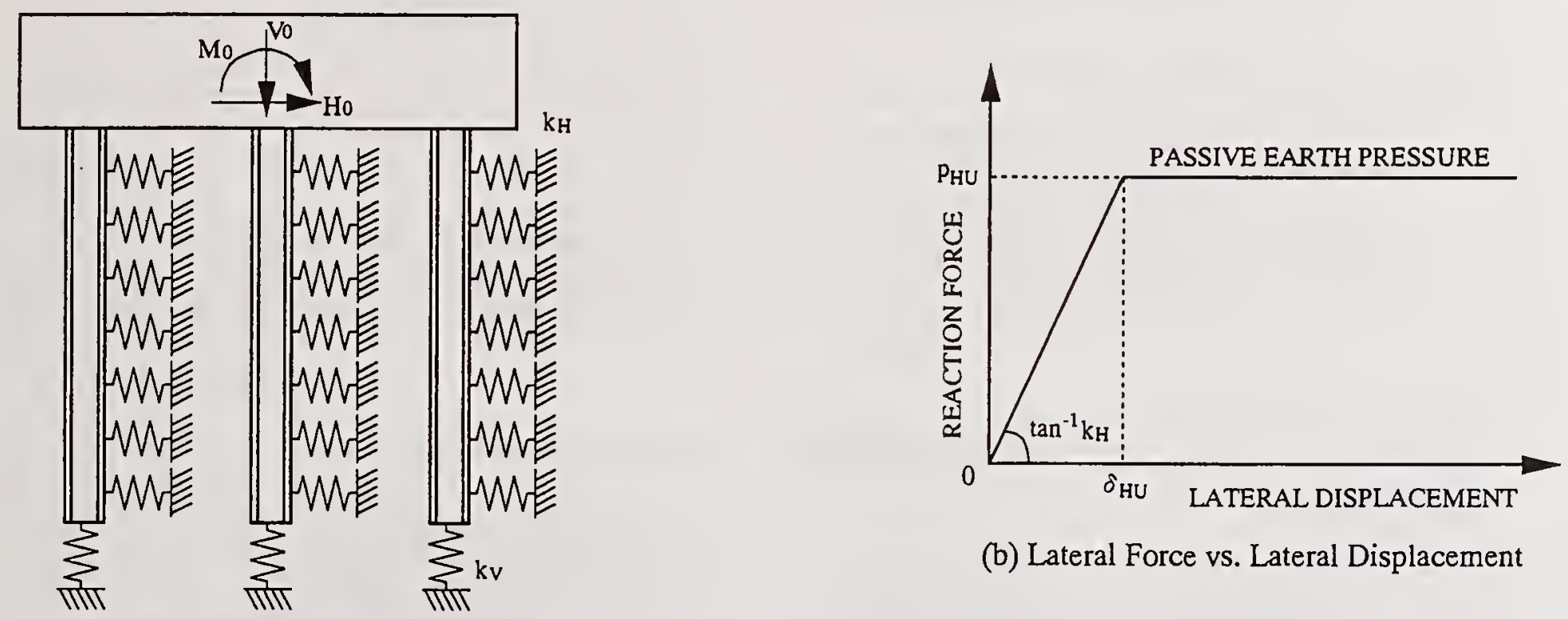

(a) Analytical Model

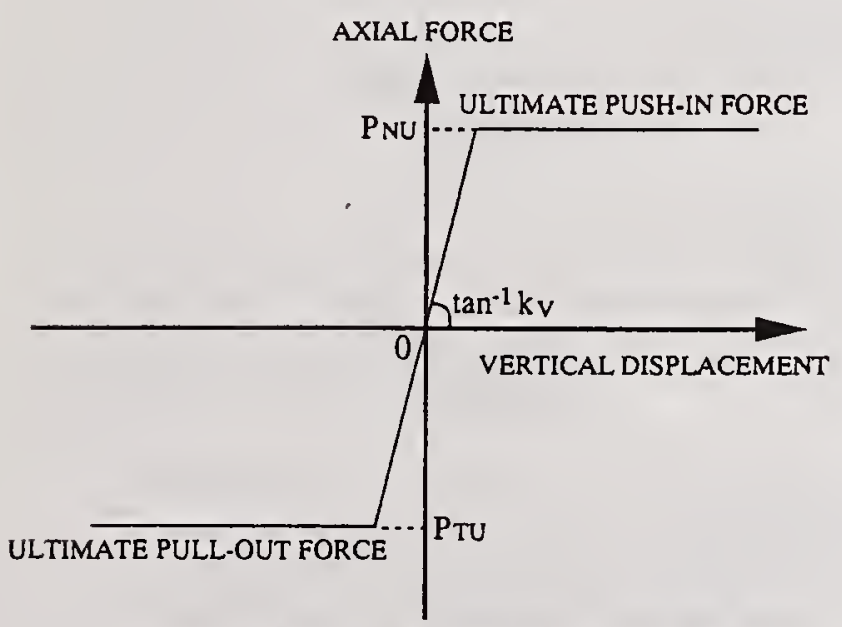

(c) Vertical Force vs. Vertical Displacement

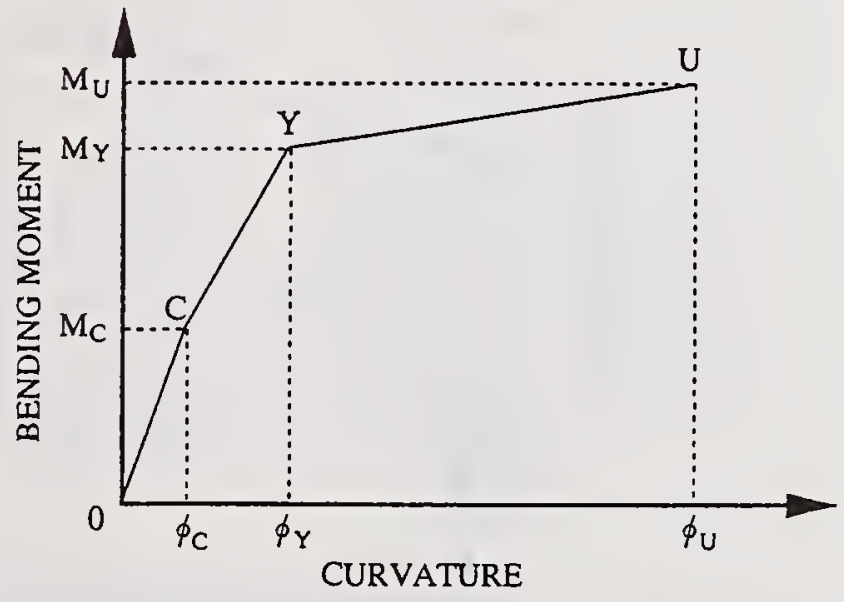

(d) Bending Moment vs. Curvature

Figure 4 Idealization of Pile Foundation for Nonlinear Analysis 


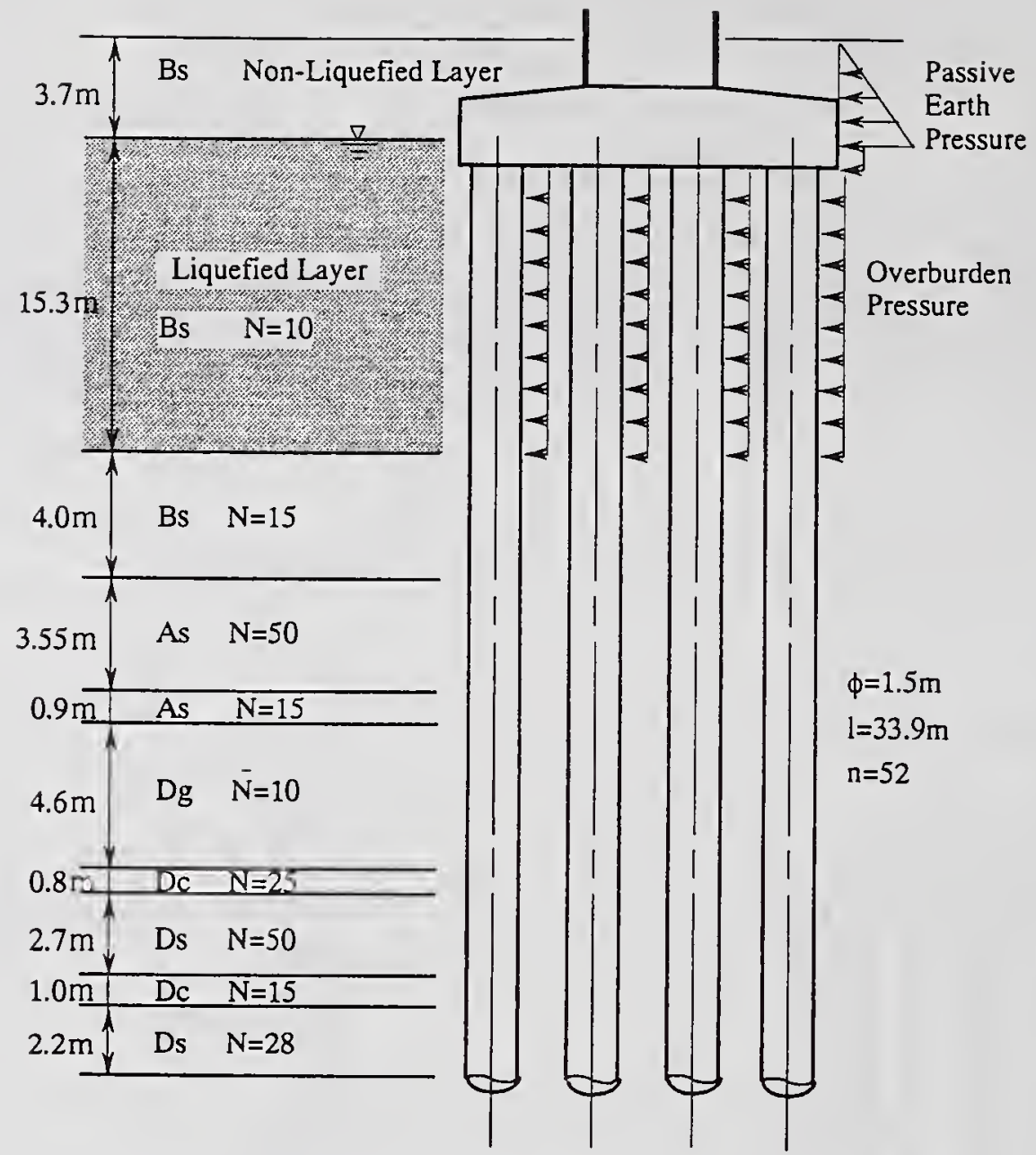

Figure 5 Analytical Model of Shin-Syukugawa Bridge

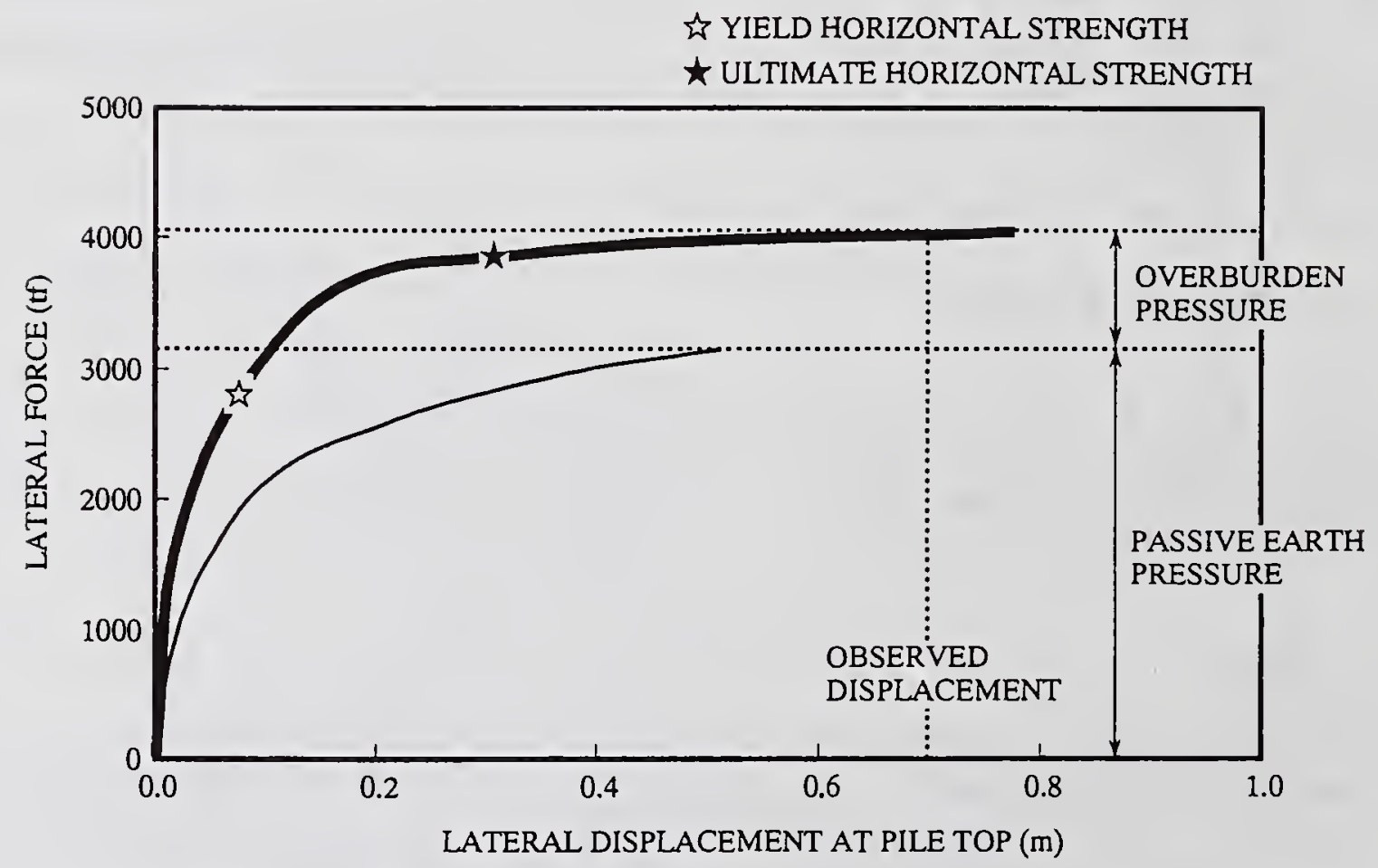

Figure 6 Relationship between Lateral Force and Displacement at Pile Top 


\title{
Preliminary Guidelines for Liquefaction Assessment using Shear Wave Velocity
}

by

\author{
Ronald D. Andrus ${ }^{1}$ and Kenneth H. Stokoe, $\mathrm{II}^{2}$
}

\begin{abstract}
This paper presents preliminary guidelines for assessing the liquefaction resistance of soils using small-strain shear wave velocity. The guidelines are based on field performance data from 17 earthquakes and in situ shear wave velocity measurements at over 40 different sites in soils ranging from sandy gravel with cobbles to profiles including silty clay layers. Additional data are needed from denser soil sites shaken by stronger ground motions to further validate the proposed liquefaction potential boundaries.
\end{abstract}

KEYWORDS: Building technology; earthquake engineering; in situ measurements; seismic testing; shear wave velocity; soil liquefaction.

\section{INTRODUCTION}

Currently there is no widely accepted procedure for assessing the liquefaction resistance of granular soils using small-strain shear wave velocity, $\mathrm{V}_{\mathrm{S}}$. A number of $\mathrm{V}_{\mathrm{S}}$-based procedures have been proposed during the past decade. These procedures were developed from analytical studies (Stokoe et al. 1988; Andrus 1994), laboratory cyclic triaxial test results (Tokimatsu et al. 1992), or a limited amount of field performance data (Robertson et al. 1992; Kayen et al. 1992; Lodge 1994).

The use of $V_{S}$ as a field index of liquefaction resistance is justified since both are influenced by density, confinement, stress history, and geologic age. The advantages of using $\mathrm{V}_{\mathrm{S}}$ include:

- $\mathrm{V}_{\mathrm{S}}$ can be accurately measured in situ using a number of techniques such as the seismic crosshole test, the Seismic Cone Penetration Test (SCPT), or the SpectralAnalysis-of-Surface-Wave (SASW) test;

- Measurements are possible in soils that are hard to sample, such as gravelly soils, and at sites where borings or soundings may not be permitted, such as many landfills;
- Measurements can be performed in small laboratory specimens, making direct comparisons between laboratory and field behavior possible;

- $\mathrm{V}_{\mathrm{S}}$ is directly related to small-strain shear modulus, $\mathrm{G}_{\max }$, a required parameter in analytical procedures evaluating dynamic shearing strain in soils; and

- For large earthquake magnitudes and long durations of shaking the cyclic shear strain needed for liquefaction decreases and approaches the threshold strain in sand $(\approx 0.02 \%)$, thus making it possible to conduct more analytical evaluations of liquefaction using $\mathrm{V}_{S}$ and $\mathrm{G}_{\max }$ as basic parameters (Dobry et al. 1981; Seed et al. 1983).

The two main limitations of using $\mathrm{V}_{\mathrm{S}}$ to evaluate liquefaction resistance are the lack of a sample for identifying non-liquefiable fine-grained soils, and its high sensitivity to weak interparticle bonding, caused by aging or cementation, which is eliminated at large strains. Thus, a limited amount of drilling and penetration testing should be performed to identify weakly cemented soils and non-liquefiable clayey soils.

This paper presents preliminary guidelines, currently under development (Andrus and Stokoe 1996), for assessing liquefaction resistance using $\mathrm{V}_{\mathrm{S}}$. The guidelines are based on field performance data from 17 earthquakes and in situ $\mathrm{V}_{S}$ measurements at over 40 different sites (112 test arrays), resulting in a total of 177 liquefaction and non-liquefaction case histories. The 17 earthquakes are listed as follows.

\footnotetext{
${ }^{1}$ Research Civil Engineer, Structures Division, Building and Fire Research Laboratory, National Institute of Standards and Technology, Gaithersburg, Maryland, 20899.

2Professor, Department of Civil Engineering, University of Texas, Austin, Texas, 78712.
} 


\section{Earthquake}

1906 San Francisco, California

1964 Niigata, Japan

1975 Haicheng, PRC

1979 Imperial Valley, California

1981 Westmorland, California

1983 Borah Peak, Idaho

1986 Event LSST4, Taiwan

1986 Event LSST7, Taiwan

1986 Event LSST8, Taiwan

1986 Event LSST12, Taiwan

1986 Event LSST13, Taiwan

1986 Event LSST16, Taiwan

1987 Elmore Ranch, California

1987 Superstition Hills, California

1989 Loma Prieta, California

1993 Hokkaido-nansei-oki, Japan

1995 Hyogo-ken Nanbu, Japan

\section{ESTIMATING LIQUEFACTION RESISTANCE}

The most widely used procedure for evaluating the liquefaction resistance of granular soils is the stress approach by Seed and his colleagues (1971, 1982, and 1985) based on modified Standard Penetration Test (SPT) blow count. Following the general format of this approach, Robertson et al. (1992) developed a procedure based on modified $\mathrm{V}_{\mathrm{S}}$.

\subsection{Cyclic Stress Ratio}

In the stress approach, liquefaction resistance is related to the ratio of cyclic shear stress to initial vertical effective stress, called cyclic stress ratio. The cyclic stress ratio, $\tau_{\mathrm{av}} / \sigma_{\mathrm{v}}^{\prime}$, at a particular depth in a level soil deposit can be expressed as (Seed and Idriss 1971):

$$
\tau_{\mathrm{av}} / \sigma_{\mathrm{v}}^{\prime}=0.65\left(\mathrm{a}_{\max } / \mathrm{g}\right)\left(\sigma_{\mathrm{v}} / \sigma_{\mathrm{v}}^{\prime}\right) \mathrm{r}_{\mathrm{d}}
$$

where $\tau_{\mathrm{av}}$ is average cyclic shear stress caused by the earthquake, $\sigma_{v}^{\prime}$ is initial effective vertical (overburden) stress, $\sigma_{\mathrm{v}}$ is total overburden stress, $a_{\max }$ is peak horizontal ground surface acceleration, $g$ is acceleration of gravity, and $r_{d}$ is a shear stress reduction factor. The factor $r_{d}$ can be estimated by:

$$
r_{d}=1-0.015 z
$$

where $\mathrm{z}$ is depth in meters.

\subsection{Modified Shear Wave Velocity}

Robertson et al. (1992) modified $\mathrm{V}_{S}$ by:

$$
\mathrm{V}_{\mathrm{S} 1}=\mathrm{V}_{\mathrm{S}}\left(\mathrm{P}_{\mathrm{a}} / \sigma_{\mathrm{v}}^{\prime}\right)^{0.25}
$$

where $\mathrm{P}_{\mathrm{a}}$ is a reference stress, typically $100 \mathrm{kPa}$, and $\sigma_{v}$ is in $\mathrm{kPa}$. They chose to modify in terms of $\sigma_{v}$ to follow the traditional way SPT and Cone Penetration Test (CPT) data are modified. The exponent of 0.25 was selected based on laboratory studies (Hardin and Drnevich 1972). Equation 3 assumes that the coefficient of earth pressure at rest equals 1 .

\subsection{Development of $\mathrm{V}_{\mathrm{S}}$-based Charts}

Field performance data for magnitude 7 earthquakes are shown in Figure 1. The occurrence of liquefaction is based on the appearance of sand boils, ground cracks and fissures, or ground settlement. For each case history, the shear wave velocity shown is the average of values reported for the most vulnerable layer, and modified using Equation 3. Since most attenuation relationships are for the randomly oriented horizontal component of ground motion rather than the larger of two horizontal components, the values of $a_{\max }$ used to estimate the cyclic stress ratios are based on the randomly oriented horizontal component that would have occurred at the site in the absence of liquefaction.

The preliminary liquefaction potential boundary shown in Figure 1 is drawn to pass through the origin, include nearly all liquefaction case histories, and become vertical at higher values of $\mathrm{V}_{\mathrm{S1}}$. A boundary passing through the origin is supported by the following relationship between cyclic stress ratio and $\mathrm{V}_{\mathrm{S} 1}$ for a line of constant average cyclic shear strain, $\gamma_{a v}$, (Dobry 1996):

$$
\tau_{\mathrm{av}}{ } \sigma_{\mathrm{v}}^{\prime}=\mathrm{f}\left(\gamma_{\mathrm{av}}\right) \mathrm{V}_{\mathrm{Sl}}{ }^{2}
$$

A vertical boundary at higher values of $\mathrm{V}_{\mathrm{S1}}$ is justified since dense granular soils exhibit dilative behavior even at large strains. Based on engineering judgment, a value of about $280 \mathrm{~m} / \mathrm{s}$ is assumed as an upper bound for most contractive soil types. This potential boundary is similar to the boundaries proposed by Kayen et al. (1992) and Lodge (1994) using field performance data primarily from the 1989 Loma Prieta, California earthquake.

For earthquakes with magnitude between 5.5 and 8.5 , liquefaction potential boundaries can be formed using all available field performance data, as shown in Figure 2. The preliminary magnitude scaling factors used to construct these boundaries are listed in column 6 of Table 1 . These scaling factors compare well with SPTbased factors developed in recent years by other investigators, also listed in Table 1 . The 
boundaries for magnitude $6,6.5$ and 7.5 earthquakes shown in figure 2 correctly predict liquefaction at all sites where surface manifestations of liquefaction were observed. The few liquefaction cases that lie slightly below the liquefaction boundary for magnitude 7 earthquakes are sites where the ground is sloping and/or where liquefaction may have been marginal.

It is interesting to note that similar liquefaction potential boundaries can be constructed using $\mathrm{V}_{\mathrm{S}}$ and $\mathrm{a}_{\max }$ directly, as shown in figure 3 . The number of non-liquefaction case histories incorrectly classified in figure 3 is more or less the same as the number of non-liquefaction case histories incorrectly classified in figure 2 . Figure 3 suggests that liquefaction will never occur in any earthquake if the shear wave velocity in the upper $12 \mathrm{~m}$ of soil exceeds about $240 \mathrm{~m} / \mathrm{s}$. A similar but preliminary conclusion was reached by Seed et al. (1983). They concluded that liquefaction will never occur if the shear wave velocity in the upper $15 \mathrm{~m}$ of soil exceeds about $366 \mathrm{~m} / \mathrm{s}$. The boundaries shown in figure 3 provide a simpler assessment procedure than the stress-based approach. However, their application should be limited to initial screening of sites with characteristics similar to the database (depth of most vulnerable layer less than $12 \mathrm{~m}$, and depth of water table 0.5-7.6 m).

\section{CONCLUSIONS}

The case histories presented represent a wide range of soil types, ranging from sandy gravel with cobbles to profiles including silty clay layers. Thus, for current use, the preliminary liquefaction potential boundaries presented in figures 1 and 2 are recommended for all liquefiable soil types. Non-liquefiable soil types include fine-grained soils with clay contents greater than $15 \%$, liquid limits greater than $35 \%$, or moisture contents less than $90 \%$ of the liquid limit (Seed and Idriss 1982). The potential boundaries presented in figure 3 are suggested for initial screening of sites only where conditions are similar to the database, which can be viewed from the figure. Additional welldocumented case histories of all types of soil that have and have not liquefied during earthquakes should be compiled, particularly denser deposits shaken by stronger ground motions.

\section{ACKNOWLEDGMENTS}

The writers gratefully acknowledge the valuable review of this work by the Workshop (1996). We also thank Ricardo Dobry, Rensselaer Polytechnic Institute, and Riley Chung, National Institute of Standards and Technology, for their comments, which greatly enhanced the quality of this paper.

\section{REFERENCES}

1. Ambraseys, N. N. (1988). "Engineering Seismology," Earthquake Engrg. and Structural Dynamics, Vol. 17, p. 1-105.

2. Andrus, R. D. (1994). "In Situ Characterization of Gravelly Soils That Liquefied in the 1983 Borah Peak Earthquake," Ph.D. Dissertation, Univ. of Texas at Austin, 533 p.

3. Andrus, R. D., and Stokoe, K. H., II (1996). "Guidelines for Evaluation of Liquefaction Resistance using Shear Wave Velocity," Proc. NCEER Workshop on Evaluation of Liquefaction Resistance, held in Salt Lake City, UT, January 4-5.

4. Arango, I. (1996). "Magnitude Scaling Factors for Soil Liquefaction Evaluation," Paper presented at the NCEER Workshop on Evaluation of Liquefaction Resistance, held in Salt Lake City, UT, January 4-5.

5. Dobry, R. (1996). Personal communication.

6. Dobry, R., Stokoe, K. H., II, Ladd, R. S., and Youd, T. L. (1981). "Liquefaction Susceptibility from SWave Velocity," Proc., In Situ Testing to Evaluate Liquefaction Susceptibility, ASCE National Convention, held in St. Louis, MO.

7. Hardin, B. O. and Drnevich, V. P. (1972). "Shear Modulus and Damping of Soils, Measurement and Parameter Effects," J. of the Soil Mechanics and Foundation Div., ASCE, New York, NY, Vol. 98, SM7, pp. 667-692.

8. Kayen, R. E., Mitchell, J. K., Seed, R. B., Lodge, A., Nishio, S., and Coutinho, R. (1992). "Evaluation of SPT-, CPT-, and Shear Wave-Based Methods for Liquefaction Potential Assessment Using Loma Prieta Data," Proc., 4th 
Japan-U.S. Workshop on Earthquake Resistant Design of Lifeline Facilities and Countermeasures for Soil Liquefaction, Technical Report NCEER-92-0019, held in Honolulu, HI, M. Hamada and T. D. O'Rourke, Eds., Nat. Ctr. for Earthquake Engrg. Res., Buffalo, NY, Vol. 1, pp. 177-204.

9. Lodge, A. L. (1994). "Shear Wave Velocity Measurements for Subsurface Characterization," Ph.D. Dissertation, Univ. of California at Berkeley.

10. Robertson, P. K., Woeller, D. J., and Finn, W. D. L. (1992). "Seismic Cone Penetration Test for Evaluating Liquefaction Potential Under Cyclic Loading," Can. Geotech. J., Vol. 29, pp. 686-695.

11. Seed, H. B., and Idriss, I. M. (1971). "Simplified Procedure for Evaluating Soil Liquefaction Potential," J. of Soil Mechanics and Foundation Div., ASCE, New York, NY, Vol. 97, SM9, pp. 1249-1273.

12. Seed, H. B., and Idriss, I. M. (1982). Ground Motions and Soil Liquefaction During Earthquakes, Monograph, EERI, Oakland, CA, $134 \mathrm{p}$.

13. Seed, H. B., Idriss, I. M., Arango, I. (1983). "Evaluation of Liquefaction Potential Using Field Performance Data," J. of Geotech. Engrg., ASCE, Vol. 109, No. 3, pp. 458-482.
14. Seed, H. B., Tokimatsu, K., Harder, L. F., and Chung, R. M. (1985). "Influence of SPT Procedures in Soil Liquefaction Resistance," J. of Geotech. Engrg., ASCE, Vol. 111, No. 12, pp. 1425-1445.

15. Stokoe, K. H., II, Roesset, J. M., Bierschwale, J. G., and Aouad, M. (1988). "Liquefaction Potential of Sands from Shear Wave Velocity," Proc., 9th World Conf. on Earthquake Engrg., held in Tokyo, Japan, Vol. III, pp. 213-218.

16. Tokimatsu, K., Kuwayama, S., and Tamura, S. (1991). "Liquefaction Potential Evaluation Based on Rayleigh Wave Investigation and Its Comparison with Field Behavior," Proc., 2nd Int. Conf. on Recent Advances in Geotech. Earthquake Engrg. and Soil Dynamics, held in St. Louis, MO, S. Prakash, Ed., Univ. of Missouri-Rolla, Vol. I, pp. 357-364.

17. Workshop (1996). NCEER Workshop on Evaluation of Liquefaction Resistance, held in Salt Lake City, UT, January 4-5.

18. Youd, T. L. (1996). "Magnitude Scaling Factors," Proc. NCEER Workshop on Evaluation of Liquefaction Resistance, held in Salt Lake City, UT, January 4-5.

Table 1. Magnitude Scaling Factors Obtained by Various Investigators (modified after Youd 1996)

\begin{tabular}{c|c|c|c|c|c}
\hline \hline \multirow{2}{*}{$\begin{array}{c}\text { Moment } \\
\text { Magnitude, } \\
\mathrm{M}_{\mathrm{W}}\end{array}$} & \multicolumn{5}{|c}{ Magnitude Scaling Factor } \\
\cline { 2 - 5 }$(1)$ & $\begin{array}{c}\text { Seed and } \\
\text { Idriss (1982) }\end{array}$ & $\begin{array}{c}\text { Ambraseys } \\
(1988)\end{array}$ & $\begin{array}{c}\text { Youd } \\
(1996) \\
(3)\end{array}$ & $\begin{array}{c}\text { Arango } \\
(1996) \\
(5)\end{array}$ & This Paper \\
\hline 5.5 & 1.43 & 2.86 & 3.26 & $2.25-3.00$ & $(6)$ \\
6.0 & 1.32 & 2.20 & 2.15 & $1.75-2.00$ & 2.75 \\
6.5 & 1.19 & 1.69 & 1.50 & $1.50-1.57$ & 1.65 \\
7.0 & 1.08 & 1.30 & 1.20 & 1.25 & 1.25 \\
7.5 & 1.00 & 1.00 & 1.00 & 1.00 & 1.00 \\
8.0 & 0.94 & 0.67 & 0.90 & 0.75 & 0.75 \\
8.5 & 0.89 & 0.44 & 0.77 & 0.62 & 0.60 \\
\hline \hline
\end{tabular}




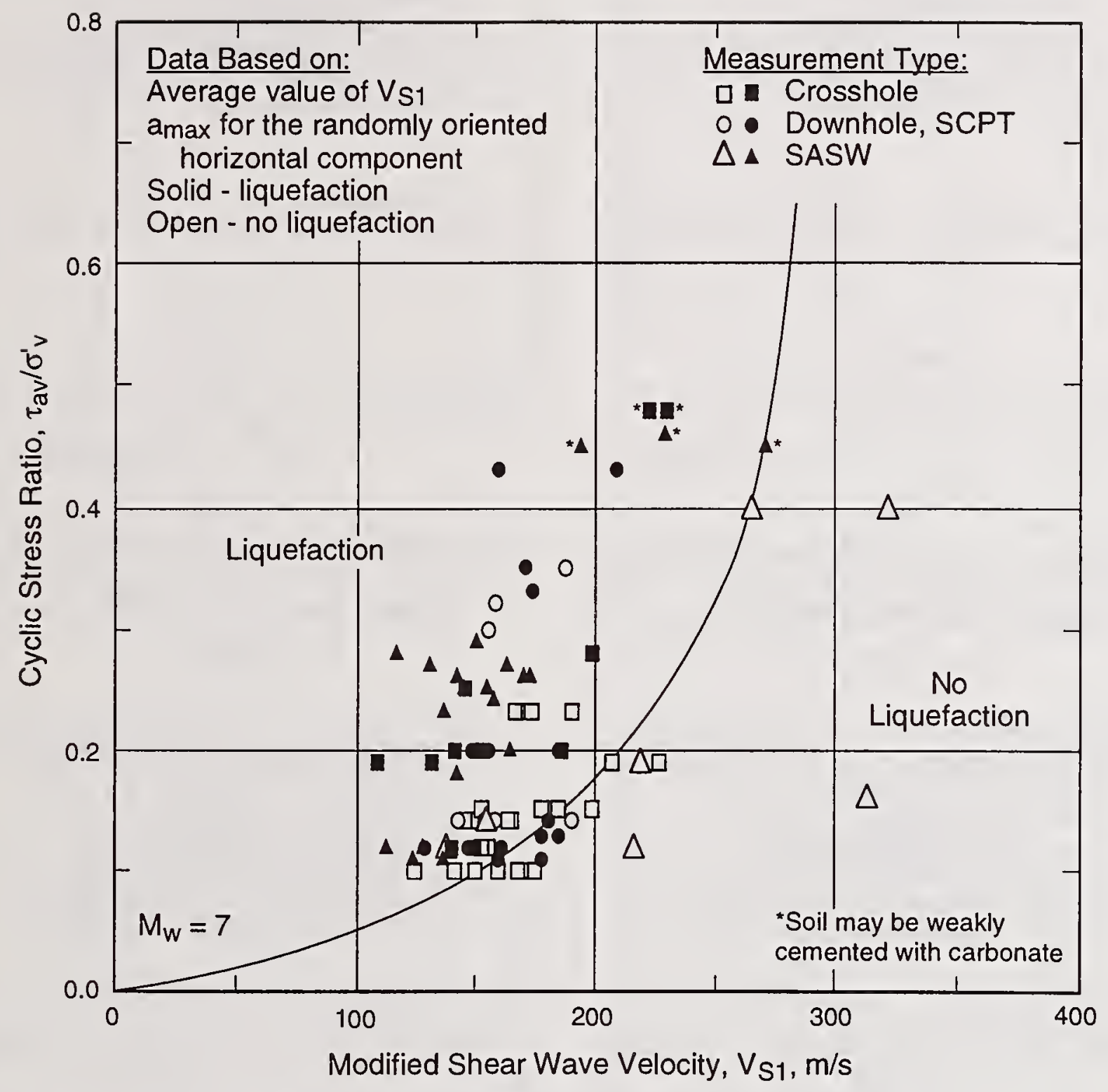

Figure 1. Preliminary Liquefaction Potential Boundary Based on Modified Shear Wave Velocity and Cyclic Stress Ratio with Results from Magnitude 6.9 to 7.0 Earthquakes. 


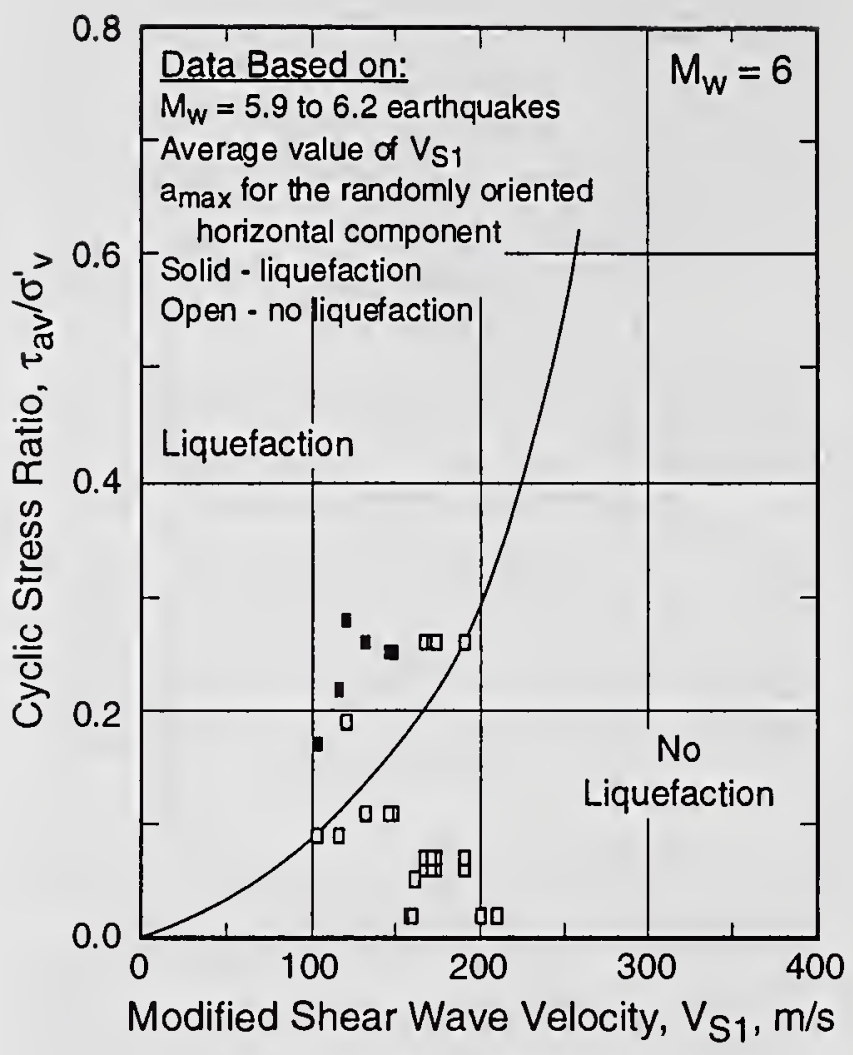

(a) $M_{W}=6$

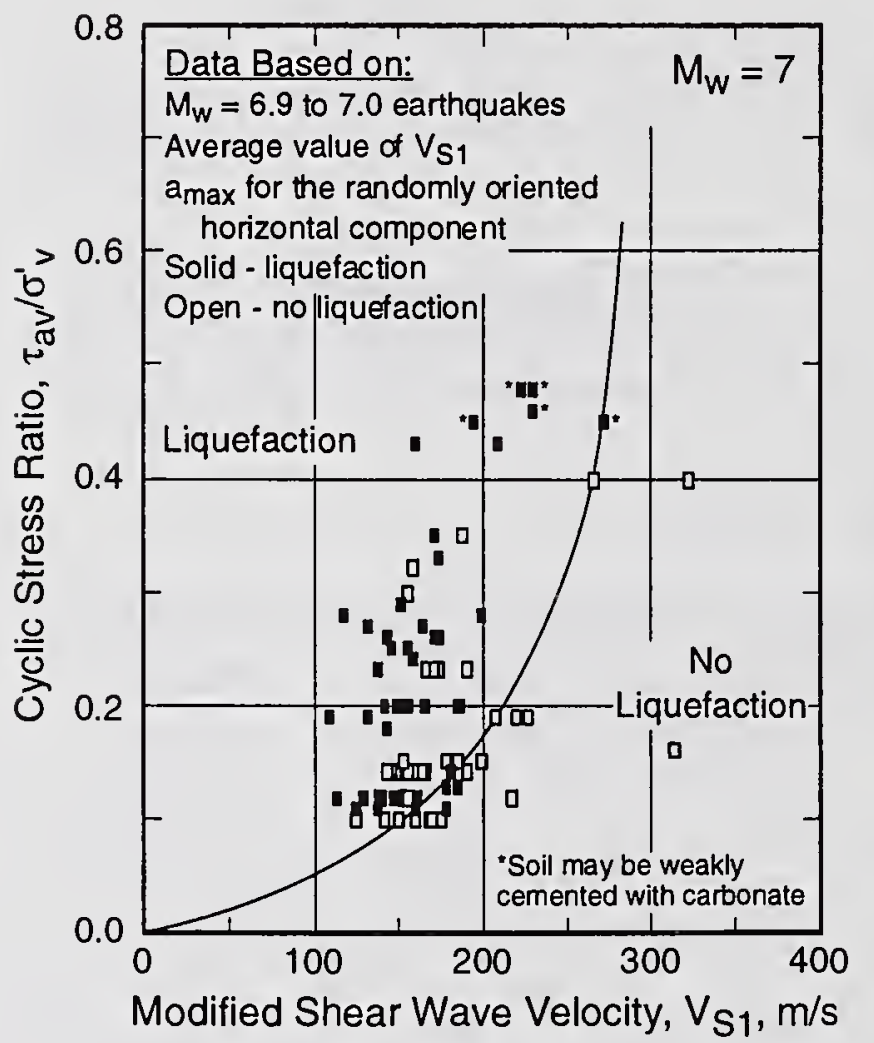

(c) $M_{W}=7$

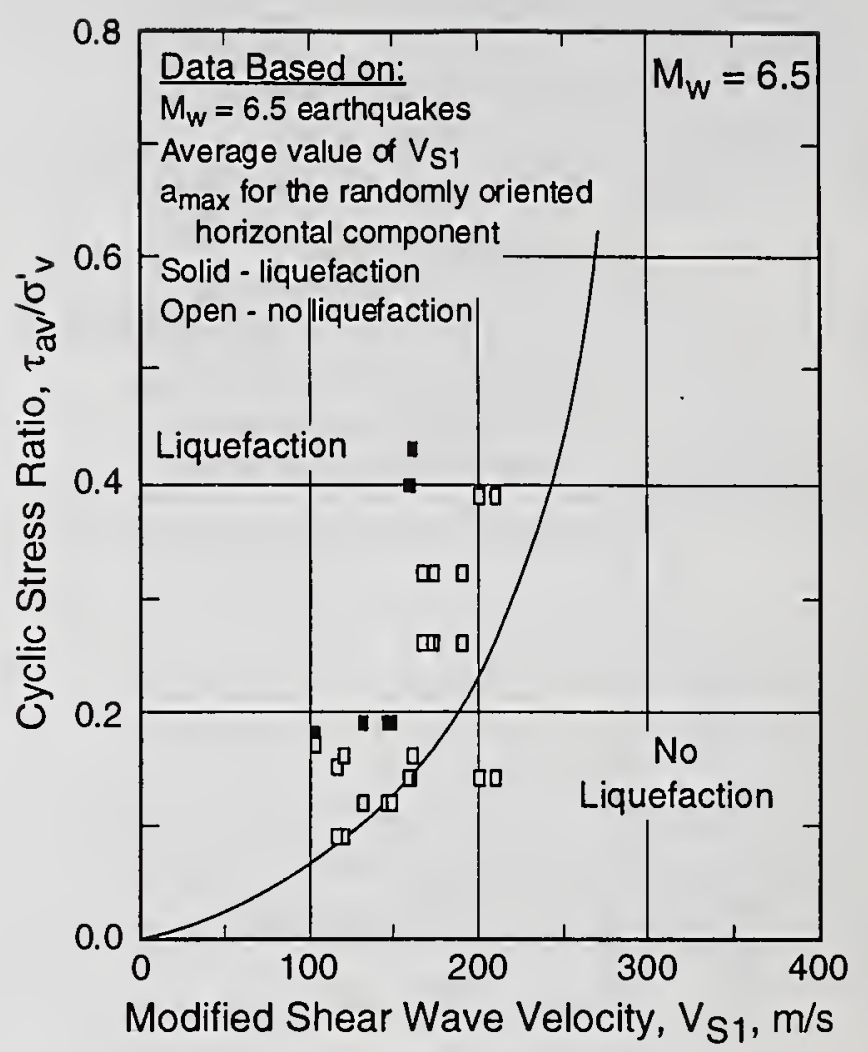

(b) $M_{w}=6.5$

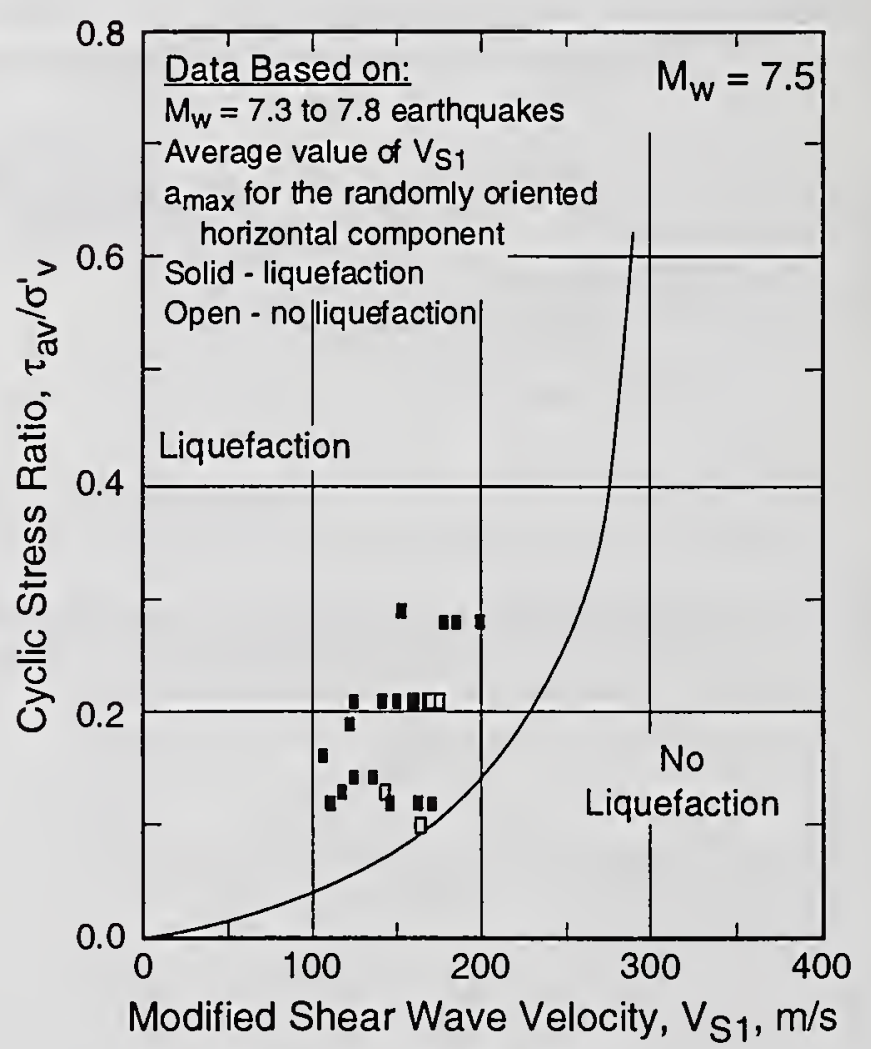

(d) $M_{w}=7.5$

Figure 2. Preliminary Liquefaction Potential Boundaries Based on Modified Shear Wave Velocity and Cyclic Stress Ratio with Results from 17 Earthquakes. 


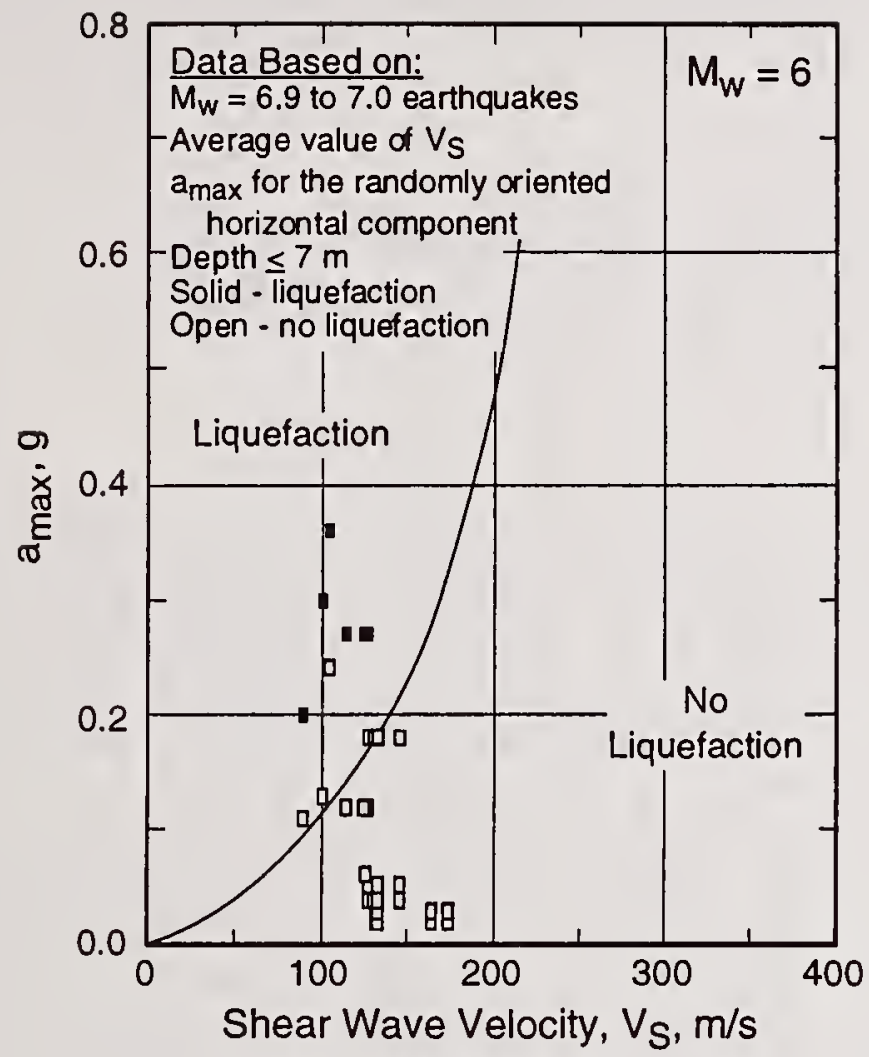

(a) $M_{W}=6$

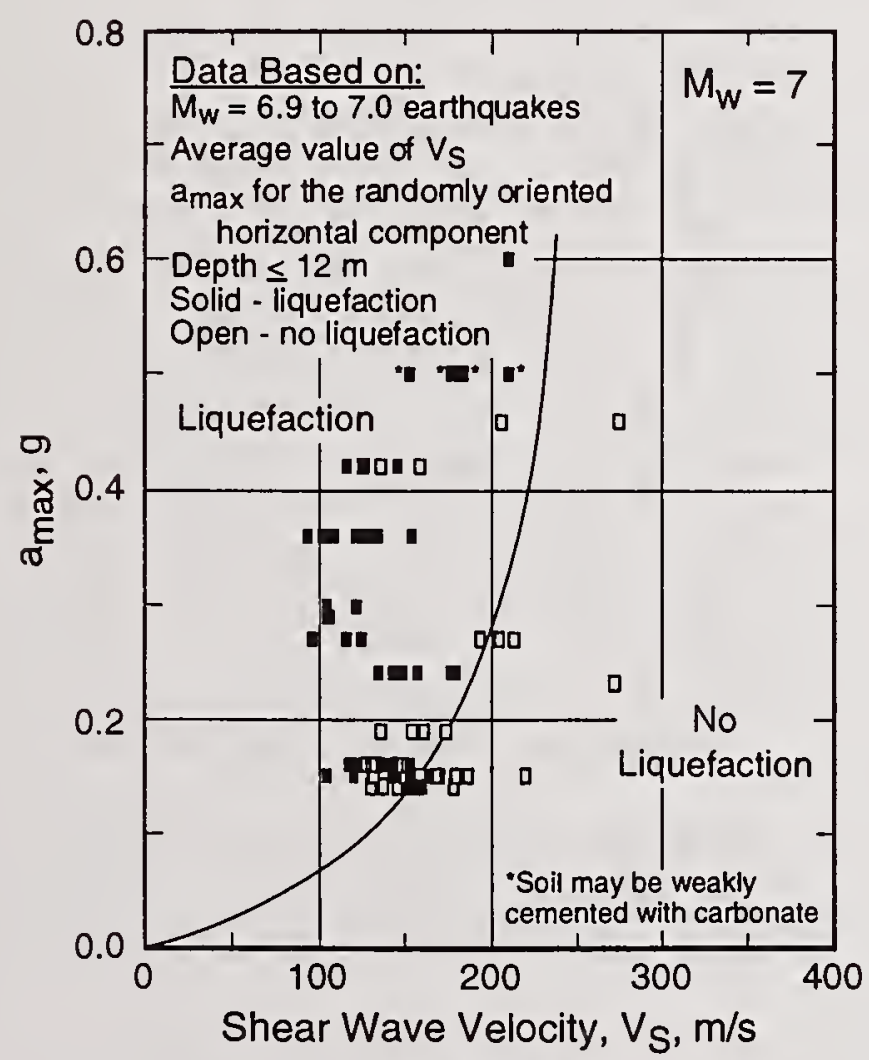

(c) $M_{w}=7$

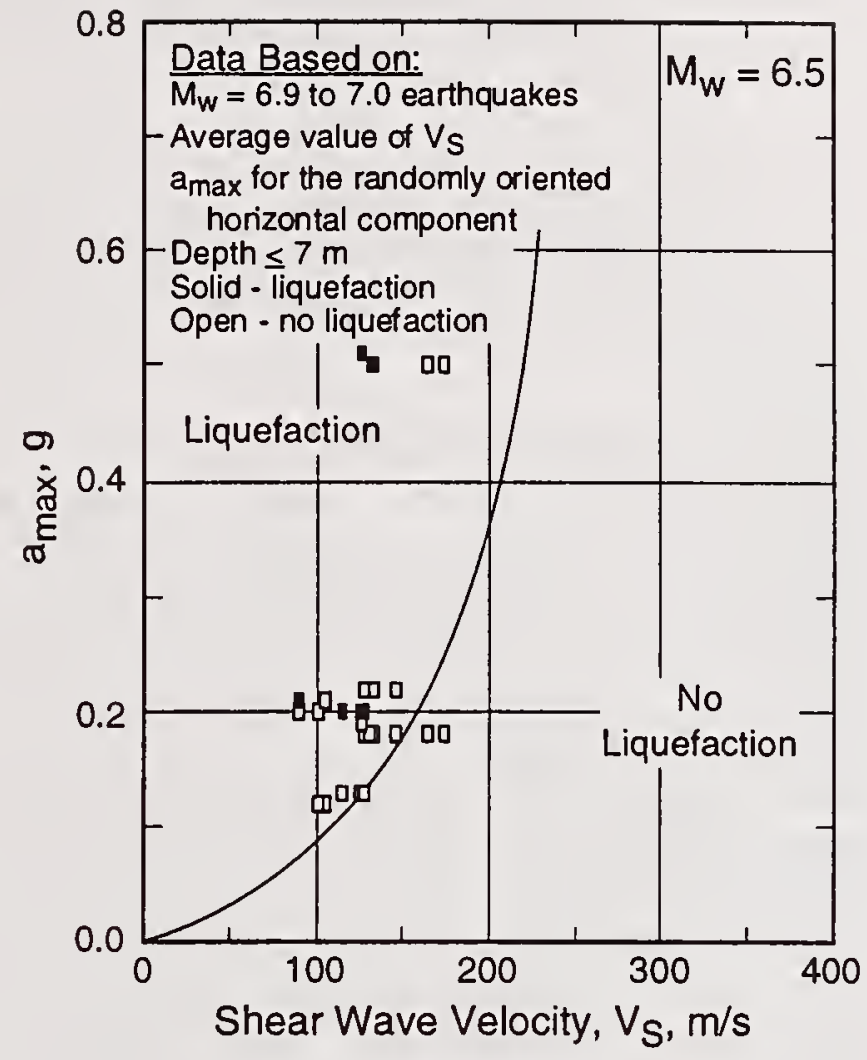

(b) $M_{W}=6.5$

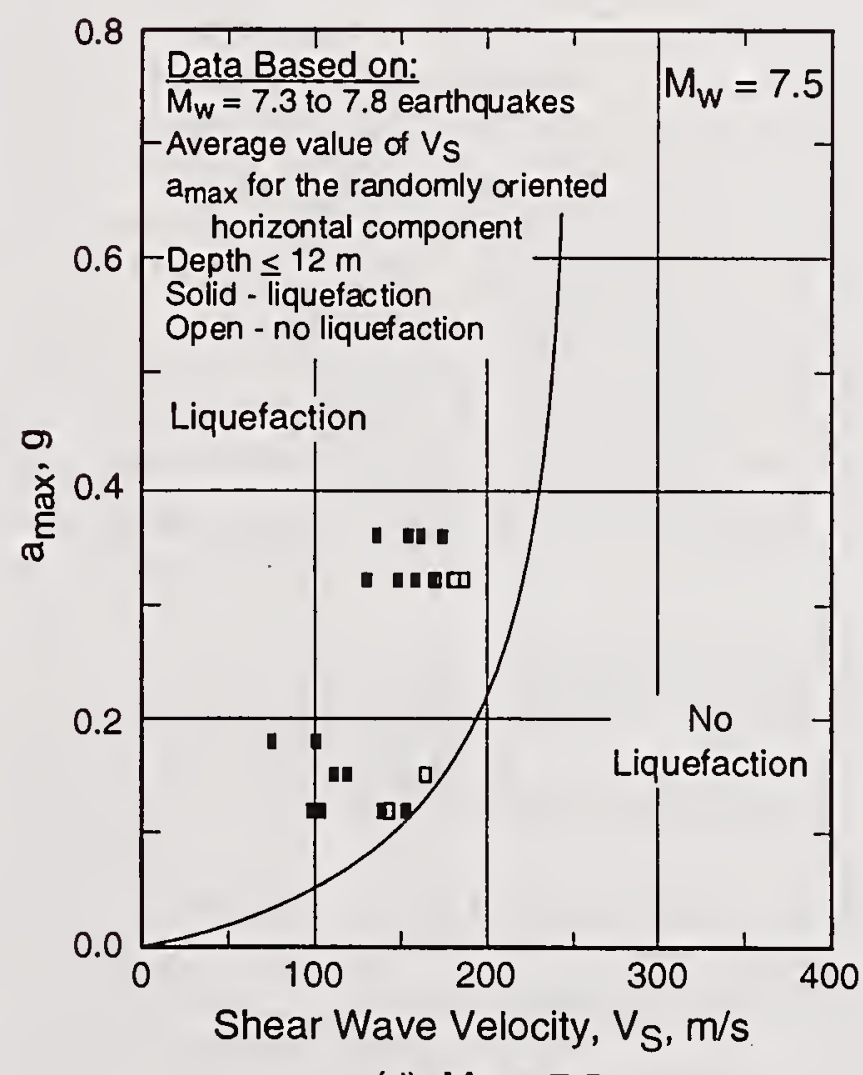

(d) $M_{W}=7.5$

Figure 3. Preliminary Liquefaction Potential Boundaries Based on Shear Wave Velocity and Peak Horizontal Ground Surface Acceleration with Results from 17 Earthquakes. 



\title{
DAMAGE INVESTIGATION OF \\ STEEL BUILDINGS IN SPECIFIC AREAS OBSERVED FROM THE 1995 HYOGOKEN-NANBU EARTHQUAKE
}

\author{
By \\ MIDORIKAWA Mitsumasa1), HASEGAWA Takashi2), MUKAI Akiyoshi3), \\ NISHIYAMA Isao4), FUKUTA Toshibumi5), and YAMANOUCHI Hiroyuki6)
}

\begin{abstract}
An investigation team investigated the damage to steel building structures that suffered from the 1995 Hyogoken-nanbu earthquake. The team investigated the damage to a total number of 650 steel buildings, located in the three specific areas of the city of Kobe where many structures suffered significant damage, in order to determine the damage ratio of each damage level for all steel buildings in these areas. The damage to all steel buildings taller than or equal to three stories was investigated in the three areas: the parts of Higashinada-ku, Chuo-ku, and Hyogo-ku. The investigation was made mainly from the exterior and also from the inside as much as possible. The scope of the investigation was to record the extent and types of damage to steel buildings. The damage levels were classified into four levels, that is, No damage, Minor damage, Moderate damage, and Severe damage including Collapse. Among the investigated buildings, 112 were rated as Severe/Collapse, 93 as Moderate, 212 as Minor, and 220 as No damages. The results showed that the ratio of the number of the buildings of Severe/Collapse damage which were designed and constructed according to the current seismic provisions of the Building Standard Law of Japan (BSLJ) is about one third of that according to the former ones.
\end{abstract}

KEY WORDS: Hyogoken-nanbu earthquake, damage survey, steel buildings, specific areas, damage levels, previous and current seismic codes.

\section{INTRODUCTION}

In the early morning of January 17,1995 , an earthquake, which measured $\mathrm{M}_{\mathrm{JMA}} 7.2$ on the JMA (Japan Meteorological Agency) magnitude (moment magnitude $\mathrm{M}_{\mathrm{W}}$ 6.9), shook the Kobe and Awaji areas. The Hyogoken-nanbu earthquake produced some of the highest accelerations and velocities ever recorded in Japan, both on the ground and in structures. The highest JMA Seismic Intensity assigned was VII, which is the severest intensity, at several locations spreading over the east-to-west belt in the affected region. Significant damage was observed in some parts of the following areas: Suma-ku, Nagata-ku, Hyogo-ku, Chuo$\mathrm{ku}$, Nada-ku, Higashinada-ku, Ashiya City, Nishinomiya City, Takarazuka City, and Awajishima Island. Damage to building structures varied widely but included numerous cases of partial and complete collapse. This event has been the costliest natural disaster in the history with an estimated 10 trillion yen in property damage. The official death toll was 6,308 which included 789 death related to the indirect effects of the earthquake, and there were 43,177 injured. Damaged houses including complete/partial destroy and slight damage were 436,416 , and damaged buildings were 4,702 . These results mentioned above were investigated by the Fire Defense Agency and summed up upon December 27, 1995.

1) Head, Structure Div., Building Research Institute, Ministry of Construction, 1 Tachihara, Tsukuba, Ibaraki, 305 Japan.

2) Research Engineer, Structural Dynamics Div., BRI, MOC.

3) Senior Research Engineer, Structure Div., BRI, MOC.

4) Coordinator for International Research Cooperation, BRI, MOC.

5) Head, Large Scale Structure Testing Div., BRI, MOC.

6) Director, Structural Engineering Dept., BRI, MOC. 
Shortly after the Hyogoken-nanbu earthquake, the Building Research Institute established an investigation project team of research engineers to conduct a post-earthquake investigation. The project team covered the following subjects: recorded ground and structure motions, structural engineering including reinforced concrete buildings, steel buildings, and wooden houses, geotechnical engineering, emergency risk assessment, fire-related aspects, and nonstructural damage. The results of the activities of the project team have been reported in Ref. 1.

After a month from the Hyogoken-nanbu earthquake, investigation teams of research engineers and practitioners were established to conduct a post-earthquake damage investigation on buildings that suffered from the earthquake. One of the investigation teams investigated the damage to steel building structures. The members of the investigation team of steel buildings were from the Building Research Institute, the Kozai Club, and the Lath Sheet Kogyo-kai. This team worked in four days of February, 1995, and investigated the damage to a total number of 655 buildings considered to be steel structures, located in the three specific areas of the city of Kobe as shown in Fig. 1, in order to determine the damage ratio of each damage level for all steel buildings in these areas.

\section{DAMAGE SURVEY}

The damage to all steel buildings taller than or equal to three stories was surveyed in the following three areas of the city of Kobe as shown in Fig. 1: the parts of Higashinada-ku, Chuo-ku, and Hyogo-ku, where many structures suffered significant damage, from February 20 to 23, 1995. In Higashinada-ku, the surveyed area of $7,589,000 \mathrm{~m}^{2}$ included three railways of Hankyu, JR and Hanshin. The surveyed area of $989,000 \mathrm{~m}^{2}$ in Chuo-ku covered from the north side of Sannomiya Railway Station to the Kobe Marine Meteorological Observatory. In Hyogo-ku, surveyed was the area of $1,296,000 \mathrm{~m}^{2}$ where Municipal Subway, Kobe Express Railway and JR are passing through. The total area surveyed was $9,874,000 \mathrm{~m}^{2}$. Old steel buildings built with light-gauged beams and columns were not investigated, although many of them were significantly damaged. The investigation was made mainly from the exterior of buildings, and also from the inside as much as possible. The scope of the investigation was to record the extent and types of damage to steel buildings. For each building surveyed, the investigators filled out the standard data forms and took some photographs showing notable damage. The damage levels were classified into four levels, that is, No damage, Minor damage, Moderate damage, and Severe damage including Collapse.

The following general guideline was adopted to judge the damage level.

Severe/Collapse Damage: Collapse of the entire building or a story of the building. Serious damage to structural members such as beams, columns, and connections; and significant residual lateral deformations to an extent considered to be beyond repair.

Moderate Damage: Buckling and/or rupture of bracing members; and plastification of beams and columns. Small residual lateral deformations to an extent considered to be repairable. Any damage not assigned as Minor or Severe/Collapse.

Minor Damage: No damage to major structural members such as beams and columns. Minor cracking and spalling of exterior finishes.

After completing the field investigation, the structural type of all steel buildings surveyed was reexamined and the year of construction of them was identified from the official records. Some buildings had been demolished or under demolition during the field investigation. They were not included in this damage investigation.

\section{RESULTS}

A total number of 655 buildings considered to be steel structures were investigated in the field investigation. As a result of the reexamination, it was found out that five of 655 buildings were not steel structures. Therefore, the investigated results for 650 steel buildings are presented in this report.

Table 1 shows the number of the buildings with respect to the number of stories, though it unexpectedly includes the one and two story buildings. The number of the buildings with respect to the number of stories slightly varies in 
each area. The reason is that the ratio of residential area is large in the parts of Higashinada-ku and Hyogo-ku, while that is small in the part of Chuo-ku. In total, almost a half of the investigated buildings are three stories tall and about $85 \%$ of them are lower than or equal to five stories.

Table 2 shows the number of the buildings with respect to occupancy, and the number in parentheses indicates the ratio of them. In the part of Chuo-ku, the number of the investigated buildings with respect to occupancy is the largest for shops followed by residential houses and offices. On the contrary, in the parts of Higashinada-ku and Hyogo-ku, that is the largest for residential houses followed by shops and offices. These results are also related to the ratio of residential area. In total, the ratios of the buildings with respect to occupancy are $37 \%$ for shops, $36 \%$ for residential houses, and $16 \%$ for offices.

Table 3 shows the number of the buildings with respect to damage level, and the number in parentheses indicates the ratio of them. Among 650 steel buildings, 112 were rated as Severe/Collapse, 93 as Moderate, 212 as Minor, and 220 as No damages. On comparing the ratio of the buildings of Severe/Collapse damage among three areas, the largest is $25.0 \%$ in the part of Higashinada-ku followed by $19.3 \%$ in the part of Chuo-ku and $11.5 \%$ in the part of Hyogo-ku. In total, the ratio of the buildings of Severe/Collapse damage is $17.2 \%$; that of Moderate damage $14.3 \%$; that of Minor damage $32.6 \%$; and that of No damage $33.8 \%$.

Figure 2 shows the comparison of the number and ratio of the buildings at each damage level between the buildings designed and constructed according to the previous seismic provisions of BSLJ (before 1981) and the current ones (after 1982). The current seismic code has been revised in 1981. The number of the buildings according to the previous code is 315 , and that according to the current code is 241 . The ratios of the buildings, designed according to the previous and current codes, of Severe/Collapse damage are $25 \%$ and $9 \%$ respectively, while those of No damage is $20 \%$ and $51 \%$ respectively. It is noted that the ratio of the buildings, designed according to the current code, of Severe/Collapse damage is much smaller than and the ratio of No damage is much larger than the ratio of the buildings designed according to the previous code.

Table 4 shows the number of the buildings damaged to each structural member and element, and the number in parentheses indicates the ratio of them. The number and ratio of the buildings at each damage level are compared between the buildings designed according to the previous and current codes. The ratios of the buildings, damaged to columns, designed according to the previous and current codes are $10.2 \%$ and $4.6 \%$; those to beams $3.2 \%$ and $3.3 \%$; those to braces $6.7 \%$ and $1.7 \%$; those to column bases $16.5 \%$ and $5.0 \%$; those to bolted connections $2.9 \%$ and $0.4 \%$; and those to welded connections $3.2 \%$ and $4.1 \%$, respectively. The ratios of the buildings, damaged to columns, braces, column bases, and bolted connections, designed according to the current code are smaller than those designed according to the previous code. It is remarkable that the ratios of the buildings, damaged to beams and welded connections, designed according to the current code are almost the same as or even larger than those designed according to the previous code.

Figure 3 shows the number and ratio of the buildings at each damage level by the number of stories. The ratio of the buildings of No or Minor damages are more than $60 \%$. The ratio of the buildings of Severe/Collapse damage is $19.4 \%$ for three stories, $22.4 \%$ for four stories, $10.0 \%$ for five stories, and less than $10 \%$ for the buildings taller than five stories. It is pointed out that the ratio of the three and four story buildings of Severe/Collapse damage is about 20\% and much higher than that of the other buildings. Among the buildings designed according to the previous code, the ratio of the buildings of Severe/Collapse damage is $24.5 \%$ for three stories, $30.8 \%$ for four stories, and $21.2 \%$ for five stories. Among the buildings designed according to the current code, the ratio of the buildings of Severe/Collapse damage is $11.8 \%$ for three stories, $10.5 \%$ for four stories, and $3.0 \%$ for five stories.

\section{SUMMARY AND CONCLUSIONS}

The damage investigation to steel building structures that suffered from the 1995 Hyogoken-nanbu earthquake was conducted in 
order to determine the damage ratio of each damage level for all steel buildings in specific three areas of the city of Kobe, where many structures suffered significant damage: the parts of Higashinada-ku, Chuo-ku, and Hyogo-ku. A total number of 650 steel buildings, taller than or equal to three stories, were investigated in the field investigation.

The conclusions from the presented investigation can be summarized as follows:

(1)Approximately a half of the investigated buildings are three stories tall and about $85 \%$ of them are lower than or equal to five stories.

(2) The ratios of the buildings with respect to occupancy are $37 \%$ for shops, $36 \%$ for residential houses, and $16 \%$ for offices.

(3)Among the investigated buildings, 112 were rated as Severe/Collapse, 93 as Moderate, 212 as Minor, and 220 as No damages. On comparing the ratio of the buildings of Severe/Collapse damage among three areas, the largest is $25 \%$ in the part of Higashinada-ku followed by $19 \%$ in the part of Chuo-ku and $12 \%$ in the part of Hyogo-ku. In total, the ratio of the buildings of Severe/Collapse damage is $17 \%$; that of Moderate damage $14 \%$; that of Minor damage $33 \%$; and that of No damage $34 \%$.

(4)The ratios of the buildings, designed according to the previous and current codes, of Severe/Collapse damage are $25 \%$ and $9 \%$ respectively, while those of No damage is $20 \%$ and $51 \%$ respectively. It is noted that the ratio of the buildings, designed according to the current code, of Severe/Collapse damage is much smaller than and the ratio of No damage is much larger than the ratio of the buildings designed according to the previous code.

(5)The ratios of the buildings, damaged to beams and welded connections, designed according to the current code are almost the same as or even larger than those designed according to the previous code. On the contrary, the ratios of the buildings, damaged to columns, braces, column bases, and bolted connections, designed according to the current code are smaller than those designed according to the previous code.

(6)The ratio of the buildings of Severe/Collapse damage is $19 \%$ for three stories, $22 \%$ for four stories, $10 \%$ for five stories, and less than $10 \%$ for the buildings taller than five stories. It is pointed out that the ratio of the three and four story buildings of Severe/Collapse damage is much higher than that of the other buildings.

\section{Acknowledgments}

The writers gratefully wish to express their gratitude to the members of the damage investigation team of steel buildings from the Kozai Club and the Lath Sheet Kogyo-kai for their cooperation in the field investigation. The writers also gratefully acknowledge the support of the municipal authorities of the city of Kobe.

\section{Reference}

1) Building Research Institute, "A Survey Report for Building Damages due to the 1995 Hyogoken-nanbu Earthquake," March, 1996. 


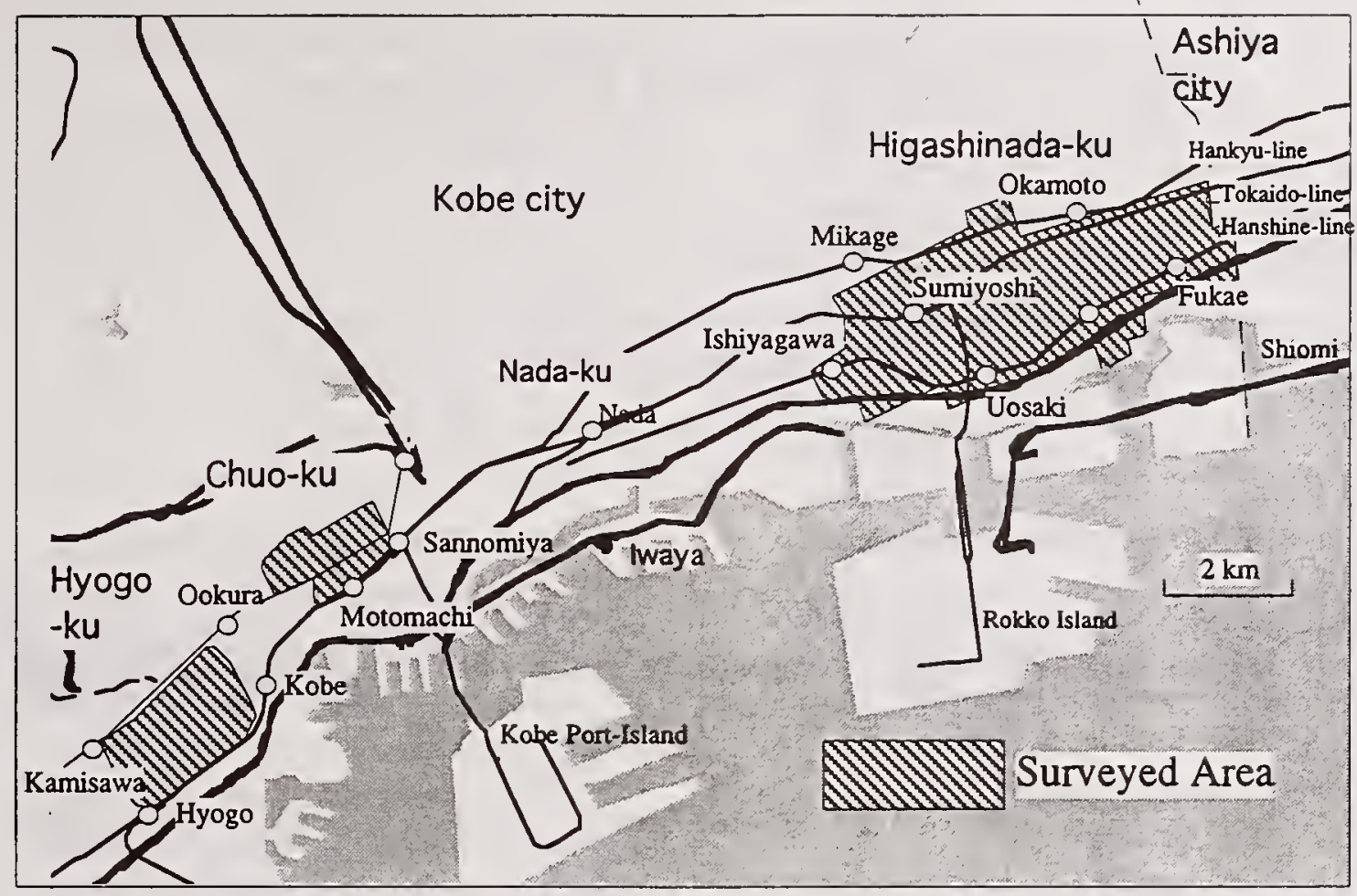

Fig. 1 Surveyed Area

Table 1 Number of Buildings with Respect to the Number of Stories

\begin{tabular}{|c|c|c|c|c|}
\hline Story & Higashinada-ku & Chuo-ku & Hyogo-ku & Total \\
\hline 1 & $2(1.2 \%)$ & $0(0.0 \%)$ & $0(0.0 \%)$ & $2(0.3 \%)$ \\
\hline 2 & $5(3.0 \%)$ & $0(0.0 \%)$ & $2(0.7 \%)$ & $7(1.1 \%)$ \\
\hline 3 & $88(52.4 \%)$ & $57(30.5 \%)$ & $154(52.2 \%)$ & $299(46.0 \%)$ \\
\hline 4 & $45(26.8 \%)$ & $48(25.7 \%)$ & $73(24.7 \%)$ & $166(25.5 \%)$ \\
\hline 5 & $13(7.7 \%)$ & $30(16.0 \%)$ & $37(12.5 \%)$ & $80(12.3 \%)$ \\
\hline 6 & $3(1.8 \%)$ & $10(5.3 \%)$ & $9(3.1 \%)$ & $22(3.4 \%)$ \\
\hline 7 & $1(0.6 \%)$ & $9(4.8 \%)$ & $7(2.4 \%)$ & $17(2.6 \%)$ \\
\hline 8 & $0(0.0 \%)$ & $10(5.3 \%)$ & $3(1.0 \%)$ & $13(2.0 \%)$ \\
\hline 9 & $1(0.6 \%)$ & $9(4.8 \%)$ & $4(1.4 \%)$ & $14(2.2 \%)$ \\
\hline$\geqq 10$ & $0(0.0 \%)$ & $4(2.1 \%)$ & $5(1.7 \%)$ & $9(1.4 \%)$ \\
\hline Unidentified & $10(6.0 \%)$ & $10(5.3 \%)$ & $1(0.3 \%)$ & $21(3.2 \%)$ \\
\hline Total & $168(100 \%)$ & $187(100 \%)$ & $295(100 \%)$ & $650(100 \%)$ \\
\hline
\end{tabular}

Table 2 Number of Buildings with Respect to Occupancy

\begin{tabular}{|l|c|c|c|c|}
\hline Occupancy & Higashinada-ku & Chuo-ku & Hyogo-ku & Total \\
\hline Office & $35(16.0 \%)$ & $29(12.4 \%)$ & $73(16.7 \%)$ & $137(15.4 \%)$ \\
\hline Shop & $52(23.7 \%)$ & $127(54.3 \%)$ & $152(34.8 \%)$ & $331(37.2 \%)$ \\
\hline Residence & $91(41.6 \%)$ & $50(21.4 \%)$ & $177(40.5 \%)$ & $318(35.7 \%)$ \\
\hline Hospital & $5(2.3 \%)$ & $3(1.3 \%)$ & $5(1.1 \%)$ & $13(1.5 \%)$ \\
\hline School & $0(0.0 \%)$ & $1(0.4 \%)$ & $0(0.0 \%)$ & $1(0.1 \%)$ \\
\hline Factory & $10(4.6 \%)$ & $0(0.0 \%)$ & $8(1.8 \%)$ & $18(2.0 \%)$ \\
\hline Warehouse & $13(5.9 \%)$ & $0(0.0 \%)$ & $7(1.6 \%)$ & $20(2.2 \%)$ \\
\hline Public office & $0(0.0 \%)$ & $2(0.9 \%)$ & $0(0.0 \%)$ & $2(0.2 \%)$ \\
\hline Unidentified & $13(5.9 \%)$ & $22(9.4 \%)$ & $15(3.4 \%)$ & $50(5.6 \%)$ \\
\hline Total & $219(100 \%)$ & $234(100 \%)$ & $437(100 \%)$ & $890(100 \%)$ \\
\hline
\end{tabular}

Note: Some of the buildings have two or more occupancies. 
Table 3 Number of Buildings at Each Damage Level

\begin{tabular}{|l|c|c|c|c|c|}
\hline & \multicolumn{2}{|c|}{ Higashinada-ku } & \multicolumn{2}{|c|}{ Chuo-ku } & \multicolumn{2}{|c|}{ Hyogo-ku } & \multicolumn{2}{c|}{ Total } \\
\hline No Damage & $59(35.1 \%)$ & $65(34.8 \%)$ & $96(32.5 \%)$ & $220(33.8 \%)$ \\
\hline Minor Damage & $32(19.1 \%)$ & $52(27.8 \%)$ & $128(43.4 \%)$ & $212(32.6 \%)$ \\
\hline Moderate & $29(17.3 \%)$ & $28(15.0 \%)$ & $36(12.2 \%)$ & $93(14.3 \%)$ \\
\hline Severe/Collapse & $42(25.0 \%)$ & $36(19.3 \%)$ & $34(11.5 \%)$ & $112(17.2 \%)$ \\
\hline Unidentified & $6(3.6 \%)$ & $6(3.2 \%)$ & 1 & $10.3 \%)$ & $13(2.0 \%)$ \\
\hline Total & $168(100 \%)$ & $187(100 \%)$ & $295(100 \%)$ & $650(100 \%)$ \\
\hline
\end{tabular}

Number of Buildings at Each Damage Level $\begin{array}{lll}\text { No Minor } & \text { Severe/ } \\ \text { Damage Damage Moderate Collapse Others }\end{array}$

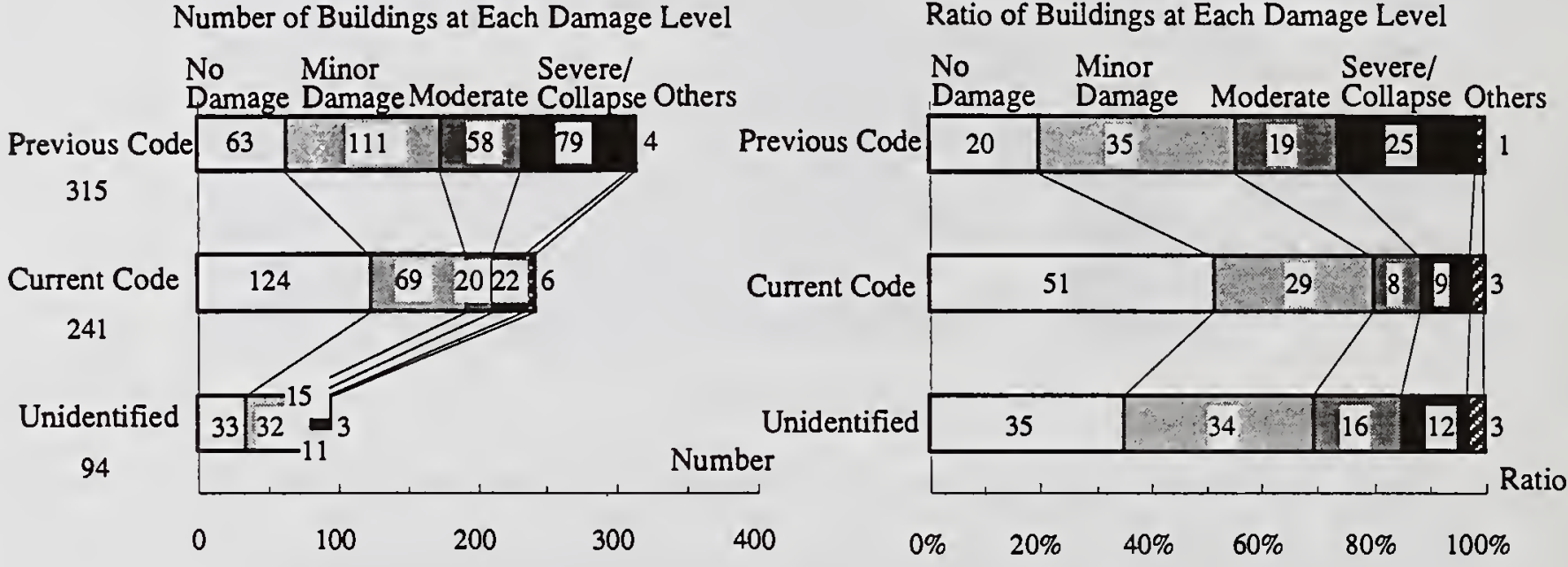

Ratio of Buildings at Each Damage Level

Fig. 2 Number and Ratio of Buildings at Each Damage Level

Table 4 Number of Buildings Damaged to Each Structural Member and Element

\begin{tabular}{|c|c|c|c|c|c|c|}
\hline $\begin{array}{l}\text { Member \& } \\
\text { Element }\end{array}$ & Column & Beam & Brace & Column Base & Bolted Connection & Welded Connection \\
\hline $\begin{array}{c}\text { Previous Code } \\
315\end{array}$ & $(32 / 315=10.2 \%)$ & $\begin{array}{c}10 \\
(10 / 315=3.2 \%)\end{array}$ & $\stackrel{21}{(21 / 315=6.7 \%)}$ & $\begin{array}{c}52 \\
(52 / 315=16.5 \%)\end{array}$ & $(9 / 315=2.9 \%)$ & $\begin{array}{c}10 \\
(10 / 315=3.2 \%)\end{array}$ \\
\hline $\begin{array}{c}\text { Current Code } \\
241\end{array}$ & $\begin{array}{c}11 \\
(11 / 241=4.6 \%)\end{array}$ & $\begin{array}{c}8 \\
(8 / 241=3.3 \%)\end{array}$ & $\left(4 / 241^{4}=1.7 \%\right)$ & $\stackrel{12}{(12 / 241=5.0 \%)}$ & $\stackrel{1}{1}$ & $\begin{array}{c}10 \\
(10 / 241=4.1 \%)\end{array}$ \\
\hline $\begin{array}{l}\text { Unidentified } \\
94\end{array}$ & $\begin{array}{c}10 \\
(10 / 94=10.6 \%)\end{array}$ & $\begin{array}{c}0 \\
(0 / 94=0 \%)\end{array}$ & $\begin{array}{c}7 \\
(7 / 94=7.4 \%)\end{array}$ & $\begin{array}{c}11 \\
(11 / 94=11.7 \%)\end{array}$ & $\begin{array}{c}0 \\
(0 / 94=0 \%)\end{array}$ & $\begin{array}{c}0 \\
(0 / 94=0 \%)\end{array}$ \\
\hline
\end{tabular}

Note: The number of buildings damaged to columns and beams includes that damaged to bolted and welded connections.
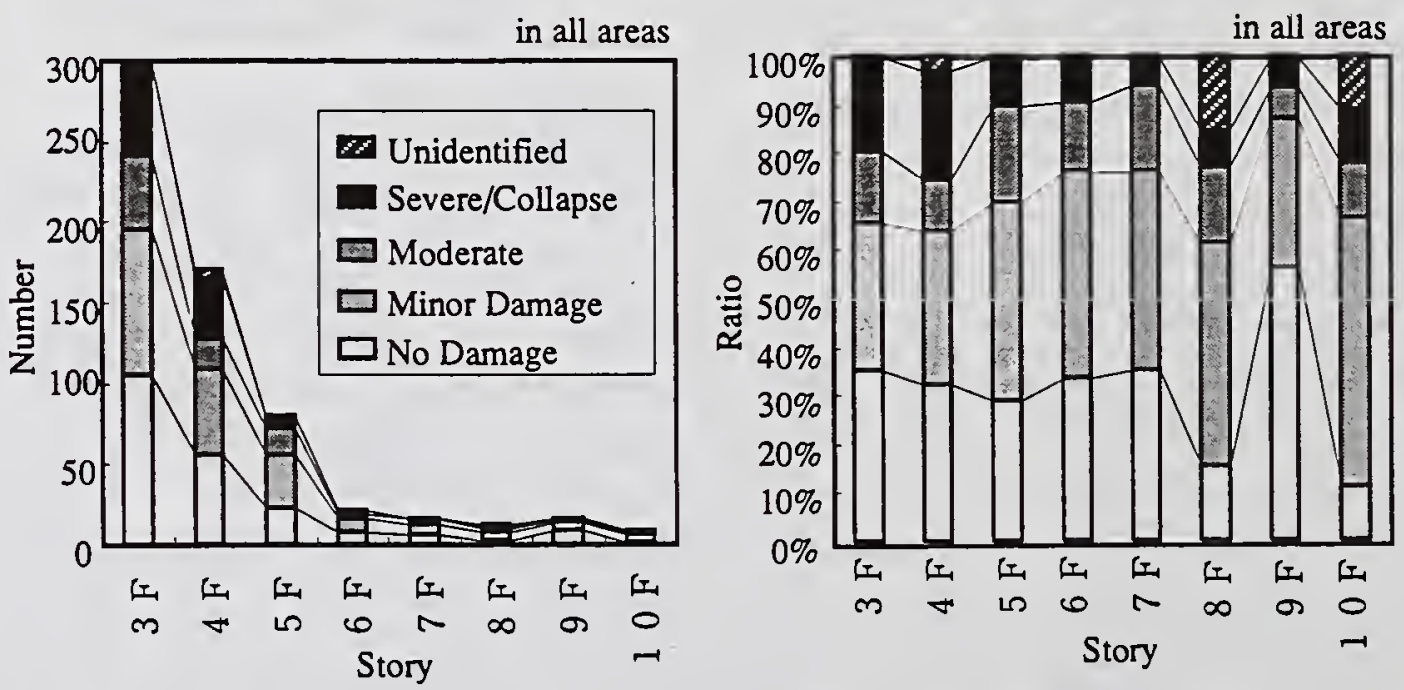

Fig. 3 Number and Ratio of Buildings at Each Damage Level by Story Number 


\title{
AN INTEGRATED PROGRAM TO IMPROVE THE PERFORMANCE OF STEEL MOMENT RESISTING FRAME BUILDINGS
}

\author{
by \\ STEPHEN A. MAHIN ${ }^{1}$ AND MICHAEL G. MAHONEY ${ }^{2}$
}

\section{ABSTRACT}

This paper reviews the performance of welded steel moment resisting frame (WSMF) buildings during the Northridge earthquake, and examines some of the studies being undertaken in the U.S. as part of a project funded by the Federal Emergency Management Agency (FEMA) to devise improved methods for designing new steel frame structures and for inspecting, evaluating and repairing seismic damage to these types of structures.

One of the important lessons of the Northridge earthquake of January 17, 1994, was the widespread and unanticipated brittle fractures in welded steel beam to column connections. No casualties or collapses occurred as a result of these connection failures, and some welded steel moment frame buildings were not damaged at all. However, a wide spectrum of brittle connection damage did occur, ranging from minor cracking to completely severed columns. Damage was so severe in some buildings that all of the moment resisting connections at one or more floors fractured, or significant permanent lateral displacements occurred. The result has been a loss of confidence in the procedures used to design and construct welded connections in steel moment frames, and a concern these structures may not be sufficiently safe.

FEMA has initiated a two phase program to develop reliable and cost-effective methods for the inspection, evaluation, repair, rehabilitation and construction of steel frame structures. This program is being managed and administered by the SAC Joint Venture. This joint venture consists of three not-for-profit organizations: the Structural Engineers Association of California (SEAOC), the Applied Technology Council (ATC) and the California Universities for Research in Earthquake Engineering (CUREe).

\section{KEYWORDS}

Steel Buildings, Moment-Resisting Frames, Design Criteria, Inspection, Evaluation, Repair, Rehabilitation, Experimental Investigations, Dynamic Analyses

\section{INTRODUCTION}

One of the important lessons of the Northridge earthquake of January 17, 1994, was the widespread and unanticipated brittle fractures in welded steel beam to column connections. The economy, versatility and presupposed high plastic deformation capacity of welded steel moment-resisting frame (WSMF) buildings has resulted in their common usage in Los Angeles as well as in other regions of high and moderate seismicity. No casualties or collapses occurred as a result of these connection failures, and some steel moment frame buildings in areas of moderate shaking were not damaged at all. However, a wide spectrum of brittle connection damage did occur, ranging from minor cracking to completely severed columns. The most commonly observed damage occurred in or near the welded joint of a girder bottom flange to the supporting column flange, and complete brittle fractures occurred in many of these joints. Damage was so severe in some buildings that all of the moment resisting connections at one or more floors fractured, or significant permanent lateral displacements occurred.

Thus far, almost 200 damaged steel buildings have been identified. Damage occurred in new as well as old buildings; and in both tall and short structures. While inadequate workmanship played a role in the

\footnotetext{
$\overline{1}$ Nishkian Prof. of Structural Engineering, 777 Davis Hall, University of California, Berkeley, CA 94720

2 Senior Geophysicist, Federal Emergency Management Agency, $500 \mathrm{C}$ St. SW, Washington, DC 20472
} 
damage observed in some structures, most damaged buildings are believed to be constructed consistent with modern codes and standards of practice.

The effect of these observations has been a loss of confidence in the procedures used to design and construct welded connections in steel moment frames, and a concern that structures incorporating these connections may not be sufficiently safe. Current professional judgment is that historic practices used in the U.S. for the design and construction of WSMF connections do not provide adequate reliability and safety. As a consequence, pre-qualified connection details and design methods contained in the major U.S. building codes have been rescinded, and emergency code provisions generally stipulate that new designs must be substantiated by testing or test-backed calculations.

To develop effective and economic design procedures and construction standards, and to restore public and professional confidence, several fundamental questions must be answered. These include:

- What happened to WSMF buildings during the Northridge earthquake?

- What caused the observed damage?

- How to identify WSMF buildings that may have sustained damage?

- How safe are damaged WSMF buildings and do they need to be repaired?

- How can damaged buildings be reliably repaired and/or upgraded?

- How to design and construct new buildings so they will not sustain similar damage in future earthquakes?

- Can the vulnerability of existing WSMF buildings to future earthquakes be reliably determined and mitigated through effective rehabilitation procedures?

- What are the economic, social and political impacts of any required changes in design and construction practices?

Answering these questions involves consideration of many complex technical, professional and economic issues including metallurgy, welding, fracture mechanics, connection behavior, system performance, and practices related to design, fabrication, erection and inspection. Unfortunately, current knowledge of many of these issues is inadequate.

The Federal Emergency Management Agency (FEMA), as part of its role in the National Earthquake Hazards
Reduction Program (NEHRP), is charged with reducing the ever increasing price that earthquakes are costing this country. Preventing losses before they happen, an action which we refer to as mitigation, is the only truly effective way of reducing this cost. In this light, the role of this nation's building code and standards in mitigating earthquake losses is critical, and FEMA is committed to supporting this nation's seismic codes and standards to keep them among the best in the world.

Because the damage that resulted from the Northridge earthquake had called into question the design assumptions and building code requirements associated with steel moment frame construction, and because it was not known at that time what repair or retrofitting techniques would be adequate, and because of the unknown life safety hazard of the damaged buildings (including critical facilities), it was crucial that adequate hazard assessment criteria and repair and/or retrofitting procedures be identified as soon as possible. This would then need to be followed by the development of reliable and cost-effective methods for the inspection, evaluation, repair, rehabilitation and construction of steel frame structures.

To resolve this issue in the most effective manner possible, FEMA elected to following a two phase approach. Phase 1 was the development of guidance to provide guidance for the repair and retrofitting of damaged buildings; Phase 2 is the research and .development of a final resource document for the various building codes and standards that address the design of new construction and the repair and/or rehabilitation of existing steel moment frame buildings. Both phases would be part of a coordinated, problemfocused program of research, investigation and professional development in order to develop and validate reliable and cost-effective seismic-resistant design and rehabilitation procedures for WSMF structures.

Both phases of this program have been contracted to, and are managed and administered by the SAC Joint Venture. This joint venture consists of three not-forprofit professional and educational organizations: the Structural Engineers Association of California (SEAOC), the Applied Technology Council (ATC) and the California Universities for Research in Earthquake Engineering (CUREe). The program actively involves engineers, researchers, construction experts and other specialists from throughout the U.S. 
As of this paper, the Phase 1, which included limited amounts of laboratory and field testing as well as other topical investigations, is essentially complete. The primary product of Phase 1 is the Interim Guidelines: Evaluation, Repair, Modification and Design of Welded Steel Moment Frame Structures [1]. This document has been completed and is now available from FEMA. Copies of the Interim Guidelines can ordered directly from FEMA by calling 1-800-480-2520. The document identification number is FEMA-267.

The goal of the second phase is to identify long-term solutions and to develop and verify reliable and costeffective seismic design criteria for steel frame structures.

\section{PROJECT DESCRIPTION}

The focus of the first phase of the project was on the development of specific design advisories, guidelines and other criteria for design, inspection, evaluation, repair, modification and rehabilitation of WSMF structures. The Interim Guidelines [1] developed in Phase 1 were written by a committee of ten experts from a variety of disciplines. The Guidelines were subjected to extensive review by engineers, researchers, building regulators and other public officials, and representatives from the steel and construction industries. The scope of the Interim Guidelines includes welding procedures, quality assurance, post-earthquake actions, and new construction. Specific chapters cover: (a) welding and metallurgy; (b) quality control and assurance; (c) visual inspection; (d) non-destructive testing; (e) classification and implications of damage; (f) postearthquake evaluation; (g) post-earthquake inspection; (h) post-earthquake repair and modification; and (i) new construction.

The following specific tasks were performed under the Phase 1 effort to support the development of the Interim Guidelines and the planning of Phase 2:

1. Inspect and Assess Damaged Buildings;

2. Perform a Detailed Assessment of Select Buildings;

3. Characterize Ground Motions;

4. Develop Design Advisories;

5. Assessment of Current Knowledge;

6. Conduct Laboratory Tests;

7. Develop Draft Interim Guidelines;

8. Conduct a Users Workshop to Review the Guidelines;

9. Finalize and Publish Interim Guidelines, and;

10. Conduct Regional Training Seminars.
The following sections describe some of these studies as they relate to the inspection, evaluation and repair of existing WSMF buildings.

\subsection{Survey of Northridge Building Damages}

A systematic effort has been undertaken to assess the actual performance of steel buildings the Northridge earthquake. Three levels of survey were conducted. In the first, a brief questionnaire was sent to more than two hundred, randomly-selected owners of steel buildings. This preliminary survey was used to estimate the overall scope of damage to steel buildings and to help identify geographic areas where steel buildings were damaged. Based on this and other more detailed surveys, the Interim Guidelines recommended detailed inspection of steel buildings where ground motions exceeded $0.2 \mathrm{~g}$.

A second level of survey was carried out by engineers on damaged steel frames. Detailed information was obtained on 89 buildings regarding the types and locations of damage observed and their structural configuration, materials and detailing. This second survey has been supplemented by a detailed survey of damage in eight buildings selected for dynamic analyses. Results of these surveys were used to further identify methods that can be used to select buildings for inspection, and the joints within a suspect buildings that should be inspected. For example, it was found that on average, $70 \%$ of the floors of the buildings surveyed had serious damage to at least one welded joint. Only $25 \%$ of the connections were found with no damage. About $20 \%$ of the building frames included in the study had more than $40 \%$ of their connections damaged; and in a few instances, all of the connections at one or more floors were damaged.

Damage in low rise structures appears to be more or less uniformly distributed over height (with slightly more severe damage occurring near the bottom of the structure), whereas tall buildings exhibited greatest damage in the upper half. Survey results also show that damage tends to congregate; thus, finding a severely damaged connection as part of an inspection process could serve as a trigger for inspection of other nearby connections.

\subsection{Detailed Analyses of Northridge Steel Buildings}

Twelve buildings subjected to the Northridge earthquake were selected for detailed analysis by consultants using elastic and nonlinear analysis 
programs. Buildings were selected with heights ranging from 2 to 17 stories, and in locations varying from Santa Clarita on the north of the epicenter to Santa Monica on the south. The analyses were intended to help identify the causes of the damage, as well as the reliability of various analytical methods and modeling assumptions in predicting the observed damages. In four of the buildings, recordings of response during the Northridge earthquake were available and in three other cases, ambient vibration tests were performed. For comparison purposes, two buildings that did not have any apparent damage and were immediately adjacent to damaged buildings were included in the study.

The analysis results indicate that the buildings were very strong when compared with the design forces incorporated in current U.S. building codes. For many of the building sites the estimated response spectra were nearly double those considered in building codes (assuming elastic response, $\mathrm{R}=1$ ). Elastic analysis results showed that the most heavily damaged buildings were only stressed 2 to 3 times their capacities, suggesting that the buildings may be 4 to 8 times stronger than required. The main reason for this over-strength appears to be the use of large members to satisfy stringent drift requirements.

Analysis results show poor correlation with observed damage. The most heavily stressed joints are the most likely to be damaged; however, the precise location and severity of damage is not reliably predicted by analysis. The $60 \%$ most highly stressed connections have roughly equal chance of being damaged.

Similarly, areas of low computed stress were subject to damage. The reasons for these differences include the effect of initial defects and poor workmanship, and the limitations of the analytical methods. More detailed elastic and inelastic analyses shed some light on this last possibility. First, both types of analyses indicate that higher mode effects were very important. Thus, static lateral force methods in the elastic range, and nonlinear push-over analysis are of limited value for longer period structures. The predicted distribution of damage is highly sensitive to small perturbations in the spectral characteristics of the ground motions considered.

Another aspect of this difficulty is that traditional models ignore or only crudely treat deformations in the beam to column panel zones. More refined analyses, especially those performed in the inelastic range, indicated that panel zone deformations were significant. Review of experimental data and finite element results suggests that in addition to anticipated axial deformations, high local bending and shear distortions are induced in both the beam and column flanges near the welded joint due to panel zone yielding and other causes. Composite slab effects were also found to have an important effect on local deformations, and overall structural stiffness and periods. Current methods for modeling these phenomenon are quite simple and may be inadequate in many situations.

\subsection{Preliminary Test Program}

A total of 37 tests of full size beam-to-column connection subassemblies were done as part of this preliminary investigation. Twelve test specimens (like those shown schematically in Fig. 1) were constructed utilizing pre-Northridge details, half of the specimens had W36x150 beams and half had W30x99 beams. Fourteen-inch wide-flange sections were used as columns in both cases. Dual certified $\left(\mathrm{f}_{\mathrm{y}}>50 \mathrm{ksi}\right)$ steel was used in all cases. Slabs were not included in any of the specimens. These specimens exhibited brittle appearing fractures; some specimens fractured without any plastic deformation, while a few were able to deform to a plastic rotation of about 0.02 prior to fracturing.

These damaged specimens were repaired or upgraded. - Repair consisted of simply rewelding the connections using high notch toughness FCAW procedures; backing bars were removed, the root pass of the CJP weld on the beam flange to column flange connection was air-arc gouged and repaired with a fillet weld. This is the prevalent practice in repairs of damaged buildings in the Los Angeles area. Test results indicated that the repaired specimens, constructed with careful quality control, were able to retain their predamage strength and stiffness. Plastic rotation capacities were not significantly different from those achieved in the first tests.

Some of the specimens were upgraded in an attempt to improve their plastic deformation capacity. In the cases investigated, inclined haunches were applied to one or both sides of the beam at its connection to the column. This detail attempted to move the plastic hinge in the beam away from the face of the column to the end of the haunch. These tests supplemented earlier tests by others which utilized trapezoidal and rectangular shaped cover plates, vertical fins, or side plates. Test results on the triangular haunches indicate 
that they are generally able to increase the plastic deformation capacity of the connection to at least a plastic rotation of 0.03 .

Four beam-column assemblages were removed during the demolition of a heavily damaged building. These specimens were tested in their damaged condition as well as following repairs. Four tests have also been conducted on details believed appropriate for new construction. Simple weldment specimens were used to assess effects of various weld procedures, initial defects, materials, repair methods and loading rates.

\subsection{Recommendations for Evaluation, Inspection and Repair}

Based on the results of the studies described above, additional studies undertaken by others, practical considerations and expert opinion, a preliminary methodology was developed as part of this Project for the inspection, evaluation and repair of WSMF buildings subject to damaging earthquakes. The overall process is illustrated in Table 1 . This consists of a preliminary evaluation in which key parameters are examined to identify the need to conduct a detailed inspection and evaluation of a particular building. A building believed to have sustained structural damage is then subjected to additional analysis and physical inspection to assess its likely state of damage, represented by two parameters: $D_{i}$ and $P$, where $D_{i}$ is the likely damage index at a floor " $i$ " and $P$ which represent the probability that the damage index for any floor in the building exceeds $1 / 3$. Recovery actions to be taken depend on the values of $D_{i}$ and $P$, and range from doing nothing to completely modifying the structural system. Detailed procedures for repairing or modifying damaged connections are included in the Interim Guidelines [1].

\subsubsection{Selection Of Buildings For Detailed Inspection}

The widespread damage to welded and other connections in WSMF buildings during the Northridge earthquake supports the need for rigorous postearthquake evaluation of buildings incorporating vulnerable welded moment-resisting connections. The Interim Guidelines identify several triggers that would be appropriate to initiate a detailed evaluation as indicated in Table 1. The Interim Guidelines indicate that a structural analysis is not necessary, but may be performed.
As a class, it was believed that existing undamaged WSMF buildings appear to have a lower risk of collapse than many other types of buildings with known seismic vulnerabilities, the performance of which is currently implicitly accepted. Consequently, mandated or emergency programs to upgrade the performance of these buildings does not appear necessary to achieve levels of life safety protection currently tolerated in the U.S. However, the risk of collapse is definitely greater than previously thought. Thus, the Interim Guidelines recommended that individual owners should be made aware of the increased level of seismic risk and encouraged to perform modifications to provide more reliable seismic performance, particularly in buildings housing many persons, or in critical occupancies.

\subsubsection{Evaluation of Damage State, Safety and Recovery Actions}

Once a building is suspected of having sustained earthquake damage, the damage state and safety of the building must be assessed. The Interim Guidelines recommend an eight step procedure, as outlined below:

1. Assign connections to groups

2. Determine sample of connections to be initially inspected in each group

3. Make inspections and find connection damage factor, $d_{j}\left(0<d_{j}<10\right)$

4. Perform additional inspections near badly damaged connections

5. Estimate average damage index D for connections in group

6. Determine probable $\mathrm{D}_{\max }$ at any floor and probability $P$ that one floor has $D_{\max }>1 / 3$

7. Determine appropriate actions from $D_{\max }$ and $P$

\section{Prepare report to owner}

The welded steel moment connections in a structure are divided into groups expected to have similar mechanical characteristics. An initial sampling of connections from each group is made. Visual and nondestructive methods are used to identify structural damage in these connections. Three methods have been recommended in the Interim Guidelines to select the inspected connections: random sampling; a deterministic pattern selection process; and an analytically-based process. Because of the weak correlation between analytical predictions and observed damage, it was felt adequate to randomly 
select the locations of the connections to be inspected. Typically, 10 to $30 \%$ of the connections are inspected as a minimum, with a larger percentage required when smaller numbers of connections form the group.

Detection of severe damage triggers the need for additional inspections of adjacent connections. This and other requirements (Table 3 ) can substantially enlarge the number of inspections.

It is desirable to rationally estimate the effect of any detected damage has on the stiffness, strength and deformability of the connections. Given the difficulties in making this assessment, a simple connection damage index $\mathrm{d}_{\mathrm{j}}$ is suggested in the Interim Guidelines. The connection damage indices vary between 0 (for no damage) and 10 for total loss of effective capacity. Various categories of damage are considered, including damage to welds, girders, columns, shear tabs, and panel zones.

It is also recognized that the structural deformations causing the damage in the welded beam to column connections may cause damage in other types of welded or bolted connections. Thus, the Interim Guidelines recommend that inspection be extended to these types of connections under certain circumstances.

To assess the safety and need for specific recovery actions, a floor level damage index $\mathrm{D}_{\mathrm{i}}$ is computed. This index ranges from 0 (no damage) to 1 (complete loss of connection capacity at a floor). First order, second moment statistical procedures (assuming normal distributions of damage) are used along with the $d_{j}$ values determined for the inspected connections to estimate the maximum likely value of $\mathrm{D}_{\mathrm{i}}$ at a floor and the likelihood $(\mathrm{P})$ that any $\mathrm{D}_{\mathbf{i}}$ exceeds $1 / 3$. The values of $P$ and the maximum $D_{i}$ value for all floors $\left(\mathrm{D}_{\max }\right)$ are used to determine appropriate recovery actions. Recommended recovery actions are shown in Table 2.

When a WSMF experiences damage to a significant percentage of its moment-resisting connections (on the order of $25 \%$ in any direction of resistance), in addition to repair, consideration should be given to modifying the configuration of the individual damaged connections and possibly some or all of the undamaged connections to provide improved performance in the future. However, partial modifications to the structural system should be made with due consideration of the effect on overall system behavior. When a WSMF building has had many seriously damaged connections (on the order of $50 \%$ in any direction of resistance), owners should be informed that this damage may have highlighted basic deficiencies in the existing structural system, or a geologic feature which unusually amplifies site motion. In such cases the existing system should be both repaired and modified to provide an acceptably reliable structural system. Modifications may consist either of local reinforcement of individual connections and/or alteration of the structure's basic lateral-forceresisting system.

\subsubsection{Inspection Procedures}

The Interim Guidelines contain precise recommendations for the conduct of the inspections. These include methods for exposing, visual inspections and nondestructive testing of connections, qualifications of inspectors, and a standardized classification and reporting system. Emphasis is placed on the need for careful visual inspection, as supplemented by the use of magnetic particle testing and liquid dye penetrant testing. While the use of ultrasonic testing is encouraged, difficulties exist in detecting fractures in joints, especially at the beam to column connections where backing, runout tabs and other conditions may lead to spurious images

\subsubsection{Repair of Earthquake Damages}

Currently, the vast majority of connections damaged by the Northridge earthquake are being simply repaired to their pre-earthquake condition. As used in the Interim Guidelines, the term repair means restoration of the strength, stiffness and deformation capacity of structural elements that have been damaged or have construction defects. Modification means actions taken to enhance the capacity of either damaged or undamaged elements.

Currently, there is no clear evidence that one welding procedure can always produce better welds and structural performance. However, it appears that poor workmanship and inadequate structural details can produce poor performance regardless of the welding procedure. Thus, it is imperative that repair techniques fully account for proper welding procedures and incorporate rigorous quality control and assurance programs. A written Welding Procedure Specification is required to provide specific instruction to the welder and inspector for each weld condition encountered. In particular, care must be 
exercised in using proper pre-heat and post-heat, electrode diameters and deposition rates, and inspection procedures. Special reference is made in the Interim Guidelines to the desirability of using weld filler material with high impact toughness $(>20$ ft-lbs at $0_{-}$F).

Several examples of repairs are cited in the Interim Guidelines. In situations where a fracture has occurred in or near the weld joining the beam and column flanges, it is recommended that the backing bar be removed and the root pass be air-arc back gouged and subsequently repaired with a fillet weld. Any fractures in the weld and base metal should be air-arc gouged, ground to achieve proper fit up, rewelded, and inspected. In some circumstances the fracture may extend into the column (e.g., a divot of column base material may be removed by the fracture) and it may be necessary to rebuild the column section by filling the divot with weld material, grinding the repair weld surface smooth, and inspecting the repaired column flange. In all welding situations, it is recommended that the engineer should consult with knowledgeable experts in the fields of welding and inspection.

In some cases it is necessary to replace portions of a member. For instance, it may be necessary to remove the bottom flange of a beam due to severe damage or to gain access to make repairs to the column flange. In such cases, the beam flange may be replaced by a plate. Care needs to be exercised in orienting the plate with the rolling direction in the proper direction. In some cases, the plate can be welded in the same location as the original flange (welding the plate to the beam web along the $\mathrm{K}$ line as well as to the column and beam flange). In other cases it may be acceptable to weld a plate to the surface of the existing flange. In both cases, care must be taken regarding local details, welding procedures and avoidance of local or lateral buckling of the flange and/or web.

It may be desirable to improve behavior of a connection through modification. Currently, most approaches involve moving the plastic hinge away from the face of the column where welds join the beam to the column, and are represented in Figure 2. This may be accomplished by locally strengthening the beam near the column face, or locally weakening the beam at a location where the plastic hinge is desired. Local strengthening can be accomplished by addition of cover plates, side plates, vertical fins, haunches and knee braces. Weakening of the beam away from the face of the column can be achieved by reducing the area of the flanges by drilling holes in the beam flanges or by trimming the width of the flanges.

Because behavior of modified details have not worked satisfactorily in all cases, it is necessary to confirm designs using tests or test-validated calculations. Recommendations are made in the Interim Guidelines regarding the loading and instrumentation program, as well as for situations where new tests are required. Plastic rotation capacities recommended for modified details for use in existing buildings are 0.025 radians. This is lower than recommended values for new buildings ( 0.03 radians) since it is not expected that existing buildings will be designed for the same level .of reliability as new structures.

Design recommendations for modified details are based on realistic estimates of actual material properties including strain hardening effects. Similarly, moving the plastic hinge towards the midspan of a beam will increase the plastic rotation demands and, when the beam is strengthened at its end, increase the moment at the face of the column . This increase in moment will require careful evaluation of demands on the panel zone and column, in order to avoid unwanted plastic deformations in these locations.

\subsection{Phase 2}

The second phase of this project is a three year effort to research and develop Design Criteria for Steel Moment Resisting Frame Construction for use by the various building codes and standards. This resource document will address the design of new steel moment frame buildings and the rehabilitation of existing construction.

Based on a competitive evaluation and selection process, FEMA found the SAC Joint Venture to be the most technically qualified firm to perform this work.. Funding for Phase 2 consists of over $\$ 6$ million from the President's Northridge Earthquake Emergency Fund as well as $\$ 2.5$ million of FEMA earthquake program funds that have been designated from FEMA's Problem Focused Studies Project.

The SAC Joint Venture has just completed the first two tasks, selection of a Project Oversight Committee and development of a Project Work Plan. Upon FEMA approval of the Project Work Plan, SAC will begin work on the main tasks, which include assessing our current knowledge of steel building performance, conducting topical investigations, developing a series 
of state of the art reports, conducting a comprehensive testing program, developing an inspection program, assess the economic, social and political impacts, and writing the final document, "Design Criteria for Steel Moment Frame Buildings." Completion of that document is tentatively scheduled for the end of 1998 .

\section{CONCLUSIONS}

While the Interim Guidelines represent current U.S. thinking on the proper evaluation, inspection and repair of existing WSMF buildings as well as for the design and construction of new ones, there are clearly many uncertainties and unresolved questions. In Phase 2 of the FEMA/SAC Steel Project additional research and testing will be conducted to more clearly define the parameters controlling the performance of connections and systems, and to develop and verify procedures for design and rehabilitation of moment frame structures. Efforts will be made to cooperate with related activities worldwide.

It is a serious situation when a disaster such as the Northridge earthquake calls into question an entire section of the building code. Both FEMA and the SAC Joint Venture are pleased to be part of a project that recognized and is addressing an urgent need that arose out of the Northridge disaster, and has brought together the best of the research and engineering fields into one national project. This is an effort that has combined the best of both worlds; the research and testing capabilities of the academic community along with the practical design experience of the engineering community. With the Interim Guideline that can now be used for repairing damaged buildings and improving new construction and with the work that will be done in Phase 2, steel moment frame buildings will be able to provide the level of seismic safety that the citizens of this country have a right to expect.

\section{REFERENCES}

Federal Emergency Management Agency, Interim Guidelines: Evaluation, Repair, Modification and Design of Welded Steel Moment Frame Structures, FEMA \#267, August 1995, Federal Emergency Management Agency, Washington DC.

\section{ACKNOWLEDGMENTS}

The information reported herein was prepared under contract (EMW-95-K-4672) to the Federal Emergency -Management Agency. The authors are indebted to the efforts and work of numerous individuals and organizations that have participated in the FEMA/SAC Steel Project. The findings, conclusions and recommendations summarized in this paper are not intended for use in design or evaluation of structures. They do not represent official policy of FEMA or the SAC Joint Venture.

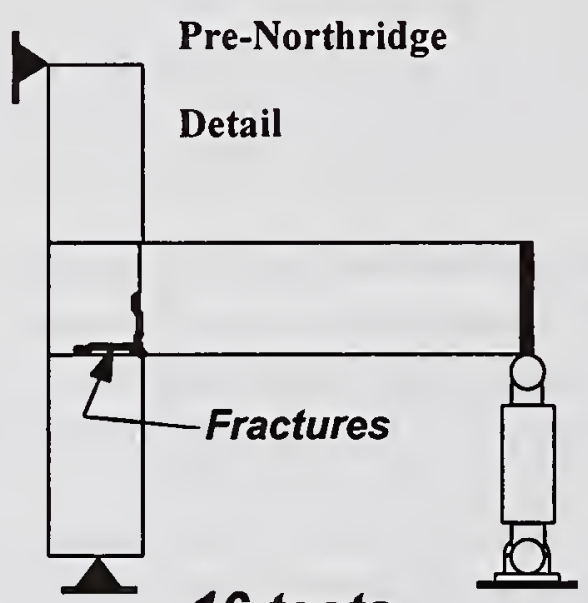

16 tests

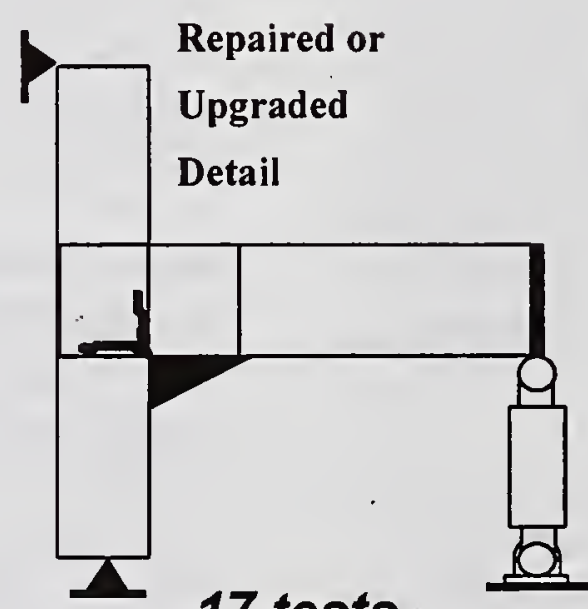

17 tests

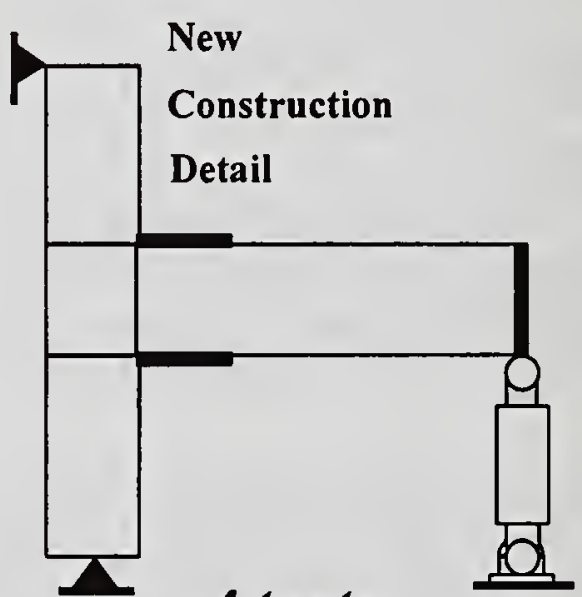

4 tests

Figure 1 - Preliminary Test Program 


\begin{tabular}{|c|c|c|}
\hline Preliminary Evaluation & Detailed Evaluation & Recovery Actions \\
\hline $\begin{array}{l}\text { Estimate ground } \\
\text { motion at site } \\
\text { - Proximity to fault } \\
\text { rupture } \\
\text { - Preliminary inspection } \\
\text { of damage to } \\
\text { architectural and } \\
\text { exposed structural } \\
\text { elements } \\
\text { - Observe damage in } \\
\text { neighboring buildings }\end{array}$ & $\begin{array}{l}\text { - Analyze building and/or } \\
\text { - Inspect sample of connections in } \\
\text { building } \\
\text { - random selection } \\
\text { - deterministic selection } \\
\text { - analytic selection } \\
\text { - Evaluate damage state } \\
\text { - assign damage intensity factor, } \\
\mathrm{d} \mathrm{g}, \text { to each connection } \\
\text { - estimate damage index } \mathrm{D} \text { for } \\
\text { structure } \\
\text { - probability } P \text { that damage on at } \\
\text { least one floor exceeds } 1 / 3\end{array}$ & $\begin{array}{l}\text { - Building occupancy } \\
\text { - continued, or } \\
\text { - interrupted } \\
\text { - Repairs } \\
\text { - not required, } \\
\text { - some damaged } \\
\text { connections, or } \\
\text { - all damaged connections } \\
\text { - Modification of connections } \\
\text { or system }\end{array}$ \\
\hline
\end{tabular}

Table 1 - Basic Steps in Evaluation Process

\begin{tabular}{|r|l|}
\hline Damage State & Recommended Recovery Action \\
\hline All cases & Repair all connections found with $\mathrm{d}_{\mathrm{j}}>5$ \\
\hline $\mathrm{P}>5 \%$ or $\mathrm{D}_{\max }>0.1$ & Repair all connections found with $\mathrm{d}_{\mathrm{j}}>2$ \\
\hline $\mathrm{P}>10 \%$ or $\mathrm{D}_{\max }>0.2$ & $\begin{array}{l}\text { Inspect all connections. Repair all } \\
\text { connections found with } \mathrm{d}_{\mathrm{j}}>2\end{array}$ \\
\hline $\mathrm{P}>25 \%$ or $\mathrm{D}_{\max }>0.33$ & $\begin{array}{l}\text { Inspect all connections. Unsafe conditions } \\
\text { may exist, careful assessment of building } \\
\text { safety is required. Repair all connections } \\
\text { found with } \mathrm{d}_{\mathrm{j}}>1 \text {. }\end{array}$ \\
\hline $\mathrm{D}_{\max }>0.5$ & $\begin{array}{l}\text { Inspect all connections. Unsafe } \\
\text { condition exists. Careful assessment of } \\
\text { structure is required. Repair all damage and } \\
\text { modify connections or system for improved } \\
\text { performance. }\end{array}$ \\
\hline
\end{tabular}

Table 2 - Recommended Recovery Actions as a Function of $\mathrm{P}$ and $\mathrm{D}_{\max }$ 

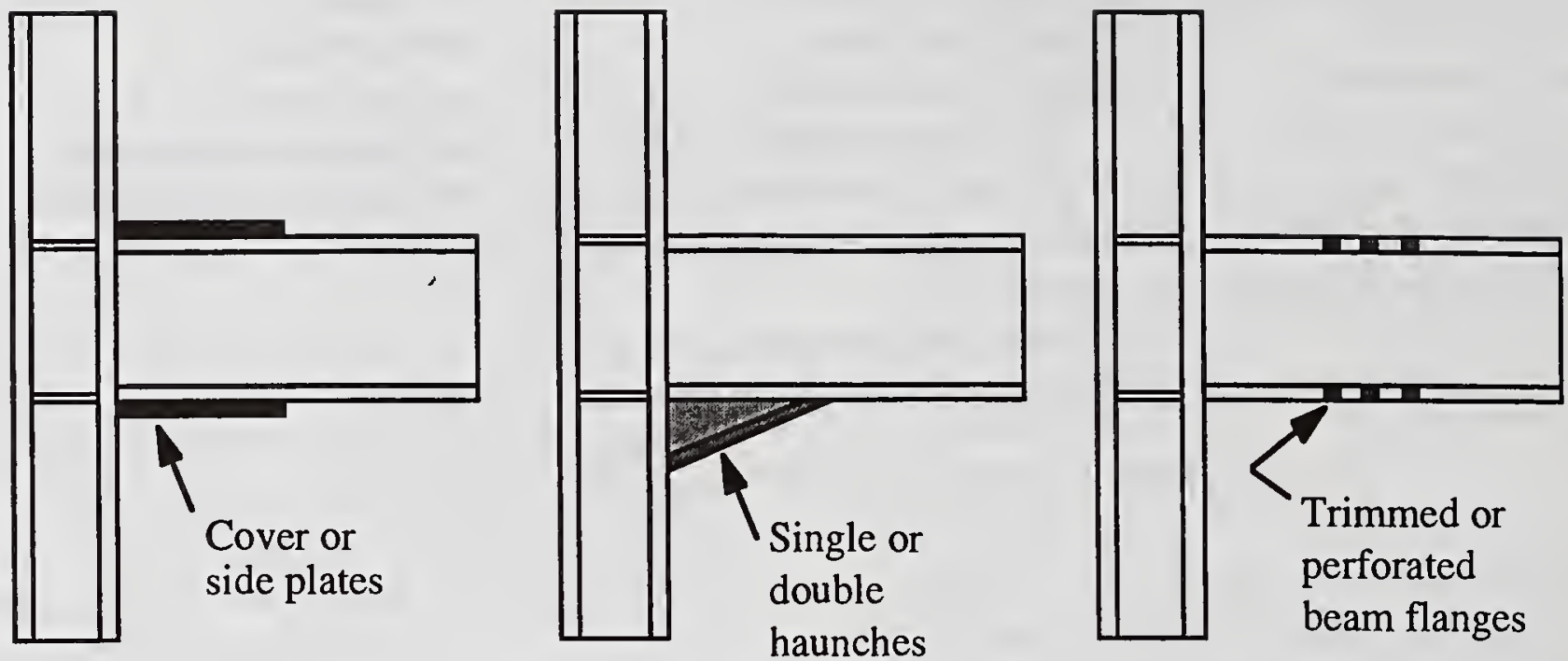

Figure 2 - Typical Approaches for Modifying Connections to Move Plastic Hinge Away From Column Face 


\title{
Recent Developments in Strong-Motion Attenuation Relationships
}

\author{
by
}

\author{
William B. Joyner and David M. Boore*
}

\begin{abstract}
New strong-motion relationships incorporating data recorded since 1988 show smaller spread than older relationships. The new relationships for soil sites agree more closely at magnitude 6.5 than at magnitude 7.5 , reflecting the larger number of data for magnitudes near 6.5 .
\end{abstract}

\section{INTRODUCTION}

In 1988 we published a review of the subject of strong ground motion in earthquakes (Joyner and Boore, 1988). The general statements we made at that time are still applicable, but so many strong-motion data have been recorded since then that the specific attenuation relationships described in the review should be regarded as outdated. In this paper we describe and compare more recent relationships.

\section{NEW RELATIONSHIPS}

Here we present a number of widely used relationships applicable to ground motion from shallow earthquakes in western North America. Inclusion or exclusion of a relationship in our comparison signifies nothing regarding endorsement or nonendorsement of the relationship.

\subsection{Boore et al., $(1993,1994)$}

Our earlier relationships (Joyner and Boore, 1981,1982 ) for horizontal peak acceleration, velocity, and response spectra were based on data obtained through 1980. Many more data have been recorded since then. Three Califormia earthquakes in particular (1989 Loma Prieta, 1992 Petrolia, and 1992 Landers) have provided data for a range of magnitude and distance, critical for engineering design, which was poorly represented in our previous work. Our long-term goals are to develop relationships incorporating all of the data recorded since our earlier work and to extend the period range covered by the relationships, which will require reprocessing all of the data. Pending the completion of this work we produced an interim report (Boore et al., 1993, 1994) using the earlier data set augmented by the three large, recent California earthquakes.

The new relationships give horizontal peak acceleration and response spectra from 0.1 to 2.0 seconds for $2,5,10$, and 20 percent damping in terms of moment magnitude, earthquake distance and site conditions. In an unpublished but widely distributed short note, we modified the relationships to differentiate three earthquake mechanism categories: (1) strike-slip, (2) reverse-slip or oblique-reverseslip, or (3) mechanism unspecified. There are no earthquakes in the data sets with normal or normal-oblique mechanisms. The data sets are restricted to earthquakes in western North America with moment magnitude greater than 5.0 and to shallow earthquakes, defined as those for which the fault rupture lies mainly above a depth of $20 \mathrm{~km}$.

Because the rupture surface for earthquakes may extend over tens or hundreds of kilometers,

- U.S. Geological Survey, Menlo Park, California 94025 
there is ambiguity in defining the source distance for a strong-motion record. Various measures of source distance have been used in the development of attenuation relationships, as illustrated in Figure 1. We use the closest distance to the vertical projection of the rupture surface on the surface of the earth (D5 in Figure 1). Differently stated, we use the closest horizontal distance from the station to the area on the earth's surface that lies directly above the rupture. Figure 2 shows the distribution of the strong-motion data in terms of distance and moment magnitude and the role of the three added earthquakes in filling the gap in the older data at short distance and large magnitude.

Boore et al. (1993) account for site conditions by assigning sites to four categories based on the average shear-wave velocity to a depth of $30 \mathrm{~m}$. In an improvement on that scheme, Boore et al. (1994) express the effect of site conditions directly in terms of the average shear-wave velocity to $30 \mathrm{~m}$. The coefficients of average shear-wave velocity they obtained compare very well with those determined independently by Midorikawa et al. (1994) from Japanese data as well as with the coefficients proposed by Borcherdt (1994) for determining short-period and mid-period amplification factors in building codes (Figure 3). In order to compare the relationships of Boore et al. (1994) with others, values of shear-wave velocity to 30 $\mathrm{m}$ are needed for an average rock site and an average soil site. Figure 4 shows downhole shear-wave velocity measurements for rock and soil sites (some at sites where strong-motion records have been obtained, some not). An analysis of downhole data (Boore and Joyner, 1996), most of which is shown in Figure 4, gives values of $620 \mathrm{~m} / \mathrm{sec}$ for the average rock site and $310 \mathrm{~m} / \mathrm{sec}$ for the average soil site.

The standard error of an individual estimate from our relationships ranges between values corresponding to factors of 1.5 and 2.0, depending upon period and damping. These values are comparable to those for other relationships.

Our new relationship for peak horizontal acceleration is compared on Figure 5 with our earlier relationship (Joyner and Boore, 1982). On Figure 6 our new acceleration relationship for strike-slip earthquakes is compared with data recorded in the 1995 Hyogoken-Nambu (Kobe) earthquake. Unlike the typical Japanese earthquakes, which are subductionzone events, the Hyogoken-Nambu earthquake was a shallow crustal event, like the typical California earthquake. For that reason the general agreement of the recorded data with the curves on Figure 6 should not be surprising. On Figure 7 our new relationships for horizontal response spectra is compared with our earlier relationships (Joyner and Boore, 1982).

There are three important ways in which our relationships differ from those of most other authors. The first of the three is the choice of distance definition, described above. The second important difference is that our relationships have the same magnitude scaling at all source distances. Most other relationships have smaller magnitude scaling at short distances than at long distances (e.g. Campbell and Bozorgnia, 1994). We have examined the question of magnitude scaling at short distances by Monte Carlo simulation and also by examining the magnitude dependence of residuals to our relationships at distances less than $10 \mathrm{~km}$. Both approaches showed no statistically significant differences in magnitude scaling at short distances. The third important difference is that we do the regression analysis of response spectra at each period independently. Most other analysts do regression analysis on spectral ordinates normalized by peak acceleration and then multiply the results by the value of peak acceleration given by regression analysis of acceleration data. 
2.2 Abrahamson and Silva (1995, written communication, 1995)

The Abrahamson and Silva relationships give horizontal and vertical peak acceleration, velocity, displacement, and response spectral values for periods of 0.01 to 10.0 seconds and damping of $0.5,1,2,5,7,10,15$, and 20 percent of critical. The magnitude measure is moment magnitude and the definition of distance is the closest distance to the rupture surface (D4 in Figure 1). Site conditions are characterized as rock or deep soil and source mechanisms as strike-slip, reverse-slip, or reverse-oblique-slip. The relationships take account of whether a site is on the hanging wall or the footwall of a dipping fault. The relationships are based on 543 recordings of 98 shallow earthquakes recorded world-wide between 1935 and 1994 for the magnitude range of 4.5 to 7.5. Further information can be found on the we b s ite : http://www.holonet.net/abrahamson

\subsection{Campbell and Bozorgnia (1994)}

The Campbell and Bozorgnia relationship gives peak horizontal acceleration in terms of moment magnitude, distance, source mechanism, and site conditions. The definition of distance is the closest distance to the seismogenic rupture, which is the part of the rupture that lies below a depth of about $3 \mathrm{~km}$. Sites are assigned to one of three categories--- 1) soft rock, 2) hard rock, or 3) deep soil--- and source mechanisms to one of two categories-- (1) strike-slip and normal-slip or (2) reverse-slip and reverseoblique-slip. The Campbell and Bozorgnia relationship is based on 645 recordings of 47 shallow earthquakes recorded world-wide between 1957 and 1993 within a distance of 60 $\mathrm{km}$.

2.4 Idriss (1993, written communication, 1994)

The Idriss relationships give horizontal peak acceleration (Idriss, written communication,
1994) and response spectral values (Idriss, 1993) from 0.03 to 5.0 seconds for 5 percent damping at rock sites in terms of magnitude, distance, and source mechanism. Moment magnitude is used in the relationship for peak acceleration (Idriss, 1994, written communication). For response spectra local magnitude $M_{L}$ is used for magnitude (unspecified) less than or equal to 6 , and surface-wave magnitude $M_{S}$ is used for magnitude (unspecified) greater than 6. This prescription gives a result generally similar to moment magnitude. The definition of distance is the closest distance to the rupture surface (D4 in Figure 1). Source mechanisms are assigned to one of three categories--- 1) strike-slip, 2) reverse-slip, or 3) reverse-oblique-slip.

\subsection{Geomatrix (1995; Sadigh et al., 1993)}

The Geomatrix relationships give horizontal and vertical peak acceleration and response spectral values for 5 percent damping at rock sites in terms of moment magnitude, distance, and source mechanism. The horizontal spectral values are provided at periods between 0.05 and 7.5 seconds and the vertical values for periods between 0.04 and 3.0 seconds. The equations are given by Sadigh et al. (1993) with modifications described by Geomatrix (1995). The definition of distance is the closest distance to the rupture surface (D4 in Figure 1). Source mechanisms are assigned to one of three categories--- 1) strike-slip, 2) reverse-slip, or 3) reverse-oblique-slip.

\section{COMPARISON OF RELATIONSHIPS}

On Figure 8 relationships are compared for peak horizontal acceleration for strike-slip earthquakes at soil sites for magnitudes 6.5 and 7.5. Figure 8 shows two features that appear in all of the following comparisons. At all distances the spread among different relationships is much smaller for magnitude 6.5 than for magnitude 7.5 , reflecting the fact that many more data are available for magnitudes 
near 6.5 than for magnitudes near 7.5. The second feature to note is the very different magnitude scaling at short distance compared to long distance for the Campbell and Bozorgnia (1994) relationship, the modestly different scaling for the Abrahamson and Silva (written communication, 1995) relationship, and the same scaling for the Boore et al. (1994) relationship. The different relationships for 0.3 second horizontal response at soil sites are compared on Figure 9 and for 1.0 second response on Figure 10 . The different relationships for 1.0 second response at rock sites are compared on Figure 11. The maximum spread between different relationships shown on Figures 7 through 10 is significantly smaller than shown by Joyner and Boore (1988), presumably reflecting the influence of the additional strong-motion data recorded since 1988.

\section{REFERENCES}

1. Abrahamson, N. A., and Silva, W. (1995). "A Consistent Set of Ground Motion Attenuation Relations Including Data from the 1994 Northridge Earthquake." (Abstract) Seismological Research Letters, v. 66, p.23.

2. Boore, D. M., Joyner, W. B., and Fumal, T. E. (1993). "Estimation of Response Spectra and Peak Acceleration from Western North American Earthquakes: An Interim Report." U.S. Geological Survey Open-File Report 93-509, 72 p.

3. Boore, D. M., Joyner, W. B., and Fumal, T. E. (1994). "Estimation of Response Spectra and Peak Acceleration from Western North American Earthquakes: An Interim Report, Part 2." U.S. Geological Survey Open-File Report 94-127, 40 p.

4. Boore, D.M. and Joyner, W.B. (1994). "Prediction of Ground Motion in North America." Proc. ATC-35 Seminar on New Developments in Earthquake Ground Motion
Estimation and Implications for Engineering Design Practice, Applied Technology Council, Redwood City, California, ATC 35-1, p. 6-1 -6-41.

5. Boore, D. M., and Joyner, W. B. (1996). "Site Amplification for Generic Rock Sites." In preparation.

6. Borcherdt, R.D. (1994). "Estimates of SiteDependent Response Spectra for Design (Methodology and Justification)." Earthquake Spectra, v. 10, p. 617--653.

7. Campbell, K. W., and Bozorgnia, Y. (1994). "Near-Source Attenuation of Peak Horizontal Acceleration from Worldwide Accelerograms Recorded from 1957 to 1993." Fifth U.S. National Conference on Earthquake Engineering, Chicago, Illinois, July 10--14, 1994.

8. Geomatrix (1995). "Adjustments to Rock Response Spectra for Caltrans Toll Bridges in Northern California." A Report to the Business, Transportation, and Housing Agency (Caltrans), Division of Structures, Sacramento, California.

9. Hamada, M., Isoyama, R., and Wakamatsu, K. (1995). "The 1995 Hyogoken-Nambu (Kobe) Earthquake - Liquefaction, Ground Displacement and Soil Conditions in Hanshin Area." Association for Development of Earthquake Prediction, Wasada University School of Science and Engineering, Japan Engineering Consultants.

10. Idriss, I. M. (1993). "Procedures for Selecting Earthquake Ground Motions at Rock Sites." A Report to the National Institute of Standards and Technology, Department of Civil and Environmental Engineering, University of California, Davis, revised 1993.

11. Joyner, W. B., and Boore, D. M. (1981). "Peak Horizontal Acceleration and Velocity from Strong-Motion Records Including Records 
from the 1979 Imperial Valley, California, Earthquake." Bulletin Seismological Society of America, v. 71, p. $2011--2038$.

12. Joyner, W. B., and Boore, D. M. (1982). "Prediction of Earthquake Response Spectra." U.S. Geological Survey Open-File Report 82-977, 16 p.

13. Joyner, W. B., and Boore, D. M. (1988). "Measurement, Characterization and Prediction of Strong Ground Motion." Proceedings of Conference Earthquake Engineering and Soil Dynamics II, Geotechnical Engineering Division, American Society of Civil Engineers, Park City, Utah, June 27--30, 1988, p. 43--102.

14. Midorikawa, S., Matsuoka, M., amd Sakugawa, K. (1994). "Site Effects on StrongMotion Records Observed During the 1987 Chiba-Ken-Toho-Oki, Japan Earthquake." Proc. 9th Japan Earthq. Eng. Symp., v. 3, p. E085-E090.

15. Sadigh, K., Chang, C.-Y., Abrahamson, N. A., Chiou, S. J., and Power, M. S. (1993). "Specification of Long-Period Ground Motions: Updated Attenuation Relationships for Rock Site Conditions and Adjustment Factors for Near-Fault Effects." Proceedings of ATC-17-1 Seminar on Seismic Isolation, Passive Energy Dissipation, and Active Control, San Francisco, California, March 11--12, 1993, Applied Technology Council, v. 1: Seismic Isolation Systems, p. 59--70. 

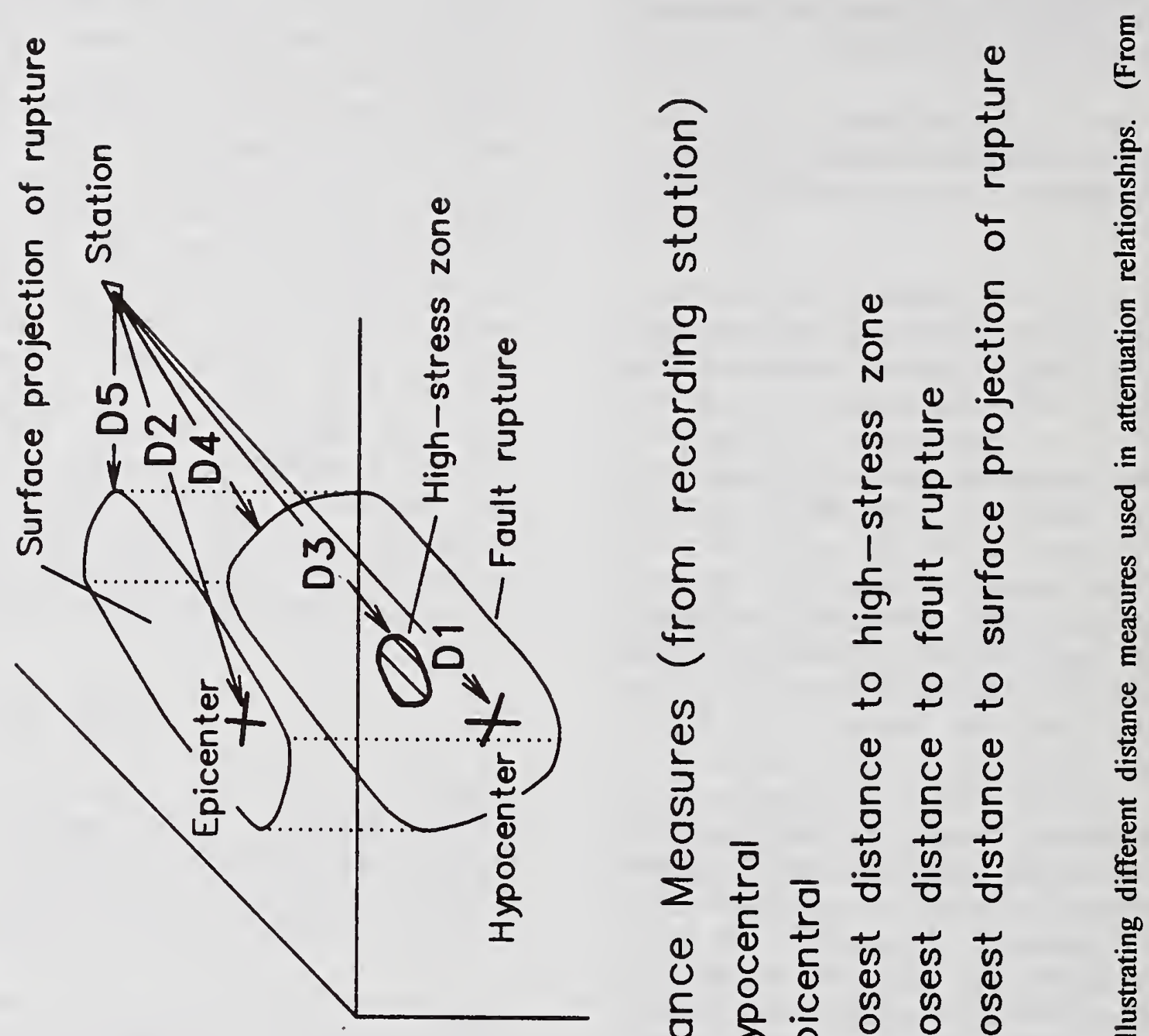

U

ᄃ

ज I

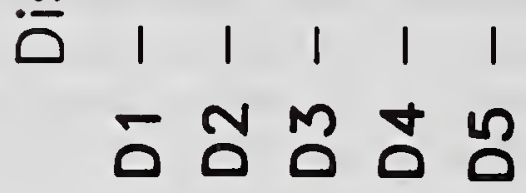

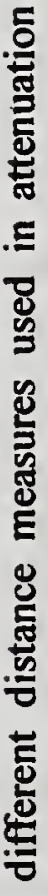

总

हิ

ํํㅇ

- 들

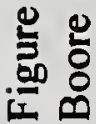



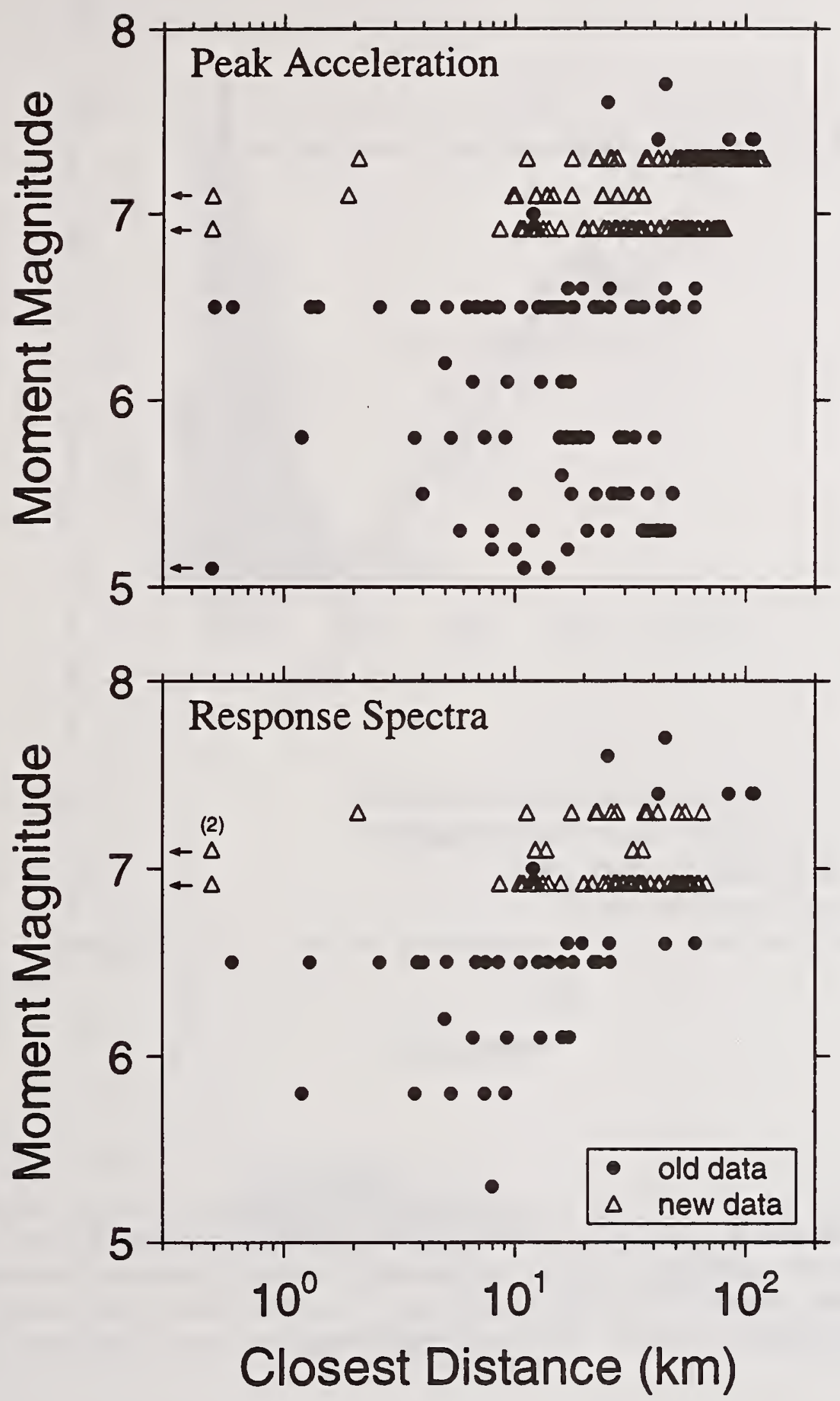

Figure 2. The distribution of the Western North American data in magnitude and distance space (each point represents a recording). The data points labeled "old data" were used in previous studies (Joyner and Boore, 1981, 1982); the "new data" were added in the recent work of Boore et al. (1993). The points in the top and bottom frames were used in developing equations for peak acceleration and response spectra, respectively. (From Boore et al., 1993.) 


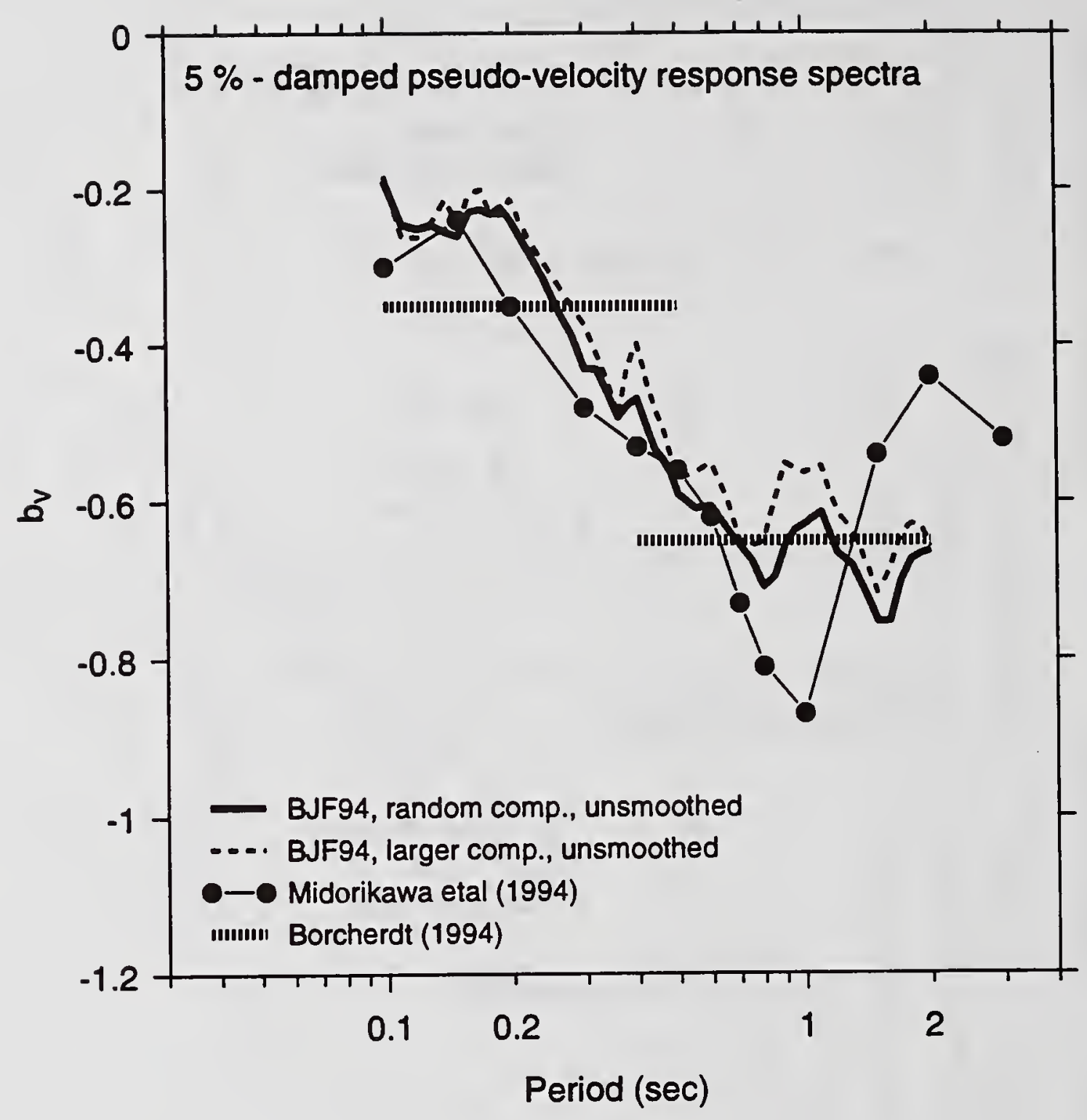

Figure 3. The coefficient that controls the shear-velocity dependence of response spectral amplification, as determined for California data (BJF94 = Boore et al, 1994) and Japanese data (Midorikawa et al, 1994). Also shown are the coefficients proposed by Borcherdt (1994) for determining short-period and mid-period amplification factors in building codes (these were determined from Fourier spectral amplitude spectra of recordings from the 1989 Loma Prieta earthquake). (From Boore et al, 1994.) 

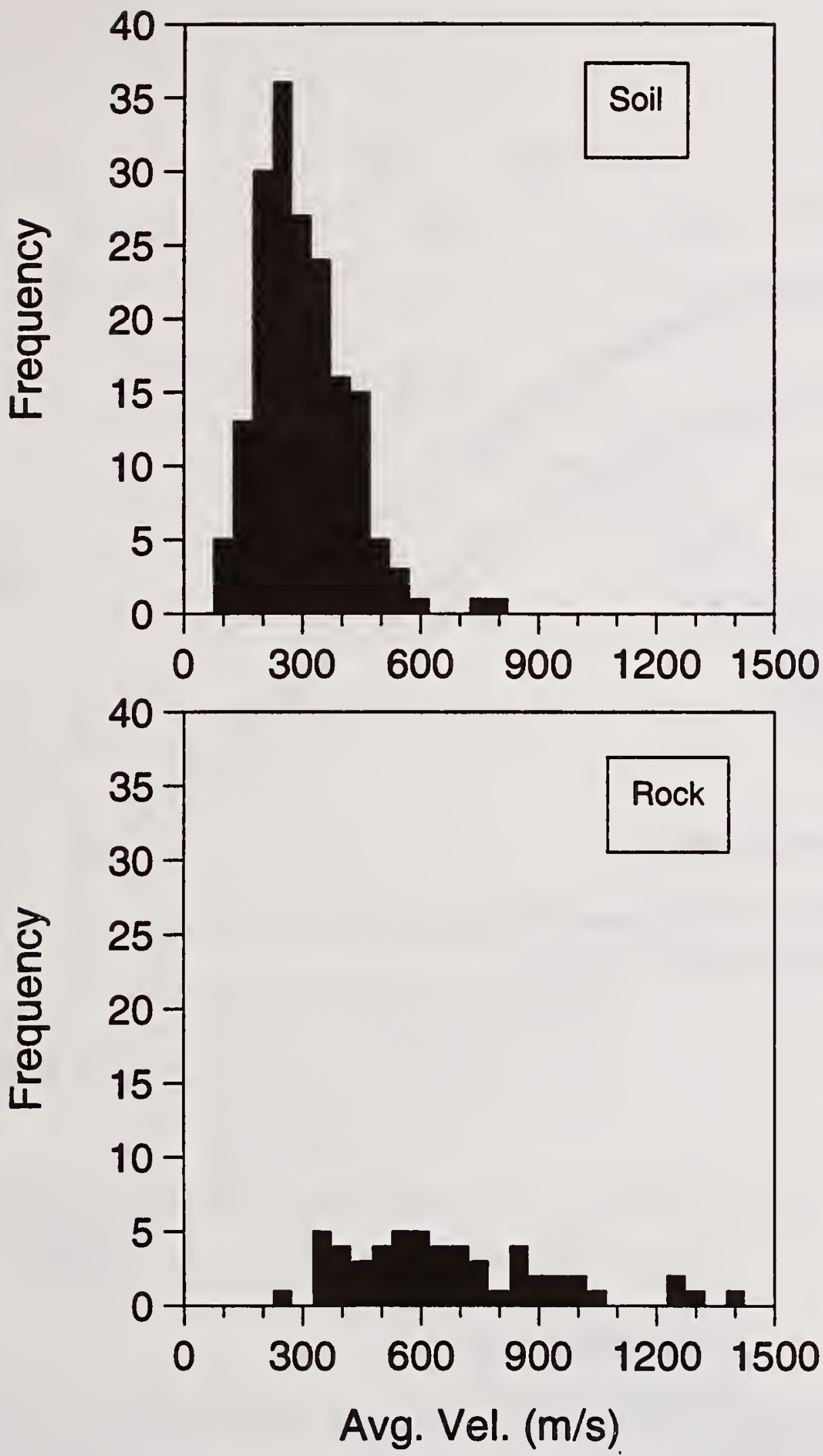

Figure 4. Histograms of shear velocity averaged over the upper $30 \mathrm{~m}$, from downhole surveys in boreholes. Many of the boreholes did not quite reach $30 \mathrm{~m}$, and for the sake of estimating representative velocity distributions, small extrapolations of the travel time to $30 \mathrm{~m}$ were used in computing the average velocities. (From Boore and Joyner, 1996.) 


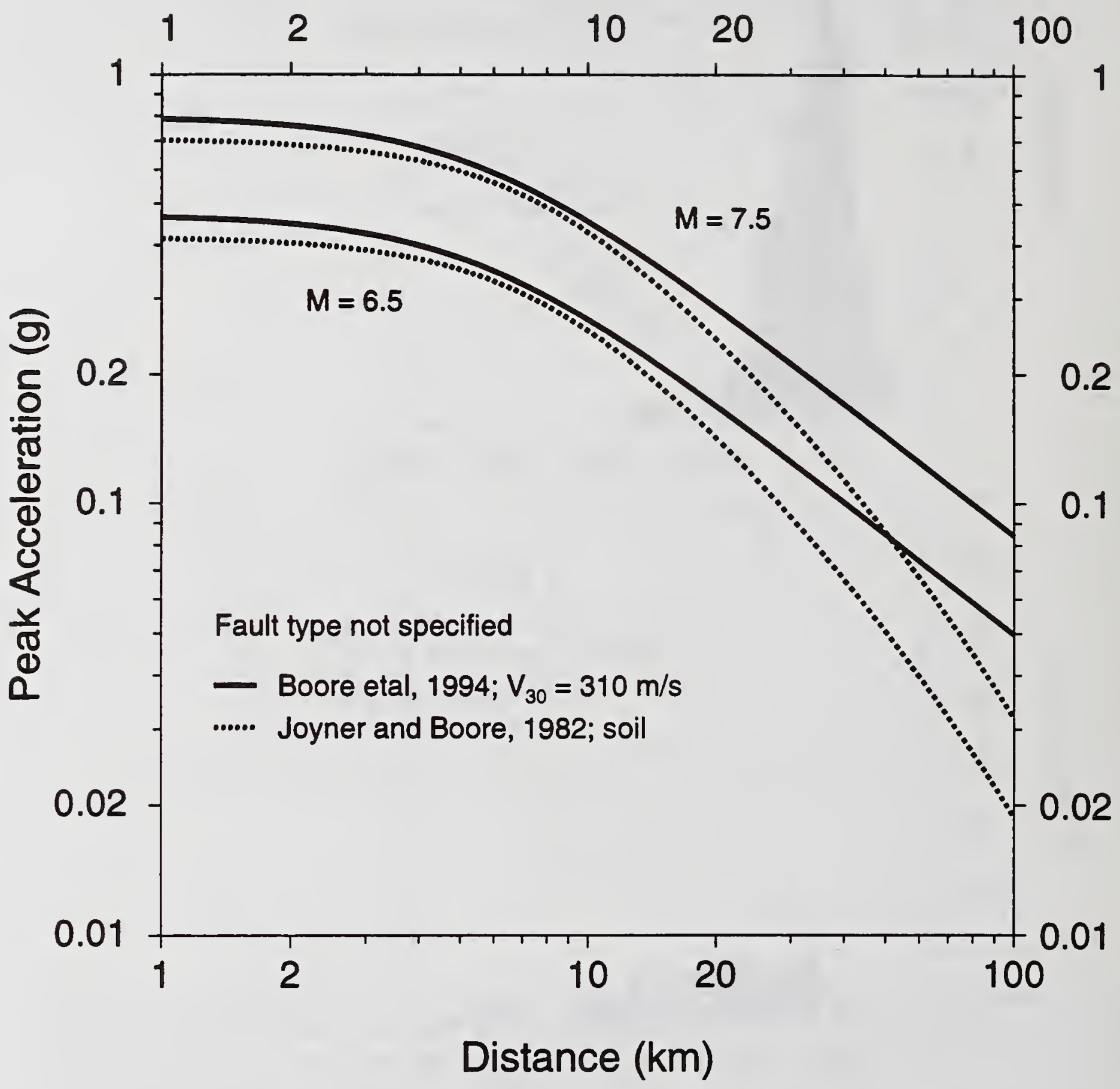

Figure 5. Peak horizontal acceleration at soil sites for moment magnitude 6.5 and 7.5 as given by Boore et. al (1994) and Joyner and Boore (1982). 


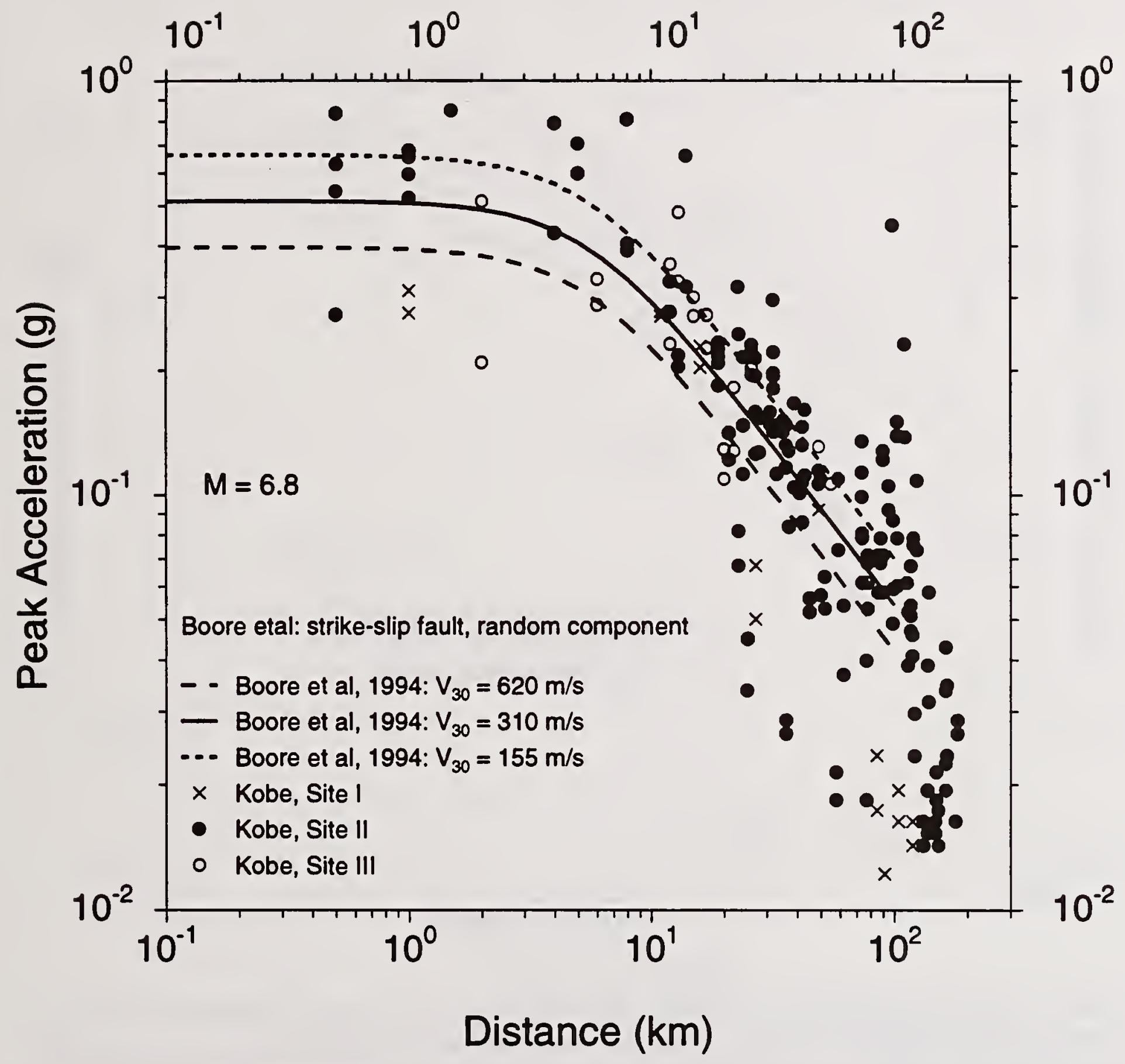

Figure 6. Peak horizontal acceleration for moment magnitude 6.8 at sites where the average shear-wave velocity to $30 \mathrm{~m}$ is $620 \mathrm{~m} / \mathrm{sec}$ (rock), $310 \mathrm{~m} / \mathrm{sec}$ (firm soil), and $155 \mathrm{~m} / \mathrm{sec}$ (soft soil) as given by Boore et al. (1994) compared with data recorded in the Hyogoken-Nambu (Kobe) earthquake for site class I (rock), II (diluvium and stiff alluvium), and III (soft alluvium and reclaimed ground) (Hamada et al., 1995). 


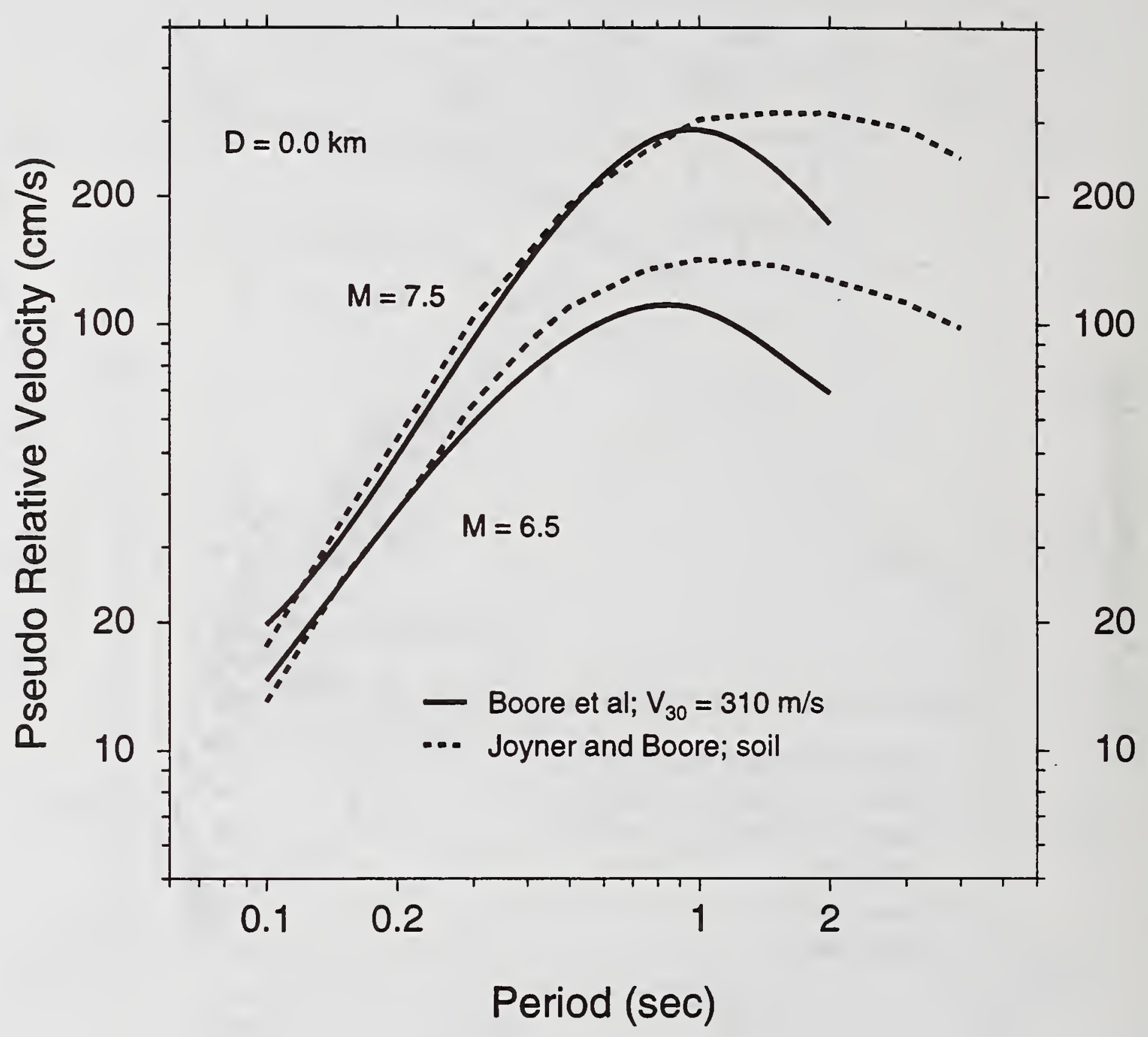

Figure 7. Horizontal pseudo-relative-velocity response spectra at soil sites for magnitude 6.5 and 7.5 at zero distance, as given by Boore et al. (1994) and Joyner and Boore (1982). 


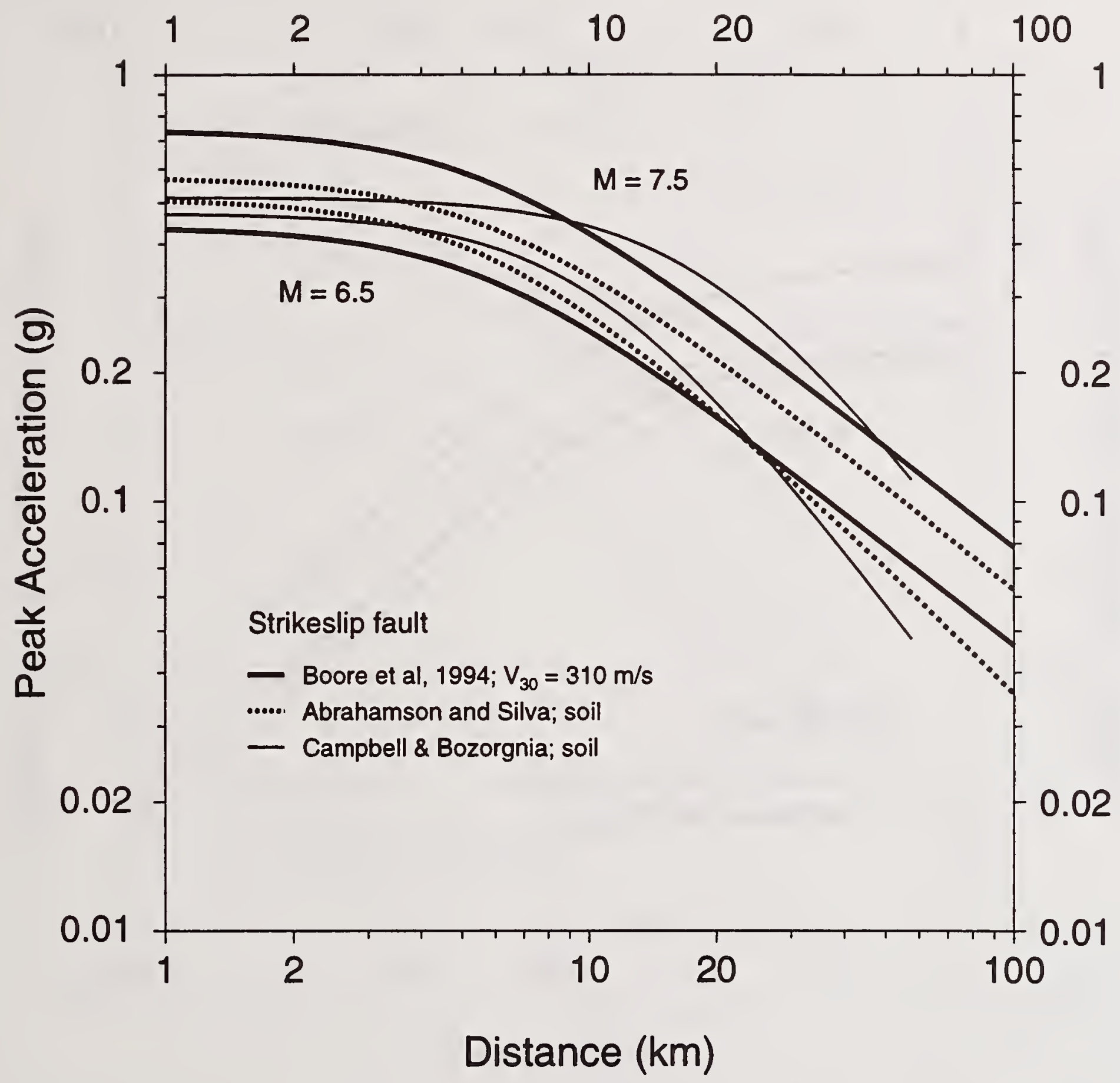

Figure 8. Peak horizontal acceleration at soil sites for moment magnitude 6.5 and 7.5 as given by Boore et. al (1994), Abrahamson and Silva (written communication, 1995), and Campbell and Bozorgnia (1994). 


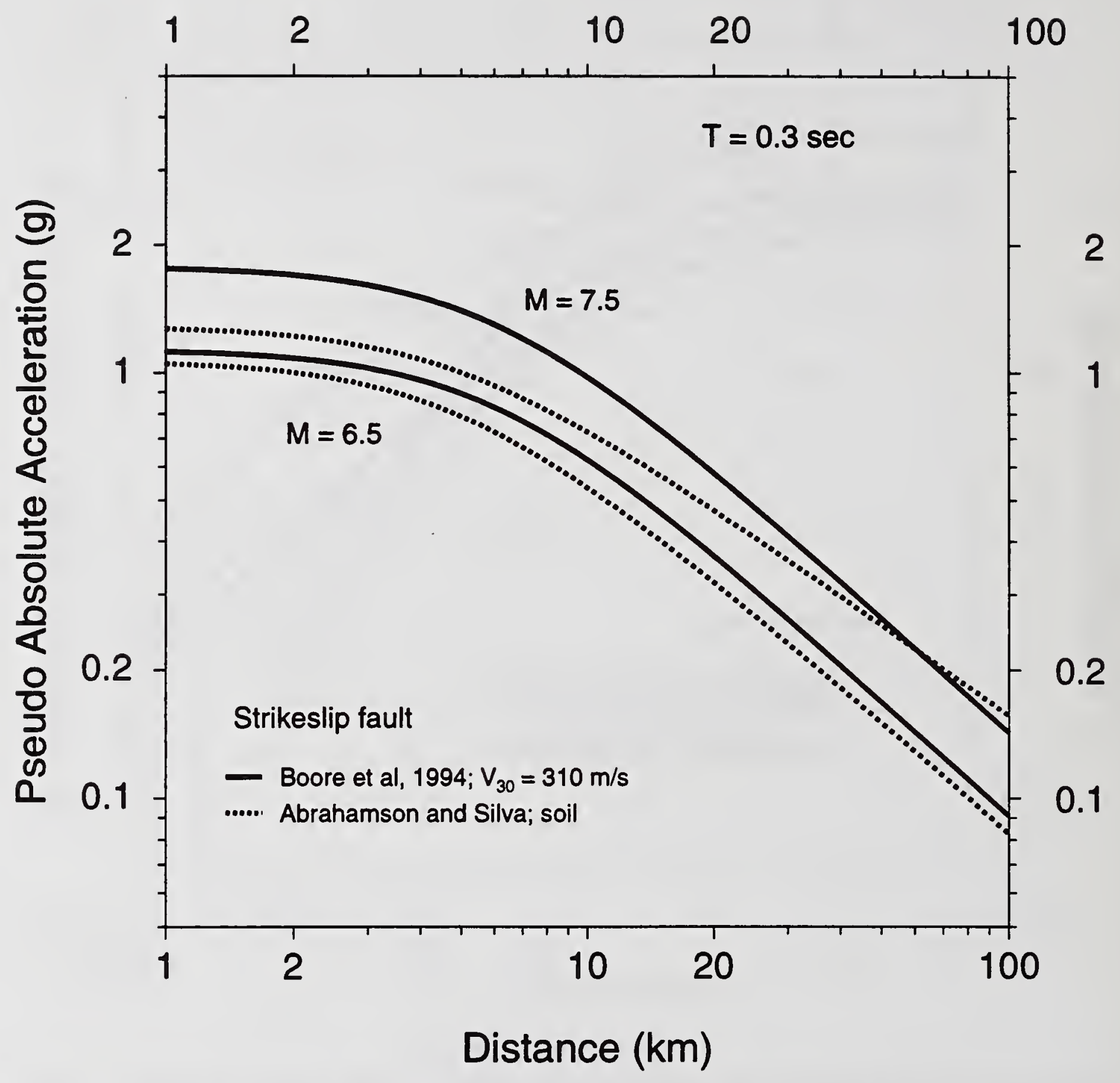

Figure 9. Horizontal pseudo-absolute-acceleration response at $0.3 \mathrm{sec}$ at soil sites for moment magnitude 6.5 and 7.5 as given by Boore et. al (1994) and Abrahamson and Silva (written communication, 1995) 


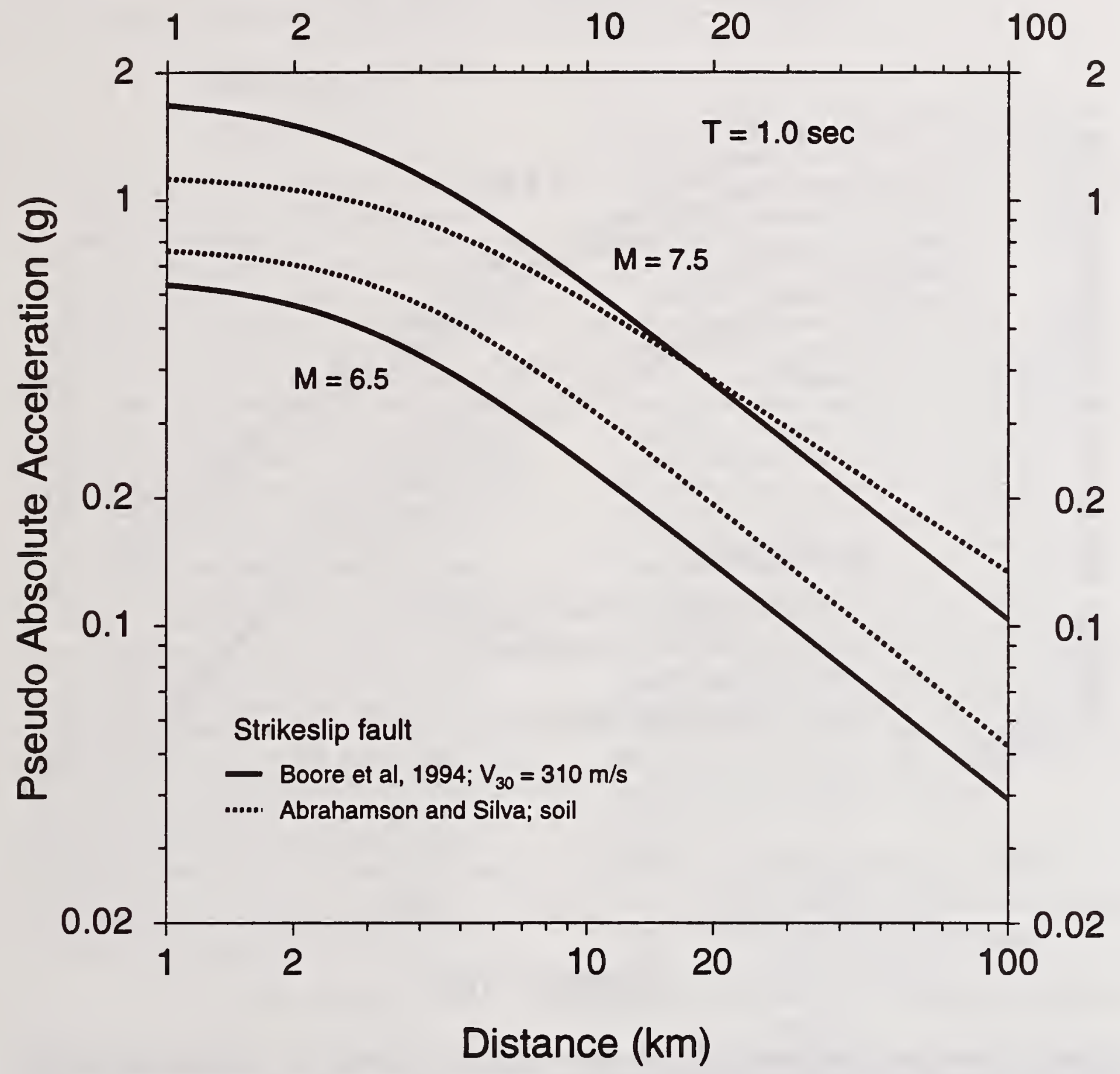

Figure 10. Horizontal pseudo-absolute-acceleration response at $1.0 \mathrm{sec}$ at soil sites for moment magnitude 6.5 and 7.5 as given by Boore et. al (1994) and Abrahamson and Silva (written communication, 1995) 


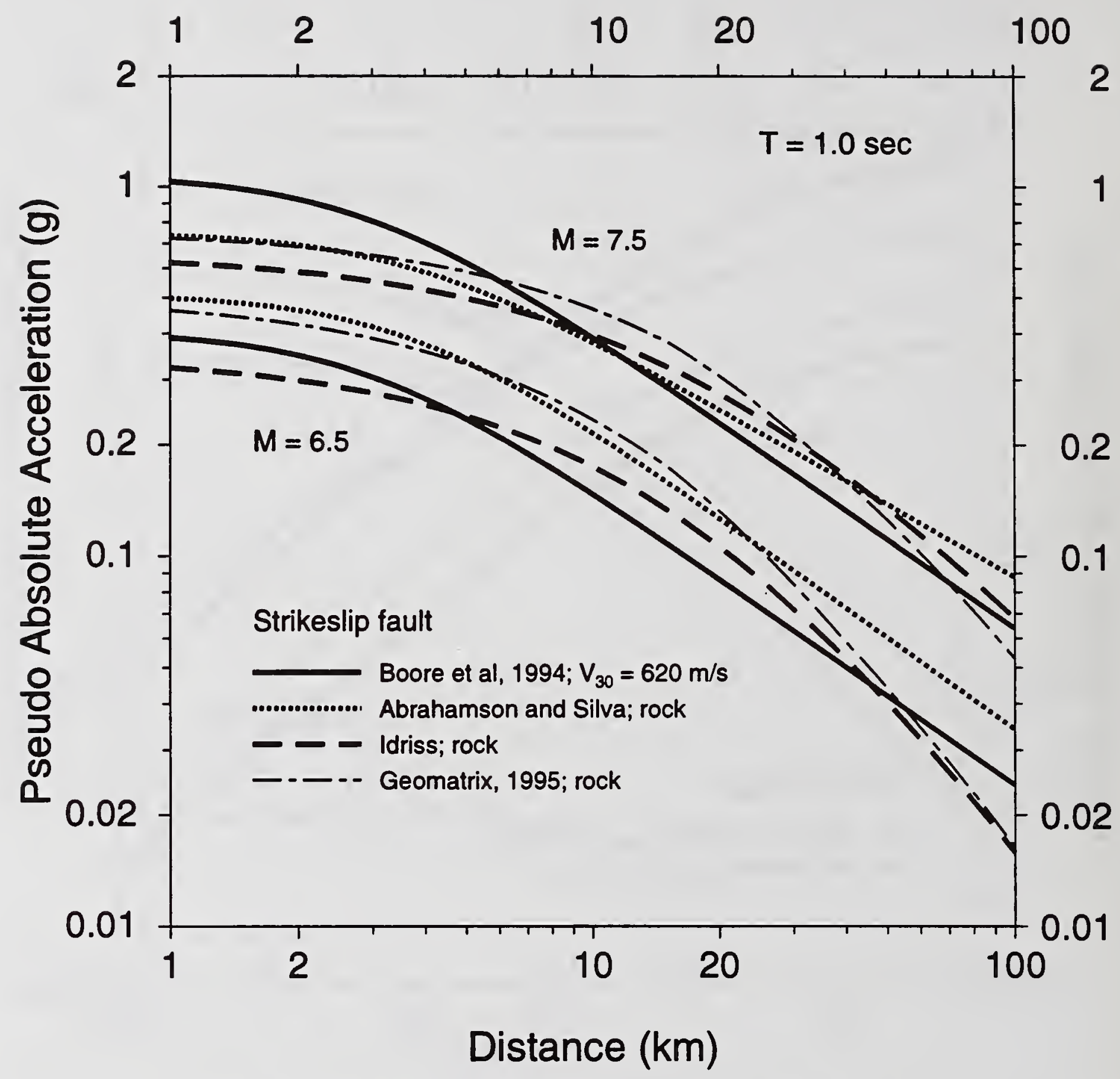

Figure 11. Horizontal pseudo-absolute-acceleration response at $1.0 \mathrm{sec}$ at rock sites for moment magnitude 6.5 and 7.5 as given by Boore et. al (1994), Abrahamson and Silva (written communication, 1995), Idriss (written communication, 1994), and Geomatrix (1995, Sadigh et al., 1993). 


\title{
TOPOGRAPHICAL EFFECT IN THE EVALUATION OF DESIGN GROUND MOTION
}

\author{
by
}

\author{
I. OKAWA ${ }^{1)}$, T. KASHIMA ${ }^{1)}$, S. KOYAMA ${ }^{1)}$
}

\begin{abstract}
The surface geological condition is, more or less, taken into account in most seismic structural design provisions or requirements. In view of the shortcoming of the effect of topography in the current seismic design practice, however, a research project was set up for establishing a methodology of local site effect including the topographical effect. We investigated the representative patterns of subsurface topography in urban area of Japan. The topography was roughly classified into four categories, slope, hill, sediment-filled valley, dipping base layer. For slope, the angle and the height of the slope vary with its location. The general tendency and dimensions of each topography were provided for districts. The literature survey was also conducted to obtain the actual behaviors of ground during past earthquakes clearly justifying the topographical effect on earthquake-induced ground motions and the subsequent structural damage. The analytical study was conducted to find the effectiveness of each of the topography parameters such as angle and heights. A Ricker's wavelet input is used to make problems as simple as possible. In this paper, research on the amplification characteristics of surface ground including topographical effect on seismic motion is shown with some considerations found in the interim compilation of analytical results for the final evaluation technique.
\end{abstract}

KEYWORDS: Ricker's Wavelet, Slope Angle, Sediment-filled Valley, Damage

\section{INTRODUCTION}

It is long been pointed out that geological condition has influence on earthquake ground motion. The methodology to evaluate it, however, is still under development. It is partly because the topography or surface geology has not been studied well from the view point of dynamic characteristics of ground, and partly because the property has not been verified through measurement, that is, earthquake recording, and also because the analytical investigation needed large computer power. In addition, there are site specific situation in the seismic environment of each site, such as the seismicity and the wave propagation.
The past earthquake damage might be mostly due to the amplification of irregular soil conditions or surface topography. With these in mind, we started the study for incorporating the effect of topography into the evaluation of design ground motion. As this study is now in its final stage, the evaluation methodology is now being constructed as the final fruit.

In this study, we summarized the feature of topography for each area in Japan, and determine the representative topographies of urban area in Japan, that is, Tokyo, Osaka, Nagoya, Yokohama, etc., and consequently, constructed analytical models for the topographies, and performed model computation with several parameters, that is, input condition, the dimension of topography, slope angle of base inclination. We made a preliminary methodology for the evaluation by incorporating the findings from measurement into the analytical results. We are now constructing the final version of the evaluation technique, although it is not included in this paper.

A guideline for design earthquake motion for the buildings requiring dynamic analysis was proposed by the Building Research Institute and the Building Center of Japan. (BRI et al., 1992.) The design response spectrum specified for horizontal motion $H S(T)$ is to be computed using the following expression. $H S(T)=\zeta \cdot H B(T) \cdot H L(T) \cdot H G\left(T_{i}\right)$ where

$\zeta \quad$ : Seismic activity coefficient

$H B(T)$ : Basic response spectrum for horizontal motion

$H L(T)$ : Coefficient of longer period component for horizontal motion

$H G\left(T_{i}\right)$ : Coefficient of soil amplification for horizontal motion

The computed spectrum is further modified with the coefficients of both liquefaction and topographical effect, when the possibility of liquefaction in sandy soil is high, and/or when the effect of surface land form can not be ignored. The expression is thus.

$$
H S^{\prime}(T)=H S(T) \cdot H P(T) \cdot H I(T)
$$

where,

$H(T) \quad$ : Coefficient of topographical effect for horizontal motion

HP(T) : Coefficient of liquefaction for

1) Building Research Institute, Ministry of Construction Tatehara-1, Tsukuba, Ibaraki 305, Japan 
horizontal motion

\section{SURFACE GEOLOGY AND TOPO- GRAPHY IN URBAN AREAS OF JAPAN}

The geometrical irregularity in geology is classified into two types. One is the irregularity of surface landform, and the other is the irregularity of interfaces of soil layers. The former includes the slope (cliff), hill, and valley, etc. The latter includes the sediment-filled valley, the dipping base layer and horizontal discontinuity of layers due to fault, etc.

The representative soil conditions of (1) Slope, (2) Hill, (3) Sediment-filled Valley, and (4) Dipping Base Layer were selected as shown in Fig.1 and examined the distribution of the following parameters for each of the urban areas in Japan. From the survey, average values of simplified topography parameters are summarized for some district of Japan.

A location has its specific geological structure. Consequently, the seismic motion thus transmitted through such strata has site specific properties in ground motions. We examined the current status of the deep structure of areas in Japan, such as Kanto plain, Osaka plain, Noubi plain, Sendai plain, Niigata plain, etc. The deep subsurface structure has not been well investigated in Japan.

\section{Damage and topography}

For the following earthquakes, damage had been presumably caused by the influence of topography. During the Tokachi-oki, 1968 earthquake $(M=7.8)$, major damage occurred to the building located along the hill edge, especially in the direction orthogonal to the slope. (Yamahara, 1971) During the Miyagi-ken-oki, 1978 earthquake $(M=7.4)$, major damage occurred to the wooden houses built on the alluvial lowland and to the housing site on reclaimed hilly zone. During the Friuli, Northern Italy, 1976 earthquake ( $M=5.5)$, major damage occurred at the hilly district on the alluvial fan, at cliff edge, and on the steep hill. (AIJ, 1979)

During the Chile earthquake ( $M s=7.8)$, a ridge effect is observed at the hilly zone close to the epicenter. (Celebi, 1987) From the Michoacan, 1985 earthquake (Ms=8.1), major damage occurred in the transition zone between rock site and deep sediment-filled zone. During the Whittier Narrows, 1987 earthquake $\left(M_{L}=5.9\right)$, a locally large MMI was observed. There is an analysis that explains the damage due to the irregular soil condition. (Kawase, 1990)

The results of earthquake recording, microtremor measurement, seismic intensity distribution, and damage features are summarized as follows. Cliff is herein defined as the steeper form of slope.

Slope: The dominant frequency and the amplification vary with the height of the hill and the dominant frequency varies with the incident angle of the input motion. The dominant frequency of microtremor and amplitude have good correlation with seismic intensities estimated from questionnaires.

Cliff: It was pointed out by the earthquake recording that amplification becomes larger to the direction orthogonal to the cliff than the horizontally parallel direction to the cliff and the difference becomes less for potion away from the edge. It is also shown that major damage is observed for the direction orthogonal to the cliff. Mountain (Hill): It was pointed out from earthquake recording that larger amplification is found at the top of the mountain and the dominant frequency differs between top and skirt of the mountain.

Sediment-filled Valley: It was pointed out from earthquake recording that the amplification and the dominant frequency vary with the thickness of alluvial deposit, and a surface wave is observed generated from the edge of the valley. This tendency is observed for seismic intensity distribution and the good correlation between thickness of the alluvium and the seismic intensity.

Dipping Base Layer: It was pointed out from earthquake observation that amplification and dominant frequency changes with the depth of overlying layer at the dipping portion, a surface wave is observed generated from the edge of the base layer, and furthermore, dominant frequency at the surface wary with the incident angle at the base layer.

For deep subsurface structure, the following has been pointed out.

(1) Surface wave will be generated reflecting the deep subsurface structure of the Kanto plain (basin) due to the shallow earthquake occurring around Kanto plain except for the rather deeper ones. This surface wave holds specific dominant period corresponding to the deep structure of the transmitting path.

(2) Many researchers support that the propagation of the surface wave is not straight forward from the epicenter to the station, but the propagation or reflection occurs at the edge of the Kanto basin.

(3) The state of the art on the deep subsurface structure in Kanto plain is not sufficient for the evaluation of design motions for long period building.

\section{DESCRIPTION OF THE ANALYTICAL MODEL REPRESENTING THE TOPOGRAPHY}

The computer analyses were conducted for two sets of representative topographies, that is, slope and sedimentfilled valley. The analytical model for slope came from the existing landform at Kushiro District Meteorological Observatory. Kushiro landform was selected for the analyses. There had been dense earthquake recording arrays and microtremor arrays. There has been comparative earthquake recording after Kushiro earthquake. The geological data around the site is known by the survey on the site. 
The two dimensional models of topographies were used for the analyses. The analytical method used here was finite element method for SV wave, finite difference method and boundary element method for SH wave. The nonlinearity in soil property was not considered in this study. The input motion for the analysis is so called Ricker's wavelet. The result was compared with the result by the one-dimensional propagation model (denoted as ID hereafter). The comparison was also made for identifying the geographical position showing larger topographical effect on seismic motion. Further, the degree of simplification in forming the analytical model, the kinds of seismic waves (P-SV, SH waves), influence of impedance ratio and slope angle were also examined by the parametric computations.

\section{Computational results for slope}

The model for computer analyses for slope are shown in Fig.2. The model-1 is the realistic model derived from the soil data. The model- 2 is the simplified model of model- 1 to check the modeling scheme. The model-3 and model-4 are used to check the influence of slope angle and impedance ratio of layers. The dominant frequency of the input motion defined as exposed bedrock motion is $4 \mathrm{~Hz}$ as shown in Fig.3. For slope model, the incident SH or SV wave is applied to the two dimensional soil models. Comparisons were made between two amplification ratios. One is the ratio between surface response and input motion for two dimensional case (2D hereafter). The other is those for one dimensional model for each location.

Since the influence of slope was found only at the limited portions closer to the lower part of the slope, the comparative study was mainly made for the uphill, the upper part of the hill. The analytical methods used herein are 2-dimensional FEM and BEM. We had acknowledged rough coincidence between the computational results for two methods. Figure 4 shows the spatial distribution of transfer functions of model-1 for SH and SV wave incidence cases together with ID case. The difference in transfer function is larger for portions closer to the slope edge and becomes smaller for distances away from the edge. When using the simplified model-2, a similar tendency with model- 1 is observed in Fig.5. Two transfer functions for model-1 and model-2 is compared in Fig. 6 for SV. This difference is caused by the model simplification. The result shows that the modeling scheme has an influence on the transfer function. When the transfer function is normalizedwith the one with the 1D basis, (denoted as normalized transfer function hereafter), the difference between two normalized transfer functions becomes smaller as shown in Fig.7. The ground response at the upper part of the hill consists of two types of waves, that is, the body wave propagating from the lower layer, and the wave propagating horizontally from the slope. The latter can be recognized as separate wave from portions much away from the edge. This wave is called a later phase (wave). The propagation velocity for the later phase is the phase velocity of the Love wave for the SH wave incidence, and the phase velocity of the Rayleigh wave for the SV wave incidence. Namely, the later phase generated at the edge of each topography is dominated with surface wave. For portion away from the edge, the generated later phase will be attenuated, and there might be small difference in amplification compared with the amplification from ID basis. It is seen from the analysis using SH and SV, that the peak frequency of the transfer function is 3.5 to $6 \mathrm{~Hz}$. The maximum amplitudes of the computed responses fluctuate along the hilltop. The maximum transfer function occurs at 18 and 100 meters from the edge for $\mathrm{SH}$ case, and at 40 meters for SV case. The maximum amplitude in time history occurs at about 10 meters from the edge for $\mathrm{SH}$ wave incidence, and at 20 meters from the edge for SV wave incidence. The maximum amplitude approximately 1.5 times larger than the one for $1 \mathrm{D}$ case. The influence of the different propagating velocity of the later phase is more apparent in SH wave incidence than in SV wave incidence for larger amplitude variation.

The influences of slope angle upon the normalized transfer function and the maximum amplitude in time domain are shown in Fig.8 and Fig.9, respectively. The influence of slope angle ranging 25 to 60 degrees becomes larger in transfer function for the closer to the edge and for higher frequency. However, there is a small influence of slope angle in both of transfer function and time domain response.

The maximum amplitudes of ground responses in reference with the results of $1 D$ results are shown in Fig. 10 for 4 cases of impedance ratios. It is seen from the figure that the influence of impedance ratio is relatively small.

\section{Computational results for sediment-filled valley}

The analytical model for sediment-filled valley is shown in Fig.11 The variations of the models are summarized in Table 2 The model is symmetrical. The shapes of the models were determined with reference of actual landforms and considering the frequency content, number of elements, dimension of element, computation efficiency. These models are basically constructed as two dimensional half space with trapezoidal alluvial deposit. The impedance ratio between two soil deposits is assigned as $\mathbf{3}$ for standard case.

The Ricker's wavelet is also used as input motion for this case, however, the dominant frequency is $2.17 \mathrm{~Hz}$ and the peak amplitude occurs at 1.5 second from the beginning in the time domain as shown in Fig.12. The analytical methods used are finite difference method and boundary element method for SH wave incidence cases and finite element method is used for SV incidence case. The division of elements was made so 
that we may discuss the dynamic properties less than 10 $\mathrm{Hz}$.

The analyses were made for three types of models with different horizontal widths of the valley. It is seen from Fig. 13 that the secondary surface wave generated at the edge of the valley propagates in horizontal direction, and repeats reflection, gradually attenuates. The overlapping of waves changes the pattern of distribution of peak values. As valley becomes narrow, the peak amplitude tends to take its largest at the middle point of the valley. The transfer functions for 1D and 2D cases are compared at several points of the surface. The fluctuation of the transfer function with frequency is large when the damping is smaller. When the damping is larger, however, the transfer functions for both cases become smoother and are comparable each other at points away from the dipping base. For areas close to the edge of the valley, the difference becomes eminent. For cases with narrower valley, the influence of the valley edge extends to the closer point to the valley edge.

\section{CONCLUSIONS}

The typical site conditions in urban area considering the irregularity in topography was surveyed.

The topographically irregular soil conditions in urban area in Japan are specified and represented with dimension of landform, angle of slope, distance from the edge, etc. The spatial variation of ground motion properties such as maximum amplitudes, transfer function and predominant periods are computed for each of cases.

\section{ACKNOWLEDGMENT}

This research has been implemented as part of the research project of the Ministry of Construction, Government of Japan. For the project, a research committee (Chairperson: Dr. Tadao Minami, Professor of the University of Tokyo) was organized in the Japan Institute of Construction Engineering (JICE). Under the auspices of the committee, a working group (Head: Dr. Kazuoh Seo, Professor of Tokyo Institute of

Technology) was organized. The literature survey, model formation and computations were conducted by the members of working group.

\section{REFERENCES}

AIJ (1987). Reconnaissance Report of 1985 Mexico Earthquake, (in Japanese)

BRI and BCJ (1992). A Guideline for Composing Design Earthquake Ground Motion for Dynamic Analysis of Buildings, Appendix of Annual Report of the Committee on Technical Guideline for Design Earthquake Ground Motion

BRI, JICE (1993). Annual Report of the Project for 1992 fiscal year, (in Japanese)

BRI, JCE (1994). Annual Report of the Project for 1993 fiscal year, (in Japanese)

Celebi, M., (1987). Topographical and Geological Amplifications Determined from Strong-Motion and Aftershock Records of the 3 March 1985 Chile earthquake, B.S.S.A., 77, 1147-1167

Kawase, H. (1990). Topography effect at the critical SV-wave incidence: Possible Explanation of Damage Pattern by the Whittier Narrows, California earthquake of 1 October 1987, B.S.S.A., 80, pp.1-22

Yamahara, H., (1971). Soils and School, Planning of School Building, AIJ, (in Japanese)

Table 1. Average values of simplified topography parameters for areas of Japan

\begin{tabular}{ccccccc}
\hline & & Tokyo & Osaka & Nagoya & Yokohama & Kawasaki \\
\hline Slope & $\theta(\mathrm{deg})$ & 10 & $<5$ & - & $40-60$ & $20-40$ \\
& $\mathrm{H}(\mathrm{m})$ & $10-20$ & $10-30$ & - & $5-15$ & $5-20$ \\
\hline Hill & $\mathrm{L}(\mathrm{m})$ & $100-500$ & $<500$ & $100-400$ & - & - \\
& $\mathrm{H}(\mathrm{m})$ & $5-10$ & $<10$ & $5-20$ & - & - \\
& $\mathrm{D}(\mathrm{m})$ & $300-900$ & $200-500$ & $200-1300$ & - & - \\
\hline Sediment- & $\mathrm{L}(\mathrm{m})$ & $100-400$ & - & vary & - & - \\
filled Valley & $\mathrm{H}(\mathrm{m})$ & $3-4$ & - & $5-16$ & - & - \\
\hline Dipping & $\mathrm{L}(\mathrm{m})$ & $100-300$ & $100-400$ & 500 & - & - \\
Base Layer & $\theta(\mathrm{deg})$ & $<1$ & $0.2-0.6$ & $0.4-0.8$ & - & - \\
\hline
\end{tabular}

Table 2 Analytical model of sediment-filled valley

\begin{tabular}{|c|c|c|c|c|c|}
\hline & & Sediment-filled & Valley & Bedroc & \\
\hline & $\begin{array}{l}\text { width } \\
\text { (m) }\end{array}$ & $\begin{array}{c}\text { depth } \\
(\mathrm{m})\end{array}$ & $\begin{array}{c}\begin{array}{c}\text { side inclination } \\
\text { (deg) }\end{array} \\
\end{array}$ & $\begin{array}{l}\text { side boundary } \\
\text { (m) }\end{array}$ & $\begin{array}{c}\text { lower boundary } \\
\text { (m) }\end{array}$ \\
\hline Model-A & 200 & 15 & 45 & 200 & 75 \\
\hline Model-B & 100 & 15 & 45 & 200 & 75 \\
\hline Model-C & 50 & 15 & 45 & 200 & 75 \\
\hline
\end{tabular}




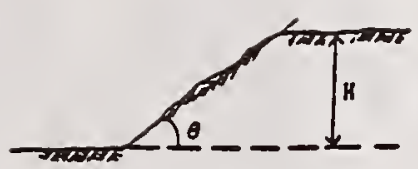

(a) Slope

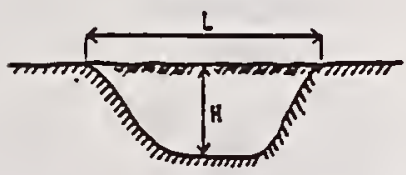

(c) Sediment-filled Valley

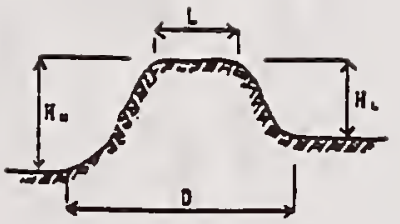

(b) Hill

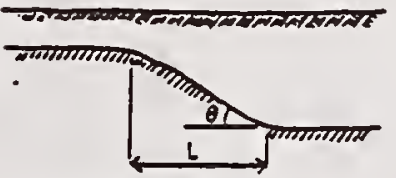

(d) Dipping Base Layer

Fig.1 Representative topography

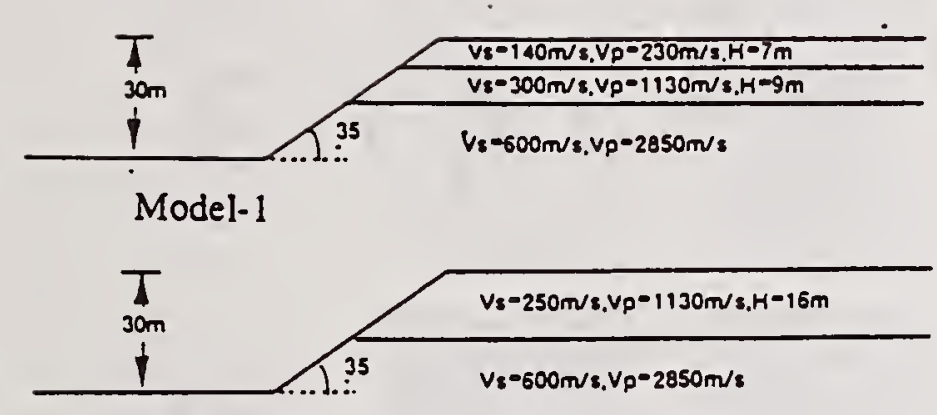

Model-2

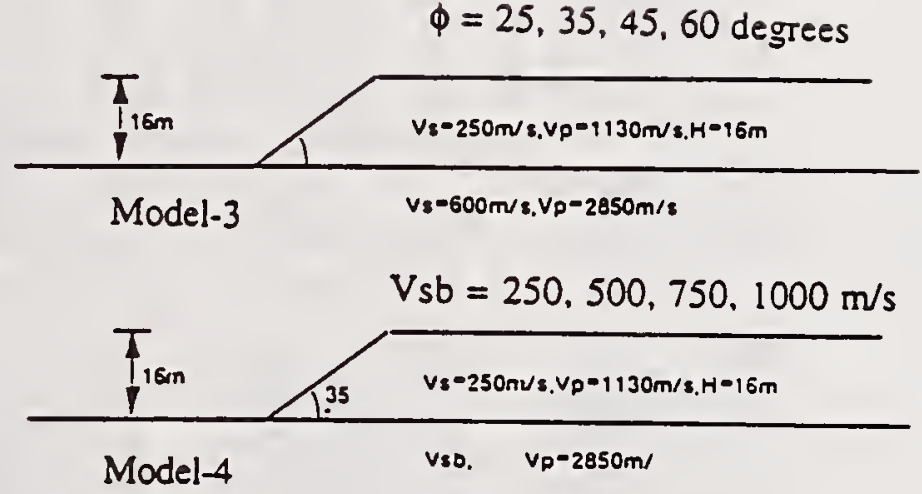

Fig.2 Analytical model for slope
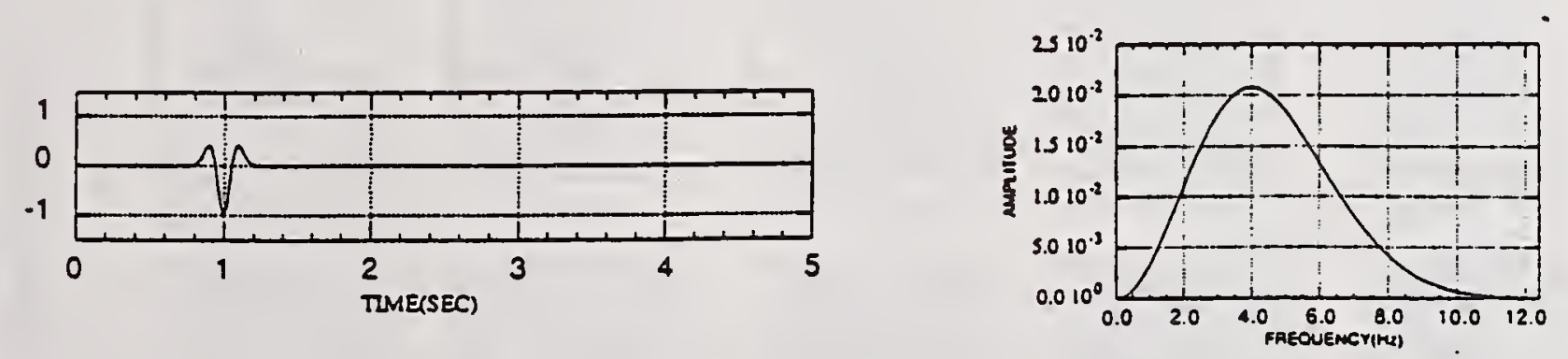

Fig.3 Ricker's wavelet as acceleration input motion at exposed bedrock 

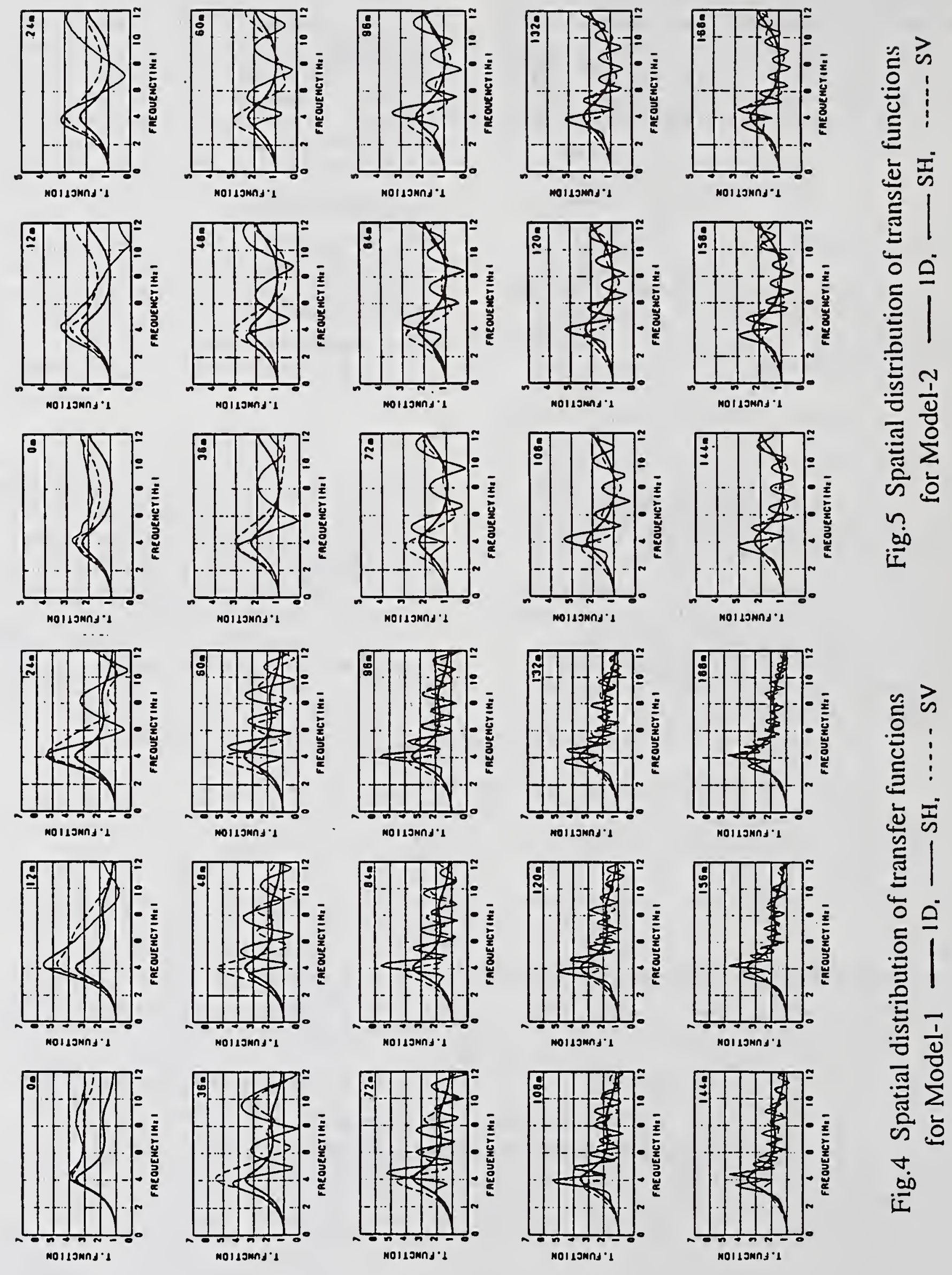

总

|

丞

mollowns.

nol somens 1

Mol I Imกs.

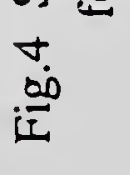



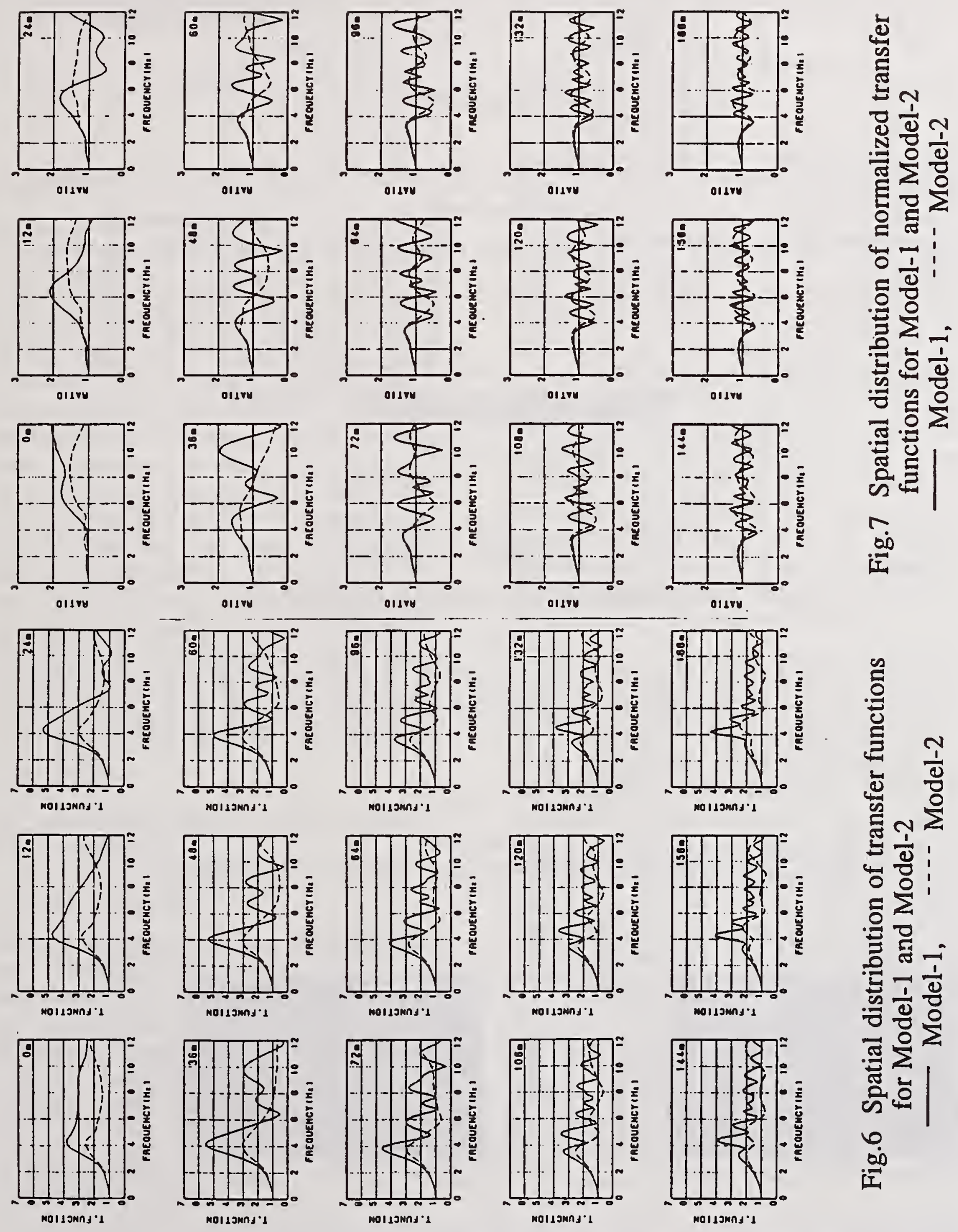

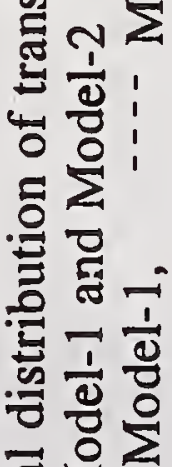

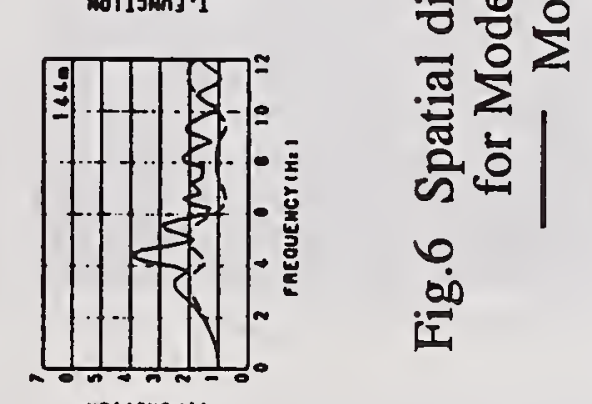



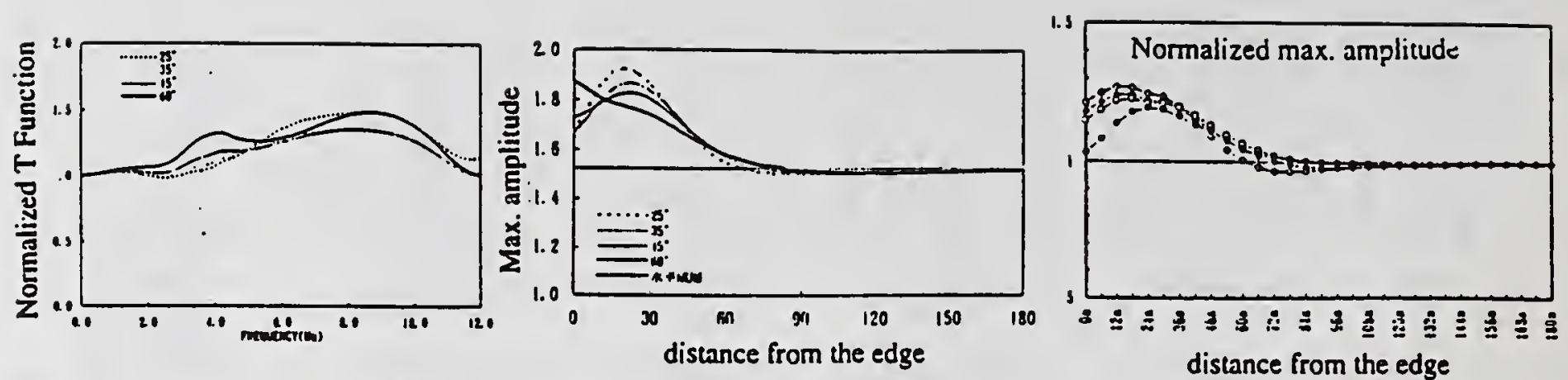

Fig.8 Normalized transfer function Fig.9 Maximum amplitude Fig.10 Normalized maximum amplitude

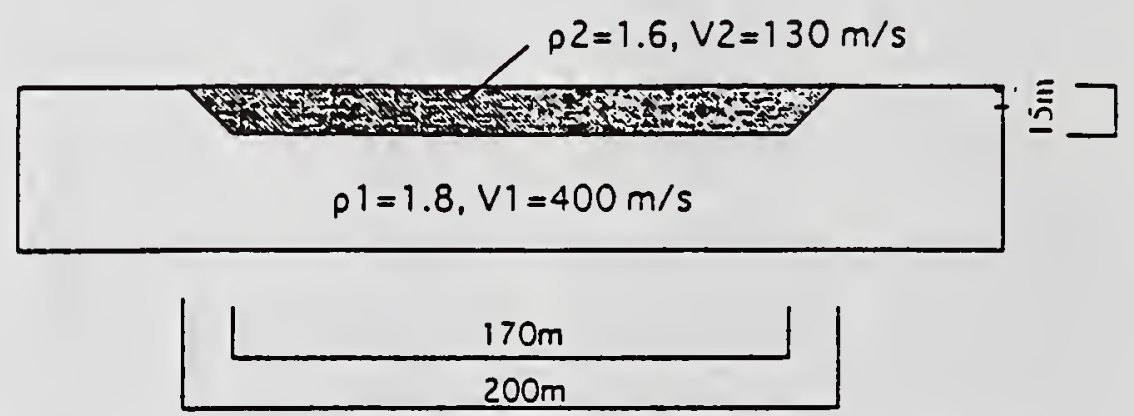

Fig.11 Analytical model of sediment-filled valley for Model-A

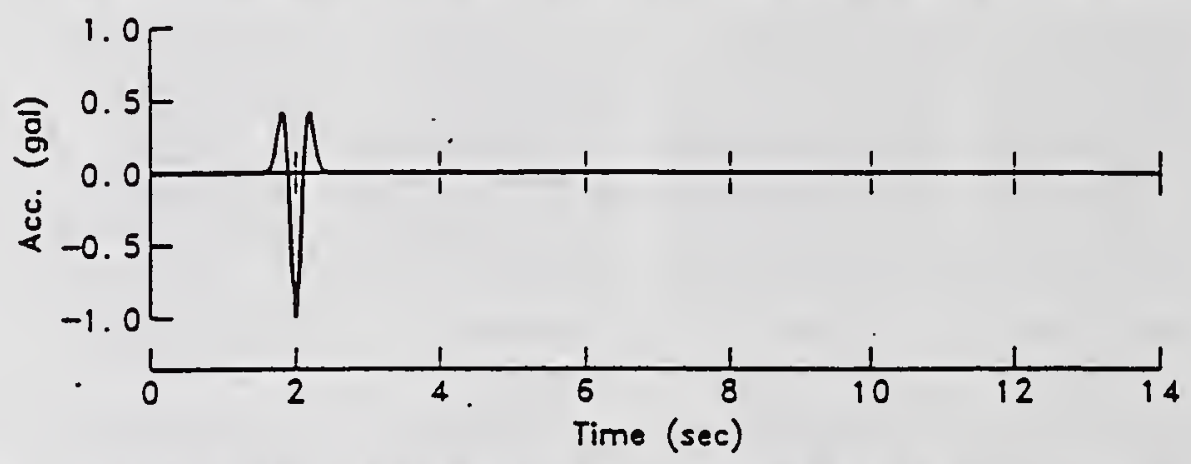

Fig.12 Ricker's wavelet as acceleration input motion at exposed bedrock
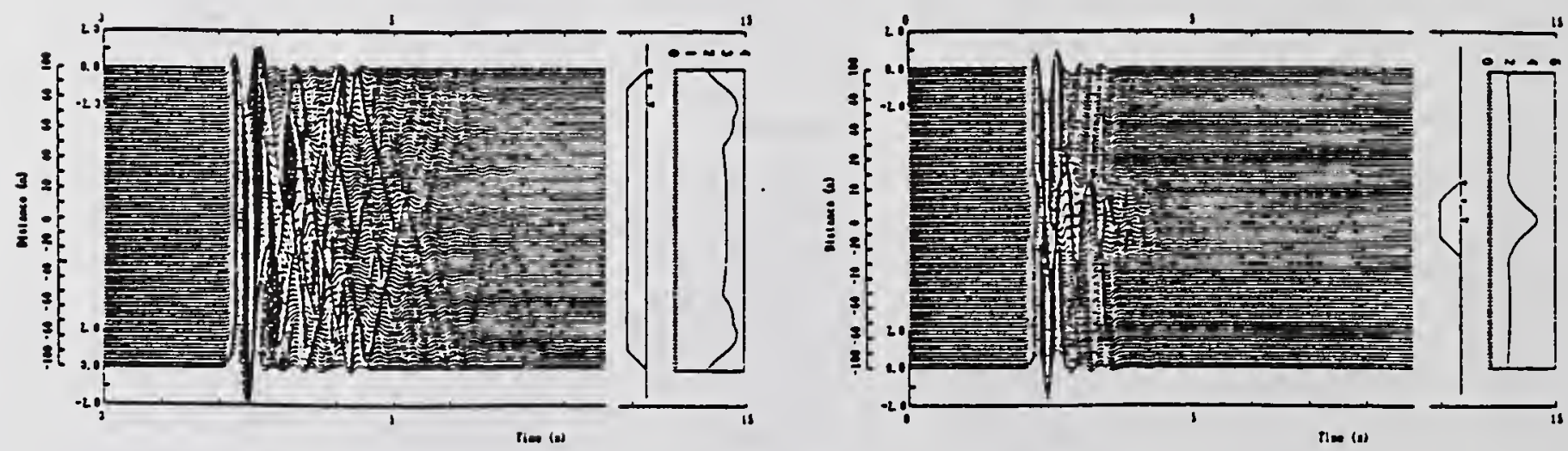

Fig. 13 Response waveform at the surface and the distrioution of maxima for Model-A and Model-C 


\title{
Preliminary Estimates of Ground-Motion Amplification \\ for the Northridge and Hyogo-ken Nanbu Earthquakes of January 17, 1994 and 1995
}

by

\author{
Roger D. Borcherdt
}

\begin{abstract}
Strong ground shaking generated by the Northridge and Hyogo-ken Nanbu (HanshinAwaji) earthquakes of January 17, 1994 and 1995, resulted in combined property losses exceeding 120 billion U.S. dollars, and $\mathbf{5 3 0 0}$ deaths, either directly through shaking-induced structural failure or indirectly through shakinginduced liquefaction and landslide failures. The strong-motion instruments, which recorded these earthquakes provided unprecedented sets of ground motion measurements on both stiffand soft-soil deposits. These measurements provide important new estimates of groundmotion amplification by soil deposits at high input shaking levels to better understand the nature resultant earthquake losses. Preliminary implications for site dependent design spectra are examined. Results presented here are reproduced because of interest for this Joint Meeting from Borcherdt (1996a and 1996b).
\end{abstract}

\section{KEYWORDS}

Site amplification, strong motion, attenuation, site-specific design.

\section{INTRODUCTION}

The extensive losses to property and life from the Northridge and Hyogo-ken Nanbu earthquakes of January 17, 1994 and 1995 were due in large part to strong ground shaking. Consequently, understanding its nature in relation to source rupture characteriștics, crustal propagation effects and effects of local site

\footnotetext{
- United States Geological Survey

Menlo Park, CA 94025
}

conditions is of special interest for new sitespecific building code provisions. Strongmotion stations in the Los Angeles and KobeOsaka basin regions provided unprecedented documentation of the nature of strong shaking near the earthquake source. The Northridge earthquake provided forty-two recordings on sites underlain by materials ranging from stiff soil to hard rock within $25 \mathrm{~km}$ of the epicenter with ground acceleration exceeding $0.9 \mathrm{~g}$ at seven sites. The Hyogo-ken Nanbu earthquake provided more than 26 recordings within $25 \mathrm{~km}$ of the extended rupture surface with many of these sites being located on "soft" Holocene soil deposits. These data provide an especially important opportunity to document the nature of strong shaking on "stiff" and "soft" soil sites at high levels of shaking near the source.

\section{SOURCE RUPTURE CHARACTERISTICS}

The Northridge earthquake occurred in a region of compressional tectonics associated with a major regional bend in the strike of the San Andreas fault. The earthquake of moment magnitude $M_{w} 6.7$ occurred on a thrust fault, dipping 42 degrees to the south with a strike of 122 degrees. Inversion of strong-motion and teleseismic data (Wald and Heaton, 1994), suggest that rupture initiated at a depth of about $18-19 \mathrm{~km}$, extended to within $7-8 \mathrm{~km}$ of the earth's surface along a slip vector oriented $109^{\circ}$. Rupture extended updip about $20 \mathrm{~km}$ over a surface about $14 \times 15 \mathrm{~km}$ and lasted about 7 seconds yielding a seismic moment of $1.2 \times 10^{26}$ dyne-cm with the largest slip of nearly 4.0 meters occurring near the deepest portion of the 
fault $(17-18 \mathrm{~km})$. Strong ground motions were significantly larger north of the epicenter due to the directivity associated with updip propagation of the rupture.

The Hyogo-ken Nanbu earthquake occurred in an area of complex faulting about $200 \mathrm{~km}$ from the Nankai trough, which forms the boundary between the Philippine Sea and Eurasian plates. The earthquake of magnitude 7.2 (JMA) and $M_{w} 6.9$ is the largest and most severe earthquake to affect the region this century. Source rupture characteristics inferred from teleseismic and regional data by Kikuchi (1995) suggest rupture initiated at a depth of about $14.3 \mathrm{~km}$ on the Nojima fault. It was comprised of three subevents of moment magnitudes $6.8,6.3$, and 6.4 each with a predominant strike-slip source mechanism. Rupture occurred along a $46 \mathrm{~km}$ segment of the fault at an average depth of about $8 \mathrm{~km}$ and reached the surface along a $9 \mathrm{~km}$ segment with maximum surface displacements of $1.7 \mathrm{~m}$ right-lateral, horizontal and $1.0 \mathrm{~m}$ vertical (T. Masaharu, pers. commun.,1995). Duration of total rupture lasted about 11 seconds.

Comparison of source characteristics suggests the earthquakes are about the same magnitude (Northridge, $M_{w}$ 6.7; Hyogo-ken Nanbu, $M_{w}$ 6.9), with longer rupture duration for the Hyogo-ken Nanbu earthquake (11 seconds as opposed to 8 or 9 seconds). The rupture mechanism is predominantly strike slip or horizontal for the Hyogo-ken Nanbu earthquake compared to relatively larger vertical components of motion associated with thrust faulting for the Northridge earthquake. The average depth of rupture and hypocentral depth for the Hyogo-ken Nanbu earthquake is less than that for the Northridge earthquake. Rupture for the Hyogo-ken Nanbu earthquake reached the surface on Awaji Island and may have come within $4 \mathrm{~km}$ of the surface beneath Kobe City. Rupture was inferred not to extend closer than 6 to $7 \mathrm{~km}$ of the surface for the Northridge event.

\section{GROUND MOTION ATTENUATION}

Locations and peak amplitude information for the strong motion recordings have been compiled from a variety of original data sources for the Northridge earthquake (Borcherdt, 1995) and the Hyogo-ken Nanbu earthquake (Borcherdt, 1995b). Contour maps of peak vertical and horizontal acceleration were derived from the strong motion recordings of both events and superimposed upon available digital geologic maps. (Wentworth, et al.,1994; 1995; Borcherdt and Wentworth, 1995). The contour maps for the Northridge earthquake show a general north-south elongation consistent with the inferred thrust rupture characteristics of the source. The contour maps for the Hyogo-ken Nanbu earthquake suggest a linear zone of intense ground shaking underlain by Holocene soil deposits parallel to the surface projection of the crustal rupture zone. The maps for both earthquakes emphasize that the peak values decrease rapidly away from the immediate epicentral region with local anomalies due to topographic and local site amplification.

Peak horizontal accelerations as reported for the Hyogo-ken Nanbu and Northridge earthquakes are plotted versus the closest distance to seismogenic rupture. Attenuation curves developed by Boore et al. (1994) are superimposed with projected surface rupture distance converted to seismogenic-rupture distance using average depths of 4 and $6 \mathrm{~km}$, respectively (Fig. 1). Curves of Campbell and Borzognia (1994) also are superimposed. The peak values for the Hyogo-ken Nanbu earthquake tend to be less than those for the Northridge earthquake for sites within 4 to 20 $\mathbf{k m}$ of the seismogenic source, but greater at distances exceeding about $30 \mathrm{~km}$. These differences in amplitude are roughly consistent with differences in source mechanism and types of geologic site conditions. The source mechanism for the Northridge earthquake is predominantly vertical movement on a thrust fault. Such source mechanisms typically generate higher peak accelerations near the source than comparable sized strike-slip mechanisms. The geologic conditions beneath a majority of the recording sites for the Hyogoken Nanbu earthquake are soft-soil (Holocene) deposits with higher amplification capabilities for ground motions near one second period than 
the stiff Pleistocene deposits beneath many of the recording sites for the Northridge earthquake. Consequently, the high frequency motions near the source might be expected to be larger for the Northridge earthquake, but the longer period motions at some distance from the source might be expected to be larger for the Hanshin- earthquake. Attenuation curves derived by Boore, et al, 1994 when extrapolated to soft soils using an average shear-wave velocity of $200 \mathrm{~m} / \mathrm{s}$ fit the data quite well.

\section{INFLUENCE OF LOCAL SITE CONDITIONS}

The relatively large accelerations recorded at several of the sites for both earthquakes raise important questions concerning the influence of local site conditions on high levels of incoming high-level bedrock motions near the source. To examine the influence of local site conditions, the peak motions and amplitude spectra (Northridge) for each component were normalized by the corresponding value determined for a nearby station on firm to hard rock. Each ratio was also normalized by the corresponding reciprocal ratio of distances to the zone of largest energy release. Groups of stations for normalization were determined from

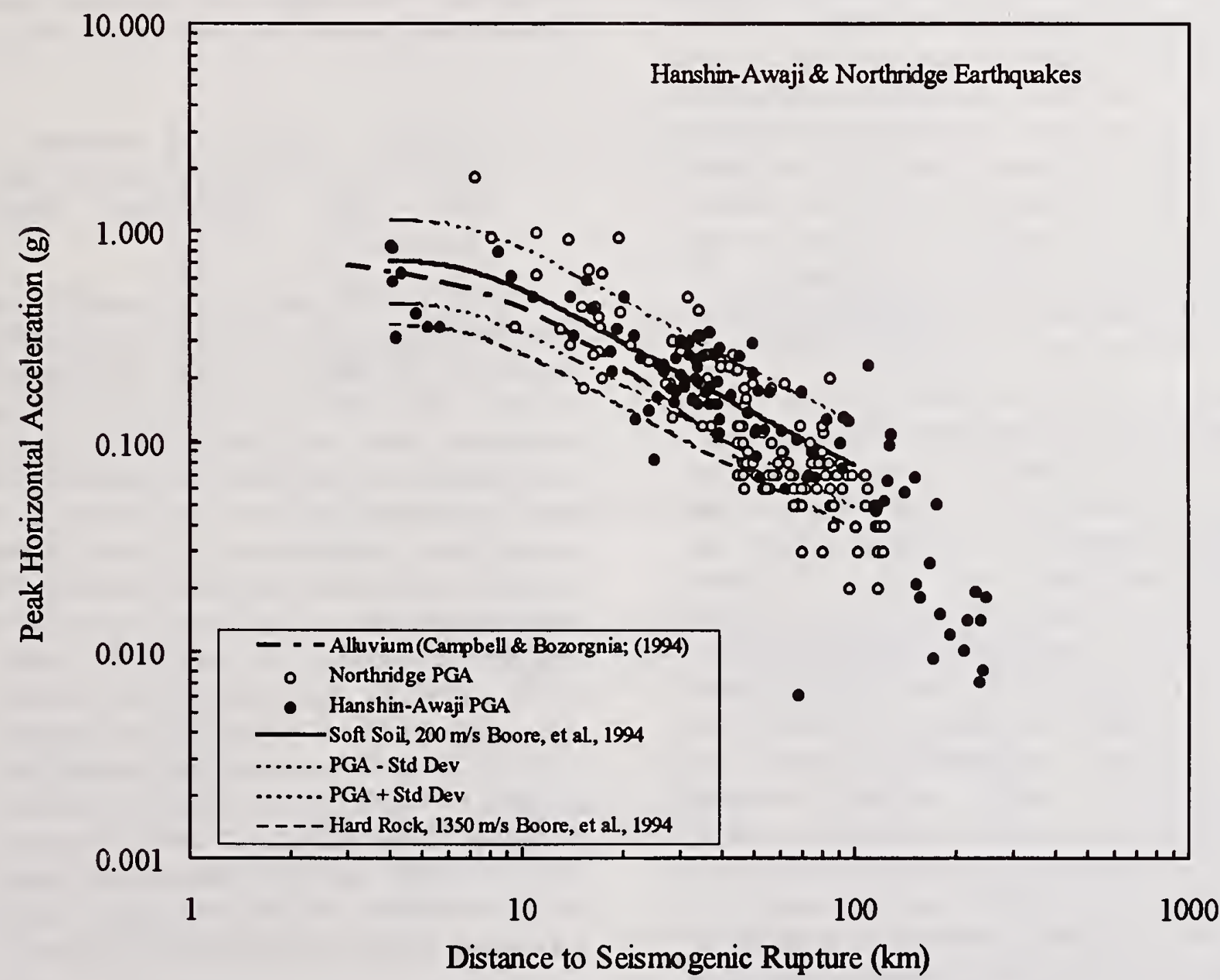

Fig. 1. Preliminary compilation of peak horizontal acceleration as a function of closest distance to seismogenic rupture for the Northridge and Hyogo-ken Nanbu (Hanshin-Awaji) earthquakes. 
22.5 (Northridge) and 45 (Hyogo-ken Nanbu) degree azimuthal windows measured with respect to polar coordinate systems oriented parallel to the strike of the faults and segmented into $25 \mathrm{~km}$ distance intervals with origin at the epicenter. If no normalization station occurred in the window, then the closest normalization station in the azimuthal window was chosen (see Borcherdt, 1994 and 1995 for detailed discussion).

\subsection{Amplification vs. Input Ground Motion Level for "Stiff" Soil Sites (Northridge Earthquake)}

To quantify the dependence of the measured amplifications on input ground motion level for the Northridge earthquake, the acceleration ratios and the average spectral amplifications are plotted as a function of the "input" or base acceleration inferred at each site (Figs. 2a, 2b, and $2 c)$. The "base" acceleration is defined as the value recorded at the surface normalized by the inferred acceleration ratio. Plots are shown for ratios of average peak horizontal (radialtransverse) acceleration (Fig. 2a) and average spectral ratio, $\mathrm{Fa}$,for the short-period (0.1 - 0.5 s;) band (Fig. 2b) and the average spectral ratio, $\mathrm{Fv}$,for mid-period (0.4 - $2.0 \mathrm{~s}$ ) band (Fig. 2c).

Geologic classifications for the sites were determined from recent digital GIS compilations of the surficial geology for the Los Angeles basin (Wentworth, et al., 1995). The sites are classified according to recently defined site classes (Borcherdt, 1994) into a combined "stiff" soil to "soft" rock site class, designated $S C$ II+III or using NEHRP designations C+D and a "firm-hard" rock site class, designated $S C$-I $b$ or NEHRP B. Use of the combined site class reduces uncertainty in the site classification, until ongoing detailed investigations are completed at each site. Shearwave velocities for $S C I I+I I I$ range from 200 to $700 \mathrm{~m} / \mathrm{s}$ with an average velocity inferred to be about $363 \mathrm{~m} / \mathrm{s}$. Shear-wave velocities for the $S C$ $I b$ exceed $700 \mathrm{~m} / \mathrm{s}$ with an average velocity of about $867 \mathrm{~m} / \mathrm{s}$. Rigorous definitions of the site classes are provided by Borcherdt, 1994.
The acceleration ratios show a slight trend to decrease with increasing "base" acceleration level (Fig. 2a) as evident in the small negative exponent of the power-law regression curve. The zero slope of the linear regression curve suggests no dependency on base acceleration level.

The average spectral ratios for the short-period (0.1 - $0.5 \mathrm{~s}$;) band (Fig. 2b) suggest a slight tendency to increase with increasing base acceleration level as evident in the positive exponent and slopes for the regression curves. However, scatter in the data suggests that this trend is probably, not meaningful. The average spectral ratio for the mid-period band (0.4 - 2.0 s) band (Fig. 2c) tends to increase with increasing base acceleration level. These preliminary observations are consistent with more detailed observations for the entire data set (Borcherdt, 1995).

\subsection{Preliminary Amplification Estimates vs. Input Ground Motion Level for "Soft" Soil Sites (Hyogo-ken Nanbu Earthquake)}

As a preliminary attempt to quantify the response characteristics of "soft" soil deposits (Holocene deposits) at high input-ground motion levels for the Hyogo-ken Nanbu earthquake, ratios of average peak horizontal acceleration were computed with respect to the Kobe University (KC-KUN) site for which an average peak acceleration of $270 \mathrm{~cm} / \mathrm{s}^{2} \mathrm{~g}$ was recorded at a distance of about $1.3 \mathrm{~km}$ from the surface projection of the crustal rupture zone. The site is underlain by hard rock (Sugito, 1995). Geologic classifications for the other sites were obtained from the GIS superposition of station locations on the digital Geologic Map of Japan $(1: 1,000,000$ scale, Geological Survey of Japan, 1992, Borcherdt and Wentworth, 1995). The resultant classification is preliminary as it is dependent on both the accuracy of the station coordinates and the published map scale.

The average of the acceleration ratios, normalized by the reciprocal ratio of the seismogenic-rupture distance, are plotted versus "base" or input acceleration levels. The ratios 
are plotted only for sites underlain by Holocene soils that are located along strike at distances less than $22 \mathrm{~km}$ (Fig. 3). The mean and standard deviation for these acceleration ratios are 2.6 and 1.3 , respectively.
The ratios of average peak acceleration show a well defined trend to decrease with increasing "base" acceleration level (Fig. 3). This trend is evident in both the negative slope of the linear
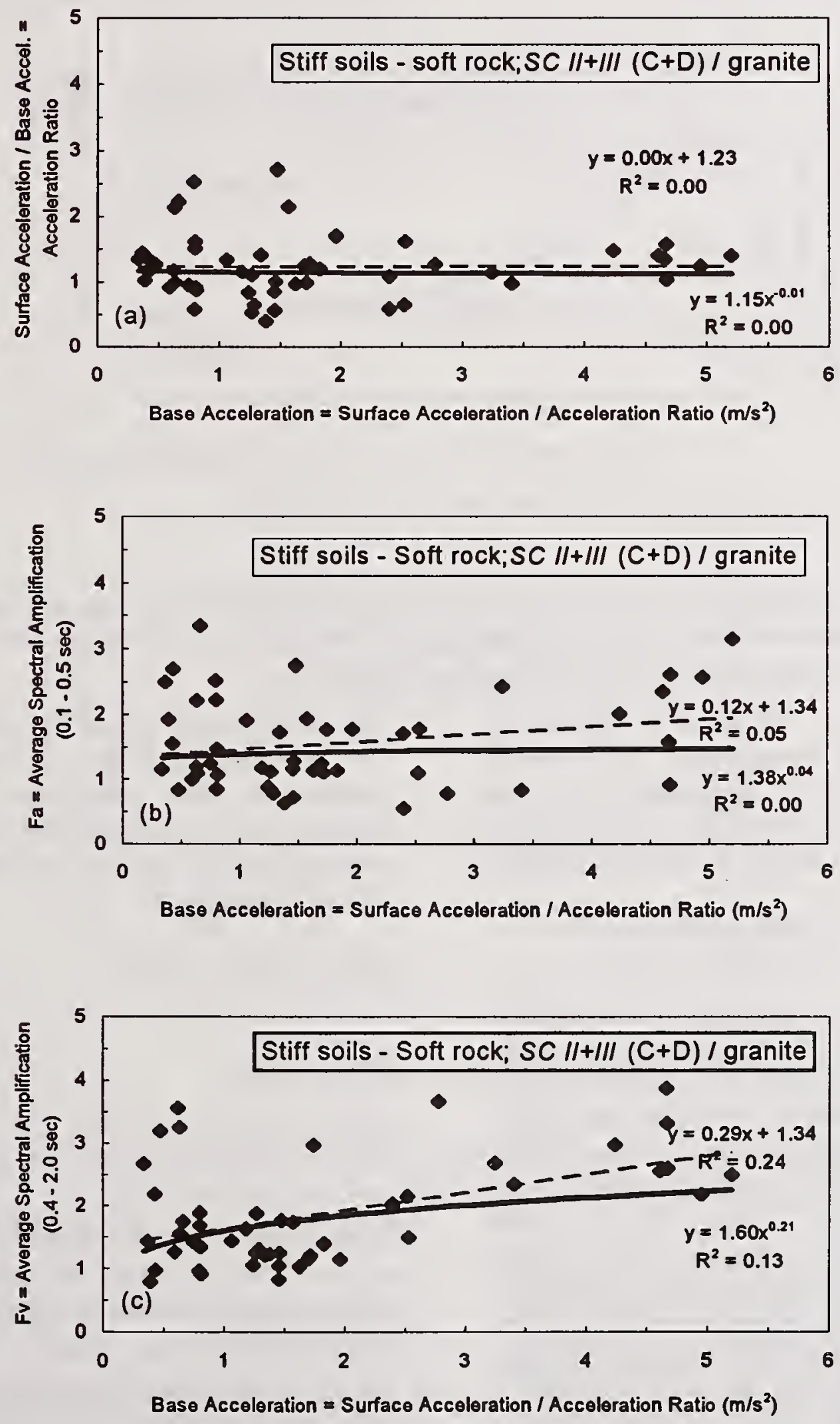
Fig. 2. Acceleration ratio (a), average spectral amplification ratio for the short-period ( $0.1-0.5 \mathrm{~s})$ band (b), and average spectral amplification ratio for the mid-period $(0.4-2.0 \mathrm{~s})$ band (c) versus base acceleration for "stiff soil - soft rock sites" (SC II+III; NEHRP C+D) determined from strong-motion recordings of the Northridge earthquake. Power law and linear regression curves fit to the data are superimposed.

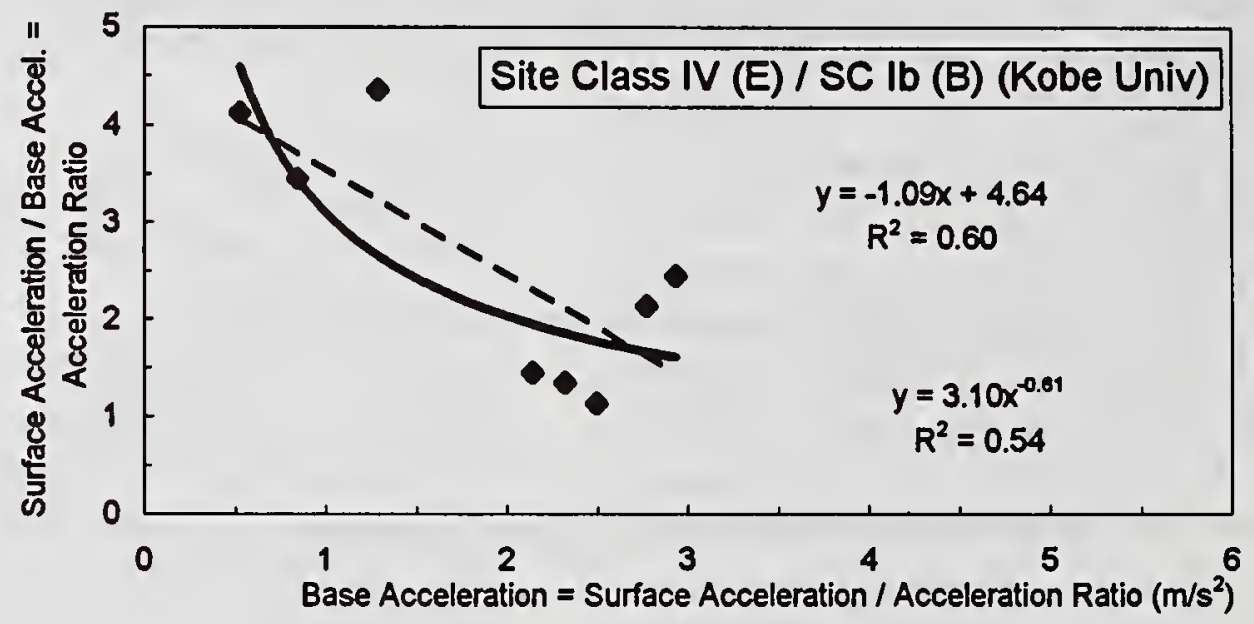

Fig. 3. Preliminary acceleration ratios versus base acceleration for "soft" Holocene soil deposits (SC IV; NEHRP E) determined from peak acceleration reported for the Hyogo-ken Nanbu earthquake. Power law and linear regression curves fit to the data are superimposed.

regression curve and the negative exponent of the power law regression curve. These results must be considered as preliminary. Further evaluation, based on detailed site evaluations are needed to improve quantification of these results

\section{PRELIMINARY IMPLICATIONS FOR SEISMIC DESIGN PROVISIONS}

Improvements in estimates of site-dependent, earthquake-resistant design spectra are under review for incorporation into United States building code provisions (NEHRP and UBC). These new developments better account for the amplification effects of local geological deposits in earthquake resistant design. They are based on new unambiguous definitions of site classes and amplification factors derived from empirical and numerical modeling results. Values for the amplification factors as a function of input ground motion level and site class are specified by Borcherdt (1994).
The amplification factors $\mathrm{Fa}$ and $\mathrm{Fv}$ for shortand mid- period motion are predicted as a function of mean shear-wave velocity $v$ for various input ground-motion levels, $I$, with respect to a reference ground condition by the following equations:

$$
F_{a}(v, I)=\left(v_{o} / v\right)^{m_{a}},
$$

and

$$
F_{v}(v, I)=\left(v_{o} / v\right)^{m_{v}} \text {, }
$$

where, $m_{1}$ and $m_{v}$ are exponents which depend on the level of base input motion. These equations can be used to rigorously compare results derived here.

Results derived from the Northridge earthquake for sites on "stiff soils - soft rock" suggest that the amplification factors $\mathrm{Fa}$ and $\mathrm{Fv}$ do not show a strong tendency to decrease with increasing 
"base" acceleration. This trend as specified in Figs. $2 b$ and $2 c$ by the power law regression curves is replotted in Figs. $4 a$ and $4 b$. Superimposed on these trends are the trends implied by recent NEHRP code provisions. (The code trends are specified by equations 1a and $1 \mathrm{~b}$ with $\mathrm{v}=363 \mathrm{~m} / \mathrm{s}$ for $\mathrm{SC}-\mathrm{II}+\mathrm{III}, \mathrm{v}_{0}=$ $867 \mathrm{~m} / \mathrm{s}, \mathrm{m}_{\mathrm{a}}=0.35$ and -0.05 and $\mathrm{m}_{\mathrm{v}}=0.65$ and 0.45 for input acceleration levels of 0.1 and $0.4 \mathrm{~g}$ ;Borcherdt, 1994.)

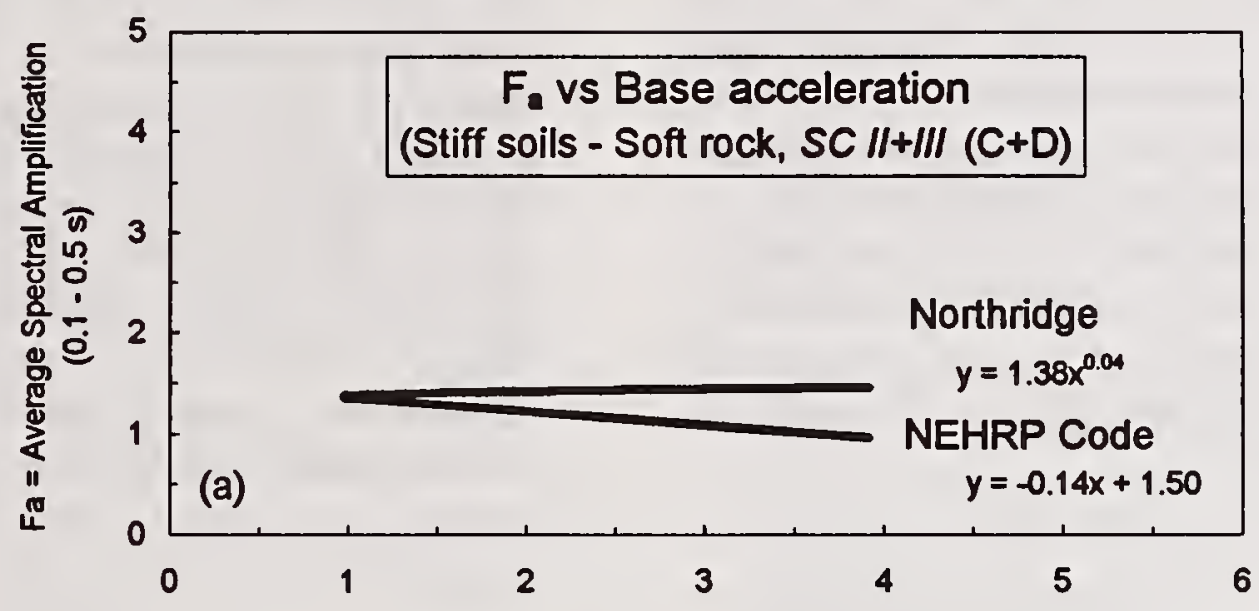

Base Acceleration $=$ Surface Acceleration $/$ Acceleration Ratio $\left(\mathrm{m} / \mathrm{s}^{2}\right)$

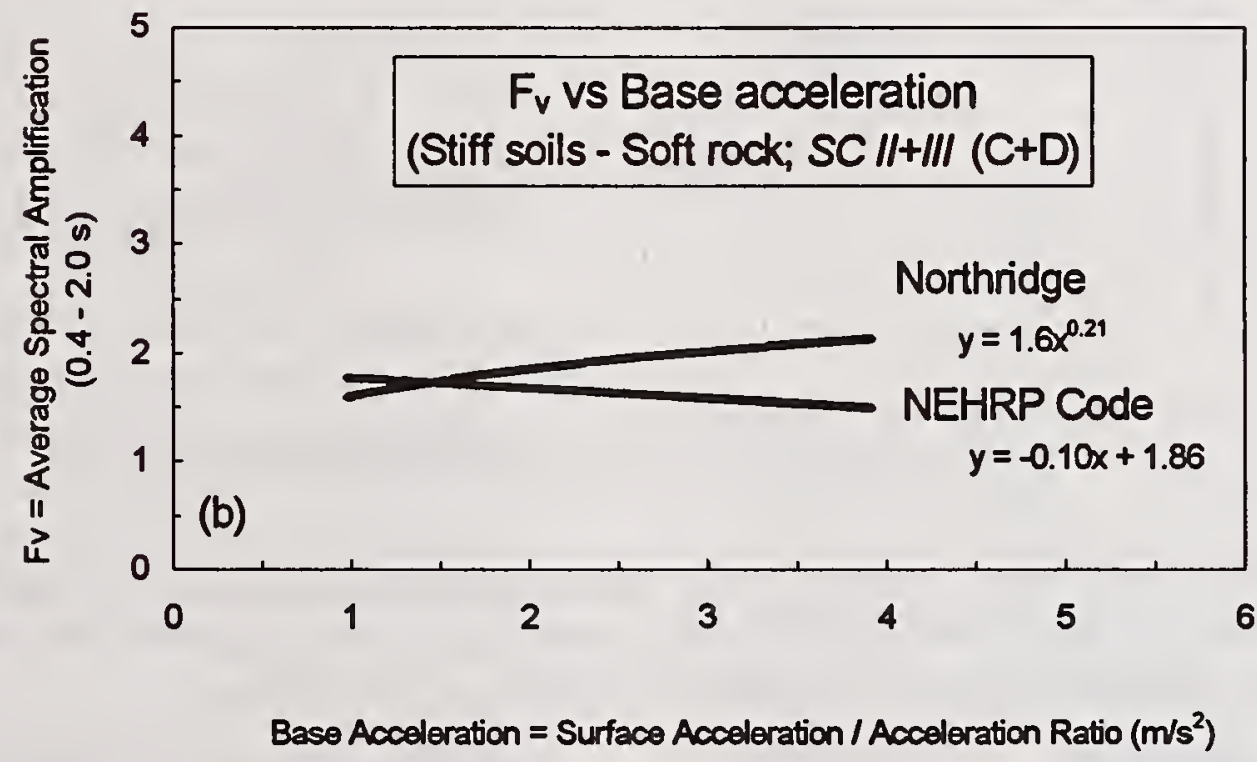

Fig. 4 Site-specific amplification factors versus base acceleration level for sites on stiff soils to soft rock (SC II+III; C+D) implied by the Northridge earthquake and the NEHRP code provisions for the shortperiod band, (a) and the mid-period band, (b).

The amplification factors implied by the Northridge earthquake are in good agreement with those suggested for the code provisions at the $1 \mathrm{~m} / \mathrm{s}^{2}$ base acceleration level. For higher levels of acceleration the factors implied by Northridge become increasingly greater than those proposed for the NEHRP code provisions.
However, for the "stiff soil -soft rock" sites being considered the absolute amounts of amplification are not large in comparison with those for soft soils and hence, may not be of significance for many applications. These preliminary Northridge results suggest that for "stiff soil - soft rock" sites similar to those in the Los Angeles basin that Fa and Fv values of 
$(1.4,1.8)$ as predicted by equation 1 for base ground acceleration levels near $1 \mathrm{~m} / \mathrm{s}^{2}$ base provide simple and conservative estimates for site-specific design.

The preliminary results from the Hyogo-ken Nanbu earthquake for "soft" soil sites suggest that the acceleration ratios and hence the $\mathrm{Fa}$ factors do show a well defined decrease with increasing base acceleration level. This trend as specified in Fig. 3 by the power law regression curve is replotted in Fig. 5. Superimnposed on this trend is the trend implied by recent NEHRP code provisions for "soft soils". (The code trend is specified by equations $1 \mathrm{a}$ with $\mathrm{v}=150 \mathrm{~m} / \mathrm{s}$ for $S C I V(\mathrm{E}), \mathrm{v}_{0}=1050 \mathrm{~m} / \mathrm{s}$ for $S C I b(\mathrm{~B}), \mathrm{m}$.
$=0.35$ and -0.05 for input acceleration levels of 0.1 and $0.4 \mathrm{~g}$;Borcherdt, 1994.)

The very preliminary results reported here for the Hyogo-ken Nanbu earthquake for "soft" soils appear to be in relatively good agreement with those suggested for the code provisions in that the general trend and amounts of amplification suggested by the power law regression curve are similar to those in the proposed code provisions. These preliminary results suggest that the values of amplification observed in the Kobe City area may be larger than those currently specified for $\mathrm{Fa}$ in the current NEHRP provisions. Additional information on seismic velocity profiles at each site are needed for a definitive conclusion.

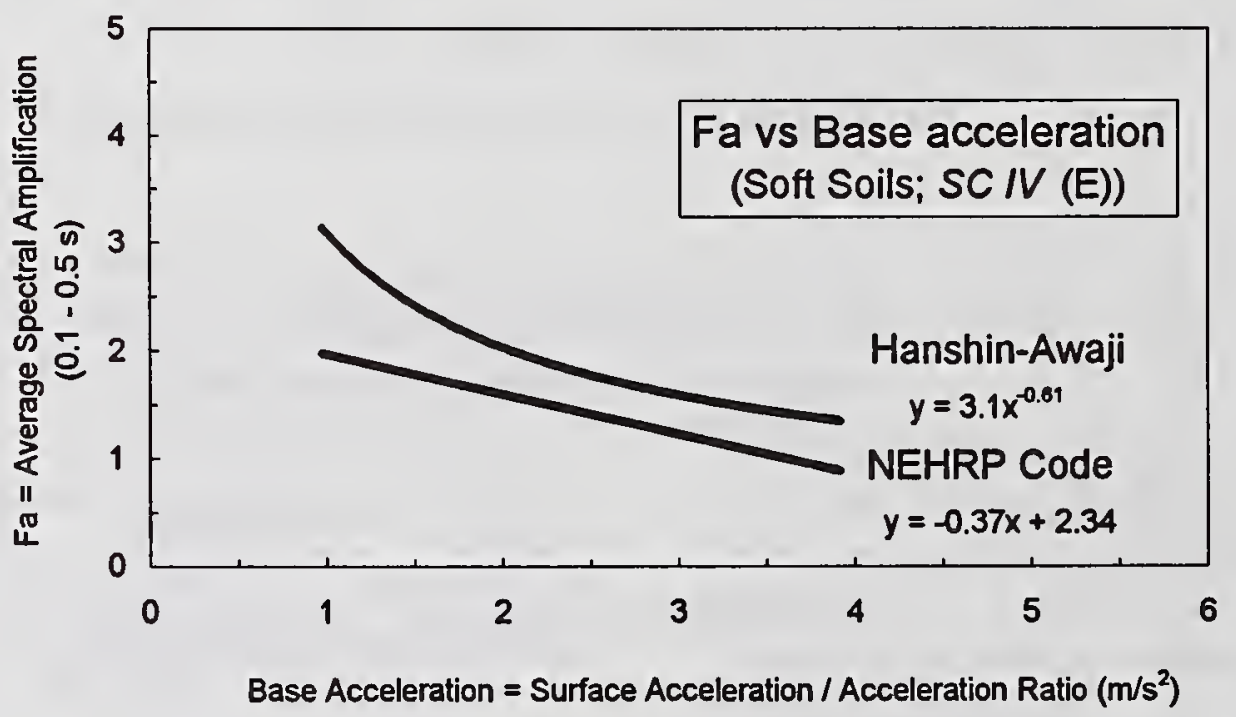

Fig. 5 Site-specific amplification factors versus base acceleration level for sites on soft soils (SC IV; NEHRP E) implied by the strong ground motion recordings of the Hyogo-ken Nanbu (Hanshin-Awaji) earthquake and the NEHRP code provisions for the short-period band band.

\section{ACKNOWLEDGMENTS}

The important efforts of various public and private agencies in the acquisition of the strong motion data reported herein are appreciated, including CDMG, USGS, USC, and LA Dept of Water and Power for the Northridge data and Public Works Research Institute, The National Research Institute for Earth Science and Disaster Prevention, Science and Technology Agency, The Disaster Prevention Research Institute, Kyoto University, the Earthquake Research Institute, University of Tokyo, Department of
Civil Engineering, Gifu University, the Port and Harbor Research Institute, the Architectural Institute of Japan, The Committee on Earthquake Observation and Research in the Kansai Area, Osaka Gas, Japan Railway, Japan Highways, Japan Meteorological Agency, Ministry of Construction, Building Research Institute, Geological Survey of Japan and others for the Hyogo-ken Nanbu data are appreciated. A special note of thanks is expressed to $Y$. Iwasaki, K. Ontani, M. Sugito, and M. Watabe, and numerous other colleagues for information and personal contributions. The efforts of $\mathrm{C}$. 
Wentworth in compiling the geologic maps required for geologic classifications of the strong-motion stations are appreciated. The efforts of G. Glassmoyer in assembling the Northridge data for spectral processing were especially helpful.

\section{REFERENCES}

Boore, D.M., Joyner, W.B., and Fumal, T. (1994). Estimates of response spectra and peak accelerations from western North American earthquakes; an interim report part 2 (with insert). U. S. Geological Survey Open File Report 94-127, 39 pp.

Borcherdt, R.D. (1994b). Estimates of sitedependent response spectra for design (Methodology and Justification), Earthquake Spectra, 10, p. 617-653.

Borcherdt, R.D. (1995). Strong ground motion generated by the Hanshin-Awaji (Hyogo-ken Nanbu) earthquake of January 17. 1995 in "The Hyogo-ken Nanbu earthquake of January 17. 1995" J.P Moehle, ed., Earthquake Engineering Research Center Report No. , University of California, Berkeley, CA, in press.

Borcherdt, R.D. and Glassmoyer, G. (1992). On the characteristics of local geology and their influence on ground motions generated by the Loma Prieta earthquake in the San Francisco Bay region, California: Bulletin of the Seismological Society of America, 82, p. 603-641.

Borcherdt, R.D. and Wentworth, C.W. (1995a). Strong-ground motion generated by the Northridge earthquake of January 17, 1994: Implications for seismic design coefficients and seismic zonation, Fifth International Conference on Seismic Zonation, Procs., Nice, France, v. II, pp 964 - 971.

Borcherdt, R. D. and Wentworth, C.W. (1995b). Preliminary map of peak horizontal ground acceleration for the Hanshin-Awaji earthquake of January 17,1995, Japan, Part II of 2 - Description of mapped data sets, $U$. $S$. Geological Survey Open File Report No. 259 $B$, pp.
Borcherdt, R.D., 1996a, Preliminary amplification estmates inferred from strongmotion recordings of the Northridge earthquake of January 17, 1994, International Workshop on Site Response, Procs., vol. 2, pp 21-46.

Borcherdt, R. D., 1996b, Strong ground motions generated by the Northridge and HanshinAwaji earthquakes of January 17, 1994 and 1995; Implications for site specific design factors, Eleventh World Conference on Earthquake Engineering, Procs., in press.

Campbell, K. W. and Bosorgnia, Y. (1994). Near-source attenuation of peak acceleration from worldwide accelerograms recorded from 1957 to 1993, Proc. Fifth U.S. National Conference on Earthquake Engineering, Chicago Illinois, 1994.

Geological Survey of Japan, 1992, Geological Map of Japan, CD-ROM Version, Third Edition, CD-ROM series of Earth Science Databases, CDGSJ92010, Map Scale $1: 1,000,000$.

Kikuchi, M. (1995). The Mechanism of the Hyogo-ken Nanbu earthquake of January 17,1995, in YCU (Yokohama City University) Seismology Report No. 38.

Kuribashi, E. (1995). The Japan's earthquake in Kobe of January 17,1995, The Hyogo-ken Nanbu earthquake), a reconnaissance report, Toyohashi University of Technology, Research Report No. 95-1.

Nakakita, U., and Watanabe, Y. (1977). Soil stabilization by preloading in Kobe Port Island, in Proceedings of the 9th International Conference on Soil Mechanics and Foundation Engineering, Tokyo, Case History Volume, p. 611-622.

Nakamura,Y. (1995). Waveform and its analysis of the 1995 Hyogo-ken-Nanbu earthquake, JR Earthquake Information No. 23c, 46 pp.

Nakamura,Y., Kazutoshi, H., Saita, J., and Sato, S. (1995). Strong Accelerations and damage of the 1995 Hyogo-ken Nanbu earthquake, $J R$ Earthquake Information No. 23b, $25 \mathrm{pp}$. 
Prompt report on strong-motion accelerograms No. 46 (1995). The National Research Institute for Earth Science and Disaster Prevention, Science and Technology Agency. $42 \mathrm{pp}$.

Wentworth, C.W., Borcherdt, R. D., and Mark, R. (1995). Preliminary map of peak horizontal ground acceleration for the Hanshin-Awaji earthquake of January 17,1995, Japan, Part I of 2, U. S. Geological Survey Open File Report No. 259 A, pp.

Porcella, R.L., Etheridge, E.C., Maley, R.P., and Acosta, A.V. (1994). Accelerograms recorded at USGS national strong-motion network stations during the $\mathrm{Ms}=6.6$ Northridge, California earthquake of January 17, 1994, U. S. Geological Survey Open-File Report 94-141, 100 pp.

Shakel, A., Huang, M., Darragh, R., Cao, T., Sherburne, R., Malhotra, P., Cramer, C., Sydnor, R., Grazier, V., Maldonado, G., Petersen, C., and Wampole, J. (1994). CSMIP Strong-motion records from the Northridge, California earthquake of January 17. 1994, California Strong-Motion Instrumentation Program Report No. OSMS 94-07, $308 \mathrm{pp}$.

Sugito, M. (1995). Characteristic of strong ground motion, in Comprehensive Study of the Great Hanshin Earthquake,United Nations Centre for Regional Development (UNCRD), UNCRD Rept. 12, 244 pp.

Tognazzni,R.A. (1994). Processed LADWP power system strong-motion records from the Northridge, California earthquake of January 17,1994, Linvall, Richter, Benuska, No. 007-027.

Trifunac, M.D., Todorovska, M.I., and Ivanovic', S.S. (1994). A note on the distribution of uncorrected peak ground accelerations during the Northridge earthquake of 17 January, 1994, University of Southern California, in press.

Wald, David J. and Heaton, Thomas H. (1994). A dislocation model of the 1994 Northridge, California determined from strong ground motions, U.S. Geological Survey Open-File Rept. 94-278, 53pp.

Wentworth, C.M., Borcherdt, R.D., Mark, R.K. and Boore, D.M. (1994). Maps of peak acceleration recorded for the Northridge, California, earthquake of January 17, 1994 and general geology of the epicentral region, U.S. Geological Survey Open-File Report 94-197, 3pp. 


\title{
Damage to Communication Tunnels Caused by Liquefaction and Other Phenomenon During the Hanshin-Awaji Earthquake and Future Countermeasures
}

\author{
by \\ Yuzo Yamaguchi* / Masayuki Tsuchiya*
}

\begin{abstract}
The Hanshin-Awaji Earthquake which occurred on January 17, 1995 caused enormous damage to above ground buildings including reinforced concrete buildings. In the Kobe district, where the damage was particularly severe, there are approximately $4.8 \mathrm{~km}$ of open-cut tunnels and $5.2 \mathrm{~km}$ of shield tunnels. However, the cables encased in these tunnels sustained absolutely no damage whatsoever and the tunnels are able to sufficiently carry out their intended functions, thus verifying their high reliability with respect to earthquakes. However, examining the tunnels as underground structures showed that lateral and vertical faulting of up to ten or more centimeters had occurred at the expansion joints of open-cut tunnels attached to buildings and shafts, etc. in areas experiencing a seismic intensity of 7 (ruinous earthquake), and that leakage had occurred in these areas. In addition, cracks had formed in a number of walls in general tunnel sections. Particularly noteworthy was the fact that even among areas which experienced the same level of seismic intensity, this damage was more severe in areas where liquefaction occurred. This thesis aims to illustrate the state of earthquake damage to open-cut tunnels and shield tunnels, and to describe future earthquakeproofing measures centering on existing tunnels.
\end{abstract}

KEYWORDS: earthquake-proofing measures, Hanshin-Awaji Earthquake, liquefaction, open-cut tunnel, shielḍ tunnel

\section{CONFIGURATION OF NTT'S COM- MUNICATION CIVIL FACILITIES}

Civil facilities which house communication cables can be broadly classified into the four categories of wiring pipeline facilities which correspond to cap- illaries, pipeline and highly-reliable conduits which correspond to arteries, and tunnel facilities which correspond to main arteries. (Fig. 15)

Of these, tunnel facilities are constructed near buildings containing switchboards and other places where cables converge, and are capable of housing many cables by laying these cables on shelves provided to the left and right of a central passageway. In addition, not only can people enter the insides of tunnels to lay cables and perform maintenance work without affecting road traffic or the local environment, but tunnels also boast the highest reliability with respect to earthquakes. Tunnel construction methods in urban areas are broadly divided into open-cut tunnels and shield tunnels. Sectional views of these tunnels are shown in Figs. 1 and 2.

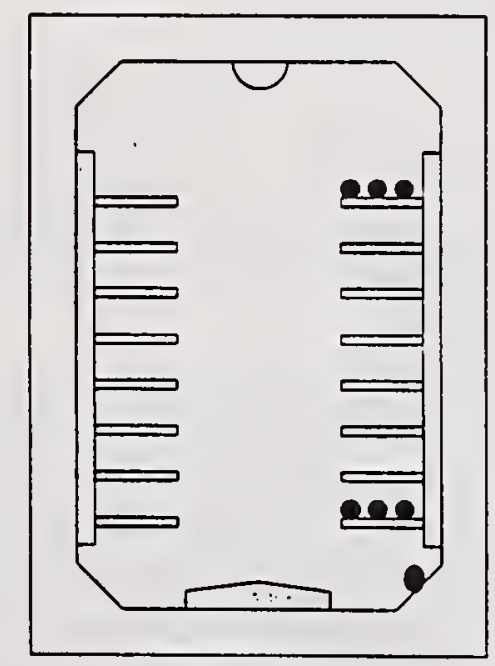

Fig. 1 Sectional drawing of a open-cut tunnel

\footnotetext{
* NIPPON TELEGRAPH AND TELEPHONE CORPORATION NTT Access Nerwork System Laboratories 1-7-I Hanabatake, Tsukuba-city. Ibaraki. 305 Japan
} 


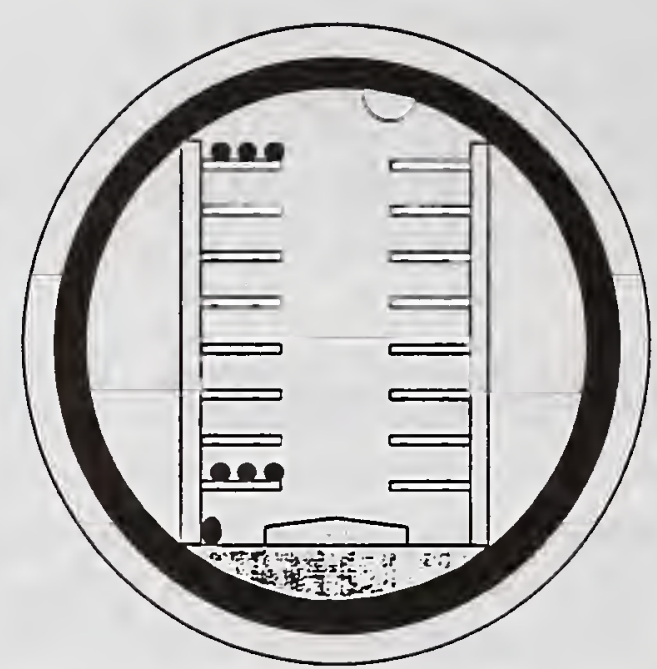

Fig. 2 Sectional drawing of a shield tunnel

\section{EXISTING EARTHQUAKE-PROOF TUNNEL STRUCTURES}

The main types of earthquake-proof structures for current open-cut tunnels and shield tunnels are described below.

(1) Open-Cut Tunnel Expansion Joints

Expansion joints are installed in the following types of locations in order to release the stress produced by earthquakes in the direction of the tunnel axis. (Fig. 16)

a) Places where tunnels are attached to buildings, approximately $\mathrm{l}$ to $2 \mathrm{~m}$ on the tunnel side from the outer wall of the building

b) Places where the soil changes noticeably

c) Places where the tunnel cross section changes noticeably

d) Places where pile foundations, etc. have been laid and support conditions vary

Expansion joints generally adopt a collar structure. However, a socket structure is used when it is particularly necessary to integrate the tunnel with a structure, or when integration is considered best from a construction viewpoint. Normally, the gap for these joints is $2 \mathrm{~cm}$ and asphalt materials are used as joint fillers. Joint fillers are also used to break the connection between collars and the outer walls of tunnels.

(2) Secondary Covering of Shield Tunnels with Earthquake-proofing Reinforcing Steel Bars

Earthquake-proofing reinforcing steel bars (rebars) are inserted within the secondary covering in the following types of locations in order to increase the cross sectional rigidity of tunnels to withstand the stress generated by earthquakes. (Fig. 17)

a) Places where the soil changes suddenly

b) Places where shield tunnels are attached to shafts

Regarding types of earthquake-proofing re-bars, in the case of a), D13 re-bars are installed at $30 \mathrm{~cm}$ intervals for $25 \mathrm{~m}$ to the left and right of locations where the soil changes suddenly. In the case of $b$ ), D22 re-bars are installed at $30 \mathrm{~cm}$ intervals for $12 \mathrm{~m}$ from the shaft.

\section{DAMAGE}

(1) Overview of Communication Tunnels in Kobe Kobe City contains approximately $10 \mathrm{~km}$ of communication tunnels, of which $4.8 \mathrm{~km}$ is open-cut tunnels and $5.2 \mathrm{~km}$ is shield tunnels with the oldest tunnel constructed in 1964. The overlying layer is approximately 2 to $4 \mathrm{~m}$ for open-cut tunnels, and approximately 10 to $25 \mathrm{~m}$ for shield tunnels. (Fig. 18)

(2) Damage

Most of the Kobe tunnel routes run through areas which experienced a seismic intensity of 6 or 7 . Although above ground buildings including reinforced concrete buildings suffered extensive damage in these areas, the damage to open-cut tunnels was limited to cracks in some walls and leakage caused by joint displacement. For shield tunnels, the only damage occurred in locations where shield tunnels had protruded approximately $\mathrm{I} \mathrm{cm}$ into the interior of some shafts. The results of a survey conducted of tunnels in the Kobe Sannomiya area following the earthquake are described below. Note that the maximum acceleration measured at the point closest to these areas was between 600 to 800 gal.

a) Damage to expansion joints

- The earthquake produced offsetting in some expansion joints, causing groundwater to flow into the tunnels in some of these locations. Of the 37 joint locations surveyed, 17 locations showed evidence of offsetting. (Photo 1, 2)

Although all of the surveyed joints were located in areas experiencing a seismic intensity of 7 , the damage in areas where liquefaction occurred 
clearly differed from that in areas where liquefaction did not occur. Fig. 19 shows the expansion joint displacement. Here, the maximum displacement was $18 \mathrm{~cm}$. Fig. 3 shows the occurrence of joint widening by attachment location for joints experiencing displacement of $2 \mathrm{~cm}$ or more. This table reveals a clear difference between areas with and without liquefaction.

Fig. 4 shows the occurrence of leakage of $50 \mathrm{l} / \mathrm{min}$ or more from joints by attachment location.

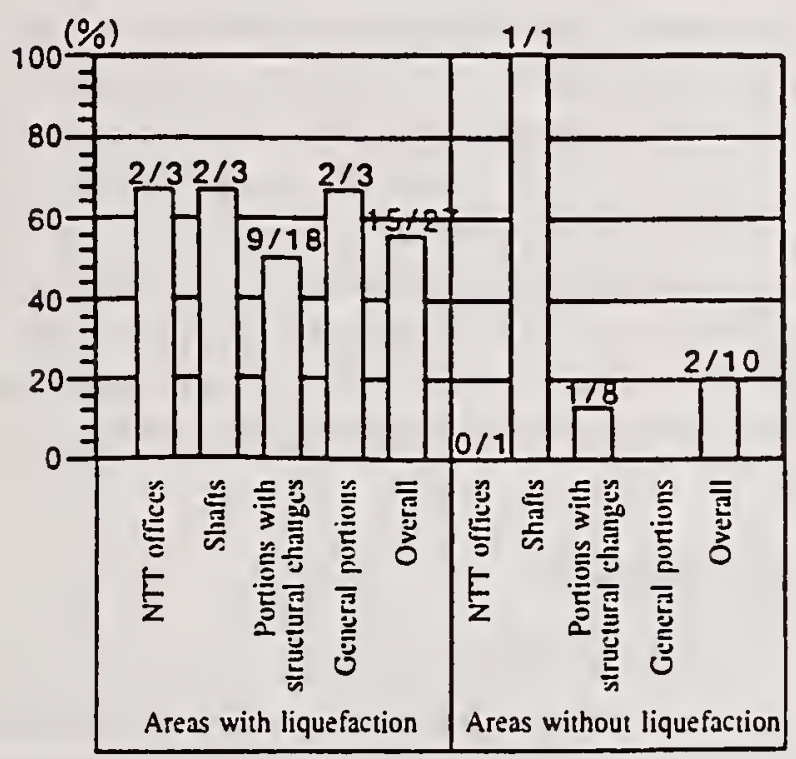

Fig. 3 Locations experiencing joint widening of $2 \mathrm{~cm}$ or more

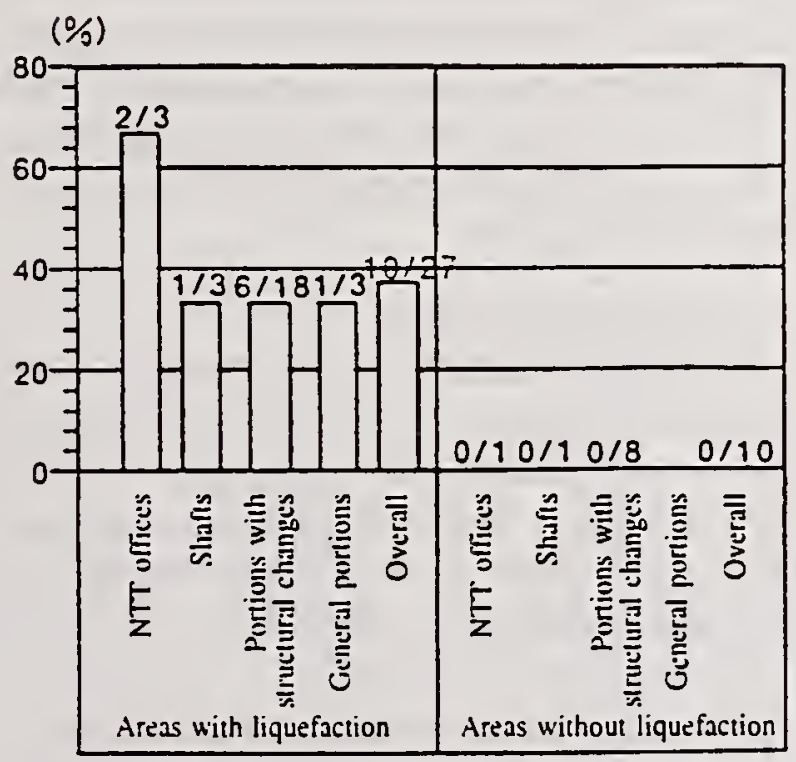

Fig. 4 Joint locations experiencing leakage of $50 \mathrm{l} / \mathrm{min}$ or more
Leakage from the joints of open-cut tunnels caused groundwater to flow into these runnels. This groundwater then flowed from the open-cut tunnels to shield tunnels where it accumulated at the lowest point. Normally, water leaking into the tunnels is pumped up above ground by pumps installed inside the tunnels. However, in addition to producing high amounts of leakage from expansion joints, this earthquake also caused a power stoppage inside the tunnels thereby preventing regular pump operation. Therefore, movable pumps were carried into the tunnels in order to pump up this water.

b) Damage to general portions of open-cut tunnels

The earthquake also created cracks in the general portions of tunnels. The number of cracked locations and occurrence ratio for areas with and without liquefaction are shown in Table 1. The amount of leakage from cracked locations was relatively small compared to that from expansion joints, and these locations were repaired by injecting urethane, etc.

Table 1 Damage to general portions

\begin{tabular}{|c|c|c|c|}
\hline & $\begin{array}{c}\text { Open-cut } \\
\text { tunnel length }\end{array}$ & $\begin{array}{c}\text { No. of cracked } \\
\text { locations }\end{array}$ & $\begin{array}{c}\text { No. of cracked } \\
\text { locations per } \\
100 \mathrm{~m}\end{array}$ \\
\hline $\begin{array}{c}\text { Areas with } \\
\text { liquefaction }\end{array}$ & $600 \mathrm{~m}$ & 37 & 6.2 \\
\hline $\begin{array}{c}\text { Areas without } \\
\text { liquefaction }\end{array}$ & $480 \mathrm{~m}$ & 1 & 0.2 \\
\hline Total & $1080 \mathrm{~m}$ & 38 & 3.5 \\
\hline
\end{tabular}

c) Damage to cast iron manhole covers

The earthquake motion produced offsetting in the neck portions of cast iron manhole covers for open-cut tunnels, resulting in leakage in some of these locations. Of the 22 manhole covers surveyed, displacement was confirmed in 11 locations. Cast iron manhole covers (Fig. 20) differ from tunnel joint structures in that the displacement resistance is the same in all directions. Therefore, manhole covers are determined to be a useful reference for understanding characteristics of earthquake motion (scale, direction) occurring on the ground surface. Surveys were conducted regarding the amount and direction of manhole cover displacement, and the sum total of the displacement was calculated. The results showed 
that the displacement in the north-south direction far exceeded that in the east-west direction. This indicates that the earthquake motion in the northsouth direction also exceeded that in the east-west direction. The sum total of the displacement for all manhole covers is shown in Fig. 5, and photographs of actual manhole cover conditions are shown in Photo 3.

Table 2 Damage to cast iron manhole covers

\begin{tabular}{|c|c|c|c|c|}
\hline & $\begin{array}{c}\text { Surveyed } \\
\text { locations }\end{array}$ & $\begin{array}{c}\text { Offset } \\
\text { locations }\end{array}$ & $\begin{array}{c}\text { Offset occur- } \\
\text { rence ratio }\end{array}$ & $\begin{array}{c}\text { Total offset } \\
(\mathrm{mm})\end{array}$ \\
\hline $\begin{array}{c}\text { Areas with } \\
\text { liquefaction }\end{array}$ & 13 & 10 & $77 \%$ & 500 \\
\hline $\begin{array}{c}\text { Areas } \\
\text { without } \\
\text { liquefaction }\end{array}$ & 9 & 1 & $11 \%$ & 50 \\
\hline
\end{tabular}

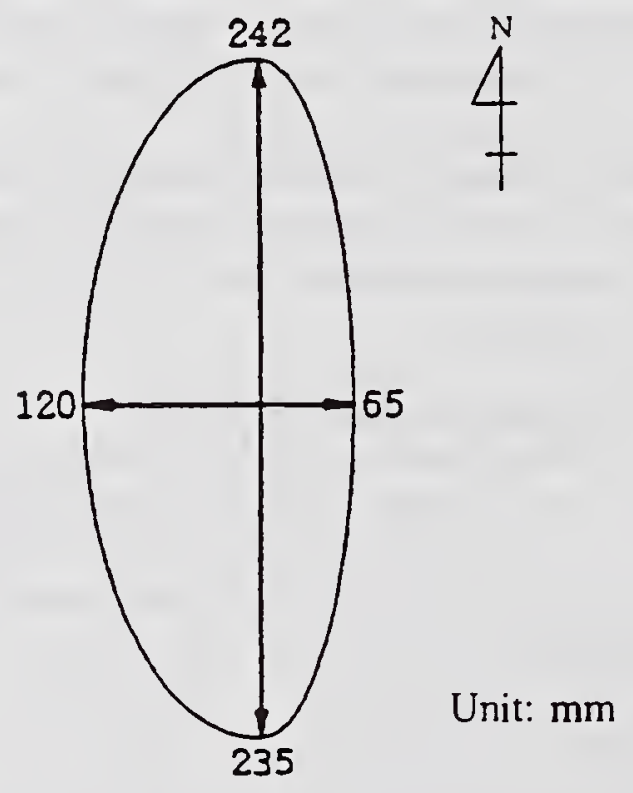

Fig. 5 Diagram showing the sum total of cast iron manhole cover offset

d) Damage to shield tunnels

Of the seven locations surveyed, shield tunnels were found to have protruded about 1 to $2 \mathrm{~cm}$ into the shaft portals along the direction of the tunnel axis in three locations. However, shield tunnels sustained no damage whatsoever in general tunnel portions. (Photo 4)
(3) Investigation of Open-Cut Tunnel

Floating Caused by Liquefaction

As previously mentioned, tunnel damage resulting from the Hanshin-Awaji earthquake varied widely between areas where liquefaction did or did not occur. In addition, when the results of level measurements inside tunnels carried out both before and after the earthquake were compared, floating was found to have occurred for open-cut tunnels in areas where liquefaction occurred.

a) Results of level measurements inside tunnels Fig. 21 shows the difference in levels before and after the earthquake as measured longitudinally inside tunnels in areas where liquefaction occurred. These levels were measured using the survey points of buildings containing switchboards to which the tunnels are connected as fixed points. These results show that while tunnels in these areas experienced floating of up to $9 \mathrm{~cm}$, there was next to no floating in areas where liquefaction did not occur.

b) Soil conditions

(1) Soil data

Fig. 22 shows a bar graph for soil in areas where liquefaction occurred. These areas have sandy soil with an $\mathrm{N}$ value of 15 or less up to $\mathrm{GL}-7.5 \mathrm{~m}$, and have groundwater at roughly $\mathrm{GL}-2.0 \mathrm{~m}$ in contrast to a tunnel overlying layer at $\mathrm{GL}-2.1 \mathrm{~m}$.

Fig. 23 shows a bar graph for soil in areas where liquefaction did not occur. These areas are comprised of gravel with an $\mathrm{N}$ value of 25 or more below GL $-5.5 \mathrm{~m}$, and have groundwater at roughly $\mathrm{GL}-2.0 \mathrm{~m}$ in contrast to a tunnel overlying layer at $\mathrm{GL}-1.0 \mathrm{~m}$.

\section{(2) Liquefaction judgments}

Calculating the liquefaction coefficient $F \ell$ using the liquefaction judgment formula of the Japan common conduit design index produces the values shown in Table 3. These calculations were performed using the two values of $600 \mathrm{gal}$ and $800 \mathrm{gal}$ as the input acceleration. When $F \ell$ is 1 or less, liquefaction occurs.

$\mathrm{F} \ell=\mathrm{R} / \mathrm{L}: \quad$ Liquefaction resistance factor

$\mathrm{R}$ : $\quad$ Soil dynamic shearing strength

$\mathrm{L}=\mathrm{rd} \cdot \mathrm{Ks} \cdot \sigma \mathrm{v} / \sigma \mathrm{v}^{-}$: Soil dynamic shearing stress

Ks: Horizontal seismic coefficient

$\sigma \mathrm{v}: \quad$ Total surcharge pressure

$\sigma v *: \quad$ Effective overburden pressure 
Table 3 Liquefaction judgment calculation results

Soil data for areas with liquefaction

\begin{tabular}{|c|c|c|}
\hline $\begin{array}{c}\text { No. } \\
\text { (Depth) }\end{array}$ & Fl $(600 \mathrm{gal})$ & Fl $(800 \mathrm{gal})$ \\
\hline 1 & - & - \\
\hline 2 & 0.313 & 0.235 \\
\hline 3 & 0.252 & 0.204 \\
\hline 4 & 0.285 & 0.230 \\
\hline 5 & 0.273 & 0.220 \\
\hline 6 & 0.326 & 0.263 \\
\hline 7 & 0.458 & 0.294 \\
\hline 8 & 0.017 & 0.270 \\
\hline 9 & - & - \\
\hline 10 & - & - \\
\hline 11 & 0.329 & 0.266 \\
\hline 12 & 0.294 & 0.238 \\
\hline 13 & - & - \\
\hline 14 & - & - \\
\hline 15 & 0.101 & 0.348 \\
\hline 16 & - & - \\
\hline 17 & 0.498 & 0.402 \\
\hline 18 & 0.001 & 0.279 \\
\hline
\end{tabular}

Soil data for areas without liquefaction

\begin{tabular}{|c|c|c|}
\hline $\begin{array}{c}\text { No. } \\
\text { (Depth) }\end{array}$ & Fl $(600$ gal $)$ & Fl $(800$ gal $)$ \\
\hline 1 & 1.803 & 1.420 \\
\hline 2 & 1.255 & 0.980 \\
\hline 3 & - & - \\
\hline 4 & 2.087 & 1.690 \\
\hline 5 & 2.859 & 2.310 \\
\hline 6 & 0.909 & 0.730 \\
\hline 7 & 1.095 & 0.890 \\
\hline 8 & 2.380 & 1.930 \\
\hline 9 & 0.428 & 0.350 \\
\hline 10 & 1.305 & 1.060 \\
\hline 11 & 0.984 & 0.800 \\
\hline 12 & 0.740 & 0.590 \\
\hline 13 & 0.545 & 0.440 \\
\hline 14 & 1.117 & 0.900 \\
\hline 15 & 1.630 & 1.320 \\
\hline 16 & 1.751 & 1.410 \\
\hline 17 & 1.713 & 1.380 \\
\hline
\end{tabular}

The calculation results show that even in areas without liquefaction, liquefaction occurs when the actual seismic acceleration is substituted into the liquefaction judgment formula.

(3) Floating judgment

Open-cut tunnel floating was judged based on the floating judgment formula of the Japan common conduit design index, and floating calculations were performed using the two input accelerations of 600 and 800 gal. The floating judgment formula is as follows.

$$
F s=\frac{W s+W B+Q s+Q B}{U s+U D}
$$

Ws: Soil surcharge (including the water weight) WB: Tunnel weight

Qs: Soil shearing resistance

QB: Tunnel side friction resistance

Us: Uplift produced by hydrostatic pressure acting on the tunnel bottom

UD: Uplift produced by excess porewater pressure acting on the tunnel bottom

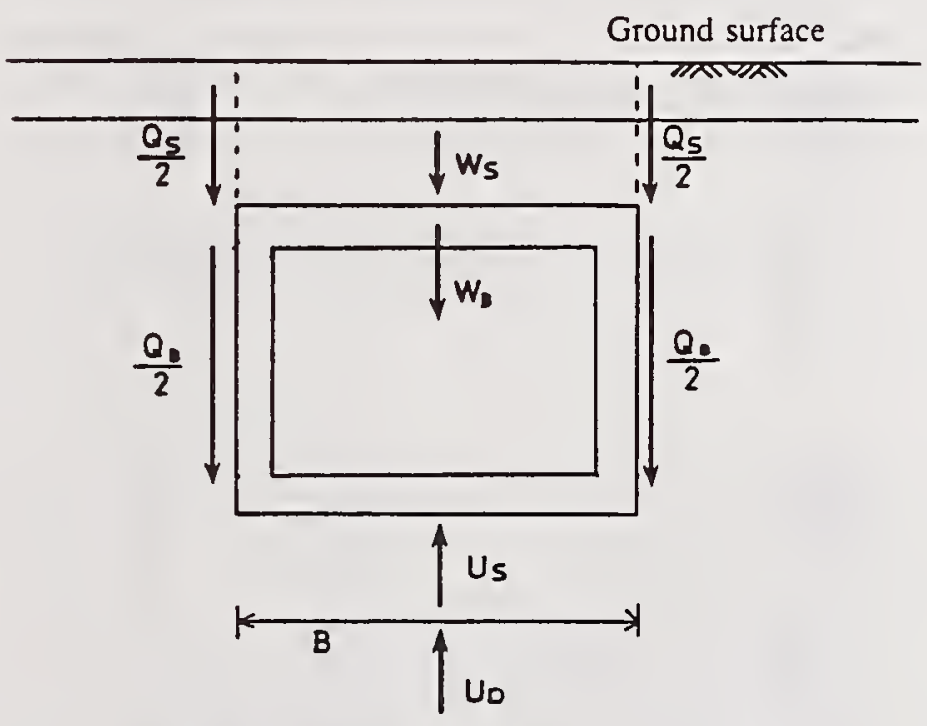

Fig. 6 Outline drawing for open-cut tunnel floating judgment

Note that the floating safety factor Fs must be 1.1 or more. Also, shear resistance and tunnel friction resistance are not considered when the liquefaction resistance factor (FL) is 1.0 or less.

The calculation results are shown on the next page. 
I) Open-cut tunnel floating judgment in areas where liquefaction occurred

\begin{tabular}{|c|c|c|}
\hline & $600 \mathrm{gal}$ & $800 \mathrm{gal}$ \\
\hline $\begin{array}{l}\text { Soil surcharge } \\
\text { (including the water weight) }(t \mathrm{f} / \mathrm{m})\end{array}$ & 8.32 & 8.32 \\
\hline Tunnel weight & 4.63 & 4.63 \\
\hline Soil shearing resistance & 0 & 0 \\
\hline Tunnel side friction resistance $(\mathrm{tf} / \mathrm{m})$ & 0 & 0 \\
\hline $\begin{array}{l}\text { Uplift produced by hydrostatic } \\
\text { pressure } \\
\text { (tf/m) }\end{array}$ & 5.46 & 5.46 \\
\hline $\begin{array}{l}\text { Uplift produced by the excess } \\
\text { porewater pressure } \\
\text { (tf/m) }\end{array}$ & 14.03 & 14.03 \\
\hline Floating safety factor (Fs) & 0.664 & 0.664 \\
\hline
\end{tabular}

The above results indicate that tunnel floating should occur. The results of actual level measurements at these points show that liquefaction caused floating of $6 \mathrm{~cm}$, thereby validating the judgment formula.

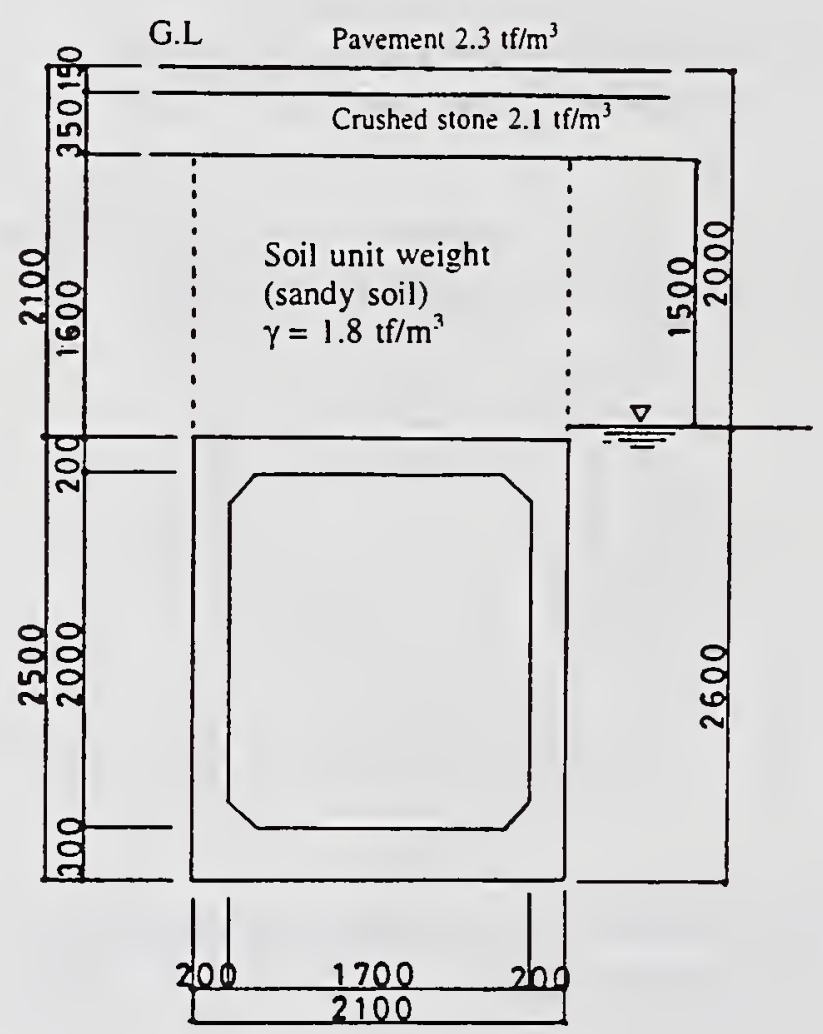

Fig. 7 Open-cut tunnel floating judgment (areas with liquefaction)
II) Open-cut tunnel floating judgment in areas where liquefaction did not occur

\begin{tabular}{|c|c|c|}
\hline & $600 \mathrm{gal}$ & $800 \mathrm{gal}$ \\
\hline $\begin{array}{l}\text { Soil surcharge } \\
\text { (including the water weight) (tf/m) }\end{array}$ & 3.98 & 3.98 \\
\hline Tunnel weight & 5.33 & 5.33 \\
\hline Soil shearing resistance & 0.58 & 0.58 \\
\hline Tunnel side friction resistance $(\mathrm{t} / \mathrm{m})$ & 4.86 & 3.53 \\
\hline $\begin{array}{l}\text { Uplift produced by hydrostatic } \\
\text { pressure } \\
(\mathrm{tf} / \mathrm{m})\end{array}$ & 5.67 & 4.62 \\
\hline $\begin{array}{l}\text { Uplift produced by the excess } \\
\text { porewater pressure }\end{array}$ & 0.95 & 4.25 \\
\hline Floating safety factor (Fs) & 2.45 & 1.51 \\
\hline
\end{tabular}

The above results indicate that tunnel floating should not occur. The results of actual level measurements at these points show that floating was not confirmed, thereby validating the judgment formula.

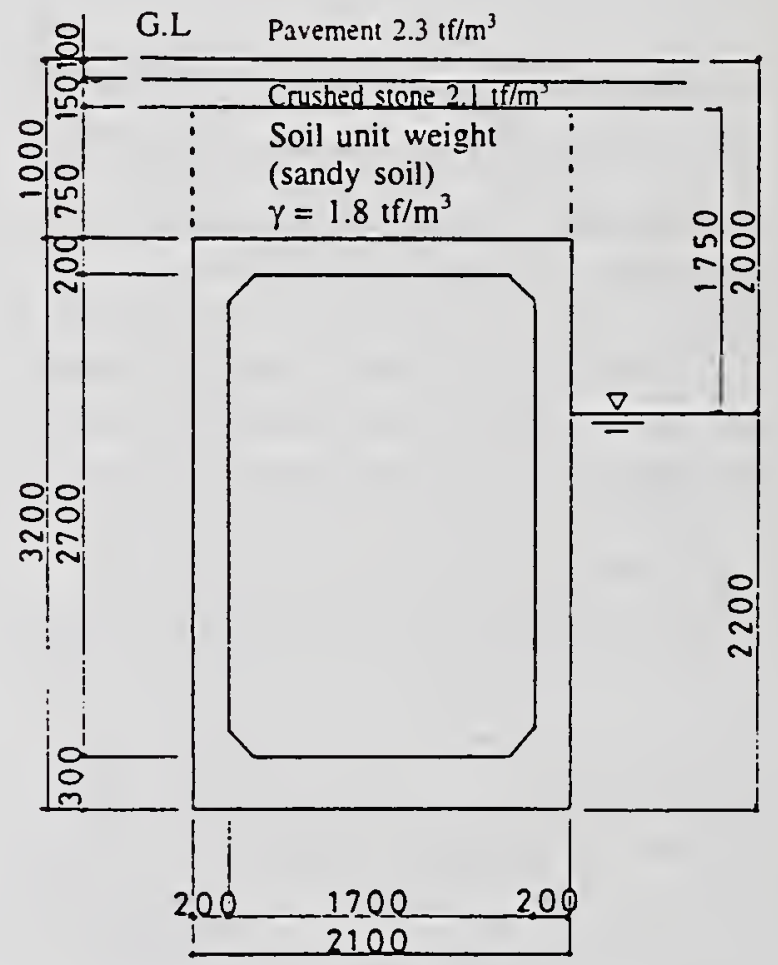

Fig. 8 Open-cut tunnel floating judgment (areas without liquefaction) 
(4) Relationship between the floating safety factor and the amount of floating

Fig. 9 shows the relationship between the floating safety factor and the amount of floating at three locations in areas where liquefaction occurred and three locations in areas where liquefaction did not occur. These figures clearly show that the amount of floating increases as the safety factor becomes smaller.

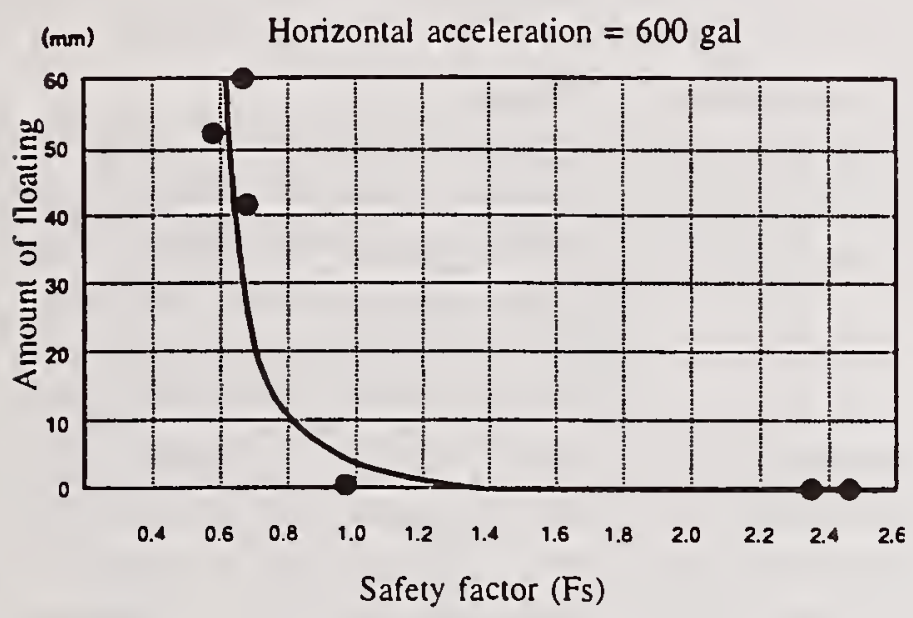

$(\mathrm{mm})$ Horizontal acceleration $=800 \mathrm{gal}$

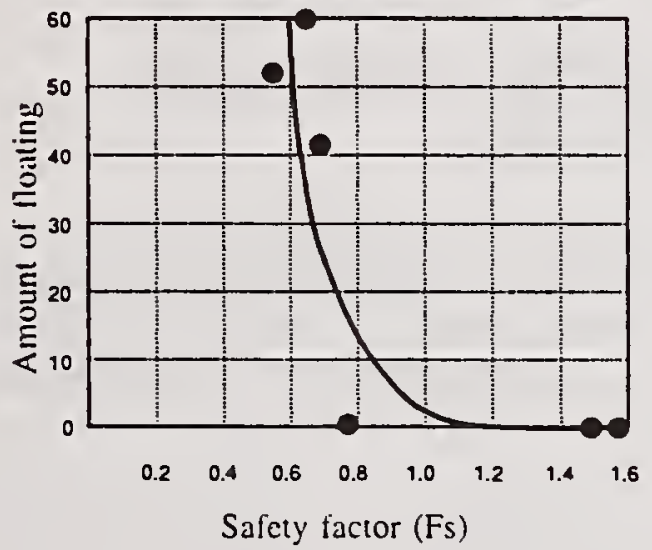

Fig. 9 Relationship between the floating safety factor and the amount of floating
(5) Examination of floating

This section examines the section changing points where floating was particularly noticeable. A typical section changing point where tunnels branch is shown in Fig. 10, and the corresponding outline drawing is shown in Fig. 11.

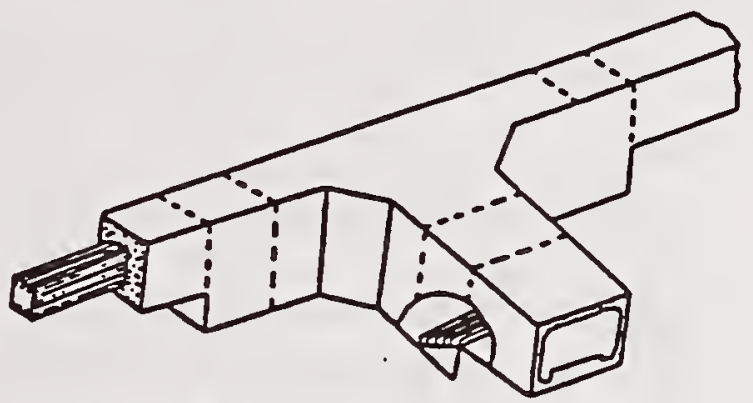

Fig. 10 Tunnel branch structure

G. L

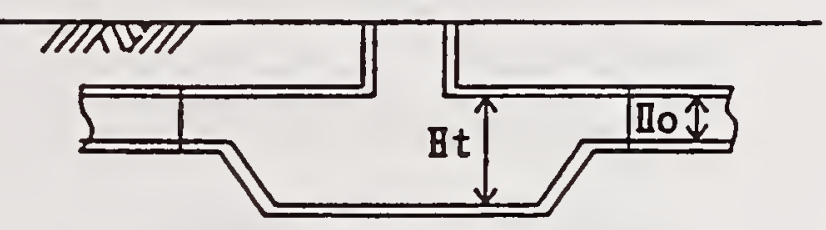

Fig. 11 Outline drawing of a tunnel branch

At this point, the liquefaction safety factor is calculated using the relationship between $\mathrm{HO}$ and $\mathrm{Ht}$ in order to grasp the relationship between the shape of section changing points and floating caused by liquefaction.

These calculations assume that

$\mathrm{Ht}=\mathrm{HO} \times(1+0.2 \mathrm{t})$ with $\mathrm{t}=1$ to 8 In other words,

$\mathrm{HO}=2.0 \mathrm{~m}$

$\mathrm{H} 1=2.4 \mathrm{~m}, \mathrm{H} 2=2.8 \mathrm{~m}, \ldots, \mathrm{H} 8=5.2 \mathrm{~m}$

The installation conditions were set as indicated below and the safety factor Fs was obtained for each value of $t$. The results showing the relationship between $\mathrm{H} / \mathrm{HO}$ and Fs appear in Fig. 12. These results indicate that the effects of floating caused by liquefaction increase in tandem with the degree of change between the shapes of the changing point and general portions.

\begin{tabular}{|lr|}
\hline Conditions & \\
Overlying layer & $2.7 \mathrm{~m}$ \\
Groundwater level & $-2.0 \mathrm{~m}$ \\
Tunnel internal height & $2.0 \mathrm{~m}$ \\
Tunnel internal width & $1.7 \mathrm{~m}$ \\
Wall thickness $\quad$ Lower floor & $30 \mathrm{~cm}$ \\
& \\
& Upper floor and \\
& side walls \\
\hline
\end{tabular}




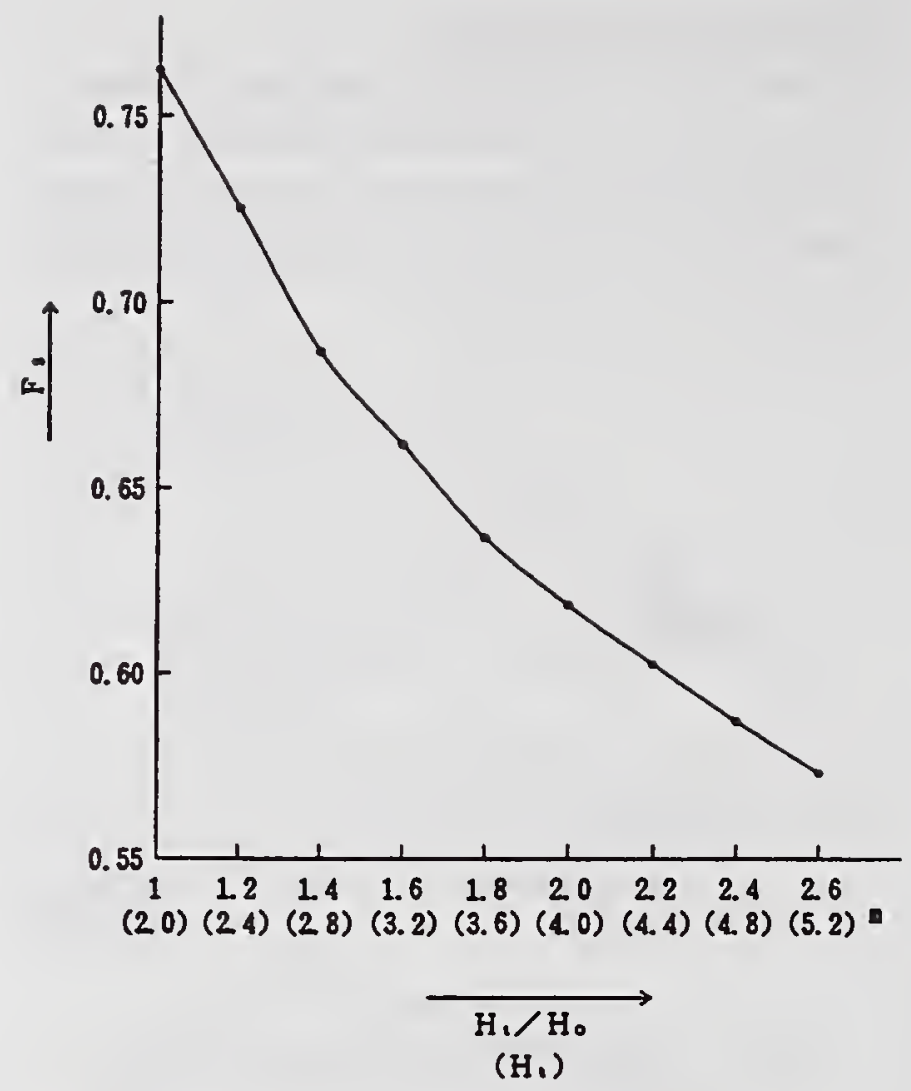

Fig. 12 Relationship between the floating safety factor and $\mathrm{Ht} / \mathrm{HO}$

Next, the shearing force $\pi$ (force per meter in the lengthwise direction of the tunnel) acting on the joints was obtained using the following equation.

$$
\begin{aligned}
\tau t & =(U s t+U D t)-(W s+W B t) \\
& =4.825+1.12 t
\end{aligned}
$$

Assuming the length of the section affected by buoyancy to be $\ell$, the joints break under the following conditions.

$$
\tau \mathrm{\tau} \times \ell>\tau \mathrm{j}
$$

$$
\tau \mathrm{j} \text { : Joint shearing strength }
$$

Here, the required joint shearing strengths assuming the affected section length $\ell=2.5 \mathrm{~m}$ are shown in Table 4.

Table 4

\begin{tabular}{|c|c|c|}
\hline$t$ & $H t(m)$ & Required shearing strength $(t)$ \\
\hline 2 & 2.8 & 17.7 \\
\hline 4 & 3.6 & 23.3 \\
\hline 6 & 4.4 & 28.9 \\
\hline 8 & 5.2 & 34.5 \\
\hline
\end{tabular}

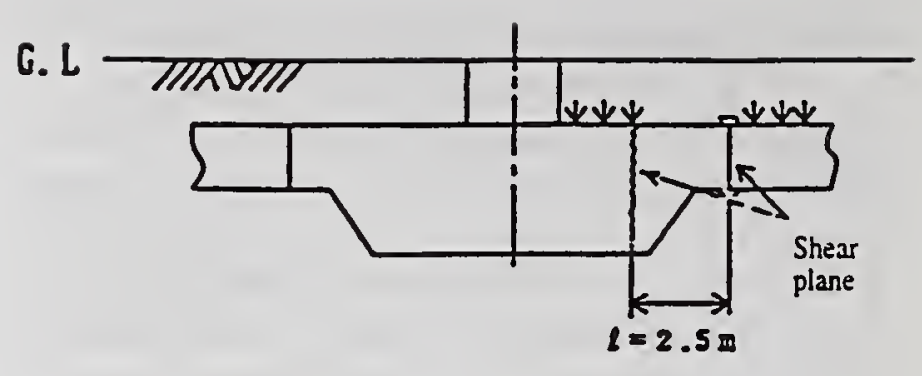

Fig. 13 Shearing force acting on joints

\section{(4) Summary of Damage}

The current survey results indicate that the probability of tunnel damage is higher in areas with liquefaction than in areas without liquefaction, and that even in areas with liquefaction this probability increases in locations where the tunnel cross section changes dramatically. This is thought to be caused by lateral flowing and floating produced by liquefaction. However, the maximum displacement was between 10 and $20 \mathrm{~cm}$, and did not result in serious damage other than damage to expansion joints, etc.

\section{EARTHQUAKE-PROOFING MEASURES}

NTT has approximately $520 \mathrm{~km}$ of existing tunnels throughout Japan which house a vast number of communication cables. The Tokyo metropolitan area in particular contains a network comprising approximately $230 \mathrm{~km}$ of tunnels. In order to implement earthquake-proofing measures which reflect the lessons learned from the Hanshin-Awaji Earthquake, these improvements must be carried out efficiently by accurately grasping the weak points of this network and establishing an appropriate order of priority. In particular, appropriate work methods must be selected when implementing earthquake-proofing measures for tunnels which contain large numbers of communication cables (Photo 5).

Upon analyzing the damage from the HanshinAwaji Earthquake, NTT decided to concentrate on tunnels located in areas where liquefaction is most likely to occur. Within these areas, the highest priority has been placed on implementing earthquake-proofing measures for joints where tunnels are attached to buildings and other areas 
where the tunnel cross section changes dramatically. Conventional liquefaction countermeasures include methods of preventing both liquefaction and deformation caused by liquefaction. However, when implementing countermeasures for existing tunnels in urban areas, these methods are limited by traffic restrictions, effects on the surrounding environment, work periods and construction costs, etc. Therefore, NTT has selected the safest and most economical work methods which can be carried out from inside existing tunnels and which keep the relaying of cables, etc. to a minimum.

(1) Introduction of Flexible Joints

The data detailing the damage in Kobe indicated a maximum floating caused by liquefaction of about $10 \mathrm{~cm}$, and a maximum expansion joint displacement of $18 \mathrm{~cm}$. In consideration of these figures, it was determined that fluctuations caused by earthquake motion and liquefaction could be handled by flexible joints. Therefore, the decision was made to install flexible joints in building and shaft attachments in areas where liquefaction is considered likely to occur. In addition, a work method was developed allowing these joints to be easily installed without having to relay the cables even in existing tunnels which house large numbers of cables. The installation diagram for flexible joints is shown in Fig. 14.
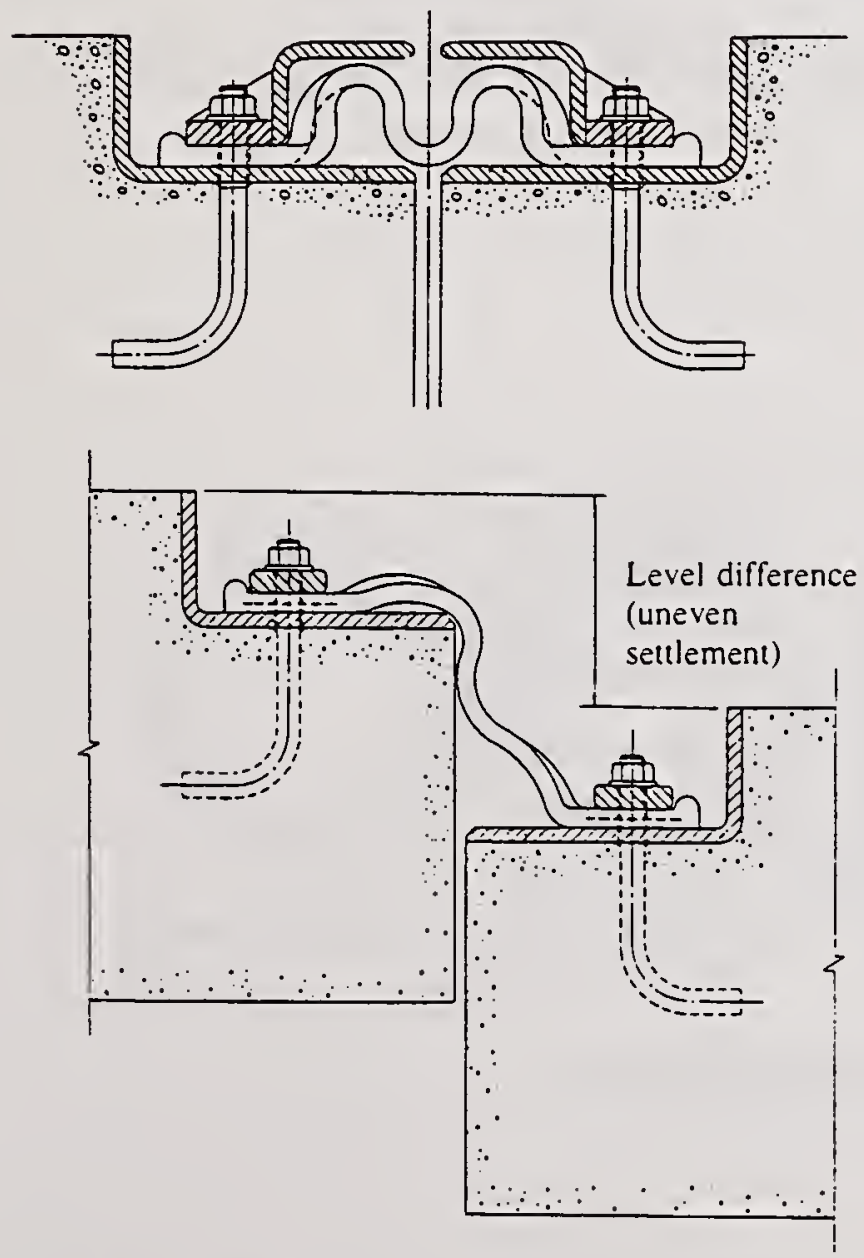

Fig. 1+ Flexible joint installation diagram

\section{(2) Experimental Verification}

Structures which afforded the greatest possible placement interval between flexible joint attachment bolts were investigated in consideration of work inside existing tunnels which house large numbers of communication cables. These joint structures were then verified to ensure that they were capable of dealing with vertical and lateral offsets of $20 \mathrm{~cm}$ and remained water resistant at a water pressure of $1 \mathrm{~kg} / \mathrm{cm}^{2}$.

Photograph 6 shows the experimental conditions. The bolt placement interval for conventional work methods is $20 \mathrm{~cm}$. However, these experiments confirmed that water resistance could be maintained even when the placement interval was increased by up to four times by redesigning the cross sectional shape of the fastener plates, etc.

\section{CONCLUSION}

NTT has linked buildings containing major switchboards in large cities with tunnels in order to ensure communications capabilities in the event of earthquakes or other disasters. The high reliability of these communication tunnel facilities with respect to large-scale earthquakes was verified by the Hanshin-Awaji Earthquake.

However, in light of the fact that further improvement in the reliability of communication infrastructure facilities will be required as we move toward an advanced information society in the future, countermeasures must be devised to counteract joint offsetting and other damage to existing open-cut tunnels caused by liquefaction, etc. Therefore, using the current earthquake damage data, the accuracy of predictions as to which areas are likely to suffer from liquefaction must be further improved, and damage simulations conducted for various floating and offsetting amounts in order to investigate efficient countermeasures.

\section{[Bibliography]}

1. Japan Common Conduit Design Index, 6.3 Liquefaction Judgments and Countermeasures for Surrounding Ground

2. Civil Engineering Handbook

3. The Japan Port and Harbor Association, Technical Standards for Port and Harbor Facilities with Commentary 


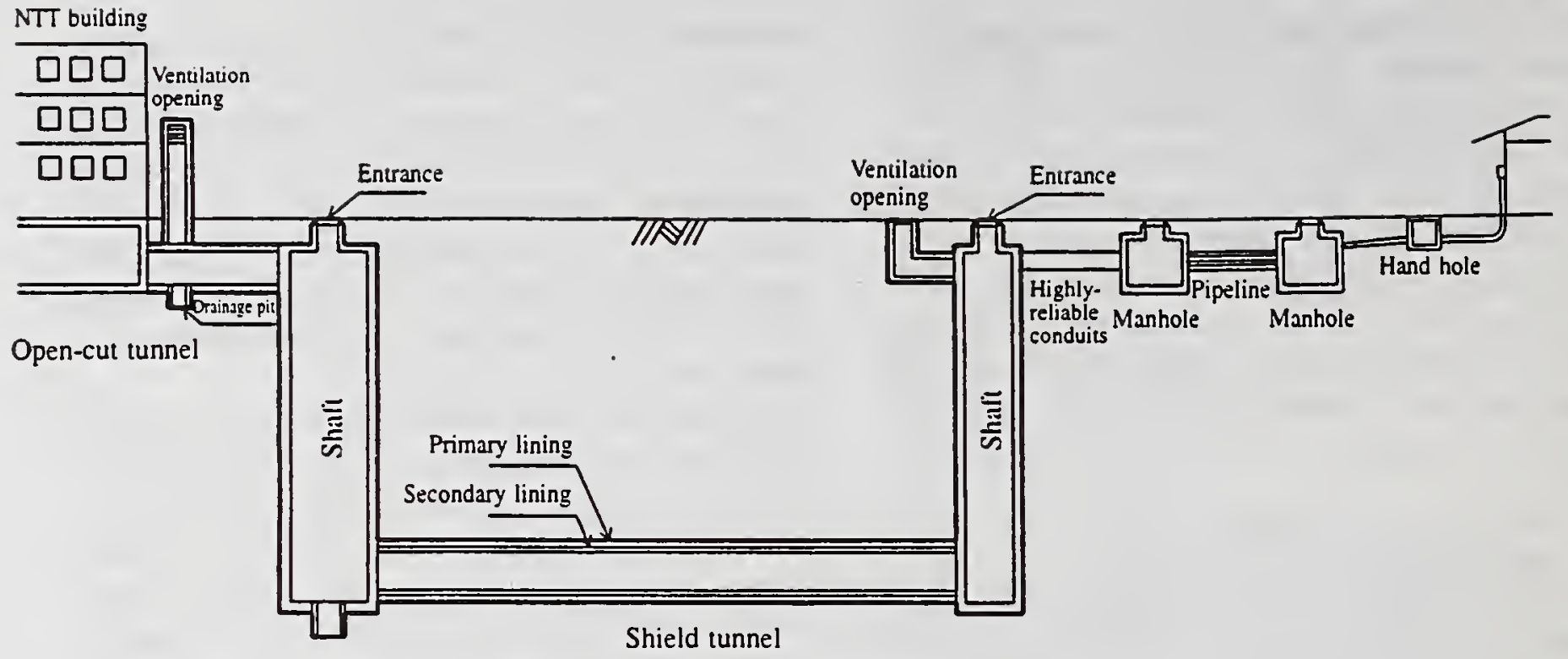

Fig. 15 Outline drawing of communication civil facilities

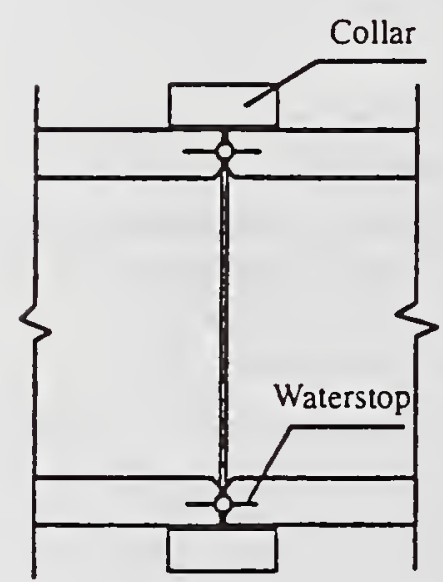

Collar joint

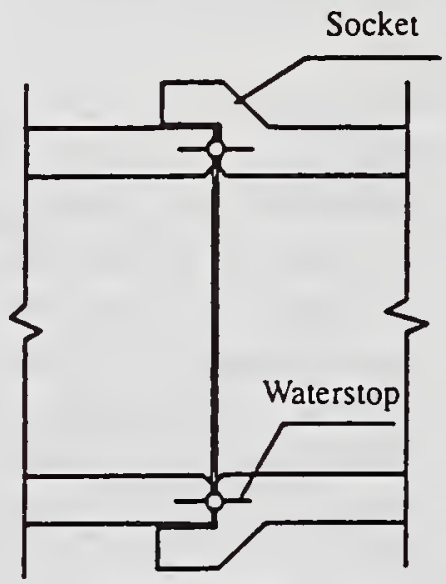

Socket joint

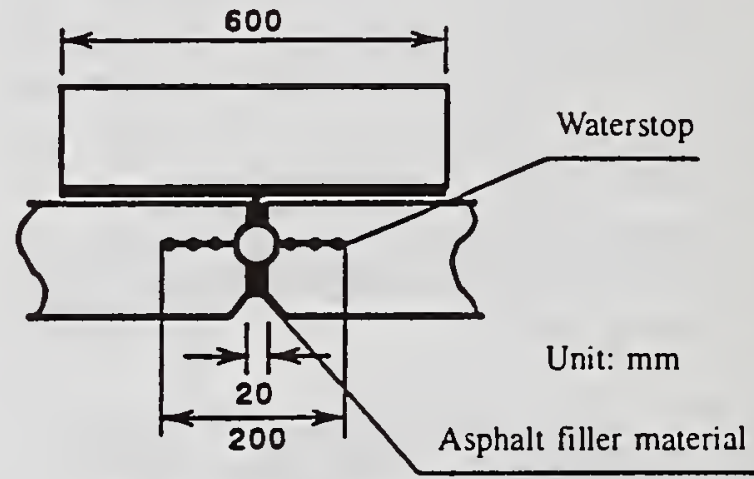

Expansion joint detail drawing

Fig. 16 Expansion joint structures

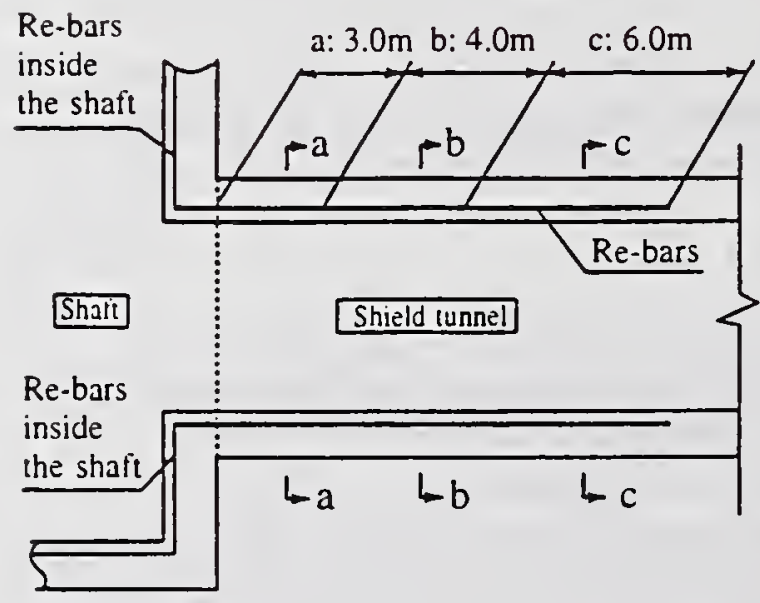

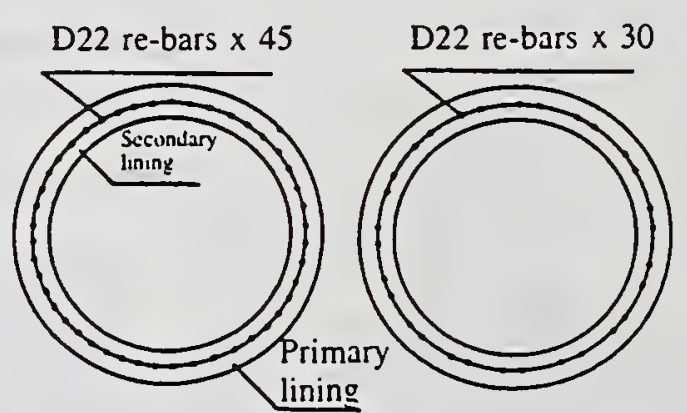

a-a cross section b-b cross section

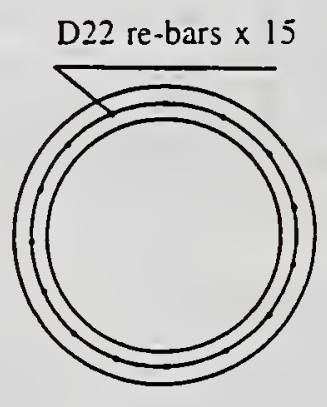

c-c cross section

Fig. 17 Earthquake-proofing re-bars for shield tunnels 


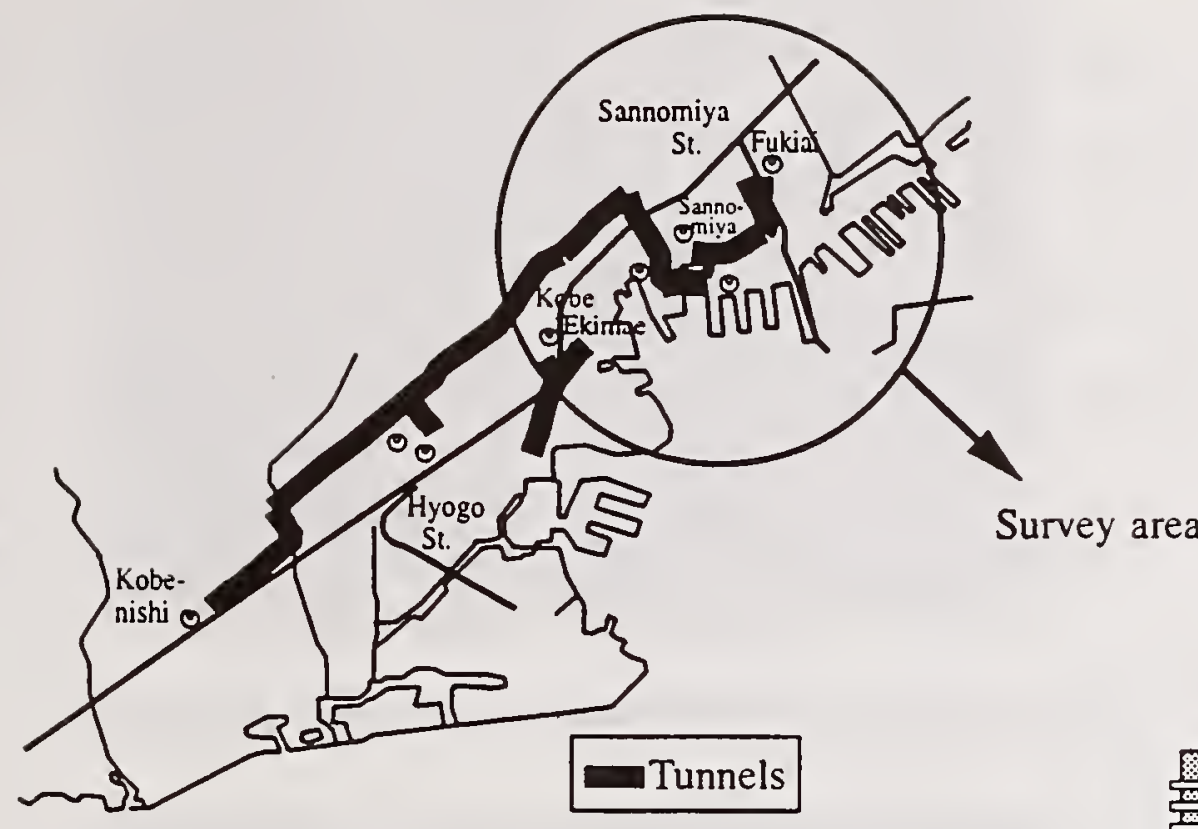

Fig. 18 Communication tunnels inside Kobe City

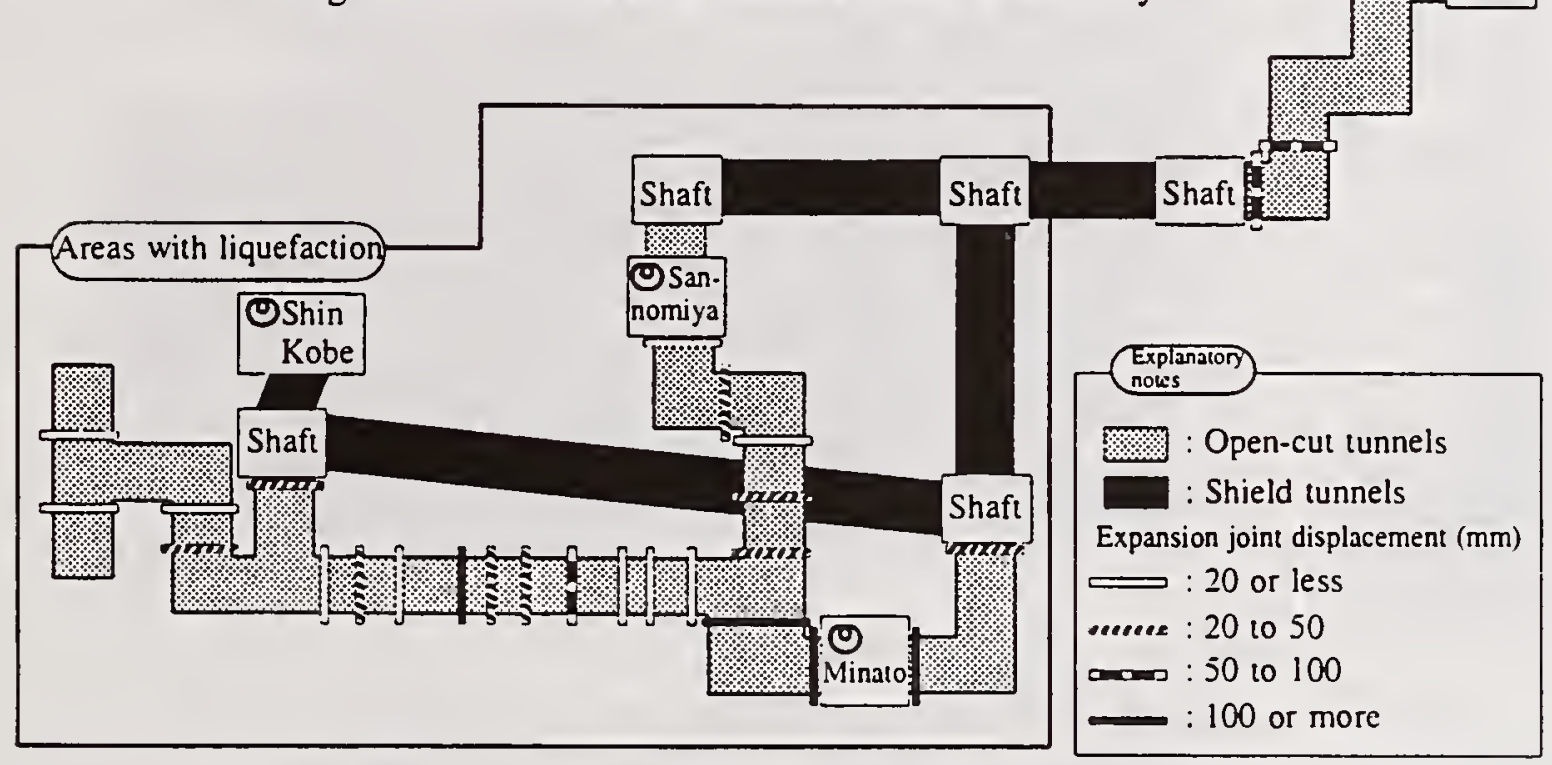

Fig. 19 Expansion joint damage

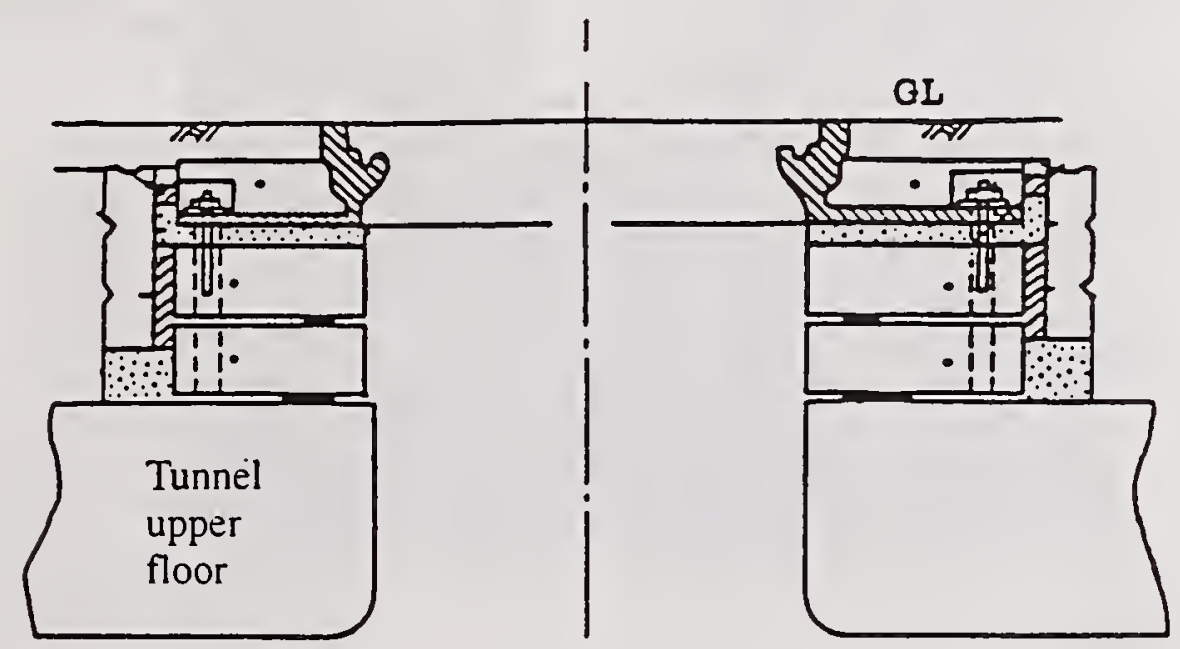

Fig. 20 Cast iron manhole cover structure 


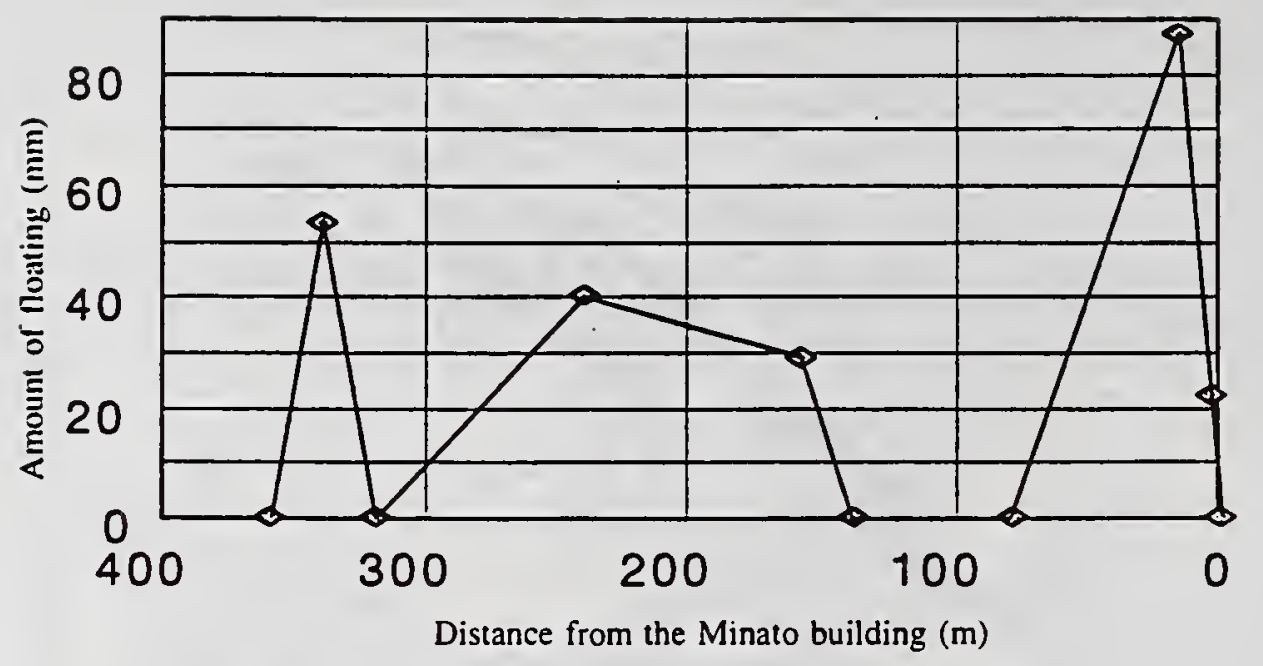

Fig. 21 Open-cut tunnel floating caused by liquefaction
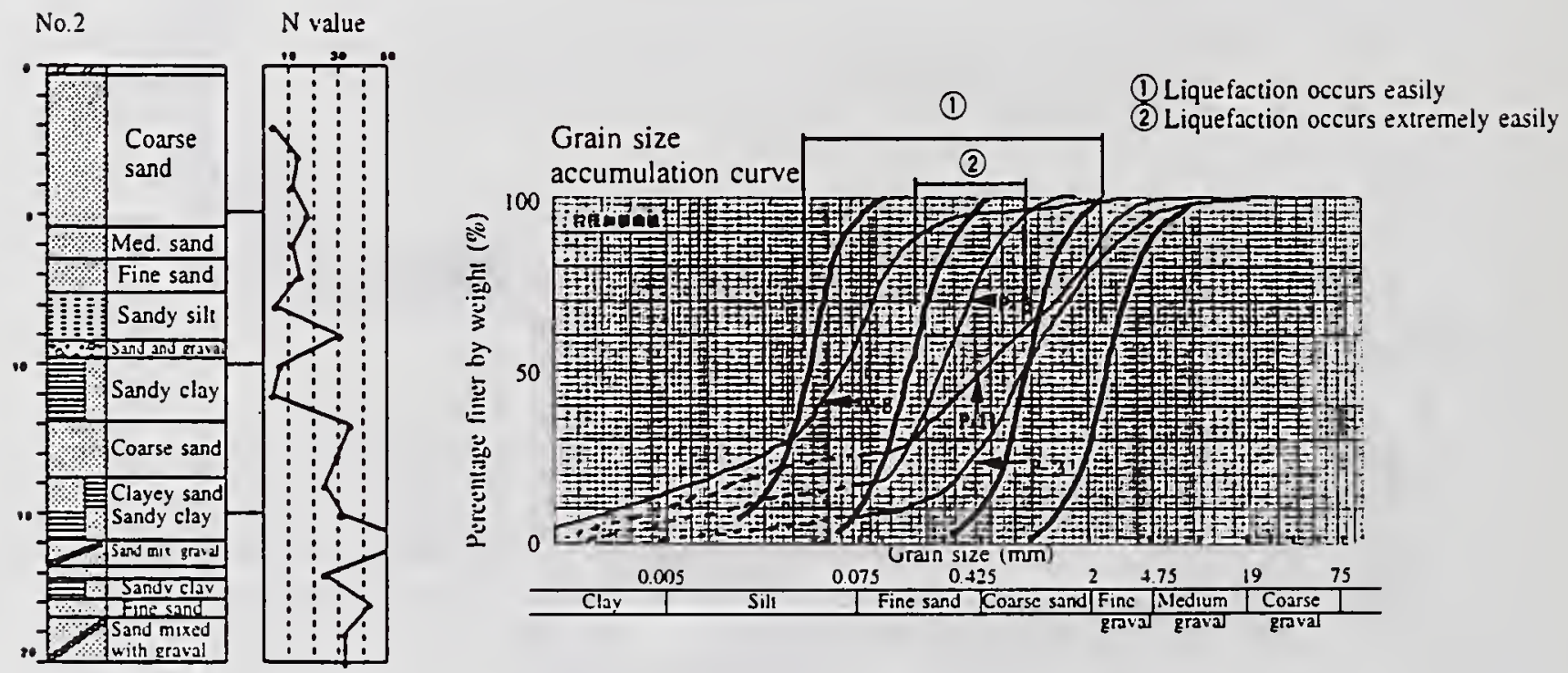

Fig. 22 Soil survey data (areas with liquefaction)
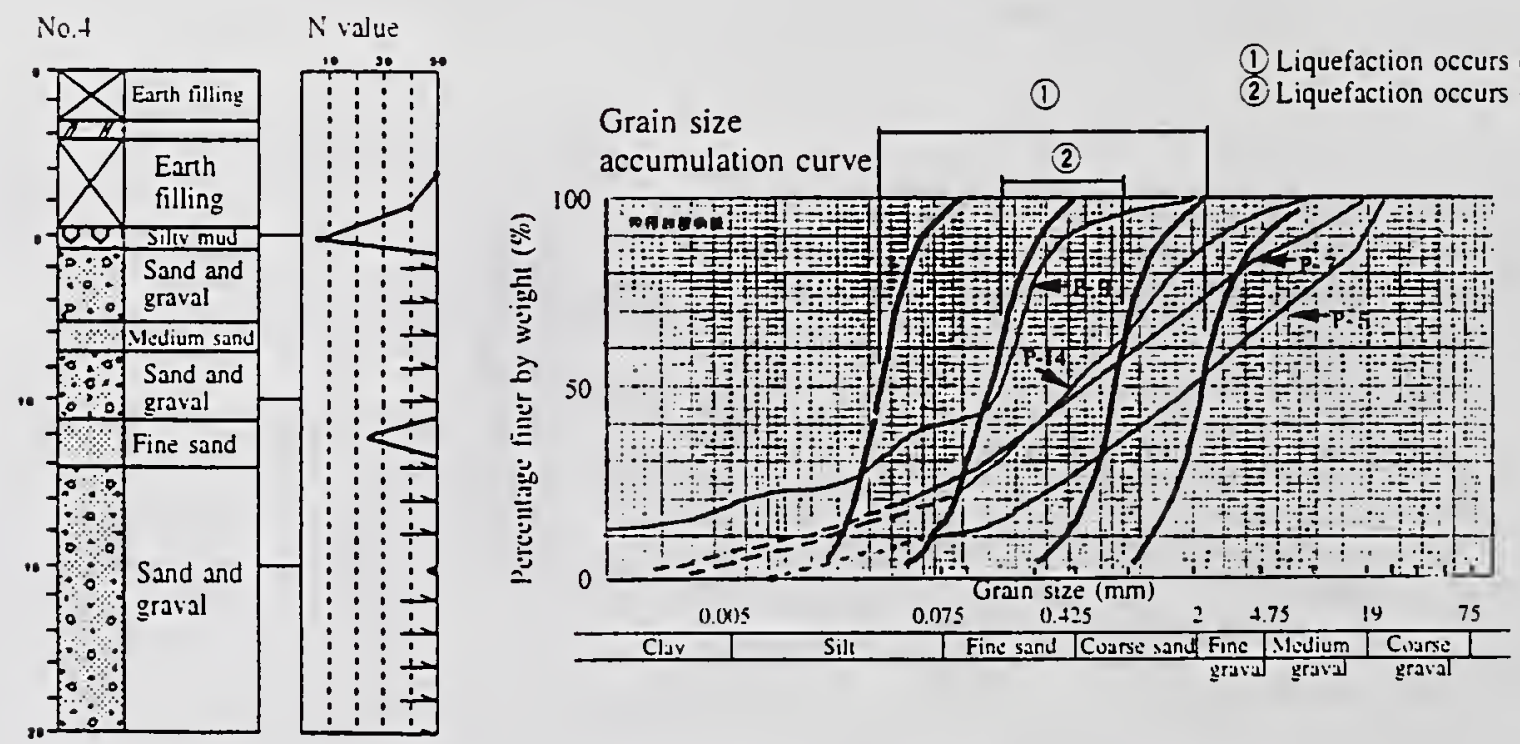

Fig. 23 Soil survey data (areas without liquefaction) 


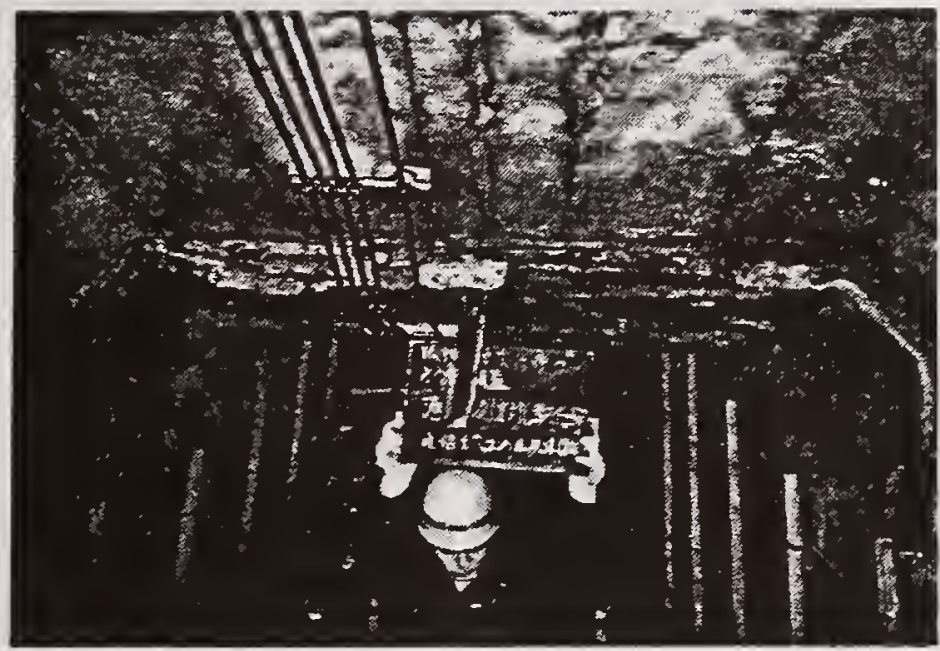

Photo 1 Expansion joint structure damage (offsetting)

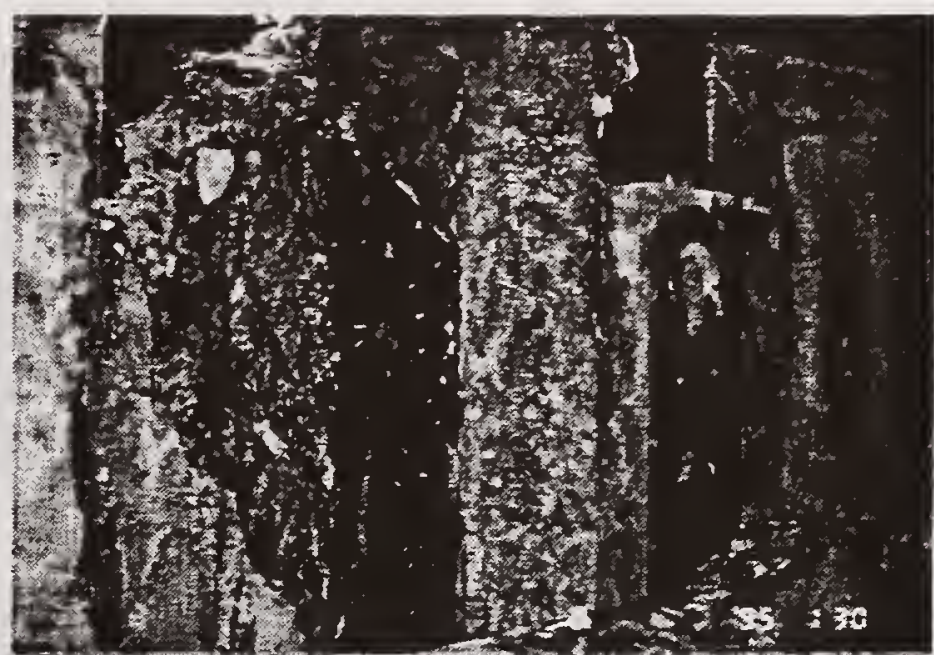

Photo 2 Expansion joint structure damage

(With the concrete is removed, the waterstops are revealed.)

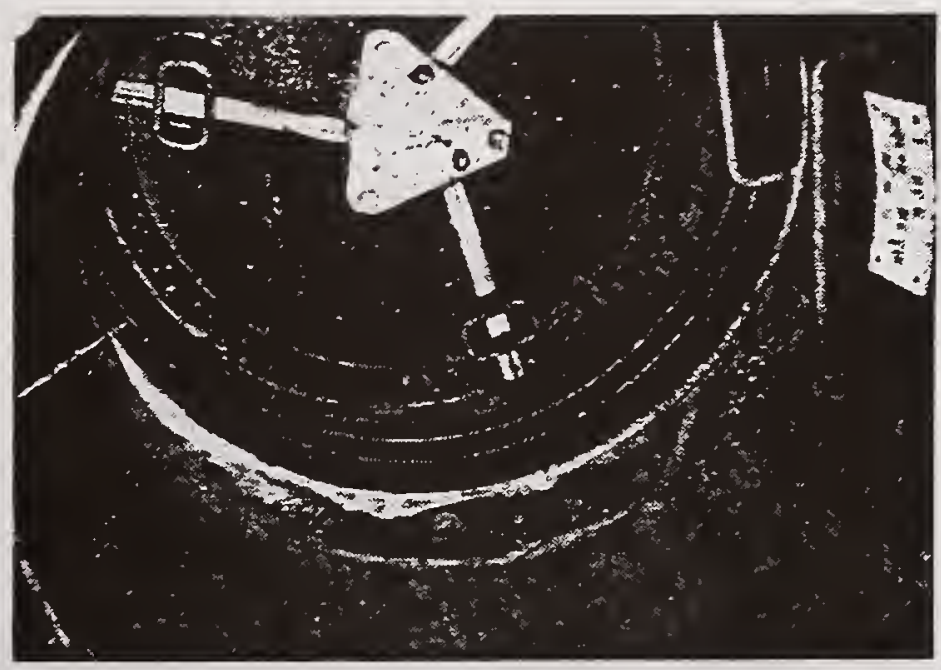

Photo 3 Cast iron manhole cover damage (offsetting) 


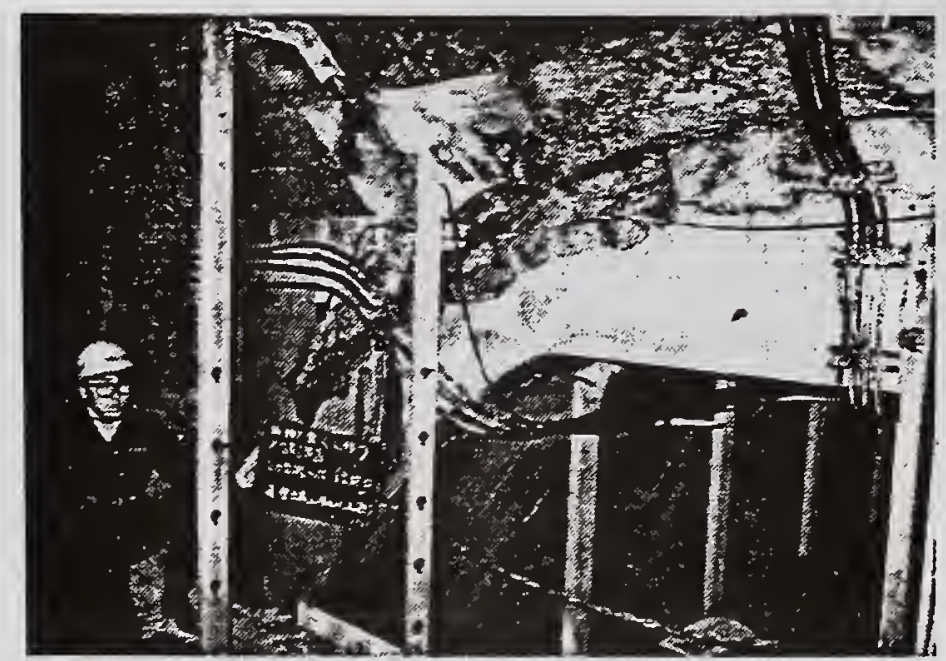

Photo 4 Shield tunnel shaft attachment damage (Tunnel has protruded approximately $1 \mathrm{~cm}$ into the interior of the shaft.)

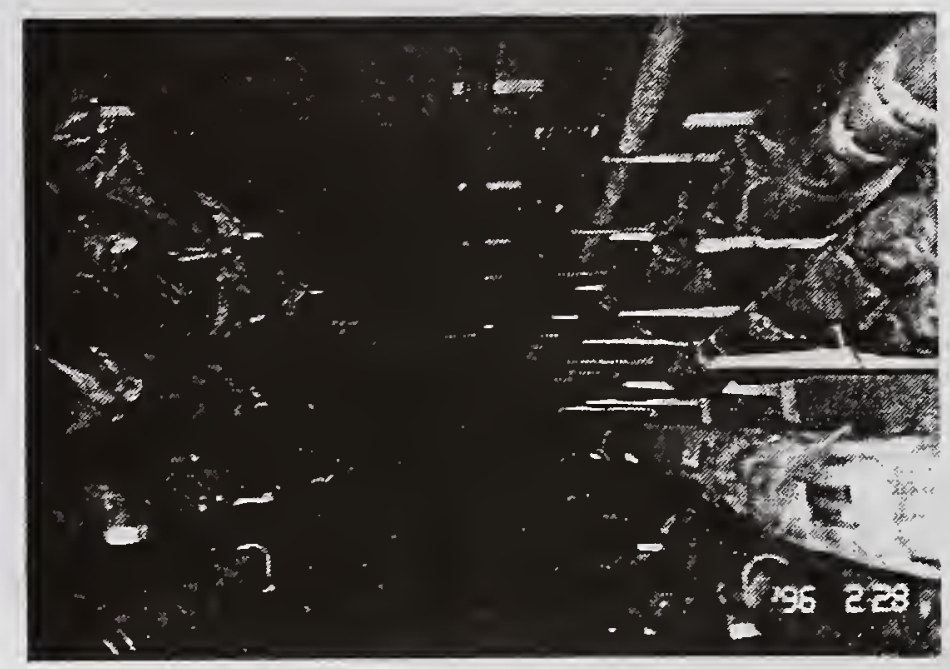

Photo 5 Conditions inside existing tunnels (Many communication cables are housed.)

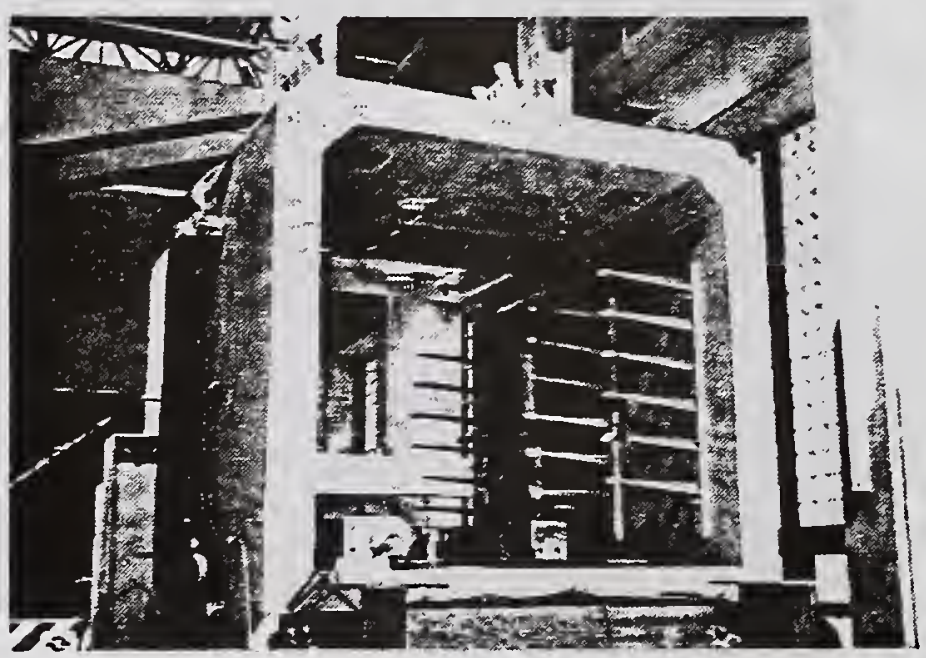

Photo 6 Flexible joint experiment for open-cut tunnels 


\title{
EFFECT OF LOAD PATH ON DAMAGE TO CONCRETE BRIDGE PIERS
}

\author{
by
}

\author{
Andrew W. Taylor ${ }^{1}$, Ashraf El-Bahy ${ }^{2}$, William Stone ${ }^{1}$ and Sashi Kunnath ${ }^{2}$
}

\begin{abstract}
In earthquake engineering studies of reinforced concrete (RC) bridge columns, a controlled, cyclic lateral load pattern with gradually increasing amplitude has traditionally been applied to laboratory test specimens. However, in actual earthquakes bridge columns are exposed to random cyclic lateral loading patterns, which are much different from typical laboratory loading patterns. Current American Association of State Highway and Transportation Officials (AASHTO) and California Department of Transportation (Caltrans) design provisions are based almost entirely on tests in which traditional, controlled laboratory loading patterns have been applied. The differences in the effects of these types of loading have never been explored systematically. In this study both types of loading (controlled, cyclic lateral loads, and random earthquake type loads) were applied to a series of twelve nominally identical, one-fourth scale circular, cantilever columns, and the differences in observed damage were studied. In this paper the experimental results are briefly summarized, and preliminary findings are discussed.
\end{abstract}

KEYWORDS: bridge columns; building technology; damage modeling; earthquake engineering; laboratory testing; random loading; reinforced concrete

\section{INTRODUCTION}

The purpose of this study is to explore both experimentally and analytically the relationship between load path and the inelastic damage induced in reinforced concrete bridge columns. Here "load path" is meant to describe the series of lateral displacements applied at the top of the column. If cyclic lateral loading causes inelastic behavior of a bridge column, the type and extent of damage induced in the column will depend on the order in which the displacements are applied. That is, damage induced by inelastic deformations is pathdependent. In this study a variety of load paths were applied to reinforced concrete bridge columns to investigate the nature of the dependency of damage on load path.

Over the last 25 years, in laboratories around the world, a large number of tests have been performed in which cyclic lateral displacements were applied to the top of cantilever reinforced concrete columns. Although the purpose of these tests was to study the seismic response of the columns, the displacement pattern applied to the columns in most cases did not resemble the displacements induced by an earthquake. The displacement patterns were usually in the form of a sawtooth wave, often with gradually increasing amplitude, as illustrated in Figure 1. However, earthquakes impart displacement patterns with random amplitudes, as shown in Figure 2. The seismic design provisions of the American Association of State Highway and Transportation Officials (AASHTO) and of the California Department of Transportation (Caltrans) are based almost entirely on tests in which the applied displacement pattern had a form similar to that shown in Figure 1. The tests conducted in this study are intended to investigate the relationship between regular, sawtooth displacement patterns widely applied in the laboratory (Figure 1), and the random displacement patterns induced by earthquakes (Figure 2).

\footnotetext{
${ }^{1}$ Structures Division, Building and Fire Research Laboratory, National Institute of Standards and Technology, Gaithersburg, Maryland, USA, 20899

${ }^{2}$ Department of Civil Engineering, University of Central Florida, Orlando, Florida, USA, 32816
} 
The experimental portion of this study consisted of laboratory tests of 12 nominally identical bridge columns which were subjected to a variety of cyclic lateral displacement patterns. These displacement patterns were in the form of sawtooth waves of constant amplitude, sawtooth waves of gradually increasing amplitude, and random displacement patterns which simulated earthquakes of various intensities. Observations were made of the progress of damage, both visually and with instrumentation. When a specimen was subjected to earthquake-type loads, several simulated earthquakes were applied sequentially to study the effects of multiple earthquakes on the same bridge column (Figure 2). The earthquake displacement patterns applied to the columns were determined from prior nonlinear dynamic analyses of the columns, using recorded earthquake accelerograms as input to the analysis. This process is explained further in Section 3.

The analytical portion of the study includes the formulation and verification of damage model hypotheses. The key feature sought in a damage model is that it apply equally to damage incurred either from a sawtooth wave displacement pattern, or a random displacement pattern. The data gathered from the 12 specimens in this study enable the testing of damage model hypotheses against both types of displacement histories.

In this paper the results of the experimental program are briefly summarized, and observations relevant to damage modeling are discussed. Since analysis of the laboratory data is still ongoing, preliminary findings are presented here. Detailed descriptions of both the experiments and analytical study will be presented in a forthcoming report.

\section{EXPERIMENTAL PROGRAM}

Figure 3 shows a test specimen and the loading apparatus. The specimens had circular cross sections and were nominally identical. The scale of the specimens was $1: 4$, and the full scale pier on which the design was based conformed to California Department of Transportation (Caltrans) specifications (Caltrans, 1992). The specimens were cast in an inverted position with an integral base block. Figure 4 shows the arrangement of reinforcement in the specimen and base block.
The column confining reinforcement was a continuous smooth spiral wire, which extended through the depth of the specimen base block. Longitudinal reinforcement consisted of 21 deformed bars distributed around the perimeter of the spiral, extending into the base block and terminating in hooks. The measured strength of the concrete (using 150 $\mathrm{mm}$ by $300 \mathrm{~mm}$ cylinders) was $38 \mathrm{MPa}$. The maximum concrete aggregate size was $13 \mathrm{~mm}$. The yield strength of the longitudinal reinforcement was $414 \mathrm{MPa}$, and the yield strength of the spiral reinforcement was 427 $\mathrm{MPa}$.

As shown in Figure 3, additional re-usable base block sections were joined to the specimen base block with post tensioning rods, and the entire base block assembly was posttensioned to the laboratory strong floor, forming a rigid base. A constant vertical load of 10 percent of the axial capacity of the gross column section was applied through a $200 \mathrm{kN}$ capacity vertical servo-hydraulic actuator. A $670 \mathrm{kN}$ capacity actuator was used to apply cyclic lateral displacements. This second actuator was controlled by a computer and servo-hydraulic system, which were programmed to apply specific lateral displacement patterns to the top of the column. The measured lateral load was corrected to account for the lateral component of the vertical actuator. A system of horizontal guide rails and ball bearing rollers, located at the top of the column, maintained the in-plane alignment of the column during testing. These rails and rollers are not shown in Figure 3 for clarity. Instrumentation consisted of load cells and displacement transducers (LVDT's) for each hydraulic actuator, an array of horizontal LVDT's to measure lateral displacement over the height of the specimen, strain gages on selected longitudinal reinforcing bars near the base of the column, clip-on external strain gages to measure curvature near the base of the column, and inclinometers to measure rotation near the base of the column.

\section{DISPLACEMENT HISTORIES}

Two types of displacement histories were applied to the specimens in this study: regular, controlled 2-D sawtooth patterns, which have historically been applied in most laboratory tests; and random 2-D patterns, which simulate earthquake loading. Both types of 
displacement histories were applied slowly, in a pseudo-dynamic mode.

The load paths of the first six specimens are illustrated in Figure 5. Specimen 1 was subjected to monotonically increasing lateral displacement to failure. Since all specimens are nominally identical, this test established basic parameters, such as initial lateral stiffness, displacement at first yield, and ultimate lateral strength, which were used in planning subsequent tests. Specimen 2 was subjected to a "standard". laboratory displacement history, detailed in Figure 1. While there is in fact no commonly accepted "standard" displacement history, many researchers have used a displacement pattern similar to that shown in Figure 1. Several cycles are applied initially at a displacement $\Delta \mathrm{y}$, which causes first yielding of the column longitudinal reinforcement. These cycles are followed by a single cycle of small amplitude which is used to measure the change in initial tangent stiffness of the column. As shown in Figure 1, subsequent groups of cycles are applied with increasing amplitudes. This continues until substantial degradation of the lateral load carrying capacity of the column is observed, usually defined as the point at which the maximum lateral load in a cycle is only 75 percent to 80 percent of the peak lateral load capacity measured during the test. Specimens 3 to 6 were subjected to constant-amplitude cycles (of $\pm 2 \Delta y, \pm 3 \Delta y, \pm 4 \Delta y$, and $\pm 5 \Delta y$, respectively) until severe deterioration of the column was observed. These tests provided data for calibration of analytical damage models which reflect damage accumulated during constant amplitude cycling.

A typical displacement history for Specimens 7 to 12 is shown in Figure 2. The details of the displacement histories for these specimens are shown in Table 1. These last six specimens were used to study the effects of real earthquake displacement histories on accumulation of damage, particularly over a series of events of varying intensity. The displacement patterns applied to Specimens 7 to 12 were derived from measured earthquake acceleration records, using the following process. Given an earthquake acceleration record, the deformation history at the top of the column was computed using the inelastic dynamic analysis program IDARC (Kunnath et al. 1992). IDARC computes the response of the column by taking into account the degradation in stiffness, lateral strength and energy dissipation capacity (pinching of the hysteresis loops) which occur as inelastic deformations progress over the course of the earthquake. The degree of stiffness degradation, strength degradation and pinching are controlled by three parameters $\alpha$, $\beta$, and $\gamma$. These parameters are determined $a$ priori, either empirically, based on past experience with tests on similar members (Kunnath et al. 1992), or analytically using correlation rules which relate $\alpha, \beta$ and $\gamma$ to the geometric and material properties of the column cross section (Stone and Taylor, 1991, 1993).

The earthquake records used in tests 7 to 12 were selected from a pool of available strong ground motion records recorded at bedrock sites in the state of California, and one record from Mexico City. Each specimen was subjected to a series of up to five earthquakes. Table 1 shows that earthquakes of a range of intensities were applied, and the order in which they were applied was varied. The pool of available earthquake records was subdivided into two main categories: minor events and major events. Minor events were intended to simulate either isolated low-intensity earthquakes, or low intensity aftershocks following a major earthquake. Minor events would cause little or no damage to the specimens in this test program, as determined from the results of the constant amplitude tests (Specimens 3 to 6). Based on observations from these tests, minor events were defined as those which caused three to five excursions into the inelastic range, with ductility demands no greater than $3 \Delta y$. Major events were divided into two types: damaging earthquakes and maximum credible events. Again, based on the results of the earlier constant-amplitude tests, damaging events were defined as those which caused multiple excursions into the inelastic range, with ductility demands greater than $3 \Delta y$, but generally less than $5 \Delta y$. The earlier tests showed that this level of ductility demand caused deterioration of the column, but that the column retained much of its strength and stiffness. Maximum credible events were those which caused cycles with ductility demands greater than $5 \Delta y$. The earlier tests also showed that just a few excursions greater than $5 \Delta y$ resulted in rapid deterioration of strength and stiffness. In some cases, where acceleration records were not available which met the desired criteria, the records were modified by simple amplitude 
scaling. These scale factors are reported in Table 1.

\section{OBSERVATIONS AND DAMAGE MODELING}

Preliminary observations from the experimental program are presented here. The experimental data is currently being analyzed, and detailed descriptions of the experimental results will be presented in a forthcoming report. The experiments are discussed in terms of two categories: the constant amplitude tests and the random amplitude (earthquake loading) tests.

\subsection{Constant Amplitude Tests}

It was observed that repeated cycling of Specimen 3 at a displacement amplitude of $\pm 2 \Delta y$ caused almost no degradation of stiffness and strength of the column. After the first full cycle at $\pm 2 \Delta y$ (during which initial yielding and cracking occurred) the hysteresis loops remained extremely stable, lying nearly on top of one another for 150 cycles. The test was stopped at 150 cycles not because the column failed, but because it was believed that no further useful information could be obtained by continuing the test. At the other extreme, Specimen 6 was subjected to cycles of $\pm 5 \Delta y$ and exhibited a rapid decrease in strength and stiffness, nearly completely losing lateral stiffness and load capacity after only 5 cycles. This rapid deterioration is illustrated in Figure 6. Specimen 5, which was cycled at $\pm 4 \Delta y$, exhibited a gradual decrease in strength and stiffness as cycling progressed (Figure 7), but the decrease was not nearly as rapid as for Specimen 6. This is illustrated in Figure 7.

Thus, for the specimens tested in this program there appears to be a threshold ductility level, of about $4 \Delta y$, above which deterioration is rapid and severe. It could be surmised that earthquakes which induce displacements of less than $4 \Delta y$ in the columns tested in this program would cause much less damage than those which induce displacements greater than $4 \Delta \mathrm{y}$. Indeed, subsequent testing under earthquake displacement patterns (Specimens 7 to 12) confirmed this observation: a series of several minor events, which caused few excursions greater than $2 \Delta y$, would result in very little damage to a column, while a single earthquake with a few excursions greater than $4 \Delta y$ would result in rapid deterioration of strength and stiffness. The apparent threshold of $4 \Delta y$ applies only to the columns tested in this program. It could be expected that similarlydesigned circular columns, with high ratios of confining reinforcement (such as those designed under the Caltrans specifications), and which were dominated by flexural rather than shearing deformations, would also exhibit such a threshold, but the level of the threshold would not necessarily be $4 \Delta \mathrm{y}$.

Another significant observation from the constant amplitude tests was that cumulative dissipated energy (the area contained within the hysteresis loops) is not good predictor of column failure. It was found that the cumulative dissipated energy at failure depended on the amplitude of the sawtooth wave. Figure 8 shows the accumulation of energy to failure for Specimens 2, 4, 5 and 6 ("standard" displacement pattern, $\pm 3 \Delta y, \pm 4 \Delta y$, and $\pm 5 \Delta y$, respectively). Results for Specimen 3 are not plotted because the specimen did not deteriorate significantly under 150 cycles at $\pm 2 \Delta y$, so a failure state was not achieved. In Figure 8 it can be seen that dissipated energy at failure is strongly dependent on the displacement history. Therefore, because of the highly variable nature of earthquakeinduced displacement histories, it is apparent that cumulative energy alone is not an acceptable measure of column damage.

\subsection{Earthquake Loading Tests}

A typical lateral load-displacement plot for one of the earthquake loading tests is shown in Figure 9. The two main observations made in these tests are described below.

First, it was observed that "minor" events (Table 1) had little or no effect on the ultimate failure of a column. That is, it made no difference if minor events occurred before or after a damaging event: the level of damage following the damaging event was essentially the same in both cases. This has important implications for the management of earthquake damage to bridge columns. It would appear that minor seismic events should be considered to have little effect on wellconfined, circular, flexure-dominated bridge columns. It remains for transportation authorities to define precisely what a "minor" event is, but it appears acceptable to not discount the strength and stiffness of wellconfined columns which have been subjected to a minor earthquake. 
Second, it was observed that failure of the columns could be classified into two general types: failure due to low cycle fatigue of the longitudinal reinforcement, called here a "low cycle fatigue failure"; and failure due to rupture of confining reinforcement, or "confinement failure." Confinement failures were observed to occur more frequently than low cycle fatigue failures. While these two classes of failure have been observed and reported by others, it is interesting to recall that the only variable in these tests was the displacement history. Thus displacement history, rather than the column configuration, determined the failure mode. This illustrates the importance of conducting nonlinear dynamic analyses of bridge columns whenever feasible, and considering a range of possible ground motions at the bridge site, rather than permitting a single earthquake record to determine the design.

With regard to analytical damage modeling, preliminary analyses of the test results indicate that cumulative fatigue models, based on variations of the classic Miner's rule (Miner 1945) for metals, can successfully track damage in columns which fail due to low cycle fatigue of the longitudinal reinforcement. However, this same approach does not apply well to columns which exhibit confinement failure. Other methods of modeling confinement failure are currently being investigated. Furthermore, the columns tested in this study were dominated by flexural behavior, and none of the findings stated here necessarily apply to short, shear-dominated columns. A similar experimental investigation of shear-dominated columns is planned.

\section{CONCLUSIONS}

The main findings of this study to date are summarized below. Since interpretation of the test data is still ongoing, these findings must be considered preliminary.

1) There appears to be a threshold ductility level for well-confined, circular, flexuredominated columns above which degradation of stiffness and strength is rapid. For the columns tested in this study this threshold ductility level was about $4 \Delta y$. Below this threshold degradation was more gradual, and for ductility demands of $2 \Delta y$ or less degradation was minimal.

2) The constant amplitude tests in this study confirm that cumulative dissipated energy at failure is strongly path dependent. Therefore cumulative energy by itself is not a reliable measure of column damage.

3) Minor earthquakes appear to have very little influence on the damage exhibited by wellconfined, circular, flexure-dominated bridge columns in subsequent major events. While the precise definition of a "minor" event is open to interpretation, this study indicates that the strength and stiffness of a well-confined, circular, flexure-dominated bridge column should not be discounted because the column has been subjected to minor events.

4) The random loading tests indicate that failure mode is path dependent. Nominally identical columns failed either due to lowcycle fatigue of longitudinal reinforcement, or due to rupture of confining reinforcement. The only variable between tests was the load path. The relationship between load path and failure mode is currently under study.

5) Cumulative fatigue methods, based on Miner's rule for fatigue of metals, appear to predict well the progress of damage in columns which failed due to low cycle fatigue of longitudinal bars. However, Miner's rule does not apply to those columns which failed due to rupture of the confining reinforcement. Other damage models are being investigated which may apply to confinement failure. Furthermore, the findings of this study apply only to well-confined, circular, flexuredominated columns. A future study is planned to investigate well-confined, circular, shear-dominated columns.

\section{ACKNOWLEDGMENTS}

The authors gratefully acknowledge the financial support of the National Center for Earthquake Engineering Research (NCEER), the California Department of Transportation (Caltrans), and the Federal Highway Administration (FHWA). 


\section{REFERENCES}

Caltrans (1992), "Bridge Design Specifications," State of California, Department of Transportation (Caltrans), Office of Structure Design, Sacramento, California, August 1986 (revisions to December 1992).

Kunnath, S.K., Reinhorn, A.M., and Lobo, R.F. (1992), "IDARC Version 3.0, A Program for the Inelastic Damage Analysis of Reinforced Concrete Structures," Report NCEER-92-0022, National Center for Earthquake Engineering Research, State University of New York at Buffalo, August 1992.

Miner, M.A. (1945), "Cumulative Damage in Fatigue," Journal of Applied Mechanics, Vol. 12, 1945, p. A-159.
Stone, W.C., and Taylor, A.W. (1991), "System Identification of Spirally Reinforced Circular Bridge Columns Subjected to Cyclic Lateral Loading," Wind and Seismic Effects; Proceedings, 23rd Joint Meeting UJNR, NIST SP 820, National Institute of Standards and Technology, Gaithersburg, Maryland, September 1991, pp 269-293.

Stone, W.C., and Taylor, A.W. (1993), "Seismic Performance of Circular Bridge Columns Designed in Accordance with AASHTO/CALTRANS Standards," BSS-170, National Institute of Standards and Technology, Gaithersburg, Maryland, February 1993.

Table 1: Earthquake records applied to Specimens 7 to 12

\begin{tabular}{|c|c|c|c|c|c|c|}
\hline $\begin{array}{c}\text { Spec. } \\
\text { No. }\end{array}$ & $\begin{array}{c}\text { Event } \\
\text { No. }\end{array}$ & $\begin{array}{l}\text { Description: } \\
\text { Event Severity } \\
\text { and Number }\end{array}$ & $\begin{array}{c}\text { Purpose } \\
\text { of Applying Event } \\
\text { to Column }\end{array}$ & Earthquake Record & $\begin{array}{l}\text { Scale } \\
\text { Factor }\end{array}$ & $\begin{array}{l}\text { Scaled } \\
\text { PGA } \\
\text { g's }\end{array}$ \\
\hline \multirow{4}{*}{7} & 1 & Damaging No. 1 & Significant damage & Loma Prieta 1989 , Presidio & 12.0 & 1.20 \\
\hline & 2 & Minor No. 1 & Aftershock & Imperial Valley 1979 , Superstition Mtn. & 1.8 & 0.34 \\
\hline & 3 & Minor No. 2 & Second aftershock & San Fernando 1971, 2011 Zonal Avenue & 1.2 & 0.10 \\
\hline & 4 & Damaging No. 2 & Failure of column & San Fernando 1971, 455 S. Figueroa St. & 3.6 & 0.54 \\
\hline \multirow{4}{*}{8} & 1 & Minor No. 1 & Minor damage & Imperial Valley 1979, Superstition Mtn. & 1.8 & 0.34 \\
\hline & 2 & Minor No. 2 & Minor damage & San Fernando 1971, 2011 Zonal Avenue & 1.2 & 0.10 \\
\hline & 3 & Damaging No. 1 & Significant damage & Loma Prieta 1989, Presidio & 12.0 & 1.20 \\
\hline & 4 & Damaging No. 2 & Failure of column & San Fernando 1971,455 S. Figueroa St. & 3.6 & 0.54 \\
\hline \multirow{5}{*}{9} & 1 & Damaging No. 3 & Significant damage & San Fernando 1971, Orion Boulevard & 3.25 & 1.43 \\
\hline & 2 & Minor No. 2 & Aftershock & San Fernando 1971, 2011 Zonal Avenue & 1.2 & 0.10 \\
\hline & 3 & Damaging No. 4 & Moderate damage & El Centro 1940 & 1.0 & 0.35 \\
\hline & 4 & Minor No. 3 & Aftershock & San Fernando 1971, 455 S. Figueroa St. & 1.0 & 0.15 \\
\hline & 5 & Damaging No. 3 & Failure of column & San Fernando 1971, Orion Boulevard & 3.25 & 1.43 \\
\hline \multirow{5}{*}{10} & 1 & Minor No. 2 & Minor damage & San Fernando 1971, 2011 Zonal Avenue & 1.2 & 0.10 \\
\hline & 2 & Damaging No. 4 & Moderate damage & El Centro 1940 & 1.0 & 0.35 \\
\hline & 3 & Minor No. 3 & Aftershock & San Fernando 1971, 455 S. Figueroa St. & 1.0 & 0.15 \\
\hline & 4 & Damaging No. 3 & Significant damage & San Fernando 1971, Orion Boulevard & 3.25 & 1.43 \\
\hline & 5 & Damaging No. 3 & Failure of column & San Fernando 1971, Orion Boulevard & 3.25 & 1.43 \\
\hline \multirow{4}{*}{11} & 1 & Damaging No. 4 & Significant damage & Northridge 1994, VA Hospital & 1.0 & 0.42 \\
\hline & 2 & Minor No. 4 & Aftershock & Northridge 1994, Griffith Observatory & 1.0 & 0.26 \\
\hline & 3 & Minor No. 5 & Minor damage & Taft 1952 & 1.0 & 0.36 \\
\hline & 4 & Damaging No. 5 & Failure of column & Mexico City 1985, SCT & 1.0 & 0.17 \\
\hline \multirow{4}{*}{12} & 1 & Minor No. 4 & Minor damage & Northridge 1994 , Griffith Observatory & 1.0 & 0.26 \\
\hline & 2 & Minor No. 5 & Minor damage & Taft 1952 & 1.0 & 0.36 \\
\hline & 3 & Damaging No. 4 & Significant damage & Northridge 1994, VA Hospital & 1.0 & 0.42 \\
\hline & 4 & Damaging No. 5 & Failure of column & Mexico City 1985, SCT & 1.0 & 0.17 \\
\hline
\end{tabular}




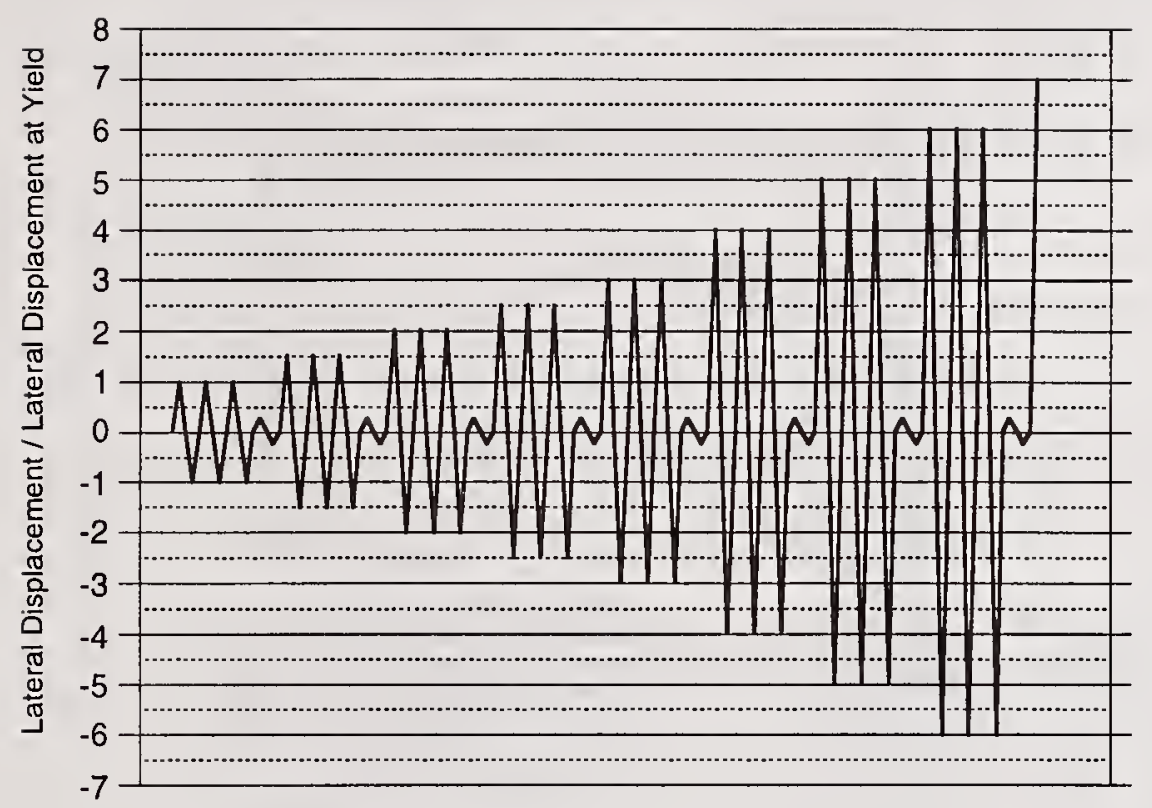

Figure 1: Typical laboratory displacement history, applied to Specimen 2

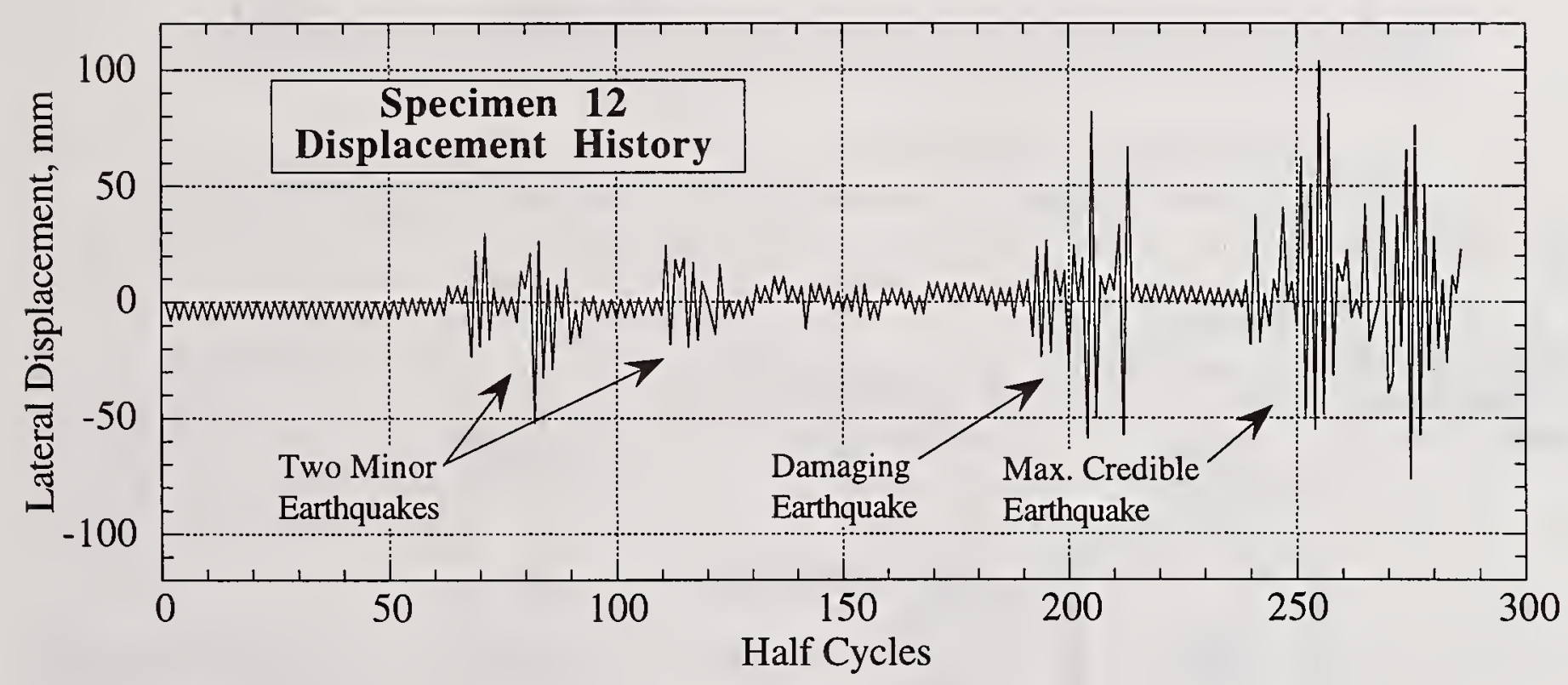

Figure 2: Typical earthquake displacement histories, applied to Specimen 12 


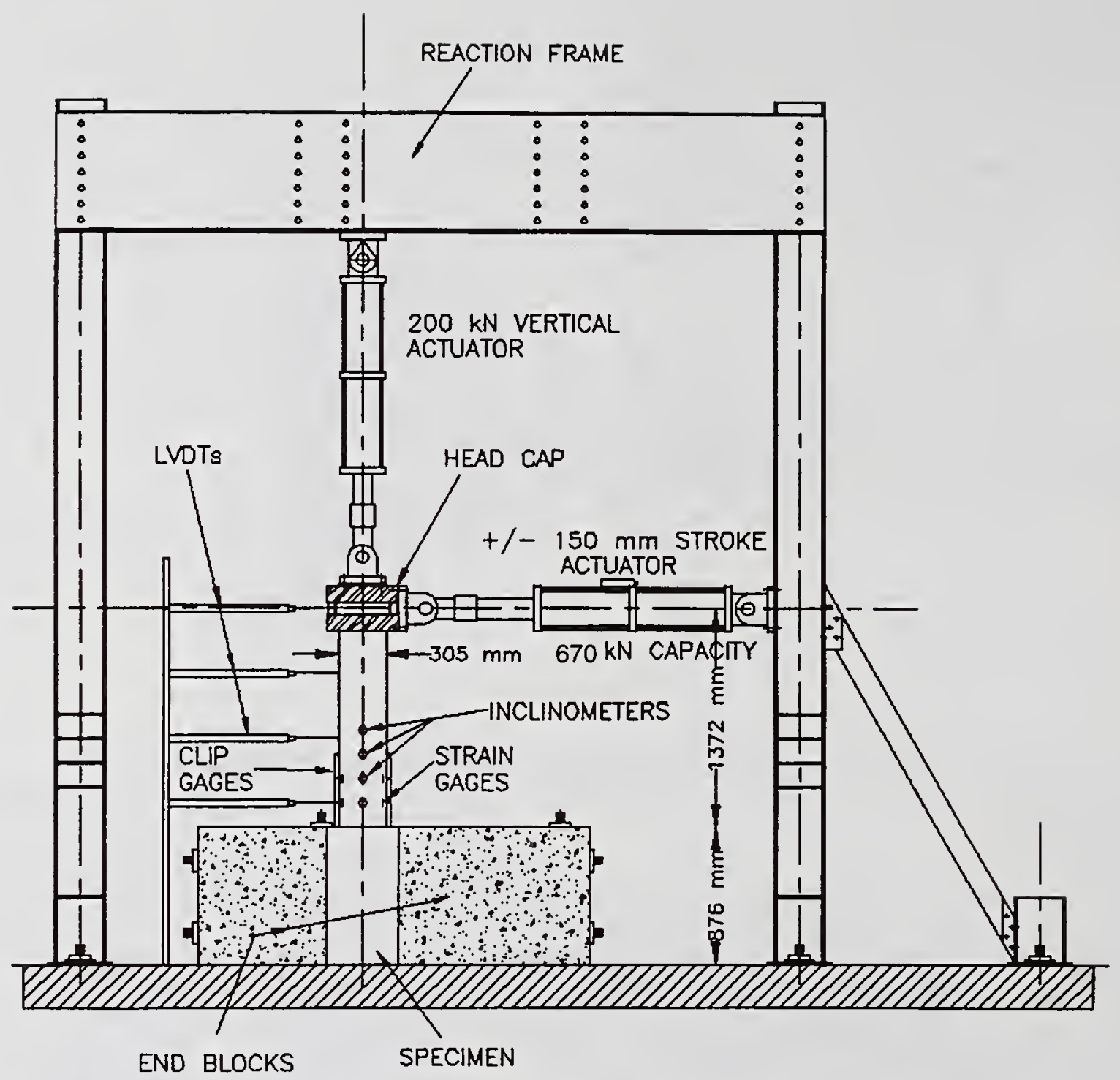

Figure 3: Load frame and instrumentation for cyclic lateral load tests
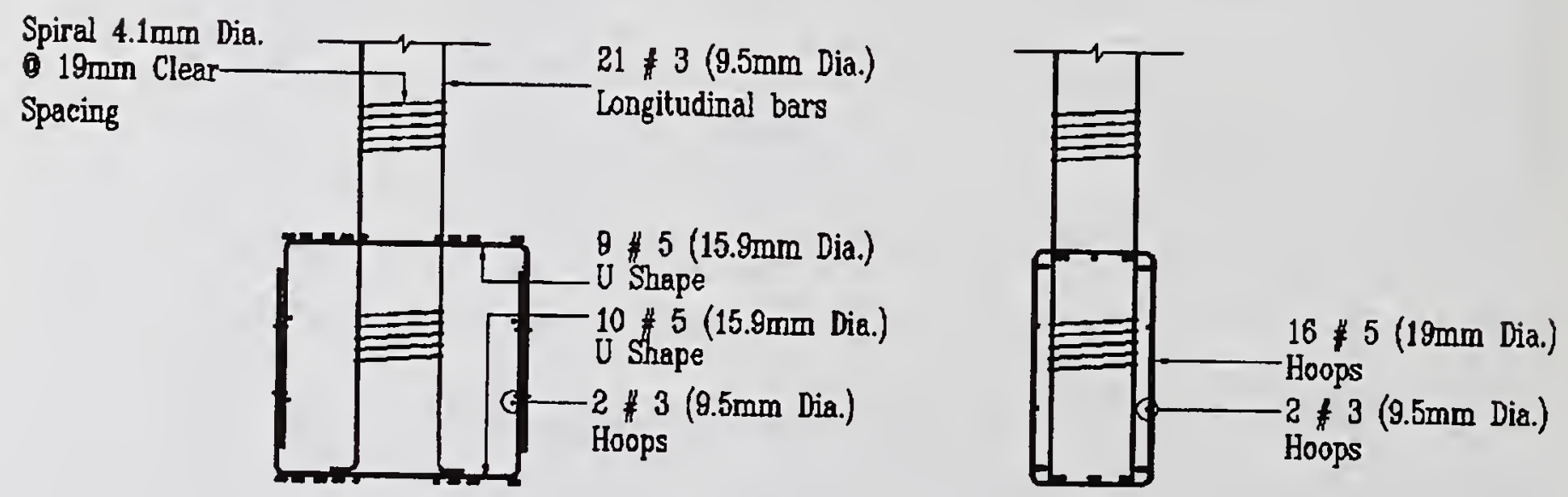

\section{Elevation}

Side View

Figure 4: Reinforcement details for column specimen and base block 


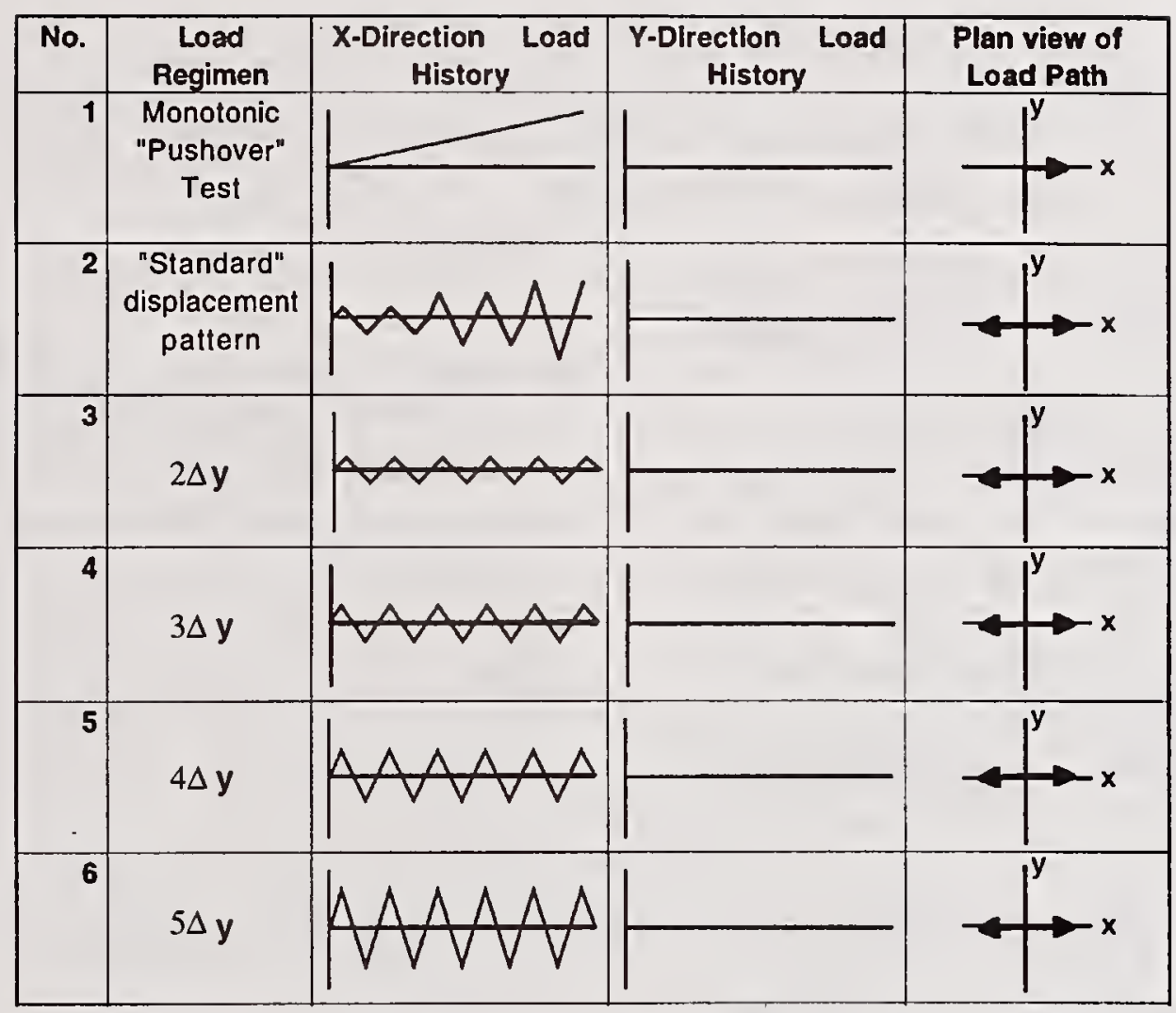

Figure 5: Displacement histories of Specimens 1 to 6
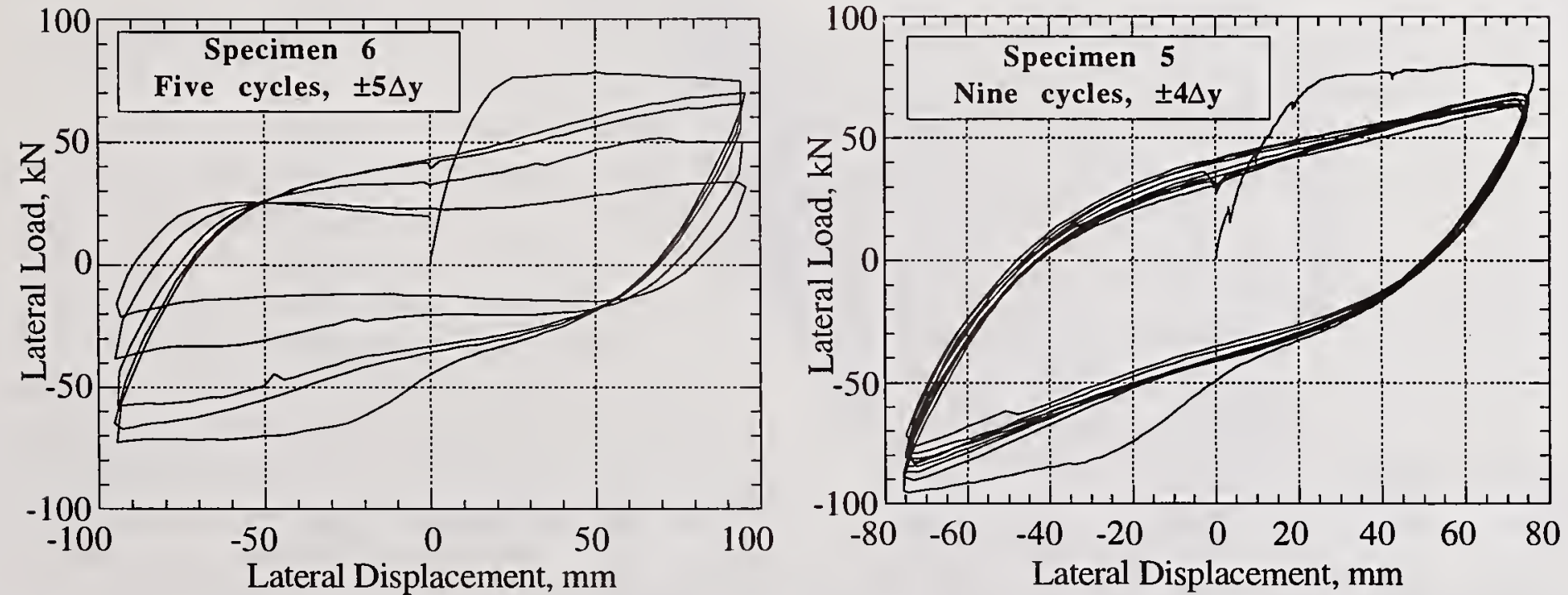

Figure 6: Lateral load-displacement plot, Spec. 6

Figure 7: Lateral load-displacement plot, Spec. 5 


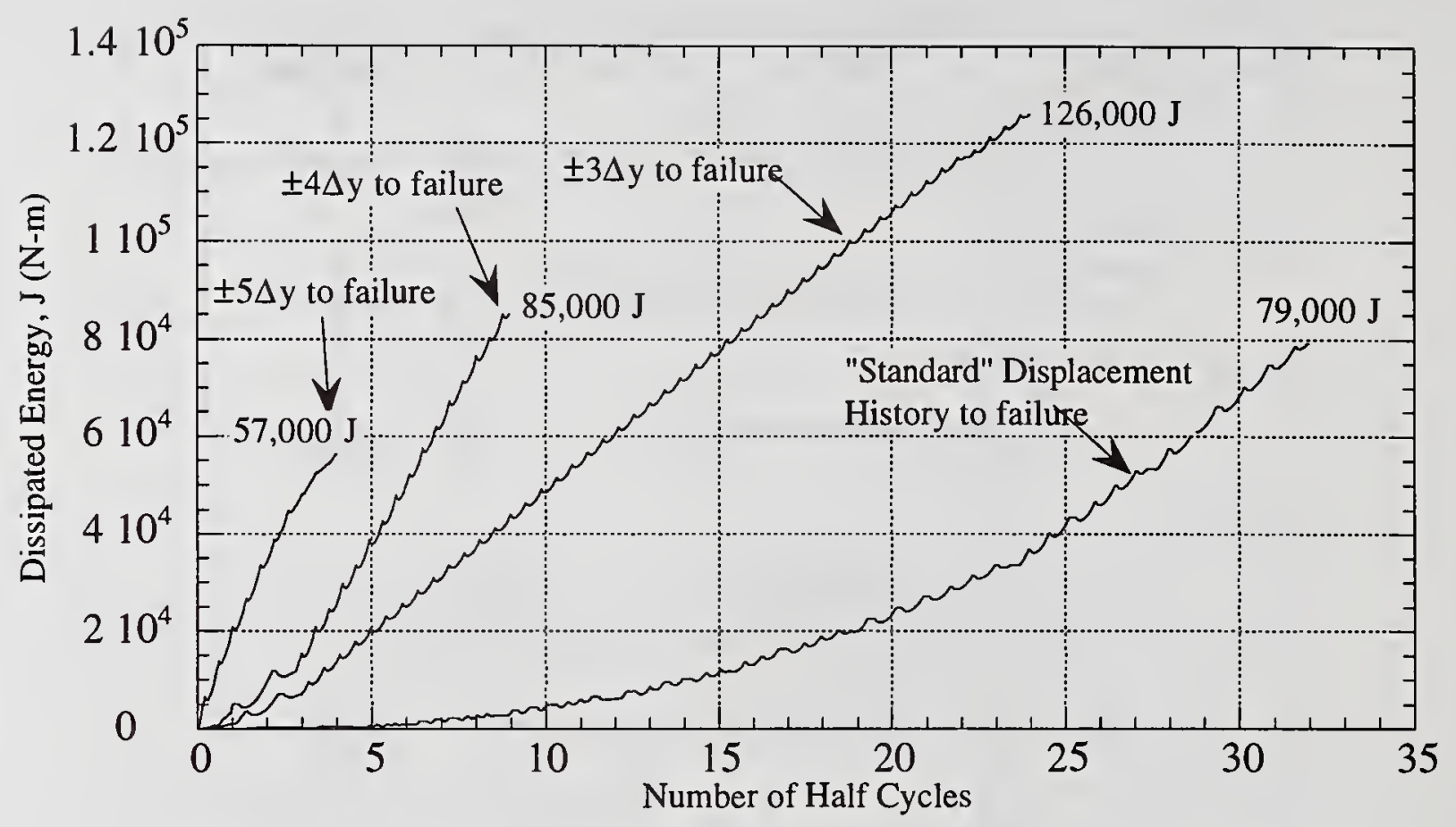

Figure 8: Cumulative energy to failure for Specimens 2, 4, 5 and 6

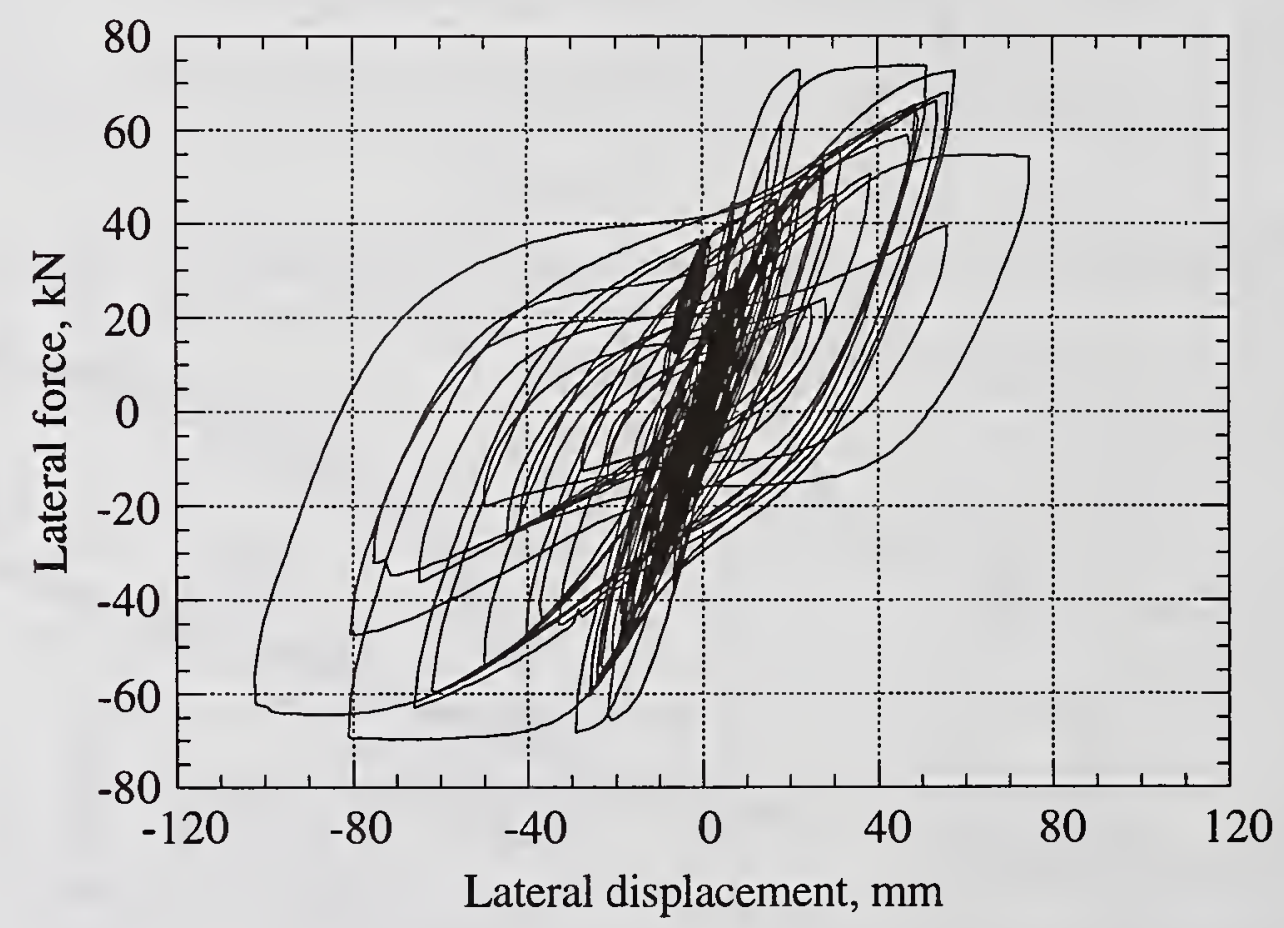

Figure 9: Lateral load-displacement plot for Specimen 12 


\title{
Guide Specifications for Reconstruction and Repair of Highway Bridges \\ Which Suffered Damage due to the Hyogo-ken Nanbu Earthquake
}

by

\author{
Kazuhiko KAWASHIMA ${ }^{1 \text { ) }}$, Kazuhiro NISHIKAWA ${ }^{2)}$, Masanori NAKANO ${ }^{3)}$ \\ Shigeki UNJOH $^{4}{ }^{\text {) }}$, Yoshitomi KIMURA ${ }^{5)}$ and Jun-ichi HOSHIKUMA ${ }^{6}$ )
}

\section{ABSTRACT}

The Hanshin/Awaji Earthquake (Hyogo-ken Nanbu Earthquake) of January 17, 1995 caused destructive damage to highway bridges. Obviously this was the first experience to cause destructive damage to structures since the 1923 Great Kanto Earthquake. Various tentative measures were taken for seismic design of reconstruction and repair of highway bridges which suffered damage due to the earthquake, seismic design of new bridges, and seismic strengthening of existing bridges.

This paper summarizes the "Guide Specifications for Reconstruction and Repair of Highway Bridges Which Suffered Damage due to the Hyogo-ken Nanbu Earthquake."

KEYWORDS : Hyogo-ken Nanbu Earthquake, Guide Specifications. Highway Bridges, Reconstructrion and Repair

\section{INTRODUCTION}

Highway bridges in Japan had been considered safe even against extreme earthquakes such as the Great Kanto Earthquake (M7.9) in 1923, because various past bitter experiences have been accumulated to formulate the seismic design method. Large lateral force coefficient ranging from $0.2 \mathrm{~g}$ to $0.3 \mathrm{~g}$ has been adopted in the allowable design approach. Various provisions for preventing damage due to instability of soils such as soil liquefaction have been used. Furthermore design details including the falling-down prevention devices have been adopted.

In fact, reflecting those provisions, numbers of lighway bridges which caused complete collapse of the superstructures was only 15 since the 1923 Great Kanto Earthquake. Based on this evidence, it has been regarded by the engineers and researchers in bridge seismic engineering that the seismic damage of highway bridges had been decreasing in recent year (3).

The Hanshin/Awaji Earthquake took place at Kobe and Awaji Island on January 17, 1995. exactly one year after the Northridge, California. USA, Earthquake, and it caused destructive damage to highway bridges. Falling-down and nearly falling-down of superstructures occurred at 9 sites. and other destructive damage occurred at 16 sites. Destructive earthquakes had not occurred at urban areas in recent years, and the earthquake revealed that there are various critical issues in seismic design and seismic strengthening of bridges in urban areas.

After the earthquake. the "Committee for Investigation on the Damage of Highway Bridges Caused by the Hyogo-ken Nanbu Earthquake (Hanshin/Awaji Earthquake)" was formulated in the Ministry of Construction to survey the damage and clarify the factors which contributed to the damage. The Committee was chaired by T. Iwasaki. Executive Director, Civil Engineering Research Laboratory. Members list is presented in an Appendix.

1) Professor, Department of Civil Engineering. Tokyo Institute of Technology

2) Head, Bridge Division, Structure and Bridge Department, Public Works Research Institute, Ministry of Construction

3) Head, Foundation Engineering Division. Structure and Bridge Department, ditto

4) Senior Research Engineer, Earthquake Engineering Division, Earthquake Disaster Prevention Department, ditto

5) Senior Research Engineer, Foundation Engineering Division, Structure and Bridge Department. ditto

6) Research Engineer. Earthquake Engineering Division, Earthquake Disaster Prevention Department, ditto 
On February 27. 1995, the Committee approved the Guide Specifications for Reconstruction and Repair of Highway Bridges Which Suffered Damage due to the Hyogo-ken Nanbu Earthquake (13). and the Ministry of Construction noticed on the same day that the reconstruction and repair of the highway bridges which suffered damage by the H/A Earthquake shall be made by the Guide Specifications. On March 30 . 1995. the Committee compiled the Interim Report on the Damage of Highway Bridges by the Hyogo-ken Nanbu Earthquake.

Although when the Guide Specifications was made there was a plan to prepare a tentative seismic design method which applies to new construction and seismic strengthening of existing highway bridges until the formal revision of the Design Specifications of Highway Bridges (4) is made, it was decided by the Ministry of Construction on May 25, 1995 that the Guide Specifications shall be tentatively used as an emergency measure for seismic design of new highway bridges and seismic strengthening of existing highway bridges until the Design Specifications of Highway Bridges is revised. Tentative measures provided in the Guide Specifications were considered appropriate for new construction and seismic strengthening.

In May. 1995, the Special Sub-Committee for Seismic Countermeasures for Highway Bridges was formulated in the Bridge Committee of the Japan Road Association. The Sub-Committee is chaired by K. Kawashima, Tokyo Institute of Technology, and its main role is to draft the revision of the Design Specifications of Highway Bridges. It is planned to complete the revision in 1996 fiscal year. Because there were various inquiries from field engineers on the application of the Guide Specifications to new construction and seismic strengthening, the Sub-Committee released on June 30, 1995 the Reference for Applying the Guide Specifications to New Bridges and Seismic Strengthening (5). It included several supplements on the way of application of the Guide Specifications as well as several design examples.

In December 1995, the Report on the Damage of Highway Bridges by the Hyogo-ken Nanbu Earthquake was issued by the Committee (12). The Report was essentially the same with the Interim Report. but statistical data on damage was updated, and damage of foundations was included.

This paper summarizes the "Guide Specifications for Reconstruction and Repair of Highway Bridges
Which Suffered Damage due to the Hyogo-ken Nanbu Earthquake" and the "Reference for Applying the Guide Specifications to New Highway Bridges and Seismic Strengthening of Existing Highway Bridges."

\section{SEISMIC DESIGN FOR RECONSTRUCTED BRIDGES AND REPAIR}

\subsection{General}

For seismic design of reconstruction of highway bridges that suffered damage due to the Hanshin/Awaji Earthquake, the "Guide Specifications for Reconstruction and Repair of Highway Bridges Which Suffered Damage due to the Hyogo-ken Nanbu Earthquake" (13) was issued by the Ministry of Construction on February 27, 1995 upon approval by the "Committee for Investigation on the Damage of Highway Bridges Caused by the Hyogo-ken Nanbu Earthquake." The Guide Specifications was applied only for reconstruction and repair of the highway bridges that suffered damage due to the Hanshin/Awaji Earthquake.

The table of contents of the Guide Specifications for Reconstruction and Repair was as:

1. General

2. Basic Principle of Seismic Design

3. Dynamic Response Analysis

\subsection{General}

3.2 Analytical Methods and Analytical Models

3.3 Input Ground Motions

4. Menshin Design

5. Check of Dynamic Strength and Ductility of Reinforced Concrete Piers

5.1 General

5.2 Stress-Strain Relation of Confined Concrete

\subsection{Hoops}

5.4 Treatment of Statically Eccentric Bending Moment

5.5 Treatment of P-Delta Effect

5.6 Termination of Main Reinforcements at Mid-height

6. Check of Dynamic Strength and Ductility of Concrete Infilled Steel Piers

6.1 General

6.2 Evaluation of Dynamic Strength and Ductility

6.3 Treatment of P-Delta Effect

7. Check of Dynamic Strength and Deformation Capability of Foundations 
7.1 General

7.2 Basic Principle for Check of Dynamic Strength and Deformation Capability

8. Bearing Supports and Surroundings

9. Falling-down Prevention Devices

10. Treatment for Lateral Spreading of Soils due to Soil Liquefaction

The following outlines the Guide Specifications.

\subsection{Basic Principle of Seismic Design}

The bridges shall be designed so that they can withstand with enough structural safety against the Hanshin/Awaji Earthquake. To achieve this goal, following basic principles shall be considered.

(1) To increase the ductility of whole bridge systems, dynamic strength and ductility shall be assured for whole structural members in which seismic effect is predominant. Although the check of dynamic strength and ductility has been adopted for reinforced concrete piers since 1990 , it has not been applied for other structural members such as steel piers and foundations.

(2) Seismic safety against the Hanshin/Awaji Earthquake shall be verified by dynamic response analysis considering nonlinear behavior of structural members.

(3) In design of elevated continuous bridges, it is appropriate to adopt the Menshin Design for distributing lateral force of superstructure to many substructures. The Menshin Design is close to the seismic isolation, but the emphasis is placed to increase energy dissipating capability and to distribute lateral force of deck to substructures $(9,13)$.

(4) Enough tie reinforcements to assure the ductility shall be provided in reinforced concrete piers, and the termination of main reinforcements at mid-height shall not be made.

(5) Concrete shall be filled in steel piers to assure dynamic strength and ductility. Steel piers designed by the current practice developed local bucking at web and flange plates although they were stiffened by longitudinal stiffeners and diaphragms. This tends to cause sudden decrease of bearing capacity in lateral direction after the peak strength and therefore less energy dissipation is anticipated. This subsequently deteriorates the bearing capacity of steel piers in vertical direction. Because it is now at the stage that technical developments are being made to avoid such behavior, it was decided to tentatively use steel piers with infilled concrete for reconstruction and repair.

(6) Foundations shall be designed so that they have enough dynamic strength and deformation capability for lateral force. The dynamic strength and deformation capability of foundations shall be larger than the flexural strength and ductility of piers to prevent damage at foundations.

(7) It is suggested to further use nubber bearings because they absorb relative displacements dereloped between a superstructure and substructures. In design of bearings, correct mechanism of force transfer from a superstructure to substructures shall be considered.

(8) The devices to prevent falling-down of a superstructure from substrictures shall be designed so that they can assure falling-down of decks. Attention shall be paid so as to dissipate energy and to increase strength and deformation capability.

(9) At those sites where potential to cause lateral spreading associated with soil liquefaction is high. its effect shall be considered in design. Because technical information to evaluate earth pressure in laterally spreading soils is limited, it is important to recognize that such evidence exists and that countermeasures shall be taken in any possible ways.

\subsection{Dynamic Response Analysis}

Besides the dynamic response analysis described in the "Part V Seismic Design" of the 1990 Design Specifications of Highway Bridges," dynamic behavior of bridges shall be carefully clarified by nonlinear dynamic response analysis, and result of the analysis shall be reflected in design.

In the dynamic response analysis, the ground motion that was recorded during the Hanshin/Awaji Earthquake with the largest intensity of ground acceleration shall be used as an input to assure the seismic safety of bridges against the Hanshin/Awaji Earthquake. The acceleration recorded at JMA Kobe Observatory as shown in Fig. 2-1 may be regarded as the input motion. Clarification of appropriate ground motion needs to be made based on future research. In Fig. 2-2, response spectra for ground motions at JR Takatori Station (15) and Higashi Kobe Bridge (Route 5, Bay Shore Line of the Hanshin Expressway) by the Hanshin/Awaji Earthquake, JMA Kushiro Observatory by the 1993 Kushiro-oki Earthquake, and Sylmar Parking Lot by the 1994 Northridge Earthquake (1) are presented for comparison.

\subsection{Menshin Design}

It is appropriate to adopt the Menshin Design to mitigate shocks associated with deck response and to reduce lateral force by increasing energy dissipation. 
Emphasis shall be placed to distribute lateral force to as many substructures as possible, and to increase energy dissipation capability. Excessive elongation of natural period to reduce lateral force shall not be made, because this increases response displacement of a deck. This causes various disadvantage such as an increase of noise and vibration associated with the adoption of large expansion joints. The Menshin Design shall not be used at the sites where potential for soil liquefaction and unstability of weak clayey materials is high. The "Manual for Menshin Design of Highway Bridges" $(8,11)$ issued in 1992 as an outcome of the Joint Research between the Public Works Research Institute and private companies may be refereed to in the Menshin Design.

For introducing the Menshin Design for existing simply supported bridges. it is suggested to connect simply supported girders to make the superstructures continuous. The "Reference for Design and Construction to Eliminate Expansion Joints from Existing Bridges" (18) issued by the Road Maintenance Center in 1995 may be refereed to for this purpose.

\subsection{Check of Dynamic Strength and Ductility of Reinforced Concrete Piers}

The check of dynamic strength and ductility shall be made for reinforced concrete piers after they are designed by the static lateral force method. The current provisions for the check were expanded in the Guide Specifications as:

(1) For evaluating the strength and the ductility of piers. the effect of confinement of concrete by ties has not been precisely considered in the current Design Specifications. A new stress-strain relation of confined concrete as shown in Fig. 2-3 was introduced (7). The "ultimate strain" was defined as the strain where concrete strength decreases $20 \%$ from its peak value.

(2) Enough ties shall be provided to assure ductility. Ties shall be of deformed bars with diameter larger than $13 \mathrm{~mm}$. The minimum interval of ties was decreased from $30 \mathrm{~cm}$ to $15 \mathrm{~cm}$ to increase ductility and shear strength. The interval of ties shall not be suddenly changed but smoothly changed to prevent sudden decrease of strength along piers.

Intermediate ties were newly introduced in rectangular piers to assure the confinement. Diameter and material of the intermediate ties shall be the same with those of the ties, and shall be placed at each level where ties are placed. The spacing of intermediate ties in lateral direction shall be less than $100 \mathrm{~cm}$.

(3) In the inverted "L" (or. "C") piers. eccentric bending moment is induced in piers due to the dead weight of decks. Such effect shall be considered in the check of dynamic strength and ductility.

(4) For slender piers, the P-delta effect sliall be considered in the check of dynamic strength and ductility.

(6) Termination of main reinforcement at mid-height shall not be made. in principle, to prevent shear failure at the terminated points.

2.6 Check of Dynamic Strength and Ductility of Concrete-Infilled Steel Piers

Although various researches have been made for dynamic strength and ductility of steel piers, they are not still sufficient to provide general stipulations for the check of dynamic strength and ductility of steel piers. Therefore, it was suggested to tentatively infill concrete in steel piers for reconstruction and repair. The procedure for the check of dynamic strength and ductility of concrete infilled steel piers follows 2.5 with some appropriate modifications.

\subsection{Check of Dynamic Strength and Ductility of Foundations}

Because the allowable stress design approach has been used for foundations, appropriate design methods for the check of dynamic strength and ductility (deformation capability) have not yet developed for foundations. It was therefore proposed to check the safety of foundations tentatively assuming that the flexural strength of piers evaluated in 4.5 shall be applied to the footing as a seismic lateral force to the foundation. In this evaluation. the safety factor for the allowable stress design were increased.

\subsection{Design of Bearings and Surroundings}

Bearings have several functions, i.e., they need to support dead weight of a superstructure and live load. allow relative movement due to elongation/shrinkage of decks, support seismic lateral force. and prevent excessive lateral movement and uplift during earthquakes. Because various functions concentrate at bearings, this makes the structure of bearings complicated. Thus. the bearings tend to be damaged during earthquakes. It was therefore suggested to provide separate structural components to share the function of bearings. This may be made by providing additional members to prevent the uplift or excessive 
relative movement.

Adoption of rubber bearings, in particular Menshin bearings that has energy dissipating capability. was recommended. Because the rubber bearings allow relative movement to occur in various directions, they are generally free from damage.

Bearings and surrounding parts of a superstructure shall be designed considering the mechanism of lateral force transfer from superstructure to substructures. For example, when tall bearings such as pin/roller type bearings are adopted, a bending moment is induced associated with the distance between the gravity center of a deck where lateral force is applied and the bottom of bearings where lateral force is supported. Although such bending moment has been ignored in the past, this shall be considered to properly design bearings and surroundings.

Bearings shall be designed so that the ultimate strength is larger than the force developed during the extreme earthquakes.

2.9 Devices to Prevent Falling-down of Superstructure from Substructure

In the current Design Specifications, it is stipulated that at both ends of superstructure, either the seat length $S_{E}$ or the installation of the devices for preventing falling-down of a superstructure from substructures shall be adopted. In the Guide Specifications, it was described to provide both the seat length and the installation of falling-down prevention devices. The falling-down prevention devices shall be so designed that they are safe against the lateral force not only in longitudinal direction but in transverse direction, and that the portion of the decks where the falling-down prevention devices are connected to should have enough strength to prevent rupture. It was suggested to adopt the falling-down prevention devices with energy dissipation capability.

\subsection{Countermeasures against Lateral Spreading associated with Soil Liquefaction}

At the sites where foundations are close to rivers and channels and where the potential of liquefaction is high and the liquefiable sandy layer is inclined, effect of lateral spreading shall be taken into account in design. Because it is difficult at this moment to properly evaluate the earth pressure due to the lateral spreading, general engineering judgment is required.
3. REFERENCE FOR APPLYING GUIDE SPECIFICATIONS TO NEW HIGHWAY BRIDGES AND SEISMIC STRENGTHENING OF EXISTING HIGHWAY BRIDGES

\subsection{General}

For increasing seismic safety of the highway bridges which suffered damage by the Hanshin/Awaji Earthquake, various new drastic changes were tentatively introduced in the Guide Specifications for Reconstruction and Repair of Highway Bridges Which Suffered Damage due to the Hyogo-ken Nanbu Earthquake. Although intensified review of design could be made when it was applied to the bridges only in the Hanshin area, it may not be so easy for field design engineers to following up the new Guide Specifications when the Guide Specifications is used for seismic design of all new highway bridges and seismic strengthening of existing highway bridges. Based on such demand, the Reference for Applying the Guide Specifications to New Bridges and Seismic Strengthening of Existing Bridges was issued on June 30, 1995 by the Sub-Committee for Seismic Countermeasures for Highway Bridges, Japan Road Association (5). Several educational seminars were held with use of the Reference at major cities such as Tokyo, Osaka, Nagoya, Hiroshima, Fukuoka and Sapporo, with the participants over 3,000 .

The table of contents of the Reference was as:

I . Application of the Guide Specifications

II . Examples of Seismic Design for New Bridges

1. Supplements

1.1 Ground Motion for Nonlinear Dynamic Response Analysis and Seismic Design Force

1.2 Check of Dynamic Strength and Deformation Capability of Foundations

1.3 Design of Falling-down Prevention Devices

1.4 Countermeasures for Soil Liquefaction

1.5 Others

2. Examples of Seismic Design

2.1 Design Example for a New Bridge Supported by Reinforced Concrete Piers

2.2 Design Example for a New Bridge Supported by Concrete Infilled Steel Piers

2.3 Design Example for a Menshin Bridge

III .Examples of Seismic Strengthening of Existing Bridges

1. Supplements 
1.1 Seismic Strengthening of Reinforced Concrete Piers

1.2 Falling-down Prevention Devices for Existing Bridges

2. Examples of Seismic Strengthening

2.1 Design Example of Seismic Strengthening for Reinforced Concrete Piers

2.2 Design Example of Falling-down Prevention Devices

\subsection{Application of the Guide Specifications}

The Reference classified the application of the Guide Specifications as shown in Table 3-1 based on the importance of the roads. All items of the Guide Specifications are applied for bridges on extremely important roads, while some items which prevent brittle failure of structural components are applied for bridges on important roads. For example, for bridges on the important roads, the items for menshin design, tie reinforcements, termination of longitudinal reinforcements, type of bearings, falling-down prevention devices and countermeasures for soil liquefaction are applied. while the remaining items such as the design force, concrete infilled steel bridges, and ductility check for foundations are not applied.

\subsection{Ground Accelerations Used for Nonlinear} Dynamic Response Analysis and Seismic Coefficient for Check of Ductility and Dynamic Strength

As reference ground motions used for nonlinear dynamic response analysis, the strong ground motion accelerations recorded by the H/A Earthquake at JMA Kobe Observatory. JR Takatori Station (15), and Higashi-Kobe Bridge (Route 5, Bay Shore Line of the Hanshin Expressway) were suggested for analysis of bridges at the Type I, II and III soil condition, respectively.

In addition to the seismic coefficient specified in the current Design Specifications for the check of ductility and dynamic strength, it was also suggested to use the seismic coefficient as

$$
\mathrm{khc}=\mathrm{c} 2 \cdot \mathrm{khco}
$$

where. $k h_{c}=$ seismic coefficient for check of ductility and dynamic strength, $\mathrm{k} \mathrm{h} \mathrm{co}=$ standard seismic coefficient and given by Table $3-2$, and $\mathrm{c}$. =zoning coefficient.

The standard seismic coefficient in Table 3-2 was tentatively provided by taking envelopes of the acceleration response spectra (damping ratio of 0.05 ) of the records measured by the Hanshin/Awaji Earthquake. The modification of the response spectra in terms of the damping ratio vs. natural period relation was incorporated (10). At mid-range natural period, was assumed to be larger at Type I ground condition (Stiff sites) than Type II (moderate) and Type III (soft soil sites) ground conditions. This reflects the fact that surface ground accelerations were smaller than the accelerations in underground at soft soil sites.

\subsection{Seismic Design of Foundations}

The check of ductility and dynamic strength (deformation capability) of foundations was more quantitatively presented. In pile foundations, the check is made as follows:

First, a foundation is analyzed by the displacement method, in which a foundation is so idealized that a rigid footing is supported by piles which are elastically supported by soils. The flexural strength of a pier shall be applied as a seismic force to foundations at the bottom of the footing together with the dead weight of superstructure. pier and soils on the footing. Safety of the foundation shall be checked so that 1) vertical load induced in piles shall be less than half of their ultimate bearing capacity. 2) lateral displacement of footing shall be less than about $30 \mathrm{~mm}$, and 3) bending moment developed in piles shall be less than their yielding moment.

When unreasonable size was required in the foundation designed by the displacement method, the nonlinear method shall be used. In the nonlinear method, a foundation is idealized as shown in Fig. 3-1. Nonlinear parameters for vertical strength. uplift. lateral movement and soil springs shall be evaluated according to the Part IV Foundations of the Design Specifications of Highway Bridges. Nonlinearity of piles shall be evaluated in the same way to reinforced concrete piers.

\subsection{Design of Falling-down Prevention Devices}

It was tentatively suggested that the following force shall be used as a design force of falling-down prevention devices.

$$
P=R_{d}
$$

where $R_{d}$ represents a reaction force at the bearing. If the reaction force is different between the adjacent 
girders, the larger value shall be used in Eq. (3-2) for restrainers which tie together two approaching girders. Allowable stress should not be increased in design of falling-down prevention devices.

Because $R_{d}$ times twice of the seismic coefficient has been so far used, Eq. (3-2) provides almost twice as large lateral force than the previous design force. Because the allowable stress has been increased $50 \%$, actual design force for falling-down prevention devices was increased almost 3 times.

Rigid type restrainers should not be used to connect two adjacent girders if the size of the two girders is significantly different. The size of the two adjacent girders should be regarded significantly different when the reaction forces of the two girders are different by a factor of 2 or the fundamental natural periods of the two structural systems are different by a factor of 1.5 .

It was suggested to provide some redundancy in the seat length in the following conditions:

(1) skew bridge (tentatively, bridges with skew angle less than 60 degree) and curved bridges (tentatively, bridges with curvature less than $100 \mathrm{~m}$ and angle formed by both ends less than 30 degree)

(2) bridges supported by slender piers with long natural period (tentatively, bridges with natural period longer than 2 second)

(3) bridges which tend to have large lateral displacement in foundations due to soil liquefaction/ lateral spreading

(4) bridges supported by slender columns with extremely short seat length

It was also suggested to provide falling-down prevention devices not only in longitudinal direction but also in transverse direction in the following bridges:

(1) skew bridge (tentatively, bridges with skew angle less than 60 degree) and curved bridges (tentatively, bridges with curvature less than $100 \mathrm{~m}$ and angle formed by both ends less than 30 degree)

(2) bridges with Gerber joints

(3) bridges supported by slender columns with very short seat length

\subsection{Termination of Longitudinal Reinforcements}

It was described in the Guide Specifications that longitudinal reinforcements shall not be terminated at mid-heights. This was acceptable because there were few bridges which were supported by tall piers in the damaged area. However, when the Guide Specifications are used nationwide, there are bridges which are supported by tall piers. Therefore. the following minimum heights were suggested if the termination is inevitable.

$$
h_{i}=H\left(1-M_{\text {y }} \text { i } / 2 M_{\text {y в }}\right)+b
$$

where, $h_{i}=i$-th height from the bottom where longitudinal reinforcements are terminated. $\mathrm{H}=$ height of a pier, $M_{\text {y }}$ - =yielding moment of a pier at $\mathrm{i}$-th terminated point, $M_{\text {у в }}=y$ ielding bending moment of a pier at bottom, and $b=$ smaller dimension between longitudinal and transverse widths of a pier.

Furthermore, it was suggested as follows:

(1) Longitudinal reinforcements should not be terminated between the bottom and 2 times $b$ from it.

(2) Longitudinal reinforcements should not be at once reduced more that $1 / 3$.

(3) Outside longitudinal reinforcements should not be terminated.

\subsection{Intermediate Ties for Circular Reinforced Concrete Columns}

It was suggested in the Guide Specifications that the intermediate ties are not required for circular reinforced concrete piers. However, they are effective to increase shear strength even in the circular piers. while confinement effect may be small. It was therefore suggested to tentatively provide the intermediate ties at every other ties in circular reinforced concrete piers. In the circular piers. the intermediate ties can be considered to contribute to shear strength, but it should not be considered to evaluate ductility in terms of the tie reinforcement ratio. It was described in the Guide Specifications that the intermediate ties can be considered to evaluate shear strength and the confinement effect in the rectangular piers.

\subsection{Seismic Strengthening of Existing Reinforced Concrete Columns \\ Because damage concentrated to single reinforced} concrete piers/columns with small concrete section. seismic strengthening is being initiated for those columns, which were designed by the pre- 1980 Design Specifications, at extremely important bridges. Main purpose of the seismic strengthening of reinforced concrete columns is to increase their shear strength, in particular in the piers with termination of 
longitudinal reinforcements without enough anchoring length. This increases ductility of columns, because premature shear failure could be avoided.

However if only ductility of piers is increased, residual displacements developed at piers after an earthquake may increase. Therefore the flexural strength should also be increased. However the increase of flexural strength of piers tends to increase the seismic force transferred from the piers to the foundations. It was found from an analysis to various types of foundations that failure of the foundations by increasing the seismic force may not be significant if the increasing rate of the flexural strength of piers is less than 2. It is therefore suggested to increase the flexural strength of piers within this limit so that it does not cause serious damage to foundations.

For such requirements, seismic strengthening by Steel Jackets with Controlled Increase of Flexural Strength was suggested. This uses steel jacket surrounding the existing columns as shown in Fig. 3-2. Epoxy resin or non shrinkage concrete mortar are injected between the concrete surface ands the steel jacket. A small gap is provided at the bottom of piers between the steel jacket and the top of footing. This prevents to excessively increase the flexural strength.

To increase the flexural strength of columns in a controlled manner, anchor bolts are provided at the bottom of the steel jacket. They are drilled into the footing. By selecting appropriate number and size of the anchor bolts, the degree of increase of the flexural strength of piers may be controlled. The gap is required to trigger the flexural failure at the bottom of columns. A series of loading tests are being conducted at the Public Works Research Institute to check the appropriate gap and number of anchor bolts. Table 3-3 shows a tentatively suggested thickness of steel jackets and size and number of anchor bolts. They are for reinforced concrete columns with a/b less than 3 , in which $\mathrm{a}$ and $\mathrm{b}$ represent the width of column in transverse and longitudinal direction, respectively. The size and number of anchor bolts were evaluated so that the increasing rate of flexural strength of columns is less than about 2 .

\section{CONCLUDING REMARKS}

The Hanshin/Awaji Earthquake was the first earthquake that hit an urban area in recent years, and revealed that various technical developments are required in both seismic design and seismic strengthening for mitigating the damage of highway bridges against extreme inland earthquakes.

This paper summarizes the Guide Specifications for Reconstruction and Repair of Highway Bridges Which Suffered Damage due to the Hyogo-ken Nanbu Earthquake and the Reference for Applying Guide Specifications to New Highway Bridges and Seismic Strengthening of Existing Highway Bridges. This was one of a series of actions taken for seismic design and seismic strengthening of highway bridges in about a year since the earthquake.

The Special Sub-Committee for Seismic Countermeasures for Highway Bridges in the Bridge Committee of the Japan Road Association is drafting the revision of the Design Specifications of Highway Bridges. This will include various lessons learned from the Hanshin/Awaji earthquake. It is planned to complete the revision in 1996 fiscal year.

\section{ACKNOWLEDGMENTS}

The contents presented here were the works conducted at the Seismic Design Working Group in the Ministry of Construction under the general guidance by the "Committee for Investigation on the Damage of Highway Bridges Caused by the Hyogo-ken Nanbu Earthuqake." The authors thanks the kind guidance and supports from the all Committee members. Special appreciation goes to Dr. T. Iwasaki, chairman of the committee. Messer. N. Miayata, Y. Iwasaki, and S. Kikuchi. Headquaters of the Ministiry of Construction.

\section{APPENDIX}

Committee Members for Investigation on The Damage of Highway Bridges Caused by The Hyogo-ken Nanbu Earthquake

Dr. T. Iwasaki, Exective Director, Civil Engineering Research Laboratory (Chairman)

Dr. Y. Fujino,Professor, Univesrity of Tokyo

Dr. H. Iemura, Professor. Kyoto Univertsity

Dr. S. Ikeda, Professor, Yokohama National University

Dr. H. Kameda, Professor, Kyoto University

Dr. T. Katayama, Professor, University of Tokyo

Dr. K. Kawashima, Professor. Tokyo Institute of Technology

Dr. Y. Onishi, Professor, Kyoto University

Mr. S. Saeki, Honshu-Shikoku Bridge Authority

Dr. K. Toki, Professor, Kyoto University 


\section{REFERENCES}

1) California Department of Conservation: Processed CSMIP Strong Motion Records from the Northridge. Califonia Earthquake of January 17, 1994, Office of Strong Motion Studies, 1994

2) Hoshikuma, J., Kawashima, K., Nagaya, K.: A Stress-Strain Model for Reinforced Concrete Bridge Piers Confined by Hoop Reinforcement, Proc. 2nd US-Japan Workshop on Seismic Retrofit of Bridges, Berkeley, CA, USA, 1994

3) Japan Road Association: Guide Specifications for Earthquake Hazard Mitigation for Road Transportation Facilities, Pre Earthquake Countenneasures, 1987

4) Japan Road Association: Design Specifications of Highway Bridges- Part I Common Part, Part II Steel Bridges, Part III Concrete Bridges, Part IV Substructures, and Part V Seismic Design, 1990

5) Japan Road Association: Reference for Applying the "Guide Specifications for Reconstruction and Repair of Highway Bridges Which Suffered Damage due to the Hyogo-ken Nanbu Earthquake" to New Highway Bridges and Seismic Strengthening of Existing Highway Bridges. 1995

6) Japan Society of Civil Engineers: Standard Specifications of Concrete, 1931, 1940, 1949, 1956, 1967, 1974, 1977, 1980

7) Kawashima, K., Unjoh, S. and Iida, H. : Seismic Inspection and Seismic Strengthening of Highway Bridges in Japan. Proc. 4th US-Japan Workshop on Earthquake Disaster Prevention for Lifeline Systems, Los Angeles, CA, USA, 1991

8) Kawashima, K., Hasegawa. K., and Nagashima, H.: Manual for Menshin Design of Highway Bridges. Proc. 24th Joint Meeting. Panel on Wind and Seismic Effects. UJNR, Gaithersburg. MD, USA. 1992

9) Kawashima, K. and Hasegawa, K: New Seismic Design Specifications of Highway Bridges in Japan, Earthquake Spectra, Vol.10, No.2, 1994

10) Kawashima, K.: Seismic Design Force of Bridges. Proc. 2nd Intemational Workshop on Seismic Design and Retrofitting of Reinforced Concrete Bridges. Queenstown New Zealand, 1994

11) Ministry of Constnuction: Manual for Menshin Design of Highway Bridges, 1992

12) Ministry of Construction: Report on the Damage of Highway Bridges by the Hyogo-ken Nanbu
Earthquake. Committee for Investigation on the Damage of Highway Bridges Caused by the Hyogo-ken Nanbu Earthquake. 1995

13) Ministry of Constnuction: Guide Specifications for Reconstruction and Repair of Highway Bridges Which Suffered Damage due to the Hyogo-ken Nanbu Earthquake, 1995

14) Miyaji. A.: Road Disaster Prevention Measures. Journal of Road, Japan Road Association. 1990

15) Nakamura. Y.: Waveform and Its Analysis of the 1995 Hyogo-ken Nanbu Earthquake. JR Earthquake Information. No.23c. Railway Technical Research Institute. 1995

16) Narita, N., Murakami, M. and Asanuma. H.: Report of the Investigation on Earthquake Damage to Shizunai Bridge. 15th Joint Meeting. US-Japan Panel on Wind and Seismic Effects. UJNR, Tsukuba, Japan. 1983

17) Ozaka, Y.. Suzuki, M.. Miyamoto. M. and Kobayashi, S.: Evaluation of Shear Strength of RC Beams with Termination of Longitudinal Reinforcements, Proc. JSCE, 378/V-1, 1987

18) Road Maintenance Center: Reference for Design and Construction to Eliminate Expansion Joints from Existing Bridges, 1995

19) Takeda, T., Sozen, M. A.. and Nielsen. N. N.: Reinforced Concrete Response to Simulate Earthquakes, Journal of Structural Engineering. ASCE, 96-12, 1970 
Table 3-1 Application of the Guide Specifications

Table 3-2 Standard Coefficient $\mathrm{k} n \mathrm{co}$

Table 3-3 Steel Jacket and Anchor Bolts

Fig. 2-1 Accelerations Measured at JMA Kobe Observatory and Computed

(a) N-S Component

(b) E-W Component

(c) U-D Component

Fig. 2-2 Response Spectra ( $\mathrm{h}=0.05)$ at JMA Kobe Observatory (NS) in comparison with the Ground Earthquake, JMA Kushiro Observatory by the 1993 Kushiro-oki Earthquake, and Sylmar Parking Lot by the 1994 Northridge Earthquake

Fig. 2-3 Stress-Strain Relation for Concrete Confined by Ties

Fig. 3-1 Idealization of Pile Foundation in the Nonlinear Analysis

Fig. 3-2 Seismic Strengthening of Reinforced Concrete Piers by Steel Jacket with Controlled Increase of Flexural Strength 
Table 3-1 Application of the Guide Specifications

\begin{tabular}{|c|c|c|}
\hline Type of Roads and Bridges & $\begin{array}{c}\text { Double Deckers, Overcrossings on } \\
\text { Roads and Railways, Extremely } \\
\text { Important Bridges from Disaster } \\
\text { Prevention and Road Network }\end{array}$ & Others \\
\hline $\begin{array}{c}\text { Expressways, Urban Expressways, } \\
\text { Designated Urban Expressways, } \\
\text { Honshu Shikoku Bridges, } \\
\text { Designated National Highways }\end{array}$ & Apply all items, in principle & Apply all items, in principle \\
\hline $\begin{array}{c}\text { Non-designated National Highways, } \\
\text { Ken Roads, City, Town and Village } \\
\text { Roads }\end{array}$ & Apply all items, in principle & Apply partially, in principie \\
\hline
\end{tabular}

Table 3-2 Standard Coefficient $\mathrm{k} \mathrm{h} c \mathrm{o}$

\begin{tabular}{|c|c|c|c|}
\hline \multirow{2}{*}{ Group I } & $T_{E Q}<0.3 \mathrm{~s}$ & $0.3 \leqq T_{E Q} \leqq 0.7 \mathrm{~s}$ & $0.7 \mathrm{~s}<T_{E Q}$ \\
& $k_{h c 0}=4.46 T_{E Q} 2 / 3$ & $k_{h c 0}=2.0$ & $k_{h c 0}=1.24 T_{E Q}-4 / 3$ \\
\hline \multirow{2}{*}{ Group II } & $T_{E Q}<0.4 \mathrm{~s}$ & $0.4 \leqq T_{E Q} \leqq 1.2 \mathrm{~s}$ & $1.2 \mathrm{~s}<T_{E Q}$ \\
& $k_{h c 0}=3.22 T_{E Q} 2 / 3$ & $k_{h c 0}=1.75$ & $k_{h c 0}=2.23 T_{E Q}-4 / 3$ \\
\hline \multirow{2}{*}{ Group III } & $T_{E Q}<0.5 \mathrm{~s}$ & $0.5 \leqq T_{E Q} \leqq 1.5 \mathrm{~s}$ & $1.5 \mathrm{~s}<T_{E Q}$ \\
& $k_{h c 0}=2.38 T_{E Q} 2 / 3$ & $k_{h c 0}=1.50$ & $k_{h c 0}=2.57 T_{E Q}-1 / 3$ \\
\hline
\end{tabular}

Table 3-3 Steel Jacket and Anchor Bolts

\begin{tabular}{|c|c|c|}
\hline Columns/Piers & Steel Jackets & Anchor Bolts \\
\cline { 1 - 2 } $\mathrm{a} / \mathrm{b} \leqq 2$ & SS $400, \mathrm{t}=9 \mathrm{~mm}$ & \multirow{2}{*}{ SD 295, D35 ctc $250 \mathrm{~mm}$} \\
\cline { 1 - 2 } $2<\mathrm{a} / \mathrm{b} \leqq 3$ & SS $+00, \mathrm{t}=12 \mathrm{~mm}$ & \\
\hline $\begin{array}{c}\text { Columns supporting Lateral Force } \\
\text { through Fixed Bearings and with } \mathrm{a} / \mathrm{b} \leqq 3\end{array}$ & \\
\hline
\end{tabular}



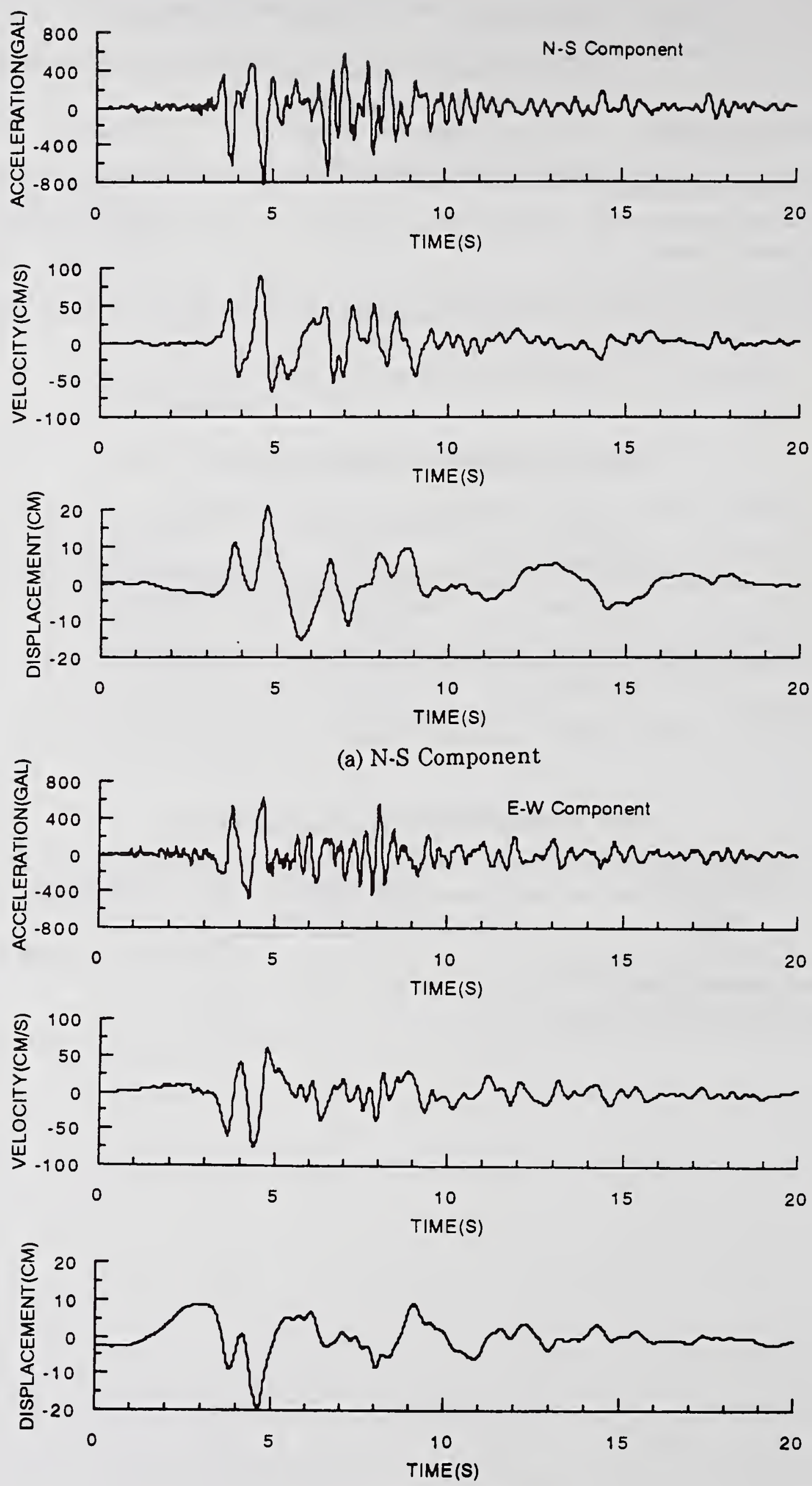

(b) E-W Component 

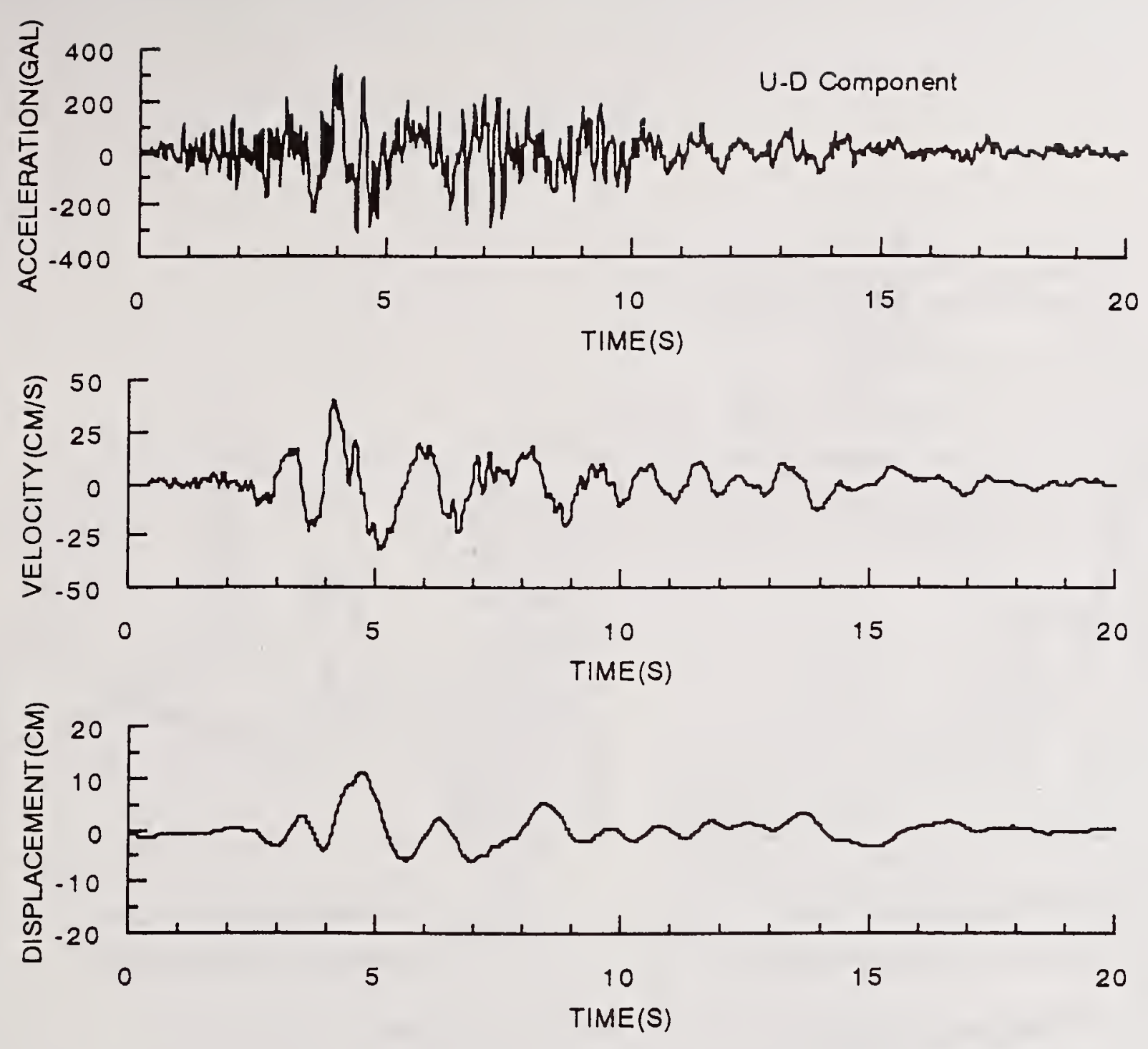

(c) U.D Component

Fig. 2-1 Accelerations Measured at JMA Kobe Observatory and Computed 


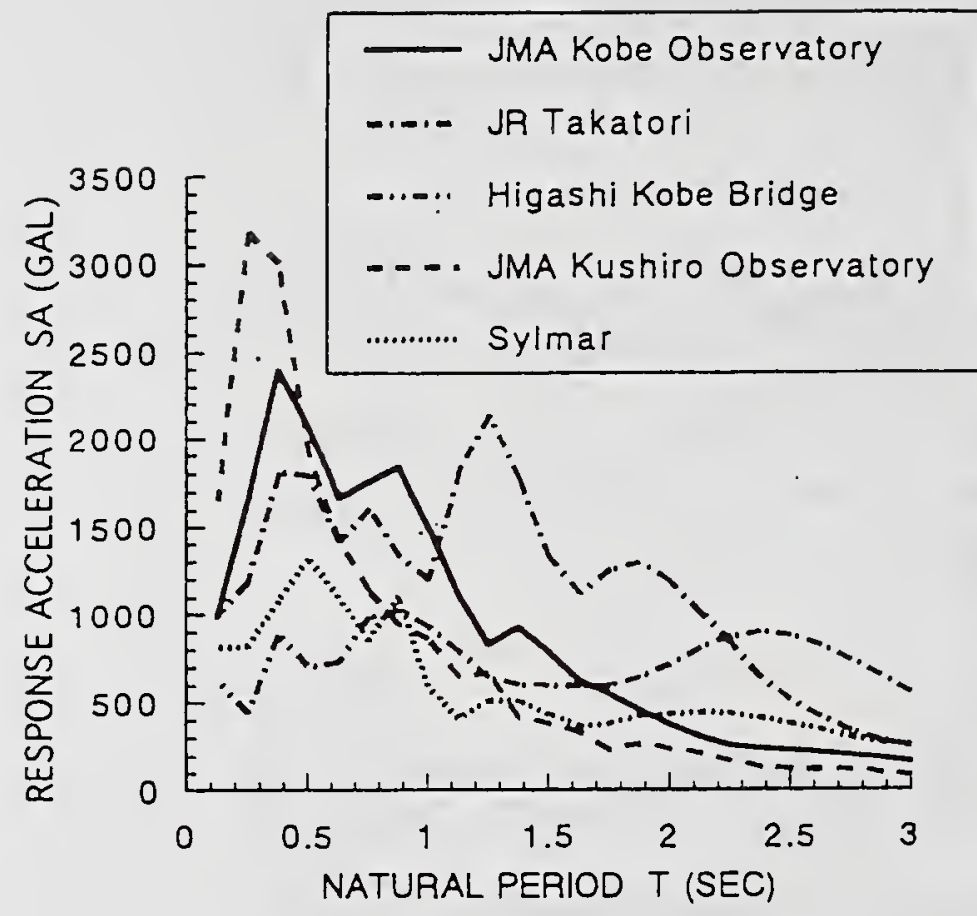

(a) Response Acceleration Spectra

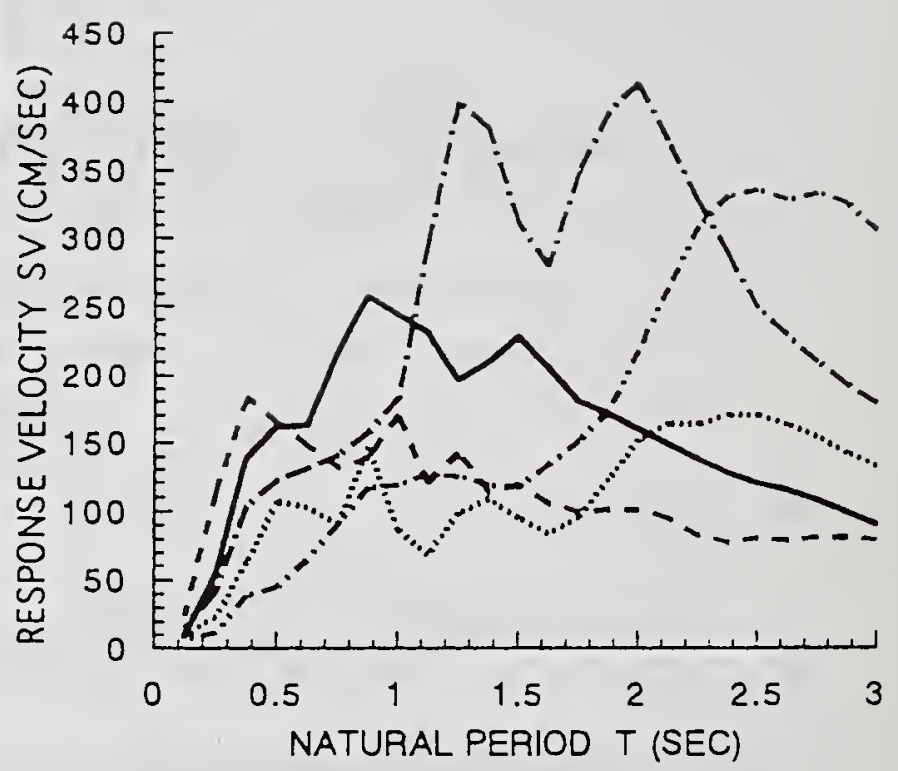

(b) Response Velocity Spectra

Fig. 2-2 Response Spectra $(\mathrm{h}=0.05)$ at JMA Kobe Observatory (NS) in comparison with the Ground Earthquake, JMA Kushiro Observatory by the 1993 Kushiro-oki Earthquake, and Sylmar Parking Lot by the 1994 Northridge Earthquake

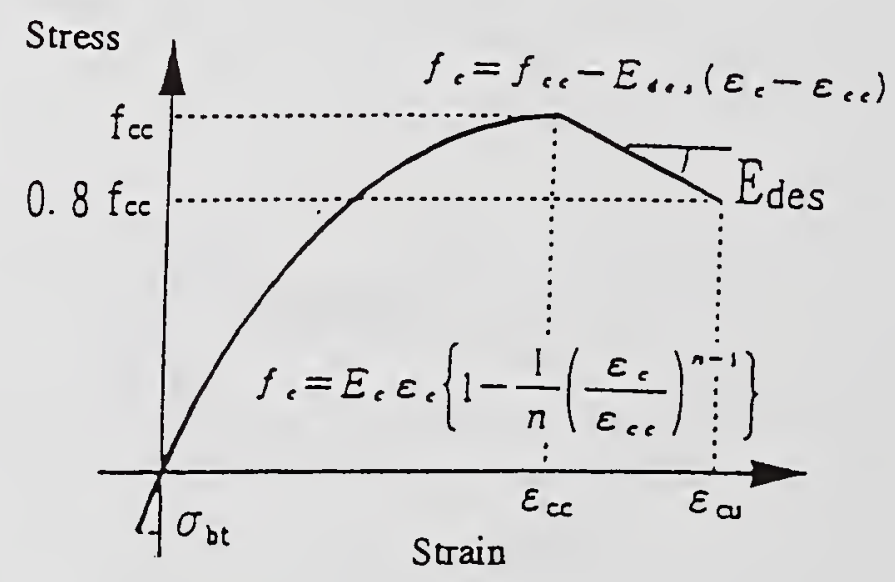

Fig. 2-3 Stress-Strain Relation for Concrete Confined by Ties 


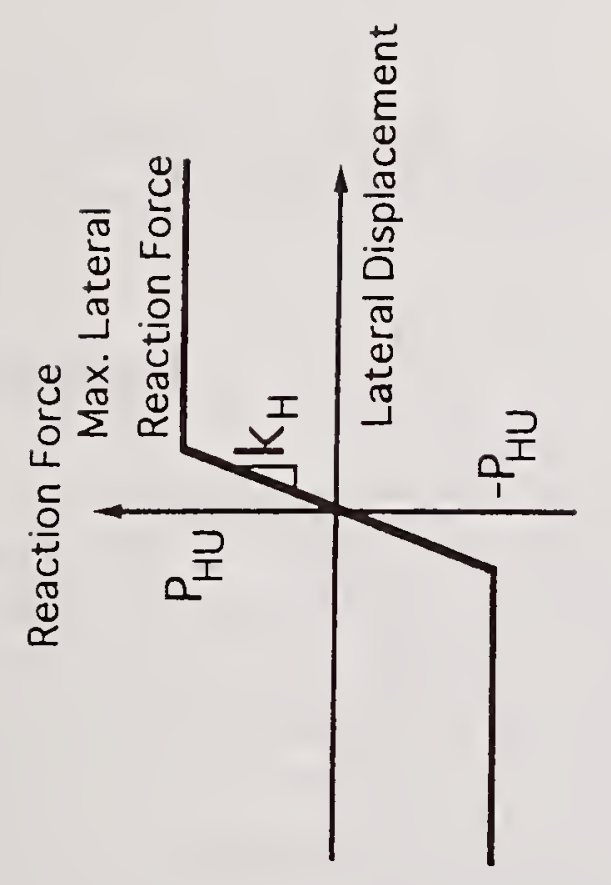

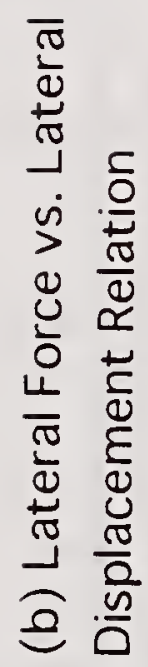
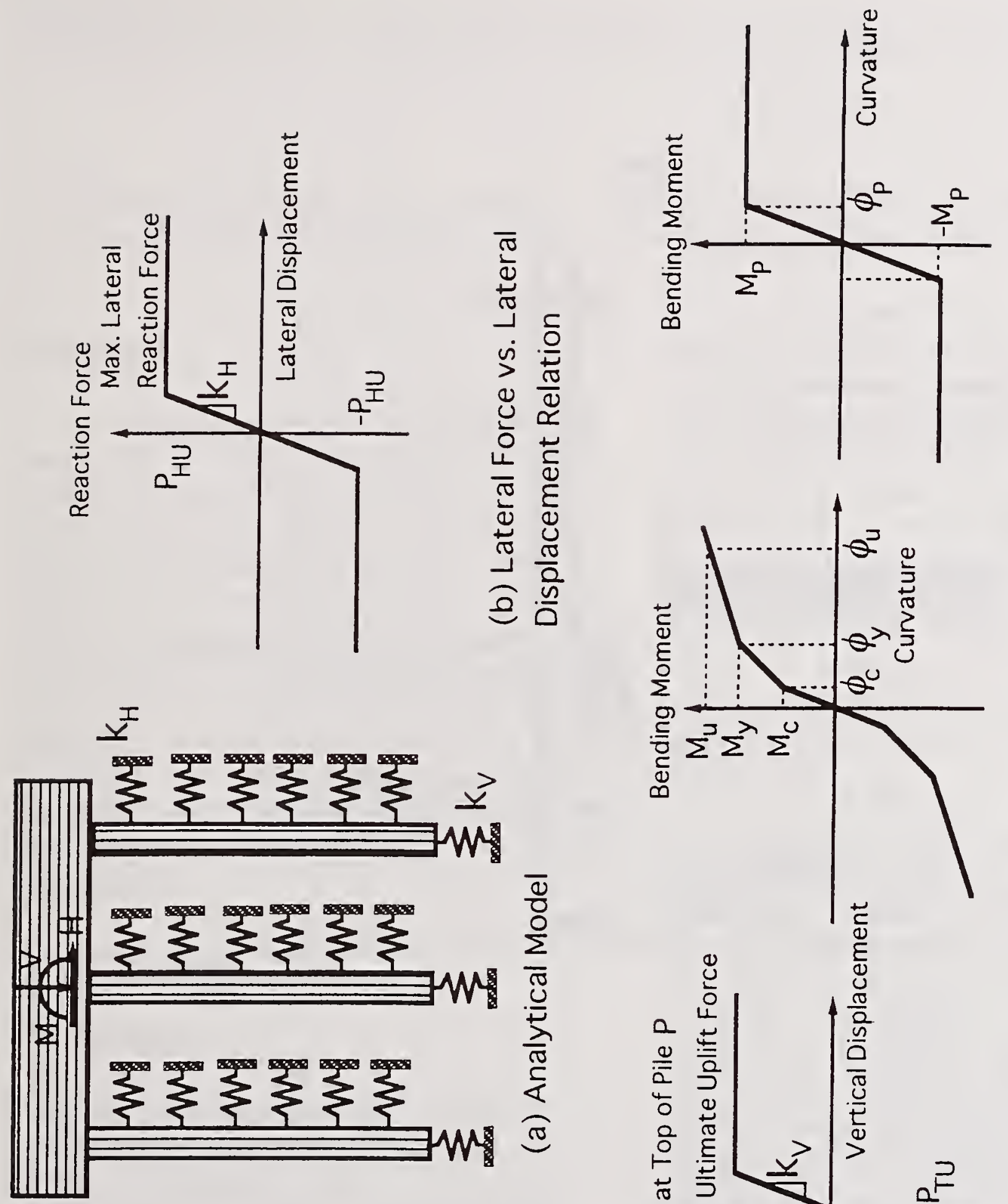

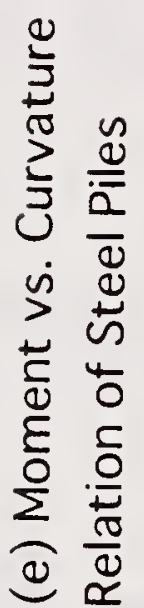

告

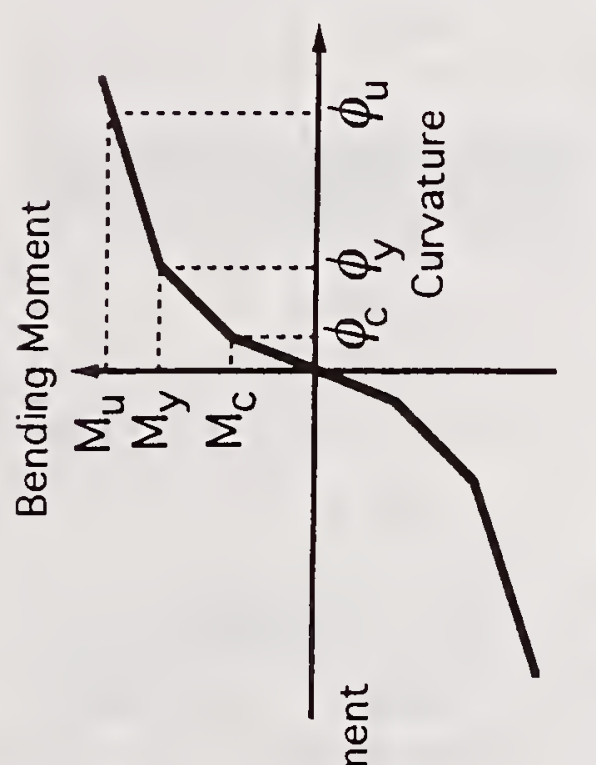

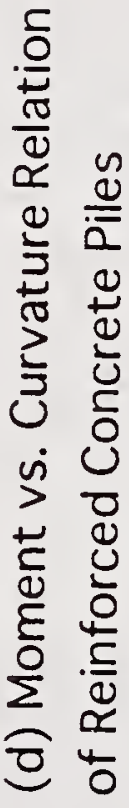

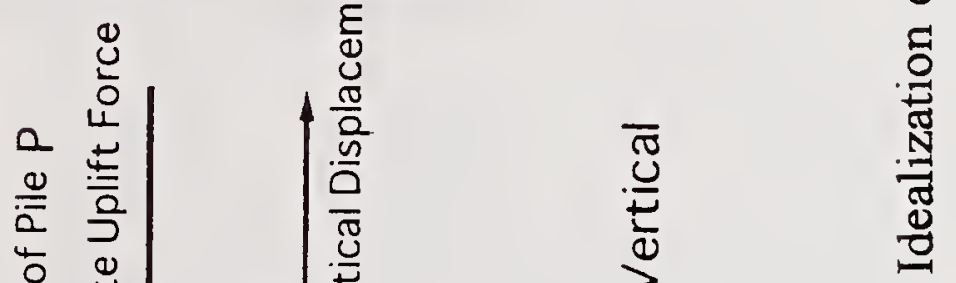

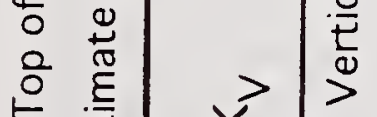

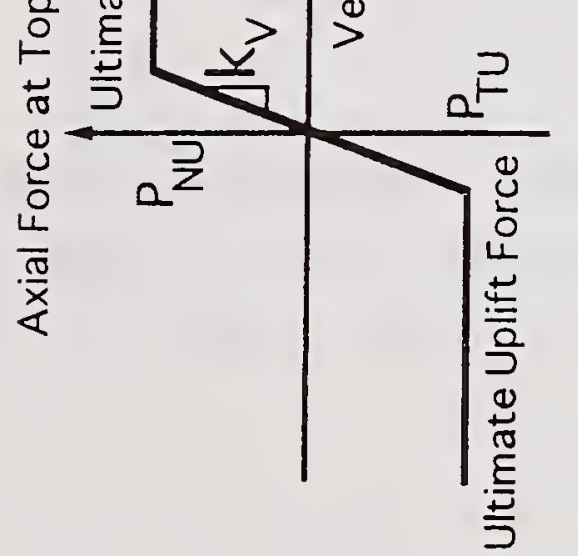

䓪

仓ั้

녿

ปู

$\stackrel{0}{>}$

(ิ) $\frac{2}{0}$ 


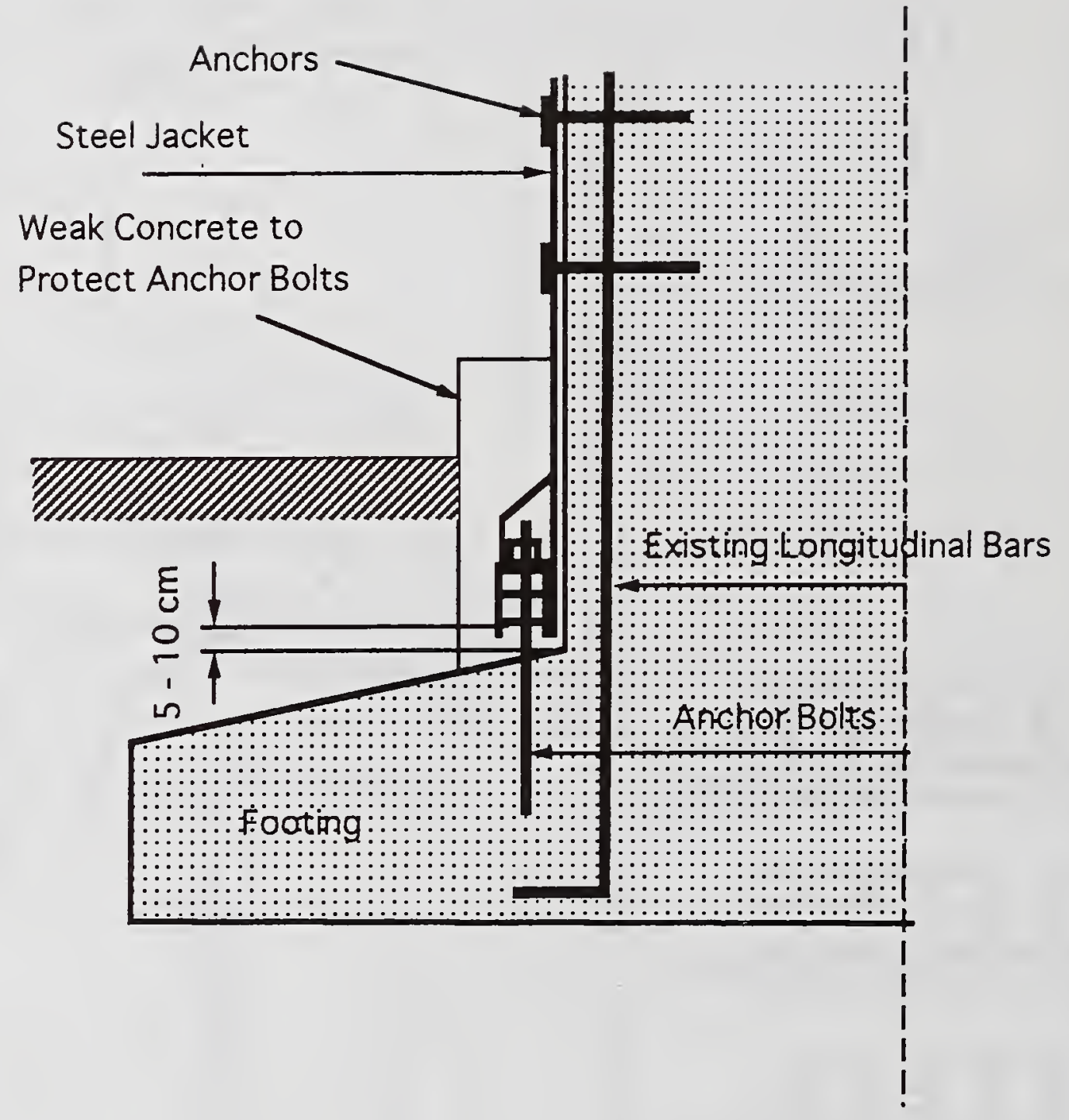

Fig. 3-2 Seismic Strengthening of Reinforced Concrete Piers by Steel Jacket with Controlled Increase of Flexural Strength 


\section{Comparison of U.S. and Japanese Highway Bridge Column Seismic Design}

U.S.

W.Phillip Yen ${ }^{1}$, Research Structural Engr.

James D. Cooper ${ }^{1}$, Chief of Structures Div
Japan

Hisanori Otsuka ${ }^{2}$, Head of Earthquake Eng. Div Toru Terayama ${ }^{2}$, Senior Research Engr..

\begin{abstract}
This paper presents the preliminary results of a U.S.-Japan cooperative research project which compares the seismic design procedures and results for a bridge pier under the same design force levels. These design were based on the current bridge design specifications of the two countries. Design results, such as column sizes and main and transverse reinforcement, are compared, and the design approaches are discussed. Following these comparative designs, one-sixth scale models of the two prototype designs will be built and tested on a shake table.
\end{abstract}

\section{INTRODUCTION}

\subsection{Background}

Recently, three large destructive earthquakes have occurred in the United States and Japan. These earthquakes, the Loma Prieta earthquake in 1989, the Northridge earthquake in 1994, and the Kobe earthquake in 1995, have severely damaged a number of highway bridges, and have cost many lives and billions of dollars. Although, most of the damaged bridges were designed and constructed prior to the implementation of modern seismic design codes, significant damages also occurred in some bridges built to more recent codes. Column failure due to insufficient ductility and inadequate shear reinforcement was found to be the most important factor causing bridge collapse or failure.

In order to better evaluate the current bridge seismic codes, and to improve bridge performance under earthquakes, a cooperative research study was initiated in the Third US-JAPAN workshop on Advanced Technology in Highway Engineering, September, 1994. The two primary tasks proposed were to design a single column bridge pier using both US and Japanese seismic design codes, and to construct scale models of each design for shake-table testing at the Public Works

${ }^{1}$ Structures Division, Turner-Fairbank Highway Research Center Federal Highway Administration

McLean, Virginia 22101

${ }^{2}$ Earthquake Engineering Division Public Works Research Institute Tsukuba Science City, Japan 
Research Institute (PWRI) Lab in Japan. The methods used for the prototype bridge column designs are based on the current seismic design specification of both countries. The U.S. side used the newly revised (Spring 1995) Division I-A: Seismic Design Provision of the American Association of State Highway Officials' (AASHTO) Standard Specification for Highway Bridges (15 edition), and the Japanese side used the Seismic Design Codes of the Japan Road Association's (JRA) Specification for Highway Bridges (1990).

\subsection{Objective}

The objective of this cooperative research study are 1) to better assess the current seismic design codes in column design, and 2) to improve bridge performance under earthquakes. The shaking-table tests of the scale models will give an indication of the adequacy of current design criteria for bridge piers. In this paper, design procedures for single column bridge piers under comparable seismic forces are discussed, and the two set of design results are compared. The difference in the two design approaches are also addressed.

\section{DESIGN CONDITIONS}

\subsection{Bridge Descriptions}

A bridge representative of the most common type in both countries was selected and is shown in Figure 1. This bridge consists of two continuous spans on tangent alignment with seat type abutments at the ends. The superstructure is assumed to have a reinforced concrete deck, and steel stringers with hinged bearings. The pier is assumed to have a hammer head cap, a single circular column, and a spread footing. In this study, only the column design is addressed.

\subsection{Seismic Design Conditions}

\section{Design Approaches}

In order to get a meaningful comparison between the US and Japanese seismic design methods, design assumption need to be identical. However, this is not feasible in every instance because the two design approaches are different. For example, a major difference between the two codes is in the way design strengths are specified. The JRA Code uses allowable stress, while the AASHTO code is based on ultimate strength. The JRA code permits increasing the allowable stress by a factor of 0.5 under seismic forces. However, it also requires a check for the ultimate horizontal strength, and uses a coefficient $\mathrm{K}_{\mathrm{hc}}$ as high as 1.0. $\mathrm{K}_{\mathrm{hc}}$ is the seismic design coefficient used to check ultimate horizontal strength during an earthquake (JRA Codes 1990).

Another difference is that forces and displacements for the "design" earthquake as specified in AASHTO are based on a low probability of their being exceeded within the normal life expectancy of a bridge. The AASHTO code specifies probabilisticallybased effective peak accelerations throughout the U.S. The JRA code uses a regional seismicity classification map to account for the intensity of design earthquake motions. This map was developed on the basis of statistical analyses from past strong motion data (Kawashima et al, 1989) which were then consolidated into three regions. This required elimination of very localized discrepancies within a region. Reasons for 
this difference may be due, in part, to the frequency of occurrence and the type of significant earthquakes that have occurred historically in both countries.

For this study, these seismic conditions were chosen to be as close as possible. Table 1 shows the seismic design conditions assigned for both US and Japanese design methods. Acceleration coefficient, site effects and inertia forces conditions are discussed as follows:

\section{A. Acceleration Coefficient}

$\begin{array}{ll}\text { AASHTO } & \mathrm{A}=0.4 \\ \text { JRA } & \mathrm{K}_{\mathrm{ho}}=0.2 / \mathrm{K}_{\text {heo }}=1.0\end{array}$

Since the two codes are quite different in their design approaches, assigning the same coefficient in both methods would be meaningless. Consequently, the same maximum response spectrum (design force) was applied for this design case. JRA requires a check for the ultimate horizontal strength by using the coefficient $\mathrm{K}_{\mathrm{hc}}$ up to 1.0 in addition to the standard horizontal seismic design coefficient $\mathrm{K}_{\mathrm{ho}}=0.2$. This $1.0 \mathrm{~g}$ force level for $\mathrm{K}_{\mathrm{hc}}$ is equivalent to a value of $\mathrm{A}=0.4$ in the AASHTO design. Utilizing single mode analysis gives a maximum value for the elastic seismic response coefficient $\mathrm{C}_{\mathrm{S}}$ of $2.5 \mathrm{~A}$ in AASHTO.

( Note: $C_{s}=\frac{1.2 A S}{T^{2 / 3}} ;$ where $S$ and $\mathrm{T}$

represent site effects coefficient and the fundamental period of the bridge)

B. Site Effects
AASHTO: Type III
JRA : Type I

In both design codes, the effects of site conditions on bridge response are determined from a site coefficient based on soil profile (or ground) types. In AASHTO, soil profiles are divided into four different soil types. These classification are based on the type of soil, (such as rock, stiff clay, soft to medium-stiff clay and silts), the depth of the soil, and shear wave velocity. A qualified geotechnical engineer's help is often needed to determine the soil profile type. The JRA states that ground type in seismic design shall generally be classified as one of three types. The determination of the ground type is by a factor $T_{G}$ which considers soil strata thickness and average shear wave velocity, and is expressed in seconds. $T_{G}$ can be obtained by a simple formula

$$
T_{G}=4 \sum_{i=1}^{n} \frac{H_{i}}{V_{s i}}
$$

Where $H_{i}$ is the thickness of the $i$-th soil layer (m) and $V_{s i}$ represents the average elastic shear wave velocity of the $i$-th soil layer.

A soil profile with a depth of $45.9 \mathrm{ft}$ $(14 \mathrm{~m})$ and an average shear wave velocity of $984 \mathrm{ft} / \mathrm{sec}(300 \mathrm{~m} / \mathrm{s})$ was assumed in this design case. With the JRA method, the ground type is clearly Type I. Under the AASHTO method, Classifying the soil from this information could be difficult since it falls somewhere between Type II and Type III. However, Type III was selected because of the shear wave velocity.

\section{Inertia Forces}

Both codes agree that inertia forces from the superstructure are assumed to be 
acting on the bridge seat in the longitudinal direction, and at the bottom of the deck (height $=2.30 \mathrm{~m}$ above the bridge seat) in the transverse direction. The pier is assumed to take the inertia of the two full spans' weight in the longitudinal direction, and half the weight of each span in the transverse direction.

\section{SEISMIC DESIGN}

\subsection{AASHTO Method}

In designing the bridge pier assumed, a single mode spectral analysis method was used since this is a right bridge of less than 7 spans with a fairly constant cross section, and can be considered regular. The seismic performance category (SPC) of this bridge is $D$ because the acceleration coefficient $(A)$ is 0.4 and the bridge is assumed to be essential. Elastic forces obtained from the single mode analysis were reduced by an $R$ factor (Response Modification Factor). This design strategy permits these elastic forces to be reduced substantially to obtain design forces for a column member that will yield first. For a single column pier design, this $\mathrm{R}$ factor is 3. Seismic loadings for both transverse and longitudinal directions were analyzed to find the most critical forces for design. In this case, longitudinal loading with the fundamental natural period $T_{L}=1.25$ was the critical design load. SAP90 was used to check the final design by reanalyzing the structures with a moment-release joint at the pier top, and the results agreed very well.

\subsection{JRA Method}

In the JRA method, design loads are obtained from a horizontal seismic coefficient method based on the allowable stress approach. A standard horizontal seismic coefficient $\mathrm{K}_{\mathrm{ho}}=0.2$ for design was used in this case. An increased design load was then used to check the ultimate horizontal strength and minimum ductility. The purpose of the ductility requirement is to ensure that brittle failure of reinforced concrete substructure elements does not occur under seismic loading. This capacity check used a coefficient for seismic checking $\mathrm{K}_{\text {hco }}=1.0$. The force level was then lowered by dividing by a ductility reduction factor $(2 \mu-1)^{1 / 2}$; in which $\mu$ is the ductility of the bridge column, and is a function of a strainstress model (Hoshikuma and Kawashima 1992).

\section{DESIGN RESULTS and COMPARISON}

As part of the comparison of results and exchange of design examples, a parametric study of different sizes was performed by both sides to make the comparison between the two design codes more meaningful. The AASHTO bridge column sizes were $7 \mathrm{ft}(2.1 \mathrm{~m})$ and $9 \mathrm{ft}$ $(2.7 \mathrm{~m})$ in diameter, while the JRA columns were $2.7 \mathrm{~m}(9 \mathrm{ft})$, and $3.2 \mathrm{~m}(10.5 \mathrm{ft})$ in diameter. Design detail of the bridge piers from both design codes are shown in Figure 2 (US) and Figure 3 (Japanese). Design loads including natural periods, axial loads, and seismic horizontal forces are compared in Table 2. Column sizes and steel reinforcement in the longitudinal direction and transverse directions are compared in Table 3 . The comparisons shown are only for the smallest sizes for each code.

\section{CONCLUSIONS AND REMARKS}

This paper presented a comparison of results 
from seismic design of a typical bridge column by both US and Japanese methods. The results here do not seek to show the stronger or weaker design but rather to compare the different design approaches, and to learn from each. From the natural periods compared in Table 3, the AASHTO pier is more flexible than the JRA pier in this case. These designs may also reflect the difference in the strong ground motion, which is affected most by the soil profile type.

\section{REFERENCES:}

AASHTO, 1995, Interim Revisions to the AASHTO Standard Specifications for Highway Bridges, "Division I-A: Seismic Design," American Association of State Highway and Transportation Officials, Washington, DC.

Japan Road Association, 1990, "Specifications for Highway Bridges," Part V: Seismic Design.

Kawashima, K., 1994, "Seismic Design Force of Bridges," Proceedings of the Second International Workshop on Seismic Design of Bridges, Queenstown, New Zealand.

Kawashima, K., and Hasegawa, K., 1994, "New Design Specification for Highway Bridges in Japan," Earthquake Spectra, Vol. 10, No. 2.

Sultan, M, and Kawashima, K. 1994, "Comparison of the Seismic Design of Highway Bridges in California and in Japan", Recent Selected publications of Earthquake Eng. Div., PWRI, Japan. (Technical Memorandum of PWRI No. 3276)
Yen, W. P., Cooper, J.D., and Friedland, I. M. 1995, "Comparison of the U.S. and Japanese Highway Bridge Seismic Design Criteria", Proceedings of the 27th UJNR Panel Meeting on Winds and Seismic Effects, Tsukuba City, Japan. 
Table 1. Seismic Design Conditions

\begin{tabular}{|c|c|c|}
\hline Boundary Condition & AASHTO & JRA \\
\hline Design Method & $\begin{array}{l}\text { Single Mode Spectral } \\
\text { Analysis Method }\end{array}$ & $\begin{array}{l}\text { Horizontal Seismic } \\
\text { Coefficient Method }\end{array}$ \\
\hline $\begin{array}{l}\text { Acceleration Coefficient } \\
\text { (Max. Response Spectrum } \\
\text { Coefficient }=1.0 \text { ) }\end{array}$ & $A=0.4$ & $\begin{array}{r}\mathrm{K}_{\mathrm{ho}}=0.2(\text { Design }) \\
\mathrm{K}_{\mathrm{hco}}=1.0 \text { (Checking Ultimate } \\
\text { Horizontal Strength) }\end{array}$ \\
\hline $\begin{array}{l}\text { Soil Profile Type/ Ground } \\
\text { Type } \\
(\mathrm{H}=14 \mathrm{~m} \text { Shear Wave } \\
\text { Velocity }=300 \mathrm{~m} / \mathrm{sec})\end{array}$ & $\begin{array}{l}\text { Soil Profile Type III } \\
S=1.5\end{array}$ & $\begin{array}{l}\text { Ground Type I }\left(\mathrm{T}_{\mathrm{G}}=0.18 \mathrm{~s}\right) \\
\mathrm{C}_{\mathrm{G}}=0.85\end{array}$ \\
\hline Connection Type & Hinge Type Fixed Bearing & Hinge Type Fixed Bearing \\
\hline Inertia Forces & $\begin{array}{l}\text { Acting on bridge seat } \\
\text { (Long. direction) } \\
\text { Acting at the bottom of the } \\
\text { deck (Trans. Direction) }\end{array}$ & $\begin{array}{l}\text { Acting on bridge seat } \\
\text { (Long. direction) } \\
\text { Acting at the bottom of the } \\
\text { deck (Trans. Direction) }\end{array}$ \\
\hline
\end{tabular}

Table 2. Comparison of Seismic Design Forces

\begin{tabular}{|l|l|l|}
\hline Description & AASHTO Method & JRA Method \\
\hline $\begin{array}{l}\text { Fundamental Natural Period } \\
\text { (longitudinal direction) }\end{array}$ & $1.29 \mathrm{sec}$ & $0.93 \mathrm{sec}$ \\
\hline Axial Load & $1196 \mathrm{kips}$ & 507 tons \\
\hline Seismic Horizontal Force & $0.62 \mathrm{X} \mathrm{Ws}$ & $0.7 \mathrm{X} \mathrm{Wj}$ \\
\hline $\begin{array}{l}\text { Design Force Reduction } \\
\text { Factor }\end{array}$ & 3 & 2.08 \\
\hline
\end{tabular}


Table 3. Comparison of Design Results

\begin{tabular}{|l|l|l|}
\hline Characterization & AASHTO Method & JRA Method \\
\hline \hline Column Size & Diameter $=7 \mathrm{ft}(2.1 \mathrm{~m})$ & Diameter $=2.7 \mathrm{~m}(9 \mathrm{ft})$ \\
\hline $\begin{array}{l}\text { Main Reinforcement } \\
\text { (longitudinal direction) }\end{array}$ & $\begin{array}{l}56-\# 18 \text { bars } \\
(56-D 57)\end{array}$ & $\begin{array}{l}\text { 2X54-D51 bars } \\
\text { (2X54-\#16 Double layer) }\end{array}$ \\
\hline Transverse Reinforcement & $\begin{array}{l}\# 7 @ 3 "(D 22 @ 75) \\
(\text { Spiral type })\end{array}$ & $\begin{array}{l}\text { D22 @150 (\#7@6") } \\
(\text { Hoop type) }\end{array}$ \\
\hline Concrete Gross Area & $38.48 \mathrm{ft}^{2}\left(3.57 \mathrm{~m}^{2}\right)$ & $5.73 \mathrm{~m}^{2}\left(61.63 \mathrm{ft}^{2}\right)$ \\
\hline & & \\
\hline
\end{tabular}

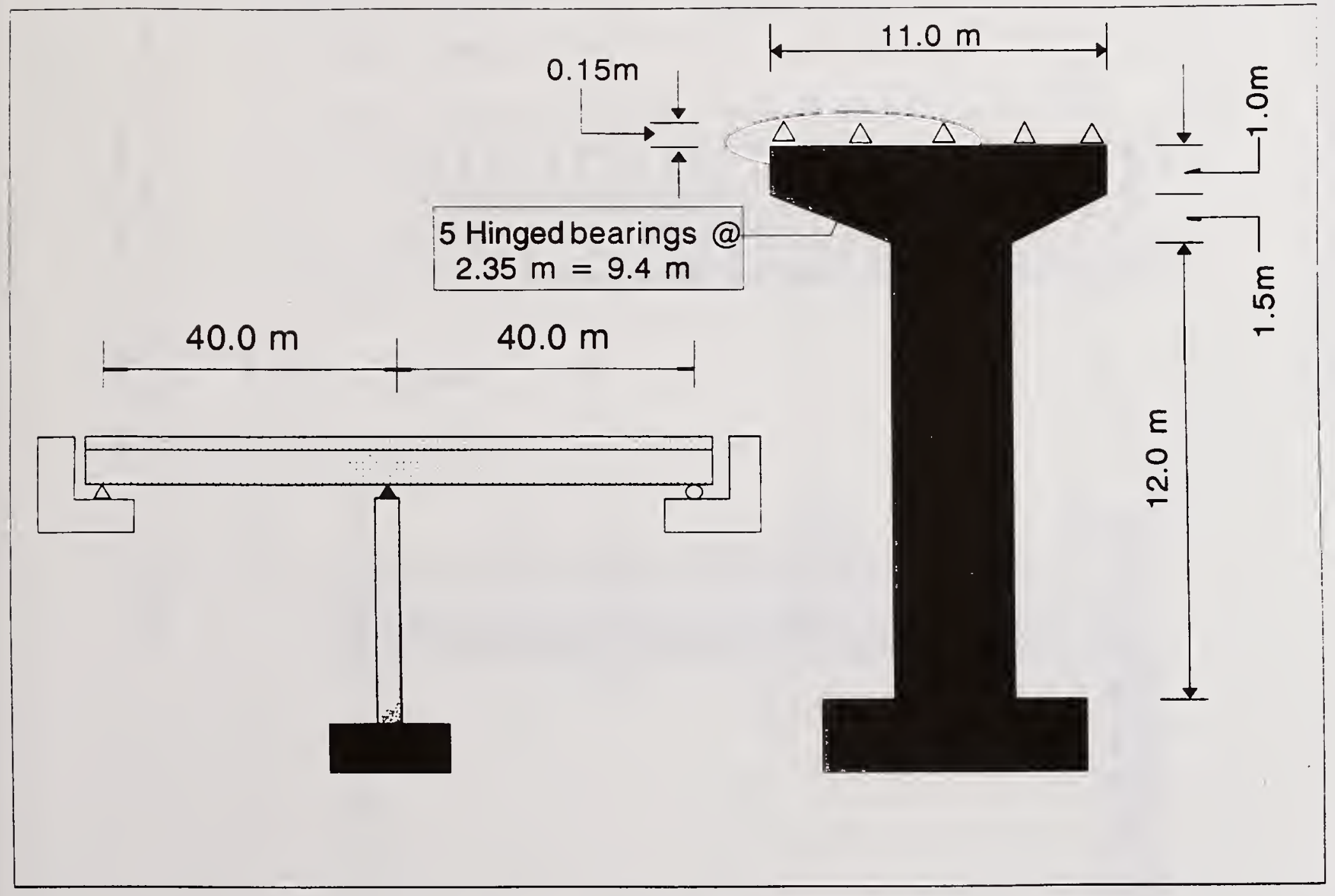

Figure 1. Bridge Column Dimensions 


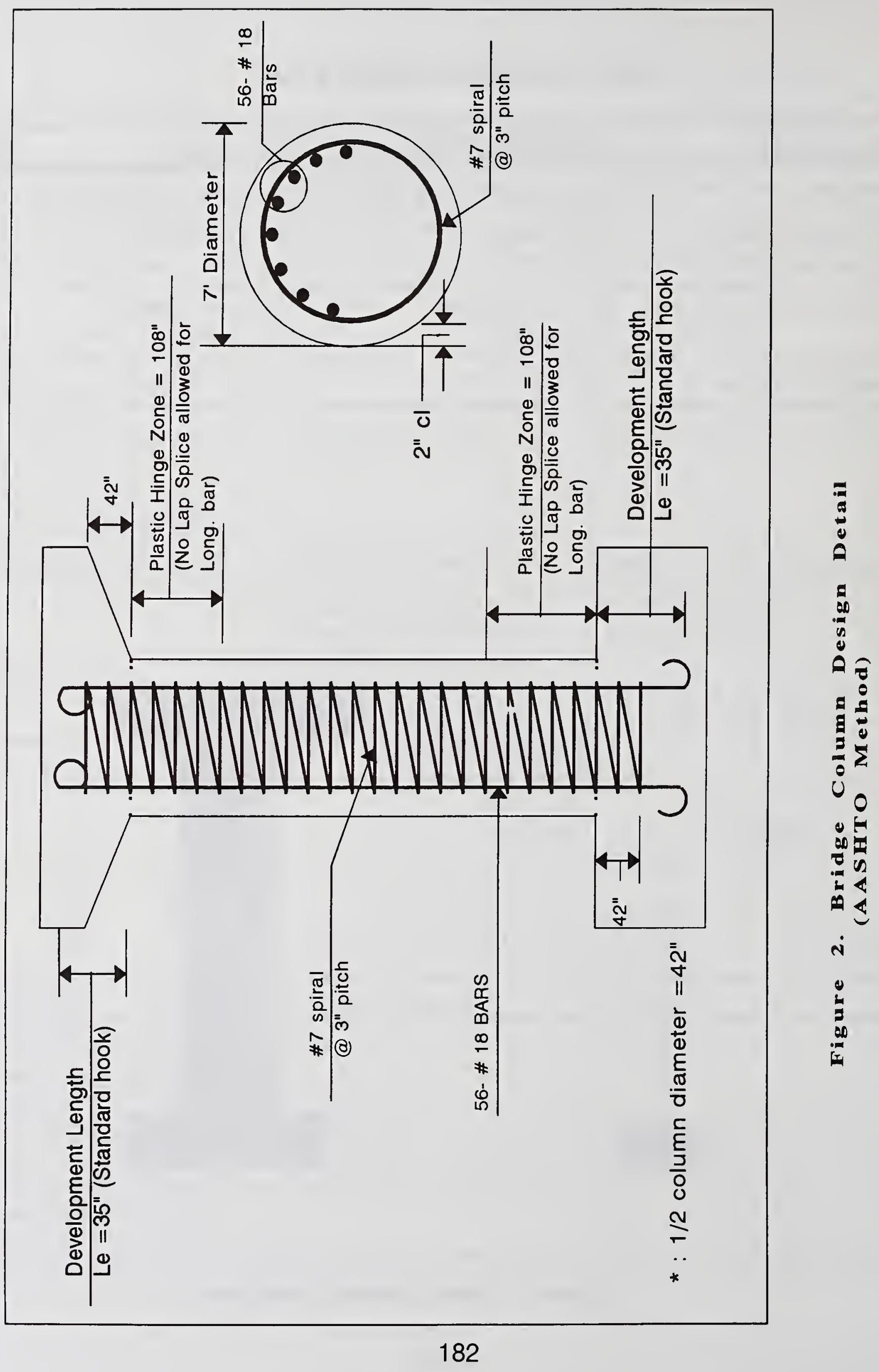



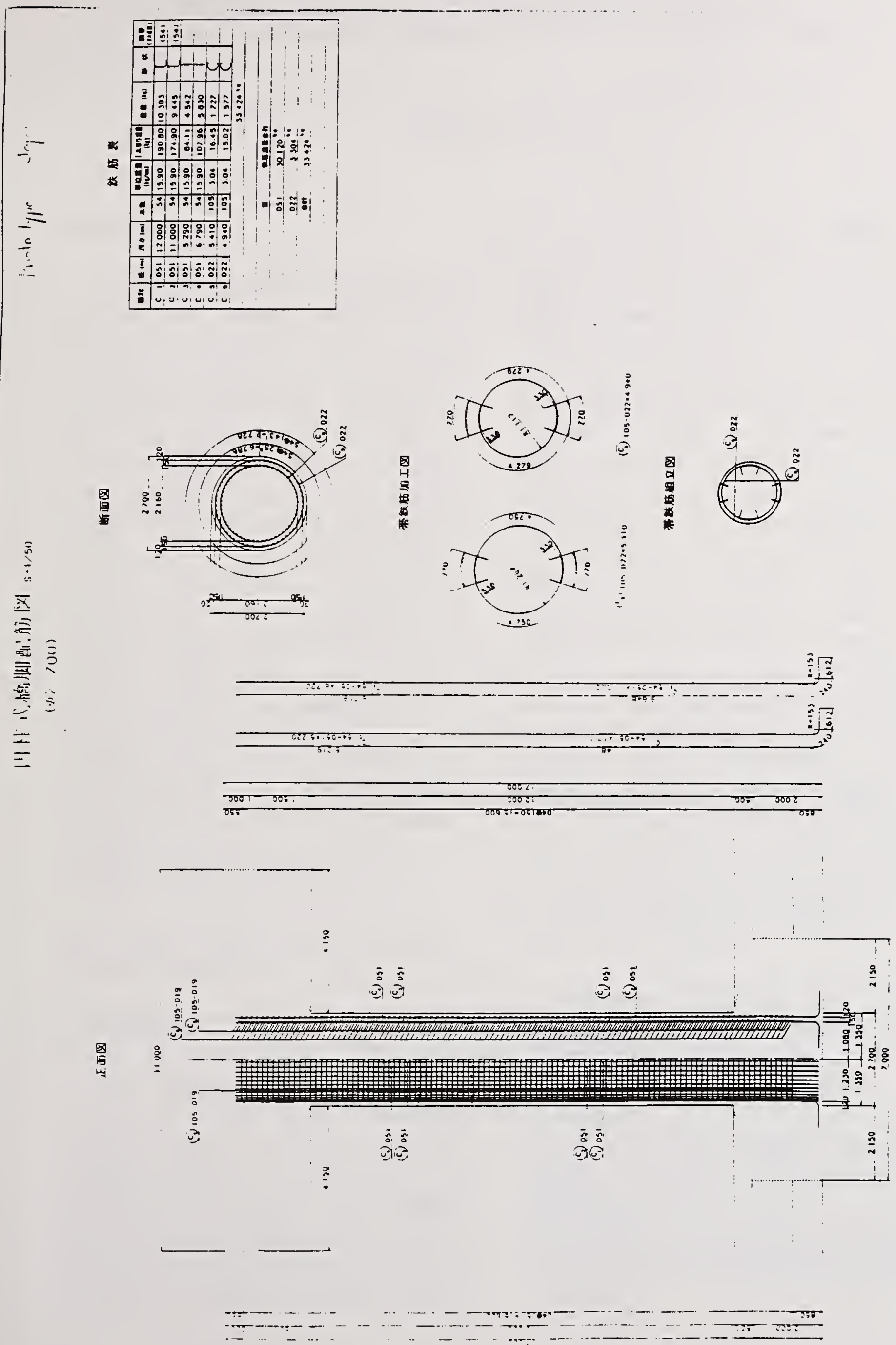



\title{
RESIDUAL DISPLACEMENT RESPONSE SPECTRUM AND ITS APPLICATION TO REINFORCED CONCRETE BRIDGE PIERS
}

\author{
Kazuhiko Kawashima ${ }^{1}$, Gregory A. MacRae ${ }^{2}$, Jyun-ichi Hoshikuma ${ }^{3}$ \\ and Kazuhiro Nagaya 4
}

\begin{abstract}
A structure subjected to strong ground shaking may develop large residual displacements after the shaking due to nonlinear response. The residual displacement causes various problems for repair and reconstruction of structures after an earthquake. This paper proposes residual displacement response spectra, which describe the residual displacement developed in a one-degree-of-freedom oscillator with various natural periods, damping ratios, ductility factors and bilinear factors. Characteristics of the residual displacement ratio response spectra which is normalized by the maximum residual displacement was clarified based on 63 components of ground motion, and a design value is proposed for the residual displacement response spectra. An example of application is also presented.
\end{abstract}

Key Words: Seismic design, Nonlinear behavior, Ductility

\section{INTRODUCTION}

The Hanshin-Awaji Earthquake of January 17, 1995 caused destructive damage to bridge structures. About 250 reinforced concrete columns and 20 stiffened steel columns totally collapsed due to the strong shaking (MOC Report 1995). There were various types and amounts of damage. It should be noted that some bridge columns did not collapse but tilted and had large residual displacements at the top. Due to the difficulty to set the superstructures back to the original alignment and level, most of them were required to be rebuilt. This clearly indicates the importance in seismic design of structures to consider the residual displacement associated with nonlinear behavior during an extreme ground motion. A series of shaking table tests conducted at the Public Works Research Institute for model bridges supported by reinforced concrete columns and steel columns have shown that large residual displacements can be developed under extreme ground motions (for example, Kawashima, MacRae and Hasegawa, 1992, Kawashima and Hasegawa, 1994a). The force reduction from the elastic force level should be carefully determined not only from the peak response displacement but also from the residual displacement developed in a structure after an earthquake.

1) Professor, Department of Civil Engineering Tokyo Institute of Technology

2) Assistant Professor, University of Washington

3) Research Engineer, Public Works Research Institute, Ministry of Construction

4) Assistant Research Engineer, Public Works Research Institute, Ministry of Construction 
Various studies have been made on the nonlinear behavior of structures subjected to strong ground motions and it is well known that the residual displacement increases as the ductility of structures increases. However, the dependence of the residual displacement on the ductility under strong ground shaking has not yet been precisely investigated.

This paper proposes a residual displacement resp onse spectrum, which presents the residual displacement developed in a one-degree-of-freedom oscillator with various natural periods, damping ratios, ductility and bilinear factors, and presents an application of the residual displacement response spectra.

\section{RES IDUAL DISPLACEMENT RESPONSE SPECTRUM}

A one-degree-of-freedom oscillator is assumed to be supported by a spring with a nonlinear hy steretic restoring force characteristic. The oscillator is subjected to a ground shaking at its base. Although any hysteretic restoring force model may be assumed in the spring a bilinear model as shown in Fig 1 is assumed here for simplicity of the analysis.

The spring changes its stiffness from an initial (elastic) stiffness $k_{1}$ to a second (post-yielding) stiffness $k_{2}$ at a yield displacement $u_{y}$. The bilinear factor $r$ and the ductility factor $\boldsymbol{\mu}$ are defined as

$$
\begin{gathered}
r=\frac{k_{2}}{k_{1}} \\
\mu=\frac{u_{\max }}{u_{y}}
\end{gathered}
$$

where $u_{\max }$ is the maximum displacement of the oscillator.

To represent the energy dissipation contributed from sources other than the hysteretic energy dissipation, such as radiation of energy from a foundation to surrounding soils, a viscous damping ratio $h$ is considered in the analy sis in addition to the hy steretic damping associated with the nonlinear restoring force.

When an oscillator is subjected to a ground motion at its base, a residual displacement $u_{r}$ may be developed after the shaking has finished. The magnitude of residual displacement $u_{r}$ depends on various factors such as the ductility factor $\mu$, natural period $T$, damping ratio $h$, bilinear factor $r$ and the intensity of ground shaking. Because the displacement sometimes does not come to its rest point even at the end of ground acceleration records, a time of zero acceleration was added to the end of each record to compute the final rest point of the displacement.

Thus the residual displacements can be computed from each strong motion record for oscillators with various values of ductility factor $\mu$, natural period $T$, damping ratio $h$, and bilinear factor $r$ (MacRae, Kawashima 1993). The residual displacement plotted against natural period $T$, damping ratio $h$, bilinear factor $r$ and ductility factor $\mu$ is proposed here to be designated as a residual displacement response spectrum $S_{R D}$ from its analogy to the original definition of the response spectrum (Housner 1959).

Target ductility factors $\mu_{T}$ were selected here as 2, 4 and 6, and the yield force $F_{y}$ was obtained so that the ductility factor $\mu$ computed corresponds to the target ductility factor $\mu_{T}$. This requires some iterations as shown in Fig. 2. First one assumes $F_{y}$ to compute $u_{\max }$ for a given ground motion acceleration. If the ductility factor $\mu$ computed by Eq. (2) is not close enough 
to $\mu_{T}$, a new value of $F_{y}$ is chosen to compute $u_{\max }$ until the difference between $\mu$ and $\mu_{T}$ becomes sufficiently small. Generally 5 iterations are sufficient to have a convergence with an error of less than $0.1 \%$.

For any hysteretic curves, there may be a maximum value of the residual displacement. As shown in Fig 3, the residual displacement takes its maximum value when oscillator unloads from the maximum displacement $u_{\max }$. If it is assumed that the motion of oscillator comes to rest when the restoring force becomes zero, the maximum residual displacement $u_{r \max }$ may be written as

$$
u_{r \max }=\left\{\begin{array}{c}
(\mu-1)(1-r) u_{y}---r(\mu-1)<1 \\
\{(1-r) / r\} u_{y}---r(\mu-1) \geq 1
\end{array}\right.
$$

It is convenient to normalize the residual displacement $u_{r}$ by $u_{r \max }$ as

$$
S_{R D R}=\left|u_{r} / u_{r \max }\right|
$$

$S_{R D R}$ is designated here as a residual displacement ratio. The plots of $S_{R D R}$ against natural period $T$, damping ratio $h$, bilinear factor $r$ and ductility fact or $\mu$ are designated here as residual displacement ratio response spectra.

In the following the natural period $T$ is computed from the initial stiffness $k_{1}$ and the mass of the oscillator. The viscous damping ratio $h$ is assumed to be 0.05 that is typical for usual structures.

\section{RESIDUAL DISPLACEMENT RESPONSE SPECTRA FOR A TYPICAL RECORD}

Fig 4 shows a residual displacement $u_{r}$ computed for an oscillator with natural period $T=1 s$ subjected to a free field ground acceleration recorded in the vicinity of Itajima bridge during the
Hyuga-nada earthquake in 1968 . The record was obtained by an earthquake with magnitude 7.2 at $195 \mathrm{~km}$ from the epicenter. The ductility factor $\mu$ was assumed to be 4 . It is seen in Fig 4 that the residual displacement starts to develop at about 16 seconds, when the ground acceleration starts to become larger. It is important to note that $u_{r}$ increases as the bilinear factor $r$ decreases. In particular, the residual displacement is quite large when $r=-0.05$. It is interesting to note that although there are some responses in which the magnitude of residual displacement gradually increases or even changes direction by accumulation of drift as shown in Fig 4(d), most of residual displacements are developed by one single shift in drift as shown in Fig 4 (b) and (c).

The residual displacement was computed in the same manner for oscillators with various natural periods, and the residual displacement ratio response spectrum $S_{R D R}$ defined by Eq (4) was evaluated for the Itajima record as shown in Fig 5. The absolute acceleration response spectrum $S_{A}$ with a damping ratio of 0.05 is presented in Fig 5 for comparison. It is seen from $S_{A}$ that the predominant periods of ground motion are about $0.2 \mathrm{~s}$ and $0.7 \mathrm{~s}$. The residual displacement ratio response spectrum $S_{R D R}$ depends significantly on the natural period. Reflecting the results described in Fig 4, $S_{R D R}$ is almost 1.0 when $r$ is 0.05 while $S_{R D R}$ is less than 0.6 when $r$ is 0.1 . It is interesting to note that $S_{R D R}$ tend to have peak values at the natural periods of about $0.2-0.3 \mathrm{~s}$ and $1 \mathrm{~s}$ which are close with the predominant periods of ground motion. 


\section{ANALYSIS OF RESIDUAL RESPONSE SPECTRA}

The residual displacement ratio response spectrum $S_{R D R}$ was evaluated for 63 components of ground acceleration. They were recorded by earthquakes with magnitude ranging from 6.5 and 7.9 at free-field ground surface. Any records obtained at basement and first floor of buildings were not included.

Fig 6 shows the earthquake magnitude and the epicentral distance of the records About $71 \%$ of the records were induced by the earthquakes with magnitude larger than 7. The ground condition was classified into three groups as shown in Table 1 based on the natural period of ground $T_{g}$ (JRA 1990). The number of the records at Group I (stiff), II (medium) and III (soft) sites are 13, 37 and 13, respectively. Fig 7 shows the peak acceleration of records used in the analysis. About $1 / 3$ of the total records have peak accelerations larger than $60 \mathrm{gal}$ $\left(\mathrm{cm} / \mathrm{s}^{2}\right)$.

\section{(1) Effect of Earthquake Magnitude and Epicentral Distance}

Fig 8 shows how the residual displacement ratio response spectra $S_{R D R}$ depend on the earthquake magnitude $M$ and the epicentral distance $\Delta$ of the records. Only $S_{R D R}$ for $T=1 s$ and $\mu=4$ are presented here, because other conditions show the similar results. The earthquake magnitude is classified into $6.5 \leq M<7,7 \leq M<7.5$, and $7.5 \leq M$.

It is apparent from Fig 8 that the residual displacement ratio response spectra $S_{R D R}$ does not consistently depend on the earthquake magnitude $M$ and the epicentral distance $\Delta$.
(2) Soil Condition, Natural Period and Ductility Factor

The residual displacement ratio response spectra $S_{R D R}$ were averaged over all earthquake magnitudes and epicentral distances for three bilinear factors and the three soil conditions. Figs. 9 and 10 show the mean value $m$ and the standard deviation $\sigma$, respectively, for residual displacement ratio response spectra $S_{R D R}$ which were computed for specific combinations of natural period and ductility factor.

The dependence of the mean value $m$ of the residual displacement ratio response spectra $S_{R D R}$ on the bilinear factor $r$ is considerable. This effect will be precisely discussed later.

It is interesting to note that the soil condition is less significant for the residual displacement ratio response spectra $S_{R D R}$. The effect of natural period on $S_{R D R}$ is generally small, in particular when $r$ is -0.05 and 0.0 . When $r$ is $0.1, S_{R D R}$ seems to have slightly smaller values at natural period of about $0.1-0.2 s$ in Group I and 0.5-1s in Groups II and III. This may be related to the predominant period of ground motions in each soil condition. However from a practical point of view, it may be considered that the dependence of the residual displacement ratio response spectra $S_{R D R}$ on natural period is less significant. It should be noted that the $S_{R D R}$ of each individual record depends significantly on natural period as shown in Fig. 5.

The mean value $m$ of residual displacement ratio response spectra is less sensitive to ductility factor when $r$ is 0.0 . However, $m$ increases as ductility factor increases at $r$ larger than 0 , while the opposite is true at $r$ less than 0 . 
The standard deviation $\sigma$ of residual displacement ratio response spectra generally increases as the ductility factor increases. When $\mathrm{r}$ is $0, \sigma$ is almost independent of the ductility factor, and is about 0.3 regardless of the natural period and ground condition.

\section{(3) Effect of Bilinear Factor}

As described previously, the bilinear factor $r$ is the most significant parameter controlling the residual displacement ratio response spectra $S_{R D R}$. Therefore it is examined how $S_{R D R}$ depends on the bilinear factor $r$ in terms of the $S_{R D R}$ vs. $r$ relation. The effect of soil condition, natural period and ductility factor on the $S_{R D R}$ vs. $r$ relation is also re-examined based on the $S_{R D R}$ vs. $r$ relation.

Fig 11 shows the $S_{R D R}$ vs. $r$ relation taking the soil condition as a parameter. The result for a combination of $T=1 s$ and $\mu=4$ is presented here, because other cases exhibit similar results. While $S_{R D R}$ is about $0.2-0.3$ or less at $r \geq 0.1$, it increases sharply as $r$ approaches zero. $S_{R D R}$ is almost 1.0 at $r \leq-0.05$. Generally $S_{R D R}$ at $r>0$ is slightly larger at the Group I sites than the Group II and III sites. Fig. 11 shows how important the bilinear factor $r$ is on the residual displacement response spectra $S_{R D R}$, in particular $S_{R D R}$ at $r \cong 0$.

Fig 12 shows the $S_{R D R}$ vs. $r$ relation taking the natural period as a parameter. Because the dependence of the $S_{R D R}$ vs. $r$ relation on the soil condition was less significant as shown in Fig $11, S_{R D R}$ averaged over all the soil conditions is presented here. The general trend of the $S_{R D R}$ vs. $r$ relation is the same with that presented in Fig 11. $S_{R D R}$ at longer natural periods is slightly larger when $r>0$, while they are slightly less when $r<0$. The dependence of the $S_{R D R}$ vs. $r$ relation on natural period is not significant.

Fig. 13 shows the $S_{R D R}$ vs. $r$ relation taking the ductility factor as a parameter. Again the general trend of the $S_{R D R}$ vs. $r$ relation is the same as that presented in Figs. 11 and 12. $S_{R D R}$ with $\mu=2$ is slightly larger than $S_{R D R}$ with $\mu=4$ and 6 when $r>0$, and is slightly less when $r<0$.

From Figs. 11-13, it is apparent that the residual displacement ratio response spectra $S_{R D R}$ is small when the bilinear factor $r$ is larger than about 0.05 , and it sharply increases as $\mathrm{r}$ approaches zero. $S_{R D R}$ is almost unity when $r$ is less than 1. This general trend on the $S_{R D R}$ vs. $r$ relation is not dependent on soil condition, natural period and ductility factor.

\section{$5 S_{R D R}$ PROPOSED FOR SEISMIC DESIGN}

Based on those findings, it was decided to disregard the effect of natural period, ground condition and ductility factor on the residual displacement ratio response spectra $S_{R D R}$ and to consider only the effect of bilinear factor in evaluating the residual displacement ratio response spectra for seismic design. Because the scatter of the residual displacement ratio response spectra around the mean value is considerable, one standard deviation from the mean value is included. Fig 14 shows the residual displacement ratio response spectra $S_{R D R}$ thus evaluated, and this is proposed to be used in design.

\section{APPLICATION OF RESIDUAL DISPLACEMENT RESPONSE SPECTRA}


The residual displacement response spectra of Fig 14 can be used for any structures where the hysteresis loop shape may be reasonably approximated by a bilinear model.

An example of the application of this method is given for six reinforced concrete bridge columns as shown in Table 2 . They were designed in accordance with the equivalent static seismic design method with the lateral force coefficient of 0.2 and the allowable design approach (JRA 1990, Kawashima and Hasegawa 1994b). The column height was $15 \mathrm{~m}$ and $20 \mathrm{~m}$, and the deck length was $30 \mathrm{~m}$ and $40 \mathrm{~m}$. The deck was assumed to be simply supported plate girder with $7 \mathrm{~m}$ ( 2 lanes) wide. The columns were assumed to have rectangular cross sections $7 \mathrm{~m}$ wide in the transverse direction. Shear span ratios were either 7.1 or 9 in the longitudinal direction. These columns were assumed to be subjected to an earthquake excitation in longitudinal direction. The natural periods of columns assuming the uncracked concrete stiffness ranged from $0.63 \mathrm{~s}$ to $1.11 \mathrm{~s}$

If it is assumed here that the hy steresis loops of the reinforced concrete columns can be idealized by the Takeda model (Takeda, Sozen and Nielsen, 1970), the lateral force vs. displacement relationship after the initial cycle may be bilinear as shown in Fig 15 with the initial stiffness $k_{1}$ and the post-yield stiffness $k_{2}$. It should be noted that although the original Takeda model assumes trilinear hy steresis, bilinear is assumed here by disregarding the effect of cracking These parameters may be evaluated based on the primary curve of the cracked columns.

The primary curve was evaluated here according to the Seismic Design Specifications of Bridges of the Japan
Road Association (JRA, 1990), and the yield force $F_{y m}$, ultimate force $F_{u m}$, yield displacement $u_{y m}$, and the ultimate displacement $u_{u m}$ of the columns were obtained as shown in Table 3. From those values, the initial stiffness $k_{1 m}$ and the second stiffness $k_{2 m}$ on the primary curve are obtained as

$$
\begin{gathered}
k_{1 m}=\frac{F_{y m}}{u_{y m}} \\
k_{2 m}=\frac{F_{u m}-F_{y m}}{u_{u m}-u_{y m}}
\end{gathered}
$$

The stiffness of the bilinear loop $k_{1}$ and $k_{2}$ from the Takeda model corresponding to the maximum displacement $u_{\max }=\mu u_{y}$ are obtained from Fig. 15 as

$$
\begin{gathered}
k_{1}=\frac{k_{1 m}}{\mu_{m}^{\alpha}} \\
k_{2}=r k_{1}
\end{gathered}
$$

where

$$
\begin{aligned}
r & =\frac{F_{\max }}{2 \mu_{m} u_{y m} k_{1}-F_{\max }} \\
F_{\max } & =F_{y m}\left\{1+r_{m}\left(\mu_{m}-1\right)\right\}
\end{aligned}
$$

The yielding displacement $u_{y}$ and ductility factor $\mu$ are

$$
\begin{aligned}
& u_{y}=\frac{F_{\max }}{2 k_{1}} \quad(\mu>1) \\
& \mu=\frac{\mu_{m} u_{y m}}{u_{y}}
\end{aligned}
$$

The coefficient $\alpha$ in Eq. (7) represents the degree of stiffness degradation, and is assumed here to be 0.5 (Priestley, MacRae and Tao 1993).

Residual displacements were computed by arbitrarily assuming a ductility factor $\mu_{m}$ of 10 . Based on $\mu_{m}$ and the parameters for primary curve, the bilinear factor $r$ can be evaluated by Eq. (9). Because the maximum residual displacement $u_{r \max }$ and the residual 
displacement response spectra $S_{R D R}$ by Eq. (4) can be evaluated by Eq. (3) and Fig. 14, respectively, the residual displacement developed at the top of columns $\left|u_{r}\right|$ is obtained as shown in Table 4.

Table 4 shows that the bilinear factor $r$ for the columns is in the range of 0.21 to 0.25 . The residual displacement ratio response spectra $S_{R D R}$ from Fig 14 is about 0.3 considering one standard deviation from the mean value for safety. The residual displacement $u_{r}$ predicted to occur at the top of the columns ranges from $6 \mathrm{~cm}$ to $16.9 \mathrm{~cm}$. Those correspond to $0.18-0.20$ of the peak displacement $\mu_{m} u_{y m}$, and are larger in the more flexible columns with large $u_{y m}$.

It should be noted that reinforced concrete columns which are subjected to a pulse type motion and which do not deform approximately the same amount in positive and negative directions may have larger residual displacements because its hysteresis loop does not match the bilinear approximation as shown in Fig. 15 (Takeda, Sozen and Nielsen 1970).

Also, structures with lower bilinear factors $r$ or eccentrically loaded reinforced concrete cantilever columns are likely to have significantly greater residual displacements than those presented herein.

\section{CONCLUSIONS}

For evaluating the residual displacements developed at structures subjected to large ground motions, residual displacement response spectra $S_{R D}$ and residual displacement ratio response spectra $S_{R D R}$ were proposed, and their characteristics were clarified based on 63 components of free-field ground accelerations. An application of the residual displacement ratio response spectra $S_{R D R}$ to cantilevered bridge columns was also presented. Based on the results presented herein, the following conclusions may be deduced:

(1) The residual displacement ratio response spectrum $S_{R D R}$, which is defined as residual displacement response spectra $S_{R D}$ normalized by the maximum residual displacement $u_{r \text { max }}$ given by Eq. (3), is almost independent of the earthquake magnitude, the epicentral distance of the acceleration data and the soil conditions.

(2) The residual displacement ratio response spectra $S_{R D R}$ depend significantly on the bilinear factor $r$. The residual displacement ratio response spectra is small at $r>0$, but it sharply increases as $r$ approaches 0 . It is almost 1.0 at $r<-0.05$.

(3) The dependence of natural period, soil condition and ductility factor on the residual displacement ratio response spectra $S_{R D R}$ vs. bilinear factor $r$ relation is not significant. A design value for the residual displacement ratio response spectra $S_{R D R}$ was proposed as a parameter of the bilinear factor $r$ as shown in Fig 14, based on the averaged value of the residual displacement ratio response spectra for 63 ground acceleration records. To consider the significant scatter around the mean value, one standard deviation from the mean value was included in the proposed relation.

(4) Residual displacements developed at the crest of reinforced concrete bridge columns were computed based on the residual displacement ratio response 
spectra proposed herein. The maximum residual displacement at the pier crest is $16.9 \mathrm{~cm}$ for a $20 \mathrm{~m}$ high column.

\section{REFERENCES}

1) Housner, G. W. (1959), "Behavior of structures during earthquakes." Proc. ASCE, 85, Em 4, 109-129

2) Japan Road Association (1990), "Part V Seismic design, Design specifications of highway bridges."

3) Kawashima, K., MacRae, G. A. and Hasegawa, K. (1992), "The strength and ductility of steel bridge piers based on loading tests" Journal of Research, 29, Public Works Research Institute, Tsukuba, Japan.

4) MacRae, G. A. and Kawashima, K. (1993) "The seismic response of bilinear oscillators using Japanese earthquake records," Journal of Research, 30, Public Works Research Institute, Tsukuba, Japan.

5) Kawashima, K. and Hasegawa, K. (1994a), "Experimental investigation on nonlinear seismic response of bridge columns and accuracy of equal energy assumption." Proc. Japan Society of Civil Engineering, 483/I-26, 137-146

6) Kawashima, K. and Hasegawa, K. (1994b), "New seismic design specifications of highway bridges in Jap an." Earthquake Spectra, 10 (2), 333356

7) Ministry of Construction. (1995). "Report on damage of highway bridges by the Hyogo-ken Nanbu Earthquake," Committee for Investigation on the Damage of Highway Bridges Caused by the Hyogo-ken Nanbu Earthquake, Tokyo, Japan.

8) Priestley, M. J. N., MacRae, G. A. and Tao, J. (1993) "P- $\Delta$ effect in seismic regions," Structural Systems Research Project Report, No. 93-5, University of California, San Diego.

9) Takeda, T., Sozen M. A. and Nielsen N. N. (1970), "Reinforced concrete response to simulated earthquakes," Journal of Structural Engineering ASCE, 96-12, 2557-2573 
Table 1 Definition of Ground Condition

\begin{tabular}{|c|c|c|c|c|c|}
\hline Case & Height (m) & $\begin{array}{c}\text { Shear Span } \\
\text { Ratio }\end{array}$ & Width (m) & $\begin{array}{c}\text { Span Length } \\
(\mathrm{m})\end{array}$ & $\begin{array}{c}\text { Natural } \\
\text { Period (s) }\end{array}$ \\
\hline 1 & 15 & 7.1 & 2.1 & 30 & 0.63 \\
\hline 2 & 15 & 7.1 & 2.1 & 40 & 0.75 \\
\hline 3 & 15 & 9 & 1.67 & 30 & 0.91 \\
\hline 4 & 15 & 9 & 1.67 & 40 & 1.00 \\
\hline 5 & 20 & 7.1 & 2.8 & 40 & 0.86 \\
\hline 6 & 20 & 9 & 2.22 & 40 & 1.11 \\
\hline
\end{tabular}

Table 2 Bridge Columns Analyzed

\begin{tabular}{|l|l|l|}
\hline N it ura: Period & $\begin{array}{l}\text { Ground } \\
\text { Condition }\end{array}$ & \multicolumn{1}{|c|}{ Geological Definition } \\
\hline $\mathrm{T}_{\mathrm{G}}<0.2 \mathrm{~s}$ & Group I & $\begin{array}{l}\text { Tertiary or older rock, or } \\
\text { diluvium with } \mathrm{H}<10 \mathrm{~m}\end{array}$ \\
\hline $0.2 \mathrm{~s} s \mathrm{TG}<0.6 \mathrm{~s}$ & Group II & $\begin{array}{l}\text { Diluvium with } \mathrm{H} \geq 10 \mathrm{~m} \text {, or } \\
\text { alluvium with H }<25 \mathrm{~m} \\
\text { including soft layer with } \\
\mathrm{H}<5 \mathrm{~m}\end{array}$ \\
\hline $0.6 \mathrm{~s} \leq \mathrm{TG}$ & Group III & $\begin{array}{l}\text { Other than the above, usually } \\
\text { soft alluvium or reclaimed } \\
\text { land }\end{array}$ \\
\hline
\end{tabular}

Table 3 Yield Displacement, Natural Period and Bilinear Factor

\begin{tabular}{|c|c|c|c|c|c|c|c|}
\hline Case & $u_{y m}(\mathrm{~cm})$ & $u_{u m}(\mathrm{~cm})$ & $F_{y m}(\mathrm{kN})$ & $F_{u m}(\mathrm{kN})$ & $k_{1 m}(\mathrm{kN} / \mathrm{cm})$ & $k_{2 m}(\mathrm{kN} / \mathrm{cm})$ & $r_{m}$ \\
\hline 1 & 2.94 & 53.5 & 1,217 & 1,429 & 414.0 & 4.18 & 0.0101 \\
\hline 2 & 4.12 & 47.2 & 1,497 & 1,766 & 363.5 & 6.23 & 0.0171 \\
\hline 3 & 6.03 & 50.0 & 1,099 & 1,271 & 182.2 & 3.92 & 0.0215 \\
\hline 4 & 7.00 & 48.4 & 1,344 & 1,563 & 192.0 & 5.30 & 0.0276 \\
\hline 5 & 4.98 & 70.7 & 1,780 & 2,159 & 357.4 & 5.77 & 0.0162 \\
\hline 6 & 9.4 & 70.9 & 1,740 & 2,679 & 185.0 & 5.52 & 0.0298 \\
\hline
\end{tabular}

Table 4 Residual Displacement Developed at Top of Columns

\begin{tabular}{|c|c|c|c|c|c|c|c|}
\hline Case & $\mu$ & $k_{1}(\mathrm{kN} / \mathrm{cm})$ & $u_{y}(\mathrm{~cm})$ & $r$ & $u_{r \max }(\mathrm{cm})$ & $S_{R D R}$ & $u_{r}(\mathrm{~cm})$ \\
\hline 1 & 5.80 & 130.9 & 5.07 & 0.21 & 19.26 & 0.31 & 6.0 \\
\hline 2 & 5.48 & 115.0 & 7.52 & 0.22 & 26.16 & 0.31 & 8.0 \\
\hline 3 & 5.30 & 57.6 & 11.38 & 0.23 & 37.54 & 0.30 & 11.3 \\
\hline 4 & 5.07 & 60.7 & 13.82 & 0.25 & 42.36 & 0.29 & 12.3 \\
\hline 5 & 5.52 & 113.0 & 9.02 & 0.22 & 31.76 & 0.31 & 9.7 \\
\hline 6 & 4.99 & 58.5 & 18.85 & 0.25 & 56.30 & 0.30 & 16.9 \\
\hline
\end{tabular}




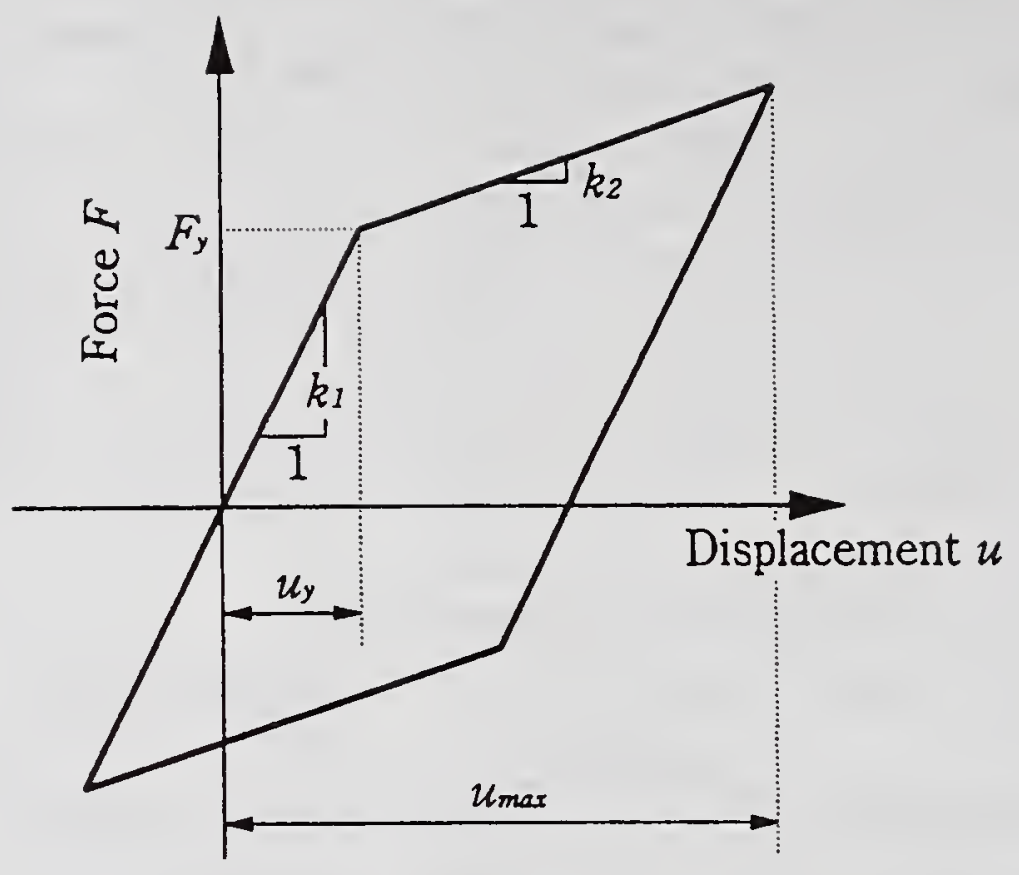

Fig. 1 Definition of Bilinear Hysteresis Model

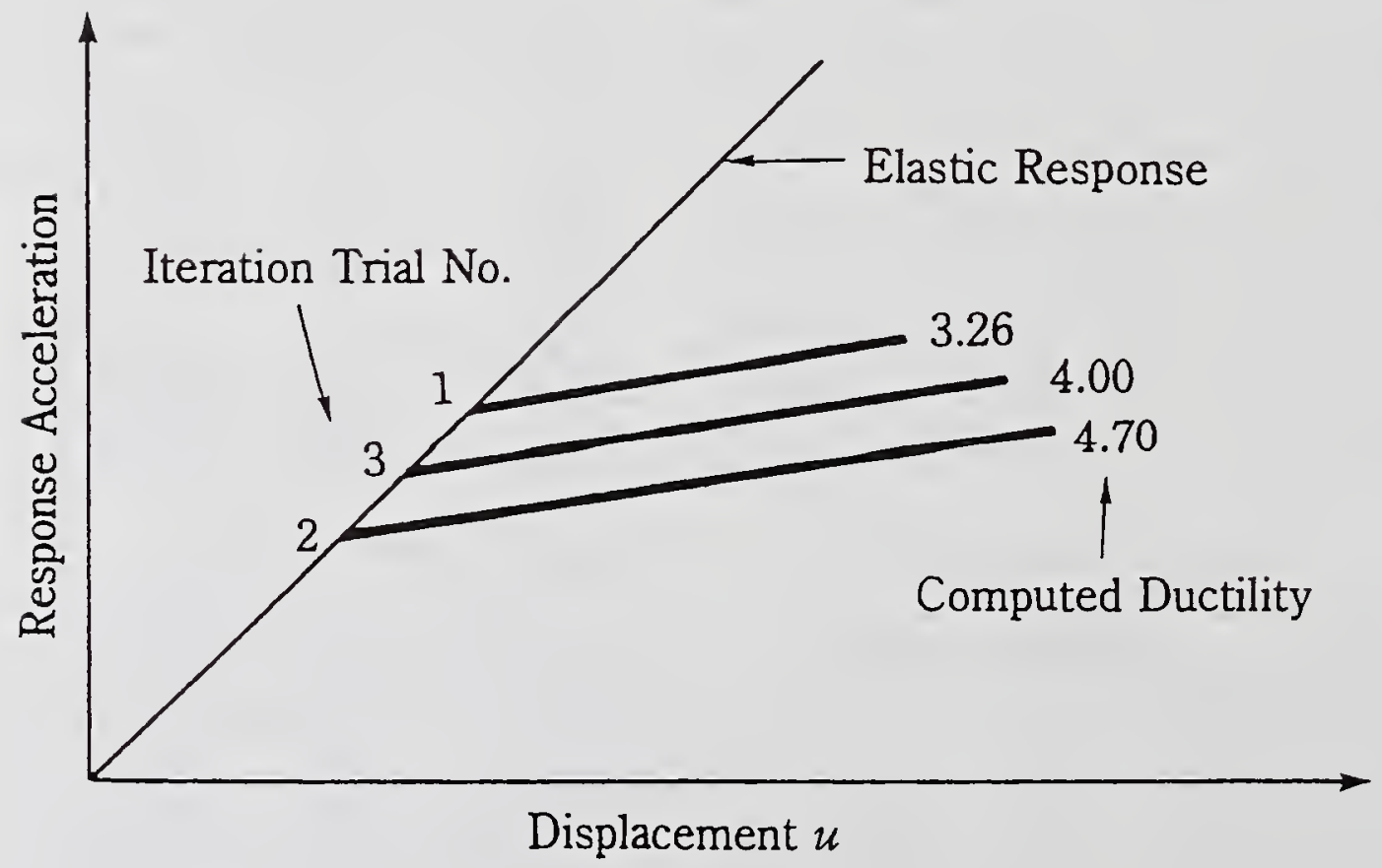

Fig. 2 Iteration Required to Compute Target Ductility Factor 


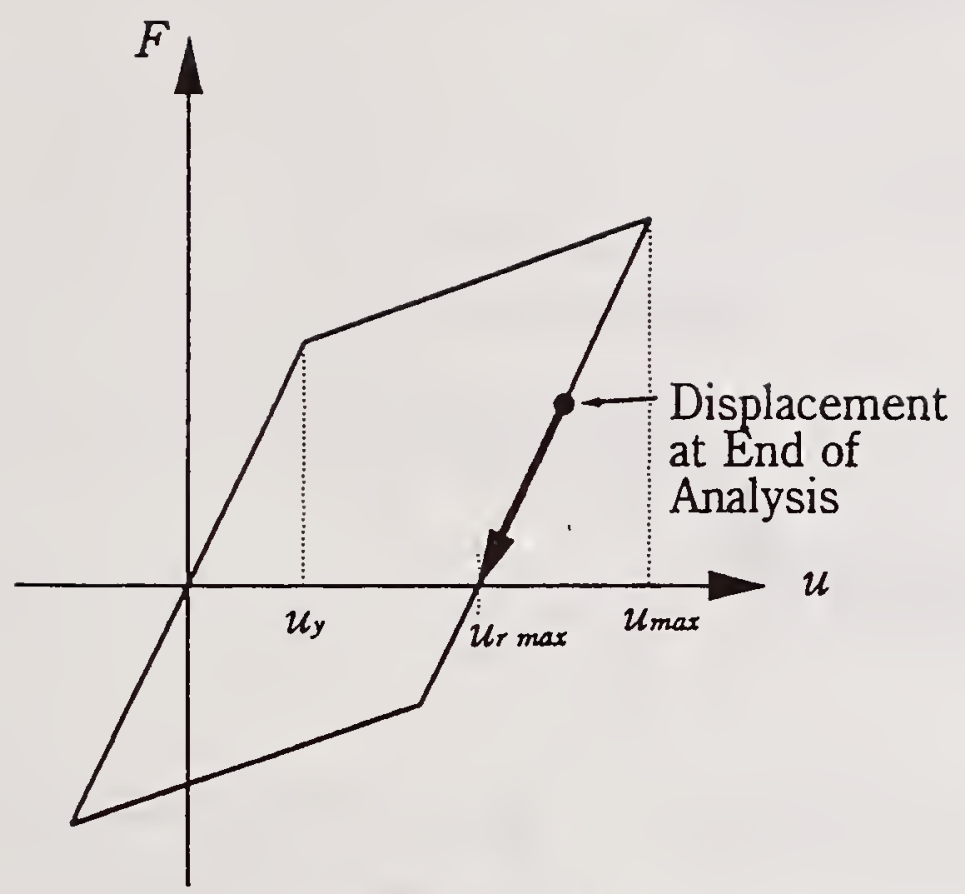

(a) $r(\mu-1)<1$

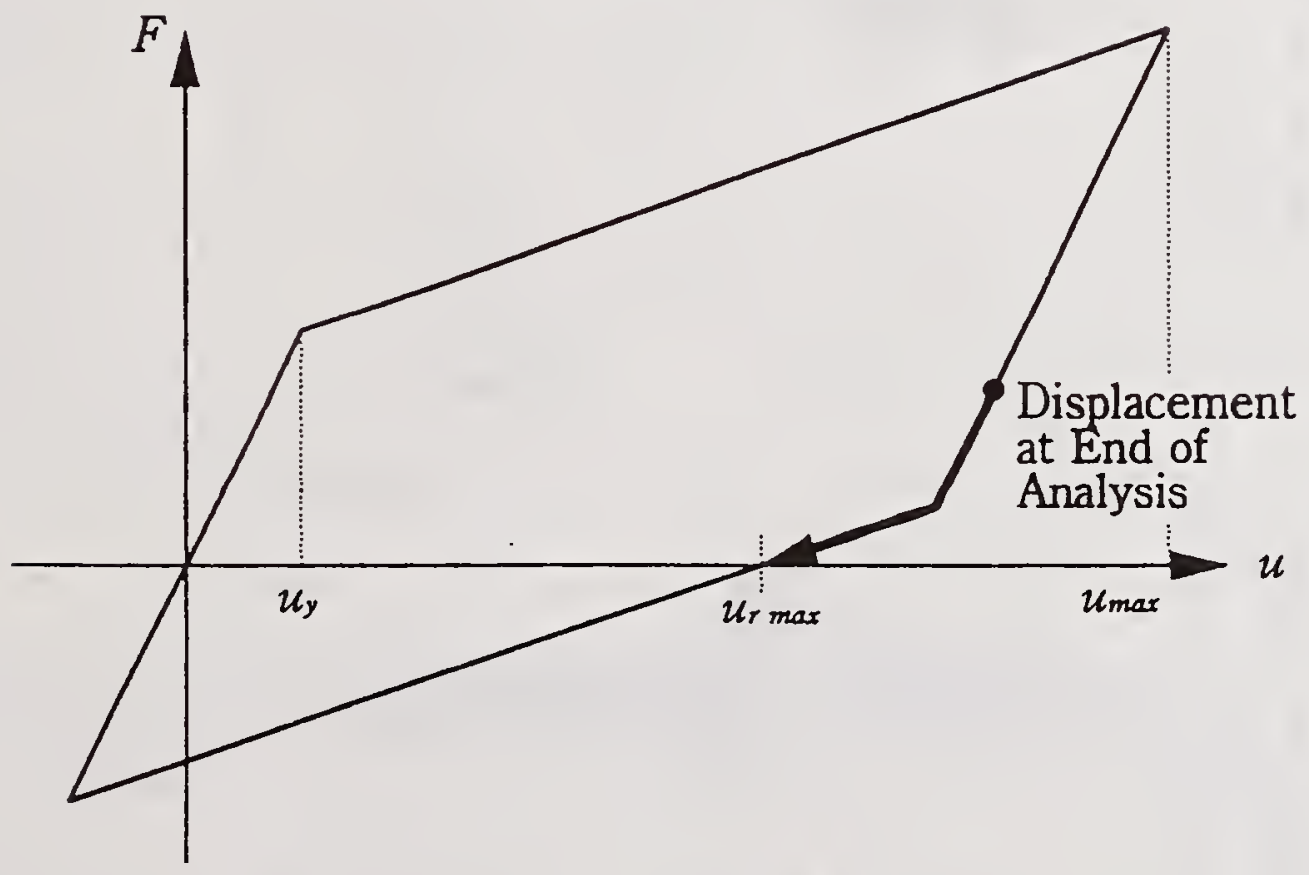

(b) $r(\mu-1) \geqq 1$

Fig. 3 Maximum Residual Displacement 


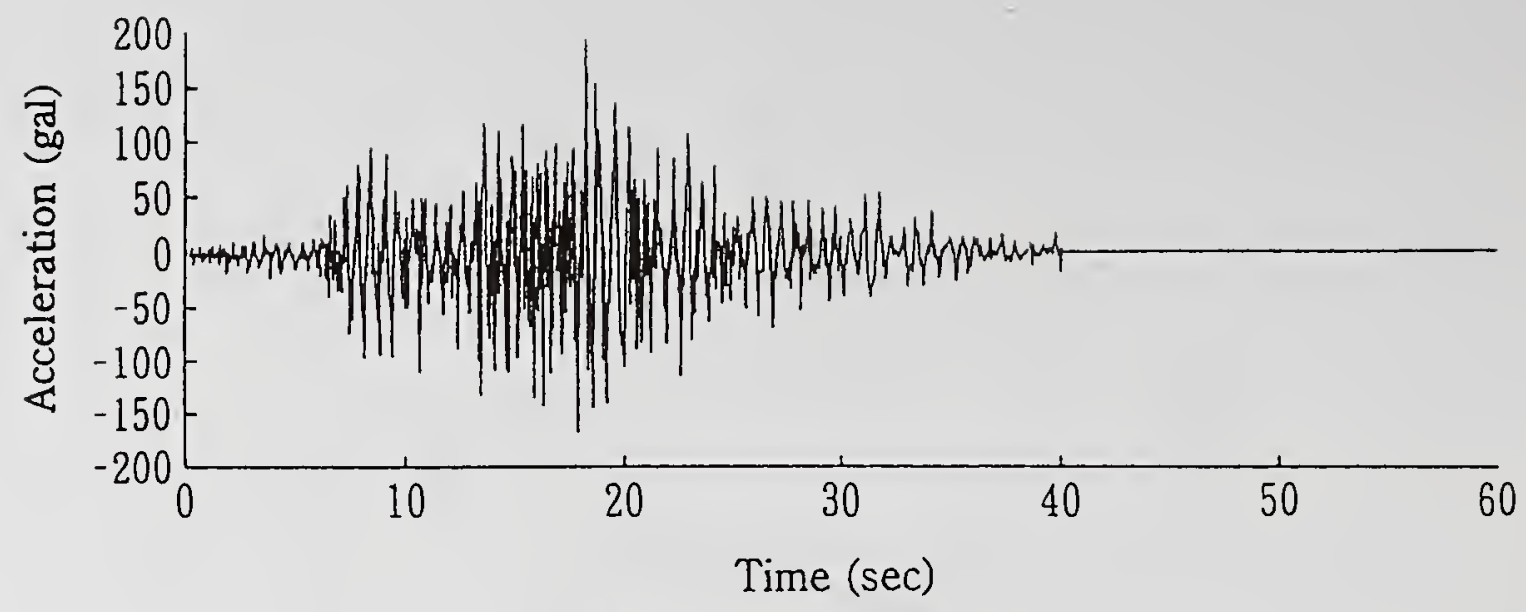

(a) Input Acceleration

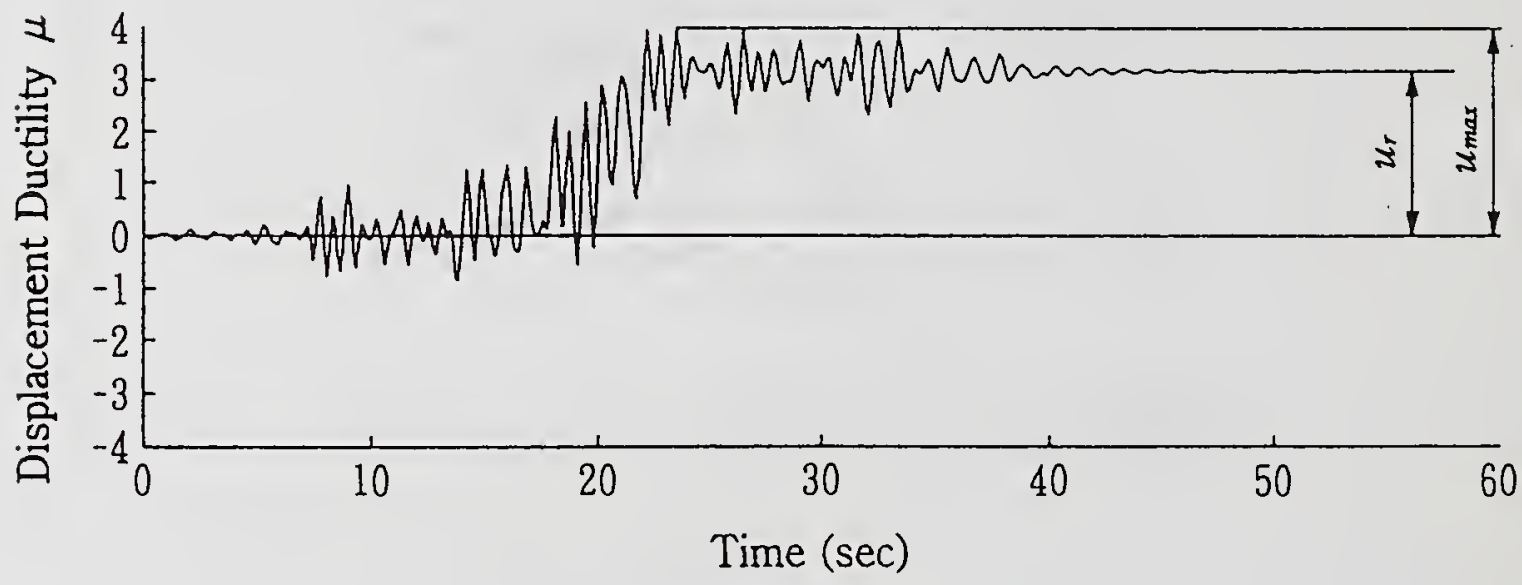

(b) $r=-0.05$
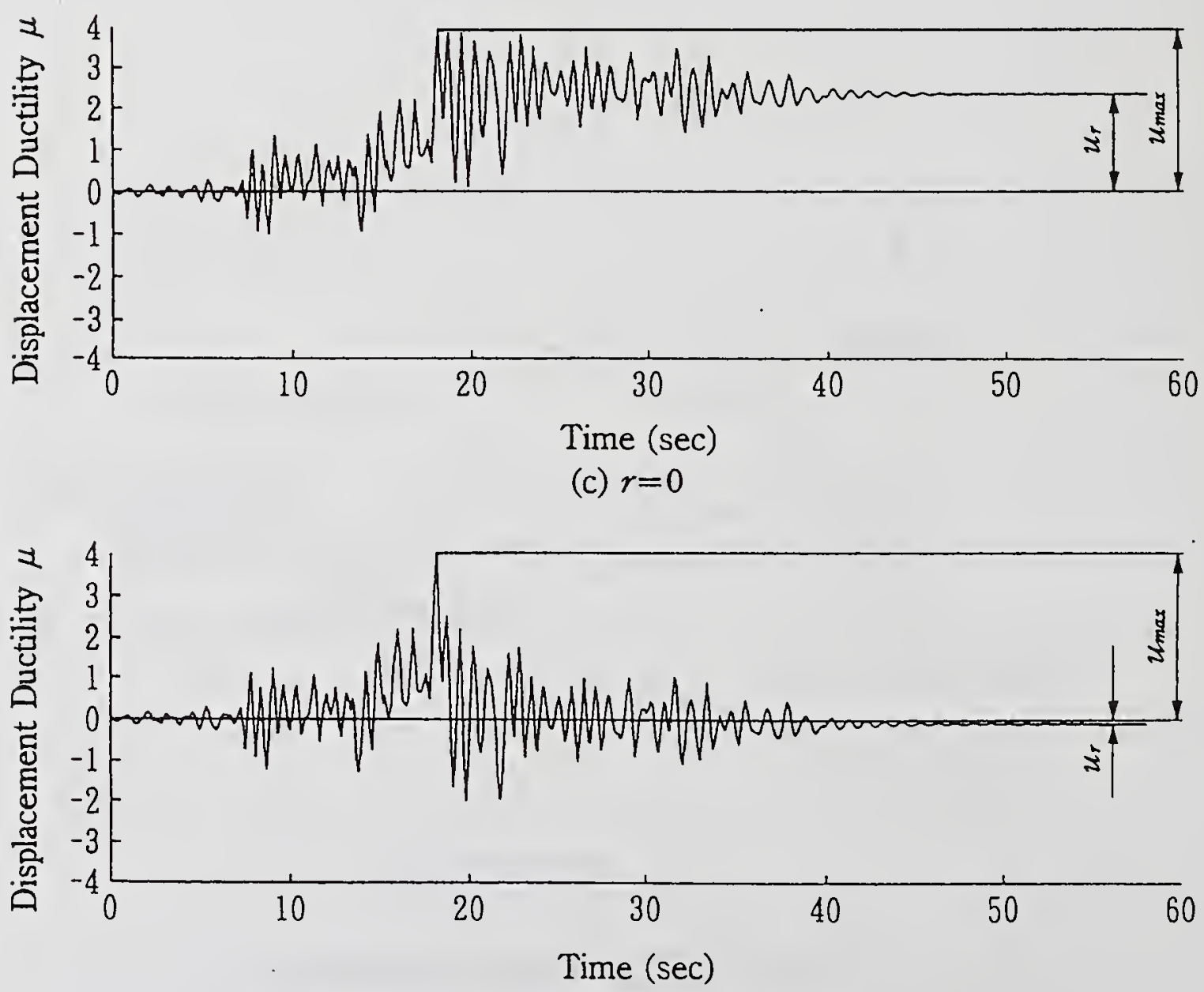

(d) $r=0.1$

Fig. 4 Residual Displacement for Itajima Record ( $T=1 \mathrm{~s})$ 


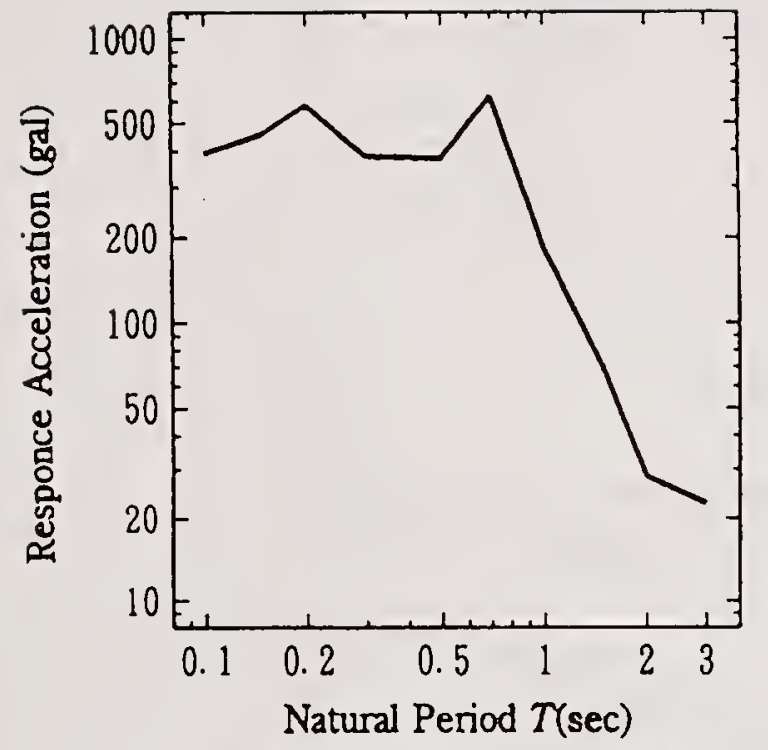

(a) Response Acceleration

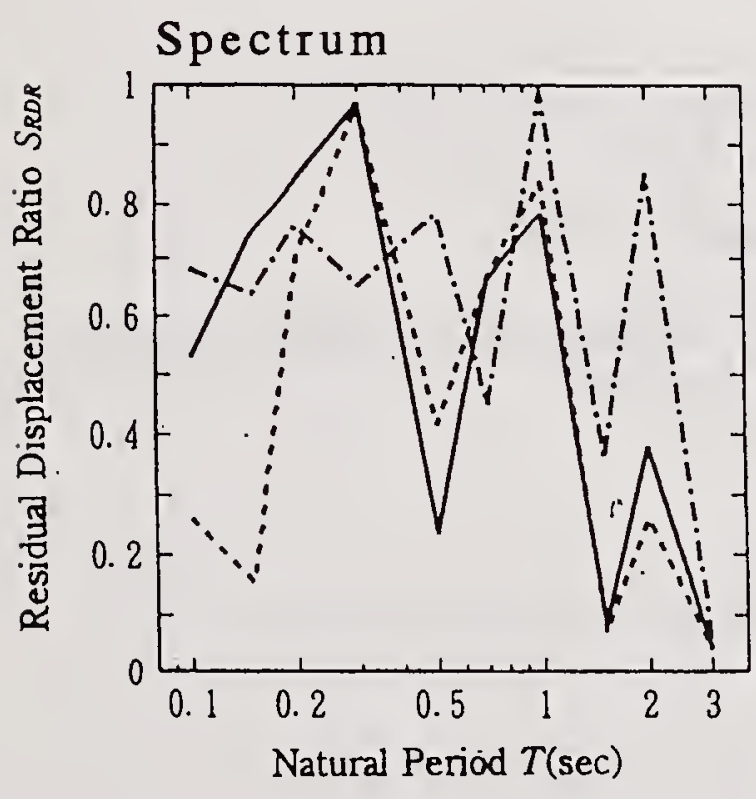

(c) $r=0$

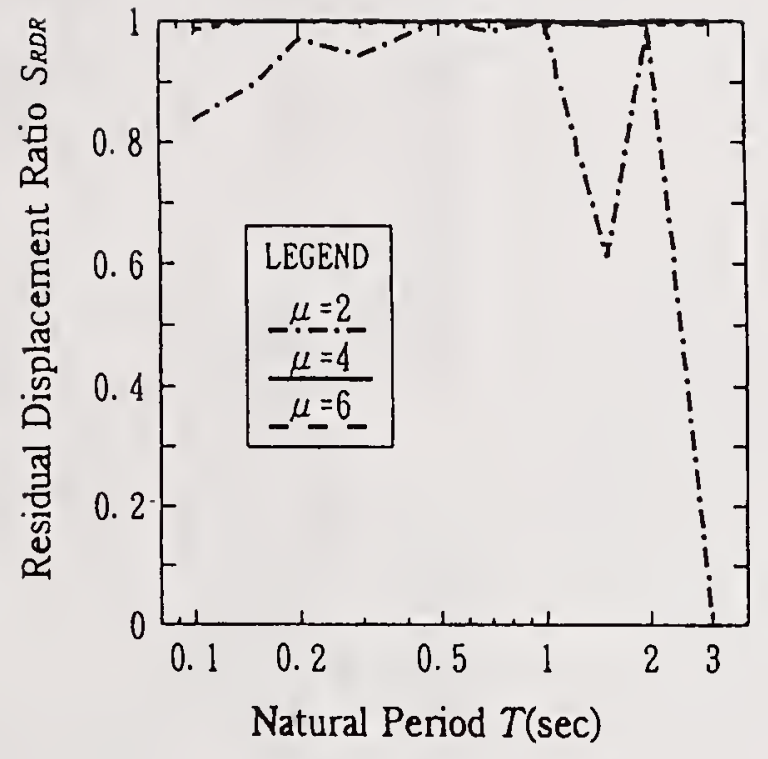

(b) $r=-0.05$

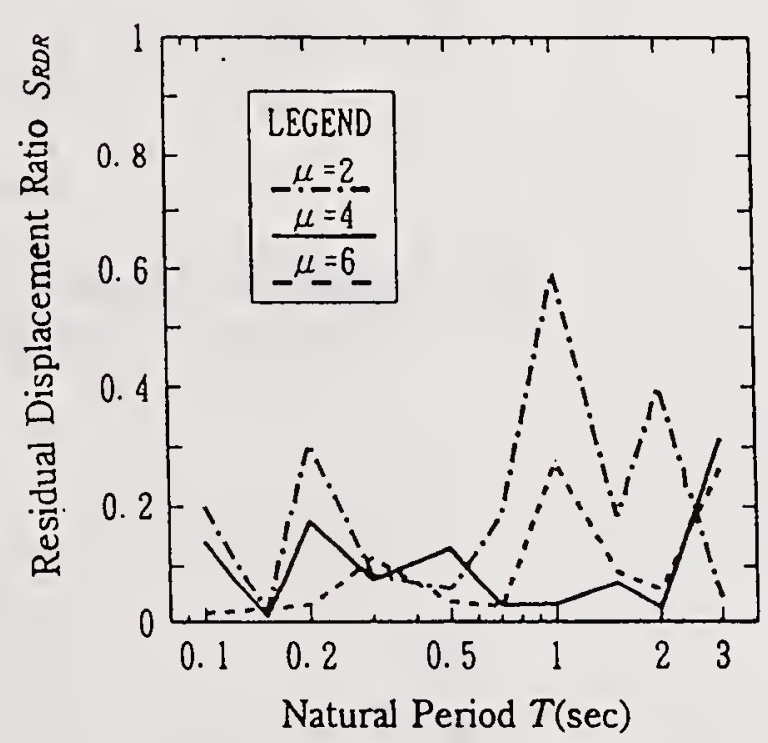

(d) $r=0.1$

Fig. 5 Residual Displacement Ratio Response Spectra $S_{R D R}$ for Itajima Record 


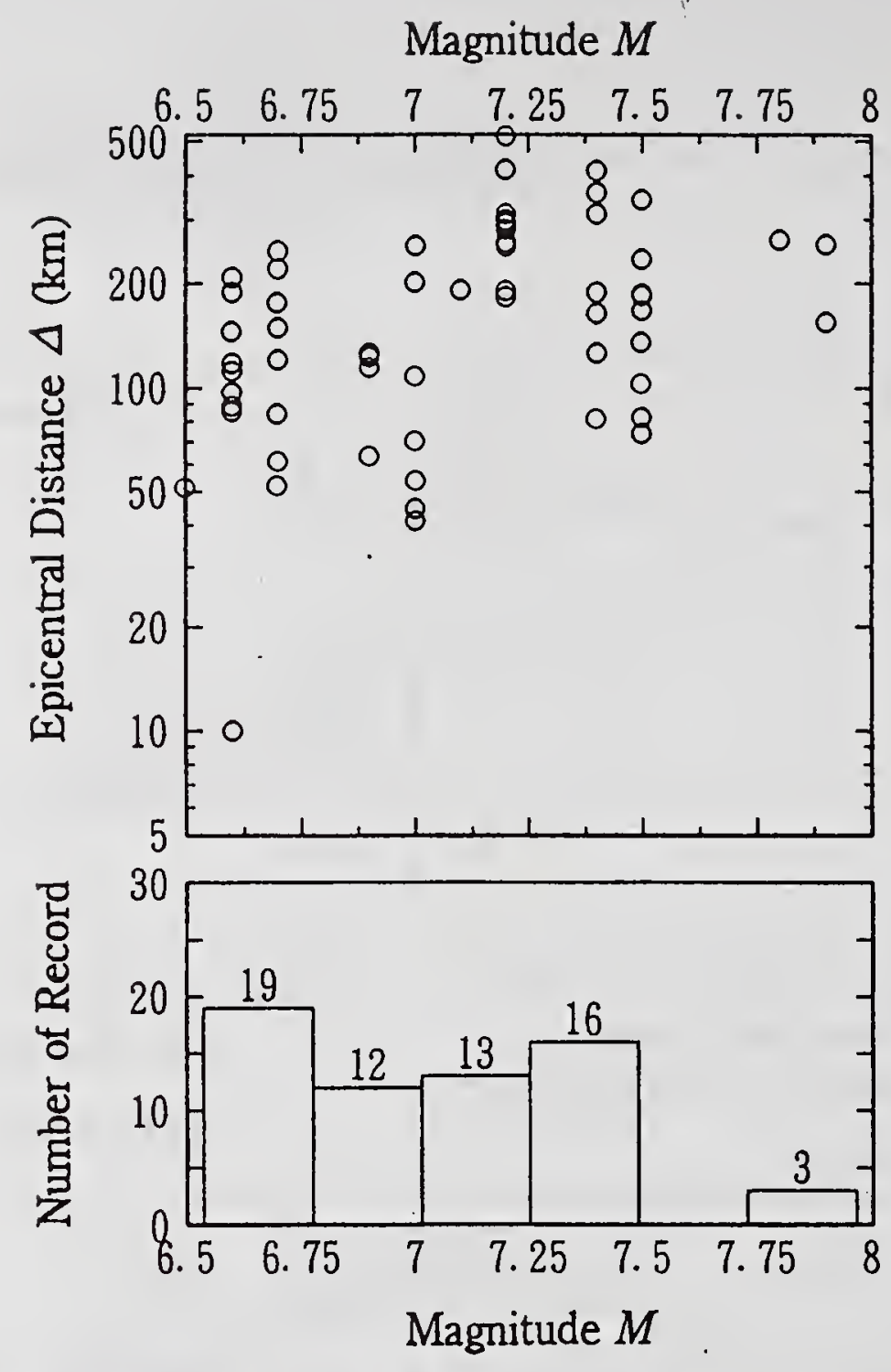

Fig. 6 Magnitude of Earthquake and Epicentral Distance of Ground Accelerations Used in Analysis

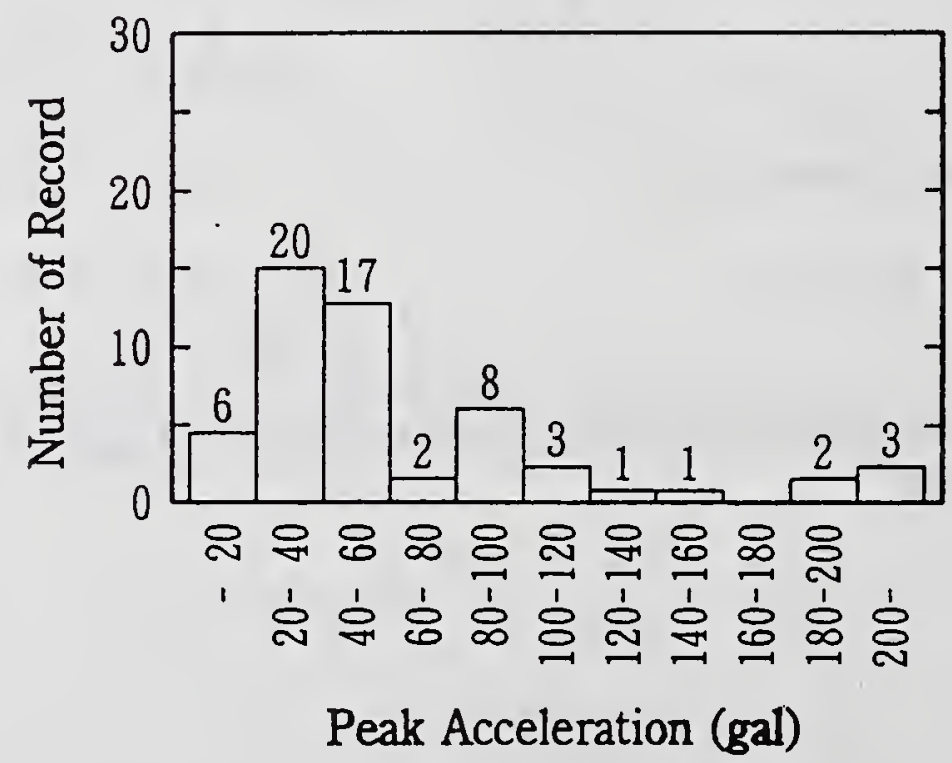

Fig. 7 Peak Ground Accelerations 


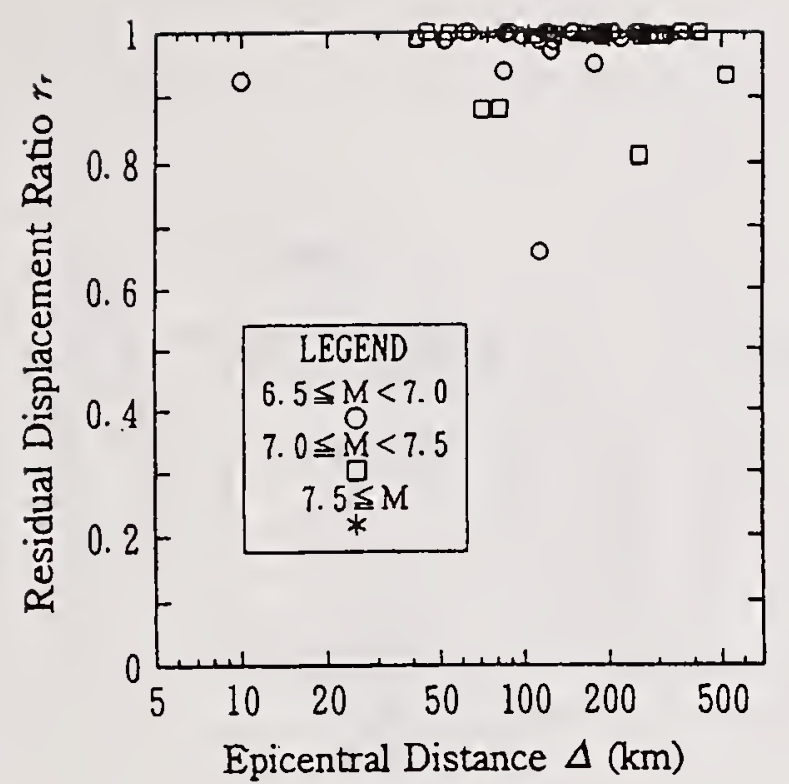

(a) $r=-0.05$

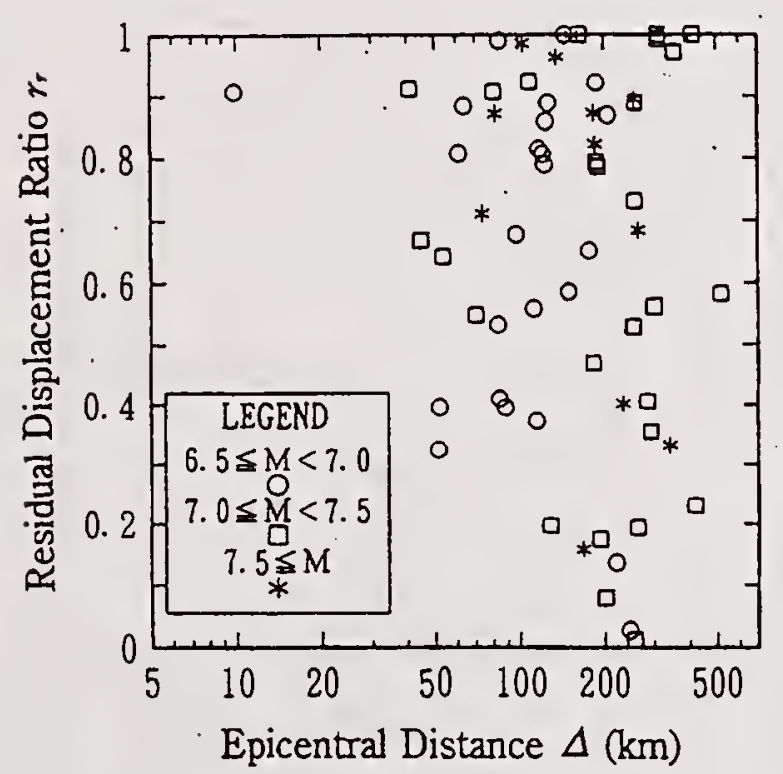

(b) $r=0$

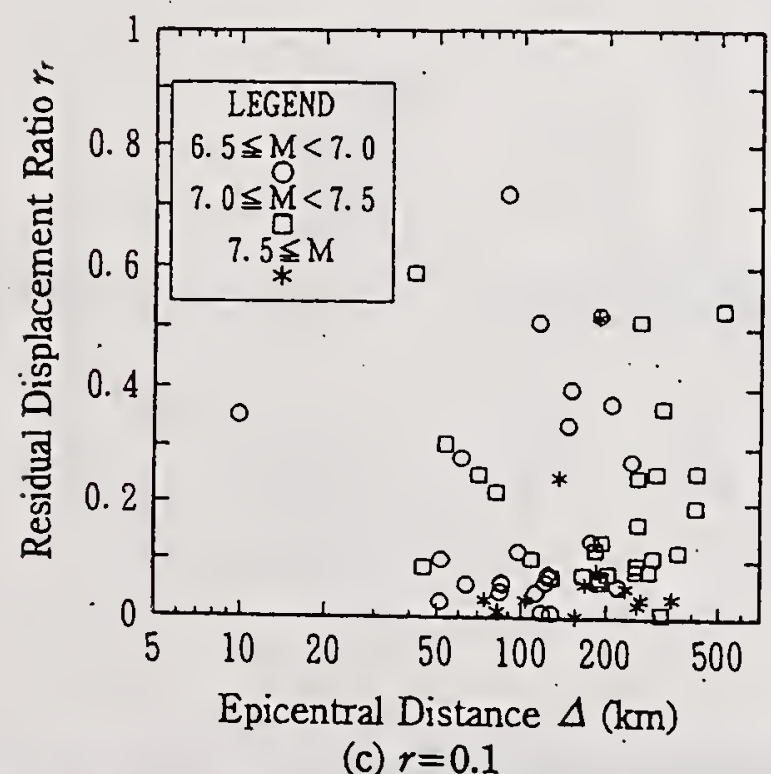

Fig. 8 Effect of Earthquake Magnitude and Epicentral Distance on Residual

Displacement Ratio Response Spectra $S_{R D R}$ for $\mathrm{T}=1$ s and $\mu=4$ 
Group I
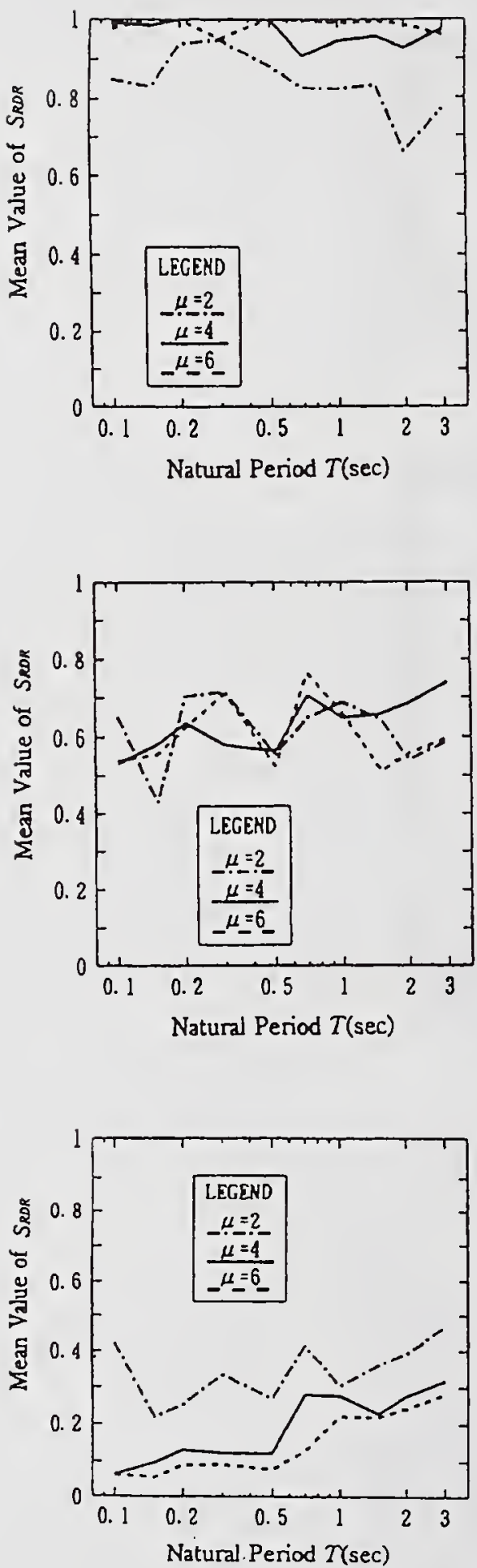

Group II

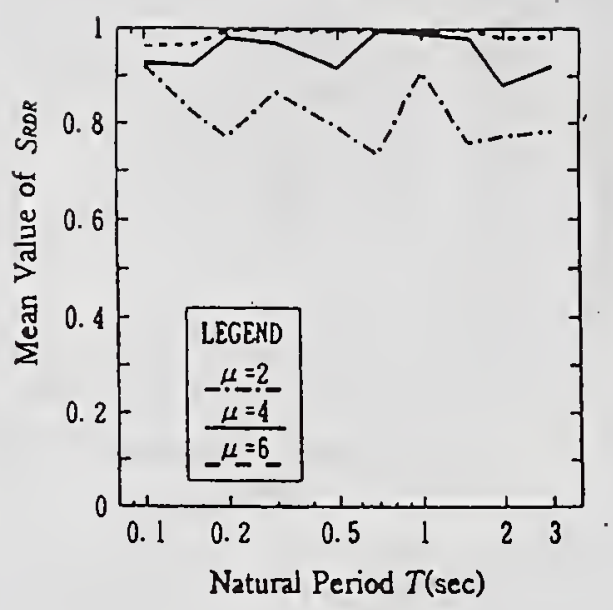

(a) $\mathrm{I}=-0.05$

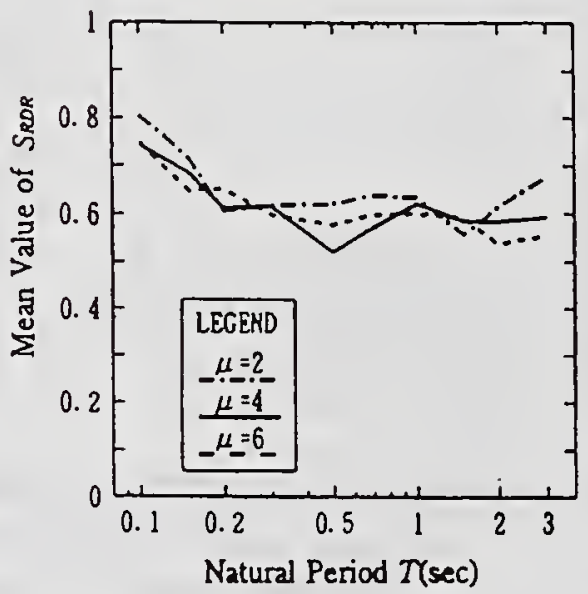

(b) $\mathrm{r}=0$

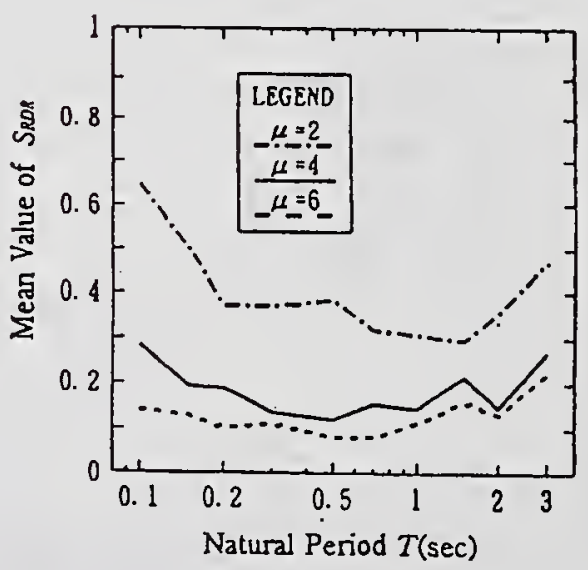

(c) $\mathrm{r}=0.1$
Group III
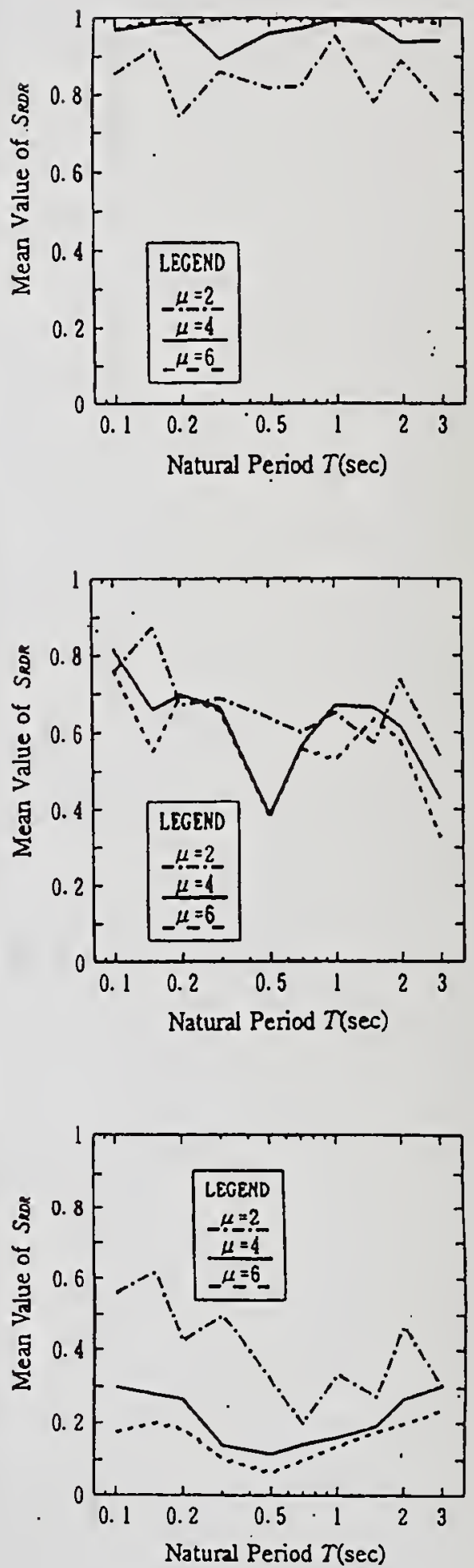

Fig. 9 Mean Value of Residual Displacement Ratio Response Spectra $S_{R D R}$ 

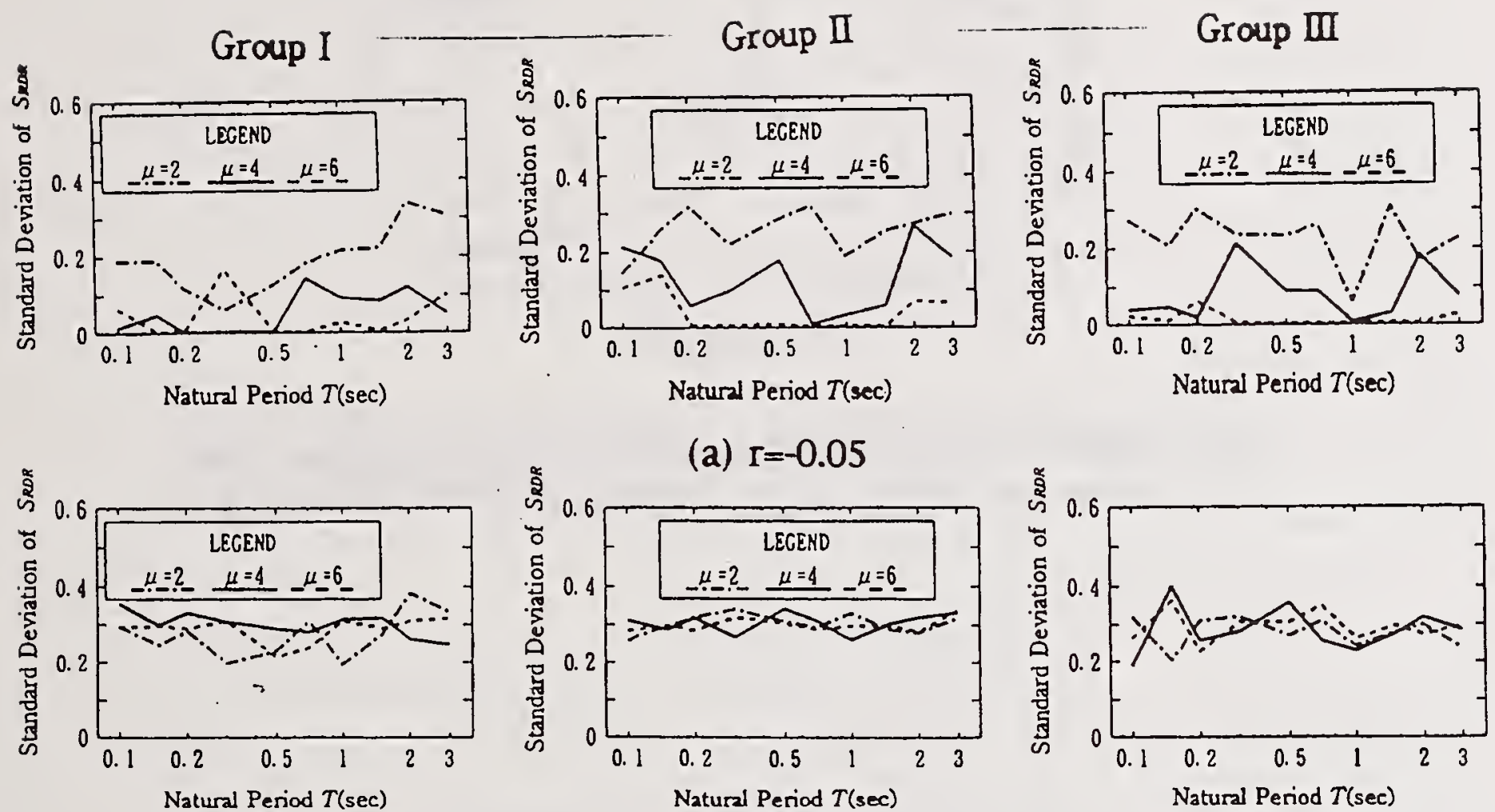

(a) $\mathrm{r}=-0.05$
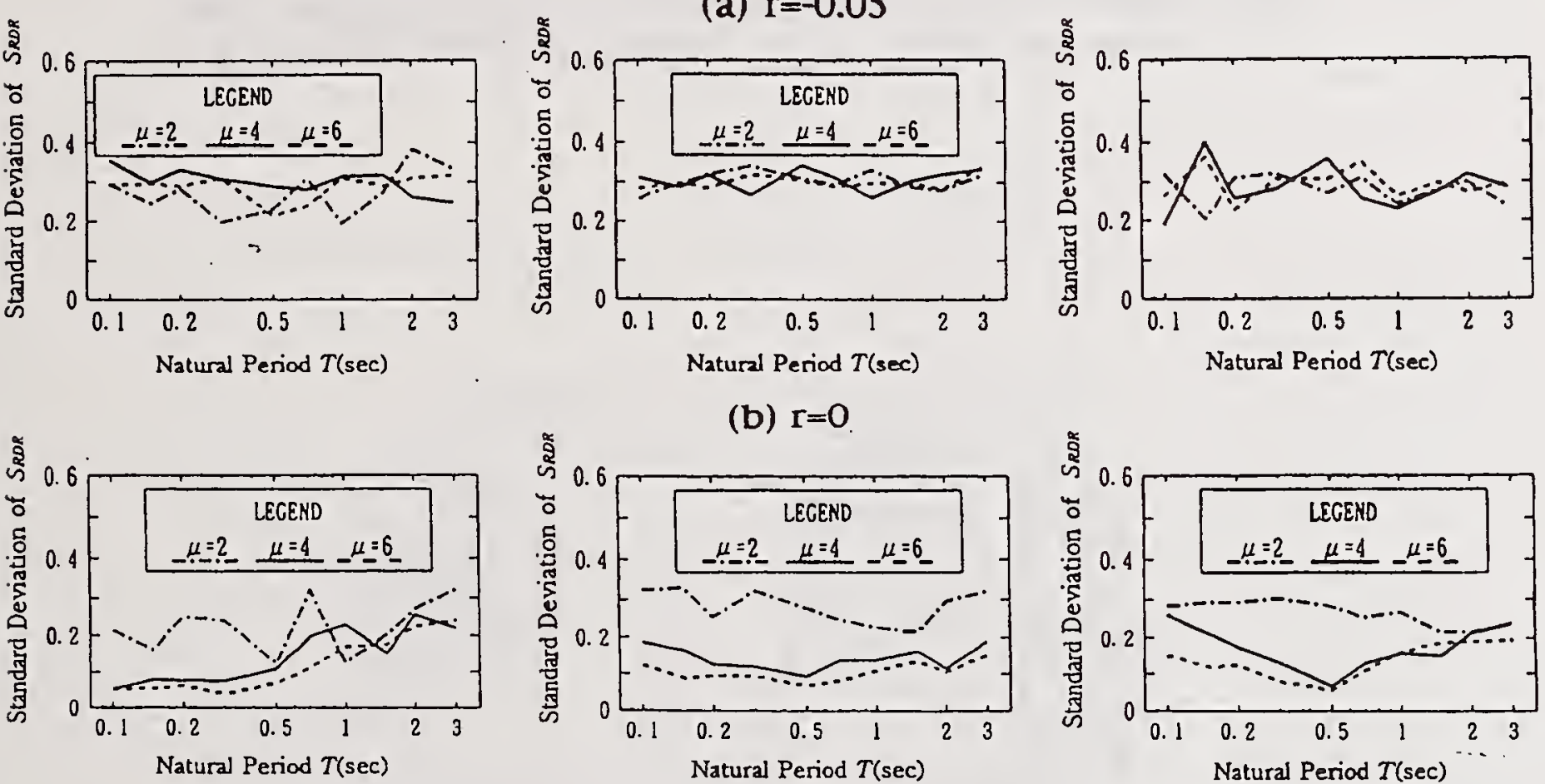

(b) $\mathrm{r}=0$.
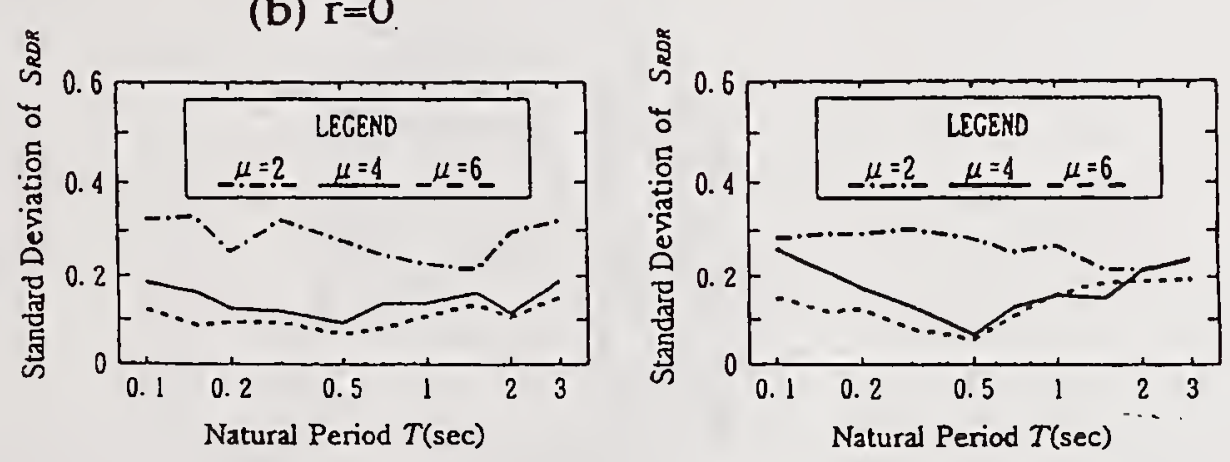

(c) $\mathrm{r}=0.1$

Fig. 10 Standard Deviation of Residual Displacement Ratio Response Spectra $S_{R D R}$ 


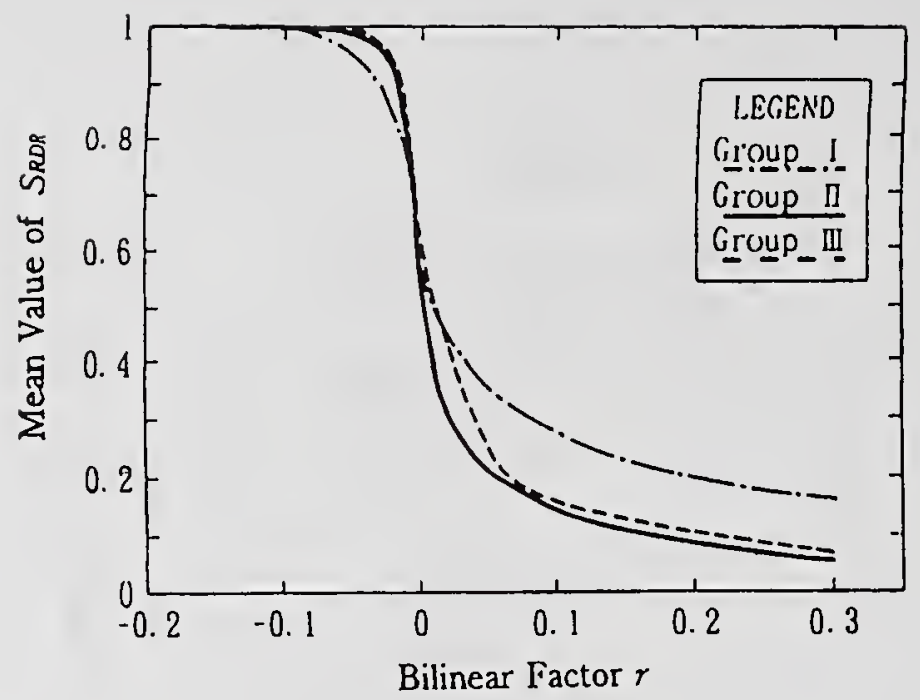

Fig. 11 Effect of Ground Condition on the Residual Displacement Ratio Response Spectra $S_{R D R}$ vs. Bilinear Factor $r$ for $\mathrm{T}=1 \mathrm{~s}$ and $\mu=4$

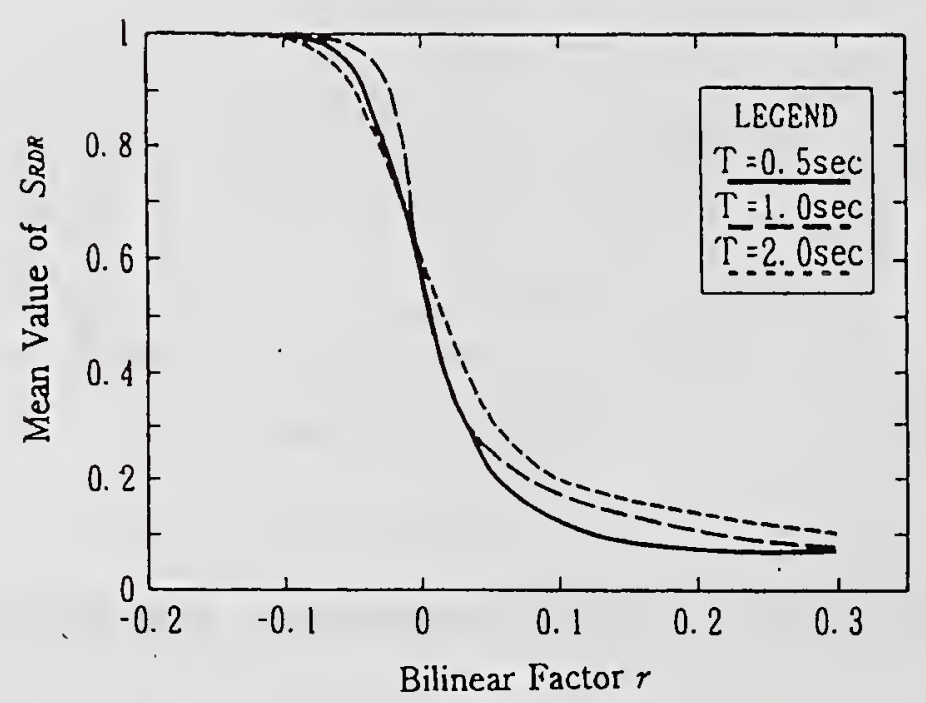

Fig. 12 Effect of Natural Period on the Residual Displacement Ratio Response Spectra $S_{R D R}$ vs. Bilinear Factor $r$ 


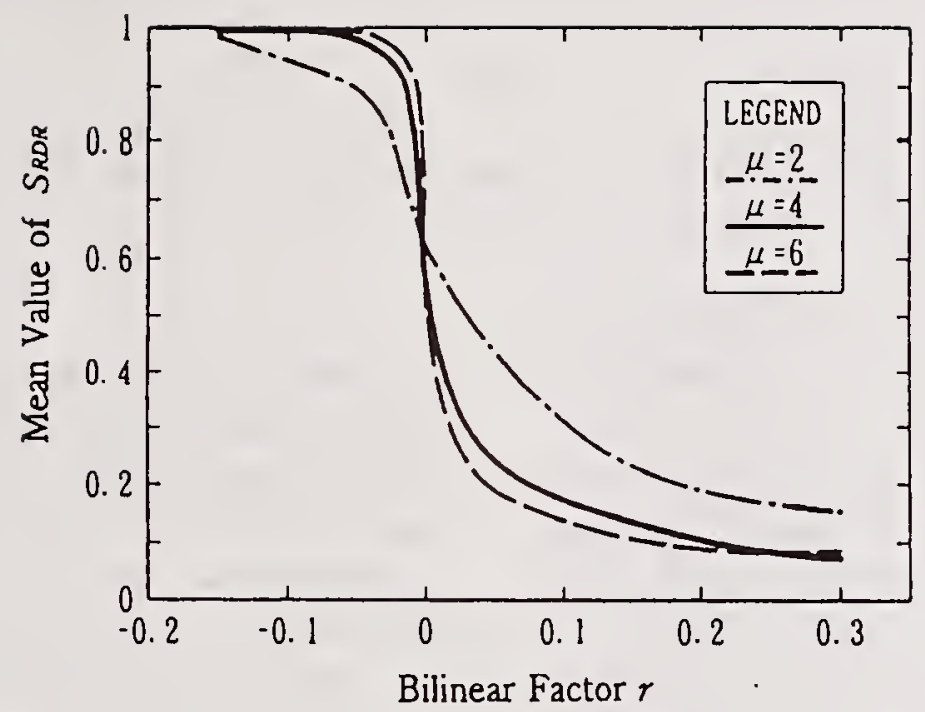

Fig. 13 Effect of Ductility Factor on the Residual Displacement Ratio Response Spectra $S_{R D R}$ vs. Bilinear Factor $r$

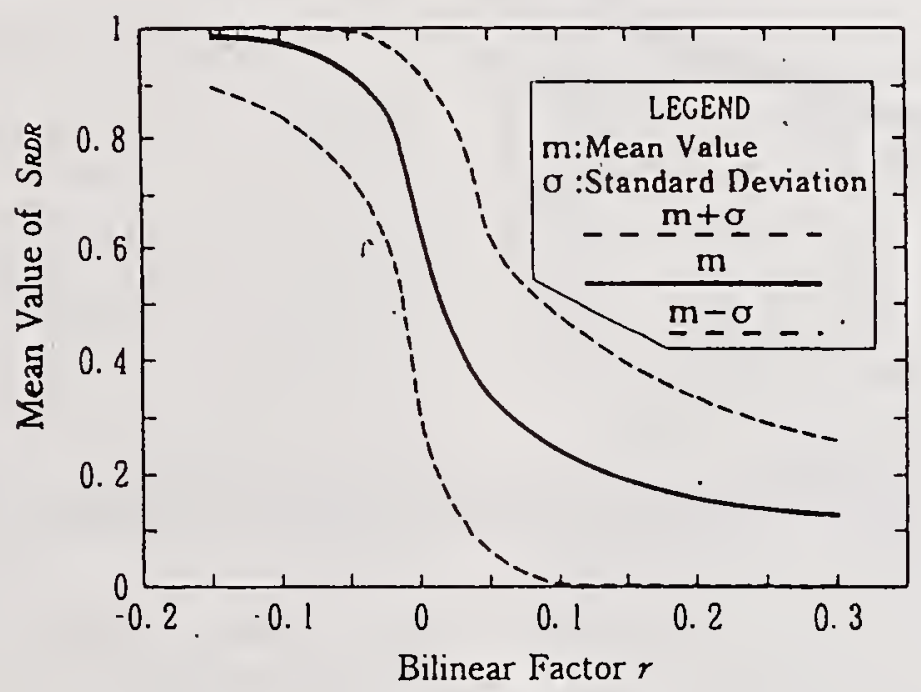

Fig. 14 Residual Displacement Ratio Response Spectra $S_{R D R}$ vs. Bilinear Factor $r$ Proposed for Design 


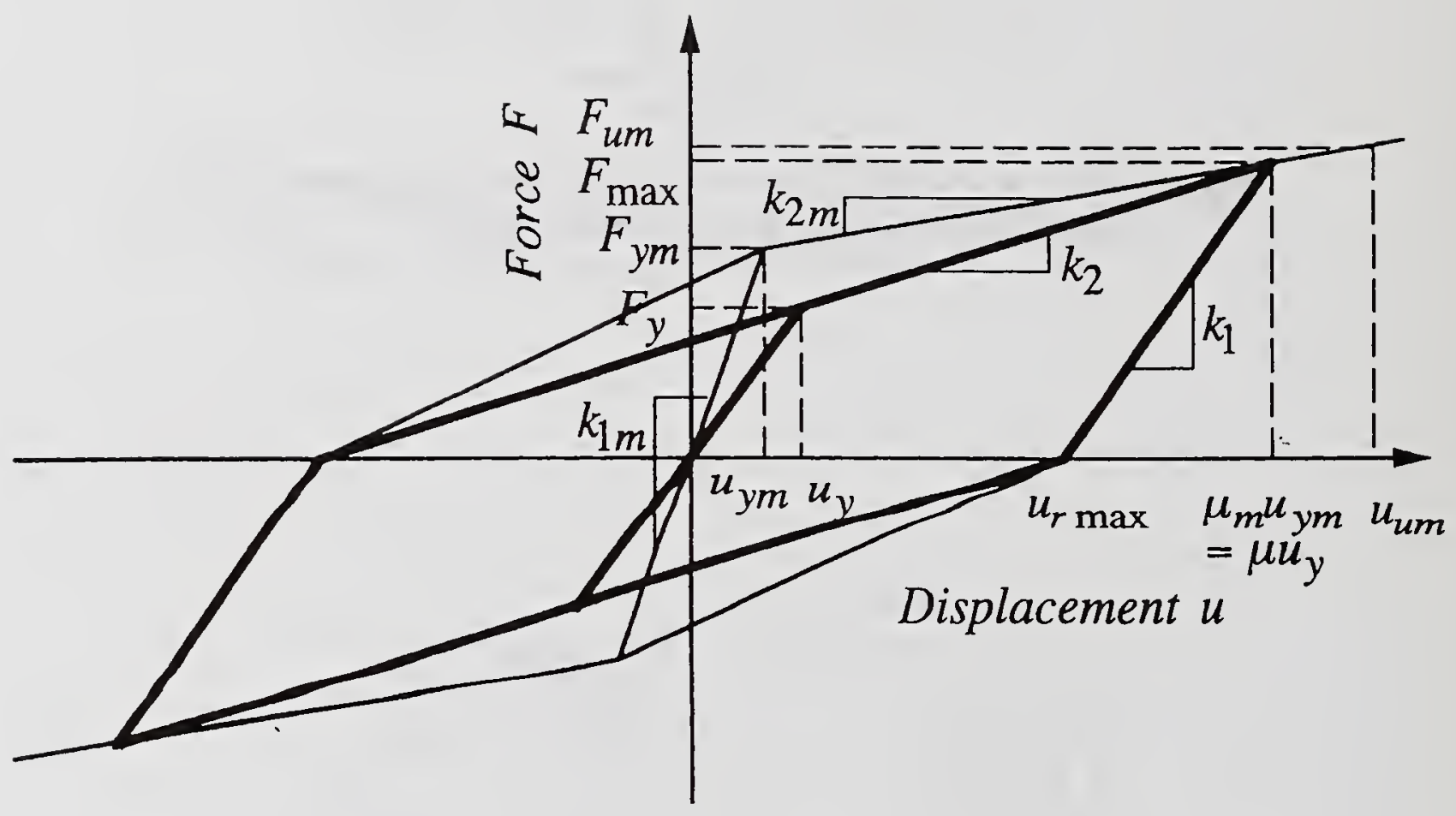

Fig. 15 Hysteresis Loop for Reinforced Concrete Columns 


\title{
ANALYSIS OF DAMAGED FOUNDATIONS OF HIGHWAY BRIDGES IN THE 1995 HYOGO-KEN NANBU EARTHQUAKE
}

\author{
by \\ Michio Okahara ${ }^{\text {1) }}$, Masanori Nakano ${ }^{2)}$, Yoshitomi Kimura ${ }^{32}$
}

\begin{abstract}
A bore hole television system was used to survey damage to the foundations of road bridges caused by the Hyogo-ken Nanbu Earthquake. The foundation bodies of some bridges were cracked, but no foundation subsidence, steel reinforcement rupture, nor cover concrete separation damage occurred. But residual displacement was found in some pile foundations near the shoreline where liquefaction caused ground flow. Loading tests were performed on piles which cracked, the results were analyzed, and the analytical results confirmed that the damage to the pile bodies had only a slight effect on the horizontal strength of the foundations.
\end{abstract}

KEYWORDS : Earthquake damage, Hyogo-ken Nanbu Earthquake, Highway bridges, Foundations, Horizontal strength

\section{INTRODUCTION}

The Hyogo-ken Nanbu Earthquake of January 17, 1995 caused extensive damage to road bridges: collapsed bridge piers, fallen bridges, etc. ${ }^{1)}$. It was impossible to survey bridge foundation damage immediately after the earthquake because the foundations are underground, but the state of damage to the foundations was surveyed in conjunction with restoration work. At the result, it was confirmed that a number of foundations were cracked or suffered horizontal residual displacement.

This paper presents an outline of the state of damage to foundations of road bridges based on the results of the foundation survey and describes characteristics of the damage. It also reports on vertical loading testing, horizontal loading testing, and pile bending testing performed using damaged pile foundation to clarify the effect of the pile body damage on the horizontal strength of the foundations.

\section{STATE OF THE DAMAGE TO BRIDGE PIER FOUNDATIONS}

\subsection{Survey of the Damage to Bridge Pier Foundations}

A survey of the damage to bridge pier foundations was conducted on the No.3 Kobe Line and No.5 Wangan Line of the Hanshin Expressway, at the Hamate Bypass of National Highway No.2, and on the Meishin and Chugoku Expressways. But the survey of the Meishin and Chugoku Expressways was limited to seven viaducts where the damage to the bridge piers was relatively severe (Onishi, Mizudo, Moribe, Tsuto, and Kawaraginishi Viaducts on the Meishin Expressway and the Takarazuka and Kouda Viaducts on the Chugoku Expressway). Figure 1 shows location of the surveyed bridges.

During the planning of the survey on the Hamate Bypass on National Highway No.2, the No.3 Kobe Line of the Hanshin Expressway, the Meishin Expressway, and the Chugoku Expressway, the bridge piers actually surveyed were selected considering the structure of the piers, the degree of damage to each one, local factors, and so on, so that the survey would not be concentrated on a narrow range of pier categories or degrees of damage. On the other hand, on the No.5 Wangan Line of the Hanshin Expressway on the other hand, the bridge piers selected for the survey were mostly at locations where liquefaction caused substantial ground flow.

Table 1 shows the number of bridge piers in the survey area and the number that were actually surveyed. Most of the bridge pier foundations surveyed were pile foundations (cast-in-place pile foundations). It was assumed that spread foundations

1) Research Coordinator for Advanced Technology, Planning and Research Administration, Public Works Research Institute, Ministry of Construction.

2) Head, Foundation Engineering Division, Structure and Bridge Department, ditto.

3) Senior Research Engineer, Foundation Engineering Division, Structure and Bridge Department, ditto. 
would suffer little damage because they are constructed on good quality ground and evidence was not found in the surrounding ground that these foundations had undergone large deformation, but as a precaution, 17 spread foundations were included in the survey. Most of the caisson foundations surveyed were subjected to the effects of ground flow caused by liquefaction and those supporting bridge piers with large residual horizontal displacement. Five diaphragm wall foundations were selected for inclusion in the survey, because there are few foundations of this kind in the survey area and even where ground flow occurred in the ground surrounding them, almost no residual horizontal displacement appeared in the bridge piers.

The survey of the spread foundations was performed by excavating the ground to the top surface of the footing to visually check for cracking of the footing. Because it would have been difficult to visually survey the pile foundations (cast-in-pile foundations), caisson foundations, and diaphragm wall foundations for cracking by digging down to each foundation, the survey was done with a bore hole television system. To do this, core boring was performed from the top of the footing into the pile or body of the foundation, and a borehole camera was lowered into this hole to inspect the interior of the foundation for cracking. The width of cracks observed by a bore hole television system have been assessed as more than three times the width of the cracks found when the foundation was actually excavated and inspected visually, because during the boring of the concrete, concrete around the cracks is removed, and the illumination used during camera observations produces shadows around the cracking. For the final damage assessments, the actual crack width was considered to be about $1 / 3$ the width found using the bore hole television system (see Photograph 1).

Some of the bridge piers on the No.5 Wangan Line of the Hanshin Expressway were found to have residual horizontal displacement caused by ground flow around the bridge pier under the effects of liquefaction. For this reason, after the earthquake, a survey of bridge pier positions was carried out using the artificial satellite system called the Global Positioning System (GPS) and the findings were compared with management documents to assess the residual horizontal displacement of the bridge piers. The method used to assess the residual horizontal displacement of the bridge piers is discussed in detail as part of 3.

\subsection{Damage to Bridge Pier Foundations}

1) Damage to Pile Foundations

The degree of damage to pile foundations is categorizes in four ranks from rank a to rank d, as shown in Table 2. The pile foundations did not suffer severe settlement, pile body failure, or failure of their reinforcement for which would effect their overall stability, some of them suffered residual horizontal displacement caused by ground flow under the effects of liquefaction and bending cracking of pile bodies.

Table 3 presents the damage to pile foundations on each road surveyed. It reveals that pile foundations suffered the most serious damage on No.5 Wangan Line of the Hanshin Expressway, with about $11 \%$ of those surveyed on this road suffering damage assessed as rank $b$. This damage is assumed to have been caused by liquefaction or by the ground flow generated by liquefaction. On roads other than the No.5 Wangan Line of the Hanshin Expressway, only minor damage in rank $\mathrm{c}$ and $\mathrm{d}$ was discovered.

\section{2) Damage to Spread Foundations}

No cracking or other damage was found on the 17 spread foundations surveyed on the No.3 Kobe Line of the Hanshin Expressway and the Chugoku Expressway.

\section{3) Damage to Caisson Foundations}

Eight caisson foundations were surveyed on the No.5 Wangan Line of the Hanshin Expressway, two on the No.3 Kobe Line of the same expressway, and five on the Hamate Bypass of the National Highway No.2. On the No.5 Wangan Line of the Hanshin Expressway, one caisson foundation located near a canal was damaged; it suffered bending cracking equivalent to rank $c$ damage to a pile foundation. This damage is assumed to have been caused by the relatively large residual horizontal displacement of the foundation and ground deformation caused by ground flow in the surrounding ground. But aside from this one case, the caisson foundations were undamaged, or if they were damaged, it was extremely minor.
4) Damage to Diaphragm Wall Foundations
The results of a survey of five diaphragm wall foundations on the No.5 Wangan Line of the 
Hanshin Expressway revealed that the foundation bodies suffered bending cracking equivalent to rank d damage to a pile foundation, but this damage was very slight.

\section{CHARACTERISTICS OF THE DAMAGE TO BRIDGE PIER FOUNDATIONS}

\subsection{State of Crack of Pile Bodies}

The No.5 Wangan Line is constructed on reclaimed land with a reclaimed stratum thickness ranging from $9 \mathrm{~m}$ to $22 \mathrm{~m}$. The Hyogo-Ken Nanbu Earthquake caused liquefaction in the ground surrounding many foundations and shifted the ground near canals towards the canals. These events resulted in large residual horizontal displacement of bridge piers and bending cracking of pile bodies of pile foundations.

Figure 2 shows examples of cracking of pile bodies. Sample (a) shows the widest crack discovered during the survey. This pile body crack was $4 \mathrm{~mm}$ wide at its widest point, and many of them were found within the reclamation soil stratum, particularly in the top of the pile. Some cracks also occurred in the allurvial clay stratum. A study within a range of $5 \mathrm{~m}$ from the bottom surface of the footing reveals that the sub-total of the crack width equals $8.6 \mathrm{~mm}(4+1.3+1.3+1.0+1.0)$, and when calculated in terms of the unit length of the pile, it is $1.7 \mathrm{~mm} / \mathrm{m}$. Considering the fact that the diameter of the piles is $1.5 \mathrm{~m}$, this can be considered as small damage. Figure 2 (b) shows the pile foundation for the bridge pier with the largest residual horizontal displacement. Within a range of about $6 \mathrm{~m}$ from the bottom surface of the footing, there are 12 cracks with a width of $0.5 \mathrm{~mm}$ or greater, but the widest of these cracks is rather small, at only $2 \mathrm{~mm}$.

Table 4 shows the results of the mode of cracks in 17 pile foundations with the rank $b$ degree of damage, the severest rank observed in all the pile foundations surveyed on the No.5 Wangan Line. In the reclaimed stratum, all 17 foundations were cracked. The average values for the 17 foundations are 10 cracks, crack width of $1.5 \mathrm{~mm}$, and a reclaimed stratum thickness of $14 \mathrm{~m}$. The damage to these foundation piles can be defined as extremely slight. Cracks also appeared in the alluvial clay stratum, but far fewer than in the reclaimed stratum.

\subsection{Residual Horizontal Displacement of the Piers} Along the No.5 Wangan Line, liquefaction accompanied by ground flow occurred in the ground around bridge piers near the shoreline, causing considerable residual horizontal displacement to the bridge piers. For this reason, the analysis included a study and clarification of the relationship of the horizontal displacement of the ground around the bridge piers with the residual horizontal displacement of the bridge piers.

The horizontal displacement of the ground was found using the results of an aerial photography survey carried out by Hamada et al. ${ }^{2)}$ They used three survey stations established on Rokko Island as control points for the aerial photography survey, but for this study, six survey stations established for the survey of the bridge pier locations for the No.5 Wangan Line of the Hanshin Expressway were used as the control points. As examples, Figure 3 and Figure 4 present results showing the horizontal displacement of the ground and the residual horizontal displacement of the bridge piers of the Rokko Island Bridge and its approach that connect with Rokko Island and Uozaki Hama. While the aerial photography survey of Hamada et al. found the displacement vectors of manhole covers and other fixed objects on the ground surface, in addition to that, this survey found the displacement vectors at intersection points of a grid crossed at intervals of 20 m. The residual horizontal displacement of bridge piers, found from another survey performed after the earthquake, represents the displacement of bridge pier body at approximately $1 \mathrm{~m}$ height above the ground.

When the horizontal displacement vectors of the ground and bridge piers are found in this way, almost along No.5 Wangan Line they include about $20 \mathrm{~cm}$ displacement evenly in the south-west direction. And triangulation point near the No.5 Wangan Line also shifted the same distance to the south-west. This displacement can be interpreted in various ways: as ground displacement caused by fault movement or as a wide-area ground movement, but because uniform displacement occurred over a certain range, the horizontal displacement of the ground and the residual horizontal displacement of the bridge piers were modified after deducting this value. The horizontal displacement vectors found in the way include a certain degree of error because of differences in the precision of the photographic surveys performed before and after the earthquake, and of variations in the way the aerial photographs. For this analysis, the precision of the measurement of 
the horizontal displacement of the ground is estimated to be $\pm 30 \mathrm{~cm}$, and the bridge pier residual horizontal displacement measurement precision is estimated to be $\pm 10 \mathrm{~cm}$.

Figure 5 shows the relationship of the residual horizontal displacement of the bridge piers with the horizontal displacement of the ground around the bridge piers in Rokko Island, Uozaki Hama, and Fukae Hama. The results are considerably scattered, but overall, the residual horizontal displacement of the bridge piers tends to increase as the horizontal displacement of the surrounding ground rises. But the extent of the displacement of bridge piers which occurs when certain ground displacement occurs varies according to the rigidity of the foundation, and the residual horizontal displacement is smaller in the case of caisson foundations or diaphragm wall foundations: types with greater stiffness than pile foundations.

\section{HORIZONTAL STRENGTH OF DAMAGED PILE FOUNDATIONS}

\subsection{Pile Loading Tests}

To confirm the effect of pile damage on overall pile foundations, loading testings were performed on piles of the No.3 Kobe Line of the Hanshin Expressway. The degree of damage to the pile foundation was assessed as rank c damage:a crack with a width of about $2 \mathrm{~mm}$ was found near the top of the pile as shown in Photograph 2 but its concrete was not crushed and its reinforcement bars did not swell out.

The loading testing included three tests : pile body bending,vertical loading,and horizontal loading tests. Three of the 19 piles were cut for use as test piles. Specimens were taken from these cut test piles for use in compressive strength testing of the concrete cores and for tensile strength testing of the reinforcement bar. Table 5 shows the results of the compressive strength testing of the concrete cores. The average value of the strength of the concrete of the pile bodies was about 1.8 times the design strength of $240 \mathrm{kgf} / \mathrm{cm}^{2}$ and represents considerable strength. Table 6 presents the results of the tensile testing of the reinforcement bar. The results, that the yield points of three of the five reinforcement bar are not clear, shows that these reinforcement bars received a stress history that exceeds the yield point. An examination of arrangement of the reinforcement at the cut section of the piles bodies showed they were as shown as designed.

Pile body bending testing was performed on the pile tops where cracking appeared as shown in Figure 6 . Test piles were obtained by cutting the pile bodies at a depth of $2.8 \mathrm{~m}$ below the bottom surface of the footing, then horizontal loading was done at a depth of $2.5 \mathrm{~m}$ below the footing using adjacent piles as the reaction piles. The loading, which was one-direction multi-stage loading, was performed up to $25 \mathrm{tf}$, equivalent to about $60 \%$ of the calculated yield bending moment of the tops of the piles. Figure 7 shows the relationship of the horizontal load with the horizontal displacement at the loading point. In order to grasp the effects of the decline in stiffness of the top of the piles,the relationship of the horizontal loading with the horizontal displacement of the piles when the pile tops are assumed to be sound was found through analysis, and this was compared with the results of the loading testing. The analysis of a sound pile referred to here was performed using the stress-strain relationship of concrete indicated in the "Guide Specifications for Reconstruction and Repair of Highway Bridges Which Suffered Damage due to the Hyogo-ken Nanbu Earthquake" (Ministry of Construction, Feb.24, 1995), and in this analysis the horizontal displacement by pulling the main reinforcement bars out of the footing is included. According to the material testing described above, the yield strength of the reinforcement bar and the compressive strength of the concrete in the pile body were assessed as $3,750 \mathrm{kgf} / \mathrm{cm}^{2}$ and $425 \mathrm{kgf} / \mathrm{cm}^{2}$ respectively. The horizontal displacement of the loading testing is greater than the analytical value for the same horizontal load when the pile tops are considered to be sound, and the stiffness of the pile tops declines.

To perform the vertical loading testing and the horizontal loading testing, two piles were cut at a depth of $1.2 \mathrm{~m}$ from the bottom surface of the footing, and the piles below this level used as the specimens for the two tests. Vertical loading was applied to the top of one pile and horizontal loading to the top of the other. Figure 8 shows the amount of loading - amount of settlement relationship for the vertical loading testing. It confirmed a bearing capacity as high as 450 tf : a value exceeding the design ultimate bearing capacity of 436 if calculated by the present Specifications for Highway Bridges. The pile top settled $1.3 \mathrm{~cm}$, much less than $10 \mathrm{~cm}$, which is $10 \%$ of the pile diameter, and the amount of 
settlement usually forecast when calculating the ultimate bearing capacity of piles, which confirms that the ultimate bearing capacity of the pile exceeds the design ultimate bearing capacity. Figure 9 presents the amount of loading - horizontal displacement curve obtained from the horizontal loading testing. This figure shows that the value of the coefficient of ground reaction in the horizontal direction found assuming that the horizontal displacement is $1 \%$ of the pile diameters is 1.9 $\mathrm{kgf} / \mathrm{cm}^{3}$, which coincides closely with $2.3 \mathrm{kgf} / \mathrm{cm}^{3}$, the coefficient of ground reaction in the horizontal direction estimated from the $\mathrm{N}$ value obtained from a standard penetration test according to Specifications for Highway Bridges.

\subsection{Evaluation of the Strength of the Pile Foundations}

In order to evaluate the effect of the earthquake damage to piles on the behavior of overall foundations, the foundations which underwent the loading testing were used as the object of an analysis performed to find the resistance properties of pile foundations employing a method which accounts for the non-linear behavior of foundations. The analytical model is shown in Figure 10.

The resistance properties in the axial direction of a pile are modelled as a bi-linear model with the ultimate bearing capacity and the ultimate pull-out force as the upper limit values by treating the axial direction spring constant $\mathrm{Kv}$ of the pile found from the vertical loading testing as the initial gradient. The ground resistance in the direction perpendicular to the axial direction of the pile is modelled as a bi-linear model with the upper limit $\mathrm{p} \mathrm{HU}_{\mathrm{HU}}$ and the initial gradient $\mathrm{k}_{\mathrm{H}} \mathrm{c}$ calculated from the following formulae.

$$
\begin{aligned}
& \mathrm{k}_{\mathrm{H}_{\mathrm{O}}}=\eta_{\mathrm{k}} \cdot \alpha_{\mathrm{K}} \cdot \mathrm{k}_{\mathrm{H}} \\
& \mathrm{p}_{\mathrm{HU}}=\eta_{\mathrm{P}} \cdot \alpha_{\mathrm{P}} \cdot \mathrm{pu}
\end{aligned}
$$

Where:

$\mathrm{k}$ но: Design horizontal subgrade reaction coefficient $\left(\mathrm{kgf} / \mathrm{cm}^{3}\right)$

pнu: Upper limit value of the horizontal subgrade reaction $\left(\mathrm{kgf} / \mathrm{cm}^{2}\right)$

$\mathrm{k}_{\mathrm{H}}$ : The horizontal subgrade reaction coefficient $\left(\mathrm{kgf} / \mathrm{cm}^{3}\right.$ ) during the earthquake, it is found from the Specifications for Highway Bridges. Here it is set based on the horizontal loading testing of the pile.

$\mathrm{p}_{\mathrm{u}}$ : The passive earth pressure strength $(\mathrm{kgf} / \mathrm{cm}$ ${ }^{2}$ ) during the earthquake, it is found using
Coulomb's passive earth pressure coefficient based on the ground constant obtained from the soil testing. Here it considers the weight of the soil up to the ground surface to be the overburden load.

$\alpha_{k}$ : Corrective coefficient of the horizontal subgrade reaction coefficient of a single pile

$\alpha_{p}:$ Corrective coefficient of the upper limit value of the horizontal subgrade reaction of a single pile

$\eta_{k}$ : Corrective coefficient of the horizontal subgrade reaction coefficient accounting for the pile group effect

$\eta_{p}$ : Corrective coefficient of the upper limit value of the horizontal subgrade reaction accounting for the pile group effect

The values used for $\alpha_{k}$ and $\alpha_{p}$ are shown in Table 7. These were found from an analysis of the results of horizontal loading testing of existing single piles.

The corrective coefficient of the horizontal subgrade reaction coefficient accounting for the pile group effect $\eta_{\mathrm{k}}$ used was the following value.

$$
\eta_{k}=2 / 3
$$

The corrective coefficient of the upper limit value of the horizontal subgrade reaction accounting for the pile group effect $\eta_{\text {o }}$ used was the following value.

Cohesive Soil : $\eta_{p}=1.0$

Sandy Soil :

$$
\begin{aligned}
\eta_{D} \cdot \alpha_{D}= & \text { Center interval between the } \\
& \text { piles in the direction } \\
& \text { perpendicular to the loading / } \\
& \text { pile diameter }\left(\leqq \alpha_{D}\right) \text { (5) }
\end{aligned}
$$

In the case of piles other than the front row of piles in sandy ground, it is $1 / 2$ of the value shown in formula (5). The value of $\eta_{k}$ and $\eta_{0}$ for these piles was found based on the results of the analysis of loading testing of pile groups.

The ground resistance and bending stiffness of the piles were estimated based on data obtained from the loading testing and material testing described above. Because the bending test of the pile indicates that as shown in Figure 9, earthquake reduces the bending stiffness of the pile top, the bending stiffness of the pile top is reduced as shown in Figure 11 to a value about $2 / 3$ of that when the pile top is assumed to be sound, so that analytical result of the horizontal load - horizontal displacement relationship of a pile will be equivalent to the bending testing results.

Figure 12 shows the results of the above 
described analysis of the horizontal load - horizontal displacement relationship of the overall pile foundation A comparison of this relationship when the pile has not been damaged with the relationship in a case where the pile top is assumed to have been damaged reveals that in the damaged case, the horizontal displacement under the same horizontal loading is slightly larger, but that the maximum horizontal bearing strength of the pile foundation hardly declines at all, demonstrating that damage to the pile body has only a slight effect on the overall pile foundation.

\section{CONCLUSIONS}

The results of survey of the damage to bridge pier foundations by the Hyogo-ken Nanbu Earthquake have been studied and organized and an outline of the damage and its characteristics prepared. Loading testing was performed on cracked piles to clarify the effects of the damage to the pile bodies on the horizontal strength of the foundations. The main results obtained from these survey are summarized as follows:

(1) The foundations did not suffer severe settlement, pile body failure, or failure of their reinforcement for which would effect their overall stability.

(2) Near the channels where liquefaction caused ground flow, some foundations suffered horizontal residual displacement. There was little residual displacement in the case of caisson foundations, diaphragm wall foundations, with a high degree of stiffness, even those at locations where equally severe ground flow occurred.

(3) Vertical loading testing, horizontal loading testing, and pile bending testing were performed on damaged pile foundation. The results revealed that despite a decline in stiffness at the tops of the cracked piles, the earthquake did not effect the vertical bearing strength or horizontal resistance of the piles.

(4) In order to evaluate the effect of the damage to pile bodies on the behavior of overall foundations, the foundation which underwent the loading testing were used as the object of an analysis performed to find the resistance properties of the pile foundations. When the damage to the pile bodies was accounted for, the horizontal displacement produced by the same horizontal load increased slightly, but there was almost no decline in the maximum horizontal strength of the pile foundation

In order to perform structural design accounting for an earthquake as severe as the Hyogo-ken Nanbu Earthquake, it is essential to study the displacement properties and dynamic strength of foundations during earthquakes. A method of evaluating displacement properties and dynamic strength during earthquakes that accounts for the non-linear properties of ground resistance must be developed.

This paper is quote from the Report on the Damage of Highway Bridges by the Hyogo-ken Nanbu Earthquake, Committee for Investigation on the Damage of Highway Bridges by the Hyogo-ken Nanbu Earthquake ${ }^{\text {s) }}$.

\section{REFERENCE}

1) Iijima,T., Nakaoka,T. and Koga,Y. : Infrastructure Damage by the 1995 Hyogoken Nanbu Earthquake, UJNR Wind and Seismic Effects Proceedings of the 27th Joint Meeting, 1995.

2) Hamada,M., Isoyama, $R$ and Wakamatsu,K : The 1995 Hyogoken-Nanbu (Kobe) Earthquake, Liquefaction, Ground Displacement and Soil Condition in Hanshin Area, Association for Development of Earthquake Prediction, The School of Science and Engineering, Waseda University, Japan Engineering Consultants, 1995.

3) Ministry of Construction : Guide Specifications for Reconstruction and Repair of Highway Bridges which Suffered Damage due to the Hyogo-ken Nanbu Earthquake, 1995.

4) Japan Road Association : Specifications for Highway Bridges, 1994.

5)Ministry of Construction : Report on the Damage of Highway Bridges by the Hyogo-ken Nanbu Earthquake, Committee for Investigation on the Damage of Highway Bridges by the Hyogo-ken Nanbu Earthquake, 1995. 
Table 1 Number of Bridge Piers in the Survey Area and Number of Bridge Piers Surveyed

(Number of Bridge Piers)

\begin{tabular}{|c|c|c|c|c|c|c|}
\hline \multirow[b]{2}{*}{ Road } & \multirow[b]{2}{*}{ Category } & \multicolumn{4}{|c|}{ Type of Foundation } & \multirow[b]{2}{*}{ Totals } \\
\hline & & $\begin{array}{l}\text { Spread } \\
\text { Foundation }\end{array}$ & $\begin{array}{l}\text { Caisson } \\
\text { Foundation }\end{array}$ & $\begin{array}{c}\text { Pile } \\
\text { Foundation }\end{array}$ & $\begin{array}{l}\text { Diaphragm } \\
\text { Wall } \\
\text { Foundation }\end{array}$ & \\
\hline \multirow{2}{*}{$\begin{array}{c}\text { No.3 Kobe Line } \\
\text { Hanshin } \\
\text { Expressway }\end{array}$} & $\begin{array}{l}\text { All Bridge } \\
\text { Piers in the } \\
\text { Area Surveyed }\end{array}$ & $133(12 \%)$ & $44(4 \%)$ & $929(84 \%)$ & $0(0 \%)$ & $1106(100 \%)$ \\
\hline & $\begin{array}{c}\text { Bridge Piers } \\
\text { Surveyed }\end{array}$ & 12 & 2 & 109 & 0 & 123 \\
\hline \multirow{2}{*}{$\begin{array}{c}\text { No.5 Wangan } \\
\text { Line, Hanshin } \\
\text { Expressway }\end{array}$} & $\begin{array}{l}\text { All Bridge } \\
\text { Piers in the } \\
\text { Area Surveyed }\end{array}$ & $0(0 \%)$ & $52(15 \%)$ & $280(81 \%)$ & $13(4 \%)$ & $345(100 \%)$ \\
\hline & $\begin{array}{c}\text { Bridge Piers } \\
\text { Surveyed }\end{array}$ & 0 & 8 & 153 & 5 & 166 \\
\hline \multirow{2}{*}{$\begin{array}{l}\text { National } \\
\text { Highway No.2, } \\
\text { Hamate Bypass }\end{array}$} & $\begin{array}{l}\text { All Bridge } \\
\text { Piers in the } \\
\text { Area Surveyed }\end{array}$ & $0(0 \%)$ & $15(21 \%)$ & $57(79 \%)$ & $0(0 \%)$ & $72(100 \%)$ \\
\hline & $\begin{array}{c}\text { Bridge Piers } \\
\text { Surveyed }\end{array}$ & 0 & 5 & 20 & 0 & 25 \\
\hline \multirow{2}{*}{$\begin{array}{c}\text { Meishin } \\
\text { Expressway } \\
\text { and } \\
\text { Chugoku } \\
\text { Expressway }\end{array}$} & $\begin{array}{l}\text { All Bridge } \\
\text { Piers in the } \\
\text { Area Surveyed }\end{array}$ & $152(22 \%)$ & $0(0 \%)$ & $532(78 \%)$ & $0(0 \%)$ & $684(100 \%)$ \\
\hline & $\begin{array}{c}\text { Bridge Piers } \\
\text { Surveyed }\end{array}$ & 5 & 0 & 21 & 0 & 26 \\
\hline
\end{tabular}

Table 2 Categorization of Damage to Pile Foundation

\begin{tabular}{|c|l|}
\hline $\begin{array}{c}\text { Degree of } \\
\text { Damage }\end{array}$ & \multicolumn{1}{c|}{ Definition } \\
\hline a & Settlement of the foundation accompanied by considerable residual horizontal displacement. \\
\hline b & $\begin{array}{l}\text { Considerable residual horizontal displacement of the foundation. } \\
\text { Bending cracking of the pile body. }\end{array}$ \\
\hline c & Minor bending cracking of the pile body. \\
\hline d & No damage to the pile or slight bending cracking. \\
\hline
\end{tabular}

Table 3 Degree of Damage to Pile Foundations (Number of Bridge Piers)

\begin{tabular}{|c|c|c|c|c|c|}
\hline \multirow{2}{*}{ Road } & \multicolumn{5}{|c|}{ Degree of Damage } \\
\cline { 2 - 6 } & $\mathrm{a}$ & $\mathrm{b}$ & $\mathrm{c}$ & $\mathrm{d}$ & 計 \\
\hline $\begin{array}{c}\text { No3.Kobe Line, } \\
\text { Hanshin } \\
\text { Expressway }\end{array}$ & $0(0 \%)$ & $0(0 \%)$ & $17(16 \%)$ & $92 \quad(84 \%)$ & $109(100 \%)$ \\
\hline $\begin{array}{c}\text { No.5 wangan } \\
\text { Line, Hanshin } \\
\text { Expressway }\end{array}$ & $0(0 \%)$ & $17(11 \%)$ & $57(37 \%)$ & $79 \quad(52 \%)$ & $153(100 \%)$ \\
\hline $\begin{array}{c}\text { National } \\
\text { Highway No.2, } \\
\text { Hamate Bypass }\end{array}$ & $0(0 \%)$ & $0(0 \%)$ & $10(50 \%)$ & $10 \quad(50 \%)$ & $20(100 \%)$ \\
\hline $\begin{array}{c}\text { Meishin Expressway } \\
\text { and } \\
\text { Chugoku Expressway }\end{array}$ & $0(0 \%)$ & $0(0 \%)$ & $0(0 \%)$ & $21(100 \%)$ & $21(100 \%)$ \\
\hline
\end{tabular}


Table 4 Occurrence of Cracking in Pile Bodies at 17 Pile Foundations With Damage in Rank b

(No.5 Wangan Line of the Hanshin Expressway)

\begin{tabular}{|c|c|c|c|c|}
\hline Stratum & $\begin{array}{c}\text { Number of Bridge } \\
\text { Piers with Cracking }\end{array}$ & $\begin{array}{c}\text { Average Stratum } \\
\text { Thickness (m) }\end{array}$ & $\begin{array}{c}\text { Average Number of } \\
\text { Cracks in the Stratum }\end{array}$ & $\begin{array}{c}\text { Average Crack } \\
\text { Width (mm) }\end{array}$ \\
\hline $\begin{array}{c}\text { Reclamation } \\
\text { Stratum }\end{array}$ & 17 & 14 & 10 & 1.5 \\
\hline $\begin{array}{c}\text { Alluvial Clay } \\
\text { Stratum }\end{array}$ & 3 & 6 & 3 & 1.2 \\
\hline
\end{tabular}

Table 5 Results of the Compressive Strength Test of the Concrete Core of the Pile Tops (No.126 Pier)

\begin{tabular}{|c|c|}
\hline Core No. & Compressive Strength $\left(\mathrm{kgf} / \mathrm{cm}^{2}\right)$ \\
\hline 1 & 396 \\
\hline 2 & 429 \\
\hline 3 & 450 \\
\hline $\begin{array}{c}\text { Average } \\
\text { Value }\end{array}$ & 425 \\
\hline
\end{tabular}

Table 6 Result of the Tensile Test of the Reinforcement Bars (D29) of the Pile Tops (No.126 Pier)

\begin{tabular}{|c|c|c|}
\hline $\begin{array}{c}\text { Number of } \\
\text { Reinforcement Bar }\end{array}$ & $\begin{array}{c}\text { Yield Strength } \\
\left(\mathrm{kgf} / \mathrm{cm}^{2}\right)\end{array}$ & $\begin{array}{c}\text { Tensile Strength } \\
\left(\mathrm{kgf} / \mathrm{cm}^{2}\right)\end{array}$ \\
\hline 1 & 3,860 & 5,790 \\
\hline 2 & 3,640 & 5,390 \\
\hline 3 & No yield point & 5,540 \\
\hline 4 & $\prime \prime$ & 5,350 \\
\hline 5 & 3,750 & 5,350 \\
\hline Average & $>3,000$ & 5,480 \\
\hline Standard Values & $4,900 \sim 6,300$ \\
\hline
\end{tabular}

* ) Predicted value in current JS standard is 4,500 to $6,100 \mathrm{kgf} / \mathrm{cm}^{2}$

Table 7 Corrective Coefficient

\begin{tabular}{|c|c|c|}
\hline Type of soil Layers & $\alpha_{k}$ & $\alpha_{\triangleright}$ \\
\hline Sandy Soil & 1.5 & 3.0 \\
\hline Cohesive Soil & 1.5 & 1.5 \\
\hline
\end{tabular}

Note: $\alpha_{\mathrm{P}}=1.0$ in Soft Layers with $\mathrm{N} \leqq 2$ 


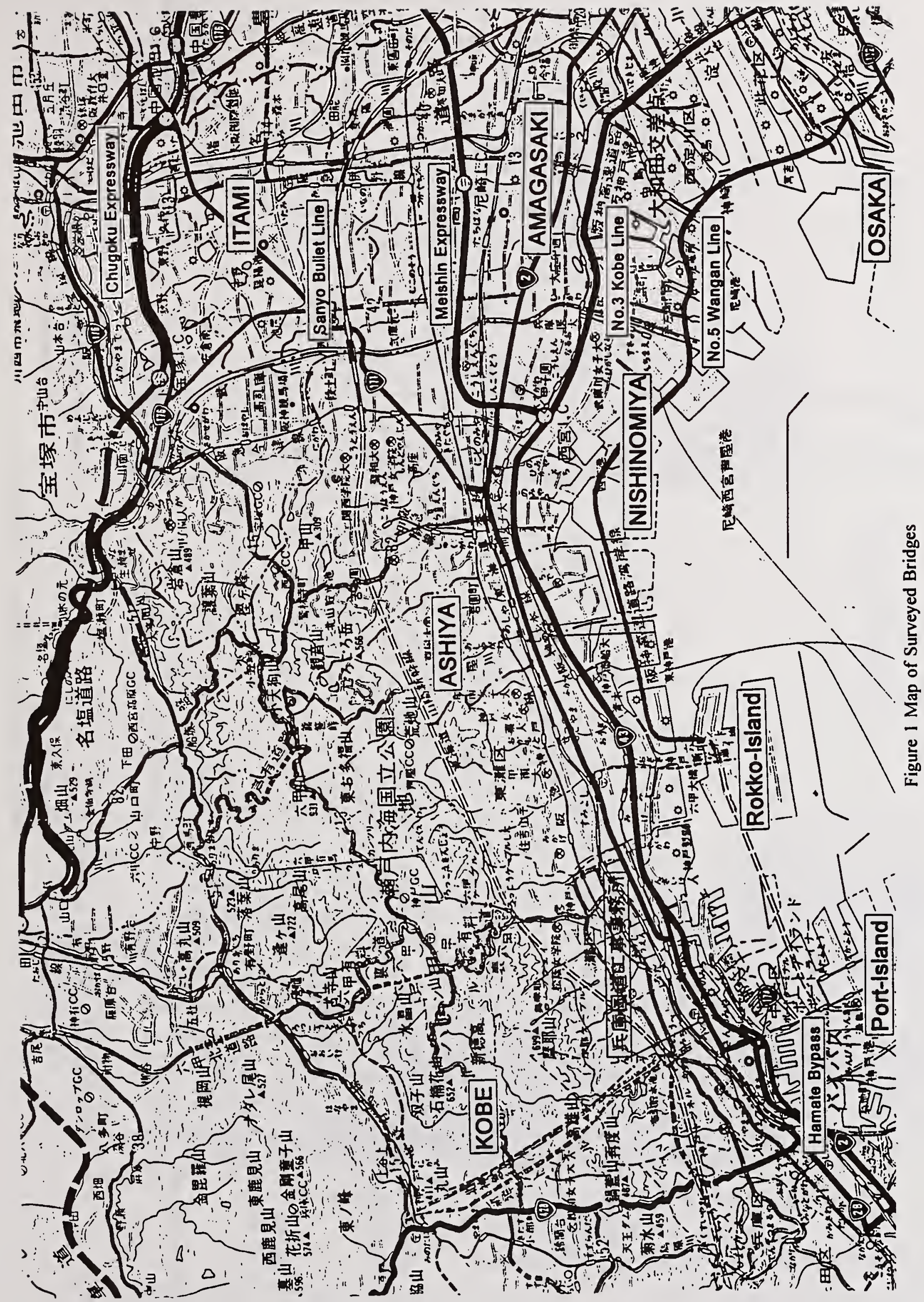




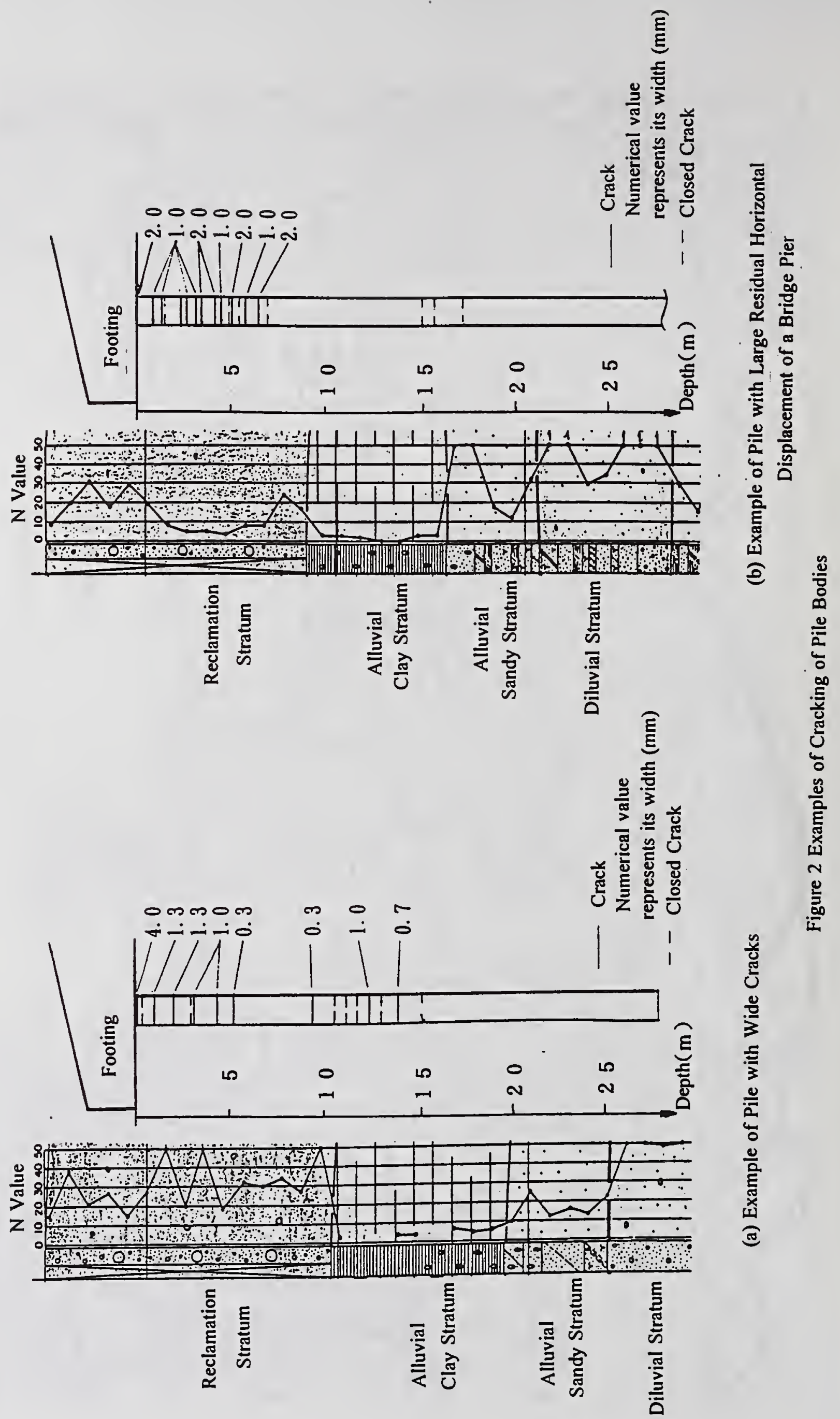




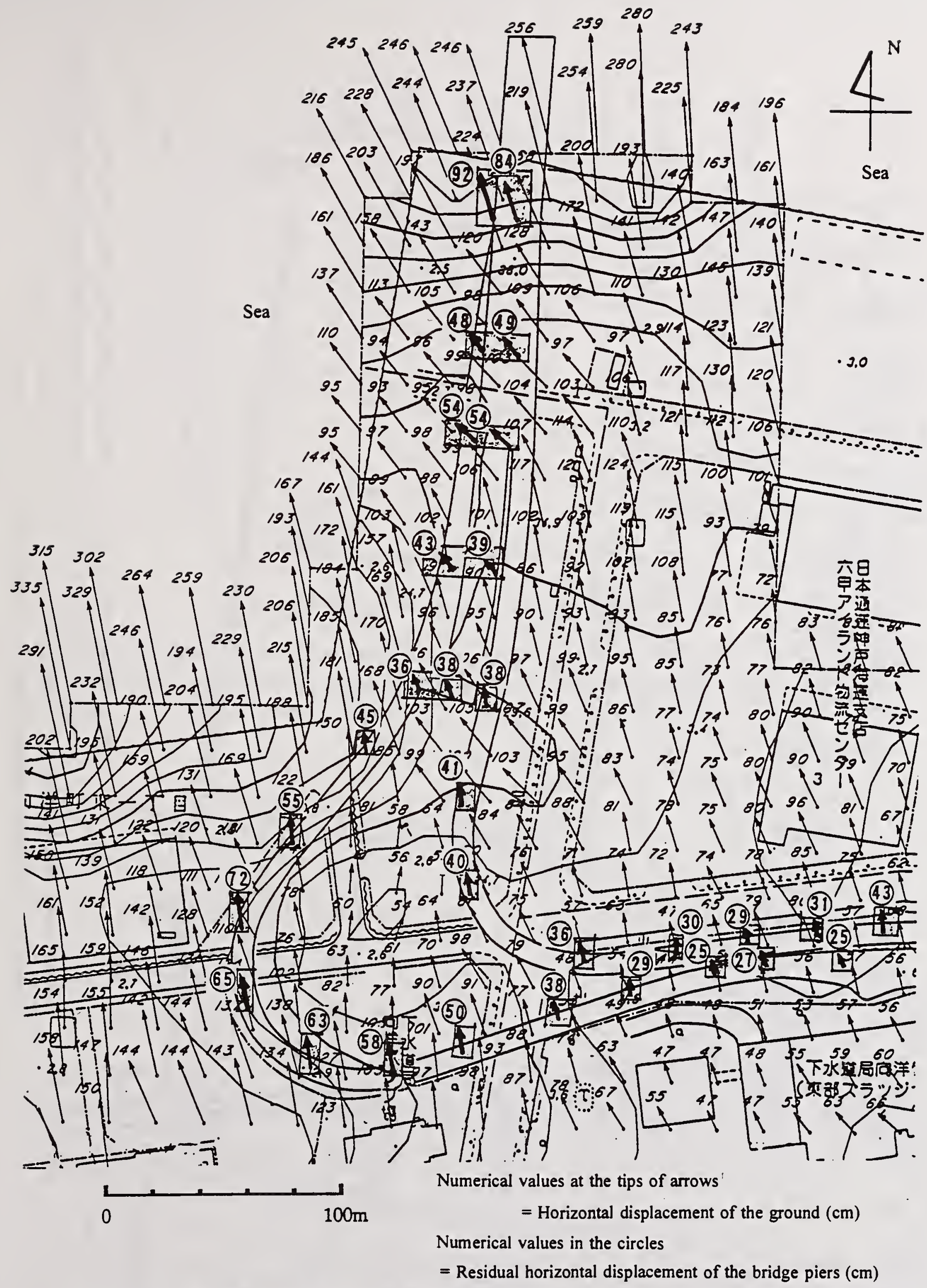

Figure 3 Horizontal Displacement of Ground and Residual Horizontal Displacement of Bridge Piers at Rokko Island

(Horizontal Displacement of the Ground Obtained by Modifying the Results of a Survey by Hamada et al. ${ }^{2 \text { ) }}$ ) 


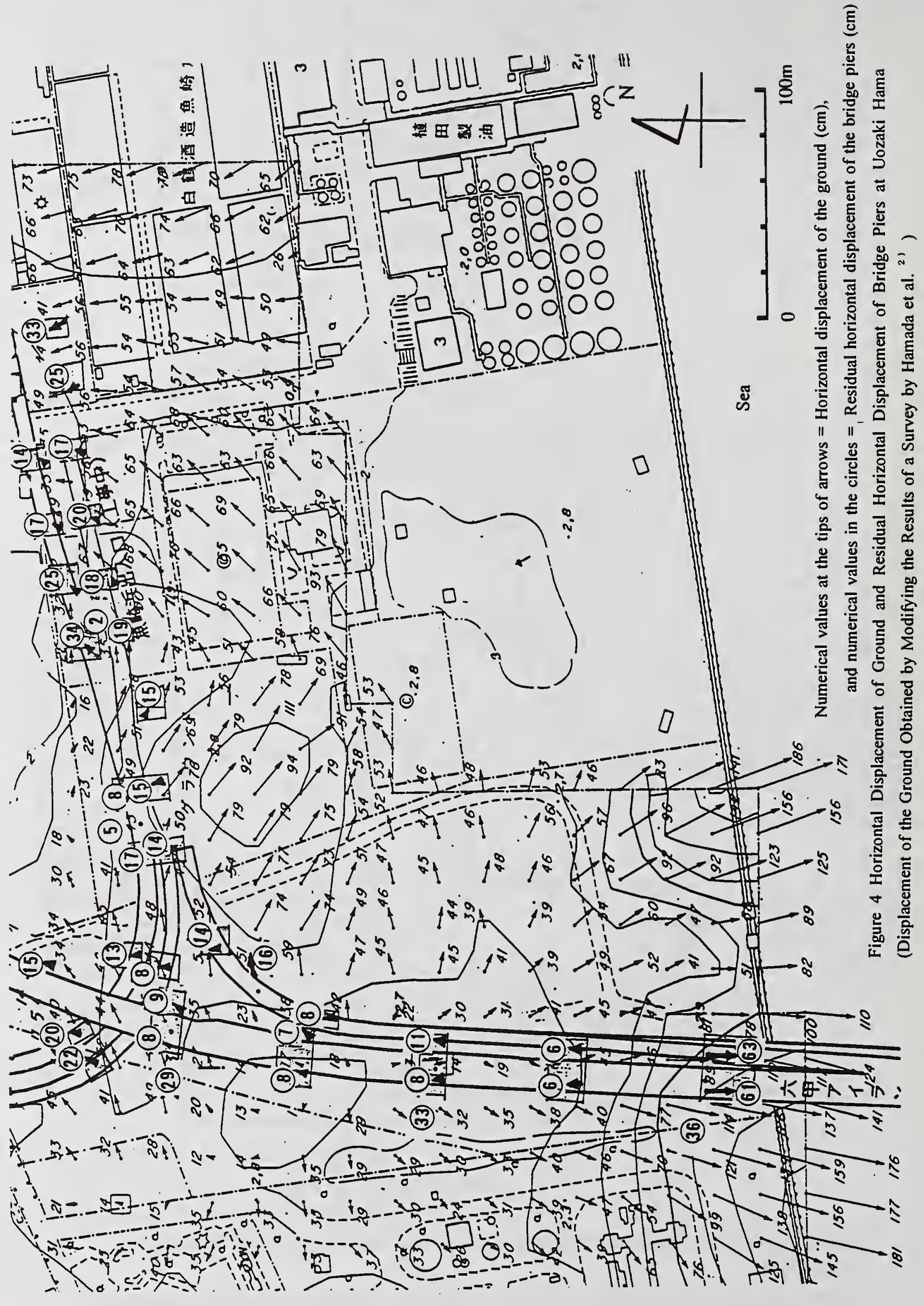




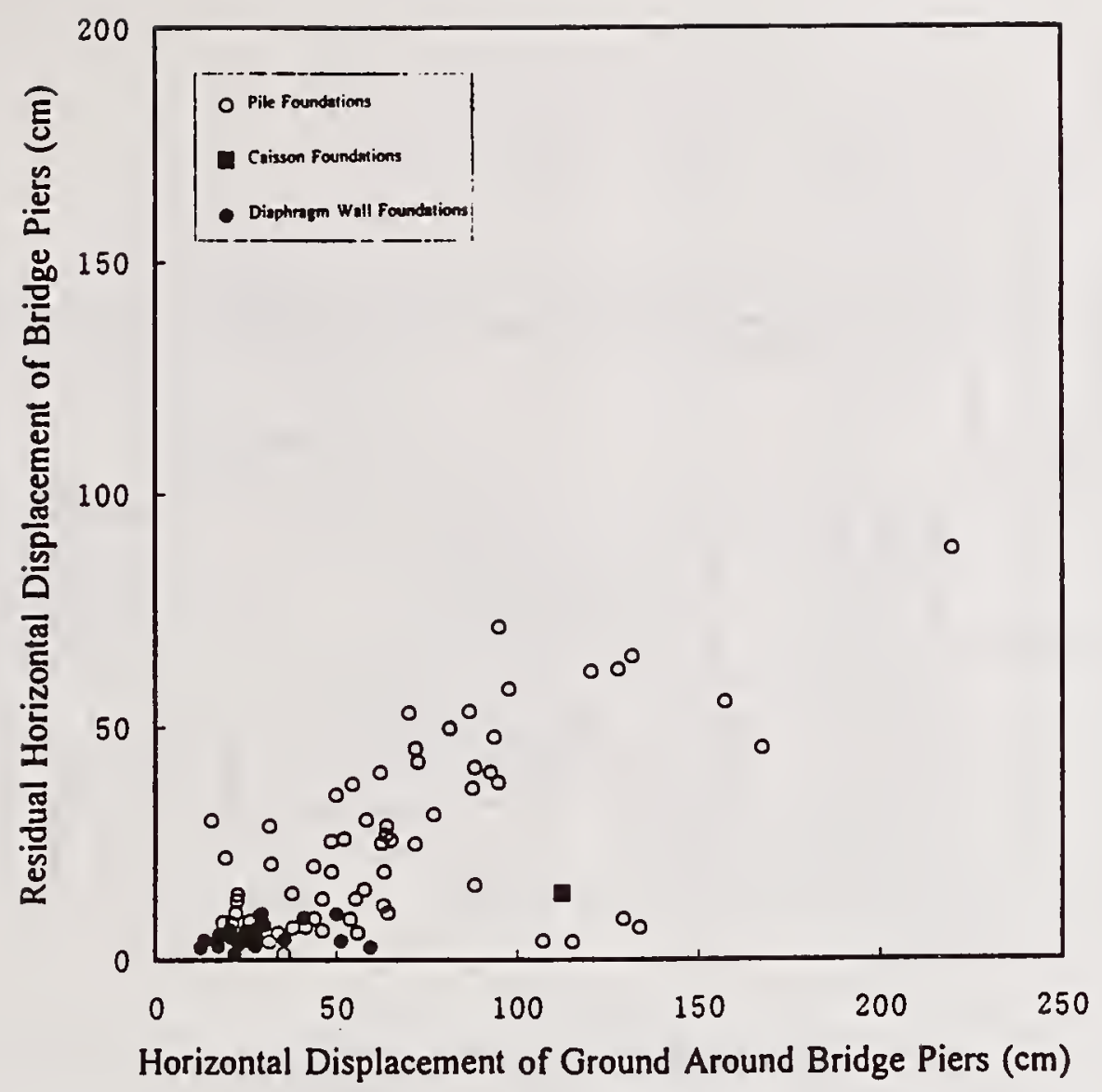

Figure 5 Ground Horizontal Displacement - Bridge Pier Residual Horizontal Displacement Relationship (For Bridge Piers on the No.5 Wangan Line of the Hanshin Expressway at Rokko Island, Uozaki Hama, and Fukae Hama) 


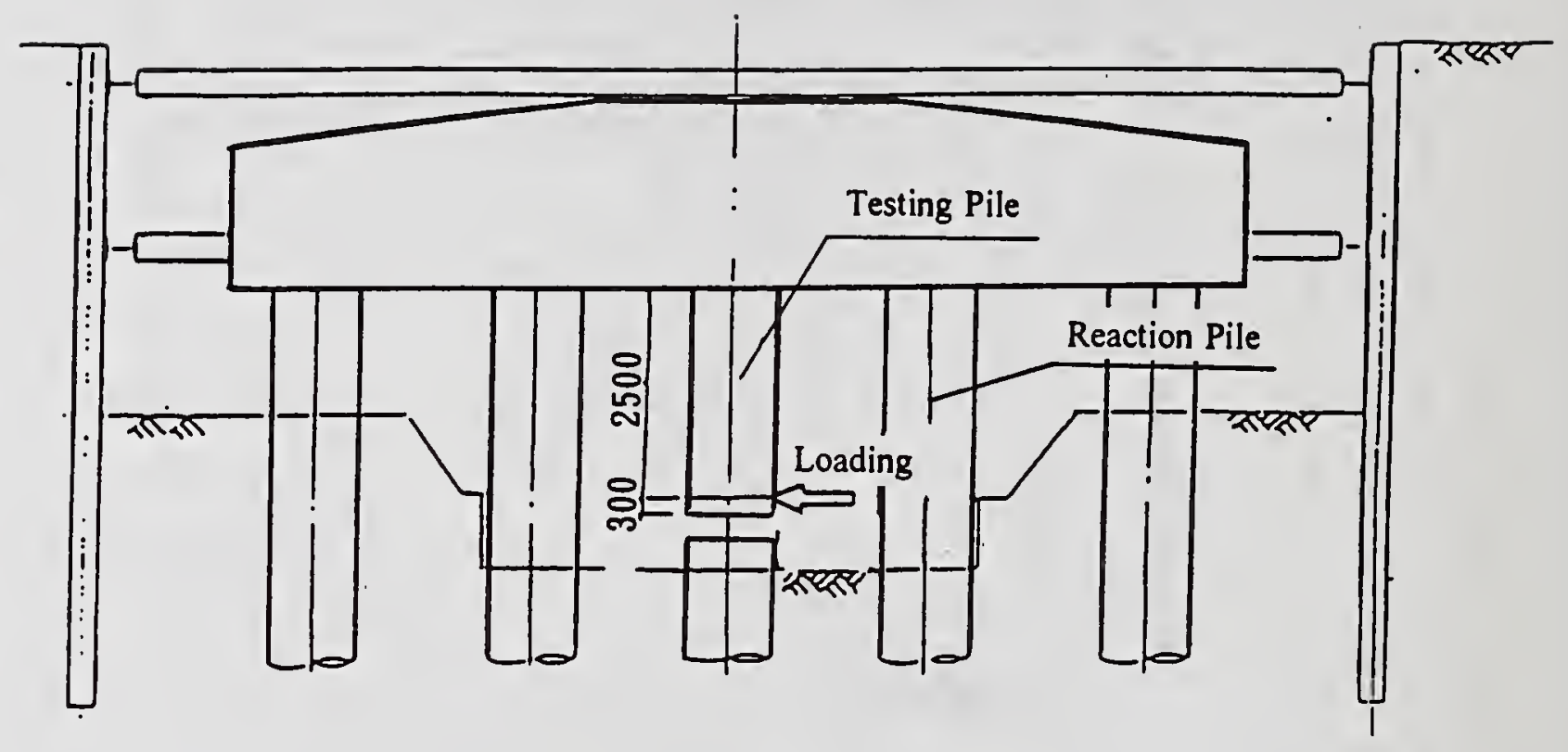

Figure 6 Pile Bending Test (No.126 Pier)

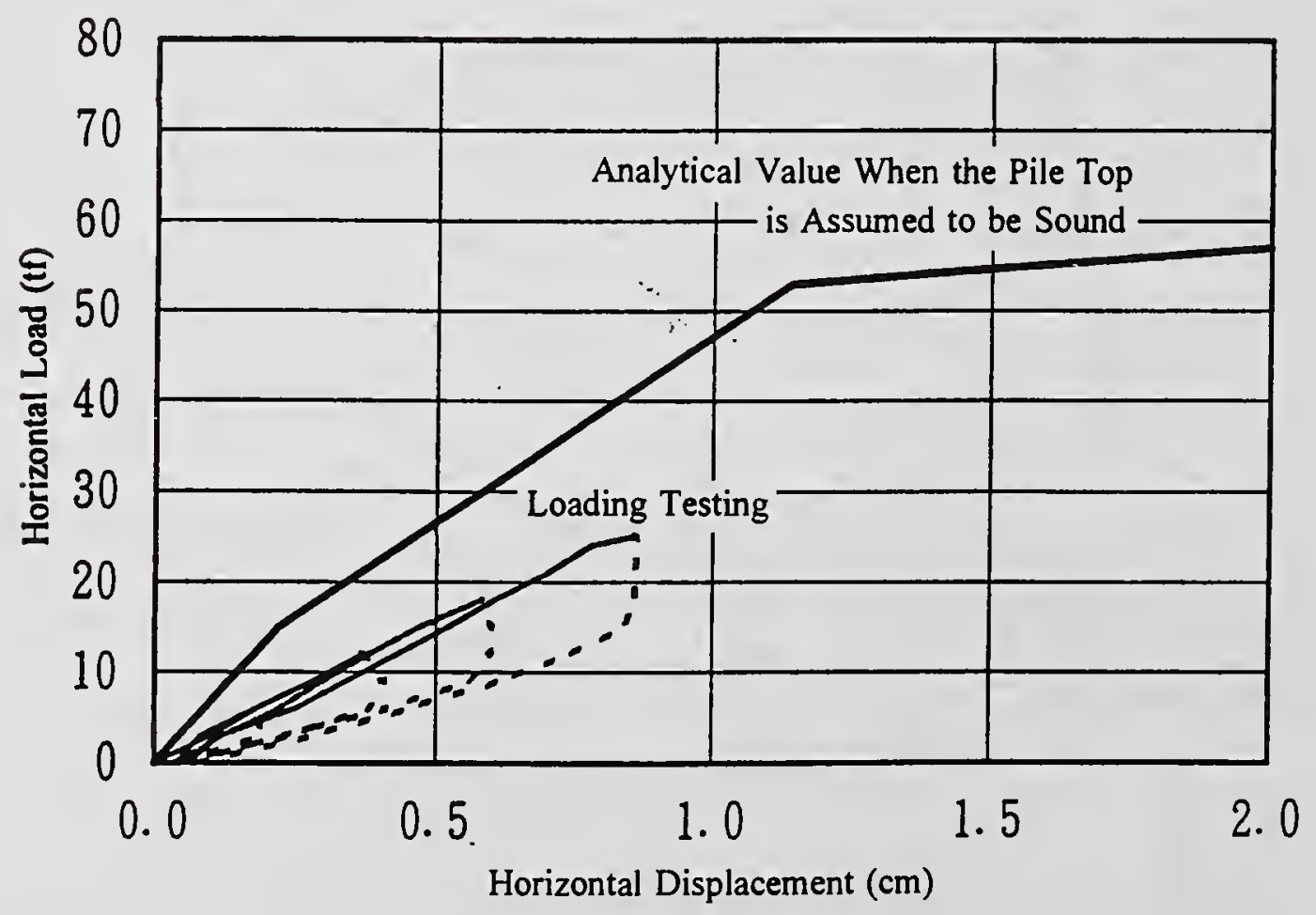

Figure 7 Horizontal Load - Horizontal Displacement at the Loading Point During Pile Bending Testing (No.126 Pier) 


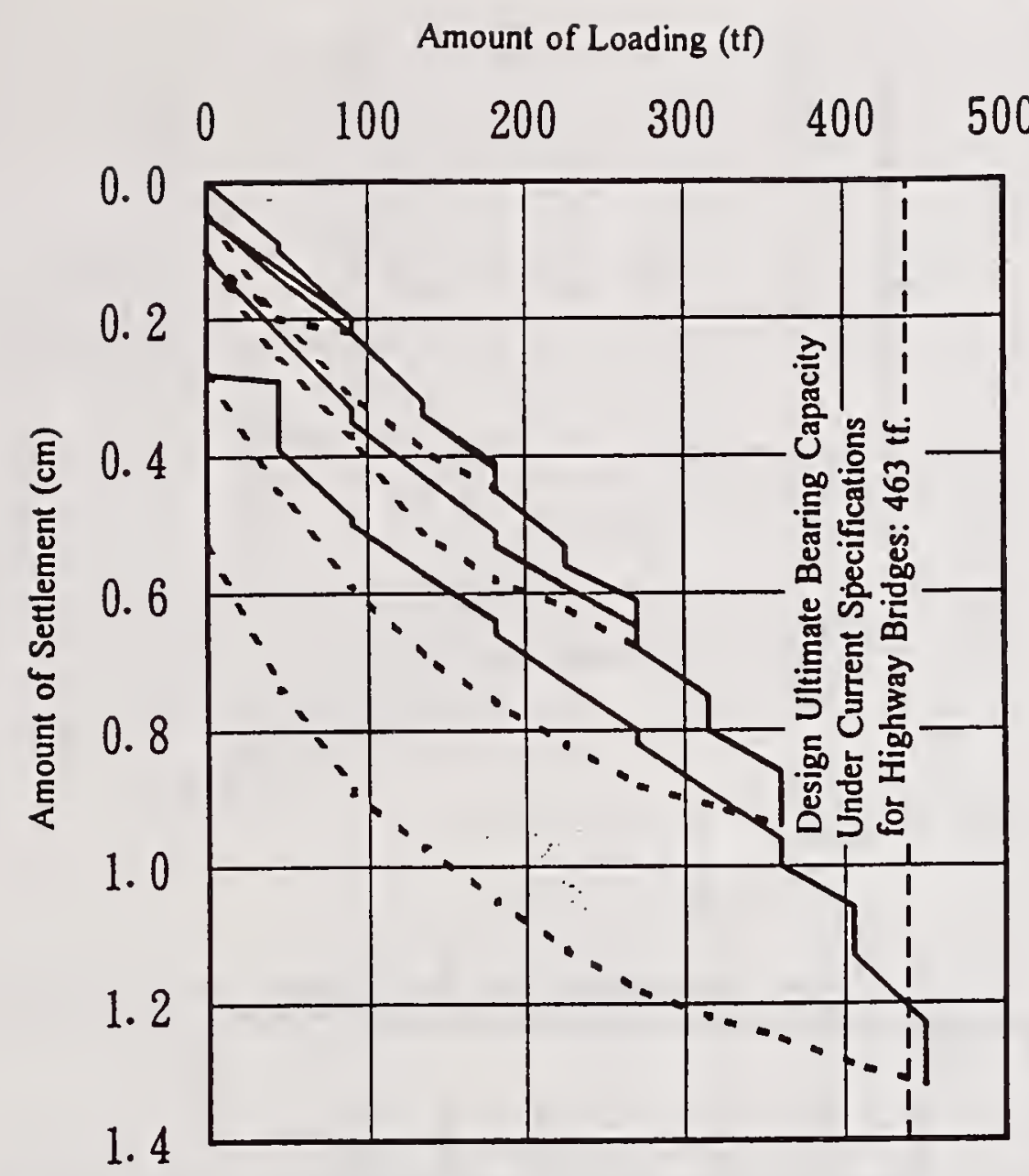

Figure 8 Amount of Loading - Amount of Settlement Curve During the Vertical Loading Test of the Piles (No. 126 Pier)

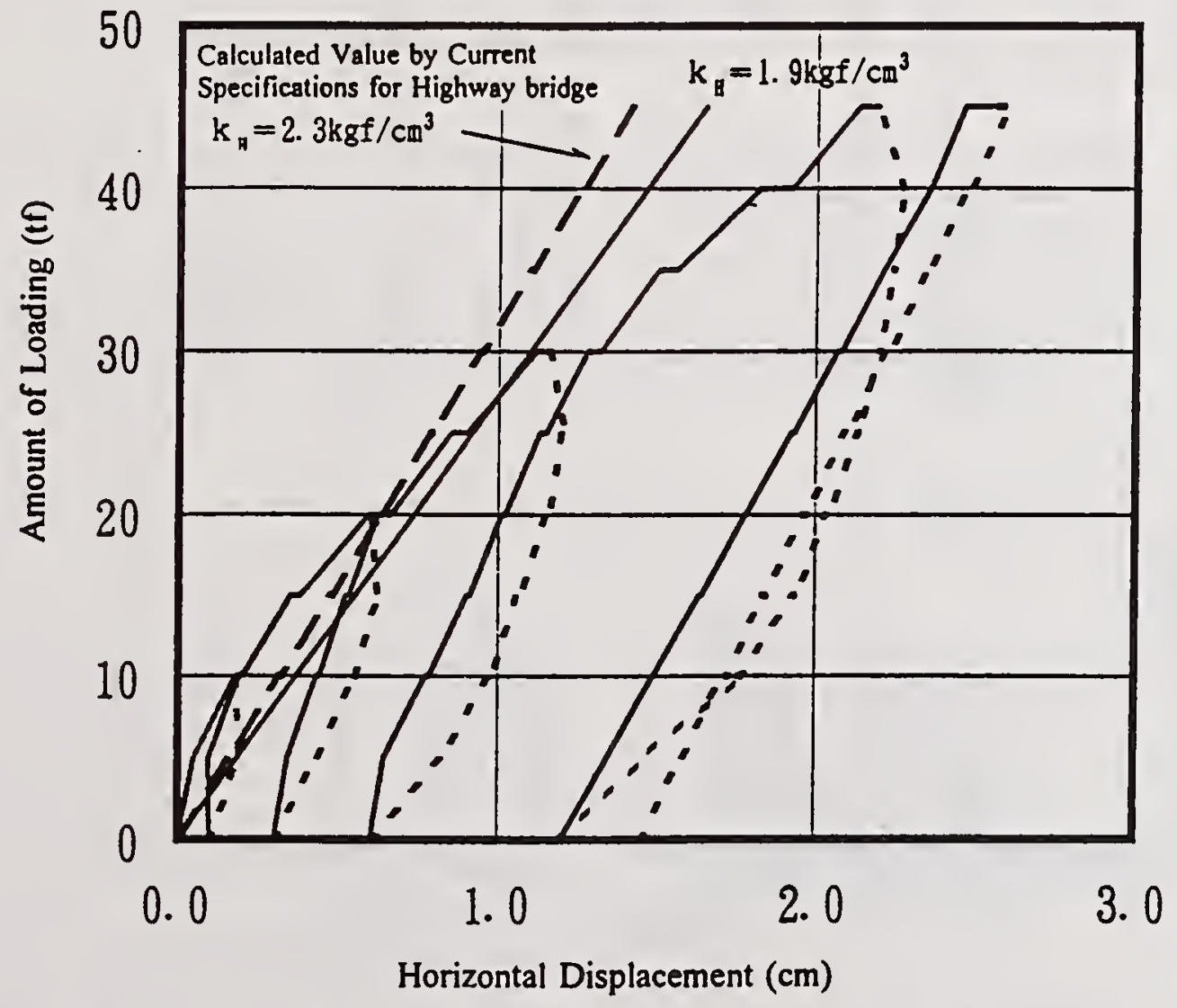

Figure 9 Amount of Loading - Horizontal Displacement Curve for the Horizontal Loading test of the Piles (No.126 Pier) 

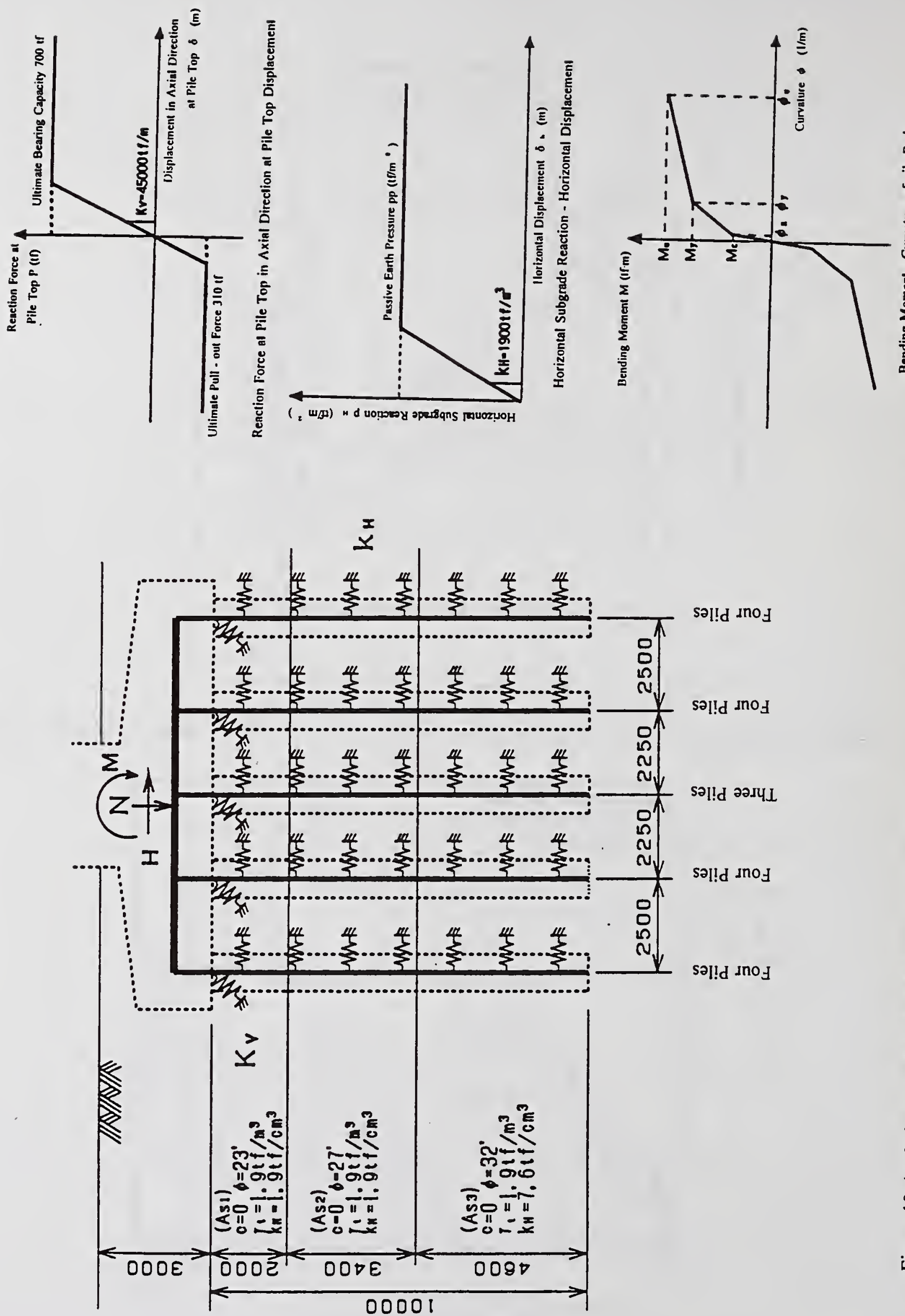

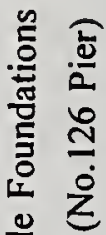




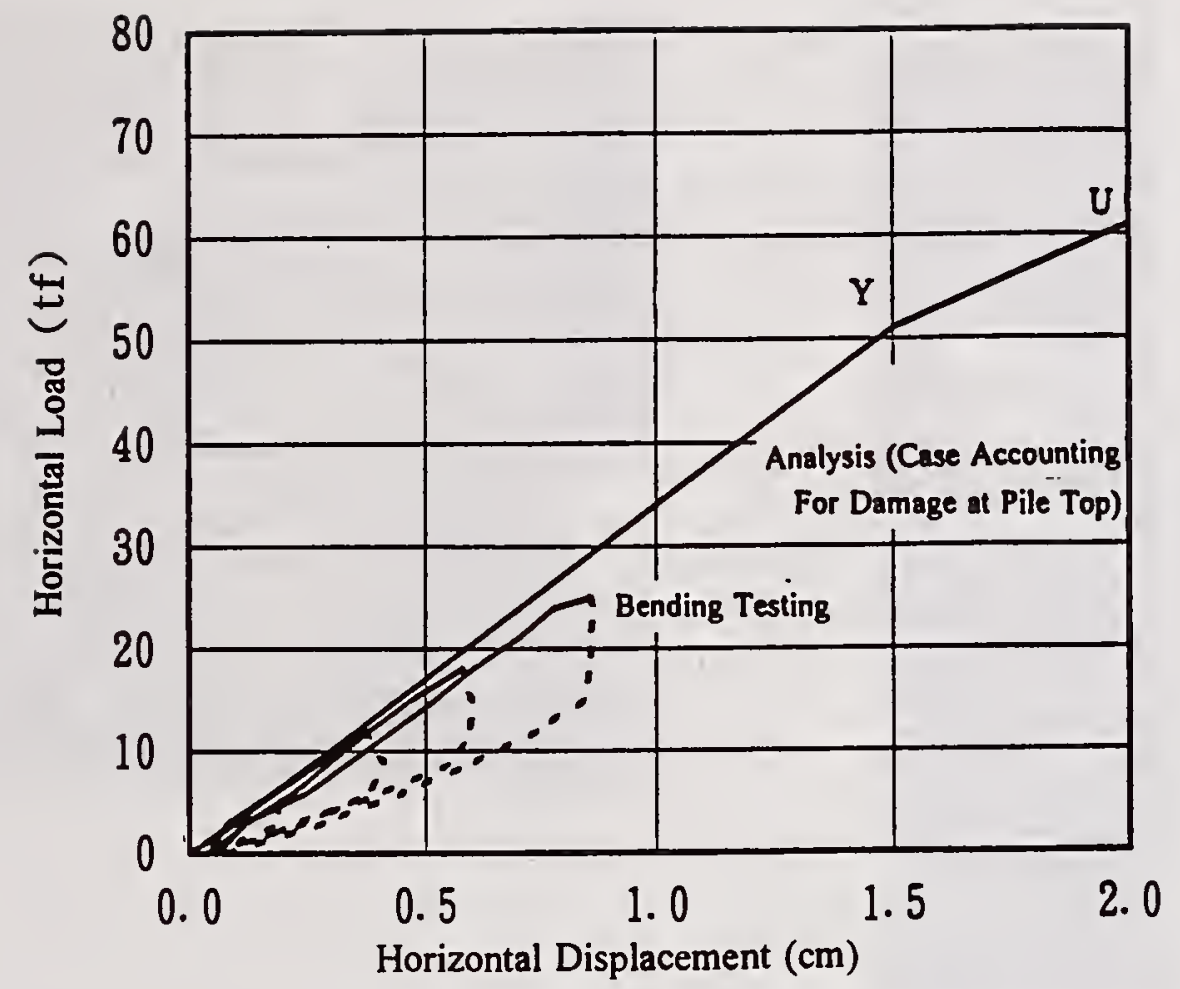

Figure 11 Horizontal Load - Horizontal Displacement Curve at the Loading Point During the Pile Bending Test (No.126 Pier)

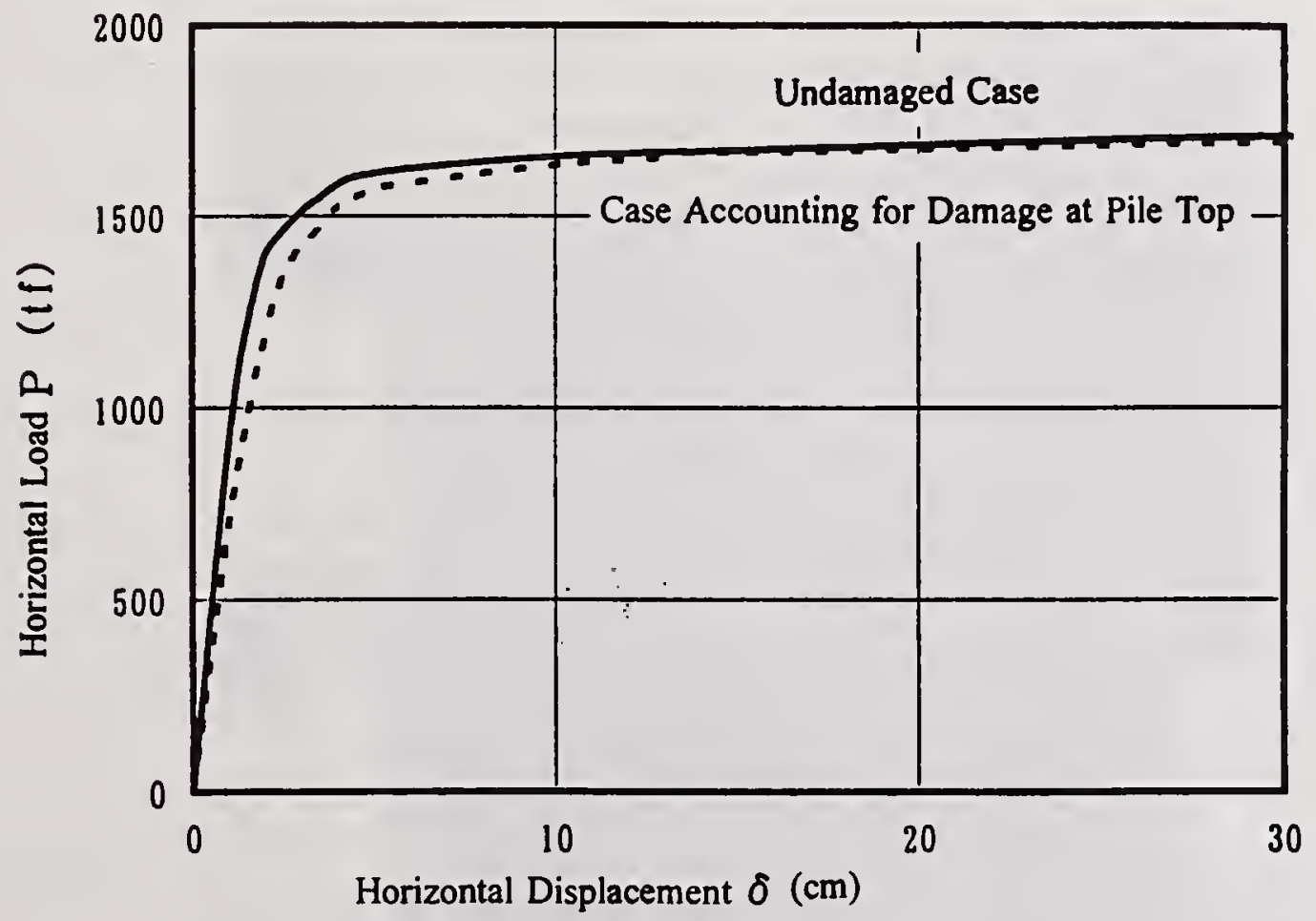

Figure 12 Effect of Pile Body Damage on the Horizontal Load Horizontal Displacement Curve of the Foundation (No.126 Pier) 


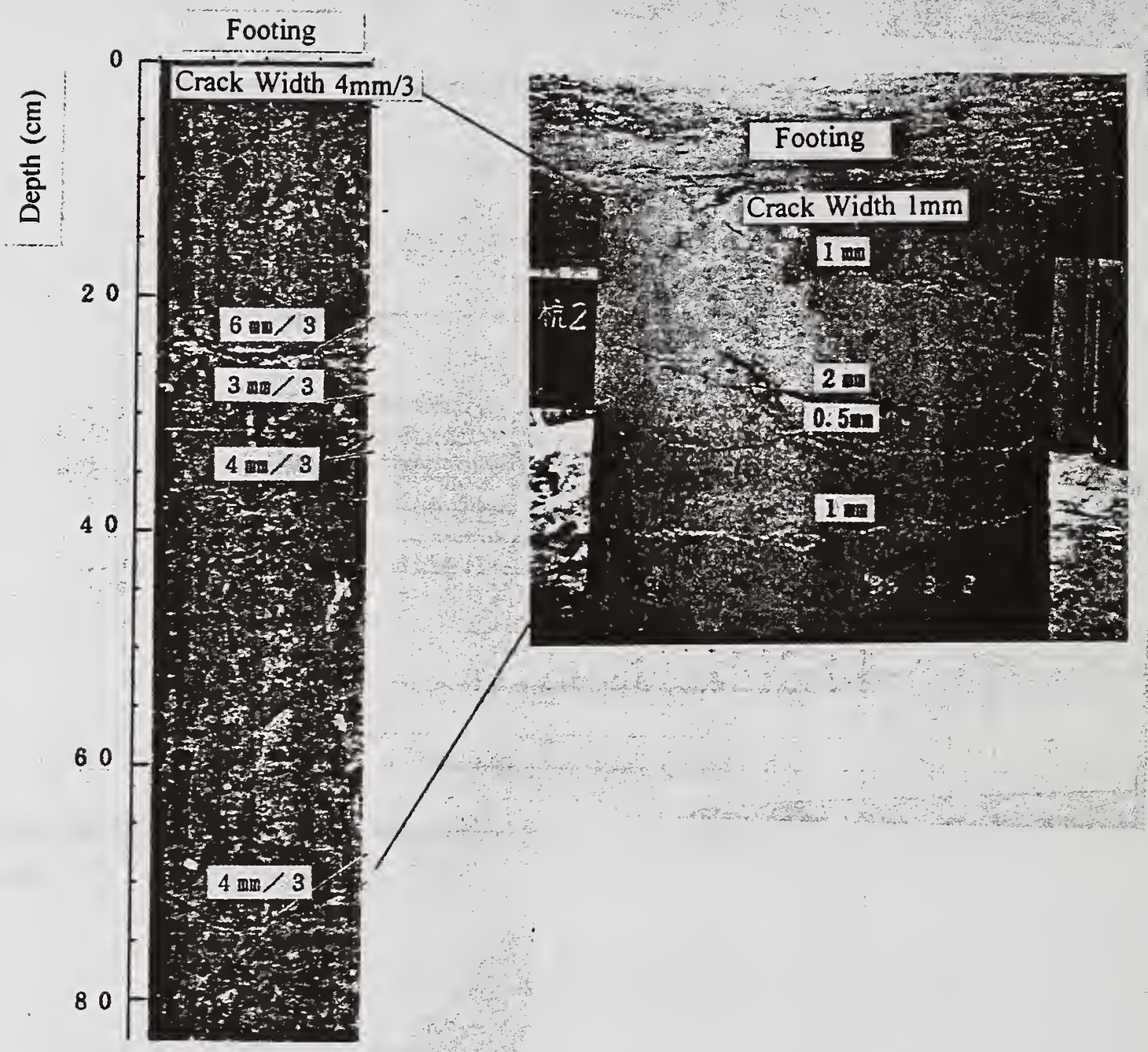

(a) Bore Hole Television System

(b) Excavating

Photograph 1 Survey the Damage to Foundations

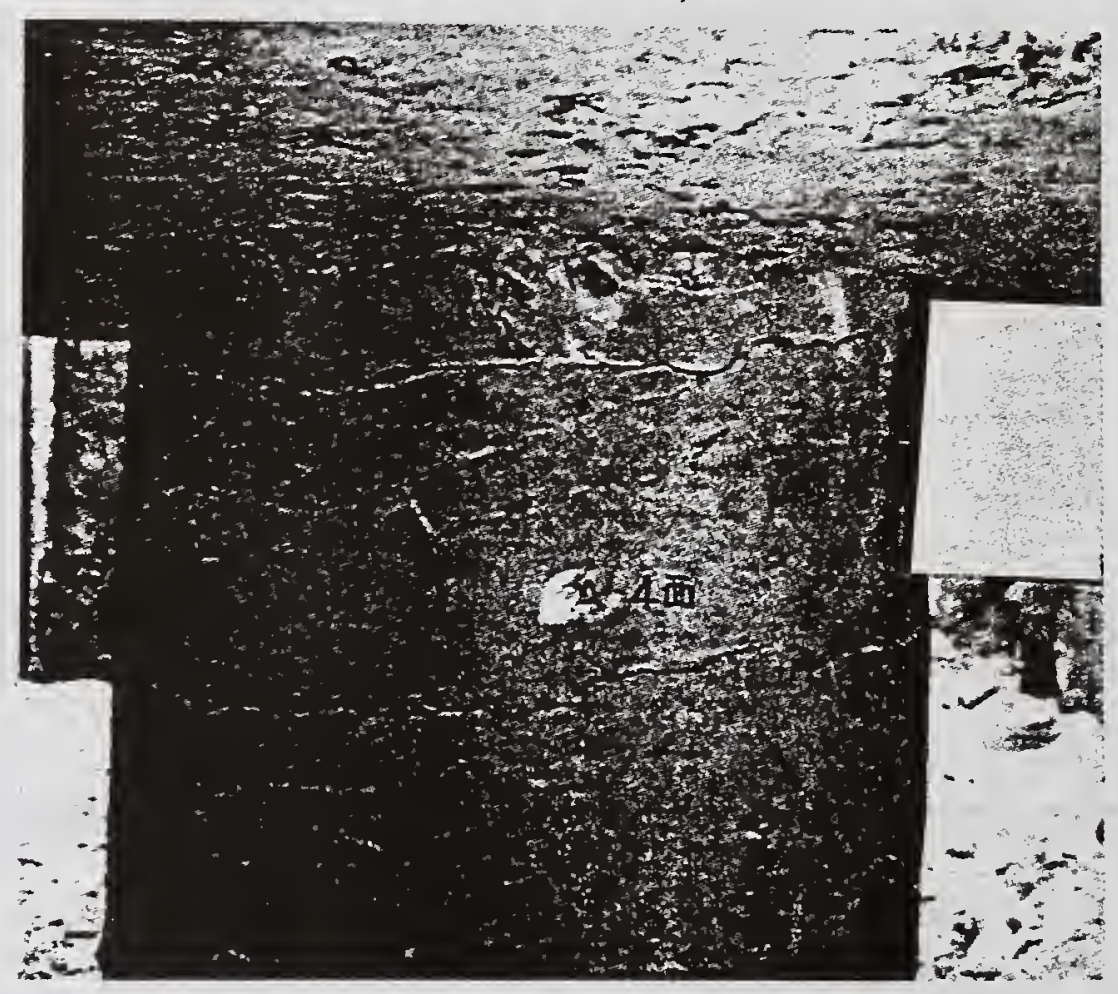

Photograph 2 Damage to Pile Body (No.126 Pier) 


\title{
Evaluation of Fault Rupture Geometry on Design Ground Motions
}

by

\author{
D. R. H. O'Connell and J. P. Ake \\ U. S. Bureau of Reclamation \\ Seismotectonics and Geophysics Group \\ Denver Technical Center \\ Denver, CO
}

\begin{abstract}
Simulations of complex fault rupture and associated near-field ground motions and existing strong motion recordings are used to illustrate the importance of fault rupture geometry on near-field ground motion estimates for engineering applications. This study confirms other recent investigations of near-field ground motions from the 1989 Loma Prieta, 1994 Northridge, and 1995 Kobe earthquakes: in the near-field. directivity and focal mechanism can be more important than distance in controlling engineering ground motions at a particular site. Specifically, observed updip nearfield peak velocities exceeding $100 \mathrm{~cm} / \mathrm{sec}$ from thrust faults are a direct consequence of coincident directivity and maximal $S_{V}$ radiation patterns.
\end{abstract}

\subsection{INTRODUCTION}

One goal of strong-motion seismology has been the prediction of ground motions for engineering applications. Our task is to predict the site-specific ground motions in advance of the occurrence of a future earthquake given some knowledge of the regional geology and the specific fault that may rupture. Several recent earthquakes have provided extensive data that expands our understanding of some of the important physical phenomena. In this paper we will utilize a complex fault rupture simulation technique to develop estimates of ground motions for sites in the near-field of the 1994 Northridge earthquake and compare those results to observed strong-motion data. Using this methodology we will then illustrate the prediction of ground motions at a site near Ventura, California for future earthquakes on the Red Mountain fault.

\subsection{Methodology}

To synthesize near-field ground motions from a finite rupturing fault we use a kinematic approach
(Spudich and Archuleta, 1987). This method requires specification of the temporal rupture characteristics on the fault. Ground velocity, dU/dt, depends on the convolution of the

$$
\frac{d U}{d t}=\sum_{i j}^{n m} \overline{d S}_{i j} \otimes G_{i j}
$$

time evolution of the slip time function. $S_{i j}$, and the Green functions, $G_{i j}$, the impulse responses between the site of interest and positions on the fault as described by equation 1 (see Figure 1). We assume that fault rupture initiates at some point on the fault (the hypocenter) and proceeds outward along the fault surface. The pertinent parameters are the fault length and width. the direction of slip (rake), the hypocenter position on the fault, the position of receiver site relative to the fault, the slip time function at each point on the fault rupture, the velocity at which the fault ruptures away from the hypocenter, and the velocity at which the fault rupture stops along the rupture surface. The FATT-VSDASP-RRH model (described below) is used to generate the fault parameters.

The reflectivity method of Kind (1978) is used to calculate $G_{i j}$ and the tau- $p$ frequency domain distance interpolation method of Henry and others (1980) and Kappus and others (1990) is used to obtain $G_{i j}$ at required source-receiver distances. Approximate depth interpolation between Green functions consists of increasing the distance by a small amount to increase the S-P time of the shallower Green function. Since Green functions are spaced $0.1 \mathrm{~km}$ apart in depth, this is a reasonable approximation.

The computation demands scale as $f^{5}$, where $f$ is frequency, effectively limiting the maximum feasible frequency for the calculations to $10 \mathrm{~Hz}$. Consequently, this method is most applicable to the S- 
wave portion of ground motion, the method cannot reproduce the frequency bandwidth of typical high frequency P-wave phases. The method is unlikely to produce realistic vertical peak ground accelerations that are controlled by S->P converted phases that typically contain substantial spectral content above $10 \mathrm{~Hz}$.

The Kostrov slip function provides a realistic description of dynamic slip on complex faults and is commonly used in rupture simulations (Spudich and Archuleta, 1987). We use the approximation to the Kostrov slip function of O'Connell and Ake (1995), $s(r, t)$. This slip velocity function represents the dynamic solution for a circular constant stress-drop rupture in a homogeneous medium. Consequently it is designated a "quasi-dynamic" slip function for more general rupture geometries and material properties.

The velocity at a site relative to the fault rupture is calculated in the frequency domain as,

$$
\dot{u}(\underline{x}, \omega)=\sum_{i, j=0}^{n, m} \dot{s}_{i j}(\underline{r}, \omega) \mathbf{G}_{i j}(\underline{r}, \omega) \mathbf{R}_{i j}^{\mathrm{T}}(\underline{r}) D_{i j}(\underline{r}, \omega)(2)
$$

where $\dot{s}_{i j}(\underline{r}, \omega)$ are the frequency-domain equivalents of $s(r, t), \quad \mathbf{G}_{i j}(\underline{r}, \omega)$ are vectors of the impulse response traction Green functions, $\mathbf{R}_{i j}(\underline{r})$ are vectors containing the rupture orientation and rake dependent radiation coefficients. and $D_{i j}(\underline{r}, \omega)$ are the rupture-time and travel-time, delays calculated using the FATT-VSDASP-RRH model, which will be discussed below.

\subsection{Kinematic Description of Finite Fault Rup- ture- FATT-VSDASP-RRH Model}

The FATT-VSDASP-RRH model consists of fractal asperity and travel-time (FATT) randomizations that includes variable high effective stress circular asperities (VSDASP) imbedded in a fault with a background of lower effective stresses combined with fractal randomized rupture and healing velocities (RRH). Fractal randomization of stress drops, rupture, healing and S-wave velocities is consistent with the investigations of Frankel and
Clayton (1986) and Frankel (1991). Frankel

(1991) showed that a fractal distribution of asperities and stress drops can explain many aspects of earthquake rupture and observed ground motions.

High stress drop asperities provide the dominant high frequency radiation of seismic energy. Asperities have regions around their perimeter that provide smooth transitions of effective stresses from the asperity interiors to the background regions of the fault (Figure 2). The transition regions also allow for transitional changes in average rupture and healing velocities. Average rupture and healing velocities and randomization amplitudes are independently specified for the asperity interiors. Additionally, asperities are allowed to heal from their perimeters inward. This provides quite heterogeneous distributions of rise time on the fault. Self-healing asperities can have short rise times. while background regions of the fault that are far from healing boundaries (fault edges) can have substantially longer rise times, consistent with the results of Mikumo and Miyatake $(1987 ; 1993)$ and Fukuyama and Mikumo (1993). Short rise times in the asperities provide high amplitude and frequency radiation consistent with Heaton's (1990) observation of relatively short rise times for rupture models of large earthquakes. Longer rise times in the lower effective stress background region provide sufficient additional seismic moment to provide total moments consistent with observed moment magnitudes. If short rise times are assumed everywhere on a fault then the asperities are required to provide most of the moment and estimated effective stresses are unreasonably high. This parameterization provides a means to explain low and high frequency observations of large earthquakes. but requires less extreme effective stresses in the asperities than the constant rise time model. The Von Karman fractal randomization of Frankel and Clayton (1986) is used to randomize background effective stress variations, rupture and healing velocities in the RHH model described below, and S-wave velocities. The same randomization is used for all rupture quantities, as it would be expected that high stresses and velocities would be spatially coincident.

Any realistic rupture initiates at a given time and stops at a some later time. To describe the RRH 
process we define starting, stopping. and healing times for all points of a fault rupture. The rupture relocity, $V_{r}$, is allowed to vary randomly between $0.65 V_{s}$ and $1.0 V_{s}$, where $V_{s}$ is local shear-wave velocity Variations in $V_{r}$ simulate the effect of inhomogeneous rupture propagation that strongly influences high frequency motions. The stopping position function consists of all or part of the final edges of the rupture or asperities where stopping begins on the fault. The healing velocity, $V_{h}$, is allowed to vary between $0.9 V_{s}$ and $1.1 V_{s}$. At each point on the fault, the slip velocity is linearly reduced to zero over a healing interval of $0.05 \mathrm{sec}$. A healing causality condition is imposed such that healing points can only heal portions of the fault that have rupture arrival times less than the healing points' rupture times. This allows slip to go to zero at the edges of the fault and produces realistic slips in the interior of the fault.

Frankel and Clayton (1986) showed that the Von Karman slowness randomization can explain observed crustal travel-time variations and seismic scattering behavior. A similar fractal distribution of stress drops on finite rupture faults can explain the $\mathrm{w}^{2}$ spectrum radiated by large earthquakes (Frankel, 1991; Herrero and Benard, 1994). Consequently, it provides an adequate means to randomize stress drops and S-wave velocities along a finite fault. The Von Karman fractal distribution of Frankel and Clayton (1986) with a correlation distance of $10 \mathrm{~km}$ is used to generate two-dimensional randomizations of S-wave velocities on the fault. This randomization is superimposed on the vertically heterogeneous S-wave velocity structure appropriate for the site of interest and a twodimensional finite-difference travel time routine is used to calculate all rupture and healing travel times.

\subsection{Isochron Tools For Understanding Near- Field Ground Motions}

Point source summation seismograms are difficult to interpret. It is difficult to identify the regions of the fault that contribute to specific portions of a seismogram. Bernard and Madariaga (1984) and Spudich and Frazer (1984) developed the isochron integration method to compute near-field seismo- grams for finite fault rupture models. Isochrons are defined as all the positions on the fault that contribute seismic energy at a specific receiver position at the same time. By plotting isochrons projected on a fault, times of large amplitudes in a seismogram can be associated with specific regions of fault rupture or healing.

The simplest way to employ the isochron method in the near field is to assume that all significant seismic radiation from the fault consists of first Swave arrivals. This assumption is verified in subsequent sections. A further simplification is to use a simple slip velocity pulse. Let $f(t)$ be the slip function, For simplicity we assume $\ddot{f}(t)=\delta\left(t-t_{r}\right)-\delta\left(t-t_{h}\right)$ where $t_{r}$ is rupture time, and $t_{h}$ is healing time. Then. all seismic radiation from a fault can be described with rupture and healing isochrons. Velocity and accelerations from rupture or healing can be calculated (Spudich and Frazer, 1984) from

$$
\begin{gathered}
v(x, t))=\ddot{f}(t) \otimes \int_{y(t, x)}(s \cdot G) c d l \\
a(x, t)=\ddot{f}(t) \otimes \int\left[c^{2}\left(\frac{d s}{d q} \cdot G\right)+c^{2}\left(\frac{d G}{d q} \cdot s\right)+\frac{d c}{d t}(s \cdot G)\right] d t
\end{gathered}
$$

where $c$ is isochron velocity, $s$ is slip velocity (either rupture or healing), $G$ is the ray theory Green function.

The FAT-VSDASP-RRH source model sometimes produces isochron caustics (regions of a fault with infinite isochron velocities) that can produce unrealistic peak accelerations using isochron integration (O'Connell and others. 1995). Spudich and Frazer (1984) showed that $c$ can be eliminated from (3) by integrating along an isochron over a finite time window defined by the isochrons $t-d t$ and $t+d t$. By limiting the integration to frequencies lower than $10 \mathrm{~Hz}(d t=0.05 \mathrm{~s})$ extreme peak accelerations are reduced, making the isochron method useful for qualitatively evaluating accelerations. This approach is used here with a first order approximation where (3) is reduced to a point source summation of over the isochron strip corresponding to the finite time window. We exploit this feature to efficiently calculate velocities for a large 
number of receiver positions relative to a fault. For the isochron integrations $G$ is approximated as

$$
G(x, \xi)=\frac{F(x, \xi) \cdot \dot{W}(x, \xi)}{4 \pi \sqrt{\rho(x) \rho(\xi) \beta(x)} \beta(\xi)^{5 / 2} \sqrt{(x-\xi)^{2}}}
$$

where $x$ is the receiver position, $\xi$ is position on the fault, $F(x, \xi)$ is the source radiation term, $\tilde{W}(x, \xi)$ is the free surface amplification factor, $\rho$ is density, and $\beta$ is S-wave velocity. In this approximation. only first $S$-wave arrivals are included in the calculation. Although ray spreading factors are simply approximated by the inverse sourcereceiver distance, an S-wave velocity model developed for this area is used to calculate, $\beta(\xi)$, takeoff angles for $F(x, \xi)$, and incidence angles for $\check{W}(x, \xi)$ to incorporate first-order geometric effects of vertically heterogeneous velocity structure. This produces realistic partitioning of the direct SV arrival between vertical and horizontal components of ground motion.

Since isochrons are central to understanding pointsource summation seismograms, we provide explicit expressions for rupture and healing isochrons to illustrate how both source and propagation factors can affect seismograms. The arrival times of rupture at a specific receiver are

$$
T_{r}(x)=t_{\beta}(x, \xi)+t_{r}(\xi)
$$

where $x$ is the receiver position, $\xi$ are all fault positions, ${ }^{t} \beta$ are S-ivave propagation times between the receiver and all fault positions, and $t_{r}$, is the rupture time at all fault positions. The arrival times of healing at a specific receiver are

$$
T_{h}(x)=T_{r}(x)+R(\xi)
$$

where $R$ are the rise times at all fault positions.

From (6) and (7) it is clear that both fault rupture variations and $\mathrm{S}$-wave propagation time variations effect isochron velocities. Often, most attention has been focused on the effects of variations of fault rupture in (6) and (7). Equations (6) and (7) help illustrate how $\mathrm{S}$-wave propagation time varia- tions caused by anisotropy and heterogeneity can significantly influence peak near-field velocities and accelerations.

It is interesting to interpret ( 3 ) and (4) in the context of point-source summation seismograms. When isochron velocities become large on a substantial area of a fault it simply means that all point sources sum at nearly the same time at the receiver and velocities remain finite, but potentially large. In this way isochrons are a powerful tool to dissect waveforms produced by pointsource summation as well as understanding existing seismograms when information is available about the rupture process. Times of large waveform amplitudes can be directly associated with the regions of the fault that have corresponding isochrons and large isochron and slip velocities.

\subsection{Anisotropy and Heterogeneity in S-Wave Propagation}

An analysis of the distribution of S-wave arrival times acquired from small earthquakes recorded close to our site of interest suggests that a random fluctuation of arrival times should be incorporated into the $1 \mathrm{D}$ reflectivity Green functions to account for 3D heterogeneous velocity structure. Since the S-wave arrivals dominate strong motion, incorporation of S-wave travel time variations associated with anisotropy and heterogeneity into the Green functions should produce more realistic phasing of simulated ground motions.

The influences of anisotropy are clearly evident in the waveform data acquired at this site. Inspection of the three-component wareforms from about 20 earthquakes occurring north of the surface trace of the Red Mountain fault rereal a pattern of S-wave splitting consistent with fracture induced anisotropy associated with east-west faults as observed by Li (1994) in the eastern Transverse Ranges. Swaves polarized approximately orthogonal to local faults tend to be delayed relative to those polarized parallel to the faults. To approximate this behavior, one function is used to apply time shifts to the radial and vertical Green function components and a different function is used to apply the anisotropy time shift to the transverse Green function component. 


\subsection{FATT-VSDASP-RRH MODEL VALIDA- TION: NORTHRIDGE NEAR-FIELD GROUND MOTIONS}

One means to evaluate the ability of the FATTVSDASP-RRH model to produce realistic accelerations and velocities is to compare the synthetic waveforms to empirical strong motion recordings. The January 17, $1994 \mathrm{M}_{\mathrm{W}} 6.7$ Northridge, California, earthquake occurred in the same tectonic setting as our site of interest and on a fault with a geometry similar to the Red Mountain thrust source. Rupture occurred on a $45^{\circ}$ south-dipping fault with an average rake of $105^{\circ}$ (Jones and others, 1994; Wald and others, 1996; Dreger, 1994). The earthquake was recorded by numerous strong motion instruments. Several near-field strong motion stations (Newhall - LA County fire stations and Sylmar - County hospital parking lot, for example) are located in updip positions relative to the earthquake rupture that are quite similar to our site's position relative to the Red Mountain fault. The velocity structure near the Northridge earthquake (Haase and Hauksson, 1995) is similar to the velocity structure near our site of interest. Consequently, synthetic. FATT-VSDASP-RRH waveforms can be compared to selected recordings from the Northridge earthquake to evaluate the ability of the FATT-VSDASP-RRH model to produce realistic accelerations and velocities. It should be noted that all of the results presented here have were developed using data (S-wave travel time variations and scattering functions) specific to our site of interest (near Ventura). Only the fault rupture parameters are specific to the Northridge event. No site-specific information for the strong-motion stations was used in the validation exercise.

The Northridge earthquake ruptured from about 20 $\mathrm{km}$ depth to about 5-7 km depth and the fault length was about 15-20 km (Wald and others; 1995. Hudnut and others, 1994; Dreger; 1994). The Newhall and Sylmar stations are located about $12 \mathrm{~km}$ west and $1 \mathrm{~km}$ east, respectively, from the hypocentral strike position in the rupture plane and are located on the upthrown side of the fault (Hudnut and others, 1994: Wald and others, 1995).

We have produced a FATT-VSDASP-RRH rupture model for Northridge consistent with the source models of Wald and others (1996) and Zeng and Anderson (1996). Corresponding synthetic ground motions for several strong motion recording sites of the 1994 Northridge earthquake reproduce observed horizontal and vertical velocities and horizontal accelerations quite well. Additionally, we have used the isochron method to compute estimates of peak horizontal velocity over a $3600 \mathrm{~km}^{2}$ near-field grid for comparison with the actual observations of peak horizontal velocities. Synthetic and observed ground motions are also compared with estimates computed from existing strong-motion attenuation relationships.

One useful by-product of the rapid computation of isochron results is the ability to evaluate the spatial and temporal evolution of ground motions. Figure 3 shows contours of simulated peak horizontal velocity at $1 \mathrm{~s}$ intervals in fault coordinates for the Northridge rupture simulation. The positions of several relevant strong-motion sites are shown as well. Near the northwest corner of the fault (near stations Sylmar and Rinaldi) very large motions are both predicted and observed in a short time interval between 7.8 and 9.8 seconds. To the north of the rupture surface (near the Newhall station) the maximum motions are slightly smaller but the duration of strong motions is considerably longer, 9.8 to 13.8 seconds.

To help interpret the individual strong motion simulations produced with the FATT-VSDASP-RRH rupture model as well as the observed recordings we have computed isochron plots for individual stations. An example for station NWS (north of the fault) is shown on Figures 4 and 5. Figure 4 illustrates rupture isochrons and Figure 5 healing isochrons. Comparison of the peak velocity contributions between the two figures illustrates that most of the site velocity is contributed by the rupture process. The large distance between the isochrons in Figure 4 illustrates that a large portion of the fault surface contributes arrivals in a small time window (i.e. high isochron velocities). Slip velocities from the large asperity located closest to station NWS contributes the large pulse observed on the synthetic records. There is clearly more high frequency energy in the synthetic arrivals than in the observed recordings. The Green 
functions were computed for the velocity structure in the western Transverse Range and exhibit less attenuation than is anticipated for the region near Northridge.

A common methodology for predicting ground motions for engineering analysis has been the use of empirical attenuation relationships. Recent attenuation relationships relate ground motion parameters of interest to earthquake magnitude and some source-site distance measure along with fault-type, site conditions, and in some cases fault geometry (c.f. Boore and others, 1993 and 1994; Campbell and Borzorgnia, 1994; Sadigh and others, 1993; Abrahamson and Silva, 1996). Often, based upon the results of these relationships, one or more existing strong-motion recordings are selected for use in the dynamic analysis of bridges, dams or other structures. The most recent of these relationships provide a reasonable, averaged estimate of the expected ground motions for many scenarios. However, for situations in close proximity to the fault surface the fault normal component of motion may be significantly larger than the fault parallel component (Somerville and others, 1996). Likewise in cases where a site is located near an asperity on the fault surface motions can be larger than predicted. Recent observations from the 1992 Landers, 1994 Northridge, and 1995 Kobe earthquakes show that rupture directivity significantly influences observed ground motions. To evaluate the ability of empirical attenuation relationships to estimate future ground motions in near-field situations we have computed peak acceleration and velocity estimates for the Northridge earthquake over the same grid as for the isochron methodology.The relationship of Abrahamson and Silva (1996) was used to produce estimates of acceleration values and the relationship of Campbell (1990) was used to produce the peak velocity values. The spatial distribution of observed peak horizontal velocity is compared to the isochron predictions in Figure 6 and Campbell 's (1990) empirical prediction in Figure 7. The observational data shown in Figures 6 and 7 is from Wald and others (1996).

The empirical relationships are smoothed averages of a number of observations and thus do not possess the spatial variability evident in the isochron simulations. The isochron results suggest very high local gradients in the velocity field updip of the fault surface. (see Figure 6). Changes of 70 $\mathrm{cm} / \mathrm{sec}$ in peak velocity are observed over distances of $\sim 5 \mathrm{~km}$. The simulated peak velocities agree quite well with the observations at stations PARD, Newhall, NWS, Rinaldi, and Sylmar. The empirical predictions of Abrahamson and Silva (1996) for peak accelerations give reasonable agreement with the simulations and observations in smoothed sense. The velocity predictions of Campbell (1990) seriously underpredict the simulations and observations in the updip region even at the 84-percentile level (Figure 7).

Ground motion predictions in a "back-azimuth" (i.e. towards the south) are considerably lower than observed values. This appears to be due to at least three factors, (1) stations in the southern San Fernando Valley and northwestern Los Angeles Basin did not experience forward directivity effects. (2) because of the dip of the fault these sites had a larger source-site distance than up-dip stations. (3) significant three-dimensional basin effects appear to have enhanced late-time arrivals at these stations. Olsen and Archuleta (1996) have investigated this observation with a three-dimensional finite-element approach and suggest significant basin effects in these areas.

\subsection{PREDICTION OF FUTURE GROUND MOTIONS}

Obviously we can not know a priori the rupture geometry, distribution of asperities and slip history on the fault surface at sites where we must predict ground motions from a fault for design purposes. We have chosen to use the FATT-VSDASP-RRH reflectivity model to predict motions for a site near the Red Mountain Fault north of Ventura, California (Figure 8). The approach we have chosen to use is computation of a large number of plausible simulations developed using the FATT-VSDASPRRH model to develop a distribution of ground motion values at the site of interest. From this distribution, motions can be selected that are consistent with a desired level of conservatism. An example of the resulting distribution is shown in Figure 9 for PHA and PHV. Figure 10 displays the relationship between the hypocentral depth and 
strike position and resulting ground motions at the site of interest. This figure illustrates a fundamental observation, large ground motions can be expected when the hypocenter is located relatively deep and downdip from the site and maximal Swave radiation patterns are located between the hypocenter and the site (thrust faulting). This zone defines a region of hypocenter positions where a substantial portion of the total fault area (as high as $40 \%$ ) can contribute coherent motions at the site in a very short $(\sim 1 \mathrm{sec})$ time window.

\subsection{CONCLUSIONS}

The results of this study confirm other recent investigations of near-field ground motions from the 1989 Loma Prieta, 1992 Landers. 1994 Northridge, and 1995 Kobe earthquakes. Specifically, in the near-field, directivity and focal mechanisms (maximal SV radiation patterns associated with thrust faulting) can be more important than distance in determining engineering ground motions at a particular site.

\subsection{REFERENCES}

Abrahamson, N.A., and Somerville, P.G., 1996, Effects of the hanging wall and footwall on ground motions recorded during the Northridge earthquake, Bulletin of the Seismological Society of America, 86, S93-S99.

Abrahamson, N. A., and Silva, W., 1996, Preliminary attenuation relations for horizontal response spectra including data from the 1994 Northridge earthquake, submitted to Bull. Seismol. Soc. America.

Bernard. P.. and Madariaga, R.. 1984. A new asymptotic method for the modeling of nearfield accelerograms, Bulletin of the Seismological Society of America, 74, 539-557.

Boore, D. M., Joyner, W. B., and Fumal, T. M., 1993, Estimation of response spectra and peak accelerations from western North America earthquakes: an interim report, U.S. Geological Survey Open-File Report No. 93-509, 72 pp.

Boore, D. M., Joyner, W. B., and Fumal, T. M., 1994, Estimation of response spectra and peak accelerations from western North America earthquakes: an interim report. Part II, U.S. Geological Survey Open-File Report No. 94127. $40 \mathrm{pp}$.

Campbell, K.W., and Bozorgnia, Y., 1994, Nearsource attenuation of peak horizontal acceleration from world-wide accelerograms recorded from 1957 to 1993, Proc. Fifth U.S. National Conference on Earthquake Engineering. Chicago, IL.

Campbell, K.W., 1990, Reanalysis of strong ground motion recordings; empirical prediction of near-source ground motion for Diablo Canyon Power Plant site, San Luis Obisbo, California, Report to the U.S. Nuclear Regulatory Commission.

Dreger, D. S., 1994, Empirical Green's function study of the January 17, 1994 Northridge mainshock $\left(M_{w} 6.7\right)$, Geophys. Res. Lett. v. 21 , 2633-2636.

Frankel, A., and Clayton, R.W., 1986, Finite difference simulations of seismic scattering: Implications for propagation of short-period seismic waves in the crust and models of crustal heterogeneity, Journal of Geophysical Research, 91. 6465-6489.

Frankel, A., 1991, High-frequency spectral falloff of earthquakes, fractal dimension of complex rupture, $b$ value, and the scaling of strengths on faults, Journal of Geophysical Research. 96, 6291-6302.

Frankel, A., 1993, Three-dimensional simulations of ground motions in the San Bernardino Valley, California, for hypothetical earthquakes on the San Andreas Fault, Bulletin of the Seismological Society of America, 83, 1042-1063.

Fukuyama, E., Mikumo, T., 1993. Dynamic rupture analysis: Inversion for the source process of the 1990 Izu-Oshima, Japan, earthquake (M $=6.5$ ), Journal of Geophysical Research, 1: 98, 6529-6542.

Hauksson, E., Jones, L.M., and Hutton, K., 1995. The 1994 Northridge earthquake sequence in 
California: Seismological and tectonic aspects, Journal of Geophysical Research, 100, 12,33512.355 .

Heaton, T.H., 1990. Evidence for and implications of self-healing pulses of slip in earthquake rupture, Physics Earth Planetary Interiors, 64, 120.

Heaton, T.H., and Wald, D., 1994. Strong ground motions from the Northridge earthquake; were they anomalous or a warning of things to come?, EOS, 75, 175.

Henry, M., Orcutt, J.A., and Parker, R.L., 1980. A new method for slant stacking refraction data, Geophysical Research Letters, 7, 1073-1076.

Kappus, M.E., Harding, A.J., and Orcutt, J.A., 1990. A comparison of tau-p transform methods, Geophysics, v. 55, 1202-1215.

Kind, R., 1978. The reflectivity method for a buried source. Journal of Geophysics, 44, 603-612.

Mikumo, T., and Miyatake, T., 1987, Numerical modeling of realistic fault rupture processes, in; Seismic strong motion synthetics, B.A. Bolt, ed., Academic Press, New York, 328 pp.

Mikumo, T., and Miyatake, T., 1993. Dynamic rupture processes on a dipping fault, and estimates of stress drop and strength excess from the results of waveform inversion, Geophysical Journal International, v. 112, 481-496.

Li, Y.G., 1995. Shear-wave splitting observations and implications in the Los Angeles Basin and adjacent areas, California, Seismological Research Letters, 66. 39.

O'Connell, D.R., and Ake, J.P., 1995, Ground motion analysis for Hoover dam, U.S. Bureau of Reclamation Seismotectonic Report 94-1, $114 \mathrm{pp}$

O'Connell, D.R., Ake, J.P., and Block. L., 1995, Ground motion analysis for Bradbury dam, U.S. Bureau of Reclamation Seismotectonic Report 94-5, 126 pp.

Olsen, K.B., and Archuleta, R.J., in press, 3-D simulation of earthquakes on the Los Angeles fault system, Bulletin of the Seismological Society of America.

Sadigh, K.. Abrahamson, C.Y., Chiou, S.J., and Power. M.S., 1993, Specification of longperiod ground motions: Updated attenuation relationships for rock site conditions and adjustment factors for near-fault effects, Proceedings of ATC-17-1 Seminar on Seismic 1solation. Passive Energy Dissipation, and Active Control. vol. I, San Francisco, California.

Somerville. P.G., 1993, Engineering applications of strong motion simulation: Tectonophysics, $218,195-219$.

Spudich, P.. and Frazer, L.N., 1984. Use of ray theory to calculate high-frequency radiation from earthquake sources having spatially variable rupture velocity and stress drop, Bulletin of the Seismological Society of America, 74, 20612082.

Spudich, P., and Frazer, L.N., 1987. Errata for "Use of ray theory to calculate high-frequency radiation from earthquake sources having spatially variable rupture velocity and stress drop", Bulletin of the Seismological Society of America, 77. 2245.

Spudich, P., and Archuleta, R.J., 1987. Techniques for earthquake ground-motion calculation with applications to source parameterization to finite faults, in; Seismic strong motion synthetics. B.A. Bolt, ed., Academic Press, New York, 328 pp.

Wald. D.I.. Heaton, T.H, and Hudnut, K.W., 1996. The slip history of the 1994 Northridge, California, earthquake determined from strongmotion, teleseismic, GPS, and leveling data, Bulletin of the Seismological Society America, v. 86 no.1B. pp. S49-S70

Zeng, Y, and Anderson, J.G., 1995. A composite source modeling of the 1994 Northridge earthquake using genetic algorithm, Seismological Research Letters, 66, 52. 


$$
\dot{U}=\sum_{i j}^{n m} \dot{S}_{i j} \otimes G_{i j}
$$
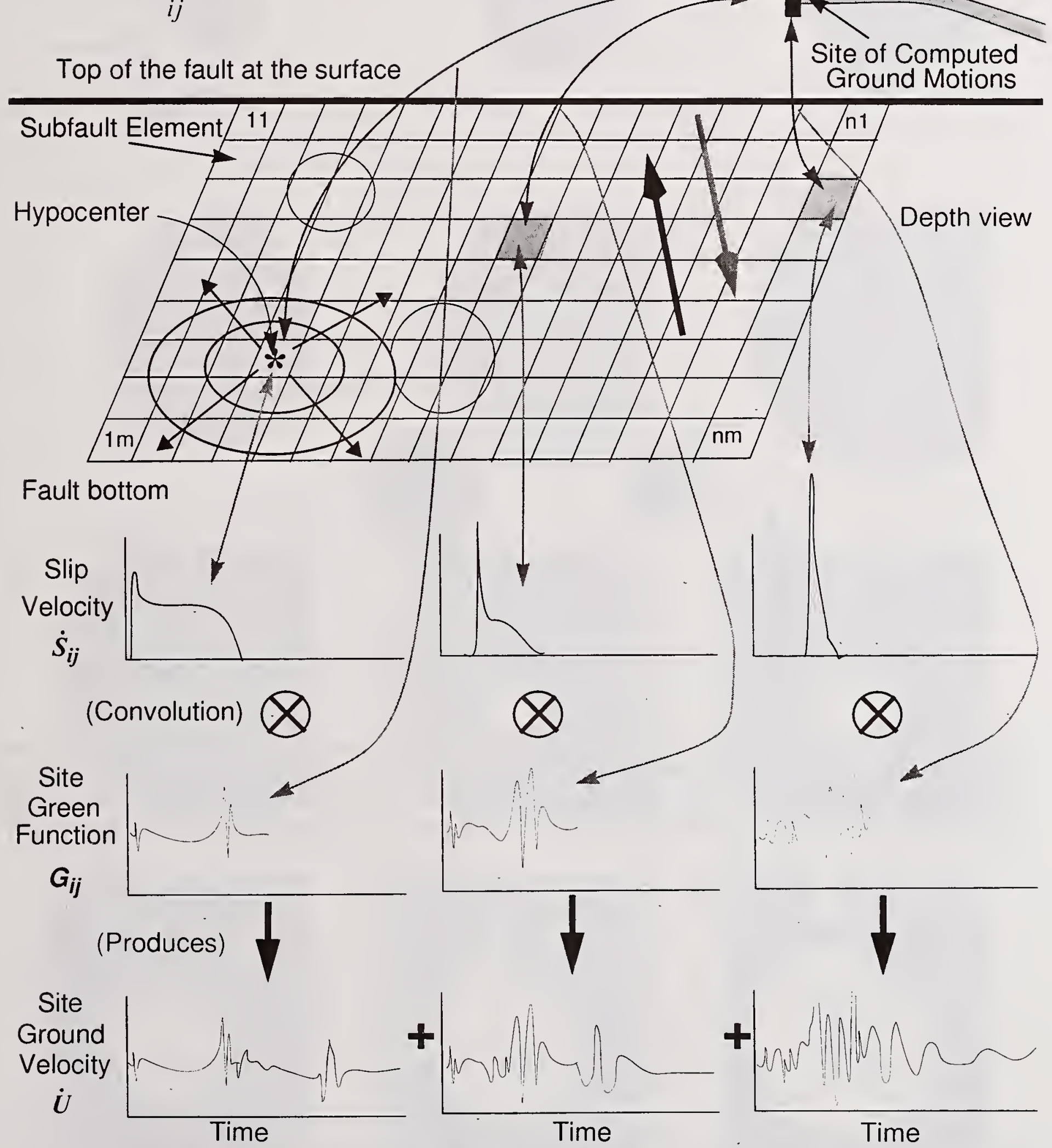

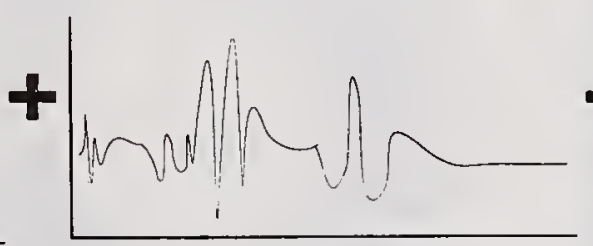

Time

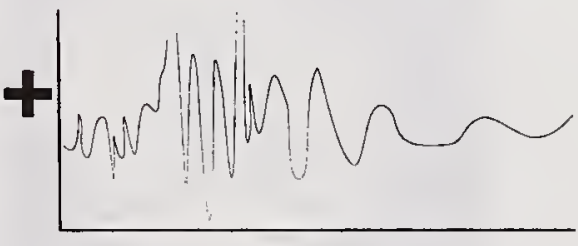

Time

Figure 1. Schematic diagram of finite fault rupture calculation of ground motions. Three discrete subfault elements in the summation are shown. Rings and arrows emanating from the hypocenter represent the time evolution of the rupture. The Green functions actually consist of eight components of ground motion and three components of site ground velocities are calculated. Large arrows denote fault slip orientation which is shown as predominantly reverse slip with a small component of right-lateral strike slip. 


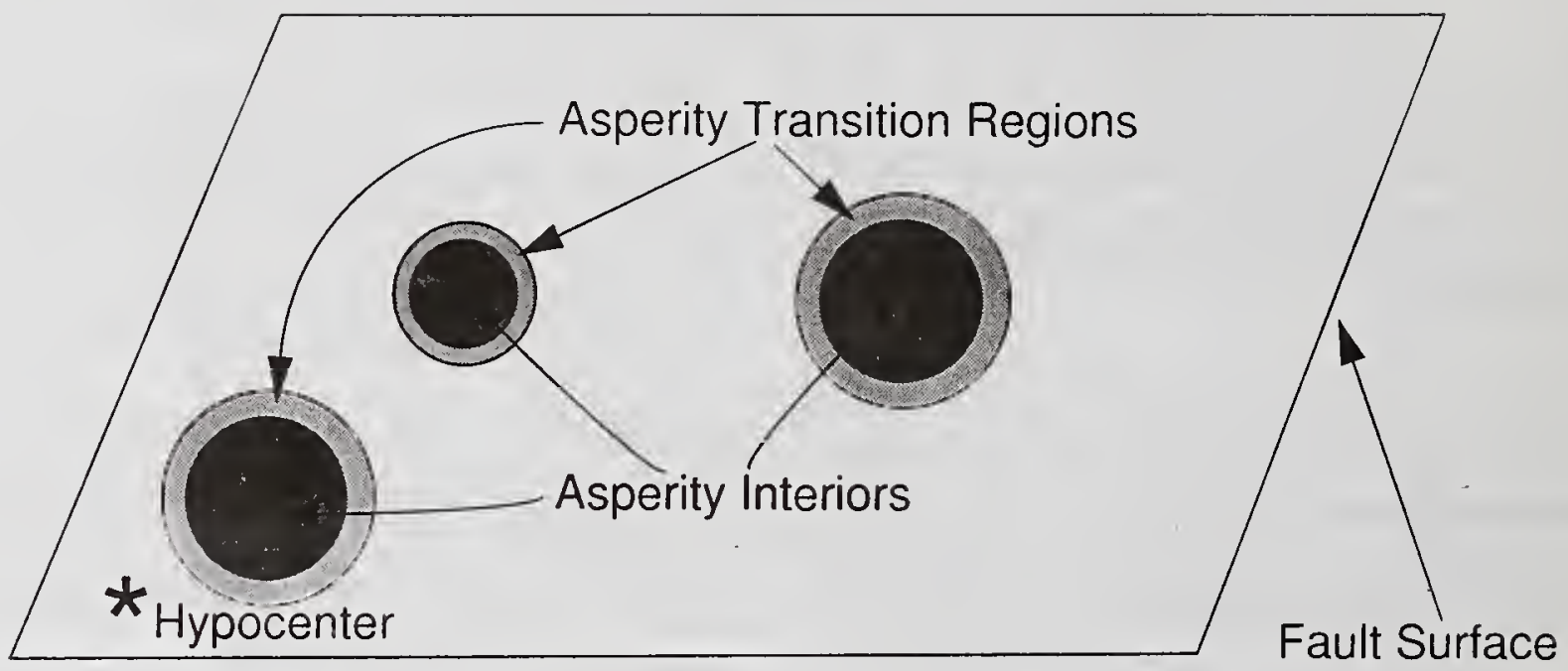

Figure 2. Schematic representation of asperities on a fault. The darkest regions are asperity interiors with high effective stresses, the lighter regions are asperity transitions regions over which effective stresses smoothly decrease from the values in the asperity interiors to background effective stresses. The unshaded portion of the fault is the background region of lower effective stresses. The hypocenter is shown as a star. 

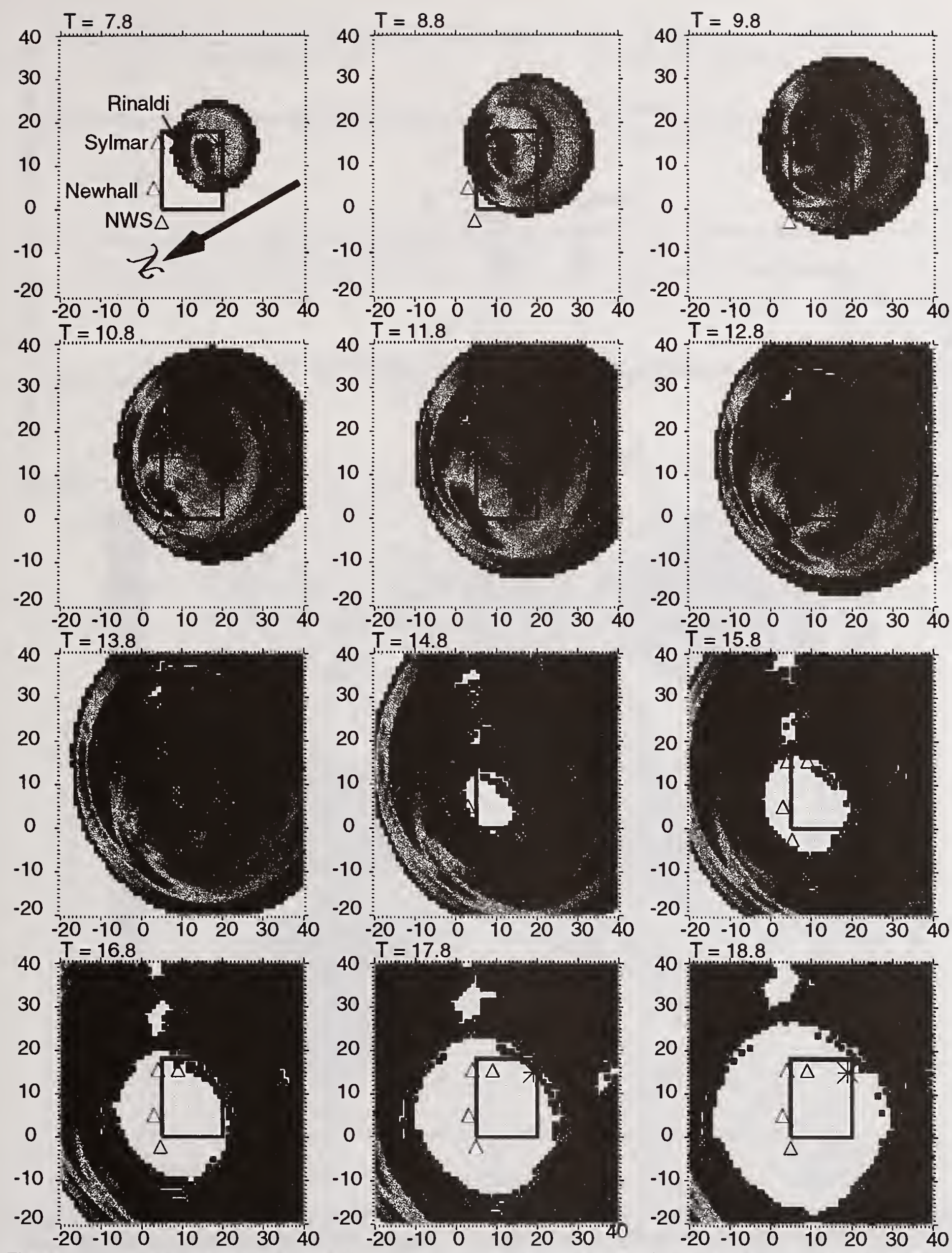

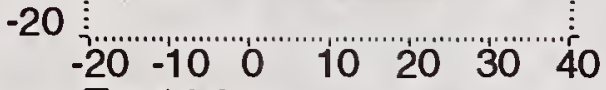
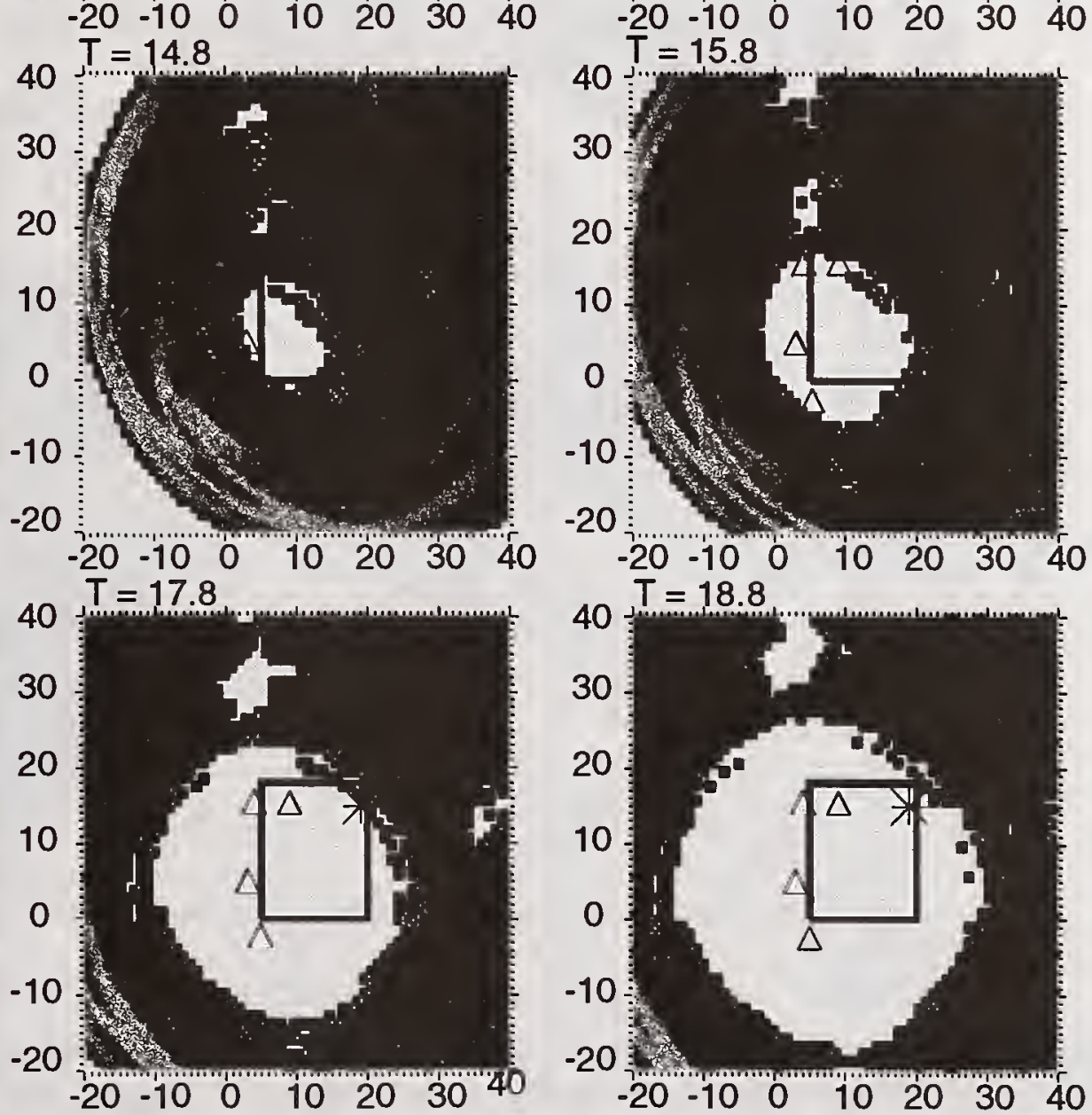

Figure 3. Contours of simulated peak horizontal velocity at $1 \mathrm{~s}$ intervals (maximum is magenta) in fault coordinate map view. Position $(0,0)$ is the updip projection of the northwest corner of the Northridge fault to the surface, the rectangle is the map view of the fault plane, the epicenter is the star, time from initiation of rupture is shown above each upper left corner, and stations are triangles labeled in the first frame. 


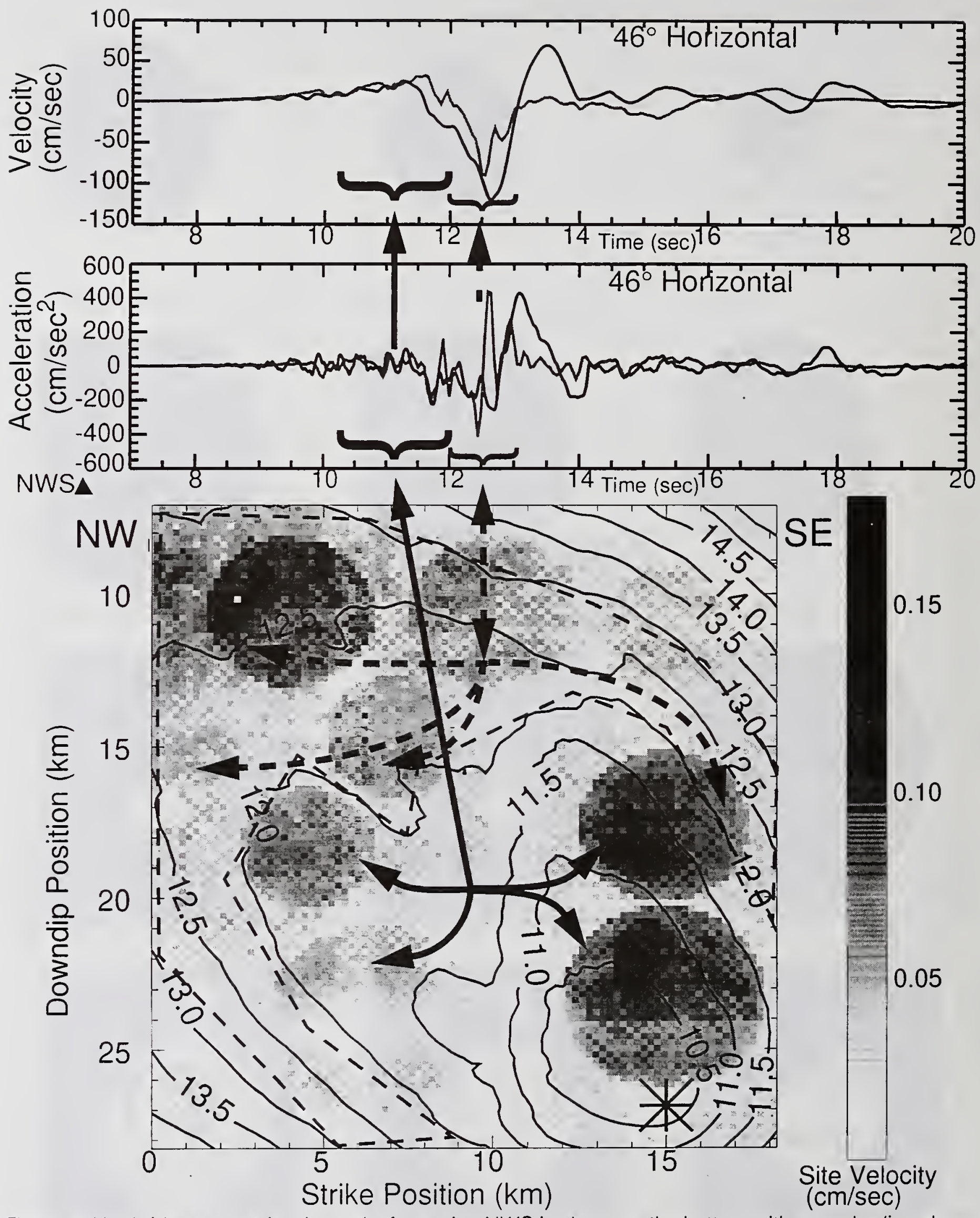

Figure 4. Northridge rupture isochron plot for station NWS is shown at the bottom with gray shading showing the site velocity contribution from each fault element. Observed (black) and synthetic (gray) $46^{\circ}$ horizontal velocity (top) and acceleration (middle) records are shown with the solid arrows from the isochron plot showing the arrivals produced on the eastern end of the fault prior to 12.0 s and dashed arrows showing the contribution from the dashed line region between $12 \mathrm{~s}$ and $13 \mathrm{~s}$ that produce the largest peak amplitudes. Hypocenter position is shown as the star. The position of NWS is shown as the filled triangle. 

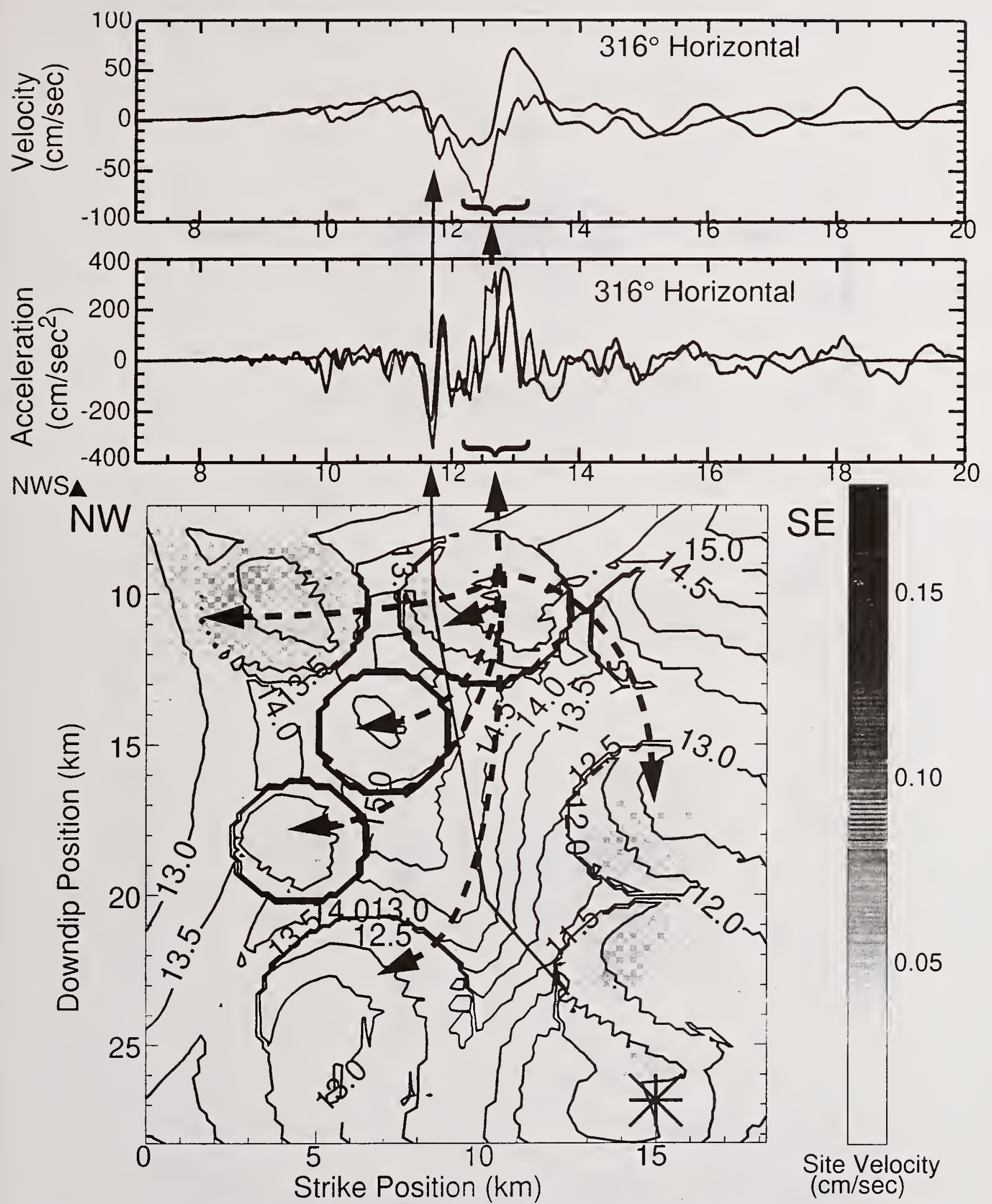

Figure 5. Same as Fig. 4-9, except healing isochrons for station NWS are shown at the bottom and the $316^{\circ}$ horizontal velocity (top) and acceleration (middle) are shown. The same velocity scale is used to emphasize that healing contributions from the fault to site velocity are much.smaller than from rupture. The solid arrow shows the healing between $11.5 \mathrm{~s}$ and $12 \mathrm{~s}$ from the asperity near the hypocenter and the dashed arrows shown that healing phases between $12 \mathrm{~s}$ and $13.5 \mathrm{~s}$ come from six asperities located in quite distinct portions of the fault. 

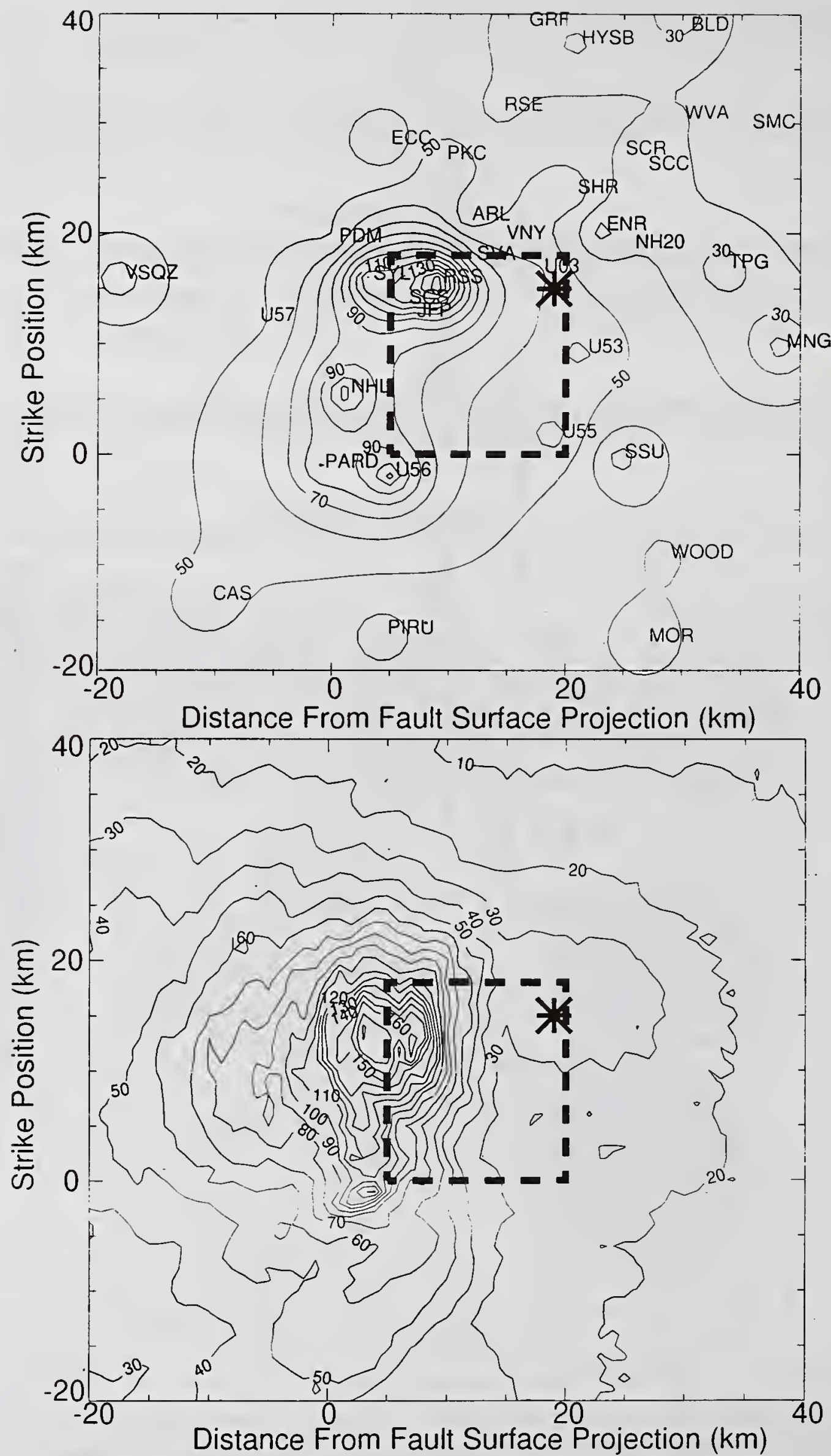

Figure 6. Contours of observed Northridge peak velocities in $\mathrm{cm} / \mathrm{sec}$ (top) and isochron predicted peak velocities (bottom) for a $60 \times 60 \mathrm{~km}^{2}$ area. The surface projection of the Northridge fault plane (Wald and others, 1996) is shown as the dashed rectangle and the epicenter is the star. Station names indicate positions of observed values. 

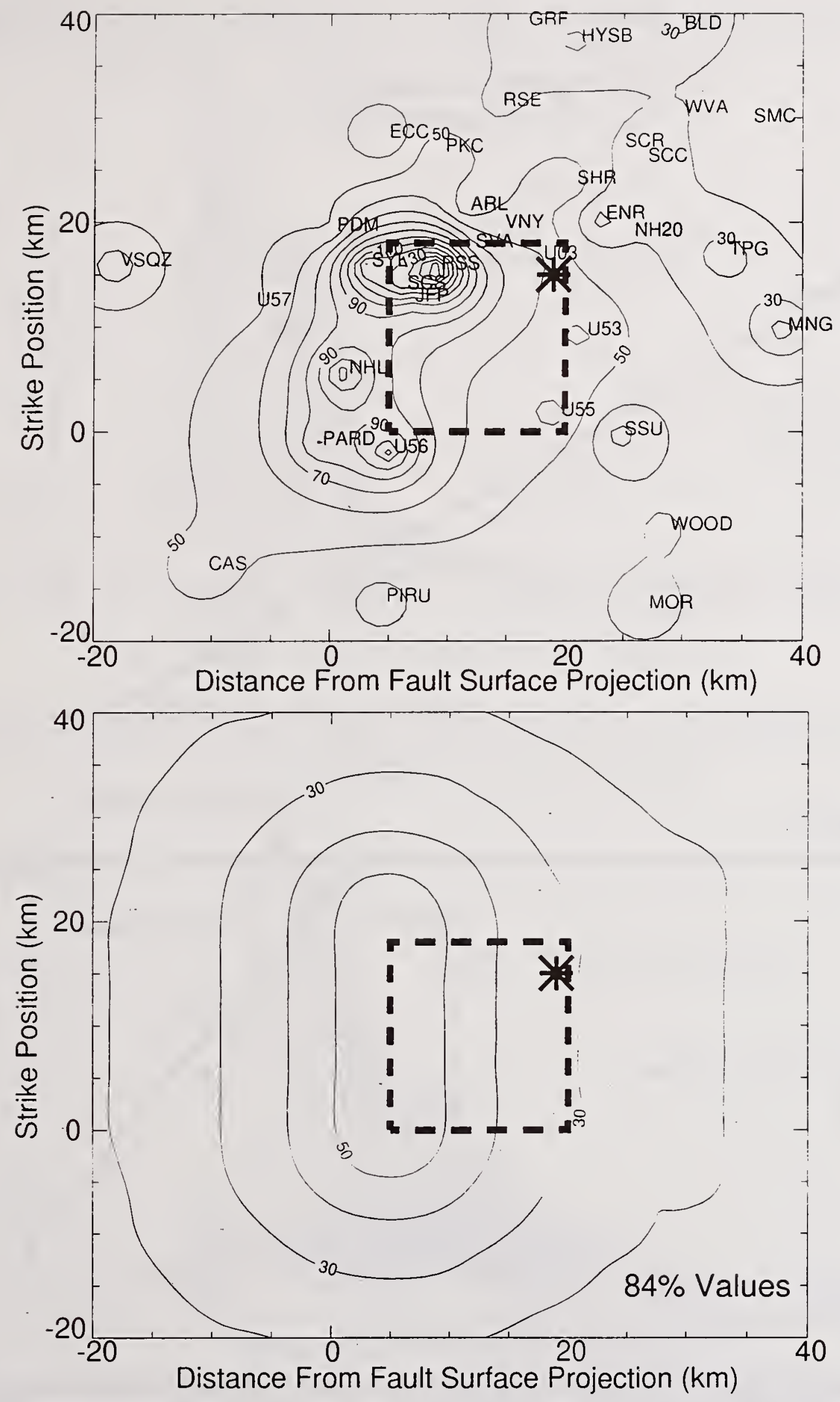

Figure 7. Contours of observed Northridge peak velocities in $\mathrm{cm} / \mathrm{sec}$ (top) and emperical prediction peak velocities (bottom, from Campbell (1990)) for a $60 \times 60 \mathrm{~km}^{2}$ area. The surface projection of the Northridge fault plane (Wald and others, 1996) is shown as the dashed rectangle and the epicenter is the star. Station names indicate positions of observed values. 


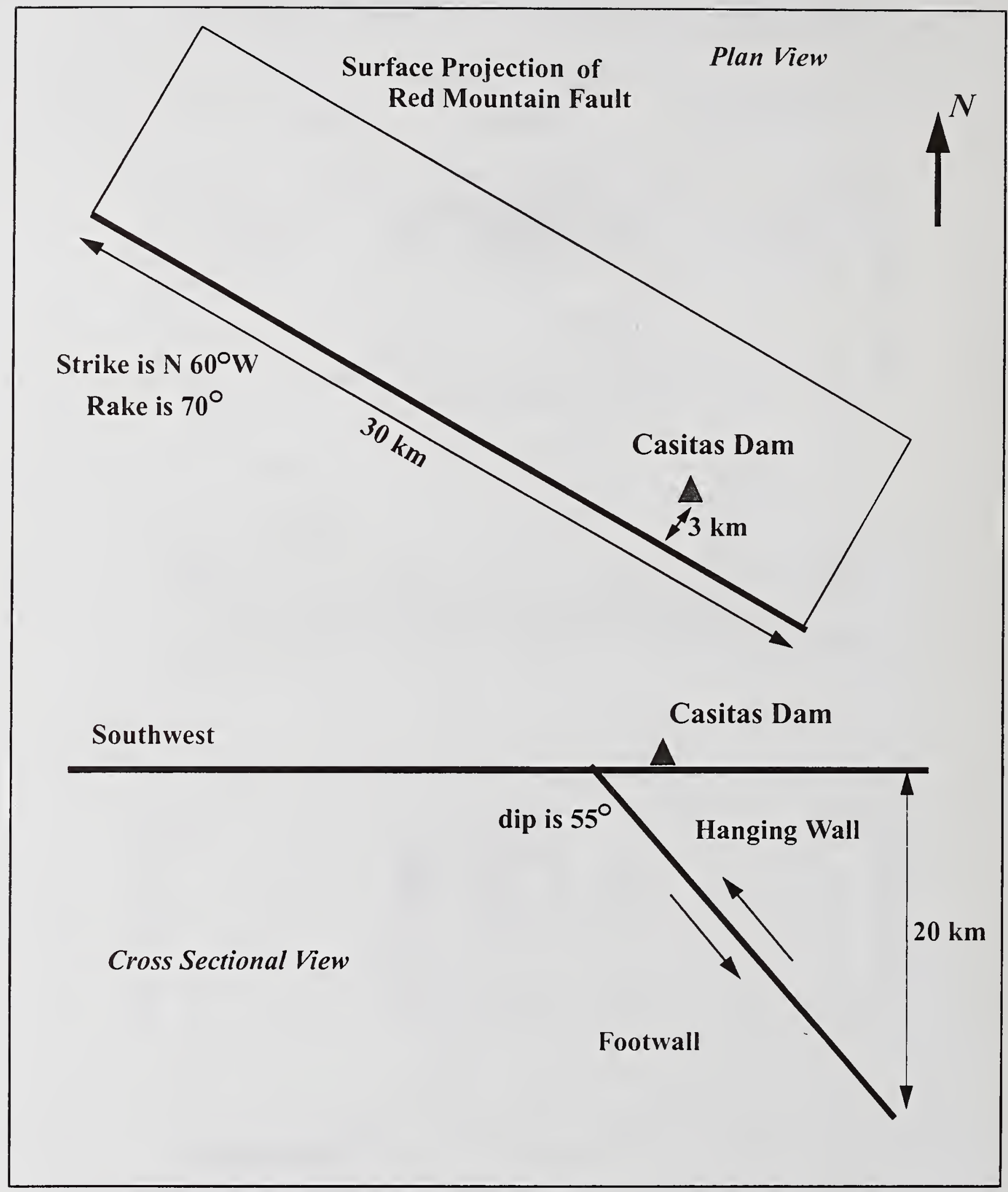

Figure 8. Schematic illustration of relationship between site of interest for ground motion computations (indicated by solid, dark triangle) and Red Mountain fault. Estimated magnitude of Red Mountain fault, $M_{w}$ 6.9 , based on average values suggested by rupture length and rupture area relations. Seismogenic depth and dip of fault based on geologic information and microseismicity. 


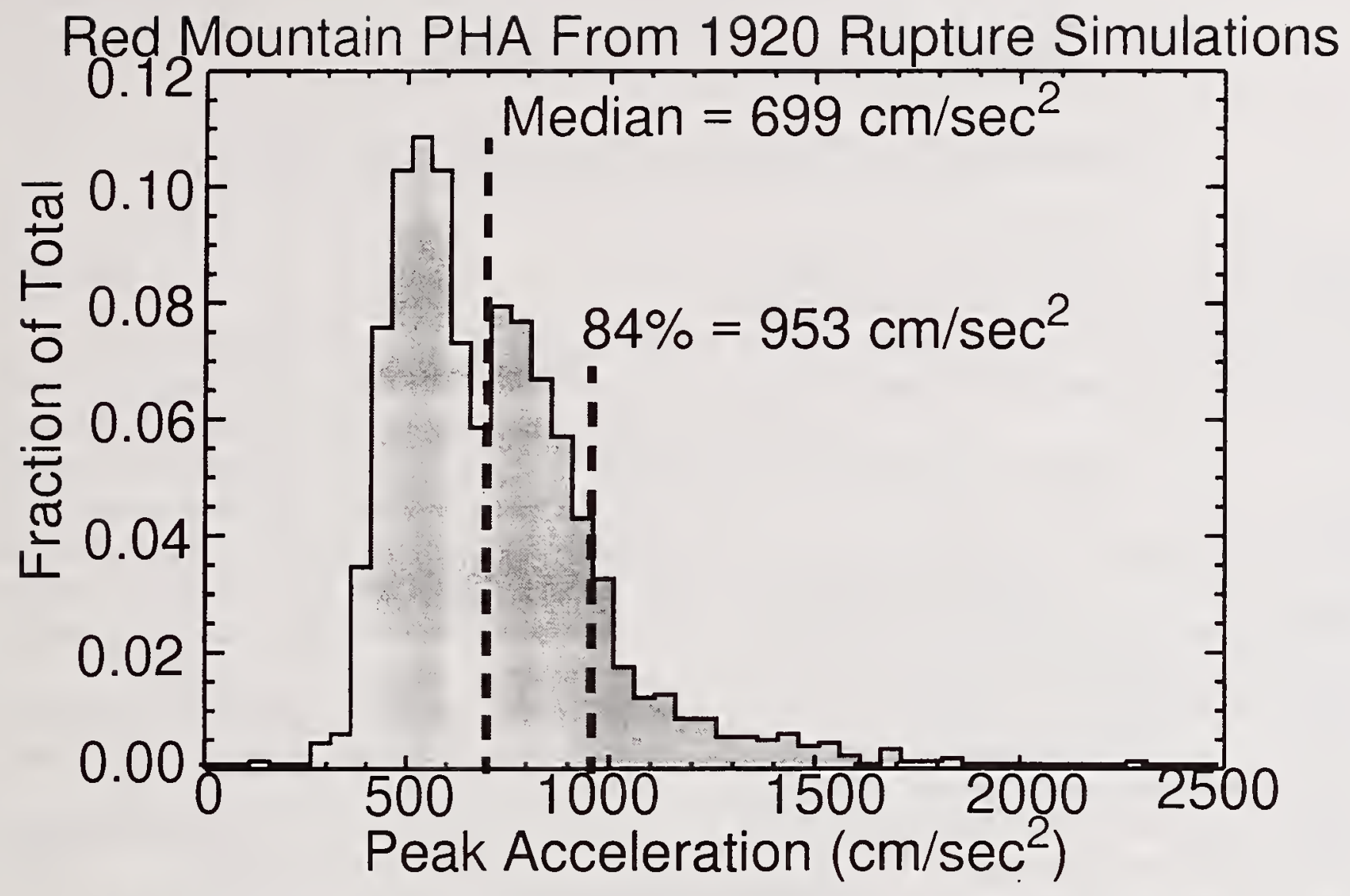

Red Mountain PHV From 1920 Rupture Simulations

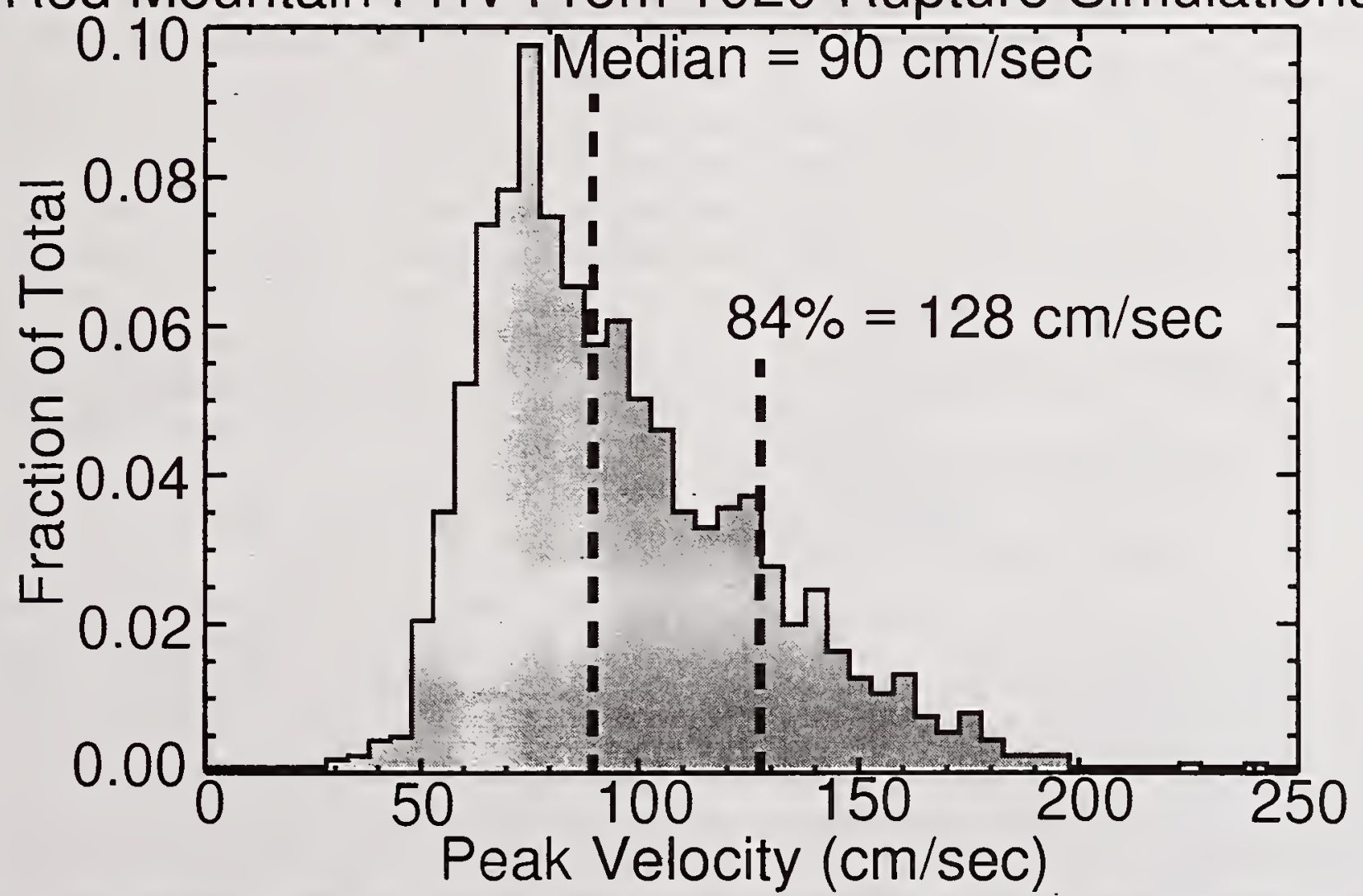

Figure 9. Histograms of peak horizontal acceleration (top) and peak horizontal velocity from 1920 simulations of the Red Mountain fault using the FATT-VSDASP-RRH rupture model. Ten strike positions and eight hypocentral depths were used. A total of 24 rupture simulations were calculated for each position (eight asperity models times three travel-time randomizations) to produce the 1920 simulations. 

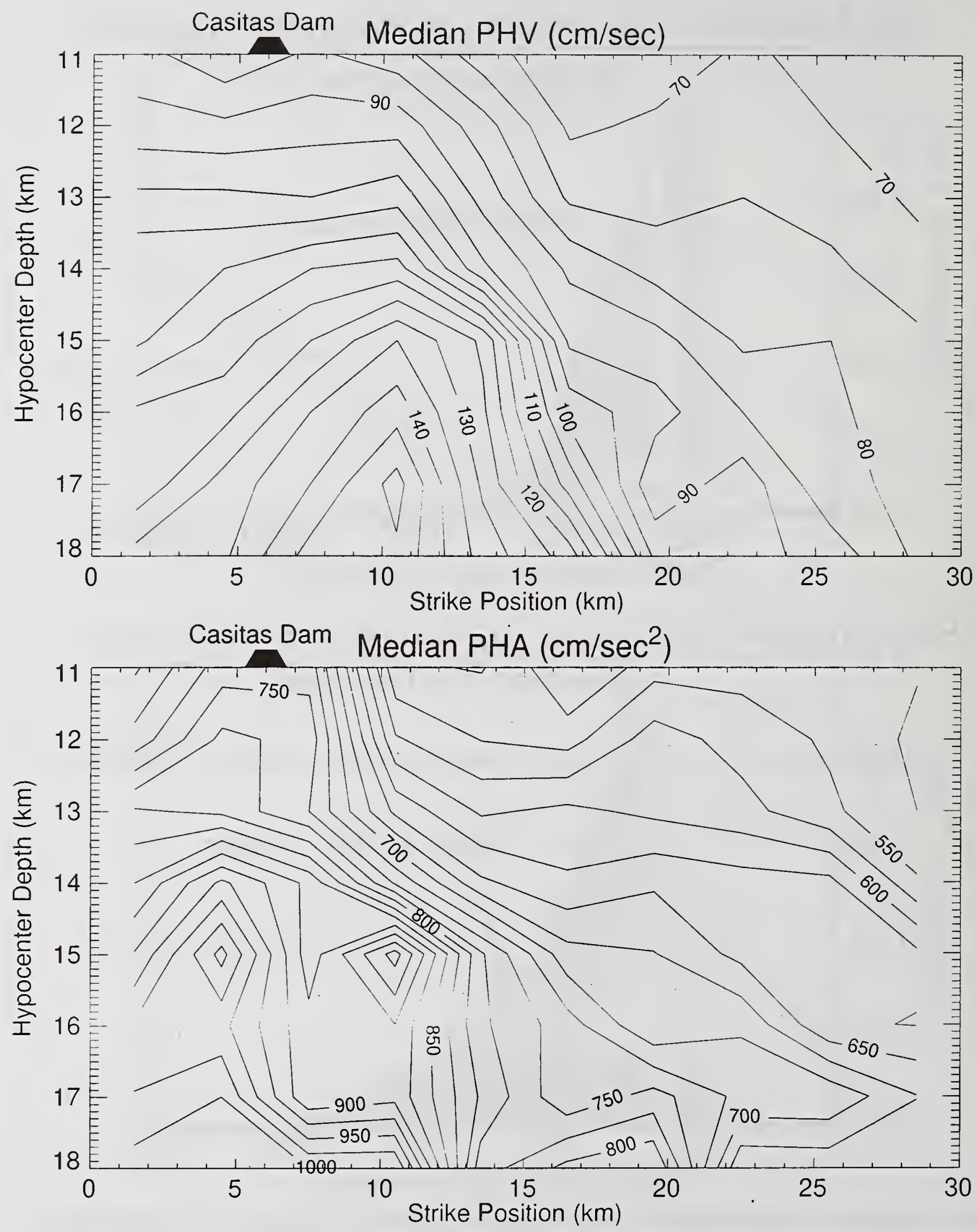

Figure 10. Contours of median peak horizontal velocities (top) and horizontal accelerations (bottom) as a function of hypocenteral depth and strike position for 1920 rupture simulaitons of the Red Mountain fault. Ten strike positions and eight hypocentral depths were used. A total of 24 rupture simulations were calculated for each position (eight asperity models times three travel-time randomizations). 


\title{
Damage to Port Facilities of KOBE Port by The 1995 Hyogo-Ken Nanbu Earthquake and Their Reconstruction
}

by

\author{
Tatsuo Uwabe*,Ken Oikawa**, Tatsuo Wako*** and Takahiro Sugano****
}

\section{ABSTRACT}

Port facilities of Kobe port were seriously damaged by the 1995 Hyogo-Ken Nanbu Earthquake, particularly for gravity type quaywalls except earthquake-proof ones at Maya wharf. Immediately after earthquake, reconstruction plan to recover the function of Kobe port within 2 years was decided based on 1) to achieve quick recover the function of port function and 2)reconstruction with consideration on future function.

KEYWORDS: Earthquake damage; Port facilities; Reconstruction; Earthquake ground motion

\section{INTRODUCTION}

The 1995 Hyogo-Ken Nanbu earthquake which took place early in the morning on January 17,1995 brought tremendous damage to port facilities of Kobe port, a representative international trading port in Japan, and gave a severe effect to economical activity both in Japan and Asia. Immediately after the earthquake, Ministry of Transport and Kobe city (port management body) carried out a survey to evaluate the damages and prepared are construction plan. Total damage of port facilities estimated 550 billion yen.

This paper describes earthquake ground motion, damage to port and their reconstruction.

\section{EARTHQUAKE GROUND MOTION}

The 1995 Hyogo-Ken Nanbu Earthquake of M7.2, which hypocenter is located at the northern part of Awajishima Island, is the right-under type one caused by movement of a active fault which runs below Awajishima Island and Kobe as shown Fig. 1 with seismic intensities recorded in Osaka Bay area. Earthquake motion measured by SMACB2 type accelerograph placed on the ground surface at Kobe Port Construction Office is shown in Fig.2. The maximum acceleration for the horizontal direction is 502 $\mathrm{cm} / \mathrm{s}^{2}\left(\mathrm{~N} 45 \mathrm{~W}\right.$ component) and $283 \mathrm{~cm} / \mathrm{s}^{2}$ (UD component) for the vertical one. Motion of this earthquake is characterized by 1) its relative short duration of main shock of 5 to 10 seconds, 2) horizontal motion being predominant to north-south direction.

\section{OUTLINE OF KOBE PORT}

Kobe port, one of the major ports in Japan together with Yokohama port has been

developed since beginning of 20th century. Shin-ko piers No. 1 to No. 6, Hyogo pier and central pier has already been developed before the world war II. These facilities which were seriously damaged by the war were immediately restored, Shin-ko piers No.7 and No.8 and Maya wharf were newly developed after the war. Construction of Port-Island, first large scaled man-made island in Japan, was started from 1966 and completed in 1981 followed by reclamation of Rokkou-Island. which was completed in 1990. Twenty one container berths which are mostly located at two man-made islands were under operations in Kobe port. Annual amounts of containers at Kobe port reaches $2,700,000$ container, which is about $30 \%$ of the total amount of Japan, and keeps No.1 position in Japan. Fig.3 shows plain view of Kobe port.

\section{DAMAGE TO PORT FACILITIES}

Damage to port facilities which are quaywall, breakwater and reclaimed

land are outlined in the followings.

*Chief of Earthquake Disaster Prevention Laboratory, Port and Harbour Research Institute, Ministry of Transport, Nagase 3-1-1, Yokosuka, Japan 239

**The 3rd District Port Construction Bureau, MOT, Onohamacho 7-30,Chuo-ku, Kobe, Japan 651

*** Head of Geotechnical Engineering Division, PHRI, MOT( Former The 3rd District Port Construction Bureau) ****Chief of Structural dynamics laboratory, PHRI, MOT 
(1)Quaywall

Structures of quaywalls at Kobe port are mostly gravity type such as concrete caisson and block with a few steel structure jetties. Design of these structures in Japan is carried out under the "Technical Standards for Port and

Harbour Facilities 1)". Seismic design is generally conducted by seismic coefficient method and seismic coefficient is determined by regional earthquake activity, ground condition and importance of the structures. Clear differences were observed in damage according to seismic coefficient adopted in design and direction of face line.

Quaywalls designed for small seismic coefficient of 0.15 to 0.18 were mostly damaged seriously while earthquakeproof berths with 0.25 at Maya wharf shown in Fig.4 were not subjected to any significant damage. It was also observed that the damage of the quaywalls directed to eastwest is larger than that directed to north-south.

Gravity type quaywalls slid to offshore side reaching $1 \mathrm{~m}$ to $5 \mathrm{~m}$ and subsided $1 \mathrm{~m}$ to $2 \mathrm{~m}$ subsidence of $3 \mathrm{~m} \sim 4 \mathrm{~m}$ at the back site due to lateral deformation of the quaywall as indicated in Fig.5. Buckling and de-railing caused by crotch-tear generated by sliding of the quaywall 1 were also observed for gantry cranes.

\section{(2)Breakwater}

Damage observed for breakwater were mostly settlement reaching $2 \mathrm{~m}$ in maximum.

Differential displacement and settlement were rather small.

\section{(3)Reclaimed land}

Liquefaction took place at most and limited parts of PortIsland and Rokkou-Island, respectively, which were reclaimed by well graded Masa soil, de-composed granite, of which gradation curve is shown in Fig. 6 together with poorly graded sands with high liquefaction potential used for reclamation in other areas. Though catastrophic failure observed for structures in Niigata earthquake did not take place, settlement reaching $0.5 \mathrm{~m}$ in maximum was entirely observed and trafficability was seriously damaged by liquefied sand covering the ground surface.

\section{RECONSTRUCTION OF KOBE PORT}

\section{(1) Fundamental approach}

In order to recover the function of Kobe port as the hubport in Asia together with

taking into its future function for 21 th century, it was determined that the reconstruction should be done with considerations on l)quick recovery of port function, 2) increase of eanhquake-proof,3) cooperation with reconstruction of city area and 4) reconstruction as the international hub-port.

1) Quick recovery of port function

In order to rectuce the effect of damage port function, provisional use as aimed for slightly damaged quaywall which are restored with a slight repairing. For facilities seriously damaged, it was planned to enable their use step by step. It is also important to repair the breakwater function quickly in order to maintain the safety of facilities from storm surge and tide.

2)Increase of earthquake-proof

Earthquake-proof is increased for damaged structures according to their priority. In restoration of quaywall, increase of seismic coefficient and combination of structures with different seismic. response are taken into account also according to the priority of the facilities.

Earthquake-proof quaywall is constructed at various locations among container, ferry and existing wharf. A value of 0.25 is used as the design seismic coefficient for the earthquake - proof quaywalls, considering that Maya quaywall actually resisted the earthquake force without destruction. For ordinary quaywall, the design seismic coefficient is increased from 0.18 to 0.2 .

3) Cooperation with reconstruction of city area.

In order to cooperate with the reconstruction work for city, waste materials in the city are used for reclamation.

4)Reconstruction as the international hub-port

Construction of large scaled container berth together with redevelopment of existing wharf was planned to be progressed in order to satisfy the function as the international hub-port.

(2) Increase of earthquake-proof quaywall

In restoration oft the structures seriously damaged, design for recovery was done based on following three plans,

1) Construction of new quaywall in front of the damaged one.

This design was adopted when the damaged quaywalls can no longer be used as they were originally and removal of displaced structures is impossible. A typical restored cross-section is shown in Fig.7 The gravity caissoncomposite quaywall was changed to piled jetty type quaywall.

2) Reduction of earth pressure of the back site.

This design was adopted when damage is rather small. The existing quaywalls can resist only by reducing the active earth pressure behind them. Cement mixing method or replacement method using blast furnace slag is used to recuce the earth pressure by adding cohesion to the fill 
material behind the revetment. An example of this method is shown in Fig.8.

3) Reconstruction of the quaywall with temporary release of caisson with considerations on degree of damage and locations o structures.

This design was adopted when no space exists in front of them. In case of reconstruction of the gravity caisson, the sliding resistance must be increased, for example, by placing an asphalt mat beneath the caisson. An example of this method is shown in Fig.9.

(3) Schedule for reconstruction works

It was firstly decided to restore the function of Kobe port within 2 years. Among 2l

container berths provisional use of 8 berths was planed to be achieved until end of June, 1995 with temporary repairing as shown in Fig.10. Full-scaled reconstruction was commenced from April,1995 and complete within 2 years. Seven ferry berths and $50 \%$ of other quaywalls were restored until end of December, 1995. Function of important breakwaters was recovered by the end of September, 1995 against the attack of typhoon.

\section{SUMMARY}

Port facilities of Kobe port were seriously damaged by the 1995 Hyogo-Ken Nanbu Earthquake, particularly for gravity type quaywalls except earthquake-proof ones at Maya wharf. Many bridges connecting the city and manmade island were also damaged. Immediately after earthquake, reconstruction plan to recover the function of Kobe port within 2 years was decided based on 1) to achieve quick recover the function of port function and 2)reconstruction with consideration on future function. Full-scaled reconstruction are now under way at the entire area of Kobe port and some of the container berths were already under provisional use.

\section{REFERENCES}

1)Ministry of Transport(ed.):Technical Standards for Port and Harbour Facilities in Japan, new edition, Overseas Coastal Area Development Institute of Japan,1991

2)Wako,T. : Damage to port facilities of Kobe Port by the 1995 Hyogoken-Nanbu earthquake and their reconstruction plan, Proc. Int. Symp. on Coastal Ocean Space Utilization, 1995

3)Kamon,T., T. Wako, K. Isemura, K. Sawa, M. Mimura, K. Tateyama and S. Kobayashi : Geotechnical Disasters on the waterfront,Soils and Foundations,
Special Issue on Geotechnical Aspects of the January 17 1995 Hyogoken-Nanbu Earthquake, 1996

4)Wako, T. , K. Oikawa, Y. Matunaga and E. Naruse : Damage to Kobe Port Facilities by the Hyogoken-nanbu Earthquake and their Reconstruction, Tsuchi-to-Kiso, The Japanese Geotechnical Society, Vol.44,No.3,1996 
UN IT: $\mathrm{ca} / \mathrm{s}^{2}$

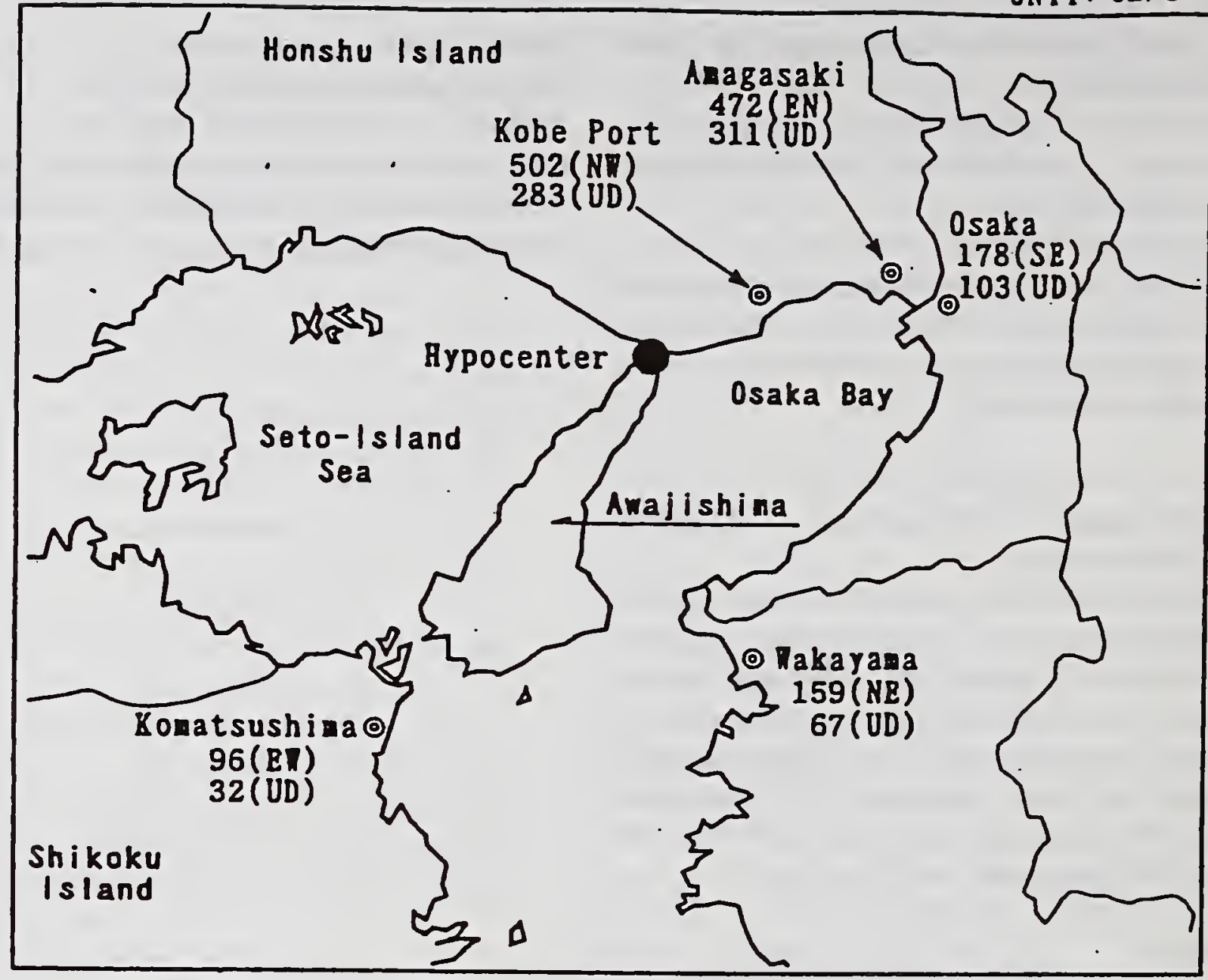

Fig. 1 Location of hypocenter and seismic intensities recorded in Osaka Bay area

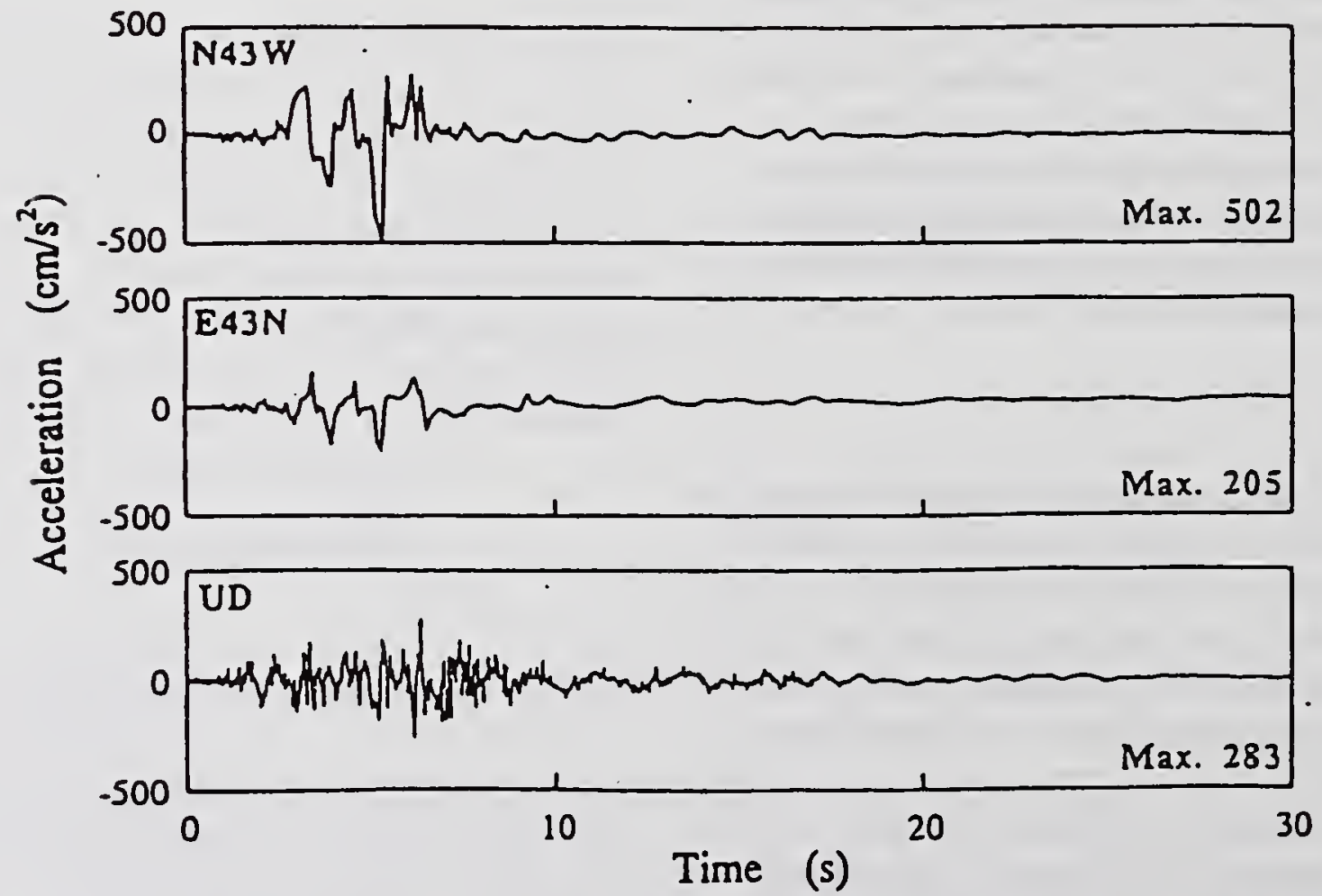

Fig. 2 Strong-motion acceleration measured on ground surface at Kobe Port Construction Office 


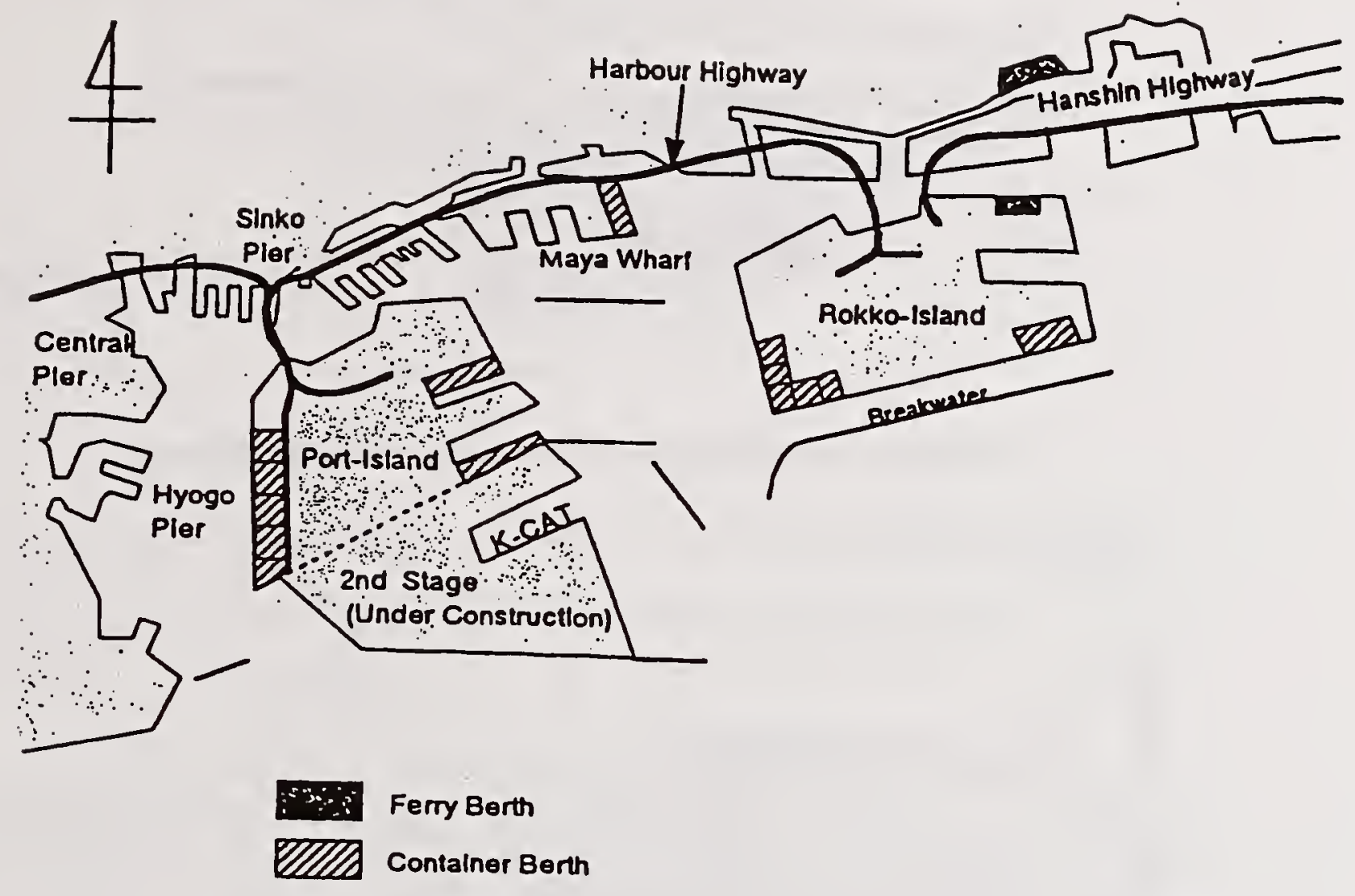

Fig. 3 Plain view of Kobe Port

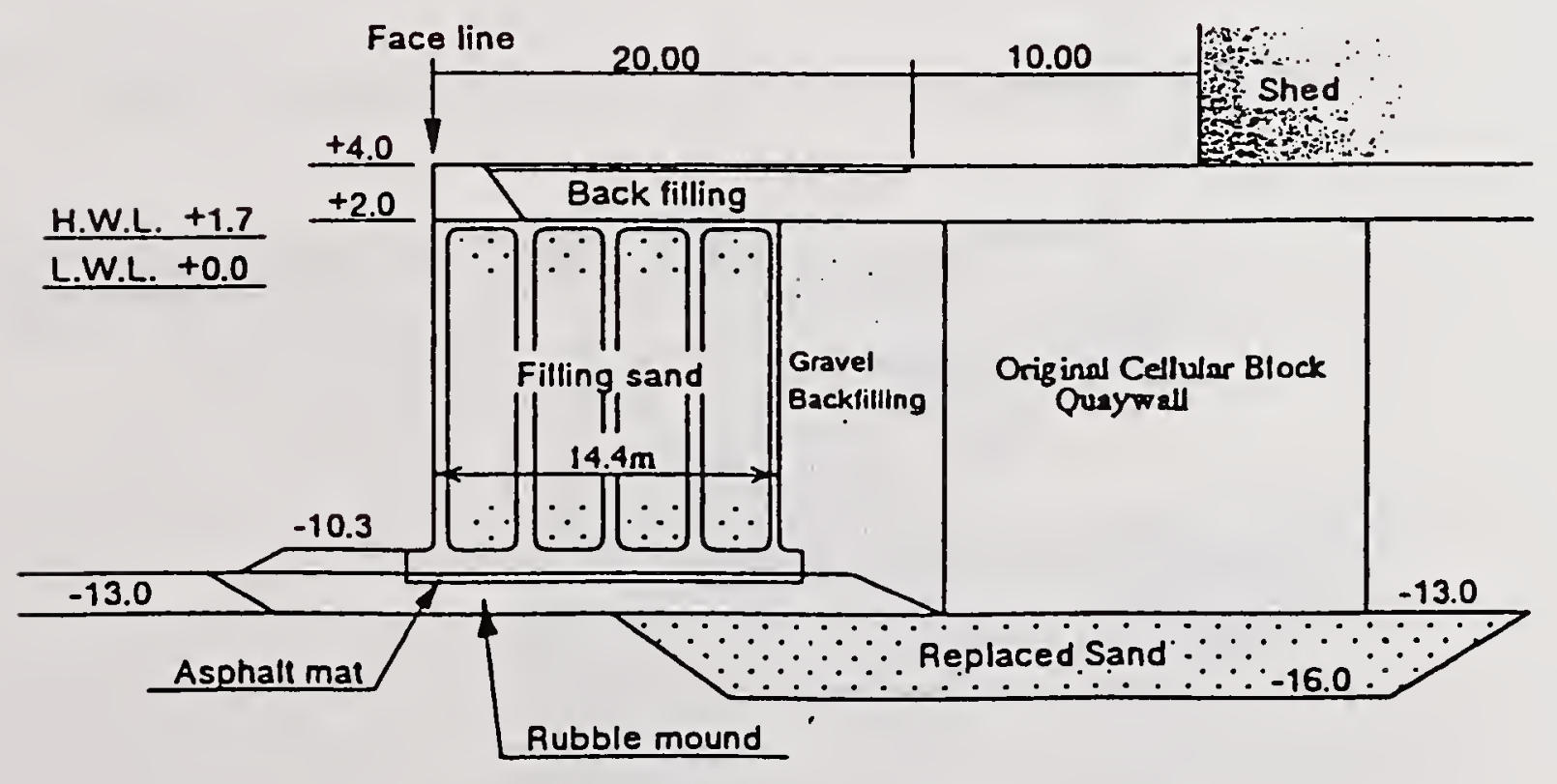

Fig. 4 Earthquake-proof quaywall at Maya wharf 


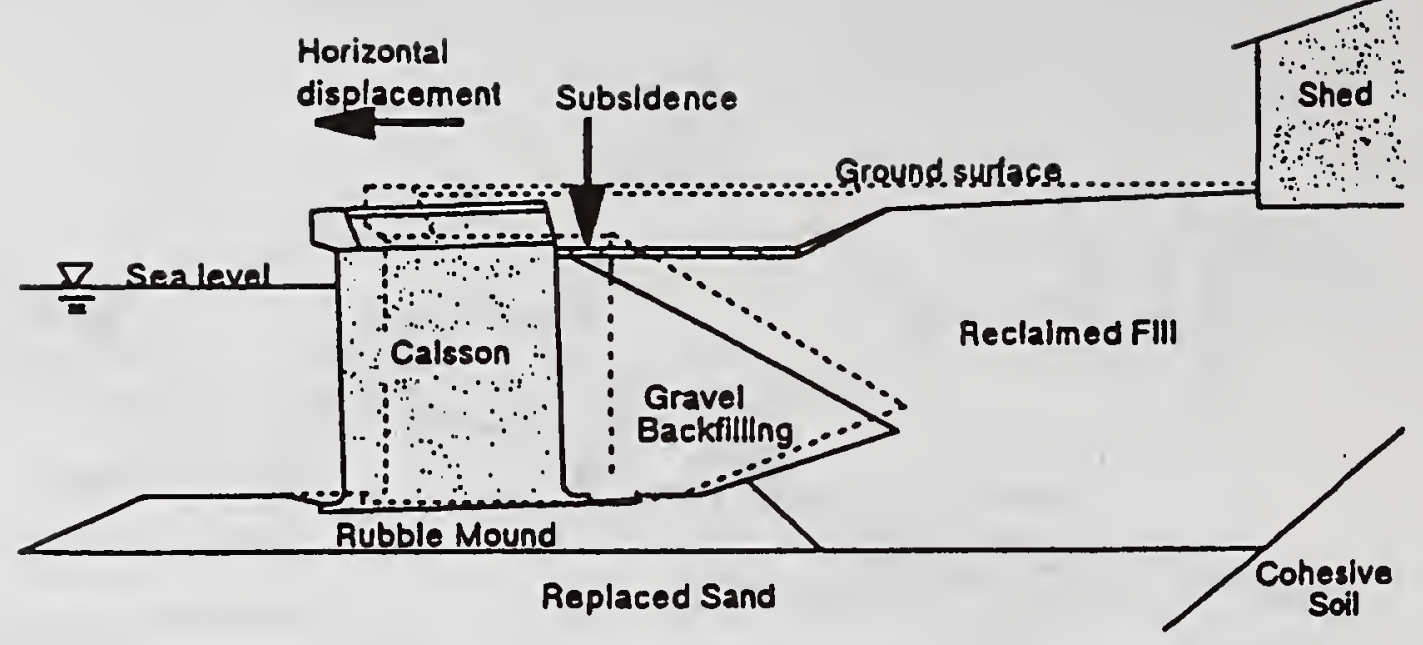

Fig. 5 Typical damage observed for gravity type quaywall

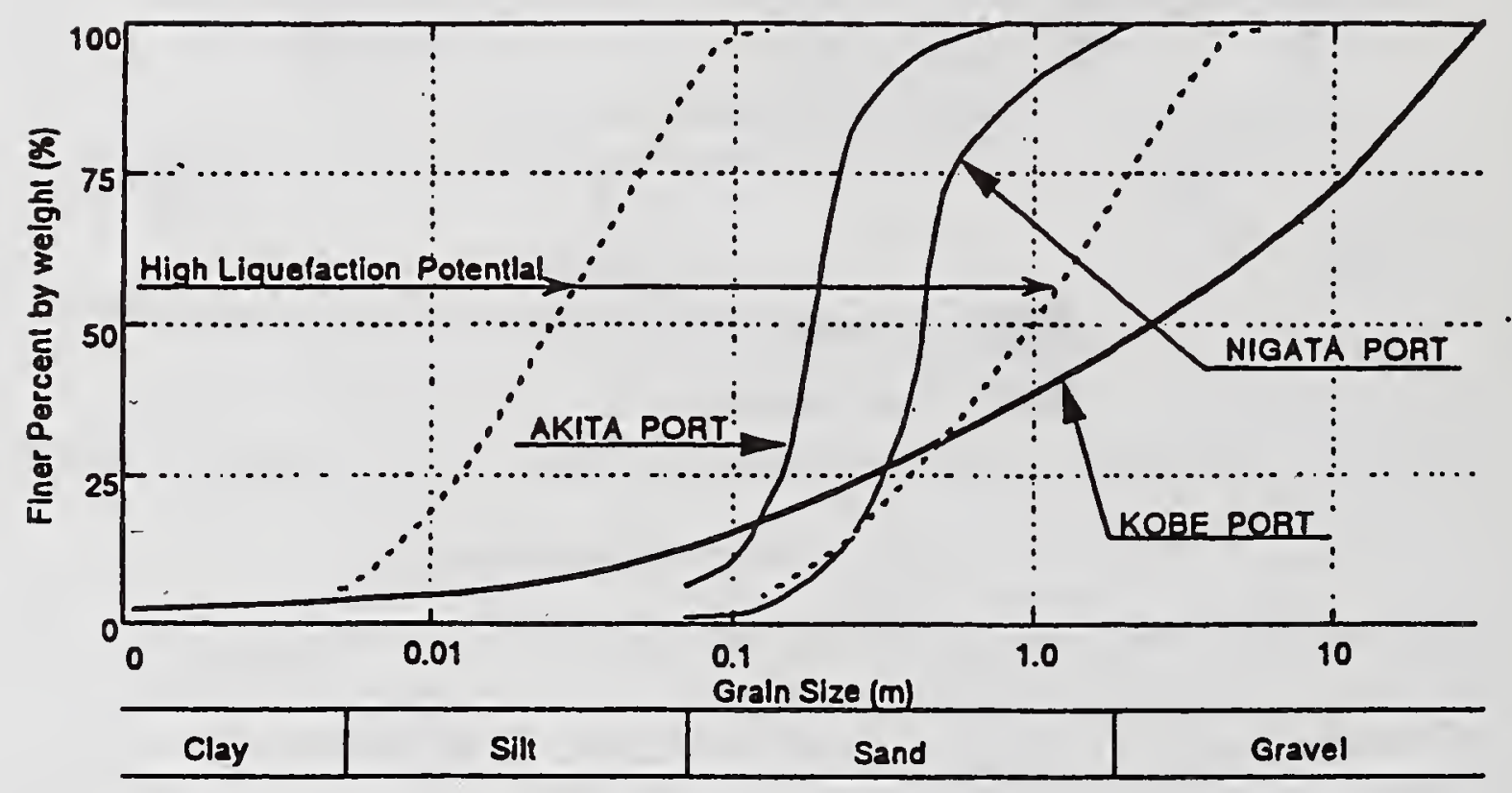

Fig. 6 Gradation curve of Masa soil used for reclamation in Kobe

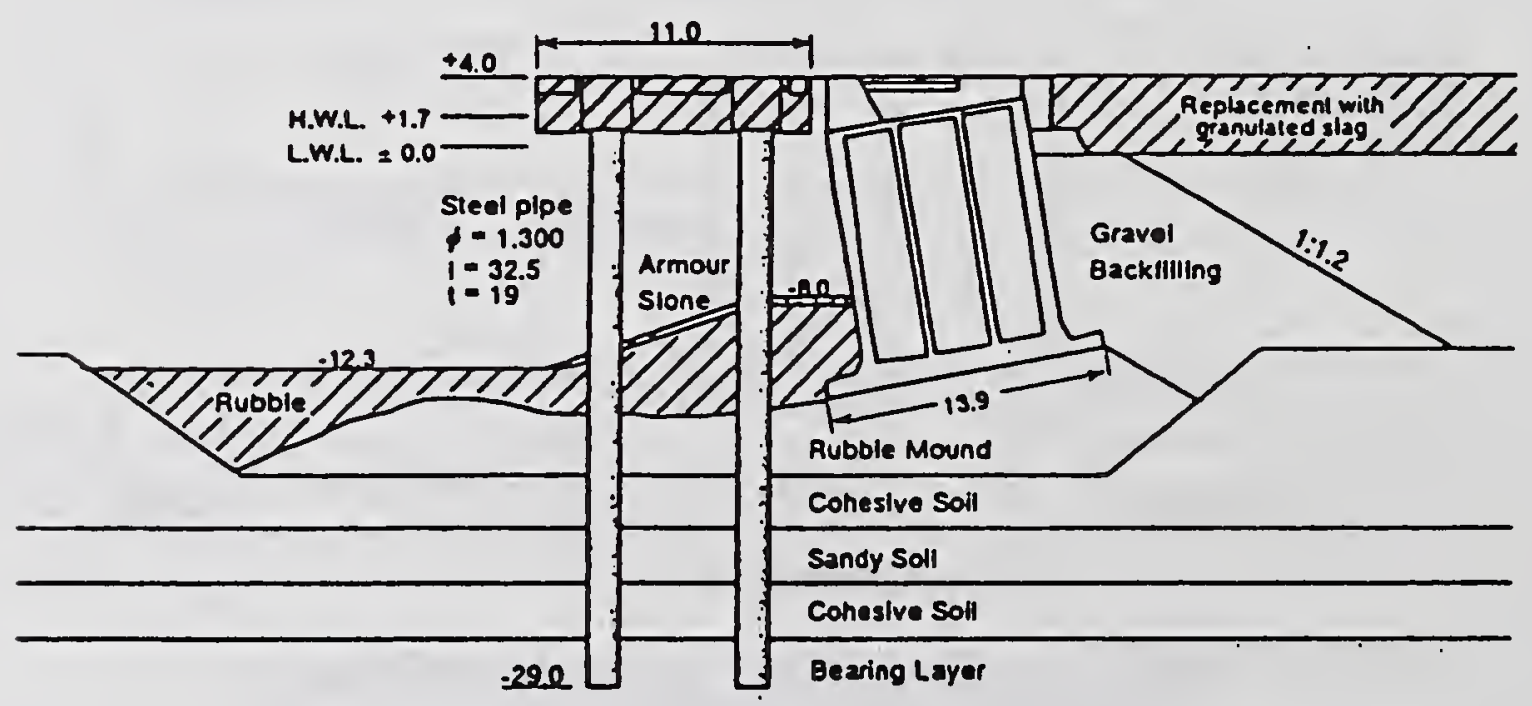

Fig. 7 Restoration of quaywall in front of the damaged one 


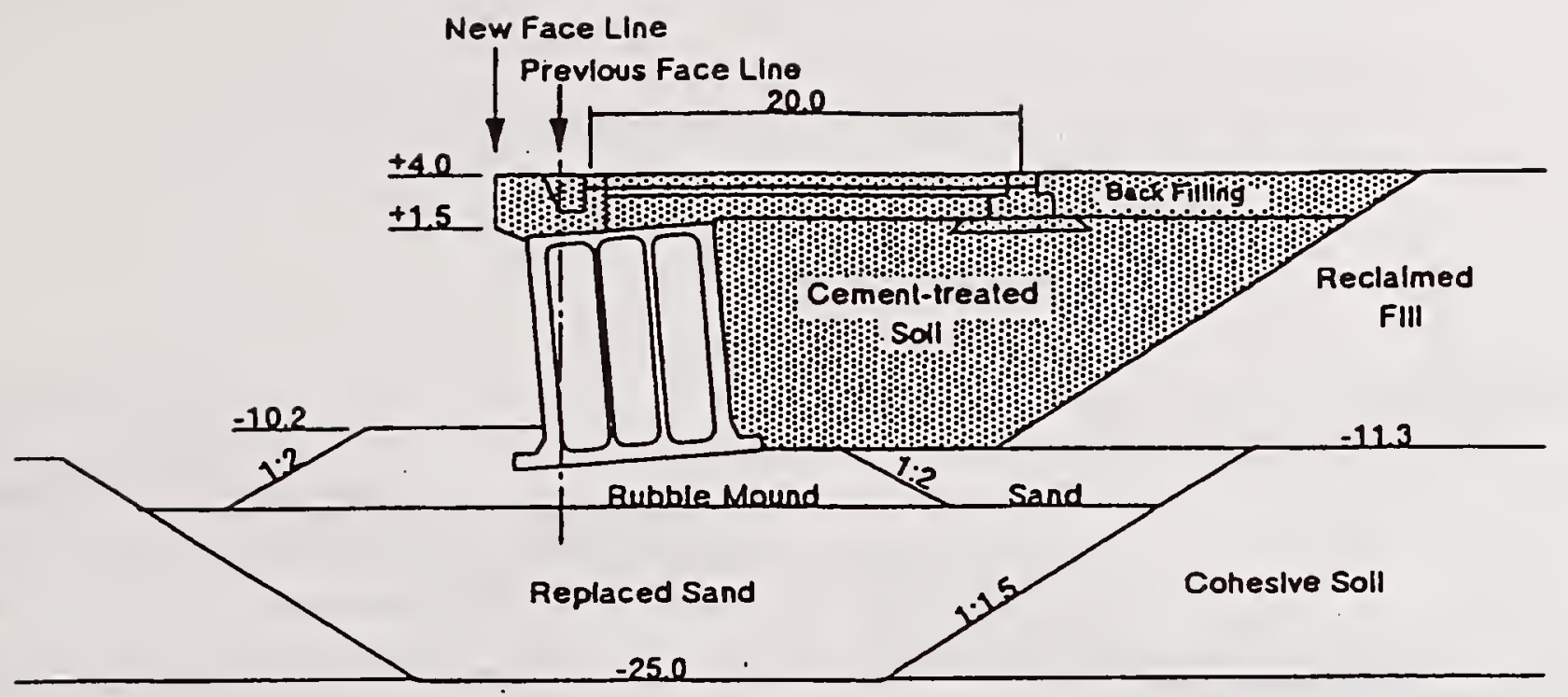

Fig. 8 Restoration of quaywall using cement-treated soil

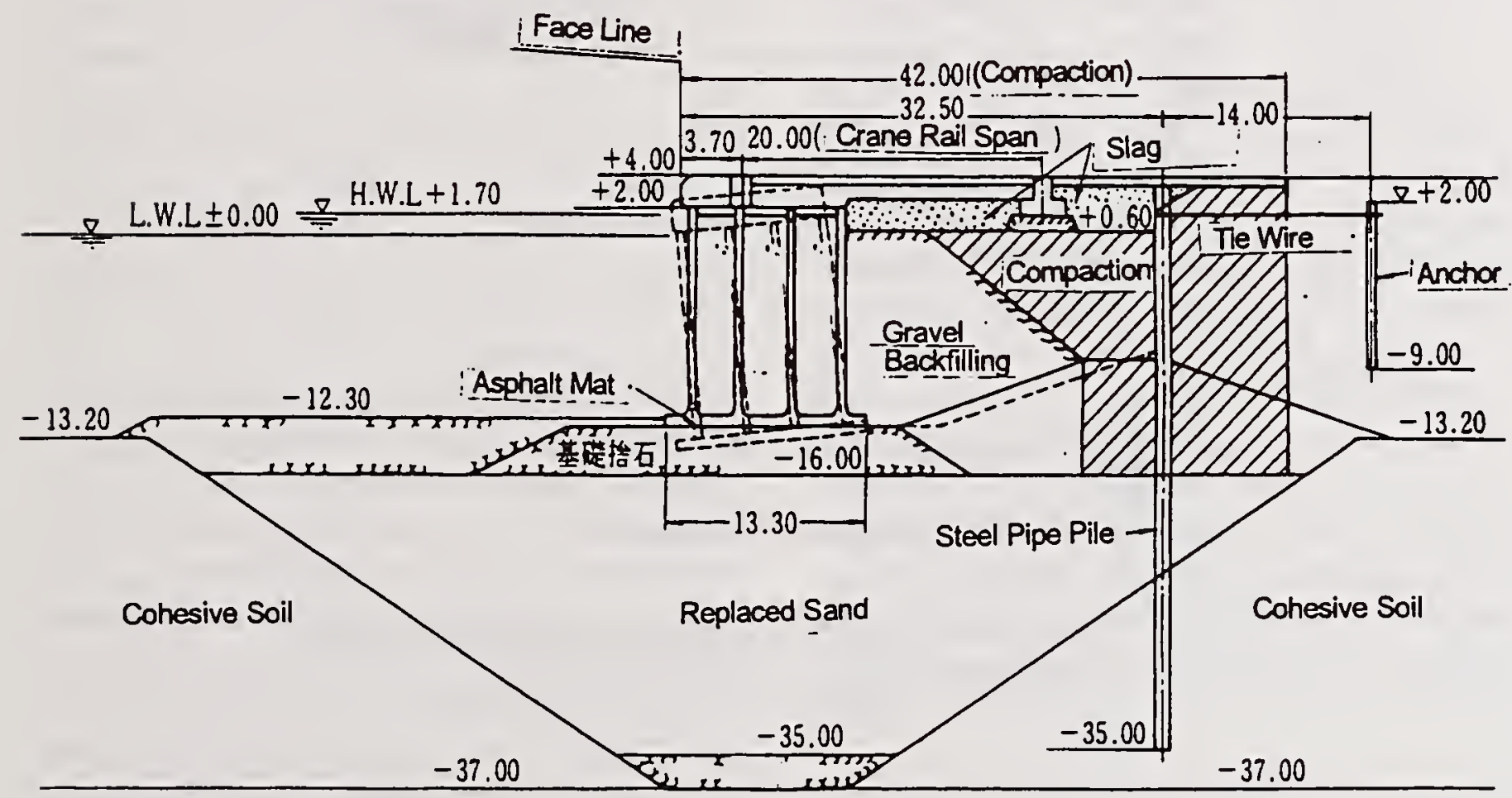

Fig.9 Restoration of quaywall using existing caisson 


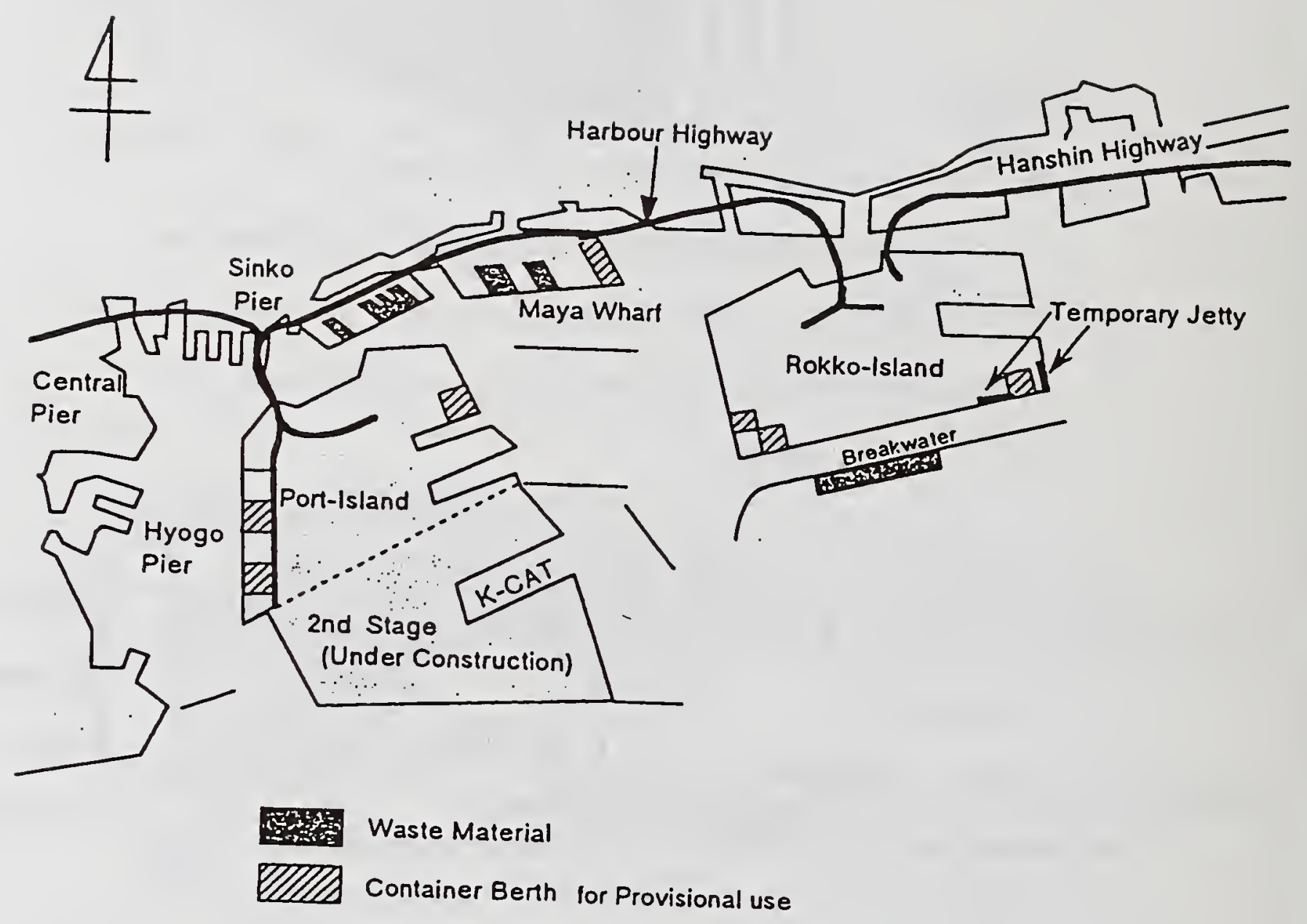

Fig.10 Provisional use of container berth and location for the use of waste material in Kobe port 


\title{
Major Factors of Damages of Reinforced Concrete Buildings due to the 1995 Hyogo-ken Nanbu Earthquake
}

by

\author{
H. Hiraishi ${ }^{1)}$, T. Kaminosono ${ }^{2)}$, M. Teshigawara ${ }^{3)}$ and S. Nakata ${ }^{4)}$
}

\begin{abstract}
Reinforced concrete buildings were severely damaged due to the 1995 Hyogo-ken Nanbu Earthquake, and some of them completely collapsed Most of these damaged buildings were those designed by the previous Japanese design code. Particularly the damage of medium high-rise buildings designed by the previous code was distinguished The number of damaged buildings which were designed by the current Japanese design code revised in 1981 and were classified as "severely damaged" or "collapsed" is very few except for the buildings with particular structural layout. This paper describes the major factors on two destructive typical damages of reinforced concrete buildings. One is the complete collapse of mid-height story of medium high-rise buildings from seven to twelve stories which were found only for the buildings designed by the previous code. The other is the collapse of piloti of buildings with the soft first story which were found for the buildings designed by both the previous and current codes. Through this studies, it was concluded that, the location of the story which suffered damage like pancake collapse depended on vibration mode as well as strength distribution along the height of the buildings and insufficient lateral capacity and ductility of columns at that story caused such collapse, and that there were many factors which caused severe damage of piloti buildings, and reinforced concrete walls considered as non-structural walls were one of most important factors. The paper also proposes some design recommendation to avoid such catastrophic collapse.
\end{abstract}

KEYWORDS : 1995 Hyogo-ken Nanbu earthquake; earthquake damage; reinforced concrete buildings; collapse of mid-height story; piloti.

\section{COMPLETE COLLAPSE OF A MID-HEIGHT STORY OF MEDIUM HI-RISE BUILDINGS}

Damage example

Photograph 1 shows a typical damage example of the eight-story office building which was designed by the previous code. This building had reinforced concrete framing in the upper four stories supported by steelencased reinforced concrete(SRC) framing in the lower four stories, and steel in the column was developed up to the mid-height of the fifth story columns. The sixth story completely collapsed. Except sixth story, the damage level of the story was slight or small, as a whole, although some damages were observed such as the fracture of joint steel at the splice of steel due to tension, damage of column bases due to pulling out of anchor bolts at the base plate of steel, and damages of columns at the fifth story due to falling down of sixth story. The size of columns at the sixth and seventh stories was $65 \mathrm{~cm} \times 65 \mathrm{~cm}$ and longitudinal steel bars in these columns were eight round bars with a diameter of $22 \mathrm{~mm}$ although the size and longitudinal steel bars in fifth story columns were $75 \mathrm{~cm} \times 75 \mathrm{~cm}$ and twenty round bars with a diameter of $25 \mathrm{~mm}$, respectively.

1) Associate Director for Composite Structures Research, Building Research Institute (BRI), Ministry of Construction, Japanese Government Tatehara 1, Tsukuba City, Ibaraki Pref. 305, JAPAN

2) Head, Construction Techniques Division, Production Dept. BRI.

3) Senior Research Associate, International Institute of Seismology and Earthquake Engineering. BRI.

4) Director, Production Dept. BRI. 
The ratio of the amount of cross sectional area of the longitudinal steel bars to the cross sectional area of the sixth story column was about $0.8 \%$ which was the minimum requirement specified in the previous code.And the amount of the longitudinal steel bars in the sixth story column was about one fourth as small as that in the fifth story column.

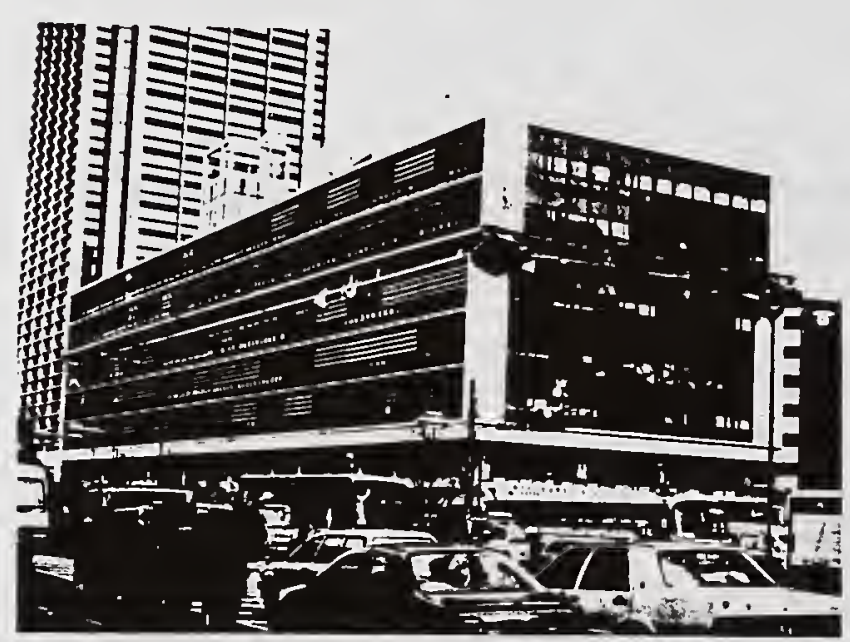

Photo.1. Complete collapse of mid-height story of a eight story building.

Design shear forces specified in the current and previous codes.

This damage pattern was found only in the buildings designed by the previous code. Therefore, in this section, the design shear force specified in the previous code is discussed by compared with that in the current code.

In the previous code, allowable stress design was specified for the horizontal earthquake force $\mathrm{Fi}$ at $\mathrm{i}$-th floor was given by Eq. (1).

$$
\mathrm{F}_{\mathrm{i}}=\mathrm{Z} \cdot \mathrm{G} \cdot \mathrm{K} \cdot \mathrm{W}_{\mathrm{i}}
$$

where,

$$
\begin{aligned}
\mathrm{Z}= & \text { seismic zone coefficient }(=0.8 \sim 1.0 \text { and } \\
& 1.0 \text { for Kobe), } \\
\mathrm{G}= & \text { soil-structure coefficient }(=0.8 \sim 1.0 \text { and } \\
& 1.0 \text { in the most area in Kobe defined as the } \\
& \text { largest value of VII of Japanese seismic } \\
& \text { intensity scale }), \\
\mathrm{K}= & \text { seismic coefficient (=0.2 to height of } 16 \mathrm{~m} \\
& \text { and below, and increased by } 0.01 \text { for every } \\
& 4 \mathrm{~m} \text { above }), \text { and } \\
\mathrm{Wi}= & \text { sum of dead and live loads of } \mathrm{i} \text {-th story. }
\end{aligned}
$$

In the current code, the lateral seismic force in current code is given by Eq. (2).

$$
\begin{aligned}
& Q_{i}=C_{i} \sum_{i=1}^{n} W_{i} \\
& C_{i}=Z \cdot R_{t} \cdot A_{i} \cdot C_{o}
\end{aligned}
$$

where,

$$
\begin{aligned}
\mathrm{Qi}= & \text { seismic shear force at } \mathrm{i}-\mathrm{th} \text { story, } \\
\mathrm{n}= & \text { number of stories, } \\
\mathrm{Ci}= & \text { story shear coefficient, } \\
\mathrm{Z}= & \text { seismic zoning factor }(=0.7 \sim 1.0 \text { and } 1.0 \\
& \text { for Kobe), } \\
\mathrm{Rt}= & \text { vibration characteristics factor and } 1.0 \text { if } \\
& \text { natural period of a building is less than } \\
& 0.6 \text { and the type of soil is so soft as that } \\
& \text { of most area in Kobe defined as VII of the } \\
& \text { Japanese seismic intensity scale, } \\
\mathrm{Ai}= & \text { vertical distribution factor, and } \\
\mathrm{Co}= & \text { standard shear coefficient, and not less } \\
& \text { than } 0.2 \text { for the strong earthquakes which } \\
& \text { can occur several times during the } \\
& \text { lifetime of the building, and not less than } \\
& 1.0 \text { for the severe earthquakes which } \\
& \text { could occur once in the life time. }
\end{aligned}
$$

The stresses in the structural members shall be less than allowable stress for strong earthquakes given by Eq (2) and the lateral load carrying capacity of each story shall be greater than Eq. (4) for severe earthquakes.

$$
\mathrm{Q}_{\mathrm{i}}=\mathrm{A}_{\mathrm{i}} \cdot \mathrm{C}_{\mathrm{o}} \sum_{\mathrm{i}=1}^{\mathrm{n}} \mathrm{W}_{\mathrm{i}}
$$

Where,

$$
\begin{aligned}
\text { Qun = } & \text { required ultimate capacity for lateral } \\
& \text { load of a story, } \\
\text { Ds = } & \text { structural characteristics factor and } 0.3 \\
& \text { for most ductile reinforced concrete } \\
& \text { frames, and }
\end{aligned}
$$

Fes = a shape factor which considers the rigidity and eccentricity factors and 1.0 for the building whose structural layout is regularly and well-balanced.

Equations (2) and (4) are simply rewritten by Eq. (5) for strong earthquakes and $\mathrm{Eq}$ (6) for severe earthquakes respectively, for the most of low-rise and 
medium high-rise buildings in Kobe, if the minimum values of $\mathrm{Co}$, Ds and Fes are considered.

$$
\begin{aligned}
& Q_{i}=0.2 A_{i} \cdot \sum_{i=1}^{n} W_{i} \\
& Q_{u n}=0.3 A_{i} \cdot \sum_{i=1}^{n} W_{i}
\end{aligned}
$$

In the following discussions, it is assumed that the mass of each story is the same, and the story height is $3.0 \mathrm{~m}$. Figure 1 shows story shear coefficients calculated by Eqs. (1), (5) and (6), and values of Eq. (1) times 1.5 . By comparing the design story shear coefficients by Eqs. (1) and (5) because same allowable stress design is specified for these shear forces, in the both previous and current codes, it is easily found that design shear force specified in the previous codes is considerably smaller than that in the current code, at the upper stories of a building. And if the ultimate capacity for lateral load of each story of a building may be 1.5 times that defined by Eq. (1) and Eq. (6) is minimum requirement for severe earthquakes, the shortage of the ultimate capacity of a story designed by the previous code is much remarkable as the location of the story of a building is higher. However, the ultimate capacity of the stories near the uppermost story of a building designed by the previous code may be more than minimum ultimate capacity required by current code, because of minimum requirement such as size of members, minimum reinforcement, etc.

Estimation of Ultimate Capacity for lateral Load of Buildings Designed by the Previous Code

The ultimate capacity of columns of a story is assumed to be sum of ultimate lateral capacity of columns of a story considered, because the failure mechanism of this damage pattem is the complete collapse of a certain story. It is also assumed that the shear capacity of these columns is higher than their flexural capacity .

The flexural capacity of a column is given by Eq. (7).

$$
\mathrm{M}_{\mathrm{u}}=0.8 \mathrm{a}_{\mathrm{t}} \cdot \sigma_{\mathrm{y}} \cdot \mathrm{D}+0.5 \mathrm{~N} \cdot \mathrm{D}\left(1-\frac{\mathrm{N}}{\mathrm{b} \cdot \mathrm{D} \cdot \sigma_{\mathrm{B}}}\right)
$$

where,

$$
\begin{aligned}
\mathrm{Mu}= & \text { flexural strength of a column }(\mathrm{N} \mathrm{mm}), \\
\mathrm{at}= & \text { amount of cross sectional area of } \\
& \text { longitudinal tensile steel bars }(\mathrm{mm} 2), \\
\text { sy = } & \text { tensile yield strength of longitudinal } \\
& \text { steel bars }(\mathrm{MPa}) \\
\mathrm{N}= & \text { axial force in a column }(\mathrm{N}), \\
\mathrm{sB}= & \text { compressive strength of concrete }(\mathrm{MPa}), \\
\mathrm{b}= & \text { width of a column }(\mathrm{mm}), \text { and } \\
\mathrm{D}= & \text { depth of a column }(\mathrm{mm})
\end{aligned}
$$

Equation (7) is rewritten by Eq. (8), if $N /\left(b \cdot D \cdot \sigma_{B}\right)$ is assumed to be 0.1 .

$$
M_{u}=0.8 a_{\mathrm{f}} \cdot \sigma_{y} \cdot D+0.45 \mathrm{~N} \cdot \mathrm{D}
$$

The shear Qm of a column at the flexural strength at both ends is given by Eq. (9).

$$
\mathrm{Q}_{\mathrm{m}}=2 \mathrm{M}_{\mathrm{u}} / \mathrm{h}_{\mathrm{o}}
$$

where,

$$
\text { ho = clear height of a column (mm). }
$$

The ultimate capacity for lateral load of i-th story of a building is given by dividing sum of $\mathrm{Qm}$ of each column at i-th story by their sum of axial force, and the shear coefficient $\mathrm{mCi}$ of $\mathrm{i}$-th story at the ultimate capacity is given by Eq (10). Here, the following assumptions are used.

i) The dimensions of depth and width of every column are the same.

ii) at in each column in a certain story considered is the same.

iii) $\mathrm{D} / \mathrm{ho}$ is $1 / 3$ for every column.

iv) The ratio of the sum of cross sectional area of the columns to the floor area at a certain story considered is $1 / 100$.

v) The mean unit mass of a building is $1.2 \mathrm{t} / \mathrm{m} 2$.

vi) sy is $360 \mathrm{MPa}$. 


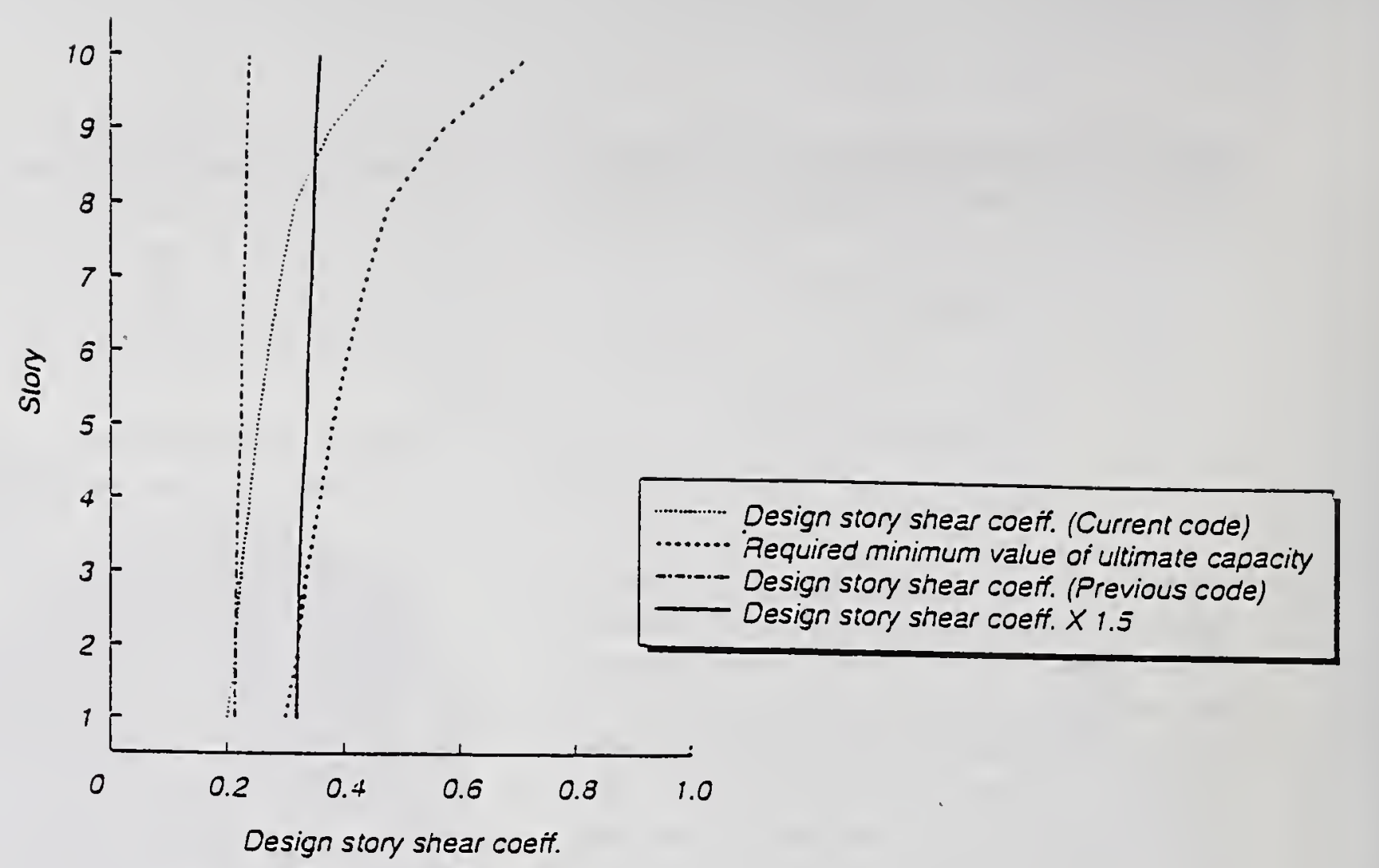

Fig.1. Design story shear coefficients specified in the previous and current codes.

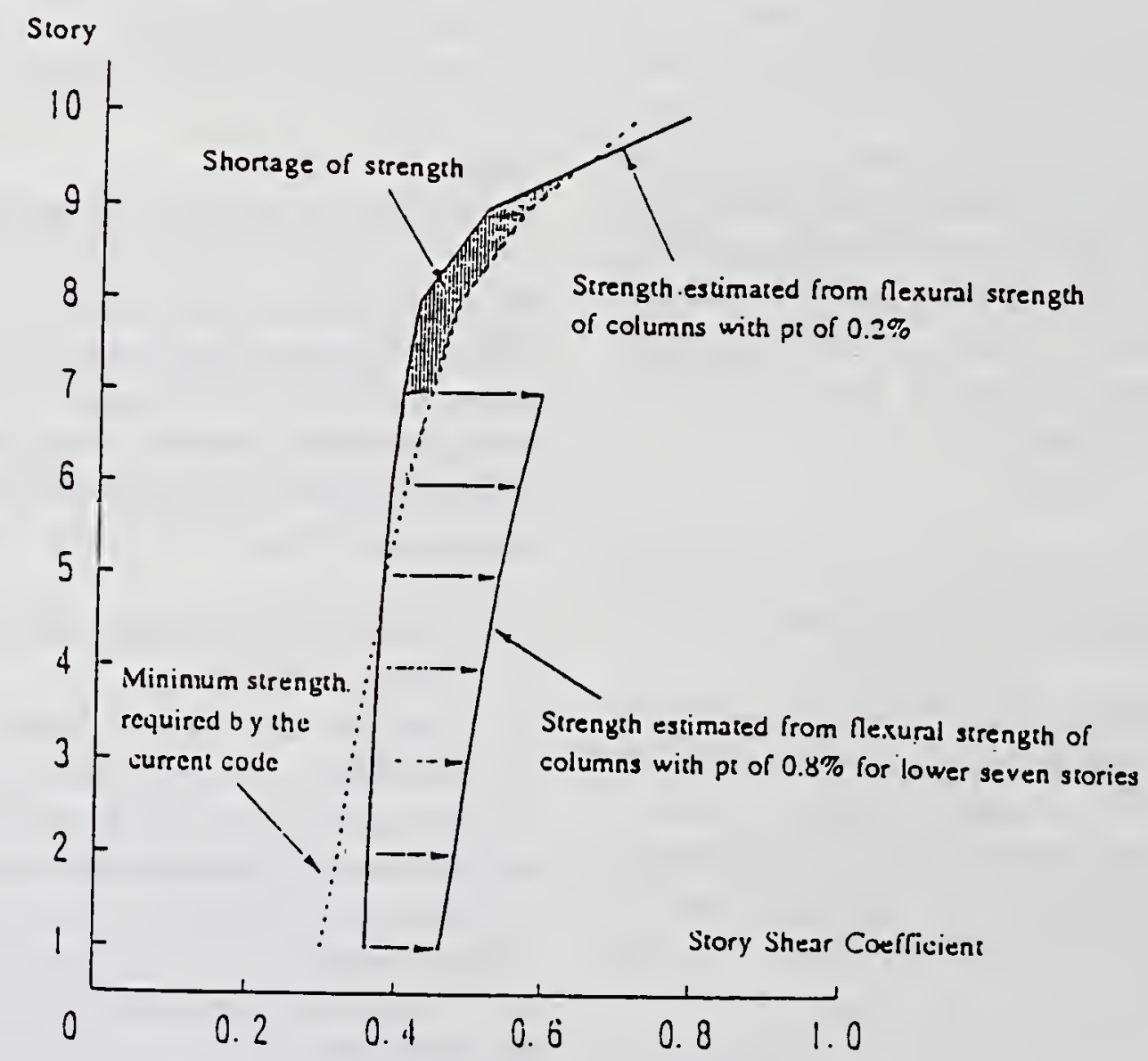

Fig.2. Estimated ultimate capacity of the buildings designed by the previous code and minimum ultimate capacity required by the current code. 


$$
{ }_{m} C_{i}=\frac{160}{n+1-i}{ }_{i} P_{t}+0.3
$$

where,

$$
\begin{aligned}
\mathrm{iPt}= & \text { at } /(\mathrm{bd}) \text { of the column at } \mathrm{i} \text {-th story } \\
\mathrm{n}= & \text { number of stories of a building, and } \\
\mathrm{i}= & 1+\text { number of stories of a building } \\
& \text { above } \mathrm{i} \text {-the story. }
\end{aligned}
$$

The first term and the second term in the right-hand side of Eq. (10) represent terms related to the longitudinal steel bars and axial force, respectively. The ultimate lateral capacity of 0.3 of story shear coefficient provided by the axial force may be large enough to satisfy allowable stress for about 0.2 of story shear coefficient specified in the previous code. This results means that longitudinal steel bars of most of columns designed by the previous code were arranged by referring to their minimum requirement. However, when the axial force is reduced to be half due to up-down input motion, the second term become 0.15 . Thus the ultimate capacity of buildings is remarkably affected by up-down motion.

\section{Discussion}

Equation (10) is the result based on flexural strength of columns considering damage patterns caused by the earthquake. If columns will fail before they reach flexural yielding or beams reach their ultimate strength, the ultimate capacity for lateral load of the story become smaller value than that given by $\mathrm{Eq}$ (10), so values that given by Eq (10) is one of the possible maximum value of the ultimate capacity. Figure 2 shows the result of pt of $0.3 \%$ which corresponds to the ratio of the minimum requirement of $0.8 \%$ of longitudinal steel bars by comparing the minimum requirement of ultimate capacity specified in the current code given by $\mathrm{Eq}(6)$. The shortage of the ultimate capacity comparing to 0.3 of Ds is remarkable at mid-height stories of the building.

In existing buildings, the dimensions of columns and amount of the longitudinal steel bars in columns are usually lager in the lower stories, and in Japan the lower stories of a building are commonly constructed by SRC if a building is higher than $21 \mathrm{~m}$. Such construction practice enhances the ultimate lateral capacity of lower stories of the building. In Fig. 2, the estimated value of ultimate lateral capacity of lower seven-story in which pt of columns is assumed to be $0.8 \%$ considering steel plate in columns is also shown. The shortage of ultimate lateral capacity of mid-height stories is furthermore distinguished. The building shown in Photograph 1 is the typical damage example in which reinforced concrete sixth story above lower SRC stories completely collapsed.

Figure 3 shows the case studies for 10, 8, 6 and 4story buildings. The solid line shows the story shear coefficient of ultimate lateral strength given by $\mathrm{Eq}$ (10) in which pt is $0.3 \%$, and the dashed lines show $\alpha$ Ai which has Ai distribution profile and comes in contact with the solid line. The multiplier $\alpha$ corresponds to Ds. The more the number of story of a building is, the higher the relative contact point is and the smaller the $\alpha$ is. The relative contact point and the value of $\alpha$ is largely affected by the shear distribution profile during earthquakes. It is expected that this profile is closer to Ai distribution rather than design shear distribution specified in the previous code.

\section{COLLAPSE OF PILOTI BUILDINGS}

\section{Damage Example}

Photograph 2 shows a five-story building whose first story completely collapsed This building was designed by the current design code. There are reinforced concrete walls in the upper four stories. This type of structures is called as piloti buildings and they suffered severe damage including those designed by the current code. Any severe damage was not observed in the upper four stories. The structural slit where thickness of concrete wall was half of that of the in-panel wall was placed between columns and in-panel walls. In the structural design, these in-panel walls were considered as non-structural walls and their structural effect was not considered. However, these walls might have worked as shear walls during the earthquake. Four of five piloti buildings which were designed by the current code and were identified as completely collapse by Building Research Institute had similar non-structural walls in the upper stories. 


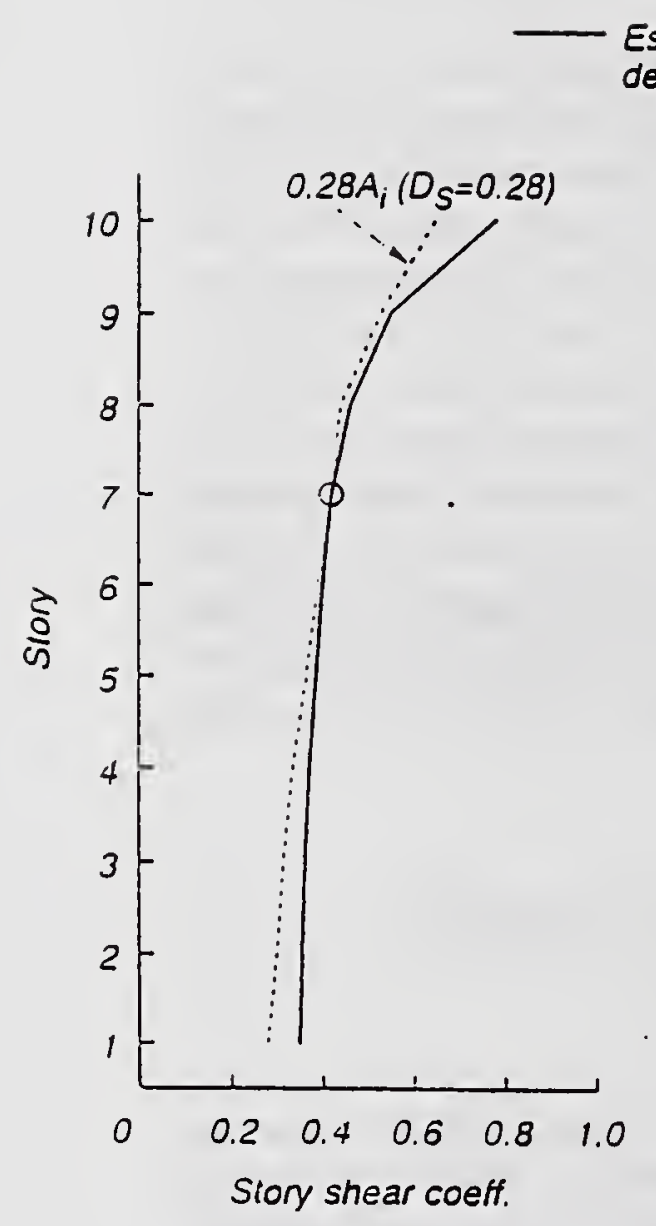
Estimated ultimate capacity of a building
designed by the previous code
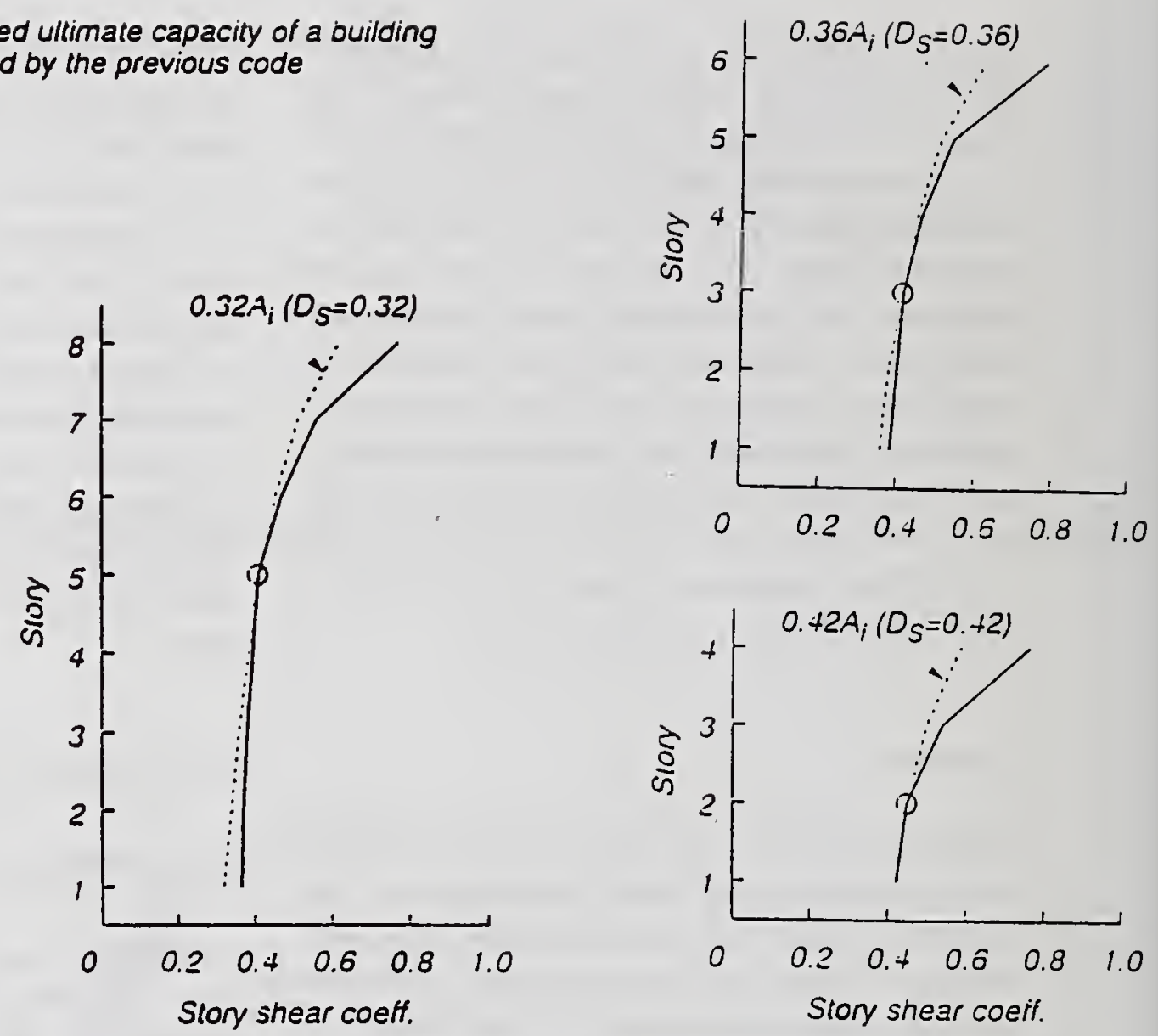

Fig. 3. Estimated ultimate capacity of $10,8,6$ and 4-story buildings with $0.2 \%$ of $\mathrm{p}_{1}$. 


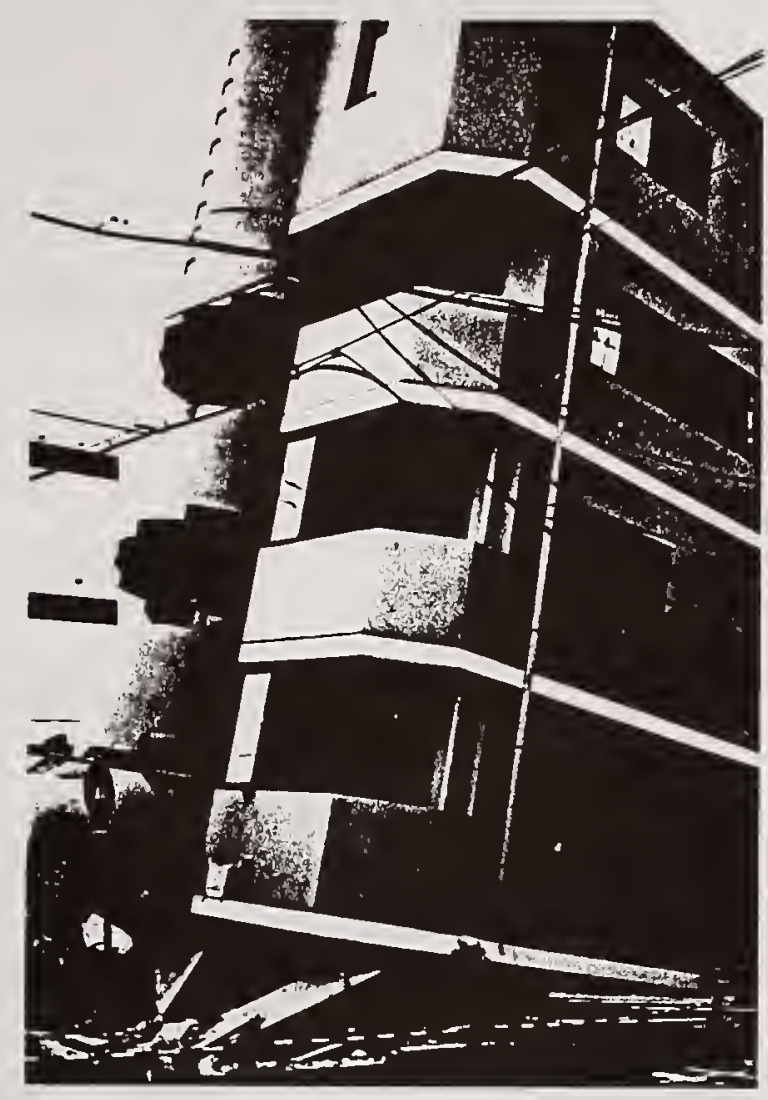

Photo. 2. Complete collapse of a piloti building.

Factors for Damage

There are many factors which might have cased such damages. These factors are discussed below.

1) Shear distribution profile.

Response shear distribution profile along the height of the building due to input earthquake motion may be top heavy distribution like Ai distribution if the structural layout of the buildings are wellbalanced and regularly shaped. However, this distribution profile is not appropriate for design shear for piloti buildings because of soft stiffness of the piloti story (see Fig. 4).
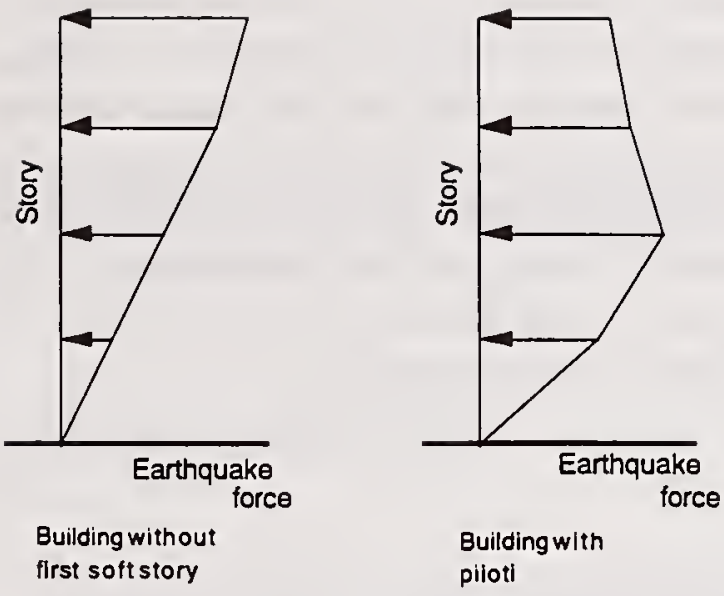

Fig. 4. Examples of earthquake force distribution of building with and without first soft story.

2) Axial force and shear force.

During earthquake response, forces and moments in the piloti columns changes significantly even after yield mechanism is formed and it is not easy to find appropriate design forces and moments.

3) Rigidity Factor and eccentricity Factor.

In the current design code, the effects of non-uniform rigidity in the vertical direction and eccentricity between centers of mass and rigidity on structural performance are specified. However, the rigidity of members, particularly that of shear walls remarkably changes depending on damage degree. Therefore, these effects continuously change during dynamic response because the members in the piloti story may suffer damages such as cracks of concrete and yielding of steel bars, while those in the upper stories may suffer little damage. In the structural design, such change of the rigidity should be considered.

4) Seismic performance of buildings with story collapse mechanism

Input energy is dissipated mostly in the soft story of piloti buildings, so piloti columns should be ductile enough. This required ductility of columns needs to be further researched Another subjects to be considered is restoring force characteristics of columns subjected to high axial force. In these columns such as piloti columns, the load carrying capacity remarkable decreases after the maximum capacity even if they fail in flexure (see Fig. 5). If the $\mathrm{P}=$ effect is considered, it is easily found that this descending slope after the maximum capacity should be emphasized to be considered because it affects 
significantly the seismic performance of buildings. On the other hand buildings with beam yielding mechanism have not such problem because the load carrying capacity continuously increases even after beam yielding due to effects of strain hardening of steel bars, yielding of slab reinforcement, etc. Essentially, piloti columns should be designed to remain before maximum capacity.
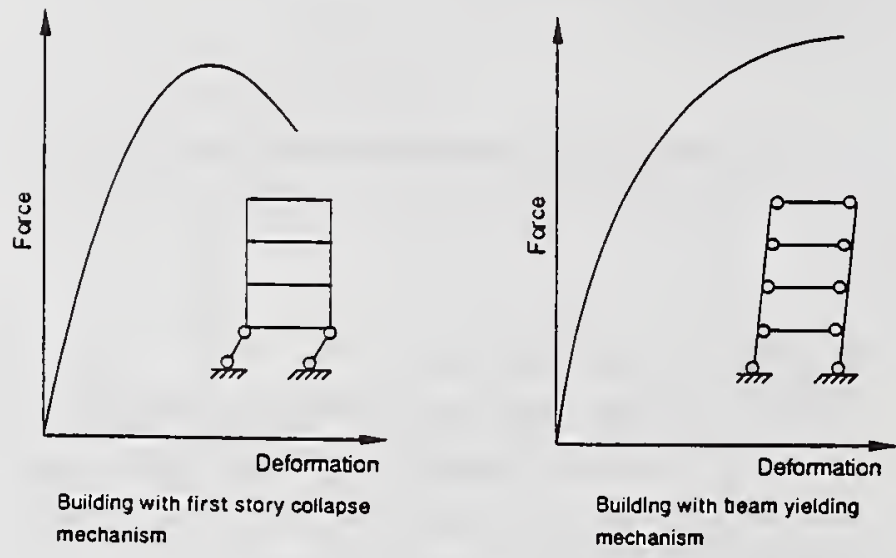

Fig. 5. Idealized restoring force versus deformation relations of the buildings.

\section{CONCLUSIONS}

This paper described two types of destructive damage patterns of reinforced concrete buildings which might have caused mass loss of human lives: complete collapse of mid-height story and collapse of piloti of the soft first story. The followings were concluded.

1. The location of the story which suffered severe damage like pancake collapse depends on vibration mode as well as ultimate capacity distribution along the height of the buildings. Insufficient lateral capacity and ductility of columns at certain story caused such collapse.

2. There are many factors which caused collapse of piloti columns. Essentially, piloti columns should be designed to remain before their maximum strength. 


\title{
PUSH OVER LABORATORY TESTING OF UNREINFORCED MASONRY INFILLS
}

\author{
by \\ Ghassan Al-Chaar ${ }^{1}$, Steve Sw' eney ${ }^{1}$, and Pamalee Brady ${ }^{1}$
}

\section{ABSTRACT:}

The U. S. Army Construction Engineering Research Laboratories, USACERL, Performed push over laboratory tests on three models of reinforced concrete frames with masonry infill. These tests where part of a study of the ultimate strength boundary and the residual strength of infilled concrete frames. This paper describes the failure mechanisms of the specimens, and includes a brief discussion on major parameters that describe the behavior.

\section{INTRODUCTION:}

Test assemblies consist of masonry infilled R/C frame. In analysis, the redundant constraints between the infill and the frame yield more unknown forces than equilibrium equations can resolve, and therefor is a statically indeterminate problem. Thus, the composite behavior of such structural entities is best revealed experimentally. The USACERL push over tests is part of a larger research effort to further the understanding of the composite behavior of $\mathrm{R} / \mathrm{C}$ frame with masonry infills. Dynamic testing of the two small scale specimens has been reported previously (Al-Chaar, 1993) and called halfscale strong and weak frames infilled with half-scale brick masonry units. The third model tested is similar in shape to the weak and strong frames, it is twice the scale, and it is referred to herein as the large frame. Scaled concrete block units were used to infill the large frame opening. All three frames were used for testing previously and were partially damaged as manifested in small cracks within the frame. The infill in the weak and strong frame also was damaged in previous tests, while the infill in the large frame was undamaged. The previous tests, however, reached the lower boundary of the inelastic limit of the frames. Table 1 below describes the dimensions and the material properties of the three models. In-plane monotonic loading, stroke-control push over tests were carried out to further understand the inelastic behavior of these physical models as they are subjected to drift ratio where the models are severely damaged beyond repair. These tests provided information beyond the elastic limit of the models which was not achieved in the dynamic tests.

\section{EXPERIMENTAL SETUP:}

As shown in Figure 1, two stroke-controlled hydraulic actuators were installed on steel reaction frames. The actuators were capable of applying in-plane lateral monotonic loading on the center of the top beam in each specimen. A stroke of nearly 6 inches was imposed slowly, over 15 minutes, while other dependent parameters were recorded in two second intervals. Some of the major

${ }^{1}$ Research Structural Engineers, U. S. Army Construction Engineering Research Laboratories, P. O. Box 9005 Champaign, Illinois 61826-9005 
parameters acquired during the test were loads, drift, diagonal deformation, and joint rotation. Greased Teflon plates were installed between the actuators and the beam to eliminate any shear effect resulting from friction between the two components. Modes of failure were observed during the tests, indicated by crack propagation in the infill panels and the formation of cracks and hinges in the $\mathrm{R} / \mathrm{C}$ frames.

\section{FAILURE MECHANISMS OF INFILLED R/C FRAMES:}

The three models failure mechanism are compared to the family of failure mechanism types presented by Mehrabi and Shing, showed in Figure 2, (Mehrabi, 1996).

\subsection{The strong frame model:}

The failure mechanism observed in the infill was a diagonal tension crack propagating along the diagonal strut. The stair crack initiated at the upper corne: of the windward side of the specimen. As seen in Figure 3, the crack propagated 45 degrees toward the center and branched into two main horizontal cracks, then they merged into one crack toward the opposite corner. This crack pattern deviated slightly from types identified by Mehrabi. This is probably due in part to the pre-cracks presented from previous out-ofplane tests. However, hinges in the $\mathrm{R} / \mathrm{C}$ frame formed similar to type E4 or E6 described by Mehrabi. Figure 6 shows the location of the hinges.

\subsection{The weak frame model:}

Stair step cracks initiated again at the infill upper corner of the windward side of the specimen. As seen in Figures 5 and 6, these cracks propagated wider and branched into three main horizontal cracks, then they merged in two cracks toward the opposite corner of the infill. This mode of failure is identified as type C5, with diagonal cracks and two hinges in the windward column, (Mehrabi, 1996). Again, because this model was previously tested out-of-plane, cracks from previous tests likely caused the formation of secondary cracks under in-plane testing. As the stroke increased, hinges initiated at the bottom of the windward column followed by a wide crack in the leeward column, and in the beam approximately to one beam depth away from the windward column. A dead zone remained intact below the bottom cracks. Figure 7 shows the $R / C$ frame deformations of the weak frame model.

\subsection{The large frame model:}

Failure type D1 as described by Mehrabi was clearly observed. The failure surface clearly indicated poor bond between the mortar and the concrete blocks. Also, as illustrated in Figure 8 , zones in triangles 1 and 2 shows vertical tension cracks unlike zone 3 that exhibited pure joint slippage between all courses.

\section{LOAD VS DRIFT OF THE MODELS:}

\subsection{The strong frame model:}

As shown in Figure 9, the initial strength of the strong frame model was 28.2 kips at driftheight ratio of $4.7 \%$. The structure, beyond the ultimate strength, exhibited ductile behavior important in dynamic capacity evaluation. A drift-height ratio increased nearly three times at approximately $30 \%$ reduction in strength of the strong frame 
model. The residual strength at $15 \%$ drift is approximately $40 \%$ the ultimate strength. These values indicated a high energy dissipation capability of this type of model, characteristics that are important in resisting seismic loads.

\subsection{The weak frame model:}

The weak frame load-drift curve exhibited a different behavior from the strong frame model. An initial strength of 12.8 kips at 1.6 $\%$ drift ratio was achieved. The load resistance between $1.6 \%$ and $3.6 \%$ drift ratio decreases by $32 \%$ and than increased to $130 \%$ of the initial strength, at $10 \%$ drift. The first peak explained the infill initial strength, where the second peak indicates the composite resistance of the infill and the frame after the formation of severe cracks on the infill. The failure mechanism of the weak frame appears to show poor interactions in the early deformation of the model and overall poor composite resistance: Although this model residual strength at the second peak strength is only $60 \%$ of the strong frame model ultimate strength, its still exhibits ductile characteristic, but at a lower level of load resistance and residual strength.

\subsection{The large frame model:}

The large frame load versus $\%$ drift ratio curve in Figure 9, shows a very low initial strength of 11.9 kips at $1.3 \%$ drift ratio. This is due in part for the low prism strength of the concrete masonry infill blocks. The similarity in shapes of the load-drift ratio curves of the strong and large frames is very apparent despite their different modes of failure. This observation may lead to develop a function that can be applied to a family of curves for similar infill and frame relative rigidities. Due to 6 inches stroke limitation, the drift ratio beyond $9 \%$ was not carried out.

All three frames were able to achieve $9 \%$ drift height ratio value, way beyond the initial strength of the three models. At this drift state, the ratios of the residual strengths to initial strengths are approximately $90 \%$, $120 \%$, and $60 \%$ for the strong frame model, weak frame model and large frame model, respectively. Accountability for variations in models parameters such as prism strength, and scaling between the models, will be encompassed in future work.

\section{DIAGONAL DEFORMATION OF THE INFILLS:}

The diagonal deformations of the infills for the three models were measured and plotted against the corresponding drifts and loads. The load versus diagonal deformation curves, shown in Figure 10, were limited to a stroke of 2.3" where the limits of the LVDT were reached. However, from these curves, it can be seen that the compression and tension deformations were uniform. From Figure 11, the diagonal deformations within the first 2 inches of loading were linearly deformed. Thus, diagonal deformation of the infill can be modeled as a linear inelastic change in shape that it is a characteristic of the composite behavior of the R/C frame with infill.

\section{JOINTS ROTATIONS OF R/C FRAMES:}

To study the rotations in selected critical sections at which plastic hinges may form, experimental measurements in the tested models were compared with rotations computed from analysis on identical R/C frames without infills, using RISA2D 
structural program. Critical sections 1 and 2 are located above the windward and leeward column base joints, respectively. Sections 3 , 4 , are located in the beam 4" from the face of the windward and leeward columns, respectively.

\subsection{Strong Frame Model:}

An analytical R/C frame identical to that of the strong frame model, was subjected to an inplane lateral load. The rotation in sections 1 , 2,3 , and 4 , were computed to be 0.00257 , $0.00250,0.00345$, and 0.00329 , respectively. These results are compared to the test results shown in Figure 12. The largest rotations from the test were in section 3 , the windward end of the beam, and section 2, the base of the leeward column. the smallest rotation was in section 1. This is not unexpected in that with the direction of loading, the windward column was braced by the infill, but on the leeward side the infill and column separated. The infill therefore created a non-symmetrical moment redistribution in the frame. One potential benefit however of the composite action of the infill and the $\mathrm{R} / \mathrm{C}$ frame is a redistribution of the moment caused by the infill from critical sections to less critical section of the frame and transformation of some loading moments to loading in shear. This however can also have an adverse effect as well. Simple calculations yielded elastic rotation capacity of columns and the beam in the strong frame model on the order of $1.04 \times 10^{-3}$ radians. All measured rotations on the model significantly exceeded the calculated elastic rotation value.

\subsection{Weak Frame Model:}

Weak frame rotation varied significantly from the strong frame and large frames models. The rotations measured in the weak frame were large relative to rotations measured in the in strong frame. The magnitudes of weak frame rotations did not vary as seen in both the strong and large frames. The rotation beyond the elastic limit remained linear. The formed diagonal strut resulted in shear failure at the bottom of the leeward column and the windward end of the beam. It appears that in the stiffer strong frame, the rotation was dominated by shear in the diagonal strut, while weak frame rotation was dominated by moment.

\subsection{Large Frame Model:}

The rotations of sections under consideration behaved similarly to the strong frame in terms of reduction observed in the rotations at the beam windward end and the bottom of the leeward column. It should be reminded that these same two frames had very similar load versus drift behavior as well.

\section{Summary and Conclusion:}

The three models were tested under stroke controlled monotonic loading. The failure mechanism of three models compared to Mehrabi's failure mechanism types and all agreed to one of Mehrabi's type with minor differences seen in the weak and strong frames due to the presence of minor cracks from outof-plane loading.

The residual strength and the drift capability of a model can be used as an index to compare performance of a model. Exact comparison among the three models must account for scaling effects and configuration, which are not accounted for in this paper.

The behavior of these models needs to be studied beyond the initial strength. Ultimate 
strength capacity, and residual strength need to be identified in terms of the models parameters.

The outstanding composite behavior of $\mathrm{R} / \mathrm{C}$ frames with masonry infills, is obviously due the ability of the models to redistribute loads that supposedly resisted by the R/C frame or the infill along. The rotations of sections where hinges may form, were controlled by the relative stiffness between the $R / C$ frames and their infills. Finally, although the all model constructed from non-ductile components, the composite behavior exhibited remarkable ductile behavior, characteristic that is highly desirable in design of structures in high seismic zones.

\section{REFERENCES:}

1. Al-Chair, G., Angel, R, and Abrams, D. P., " Dynamic Testing of Unreinforced Brick Masonry Infills," Proceeding of Symposium on Advances in Engineering for Concrete and Masonry Structures, April 24-28, 1994.

2. Mehrabi, B. A., Shing, P. B, and Schuller, P. M., "Experimental Evaluation of MasonryInfilled RC Frames," ASCE, Journal of Structural Engineering MAR. 1996 VOL. 122 No. 3.

Table 1: Summary of Dimensions and Material Properties of Tested Models:

\begin{tabular}{|c|c|c|c|}
\hline Parameters & $\begin{array}{l}\text { Half-Scale Strong } \\
\text { Frame Model }\end{array}$ & $\begin{array}{l}\text { Half-Scale Weak } \\
\text { Frame }\end{array}$ & Large Frame \\
\hline The height of column, $h$ & $35^{\prime \prime}$ & $35^{\prime \prime}$ & $56.125^{\prime \prime}$ \\
\hline Length of the beam, $\mathrm{L}$ & $54^{\prime \prime}$ & $54^{\prime \prime}$ & $72^{\prime \prime}$ \\
\hline Infill thick $x$ height $x$ width & $1.75^{\prime \prime} \times 32^{\prime \prime} \times 48^{\prime \prime}$ & $1.75^{\prime \prime} \times 32^{\prime \prime} \times 49^{\prime \prime}$ & $4^{\prime \prime} \times 52.25^{\prime \prime} \times 64^{\prime \prime}$ \\
\hline Masonry Units' dimensions & $1^{\prime \prime} \times 4^{\prime \prime} \times 1.75$ & $1^{\prime \prime} \times 4^{\prime \prime} \times 1.75$ & $4^{n} \times 8^{n} \times 4$ \\
\hline Masonry unit/ compressive strength & clay & clay & concrete/ $1041 \mathrm{psi}$ \\
\hline Mortar type/ mortar cube strength & $\mathrm{N}$ & $\mathrm{N}$ & N/792 psi \\
\hline Column width/depth, $W_{c}, d_{c}$ & $6^{\prime \prime} \times 6^{\prime \prime}$ & $5^{\prime \prime} \times 5^{\prime \prime}$ & $8^{n} \times 5^{n}$ \\
\hline Beam width/depth, $d_{c}$ & $5^{\prime \prime} \times 6^{\prime \prime}$ & $4^{\prime \prime} \times 6^{\prime \prime}$ & $7.75^{\prime \prime} \times 5^{\prime \prime}$ \\
\hline Infill fm (E'm) & $5000 \mathrm{psi}$ & $5000 \mathrm{psi}$ & $190 \mathrm{psi}$ \\
\hline Concrete f', E'c & $4000 \mathrm{psi}$ & $4000 \mathrm{psi}$ & 4220 psi $3700 \mathrm{ksi}$ \\
\hline Beam stirrups & 6. ga & $6 \mathrm{ga}$. & 3/16" dia. \\
\hline Column ties & $6 \mathrm{ga}$. & $6 \mathrm{ga}$. & 3/8" dia. \\
\hline Beam Longitudinal Reinforcement & $\begin{array}{l}\text { 3-\#3 (top), 3-\#3 } \\
\text { (bot). }\end{array}$ & $\begin{array}{l}\text { 3-\#3 (top), 2-\#3 } \\
\text { (bot.) }\end{array}$ & $\begin{array}{l}\text { 3-3/8 " dia. (top), 2-3/8 " dia } \\
\text { (bot.) }\end{array}$ \\
\hline Column Longitudinal Reinf. & $6-\# 3$ & $4-\# 3$ & 4-3/8" dia. \\
\hline
\end{tabular}




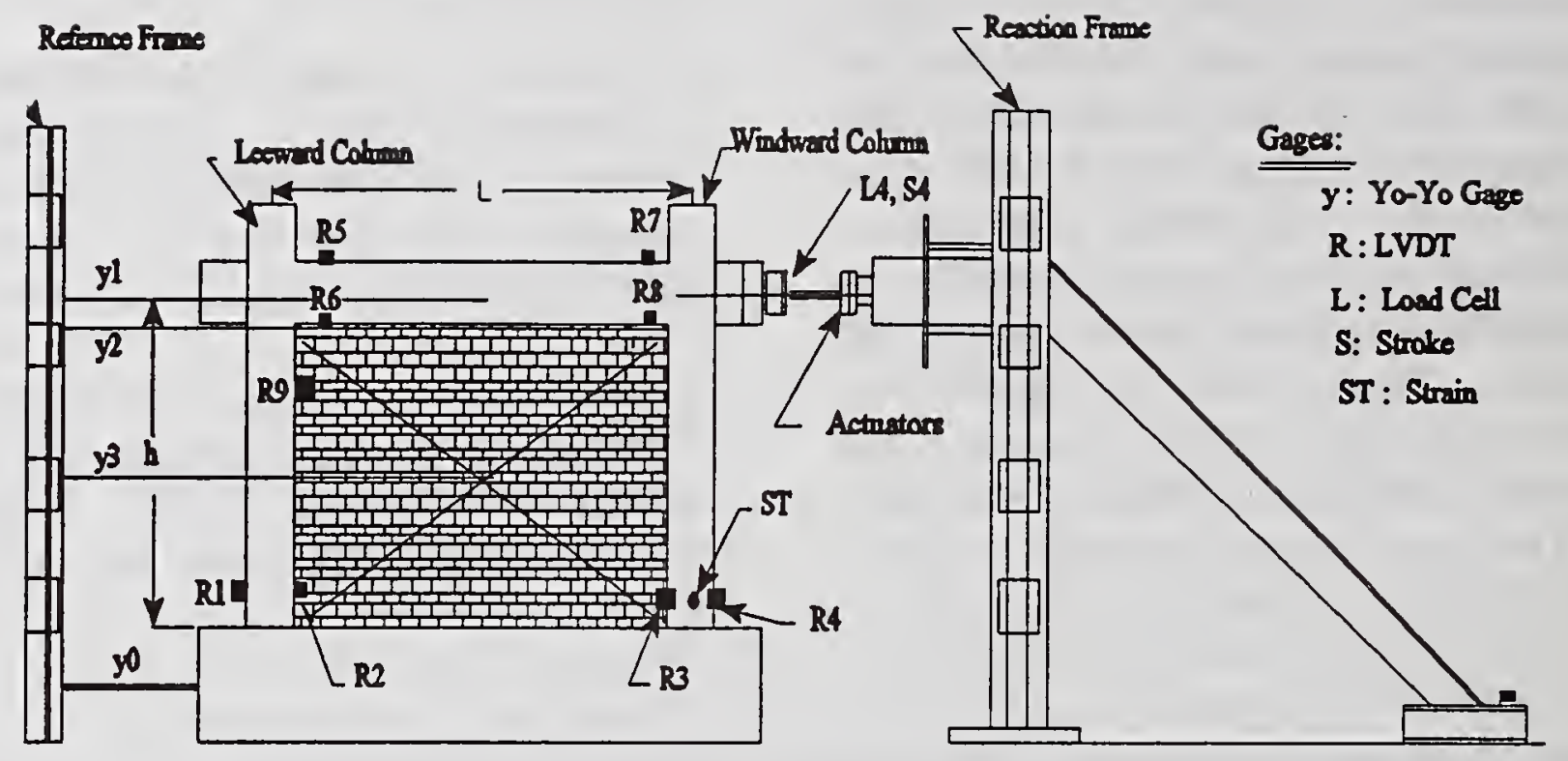

Figure 1: Push Over Test Setup and Instrumentations

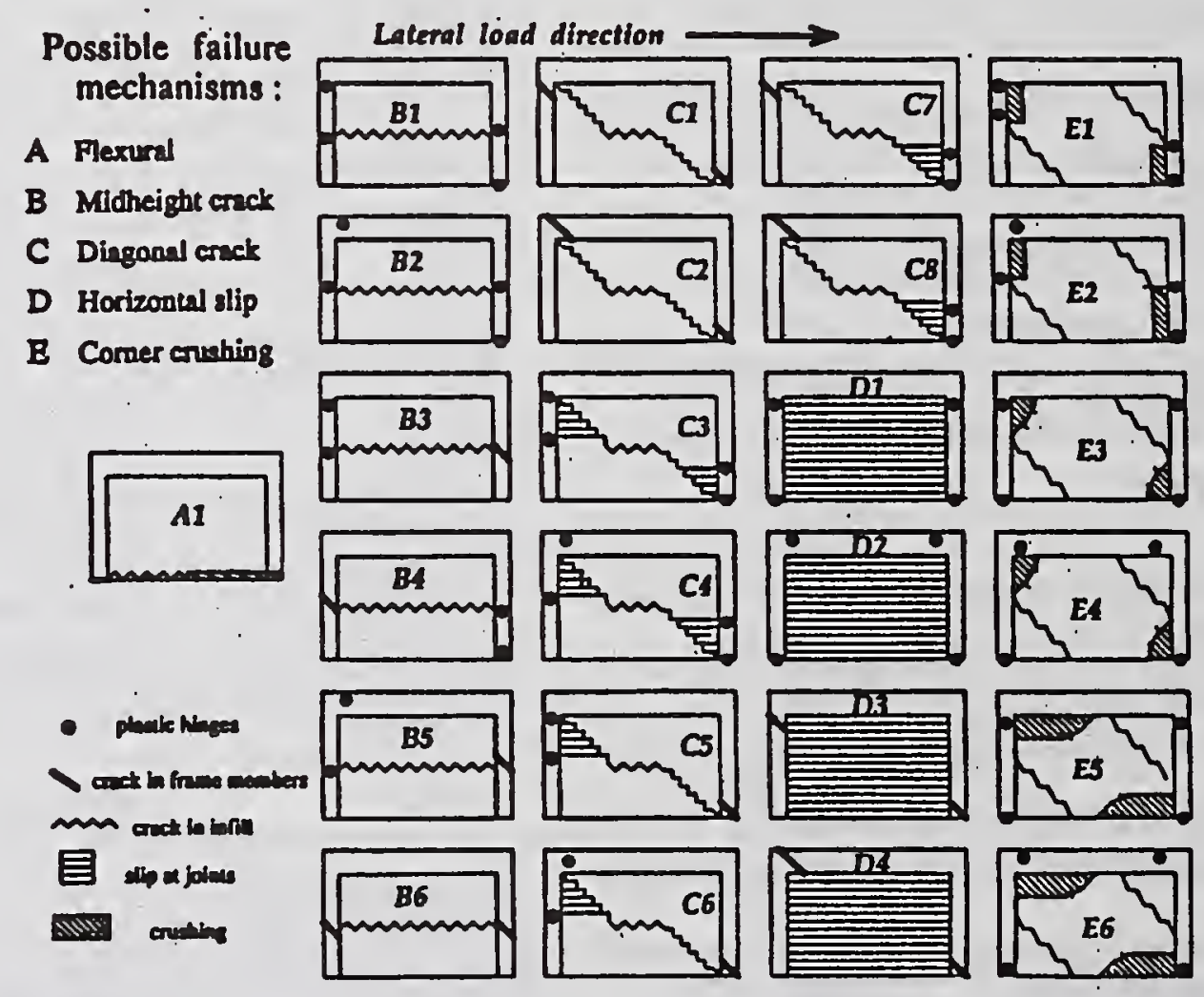

Figure 2: Failure Mechanism of Infilled Frame (Mehrabi, 1996) 


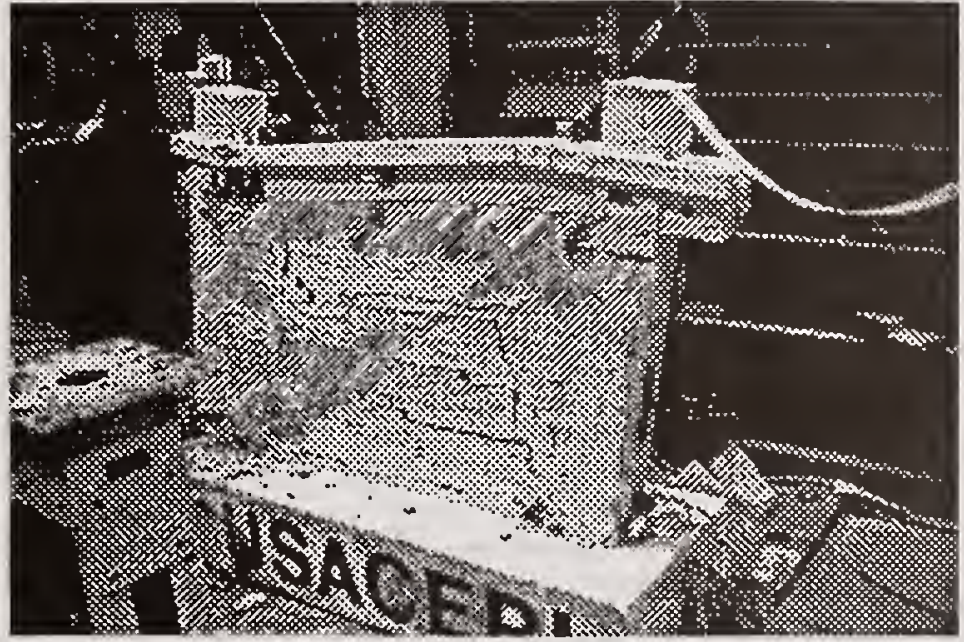

Figure 3: Strong Frame Deformation After the Push Over Test.

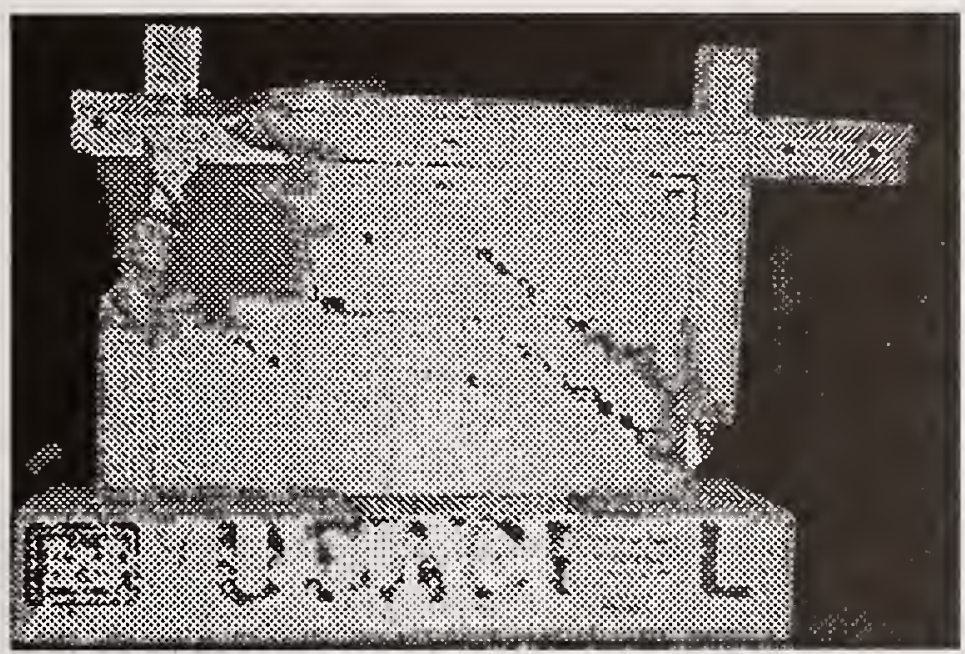

Figure 5: Weak Frame Deformation After the Push Over Test (Front Side)

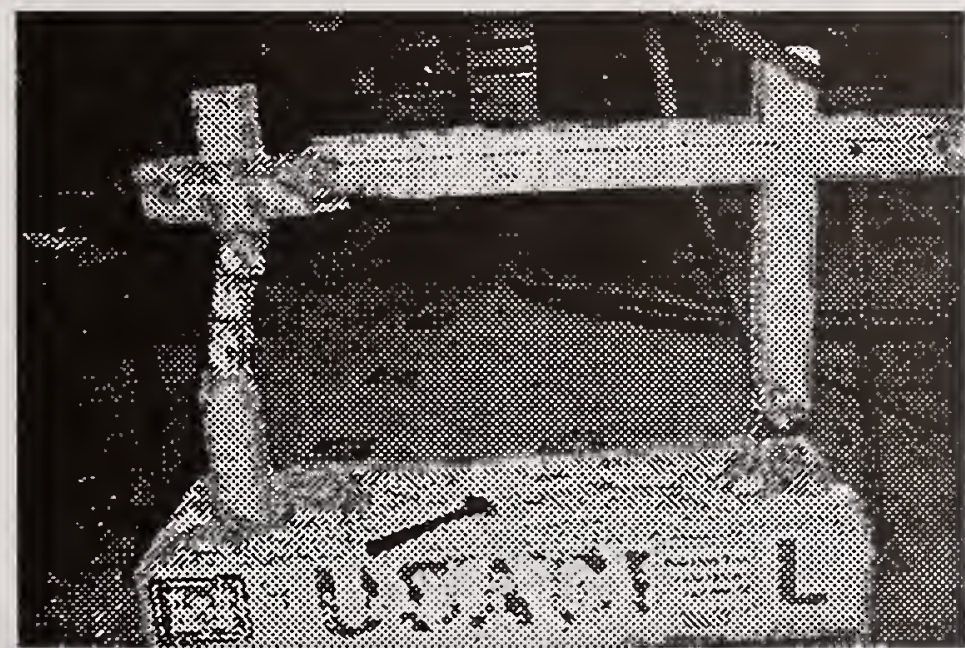

Figure 7: Weak Frame Hinges Failure on the R/C Frame

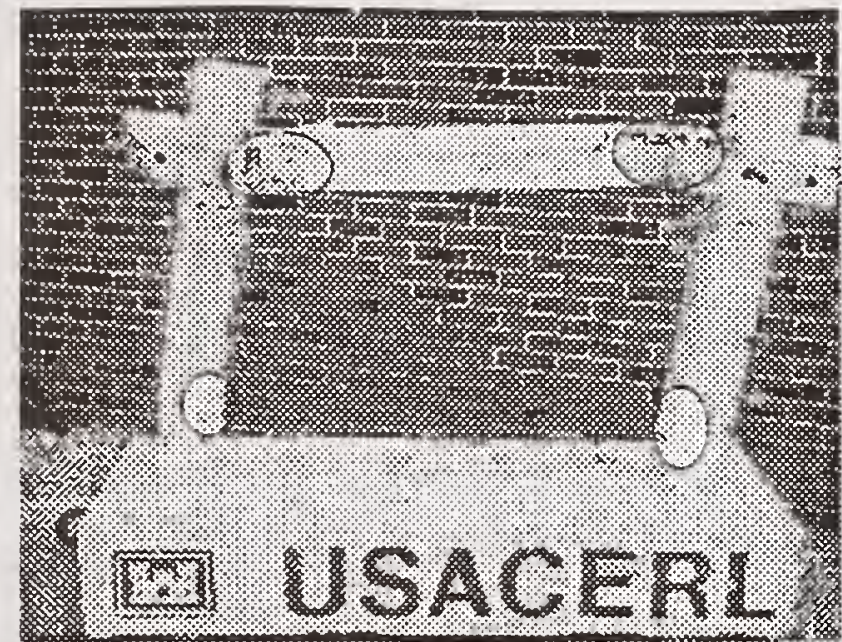

Figure 4: Strong Frame Hinges on the R/C Frame

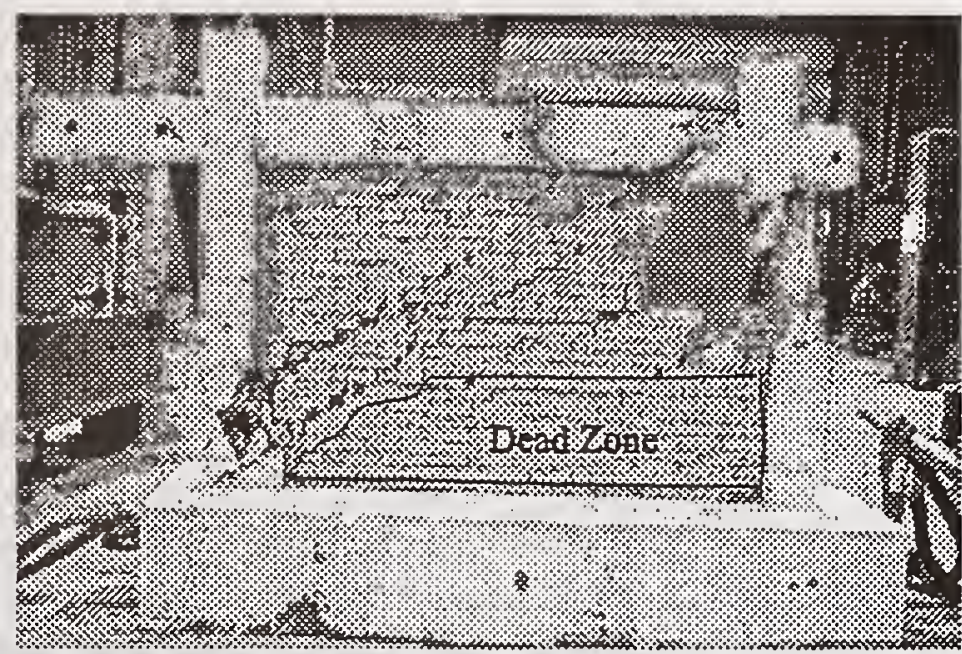

Figure 6: Weak Frame Deformation After the Push Over Test (Back Side)

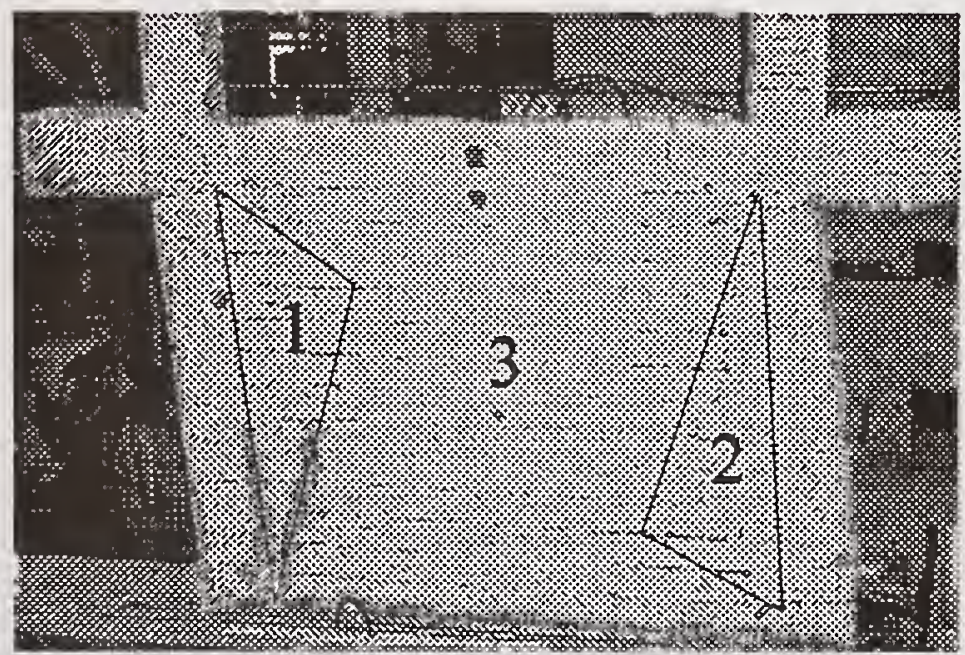

Figure 8: Large Frame Failure Mechanism 


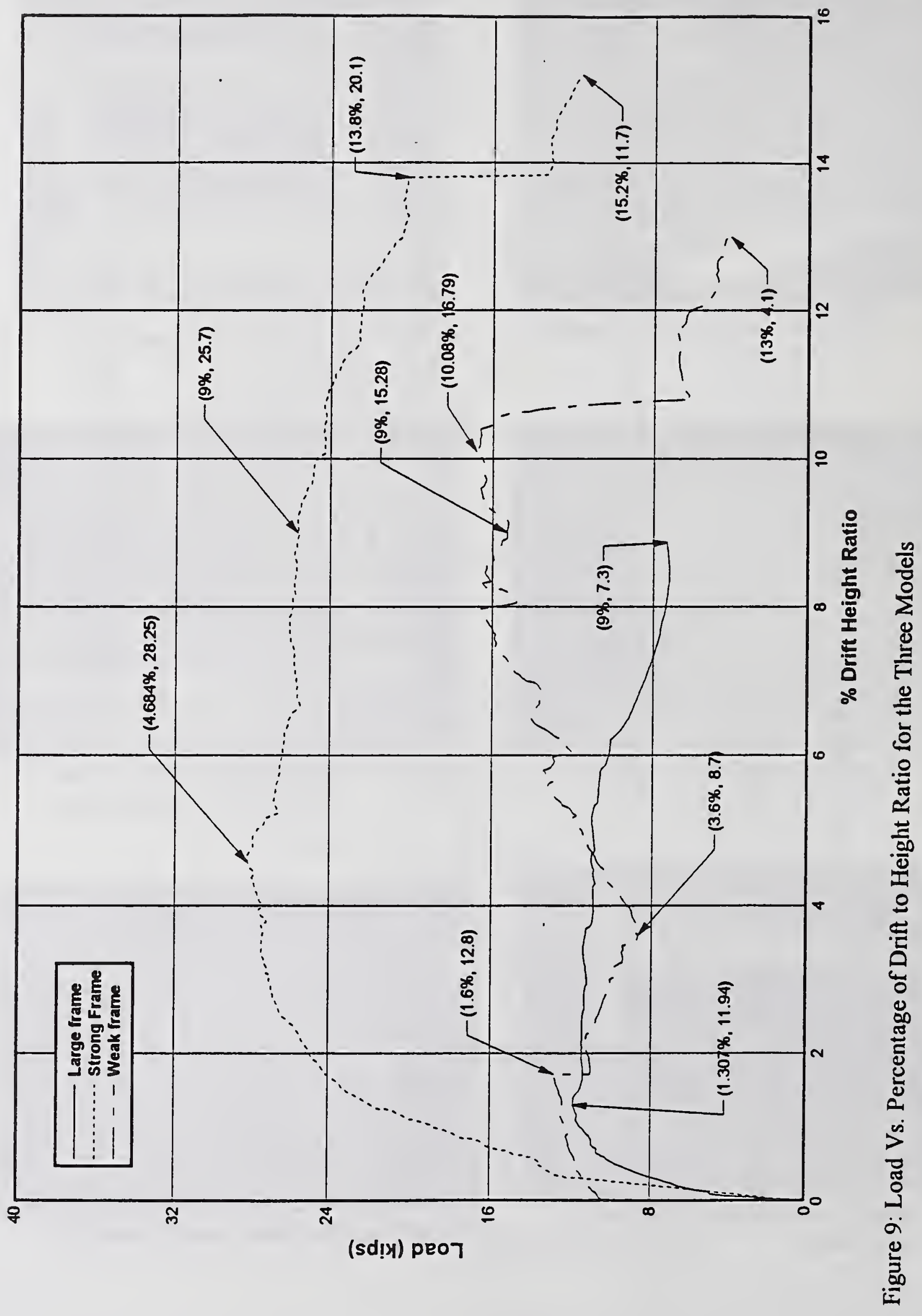



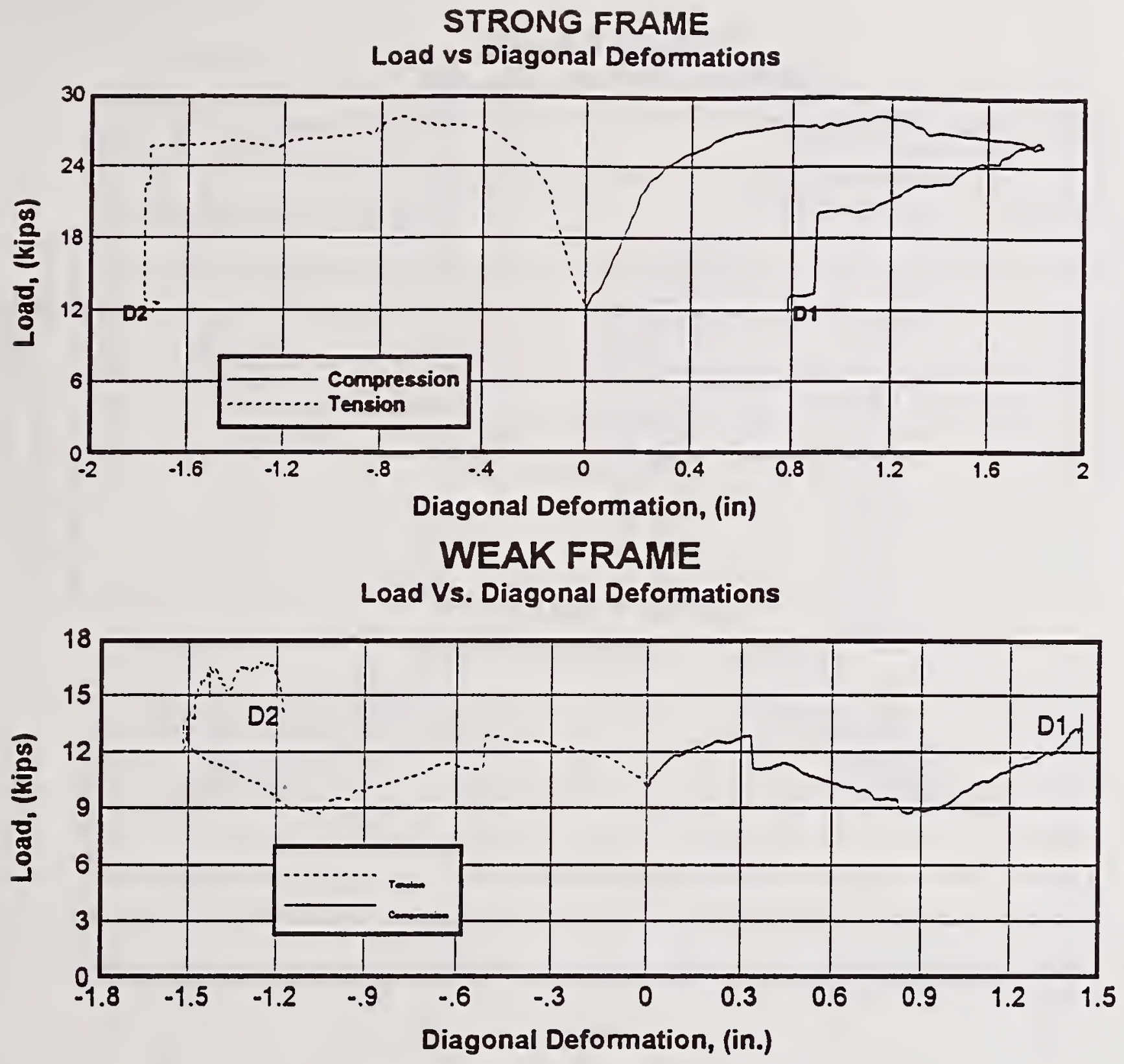

LARGE FRAME

Load vs Diagonal Deformations

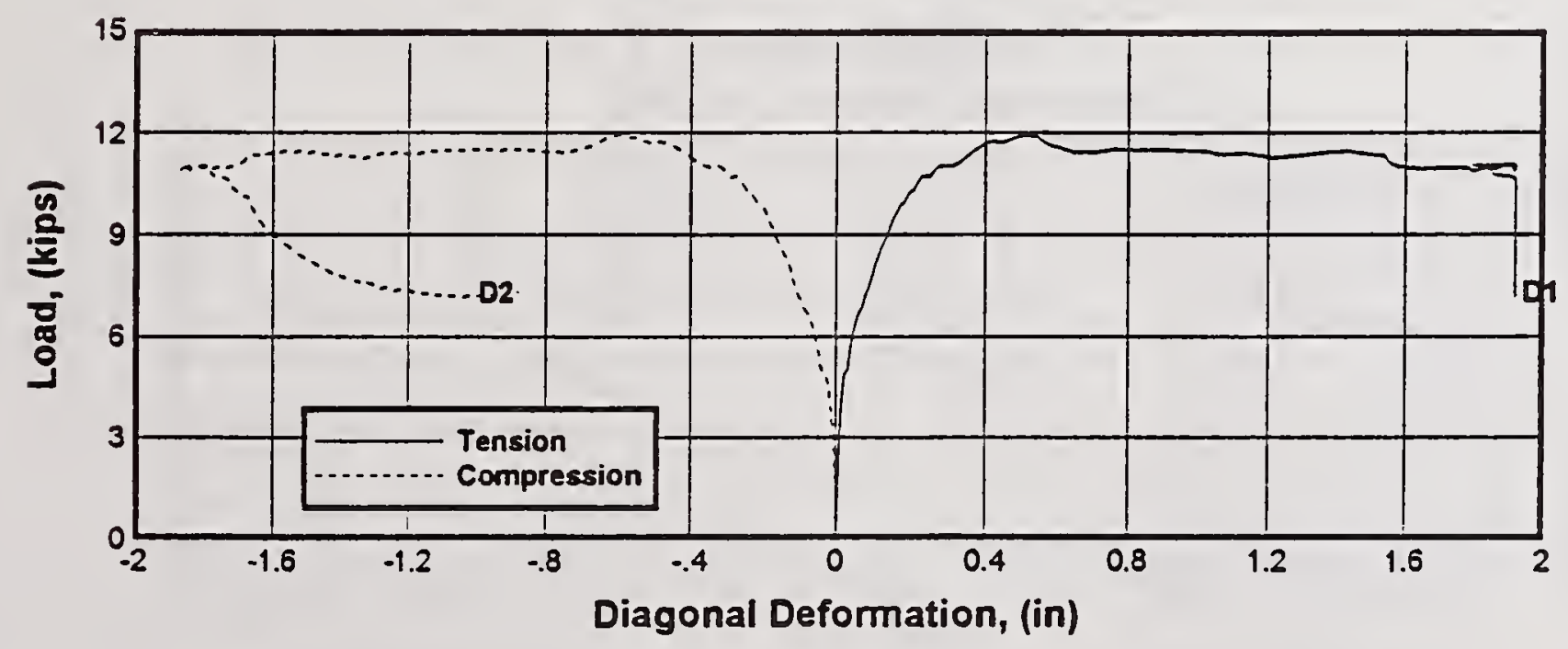

Figure 10: Load Vs. Diagonal Deformation for the Strong, Weak, Large Frame Models 

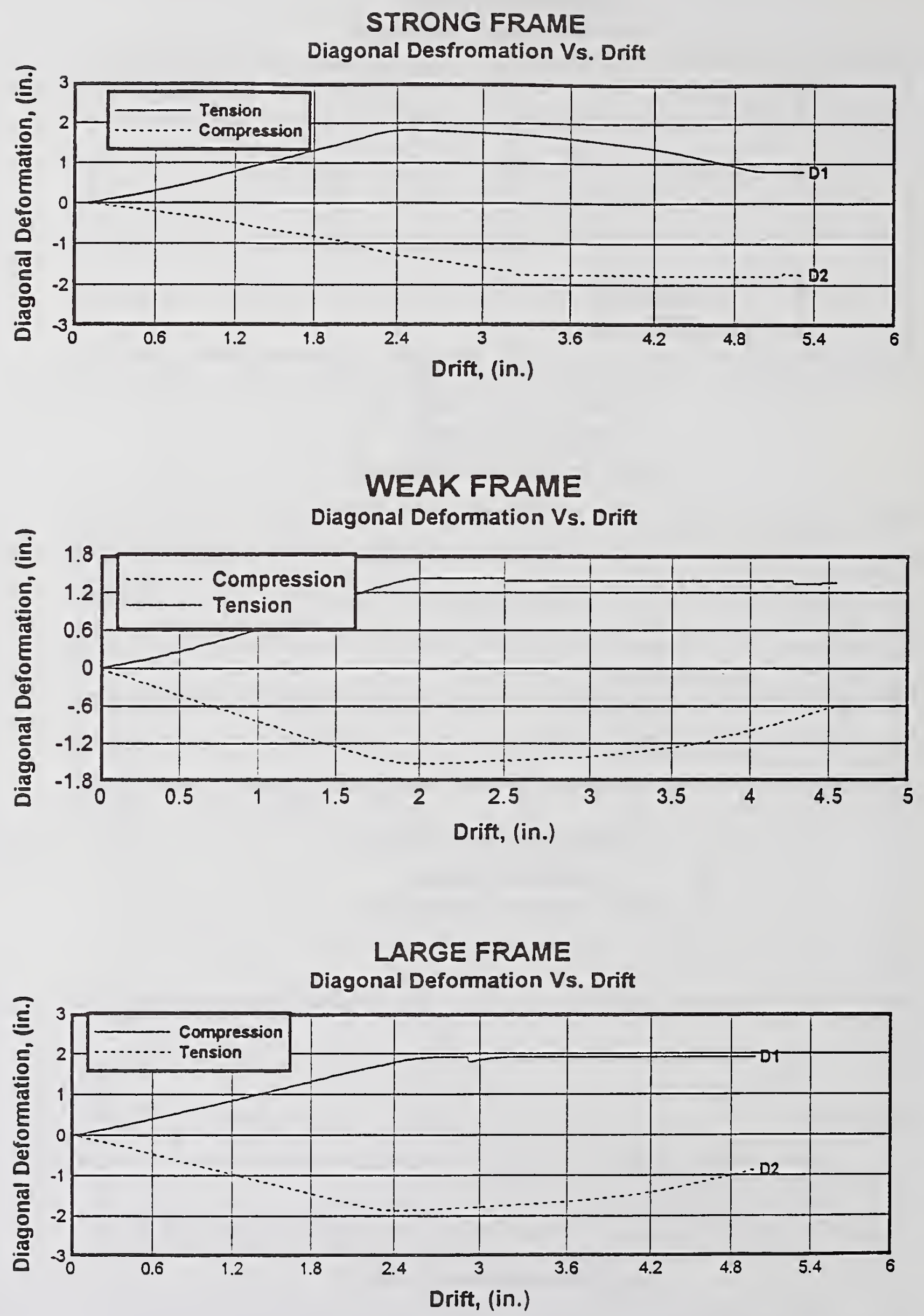

Figure 11: Diagonal Deformation Vs Drift for the Strong, Weak, Large Frame Models 

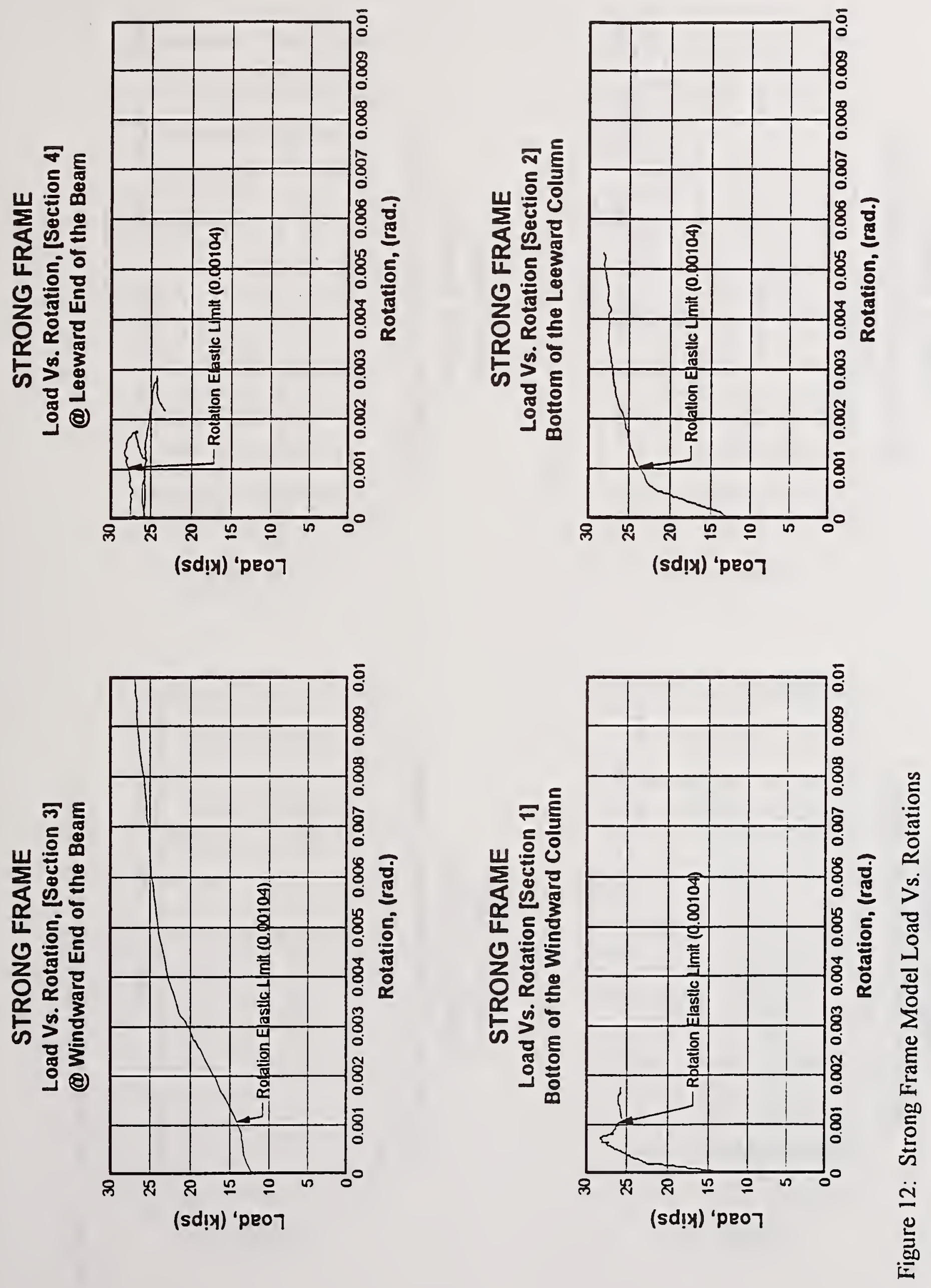

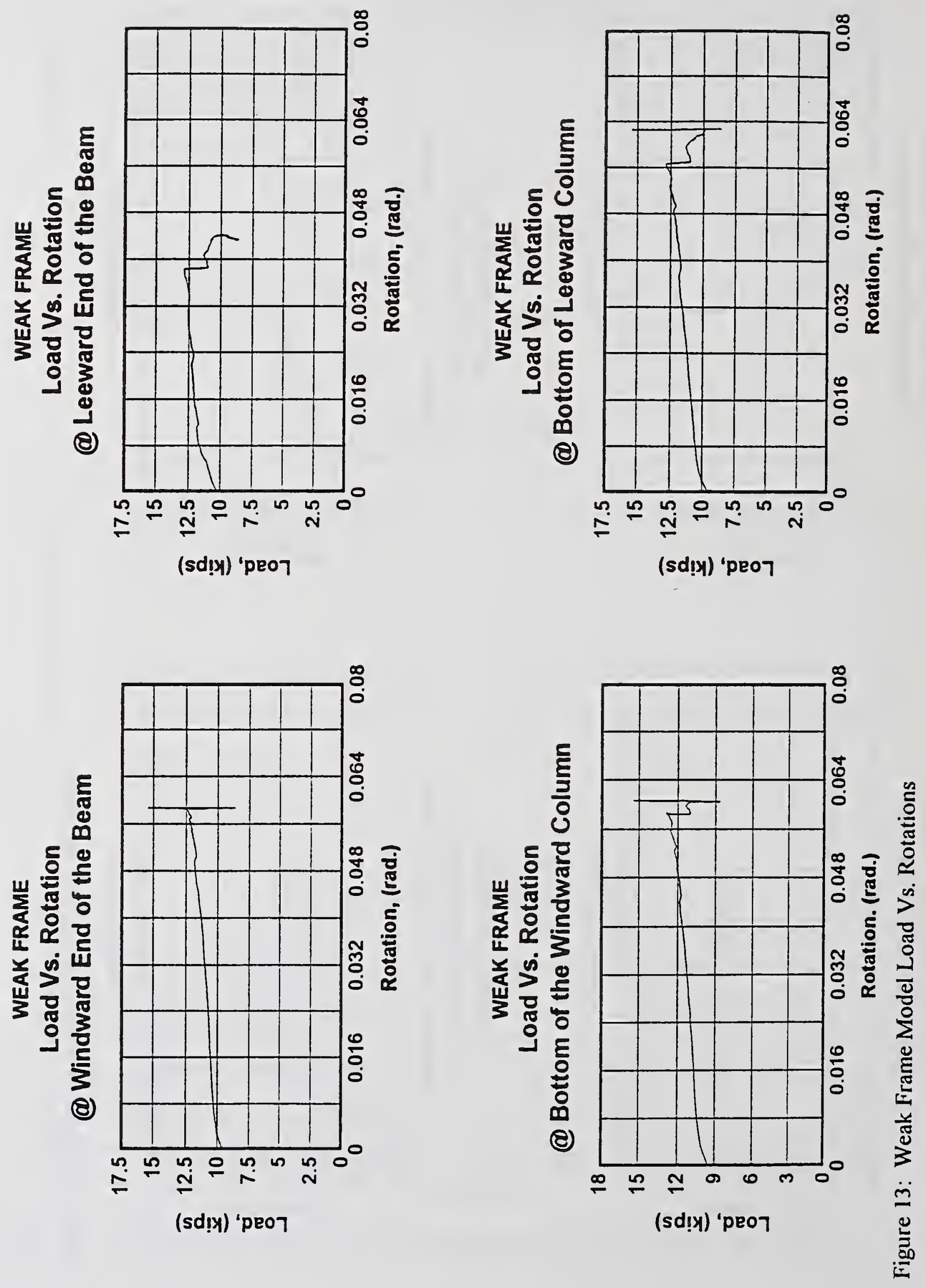

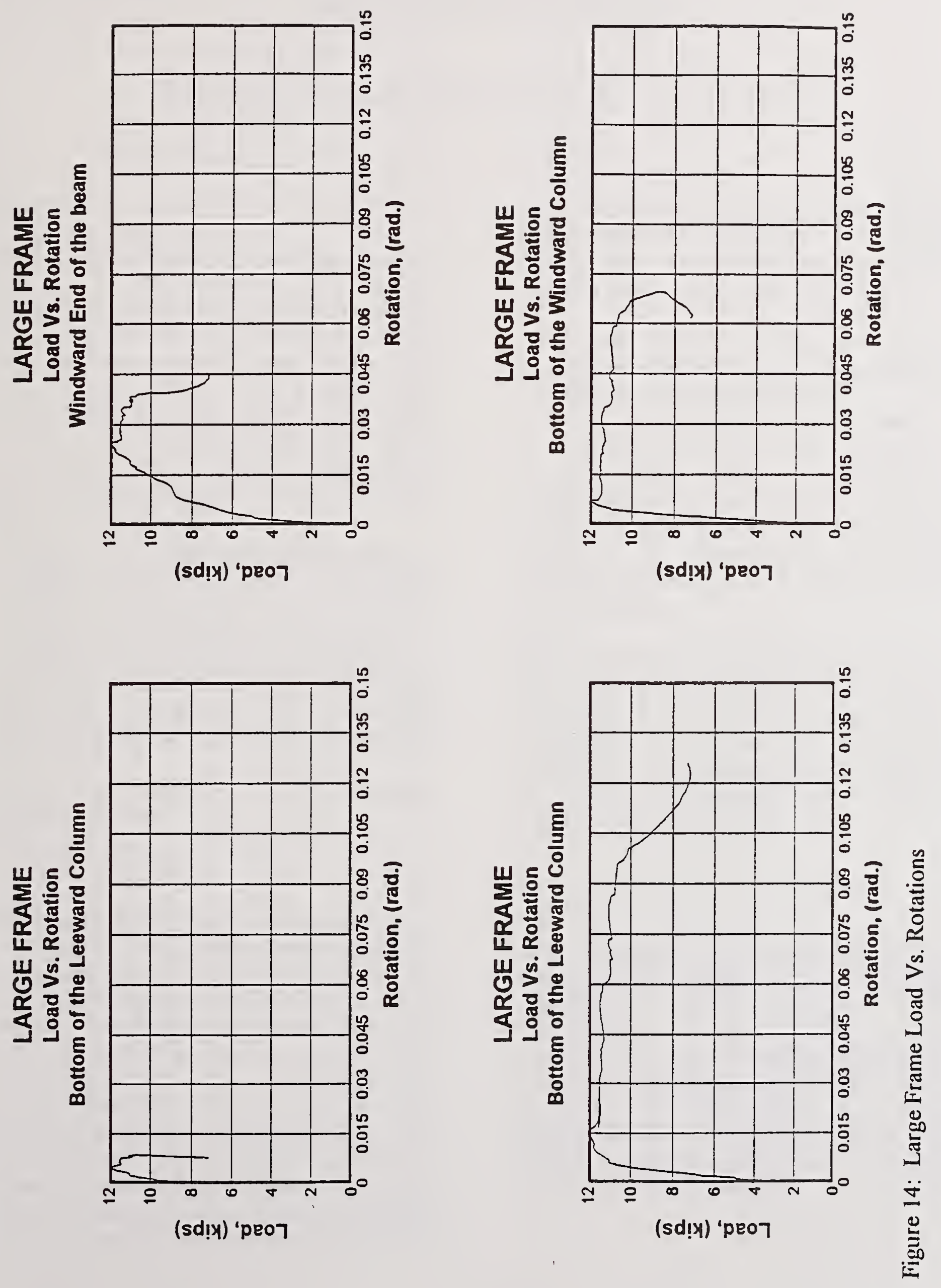



\title{
Designs and Techniques for the Restoration \\ of the Earthquake-damaged \\ Hanshin Expressway Kobe Route
}

\author{
Hisamori Ohtsuka ${ }^{1)}$, Hiroyuki Nakajima ${ }^{2)}$, Hidenao Hayashi ${ }^{3)}$ and Kenji Kosa ${ }^{4)}$
}

\section{ABSTRACT}

The Great Hanshin Earthquake that occurred at dawn on January 17, 1995, caused tremendous damage to the Hanshin Expressways. The most severely affected was the Kobe Route (Route 3) in the Hyogo prefectural area where piers over a length of 635 meters toppled and four other elevated sections collapsed. The restoration work is being carried out in accordance with the "Specifications for the Restoration of Highway Bridges stricken by the Great Hanshin Earthquake", following the basic policies described below.

a) Improve the deformation performance and strength of individual structures, so that the entire bridge can withstand seismic force.

b) Reuse as many components as possible by repairing and reinforcing existing structures.

Restoration of a total of $27.7 \mathrm{~km}$ of the damaged section is now in progress. Complete restoration of the entire Kobe Route is scheduled for October 1996.

KEYWORDS: deformation, ductility, earthquake, reinforced concrete

\section{INTRODUCTION}

The Great Hanshin Earthquake that occurred at dawn on January 17, 1995, caused tremendous damage to the Hanshin area. The Hanshin Expressways also sustained serious damage. The most severely affected was the Kobe Route (Route 3) in the Hyogo prefectural area where piers over a length of 635 meters fell sideways and four other elevated sections collapsed. Before the disaster, an average of 115,000 vehicles used the Kobe Route every day, accounting for $40 \%$ of the east-west traffic between Kobe and Osaka. This main traffic artery is now being repaired and reconstructed, and will be restored to complete service as rapidly as possible. The restoration work has been carried out in accordance with the "Specifications for the Restoration of Highway Bridges Stricken by the Great Hanshin Earthquake", following the basic policies described below.

a) Improving the deformation performance and strength of individual structures, so that the entire bridge can withstand seismic force.

The ductility and lateralforce bearing capacity of substructures have been increased. To reduce the seismic force acting on substructures, superstructures have been improved by connecting girders or making them continuous, installing isolation or horizontal reaction-dispersing bearings, and employing light-weight steel decks for bridge floors.

b) As many components as possible have been reused by repairing and reinforcing existing structures depending on the results of damage investigation. Foundations were reused since they received relatively minor damage. Piers and girders with light damage were repaired and reinforced to improve their seismic performance.

1) Head, Earthquake Engineering Division, P.W.R.I.

2) Section Chief, Design Section, Engineering Department, Hanshin Expressway Public Corporation

3) Section Chief, Research and Design Section, Kobe Route Reconstruction Division, Hanshin Expressway Public Corporation

4) Senior Engineer, Construction Section, Kobe Route Reconstruction Division, Hanshin Expressway Public Corporation 
Restoration of a total of $27.7 \mathrm{~km}$ of the damaged sections is now in progress. The Kyobashi-Maya section in the center of Kobe city was put back into service in February 1996, and $13.3 \mathrm{~km}$ of the FukaeWakamiya section will be available this coming August. Complete restoration of the entire Kobe Route is scheduled for October 1996. Following the emergency safety measures taken immediately after the earthquake, collapsed girders and piers were removed and many damaged super- and substructures have been repaired, reinforced or rebuilt. The Corporation is currently working on the last stages of construction such as pavements, noise barriers and other facilities related to roadways.

Techniques used in restoring the expressways are described below according to the type of structure.

\section{OUTLINE OF THE DAMAGE}

The Kobe Route suffered extensive damage during the earthquake. One 635-meter elevated section was toppled at the border between Kobe and Ashiya cities, four other sections collapsed and, as seen in Table 1 , about $60 \%$ of the total of 1,106 piers were damaged. Figure 1 shows the areas where major damage occurred. Emergency investigation was carried out immediately after the earthquake. Using the results from this, damaged structures were ranked on a scale between As, A, B, C and D, in accordance with the criteria specified in the Handbook of Earthquake Countermeasures for Roads (Disaster Restoration) which judge the severity of damage caused during a disaster. Of the piers on the Kobe Route, 943 are made of reinforced concrete, $15 \%$ of which were ranked As or A, i.e. functional damage, and $35 \%$ ranked $\mathrm{B}$ or $\mathrm{C}$, i.e. relatively light damage. Flexural and shear failure was typically found in columns at the cut-off point or at ground level. Although the number of severely affected steel piers was relatively low at 11 , buckling or cracking around manholes and peeling of coatings on welds were observed in about $80 \%$ of steel piers. About $7 \%$ of superstructures fell and buckling of the girder ends was frequently found.

\section{DESIGNS OF RECONSTRUCTED REINFORCED CONCRETE PIERS}

Designs of reinforced concrete piers were checked as follows at three different levels.

a) Level 1: Design of the allowable stress, using a seismic coefficient method in accordance with "Part V Seismic Design, the Specifications for the Design of Highway Bridges".

The design horizontal seismic coefficient was increased from the previous value of 0.2 to 0.25 .

b) Level 2: Check on the lateral force bearing capacity, in accordance with the "Part V, the Specifications for the Design of Highway Bridges".

The lateral force bearing capacity, which was not taken into account in the old design, was checked. For Group II ground (alluvium and diluvium), for example, the seismic coefficient used in the check was 0.85 .

c) Level 3-1: Check on the lateral force bearing capacity in accordance with the Restoration Specifications.

The stress-strain curve of concrete is different from Level 2 which takes into account the lateral force confinement effect of reinforcements. For Group II ground (alluvium and diluvium), for example, the seismic coefficient to be used in the check was 1.75 .

d) Level 3-2: Nonlinear dynamic analysis using the seismic records of those areas where the maximum acceleration was observed during the Great Hanshin Earthquake.

Dynamic response was checked with typical waveforms for various types of ground, using records from measuring sites such as the Kobe Marine Meteorological Observatory and the Takatori Station of West Japan Railways.

Results of these investigations are shown in Fig. 2, comparing the old and new designs of a typical pier cross-section. The diameter of a circular column was increased to $3.4 \mathrm{~m}$ from the previous $3.0 \mathrm{~m}$. The old hoop ties were $13 \mathrm{~mm}$ in diameter and installed at intervals of $30 \mathrm{~cm}$, but as a result of the above studies, they were upgraded to $22 \mathrm{~mm}$ in diameter 
and placed at intervals of $12.5 \mathrm{~cm}$.

Before determining the designs and construction techniques for reinforced concrete piers, studies were carried out in three categories as described in the tree diagram (Fig. 3): a) experimental studies on the effectiveness of various reinforcing methods; b) confirmation of the practicability of techniques such as adding bars and concrete to piers, through experiments using full-scale test models prepared in accordance with the Restoration Specifications; and c) establishment of the "Construction manual for the substructures of the Hanshin Expressway Kobe Route" to specify standard techniques and assure consistent quality control. Items a) and b) are described below.

\section{EXPERIMENTAL STUDIES ON THE STRENGTHENING TECHNIQUES OF REINFORCED CONCRETE PIERS}

\section{(1) Test Models}

Piers were restored by the following two procedures depending on the degree of damage (Fig. 4): while reusing existing footings, severely-damaged piers were removed and new ones were constructed; relatively less damaged piers were repaired and reinforced. As shown in the experimental conditions and parameters of Table 2, four types of reinforcing methods were tested by experiment using a total of 15 specimens.

a) Steel plate jacketing: this is an attempt to increase the bearing capacity and confinement effect of existing piers by simply encasing them with steel plates.

b) Reinforced concrete jacketing: both the bearing capacity and confinement effect are expected to improve.

c) A combination of steel plate jacketing and reinforced concrete jacketing: the reinforced concrete jacket increases the bearing capacity, while the steel plate jacket installed around it but not anchored to the footing increases the confinement effect.

d) Rebuilding of reinforced concrete piers: a new reinforced concrete pier is unified with an existing footing by means of post-installed anchors.

To investigate the effect of reinforcement damage on the pier's bearing capacity, test models for a) to d) with different degrees of damage were strengthened with the reinforced concrete jacketing and the combined jacketing of reinforced concrete and steel plate. All test pieces were one-sixth scale models of a real bridge with square cross-sections, and loads were applied to them as indicated in Fig. 5.

\section{(2) Experimental Results and Discussion}

Figure 6 shows the typical relationship between the load applied to a test model and the amount of horizontal displacement, and Fig. 7 is a typical loaddisplacement envelope linking every first applied load under the reversed cyclic lateral loading. Results of both calculations and experiments are shown in Table 3. In the experiments the maximum bearing capacities of the standard model were about 24.5 tf and those of the reinforced models, except the model strengthened by the steel plate jackets, were around $36 \mathrm{tf}$, suggesting an increase of about 1.5 times in bearing capacity. One of the steel plate jacket models was anchored to the footing; it exhibited a maximum bearing capacity of $35.1 \mathrm{tf}, 1.4$ times the standard model. The experimental maximum bearing capacities closely agreed with the corresponding analysis values. Figure 8 shows the ductility factors of the test models, with the displacement when the load had dropped to $80 \%$ of its maximum being taken as the ultimate value. The experimental values, even after modification for the loss due to the pull-out of reinforcements, satisfied the analysis values derived from the Restoration Specifications. The ductility factor exceeded 10 for some of the reinforced concrete jacket models, well above the analysis values. Figure 9 shows the relationship between the ductility factor and the hoop tie ratio in the reinforced concrete jacket models. With the higher hoop tie ratio, the ductility factor increased from 6 to around 9 , suggesting that the increased number of hoop ties contributes to the improvement of ductility. Taking into account that the hoop tie ratio is usually limited to about $0.7 \%$ in actual structures, the ductility factor of 10 might be a reasonable upper limit for normal reinforcement with reinforced concrete. Figure 10 shows the energy absorption area enclosed by the load-horizontal displacement envelope of each model. There is a similar tendency in energy absorption area with the ductility factor, with the reinforced concrete jacket model having outstanding values. Figure 11 shows the relationship between the 
hoop tie ratio and energy absorption ratio in the reinforced concrete jacket model, where the absorption ratio increased from 15 to 22 with the increase in the hoop tie ratio. Increasing the number of hoop ties contributes to the improvement of ductility.

\section{EXPERIMENTS FOR CONFIRMING THE PRACTICABILITY OF RECONSTRUCTION TECHNIQUES FOR REINFORCED CONCRETE PIERS BASED ON THE RESTORATION SPECIFICATIONS}

Reconstruction techniques were tested for their practicability using full-scale test models. Two had rectangular cross-sections of $3 \times 3 \mathrm{~m}$ and one had a circular cross-section with a diameter of $3 \mathrm{~m}$. They were all $6 \mathrm{~m}$ tall. Comparison was carried out between the three methods in Fig. 12 for installing hoop ties during reconstruction and also between the other three methods in Fig. 13 for the installation of intermediate hoop ties. Normal concrete (slump: 8 $\mathrm{cm}$ ) was compared with flowing concrete (slump: 18 $\mathrm{cm}$ ) containing super AE plasticizer to increase workability. After these comparative studies, the following techniques and materials were chosen as the standard for restoration work:

a) For installing hoop ties during reconstruction, the 4-section (rectangular) and 3-section (circular) hooking methods which provide the best practicability, or the 2-section flare welding method that can be implemented even if main reinforcements are supported, were used.

b) For adding intermediate hoop ties, two acuteangled hooks bent at one end were used in place of one acute-angled hook at both ends since the latter hook is difficult to insert because of space constraints.

c) Normal concrete was used since this type proved successful in tests.

\section{RECONSTRUCTION OF REINFORCED CONCRETE PIERS}

A composite structure was seiected as a standard structure for rebuilding reinforced concrete piers. Reinforced concrete columns were designed to satisfy the Restoration Specifications, and steel beams were employed to reduce the construction time. Figure 14 shows the structure of a rebuilt pier.

Before reconstruction, old damaged piers were removed approximately to ground level $(1.5 \mathrm{~m}$ above the top of the footing). After removing the old concrete from a column, the axial main reinforcements were erected, reusing the old intact bars, while installing additional reinforcements with post-installed anchorages.

Hoop ties with a diameter of $22 \mathrm{~mm}$ were then installed at intervals of $12.5 \mathrm{~cm}$.

The column was erected to a height $2.5 \mathrm{~m}$ below the base of the beam, beam supports were assembled, and the steel beam was installed. Column axial main reinforcement bars were inserted through the holes in the lower flanges at the corners of the steel beam, and the column was filled with concrete.

\section{REPAIR AND REINFORCEMENT OF REINFORCED CONCRETE PIERS}

The combined use of reinforced concrete and steel plate jackets was selected as the standard method for strengthening existing reinforced concrete piers. The steel plate jacket in this technique is intended to increase the ductility and shear bearing capacity of the pier, so it was not anchored to the footing. Details of the reinforcement are shown in Fig. 15. The steel plate jacket was regarded as hoop ties in the design. The reinforced concrete jacket was designed to have a thickness of at least $30 \mathrm{~cm}$ from the surface of the existing concrete cover. After impregnating resin into cracks, the surface of the existing concrete was chipped. Any loose parts were removed, and bars which had buckled, failed or yielded during the earthquake were replaced. The reinforcement bars were then installed by post-installed anchorage. These additional reinforcement bars were of the same type and diameter as the existing main reinforcements, and laid at intervals of between 20 and $30 \mathrm{~cm}$. Hoop ties and then steel plates were installed. Studs were used to unite the steel plate jacket to the concrete jacket. Finally, concrete was injected into the space between the steel plate jacket and the old concrete. Flowing concrete was used in this technique. 


\section{REPAIR AND REINFORCEMENT OF STEEL STRUCTURES}

\section{(1) Steel Piers}

Steel piers were removed and reconstructed where columns had been substantially buckled or cracks had developed around the circumference. Where repair by partial replacement of elements was judged possible, the load of the superstructure was temporarily removed, damaged sections were cut out and removed, and new elements were installed in their place. There are several measures to increase the lateral force bearing capacity of steel piers: adding ribs to the interior of a pier, placing concrete inside the pier, and so on. In the restoration of the Kobe Route, the latter technique was used in accordance with the Restoration Specifications.

\section{(2) Steel Girders}

Reconstructed girders were designed as normal new girders, but steel decks were employed as the floor material to reduce the weight of the superstructure. Main girder buckling was often found where end cross beams had knee braces, so a full-web structure is now employed for the end cross beams to reinforce the girders. Steel girders were made continuous or connected to each other to make the structure more seismic-resistant.

Steel bearings were replaced with isolation rubber bearings so that horizontal forces are dispersed and damped. To help prevent a bridge from falling off its supports, the conventional plate-type device was replaced with a $\mathrm{PC}$ cable type that can also move perpendicular to the bridge axis.

\section{REPAIR AND REINFORCEMENT OF FOUNDATIONS}

Foundations were checked for damage over the full length of their piles by core boring. Although small cracks were found in some pile caps, the overall damage was light. Loading tests were performed on the most severely damaged piles. The results suggested that their load bearing capacity had not been reduced. To assure safety, however, cracks were impregnated with resin so reinforcement bars inside the piles are protected from corrosion. All Benoto pile foundations were checked for their bearing capacity under seismic loads by a method that takes nonlinear behavior into account, in accordance with the "Reference for Application of the Specifications for Restoration of the Highway Bridges Damaged by the Great Hanshin Earthquake". Five foundations whose bearing capacity was judged insufficient were reinforced with additional piles.

\section{DESIGNS AND TECHNIQUES FOR THE REBUILDING OF CONTINUOUS SECTIONS}

\section{(1) Fukae Section [a Mushroom-shaped Pier (Pilz) Section]}

There were two sections on the Kobe Route where structures toppled or collapsed over $635 \mathrm{~m}$ and 686 $\mathrm{m}$, respectively. The old structures in these sections were removed completely except for the foundations, and all were reconstructed. One of the two was the Pilz section that was widely reported on TV and in the newspapers, where a 635-meter stretch of 18 spans of the unified super- and substructures toppled. In the reconstruction design, the existing main reinforcements in the base of the columns was ignored since it was considered to have been subjected to extraordinary stress, so new main reinforcements $35-\mathrm{mm}$ in diameter are now unified with the footing by post-installed anchorage. The shape of the piers was changed from a circular column of $3 \mathrm{~m}$ diameter to a wall-type column $3 \times 6$ m (Figs. 19 and 20) to accept post-installed anchors inserted at $20-\mathrm{cm}$ intervals.

The columns were slightly rounded to match the landscape. The diameter of hoop ties was increased from $13 \mathrm{~mm}$ to $16 \mathrm{~mm}$, and their interval was reduced from $30 \mathrm{~cm}$ to $12.5 \mathrm{~cm}$. The intermediate hoop ties were laid at intervals of $60 \mathrm{~cm}$. Steel floor slabs were employed so that the old, reused foundations would not be overloaded. Girders were made continuous where possible, and isolation rubber bearings were used. The new superstructure is to be 9 spans of twin continuous box girders with steel decks.
(2) Benten Section (Continuous Rigid Frame Bridge)

This section is a 686-meter viaduct of 24 spans above 
National Road No. 2. The old structure consisted of 30-meter spans of simple composite or continuous non-composite I girders with cross beams supported by independent single reinforced concrete columns (Fig. 22). Since the columns were sited in the median strip and sidewalks, they were only $1 \mathrm{~m}$ wide and steel bearings were used to connect them to the superstructure. The concrete columns failed due to shear during the earthquake, causing three girders to collapse and five girders to buckle. Rigid connection to the base would not have been sufficient to assure adequate bearing capacity of the existing foundations, so the restoration design adopted a multi-span continuous rigid frame structure with isolation bearings installed in the bases of the piers. The number of continuous spans was set at 19 , taking into account the movement due to thermal stress and earthquakes and the torsional deformation (the end piers are single columns) at the ends of a continuous girder.

\section{CLOSING WORDS}

As stated so far, the working conditions are tough and there are many difficult technical problems surrounding the restoration of the Kobe Route. However, due to around-the-clock work and tremendous efforts by the staff as well as contractors, it has been possible to drastically reduce the construction period from the initial estimate of three years. Work is progressing toward complete restoration of the entire network by October 1996. The authors express their deep gratitude to all the people concerned and ask for continuous support and cooperation. 
Table 1 Ranking of damaged piers

\begin{tabular}{|l|r|r|r|r|r|r|}
\hline & \multicolumn{1}{|c|}{ As } & \multicolumn{1}{c|}{ A } & \multicolumn{1}{c|}{ B } & \multicolumn{1}{c|}{ C } & \multicolumn{1}{c|}{ D } & \multicolumn{1}{c|}{ Total } \\
\hline Steel piers & 3 & 8 & 12 & 112 & 28 & 163 \\
\hline Concrete piers & 64 & 78 & 102 & 225 & 474 & 943 \\
\hline Total & 67 & 86 & 114 & 337 & 502 & 1,106 \\
\hline
\end{tabular}

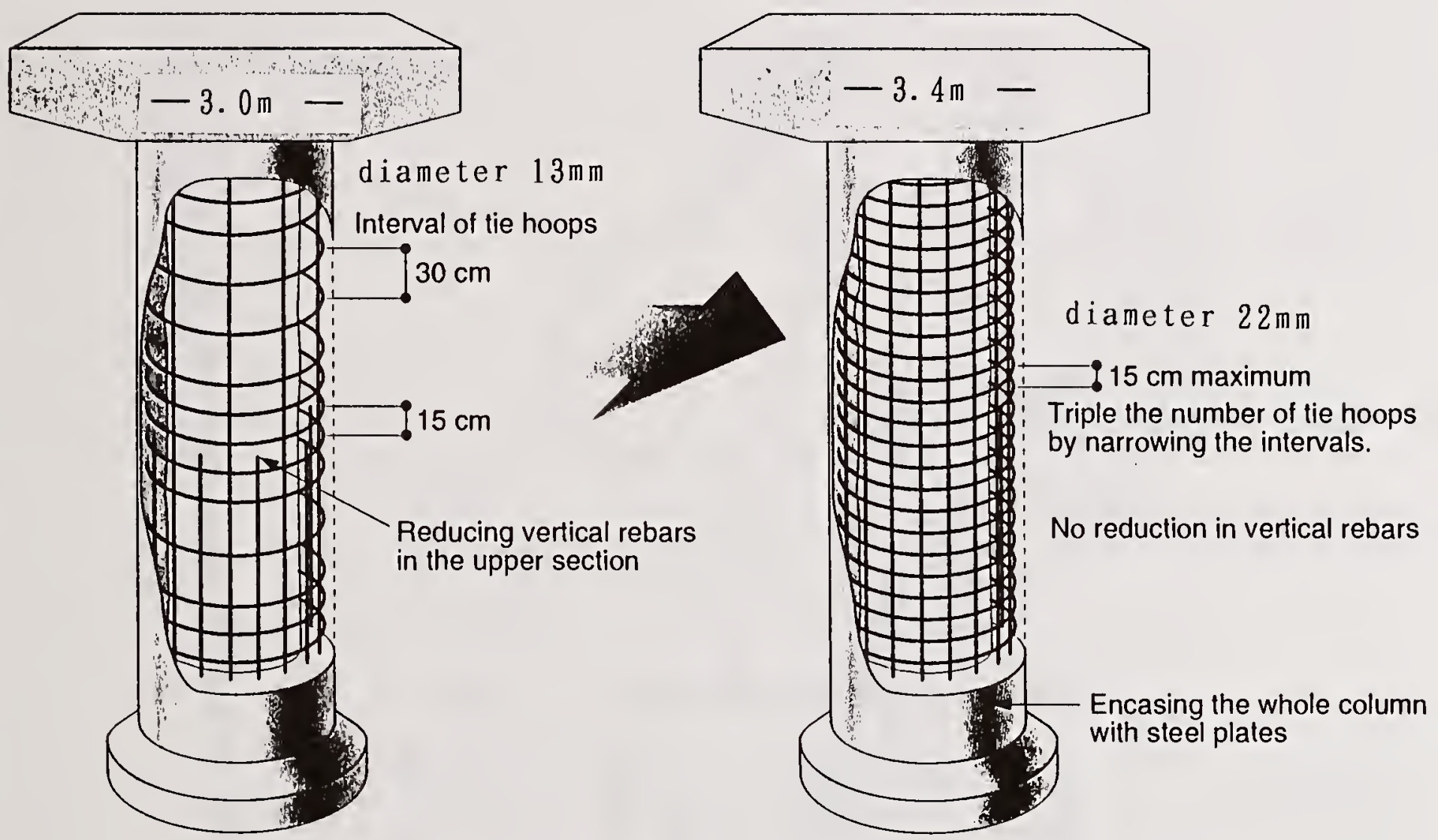

Figure 2 Results of checks on reinforced concrete piers

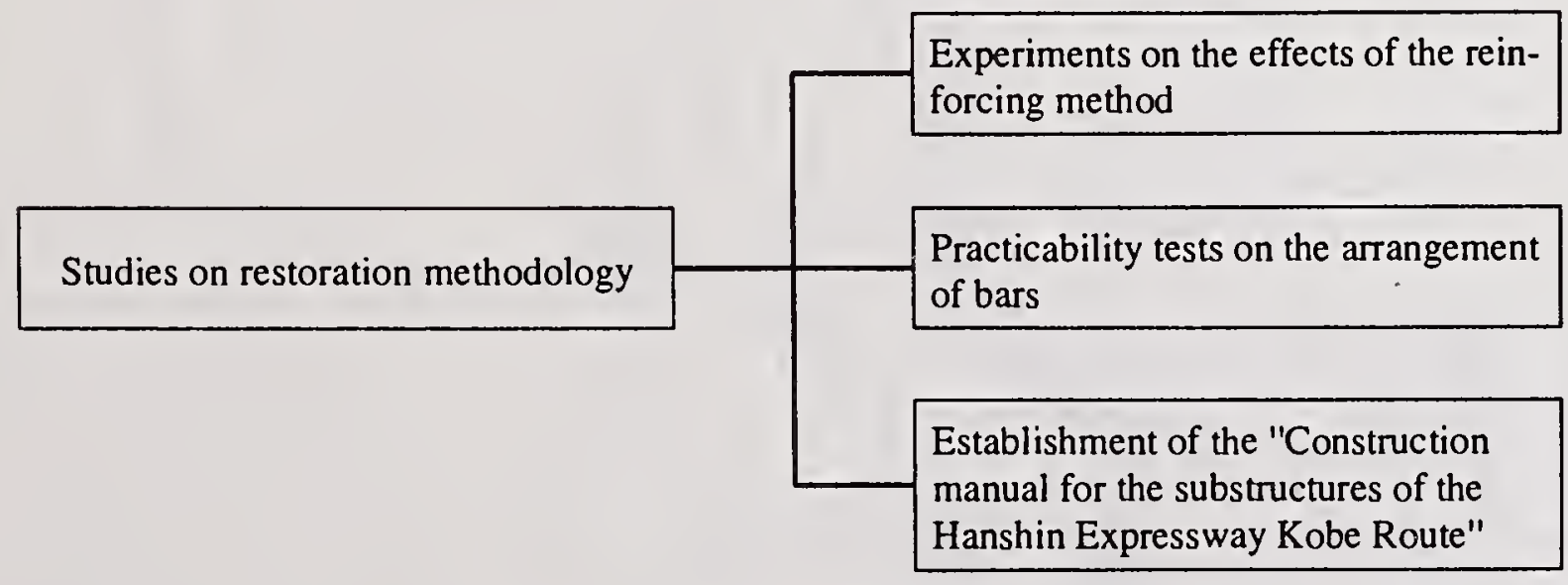

Figure 3 Investigation procedures 


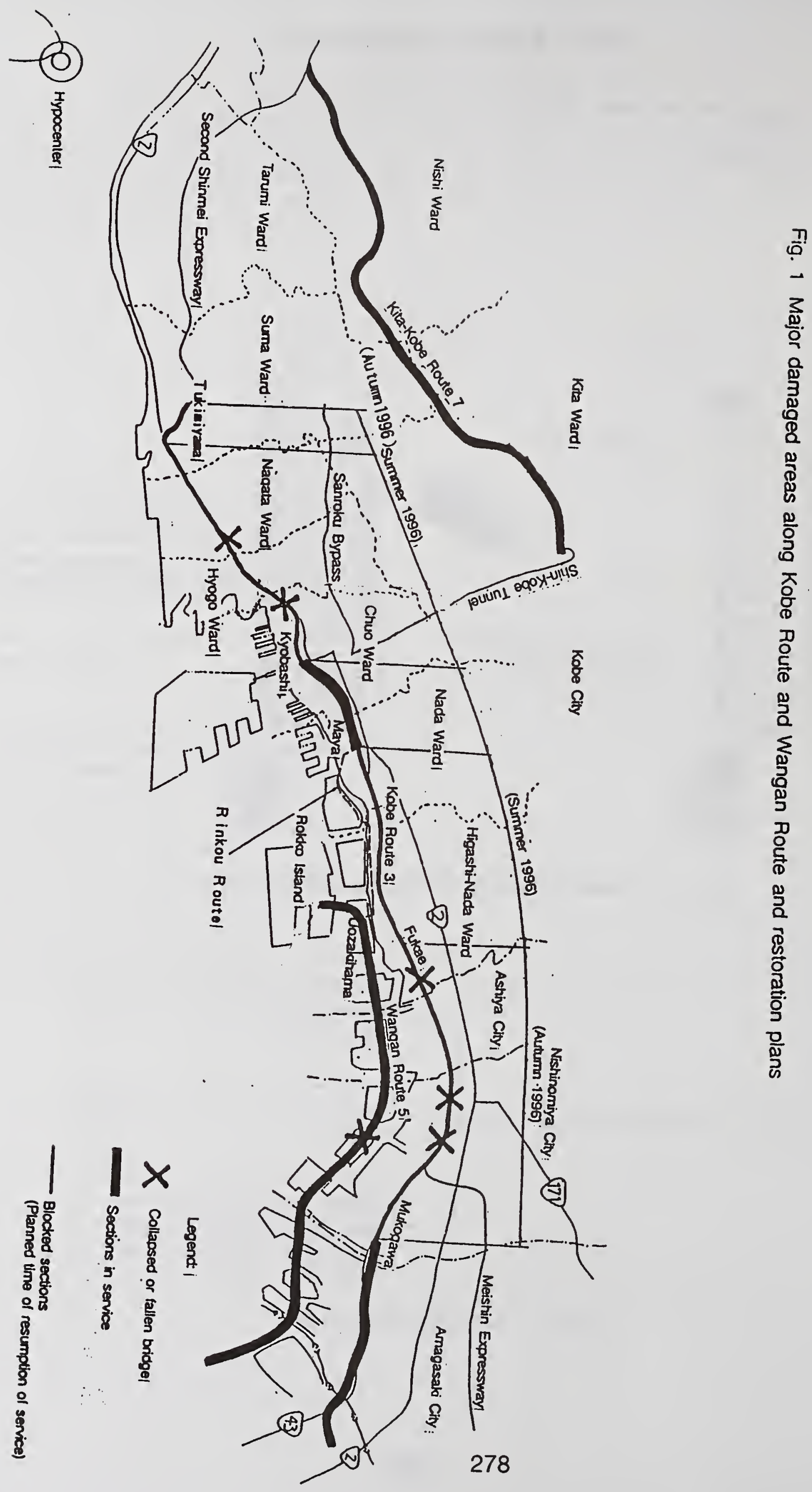


Table 2 Experimental conditions and parameters

\begin{tabular}{|c|c|c|c|c|c|c|c|c|c|}
\hline $\begin{array}{l}\text { Test model } \\
\text { No. }\end{array}$ & $\begin{array}{l}\text { Reinforcement } \\
\text { technique }\end{array}$ & $\begin{array}{l}\text { Existing pier } \\
\text { cross-section }\end{array}$ & $\begin{array}{c}\text { Cross-section } \\
\text { after } \\
\text { reinforcement }\end{array}$ & $\begin{array}{l}\text { Reinforcement } \\
\text { ratio }\end{array}$ & Hoop tie & $\begin{array}{l}\text { Design horizon- } \\
\text { tal seismic co- } \\
\text { efficient (Khco) }\end{array}$ & $\begin{array}{l}\text { Reinforcing sleel } \\
\text { anchorage }\end{array}$ & Anchorage length & Remarks \\
\hline 1 & Existing & \multirow{15}{*}{$\begin{array}{l}\text { Square, } \\
60 \mathrm{~cm} \times 60 \mathrm{~cm}\end{array}$} & \multirow{4}{*}{-} & \multirow{4}{*}{$P=0.51 \%$} & \multirow{4}{*}{$P w-0.11 \%$} & \multirow{4}{*}{0.78} & & & Damage rank C \\
\hline 2 & Existing & & & & & & & & Damage rank C \\
\hline 3 & Existing & & & & & & & & Damage rank B \\
\hline 4 & Existing & & & & & & & & Damage rank B \\
\hline 5 & Steel plate jacket & & \multirow{3}{*}{$\begin{array}{l}\text { Square, } \\
60 \mathrm{~cm} \times 60 \mathrm{~cm}\end{array}$} & $P=0.85 \%$ & \multirow{3}{*}{$P w=0.64 \%$} & 1.50 & $\begin{array}{l}\text { Post-installed } \\
\text { resin anchor }\end{array}$ & $\begin{array}{l}\text { To the footing } \\
\text { bottom bar" }\end{array}$ & $\begin{array}{l}\text { The bottom ends of the steel } \\
\text { plates are anchored. }\end{array}$ \\
\hline 6 & Steel plate jacket & & & \multirow[t]{2}{*}{$P=0.61 \%$} & & \multirow[t]{2}{*}{1.41} & & & $\begin{array}{l}\mathrm{V}_{\mathrm{g}}-0 \mathrm{~cm} \\
\text { ( } \mathrm{Vg} \text { : clearance between the } \\
\text { steel plate and the footing) }\end{array}$ \\
\hline 7 & Steel plate jacket & & & & & & & & $v_{8}-5 \mathrm{~cm}$ \\
\hline 8 & $\begin{array}{l}\text { Reinforced concrete } \\
\text { jacket }\end{array}$ & & \multirow{8}{*}{$\begin{array}{l}\text { Square. } \\
70 \mathrm{~cm} \times 70 \mathrm{~cm}\end{array}$} & \multirow{4}{*}{$P=0.61 \%$} & \multirow{2}{*}{$P w=0.70 \%$} & \multirow{2}{*}{217} & $\begin{array}{l}\text { Post-installed } \\
\text { resin anchor }\end{array}$ & $\begin{array}{l}\text { To the footing } \\
\text { bottom bare }\end{array}$ & $\begin{array}{l}\text { Test model No. } 1 \text { reused } \\
\text { affer the experiment }\end{array}$ \\
\hline 9 & $\begin{array}{l}\text { Reinfored concrete } \\
\text { jacket }\end{array}$ & & & & & & $\begin{array}{l}\text { Post-installed } \\
\text { resin anchor }\end{array}$ & $\begin{array}{l}\text { To the footing } \\
\text { bottom bar* }\end{array}$ & $\begin{array}{l}\text { Test model No. } 3 \text { reused } \\
\text { after the experiment }\end{array}$ \\
\hline 10 & $\begin{array}{l}\text { Steel plate }+ \\
\text { reinfored concrete }\end{array}$ & & & & \multirow{2}{*}{$P w=0.65 \%$} & \multirow{2}{*}{1.97} & $\begin{array}{l}\text { Post-installed } \\
\text { resin anchor }\end{array}$ & $\begin{array}{l}\text { To the footing } \\
\text { bottom bar }\end{array}$ & $\begin{array}{l}\text { Test model No. } 2 \text { reused after } \\
\text { the experiment: } V_{8}-5 \mathrm{~cm}\end{array}$ \\
\hline 11 & $\begin{array}{l}\text { Steel plate + } \\
\text { reinfored concrete }\end{array}$ & & & & & & $\begin{array}{l}\text { Post-installed } \\
\text { resin anchor }\end{array}$ & $\begin{array}{l}\text { To the footing } \\
\text { bottom bar }\end{array}$ & $\begin{array}{l}\text { Test model No. } 4 \text { reused after } \\
\text { the experiment; } V_{8}-5 \mathrm{~cm}\end{array}$ \\
\hline 12 & $\begin{array}{l}\text { Reinforeed concrete } \\
\text { rebuilding }\end{array}$ & & & \multirow{4}{*}{$P=0.61 \%$} & \multirow{3}{*}{$P w=0.27 \%$} & \multirow{3}{*}{1.42} & $\begin{array}{l}\text { Before concrete } \\
\text { casting }\end{array}$ & $\begin{array}{l}\text { To the footing } \\
\text { bottom bar" }\end{array}$ & Standard test model \\
\hline 13 & $\begin{array}{l}\text { Reinforced concrete } \\
\text { rebuilding }\end{array}$ & & & & & & $\begin{array}{l}\text { Post-installed } \\
\text { resin anchor }\end{array}$ & $\begin{array}{l}\text { To the footing } \\
\text { bottom bar }\end{array}$ & \\
\hline 14 & $\begin{array}{l}\text { Reinfored concrete } \\
\text { rebuilding }\end{array}$ & & & & & & $\begin{array}{l}\text { Post-installed } \\
\text { resin anchor }\end{array}$ & $\begin{array}{l}\text { Length required } \\
\text { from the top bar** }\end{array}$ & \\
\hline $12^{\prime}$ & $\begin{array}{l}\text { Reinforced concrete } \\
\text { rebuilding }\end{array}$ & & & & $P w=0.58 \%$ & 2.21 & $\begin{array}{l}\text { Before concrete } \\
\text { casting }\end{array}$ & $\begin{array}{l}\text { To the footing } \\
\text { bottom bar }\end{array}$ & 2G-resistant test model \\
\hline
\end{tabular}

- One half the thickness of the footing plus the anchorage length needed for calculation

* The thickness of the covering on top of the footing plus the anchorage length needed for calculation

Table 3 Results of calculation and experiments

\begin{tabular}{|c|c|c|c|c|c|c|c|c|c|c|c|c|c|c|}
\hline & \multirow[b]{2}{*}{$\begin{array}{l}\text { Test model } \\
\text { No. }\end{array}$} & \multirow[b]{2}{*}{$\begin{array}{l}\text { Piet cross- } \\
\text { section }(\mathrm{cm})\end{array}$} & \multirow[b]{2}{*}{$\begin{array}{l}\text { Reinforcement } \\
\text { ratio }\end{array}$} & \multirow[b]{2}{*}{ Hoop tie } & \multicolumn{5}{|c|}{ Experimental results } & \multicolumn{5}{|c|}{ Calculation results } \\
\hline & & & & & $\begin{array}{l}\text { Py } \\
(\text { (f) }\end{array}$ & $\underset{(\mathrm{mm})}{\delta y}$ & $\begin{array}{l}P_{u} \\
(t f)\end{array}$ & $\begin{array}{c}\delta_{u} \\
(\mathrm{~mm})\end{array}$ & $\begin{array}{c}\text { Condition at the } \\
\text { completion of } \\
\text { experiment }\end{array}$ & $\begin{array}{l}P_{y} \\
(\text { (t) }\end{array}$ & $\begin{array}{c}\delta_{y} \\
(\mathrm{~mm})\end{array}$ & $\begin{array}{l}P_{u} \\
(f)\end{array}$ & $\underset{(\mathrm{mm})}{\delta}$ & $\mu$ \\
\hline \multirow{4}{*}{ Existing piers } & 1 & \multirow{4}{*}{$60 \times 60$} & \multirow{4}{*}{$\begin{array}{l}D 10 \\
(13+15) \\
p-0.61 \%\end{array}$} & \multirow{4}{*}{$\begin{array}{l}\text { D6 } \\
4-\operatorname{ctc} 200 \\
p w-0.11 \%\end{array}$} & 20.6 & 16.6 & 24.3 & 51.7 & Cracks only & - & - & - & - & - \\
\hline & 2 & & & & 19.8 & 16.6 & 24.3 & 51.4 & Cracks only & - & - & - & - & - \\
\hline & 3 & & & & 20.8 & 16.8 & 24.7 & 87.6 & Concrete spalled & - & - & - & - & - \\
\hline & 4 & & & & 20.1 & 16.7 & 24.7 & 87.6 & Concrete spalled & - & - & - & - & - \\
\hline \multirow{3}{*}{ Steel plate jacket } & $s$ & \multirow{3}{*}{$\begin{array}{l}60 \times 60 \\
(+\mathrm{PI}- \\
1.6 \mathrm{~mm})\end{array}$} & $\begin{array}{l}\text { No. I + PII. } 6 \\
p=0.85 \% \\
\end{array}$ & \multirow{3}{*}{$\begin{array}{l}D 6 \\
4-\operatorname{ctc} 200 \\
+P 1-1.6 \\
p w-0.64 \%\end{array}$} & 27.0 & 16.4 & 35.1 & 122.2 & $\begin{array}{l}\text { Sieel plate broken, } \\
\text { bars buckled or broken }\end{array}$ & 26.6 & 14.1 & 31.7 & 51.0 & 3.62 \\
\hline & 6 & & \multirow{2}{*}{$\begin{array}{l}\text { D10 } \\
(13+15) \\
p-0.61 \%\end{array}$} & & 22.9 & 17.2 & 26.0 & 92.5 & $\begin{array}{l}\text { Seel plare bulging. } \\
\text { bars buckled or broken }\end{array}$ & 9.5 & 13.2 & 23.8 & 63.1 & 47.8 \\
\hline & 7 & & & & 23.1 & 17.2 & 25.0 & 94.9 & $\begin{array}{l}\text { Sieel plate bulging. } \\
\text { bars buckled or broken }\end{array}$ & 9.7 & 129 & 24.0 & 61.1 & 4.74 \\
\hline \multirow{2}{*}{$\begin{array}{l}\text { Reinforced con- } \\
\text { crete jacket }\end{array}$} & 8 & \multirow{2}{*}{$\begin{array}{l}70 \times 70 \\
\text { (Added thick- } \\
\text { ness: } 5 \mathrm{~cm} \text { ) }\end{array}$} & \multirow{4}{*}{$\begin{array}{l}D 10 \\
(13+15+9) \\
p-0.61 \%\end{array}$} & \multirow{2}{*}{$\begin{array}{l}\text { D6 } \times 4- \\
\text { Clc } 200+ \\
\text { D } 10 \times 2- \\
\text { Clc } 40 \\
\text { pw }-0.70 \%\end{array}$} & 28.1 & 17.0 & 37.9 & 147.3 & $\begin{array}{l}\text { Core concrete fractured, } \\
\text { bars buckled or broken }\end{array}$ & 23.4 & 10.2 & 36.3 & 81.8 & 8.02 \\
\hline & 9 & & & & 27.4 & 17.0 & 38.8 & 96.3 & $\begin{array}{l}\text { Core concrele fractured, } \\
\text { bars buckled or broken }\end{array}$ & 23.5 & 10.2 & 36.6 & 81.7 & 8.01 \\
\hline \multirow{2}{*}{$\begin{array}{l}\text { Combined use } \\
\text { of reinforced } \\
\text { concrete and } \\
\text { steel plate jackets }\end{array}$} & 10 & \multirow{2}{*}{$\begin{array}{l}70 \times 70 \\
(R C t-50 \\
+P I t- \\
1.6 \mathrm{~mm})\end{array}$} & & \multirow{2}{*}{$\begin{array}{l}4-\operatorname{ctc} 200 \\
+2-\mathrm{ctc} 80 \\
+\mathrm{PI}-1.6 \\
\mathrm{pw}-0.66 \%\end{array}$} & 27.8 & 15.0 & 38.8 & 113.2 & $\begin{array}{l}\text { Sieel plate bulging. } \\
\text { bars buckled or broken }\end{array}$ & 23.7 & 10.1 & 36.4 & 75.2 & 7.80 \\
\hline & 11 & & & & 26.6 & 15.0 & 38.7 & 94.8 & $\begin{array}{l}\text { Steel plate bulging. } \\
\text { bars buckled or broken }\end{array}$ & 23.2 & 10.2 & 36.0 & 77.9 & 7.50 \\
\hline \multirow{4}{*}{ Reconstruction } & 12 & \multirow{4}{*}{$70 \times 70$} & \multirow{4}{*}{$\begin{array}{l}\text { DI0 } \\
(13+15+9) \\
p-0.61 \%\end{array}$} & \multirow{3}{*}{$\begin{array}{l}D 6 \\
9-\operatorname{ctcl} 150 \\
p w=0.27 \%\end{array}$} & 28.7 & 18.4 & 37.0 & 112.2 & $\begin{array}{l}\text { Core concrele frac- } \\
\text { tured, bars buckled or } \\
\text { broken }\end{array}$ & 28.8 & 11.7 & 35.8 & 36.5 & 3.12 \\
\hline & 13 & & & & 29.5 & 18.4 & .37 .4 & 128.1 & $\begin{array}{l}\text { Core concrete frac- } \\
\text { tured, bars buckled or } \\
\text { broken }\end{array}$ & 28.8 & 11.7 & 36.1 & 36.5 & 3.12 \\
\hline & 14 & & & & 31.1 & 18.4 & 37.5 & 118.1 & $\begin{array}{l}\text { Core concrete frac- } \\
\text { rured. bars buckled or } \\
\text { broken }\end{array}$ & 28.8 & 11.3 & 36.1 & 36.6 & 3.24 \\
\hline & $12^{\prime}$ & & & $\begin{array}{l}9-\operatorname{ctc} 70 \\
p w-0.58 \%\end{array}$ & 28.8 & 16.7 & 36.6 & 120.3 & $\begin{array}{l}\text { Core concrete frac- } \\
\text { rured, bars buckled or } \\
\text { broken }\end{array}$ & 28.4 & 11.9 & 35.8 & 58.1 & 4.88 \\
\hline
\end{tabular}




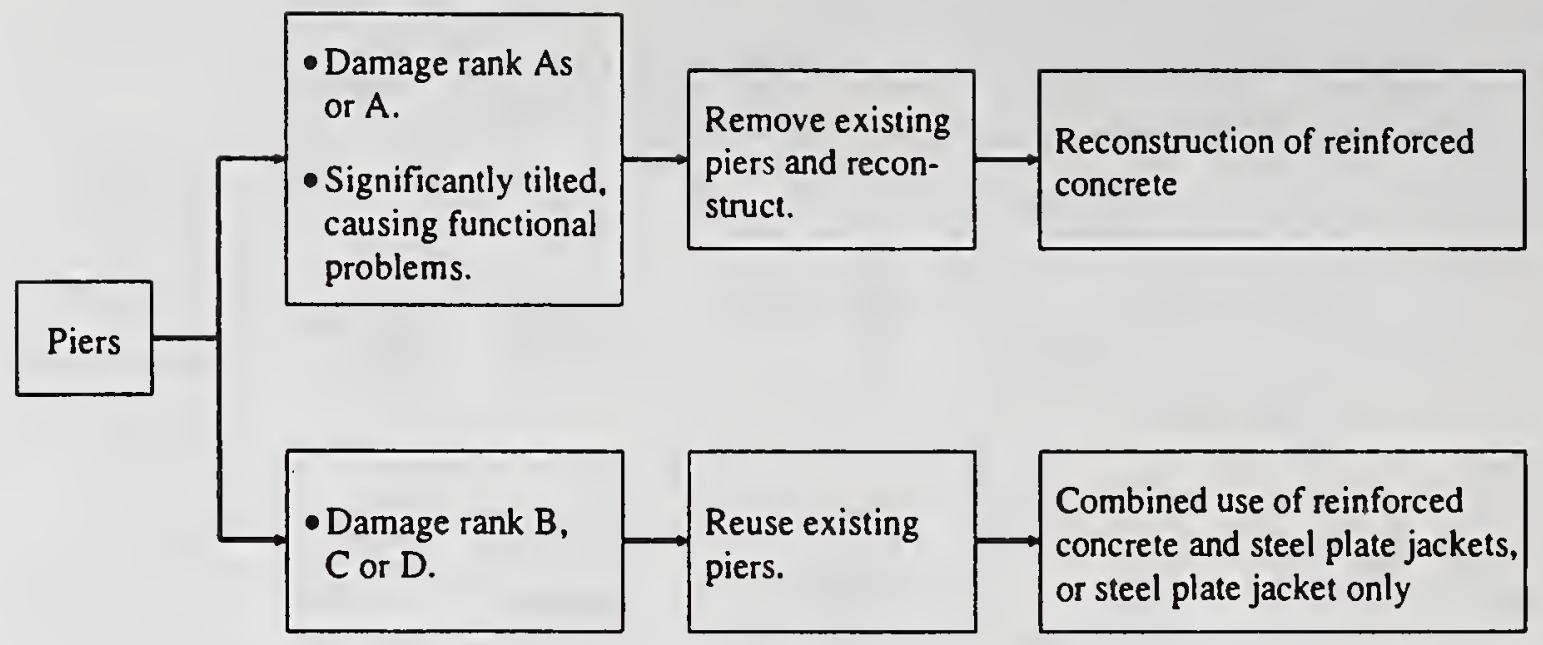

Figure 4 Pier restoration flow diagram

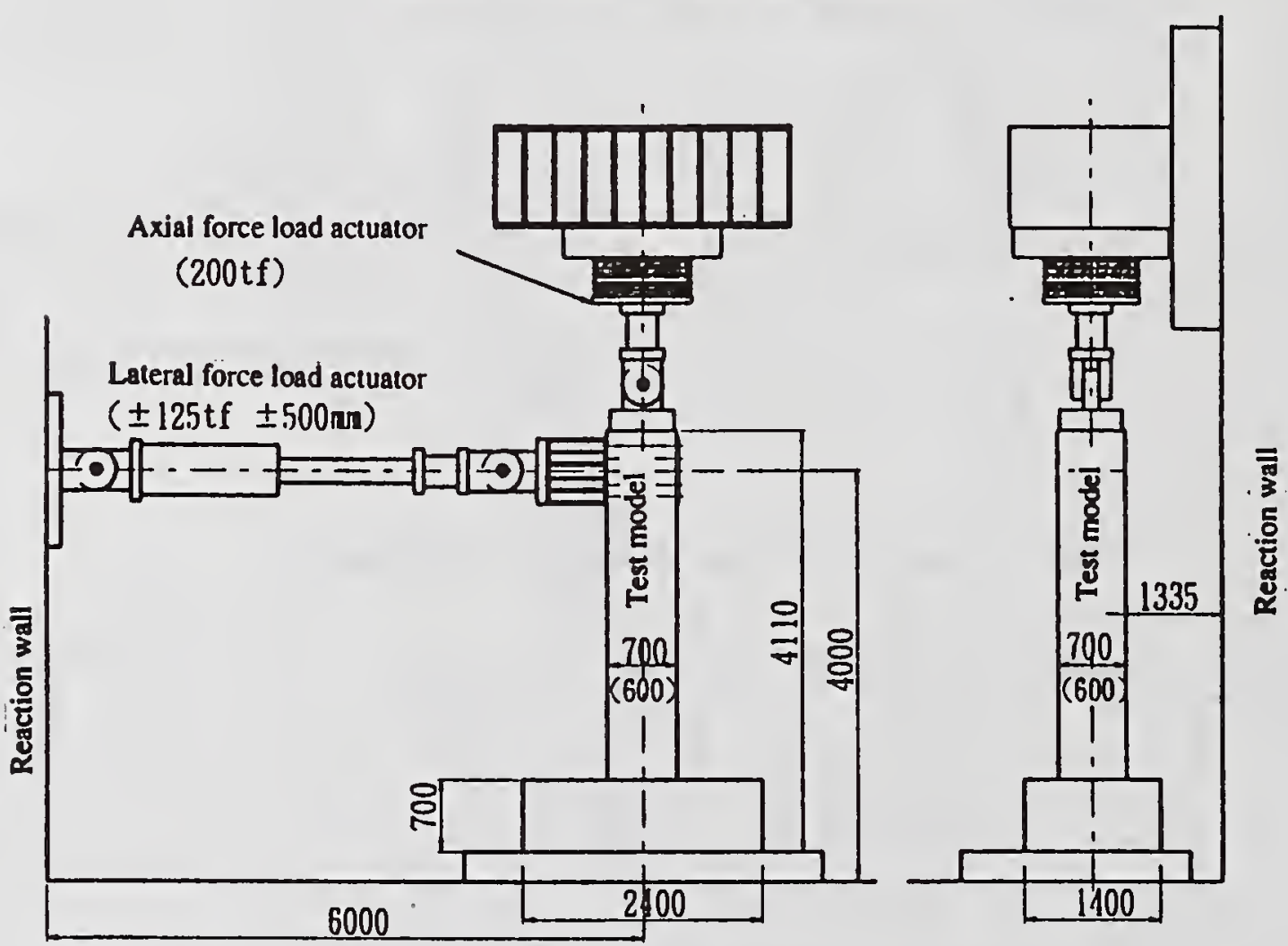

Figure 5 The test model showing details of load application

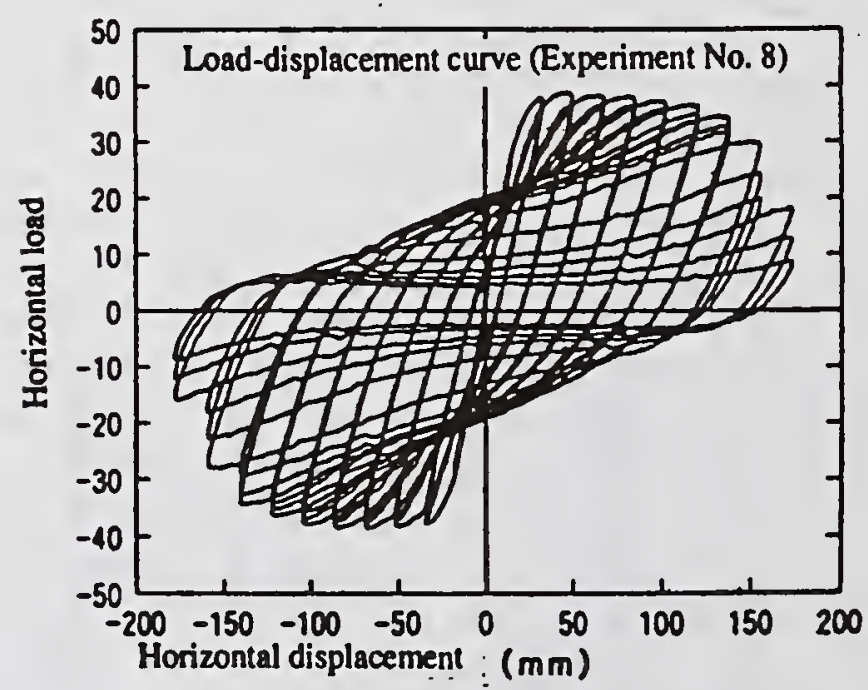

Figure 6 Load and horizontal displacement

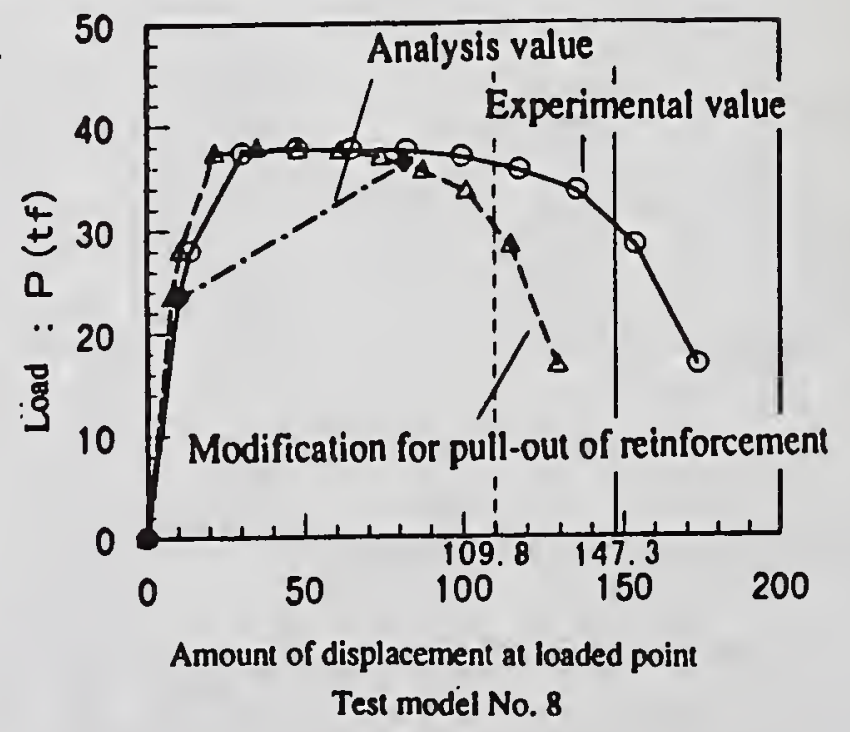

Figure 7 Load-displacement envelope 


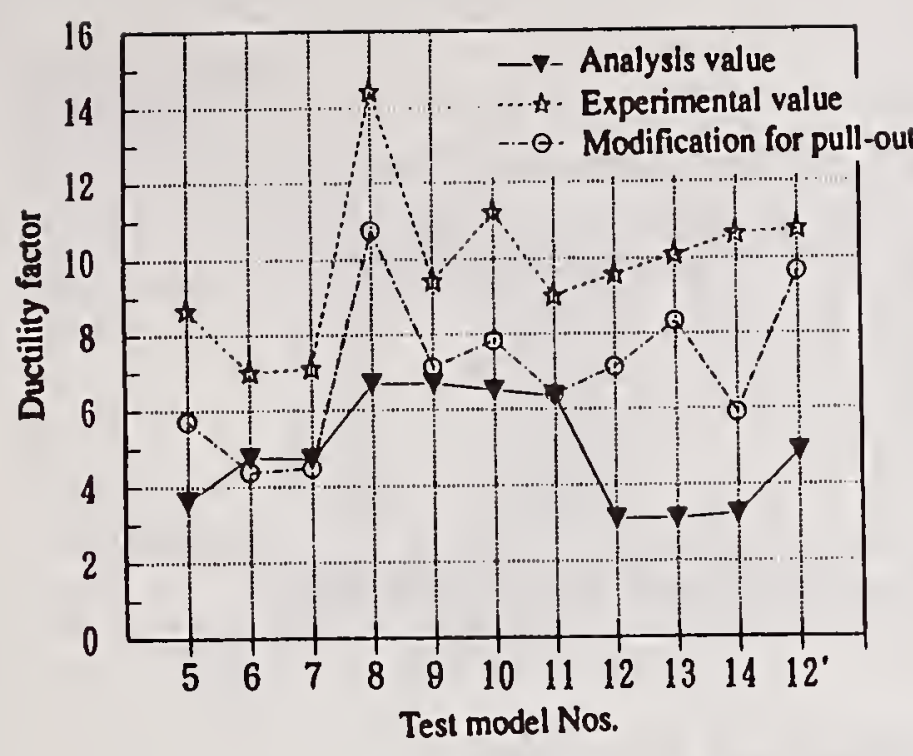

Figure 8 Ductility factor plot

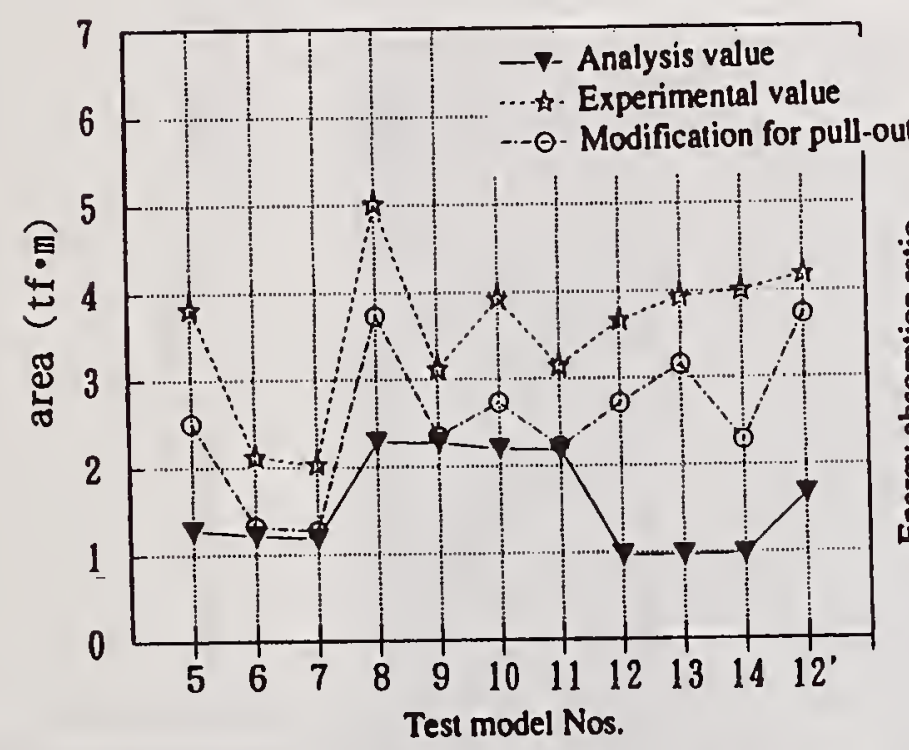

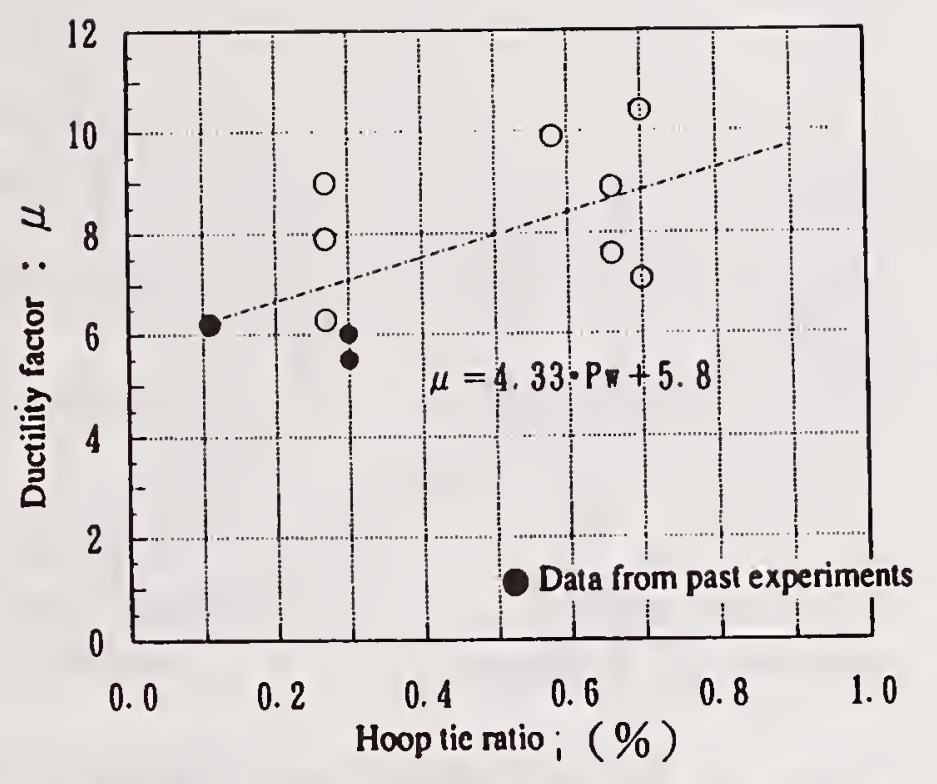

Figure 9 Hoop tie ratio and ductility factor

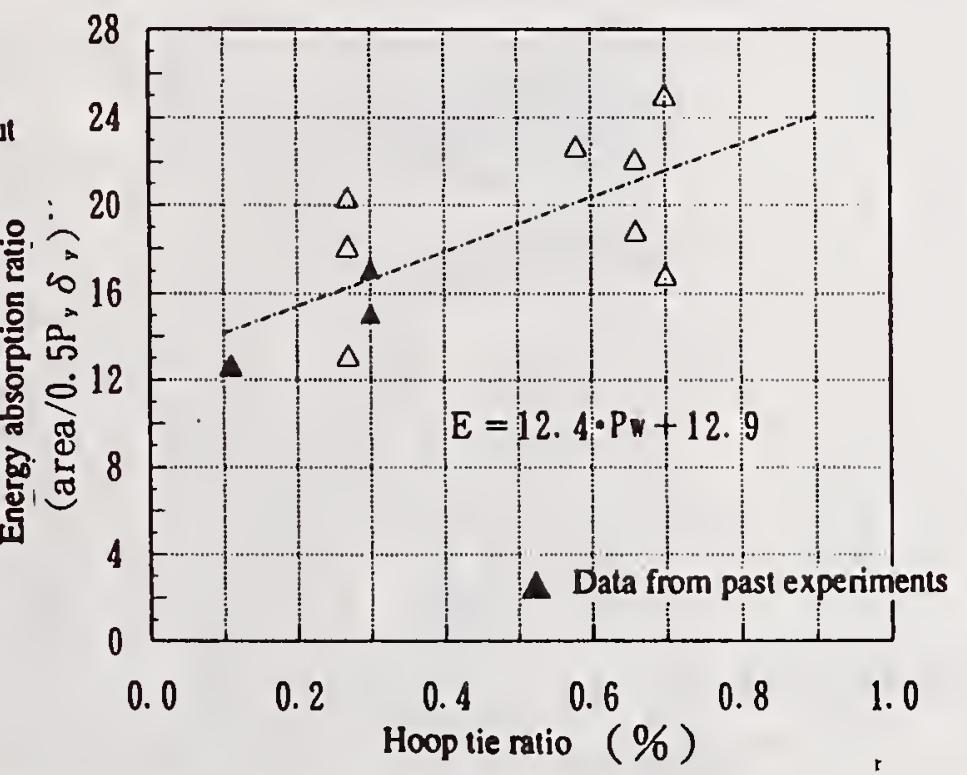

Figure 11 Hoop tie ratio and energy absorption ratio

Figure 10 Energy absorption area plot

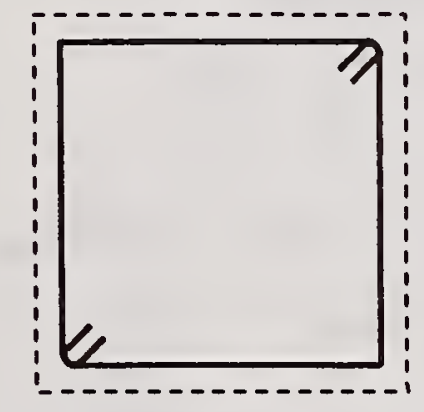

1) 2-section hooking

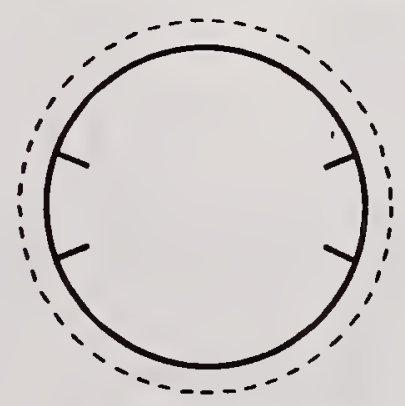

1) 2-section hooking

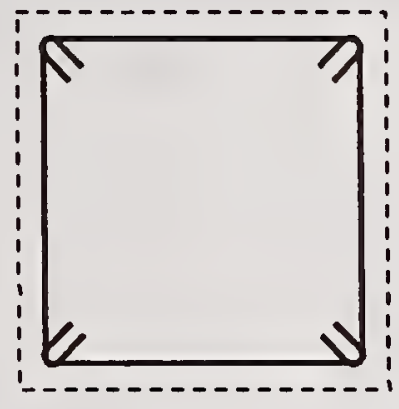

2) 4-section hooking

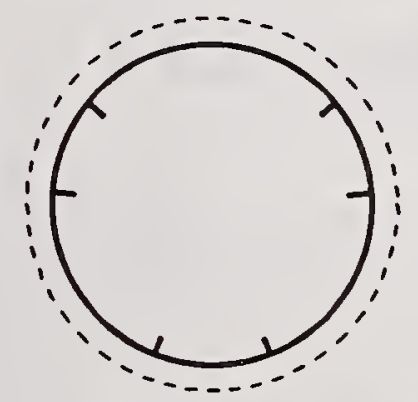

2) 3-section hooking

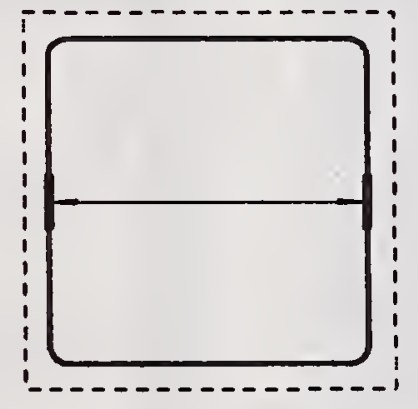

3) 2-section flare welding

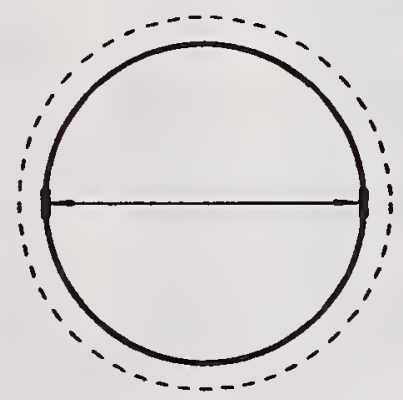

3) 2-section flare welding

Fig12 Methods of installing hoops ties 


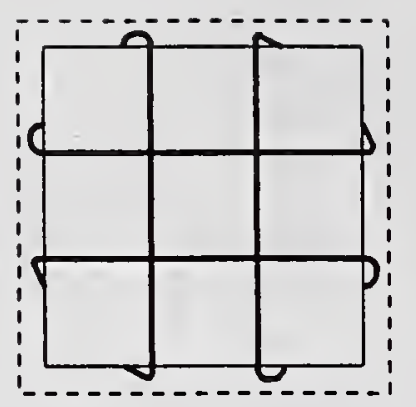

1) Acute-angled, semicirular hooking

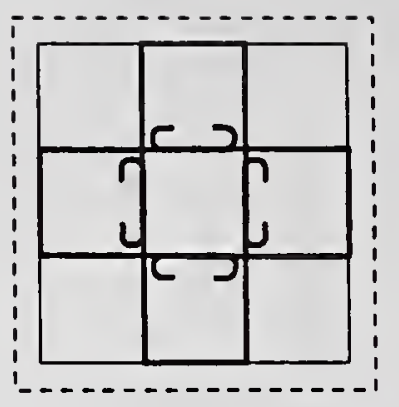

2) U-shaped section hooking

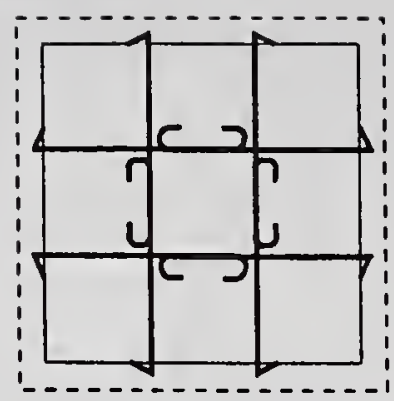

3) Acute-angled, section hooking

Fig13 Methods of installing intermediate hoop ties
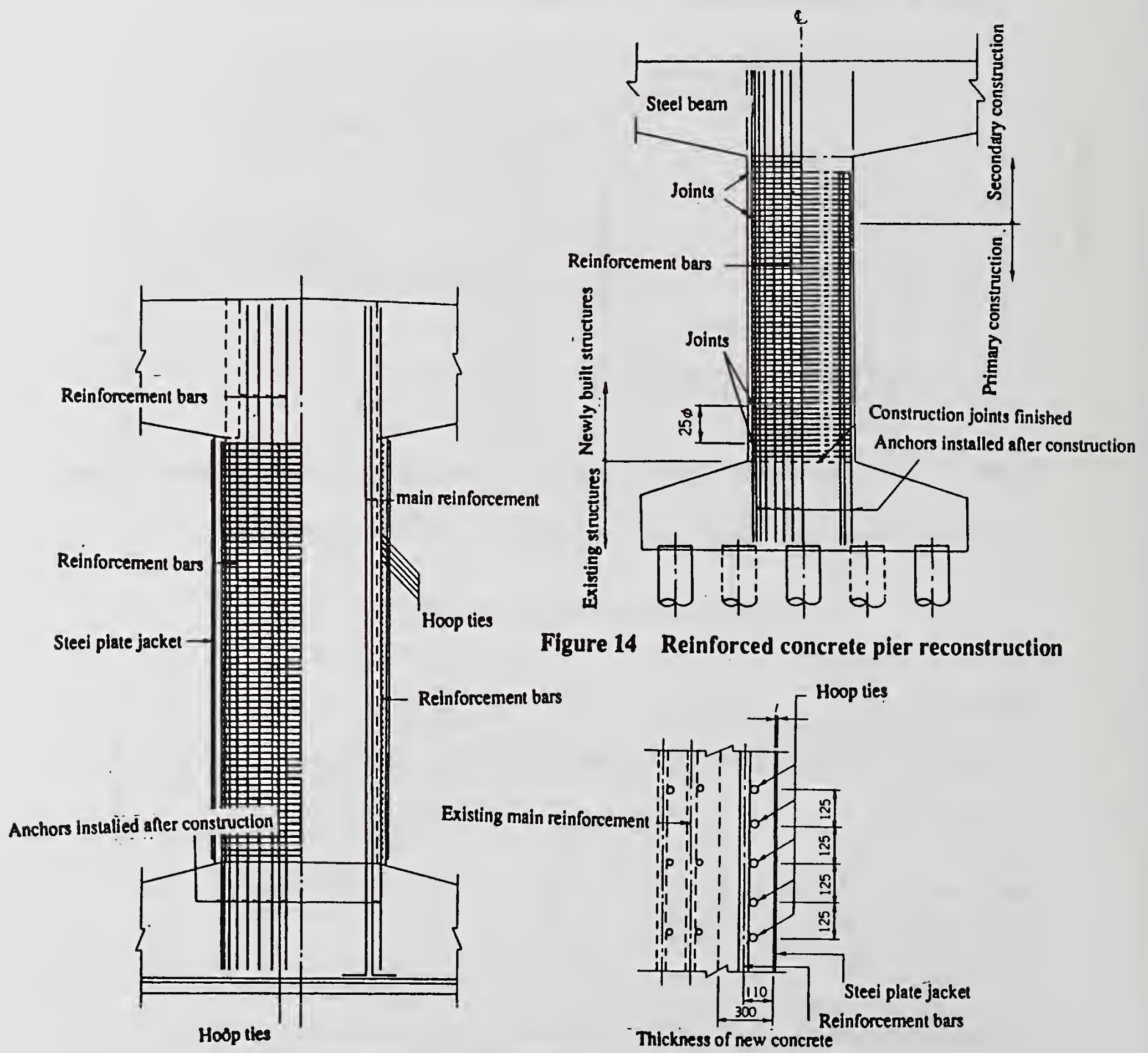

Figure 14 Reinforced concrete pier reconstruction

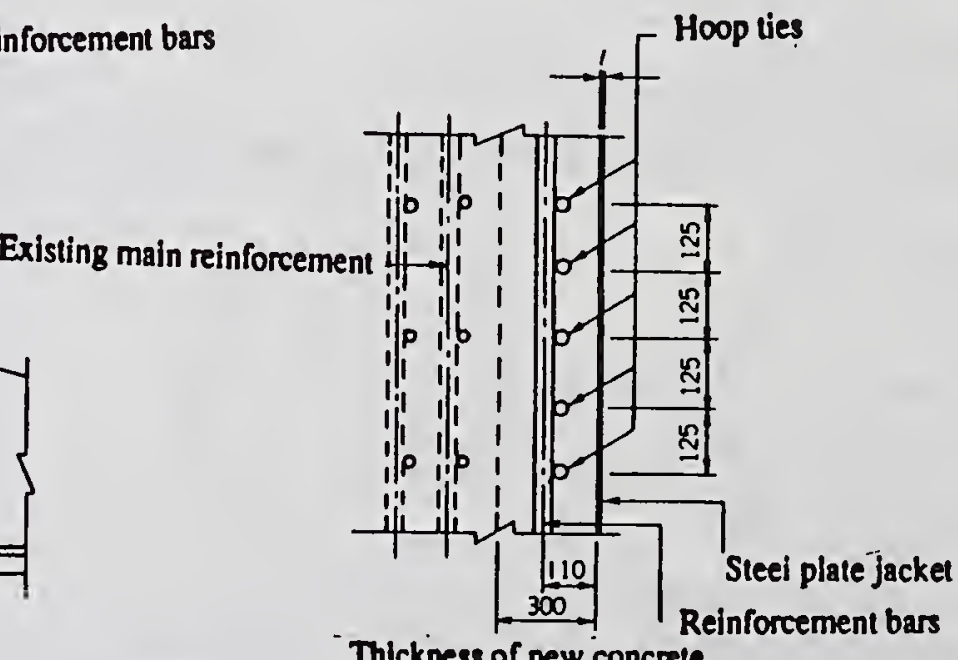

.Figure 15 Reinforced concrete pler repair and reinforcement 


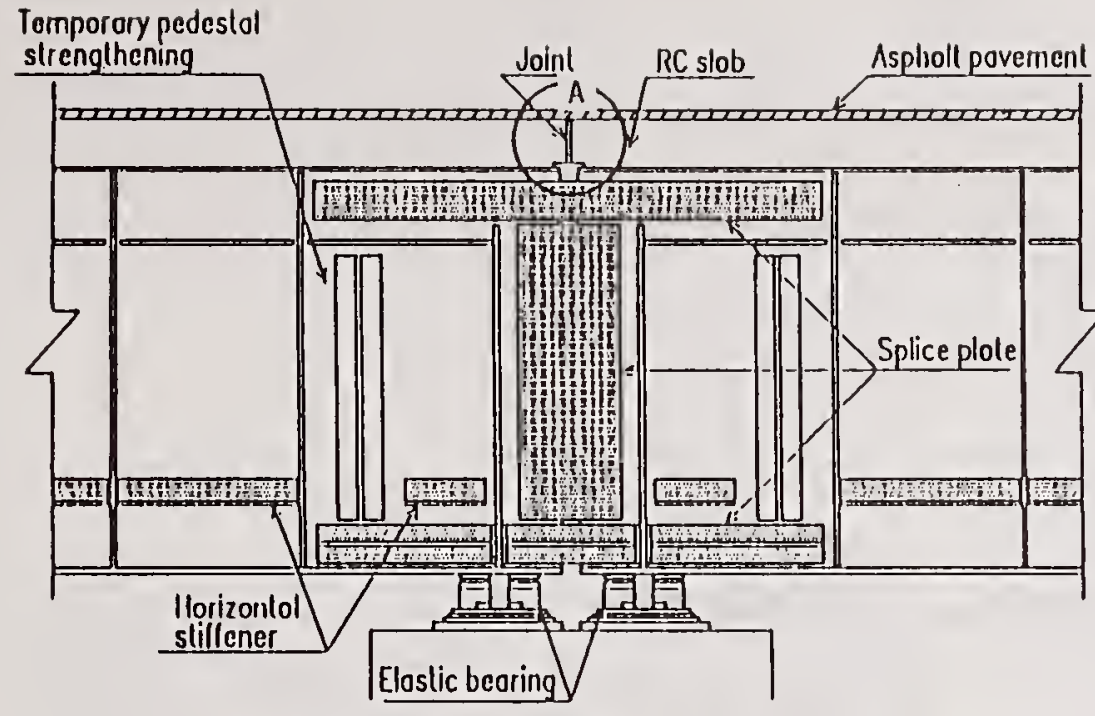

Figure 16 Connecting girders

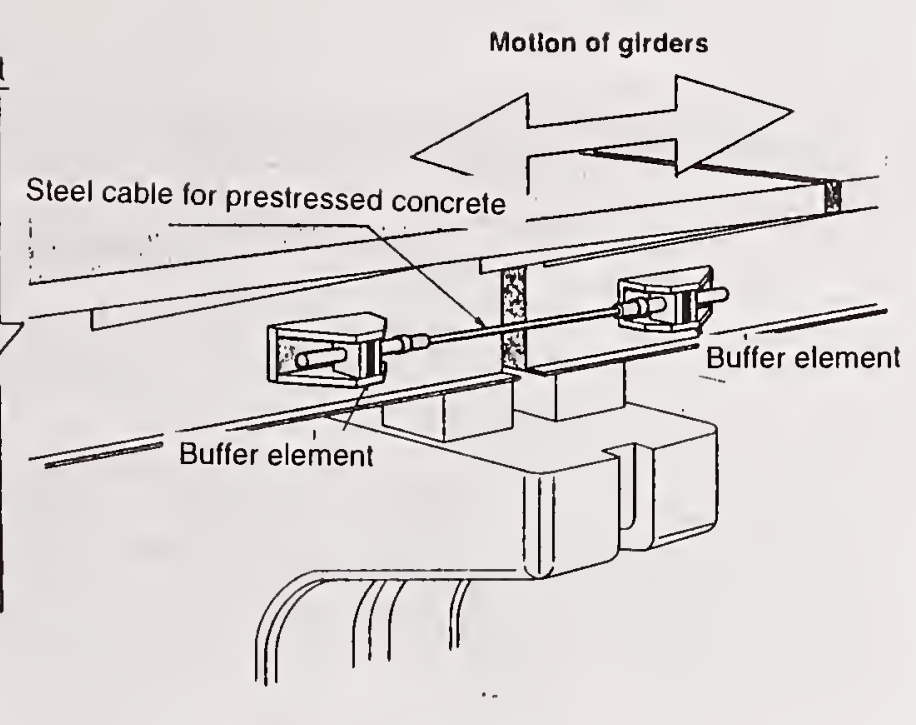

Figurel7 Bridge restrainers

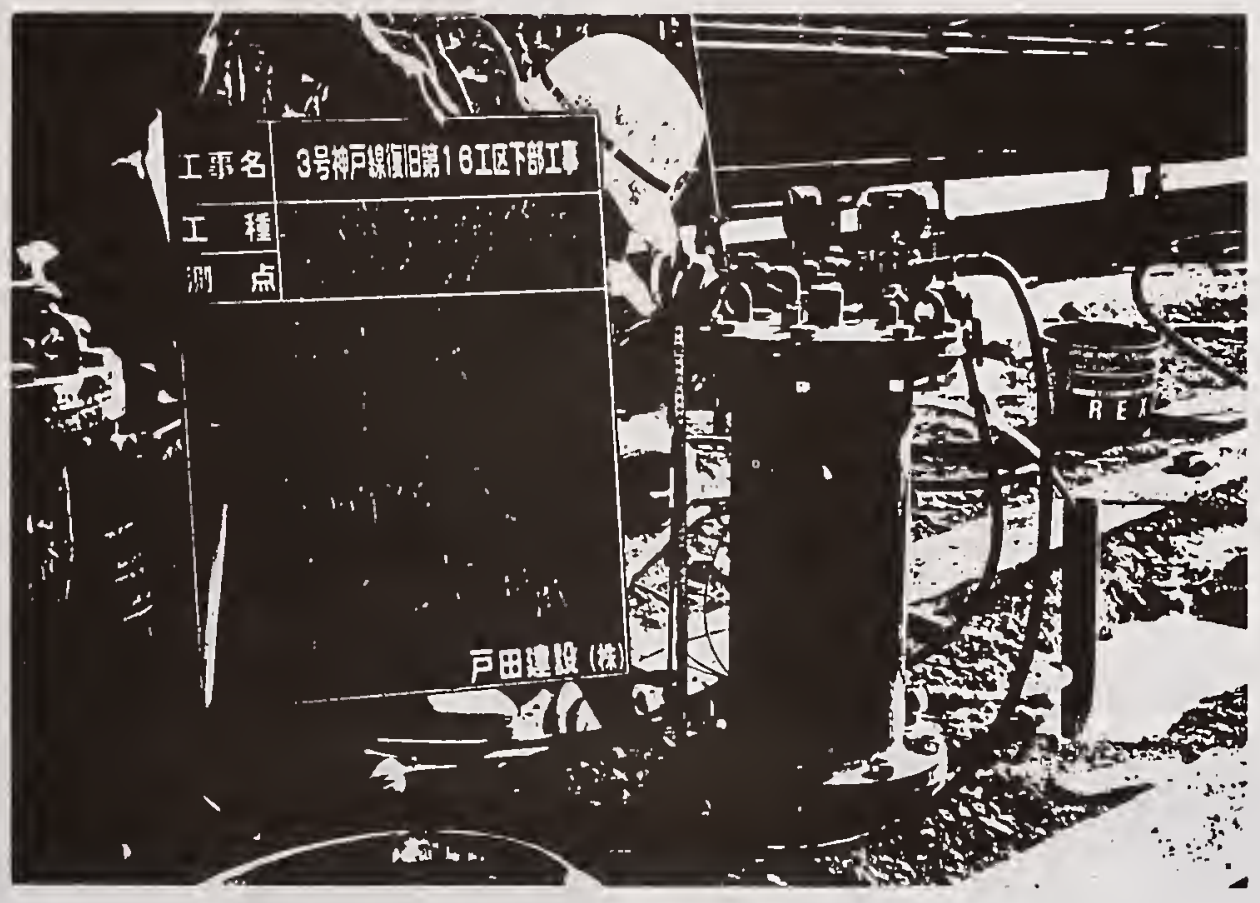

Figurel8 Injection of cement slurry into piles
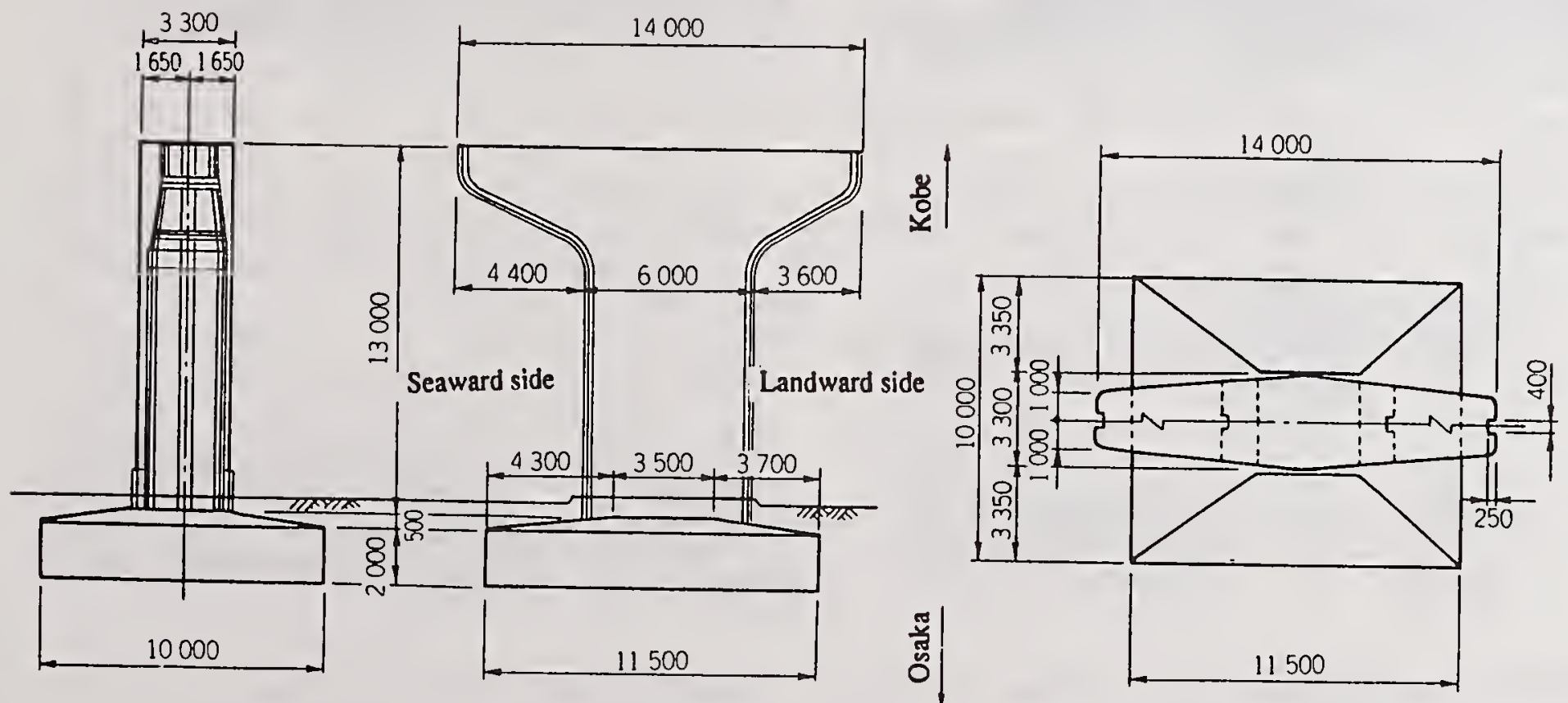

Figure 19 General view of a rebuilt pier 


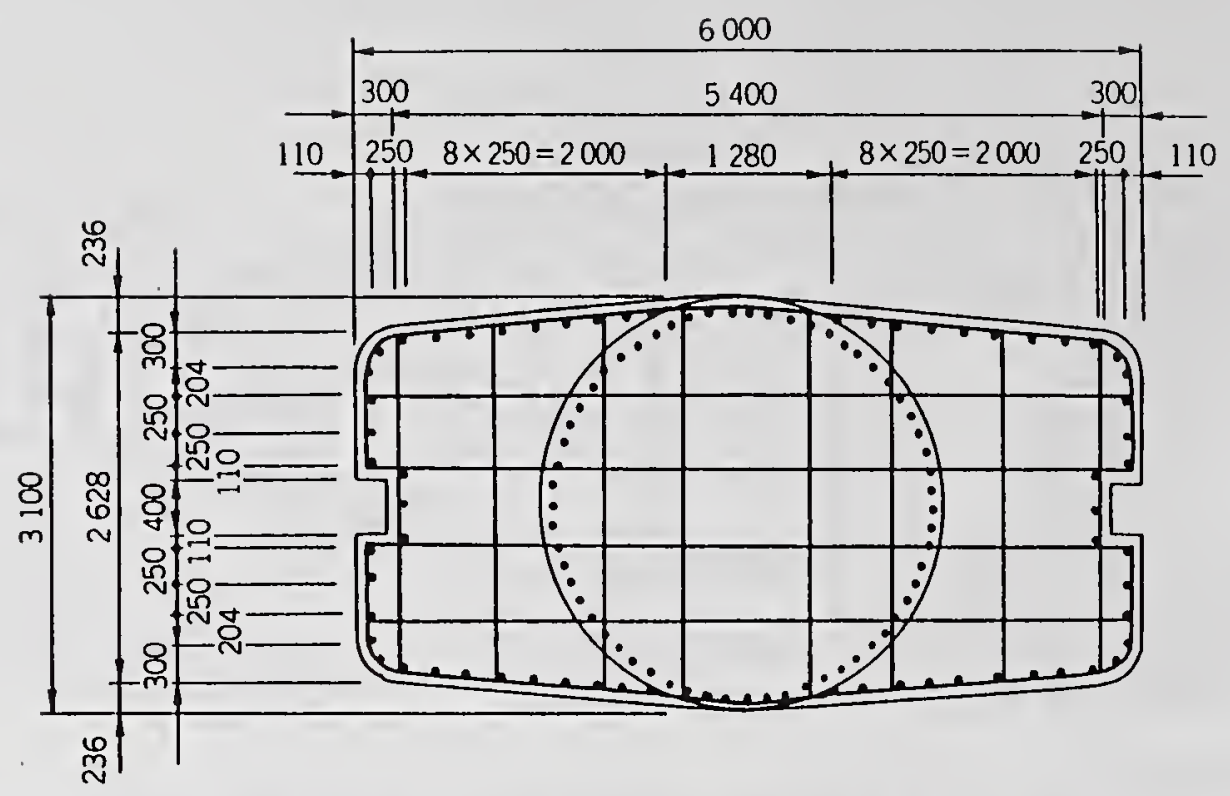

Figure 20 Arrangement of bars in a column

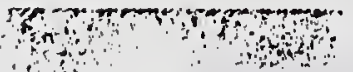

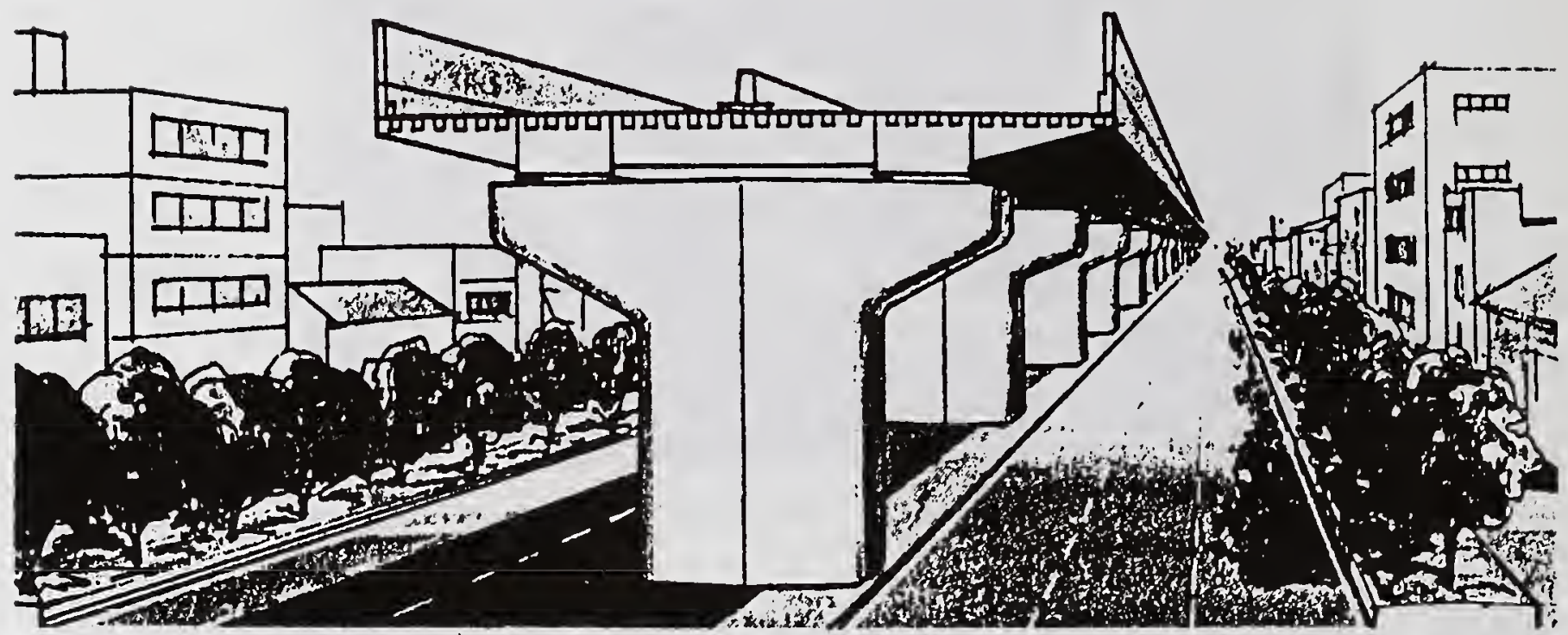

Figure 21 Artist's impression of the Fukae section
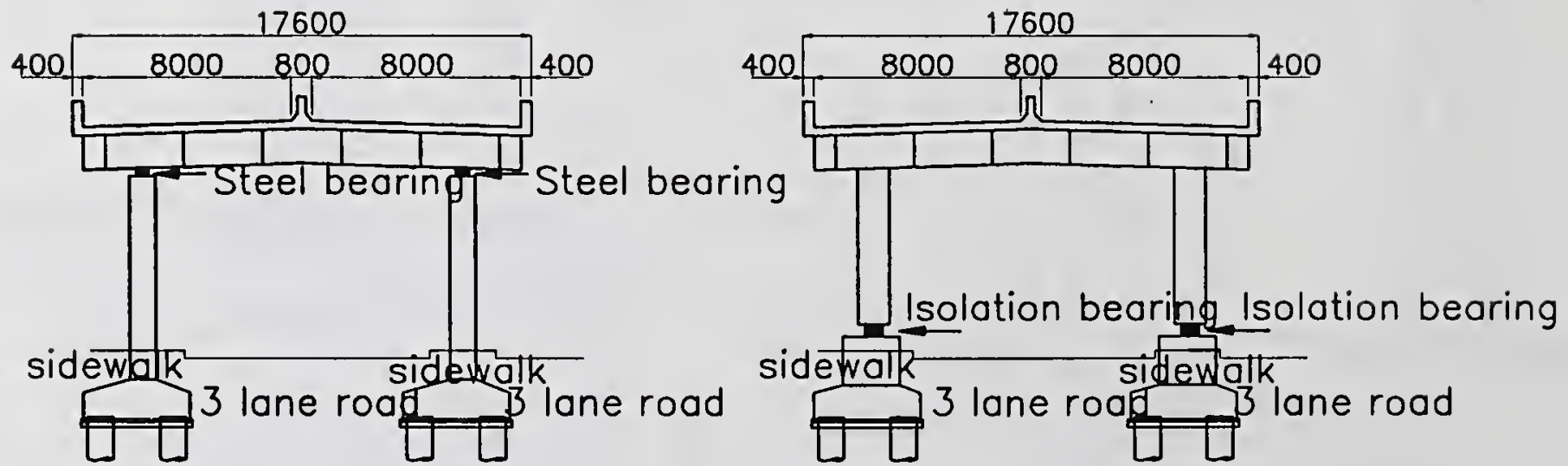

Fig.22 (Existing structure of the Benten section)

Fig.23 (New structure of the Benten section) 
Action and Concept on Performance-Based Design and Engineering System in Japan

by

\author{
Hiroyuki Yamanouchi ${ }^{11}$, Hisashi Okada' ${ }^{2}$, Yuji Ohashi ${ }^{3)}$
}

\begin{abstract}
This paper describes a framework on performance-based structural design/engineering system that should be realized in the future, and introduces a current activity that is underway toward the new structural design/engineering system at the Building Research Institute (BRI) in cooperation with many professional communities related to building structures. Also, the paper presents the relationship between the similar action at the SEAOC and the BRI in terms of structural performance concepts. Further, recent workshops on future design codes with coordination of a study group of the U.S. is introduced.
\end{abstract}

\section{INTRODUCTION}

The current structural design methods are based on either strength or ductility, or otherwise the both of a structure. Thus, overall structural performance including others than strength and ductility has not yet become conscious in the mind of not only a structural engineer but also a researcher. Namely, the global structural performance before and after structural design is not always clearly described by a structural engineer. For instance, looking at the structural performance against a specified level of seismic forces, a structural engineer cannot say the expected performance such as remaining inter-story drift, damage degree of non structural elements and lifelines, reparability and so on. This situation is strongly owing to the current prescriptive design codes that bind a structural engineer without design flexibility.

The current design codes do not clearly require target structural performance, whereas design procedures and rules are definitely and prescriptively specified as code provisions. Therefore, under this inflexible system, the performance of a designed structure cannot be clearly predicted and described even by a structural engineer who designed the structure. Furthermore, structural design itself has become "calculation" just to keep restrictedly the prescriptive specifications under code provisions.

In the future design system, on the contrary, the target or objective structural performance should firstly be defined as a clear picture, and then in order to attain the performance, a structural engineer may choose an appropriate design method and procedure. Thus, the most important thing toward the future design system is to facilitate a new design system including codes, where a structural engineer can determine target performance and realize it by choosing an appropriate design procedure. It is not until this is realized that a structural engineer can clearly explain the objective and expected performance of a structure designed by him or her to a client.

\section{STRUCTURAL PERFORMANCE}

The performance of a structure is not limited to structural safety; the word of structural performance has even wider concepts. That is, the concepts includes every structure-related performance; safety, reliability, durability, human comfort, maintainability, constructibility, aesthetics and so on. Furthermore, performance against various loads and external forces should be taken into account. The basic definition and description materials of structural performance have already been proposed by the author elsewhere (1).

\footnotetext{
1) Director, Structural Department, Building Research Institute, Ministry of Construction (BRI), Tukuba City, 305 Japan

2) Head, Aero Dynamics Division, Structural Dept., BRI

3) Head, Structural Dynamics Division, Structural Dept., BRI
} 


\section{PERFORMANCE CODE AND SPECI- FICATION CODE}

In recent years, structural technology of buildings makes progress rapidly. Various technology such as new materials, base isolation system and response control system is developing.

However, because that current structural codes of buildings in Japan are regulated for conventional structural materials and structural methods and most of the codes are specification codes that describe in detail exactly what materials are to be used, the size and spacing, current codes cannot match the new materials and new structural methods.

Therefore, it becomes necessary to convert structural codes from specification codes into performance codes that prescribe the objective to be accomplished and to allow broad leeway to the structural designers in selecting structural and structural methods that achieve required performance.

\section{BRI ACTION TOWARD NEW SYSTEM}

Considering significant needs for the new design system on the basis of performance, the Building Research Institute, Ministry of Construction, has initiated a three-year National Comprehensive R\&D Program entitled "New Structural Engineering System" from the fiscal year of 1995, in coordination with structurerelated communities such as those of structural engineers, contractors, industries, academy and so on.

The most critical mission of the Program is to show possible ways to a new structural design/engineering world where a structural engineer can clearly explain the objective and expected performance of a structure designed by him or her. For this, a lot of issues must be studied, discussed and solved; as a result of preliminary studies for formulating the Program, the major subjects to be dealt with in the Program have been identified, and the committees for the action have been organized, as shown in Table 1.
Therefore, in this project, we examine the next two technical subjects.

1. Develop performance based structural design system (Here, we examine not only seismic performance but also other performance.)

2. Convert specification codes into performance codes in the Building Standard Law

Further, we examine social subject.

3. Propose social system such as qualification of structural engineers, building confirmation procedure in the Building Standard Law and so on for performance based design system.

As shown in Table 1. we organized technical committee (convener is Prof. Okada of Tokyo University). The technical committee steers and manages this project. Under the technical committee, we settled three sub committees. The tasks of the sub committees are as follows.

Sub committee 1 : Convener is Prof. Akiyama of Tokyo University.

Subject of the sub committee is "Evaluation of performance ". This sub committee examines concept of performance of structure, definition of performance, measure of performance, design seismic action, design wind load and so on. Under this subcommittee, some working groups are settled.

Sub committee 2 : Convener is Prof. Aoki of Tokyo Institute of Technology.

Subject of this sub committee is "Object performance level". This sub committee examines opinion of clients and users of buildings, importance category of buildings, acceptable risk and so on.

Sub committee 3 : Convener is Dr. Yano of Nikken Sekkei Corporation.

Subject of this sub committee is "Social system". This sub committee examines construction procedures, design review system, qualification of structural engineers, role of building officials and so on.

COMPARISON OF TARGET PERFORMANCE MATRICES PROPOSED BY BRI/KOZAI-CLUB AND BY SEAOC 
Before the initiation of the BRI National Program, BRI and Kozai-Club (KC) have already terminated a two-year joint research work (1992-1994) on a new structural engineering system based on performance modeling steel building structures (2). In the work, definition of performance, objective performance, criteria for determining performance and so on were broadly studied and discussed.

As a result of these studies, several matrices determining target performance for design (Performance Matrix) have been proposed. As an example, Fig. 1 shows the proposed performance matrix for major structural skeletons (MS) against earthquakes. This matrix consists of four intensity levels of earthquake in terms of return periods or probabilities of exceedance in 50 years, and structural grades. The structural grade $A$ is of critical building structures such as fire stations, hospitals, public buildings and so on. The grade $\mathrm{D}$ would be for temporary buildings and grade $C$ for ordinary buildings under a minimum performance level. Further, the grade B indicates a fairly high level of performance. Each element of the matrix designates required performance corresponding to given conditions. The BRI National R\&D Program has well refereed to these results.

Also, in the United States, similar work has already been done; the Vision 2000 Committee of the SEAOC has recommended the performance based structural design procedures, as the results of the phase I work (3). In the work, the Committee has proposed performance objectives as a form of matrix. Fig. 2 introduced this performance matrix as it is.

Looking at the above two matrices (Figs. 1 and 2 ), it can be seen that both concepts are very similar in spite of the difference in terminology or wording used in those matrices. Fig. 3 shows this similarity very well; the MSPerformance Matrix shown in Fig. 1 was transferred into the Vision 2000 form in Fig. 2. Then, again in Fig. 3, the structural grades A to $\mathrm{D}$ are depicted as diagonal lines similar to those in Fig. 2. By this comparison, it can be said that in the course of the BRI/KC and SEAOC activities, they have been considering basically an almost same thing in terms of performance, and have reached similar results with somewhat different expressions. This is a noteworthy fact.

\section{NEED FOR INTERNATIONAL COOR- DINATION/COOPERATION}

In accomplishing a new structural design world in each country, it is hoped that international harmony and consistency in the conceptual framework on the new system will be attained considering the progressing borderless world. For this aim, an "international committee" is under consideration to be formed in the BRI National Program.

Partly for an initial step of the above action, a Japan-U.S. Workshop on Seismic Building Codes (Performance Based Seismic Engineering of Buildings) was held at the Earthquake Engineering Research Center, University of California, Richmond, CA. The main objectives of the workshop were:

1) to discuss the adequacy and efficiency of present Japanese and U.S. seismic codes in light of the experience derived from recent (1985-1995) significant earthquakes (particularly the 1994 Northridge and the 1995 Kobe earthquakes), and from studies conducted in the last ten years, and to identify problems whose solutions need improvement,

2) to discuss what can be done to improve present seismic code approaches, with particular attention to the interim recommendations for engineering procedures that the Vision 2000 Committee of the SEAOC has recommended for obtaining buildings with predictable and defined performance; and

3) to discuss the development of a work plan and the organization that will be needed to formulate the basic concepts and framework that can be used in Japan and the U.S. to develop practical seismic code regulations whose applications will result in facilities whose seismic performance will be predictable with a reasonable degree of confidence under the different types of earthquake ground motions that can occur during their service life. 
The resolutions and recommendations of the Workshop are fully introduced in Appendix. The recommendations of the Workshop should be thought very significant to break through current blocked situations in the structural design/engineering world and to make progress in international harmony related to a future structural engineering system based on performance.

Just one year after the 1995 Hyogo-ken-nanbu Earthquake, and two years after the 1994 Northridge Earthquake, seventh U.S.-Japan workshop on the improvement of structural design and construction practice was held. At that time we held a special meeting with some members of SEAOC and ATC to discuss the international coordination and cooperation as second step. In this meeting, the recommendation was re-affirmed and following items were recommended.

1) Each side should establish a balanced high level policy/coordination committee with no more than seven members plus ex-officio members from participating governmental agencies.

2) Formal cooperation should be continued between Japan and U.S. Next meeting should be held as soon as possible after formation of the high level committee : preferably within six months from this meeting.

\section{REFERENCES}

(1) H. Yamanouchi, "An Approach to Performance-Based Design System," the 5 the U.S.-Japan Workshop on the Improvement of Building Structural Design and Construction Practices, ATC-JSCA Joint Workshop, San Diego, Sept. 8-9, 1992.

(2) BRI/Kozai-Club Joint Research Committee, "Report on New Structural Design System," Feb. 1995 (in Japanese).

(3) The Committee of Vision 2000, "Performance Based Seismic Engineering of Buildings," SEAOC, April 3, 1995. 
Table 1 RD Project for Performance Based Design

\section{Development of Performance Based Structural Design System in Japan}

Three-year Project from 1995 Fiscal Year

Main Subjects

- Develop Performance Based Structural Design System

(Not only seismic performance but also other performance)

- Convert specific code to performance code inBuilding Standard Law

- Propose Social System for Performance Based Code

Pre-study of Performance Based Design from 1992 in cooperation with the Kozai Club (Non-profit corporation consisting of steel makers)

Organization of RD Project on Performance

Based Design System in Japan

Technical Committee

Convener: Professor Okada: Tokyo Univ.

Sub Committee 1

Evaluation of Performance

Convener : Professor Akfyama : Tokyo Univ.

Concept of performance of structure

Definition of performance

Measure of performance

Design seismic action, design loads and so on,

Under this sub committee, there are some Working Groups.

Sub Committee 2

\section{Object Performance Level}

Convener : Professor Aoki: Tokyo Institute of Tech,

Opinion of clients and users of buildings

Importance category of buildings

Acceptable risk and so on.

Sub Committee 3

Social System

Convener : Dr. Yano: Nikken Sekkei

Construction procedures

Design review

Qualification of engineers

Role of building ofticials and so on.

An International Committee (under consideration) 


\begin{tabular}{|c|c|c|c|c|}
\hline EQ Level & $L_{0}$ & $L_{1}$ & $L_{2}$ & $L_{3}$ \\
\hline $\begin{array}{l}\text { Retum } \\
\text { Period }\end{array}$ & 20 years & 100 years & 500 years & 1,000 years \\
\hline $\begin{array}{l}\text { Probability of } \\
\text { Exceedance } \\
\text { in } 50 \text { years }\end{array}$ & $92 \%$ & $39 \%$ & $9.5 \%$ & $4.9 \%$ \\
\hline $\begin{array}{l}\text { e. gor for } \\
\text { Tokyo }\end{array}$ & $0.8 \mathrm{~m} / \mathrm{s}^{2}$ & $2 \mathrm{~m} / \mathrm{s}^{2}$ & $5 \mathrm{~m} / \mathrm{s}^{2}$ & $7 \mathrm{~m} / \mathrm{s}^{2}$ \\
\hline A & No damage & No damage & $\begin{array}{c}\text { Continued } \\
\text { use }\end{array}$ & \begin{tabular}{|l}
$\begin{array}{l}\text { Usable after } \\
\text { repair }\end{array}$ \\
\end{tabular} \\
\hline B & No damage & $\begin{array}{c}\text { Continued } \\
\text { use }\end{array}$ & $\begin{array}{l}\begin{array}{l}\text { Usable after } \\
\text { repair }\end{array} \\
\end{array}$ & $\begin{array}{l}\begin{array}{l}\text { Non } \\
\text { collapse }\end{array} \\
\end{array}$ \\
\hline C & $\begin{array}{c}\text { Continued } \\
\text { use }\end{array}$ & $\begin{array}{l}\text { Usable after } \\
\text { repair }\end{array}$ & $\begin{array}{l}\text { Non } \\
\text { collapse }\end{array}$ & 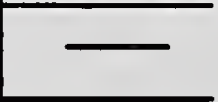 \\
\hline D & $\begin{array}{l}\text { Usable after } \\
\text { repair }\end{array}$ & \begin{tabular}{|l|}
$\begin{array}{c}\text { Non } \\
\text { collapse }\end{array}$ \\
\end{tabular} & & 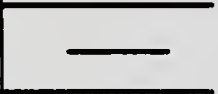 \\
\hline
\end{tabular}

Fig. 1 MS-Performance Matrix for EQ

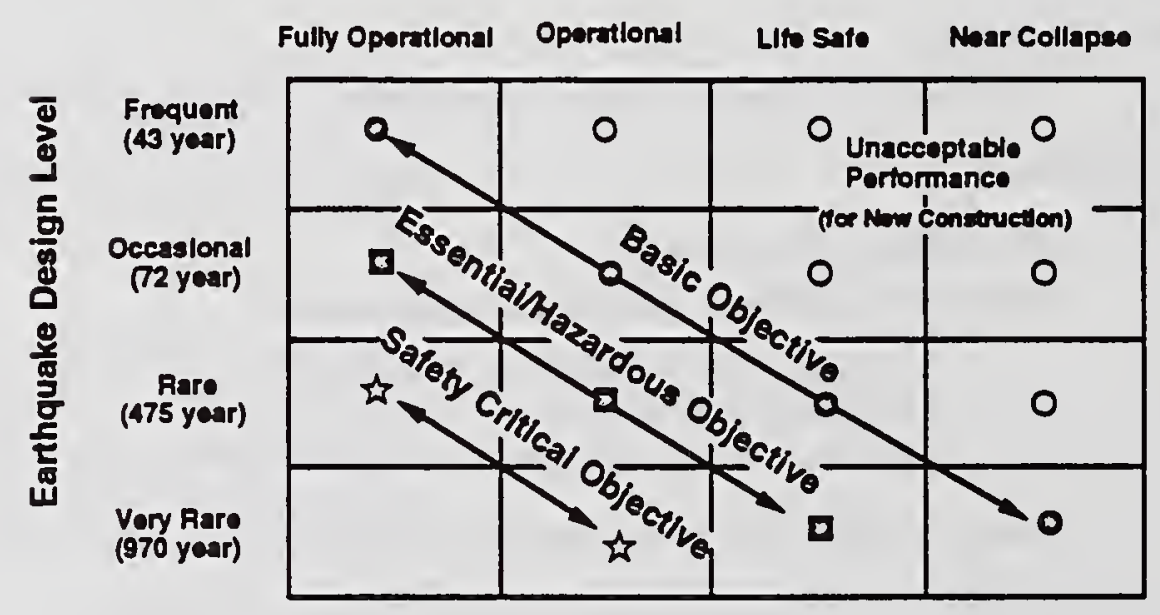

Fig. 2 Recommended Performance Objectives for Buildings Earthquake Performance Level (Vision 2000, SEAOC)

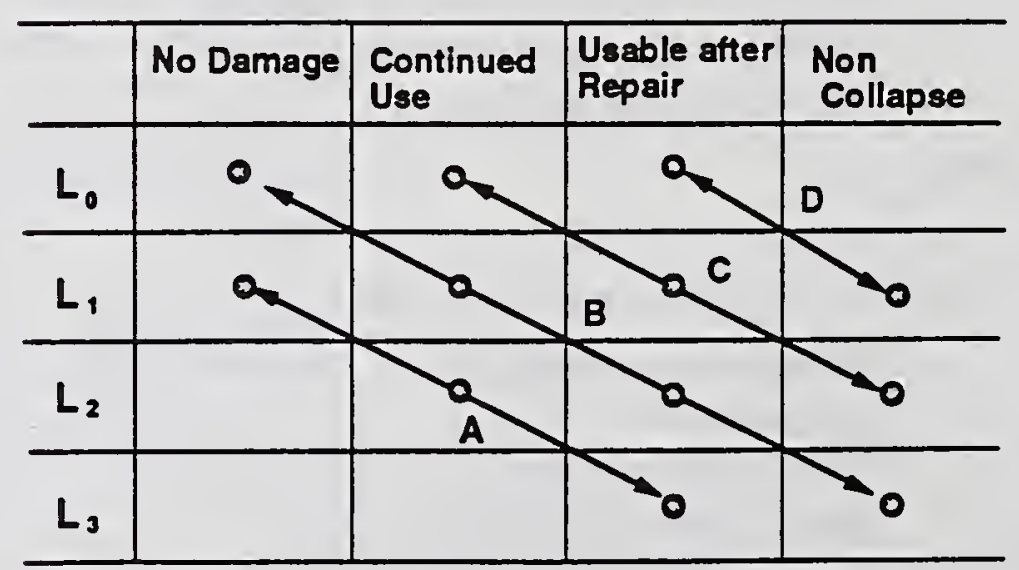

Fig. 3 MS-Performance Matrix with Vision 2000 Form 


\section{U.S.-Japan Workshop on Performance Based Seismic Engineering of Buildings 13-15 November 1995 \\ Earthquake Engineering Research Center \\ University of Califomia, Richmond, California}

\section{RESOLUTION}

After two and one-half days of presentations and detailed discussions about the experiences derived from significant earthquakes which occurred from 1985 to 1995 , the participants of the Japan-U.S. Workshop on Seismic Building Code agreed upon the following findings and recommendations.

\section{Findings:}

a. There should be international cooperation in formulating the conceptual framework for the development of more reliable seismic codes; Japan and the U.S. should take the lead in organizing such cooperation.

b. Buildings designed and constructed following modem codes showed improved performance for life-safety. However:

1. Northridge and Kobe were the first major earthquakes in large urban areas;

2. destructive power of ground motions exceeded prior experience;

3. severe damage and/or collapse of residential (non-engineered) buildings was the number one cause of excessive deaths and injuries;

4. property damage and disruption of activities in urban areas was excessive;

5. public expectations were not met;

6. design and construction quality was not adequate;

7. societal impact was widespread due to failure of infrastructure, making many buildings non functional;

8. irregular and low-redundancy buildings had problems;

9. steel and RC joints, as well as RC column reinforcement (confinement), need detailing study and material/fabrication research;

10. non-structural building systems and contents damage were amajor cause of function distuption;

11. building separation and pile foundation need improvements;

12. inventory of older existing buildings poses the biggest economic/public safety risk;

13. retrofit design and construction procedures need further study and improvement;

14. the concept of weak/soft story needs detailed study and research.

\section{Recommendations}

a. Future seismic code of buildings should be performance based.

b. Seismic design and construction should consider all aspects of building engineering.

c. A conceptual framework should be developed. The effort can most efficiently and effectively be accomplished by:

1. joint cooperation and coordination initially between the U.S. and Japan, then with other affected countries;

2. strong balanced partnership between researchers and practitioners;

3. include all relevant disciplines;

4. include multi-hazards.

d. Implementation of the conceptual framework into the development of reliable simple practical code will require first to identify the research results that are available, and second to clearly define and prioritize the focused research needed to achieve reliable code regulations. Short 
term, intermediate term, and long term research and procedures for practitioner involvement must be included.

e. Adequate education and/or training of engineers, professionals, and technical personnel who take part in design and construction projects must be considered.

f. Education of and communication with the public, government, and owners regarding the limitations of current code procedures for earthquake resistant design and construction, and proposed performance based design, must be started as soon as possible.

g. Formal cooperation should be continued between Japan and the U.S.

\section{U.S. Participants}

Craig Barnes

Vitelmo V. Bertero

Eric Elsesser

John Hooper

James Jirsa

Jack Moehle

Richard Phillips

Roland Sharpe

Andrew Whittker
Japan Participants

Nagahide Kani

Yuji Ohashi

Toshio Okoshi

Masakazu Ozaki

Yuki Sakai

Shunsuke Sugano

Takayuki Teramoto

Hiroyuki Yamanouchi

Katsumi Yano 


\title{
Composites for Construction
}

by

\author{
John B. Scalzi ${ }^{1}$
}

A new synthetic material is making inroads into the construction industry. This material is commonly referred to as Advanced Composites or Polymer Composites. It is being used, at present, primarily as a support material in the repair and retrofit of existing structures. As a primary/ structural component it is being used on offshore structures, pedestrian bridges, and many non-structural applications. The trend is to use the material in various ways for highway bridges, such as repair, retrofit and even new construction.

The material consists of many fibers of different types such as: glass, carbon, and aramids, in a matrix of various binders such as; epoxies, polyesters, and resins. The material is produced in many forms and shapes; rebars, structural shapes, prestressing tendons, cables, cloth or sheets/ laminates, tubes, and grids of two and three dimensional configurations. These products are produced by the pultrusion process of pulling the fibers through a bath of resin material and then they are hardened by a heat process.

The attractive features of the new materials for construction are: lightweight, high strength, non-conducting, non-magnetic, and corrosion resistant. Some of the materials have high stiffness and may be used to increase the stiffness when used in combination with materials of less stiffness. The feature of being non-magnetic makes it an ideal material for hospital operating rooms where non-magnetic material is desired for the structural material. The concept is technology transfer from the aerospace and pleasure boat industries where these produces have been used as a structural material for a long time.

Although the National Science Foundation has been supporting individual researchers for many years, it was not until 1984 that the researchers, together, with industry representatives developed a detailed fiveyear plan of research projects to determine the mechanical and physical characteristics of the materials. The purpose of the program is to guide future researchers to the type of research projects that fill the need to bring these products to the construction market. The plan also would assist to avoid duplication of investigations. As a result, the coordinated data would be very beneficial to develop standards and design specifications for the materials. These are needed to bring these products into practical applications. Each product needs to be researched for material characterization, ductility, environmental effects, buckling, bending, shear, temperature effects, connections, anchorages, methods of testing the products,

\footnotetext{
${ }^{1}$ Program Director

Structures and Building Systems

National Science Foundation
} 
nondestructive techniques and behavior in total systems.

An important task for all products, because of their brittleness, is the philosophy of designing structures with all ductile materials, such as, in combination with concrete. The question of sufficient ductility is very important for the safety of bridges and in other types of structures which endanger the safety of the public. Analytical methods are needed to predict the behavior of the total system when using any of the composites. Many questions need to be answered before the construction industry will accept these new composite products. The planned program is an attempt to guide the research activity in the right direction. This research is required to develop sufficient data to develop the standards and design specifications for practical applications. Although many projects are currently underway at many universities it is extremely important that coordination takes place.

An international meeting was held in June, 1996 at Bologna, Italy where many researchers and industry representatives discussed the research that is needed and discussed cooperative projects. At this meeting were engineers from Japan, Europe, Canada, the United States, and Latin American countries. This is the first international workshop of composite engineers and set the tone for future meetings.

Advanced composites are the new material for construction for the 21 st century. They will be used, at first, for repairs and retrofit of existing structures before being used as new replacements. Primarily, these materials will be used wherever corrosion resistance is a major concern, thus reducing maintenance costs and extending the life of the structure. In the light of these new materials for construction and the great amount of research data that is needed, this author recommends the UJNR Panel on Wind and Seismic Effects consider the establishment of a new task committee on composites, or include the composite material discussions in one of the existing Task Committee structure. 


\title{
Arrangement of Kyoshin Net
}

By

\author{
Keiichi OHTANI 1), Shigeo KINOSHITA 2), Hiroyuki FUJIWARA 3)
}

\begin{abstract}
Having said that, however, it is not unreasonable to then say any area in Japan could suffer a destructive earthquake. The gathering of records about strong earthquake motions is still too slow and the official reporting system is still inadequate. It is therefore necessary to formulate policy for the placement of strong motion seismographs in locations that will uniformly cover the country. Telephone lines need to be used to facilitate the collection of records, such records being comprehensively processed in the one location, published and used. To this end, the establishment of 1,000 strong motion measurement sites is being accelerated across the country, and a "Kyoshin Net" is being constructed, linked by telephone line with a processing system via a computer located in a control center. This paper is described the performance and data collection and release system of Kyoshin Net.
\end{abstract}

Key words: Kyoshin Net, Strong-motion seismograph, Digital recording, Internet

\section{INTRODUCTION}

The need to know what type of vibrations occurred in the various locations struck by an earthquake is regarded ad important information for planning countermeasures and investigating the cause of damage following an earthquake. Moreover, to more rationally implement earthquake disaster prevention measures and earthquake-proof design, it is essential to be able to estimate the precise nature of the vibrations in any given area. Having said that, however, it is not unreasonable to then say any area in Japan could suffer a destructive earthquake. The gathering of records about strong earthquake motions is still too slow and the official reporting system is still inadequate. It is therefore necessary to formulate policy for the placement of strong motion seismographs in locations that will uniformly cover the country. Telephone lines need to be use to facilitate the collection of records, such records being comprehensively processed in the one location, published and used.

For this object, we constructed the "Kyoshin Net" (Strong-motion earthquake measurement network) which is consisted 1,000 measurement locations with 3-components accelerometer covered all over the country, linked by telephone line with a processing system via a computer located in a control center, the National Research Institute for Earth Science and Disaster Prevention. When a big earthquake will occur anywhere, the control signal dispatched from control center to the measurement locations, the recorded signals are collected to the computer in a center, after that, the computer is edited and analyzed that data.

After the completion of this network, we can obtain the good strong motion record with no over-scale. If we assume that the Hyogoken-Nanbu earthquake will again occur, about 150 records will be obtained by this network. It is hope that we can possible to use estimation the real cause of damage and making the restoration planning through the rapid opening of the strong-motion data with this network. And, by the accumulation of data, it will be possible to upgrade the aseismic design of structures and the countermeasures of earthquake disaster prevention.

1) Director, Disaster Prevention Research Division, National Research Institute for Earth Science and Disaster Prevention (NIED), Science and Technology Agency (STA)

2) Head, Earthquake and Volcanic Disaster Prevention Laboratory, NIED, STA

3) Researcher, Earthquake and Volcanic Disaster Prevention Laboratory, NIED, STA 


\section{MEASUREMENT STATION}

The Kyoshin Net is a distributed sesimograph network and it consists of 1,000 stations. The average station to station distance is about $25 \mathrm{~km}$, All stations were constructed on free field. The measurement station is installed on a site 3 meters square. It commonly consists of a house made by fiber reinforced plastic, a concrete base on which a seismograph is installed, facilities for electric power and a telephone line with lighting arresters, and a fence (Photo. 1). The house is designed to withstand snow of 4 meters depth. Fig. 1 shows the drawing of the station. The figure of right hand side shows the detailed drawing of a base for cold area where the temperature becomes less than $20^{\circ} \mathrm{C}$, the base on which a seismograph is installed is constructed about $80 \mathrm{~cm}$ below the ground surface.

\section{SEISMOGRAPH}

The Kyoshin Net used a new developed digital strong-motion seismograph (Photo. 2). It has a frequency range from 0 to $30 \mathrm{~Hz}$ at a sampling frequency of $100 \mathrm{~Hz}$. This seismograph uses a 24bit $\mathrm{A} / \mathrm{D}$ converter and thus the value of $108 \mathrm{~dB}$ means the effective dynamic range. Fig. 2 shows a block diagram of recording system. A seismometer is a tri-axial force-balance accelerometer with a natural frequency of $450 \mathrm{~Hz}$ and a damping factor of 0.7. Seismic signals obtained from this seismometer are fed into amplifier and the to analog filter. This analog filter is an antialius filter for $\mathrm{A}$ to $\mathrm{D}$ converter and consists of two-stage $\mathrm{RC}$ filter. The output of $A$ to $D$ converter is a seismic signal with a sampling frequency of $800 \mathrm{~Hz}$ (Converter clock is $1.6384 \mathrm{MHz}$, thus oversampling ratio is 2,048.) Next digital filter is a decimation filter and decreases the sampling rate from $800 \mathrm{~Hz}$. to $100 \mathrm{~Hz}$. This digital filter is a three-pole Batterworth filter with a cutoff frequency of $30 \mathrm{~Hz}$. In the present seismograph, the design of decimation filter is free, so that w can make a causal recording system. Causality is an important factor for seismic wave recordings. Finally, seismic signals are stored on IC memory of
8 MB capacity.

The other specifications are as follows;

Resolution of accelerometer $15 \mathrm{mGal}$

Resolution of $\mathrm{A} / \mathrm{D}$ converter 18 bits

Recording capacity Approx. 150 minutes

Communication port 2 ports of RS-232C

Trigger level From 0.1 to $10 \mathrm{Gals}$

Trigger condition OR/AND combination of individual channel triggers

Slow code accuracy Within $1 \mathrm{~ms}$

Calibration signal $100 \mathrm{Gals}(1 \mathrm{~Hz})$

Operating temperature $-5^{\circ} \mathrm{C}$ to $50^{\circ} \mathrm{C}$

Waterproof Waterproof to 3 meters depth

Weight About $7 \mathrm{~kg}$

Power consumption About $16 \mathrm{~W}$ at $100 \mathrm{~V}$ AC

Dimensions $180(\mathrm{H}) \times 380(\mathrm{~L}) \mathrm{X} 280(\mathrm{~W})$

Fig. 3 shows the overall frequency characteristics of seismograph. The corner frequency is $30 \mathrm{~Hz}$ and the phase delay at $10 \mathrm{~Hz}$ is about 40 degrees.

\section{DATA COLLECTION}

The procedures of data collection from each station to the control center are as follows;

\section{1) Data collection at the occurrence of a big earthquake}

We will collect the data as soon as possible. Our system is consisted by the dial-up means. The data collect the following 2 steps.

(1) The maximum acceleration in which stored at the header part collect from the station where is be able to record the seismic signals.

(2) After that, the time history data collect from the same station as mentioned above.

\section{2) Periodically data collection}

We will call the station periodically (one time per month), and collect the data.

\section{DATA OPENING}

The procedures of data opening are as follows; 


\section{1) Opening the maximum acceleration}

When a big earthquake will occur, we will report the distribution of maximum acceleration (map and table) within one day after. This information will sent by Fax. to pre-registered organizations (mas media, federal and local government and several specific institutions).

\section{2) Opening the whole data}

when a big earthquake will occur, we will open the whole data which include the time history through the STA Net (Internet) within about one week. We also open the whole data collected by the periodically procedure by same way at the finishing the data editing. The minimum value of the maximum acceleration of each record is supposed to $10 \mathrm{Gals}$.

\section{DATA OPENING ON THE INTERNET}

One main feature of the Kyoshin Net is the release on the Internet. Fig. 4 shows the home page of the Kyoshin Net. This page has 4 message boxes such as introduction, how to use, news and others, and 4 data boxes such as site information, strong motion data, distribution map of maximum acceleration and characteristics of seismograph. Namely, we will send 4 kinds of data on the Internet.
We make three kinds of data files, UNIX, DOS and ASCII (Fig. 5). You can select one of these files. UNIX and DOS files are compressed by the standard methods. Each file name is constructed by site code, year, month, day, hour, minutes, point component and point compression code.

The Internet address of our home page is as follows;

\section{http://www.k-net.bosai.go.jp/}

\section{CONCLUSION}

The Kyoshin Net is constructed by the supplemental budget of 1995 . The construction started in June, 1996 and completed in March, 1996. Now, we are storing the site information to the computer system. We will officially open the Kyoshin Net home page from June, 1996.

There is no restriction on using the Kyoshin Net information and data. If you use all or part of the information including strong-motion data on the Internet, you are requested to acknowledge the data source and to send a copy of your publication to our office. 

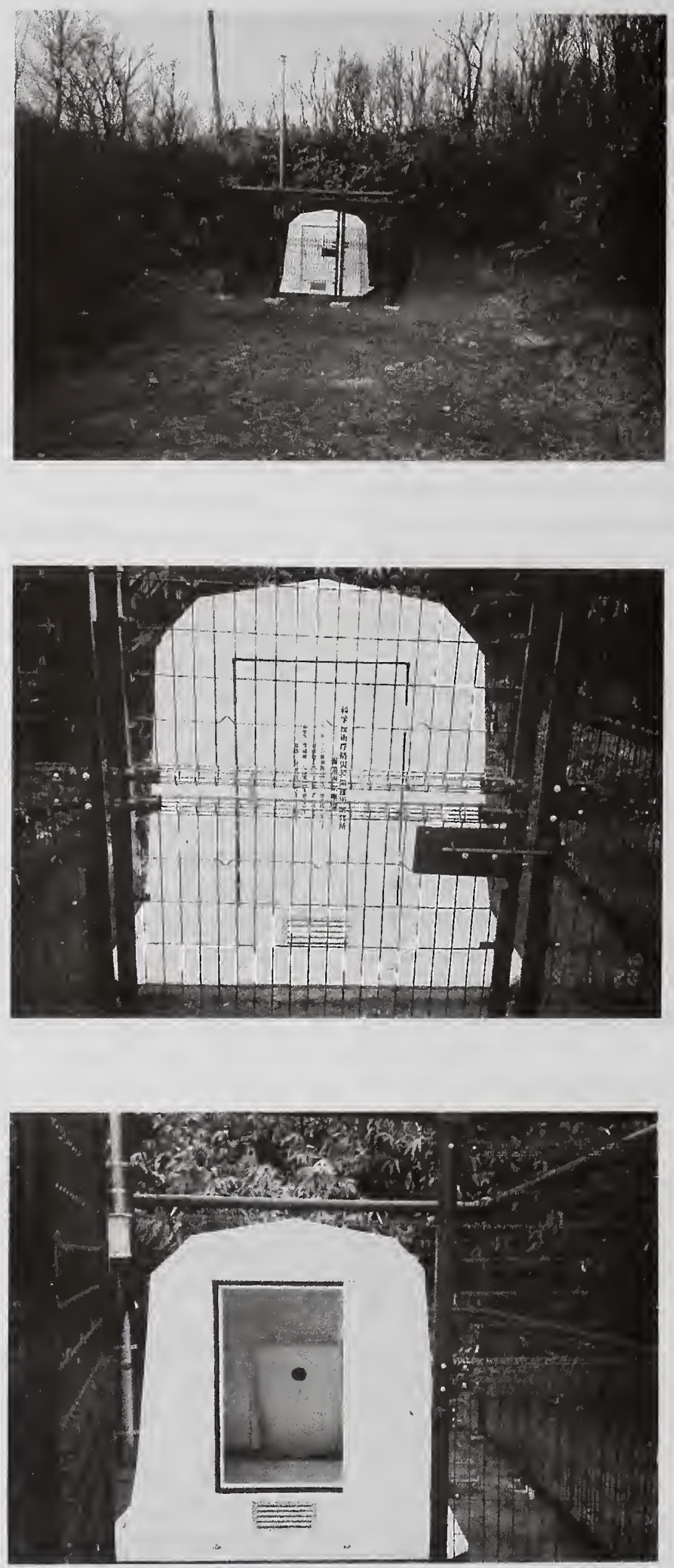

Photo 1. Measurement station for the Kyoshin Net 

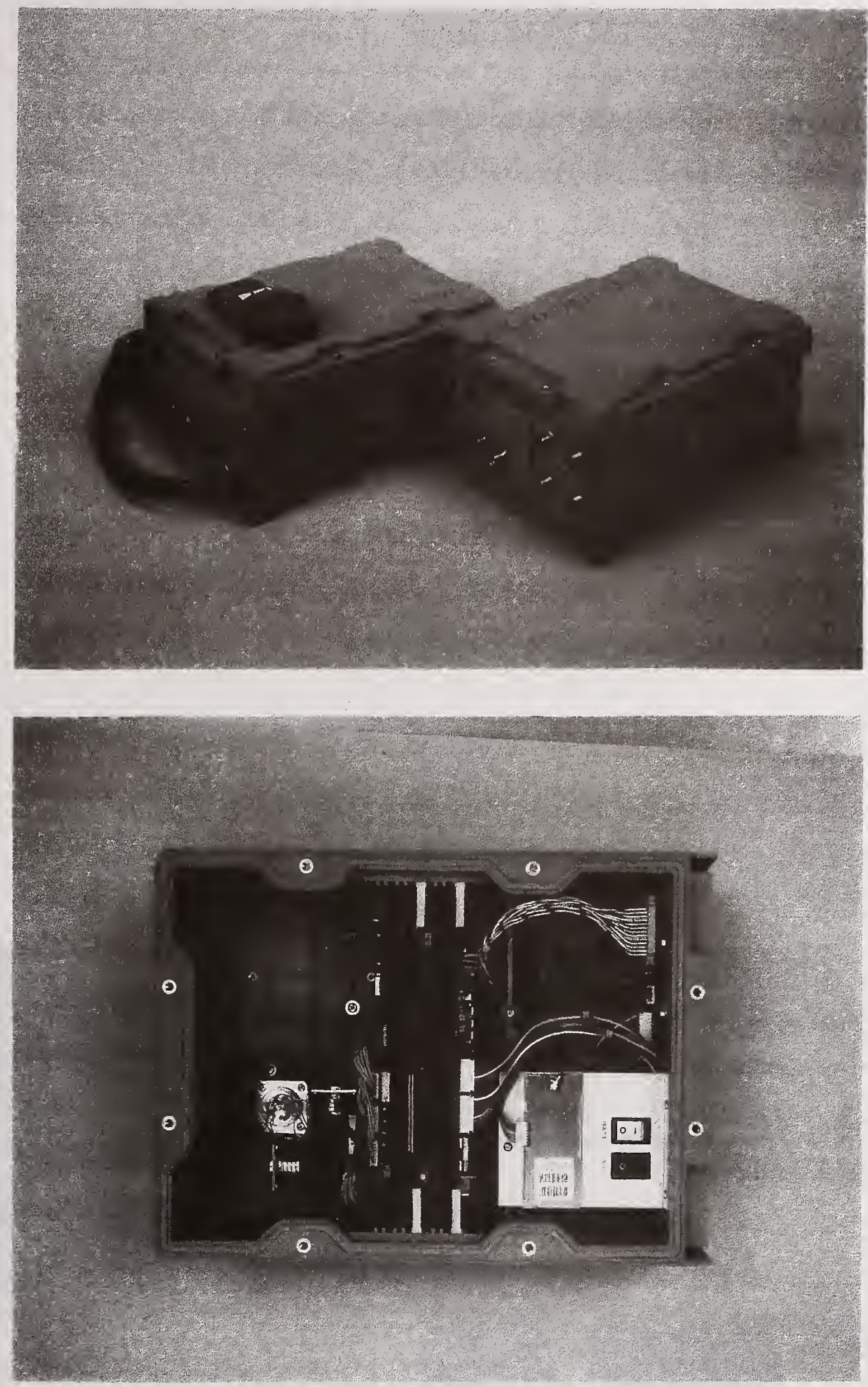

Photo 2. Seismograph for the Kyoshin Net 

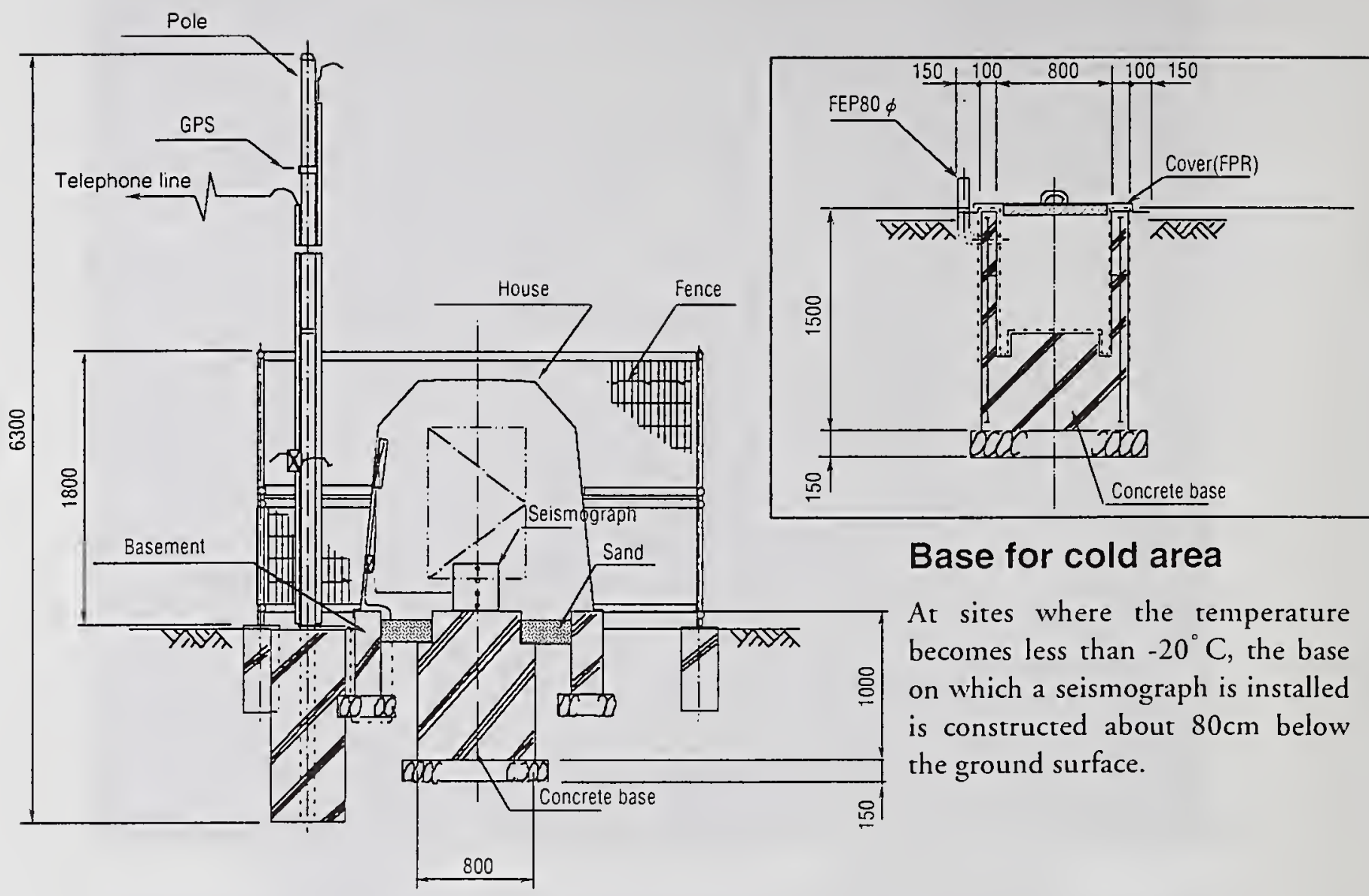

\section{Base for cold area}

At sites where the temperature becomes less than $-20^{\circ} \mathrm{C}$, the base on which a seismograph is installed is constructed about $80 \mathrm{~cm}$ below the ground surface.

Fig. 1. Drawing of the station

\section{Block Diagram}

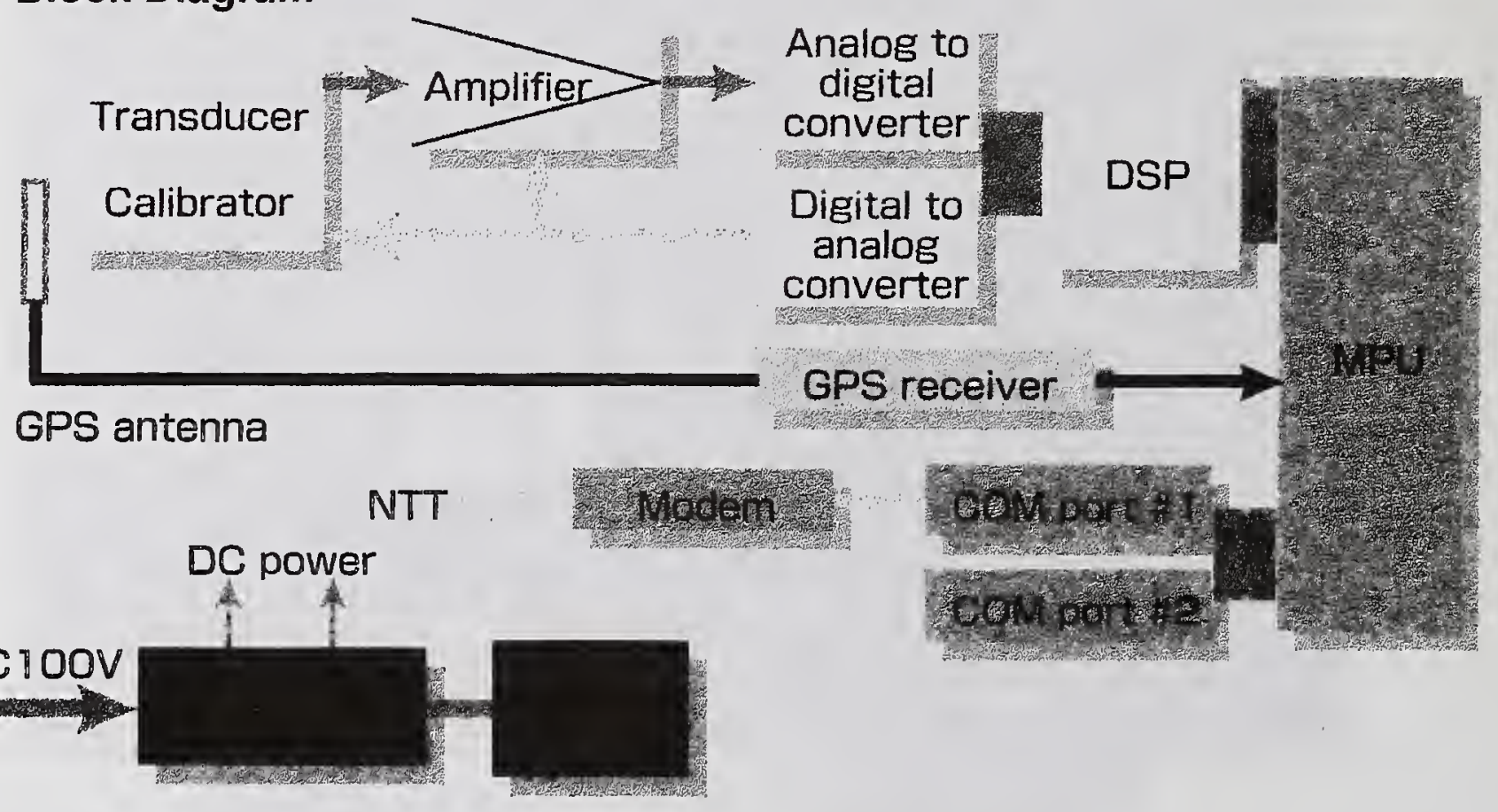

Fig. 2. Block Diagram of seismograph 

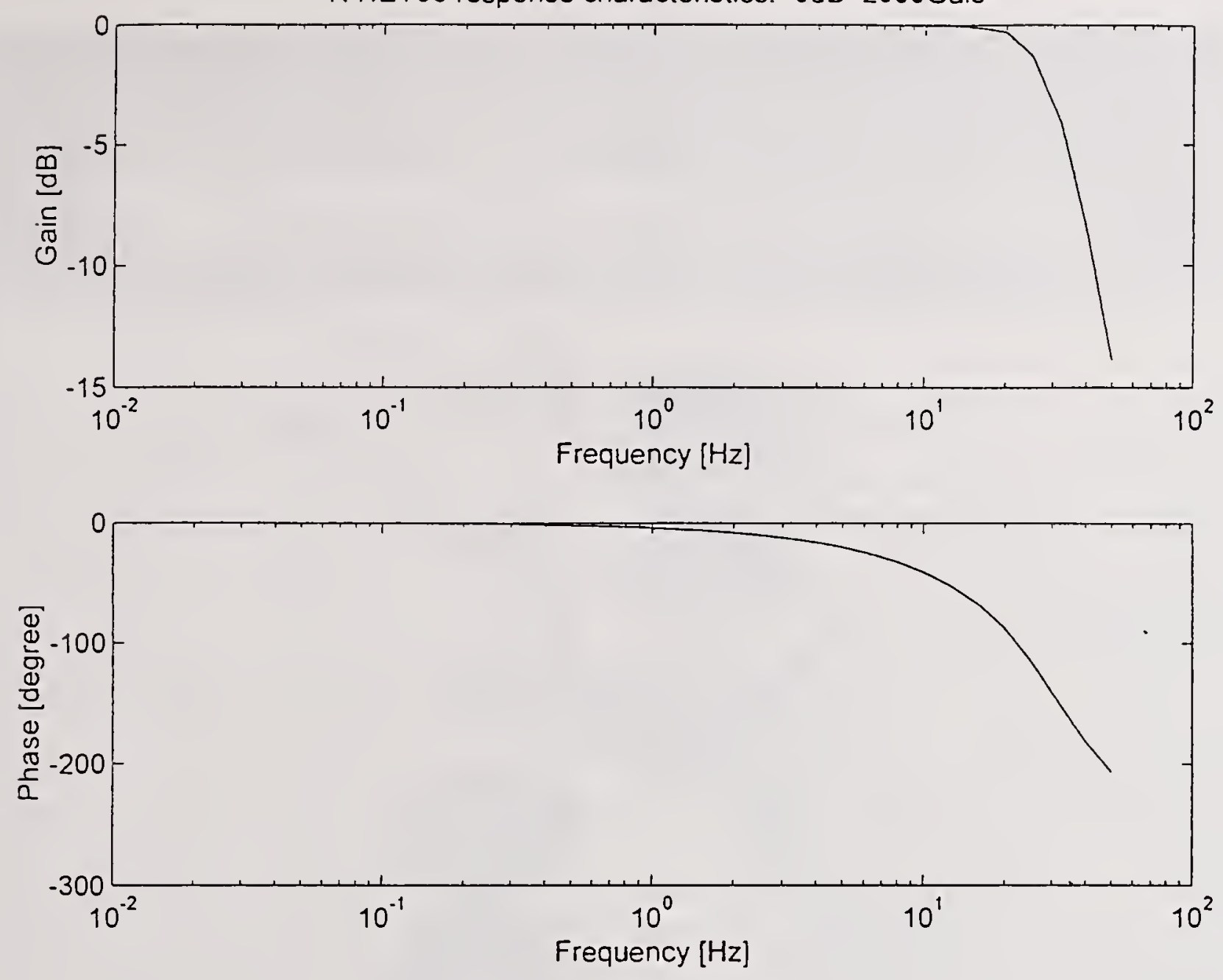

Fig. 3. Response characteristics of seismograph

\section{Strong-Motion Data}

Pleare click one of three data types.

\section{UNIX}

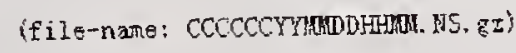

E⿱t 015

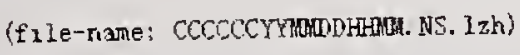

G11

(file-nare: coccccrymodothrs. NS)

A there There is no restriction on using the $\mathrm{x}$ including strong-ation dat on the publication to the following address:

Earthquake and Yolcanic Disaster Prepention Laboratory

Eational Research Institute for Earth Science and Disaster Prevention

3-1, Iennodai, Isukuba-shi, Ibaraki-kenn 305 , Japan

Fig. 5. Three kinds of data files 


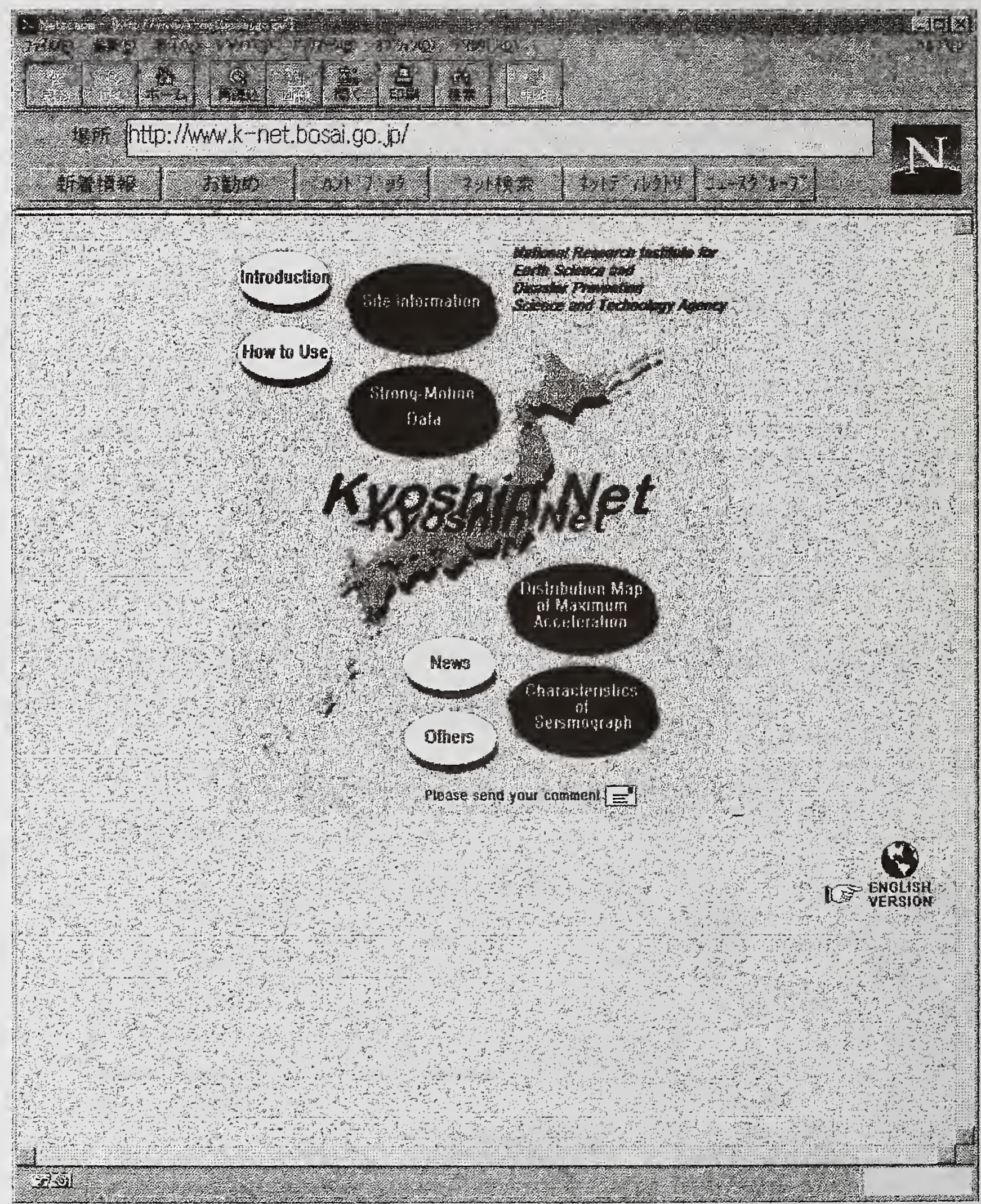

Fig. 4. Home page of the Kyoshin Net 


\title{
Seismic Stability for Sliding of Rockfill Dams
}

\author{
by
}

\author{
Tadahiko SAKAMOTO ${ }^{1)}$, Tadahiko FUJISAWA ${ }^{2)}$, \\ Akira NAKAMURA $^{3)}$ and Tomoya IWASHITA ${ }^{4)}$
}

\begin{abstract}
The Hyogoken-Nambu Earthquake (M. 7.2) caused no major damage to dams that affected their safety. Other infrastructures, however, were badly damaged. We therefore evaluated the seismic capacity of rockfill dams designed by the current design method.

We estimated that the maximum horizontal acceleration at dam site rocks near the earthquake source fault was about 220 gal from the attenuation of maximum accelerations observed at dam foundations during the quake. We conducted a dynamic analysis of the Minoogawa Dam located near the aftershock distribution zone (earthquake source fault) using the observed acceleration records. We then assessed the accuracy of the dynamic analysis method. Finally, we made a dynamic analysis and stability analysis of the rockfill dam models using the current design method. This showed that the dam body of rockfill dams constructed by the current design method would be safe enough for sliding even if the incident earthquake motion was a little stronger than that which occurred near the source fault of this earthquake.
\end{abstract}

Key Words : Rockfill Dam, Seismic Design, Earthquake Motion, Dynamic Analysis, HyogokenNambu Earthquake

\section{INTRODUCTION}

Many infrastructures and buildings were damaged by the Hyogoken-Nambu Earthquake of magnitude 7.2, which occurred on January 17, 1995. In the case of dams, special safety inspections were carried out by site offices within the river reaches administered under the River Act immediately after the earthquake at a total of 251 dams. Later, engineers of the Public Works Research Institute, Ministry of Construction conducted detailed on-site investigations, mainly at the dams which suffered minor damage.

The results confirmed that all the dams generally behaved well and did not require protective countermeasures. However, some slight damage, such as minor cracks in the crest paving, was found at a few dams. The amount of drainage water increased slightly after the earthquake at eight dams, but the total amount was small and either fell or stabilized later (Matsumoto et al., 1996).

In this paper, we reevaluated the seismic capacity of rockfill dams constructed by the current design criteria, in the light of the serious damage of other infrastructures and buildings. We estimated the characteristics and strength of the earthquake motion near the earthquake source fault from the records of accelerations observed at the foundation of dams. We conducted the dynamic analysis of the Minoogawa Dam, with a height of $47 \mathrm{~m}$ and located near the earthquake source fault, using the acceleration records observed at the dam to confirm the accuracy of the analysis. We then evaluated the stability for sliding of rockfill dams against an incident earthquake motion of slightly greater magnitude near this earthquake source fault by dynamic analyses of model dams.

\section{EARTHQUAKE MOTIONS AT DAM FOUNDATIONS DURING HYOGOKEN- NAMBU EARTHQUAKE}

\section{(1) Peak Acceleration}

Figures 1 and 2 show the distributions of the horizontal peak (either of the peak accelerations in the

1) Director General of Public Works Research Institute, Ministry of Construction Tsukuba Science City, 305 Japan

2) Director of Dam Department, ditto

3) Former Head of Fill Dam Division, ditto

4) Research Engineer, Fill Dam Division, ditto 
direction of the stream or of the dam axis, whichever is greater) and vertical peak accelerations, respectively, observed at the foundation of dams during the Hyogoken-Nambu Earthquake. These values include the values obtained at the gallery under embankment dams or at the lowest gallery in concrete dams.

The attenuation of the horizontal peak accelerations observed at the dam foundations during the earthquake with epicentral distance is shown in Figure 3, and that of the vertical peak accelerations in Figure 4. These figures also show peak accelerations measured on soil sites (Committee for Investigation on the Damage of Highway Bridges Caused by the Hyogoken-Nambu Earthquake, 1995). The figures indicate that peak accelerations at the dam sites were substantially smaller than those at the soil sites for the same epicentral distance. It can be seen that the earthquake motion at the foundation of a structure constructed on a hard rock site, such as a dam, is considerably smaller than that on a soil site consisting of alluvial or diluvial deposits.

The attenuation of horizontal peak accelerations at dam sites with distance from the earthquake source faults is shown in Figure 5, and that of vertical peak accelerations in Figure 6 . Here, the earthquake source faults, which indicate the Nojima Fault on Awaji Island and the distribution line of aftershocks occurring on the day of the main shock in Kobe, are shown in Figure 7. The dam's distance from the earthquake source fault indicates the shortest distance from the fault to each dam site. The Hitokura Dam, at which a horizontal peak acceleration of 183 gal was recorded during the earthquake, is located about 10 $\mathrm{km}$ from the fault. An acceleration record at a rock site besides dam sites was observed at a point $15 \mathrm{~m}$ underground which is located $10 \mathrm{~km}$ from the fault. The horizontal peak acceleration (component in the EW direction) was 213 gal (Izawa et al., 1995). The elastic wave ( $\mathrm{P}$ wave) velocity at the point is 2.67 $\mathrm{km} / \mathrm{s}$, which is almost equal to those at dam sites. The earthquake motion on a rock site was assessed from the acceleration records shown in Figure 5 and those observed in rock sites close to the earthquake source fault. As a result, it was estimated that the maximum horizontal acceleration in a hard rock site, on which a dam could be constructed, caused by this earthquake was about 220 gal (Committee on Evaluation of Earthquake Resistance of Dams, 1995).

Figure 8 shows the ratio of the vertical peak acceleration to horizontal peak acceleration at dam foundations, which ranges from $1 / 3$ to $1 / 1$. As the peak acceleration rises, the ratio tends to decrease.

\section{(2) Acceleration Response Spectrum}

Figure 9 shows the response spectra of the acceleration in the stream direction observed at the foundations of 25 dams during the Hyogoken-Nambu Earthquake at a damping ratio of $10 \%$. The spectra are normalized so that the peak accelerations are the unit. The average value of the response spectra for a natural period ranging from 0.1 to 0.6 seconds is about 2 . The response spectra decrease rapidly at natural periods above 0.6 seconds.

\section{(3) Natural Period of Rockfill Dams}

Using the acceleration waves observed at eight rockfill dams, we calculated the ratios of Fourier spectrum at the crest to that at the foundation, which is a frequency response function. We then obtained the fundamental natural period of dam bodies from the predominant frequency of the frequency response function. Figure 10 shows the relationship between fundamental natural period $\mathrm{T}$ and height of dams $\mathrm{H}$. The relationship is nearly linear and within the empirical equation (1) (Okamoto, 1984), shown in Figure 10, from the earthquake observations and vibration tests.

$$
T[\mathrm{sec}]=(0.35 \sim 0.65) \times \frac{H_{[m]}}{100}
$$

\section{EVALUATION OF SEISMIC CAPACITY OF ROCKFILL DAMS}

\section{(1) Seismic Design of Dams in Japan}

The structural safety design of dams has been prescribed by the provisions of the "Cabinet Order Concerning Structural Standards for River Administration Facilities, etc." and the "Regulation for Enforcement of Cabinet Order Concerning Structural Standards for River Administration Facilities, etc." These stipulate that the seismic design of dams should be based on the seismic coefficient method.

The concept of seismic design of dams based on the seismic coefficient method was proposed by Dr. Nagaho Mononobe in 1925 in the aftermath of the Great Kanto Earthquake of 1923. Komaki Dam (concrete gravity dam), which was constructed in 1930, was the first dam designed by the seismic coefficient method. The seismic design method was 
put in a statutory form by the publication of the "Design Criteria for Dams" established by the Japanese National Committee on Large Dams in 1953. Later in 1971, the criteria were partly revised by the publication of the "Design Criteria for Dams (Revised)". In 1976, the Ministry of Construction enacted the "Regulation for Enforcement of Cabinet Order Concerning Structural Standards for River Administration Facilities, etc." as the legally binding design standards for dams. In 1981, the design seismic coefficient was reviewed by the publication of the "Regulation for Enforcement of Cabinet Order Concerning Structural Standards for River Administration Facilities, etc. (Revised)", which has up to the present been in force.

In the "seismic coefficient method," the effect of the inertia force that is produced by the dam body vibration is evaluated as a static horizontal force in proportion to the weight of each section of the dam body. The proportional coefficient is called the design seismic coefficient. The lowest value of the coefficient for rockfill dams is 0.10 to 0.15 in accordance with seismic activity specified in the "Regulation for Enforcement of Cabinet Order Concerning Structural Standards for River Administration Facilities, etc." This stipulates that the safety of a rockfill dam should be secured by ensuring that the safety factor for sliding of the dam body is at least 1.2 in the structural design based on the seismic coefficient method.

Rockfill dams designed by the seismic coefficient method have not suffered any damage affecting their structural safety from any earthquakes in the past, including the Hyogoken-Nambu Earthquake. Rockfill dams designed by the seismic coefficient method are thus judged to have a high seismic capacity.

\section{(2) Dynamic Analysis of Minoogawa Dam}

Minoogawa Dam is the dam showed the greatest earthquake acceleration record of all embankment dams during the Hyogoken-Nambu Earthquake. We analyzed for the dam using the acceleration records observed at the dam to confirm the accuracy of using dynamic analysis to estimate the seismic capacity of rockfill dams.

\section{(a) Profile of Minoogawa Dam}

Minoogawa Dam was completed in 1982. It is a $47.0 \mathrm{~m}$-high zoned rockfill dam with a central earth core. The foundation rock of the dam is composed of sandstone and slate of the Tamba group in the
Paleozoic or Mesozoic era and is hard, with its $\mathrm{P}$ wave velocity, $\mathrm{Vp}$, exceeding $4 \mathrm{~km} / \mathrm{s}$ approximately. This dam was designed by the seismic coefficient method, and its design seismic coefficient was 0.15 . Figure 11 shows its standard cross section.

This dam is located $48 \mathrm{~km}$ from the epicenter and $11 \mathrm{~km}$ northeast of the east end of the aftershock zone. Seismometers are installed at the foundation (gallery) and the crest, as shown in Figure 11. During the Hyogoken-Nambu Earthquake they recorded acceleration waves with peaks of about 130 gal in the stream and dam axis directions at the foundation, and a peak of about $240 \mathrm{gal}$ in the stream direction and a peak of about $400 \mathrm{gal}$ in the dam axis direction at the crest. The quake caused no major damage. Minor transverse cracks occurred on the crest pavement and the checkpoints on the crest sank only $11 \mathrm{~mm}$ at the maximum in comparison with measurements three weeks before the quake.

b) Analysis method and conditions (for details, refer to the paper by Nakamura and Iwashita in 1996)

Dynamic analysis was adopted for the complex response analysis by the equivalent linear method. We set the density of each zone of the dam body based on the results of the control tests conducted during the banking of the dam, as shown in Table 1 . The initial shear modulus Go, with average effective principal stress were set as shown in Figure 12. The shear strain dependency of the shear modulus ratio $\mathrm{G} / \mathrm{Go}$, and hysteresis damping ratio hh were set as shown in Figure 5. . Those of the rock materials were obtained from large-scale cyclic triaxial tests. The Go, G/Go and hh of filter materials were set the same as those of inner rockfill materials (Rock II). We used the test results for the core materials of another rockfill dam as the Go, G/Go and hh of the core material. We set the Poisson's ratio using the empirical expression (Sawada et al., 1975) based on measurements of rockfill dams. As the incident earthquake waves, we used the acceleration wave, shown in Figure 14, observed at the gallery of Minoogawa Dam during the Hyogoken-Nambu Earthquake.

To take into consideration energy losses because of internal viscous damping, uneven incident waves at the dam foundation, dynamic interaction between the dam body, foundation and reservoir and so on, an equivalent damping for these effects must be added to the hysteresis damping ratio hh of the dam body material. We conducted dynamic analyses for two cases where equivalent damping ratio of $15 \%$ and 
$10 \%$ was added to hysteresis damping ratio hh.

\section{c) Results of dynamic analysis}

We compare the analyses and the observation of the time histories (shown in Figure 15) and the Fourier amplitude spectra (shown in Figure 16) of the response acceleration at the crest. In Figure 15, the analysis response wave of the stream direction component agrees well with the observation in the first half of the principal motion ( $t=4$ to $5.5 \mathrm{sec}$ ). The amplitude of the analysis response wave becomes smaller than that of the observation in the second half of the principal motion. The amplitude of the analysis response wave of the vertical direction component is smaller overall than that of the observation. In Figure 16, the Fourier spectra of the analysis in the stream direction component are almost equal to that of the observation at frequencies up to $1.2 \mathrm{~Hz}$. The spectrum of the analysis is larger than that of the observation at frequencies of 1.2 to $2 \mathrm{~Hz}$ and is smaller above $2 \mathrm{~Hz}$. The Fourier spectra of the analysis in the vertical direction component are smaller than that of the observation above $3 \mathrm{~Hz}$, whereas both of the spectra are almost equal up to about $3 \mathrm{~Hz}$. The disagreements between the analysis and observation are largely caused by threedimensional factors such as incident waves of other directions and the topography of the dam site. The observed accelerations in the stream direction are considerably larger in the second half of the principal earthquake motion, which agrees with the time zone when the acceleration in the dam axis direction at the crest exceeded $300 \mathrm{gal}$. This indicates the great effect of three-dimensional vibration.

The comparison of both the cases of adding a damping ratio of 10 and $15 \%$ to the hysteresis damping ratio hh in Figures 15 and 16 showed that the analysis result in the case of adding $15 \%$ agrees better with the observation, accurately reproducing the behavior of the dam during the earthquake.

\section{(3) Seismic Capacity of Rockfill Dams Close to Source Fault of Hyogoken-Nambu Earthquake}

\section{a) Incident earthquake wave}

As noted in section 2, the maximum horizontal peak acceleration at the rock foundation of dams during the Hyogoken-Nambu Earthquake is estimated to have been about 220 gal. Incident waves with a horizontal maximum acceleration of 250 gal were, therefore, used in the dynamic analysis to provide an adequate margin of safety. These waves can be considered to be greater than the amplitude of earthquake motions close to the source fault of the Hyogoken-Nambu Earthquake.

We selected as the incident earthquake waves four acceleration records (ACC-1 to ACC-4) observed at the dam foundations near the epicenter, the peak acceleration of which was raised to $250 \mathrm{gal}$. Our selection took account of the fact that the proportion of rise in the amplitude should be as small as possible and that the selected acceleration waves should have various frequency properties. The vertical acceleration waves were to be raised in the same proportion as their corresponding horizontal ones. Here, we used the incident waves without modification of their frequency characteristics and the duration of the observations. Figure 17 shows the acceleration response spectra of the four selected incident earthquake waves with a damping ratio of $10 \%$.

\section{b) Dynamic analysis conditions}

We prepared dam models to evaluate the seismic capacity of rockfill dams with reference to Shichigashuku Dam (completion in 1991, height of 90 $\mathrm{m}$, design seismic coefficient of 0.15 ) designed in accordance with the current design method. The finite element mesh of the dam model is shown in Figure 18. The gradient of the upstream slope is 1 : 2.6 and that of the downstream slope is $1: 2.0$. The heights of the dam models to be adopted are 63,110 and $150 \mathrm{~m}$. The water should be stored up to the normal water level.

Direct time integration using the equivalent linear method was used for the dynamic analysis. In the dynamic analysis, the physical properties of the model are assumed to be only rock materials, which account for the greater part of dam bodies. The physical properties of the material for the analysis were set on the basis of the results of the control tests during construction and large-scale triaxial tests for the Shichigashuku Dam. We set the wet density at $1880 \mathrm{~kg} / \mathrm{m}^{3}$, saturated density at $2080 \mathrm{~kg} / \mathrm{m}^{3}$ and Poisson's ratio $\nu$ at 0.35 . The initial shear modulus Go was set according to the depth D from the surface of the dam as shown in Figure 19. Figure 20 shows the curves representing the shear strain dependency of the shear modulus ratio G/Go and the hysteresis damping ratio hh of the rock material. The used damping ratio was obtained by adding $15 \%$ to the hysteresis damping ratio of the rock material, based on the comparison study described above for the 
observed and analytical response of the Minoogawa Dam during the Hyogoken-Nambu Earthquake. Rayleigh damping was used considering the dependence on frequency (Iwashita et al., 1995).

\section{c) Resisting acceleration for sliding}

We conducted convergent static stability analyses for the potential circular slide masses as shown in Figure 18. We calculated the accelerations acting on the slide masses (resisting acceleration ares) that would cause the safety factor Fs against sliding to become 1.0 as expressed by equation (2). The resisting acceleration ares is the horizontal acceleration (force) that would cause the potential slide mass to begin to slide.

$$
\int_{L}^{L}\left(\tau_{f} \times r\right) d l /\left(a_{r e s} \times \sum_{i=1}^{N} m_{i} \times r_{v i}\right)=F s=1.0
$$

Where, $\tau_{f}$ is the shear strength of the dam body materials, $r$ is the radius of the potential slide circle, $\mathrm{L}$ is the length of circular-arc of the slide mass, $i$ is the element number, $\mathrm{N}$ is the number of elements in the potential slide mass, and $\mathrm{r}$ vi is the vertical height from the center of the slide circle to the center of gravity of element $\mathrm{i}$.

We analyzed the stability for sliding of only the upstream slope, because the safety factor against sliding in the downstream slope is usually greater than that in the upstream slope. The simple slice method was used for the stability analysis.

Table 2 shows shear strength parameters of the materials for the stability analysis. The shear strength of the rock material was decided from the results of large-scale monotonic loading triaxial tests using the rock materials carried from the quarry sites. We adopted the shear strength $\tau$ fof the coarse grain materials (rock and filter) approximated by the equation (3) as an exponential function. Equation (3) expresses the dependence of internal friction angle $\phi$ on normal stress $\sigma n$ acting on the sliding surface.

$$
\tau_{f}=P_{0} \cdot A \times\left(\sigma_{n} / P_{0}\right)^{b}
$$

Where, Po is $1 \mathrm{MPa}$.

\section{(d) Evaluation of stability for sliding}

The seismic inertia force acting on a potential slide mass is expressed by the product of the mass and the acceleration of the slide mass. We evaluated the stability for sliding using "peak average acceleration of slide mass", a(t)max. The peak average acceleration of slide mass is the maximum value during the duration in the sliding direction of aave(t) which is the value of the peak seismic inertia force moment divided by the mass moment of each slide mass by equation (4):

$$
\operatorname{aave}(t)=\sum_{i=1}^{N}\left(m_{i} \times a H_{i}(t) \times r_{v i}\right) / \sum_{i=1}^{N}\left(m_{i} \times r_{v i}\right)
$$

Where, aHi(t) is the horizontal response acceleration time series acting on an element $i$ by dynamic analysis.

Figure 21 shows the distribution of peak average accelerations of slide masses with different $\mathrm{y} / \mathrm{H}$ for three heights of dam model. This figure also shows the distribution of resisting accelerations for each potential slide mass ares. Figure 21 shows that the peak average accelerations are large values in the upper part of the dam, but the values are within the resisting acceleration in all cases. This indicates that rockfill dams are safe against sliding. Moreover, the peak average acceleration of slide mass, which represents the maximum value during the duration of an earthquake, does not continue but acts on the dam body only in the peaking instant. Therefore, rockfill dams are actually safer than the results shown in Figure 21 suggest.

\section{CONCLUSIONS}

The Hyogoken-Nambu Earthquake of January 17, 1995, which was an intra-plate earthquake, occurred just below urban areas causing severe damage in the Hanshin region and on Awaji Island. However, no dam was seriously damaged.

The peak accelerations of earthquake motion observed at rock sites of dams were sufficiently smaller than those on soil sites consisting of alluvial or diluvial deposits. From the attenuation of the peak accelerations observed at dam foundations, we estimated that the maximum horizontal acceleration that would have been caused close to the earthquake source fault was about $220 \mathrm{gal}$. The construction of dams on hard bed rock sites is considered to be one of the reasons why this earthquake did not inflict major damage on any dam.

We conducted a dynamic FEM analysis of the Minoogawa Dam located near the earthquake source fault using the observed acceleration wave. The response acceleration wave of the analysis reproduced 
the observed wave with good accuracy.

We evaluated the seismic capacity of rockfill dams designed by the current design method based on the seismic coefficient method. We prepared FEM model dams and four incident earthquake waves based on the observations and conducted the analysis using them. The analysis results confirmed that the rockfill dams designed by the current design method have sufficient safety for sliding even against the magnitude of shaking that occurred close to the source fault of the Hyogoken-Nambu Earthquake.

Dams, as large-scale structures, must have sufficient stability even during earthquakes. The seismic design technology for dams and the system for observing earthquakes must be improved.

\section{ACKNOWLEDGMENTS}

We would like to extend our deep gratitude to the many persons of Osaka and Hyogo Prefectures, Water Resources Development Public Corporation and Kansai Electric Power Corporation for their cooperation in collecting earthquake acceleration records.

\section{REFERENCES}

Committee for Investigation on the Damage of Highway Bridges Caused by the Hyogoken-Nambu Earthquake, with T. Iwasaki as the chair (1995): Report on the Damage of Highway Bridges Caused by the Hyogoken-Nambu Earthquake (in Japanese)

Committee on Evaluation of Earthquake Resistance of Dams, with C. Tamura as the chair (1995): Report of Committee on Evaluation of Earthquake Resistance of
Dams (in Japanese)

Development Division, River Bureau, Ministry of Construction (1991): Seismic Design Standards for Embankment Dams (Draft)

Izawa, S. et al. (1995): Measured Earthquake Records in a Rock Site During Hyogoken-Nambu Earthquake, Architectural Institute of Japan Kinki Chapter Architectural Research Meeting (Structure) (in Japanese)

Iwashita, T., Yasuda, N., Nakamura, A., Matsumoto, N., Takeda, O. (1995): Dynamic Analysis of Rockfill Dams Considering Frequency Independent Characteristics of Radiation Damping Ratio, First International Conference on Geotechnical Engineering, Vol.1, Balkema, pp. 511-516

Matsumoto, N., Nakamura, A., Sasaki, T., Iwashita, T. (1996): Effects on Dams, A Special Issue of Soils and Foundations on Geotechnical Aspects of the January 171995 Hyogoken-Nambu Earthquake, JGS, pp.273281

Nakamura, A. and Iwashita, T. (1996): Behavior and Stability of a Rockfill Dam by Dynamic Analysis During the 1995 Hyogoken-Nambu Earthquake, Proceedings of Conference on the Great Disaster in Hanshin and Awaji, JSCE, pp.441-448 (with English summary)

Okamoto, S. (1984): Introduction to Earthquake Engineering, pp.474-479, University of Tokyo Press

Sawada, Y. and Takahashi, T. (1975): Study on the Material Properties and the Earthquake, Proceedings of the fourth Japan Earthquake Engineering Symposium, pp.695-702 
Table 1 Properties of materials of the Minoogawa Dam model

\begin{tabular}{l|c|c}
\hline Zoning & $\begin{array}{c}\text { Wet } \\
\text { Density } \\
\rho_{c}\left(\mathrm{~kg} / \mathrm{m}^{3}\right)\end{array}$ & $\begin{array}{c}\text { Saturated } \\
\text { Density } \\
\rho_{\text {sa }}\left(\mathrm{kg} / \mathrm{m}^{3}\right)\end{array}$ \\
\hline Rock I & 2120 & 2320 \\
\hline Rock I & 2030 & 2270 \\
\hline Filter & 2230 & 2350 \\
\hline Core & 2180 & 2180 \\
\hline
\end{tabular}

Table 2 Shear strength parameters for stability analysis of model dams

\begin{tabular}{|c|c|c|c|c|}
\hline \multirow{2}{*}{ Zoning } & \multirow{2}{*}{$\begin{array}{c}\text { Wet Density } \\
\left(\mathrm{kg} / \mathrm{m}^{3}\right) \\
\end{array}$} & \multirow{2}{*}{$\begin{array}{l}\text { Saturated Density } \\
\qquad\left(\mathrm{kg} / \mathrm{m}^{3}\right) \\
\end{array}$} & \multicolumn{2}{|c|}{ Strength Parameter* } \\
\hline & & & $A($ or $c)$ & $\mathrm{b}(\operatorname{or} \Phi)$ \\
\hline Rock & 1880 & 2080 & $A=1.128$ & $b=0.804$ \\
\hline Filter & 2130 & 2240 & $A=0.808$ & $\mathrm{~b}=0.908$ \\
\hline Core & 2220 & 2230 & $\mathrm{c}=98 \mathrm{kPa}$ & $\Phi=35^{\circ}$ \\
\hline
\end{tabular}

* $\tau \mathrm{f}=\mathrm{Po} \cdot \mathrm{A} \cdot(\sigma \mathrm{n} / \mathrm{Po})^{\mathrm{b}}$ or $\tau \mathrm{f}=\mathrm{c}+\sigma \mathrm{n} \tan \Phi$, where $\tau \mathrm{f}$ is the shear strength, $\mathrm{Po}$ is $1 \mathrm{MPa}, \sigma \mathrm{n}$ is the normal stress on the sliding plane, $\mathrm{c}$ is cohesion, and $\Phi$ is internal friction angle. 


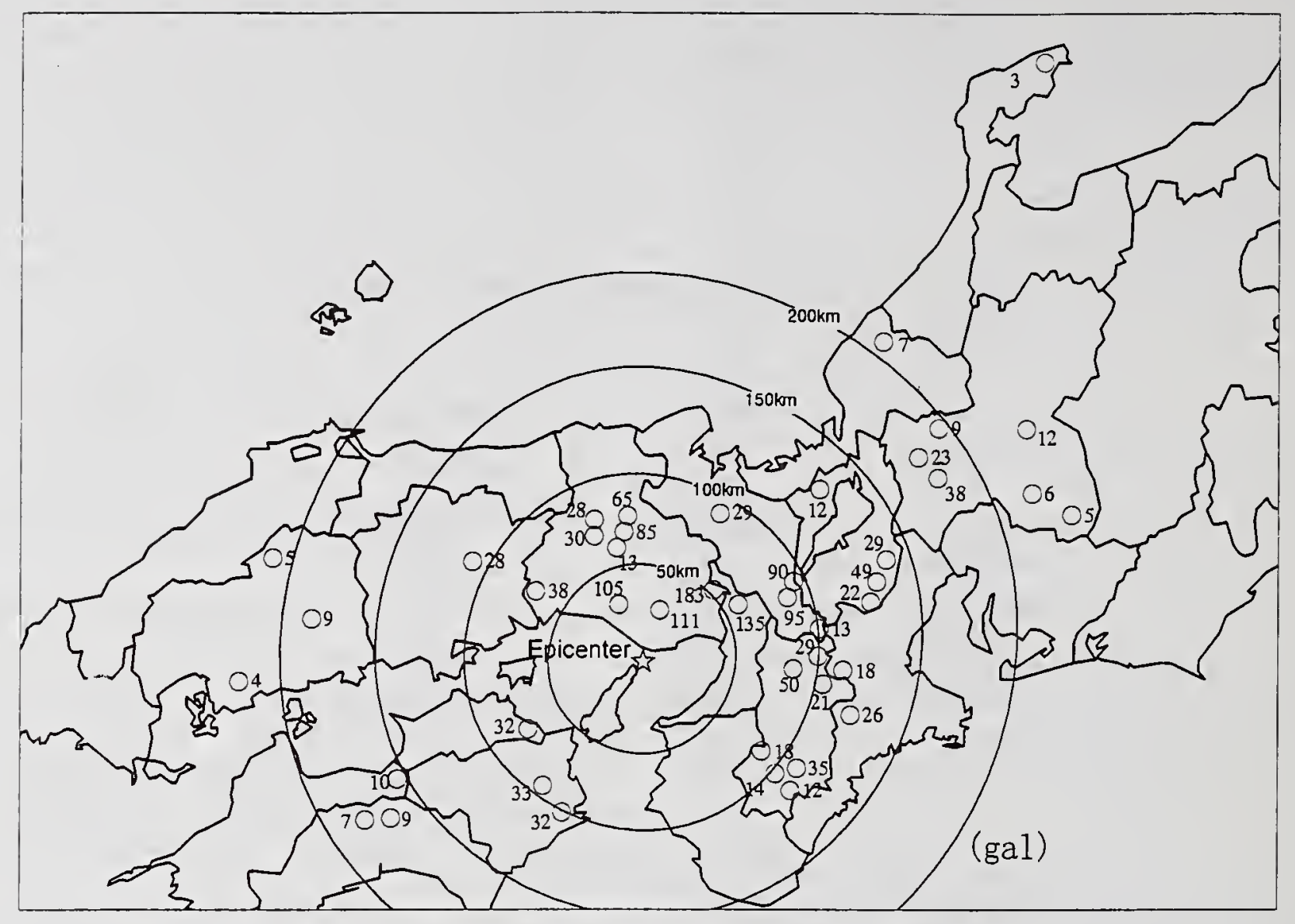

Figure 1 Horizontal peak acceleration at dam foundations

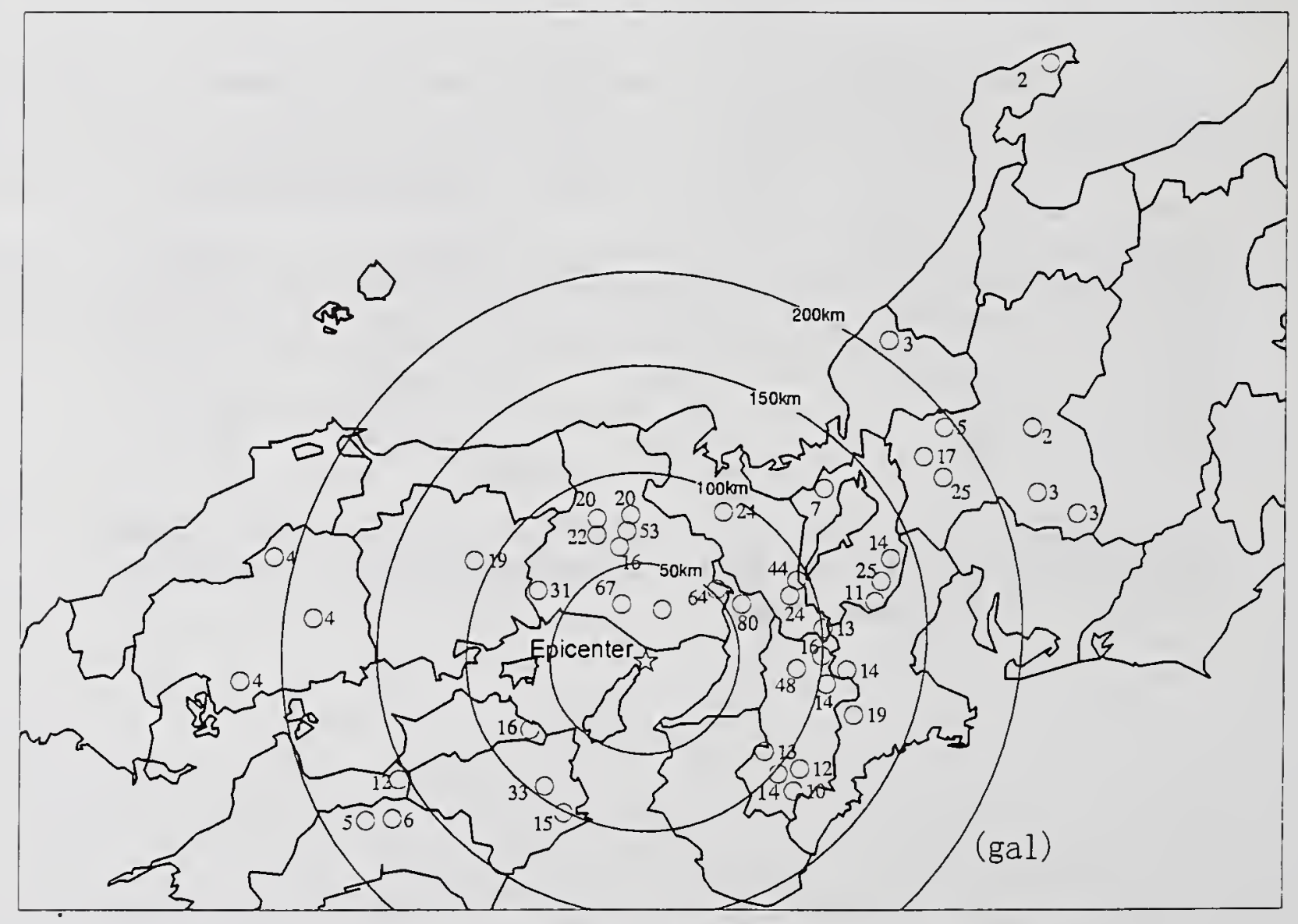

Figure 2 Vertical peak acceleration at dam foundations 


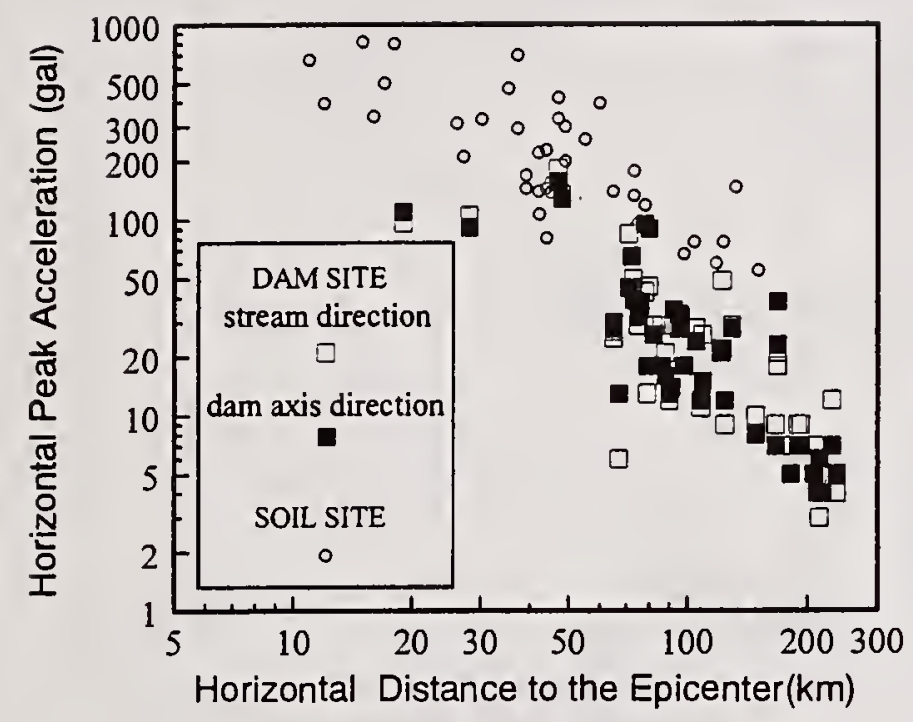

Figure 3 Attenuation of horizontal peak acceleration with epicentral distance

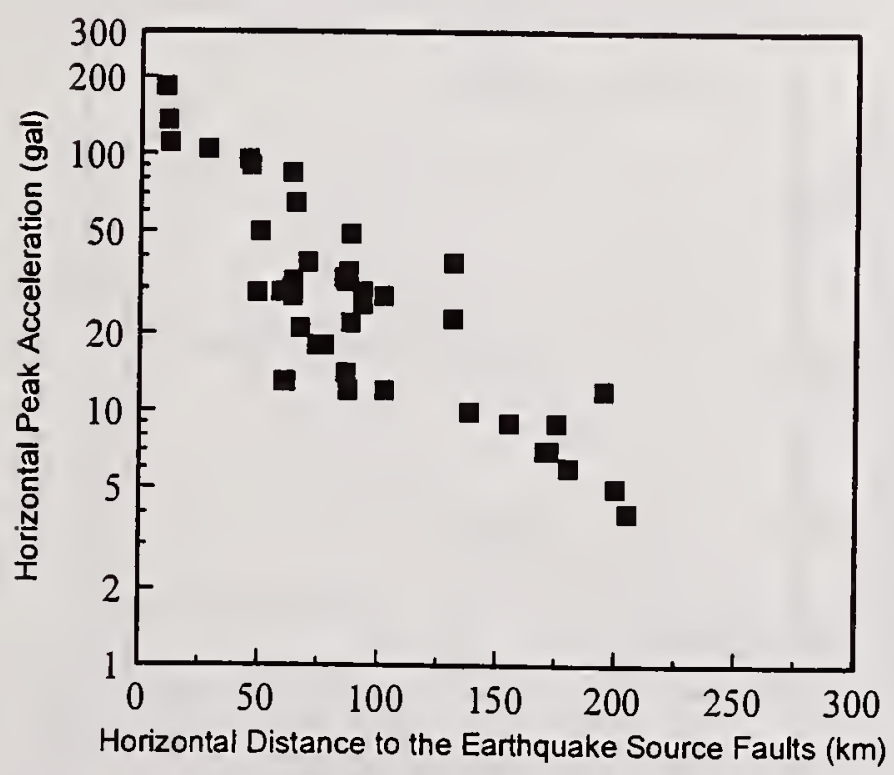

Figure 5 Attenuation of horizontal peak acceleration with distance to the earthquake source fault

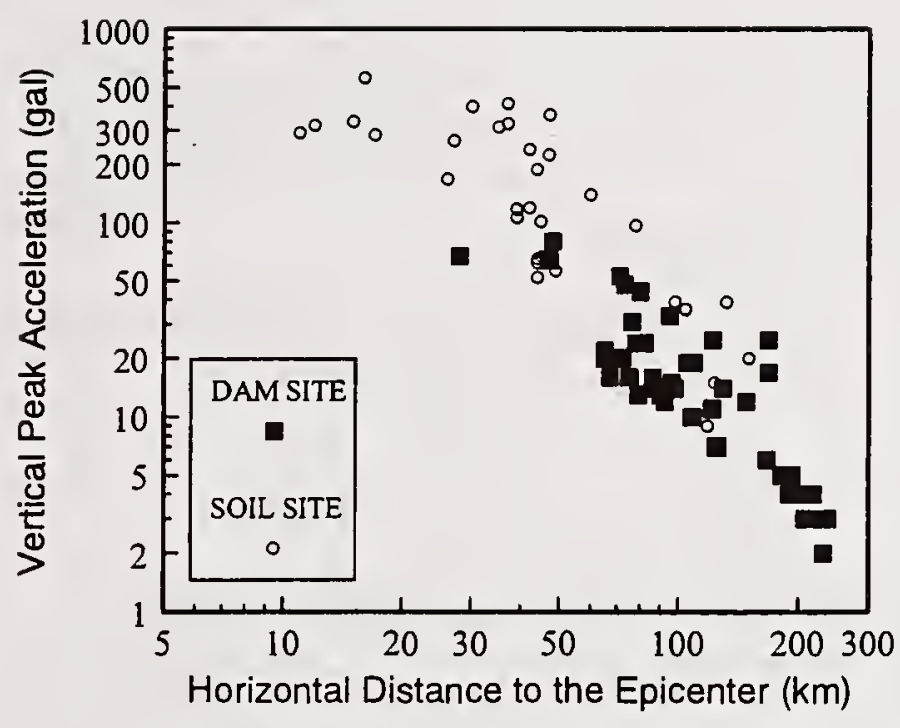

Figure 4 Attenuation of vertical peak acceleration with epicentral distance

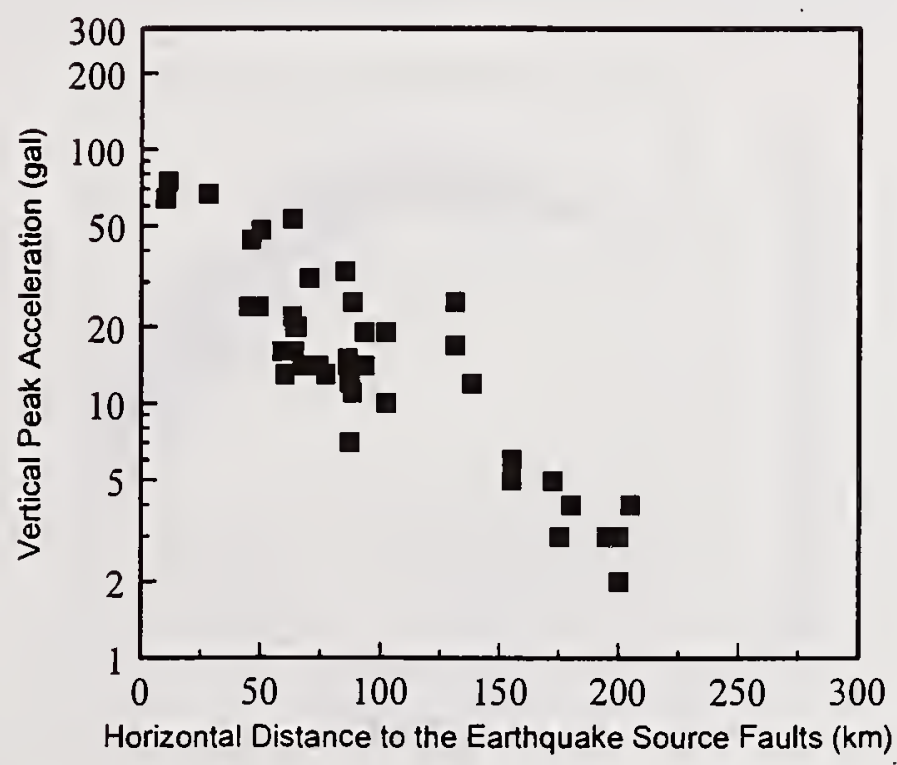

Figure 6 Attenuation of vertical peak acceleration with distance to the earthquake source fault 


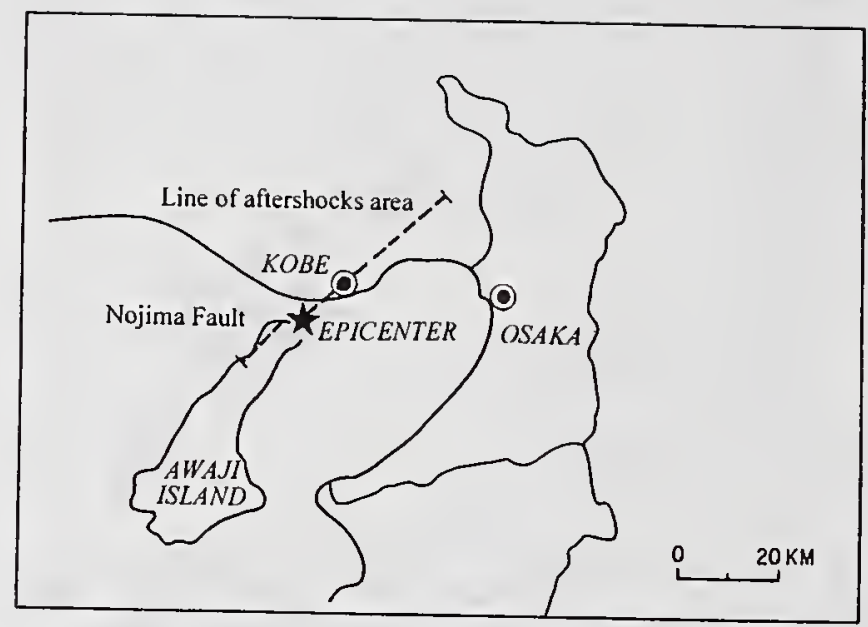

Figure 7 Earthquake source fault

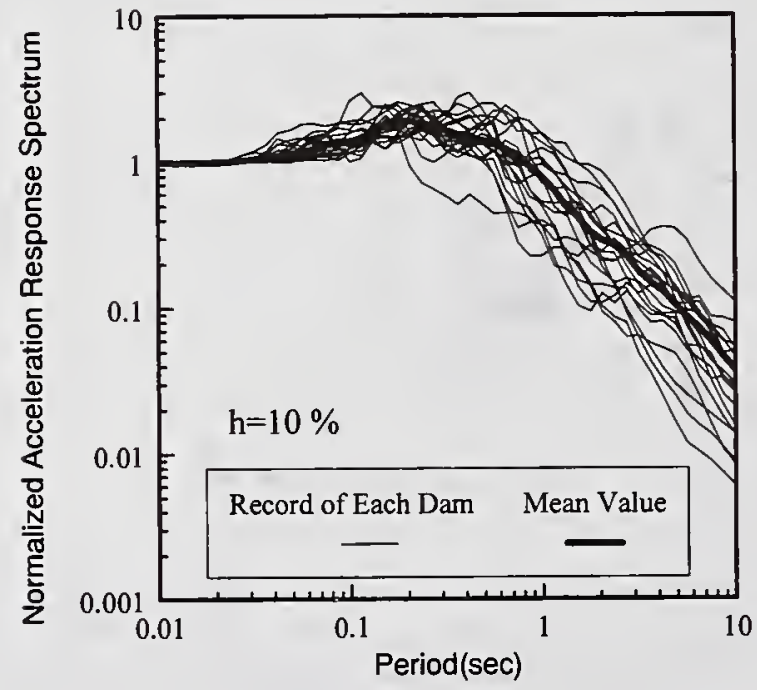

Figure 9 Acceleration response spectra at dam foundations

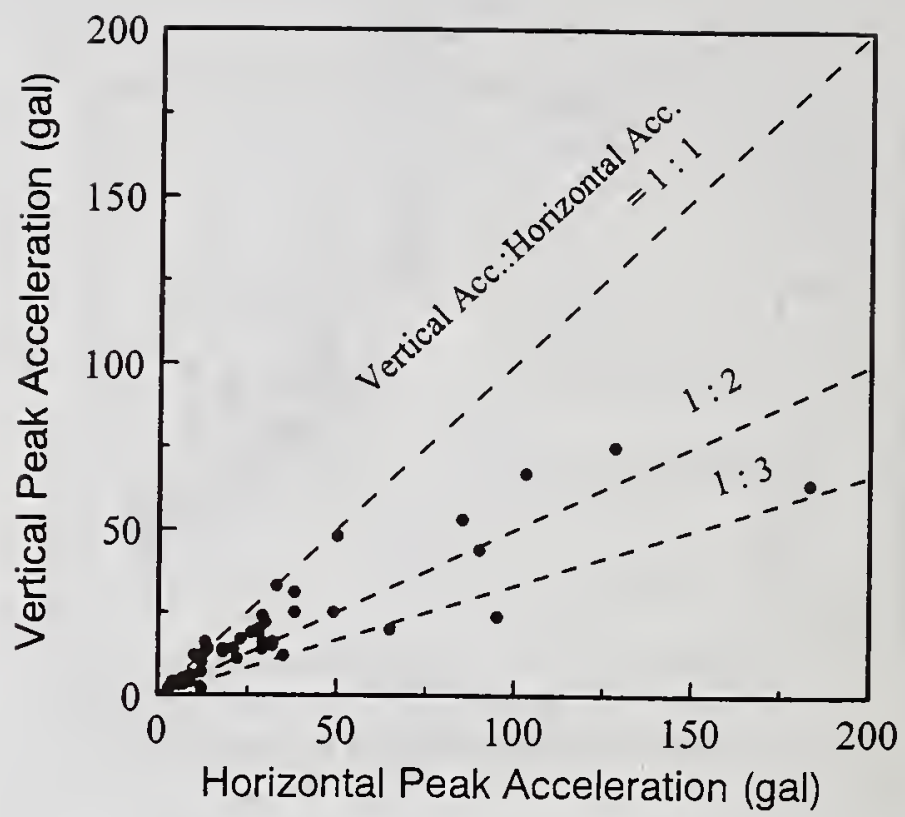

Figure 8 Ratio of vertical peak acceleration to horizontal peak acceleration

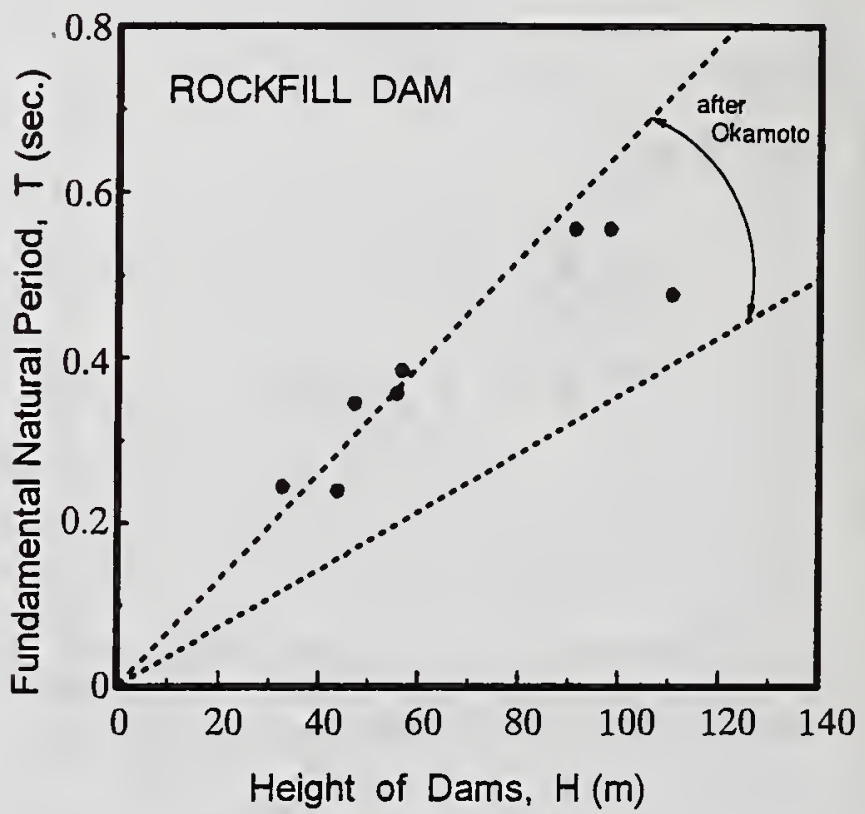

Figure 10 Relationship between natural period and dam height 


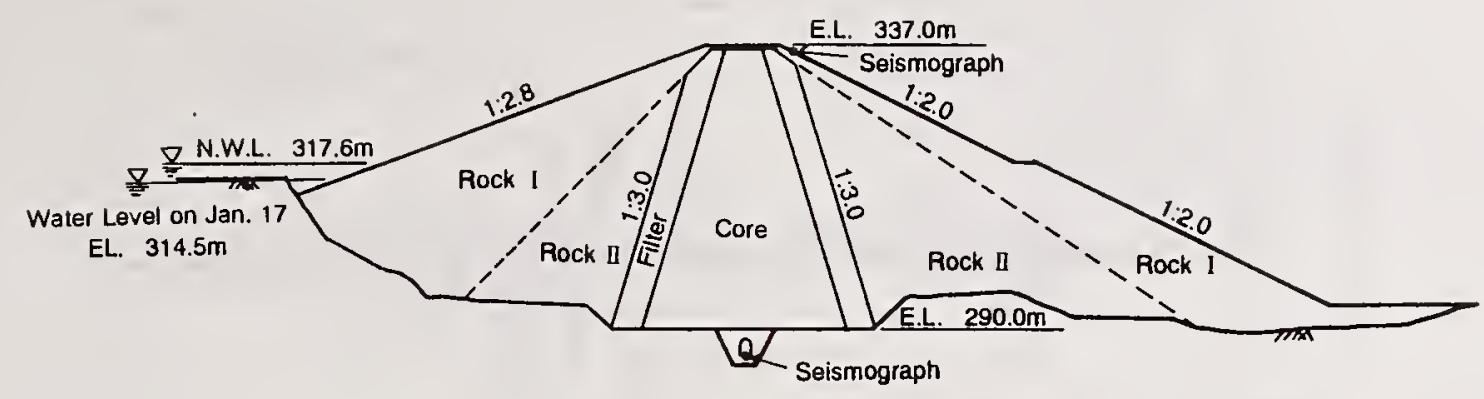

Figure 11 Cross section of the Minoogawa Dam

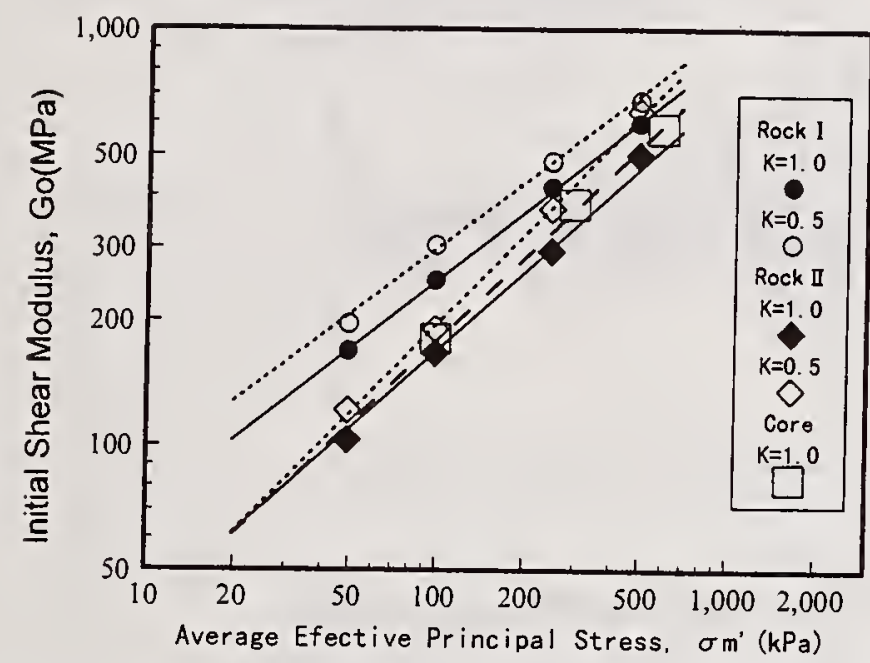

Figure 12 Initial shear modulus with average effective principal stress for the Minoogawa Dam model
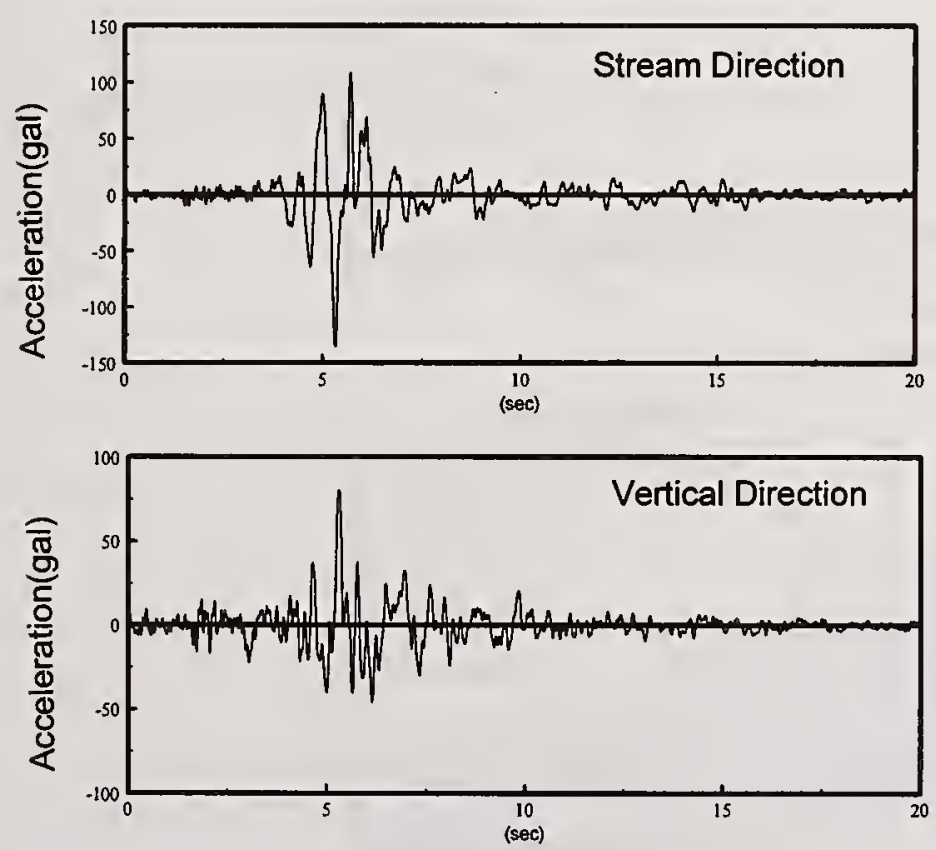

Figure 14 Incident acceleration waves observed at gallery of the Minoogawa Dam

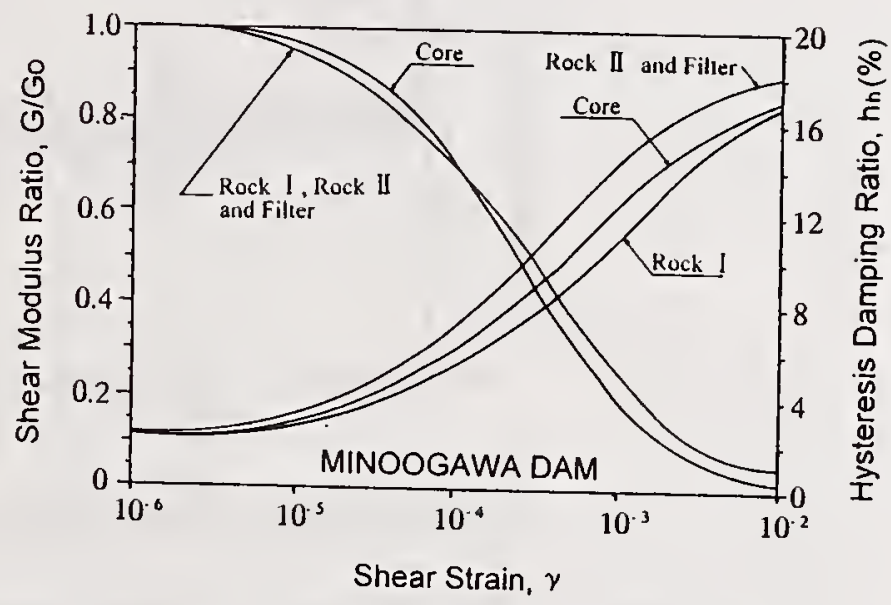

Figure 13 Shear strain dependency of shear modulus ratio and hysteresis damping ratio for the Minoogawa Dam model 

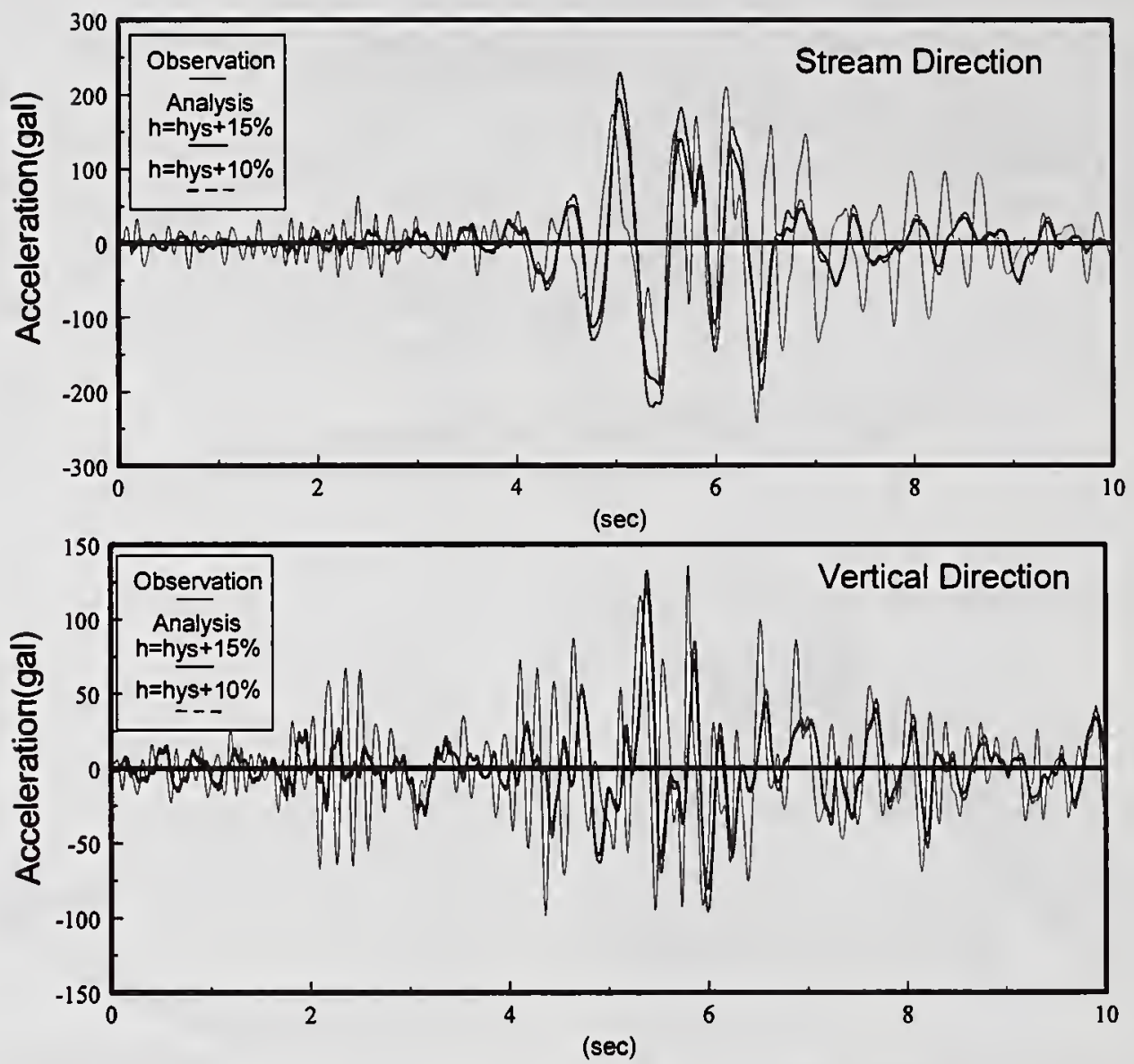

Figure 15 Response acceleration waves at the crest of the Minoogawa Dam
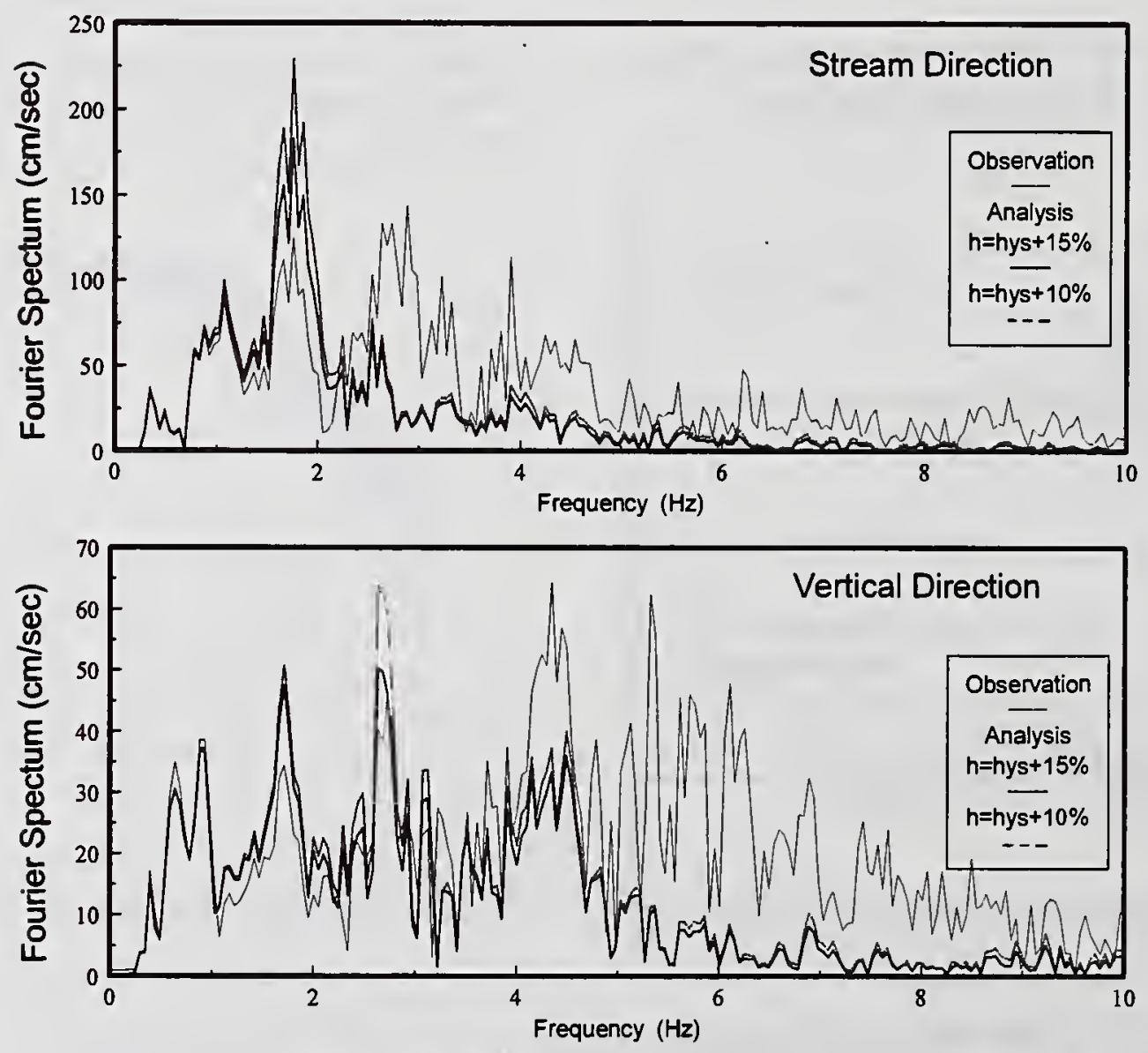

Figure 16 Response Fourier spectra at the crest of the Minoogawa Dam 

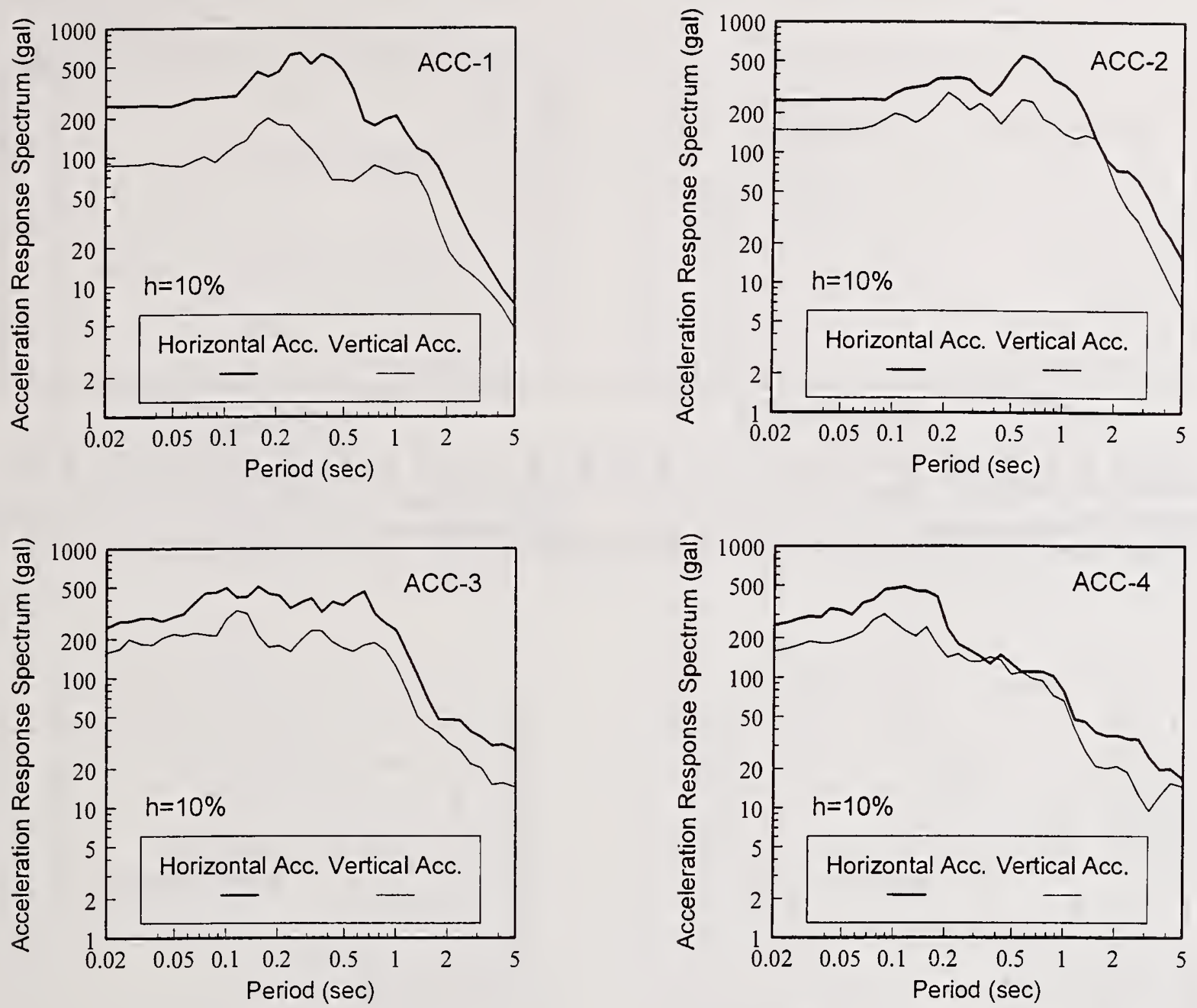

Figure 17 Acceleration response spectra of incident acceleration waves for dynamic analysis of model dams

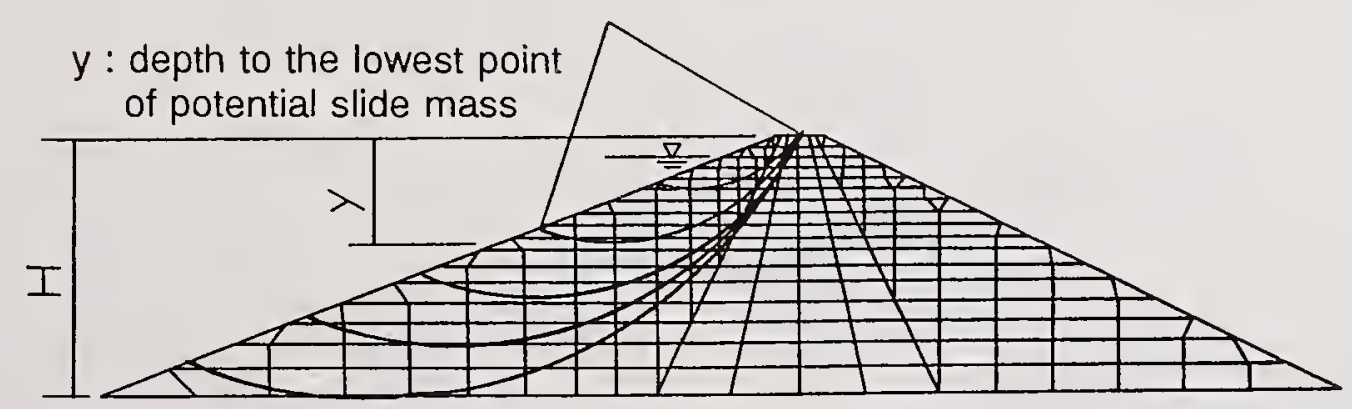

Figure 18 Finite element mesh of model dam and potential slide masses 


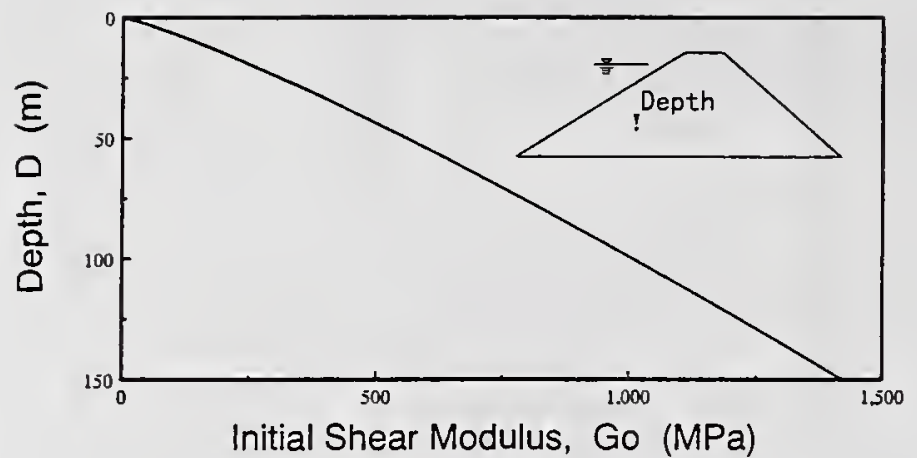

Figure 19 Distribution of initial shear modulus with depth from the slope surface

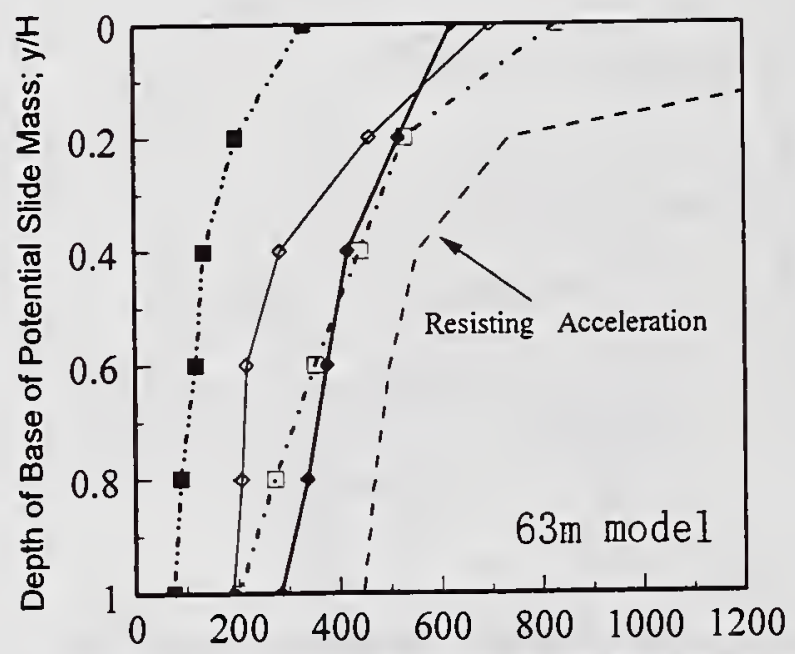

Peak Average Acceleration of Potential Slide Mass (gal)

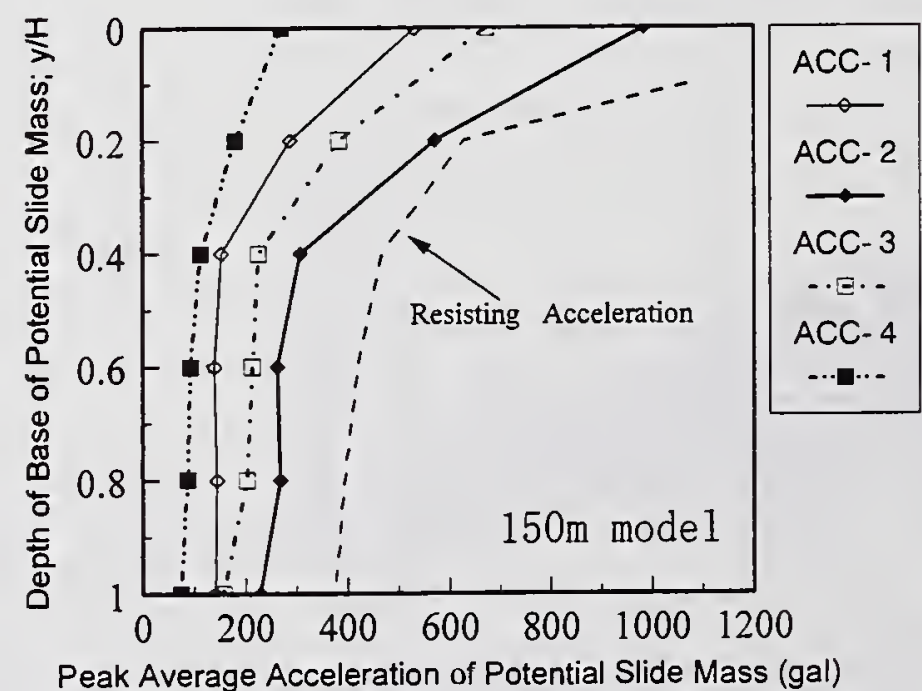

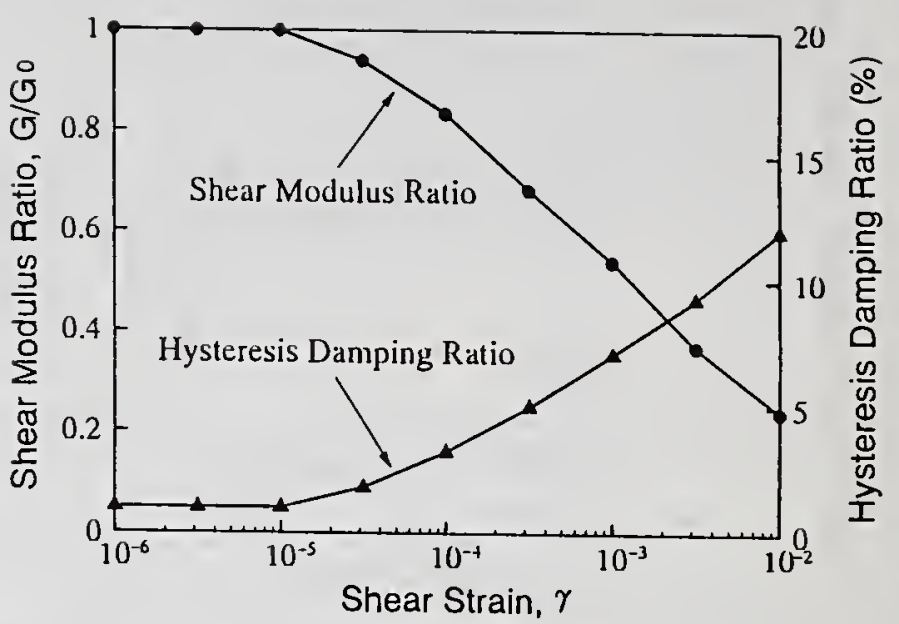

Figure 20 Shear strain dependency of shear modulus ratio and hysteresis damping ratio for model dams

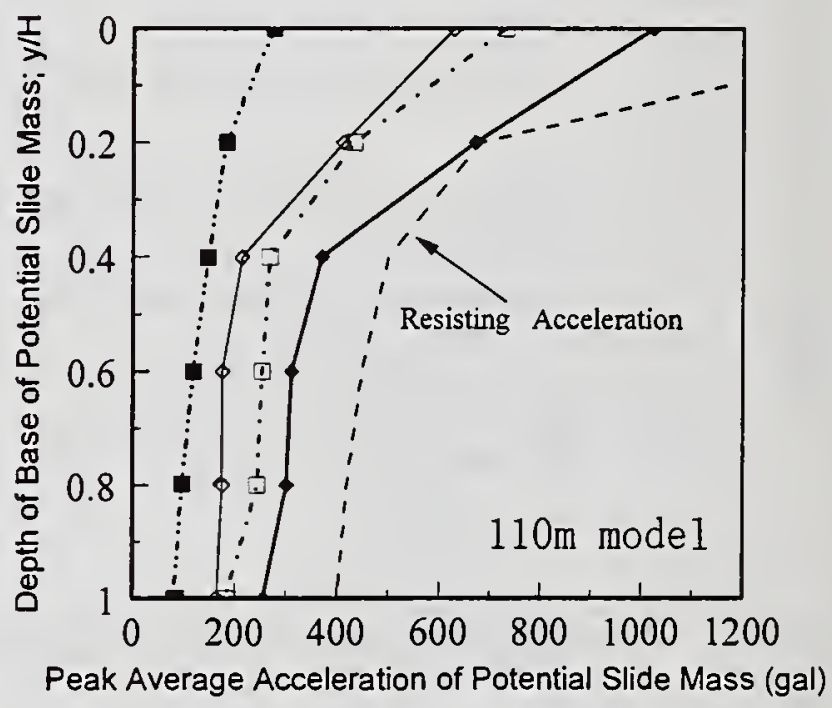

Figure 21 Peak average accelerations and resisting acceleration of potential slide masses for three heights of dam models 
SUMMARY OF JOINT COOPERATIVE RESEARCH PROGRAMS 



\title{
U.S.-Japan Cooperative Earthquake Research Program on Composite and Hybrid Structures - Research Progress and Current Status
}

\author{
by
}

\author{
Subhash C. Goel ${ }^{1}$ and Isao Nishiyama ${ }^{2}$
}

\begin{abstract}
A five-year research program on Composite and Hybrid Structures as Phase 5 of the U.S.Japan Cooperative Earthquake Research Program was recommended to be initiated in 1993 in both countries. The research work in Japan started in fiscal year 1993. However, fuller participation of researchers on both sides started in early summer 1995. The sponsorship of the program is by the National Science Foundation in the U.S. and by the Ministry of Construction along with a number of industry groups in Japan. This paper presents a brief status report of the program and research progress made todate on both sides. Because of diverse and broad scope of the subject area, the research program is organized into the following four groups: Concrete Filled Tube Column Systems (CFT); Reinforced Concrete (RC) and Steel Reinforced Concrete (SRC) Column Systems (RCS); and RC/SRC Wall Systems (HWS); New Materials, Elements and Systems (RFI). A theme structure with well selected layout, geometry and design loads for the research is also presented, which provides a common focus for various systems to be studied, and also a common prototype structure from which the components and sub-assemblages are drawn.
\end{abstract}

Key Words:

Concrete Filled Steel Tube;

RC Column with Steel Girder;

RCS Core Wall with Exterior Steel Frame;

New Materials Elements and Systems.

\section{INTRODUCTION}

The U.S.-Japan Cooperative Earthquake Research Program began in 1979 following the recommendations as outlined in the final report of the U.S.-Japan Planning Group for the program (Ref. 1). The overall objective of the total program is to improve seismic safety practices in both countries through cooperative studies to determine the relationship among full-scale tests, small-scale tests, component tests, and related analytical and design implication studies. First four phases of the program have been Reinforced Concrete (RC) Structures, Steel Structures, Masonry Structures, and Precast Concrete Structures. Research on Mixed Steel/RC Structures was identified as an important phase of the program as recommended in the planning group report.

It is widely recognized that innovative uses of two or more different materials in a structure leads to more efficient system for resisting seismic forces. During the past ten years the use of composite and hybrid structures has increased in the U.S. and Japan. In spite of some research and development work by Japanese construction companies, not enough is known at present regarding their seismic behavior or performance. Design procedures and codes for use in typical design offices are not well developed at present.

Considering the importance of developing design guidelines (a unified code development) for typical composite and hybrid structures that are used in current practice, and of developing new and innovative composite structural elements and hybrid systems using advanced new materials and/or devices, a five-year research program on Composite and Hybrid Structures was recommended as the fifth phase of the ongoing U.S.-Japan Cooperative Earthquake Research Program. The recommendations were based on a number of technical meetings of the U.S. and Japan Planning Groups and finally a Joint Planning Group Workshop held in Berkeley on September 10-12, 1992 (Ref. 2).

1 Professor, Dept. of Civil and Environmental Engrg., University of Michigan, Ann Arbor, MI 48109-2125, USA

2 Coordinator for International Research Cooperation, Building Research Institute, Ministry opf Construction, Tsukuba, Japan. 
Because of diverse and broad scope of the subject area, the research program is organized into the following four groups: Concrete Filled Tube Column Systems (CFT); RC/Steel Reinforced Concrete Column Systems (RCS); and RC/SRC Wall Systems (HWS); New Materials, Elements and Systems (RFI). A theme structure provides a common focus of the program to facilitate cross comparison between various system types identified and to derive structural elements and sub-assemblages for detailed studies.

\section{PROGRAM MANAGEMENT, COORDINATION AND CURRENT STATUS}

The research program is planned for a period of five years in both countries, and funding has been provided accordingly. Research work on the Japanese side started in the spring of 1993. However, fuller participation and coordination of research work on both sides started in early summer 1995 when the first group of U.S. research projects were awarded. Cooperation and coordination of work by all participants are most essential to successful completion of this program. Various committees have been formed for this purpose. A Joint Technical Sub-Committee (JTSC) in each of the four components of the research program provides technical advice and coordination. Each JTSC has a cochairman from each side with membership including all researchers in that area. These groups meet as often as needed. All participants and institutions are also part of the bigger Joint Technical Coordinating Committee (JTCC) to review progress and discuss scientific and technical issues on a common basis. This committee meets once a year with the last (second) JTCC meeting held in June 1995. The third JTCC meeting is scheduled to be held in November 1996 soon after the award of second year U.S. research projects. The individual JTSC groups will hold their meetings in the summer 1996. A smaller group called Joint Steering Committee (JSC), which consists of key representatives from the JTCC, oversees the entire program and provides guidance on issues that are common to the four components of the program. The overall program has a technical coordinator and a co-chairman from each side. The management chart with principal supporting groups for the program is shown in Figure 1. The progress of the research program as reported in this paper is based on proceedings of the latest US-TCC meeting held on February 7, 1996.

In addition to sharing of technical information and ideas among researchers, exchange of personnel involved is strongly encouraged. This will occur more now as the research projects on both sides are well under way. Active participation of practitioners and various industry representatives in planning, coordination and execution of the research work is also a strong feature of this program.

\section{PROGRAM OBJECTIVES}

Since the subject area of the Composite and Hybrid Structures is diverse and broad, the research program was organized into the following four groups: CFT Column Systems; RC/SRC Column Systems; and RC/SRC Wall Systems; New Materials, Elements and Systems. The first three groups aim at developing practical design guidelines (a unified code development) for typical composite and hybrid structures currently used. The last group aims at developing new and innovative composite structural elements and hybrid systems using advanced new materials and/or devices.

\section{THEME STRUCTURE}

The theme structure provides a common focus and a strong link between various components of the research program, facilitate cross comparisons between various systems to be studied, and also provides a common prototype structure from which the structural elements and sub-assemblages for detailed studies are drawn. The following criteria were used for selection of the theme structure:

- The building plan was selected so as to reflect the benefits that the hybrid structures provide over non-hybrid structures.

- The basic plan is common to various types of hybrid structures. The number of stories and the make-up and combination of structural components and details can be varied.

- Rules to determine dead load, live load and seismic forces to be used in design simulation are common in the U.S. and Japan Groups.

The basic plan selected for the program is representative of typical office buildings. As shown in Figure 2, it provides office space of 
12.8 meters in span length outside the central core. The central core is used as utility space for elevators, stairs, etc. Floor area of the central core is determined on the basis of a twenty story office building. The core area may be changed with the number of stories if desired. Six types of theme structures are selected as shown in Table 1. The reasons for selecting numbers of stories as $3,6,9,10,12$, 24 or 40 for different structure types are as follows:

- Six, twelve and twenty four stories have been used frequently in Japan for RC, SRC and steel construction, respectively.

- Six is selected as the standard (key) number of stories for RC (OPEN)-06 structure. Three and nine are selected for comparison.

- Twelve is selected as the key number for (SSRC)+W-12 (S-RC)+W-12 structures.

- Twenty four is selected as the key number for CFT(OPEN)-24 structure. Ten and forty may be necessary for comparison.

- Buildings more than forty stories may be investigated under New Materials, Elements and Systems.

Plan dimensions and layout for the above six structure types are shown in Figures 3-8.

\section{RESEARCH ON CFT SYSTEMS}

\subsection{Research Progress in Japan}

A number of experimental and analytical studies on CFT systems have been carried out and reported in the past. A literature survey of those studies and available data has been conducted and the summary report and data preparation is under way. Further investigations have been planned and are in progress to verify and expand on the existing knowledge. Stub-column tests on circular and square sections under concentric and eccentric loading have been completed. Half of the planned 28 beam-column specimens have been tested. Concrete and steel strengths and tube wall slenderness are the main variables. A number of trial designs of the theme structure of 10,24 and 40 stories have been completed and design comparisions made. Results obtained on member tests will be used in the design implication studies to derive more rational models for analysis and design. Main items of study are: confinement effects and load shared between the concrete and steel.

\subsection{Research Progress in U.S.}

A number of research projects were funded during the first year. These projects are focusing on the behavior of CFT column-toWF beam moment connections. The specimens are nearly full size and include circular and square tube sections for columns. The connection details include the use of diaphragms, shear studs, welds, and bolts. The main variables are the connection details to transfer beam forces into the column. The objectives are:

1) To determine the force transfer mechanism, examine the effects of various connection details on this mechanism, and on the connection strength, stiffness and ductility under cyclic loading.

2) Develop and evaluate practical and economical connection details for seismic resistance.

\section{3) Formulate practical design guidelines.}

Some testing work also includes study of beam-columns under combined axial force and bending. Analytical studies accompany the experimental work. The analytical models include complex finite element formulations in an effort to develop simpler empirical or mechanics based models for practical design work. Analytical work is also aiming at studying the bond and shrinkage effects, and confinement effects in CFT members subjected to different load conditions.

\section{RESEARCH ON RCS SYSTEMS}

\subsection{Research Progress in Japan}

In recent years the Japanese practice in RCS structures has moved from using heavy steel shapes encased in RC for columns to no structural steel in RC columns with steel beams passing through the RC columns. A data base of over 300 tests on RCS sub-assemblages with 30 different joint details has been prepared. However, most of those tests were carried out on strong column/connection-weak beam combinations which give little information on the force transfer mechanisms in the joint panel regions at large ductility levels. Therefore, tests in this program focus on weak joint specimens in order to obtain information on strength and ductility of the beam-tocolumns. Bond link tests have been completed and modeled into 3-D FEM. Through column and through beam tests on beam-to-column 
subassemblages have been half completed, and 3-D FEM analyses are in progress. Structural design of 6 and 12 story moment frames of the theme structure has been completed including the inelastic dynamic analyses.

\subsection{Research Progress in U.S.}

RCS structures in the U.S. generally consist of columns made of light steel shapes encased in RC. The light steel shape provides ease of erection and connection to the steel beam. Some earlier tests on RCS interior frame connections have been carried out and reported in the literature. In one research project under this program exterior connections are being studied. The joint detail variables are: lateral ties, beam bearing plates, use of FRC in place of stirrups. Effect of floor slab is also included in the study.

\section{RESEARCH ON HWS SYSTEMS}

\subsection{Research progress in Japan}

The structural system of core wall with exterior steel frame is not too common in Japan and the design methodology is not well establishes at present. Therefore, trial designs of 6,12 and 24 story theme structures with RC/SRC coupled wall have been carried out by using existing practice. The response of the resulting structures is being studied through inelastic dynamic analyses. In the meantime, three one-third scale T-shaped shear wall specimens representing the lowest story of the 12 story theme structure have been tested under different ratios of shear force to moment and varying axial force. Also, testing work on a one-third scale 2-D model of the 12 story coupled shear wall is almost complete. Large rotations of approximately $6 \%$ in the coupling beams were measured at wall drifts of $1.5 \%$.

\subsection{Research progress in U.S.}

In one research project seismic behavior of steel/composite coupling beams and their connections to the $\mathrm{RC}$ shear wall has been studied experimentally and analytically. Four one-third scale specimens were tested which represented a portion of the wall and one half length of the coupling beam from a 20 story theme structure. The effect of concrete encasement of the steel beam and details of the connection in the embedded portion have been studied.
8. RESEARCH ON NEW MATERIALS, ELEMENTS AND SYSTEMS (RFI)

The research work in this group aims at developing and application of new and advanced materials in innovative composite structural elements and systems (Research For Innovation - RFI). Thus, the studies in this group are more of feasibility type than those in the previous three groups where the objectives are to develop detailed guidelines for practical design work.

\subsection{Research Progress in Japan}

Two research groups on "Fiber Reinforced Plastic (FRP) elements" and "High Performance Concrete (HPC)" have been organized. The team includes research groups from a large number of industry partners. Feasibility studies are in progress on FRP-RC panels; application of FRP for repair and strengthening of RC members; FRP in electrical facilities; light weight concrete with high strength, ductility and stiffness; and intelligent materials.

\subsection{Research Progress in U.S.}

Significant amount of research work has been devoted to advanced cementitious and plastic composite materials. Albeit, the available information needs to be expanded to application in seismic load conditions. In one project under this program work is in progress on developing an innovative structural system consisting of steel open web steel joists encased in fiber reinforced concrete eliminating need for conventional labor intensive reinforcing bars or shear connectors. In another project application of fiber reinforced concrete in the joint regions of RCS systems is being studied.

\section{CONCLUDING REMARKS}

A brief overview of the progress of U.S.-Japan Cooperative Earthquake Research Program on Composite and Hybrid Structures has been presented in this paper. This five-year program started in 1993 in Japan and in 1995 in the U.S. The two year time lag is being taken as an opportunity to plan the future research work in a more careful and useful manner in order to derive the most benefit from the work that has already been 
completed on both sides. The overall coordination efforts, cooperation and exchange of information have been excellent. More active exchange of research personnel during the remaining period of the program will be most beneficial and pursued accordingly.

\section{REFERENCES}

1. "Recommendations for a U.S.-Japan Cooperative Research Program Utilizing Large-Scale Testing Facilities," Report No. UCB/EERC 79-26, September 1979.

2. "Recommendation for U.S.-Japan Cooperative Research Program - Phase 5 Composite and Hybrid Structures," Report No. UMCEE92-29, November 1992.

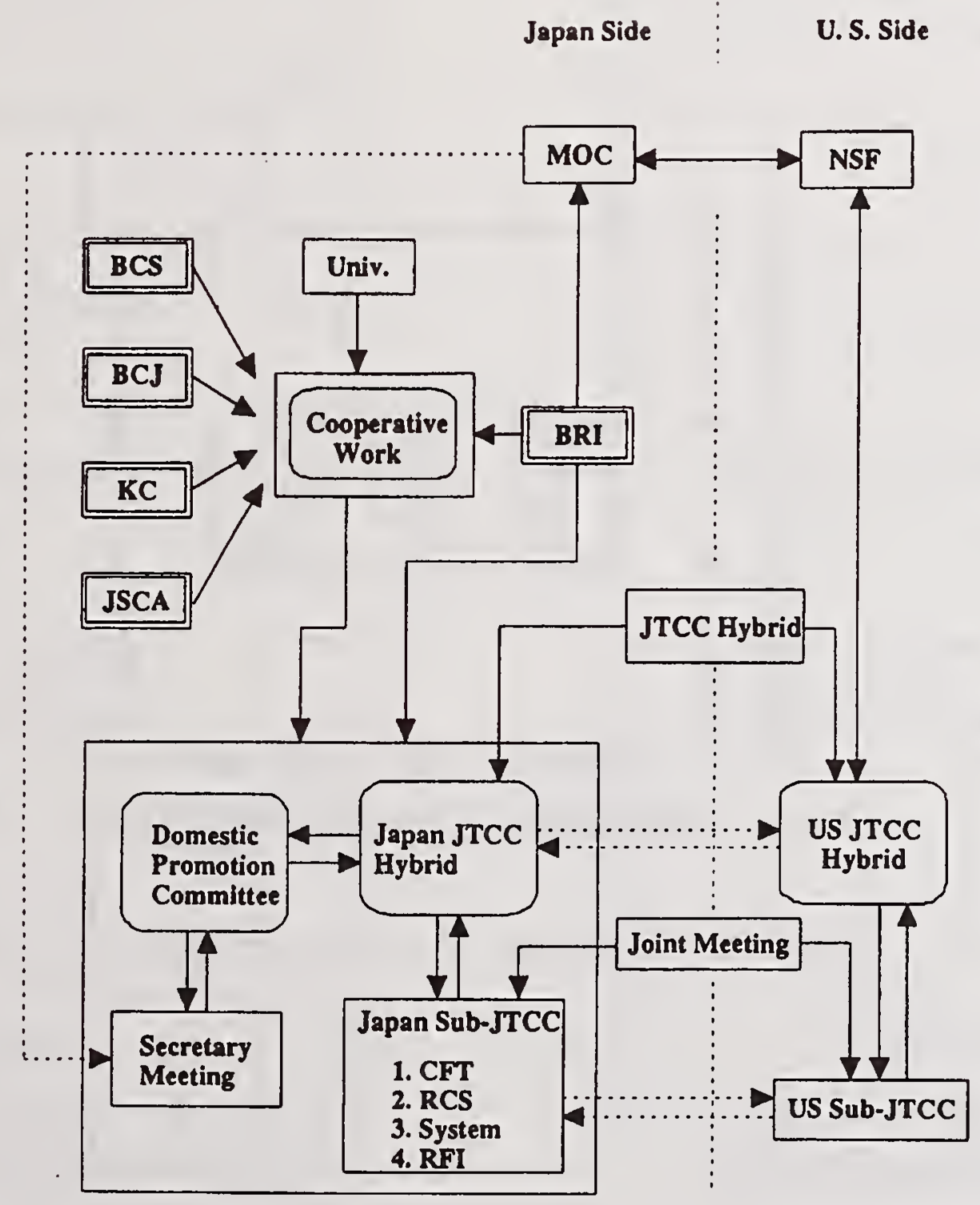

Figure 1. Organization of Cooperative Research 


\begin{tabular}{c|c|c|c|c}
\hline Name & $\begin{array}{c}\text { Number } \\
\text { of } \\
\text { Stories }\end{array}$ & $\begin{array}{c}\text { Exterior } \\
\text { Column }\end{array}$ & $\begin{array}{c}\text { Inlerior } \\
\text { Column } \\
\text { Beam }\end{array}$ & $\begin{array}{c}\text { Wall } \\
\text { and } \\
\text { Misc. }\end{array}$ \\
\hline $\begin{array}{c}\text { RC(OPEN)- } \\
06\end{array}$ & $3-6-9$ & RC & RC/S & - \\
\hline RC+W-06 & 6 & RC & RC/RC & Wall \\
\hline $\begin{array}{c}(S-S R C)+ \\
\text { W-12 }\end{array}$ & 12 & S & $\begin{array}{c}\text { SRC/ } \\
\text { SRC }\end{array}$ & Wall \\
\hline $\begin{array}{c}\text { (S-RC)+W- } \\
12\end{array}$ & 12 & S & RC/RC & Wall \\
\hline $\begin{array}{c}\text { CFT(OPEN) } \\
-24\end{array}$ & $10-24$ \\
40 & CFT & CFT/S & - \\
\hline $\begin{array}{c}\text { CFT+B/HD } \\
-24 /\end{array}$ & 24 & CFT & CFT/S & $\begin{array}{c}\text { bracel } \\
\text { hinge- } \\
\text { device }\end{array}$ \\
\hline
\end{tabular}

Table 1. Six Types of Theme Structures

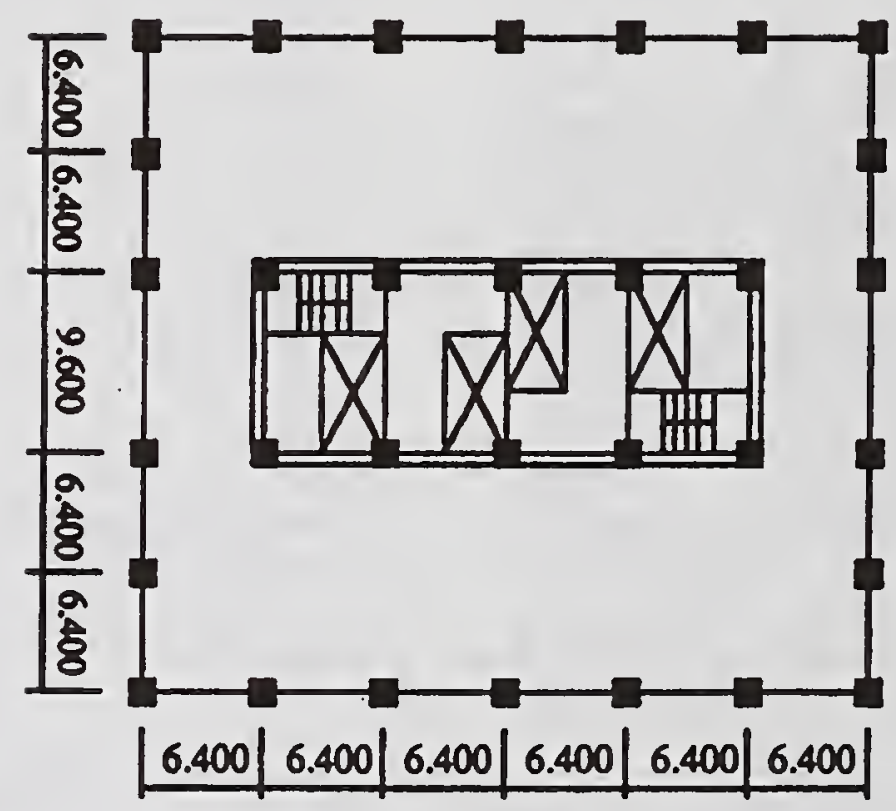

Figure 2. Prototype Plan of Theme Structure 


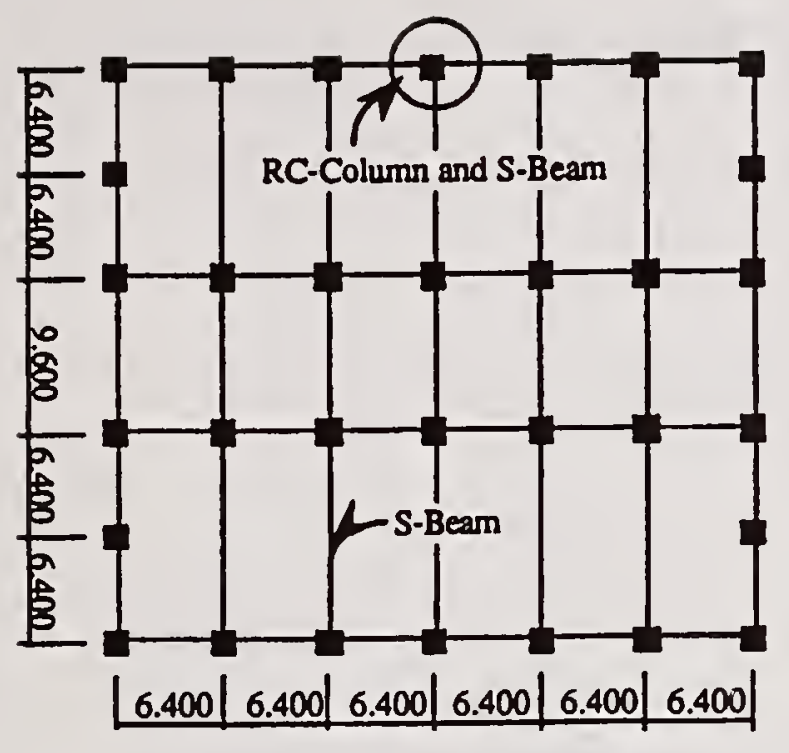

Figure 3. RC(OPEN)-06

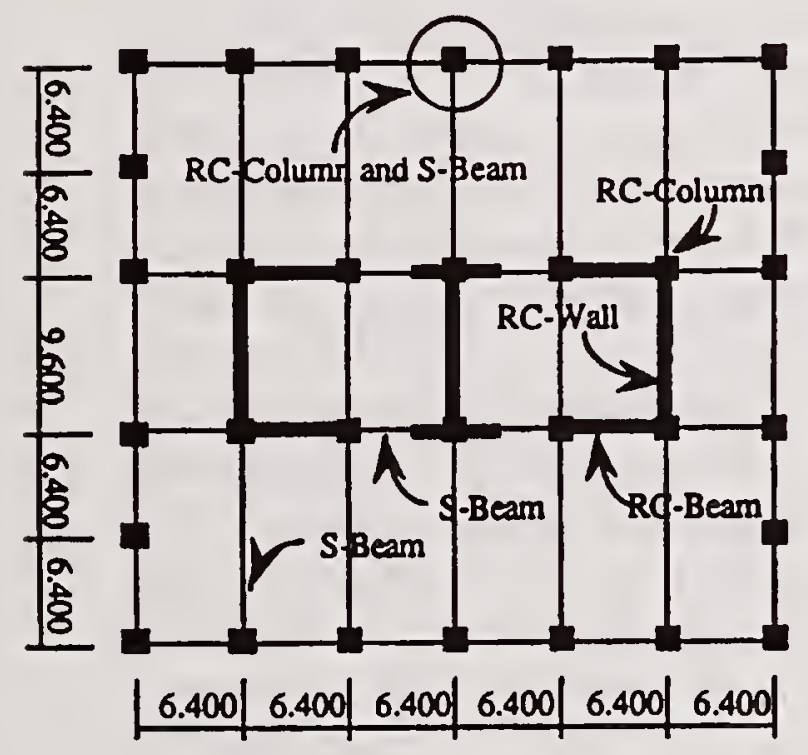

Figure 4. $\mathrm{RC}+\mathrm{W}-06$

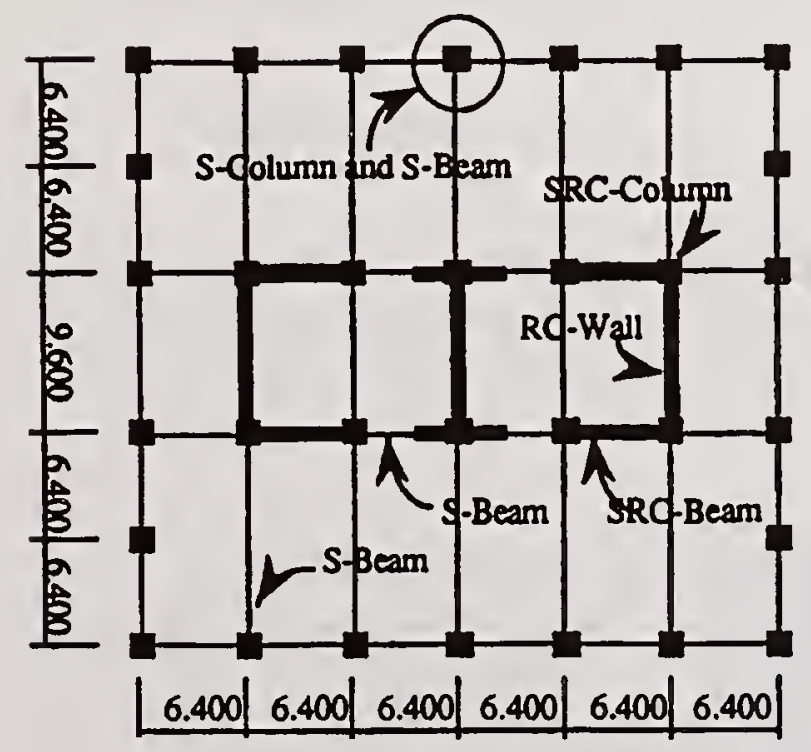

Figure 5. $(\mathrm{S}-\mathrm{SRC})+\mathrm{W}-12$

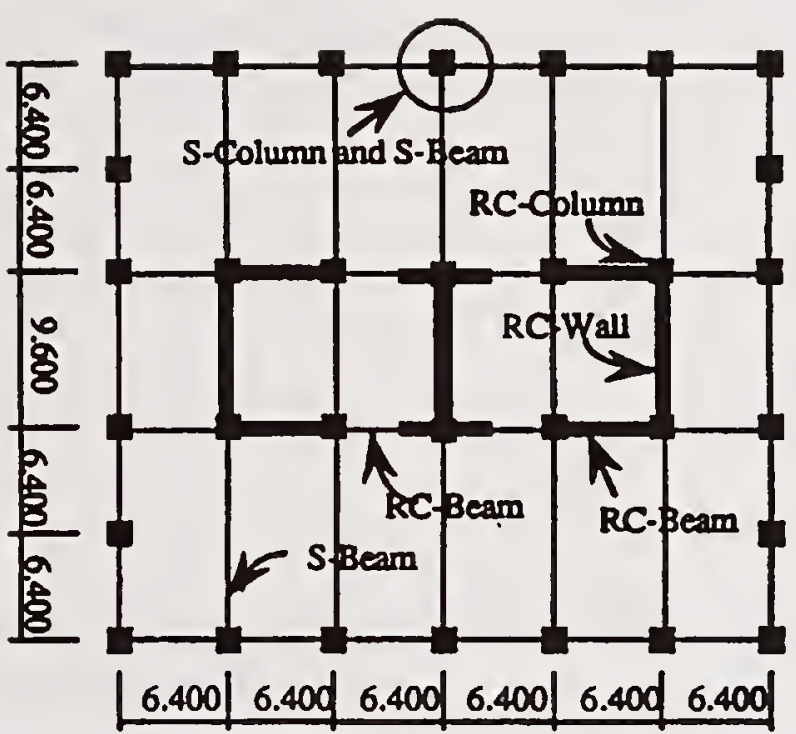

Figure 6. (S-RC)+W-12

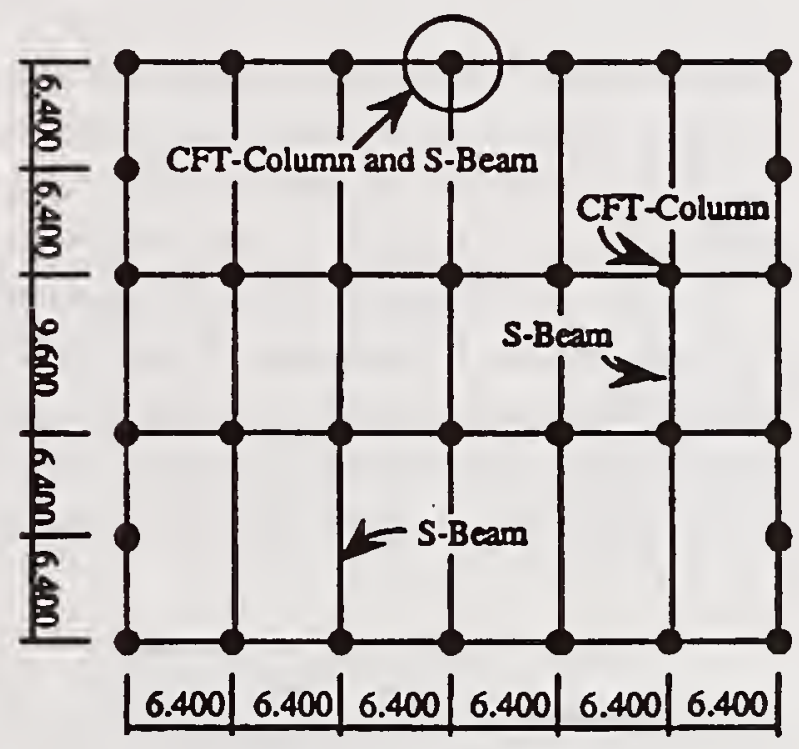

Figure 7. CFT(OPEN)-24

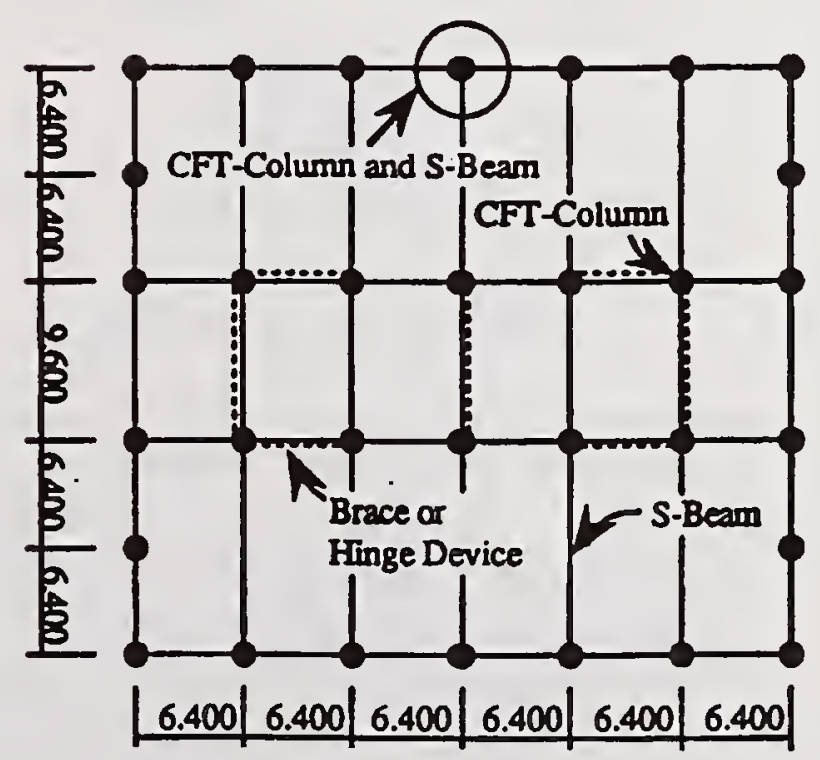

Figure 8. CFT+B/HD-24 



\title{
Design of Large-scale Liquefaction Experiment System
}

\author{
by \\ K. Ishihara * \\ T. Kagawa ** \\ N. Ogawa *** \\ C. Minowa *** \\ K. Sakai **** \\ A. Abe *****
}

\section{ABSTRACT}

A large-scale liquefaction experiment system is developed to investigate the liquefaction phenomenon and the behaviour of structures during liquefaction. The system consists of a shear box installed on the multi-purpose shaking table, grit chamber, elevated water tank, temporary storage, regulating yard and storage for the soil. The overall dimension of the shear box is $12 \mathrm{~m}$ in length (vibrating direction), $3.5 \mathrm{~m}$ in width, and $6 \mathrm{~m}$ in height. The ratio of the total weight of the shear box to that of the soil (about 400t) is $9-12 \%$. The allowable shear strain is $\pm 50 \%$; however, the limit of the deformation is $1.5 \mathrm{~m}$. Tests can be performed repeatedly by boiling of the soil. At the end of a test series, the soil will be evacuated rapidly (with an evacuation rate of about $1 \mathrm{t} / \mathrm{min}$ ) as slurry.

KEYWORDS : liquefaction; shear box

\section{INTRODUCTION}

The present paper describes the design of large-scale liquefaction experiment system. As shown in Figure 1 , the significant feature of the system is the largeness

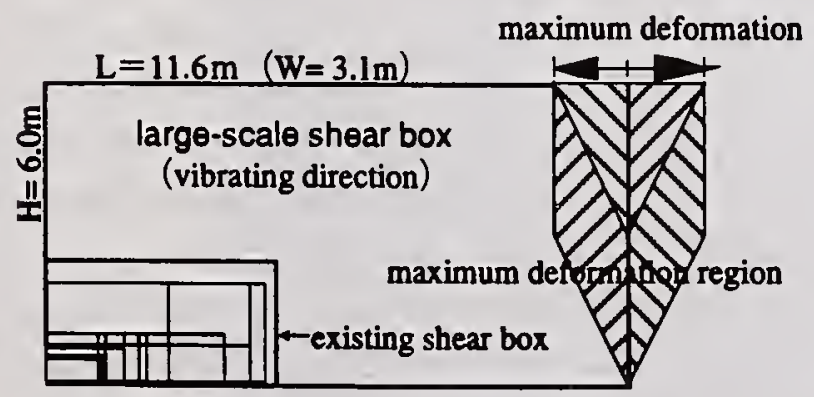

Figure 1 Comparison of shear box size of the size and the maximum deformation compared with existing shear boxes.

\section{SYSTEM DESCRIPTION}

The system, as shown in Figure 2, consists of shear box, shaking table, grit chamber, temporary soil storage, elevated water tank, regulating yard and storage for the soil. In this order, the soil circulates in the system during the vibration test.

The shear box is connected to the grit chamber through a hosepipe while the grit chamber is connected to the temporary soil storage through a soil conveyor. Among the shear box, the grit chamber

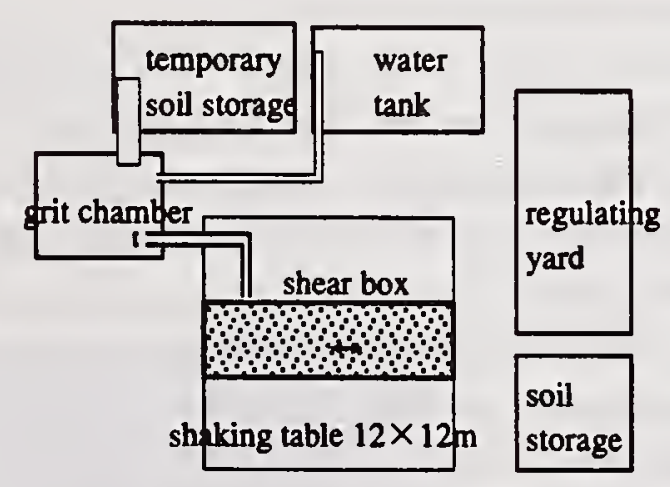

Figure 2 Layout of the system

* Science University of Tokyo, 2641, Yamazaki, Noda, Japan

** Wayne University, Detroit, MI 48202, USA

*** National Research Institute for Earth Science Disaster Prevention Science and Technology Agency, 3-1, Tennodai, Tukuba, Japan **** Kiso-Jiban Consultants Co., Ltd., 1-11-5, Kudan-kita, Chiyoda-ku, Tokyo, Japan *****Tokyo Soil Research Co., Ltd., 2-1-12, Umezono, Tukuba, Japan 
and the water tank, water supply and drainage system is incorporated. Between the soil storage and the shear box, a system is being fabricated which transports and sprays dry sand into the shear box by means of compressed air.

In order to operate the system efficiently, the following items are studied :

- soil preparation in the shear box

- regulation of the shear box and soil for the subsequent test without soil evacuation

- soil evacuation after the test

In addition, as the system utilizes a multi-purpose shaking table, the shear box is designed so that it can be assembled and disassembled for every test series.

\section{STRUCTURAL DESIGN OF FRAME}

The external dimension of the shear box is chosen to be $12 \mathrm{~m}$ in length (vibration direction), $3.5 \mathrm{~m}$ in width, and $6 \mathrm{~m}$ in height considering the constraints of the size of shaking table of $12 \mathrm{~m} \times 12 \mathrm{~m}$, the rated load (about 500t), and the height of the overhead crane of $8.5 \mathrm{~m}$. The most important design conditions of the shear frames are as follows:

Concerning the height of the frame, although a thinner plate is desirable for smooth shear deformation, steel H-beam $(\mathrm{H}-200 \times 200)$ of $20 \mathrm{~cm}$ in height and sliding layer of $1 \mathrm{~cm}$ in height are adopted considering various constraints such as weight, etc. The allowable shear displacement between frames is $\pm 50 \%$ of the height. Considering the stability of shear box, the displacement is limited at $10.5 \mathrm{~cm}$ by stoppers (slots and shear bolts) installed at the four corners of frames while the overall maximum shear displacement is limited at $1.5 \mathrm{~m}$ by the bumpers of lateral support system. The rigidity of the frame is an important factor for a large-scale system in order to keep the integrity of the frame and the smooth horizontal movement against the variation of pressures in the shear box due to liquefaction. As a result of the examination, a lateral support system is adopted to limit the lateral displacements, as shown in Figure 3.

The weight ratio of frame to soil is in the range of 9 to $12 \%{ }^{11}$, which is the ratio of an existing shear box

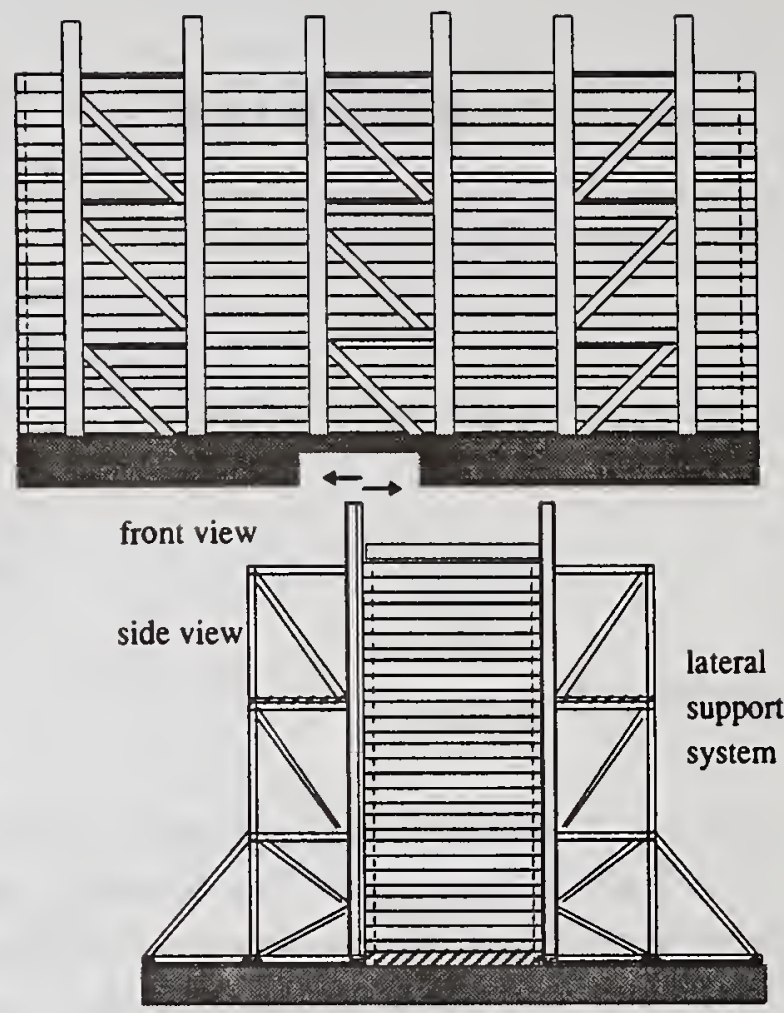

Figure 3 Shear box and lateral support system

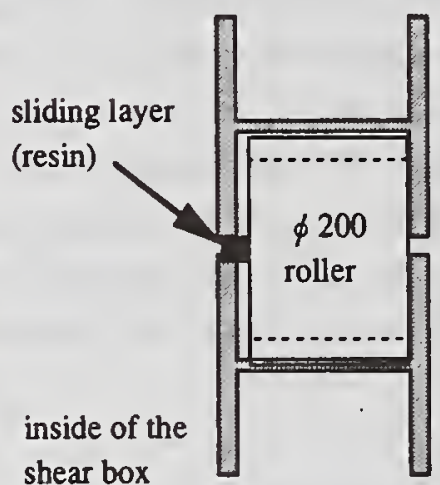

side view

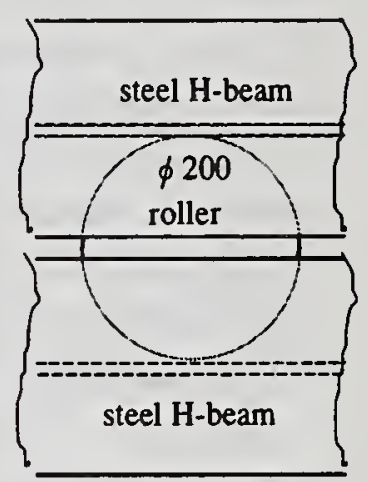

front view
Figure 4 Roller between frames

of $1.2 \mathrm{~m} \times 0.8 \mathrm{~m} \times 1.0 \mathrm{~m}$. The shear resistance (friction) of each frame is ideally the same as the soil (it would be quite complex to take into account the soil irregularity and the flowability due to liquefaction). In order to approximate the resistance to that of the soil, rollers are adopted as shown in Figure 4. The coefficient of friction between frames may be several percent.

Furthermore, the design is performed to prevent swaying and rocking of frame and self-oscillation of structural materials. 


\section{STRUCTURAL DESIGN OF SHEAR BOX}

For static study, the following items are examined considering loads such as weight of structure and soil, static earth pressure, dynamic earth pressure, water pressure, earth pressure under liquefaction $(18 \mathrm{~m})$ and inertial force of $0.5 \mathrm{G}$ :

- load distribution in the shear box

- deformation and stress of lateral support system (considering spring constants and impact force of stoppers)

- deformation and stress of shear frame (at initial state and at $1.5 \mathrm{~m}$ deformation state, with and without spring of lateral support system)

- stability of sliding and tilting of the shear box

The maximum deformations of frame in the state of soil setup, vibration and $1.5 \mathrm{~m}$ deformation of shear box after liquefaction are within $3 \mathrm{~mm}$ (the allowable deformation is $5 \mathrm{~mm}$ ).

For dynamic study, the natural frequencies and eigen modes are obtained for structural materials, frames, and lateral support system with and without soil. The natural frequencies are above $20 \mathrm{~Hz}$, confirming the safety of the system.

\section{WATER SUPPLY AND DRAINAGE}

Water supply rate of $2 \mathrm{t} / \mathrm{min}$ is enough for the boilling of soil (injection from the bottom, the top and the sides of the box). At the end of a test series, it is necessary to evacuate the soil and to disassemble the shear box immediately. For this purpose, a slurry evacuation method is adopted. The method, which consists of injecting water into the shear box to make the slurry and again in the downstream of the evacuation valve ( $\phi 200)$ to produce negative pressure, would enable the evacuation of the soil with an evacuation rate of about $1 \mathrm{t} / \mathrm{min}$.

\section{CONCLUSION}

The design of large-scale shear box (total weight about 500t) and preliminary tests (vibration test with a height of $4 \mathrm{~m}$ of shear box, and test of friction between frames with jack) are performed.

The main results are as follows :

- the ratio of the weight of the shear box to that of soil is in the range of 9 to $12 \%$

- the frame deformation at the maximum shear box deformation of $1.5 \mathrm{~m}$ is within $5 \mathrm{~mm}$

- the feasibility of soil reuse by boiling as a results of preliminary tests is verified

- the efficiency of soil evacuation method is confirmed

Basic performance tests of the system and then liquefaction tests will be carried out to extract and resolve the problems that may arise.

\section{REFERENCE}

1) Kokusho, T., Dynamic Soil Properties and Nonlinear Seismic Response of Ground, EPRI-Report No. 301 (1982)

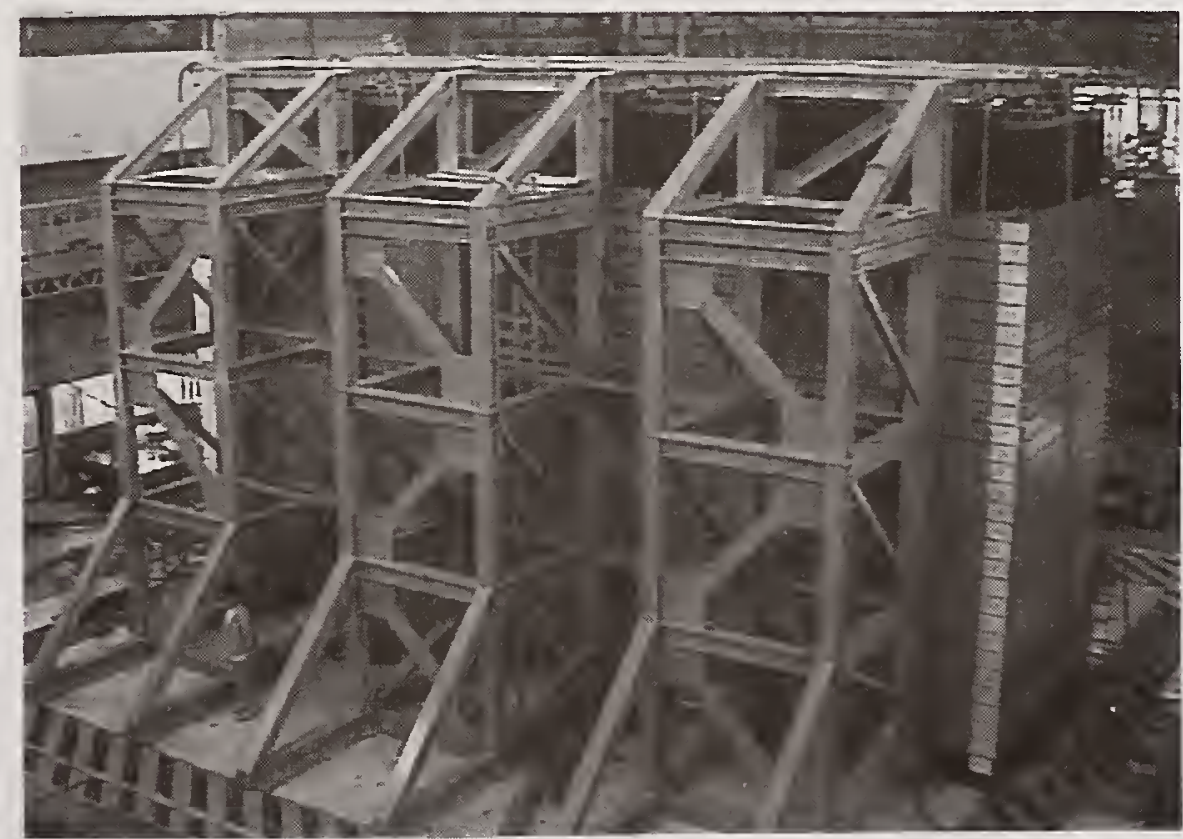



WIND ENGINEERING 



\title{
Influence of Vent Configurations on Bridge Response to Wind
}

by

\author{
Harold R. Bosch*
}

\begin{abstract}
Deck vents and open-grate sidewalks have often been used to improve or enhance the aerodynamic performance of long-span bridge structures. The new Tacoma Narrows Bridge is a good example of such an application. This paper presents the results of a wind tunnel study to investigate the significance of existing sidewalk grates in the overall stablilty of an $\mathrm{H}-$ shaped deck section for a suspension bridge. The results of tests to evaluate additional deck venting will also be presented. The tests indicate that the sidewalk grates do, in fact, play an important role in the behavior of this bridge. The status of the windward vent appears to be most significant. Deck venting, on the other hand, does not appear to uniformly enhance stability.
\end{abstract}

KEYWORDS: aerodynamics; bridges; longspan; suspension; vents; wind engineering.

\section{INTRODUCTION}

Flexible or slender structures can be sensitive to wind forces and exhibit undesirable windinduced oscillations. The engineer can often adjust the shape or modify edge details to enhance the structure's aerodynamic performance. For long-span bridges, one method of improving stability has been to install vents in the deck, shoulder, or sidewalk areas. The new Tacoma Narrows Bridge, for example, has 5 sets of vents in the deck which run the length of the bridge. The Deer Isle-Sedgwick Bridge, which will be the focus of this paper, has sidewalk vents that extend along each edge of the roadway. Since its construction in 1939, the Deer Isle bridge has been quite sensitive to the wind. There have been observations that bridge oscillations are more pronounced when the sidewalk grates are covered with snow. To confirm these observations and to establish the significance of the vents for this structure's stability, a series of tests have been conducted in the wind tunnel. Since the bridge deck was scheduled for replacement, tests have also been conducted to explore the utility of installing additional vents in the traffic lanes. Both dynamic response tests and static force tests have been performed in smooth oncoming flow. This paper will describe the experiments and test facilities, present results of the response and force measurements, and discuss these results.

\section{BRIDGE DESCRIPTION}

The Deer Isle-Sedgwick Bridge is a girderstiffened suspension bridge similar in cross section to the original Tacoma Narrows Bridge (Figure 1). The structure consists of a $1080 \mathrm{ft}$ $(329 \mathrm{~m})$ main span, with side spans of $484 \mathrm{ft}$ $(148 \mathrm{~m})$ and approach spans of $100 \mathrm{ft}(40 \mathrm{~m})$, for a total bridge length of $2308 \mathrm{ft}(704 \mathrm{~m})$. The two-lane deck is $20 \mathrm{ft}(6 \mathrm{~m})$ wide and 4.5 in $(11 \mathrm{~cm})$ thick. Stiffening girders are $6.5 \mathrm{ft}(2 \mathrm{~m})$ deep and spaced $23.5 \mathrm{ft}(7 \mathrm{~m})$ apart.

\section{AERODYNAMICS LABORATORY}

The research was conducted in the Aerodynamics Laboratory at TFHRC. Established in the late 1950's the Laboratory has been used primarily to ensure the aerodynamic stability of long span bridges. The facility includes a large lab area containing a wind tunnel, several unique test fixtures, instrumentation systems, and lab test equipment as well as an adjacent office area housing staff, computer systems, reference materials, and

* Research Structural Engineer, FHWA TurnerFairbank Highway Research Center, 6300 Georgetown Pike, Mclean, VA 22101 
records. The G.S. Vincent wind tunnel is a low velocity, open-circuit, laminar flow design. Air enters a double inlet section, passes through a diffusing section containing a series of 8 screens, and exits a 6 by $6-\mathrm{ft}(1.8$ by $1.8-\mathrm{m})$ nozzle into the test area. The air flow is quite laminar and well controlled at speeds up to $50 \mathrm{fps}(15 \mathrm{~m} / \mathrm{s})$. For experiments where turbulent flow is desired, an active turbulence generator is inserted into the circuit between the wind tunnel nozzle and the test area. With this system, large scale turbulence can be simulated in the vertical and along-wind directions, independently. The vertical angle of the wind can be changed by rotating the wind tunnel nozzle up and down or by rotating the model around its longitudinal axis as needed.

\section{SECTION MODEL}

A section model is a scaled, rigid, and geometrically faithful copy of a typical length of the prototype structure. One basic section model, built to a scale of $1 / 25$, was used for the tests reported here (Figure 2). The alternate configurations studied were achieved through simple modification of the base model. All flanges, stiffeners, floor beams, and bracing were carefully designed and fabricated to replicate prototype details. Special attention was given to the sidewalk grates to ensure a proper solidity ratio. The length of the model was set at $5 \mathrm{ft}(1.5 \mathrm{~m})$. The model width (B) was 11.25 in $(28.6 \mathrm{~cm})$, web to web, and the depth was 3.125 in $(7.9 \mathrm{~cm})$.

\section{RESPONSE MEASUREMENTS}

\subsection{Procedure}

The rigid section model was suspended in the wind tunnel test section by means of four coil springs. The size and stiffness of the springs was adjusted to provide the desired vertical and torsional vibration frequencies. For the basic test configuration, these frequencies were set to 2.05 and $5.73 \mathrm{~Hz}$, respectively. Large elliptical end plates were attached to the the model to ensure two dimensional flow near the ends. Horizontal restraining wires were attached to the ends of the model to prohibit longitudinal and lateral movement of the model. No attempt was made to block either the vertical or torsional degree-of-freedom during testing. Mechanical damping for the test setup ranged from about 0.1 to 1.5 percent of critical. The results from tests conducted at low damping levels only will be reported here. The section model was subjected to smooth oncoming flow at a fixed angle of attack of 0 degrees. The measurements were taken at a series of steady wind velocities ranging from 0 to $37 \mathrm{fps}(0-11.3 \mathrm{~m} / \mathrm{s})$. For some tests, however, the velocity range was limited due to violent, and potentially damaging, response of the model in the wind flow. At each new velocity, the wind flow and model activity were allowed to stabilize prior to data collection. Model response in its two degreesof-freedom was sampled at a rate of 50 samples per second for a period of 20 to 30 seconds. Dynamic data was filtered to remove any undesirable electronic noise prior to recording. For each test event, a 10 -second data window was selected for analysis. The two channels of motion data were demeaned and detrended to leave only the dynamic portion of each signal. Next, the root-mean-square (RMS) values were calculated from the "conditioned" time histories. Finally, the vertical and torsional calibration factors were applied.

\subsection{Results}

Dynamic response measurements were conducted on the unmodified deck section, three alternate shapes, and a proposed deck modification under a variety of conditions. Only results for the unmodified section, with sidewalk grates open or closed and with deck vents present or not present, will be discussed here. For the unmodified section with the sidewalk vents open (the normal condition), the model exhibits a large RMS rotation response of 1.42 degrees which initiates at a reduced velocity (V/NB) of about 2.10 with the peak centered around 2.75 (Figure 3). In the vertical degree-of-freedom, the model displays two distinct regions of activity centered at a V/NB of 1.75 and 5.75 , with the beginnings of a third evident at $\mathbf{8 . 7 5}$ (Figure 4). Note that this test had to be 
terminated at $18 \mathrm{fps}(5.5 \mathrm{~m} / \mathrm{s})$ due to rapidly growing vertical motion.

Since the sidewalk grates are sometimes covered with snow during the winter months, tests were conducted with the grates sealed off. For this condition, the model exhibits a small region of RMS rotational response of 0.6 degrees centered at a V/NB of 1.20 and a larger one initiating at 2.00 and climbing to an amplitude of about 2.50 degrees (Figure 3 ). In the vertical vibration mode, the model displays three zones of activity centered at $1.65,3.10$, and 6.25 with nondimensional RMS levels of .032, .034, and .022 , respectively (Figure 4 ). At the conclusion of this test vertical activity was decreasing while torsional activity was on the increase.

Since the existing bridge deck was scheduled for replacement, venting of the new deck was considered as a means for enhancing the aerodynamic behavior of this bridge. Tests were conducted with the deck vented in the center of each traffic lane. Although venting of the deck does reduce the level of vertical motion, it does not eliminate the motion entirely (Figure 5). On the other hand, this venting tends to augment the torsional motion resulting in vibration levels more than double those observed previously (Figure 6). Divergent vertical response was not noticeably affected by the deck venting and reappeared at about $17 \mathrm{fps}(5.2 \mathrm{~m} / \mathrm{s})$.

\section{FORCE MEASUREMENTS}

\subsection{Procedure}

To measure steady-state wind forces, the section model was carefully mounted in the forcebalance. This force-balance supports the model in a horizontal orientation and measures the 3 force components of lift (L), drag (D), and pitching moment (M). The balance is capable of rotating the section model about its longitudinal axis to vary the wind angle of attack. For the tests reported here, the attack angle ranges from -15 to +15 degrees. Large circular end plates are installed on the balance to ensure two dimensional flow near the model ends. Each model configuration was tested in smooth oncoming flow at a minimum of 9 distinct wind speeds and all tests were performed twice to ensure repeatability of the results. Wind speeds were carefully chosen to provide the maximum range of Reynolds number possible and to avoid regions where undesirable vibrations would develop in the model. In general, wind speeds ranged from 5 to $16 \mathrm{fps}(1.5-4.9 \mathrm{~m} / \mathrm{s})$ and the same speed settings were not necessarily selected for each configuration. During each test, readings from the balance and other laboratory instrumentation were continuously sampled at a rate of $100 \mathrm{~Hz}$ for a period of at least 83 seconds. All of the data from the force-balance was low pass filtered at $30 \mathrm{~Hz}$ prior to recording. For each test, an 83-second data window was selected for analysis. Calibration factors were applied to each channel of force data, mean forces per unit span were calculated, and these forces converted to nondimensional force coefficients.

\subsection{Results}

The drag and lift forces, which are in the wind coordinate system, are often translated to chord $(\mathrm{X})$ and normal $(\mathrm{Z})$ forces, in the bridge coordinate system, using the following:

$$
\begin{aligned}
& X=D \cos \alpha-L \sin \alpha \\
& Z=L \cos \alpha+D \sin \alpha
\end{aligned}
$$

where $\alpha$ is the wind angle or angle of attack. The orientation of these forces is illustrated in Figure 7. All forces are then reduced to dimensionless coefficients defined as:

$$
\begin{aligned}
& C_{d}=2 \mathrm{D} /\left(\rho \mathrm{U}^{2} \mathrm{~B}\right) \\
& \mathrm{C}_{1}=2 \mathrm{~L} /\left(\rho \mathrm{U}^{2} \mathrm{~B}\right) \\
& \mathrm{C}_{\mathrm{m}}=2 \mathrm{M} /\left(\rho \mathrm{U}^{2} \mathrm{~B}^{2}\right) \\
& \mathrm{C}_{\mathrm{x}}=2 \mathrm{X} /\left(\rho \mathrm{U}^{2} \mathrm{~B}\right) \\
& \mathrm{C}_{\mathrm{z}}=2 \mathrm{Z} /\left(\rho \mathrm{U}^{2} \mathrm{~B}\right)
\end{aligned}
$$

where $\rho$ is air density; $U$ is oncoming wind velocity; and $B$ is deck width.

Steady-state force measurements were conducted on the unmodified deck section and four alternate shapes under a variety of conditions. Only the results for the shape designated 
Alternate A will be presented here (Figure 8). This example was chosen since the bridge was recently changed to this shape. To evaluate the significance of the sidewalk grates for this shape, the following test cases were studied: Case 1-both grates open, Case 2-both grates closed, Case 3-windward grate closed, and Case 4-leeward grate closed. As noted earlier, the grates can become blocked when snow is present on the bridge.

For Alternate A with both sidewalk grates open, the normal coefficient exhibits a gentle positive slope with a value of about .34 for a horizontal wind (Figure 9). When both grates are closed, the slope becomes steep over most of the test range, indicating greater sensitivity to wind angle change, and $\mathrm{C}_{\mathrm{z}}$ for a horizontal wind is reduced to .06 . When only the leeward grate is closed, the change is not quite so dramatic; the slope increases a small amount and $\mathrm{C}_{\mathrm{z}}$ at zero degrees drops to about .23. For the case where the windward grate is closed, however, the normal coefficient changes in a different manner. Here, the slope of the $\mathrm{C}_{\mathbf{z}}$ curve turns significantly negative for small wind angles. This is not a desirable characteristic and can lead to vertical stability problems.

For Alternate A with both grates open, the moment coefficient is positive and exhibits a positive slope except for wind angles above +6 degrees (Figure 10). This is also true for the case where the leeward grate is closed. When the windward grate is closed or both grates are closed, however, $\mathrm{C}_{\mathrm{m}}$ takes on negative values for wind angles below about -11 degrees. When the windward grate only is closed, the moment coefficient exhibits a slight negative slope for small positive wind angles. This characteristic could indicate torsional stability problems.

In general, the chord coefficient takes on similar values, at modest wind angles, for the four cases investigated (Figure 11). For a wind angle equal to zero degrees, $C_{x}$ tends to decrease slightly when both sidewalk grates are closed. At large wind angles, however, the decrease in chord coefficient is more apparent with closure of both grates resulting in the most change.

\section{CONCLUSIONS}

For the unmodified deck section, the results indicate that the sidewalk grates perform a significant role in the dynamic behavior of this structure -- they weaken the potential vortexinduced response of the bridge. Blockage of these vents results in more frequent response, greater bridge motion amplitudes, and increased activity at lower wind speeds. Although the addition of vents in the roadway does reduce vortex-induced motion, it does not eliminate the motion entirely. With the deck venting, torsional motion amplitudes were more than doubled and divergent vertical response was not delayed. For the fairing-modified deck section, Alternate A, some changes were observed in the wind forces depending on the status of the sidewalk grates. In general, it appears that the windward vent is more important than the leeward one. When this vent is blocked, the normal and moment coefficients exhibit negative slopes for small angles of attack. These results tend to confirm observations made at the bridge site. 

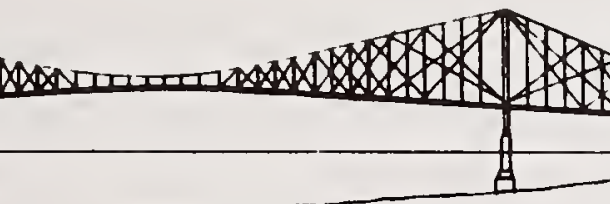

\section{(Elovation)}

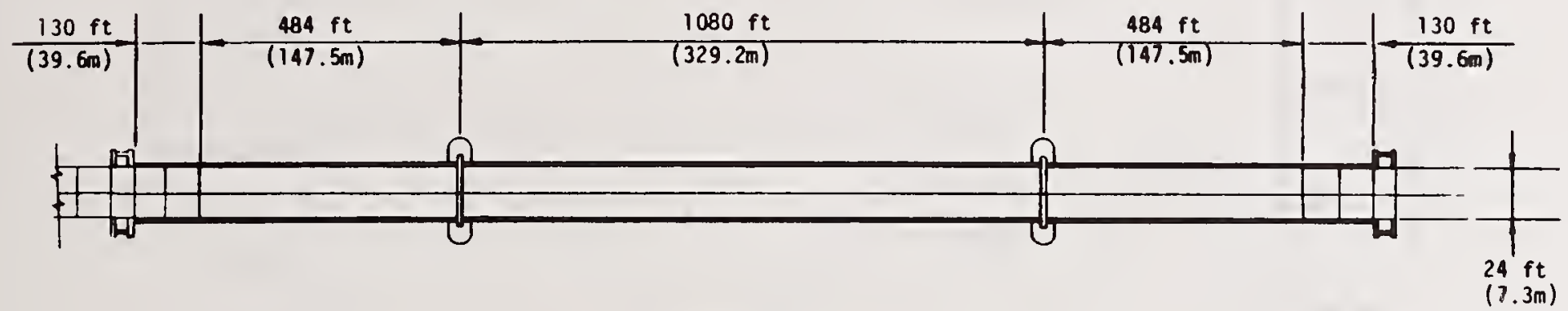

(Plon)

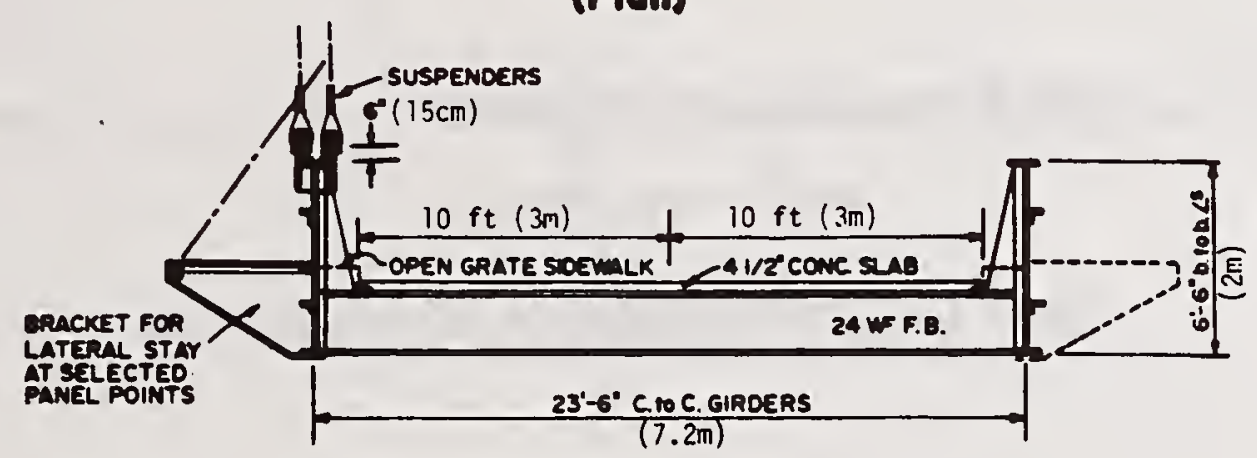

Figure 1. Deer Isle - Sedgwick Bridge.

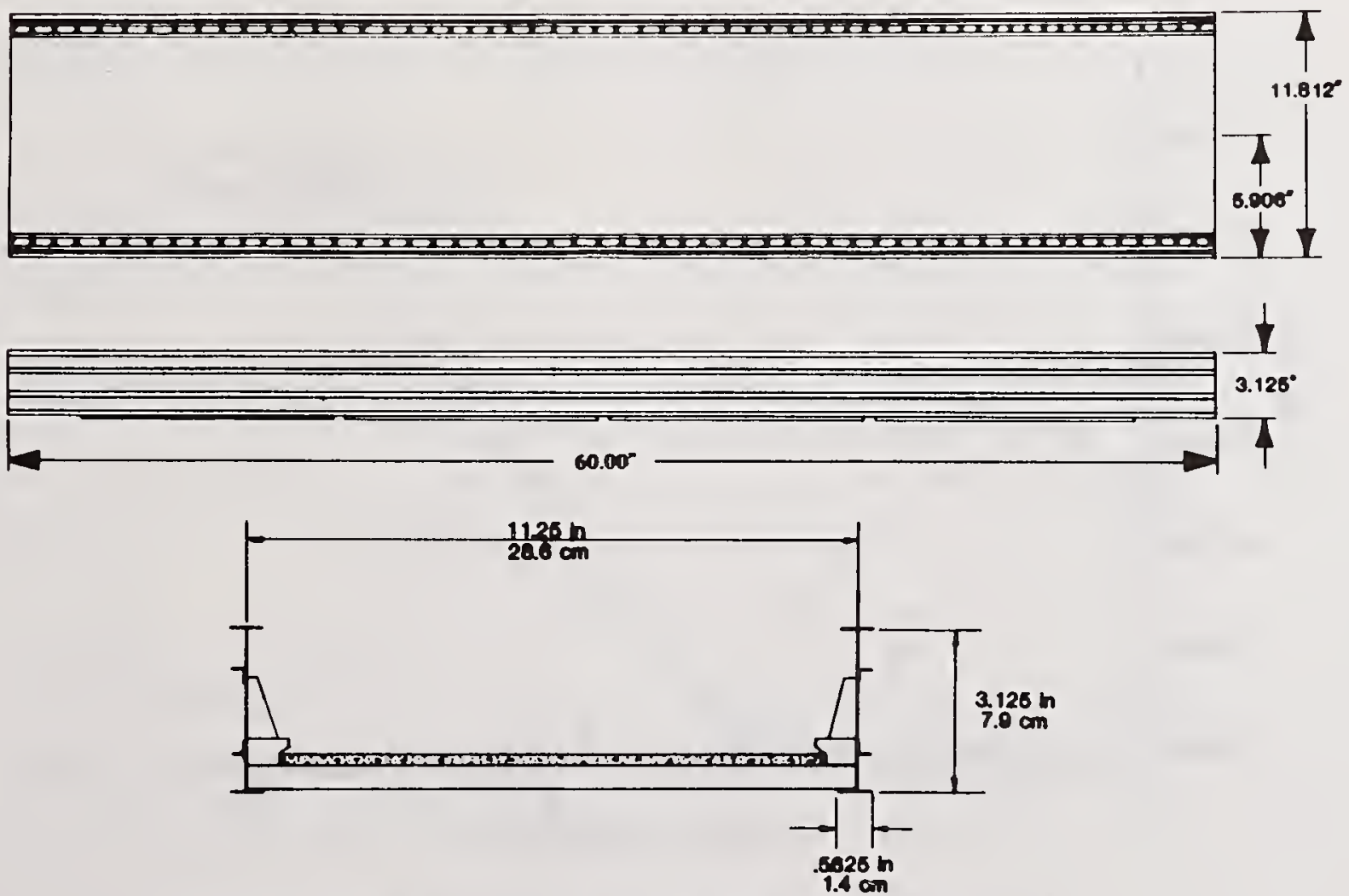

Figure 2. Bridge Section Model. 


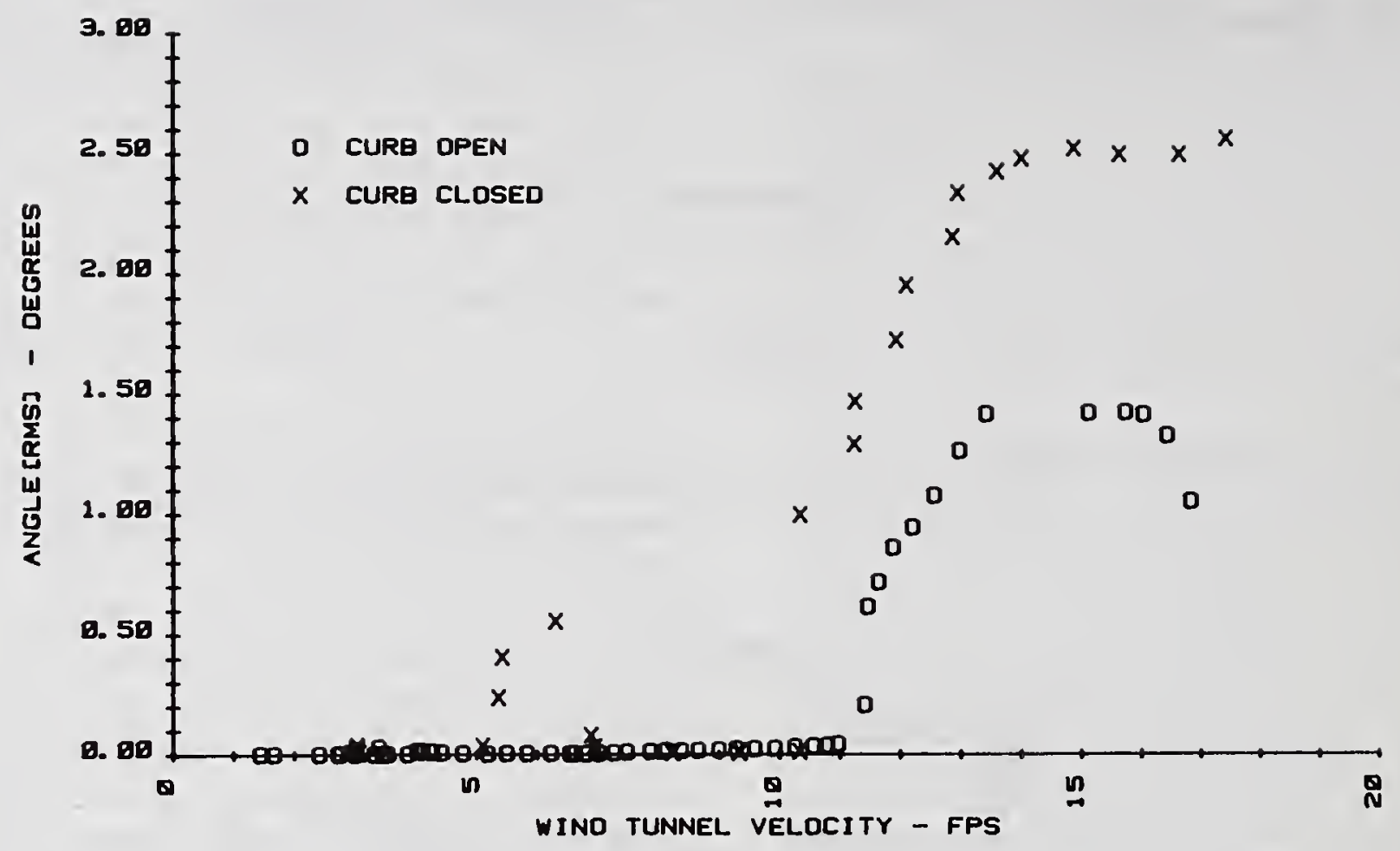

Figure 3. Torsional Response - Sidewalk Vents.

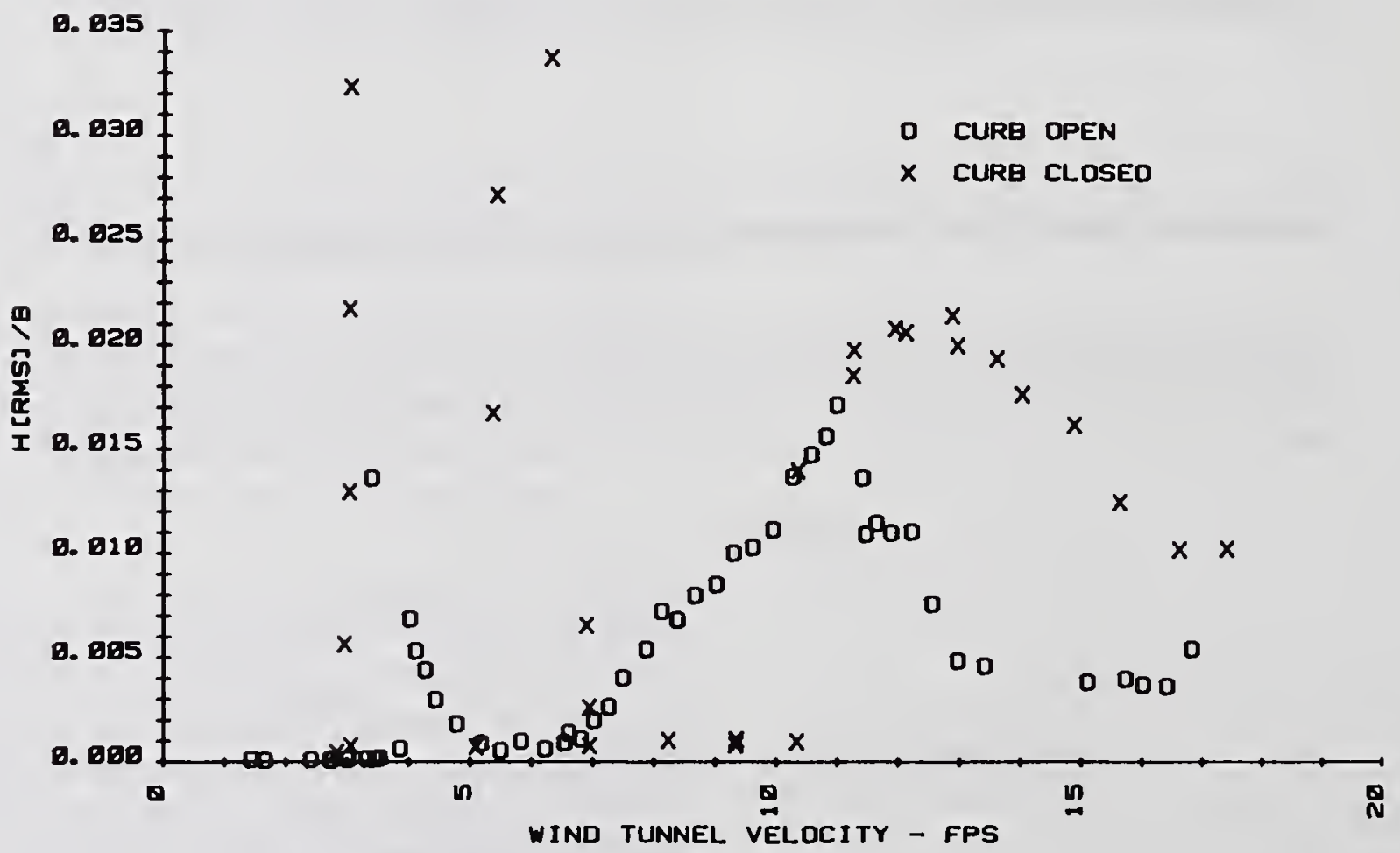

Figure 4. Vertical Response - Sidewalk Vents. 


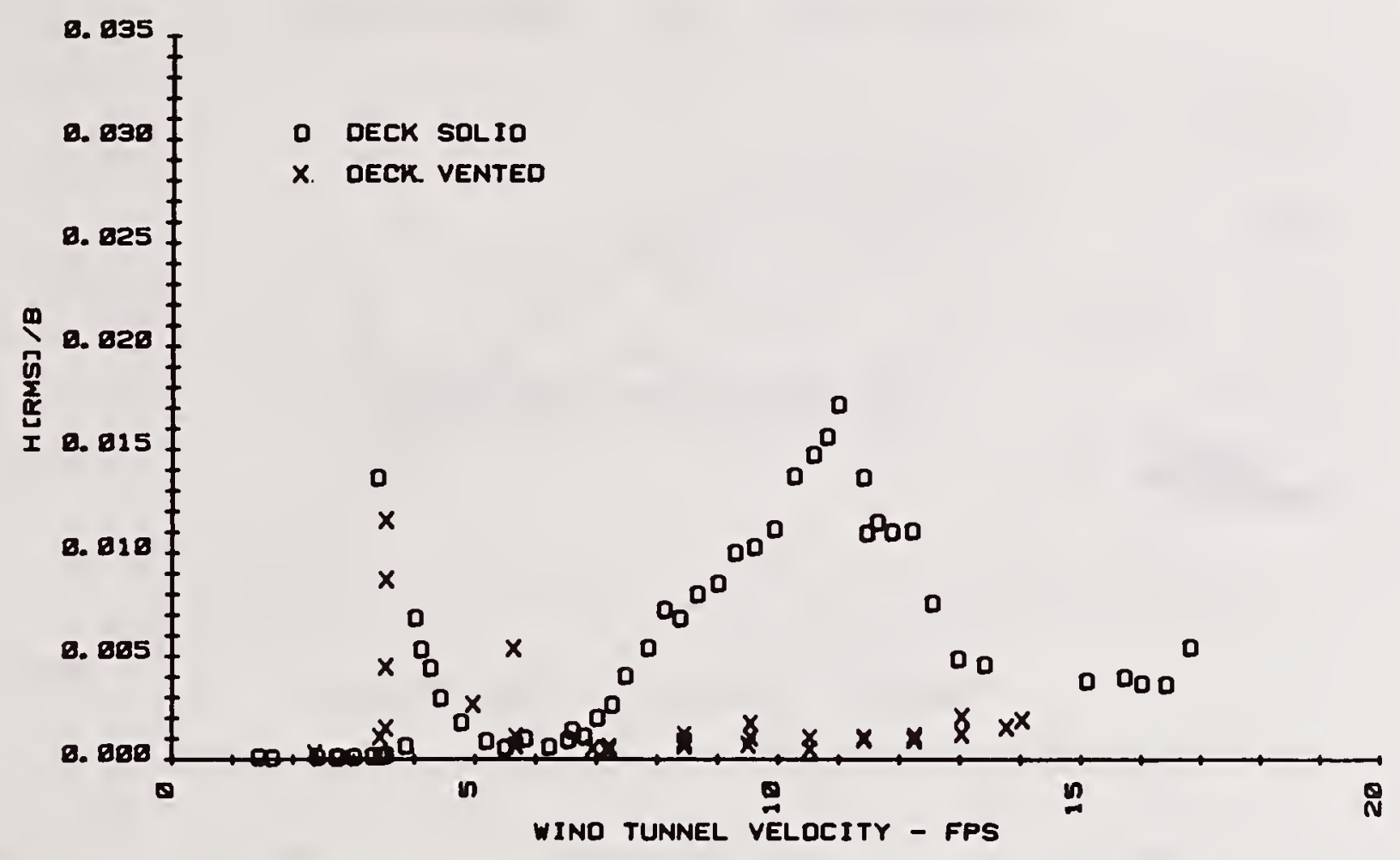

Figure 5. Vertical Response - Roadway Vents.

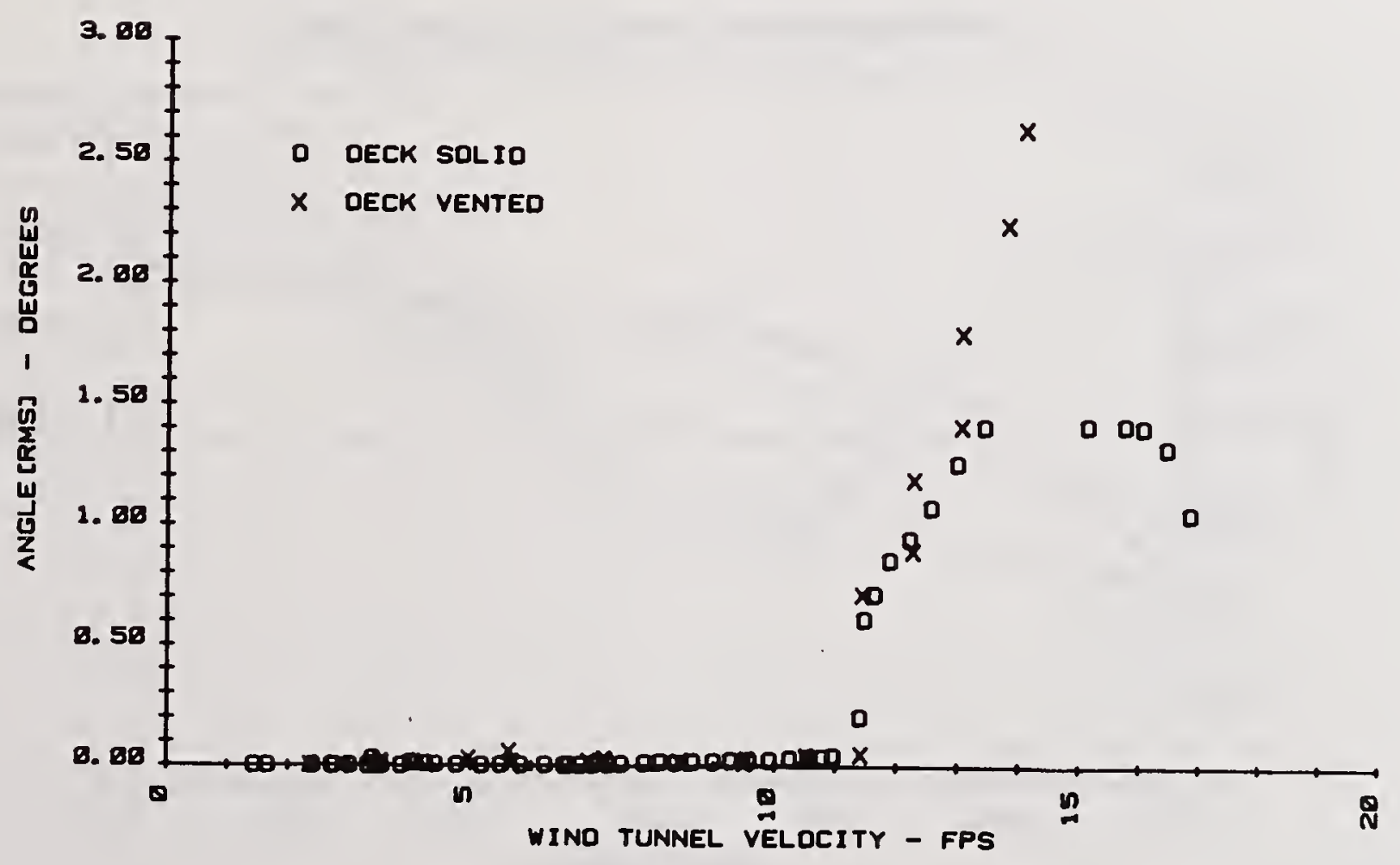

Figure 6. Torsional Response - Roadway Vents. 


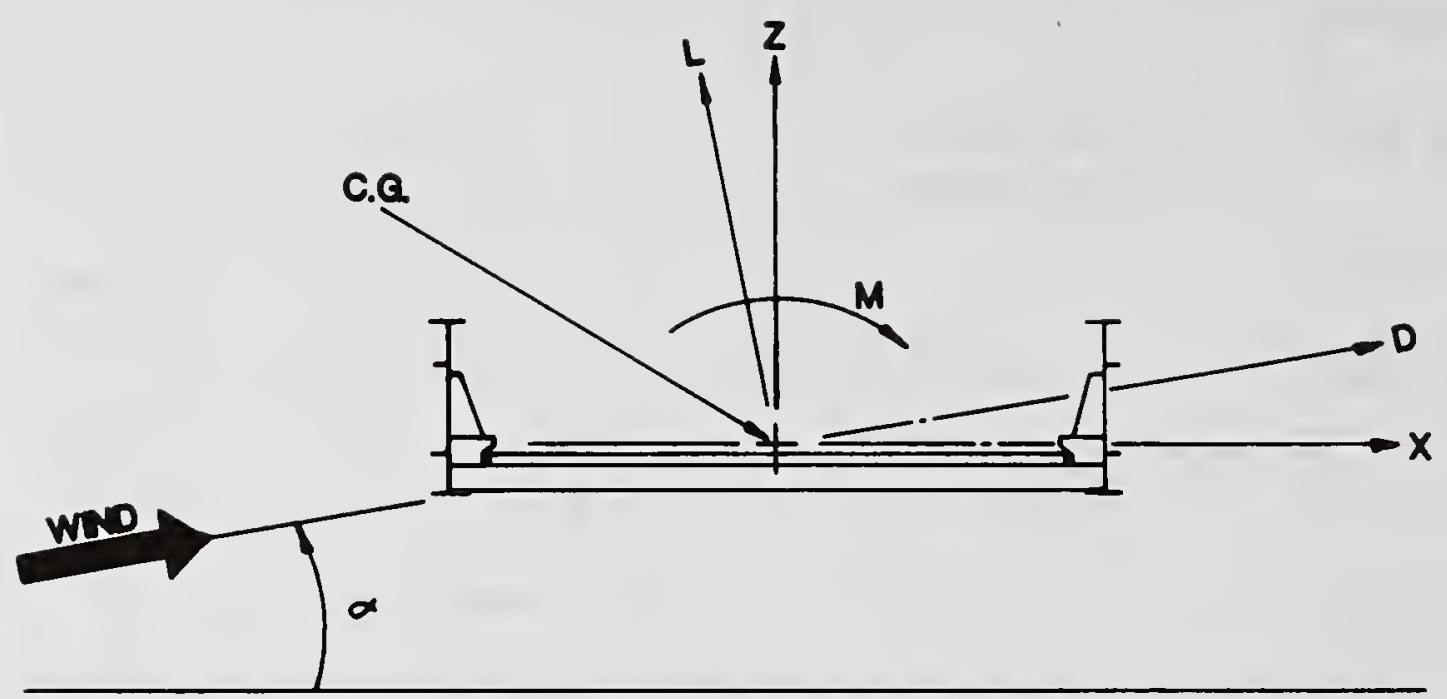

Figure 7. Orientation of Wind Forces.

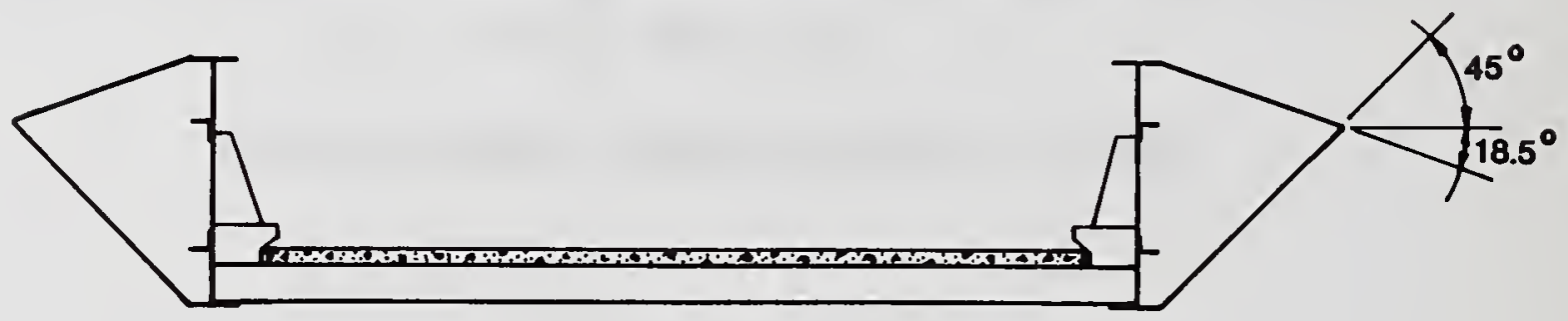

Figure 8. Configuration Alternate A.

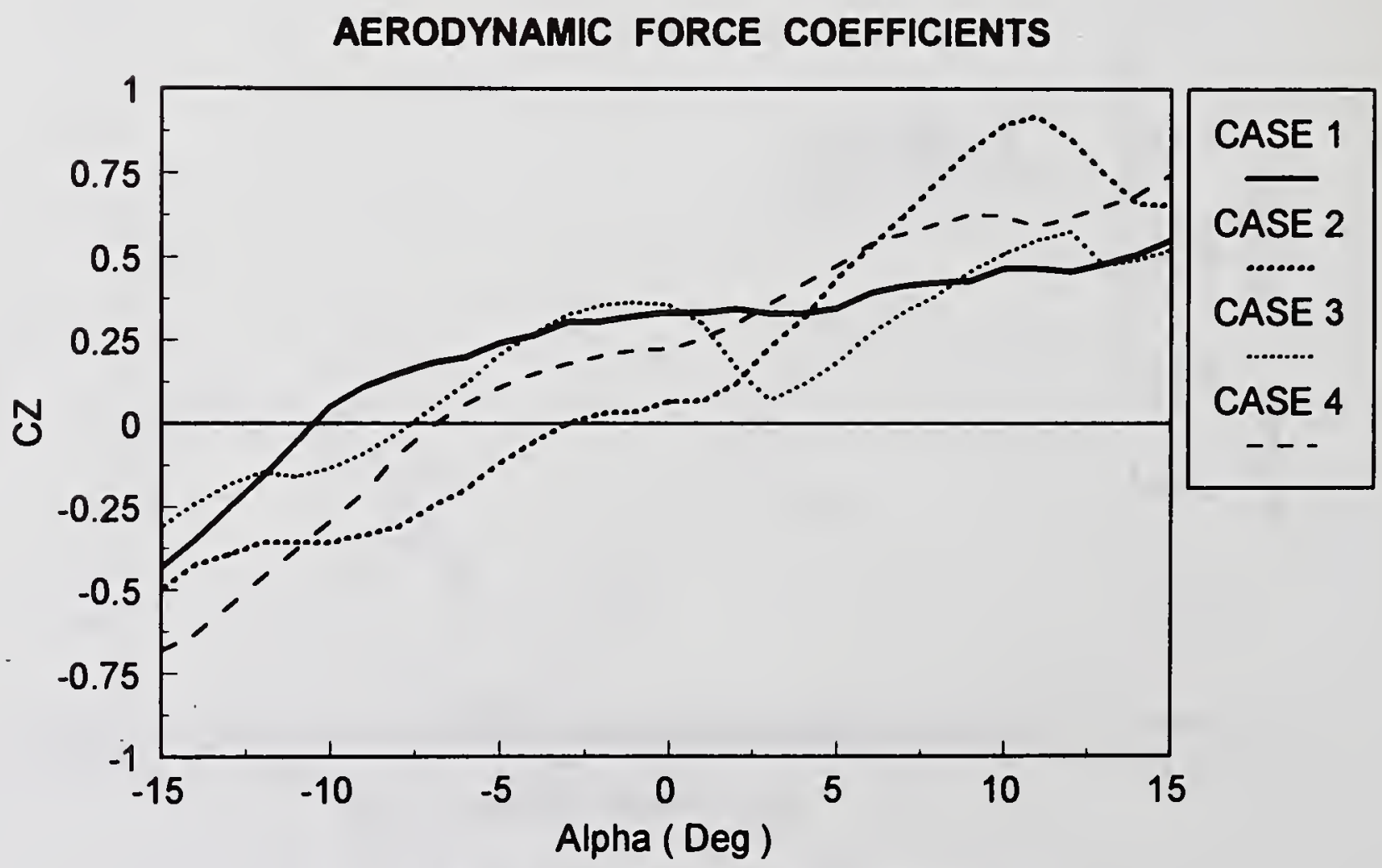

Figure 9. Normal Force Coefficients. 


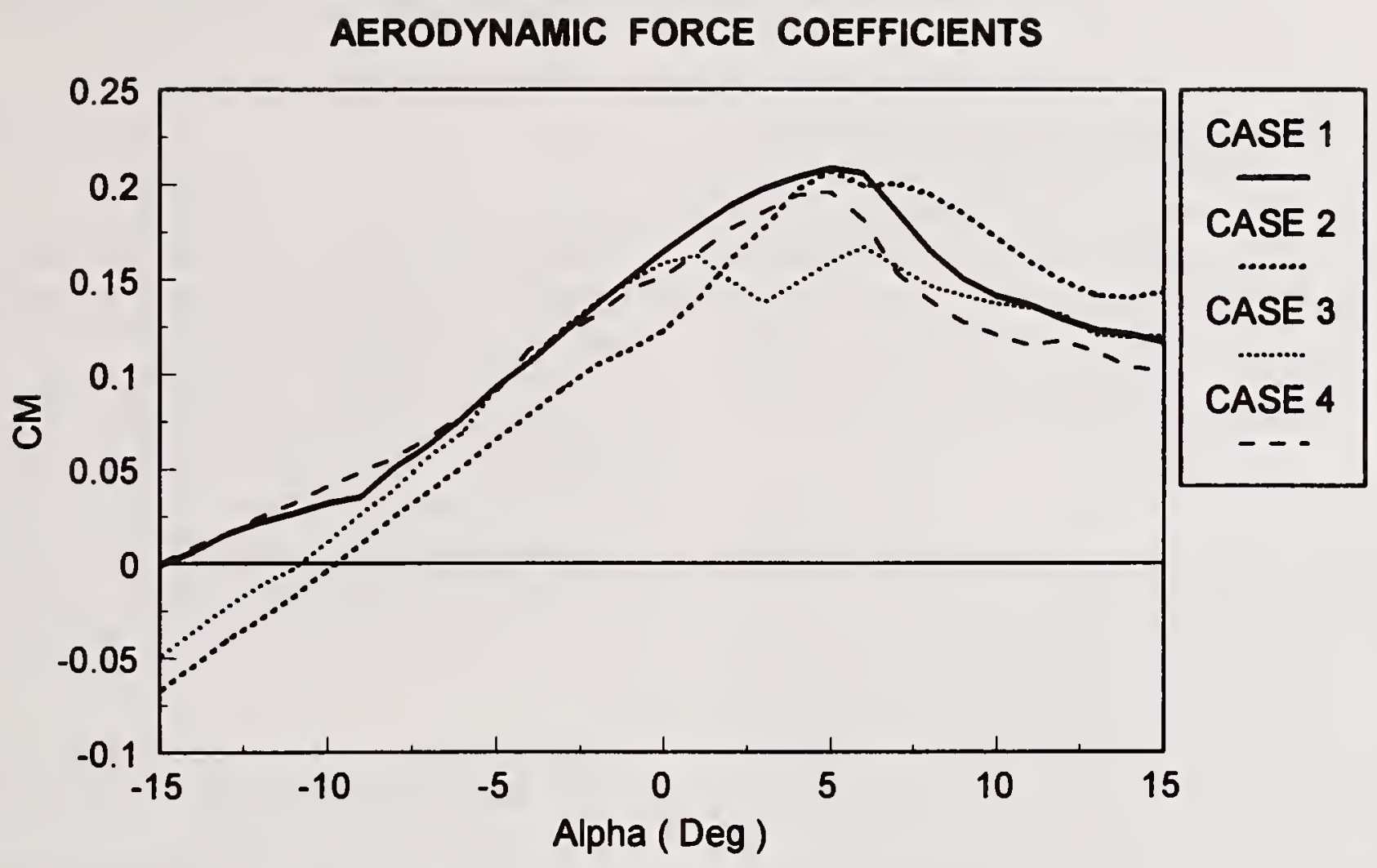

Figure 10. Pitching Moment Coefficients.

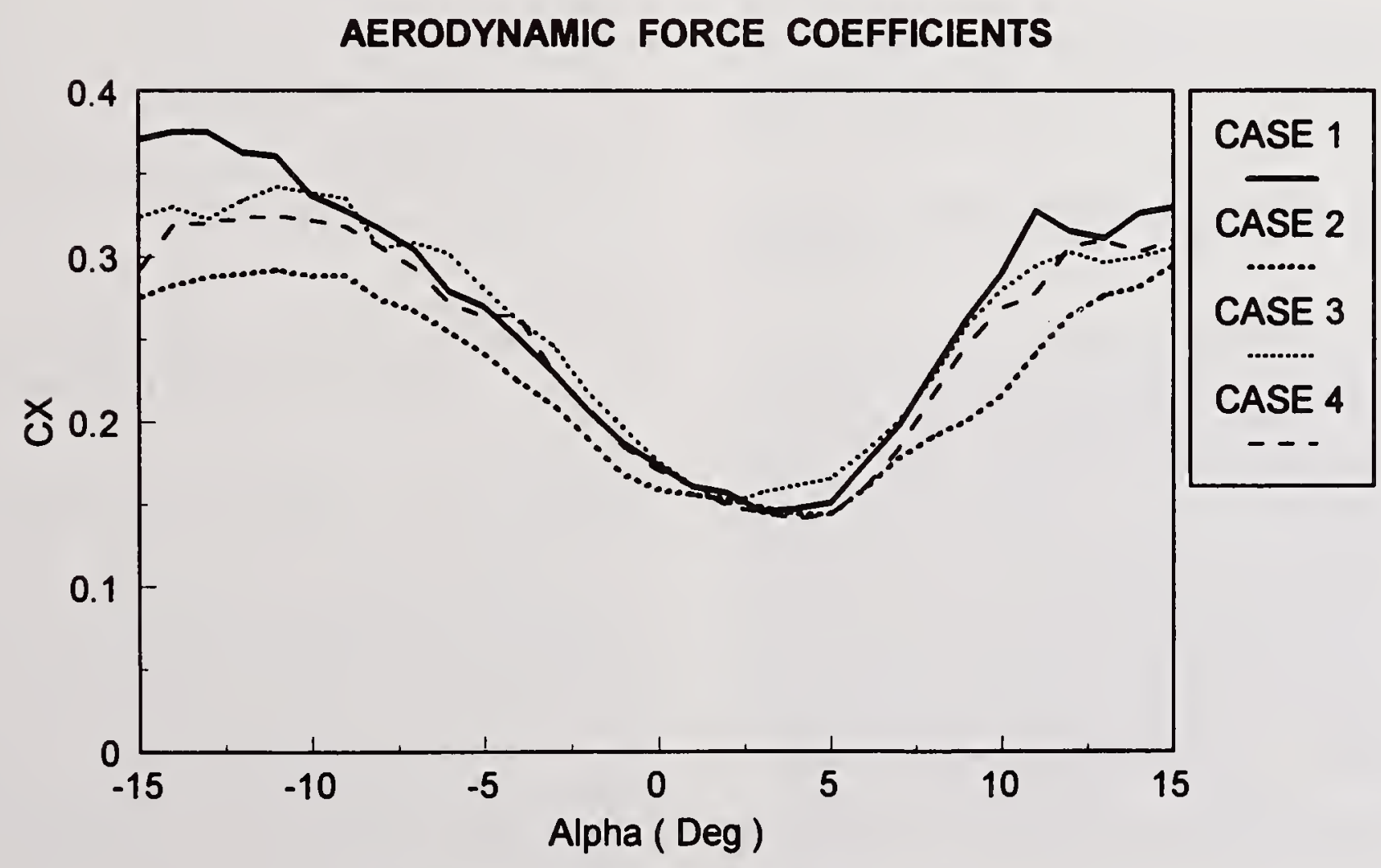

Figure 11. Chord Force Coefficients. 



\section{Aerodynamic Characteristics of Slotted Box Girders}

by

Hiroshi SATO $^{1)}$ and Katsuya OGIHARA ${ }^{2)}$

\begin{abstract}
Aerodynamic stability is one of the most important themes in the design of a super longspan bridge. To improve the aerodynamic stability of a super long-span bridge, a series of wind tunnel studies and analytical studies were conducted for slotted box girders. According to the test results and analytical results, it was found that slot at the center of girder was effective to improve the aerodynamic stability. It was also found from section model test that devices like center barrier and guide vanes increased flutter speed considerably.
\end{abstract}

KEYWORD: flutter, super long-span bridge, slotted box girder, unsteady aerodynamic force

\section{INTRODUCTION}

The Akashi Kaikyo Bridge, which is now under construction in Japan, will have the main span length of $1990 \mathrm{~m}$. In Japan and in the world, there are several plans or ideas to construct longer bridges such as the Messina Straits Bridge. In the design of such super long-span bridges, aerodynamic stability is one of the most important themes. The approaches to improve aerodynamic stability can be classified into structural one and aerodynamic one. In this paper described is the latter approach, namely to improve aerodynamic characteristics of stiffening girders using slot.

\section{EXPERIMENT ON THE EFFECT OF LOCATION AND SIZE OF SLOT}

The effect of location and size of slot on aerodynamic characteristics was examined through section model wind tunnel test. Considering a super long-span bridge which has center span length of $3,000 \mathrm{~m}$ with two side spans of $1,500 \mathrm{~m}$, the structural conditions were assumed $[1,2,3,4]$ as shown in Table- 1 . As for the cross section of the box girder, two types were considered. Model-A was $40 \mathrm{~m}$ wide, $4 \mathrm{~m}$ deep, and Model-B was $45 \mathrm{~m}$ wide, $3 \mathrm{~m}$ deep. The cross section of these two types are shown in Fig.-
1. In the models, gird rails and any other small attachments which are usually installed on bridges were neglected to evaluate the basic characteristics of slotted box girder. Slots were represented by removing some deck plates of the model. The tests were conducted in smooth flow. The test cases are listed in the Table- 2 with corresponding cross sections and test results.

\section{(1)Model-A}

From the test results of the Model-A, it was found that the slot at the center increased the flutter onset wind speed by $12 \mathrm{~m} / \mathrm{s}$ (case-1, case-5). On the other hand, it was found that the slots at the edge of the girder lowered the flutter onset wind speed(case-1, case-8). In case-10, where slots were installed at the center and edge of the girder, flutter onset wind speed was very low. This shows that the location of slot should be carefully chosen. As for the cases without fairing, the slot at the center of the girder decreased flutter onset wind speed from $27 \mathrm{~m} / \mathrm{s}$ (case-14) to $18 \mathrm{~m} / \mathrm{s}$ (case11). This implies that suitable fairing as well as center slot is required to increase flutter speed.

\section{(2)Model-B}

From the test results of the Model-B, it was found that the flutter onset wind speed was increased with the width of slot at the center of the girder(case-16,18,20).

\section{ANALYTICAL STUDY ON THE EFFECT OF SLOT}

In order to explain the effect of slot at the center of girder, preliminary analysis was conducted. For the analysis, aerodynamic forces acting on the each box of the girder were calculated using the Theodorsen's function. The aerodynamic interference between the 2 boxes was neglected. Using the above aerodynamic forces, two degreeof-freedom flutter analysis was conducted by $\mathrm{U}-\mathrm{g}$

1) Head, Structure Division, Structure and Bridge Dept., Public Works Research Institute, Ministry of Construction

2) Senior Research Engineer, Structure Division, ditto 
method $[5,6]$. The result of the flutter analysis shown in Fig.-2 indicates that the flutter onset wind speed increases with size of slot. The differences between the analysis and the experiment seems to be caused by aerodynamic interference between the 2 boxes.

\section{IMPROVEMENT OF AERODYNAMIC CHARACTERISTICS OF GIRDER}

Although wide slot at the center of the girder improves flutter characteristics, narrower slot would be preferable from the viewpoint of construction cost of towers and foundations. To improve aerodynamic characteristics, the effect of some devices was studied by section model tests. The model used in this study was the Model-B with gird rails.

The tested devices are illustrated in Fig.-3. The result is shown in Fig.-4, where the flutter speed measured from section model tests was normalized by the flutter speed predicted by the Selberg's formula. It can be seen that a center barrier and guide vanes improved flutter characteristics very well.

However, the flutter speed was not so high when angle of attack was -3 deg. as is shown in Fig.-4. It was found that the gird rails at the bottom deck increased the flutter speed considerably at this angle of attack (Fig.-5).

These devices were applied to 3 slotted box girders with different girder depth(D) as is shown in Fig.-6.

The flutter speed of these girders are shown in Fig.-7. The aerodynamic stability was excellent for the girders with $D=3 \mathrm{~m}$, and $\mathrm{D}=7 \mathrm{~m}$. However, the aerodynamic stability of the girder with $\mathrm{D}=5 \mathrm{~m}$ was lower than the other girders.

When the slot ratio $b / B^{*}$ of the girder with $\mathrm{D}=3 \mathrm{~m}$ was decreased from $25 \%$ to $20 \%$, the flutter onset wind speed dropped considerably. It seems that the slot wider than $25 \%$ of the girder width is required to maintain excellent aerodynamic stability in this case.

\section{COEFFICIENTS OF THE UNSTEADY AERODYNAMIC FORCES}

In order to investigate the aerodynamic characteristics of the slotted box girder more precisely, unsteady aerodynamic forces were measured for the girder with $\mathrm{D}=3 \mathrm{~m}$. The measurement was made by forced oscillation method [7]. Coefficients of unsteady aerodynamic forces were defined as follows.

$$
\begin{aligned}
& \mathrm{L}=\pi \rho\left\{\mathrm{b}^{2}\left[\mathrm{~L}_{\mathrm{ZR}} \omega^{2} \mathrm{Z}+\mathrm{L}_{\mathrm{ZI}} \omega \mathrm{Z}^{\prime}\right]\right.
\end{aligned}
$$

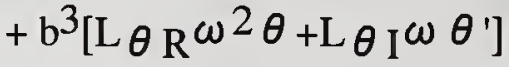

$$
\begin{aligned}
& \left.+b^{2}\left[L_{Y R} \omega^{2} \mathrm{Y}+L_{Y I} \omega Y^{\prime}\right]\right\} \\
& \mathrm{M}=\pi \rho\left\{\mathrm{b}^{3}\left[\mathrm{M}_{\mathrm{ZR}} \omega^{2} \mathrm{Z}+\mathrm{M}_{\mathrm{ZI}} \omega \mathrm{Z}^{\prime}\right]\right. \\
& +b^{4}\left[M_{\theta} R \omega^{2} \theta+M_{\theta} \omega^{\prime} \theta^{\prime}\right] \\
& \left.+b^{3}\left[M_{Y R} \omega^{2} Y+M_{Y I} \omega Y^{\prime}\right]\right\} \\
& \mathrm{D}=-\pi \rho\left\{\mathrm{bd}\left[\mathrm{D}_{\mathrm{ZR}} \omega^{2} \mathrm{Z}+\mathrm{D}_{\mathrm{ZI}} \omega \mathrm{Z}^{\prime}\right]\right. \\
& +\mathrm{db}^{2}\left[\mathrm{D}_{\theta \mathrm{R}} \omega^{2} \theta+\mathrm{D}_{\theta \mathrm{I}} \omega \theta^{\prime}\right] \\
& \left.+d b\left[D_{Y R} \omega^{2} Y+D_{Y I} \omega Y^{\prime}\right]\right\}
\end{aligned}
$$

where

$\rho:$ Air density

$\mathrm{b}, \mathrm{d}:$ Girder width and depth

$\omega$ : Angular frequency

$\mathrm{Z}, \theta, \mathrm{Y}$ : Vertical, torsional and horizontal (along wind) displacement

$Z^{\prime}, \theta^{\prime}, Y^{\prime}$ : Vertical, torsional and horizontal (along wind) velocity

L,M,D: Lift, Moment and Drag force

$\mathrm{L} * *, \mathrm{M} * *, \mathrm{D} * *$ : Coefficients of unsteady aerodynamic forces (For example, $\mathrm{M}_{\mathrm{ZI}}$ is the coefficient of imaginary part of unsteady aerodynamic moment due to vertical motion.)

Some of the calculated coefficients are shown in Fig.-8. They are compared with those of single flat plate, and with those of flat plate with slot at the center. The unsteady aerodynamic forces for these plates were derived from the Theodorsen's function. In the calculation for the slotted flat plate, aerodynamic interference between the 2 plates was neglected. As a whole, the unsteady aerodynamic forces of the slotted girder seems to be similar to those of the slotted plate rather than those of the single plate.

\section{DISCUSSION}

Among these 18 coefficients, the most important coefficients are $\mathrm{M}_{\mathrm{ZI}}, \mathrm{M} \theta \mathrm{I}, \mathrm{L} \theta \mathrm{R}$ and $\mathrm{M} \theta \mathrm{R}$. 
For 2-degrees of freedom system, the relationship between unsteady aerodynamic forces and some vibration properties can be expressed by the following formulas [8].

$$
\begin{aligned}
& \delta \mathrm{a} \fallingdotseq-\pi^{2} \mathrm{M}_{\mathrm{ZI}} \mathrm{X} / \nu-\pi^{2} \mathrm{M}_{\theta \mathrm{I}} / \nu \\
& \mathrm{X} \equiv \mathrm{z}_{0} / \theta_{0} / \mathrm{B} \fallingdotseq \pi \mathrm{L}_{\theta \mathrm{R}} /\left(-1+\left(\mathrm{f}_{\mathrm{Z}} / \mathrm{f}_{\theta}\right)^{2} \sigma^{2}\right) / \mu \\
& \sigma^{2} \equiv\left(\mathrm{f}_{\theta} / \mathrm{f}\right)^{2} \fallingdotseq 1+\pi \mathrm{M}_{\theta \mathrm{R}} / \nu
\end{aligned}
$$

Here, $\delta$ a is aerodynamic damping in logarithmic decrement, and $\mathrm{X}$ is amplitude ratio, and $\sigma$ is frequency ratio. They were derived by assuming that absolute value of aerodynamic damping and phase angle are small, and that absolute value of the amplitude ratio $X$ is small. As is shown here, $M \theta \mathrm{R}$ affects the frequency ratio $\sigma . \mathrm{L} \theta \mathrm{R}$ and $\sigma$ affect the amplitude ratio $\mathrm{X} . \mathrm{M}_{\mathrm{ZI}}, \mathrm{M}_{\theta} \mathrm{I}$ and $\mathrm{X}$ affect the aerodynamic damping.

In Fig.-8, the measured $M \theta \mathrm{R}$ of the slotted box girders is compared with that of single flat plate, and that of slotted flat plate. From the figure, it can be said that $\mathrm{M} \theta \mathrm{R}$ of the slotted plate is smaller than the single plate, and that $\mathrm{M} \theta \mathrm{R}$ of the slotted box girder is smaller than the slotted plate.

As for $\mathrm{L} \theta \mathrm{R}$, the three coefficients are almost identical.

$M_{Z I}$ will cause negative damping. From the figure, it can be said that the absolute value of $\mathrm{M}_{\mathrm{ZI}}$ for the slotted plate is smaller than the single plate. The absolute value of $M_{Z I}$ for the slotted box girder is smaller than the slotted plate.

$M \theta$ I will cause positive damping. $M \theta_{\mathrm{I}}$ for the slotted plate is almost identical with that for single plate. The absolute value of $\mathrm{M}_{\theta}$ I for the slotted box girder is smaller than the others.

The aerodynamic damping for the single plate, the slotted plate and for the slotted box girder was calculated from the above formulas, and is shown in Fig.-9. The aerodynamic damping turns negative at small reduced frequency. The critical reduced frequency for the slotted plate and slotted box girder is smaller that that for the single plate.
It means that the flutter speed for these slotted plates and slotted box girders are higher than that for single plate.

The characteristics of unsteady aerodynamic forces of the slotted box girder are summarized here. Since $M \theta \mathrm{R}$ is small, the frequency ratio $\sigma$ becomes small. Since $\left(\mathrm{f}_{\mathrm{Z}} / \mathrm{f}_{\theta}\right) \sigma$ is less than 1 and small, and since $\mathrm{L} \theta \mathrm{R}$ is positive, the amplitude ratio $\mathrm{X}$ becomes negative and its absolute value becomes small. Since $M_{Z I}$ is negative and its absolute value is small, the critical wind speed for flutter becomes high.

\section{FLUTTER ANALYSIS FOR A SUPER LONG-SPAN BRIDGE}

Using all the measured coefficients of unsteady aerodynamic forces, flutter analysis of a super long-span bridge was conducted (Table- 3 ). The main span length of the super long-span bridge was $2,500 \mathrm{~m}$, and the side span was $1,250 \mathrm{~m}$. For comparison, flutter analysis was also conducted using unsteady aerodynamic forces of the single plate derived from Theodorsen's function. The structural conditions for both cases were same.

Flutter speed for the slotted box girder was as high as about $80 \mathrm{~m} / \mathrm{s}$ as is shown in Fig.-10. On the other hand, the critical wind speed for single flat plate was as low as about $40 \mathrm{~m} / \mathrm{s}$.

\section{CONCLUSION}

It was found that box girder with slot at the center had good flutter characteristics, and it could be improved by some devices like center barrier and guide vane. It seems that the slotted box girder would be one of the possible stiffening girders for super long-span bridges.

\section{REFERENCES}

[1] Nakamura, S. et. al.. "A proposal on super long-span bridge with stiffing girder", Bridge and Foundation, 92-12, 1992, pp37-42 (in Japanese)

[2] Kawada, T., "Recent Suspension Bridge", Rikou Tosho, Tokyo, 1987 (in Japanese).

[3] Kimura M., "On cable system for long span suspension bridge with center span of $3,000 \mathrm{~m}$ ", Proc. of the $47 \mathrm{th}$ Annual Conference of the Japan Society of Civil 
Engineering, 1992, pp1018-1019 (in Japanese).

[4] Suzuki et al, "Study on Structure of Super long-span bridge with aerodynamic stability", Proc. of the 48th Annual Conference of the Japan Society of Civil Engineering, 1993, pp838-839 (in Japanese).

[5] Bisplinghoff R. L., Ashley H., and Halfman R. L. "Aeroelasticity" Addison Wesley.

[6] Washizu K., "Aeroelasticity", Kyouritsu Shuppan, Tokyo, 1957 (in Japanese).
[7] Okubo, T., Narita N. and Yokoyama K., "Some approaches for improving wind stability of cable-stayed girder bridges", Proc. of the 4th International Conference on Wind Effects on Buildings and Structures, 1975, pp241-249.

[8] Nakamura, Y. and Watanabe, K., "Flutter analysis of 2-degrees of freedom for suspension bridges", Proc. of the 32nd Annual Conference of the Japan Society of Civil Engineering, 1977, pp231-232 (in Japanese). 


\section{Table-1 Assumed Structural Condition}

\begin{tabular}{|c|c|c|c|}
\hline & & Model-A & Model-B \\
\hline Weight & $t f / m$ & 46 & 46 \\
\hline $\begin{array}{l}\text { Polor Moment } \\
\text { of Inerti }\end{array}$ & $t f \cdot m \cdot s 2 / m$ & 1,280 & 1,620 \\
\hline Natural Vertical & $\mathrm{Hz}$ & 0.050 & 0.050 \\
\hline Frequency Tortional & $\mathrm{Hz}$ & 0.105 & 0.105 \\
\hline Girder Width & $\mathrm{m}$ & 40 & 45 \\
\hline Girder Depth & $\mathrm{m}$ & 4 & 3 \\
\hline
\end{tabular}




\section{Table-2 Test Case and Result}

\begin{tabular}{|c|c|c|c|c|c|c|}
\hline cose & $\mid$\begin{tabular}{|l|} 
Mode 1 \\
Typo
\end{tabular} & slot Pottorn & $\begin{array}{l}\text { Anglo } \\
\text { of } \\
\text { At tack }\end{array}$ & Slot & Fairine & $\begin{array}{l}\text { Flutter Onset } \\
\text { Wind Speed"* }\end{array}$ \\
\hline 1 & A & 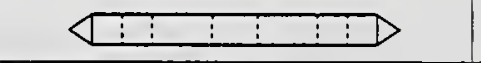 & $0^{\circ}$ & $0 \%$ & Yes & $39 \mathrm{~m} / \mathrm{s}$ \\
\hline 2 & A & $\Delta: \vdots: \vdots 1\rangle$ & $0^{\circ}$ & $0 \%$ & Yes & $38 \mathrm{~m} / \mathrm{s}$ \\
\hline 3 & A & $\triangle \square \vdots: \square$ & $0^{\circ}$ & $0 \%$ & Yes & $37 \mathrm{~m} / \mathrm{s}$ \\
\hline 4 & A & $\triangle \square \square \square$ & $0^{\circ}$ & $0 \%$ & Yes & $37 \mathrm{~m} / \mathrm{s}$ \\
\hline 5 & A & $\triangle: \square$ & $0^{\circ}$ & $20 \%$ & Yes & $51 \mathrm{~m} / \mathrm{s}$ \\
\hline 6 & A & $\triangle: \vdots: \square$ & $0^{\circ}$ & $20 \%$ & Yes & $37 \mathrm{~m} / \mathrm{s}$ \\
\hline 7 & A & $\triangle \square \square \square$ & $0^{\circ}$ & $20 \%$ & Yes & $47 \mathrm{~m} / \mathrm{s}$ \\
\hline 8 & A & $\triangle \square \square$ & $0^{\circ}$ & $20 \%$ & Yes & $25 \mathrm{~m} / \mathrm{s}$ \\
\hline 9 & A & $\triangle \square \vdots \square$ & $0^{\circ}$ & $20 \%$ & Yes & $21 \mathrm{~m} / \mathrm{s}$ \\
\hline 10 & A & $\triangle \square \square \square$ & $0^{\circ}$ & $40 \%$ & Yes & $19 \mathrm{~m} / \mathrm{s}$ \\
\hline 11 & A & $\square \vdots \quad \square \quad \vdots$ & $0^{\circ}$ & $20 \%$ & No & $18 \mathrm{~m} / \mathrm{s}$ \\
\hline 12 & A & $\triangle: \square$ & $-3^{\circ}$ & $20 \%$ & Yes & $53 \mathrm{~m} / \mathrm{s}$ \\
\hline 13 & A & $\triangle i: \square \square$ & $+3^{\circ}$ & $20 \%$ & Yes & $53 \mathrm{~m} / \mathrm{s}$ \\
\hline 14 & A & $\square \vdots: \square$ & $0^{\circ}$ & $0 \%$ & No & $27 \mathrm{~m} / \mathrm{s}$ \\
\hline 15 & A & {$[\square \square$} & $0^{\circ}$ & $20 \%$ & No & $16 \mathrm{~m} / \mathrm{s}$ \\
\hline 16 & B & 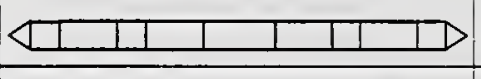 & $0^{\circ}$ & $0 \%$ & Yes & $39 \mathrm{~m} / \mathrm{s}$ \\
\hline 17 & B & 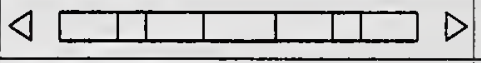 & $0^{\circ}$ & $13 \%$ & Yes & $38 \mathrm{~m} / \mathrm{s}$ \\
\hline 18 & B & $\varangle 11 \quad \square \quad \square$ & $0^{\circ}$ & $20 \%$ & Yes & $54 \mathrm{~m} / \mathrm{s}$ \\
\hline 19 & B & $\Delta \square \quad \square 1 \square \Delta$ & $0^{\circ}$ & $33 \%$ & Yes & $51 \mathrm{~m} / \mathrm{s}$ \\
\hline 20 & B & $\square \perp D$ & $0^{\circ}$ & $47 \%$ & Yes & $80 \mathrm{~m} / \mathrm{s}$ \\
\hline 21 & B & $\triangle I \square \square \square I D$ & $0^{\circ}$ & $26 \%$ & Yes & $62 \mathrm{~m} / \mathrm{s}$ \\
\hline 22 & B & $\Delta \square \square \square \triangleright$ & $0^{\circ}$ & $40 \%$ & Yes & $57 \mathrm{~m} / \mathrm{s}$ \\
\hline 23 & B & $\triangle I \square \square$ & $0^{\circ}$ & $13 \%$ & Yes & $46 \mathrm{~m} / \mathrm{s}$ \\
\hline 24 & B & $\triangleleft \square \square \square \square \square$ & $0^{\circ}$ & $47 \%$ & Yes & $64 \mathrm{~m} / \mathrm{s}$ \\
\hline 25 & B & $\square D$ & $0^{\circ}$ & $73 \%$ & Yes & $74 \mathrm{~m} / \mathrm{s}$ \\
\hline 26 & B & $\square \square \square \square$ & $0^{\circ}$ & $33 \%$ & Yes & $68 \mathrm{~m} / \mathrm{s}$ \\
\hline 27 & B & $\triangle \square \square \square$ & $0^{\circ}$ & $40 \%$ & Yes & $69 \mathrm{~m} / \mathrm{s}$ \\
\hline
\end{tabular}


Table-3

Result of Flutter Analysis

\begin{tabular}{|l|l|l|}
\hline Span Length & \multicolumn{1}{|c|}{$1,250+1,250+1,250 \mathrm{~m}$} \\
\hline Natural & Bending 1st-symm. & $0.055 \mathrm{~Hz}$ \\
\cline { 2 - 3 } Frequency & Torsion 1st-symm. & $0.097 \mathrm{~Hz}$ \\
\hline $\begin{array}{c}\text { Flutter Onset } \\
\text { Wind Speed }\end{array}$ & Single Plate & $34.54 \mathrm{~m} / \mathrm{s}$ \\
\cline { 2 - 3 } & Slotted Box & $84.18 \mathrm{~m} / \mathrm{s}$ \\
\hline
\end{tabular}



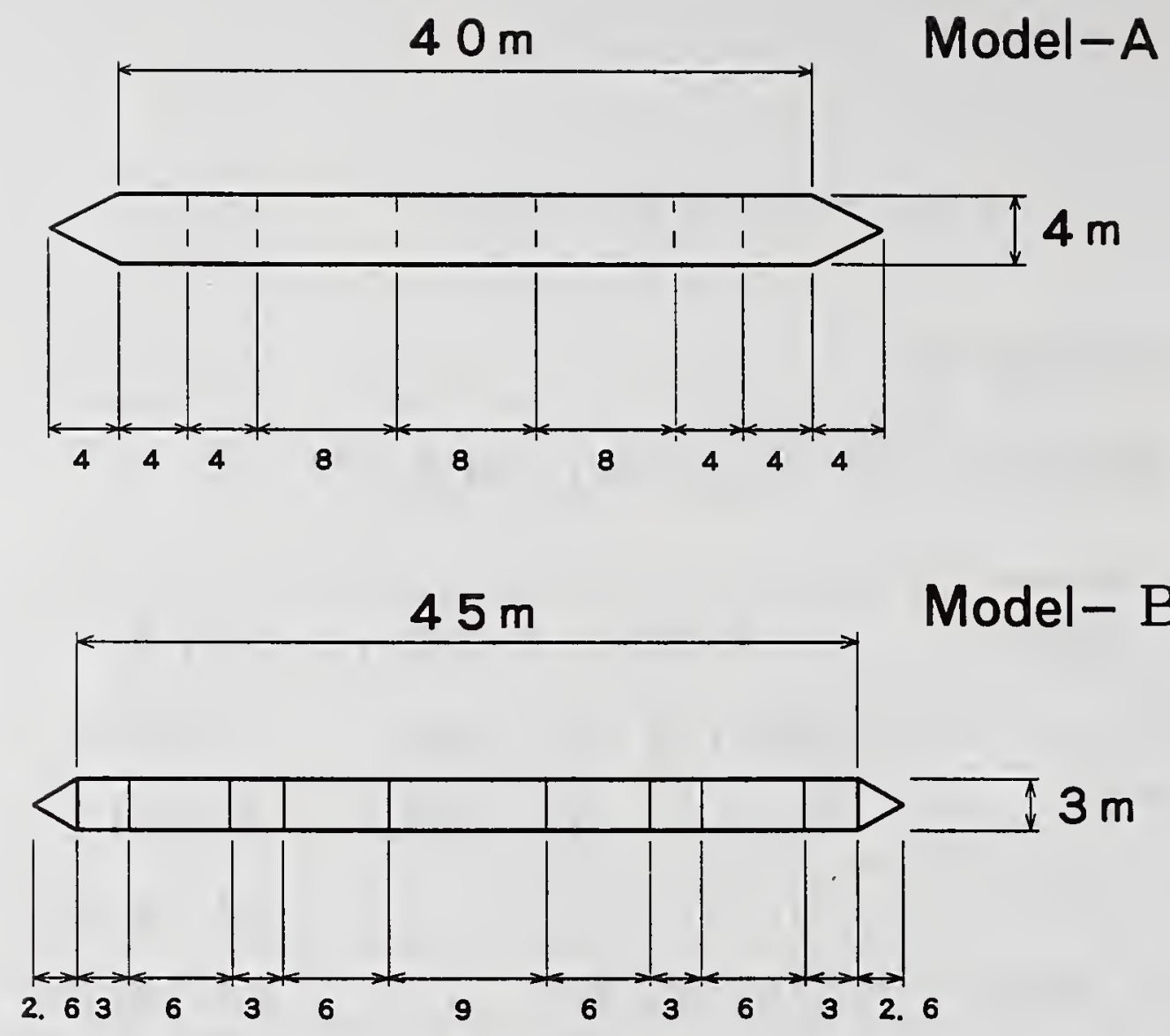

Lines in box show segment of test model

Figure-1 Cross Section of Girder

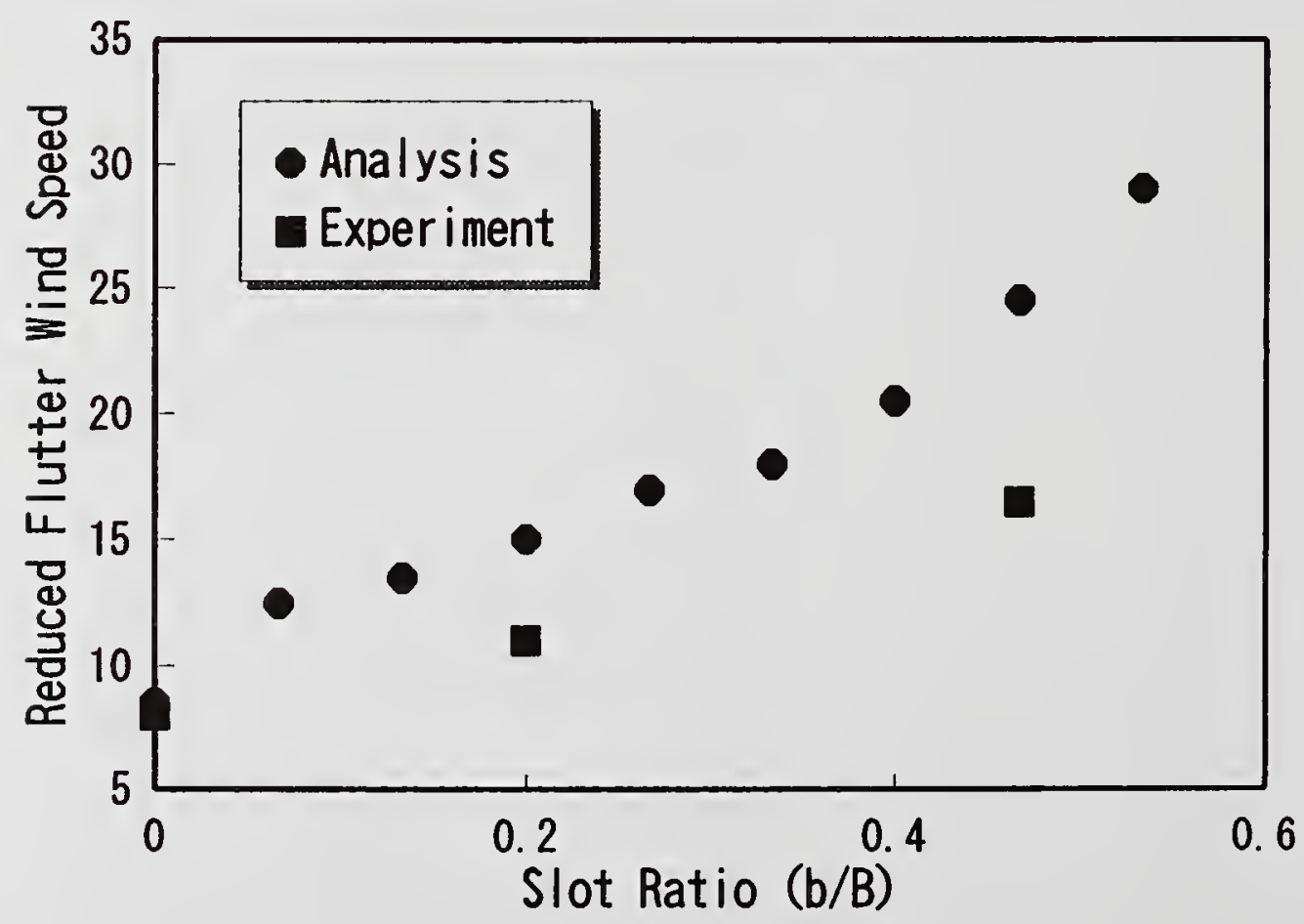

Figure-2 Result of Flutter Analysis 


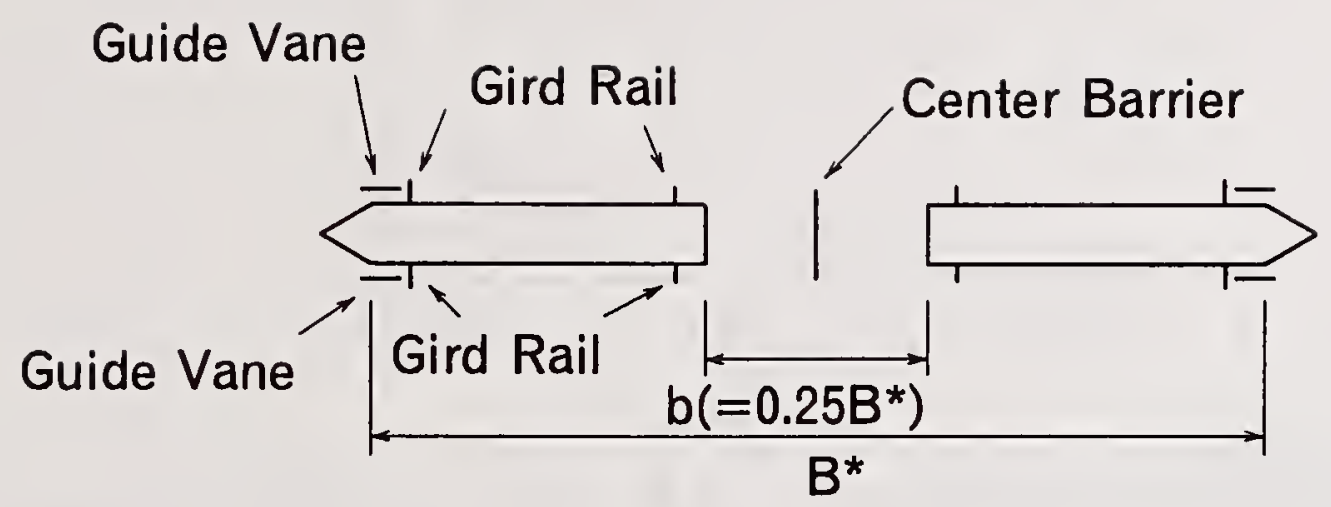

Figure-3 Tested Devices 


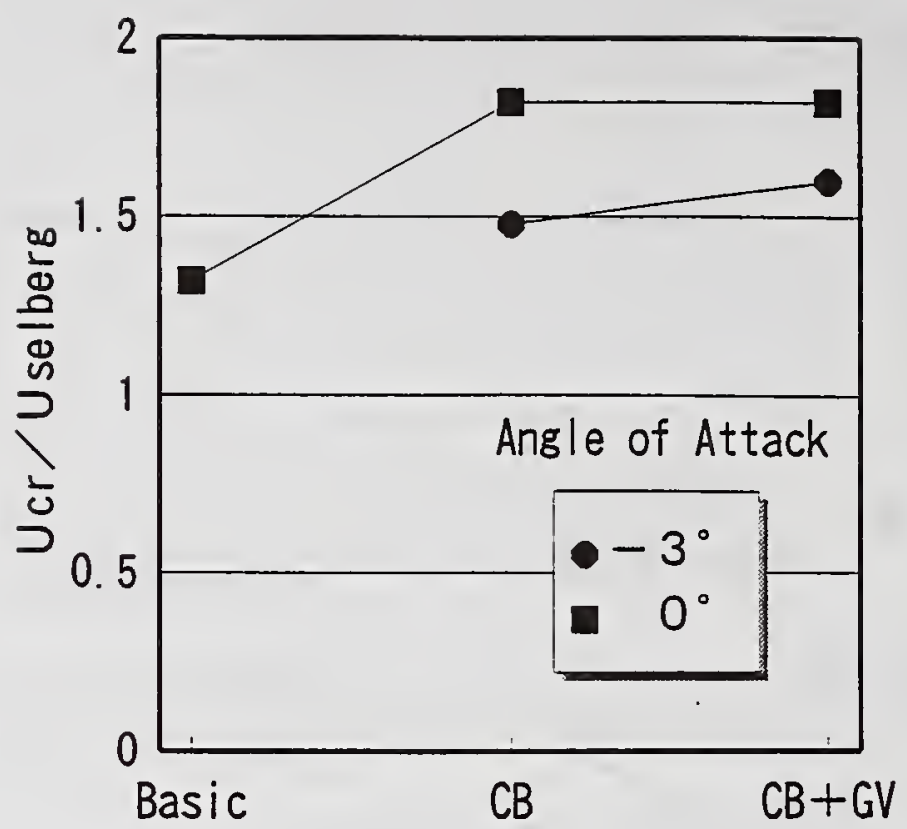

Figure-4 Effect of Tested Devices

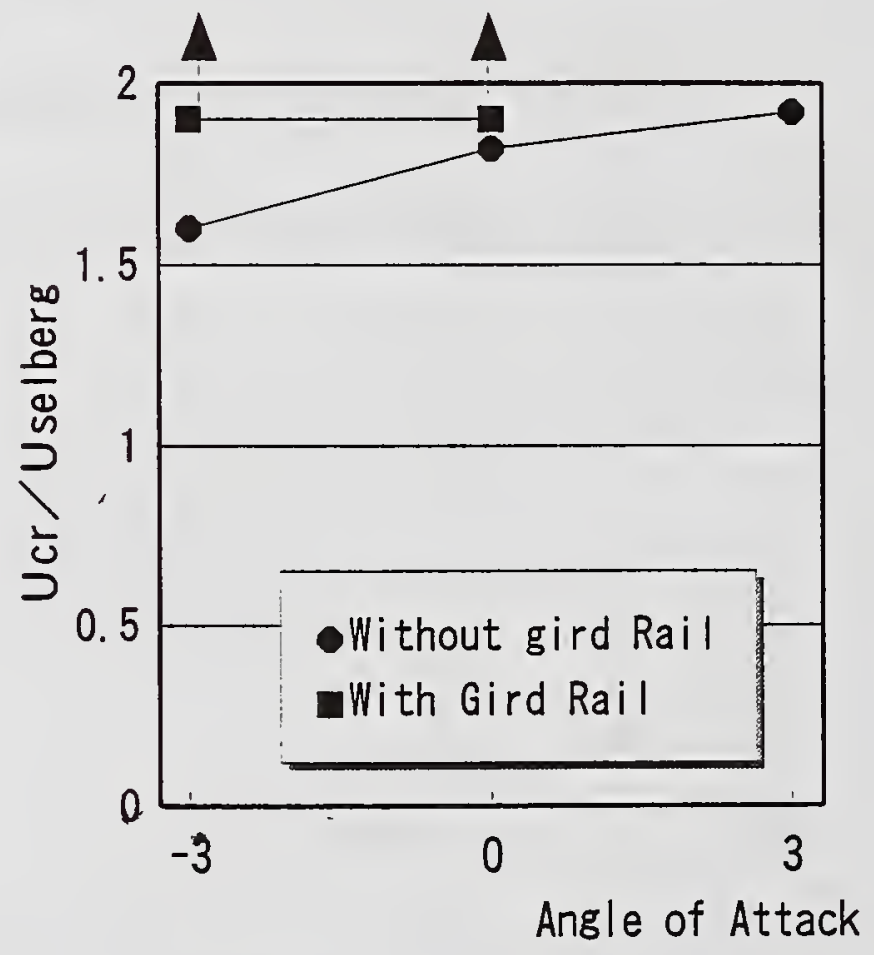

Figure-5 Effect of Gird Rails at the Bottom Deck 

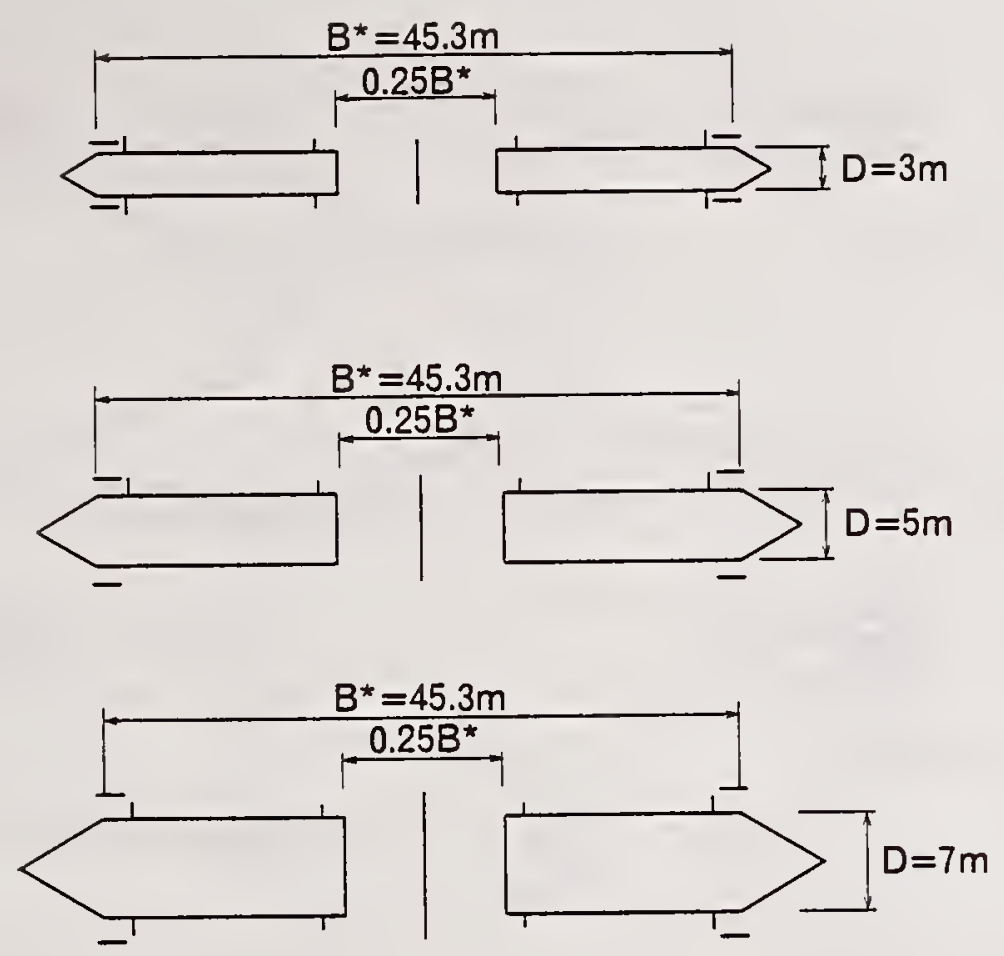

Figure-6 Cross Section Considered

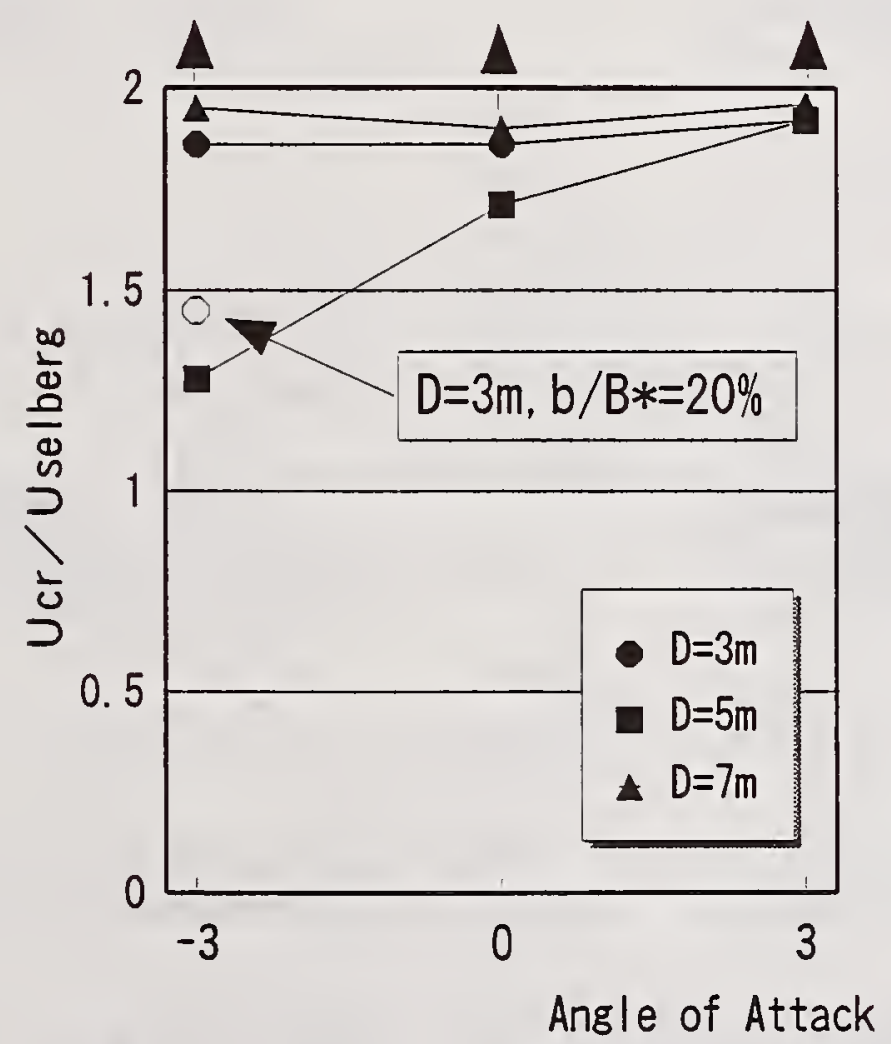

Figure-7 Effect of Gireder Depth and Slot Width 

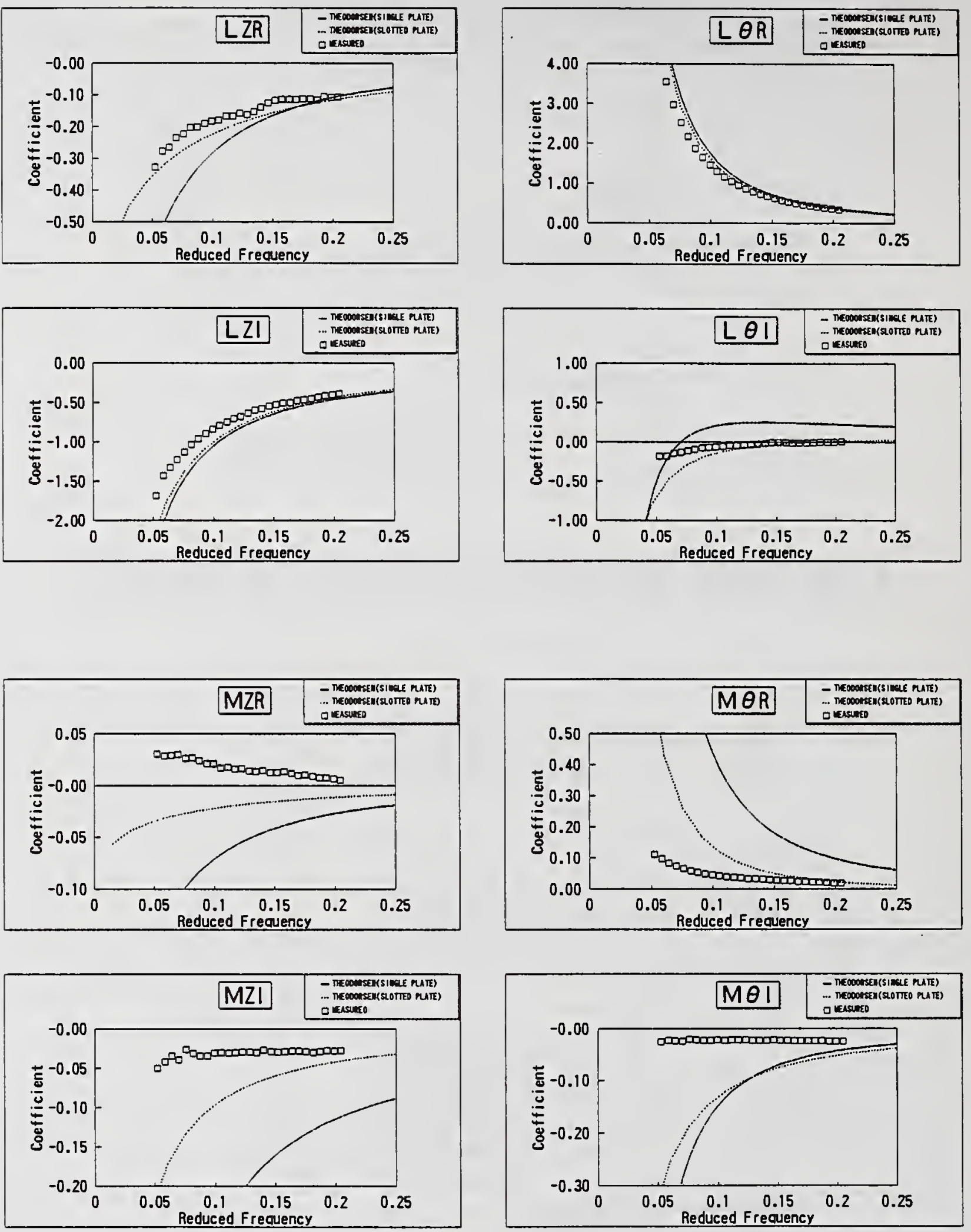

\section{Figure-8 Cofficients of Unsteady Aerodynamic Forces}




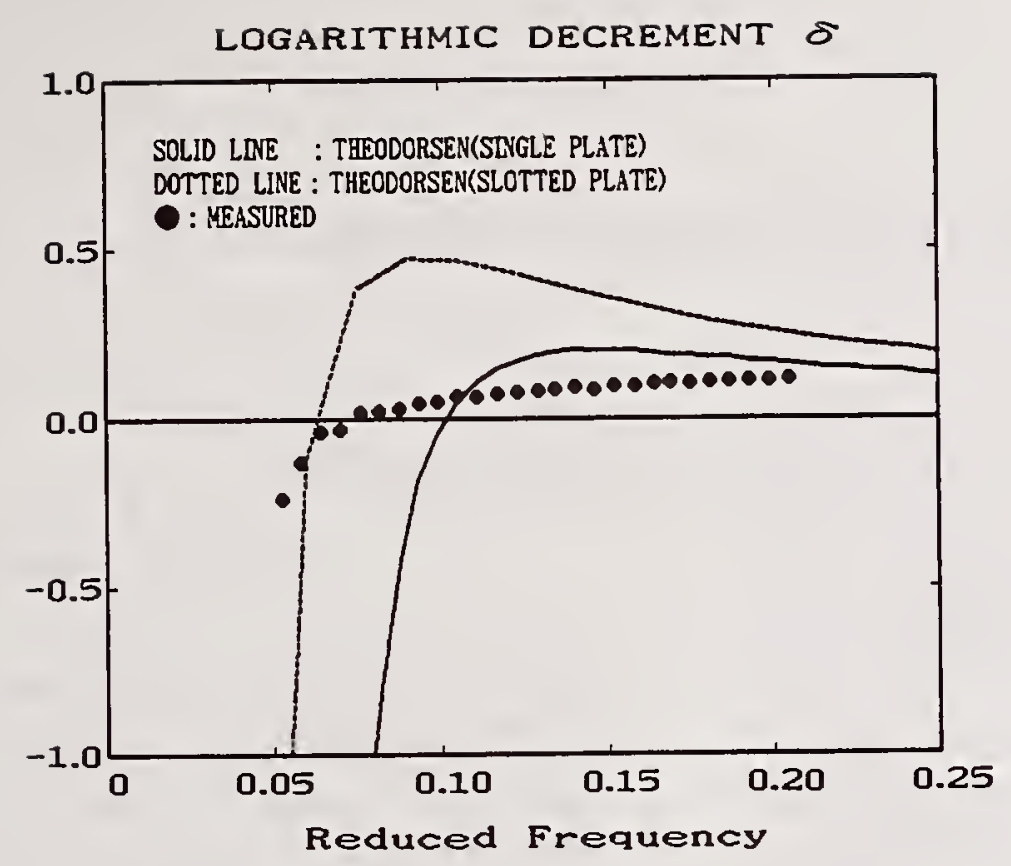

\section{Figure-9 Calculated Aerodynamic Damping}

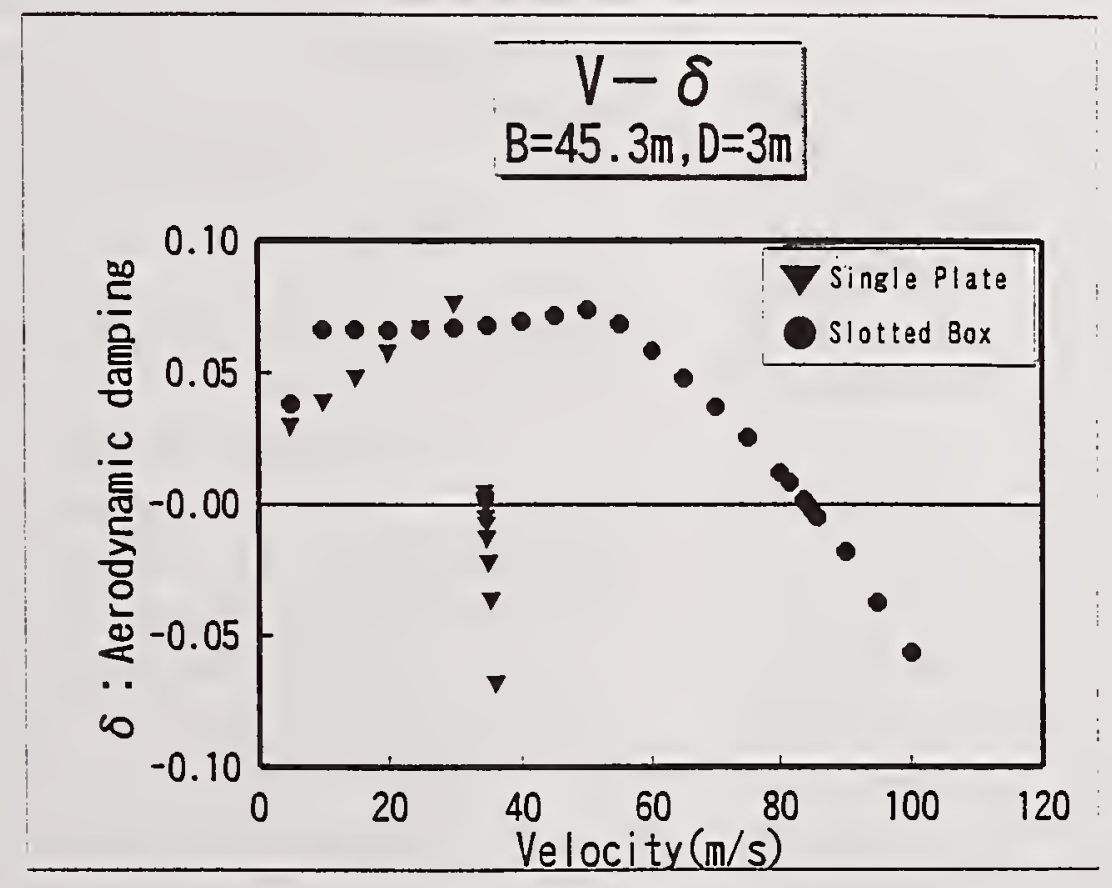

Figure-10 Result of Flutter Analysis 



\title{
Wind Engineering Research in the United States
}

\author{
by
}

\author{
Ahsan KAREEM ${ }^{1}$ and Eleanore SABADELL ${ }^{2}$
}

\section{INTRODUCTION}

This paper summarizes wind engineering research at various institutions in the U.S. Most of the information has been derived from the papers presented at the Sixth and Seventh U.S. National Conferences held in 1989 and 1993 at Houston and Los Angeles, respectively, the Ninth International Conference on Wind Engineering held in 1995 at New Delhi, and Hurricanes of 92 in Miami. The research activity is discussed here under the following topics:

1. Bluff Body Aerodynamics and Unsteady Load Effects

2. Performance of Building Envelope

3. Damage Control and Mitigation

4. Random Data Analysis, Modeling and System Identification

5. Tall Buildings and Engineering Structures

6. Mitigation and Control of Structural Response

7. Bridge Aerodynamics and Aeroelasticity

8. Knowledge-Based Expert Systems and Computational Wind Engineering

9. Hurricane Wind Speeds, Regionalization of Extreme Winds, Vortices and Cyclonic Winds

10. Wind Engineering Research Applications

\section{BLUFF BODY AERODYNAMICS AND UNSTEADY LOAD EFFECTS}

Over the past several decades, much attention has been focussed on the aerodynamics of streamline bodies; however, our knowledge of the aerodynamics of sharp-edged bluff bodies in turbulent boundary layers is far from complete. Efforts in this direction are in progress at several institutions, e.g., University of Notre Dame, Colorado State University, Clemson University, University of Minnesota, Virginia Polytechnic Institute, Johns Hopkins University and Florida Atlantic.

The various research topics undertaken in the area of bluff body aerodynamics involve extensive measurements of the pressure field around prisms, cylinders and bridge deck sections. These studies have examined the influence of scale and intensity of turbulence on pressure fluctuations. Measurements and analyses of the space-time structure of random pressure fields and area-averaged loads acting on the surface of prismatic and cylindrical bodies of different aspect ratios, exposed to simulated turbulent or turbulent boundary layer flows, have helped to improve our understanding of the complex fluid-structure interactions.

\footnotetext{
' Professor, Department of Civil Engineering, Notre Dame University

${ }^{2}$ Director, Natural and Technological Hazards Mitigation Program, National Science Foundation
} 
Several wind tunnel facilities in the U.S. have been involved in the development of measurement schemes to monitor unsteady load effects on such bluff bodies. These include both measuring fluctuating integral or local loads on buildings and bridge models and similar measurements on the full-scale structure. The measurement schemes include area-averaged pneumatic manifolding schemes, ultra-sensitive high frequency force balances, and second generation force balance to account for multiple level force measurements. The use of high speed scanning systems to monitor a large number of pressure taps are being developed that have the potential of replacing high sensitivity force balances. The senior writer has, in addition to the preceding schemes, utilized piezoelectric films to monitor area averaged loads, but the complexity of installation and the film's sensitivity to temperature, in addition to pressure, has limited its applications.

\section{PERFORMANCE OF THE BUILDING ENVELOPE}

Several institutions in the U.S. are actively involved in researching the structural resistance to wind hazards. These institutions include: Texas Tech University, Texas A\&M University, Clemson University, the University of Florida, Universities of Missouri at Columbia and Rolla, University of Notre Dame, University of Washington, Colorado State University, Johns Hopkins University, State University of New York at Buffalo, University of Hawaii, Wind Engineering Research Council, Roofing Industry Research Institute, Lawrence Livermore Laboratory, Glass Industry, Underwriters Laboratory, and Model Building Codes. The research effort spans areas concerning documentation of damage from past disaster studies to performance of building envelopes, i.e. cladding, roofing and glazing, and quantification. A further development of the research topics in structural glazing, cladding, and curtain walls and roofing follows.

Efforts to better design and to improve the performance of structural glazing, cladding and curtain walls are taking place at several academic institutions, within the glass industry, and among curtain wall consultants. Problems with performance of such systems are associated with the special nature of hurricane winds, being turbulent, sustained, varying in direction, and are often containing wind-borne debris. Measures to improve the performance of glazing in these respects are being investigated to ensure integrity of the building envelope following impact from wind-borne debris and the subsequent repetitive action of wind gusts. For the application of repetitive wind pressure with desired intensity and temporal characteristics on a portion of cladding, pneumatic chambers are being utilized. The University of Missouri at Rolla and Texas Tech are involved in glass studies, whereas Clemson University is pursuing both envelope and roofing studies.

Some attention in research has also been devoted to sealant performance. While previous studies had indicated that sealants are capable of resisting cyclic loadings, current studies have been considering their performance under the joint effects of cyclic loading and environmental factors. A joint research effort between Texas Tech University and Colorado State University, called Cooperative Research Program in Wind Engineering (CPWE), has investigated the failure strength of sealants under random wind loading. Still, while improvements in 
glazing and cladding quality are emphasized, researchers insist that integration of the designs of glass, mullions, frames, and frame anchorage would improve overall cladding performance.

Most of the studies concerning structural roofing have been initiated following major U.S. hurricanes in which it was observed that the primary failure of roofs during such extreme events occurred near roof corners and ridges. Wind tunnel studies, coupled with post-disaster investigation and full-scale measurements have proven to be vital tools in developing better roof designs. In one study, an analysis of hurricane damage was used to determine the best roof design under hurricane conditions and the impact of slope on roof performance. Another study, following the failure of classrooms in Westem Samoa in 1992, utilized wind tunnel simulations to investigate the use of "parasol" roofs, which leave an opening of $10 \%$ of the wall height at the top of the wall to reduce uplift wind forces and improve indoor comfort by venting hot air. Some work has also been done in the area of fatigue characteristics of roof pressures, using the rainflow count method as opposed to the upcrossing method to observe the characteristics of these fatigue characteristics.

Post-disaster studies have also been useful in determining the negative aspects of roofing structures, pointing out the need to fasten metal edge flashing, copings, gutters, aggregate, and rooftop air conditioners and equipment which may be ripped from the roof damaging it or becoming wind-borne missiles themselves. In one instance, a local filtering technique using the Haar function was applied to investigate the relationship between the approach flow and the dislodging of loose-laid roof pavers. Future roofing studies at Clemson will focus on measurements of flow over the roofs of scale models in a boundary layer wind tunnel using a three component fiberoptic laser Doppler anemometer system.

Most of the interest in low-rise building testing and codes has been spawned by the destructive path of the recent U.S. hurricanes, e.g. Andrew, Hugo. Based on the observations of engineers during the aftermath, suggestions have been made on the improvements to low-rise buildings, which were neglected in most engineering study until now. Many wind tunnel simulations are underway to develop improvements in building design to be incorporated into building codes. One study at Clemson utilized a device, BRERWULF, to apply fluctuating pressures to cladding panels to study its effects under loading. Current research at the University of Notre Dame will also turn toward the development of a dynamic wind load simulator to investigate the performance of building components and systems under dynamic space-time variation of loads. Such tools were used to develop retrofit roofs to withstand severe winds and improve cladding so it may better function as a structural resistance and load path. Recent studies stress the improvement of the building envelope, consideration of increased internal pressures due to envelope rupture, and the need for retrofit measures to improve the connections on existing structures.

While some research projects have devoted themselves entirely to roofing, low-rise building tests, or cladding tests, one joint project has undertaken investigations of all three topics and others, thus warranting appropriate attention. A joint research effort Texas Tech University (TTU) and Colorado 
State University (CSU), CPWE, as mentioned before, has developed a five year program funded by the National Science Foundation to investigate various topics in wind engineering, of which include areas of cladding, roofing, and low-rise structure testing. TTU possesses a field laboratory, WERFUL (Wind Engineering Research Field Laboratory), established in 1987, ideally suited for the study of low-slope roofing systems and the measurement of wind speeds and the associated wind-induced structural response of a one story test building. Not only has WERFUL proven to be a source of data for the study of single-ply membrane roofs, but it has also proven to be a vital tool in determining the average wind pressure acting on a roof purlin and the wind pressures above and below loose-laid concrete pavers over an adhered single-ply membrane roof covering. WERFUL has also been used to measure wind-induced pressure coefficients across the building centerline and the internal pressure coefficients for no opening, static openings of $1 \%, 2 \%$, and $5 \%$ and sudden openings of $2 \%$, providing insight into the increased internal pressures following the rupture of the building envelope. All this data has gone on to provide a basis for the development of analytical models for the stochastic modeling of wind speeds and the determination of wind-induced pressures and admittance functions of the modified quasi-steady theory. Other work has also been devoted to structural sealants, the details of which were mentioned earlier, as well as information on other topics which will be alluded to in the appropriate sections.

\section{Colorado State University's contributions to} this joint effort are mainly in the investigation of fundamental and applied topics of wind engineering using physical modeling, performed in their long-test section boundary layer wind tunnel, analytical solutions, and more recently, numerical simulations. The data collected from wind tunnel simulations at CSU may then be compared to the full-scale measurements from WERFUL at Texas Tech. In addition, CSU is also involved in cooperative research with Japan.

\section{DAMAGE CONTROL AND MITIGATION}

Several studies are focussing on efforts to control or mitigation of damage by eliminating poor design or construction practice, which emphasizes neither the provision of redundancies nor the elimination of weak links in structural systems that can lead to failure at wind speeds well below design values. Some of key items of interest include improved wind code specification, better code enforcement, learning from post disaster investigations, need for redundancy and ductility in manufactured homes, improved standards for building envelope systems, utilization of expert systems, computer graphics technology and self-help retrofit activities.

Aside from the concentrated efforts of individuals at several institutions devoted to damage control and mitigation, there are focussed group efforts to improve performance of structures under extreme wind events. The two leading examples are CSU/TTU Cooperative Program, mentioned earlier, and a program at Clemson University. A brief description of the program at Clemson is given here. Funded through the State of South Carolina and the Federal Emergency Management Agency (FEMA) the focus of this program is to mitigate wind hazards to low rise buildings. The major tasks 
include: evaluation of loads resulting from strong winds; evaluation of the resistance of enclosures; stability of low rise wood and masonry buildings; and improvement of codes; standards, and inspection practices. The project is slated to span five years, with work beginning at Clemson University in the summer of 1991 .

On a larger scale, the American Association of Wind Engineering (AAWE), formerly known as the Wind Engineering Research Council, Inc. (WERC), established in 1970, has also taken an active role in promoting wind hazard mitigation. AAWE hopes to implement a plan for legislative action that would foster the initiation of a National Wind Hazards Reduction Program. Such a program would provide support for wind engineering in the U.S. through improvement of understanding and codes, providing advanced methods for predicting wind loading, and encourage the development of new technology. AAWE also hopes to accomplish numerous tasks, among which include initiation of an active sharing of technology within the field primarily through their publication, "Wind Engineer," promotion and prioritization of wind engineering research, and leadership in learning from wind storms through post-storm data collection and analysis.

The dynamic load effects, structural reliability and risk assessment are receiving an increased attention from researchers while the need for practical application of these concepts to design is increasing. Dynamic effects are treated in codes primarily through gust factor approach, which has been the focus of concentrated effort particularly to improve our understanding of hurricane wind fields. The dynamic loads introduced by the acrosswind and torsion effects are being studied for developing simplified procedures for code applications, primarily with a reliability based format. Studies focussing on this aspect for both the low and high-rise construction are helping to provide a basis for preliminary discussions on reliability-based design.

The area of risk assessment has some basic focus on gathering data after a disaster and using such findings to develop a model to assess the risk of failure of constructed facilities and provide a quantitative measure to estimate the extent of damage under a particular intensity of wind storm. This includes damage to structure as well as building contents due to damaging storm winds and wave action. Various subcommittees in the U.S., including the U.S. Subcommittee on Natural Disasters Reduction (SNDR), have made it their goal to reduce human fatalities and suffering, environmental damage, and economic loss caused by natural disasters.

Computational schemes, through this effort, are being developed to forecast the probability and severity of hazardous events, namely hurricanes, over varying temporal and spatial scales. These schemes are based on a synergistic combination of essential ingredients of risk assessment, with the damage potential is being assessed through damage probability matrix, neural networks and fuzzy logic, as well as the use of probability trees. Artificial neural networks have been also developed to predict the damage of individual buildings. Work has been devoted to developing ways of expressing frequency, probability or level of confidence, and probability of frequency for quantifying the likelihood of an event. Fur hurricane models, features would include relations of the geophysical environment, 
including global warming, and features of the hurricane itself. Methods considered in such an analysis include the Monte Carlo simulation and the extended bootstrap simulation, as well as numerical models which predict the sea surface elevations and currents due to mesoscale processes like tides and storm surge. The overall risk assessment is also being considered in the light of projected consequences of global climate change. Studies in this area are being done at the University of Notre Dame, Clemson, Texas Tech, Texas A\&M, University of Washington, Stanford, National Institute of Standards and Technology and Johns Hopkins University.

In addition to university involvement, risk assessment has been approached by other organizations and private firms. The INEL Advanced Combined Environments Test Station (ACETS) Program hopes to develop a sound, scientific, engineering and economic basis for evaluating the ability of a building to resist wind loads and wind effects which will lead to reduced losses in wind storms. Its first goal is to establish realistic test methods for evaluating the performance of the building components, connections, and systems in severe wind storms. Then, INEL will focus on the development and improvement of assessment tools which will be used to identify key areas of building deficiency as well as identify appropriate levels of economic expenditure to upgrade construction practices or for expenditures for retrofitting. Thus a cost/benefit assessment scheme will be developed. Other groups involved in risk assessment include State Farm Fire and Casualty Co. and the Texas Department of Insurance, funding a program for Texas A\&M University.

Previous discussion of risk assessment has focused on the property damage and its relationship to the hazard. However, a society must view this topic from a holistic point of view and extend it to ascertain the impact of disasters on the socio-economics of the region. The use of "multiple-objective planning" to place non-monetary value on a damaged good or lost service as a result of disaster, stressing that losses must also be evaluated at both a regional and local level, is appropriate. Thus, through a "multiple-objective benefit-cost framework," both economic and environmental losses due to a disaster may be estimated. Such an analysis of damage would also consider several levels of impact, including geological, ecological, atmospheric, and human, through the "with-without principle." This principle considers all changes in the system that occurred with the disaster and all changes that would have occurred had the disaster not taken place. Meanwhile, the calculation of economic damages considers both the interruptions of production processes and the damages to assets. Such damages are direct damages. Secondary damages must also be assessed, which include the effects of the disaster which trigger a sudden reduction in demands for outputs within the effected region. Other considerations include those of cultural asset loss, i.e. the loss of historic sites or other sides which would be desirably passed on to future generations. While market values derived through appraisals are often used to estimate such losses, typically these losses are evaluated at a variety of different levels depending on the "significance" of the site.

\section{RANDOM DATA ANALYSIS MODELLING AND SYSTEM IDENTIFICATION}

The analysis, modeling and system 
identification of random data are very important aspects in wind engineering studies. Recent advances in stochastic analysis and modeling provide useful tools towards improved representation and interpretation of data. The studies in this area focus on time series modeling of random data, e.g., auto regressive and moving averages modeling (ARMA), estimation of frequency response of structures, identification of load effects on structures, simulation of stationary, nonstationary and non-Gaussian signals, conditional simulation and wavelet transforms. Activities under this topic are being pursued at different levels of concentration at various institutions involved in wind engineering research, e.g. Cornell University, University of Notre Dame, Johns Hopkins, Colorado State University, Princeton and Rice Universities.

Computer simulations have been developed for multiple wind pressure time series which are strongly non-Gaussian due to skewed spikiness in fluctuations and have strong cross-correlations of fluctuating features. Such simulations produce the exact sample cross-spectra as well as the auto-spectra of the target signals and have great flexibility in controlling non-Gaussian fluctuating features and some statistical properties of simulated signals, while preserving the target auto- and cross-spectral characteristics. However, this approach leads to generation of deterministic time histories that represent non-Gaussian features. Simulations of non-Gaussian features of wind pressure fluctuations under separated flow regions using higher-order spectral transformations and transient events by wavelet transforms have been performed. This approach leads to stochastic processes which represent non-Gaussian and non-stationary features, respectively. This is one of the current focuses of wind-related research at the University of Notre Dame. In the area of stationary processes, ARMA techniques have also been used in the simulation of the fluctuating component of wind and wind-induced pressures.

\section{TALL BUILDINGS AND ENGINEERING STRUCTURES}

In the area of tall buildings most of the innovations in structural system development come from industry, whereas, system response analysis, based on analytical considerations and wind tunnel studies, is generally conducted in universities (Colorado State University, CPP, Clemson, University of Notre Dame). Some of the work is focussed on research while other work is development related. In the research area, some work is still being done to refine the gust factor approach and to package it in a closed form expressions rather than the current version that utilizes plots. One such approach has been adopted in ASCE 7-95, ASCE standard minimum design loads for buildings and other structures. The quantification of alongwind, acrosswind, and torsional loads for a wide range of buildings of different cross-sections and aspect ratios is essential for developing coupled lateral-torsional analysis of buildings. The analysis is being simplified for code application at the University of Notre Dame.

The torsional response of tall buildings has also been considered, since it has been observed that the torsional response can have a great effect on the total response of the eccentric building. There may also be some contribution to the response of an eccentric building, in the way of interference effects, by adjacent buildings. Such interactions have been studied through wind tunnel simulations, observing that, while an isolated 
building experiences inherent turbulence, the same building with interference from surrounding structures was found to manifest wake excitation. Special concern has also been given to situations in which the frequency of vortex shedding from the interfering building coincided with the natural frequency of the eccentric principle building, causing torsional resonant buffeting to the principle building.

The research in the area of engineering structures includes towers, transmission lines, chimneys, which has been actively pursued in both academia and industry. For example, in the study of powerlines, researchers have attempted to estimate the electric drag coefficients used in determining wind forces on transmission line structures via numerical methods based on 2D Navier Stokes equations for viscous, incompressible, steady flow. Many studies have also devoted their efforts to improvement of instrumentation on power lines and towers for data collection and often utilize free-air wind tunnels to compare the drag coefficients estimated in wind tunnel studies with actual open air results. Furthermore, efforts are also being devoted to improved design of sign, signal, and luminare structures, which, in recent years, have failed under high winds injuring pedestrians and commuters below. Studies have utilized the data from wind tunnel studies to establish the static drag coefficients and root mean square estimates of the lift-coefficients of tapered cylinders in order to develop alternative, more aerodynamic cross-sectional shapes (e.g. octagonal) and designs capable of resisting cyclic loads in order to avoid future failures.

More recently, offshore platforms are receiving increased attention due to structural damage to deck structures and appurtenances in the Gulf of Mexico in the aftermath of Hurricane Andrew. As a result of the new breed of deepwater platforms, which are very sensitive to the gusting action of wind, focussed activity on the behavior of such platforms under the combined action of wind, waves and currents has developed. For such behavior to be studied, the wind fields surrounding such structures must be accurately modeled. The wind field, however, is not so much influenced by the form of the sea surface, but rather is sensitive to the energy loss and rate of momentum transfer due to surface friction. However, if a relationship between on-land wind characteristics and over-water wind characteristics is developed, existing on-land models may be somehow extended over the water to predict the wind fields. There are some difficulties with these attempts for spatial separations which may exceed the turbulence length scales, since the correlation function typically used by land-based structures inadequately describes the spatial structure of the wind field over the ocean. Further development and clarification of this approach is one topic for current study. The senior author is also involved in modeling the stochastic response of tension leg platforms to random wind and wave fields. In these studies, both the time and frequency domain procedures have been developed utilizing the Cray Y-MP to predict the nonlinear platform motion.

Under an Office of Naval Research (ONR) initiative entitled "Reliability of Nonlinear Ocean Structures Under Stochastic Excitation," several investigators are studying the response of ocean systems to extreme wind and other loadings. The senior author has a project concerning response statistics of ocean structures under wind, wave, and current loads. The major focus of this study 
rests upon the advancement of techniques for the determination of extreme response of moored floating ocean structures to wind, wave, and current loads. These improved techniques are then to be implemented in predicting the performance of such structures in different ocean environments and, hence, in predicting loading pattems. Particularly, the present effort will serve to quantify structural survivability and serviceability as well as prescribed motion control strategies for improved structural reliability. Other universities and institutions that are addressing wind related topics include Rutgers, Florida Atlantic, Stanford, NIST, and several Naval laboratories.

Proposed future off-shore structure investigations include improving quantification of windfield models, better modeling of shielding effects, investigation of overturning caused by uplift forces, understanding of overall wave profiles, better design for gust loading factors, and investigation of the vortex shedding-induced vibration on cranes and flare booms. Most research of this nature is being conducted by the R\&D groups of oil companies. At the university level, work is being done at the University of Notre Dame, Texas A\&M University, and University of Texas.

\section{MITIGATION AND CONTROL OF STRUCTURAL RESPONSE}

The current trend toward buildings of ever increasing heights and lighter facades has led to the construction of relatively flexible structures possessing quite low damping. As a result, the serviceability of these buildings is affected by the excessive accelerations experienced at the higher levels in wind storms which may cause considerable discomfort to the building occupants. Ever since the evolution of high-rise construction, efforts, both in industry and academia, to improve the performance of buildings have developed. Such efforts are devoted to a wide range of topics from considering alternative structural systems to aerodynamic modifications with particular emphasis on damping systems. Research in active and passive systems, which includes active mass dampers, tuned mass dampers, tuned liquid dampers and hybrid tuned liquid dampers in single and/or multiple damper configuration, is currently being undertaken. While passive damper study has investigated multiple damper configurations, the area of active dampers has considered frequency domain based on $\mathrm{H} 2$ control strategies for wind excited structures. Further research in the areas of tuned sloshing dampers is exploring the use of screens, nets, floating styrofoam beads, and baffles to increase the damping ability. Semi-active systems are also being considered in which the building motion is monitored and fed into a filter designed to represent the features of the optimally tuned damper. For example, semi-active tuned sloshing dampers may be incorporated with a feedback system, which adjusts a moveable sliding screen over a fixed screen or regulates opening vanes to achieve optimal damping. Research in both active and passive systems for wind applications is being carried out at the University of Notre Dame. Other institutions involved in active/passive systems studies include $3 \mathrm{M}$ Corporation, Colorado State University, CPP, University of Michigan and SUNY at Buffalo. The American Society of Civil Engineering has two special task committees, one has just completed a study concerning motion perception criteria and motion mitigation, another studying related to damping systems. The senior writer is chairing the task committee and it includes membership from Japan. 
The primary focus of this task committee is to address three important aspects of structural damping systems: a survey of inherent damping in buildings and bridges, the various methods of assessing damping levels from ambient data, and investigation of the different active and passive damping systems and their performance (Japanese building industry's experience). This would also require technology transfer through documentation of design procedures for various damping devices, including passive, active, or semi-active systems, utilizing fluid and viscoelastic dampers, as well as inertial systems like mass dampers.

A joint research program in structural control between several institutions from the U.S. and China concerns the full-scale implementation of passive and active control devices in the Nanjing Tower, a free-standing tower approximately $1000 \mathrm{ft}$ tall with two levels of observation decks, to minimize the effects of wind and earthquake loads. This project pools the knowledge of experts in structural, wind, earthquake, and control engineering to design, install, and evaluate the performance of the passive/active devices. The field testing and performance analysis will provide useful insight into the validity of modeling procedures involving wind-induced response of both the tower alone and with the addition of control devices, as well as, assess the adequacy of the passive tuned liquid dampers and the need for future developments.

In 1992, the National Science Foundation initiated a five-year research program on structural control for safety, performance, and hazard mitigation. The objective of this initiative was to address a number of important technological, as well as, practical issues of cross-disciplinary nature in order to forge close ties between industry, research and practice and to accelerate the process of implementation. The scope of this initiative includes the areas of earthquakes, natural and man-made hazard mitigation, controls, and structural and building systems. Typical areas of research funded by the program range from sensor technology, actuator dynamics, control concepts, damage control, uncertain and nonlinear systems, and the actions of wind and earthquakes. Several wind related projects are funded under this initiative which include sloshing dampers, the next generation of liquid dampers, and general topics in the control of wind excited structures.

Base isolation systems are also being explored in which passive energy absorption mechanisms are installed that significantly reduce the base shears felt by the building during a major event. Through such measures, the natural frequency of the structural system is shifted below those of the dominant excitation source, such as an earthquake or wind loads. Such isolators feature elastomeric rubber bearings, with or without lead cores, which support the building superstructure, allowing deflection and sustaining the shear that would result if the building were fixed during an earthquake and may be used in conjunction with viscous dampers at the top of the building. The development of such systems has relied upon investigations of building response in both wind tunnels and on shaking tables.

\section{BRIDGE AERODYNAMICS AND AEROELASTICITY}

Both theoretical and experimental studies are being conducted to improve our understanding of the interaction of turbulent winds with the cable stayed and suspension 
bridges. While theoretical analysis is focussing on the effect of turbulence on flutter speed of long span bridges, experimental work has turned toward improved modeling and quantification of aerodynamic forces, considering their sensitivity to turbulence characteristics and the geometric form of the bridge section. A thorough understanding of these effects is essential for improvements in both design and theory. Some recent studies have raised questions about the validity of some assumptions made in modeling, i.e. the validity of a taut-strip model vs. a section model. In addition, the assumption that the correlation time of excitation is short compared with the relaxation time of the dynamic system, which allows the use of the Markov property, may not be appropriate when noise is modeled properly. Proper modeling of noise insists that when fluctuations are introduced, they cannot be modeled as white noise, but instead as colored. This is an essential consideration since colored noise does indeed influence the system stability quite differently than colored noise. Section model studies are also underway which investigate the effect of modifications of the deck cross-section, including the addition of plates, streamlined deflectors, and railings, to enhance aerodynamic performance as well as insure aeroelastic stability.

A variety of theoretical studies have been initiated in hopes of developing mathematical simulations of the pressure forces acting on and excitation of bridge decks. Recent studies have focused on aerodynamic stability of bridges in buffeting and self-excited loads using flutter derivatives, vortex-induced vibration modeling of bridge decks, and the modification of linear analysis to nonlinear cases. One study has attempted to develop theoretical relations for bridge deck excitation by utilizing modifications of airfoil theory and exploiting the analogy of a streamlined bridge deck to a airfoil. In addition, the use of the Ibrahim Time Domain Method, the force oscillation method, and the system-identification technique in a single study confirm that good consistency in determining flutter derivatives may be achieved by using any of these three approaches. Researchers have now also found ways of utilizing computational wind engineering to determine the wind flow around and the forces acting on a bridge deck. Such techniques, one of which uses the 2D unsteady, incompressible, laminar, Navier-Stokes equations in a body-fitted, curvilinear coordinate system, allows designers to weed out bad bride deck designs before wind tunnel tests are applied.

Furthermore, some time has been devoted to exploring the validity of the Discrete Vortex Method, finding it to be effective in simulating flow around a suspension bridge for modest angles and a Reynolds Number of 200. Full-scale studies are also underway to validate the theoretical and wind tunnel findings. Johns Hopkins University, the Department of Transportation, and the University of Notre Dame are engaged in topics under this area. In the past, some of the work in this field has been conducted at Princeton and Colorado State University.

Future studies should be devoted to investigating length scale effects and the dynamics of the vortex formation near separation. Furthermore, a multi-disciplinary research project to investigate the effects of turbulence length scale and intensity on the aerodynamics of bridge deck sections utilizing actively generated turbulence flow fields is currently underway. The study 
utilizes active turbulence generation devices, consisting of controlled air jets and oscillating screens in a large cross-section wind tunnel to identify the effects of properly scaled turbulence on the aerodynamics of a variety of generic deck sections. The use of oscillating grids in this research allows for the simulation of turbulent length scales that cannot be produced with passive turbulence-generation techniques, while the jets add energy throughout the spectrum to supply energy that the grids are incapable of supplying and to ensure that the flows contain the appropriate fine-scale turbulence. Thus, this technique, by allowing for large models, permits the inclusion of additional deck geometric details that are often omitted due to scaling requirements. In order to determine unsteady buffeting and self-excited aerodynamic loads on the deck sections, synchronous pressure, pneumatically averaged pressure, and force measurements are collected. The study also relies upon system identification techniques to evaluate flutter derivatives by expressing equations of motion in a state-of-space form and utilizing the Gauss-Newton algorithm for minimization.

\section{KNOWLEDGE BASED EXPERT SYSTEMS (KBES) AND COMPUTATIONAL WIND ENGINEERING}

Knowledge based expert-systems can offer intelligent assistance to designers and planners in performing a vast array of tasks. Though KBES are not without their limitations, the potential applications of KBESs in wind engineering are many. They may include analysis and prediction of extreme winds, risk and damage assessment, design and synthesis, monitoring and control, urban and coastal community planning, and decision making for hurricane response. Currently most of the effort in expert system development is focussed on damage and risk assessment utilizing expert system shells. The University of Washington, Stanford, Texas Tech, National Institute of Standards and Technology and Clemson University are active in this area.

The NIST staff is developing an interactive computer program addressing the wind loading provisions of the ASCE standard 7-95. The software and the instructions for the user were developed by an expert system consultant under contract with NIST, which provided guidelines on the structure of the interactive program and assisted the software contractor in the interpretation of the standard wind loading provisions. The software was subjected to extensive verification.

Recent advances in computational fluid dynamics are noteworthy, but major challenges remain in simulating flows common to wind engineering where both the structural geometry and the flow field are complex. Initial work in CWE has been focussed on a model which has succeeded in reproducing some of the integral features of flow field but some discrepancies between numerical results and experimental data still remain. The flow field is modeled by the Navier-Stokes equations with appropriate boundary conditions. Turbulence models have been developed to simulate high Reynolds number flows that are not achievable with direct numerical simulation (DNS) due to computer limitations or to simulate a flow with the same Reynold's number similar to DNS but with less computational effort. Currently the most widely used turbulence model is the k-epsilon method, which has the advantage of lower 
computational effort, but with a lower level of accuracy. The large eddy simulation (LES) approach has emerged as a more attractive scheme which has the promise of providing improved results with reasonable computational effort. In LES, fluid motion scales larger than the filter size are resolved and solved directly, while the scales smaller than the filter size are modeled by a subgrid scale model. The most commonly used LES simulation relies on the Smagorinsky model for subgrid scale viscosity. Coherent flow structures are responsible for the large scale pressure field rather than the eddies associated with the transport of momentum and energy, therefore, a scheme that models essentially coherent structures is appropriate for wind engineering applications. It is referred to as coherent structure capturing (CSC) to distinguish it from LES. One should not expect CSC to simulate flow field characteristics that are associated with small scales. The LES for capturing of coherent structures has shown improved accuracy, upon comparison of predictions and experimental data, but not without high penalty in computational effort.

The development of different approaches are underway at various other institutions to improve our modeling capability of wind engineering related problems (e.g., Colorado State University, University of Notre Dame, Texas Tech, University of Washington, University of Arkansas and Johns Hopkins University).

\section{HURRICANE WIND SPEEDS, REGIONALIZATION OF EXTREME WINDS, VORTICES AND CYCLONIC WINDS}

Hurricane wind speeds may be quantified by measurement of the footprints of its wind field near shore and after landfall. Based on these measurements, recent studies have shown that the gust factors in hurricane wind field are higher than those presently used for extratropical storms. This is in part attributed to the movement of convective cell that introduces both nonstationarity as well as non-Gaussianity, thus precluding use of conventional analysis. On the simulation front, Monte Carlo based simulations of hurricanes, based on phenomenological models, along with historical data on the wind field and filling of hurricane, provide very useful information for design.

Alternative simulations based on empirical simulation schemes are also being studied which do not strictly account for the assumption of independence among the modeling parameters. In essence, the empirical simulation technique avoids, in a nonparametric way, the whole issue of joint probabilities among parameters by utilizing information based on actual historical data. Studies have also been conducted to compare Shapiro's model, new gust factor curve and radial profile exponent equal to 0.5 , with the ASCE 7-88 model for hurricanes into each model by feeding statistical information from previous hurricanes and seeing how well it simulates the winds experienced during the actual event, concluding that the Shapiro model, in most instances, appears to be superior to the more conservative ASCE 7-88 model. Continuous wind fields are also being computed from pressure data from previous hurricanes through the use of a finite-element representation called SAFER. The applied Research Associates, National Institute of Standards and Technology, Hurricane Research Laboratory, Wind Engineering Research Council, University of Notre Dame, University of Wyoming and University of Hawaii are involved in research concerning this topic. 
A new method, using computational fluid dynamics, for numerical simulation of the turbulent flow field around a structure with oblique wind angles based on a composite grid, has been proposed in a recent study. The method consists of a composite grid technique which connects two or more grids supported by a fortified solution algorithm to simulate 3D flow fields for various wind angles. Another numerical model of air flows created by the TTU/CSU joint research effort has produced a model capable of predicting the detailed flow field surrounding a building or other structure. The technique adopts a version of the CSU Regional Atmospheric Modeling System (CSU-RAMS) which is a nonhydrostatic compressible model designed for large eddy simulation. Other studies have applied techniques like discrete vortex methods which seem to show promise over grid based techniques.

In order to provide a better estimate of extreme winds at an ungauged site, regional zoning for extreme wind data collected at various weather stations in a large region is being developed. The applications are focussing on regional and the entire U.S. Colorado State University, Texas Tech University, University of Hawaii and National Institute of Standards and Technology are working toward development of such regional zoning throughout the U.S. The CSU/TTU joint effort has also been active in extreme wind research, updating the ASCE 7 wind speed map and investigating the sampling errors in extreme wind records.

While hurricane damage has captured the attention of the wind engineering community, there is always concern for tornado-type winds. Studies of tornado wind forces have been conducted in low-speed, open-circuit wind tunnels coupled with an attachment to provide circulation of the flow, as angular momentum is introduced by the rotating of a wire screen. Such studies have proven the necessity of introducing surface roughness, via sandpaper, to wind tunnel simulations to accurately reproduce the vortex flow, delaying the transition to multiple vortices at low swirl ratios. TTU/CSU program has also been active in this area, attempting to identify major parameters and examine scaling relations and techniques for simulation of high-wind phenomena. These efforts have produced parameters for meaningful wind tunnel simulations and developed a tornado or microbust generator. Even through such efforts, it is still difficult to study tornado effects in wind tunnels because of the frequent changes in wind speed and direction. Consequently, efforts are now being devoted to exploring the use of computational fluid dynamics to study tornado effects. Such CFD models apply the 3D, incompressible, unsteady Navier Stokes equations, integrated by the control volume procedure, with convective terms approximated using hybrid upwinding, solved on a rectangular grid system. There is, however, the need for future study of turbulence models like the k-epsilon model or the Reynolds stress model, focusing on their lack of proper information on the turbulence statistics of the tornado close to the boundary layer.

Besides research related to the effects of severe weather on infrastructure pursued at universities, efforts by the federal government to better detect and define events during these storms are conducted at NOAA's Hurricane Research Division in Miami and Severe Storm Laboratory in Norman, Oklahoma. The thrust of work at these laboratories focuses more on the 
meteorological aspects which are useful for wind engineering applications.

\section{WIND ENGINEERING RESEARCH APPLICATIONS}

One of the major objectives of research in wind engineering is to improve our understanding of the wind load effects on structures for subsequent implementation in codes and standards. So in this context the major application of research is for the development of codes. Building codes in each locality are responsible for the design and construction of buildings. Most communities across the United States adopt, in large part, one of the three model building codes: the National Building Code of the Building Officials and Code Administrators International (BOCA), the Standard Building Code, or the Uniform Building Code.

The provisions for wind loads in these model building codes are patterned after the ASCE standard on Minimum Design Loads for Buildings and Other Structures, ANSI/ASCE 7-93. Recently, a major effort has been completed toward the next revision of ASCE 7-93. A number of university researchers, practicing engineers and code officials have been working together to draw information from recent research findings for inclusion in the revised version of ASCE standard.

\section{CONCLUDING REMARKS}

In this article, an attempt has been made to summarize the wind engineering related activities in the U.S. Additional details can be obtained by contacting individuals in the several institutions mentioned in this paper.

The author sincerely regrets an inadvertent omission of any institution from the different wind related activities listed in this paper. Most of the information has been drawn from the bibliography and through personal contacts.

\section{ACKNOWLEDGMENTS}

The authors are deeply indebted to Ms. Tracy Kijewski for her assistance in the preparation and typing of this manuscript. The senior author was supported in part by a NSF Grant \# CMS95-22145.

\section{BIBLIOGRAPHY}

1. Hurricanes of 1992, "Andrew and Iniki One Year Later," Proceedings of a Symposium Organized by The American Society of Civil Engineers (Preprints).

2. Hurricane Alicia: One Year Later, Proceedings of the Specialty Conference, ASCE, 1985 (A. Kareem, editor).

3. Proceedings of the Sixth U.S. National Conference on Wind Engineering, Vol. I \& II, 1989 (A. Kareem, editor).

4. Proceedings of the Seventh U.S. National Conference on Wind Engineering, Vol. I \& II, 1993 (G.C. Hart, editor).

5. "Wind and the Built Environment," U.S. Needs in Wind Engineering and Hazard Mitigation, Panel on the Assessment of Wind Engineering Issues in the U.S., National Academy Press, Washington, D.C., 1993.

6. Kareem, A., "Recent Advances in Wind Engineering: Part I," Journal of Wind Engineering and Industrial Aerodynamics, Vol. 36, 1990.

7. Cermak, J.E., "Recent Advances in Wind Engineering: Part II," Journal of 
Wind Engineering and Industrial

Aerodynamics, Vol. 36, 1990.

8. Howe and Cochme, "Natural Hazard

Damage Handbook," Colorado State

University, 1991.

9. "Cooperative Program in Wind

Engineering," Inaugural Meeting of

the International Wind Engineering

Forum, Tokyo, 1994.

10. "Building an International

Community if Structural Engineers,"

Proceedings of Structures Congress

XIV, vol.2, ASCE (S.K. Ghosh \& ).

Mohammodi, editors).

11. "Engineering for Wind Hazard

Mitigation," Project Summary by the

Wind Engineering Research Council,

Inc., National Science Foundation

Form 1358, 1994.

12. "Wind Loading and Capacities of

Components, Connections and

Systems" (G229).

13. Summary Papers for the Ninth

International Conference on Wind

Engineering, 1995 (Krishna,

Chairman).

14. Schechter, M.M., Schechter, E. and

Simiu, E., "Developmental

Computer-Based Version of ASCE

7-95 Standard Provisions for Wind

Loads, " NIST Technical Note 1415 , 1996. 


\title{
Estimation of relevant internal pressure and wind loads on cladding
}

\author{
by \\ H. Okada and L. Kong \\ Aerodynamics Division, Structural Engineering Department \\ Building Research Institute ,Ministry of Construction
}

\section{ABSTRACT}

Wind loads on claddings are estimated by the difference between external pressures and internal pressures on them. Therefore, to determine both the building external and internal pressures accurately is very important. In various building regulations and standards, the design wind loads on cladding are defined as the difference between maximum external and maximum internal pressures (in a sense of the absolute values). This comes from the assumptions that external and internal pressures have different signs from each other and the correlation between them is perfect. However, external and internal pressures do not always have different signs and the correlation is not always likely to be perfect either. So far, the assumptions resulted in either over-estimation or under-estimation of wind loads on cladding. In spite of this situation, there has been relatively very little attention to the internal pressure. The effect of correlation between the internal and external pressures on cladding has not been investigated at all. In this study, the effects of the internal pressures and correlation between external and internal pressures on wind loads on claddings, are investigated. Wind tunnel tests are conducted in a simulated natural wind conditions by using building models which have various combinations of openings. From the tests, the difference in the wind load estimation between the ordinary method and the accurate methods is found to be quite large. A new concept of gust factor for the building internal pressures is introduced to provide the accurate design load.

KEYWORDS: Wind load on cladding, Internal pressure, Correlation between internal and external pressure

\section{INTRODUCTION}

Each year, strong windstorms cause serious damages in the world. Damages caused by Typhoon 9119, 9313 and etc. in Japan, Hurricane Andrew, Iniki and etc. in USA are still fresh in our memory. Looking back on the building damages, almost all are on the external elements such as roofings, window glasses, external walls and roof structures, etc. Damages on the claddings produced large increasing of internal pressure and lead the serious collapse of the building. It also produced very dangerous flying debris. Such damages warn us to pay more attention on wind resistant design of claddings.

The purpose of this work is to examine the wind loads on cladding which are formulated by a combination of external and internal pressures. Internal pressures are made from the external pressures through various openings on external elements of the building. The openings on a building can be classified as two kinds, the dominant type and leakage. A theoretical model is set up to obtain the characteristics of internal pressures through small openings. The model is verified by a speaker test. To obtain experimental data of wind loads on cladding, a wind tunnel test is conducted in a simulated natural wind. In the test, internal, external pressures on claddings and their correlation are measured. Wind loads on claddings are calculated by the ordinary method and the accurate method from the experimental data. The results are compared with each other.

\section{THEORY OF WIND LOAD ON CLADDING}

\section{Mean wind internal pressure}

It is well-known that mean wind pressure can be estimated by the mass flow balance in and out of the building. For a building with a number of $\mathrm{N}$ openings, the equation can be written as:

$$
\sum_{j=1}^{N} Q_{j}=0
$$

From which a relation between the external and internal pressures is established:

$$
\sum_{j=1}^{N} \operatorname{sign}\left(P_{e j}-P_{i}\right)\left(A_{j}\left|P_{e j}-P_{i}\right|^{\frac{1}{2}}\right)=0
$$

The sign of each term depends whether it is inflow or outflow. In the equation, power index of $1 / 2$ becomes 1 if sizes of the openings are very small and the effect of viscosity can not be 
neglected.

\section{Fluctuating component of internal pressure}

The relation of the fluctuating components of external and internal pressures was developed from the Bernoulli equation based on the internal flow condition inside the opening by $\mathrm{Liu}$ and Saathoff[1] without considering the viscous effect. The relationship can be written by the following Helmholtz model:

$$
\frac{\rho L_{e} V_{0}}{n K A P_{a}} \frac{d^{2} P_{i}}{d t^{2}}+0.5 \rho \frac{V_{0}^{2}}{n^{2} K^{2} A^{2} P_{a}^{2}} \frac{d P_{i}}{d t}\left|\frac{d P_{i}}{d t}\right|+P_{i}=P_{e}
$$

Where,

$L_{e} \quad=$ effective opening length

$$
\text { ,which is defined as: } L_{e}=L_{0}+\sqrt{\frac{\pi A}{4}} \text {. }
$$

$L_{0} \quad=$ length of opening

$P_{i}=$ internal pressure

$P_{e}=$ external pressure

$\rho=$ air density

$K$ orifice discharge coefficient

$n$ =poritropic exponent

$P_{a}$ atmospheric pressure

$A$ = opening area

$V_{0}=$ volume of building

A very important parameter, the Helmholtz frequency can be written as: $f=\frac{1}{2 \pi} \sqrt{\frac{n K P_{a} A}{\rho L_{e} V_{0}}}$,

which determines largely the characteristics of the wind induced internal pressures. However, for long and narrow openings, the viscous effect should be a dominant factor. In order to take into consideration of the viscous effect, a similar relation as the above Helmholtz model is developed from the Navier-Stokes equation for the flow inside the opening:

$$
\frac{\rho L_{e} V_{0}}{n K A P_{a}} \frac{d^{2} P_{i}}{d t^{2}}+0.94 \rho \frac{V_{0}^{2}}{n^{2} K^{2} A^{2} P_{a}^{2}} \frac{d P_{t}}{d t}\left|\frac{d P_{t}}{d t}\right|+P_{f}=P_{e}
$$

It can be easily seen that the only difference between the two equations is the damping coefficient of the second term, which is now 0.94 [2] instead of 0.5 in the original one. Therefore, the effect of adding the viscous effect is the same as to increase the damping, i.e., a loss of energy from the flow.

Verification of the theory is done by a speaker system, which is used to generate external pressure functions in a sinusoidal form at different amplitudes and frequencies. A box with a dimension of $90 \mathrm{~mm} \times 90 \mathrm{~mm} \times 55 \mathrm{~mm}$ was used to simulate the room in which one wall can be replaced by plates with different sizes of openings. Pressure transducers are connected to both the speaker and the box. During the tests, the box was fixed to the speaker, so pressures from inside and outside of the box, which represent respectively the room internal and external pressures, can be measured and recorded simultaneously by a data acquisition system. Several test pieces with different thicknesses and different sizes of openings were used. Here results for 3 of them with rectangular shape, which are listed in table 1 , are presented.

Figure 1 shows $P_{i} / P_{e}$ between the theory and experiment at $P_{e}=78 \mathrm{~N} / \mathrm{m}^{2}$ for R10L. The two theoretical results are for the two damping coefficients 0.5 and 0.94 . The Helmholtz frequency is about $52 \mathrm{~Hz}$. Experimentally, the figure shows a roughly $15 \%$ amplification of the internal pressure comparing to the external pressure around the Helmholtz frequency. Apparently the viscous effect should be included as the result without the viscous term shows a much larger value than the experimental data. However the present theory obtained a very close solution.

Figure 2 is another example of $P_{i} / P_{e}$ between the theory and the speaker test for R05L. It is interesting to see that the peak of $P_{i} / P_{e}$ disappeared completely in the test. This means that once the opening is very small, there is no need to worry the occurrence of the Helmholtz resonance. Obviously, even with the viscous effect the results of the theory and experiment are totally different. It is believed that flow physics in the opening has changed and the effect of viscosity is not only confined to a thin layer near the wall but the whole flow region. 
Another important parameter regarding to the dynamic characteristics of the opening is the phase difference between the internal and external pressures. Figure 3 shows the results for R20L. The theoretical solutions on the figure are obtained with the damping coefficient 0.94 . Though there is some difference when $f>200$ between the experiment and theory, they generally show a good agreement between the present

Table 1: Test models

\begin{tabular}{|l|l|l|}
\hline models & openings & thickness \\
\hline R05L & $0.5 \mathrm{~mm} \times 10 \mathrm{~mm}$ & $15 \mathrm{~mm}$ \\
\hline R10L & $1.0 \mathrm{~mm} \times 10 \mathrm{~mm}$ & $15 \mathrm{~mm}$ \\
\hline R20L & $2.0 \mathrm{~mm} \times 10 \mathrm{~mm}$ & $15 \mathrm{~mm}$ \\
\hline
\end{tabular}

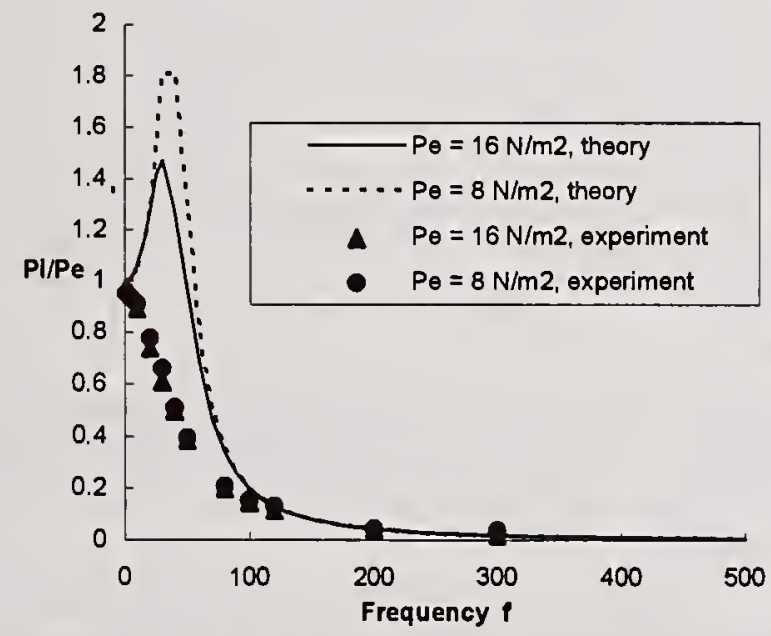

Figure 2: Comparison of $P_{i} / P_{e}$ ratio between theory with damping coefficient $=0.94$ and experiment for R05L

\section{Wind load on cladding}

As pointed out in the previous sections, the total theory and experiment. It should be pointed out that if the old damping coefficient 0.5 is used, a much larger phase value, thus a larger deviation from the experiment would be obtained. The sudden phase decrease at $\mathrm{f}=300$ shown in the graph is considered to be due to the speaker resonance at the vicinity of this particular $f$ value, which resulted in the irregularity of the signal.

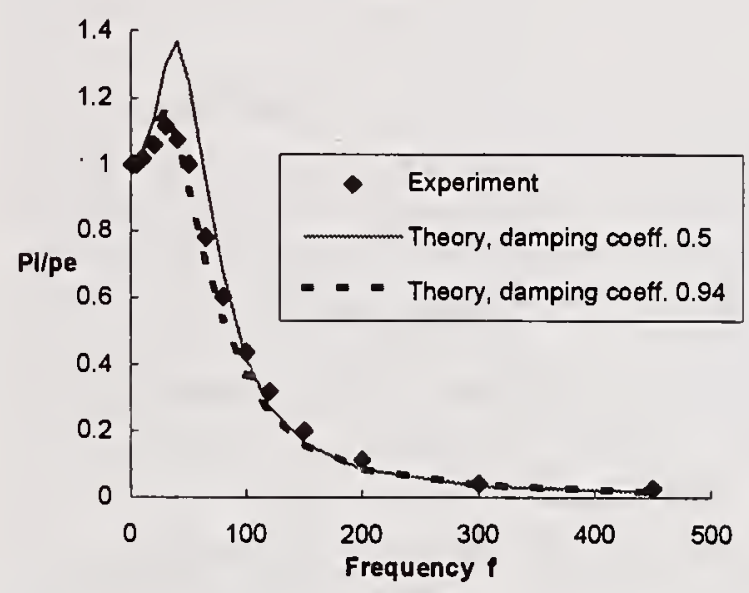

Figure 1: Comparison of $P_{i} / P_{e}$ ratio between theory and experiment for R10L, $\mathrm{P}_{\mathrm{e}}=75 \mathrm{~N} / \mathrm{m}^{2}$

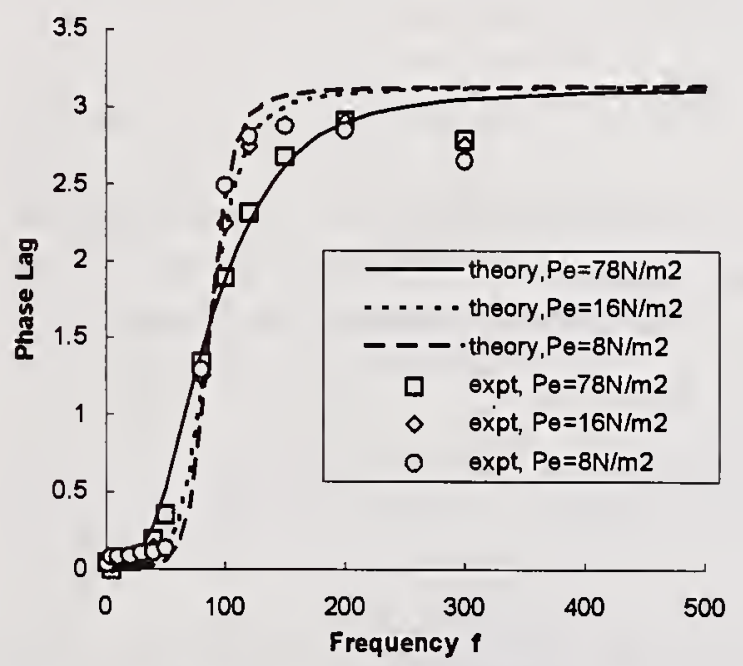

Figure 3: Phase difference between the internal and external pressures for R20L with $C_{0}=0.94$, experiment and theory with 0.94 damping coefficient

loads on cladding depend on not only the absolute internal and external pressure values but also the correlation between them. However almost all standards 
and regulations in the world give the design wind loads on cladding as the following equation or eqations based on a similar concept.

$F_{d}=G_{e} \bar{P}_{e}-G_{i} \bar{P}_{i}$

Where,

$F_{d}=$ design wind loads on cladding

$G_{e}=$ gust response factor of the external wind pressure

$G_{t}=$ gust response factor of the internal wind pressure

$\bar{P}_{e}=$ mean external wind pressure

$\bar{P}_{i}=$ mean internal wind pressure

This formula comes from the idea that the signs of external and internal pressures are different from each other and maximum loads on cladding are given by the difference between the maximum external pressure and the maximum internal pressure. However, Okada and Chino ${ }^{[3]}$ indicated in their theoretical analysis that this is not accurate because the signs of external and internal pressures are not always different from each other. Furthermore it does not take the correlation of the internal and external pressures into consideration. If the external and internal pressures are not in perfect correlation, this formula would result in either overestimation or under-estimation of wind loads. In their analysis, they proposed a new concept of internal pressure gust factor in the sense that if $G_{i} \vec{P}_{i}$ is calculated in the following way, equation (5) would give the real maximum loading.

$G_{i} \bar{P}_{i}=\bar{P}_{i}+\bar{P}_{e}\left(G_{e}-1\right)-\operatorname{sign}\left(\bar{P}_{e}-\bar{P}_{i}\right) g_{f} \sigma_{f}$

Where,

$g_{f}=$ peak factor for difference between the external and internal pressures

$\sigma_{f}=\mathrm{rms}$ of difference between the internal and external pressures

and,

$\sigma_{f}=\sqrt{\sigma_{e}^{2}+\sigma_{i}^{2}-2 \sigma_{e i}}$

Where,

$\sigma_{e}=$ rms of the external pressure

$\sigma_{i}=$ rms of the internal pressure

$\sigma_{c i}=$ covariance between the external and internal pressures

Note that the definition of the internal pressure gust factor here is not the same as the traditional concept which gives the maximum internal pressure.

By using the above theory and various experimental data of external pressures, Chino and Okada obtained the internal pressure values and their gust factors for different building configurations. Based on the results, they suggested that internal pressures between 0 to -0.4 and a gust factor of 1.3 should be adopted in building design[3],[4]. These values are from a theoretical analysis based on test results of only external pressures. The assumption behind it is that leakages are evenly distributed on all building walls and there are no dominant openings on any of the walls. It is believed that most buildings are close to this condition. These proposed values correspond to a 10 minutes averaging time in full scale test and a 0.5 second for the instantaneous values. In order to obtain a close simulation of the full scale test, the following wind tunnel test selects the same time reduction ratio.

\section{EXPERIMENTAL ARRANGEMENT}

To check the building internal pressure in a real wind condition, three sizes of building models are made for wind tunnel tests. They have two kinds of openings on their claddings. One of the opening types is made to simulate the air leakage characteristics of external walls at different equivalent opening ratios. The other is to simulate the dominant openings. Table 2 gives the model dimensions, where (W) in the table indicates the windward side of the model. The opening for the leakage type changes with the number of walls having leakages. The leakages are all $1 \mathrm{~mm}$ in diameter. There are total 13 leakage openings on the smaller size wall and 19 on the larger one. The equivalent leakage opening ratios for all models, which is defined as the area of opening over the gross area of the wall, are about the same at $0.05 \%$. This value is very common for buildings in Japan. For the dominant opening, even for the same model, it varies depending on the size of the opening area. The three sizes of dominant openings are $12 \mathrm{~mm}$ (large), $8 \mathrm{~mm}$ (medium) and $4 \mathrm{~mm}$ (small) in diameter. They are only opened on the windward side and centered at a height of $125 \mathrm{~mm}$ on the model. The arrangements of openings and leakages are given in Table 3. W, S, S, L means leakages respectively on the windward, side, side and leeward faces of the model. In this paper, only results from tests listed on the table are presented.

The wind tunnel is a boundary layer type with a sectional dimension of $3 \mathrm{~m} \times 2.5 \mathrm{~m}$. Spires are used at the test section entrance and roughness are distributed along the floor to generate a simulated atmospheric boundary layer flow in the power law profile with an index of $1 / 4$ in the following form:

$V=V_{0}\left(\frac{y}{y_{0}}\right)^{\frac{1}{4}}$

This simulated atmospheric boundary layer flow corresponds to an urban area condition. The boundary layer thickness is around $1000 \mathrm{~mm}$. Large number of 
pressure taps are mounted on both inside and outside of the models. In the tests, the external and internal pressures on the walls are measured simultaneously by a multi-pressure measuring system.

Table 2 Wind tunnel test models, dimension unit:mm

\begin{tabular}{|c|c|c|c|}
\hline Model No. & height & width & depth \\
\hline No. 1 & 200 & 100 & 100 \\
\hline No. 2 & 200 & $100(W)$ & 150 \\
\hline No. 3 & 200 & $150(W)$ & 100 \\
\hline
\end{tabular}

Table 3 Building model test conditions

\begin{tabular}{|c|c|c|c|}
\hline $\begin{array}{l}\text { test } \\
\text { number }\end{array}$ & \multicolumn{1}{|c|}{ dimension } & dominant & permeability \\
\hline test 1 & $100 \times 100 \times 200$ & no & W,S,S,L \\
\hline test 11 & $100(\mathrm{~W}) \times 150 \times 200$ & no & W,S,S,L \\
\hline test12 & $100 \times 150(\mathrm{~W}) \times 200$ & no & W,S,S,L \\
\hline test23 & $100 \times 150(\mathrm{~W}) \times 200$ & W(large $)$ & W,S,S,L \\
\hline test27 & $100 \times 150(\mathrm{~W}) \times 200$ & W(medium) & W,S,S,L \\
\hline test28 & $100 \times 150(\mathrm{~W}) \times 200$ & W(small $)$ & W,S,S,L \\
\hline
\end{tabular}

\section{RESULTS ANALYSIS}

\section{Mean internal pressure}

Based on the relation between the internal and external pressures by using the condition of mass flow balance in and out of the building, internal pressure is calculated from the external pressures. The comparison with the measured internal pressures are given in Table 4 for the three models. As expected, they are very close to each other. For all tests with or without dominant openings, with evenly distributed or with unevenly distributed leakages, the internal pressures from the experiments are all very close to their corresponding theoretical values.

Table 4 Comparison of the internal pressure coefficients

\begin{tabular}{|c|c|c|c|}
\hline test No. & models & $C_{p t}$,experiment & $C_{p i}$, theory \\
\hline No. 1 & No. 1 & -0.37 & -0.40 \\
\hline No. 11 & No. 2 & -0.31 & -0.32 \\
\hline No. 12 & No. 3 & -0.35 & -0.40 \\
\hline No. 23 & No.3 & 0.54 & 0.55 \\
\hline No.27 & No.3 & 0.40 & 0.43 \\
\hline No.28 & No.3 & -0.04 & -0.06 \\
\hline
\end{tabular}

\section{Gust factor of internal pressure}

Table 5 shows a group of experimental results at the test conditions of evenly distributed leakages and no dominant openings for all three models. These conditions are the same as in the proposals. The tabled values are chosen from the place on the model where a maximum loading is observed. From the test, it can be seen that when the maximum load is on the side wall, it appears on the front corner. If the maximum load is on the front wall, it normally locates at the up center part. $C_{p t}$ is the mean internal pressure coefficient. The last line shows on which wall the maximum load exists at the corresponding test condition and model configuration.

As expected, these values are very close to the proposed ones. Maximum loads for all three cases are on the front wall. If using the internal pressure value of -0.4 and a gust factor of 1.3 as proposed in the building code to estimate the design loads, the design will be safe.

Table 5 Leakages on all faces and without dominant opening

\begin{tabular}{|c|c|c|c|}
\hline test number & gust factor & $C_{p i}$ & maximum load \\
\hline No. 1 & 1.196 & -0.37 & front wall \\
\hline No. 11 & 1.266 & -0.31 & front wall \\
\hline No. 12 & 1.292 & -0.35 & front wall \\
\hline
\end{tabular}

\section{Error in the wind load estimations by traditional way}

Here two examples, test 1 and test 27, are given to see why the formula $F_{d}=G_{e} \bar{P}_{e}-G_{i} \bar{P}_{i}$ has overestimation of wind loads for most cases and why it has under-estimation of wind loads when the internal pressure has the same sign as the external pressure if $G_{i} \bar{P}_{i}$ uses the traditional gust factor concept. The maximum load results for test 1 are shown in Figure 3 and for test 27 are given in Figure 4 . The maximum loads estimated by using the new gust factor concept give the real maximum loads, which are compared with those estimated by using the traditional concept. For both cases, the maximum loads act on the side walls. All values of maximum loads on the graphs are in the form of coefficient as $C_{F D}$, which is normalized by the mean wind velocity pressure at the height of model. The traditional way is indeed to result either a higher loading for test 1 or a smaller loading for test 27 on the side walls. This proved that in estimation of the maximum wind loads, it is not just the separated values of the external and internal pressures that matter, it is also how they correlate each other.

\section{The effect of external-internal pressure correlation on the wind loads}

The differences between the wind loads estimated from the perfect correlation assumption and from the real loads are shown in figures 3 and 4 . Here result of wind loads estimated from the no correlation assumption are also given in Figures 5 and 6 . They are 
compared with the real wind loads as well. Underestimation of wind loads is observed in the plus external pressure zone and over- estimation in the minus

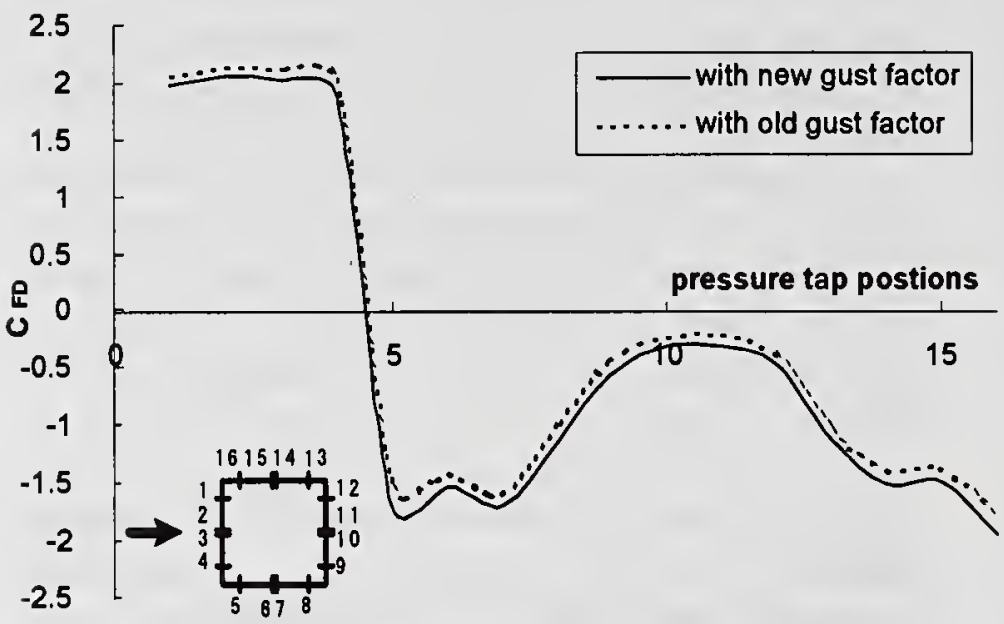

Figure 3: Comparison of the maximum loads estimated from different ways for test 1

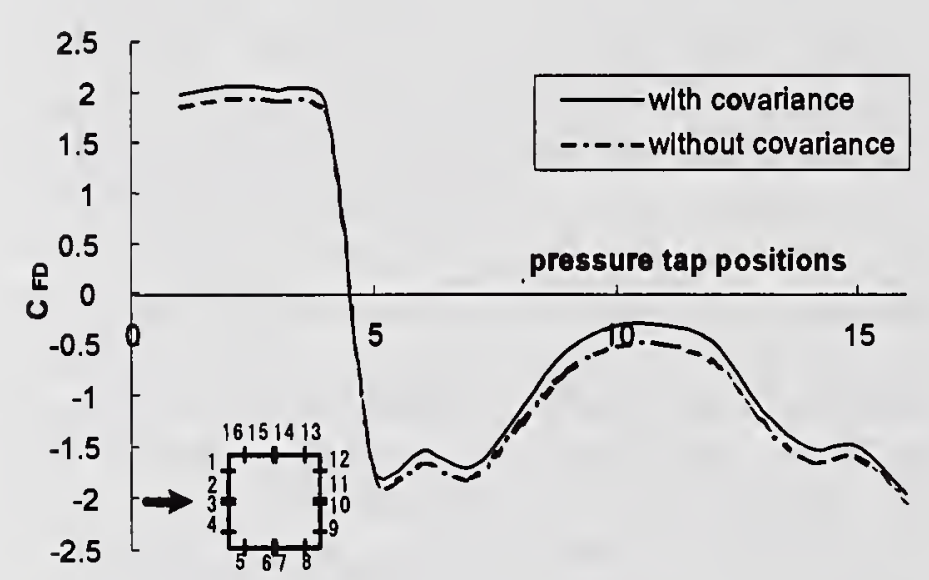

Figure 5: Comparison of the maximum load estimations by assuming no correlation of external and internal pressure with the real wind loads for test 1

\section{CONCLUSION}

The present investigation proves two points, the importance of the internal pressure in building design and the importance of the correlation between the internal and external pressures in estimating the maximum wind loads. Both of them have large effects on the implication of building safety. Though the over-estimation of maximum wind loads may only result in a higher cost in building design which is really undesired, the under-estimation of wind loads obviously would be unacceptable. On the external pressure zone in test 1 . In test 27 the over and under estimations are found in the contrary zones to test 1. The overestimation in test 27 is quite large.

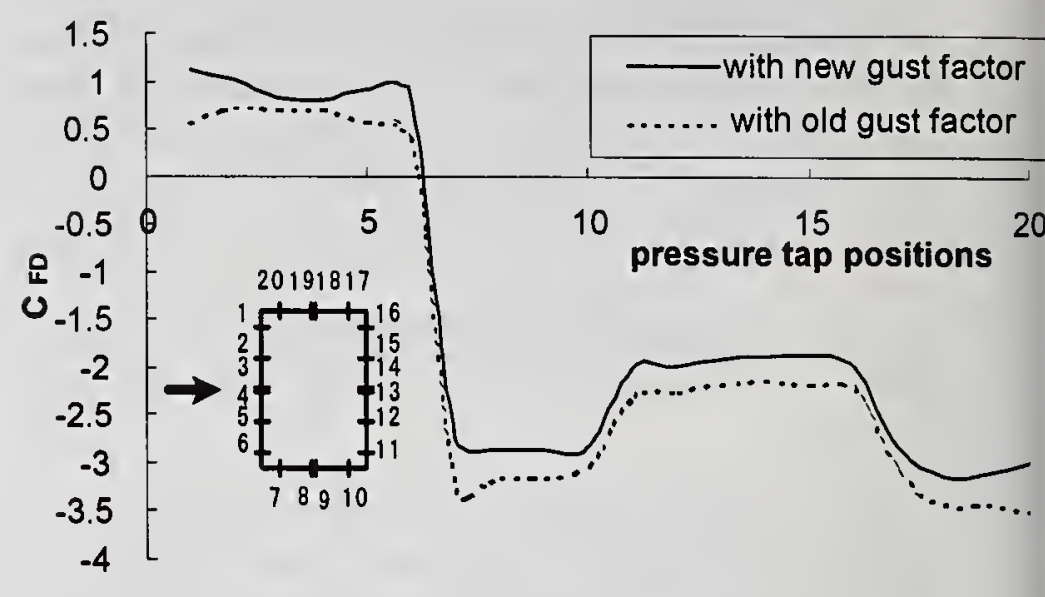

Figure 4 : Comparison of the maximum loads estimated from different ways for test 27

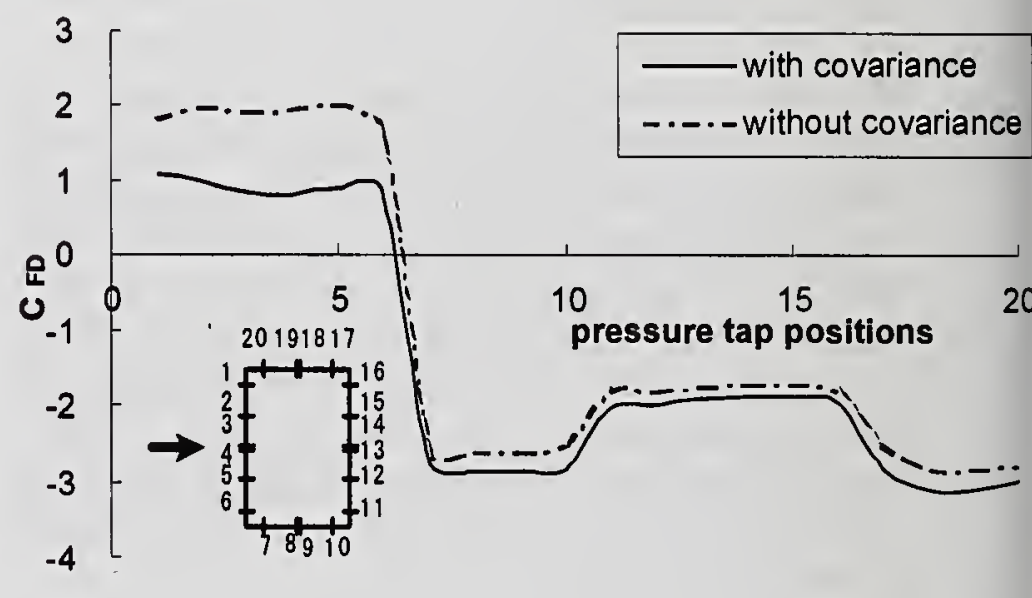

Figure 6: Comparison of the maximum load estimations by assuming no correlation of external and internal pressure with the real wind loads for test 27

other hand, the internal pressure value and gust factor proposed by Okada and Chino is proved to be correct. Usually, buildings have about the same permeabilities on all of its walls, so the internal pressure values and the gust factor in the proposal are very practical and close to real situation.

\section{REFERENCES}

[1]Liu H. and Saathoff P. J. ,"Building Internal Pressure: Sudden Change", Journal of Engineering Mechanics 
Division, ASCE, Apr. , 1981

[2] H. Okada and L. Kong, "Investigation of the dynamic characteristics of wind induced building internal pressures", to be presented at the Third International Colloquium on BBAA, July 1996, Virginia, USA.

[3] H. Okada and N. Chino, "Wind - induced internal pressures in buildings, part 2 gust response factor of internal pressure", Journal of Wind Engineering, Japan Association for Wind Engineering, No. 58, 1994.

[4] N. Chino and H. Okada, "Wind - induced internal pressures in buildings, part 1 mean internal pressures", Journal of Wind Engineering, Japan Association for Wind Engineering, No. 56, 1993. 



\title{
Descriptive Epidemiology of Wind-related Mortality
}

\author{
by
}

Josephine Malilay ${ }^{1}$, Annemarie Wasley ${ }^{1}$, Leslie A. Fiedler ${ }^{1}$

\section{ABSTRACT}

To examine the effects of wind in deaths attributed to recent tropical cyclones and tornadoes in the United States, we reviewed 174 deaths reported by medical examiners or coroners $(\mathrm{ME} / \mathrm{Cs})$ in Morbidity and Mortality Weekly Reports during 19891995. Of these 174, we found 99 windrelated deaths, including all 62 of the deaths attributed to tornadoes and 37 of the 112 deaths attributed to tropical cyclones. Of the wind-related deaths attributed to cyclones, the major causes were multiple blunt trauma, crushing injuries, head trauma, and compressional asphyxia. ME/C's cited structural failure about five times as often in wind-related deaths as in non-wind-related deaths $(\mathrm{OR}=5 ; 95 \% \mathrm{CI}=1.8-14)$. On the basis of our findings, we recommend that 1) structural failure during high winds be explored further; 2) uniform methods be established for collecting information about disaster-related deaths in which wind is a contributing factor; and 3) epidemiologic studies of cyclones and tornadoes include input from wind and construction engineers.

KEYWORDS: wind, tropical cyclones, tornadoes, health effects of disasters

\section{INTRODUCTION}

Through postdisaster investigations of natural disasters, such as hurricanes, tornadoes, and severe storms, epidemiologists and public health officials have identified certain risk factors for death or injury, such as occupancy of a mobile home or motor vehicle during the disaster. The risk factors identified have in turn formed the basis for interventions designed to reduce the number of deaths and injuries in subsequent disasters.

Wind is usually regarded as an underlying hazard of a disaster event, rather than as a disaster event per se (1). The mechanism of injury in wind-related deaths varies by the type of disaster. In tropical cyclones and nontornadic thunderstorms, most injuries are caused by extremely high winds. Injuries in particular from such high winds most often occurred indoors and were largely attributed to 1) multiple lacerations, abrasions, and fractures from flying debris; and 2) traumatic asphyxiation from massive trauma caused by collapsing walls and roofs (2).

In contrast, in a study of severe westerly gales (with wind speeds up to 96 miles per hour) in the United Kingdom, researchers found that most deaths and injuries occurred outdoors. Several fatalities occurred when people were blown off roofs or off ladders (3). Results of another study, again in the United Kingdom, showed that injuries were most likely to occur to people who were

\footnotetext{
${ }^{1}$ National Center for Environmental Health, Centers for Disease Control and Prevention, Atlanta, Georgia 30341-3724
} 
outdoors during winds that exceeded 60 knots; most of 70 injuries to 58 persons were attributed to flying debris, falling masonry, or being blown over by the wind. Only three deaths were associated with structural collapse (4).

In this paper, we examined the effects of extreme wind in deaths attributed to recent tropical cyclones and tornadoes and characterize this wind-related mortality. We also call attention to other disciplines, such as engineering and meteorology, which can contribute additional information that would be useful in designing appropriate strategies to reduce fatalities during future windrelated disasters.

\section{METHODS}

We selected four tropical cyclones and three tornadoes for which medical examiner/coroner (ME/C) data were available from the Morbidity and Mortality Weekly Report of the Centers for Disease Control and Prevention (5-13): Hurricane Hugo (1989), Hurricane Andrew (1992), Hurricane Marilyn (1995), and Hurricane Opal (1995), and tornadoes in Illinois (1990), Kansas (1992), and Alabama (1994).

We examined descriptive information provided for each person who died as a result of these storms: demographic information (age and sex), cause of death, circumstances of death, and when the death occurred in relation to the storm's impact, namely before the storm arrived (preimpact), during the storm (impact), or after the storm passed (postimpact). We defined "windrelated" deaths as those associated with the effects of wind, either directly or indirectly, according to circumstances described by the
$\mathrm{ME} / \mathrm{C}$ for those deaths.

\section{RESULTS}

Medical examiner/coroners reported a total of 174 deaths related to tropical cyclones or tornadoes, 112 (64.4 percent) related to tropical cyclones and 62 related to tornadoes. Of the 112 cyclone-related deaths, 37 were attributed to high wind and the remaining 75 were attributed to storm surge or other elements. All 62 tornadorelated deaths were wind-related.

We focused further analyses on cyclonerelated deaths in which wind was a contributing factor (Table 1). Demographic data were available for all but 1 of the 37 wind-related fatalities attributed to tropical cyclones Hugo in South Carolina, Andrew in Florida and Louisiana, Marilyn in the U.S. Virgin Islands, and Opal in the southeastern U.S. The average age of these decedents was 45 years (range: 1 to 80 years); 28 (76 percent) were male.

Thirty-one of 37 wind-related fatalities occurred during the impact phase, when wind speeds were at or near their highest (Table 2). Two deaths occurred before the impact phase: one person died of crush injuries from a tornado that preceded a hurricane, and one person sustained multiple blunt injuries to the head when her mobile home was hit by a tornado that preceded the cyclone. Four deaths occurred after the impact: one person was asphyxiated under a falling tree, two sustained head injuries when they were hit by falling trees, and one was killed by blunt force trauma when his motorcycle ran into a fallen tree.

Of the 37 wind-related deaths, 14 were 
caused by multiple blunt trauma, 7 by crushing injuries, 9 by head trauma, and 7 by compressional asphyxia (Table 3 ). Structural failure was cited more often by ME/Cs as being involved in wind-related deaths than in non-wind-related deaths (odds ratio $=5$; $95 \%$ confidence limits $=1.8-14)$. Windrelated structural failures cited by ME/Cs included "collapsing house, mobile home, or townhouse," "roof of home caving in," "tree falling onto house or mobile home," and "tree falling through roof of residence." Further, structural failure was also mentioned as a factor in 10 of 75 non-windrelated deaths. Descriptions of such nonwind-related structural failures included "storm surge in mobile home leading to drowning," "house fire started by burning candle," and "explosion caused by propane cooking device due to power outage."

\section{DISCUSSION}

Prior to Hurricane Hugo in 1989, high proportions of cyclone-related deaths were attributed to drowning from storm surge (14). In recent years, however, improved systems for issuing and disseminating warnings, more evacuations from areas in the projected track of hurricanes, and increased public atiention to hurricane warnings have led to a decrease in the proportion of cyclone-related deaths that are surge-related. Deaths are now more often associated directly or indirectly with high winds.

ME/Cs cited structural failure as a contributing factor in about one of two cyclone-related deaths attributed to high winds, but in only about one of eight deaths attributed to storm surge. Because structural failure was cited in 26 of 112 deaths, particularly in wind-related deaths, additional information about the circumstances of these deaths -- including estimated wind speeds at the time of death and building characteristics -- should be collected in future disasters.

Wind-related deaths also occurred as a result of tornadoes, including tornadoes that preceded cyclones. Presumably, most deaths happened during the impact phase, when the winds were at their highest. Any health outcomes during the pre- and postimpact phases have yet to be determined, because "preimpact," "impact," and "postimpact" phases have not been defined for tornadoes.

We used information provided by ME/Cs to CDC. This death investigation system is capable of obtaining information about victims within several days of a natural disaster; however, the system would not include disaster-related deaths that occurred during the months after the event. One advantage of this system is that for most cases, particularly for those related to tropical cyclones, we were able to obtain detailed information about the circumstances of death information that would not be available on a death certificate and which usually would be issued several weeks after a death.

Results from this study indicated the need for uniformity in collecting information about disaster-related deaths. Although we found consistency in the manner in which hurricane-related deaths were reported by $\mathrm{ME} / \mathrm{Cs}$, we found a broad range in the manner in which tornado-related deaths were reported, ranging from simple counts of deaths in a particular location, such as a school or church, to total numbers of deaths related to a tornado. A line listing of tornado-related deaths, much like those collected for cyclone-related deaths, would 
be useful for comparing the effects of different disasters, particularly those involving extreme wind.

Finally, we acknowledge the difficulty in determining the risk of mortality, windrelated or otherwise, in the population exposed to the event. Although the population census may be available for a disaster-affected area, estimating the exposed population from this source may not be feasible because residents may evacuate, or conversely, return to an area at any given time. Field methods and statistical analyses have been developed to address this issue (15).

\section{CONCLUSIONS}

As the number of deaths related to storm surge has decreased in recent years (14), the proportion of cyclone-related deaths attributable to wind has increased. These wind-related deaths, as well as wind-related injuries, need to be further characterized in order to explain the mechanisms by which wind acts as an environmental threat. In future investigations of the effects of high wind, structural failure and its components should be further explored in order to determine appropriate predictors for windrelated mortality, and more precise wind data should be collected, including data on mean wind speeds, wind speed thresholds above which the risk for injury or death increases.

Therefore, we recommend that epidemiologic studies be designed so as to involve the participation of other disciplines, including wind engineering and construction engineering. Only with the help of people from these disciplines can disaster epidemiologists fully address the factors that predict wind-related outcomes and design interventions that will prevent future windrelated fatalities.

\section{ACKNOWLEDGMENT}

We thank Debra Combs, Surveillance and Programs Branch, NCEH, CDC, for reviewing this manuscript.

\section{REFERENCES}

1. McDonald JR. Individual preparedness planning for safety and windstorm damage mitigation. In: Majumdar SK, Forbes GS, Miller EW, Schmalz RF, eds. Natural and Technological Disasters: Causes, Effects and Preventive Measures. PA: The Pennsylvania Academy of Science, 1991:384-99.

2. Eckert WG. Medicolegal aspects of tornadic storms in Kansas, U.S.A. Am J Forensic Med Pathol 1991;12:281-5.

3. Illingworth RN, Illingworth KA. Multiple casualties caused by a gale. Arch Emerg Med 1984;1:57-60.

4. Cugnoni $\mathrm{HL}$, Whitworth I. Injuries related to wind speed. Ann R Coll of Surg Engl 1992;74:294-6.

5. CDC. Medical examiner/coroner reports of deaths associated with Hurricane Hugo--South Carolina. MMWR 1989;38:754-62.

6. CDC. Deaths associated with Hurricane Hugo--Puerto Rico. MMWR 1989;38:680-2. 
7. CDC. Update: work-related electrocutions associated with Hurricane Hugo--Puerto Rico. MMWR 1989;38:718-20,725.

8. CDC. Preliminary report: medical examiner reports of deaths associated with Hurricane Andrew--Florida, August 1992. MMWR 1992;41:6414.

9. CDC. Injuries and illnesses related to Hurricane Andrew--Louisiana, 1992;42:242-3,249-51.

10. CDC. Deaths associated with Hurricanes Marilyn and Opal--United States, September-October 1995. MMWR 1996;45:32-8.

11. CDC. Tornado disaster--Illinois, 1990. MMWR 1991;40:33-6.

12. CDC. Tornado disaster--Kansas, 1991. MMWR 1992;41:181-3.

13. CDC. Tornado disaster--Alabama, March 27, 1994. MMWR 1994;43:356-9.

14. French JG. Hurricanes. In: Gregg $\mathrm{MB}$, ed. Public health consequences of disasters. Atlanta: Centers for Disease Control, 1989.

15. Malilay J, Flanders WD, Brogan D. A modified cluster sampling method for post-disaster rapid assessment of needs. Bull World Health Organ. In press. 
Table 1. Wind-related fatalities for selected tropical cyclones

\begin{tabular}{llll}
\hline & $\begin{array}{l}\text { Wind speed, miles } \\
\text { per } \\
\text { hour }\end{array}$ & $\begin{array}{l}\text { Wind-related } \\
\text { deaths } \\
\text { n }(\%)\end{array}$ & Total deaths \\
\hline Hugo, 1989: & (\%)
\end{tabular}

* Complete information was available for 9 deaths. 
Table 2. Wind-related fatalities occurring before, during, and after selected tropical cyclones

\begin{tabular}{|c|c|c|c|c|}
\hline \multirow{2}{*}{ Event } & \multicolumn{3}{|c|}{ Disaster phase } & \multirow{2}{*}{$\begin{array}{c}\text { Total } \\
\text { deaths } \\
\text { n }(\%)\end{array}$} \\
\hline & $\begin{array}{l}\text { Pre- } \\
\text { impact }\end{array}$ & Impact & $\begin{array}{l}\text { Post- } \\
\text { impact }\end{array}$ & \\
\hline \multicolumn{5}{|l|}{ Hugo, 1989: } \\
\hline South Carolina & 0 & 7 & 2 & $9(24.4)$ \\
\hline \multicolumn{5}{|l|}{ Andrew, 1992: } \\
\hline Florida & 0 & 13 & 0 & $13(35.1)$ \\
\hline Louisiana & $1^{\dagger}$ & 0 & 0 & $1(2.7)$ \\
\hline \multicolumn{5}{|l|}{ Marilyn, 1995: } \\
\hline US Virgin Islands & 0 & 1 & 0 & $1(2.7)$ \\
\hline \multirow{3}{*}{\multicolumn{5}{|c|}{$\begin{array}{l}\text { Opal, 1995: } \\
\text { Florida, Georgia, } \\
\text { Alabama, North } \\
\text { Carolina }\end{array}$}} \\
\hline & & & & \\
\hline & & & & \\
\hline Total & $2(5.4)$ & $31(83.8)$ & $4(10.8)$ & $37(100.0)$ \\
\hline
\end{tabular}

* Deaths are categorized as occurring before the tropical cyclone made landfall (preimpact), during the storm (impact), or after the storm passed (postimpact).

† Of 18 reported deaths with incomplete information, 1 death was known to have occurred during the pre-impact phase. 
Table 3. Causes of 37 wind-related fatalities from selected tropical cyclones

$\begin{array}{lll}\text { Cause of death } & \text { Number } & \text { Circumstances }\end{array}$

Preimpact phase:

-Multiple blunt

injuries to head

-Crush injury

1

Impact phase:

-All penetrating trauma 6 and/or crush injuries

-All multiple blunt trauma 4 and/or head trauma

-Asphyxiation

-Mobile home hit by pre-hurricane tornado

-Tornado preceding hurricane

4

1

2

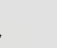

1
- Car hit by falling tree
-Struck by beam in home
-In boat
-Hit by tree
-Collapsed truck trailer used as shelter

-Collapsing trailer

-Struck by falling tree

-Mobile home struck by falling tree

Postimpact phase:

-Asphyxiation

-Head injury

1

-Blunt force trauma

1 -Hit tree while riding motorcycle

-Trapped under tree

-Struck by tree 


\section{JAPAN-SIDE PAPERS PRESENTED AT MINI-SYMPOSIA}





\title{
NEW EVALUATION TECHNIQUE OF WIND LOADS ON BUILDING EXTERNAL ELEMENTS
}

\author{
H. Okada and L. Kong \\ Aerodynamics division, Structural Department \\ Building Research Institute \\ Tsukuba, Japan 305
}

\begin{abstract}
Building external elements such as roofing, roofs, external walls, finishing of external walls and windows etc. are often received serious damages due to strong winds. The damages on the external elements are the most conspicuous among the damages of buildings due to strong winds. So we should design them with extra attentions. However we still do not have enough information to obtain the accurate wind loads. Wind loads on building external elements are related to the pressures on both sides and the correlation between the two pressures. There are fairly amount of data regarding to the pressures on their external sides. But the pressure data on the opposite side and the correlation between the two pressures are quite few. The two pressures are referred as external and internal pressures in this paper. The internal pressure should be created from the external pressures through various openings between the external elements. Both aspects of the internal pressure, its average and fluctuation, affect the load on the elements significantly. The present investigation studied both, particularly on its dynamic characteristics. An equation relates the internal pressure to the external pressure is developed from the Navier-Stokes equation. On solving the equation, a simple but very accurate method is introduced to obtain an analytical solution. The speaker test designed in the investigation verified the theoretical analysis. The procedure described here is applied to a simple building external model. From the application, it is very interesting to see that the space between the external elements and the building cladding has great role on wind loads on building external elements. And the area of openings between the external elements is found to have great effects on the wind loads.
\end{abstract}

Keywords: building external element, internal pressure, internal space, damping coefficient

\section{INTRODUCTION}

Each year, strong windstorms cause serious building damages everywhere in the world. Among the various kinds of damages, the one on the external elements is the most conspicuous. The damage on a building should be remarkably decreased after the damage on the external elements is reduced. To do that, we have to investigate the wind loads on them. The wind loads can be estimated with the pressures on their both sides, which are called the internal pressure and external pressure in this paper. Only when the internal pressure and its dynamic characteristics are accurately determined, the wind loads on external elements can be accurately estimated. Since the internal pressure is created from the external pressure, the creating process should be examined clearly. The purpose of this paper is to describe how to estimate the wind loads on building external elements. A theoretical model is set up to obtain the characteristics of the internal pressure by integrating the Navier-Stoke equation through the opening. Speaker test are conducted to verify the theory at different conditions. The procedures on the evaluation of the wind loads is applied to a simple building external model.

\section{WIND LOAD ON BUILDING EXTERNAL ELEMENT}

Wind loads on building external elements are given with the external and internal pressures and the correlation between the two pressures. The external elements on roof are classified into three types based on the setting way on the buildings. The types are explained by illustrations shown in figure 1. The first type actually is part of the building cladding itself. V-beam roof belong to this type. Internal pressure on this type is the internal pressure in the building. That is the one generally called as internal pressure. In the 
second type, internal pressures is the pressure in the space between the external element and the sheathing boards. Clay roof tile and lose laid roof block, etc. belong to this type. The last type has almost no space between the element and the sheathing board. Internal pressure in this type is likely to be the one enclosed at the time of its setting work. But it is true in this type as well as the other types that the internal pressure is created from the external pressure. Flat seam roofing is one example of the 3rd type. Regardless of the types, the wind loads is given as the following equation .

$$
F=P_{e}-P_{i}+\operatorname{sign}\left(P_{e}-P_{i}\right) g_{f} \sigma_{f}
$$

Where, $F$ : wind load on building external element

$P_{e}:$ mean external pressure

$P_{i}:$ mean internal pressure

$g_{f}:$ peak factor of wind load

$\sigma_{f}:$ rms of difference between internal and external pressures, which is given by the following equation.

$$
\sigma_{f}=\sqrt{\sigma_{e}^{2}+\sigma_{i}^{2}-2 \sigma_{e i}}
$$

Where, $\sigma_{e}:$ rms of external pressure

$\sigma_{i}:$ rms of internal pressure

$\sigma_{e i}:$ covariance of external and internal pressures

Internal pressure is created from the external pressure through the opening or gap between adjacent external elements. If the transfer function is given as $H(\omega)$, relation between fourie spectra of internal and external pressures are given by the following equation.

$$
X_{i}(\omega)=H(\omega) X_{e}(\omega)
$$

Where, $X_{i}(\omega)$ :fourie spectrum of internal pressure

$X_{e}(\omega)$ :fourie spectrum of external pressure

Rms's of external and internal pressures and covariance of external and internal pressures are given by the following equations.

$$
\begin{aligned}
& \sigma_{e}{ }^{2}=\int X_{e}(\omega) X_{e}{ }^{*}(\omega) d \omega=\int S_{e}(\omega) d \omega \\
& \sigma_{i}{ }^{2}=\int H(\omega) H^{*}(\omega) X_{e}(\omega) X_{e}^{*}(\omega) d \omega=\int|H(\omega)|^{2} S_{e}(\omega) d \omega \\
& \sigma_{e}{ }^{2}=\int X_{e}(\omega) H(\omega) X_{e}^{*}(\omega) d \omega
\end{aligned}
$$

Where, $S_{e}(\omega)$ :power spectrum of external pressure, and super script ${ }^{*}$ indicates the conjugate.

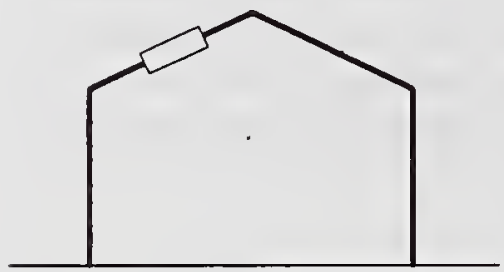

Type I

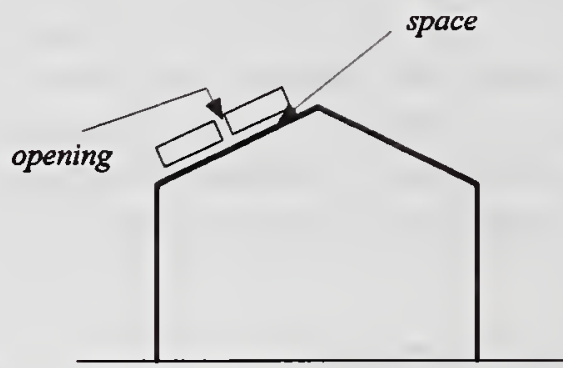

Type 2

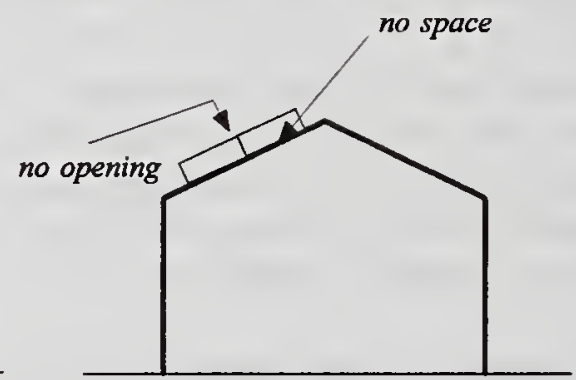

Type 3

Figure 1 Types of building external element 


\section{MEAN INTERNAL PRESSURE}

It is well-known that mean internal pressure can be estimated by the mass flow balance in and out of the openings. For a internal space connecting to the external space with a number of $\mathrm{N}$ openings, the equation can be written as:

$$
\sum_{j=1}^{N} Q_{j}=0
$$

From which a relation between the external and internal pressures is established:

$$
\sum_{j=1}^{N} \operatorname{sign}\left(P_{e j}-P_{i}\right)\left(A_{j}\left|P_{e j}-P_{i}\right|^{\frac{1}{2}}\right)=0
$$

The sign of each term depends whether it is inflow or outflow. In the equation, power index of $1 / 2$ becomes 1 if sizes of the openings are very small and the effect of viscosity can not be neglected.

\section{FLUCTUATION COMPONENT OF INTERNAL PRESSURE}

The following equation, obtained by Liu and Saathoff[1] through the unsteady Bernouli equation, governs the relation between the internal and external pressures of a building in a dominant opening condition. This equation may applied to the problem described here.

$$
\frac{\rho L_{e} V_{0}}{n K A P_{a}} \frac{d^{2} p_{i}}{d t^{2}}+0.5 \rho \frac{V_{0}^{2}}{n^{2} K^{2} A^{2} P_{a}^{2}} \frac{d p_{i}}{d t}\left|\frac{d p_{i}}{d t}\right|+p_{i}=p_{e}
$$

Where $A$ is the opening area, $V_{0}$ is the volume of the building, $P_{a}$ is the atmosphere pressure, $\rho$ is the air density, $n$ is the polytropic exponent and $K$ is the discharge coefficient of the opening. This equation is similar to the well known Helmholtz resonator in acoustics. Theoretical analysis and wind tunnel tests conducted by previous investigators $[2,3]$ showed that in a natural wind condition, the socalled Helmholtz frequency $f=\frac{1}{2 \pi} \sqrt{\frac{n K P_{a} A}{\rho L_{e} V_{0}}}$ determines the characteristics of the wind induced internal pressures. $L_{e}$ in the equation is the effective opening length defined as $L_{e}=L_{0}+\sqrt{\frac{\pi A}{4}}$ and $L_{0}$ is the actual opening length.

Previously, it has been largely believed that viscous effect is not an influential factor in the analysis for building openings. This is right if the opening is large and shallow so the boundary layer inside is very small, such as a large opening on a glass window. Most openings on buildings do occur like this. However, if the opening happens to be a very narrow one between adjacent external elements, e.g. a thin rectangular type, the previous assumption becomes invalid and the viscous effect is expected to be important. Based on this consideration, a similar relation as equation (9) is developed.

Schematically, the flow inside a rectangular opening can be simplified as in figure 2. For simplification, flow variation in the $z$ direction is ignored and the flow is approximated as a 2-D case. The Navier-Stokes equation for a two-dimensional flow in $x$-direction can be written as:

$$
\frac{\partial u}{\partial}+u \frac{\partial u}{\partial x}+v \frac{\partial u}{\partial y}=-\frac{1}{\rho} \frac{\partial p}{\partial x}+v\left(\frac{\partial^{2} u}{\partial x^{2}}+\frac{\partial^{2} u}{\partial y^{2}}\right)
$$

Because of the symmetry of the flow inside a rectangular opening, only half of the flow from the centerline is considered. The boundary layer flow in the opening is considered to be laminar because it only represents the inlet part of a straight channel flow. The velocity distributions of $u$ and $v$ have been 
given by Schlichting[4]. Here the first order of his solution is taken for simplicity. By curve fitting, the data is fit into a power series:

Velocity in $x$ direction: $u=u_{0}\left(0.0026 \eta^{3}-0.0581 \eta^{2}+0.4251 \eta\right)$

In $y$ direction: $v=\sqrt{\frac{u_{0}}{x}\left(0.0014 \eta^{4}-0.025 \eta^{3}+0.126 \eta^{2}-0.0064 \eta\right)}$

Where $\eta=y \sqrt{\frac{u_{0}}{x}} . \eta=5$ is approximately the border of the boundary layer. Integrate equation (10) in $x$ direction from entrance of the opening to inside of the room and substitute $u, v$ in it, the following equation is obtained,

$$
\frac{d u_{o}}{d t} L_{e}=\frac{p_{e}-p_{i}}{\rho}-0.94 u_{0}^{2}
$$

Then from the flow mass continuity equation, a relation between velocity $u_{0}$ and pressure $p$ can be written as $u_{o}=\frac{V_{0}}{K A n p_{a}} \frac{d P_{i}}{d t}$. Put it in equation (13), the following form is established:

$$
\frac{\rho L_{e} V_{0}}{n K A P_{a}} \frac{d^{2} p_{i}}{d t^{2}}+0.94 \rho \frac{V_{0}^{2}}{n^{2} K^{2} A^{2} P_{a}^{2}} \frac{d p_{i}}{d t}\left|\frac{d p_{i}}{d t}\right|+p_{i}=p_{e}
$$

The new equation has a damping coefficient of 0.94 . So the effect of adding the viscous term and the other convective term $v \frac{\partial u}{\partial y}$ is the same as to increase the damping. Physically this is correct since the existence of these terms consume more energy from the flow.

In the derivation, some of the integration are evaluated by their averages. For example, $\int_{e}^{i} v \frac{\partial u}{\partial y} d x=\bar{v} \frac{\overline{\partial u}}{\partial y} L_{e}$. This simplification not only represents a general picture of the flow, but also simplifies the problem greatly. Actually, since the average characteristics in the opening is examined, averaging techniques can be used in both $\mathrm{x}$ and $\mathrm{y}$ directions.
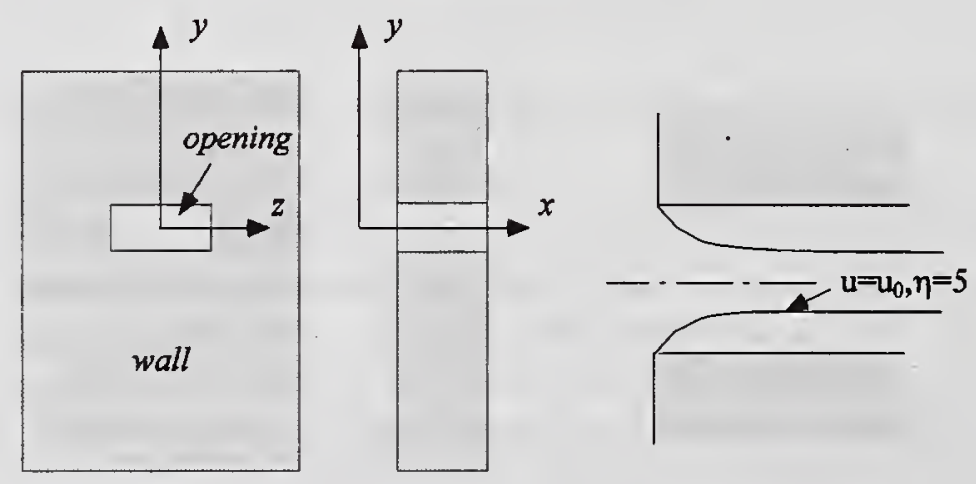

Figure 2: Flow conditions inside a rectangular opening on a building wall

\section{SIMPLIFIED METHOD}

A simplified method is used to solve equation (14) when the external pressure is in a sinusoidal form $p_{e}=P_{e} \sin (\omega t)$. Then $p_{i}=P_{i} \sin (\omega t+\phi)$. Let $A_{1}=\frac{\rho L_{e} V_{0}}{n K P_{a} A}$ and $A_{2}=C_{0} \rho\left(\frac{V_{0}}{n K P_{a} A}\right)^{2}$, where $C_{0}$ is either 0.5 or 0.94 . Substitute both $p_{e}$ and $p_{1}$ into the equation, approximate $|\cos (\omega t+\phi)|$ as 1 and combine the 
terms on the left side: $R \sin (\omega t+\phi+\Phi)=P_{e} \sin (\omega t)$, where $R=\sqrt{\left(A_{2} \omega_{2}\right)^{2} P_{i}^{4}+\left(-A_{1} \omega^{2}+1\right)^{2} P_{i}^{2}}$ and $\Phi=\tan ^{-1} \frac{A_{2} P_{i} \omega^{2}}{1-A_{1} \omega^{2}}$

A resonance would occur at the Helmholtz frequency $\omega=\frac{1}{\sqrt{A_{1}}}$ where $\phi=\frac{\pi}{2}$. At this critical condition, a significant amplification of the internal pressure will be induced. Therefore if the wind has a strong component at this frequency, the building internal pressure will increase dramatically and the load on cladding would increase accordingly. More seriously, if part of the building is flexible and has such a structural frequency, resonance will be induced and there would be a danger of collapse for that part of the building.

Finally, $P_{i}$ can be solved and presented in an analytic form,

$$
P_{i}^{2}=\frac{-\left(1-A_{1} \omega^{2}\right)^{2}+\sqrt{\left(1-A_{1} \omega^{2}\right)^{4}+4\left(A_{2} \omega^{2}\right)^{2} P_{e}^{2}}}{2\left(A_{2} \omega^{2}\right)^{2}}
$$

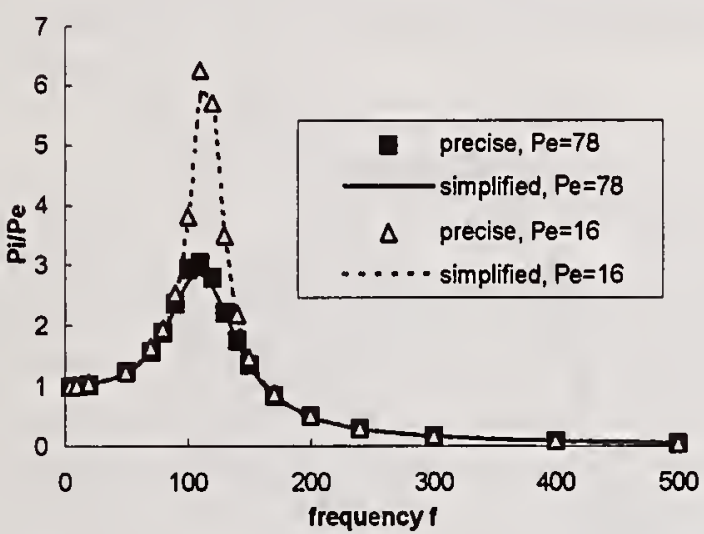

Figure 3: Comparison of $P_{1} / P$, ratio between the precise and simple methods for $\mathrm{C} 80 \mathrm{~L}$ with $C_{0}=$ 0.5

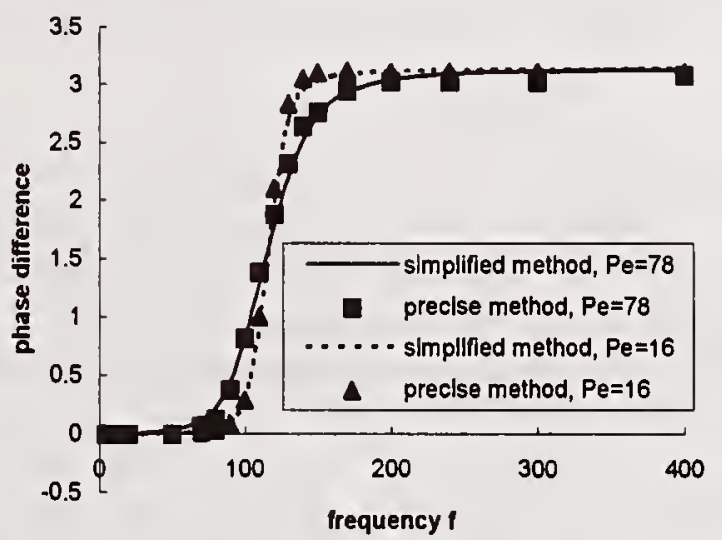

Figure 4: Comparison of the phase difference between the precise and simple methods for $\mathrm{C} 80 \mathrm{~L}$ with $C_{0}=0.5$

Qualitatively, neglecting the term $|\cos (\omega t+\phi)|$ is similar to increase the damping, which would decrease the internal pressure amplitude. The exact solution of the equation is also obtained by the RungeKutta method. The results between the simplified method and the exact method are compared in figures 3 and 4 for two external pressure amplitudes $P_{e}=16 \mathrm{~N} / \mathrm{m}^{2}$ and $78 \mathrm{~N} / \mathrm{m}^{2}$. The opening area of the model $\mathrm{C} 80 \mathrm{~L}$ is $50.27 \mathrm{~mm}^{2}$ and the thickness is $15 \mathrm{~mm}$, which gives a Helmholtz frequency about $110 \mathrm{~Hz}$. Here both calculations adopted the damping coefficient of 0.5 .

Figures 3 and 4 show that at most frequencies, there are hardly any difference between the solutions of the simplified method and the precise method for both the pressure ratio and phase value. The only noticeable difference is the peak area close to the Helmholtz frequency for the smaller external pressure $P_{e}=16 \mathrm{~N} / \mathrm{m}^{2}$. As expected, $P_{i} / P_{e}$ ratios around the Helmholtz frequency for the simplified method is smaller than that of the precise method due to increase of the damping. From figure 3 , it is also amazing to see that depending on the external pressure amplitude, $P_{i}$ could be as high as 6 times of $P_{e}$. 


\section{SPEAKER TEST AND COMPARISON WITH THE THEORY}

Table 1: Test models

\begin{tabular}{|l|l|l|}
\hline models & openings & thickness \\
\hline \hline R05L & $0.5 \mathrm{~mm} \times 10 \mathrm{~mm}$ & $15 \mathrm{~mm}$ \\
\hline R10L & $1.0 \mathrm{~mm} \times 10 \mathrm{~mm}$ & $15 \mathrm{~mm}$ \\
\hline R20L & $2.0 \mathrm{~mm} \times 10 \mathrm{~mm}$ & $15 \mathrm{~mm}$ \\
\hline C80L & $\phi 8 \mathrm{~mm}$ & $15 \mathrm{~mm}$ \\
\hline
\end{tabular}

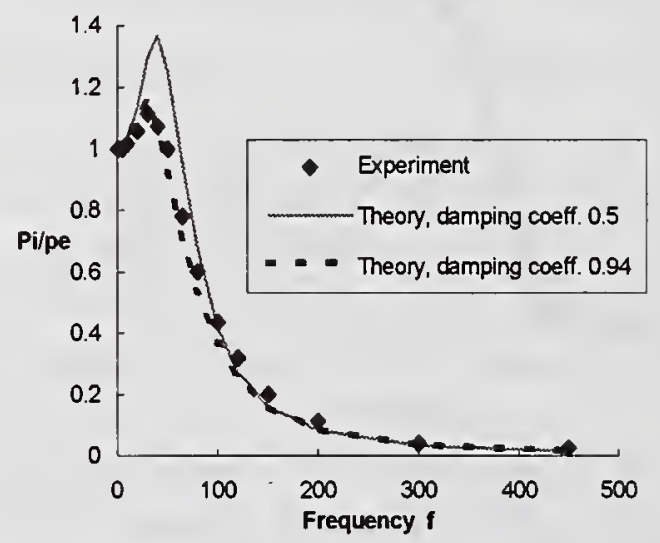

Figure 6: Comparison of $P_{i} / P_{e}$ ratio between theory and experiment for $\mathrm{R} 10 \mathrm{~L}$

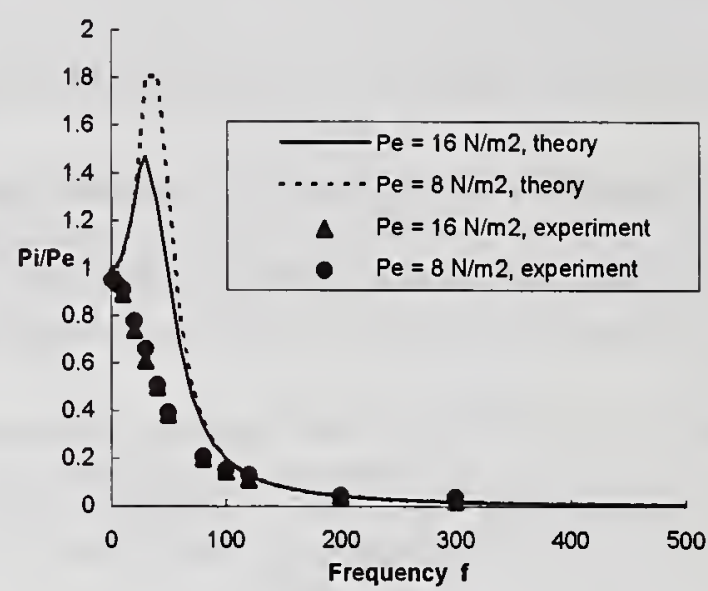

Figure 5: Comparison of $P_{i} / P_{e}$ ratio between theory and experiment for R05L with $C_{0}=0.94$

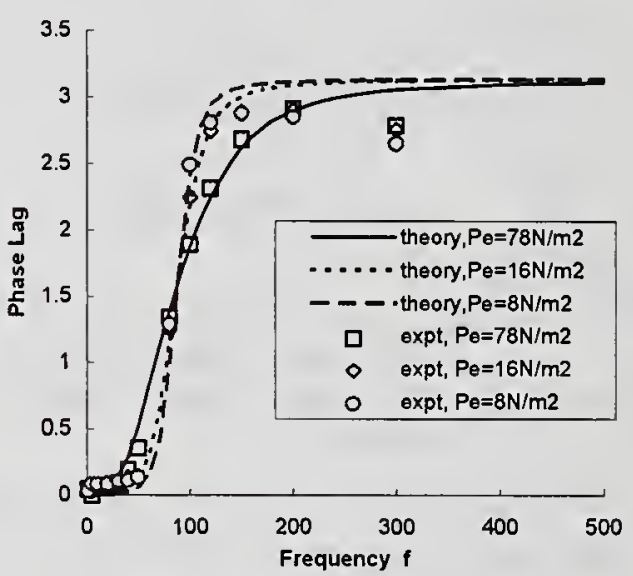

Figure 7: Phase difference between the internal and external pressures for R20L with $C_{0}=0.94$, experiment and theory

The speaker system was used to generate an external pressure function in the sinusoidal form at different amplitudes and frequencies. A box with a dimension of $90 \mathrm{~mm} \times 90 \mathrm{~mm} \times 55 \mathrm{~mm}$ was used to simulate the room in which one wall can be replaced by plates with different sizes of openings. In the tests, pressures from both inside and outside of the box are measured. Quite a few test pieces were used. Here results for 4 of them (Table 1) with two different kinds of shapes, rectangular and round, were presented.

Figure 4 shows $P_{i} / P_{e}$ between the theory and experiment at $P_{e}=78 \mathrm{~N} / \mathrm{m}^{2}$ for R $10 \mathrm{~L}$. The two theoretical results are for the two damping coefficients 0.5 and 0.94 . The Helmholtz frequency is about $52 \mathrm{~Hz}$. Experimentally, the figure shows a roughly $15 \%$ amplification of the internal pressure comparing to the external pressure around the Helmholtz frequency. Apparently the viscous effect should be included as the result without the viscous term shows a much larger value than the experimental data. However the present theory obtained a very close solution.

Figure 5 is another example of $P_{i} / P_{e}$ between the theory and the speaker test for R05L. It is interesting to see that the peak of $P_{i} / P_{e}$ disappeared completely in the test. This means that once the 
opening is very small, there is no need to worry the occurrence of the Helmholtz resonance. Obviously, even with the viscous effect the results of the theory and experiment are totally different. It is believed that flow physics in the opening has changed and the effect of viscosity is not only confined to a thin layer near the wall but the whole flow region.

Another important parameter regarding to the dynamic characteristics of the opening is the phase difference between the internal and external pressures. Figure 7 shows the results for R20L. The theoretical solutions on the figure are obtained with the damping coefficient 0.94 . Though there is some difference when $f>200$ between the experiment and theory, they generally show a good agreement between the present theory and experiment. It should be pointed out that if the old damping coefficient 0.5 is used, a much larger phase value, thus a larger deviation from the experiment would be obtained. The sudden phase decrease at $f=300$ shown in the graph is considered to be due to the speaker resonance at the vicinity of this particular $f$ value, which resulted in the irregularity of the signal.

\section{APPLICATION}

In this session, wind loads on a simple model of building external elements are obtained by using the procedure and concept shown in the previous sessions. The model is shown in figure 8. Its volume of internal space and total area of openings between adjacent elements are listed in table 3 . External pressure is assumed to be a sinusoidal function having a frequency of $\omega$ and amplitude of $100 \mathrm{kgf} / \mathrm{m}^{2}$ in the following equation.

$$
p_{e}(t)=100 \sin \omega t \quad \mathrm{kgf} / \mathrm{m}^{2}
$$

The results are shown in figures 9 to 11 . The ratio of internal pressure to external pressure is shown in figures 9(a) and (b). The ratio is 1 in the lower frequency range, and it becomes smaller than 1 when frequency becomes larger than about 5 to $10 \mathrm{~Hz}$. The frequency becomes low with the increasing of internal volume or the decreasing of area between the adjacent elements. Figure 10 shows phase angle between external and internal pressures. The phase angle is 0 in the lower frequency range. The higher the frequency is, the lager the phase angle would be. Amplitude of wind load is shown as a ratio to the external pressure amplitude in figure 11. Wind load in lower frequency is found to be 0 because the phase angle between internal and external pressures is 0 . These results show that wind loads on the external elements can be reduced by adjusting the volume of internal space and the areas of openings between adjacent elements. Note that in the present calculation in order to require wind loads on the building external elements accurately, phase angle between external and internal pressure, etc. has been taken into consideration.

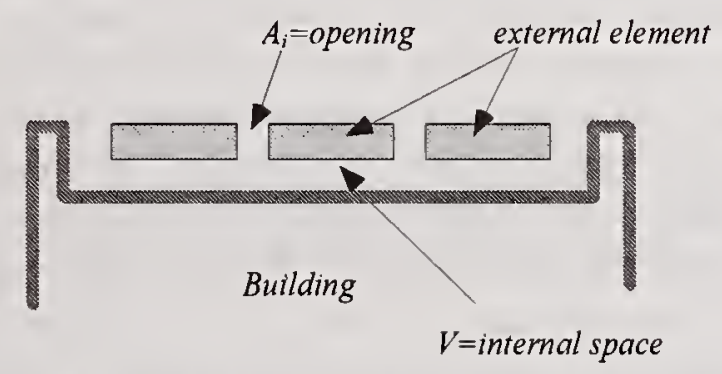

Figure 8: A model of building external elements
Table 3 Combinations of total area of openings and volume of internal space for application models ( $O$ designates models used here)

\begin{tabular}{|r|c|c|c|}
\hline \multirow{2}{*}{$V\left(\mathrm{~mm}^{3}\right)$} & \multicolumn{3}{|c|}{$\sum A_{i}\left(\mathrm{~mm}^{2}\right)$} \\
\cline { 2 - 4 } & 10 & 20 & 40 \\
\hline \hline $25 \times 10^{5}$ & & 0 & \\
\hline $50 \times 10^{5}$ & 0 & 0 & 0 \\
\hline $100 \times 10^{5}$ & & 0 & \\
\hline
\end{tabular}




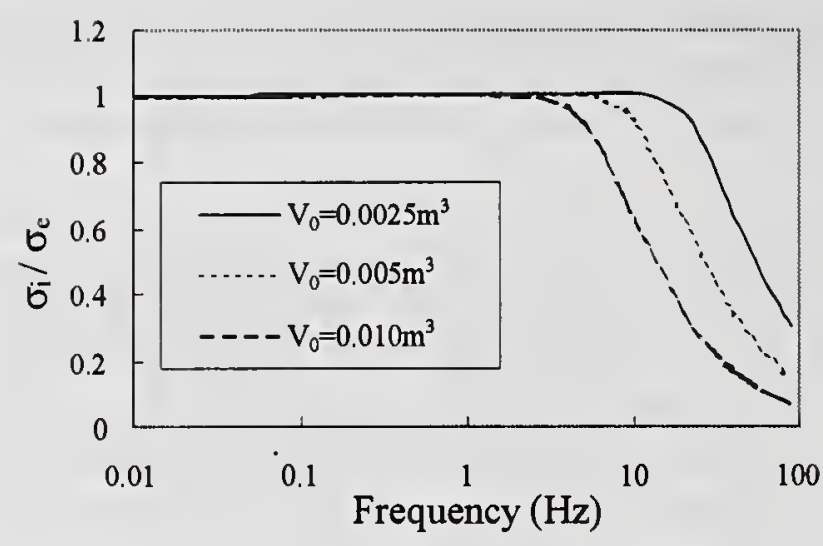

(a) $\Sigma \mathrm{A}_{\mathrm{i}}=40 \mathrm{~cm}^{2}$

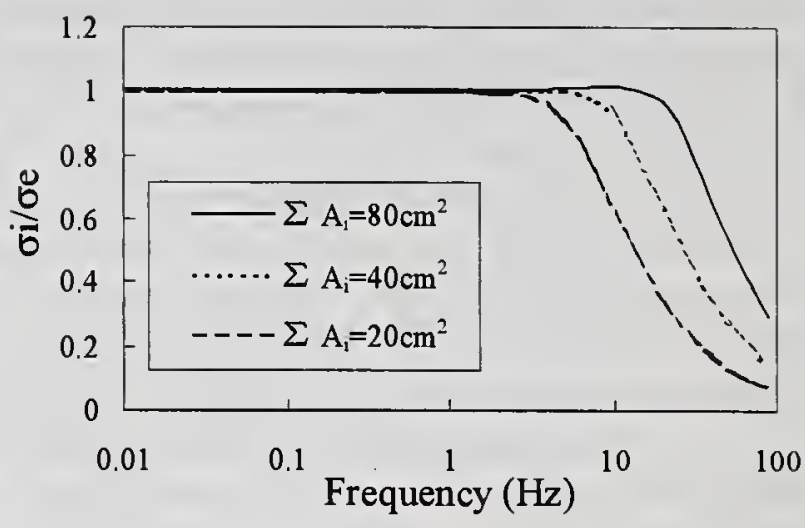

(b) $\mathrm{V}_{0}=0.005 \mathrm{~m}^{3}$

Figure 9 Ratio of internal to external pressure amplitudes

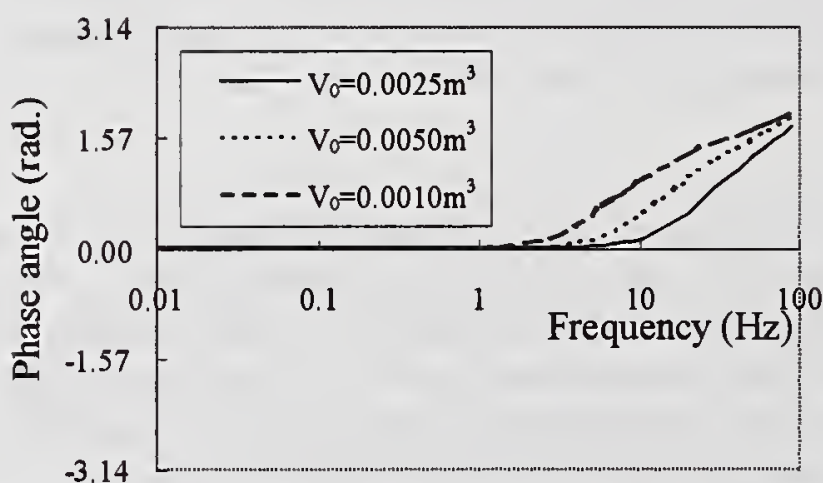

Figure 10: Phase angle between external and internal pressures

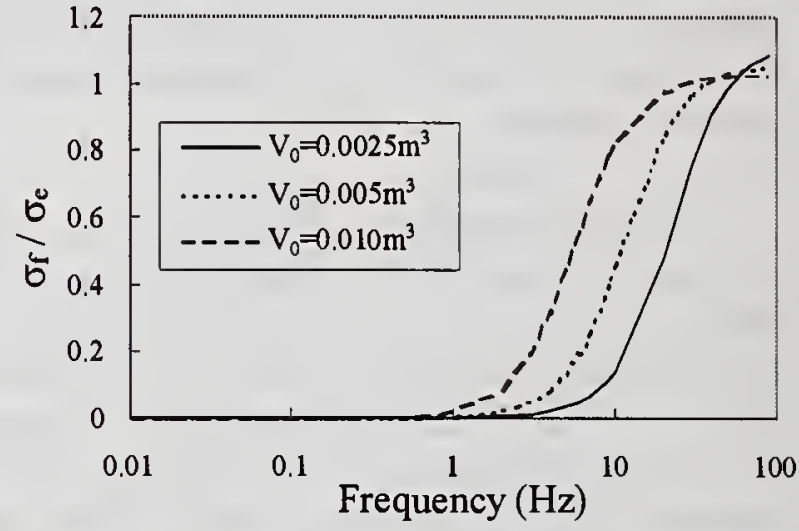

Figure 11: Ratio of load to external pressure amplitude

\section{CONCLUSIONS}

Some of the important aspects from the current study are summarized:(1) A fundamental equation is described for estimation on wind loads on building external elements; (2) A new equation with a damping coefficient 0.94 , similar to Liu's equation, is developed to obtain a better solution of the internal pressure. The simple method, employed to solve the equation, is very accurate to obtain both the amplitude and phase value of the internal pressure; (3) The speaker test can be regarded as a simplified version of the wind tunnel test. Not only it verified the theory, it is also used to predict the dynamic pressure transmission characteristics of various openings;(4)Wind loads on the building external elements are changed by adjusting area of openings between adjacent elements and volume of the internal space between the elements and sheathing board.

\section{REFERENCES}

[1] Liu, H. and Saathoff, P.J., "Building Internal Pressure: Sudden Change", Journal of the Engineering Mechanics Division, ASCE, Vol. 107, No. 2, 1981.

[2] Holmes, J.D., "Mean and Fluctuating Internal Pressures Induced by Wind", Proc. of the 5th International Conference on Wind Engineering, Fort Collins, Colorado, July 1979.

[3] Liu, H. and Rhee, K.H., "Helmholtz Oscillation in Building Models", Journal of Wind Engineering and Industrial Aerodynamics, Vol. 24, 1986, pp. 95-115.

[4] Schlichting, H., "Boundary Layer Theory", McGraw Hill Series in Mechanical Engineering, 1968. 


\title{
WIND TUNNEL STUDIES ON LONG-SPAN BRIDGES CONDUCTED AT THE LARGE BOUNDARY LAYER WIND TUNNEL IN TSUKUBA
}

\author{
by \\ Hiroshi SATO \\ Head, Structure Division, Structure and Bridge Department, \\ Public Works Research Institute, Tsukuba, JAPAN
}

\begin{abstract}
The Large Boundary Layer Wind Tunnel, whose test section is $41 \mathrm{~m}$ wide, $4 \mathrm{~m}$ high and $30 \mathrm{~m}$ long, was constructed at Public Works Research Institute (PWRI) in 1991, as one of cooperative studies between PWRI and Honshu-Shikoku Bridge Authority. By using this facility, wind tunnel studies for the Akashi Kaikyo (strait) Bridge, which will be the longest suspension bridge in the world, and for the Tatara bridge, which will be the longest cable-stayed bridge in the world, have been conducted.

From the wind tunnel studies, the safety of these bridges were confirmed. In addition, some new properties on flutter and gust response of super long-span bridges were found.
\end{abstract}

\section{KEYWORDS}

Super long-span suspension bridge, Super longspan cable-stayed bridge, Flutter, Gust response, Full aeroelastic model, Wind tunnel study, Turbulent flow, Surrounding Islands

\section{INTRODUCTION}

The study on wind effects is very important for the design of super long-span bridges. The Akashi Kaikyo Bridge (Fig.1, Photo 1), which is now under construction, will have the main span length of $1990 \mathrm{~m}$, which is $580 \mathrm{~m}$ longer than the Humber Bridge, the longest bridge in the world at present.

In Japan, the safety of proposed design of longspan bridges to wind-induced instabilities has been confirmed mainly by spring-mounted rigid sectional model test in smooth flow. Since the span length of the Akashi Kaikyo Bridge is much longer than the existent longest bridge in the world, it was thought that the wind-induced instabilities should be confirmed by more accurate wind tunnel study, namely full aeroelastic model study.

From these reasons, cooperative study on wind resistant design of super long-span bridges was started in 1989 by PWRI, Ministry of Construction and Honshu-Shikoku Bridge Authority (HSBA). The Large Boundary Layer Wind Tunnel was constructed at PWRI in 1991 as one of the cooperative efforts between PWRI and HSBA, and wind effects on the Akashi Kaikyo Bridge were investigated in smooth flow and in turbulent flow using the full aeroelastic model, whose scale ratio was $1 / 100$.

The Tatara Bridge (Fig.2, Photo 2), which is also under construction in Japan, will have the main span length of $890 \mathrm{~m}$. The bridge will be the world's longest cable-stayed bridge in future. Since the Tatara bridge has such a long span, it was thought that the aerodynamic behavior should be confirmed through full aeroelastic model test at the Large Boundary Layer Wind Tunnel in PWRI.

The Tatara bridge will be surrounded by islands. Some of the islands have high mountains up to $400 \mathrm{~m}$ above the sea level. Therefore, it was considered that topographical effect should be studied using topographical model.

In this paper described are the Large Boundary Layer Wind Tunnel and the wind tunnel studies for the Akashi Kaikyo Bridge and the Tatara Bridge conducted at the Large Boundary Layer Wind Tunnel.

\section{LARGE BOUNDARY LAYER WIND TUNNEL [1]}

\subsection{REQUIRED DIMENSIONS AND PERFORMANCE OF THE WIND TUNNEL}

At first, the model scale of $1 / 100$ was decided so that it might simulate the characteristics of the bridge and that its scale might become as small as 
possible. Then the width $41 \mathrm{~m}$ and height $4 \mathrm{~m}$ of the test section were decided to put whole the model in it. The length of the test section $30 \mathrm{~m}$ were selected in order to generate boundary layer turbulent flow.

The maximum wind speed of $12 \mathrm{~m} / \mathrm{s}$ was required considering the Froude number similarity and energy loss due to turbulence generation.

The required properties of smooth flow were as follows:

a) Turbulence Intensity ; less than $1 \%$

b) Mean Wind Speed Distribution ; less than $3 \%$

\subsection{PILOT WIND TUNNEL TEST}

In order to determine the dimensions of the wind tunnel and the building, a pilot wind tunnel test was carried out. Its scale was $1 / 16$. The pilot wind tunnel is shown in Photo 3. The main findings are as follows:

1) Specifications of the contraction nozzle ;

a) Contraction ratio 2 could satisfy the required flow properties.

b) Two steel screens were required.

c) One of steel screens should be installed at the entrance of the bell-mouth.

2) Building ;

a) The minimum length of $75 \mathrm{~m}$ was required.

b) The minimum height of $19.5 \mathrm{~m}$ was required.

3) Others ;

a) Corner-vanes at the entrance were very effective. However, those at the exit were not.

b) The flow was little affected by the inside trusses supporting the ceiling of building.

c) The flow was little muddled by the streamline-section posts of corner-vanes.

\subsection{FINAL PLAN OF THE WIND TUNNEL}

The general layout of the wind tunnel facility selected as a final plan is shown in Fig.3. The following items were determined considering the usage:

a) Three test sections were prepared: upstream section for smooth flow test, downstream section for turbulent flow test and center section for test of the model with yaw angle.

b) Sensor rooms were arranged at both sides of the test section.

c) Size and number of fans were selected as $1.8 \mathrm{~m}$ in diameter and 36 , respectively.

d) Wind speeds should be controlled by rotation cycles of fans.

\subsection{PERFORMANCE OF THE WIND TUNNEL}

Properties of a smooth flow in this wind tunnel were measured as follows:

a) Turbulence intensity; less than $0.5 \%$

b) Variation in mean speed; less than $3 \%$

Consequently, the required properties such as low turbulence and uniformity of the flow were sufficiently satisfied.

\section{WIND TUNNEL STUDY FOR THE AKASHI KAIKYO BRIDGE [1]}

\subsection{AEROELASTIC FULL MODEL OF THE AKASHI KAIKYO BRIDGE}

\section{1) Modeling of Stiffening Truss Girder}

In modeling of the stiffening truss girder, attention was paid to realizing the similarity of the stiffness without providing stiffening spine at the center of cross section. Two types of truss models were studied. One was the rigid block model connected by springs, and the other was the wholly elastic model in which four main chords were used as stiffening bars. As for the latter, it was found difficult to support floor decks at the accurate positions. Since it was known that the position of floor decks affects flutter characteristics of the bridge very much, the rigid block model type was selected.

In this type of model, each rigid block was composed of every four truss panels to simulate the geometrical shape of the actual truss girder, and springs installed between blocks to represent the mechanical characteristics. Based on the preliminary study, V-shape springs were selected. The model is shown in Fig.4.

The effects of springs and clearances between the blocks on the flutter characteristics were studied through sectional model test, and their effects were found to be small . The blocks were designed as rigid as required by using light new material of carbon fiber plate for the truss members. The detailed modeling of the truss girder was one of reasons why geometrical scale 
of $1 / 100$ was adopted.

\section{2) Modeling of Tower}

The model of tower was composed of a frame of stiffening bars and exterior wooden forms by which the geometrical shape of actual structure was simulated. The bending stiffness in the plane of bridge and torsional stiffness about tower axis were simulated by choosing an appropriate section of stiffening bars. The bending stiffness in the plane of tower was simulated by replacing the effect of actual diagonal members to that of lateral members, namely, by cutting at their connections. The axial stiffness of tower columns, however, could not be simulated correctly in this method, and it resulted small error in torsional displacement of the girder.

Fig.2 shows a frame of stiffening bars of the tower model. The level of similarity was checked by analyzing natural frequencies and static deflection of the total bridge structure. The results were almost satisfactory.

\section{3) Modeling of Cables}

As for the modeling of the cables, the mass, drag force and axial stiffness should be simulated, considering the effect of Reynolds number on drag force. Therefore, model cable was composed of a uniform wire and weight pieces. The uniform wire was used for similarity of axial stiffness, and the weight pieces for similarity of mass and drag force. The dimension and interval of weight pieces were determined from drag force measured in wind tunnel test.

Aerodynamic interaction between stiffening truss and cables near the center of main span was also considered. From the section model test results, it was determined to attach geometrically simulated weight pieces near the center of the main span. Fig. 2 shows the modeling of cables.

\section{4) Connections}

Connections of each element such as end links, tower links, cable anchors, tower bases etc. were carefully designed so as to realize the same functions as those of the actual bridge and to keep structural damping as small as possible.

\section{5) Structural Properties of the Model}

The completed full model of the Akashi Kaikyo
Bridge is shown in Photo 4. Natural frequencies measured at dynamic tests of the model agreed well with the required values, which meant that the model was fabricated with good accuracy. Structural damping of the model was small enough.

\subsection{EXPERIMENTS IN SMOOTH FLOW}

\section{1) Static Torsional Displacement}

Relation between wind velocity and static torsional displacement at the mid-point of center span is shown in Fig.5. At wind velocity of $6 \mathrm{~m} / \mathrm{s}$, that is equivalent to design wind speed of $60 \mathrm{~m} / \mathrm{s}$ for the prototype bridge, torsional displacement of -2 degrees was observed. Although the observed torsional displacement was a little larger than the analytical value due to such reasons as error in simulation of longitudinal stiffness of towers, this remarkable displacement seems to be one of distinctive features of super long-span bridges.

In addition, it was found that major cause of torsional displacement was not the aerodynamic moment but torque due to tension of inclined suspending rope caused by the aerodynamic drag force acting to the stiffening truss.

\section{2) Flutter Characteristics}

\section{a) Damping}

Relation between wind speed and logarithmic decrement is shown in Fig.6. The damping of torsional mode decreased drastically when wind speed exceeded $7 \mathrm{~m} / \mathrm{s}$. Wind speed of $8.5 \mathrm{~m} / \mathrm{s}(85$ $\mathrm{m} / \mathrm{s}$ for prototype) was flutter onset speed. Here, the vibrational mode was not pure torsion, but coupled with vertical bending mode. In case of the section model test of the attack angle of 0 degree, damping decreased from wind speed of $2 \mathrm{~m} / \mathrm{s}$, and flutter occurred at $6 \mathrm{~m} / \mathrm{s}$.

\section{b) Frequency}

As is shown in Fig.7, torsional frequency decreased as wind speed became higher, and at onset wind speed the frequency became $90 \%$ of natural frequency. On the other hand, frequencies of bending mode scarcely decreased. This tendency of frequencies was almost same as that of section model tests.

\section{c) Rotation Center}

Fig.8 illustrates the position of rotation center measured along bridge axis. The rotation center lay on the windward side at the midspan, on the 
leeward side at quarter point of center span, and on the windward side again at the middle of side spans. Flutter observed in the section model test was also coupled one in which the rotation center lay on the windward side, and the behavior was almost similar to that of the midspan of the full model.

d) Vibrational Modes

Torsional and vertical bending response at every $1 / 8$ cycle are illustrated in Fig.9. As for the torsion, flutter mode was almost same as the first symmetric one in windless condition. As for the vertical bending, however, flutter mode did not agree with any single mode in windless condition, but very complicated.

\section{3) Distinctive Feature of Flutter of Super Long- Span Bridges}

In case of ordinary suspension bridges, which have center span of about $1,000 \mathrm{~m}$, static torsional displacement is negligibly small. It was found in the full aeroelastic model test of the Akashi Kaikyo Bridge, however, that relative angle of attack cased by the static displacement was not negligibly small, and that it varied along the bridge axis. Since angle of attack affects flutter characteristics, the effects of torsional displacement on the aerodynamic stability must be considered in case of super long-span bridges, which have center span of $2,000 \mathrm{~m}$ or over.

In addition, the flutter of the Akashi Kaikyo Bridge was not stall flutter but coupled flutter, and the vertical bending mode during flutter was not single natural mode but complicated one. Therefore it does not seem that aerodynamic stability of super long-span suspension bridges can be predicted directly from spring-mounted rigid model test.

\section{4) Comparative Flutter Analysis}

Since spring-mounted rigid model could not be compared directly with the present full model test, flutter analysis was conducted considering the effect of the static torsional displacement, including higher natural modes as well as the first natural mode, and using measured aerodynamic derivatives.

At first, the following aerodynamic derivatives were considered:

Drag due to Along-wind motion; quasi-steady theory
Lift due to Heaving motion; measured

Lift due to Torsional motion; measured

Pitching moment due to Heaving motion; measured

Pitching moment due to Torsional motion; measured

The results are shown in Fig.6 and 7. The agreement with full model test was not good. Since the change of drag with angle of attack was not small at the relative angle of attack caused by static torsional displacement near the flutter speed, it was thought that the other aerodynamic derivatives should be included in the flutter analysis.

In the second analysis, the following aerodynamic derivatives were considered as well as the above ones:

Drag due to Heaving motion; measured

Drag due to Torsional motion; measured

Lift due to Along-wind motion; quasi-steady theory

Pitching moment due to Along-wind motion; quasi-steady theory

The results are shown in the same figures. The agreement was fairly well. From additional analysis, it was found that drag due to heaving motion and torsional motion was more effective than lift and pitching moment due to along-wind motion.

\subsection{EXPERIMENTS IN TURBULENT FLOW}

\section{1) Test Condition}

The same aeroelastic full model as used in smooth flow test was used.

The turbulent flow was generated by spires and roughness. In the simulation of turbulent flow, it was thought that turbulent intensity and integral scale of turbulence were the most important parameters to be similar to natural wind. The intensity of turbulence Iu for main wind direction at the deck height was assumed to be $10 \%$. Several spires and some arrangements of roughness blocks were tested, and the most suitable spires and roughness blocks were selected. 
The main properties of the turbulent flow were as follows:

power extent of wind speed profile; $1 / 5.1$

intensity of turbulence; $\quad \mathrm{lu}=9.6 \% \mathrm{Iw}=6.8 \%$ integral scale of turbulence;

$\mathrm{Lxu}=1.1 \mathrm{~m}, \mathrm{Lxw}=0.4 \mathrm{~m}$

Although the power extent of vertical distribution of mean wind speed was a little larger and the integral scale of turbulence was a little smaller, the properties of the simulated turbulent flow were thought to be fairly satisfactory.

\section{2) Test Results}

It seems obvious that the random vibrations observed at relatively low wind speeds were caused by approaching turbulence. As wind speed increases, however, characteristics of the vibration changes. The power near the torsional 1st mode becomes dominant at higher wind speeds. The increase rate of the vibrational amplitude with wind speed becomes larger at higher wind speed. It can be seen clearly in Fig. 10, where displacement and wind speeds were plotted in logarithmic scales. These changes in vibrational characteristics seem to be caused by negative aerodynamic damping, which result in flutter. The apparent damping of the model in wind, which is sum of structural damping and aerodynamic damping, was estimated by random decrement method [2], and is shown in Fig. 11. It is clear that the apparent damping becomes small at high wind speeds.

\section{3) Effect of Turbulence on Flutter}

The vibrations of the bridge model at high wind speed in turbulent flow were caused by both gust and negative aerodynamic damping. It can be said that the observed vibrations are mixture of gust response and flutter. It is difficult to separate vibrational amplitude caused by flutter from that caused by gust. Therefore, the effect of turbulence on flutter was investigated in viewpoint of damping rather than vibrational amplitude.

The relationship between wind speed and apparent damping of torsional vibration in turbulent flow is shown in Fig. 11, compared with that in smooth flow. Since the difference in apparent damping between in turbulent flow and in smooth flow is small, it can be said that the effect of turbulence on flutter is small in case of the Akashi Kaikyo Bridge.
4) Comparison between Calculated Gust Responses and Observed Ones

a) Calculation Method

For comparison, gust responses of horizontal bending, vertical bending and torsion were calculated according to the ordinary methods in frequency domain [3]. In the calculation of torsional gust responses, the effect of horizontal bending modes was considered.

As for wind and structural properties, the observed data were used. As for coefficients of drag, lift and aerodynamic moment, the data measured in sectional model test in smooth flow were used. Aerodynamic forces caused by gust were calculated according to quasi-steady theory, corrected by aerodynamic admittance and spatial correlation as follows:

i) aerodynamic admittance for drag [3]

$\mathrm{Xu} 2(\mathrm{fd})=2[\mathrm{kfd}-1+\exp (-\mathrm{kfd})] /(\mathrm{kfd}) 2$

ii) aerodynamic admittance for lift and moment [4]

$$
\begin{aligned}
\mathrm{Xw} 2(\mathrm{fb})= & (\mathrm{a}+\pi \mathrm{fb}) \\
& /[\mathrm{a}+(\pi \mathrm{a}+1) \pi \mathrm{fb}+2 \pi(\pi \mathrm{fb}) 2]
\end{aligned}
$$

iii) spatial correlation [5]

$$
\mathrm{R}(\mathrm{fb})=\exp (-\mathrm{kfb}|\mathrm{x} 1-\mathrm{x} 2| / \mathrm{B})
$$

where,

$\mathrm{a}:$ constant $(=0.1811)$

$B$ : width of stiffening truss

$D$ : depth of stiffening truss

$f$ : frequency

$\mathrm{fb}=\mathrm{fB} / \mathrm{U}$

$\mathrm{fd}=\mathrm{fD} / \mathrm{U}$

$\mathrm{k}$ : decay factor (assumed to be 8 )

$\mathrm{U}:$ mean wind speed

$\mathrm{x} 1, \mathrm{x} 2$ : coordinate along bridge axis

Aerodynamic damping for horizontal and vertical bending vibration was calculated according to quasi-steady theory. As for torsion, aerodynamic damping was assumed to be zero.

\section{b) Comparison}

The gust responses calculated at the design wind speed are shown in Table 1, compared with the responses observed in experiment. The agreement in vertical bending and in torsion was fairly good, however, the observed horizontal bending responses were much smaller than calculated ones.

One of the causes of this discrepancy is thought to be the spatial correlation which was assumed as 
the exponential function of $\mathrm{fb}|\mathrm{x} 1-\mathrm{x} 2| / \mathrm{B}$. Since the measured spatial correlation of wind speed (root co-coherence function, Fig.12) did not tend to unity as frequency became 0 when separation of measurement points were large, the calculation might lead to an overestimation as was pointed out in ref.[6] and [7]. Another possible cause of the discrepancy is thought to be aerodynamic admittance.

\section{c) Improved Calculation}

The aerodynamic admittance for this stiffening truss was measured. Using the measured aerodynamic admittance and the spatial correlation based on the turbulent flow of the wind tunnel, gust responses were calculated again. The result is shown in Table-1, which agrees with experimantal result better than the previous calculation.

\section{STUDY FOR THE TATARA BRIDGE}

\subsection{EXPERIMENT IN SMOOTH FLOW [8]}

\section{1) Aeroelastic Full Model of the Tatara Bridge}

The model was fabricated with a geometric scale of 1/70. Except for the cables, the model was designed by well known methods, i.e. steel frame was designed to achieve proper stiffness, additional mass was installed to simulate mass and polar moment of inertia, and the frame and additional mass were covered with exterior wooden forms to simulate geometrical shape.

Froude number similitude was adopted to the design of the model. This means wind speed ratio was 8.4 .

Attention was paid to the design of the cables. As well as the number of the cable, mass and tensile force of each cable was simulated. The drag force acting on each cable was also similar to the prototype bridge. Piano wires were used to simulate axial stiffness. In order to give proper mass to each cable, cylindrical mass pieces were placed at a certain interval. The mass pieces were so designed that the cables might have proper mass and drag force. For the similarity of drag force, the difference in Reynolds number were taken into account. Similar method was used for the design of cables in the model of Akashi Kaikyo Bridge. Tensile force in each cable was measured from its natural frequency, and adjusted by turning turnbuckle installed at the end of cable.

During the preliminary wind tunnel test, it was found that the stay cables of the model vibrated in wind. At certain wind speed, the vibrational amplitude became so large that stay cables might touch each other. In the real bridge, the windinduced vibration of stay cables will be eliminated by installing dampers or by some other methods. Therefore the vibration of each cable in the model was eliminated by installing thin extra cables. Through preliminary wind tunnel study, it was found that the thin extra cables would not affect aerodynamic characteristics of the model so significantly.

Photo- 5 shows the model of the Tatara bridge in the Large Boundary Layer Wind Tunnel. The structural characteristis of the model were as follows.

\section{a) Static characteristics}

Static loading tests were carried out in order to check the static characteristic of the model. Either in holizontal, vertical and torsional loading, the results showed good agreement with calculated results.

b) Dynamic characteristics

Free vibration tests in windless condition were carried out to check the dynamic characteristics of the model. It was confirmed that the model represented the prototype bridge well. The damping observed was a little larger than the target value of 0.02 .

\section{2) Wind-Induced Vibration}

The followings are results of the wind tunnel tests in smooth flow with the angle of attack $0 \mathrm{deg}$.

a)Vibrational amplitude

No divergent vibration such as flutter was observed up to the reference wind speed of flutter. When the reduced wind speed was about 1.0, small vertical bending vortex-induced vibration was observed. The vibrational mode was 1st symmetric one. Usually, when 1st symmetric vortex-induced vibration is observed, vortexinduced vibration of higher modes are expected in higher wind speeds. However, in this case, no higher modes vibration was observed.

b) Change of damping

The decrease of damping at the reduced wind 
speed of 1.0 is coincident with the appearance of vortex-induced vibration. At higher wind speed, the damping increased with the wind speed.

c)Change of frequency

The frequency of torsion, vertical and horizontal bending scarcely changed.

\subsection{EXPERIMENT WITH ISLAND MODEL [9]}

\section{1) Wind Characteristics at the Construction Site}

In order to clarify wind characteristics such as mean wind speed, wind direction, attack angle, and turbulence intensity, an anemometer was installed at the construction site of the Tatara Bridge. Wind tunnel test was also carried out using $1 / 2000$ scale topographical model of the terrain around construction site (See Fig. 13). The measured data at the site was used in order to calibrate the topographical wind tunnel test (See Fig. 14).

Fig. 15 shows the wind flow pattern measured in the wind tunnel test. From the figure, it can be seen that wind characteristics at the site are very complicated. For example, in the case of wind direction of NNW and SSE, a topographical effect is hardly recognizable. In other words, wind speed and turbulence intensity were scarcely changed by the topography. On the contrary, in the case of wind direction such as $\mathrm{NE}$ and $\mathrm{W}$, wind characteristics were changed significantly by the topography. Particularly, in the case of NE direction, the turbulence intensity was considerably increased by the topography, but the wind speed was not remarkably decreased. In the design of the long-span bridge, these wind characteristics were thought to be critical. Therefore, it was thought that the topographical effects on the bridge must be studied in the wind tunnel test with bridge model and topographical model.

\section{2) Aeroelastic Full Model of the Tatara Bridge}

The scale ratio of the model was determined as to $1 / 200$ considering the size of the wind tuntel, integral scale of turbulence and topographical model to be represented inside the wind tunnel.

Froude number similitude was not adopted to the design of the model, because the wind speed ratio 14 according to Froude number similitude seemed too large to measure wind-induced vibration accurately. The model was fabricated a little stiffer than the Froude number similitude required. The wind speed ratio was about 8 .

The model was designed by well known methods, i.e. steel frame was designed to achieve proper stiffness, additional mass was installed to simulate mass and polar moment of inertia, and the frame and additional mass were covered with exterior wooden forms to simulate geometrical shape. Each three cables of the real bridge was represented by one piano wire in the model. Mass of the cables were equally distributed to the tower and the girder.

Photo 6 show the model of the Tatara bridge in the Large Boundary Layer Wind Tunnel. Free vibration tests in windless condition were carried out to check the dynamic characteristics of the model. The damping of vertical bending mode was a little larger than the target value of 0.02 , and the damping of lateral bending mode was a little smaller.

3) Wind Tunnel Experiments of the Bridge and Island

Wind tunnel experiments were carried out for three cases of wind direction, namely 18,36 and 180 degrees. Wind direction was defined clockwise from the north direction normal to bridge axis. Three directions were chosen because they were thought to be critical from the design point of view. That is, the mean wind speed for 18 and 36 degrees was not noticeably decreased, while turbulence intensity was considerably increased. The wind direction of 180 degrees, normal to the bridge axis, was the prevailing wind at the site. The increase in turbulence intensity due to Hakata Island located in the south of the bridge site was expected to be small.

Wind tunnel experiments were conducted both with and without topographical models. In both cases, approaching flow had slight turbulence generated by spires and roughness blocks.

Fig. 16 shows the rms value of the lateral gust response of the girder at the design wind speed. The experimental results with the topographical models are compared with those without topographical models in these figures. In the case of 18 and 180 degrees, the topographical effect is hardly recognizable because there is little difference in the rms values. On the other hand, in the case of 36 degrees, the topography increased 
the gust response significantly.

\section{4) Discussion}

According to the quasi-steady theory, aerodynamic force due to approaching turbulence increases with square of mean wind speed and turbulence intensity. Fig. 17 shows the wind characteristics along the bridge axis in the three wind directions. In the case of 36 degrees, a significant increase in turbulence intensity along the bridge axis is recognized. However, the increase in turbulence intensity is associated with decrease in mean wind speed.

Another factor that influences the gust response of long-span bridges is correlation of fluctuating wind speed at different places. Table 2 shows turbulence intensity and integral scale of turbulence at the mid-point of the center span in case of 36 degree. It can be seen that the integral scale as well as intensity was increased very much by the topographical model. Fig. 18 shows cocoherence of fluctuating wind speed at two places on the bridge axis. It can be seen that the correlation is much higher in case of 36 degree than in case of 180 degree.

From these measurements, it seems that the large gust response in case of wind direction 36 degree was caused by high turbulence intensity and high space-wise correlation of the turbulent flow generated by the topographical model.

\section{CONCLUDING REMARKS}

1) The Large Boundary Layer Wind Tunnel, whose test section is $41 \mathrm{~m}$ wide, $4 \mathrm{~m}$ high and $30 \mathrm{~m}$ long, was designed and constructed based on test results of $1 / 16$ pilot wind tunnel. The low turbulence and uniformity of wind speed of the smooth flow were satisfactory.

2) Wind Tunnel Study for the Akashi Kaikyo Bridge

a) The $1 / 100$ aeroelastic full model of the Akashi Kaikyo Bridge was designed so that the similarity of shape, mass distribution and stiffness distribution might be satisfied. The stiffening truss was modeled without stiffening spine at the center of cross section. The bending stiffness in the plane of tower was simulated as well as the bending stiffness in the plane of bridge and torsional stiffness about the axis of tower. In modeling of the cables, mass, drag force and axial stiffness were simulated, and aerodynamic interaction with stiffening truss was considered.

b) In the smooth flow test, remarkable static torsional displacement was observed. It was caused mainly by aerodynamic drag force acting to the stiffening truss. Coupled flutter was observed at the wind speed of $8.5 \mathrm{~m} / \mathrm{s}(85 \mathrm{~m} / \mathrm{s}$ for real bridge), and its vertical bending vibrational mode was not similar to any of natural mode, while its torsional vibrational mode was similar to the first symmetric natural mode. Therefore it does not seem that aerodynamic stability of super long-span suspension bridges can be predicted directly from spring-mounted rigid model test.

c) In order to predict flutter of super long-span bridges by analytical way, the effect of the static torsional displacement should be considered, and higher natural modes as well as the first natural mode should be included. Besides, aerodynamic derivatives such as Drag due to Heaving motion, Drag due to Torsional motion, Lift due to Alongwind motion, and Pitching moment due to Alongwind motion should be included in addition to the conventional aerodynamic derivatives.

d) In the turbulent flow test, gust responses were observed in horizontal bending, vertical bending and torsional mode. As wind speed increased, the vibration of torsional 1st mode became dominant, and apparent damping became smaller. This seems to be the effect of flutter. Apparent damping in the turbulent flow was compared with that in the smooth flow. It was found that the effect of turbulence on flutter was small for this bridge model.

e) The observed gust responses were compared with the calculated ones. As for vertical bending and torsional responses, the agreement was fairly good, however, the observed horizontal bending responses were much smaller than calculated ones. The more accurate aerodynamic admittance or spatial correlation should be measured and applied to the calculation of gust responses.

3) Wind Tunnel Study for the Tatara Bridge

a) The aerodynamic stability of the Tatara bridge was investigated in smooth flow. No divergent vibration such as flutter was observed. This means the Tatara bridge is aerodynamically stable. The only wind induced vibration observed was vortex-induced vibration with small amplitude.

b) The gust response of the Tatara bridge was 
investigated through wind tunnel test using 1/200 full aeroelastic model in turbulent flow generated by the model of surrounding islands. When wind direction was 18 and 180 degrees clockwise from the north direction normal to bridge axis, the topographical effect was hardly recognizable. On the other hand, in the case of 36 degrees, the topography increased the gust response significantly.

c) The main reasons for the large gust response measured in case of wind direction 36 degree seem to be high turbulence intensity and high space-wise correlation caused by the topographical model.

\section{ACKNOWLEDGEMENT}

The authors would like to express their thanks to all of members of the study committee for wind resistant design of the Honshu-Shikoku bridges and its subcommittee for wind tunnel works. Discussions at the committees were essential part of this paper.

\section{REFERENCES}

[1] Sumiyoshi Y., Endo T., Miyata T., Sato H. and Kitagawa M., Experiments for the Akashi Kaikyo Bridge in a Large Boundary Layer Wind Tunnel, Proc. of International Seminar on Utilization of Large Boundary Layer Wind Tunnel, Tsukuba, Japan, 1993.

[2] Technical Committee on the Wind Resistant Design of the Honshu-Shikoku Bridge, Final reports on the observation of large scale bridge model (Part 2), JSCE, 1978 (in Japanese)

[3] Davenport A.G., Buffeting of a suspension bridge by storm winds, Proc. ASCE, Vol. 88, ST3, 1962

[4] Fung, Y.C., An Introduction to the Theory of Aeroelasticity, John Wiley \& Sons, 1955

[5] Davenport A.G., The spectrum of horizontal gustiness near the ground in high winds, Q.J. Roy. Met. Soc., Vol. 87, 1961

[6] ESDU, Characteristics of atmospheric turbulence near the ground, Part III: variations in space and time for strong winds (neutral atmosphere), 1975

[7] Irwin H.P.A.H., Wind tunnel and analytical investigations of the response of Lions' Gate Bridge to a turbulent wind, Laboratory Technical Report LTR-LA-210, National Research Council Canada, 1977
[8] Sato H., Toriumi R., Kitagawa M. and Katsuchi H., Wind tunnel experiment for a super long-span cable-stayed bridge in smooth flow, Proc. of 26th Joint Panel Meeting on Wind and Seismic Effects, UJNR, 1994.

[9] Sato H., Kitagawa M. Toriumi R., and Katsuchi $H$., Wind-induced vibrations of a super long-span cable-stayed bridge in turbulent flow generated by surrounding islands, Proc. of 27th Joint Panel Meeting on Wind and Seismic Effects, UJNR, 1995. 
Table 1 Gust Responses

\begin{tabular}{|c|c|c|c|}
\hline & $\begin{array}{c}\text { Horizontal } \\
(\mathrm{mm})\end{array}$ & $\begin{array}{c}\text { Vertical } \\
(\mathbf{m m})\end{array}$ & $\begin{array}{c}\text { Torsional } \\
\text { (deg) }\end{array}$ \\
\hline Measured & 20 & 12 & 1.4 \\
\hline $\begin{array}{c}\text { Calculated } \\
\text { (Conventional } \\
\text { calculation) }\end{array}$ & 83 & 13 & 2.9 \\
\hline $\begin{array}{c}\text { Calculated } \\
\text { (Improved } \\
\text { calculation) }\end{array}$ & 38 & 11 & 1.5 \\
\hline
\end{tabular}

Table 2 Turbulence Intensity and Integral Scale of Turbulence

\begin{tabular}{|c|c|c|}
\hline $\begin{array}{c}\text { Wind Characterinstics } \\
\text { (Center of center span) }\end{array}$ & $\begin{array}{c}\text { with } \\
\text { topographical model } \\
\beta=36^{\circ}\end{array}$ & $\begin{array}{c}\text { without } \\
\text { topographical model } \\
\beta=36^{\circ}\end{array}$ \\
\hline $\begin{array}{c}\text { Turbulence Intensity } \\
\text { Iu (\%) }\end{array}$ & 15.6 & 9.3 \\
Iw (\%) & 8.7 & 5.8 \\
& & \\
Integral Scale \\
of Turbulence \\
Lx u (m) \\
Lx w (m)
\end{tabular}




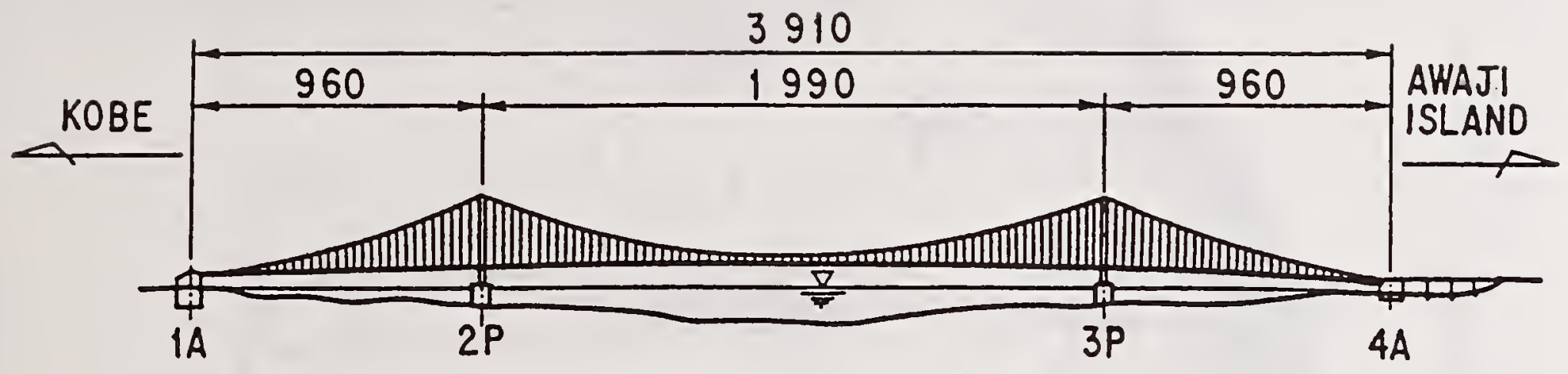

(A) GENERAL VIEW
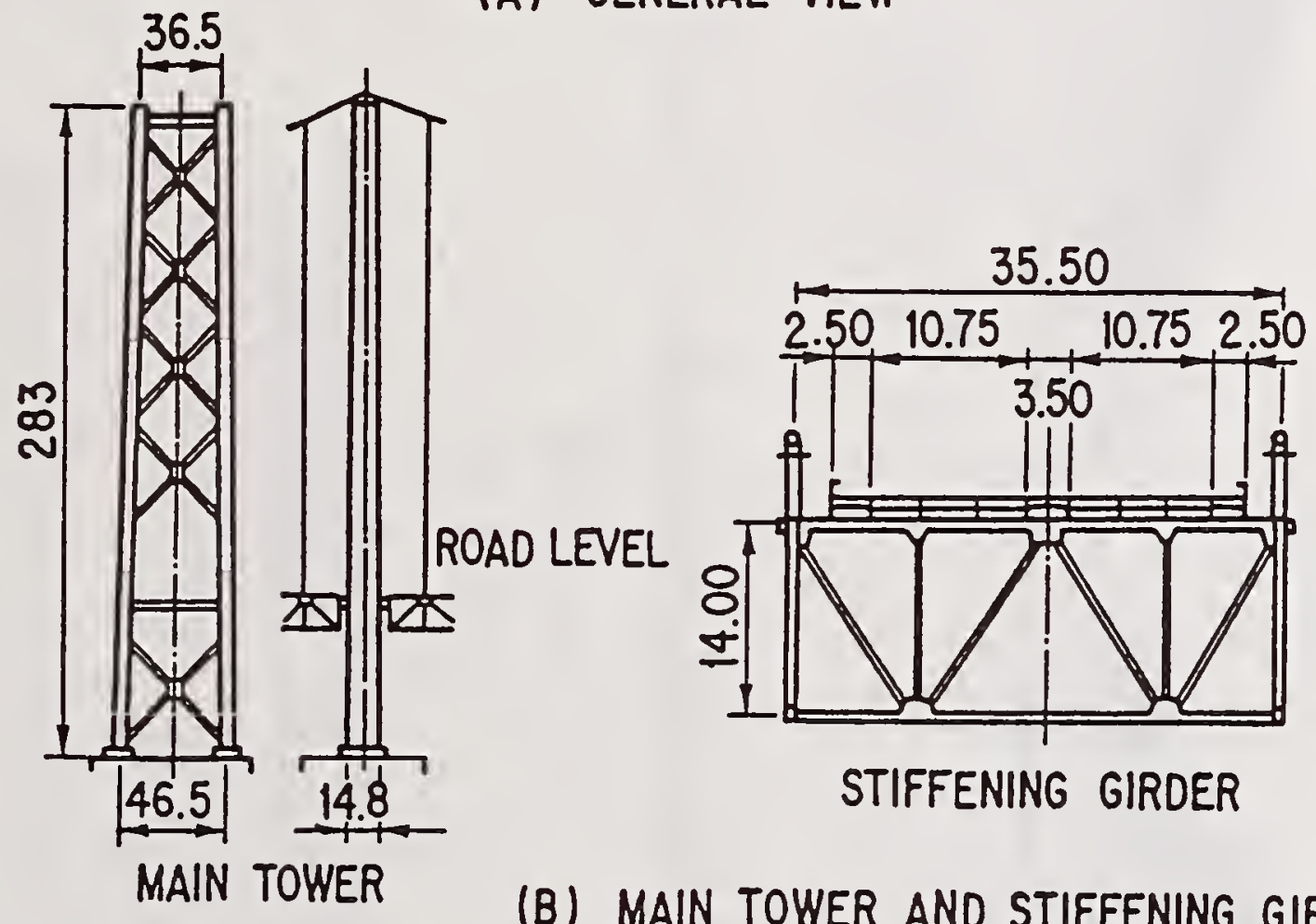

(B) MAIN TOWER AND STIFFENING GIRDER

(unit:m)

Fig. 1 Akashi-Kaikyo Bridge 


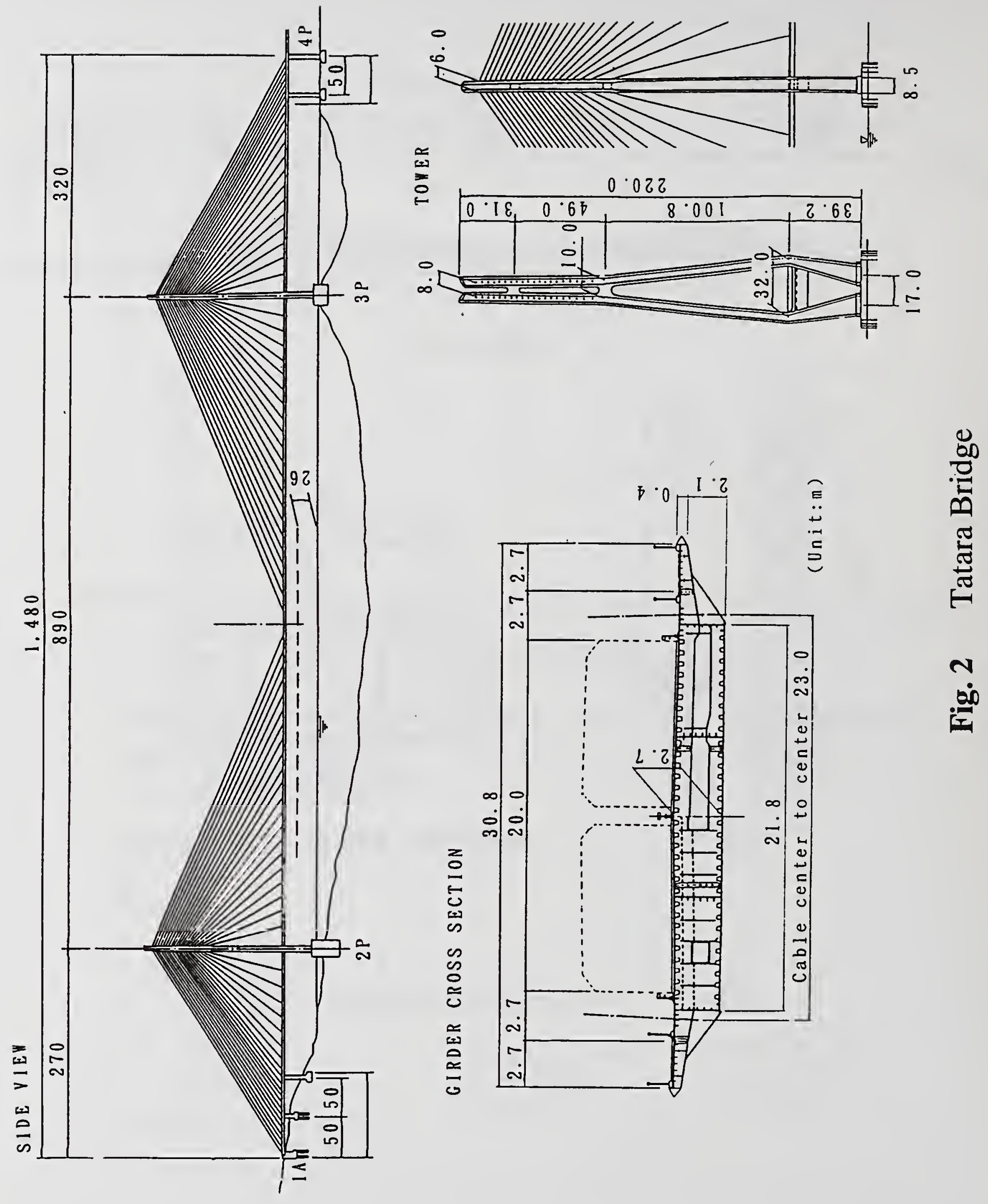




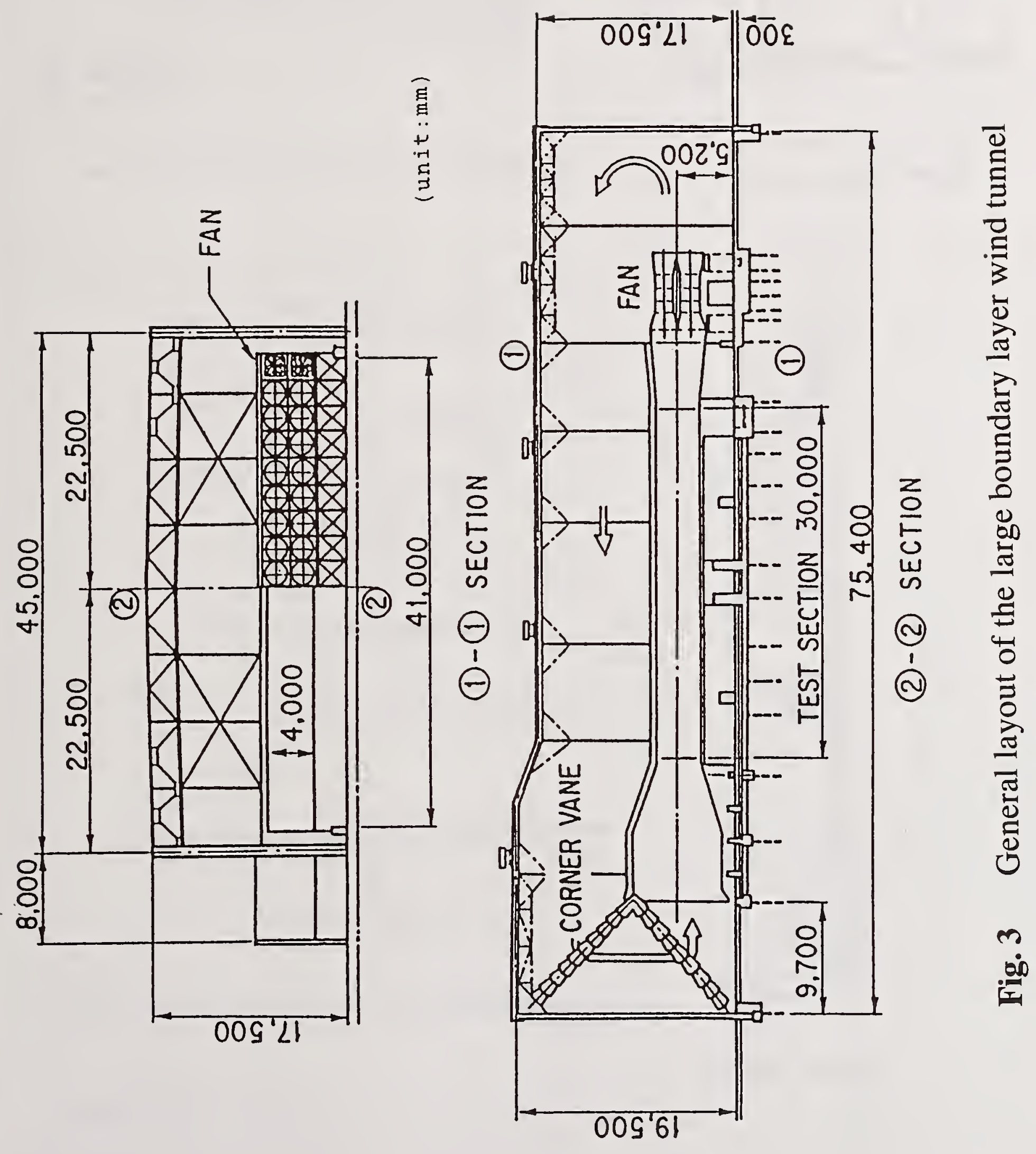




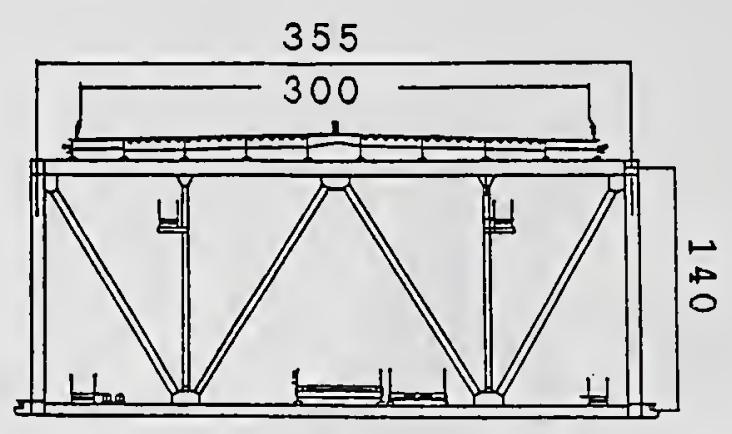

Cross section of

Truss stiffening Girder

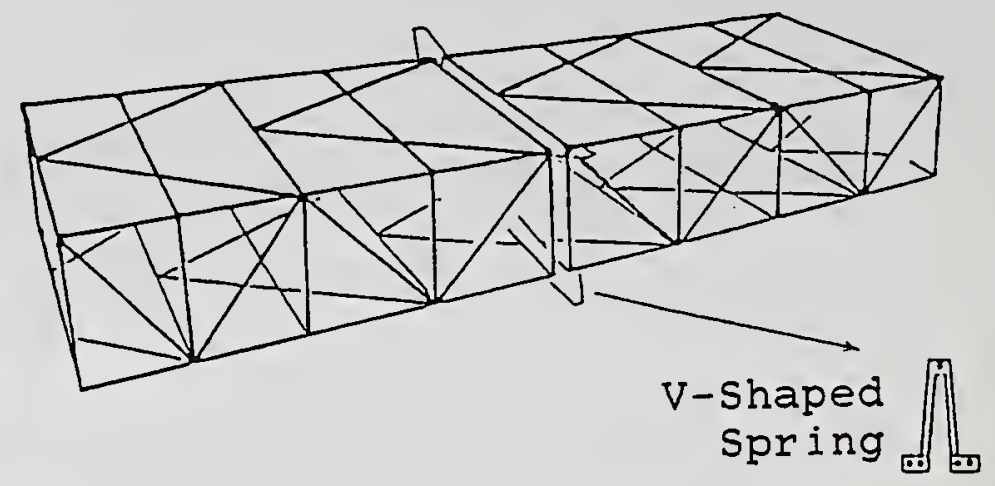

Idea of Stiffening Truss Model

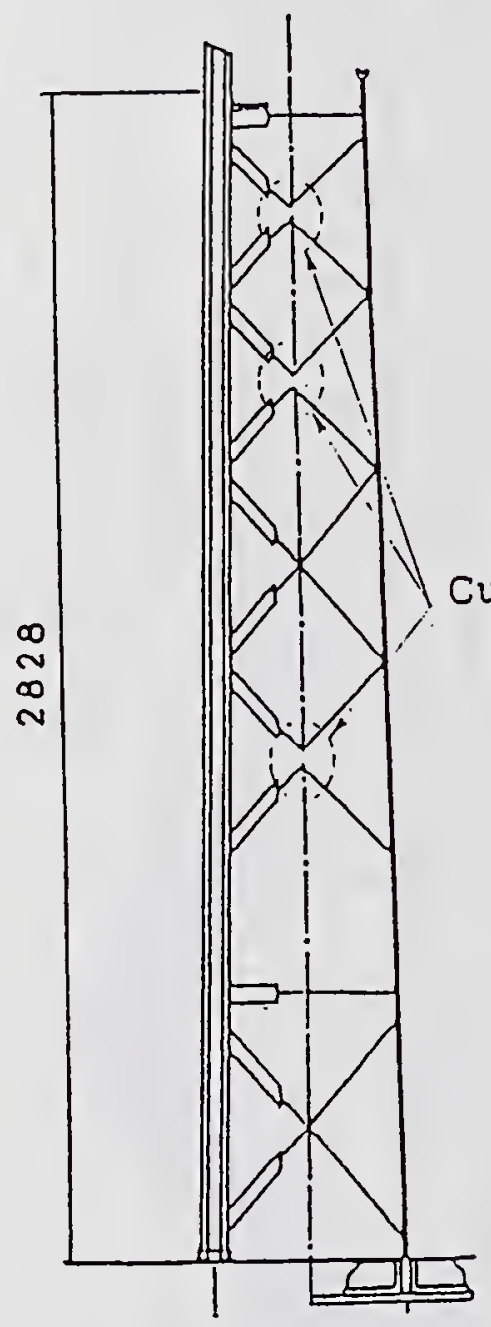

Tower Model

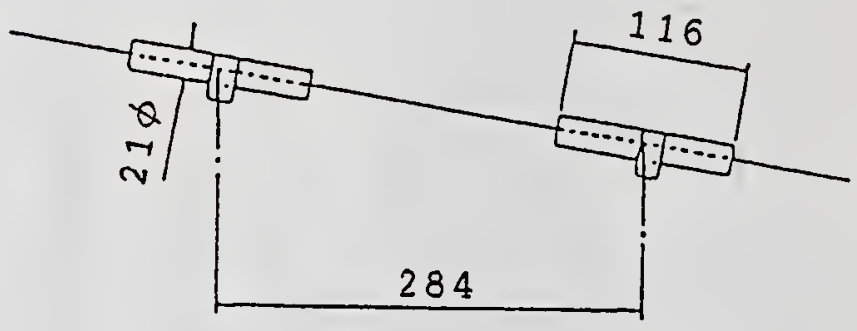

Cable Model(General Part) point

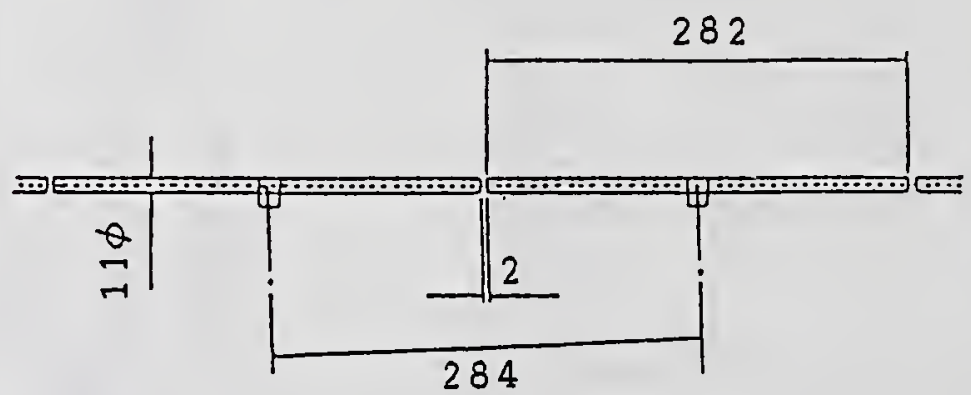

Cable Model(Near the Center of Main Span)

(Unit:mm)

Fig. 4 Full model of the Akashi-Kaikyo Bridge 


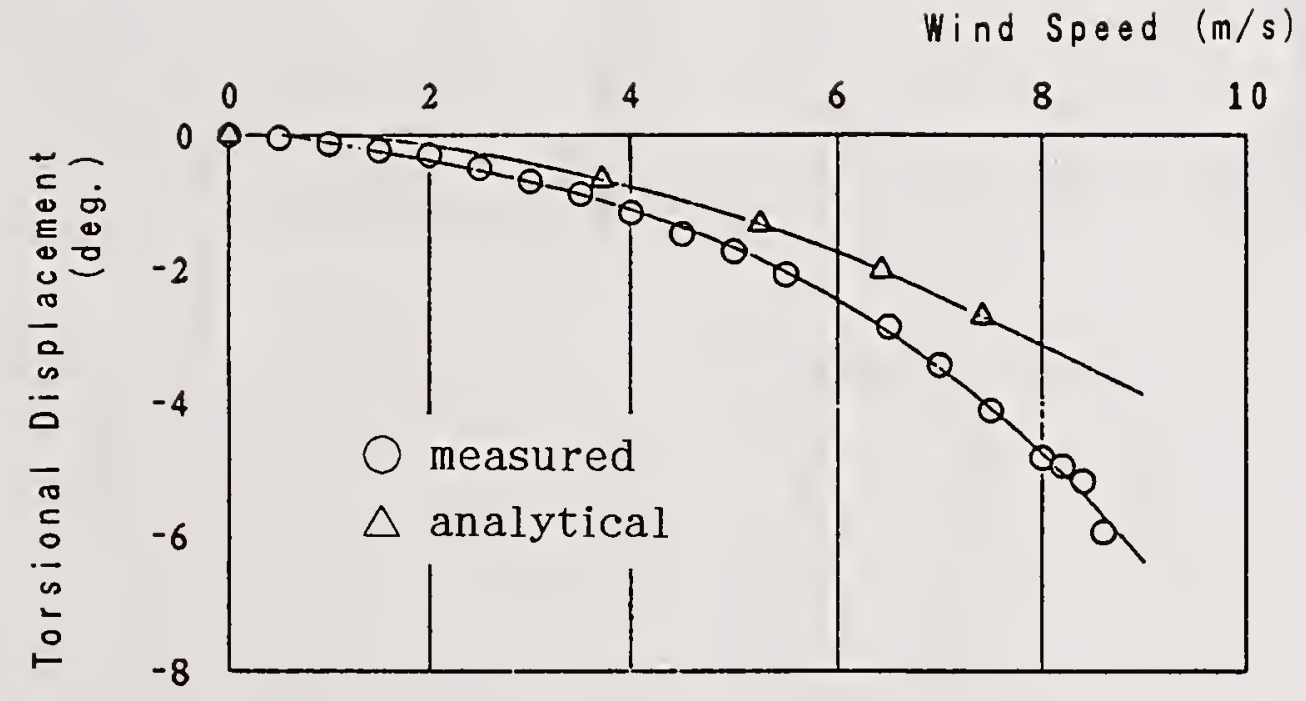

Fig. 5 Torsional displacement by wind (midspan) 

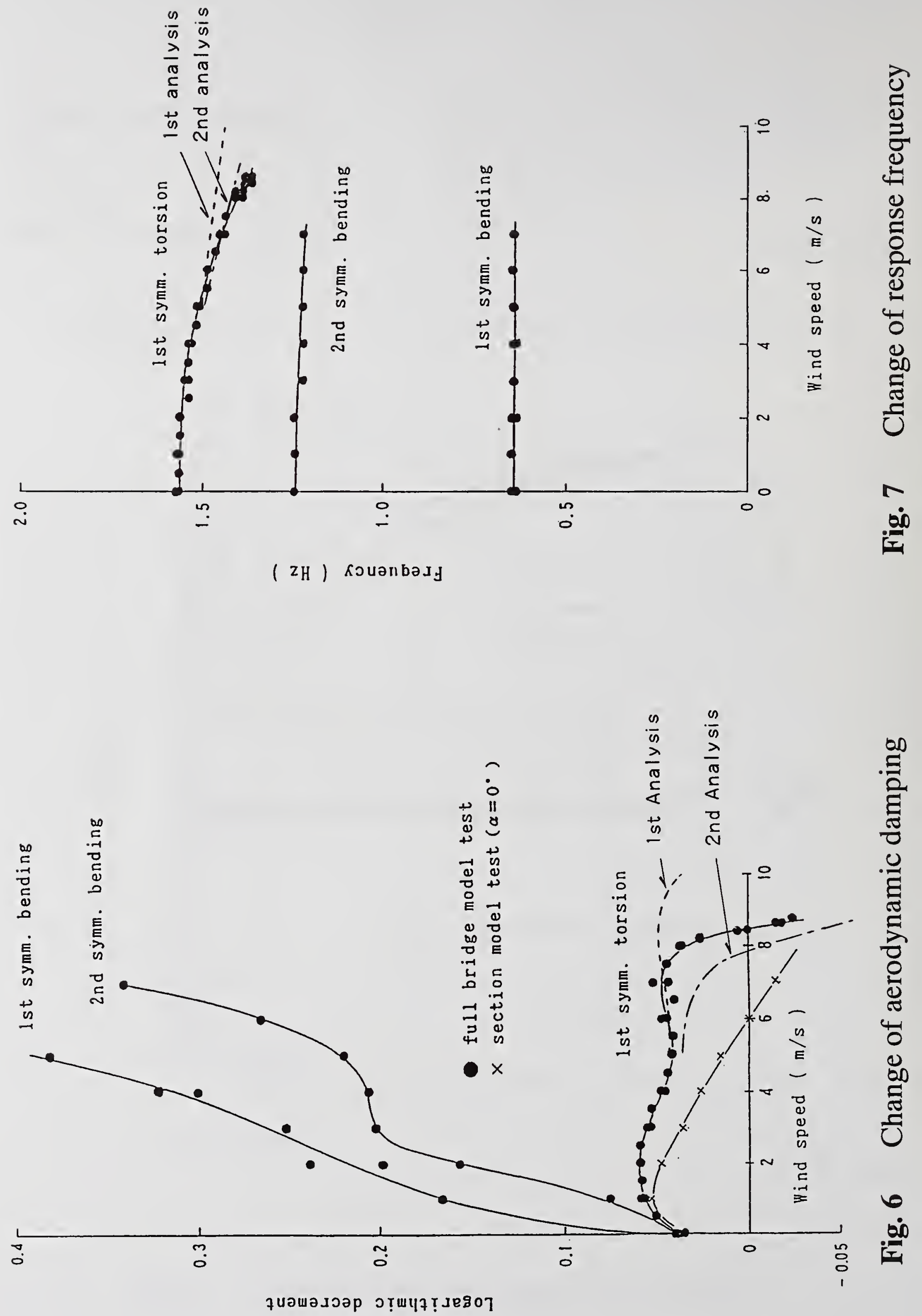

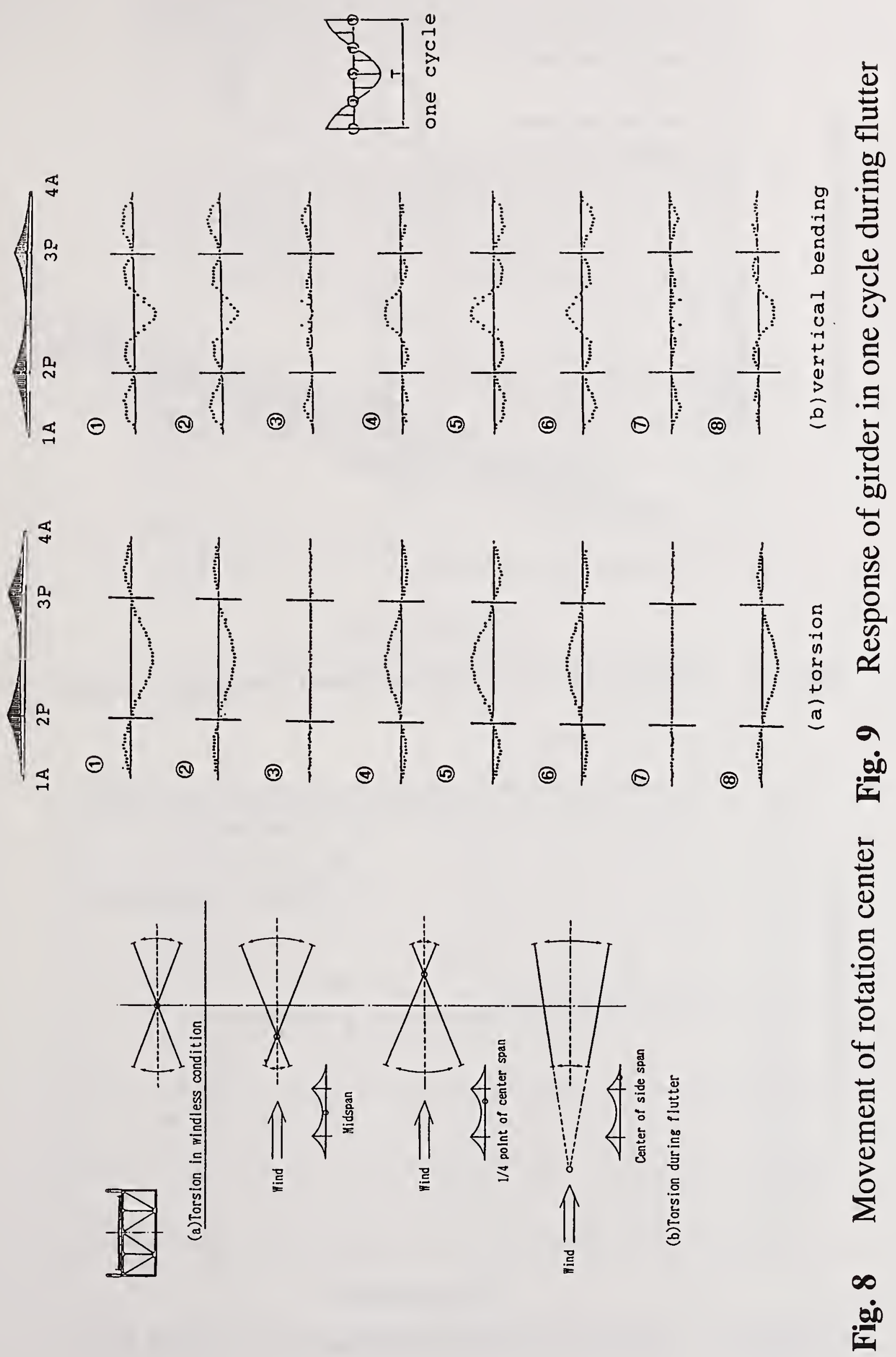


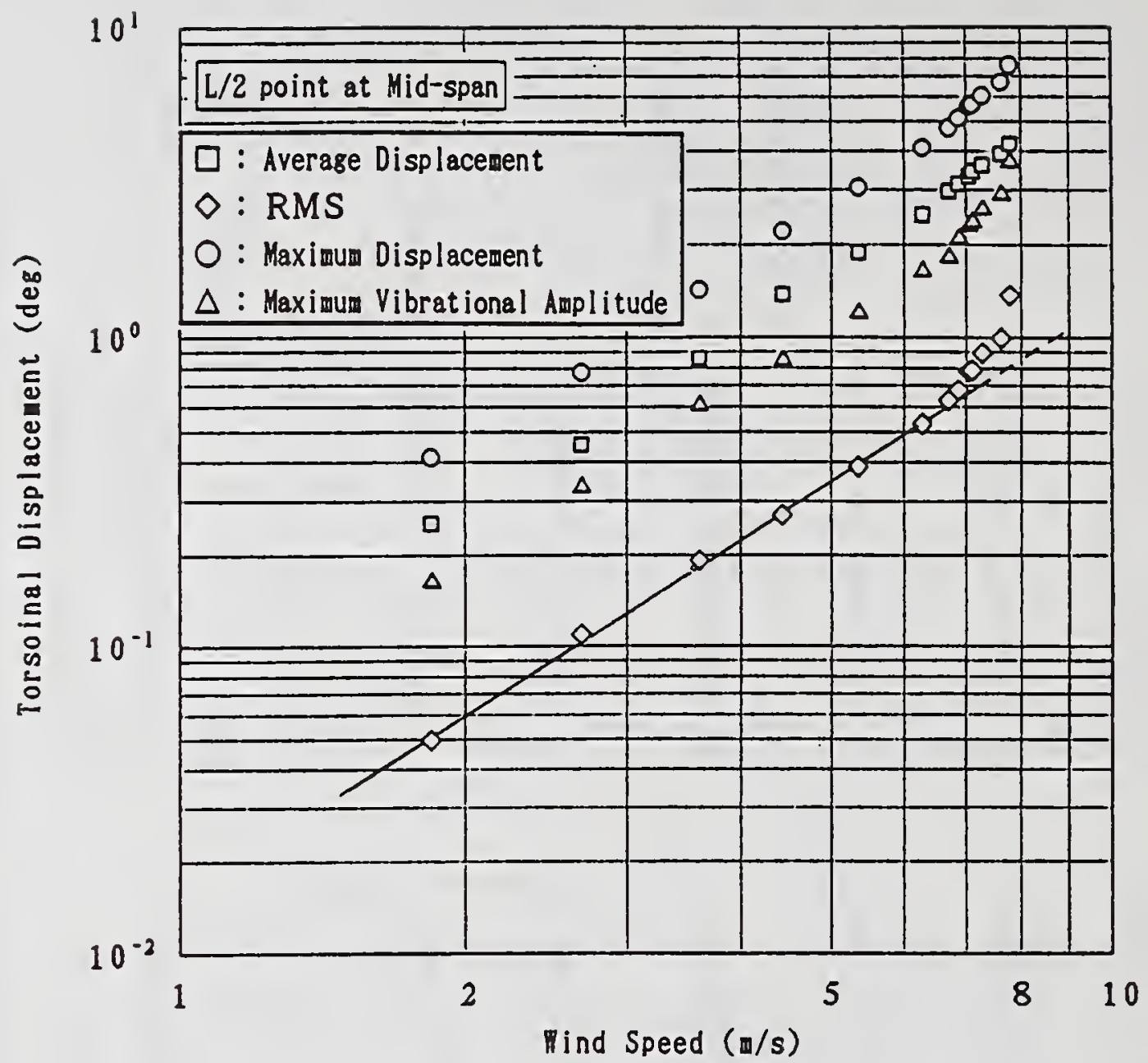

Fig. 10 Displacement in turbulent flow (logarithmic scales)

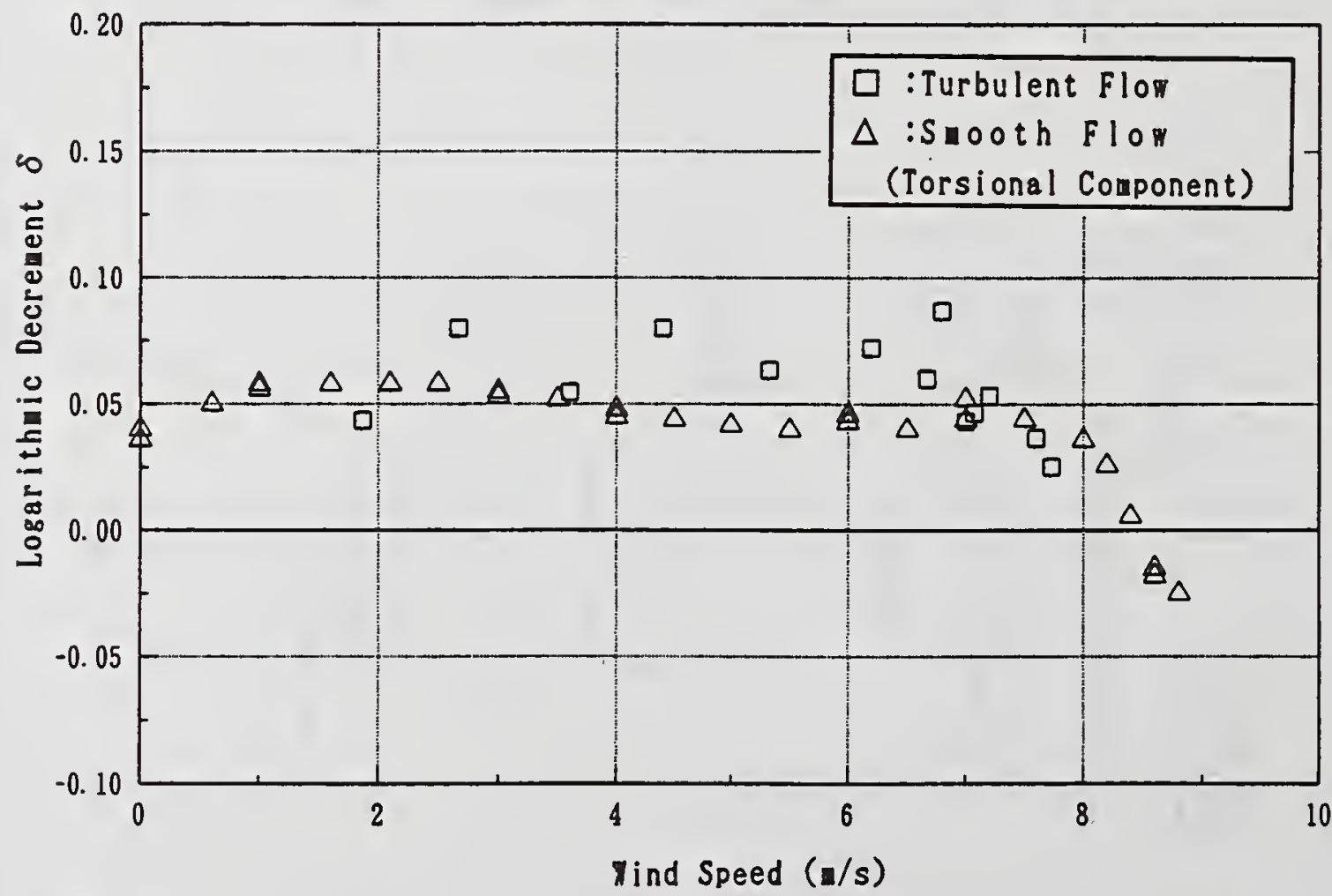

Fig. 11 Damping of model (turbulent flow, smooth flow) 


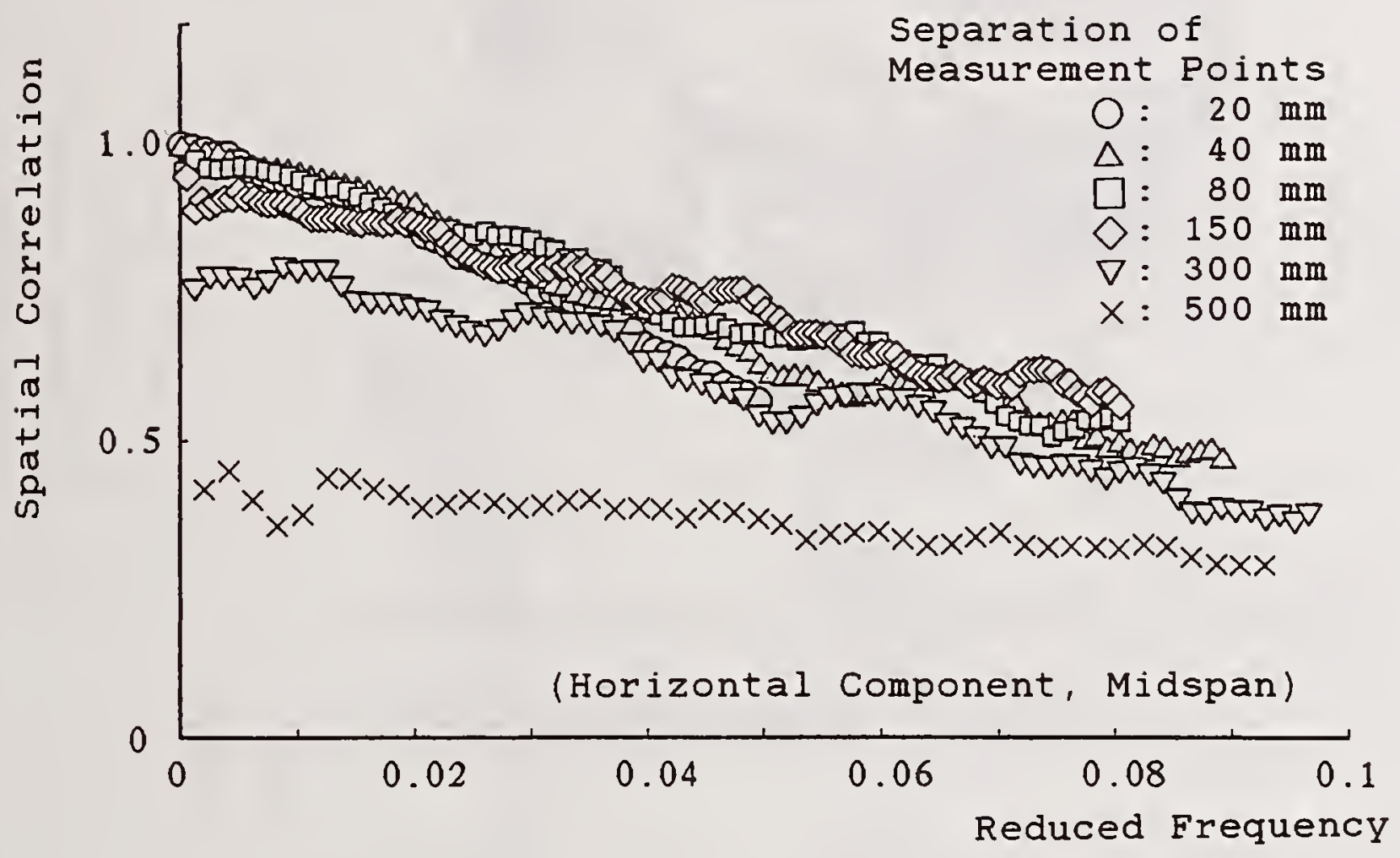

Fig. 12 Spectral correlation of wind speed 


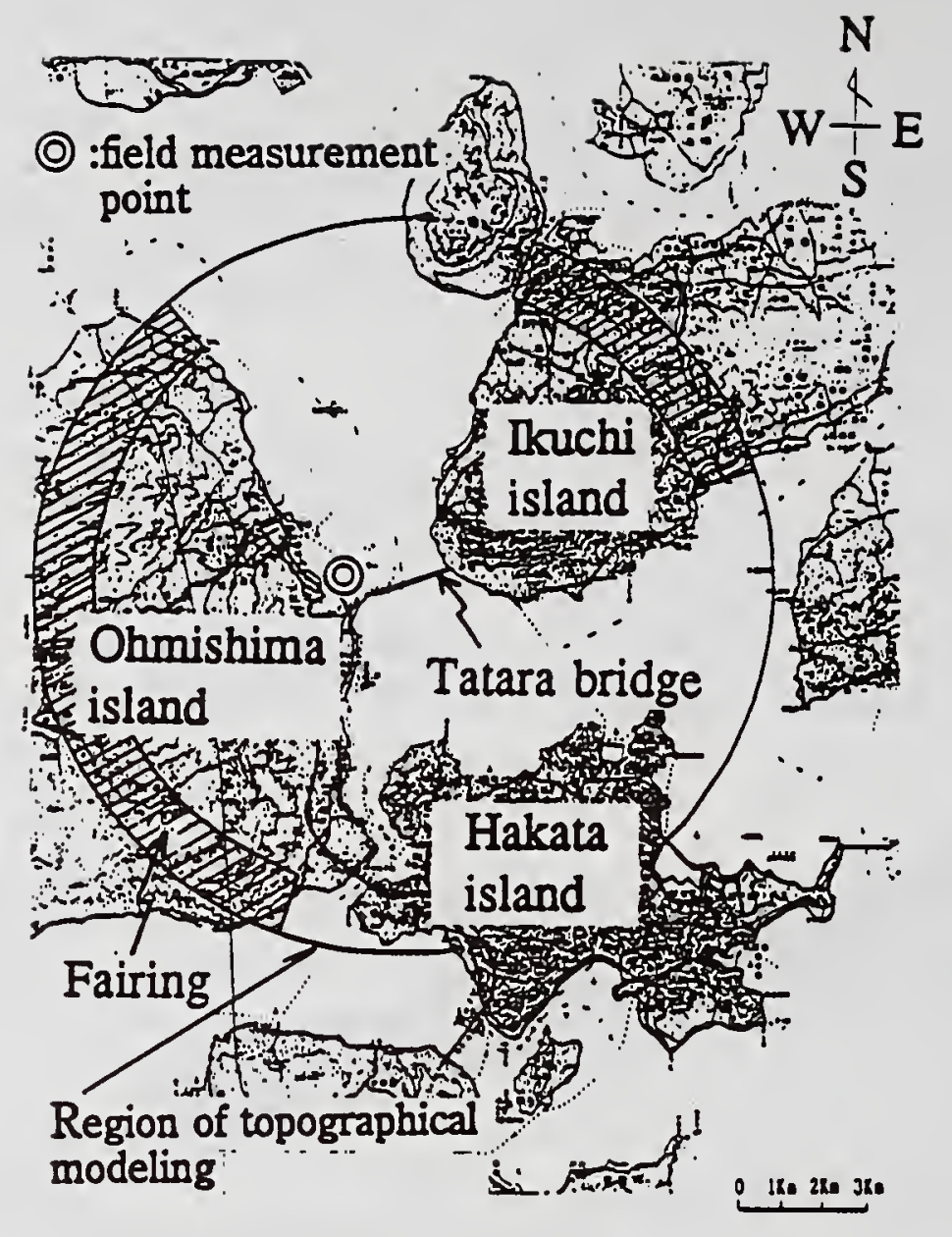

Fig. 13 Location of the Tatara Bridge and region of topographical modeling

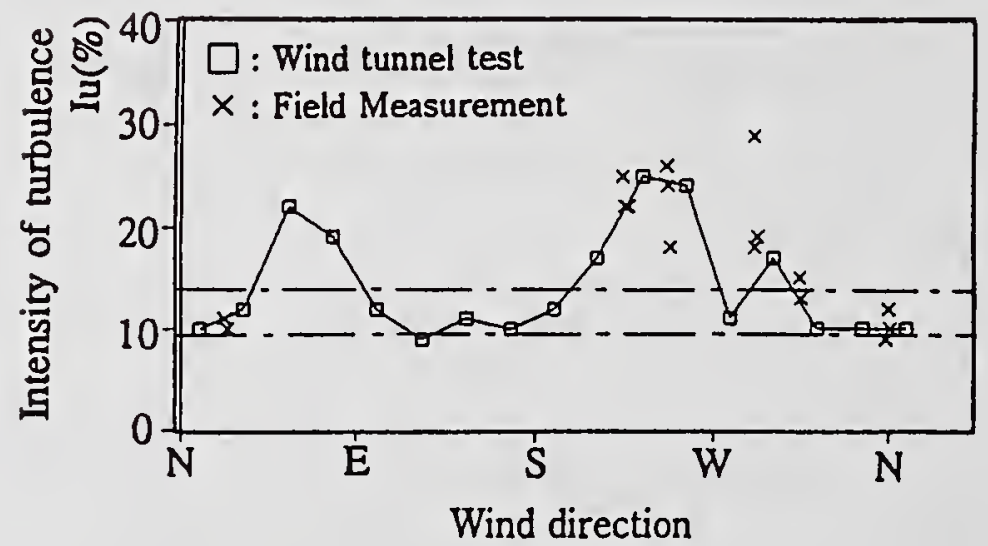

Fig. 14 Turbulent intensity at the site of the Tatara Bridge 


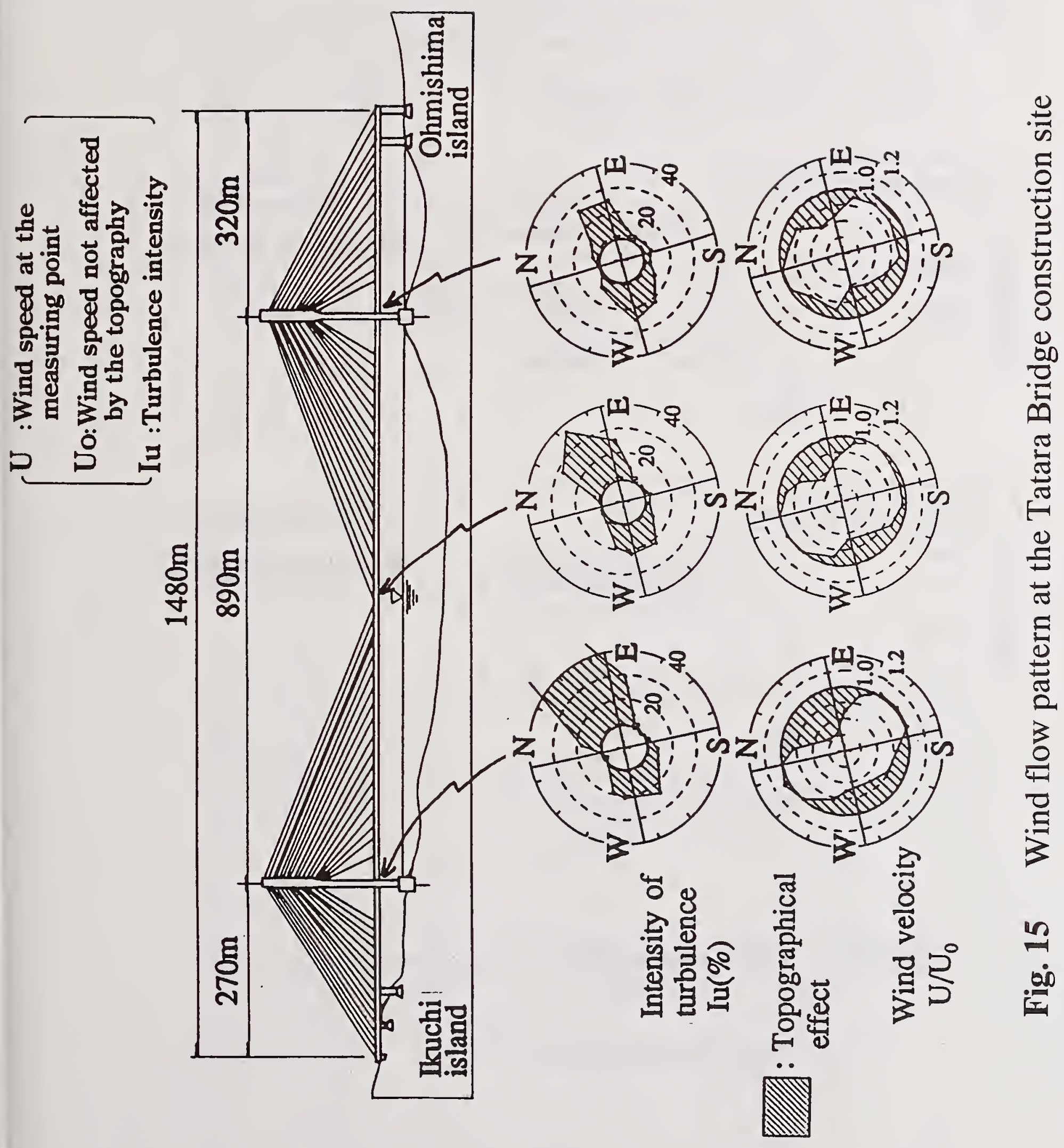



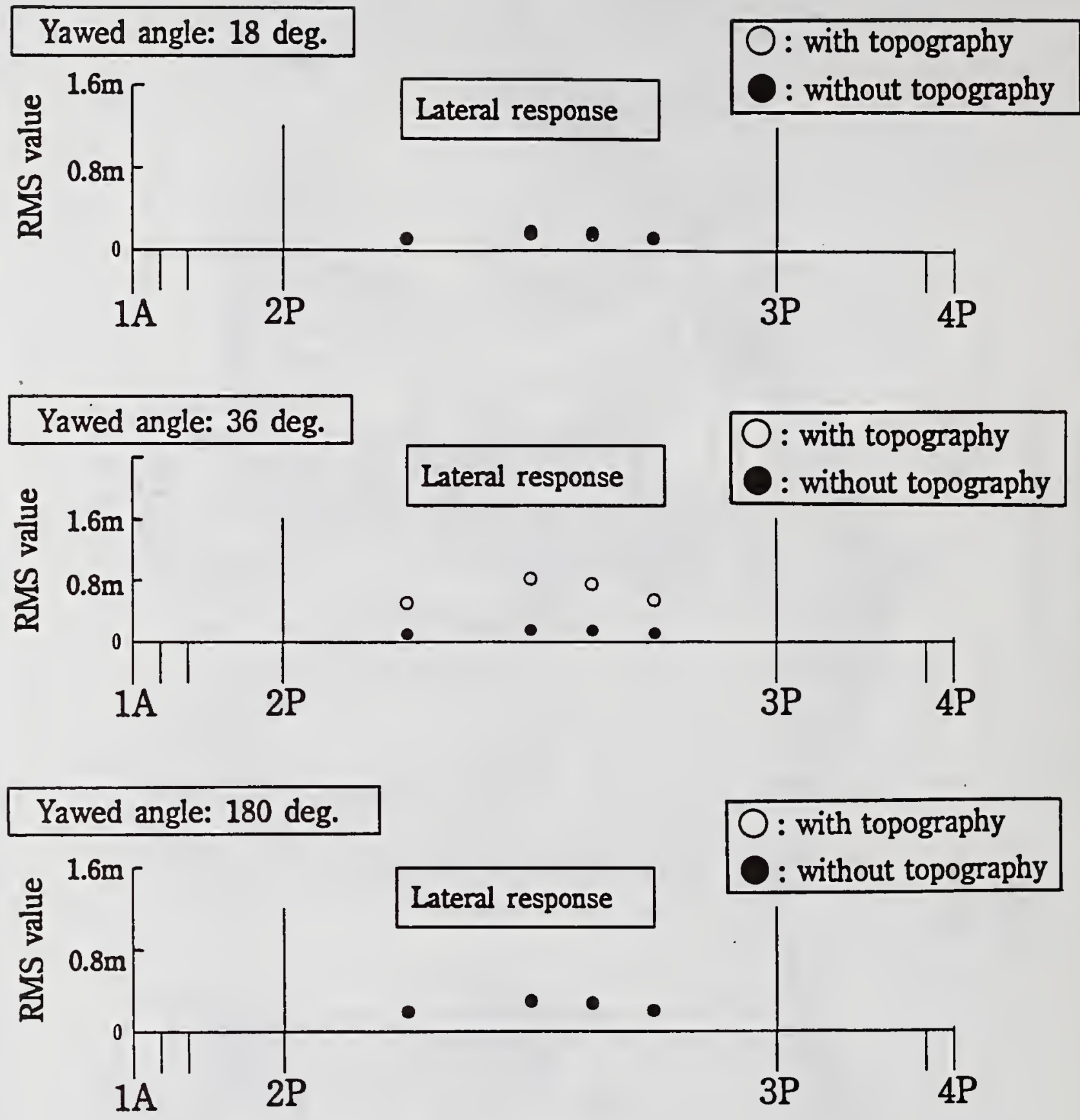

Fig. 16 RMS value of girder's gust response 


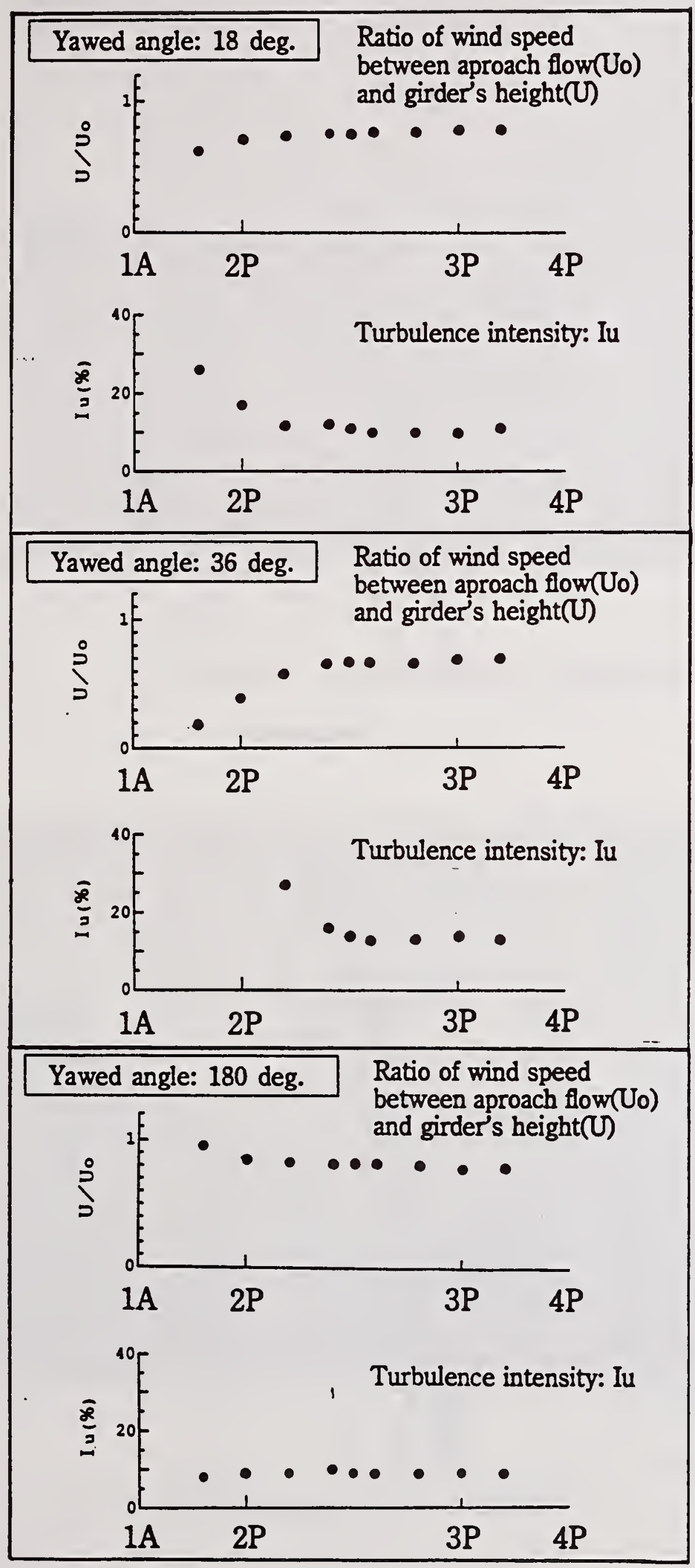

Fig. 17 Wind characteristics along bridge axis 

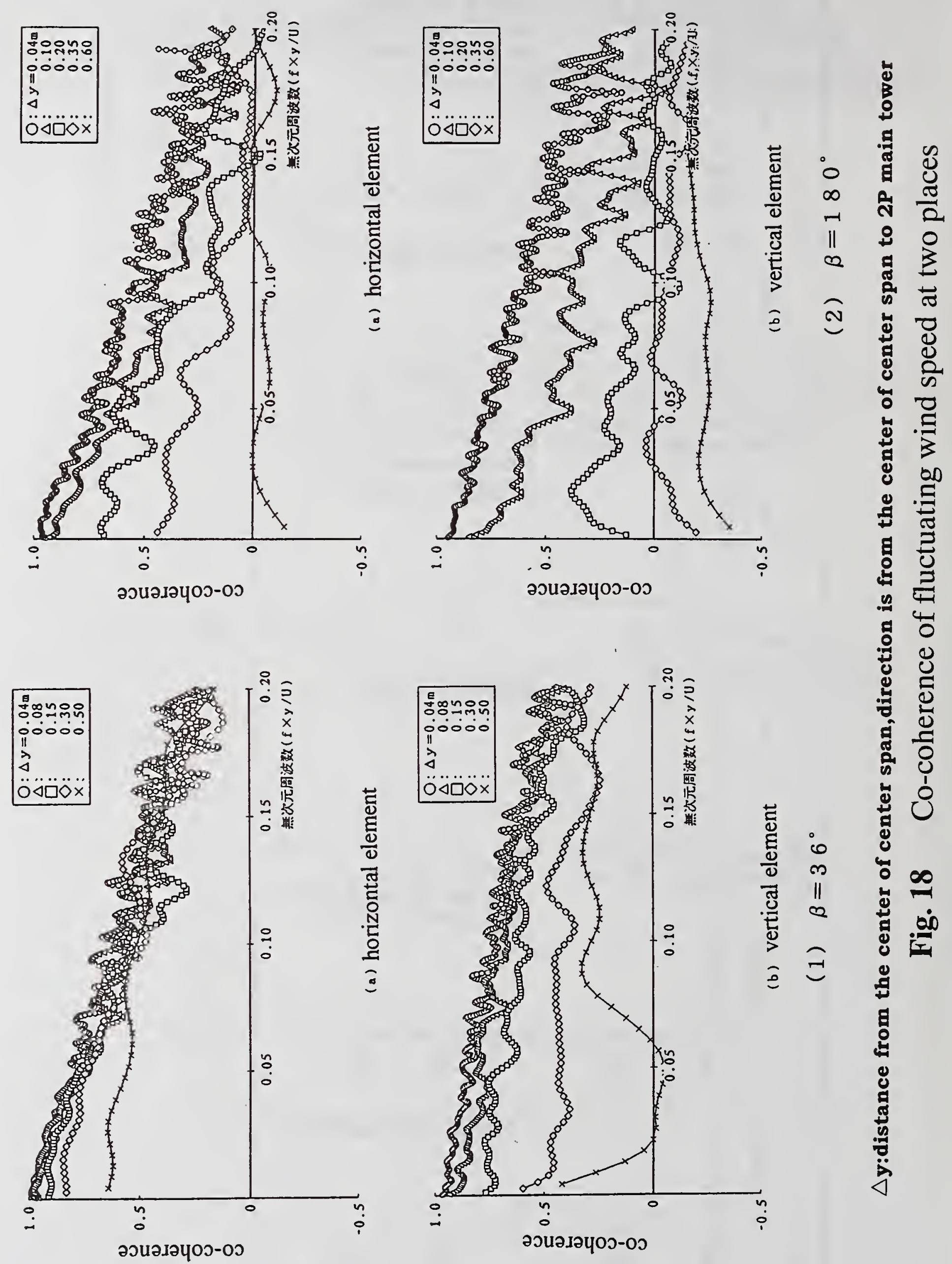


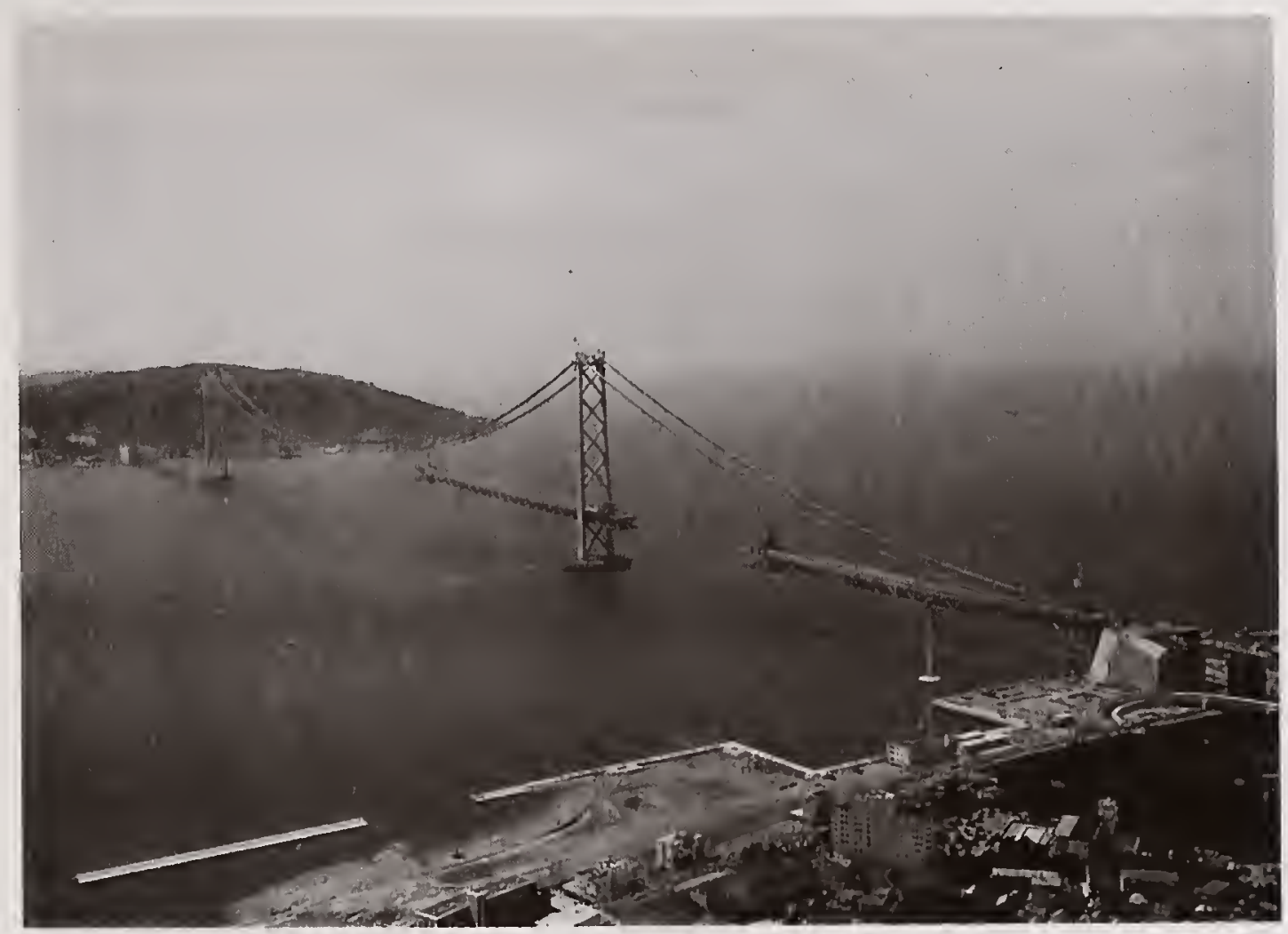

Photo 1 Akashi-Kaikyo Bridge

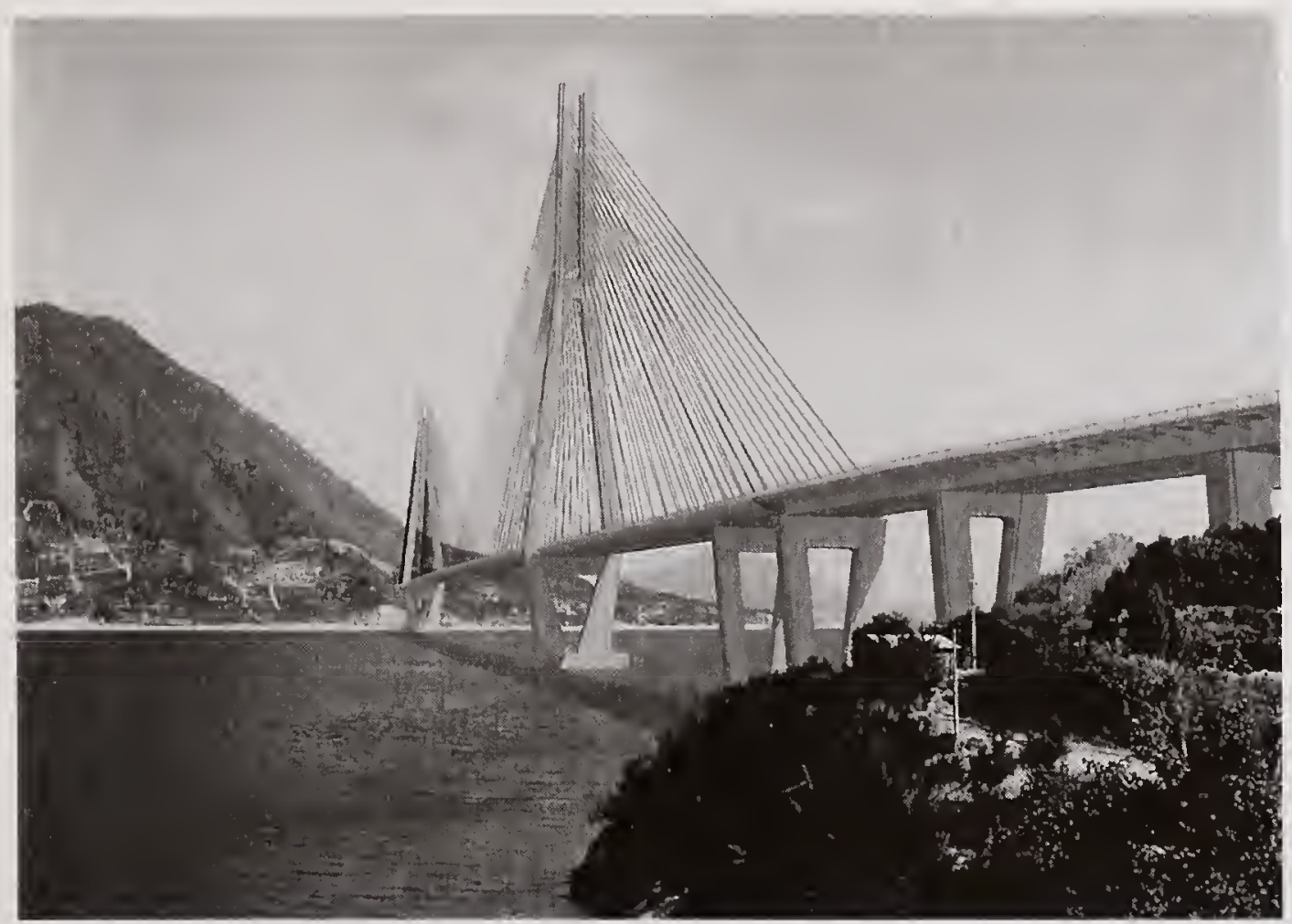

Photo 2 Tatara Bridge 


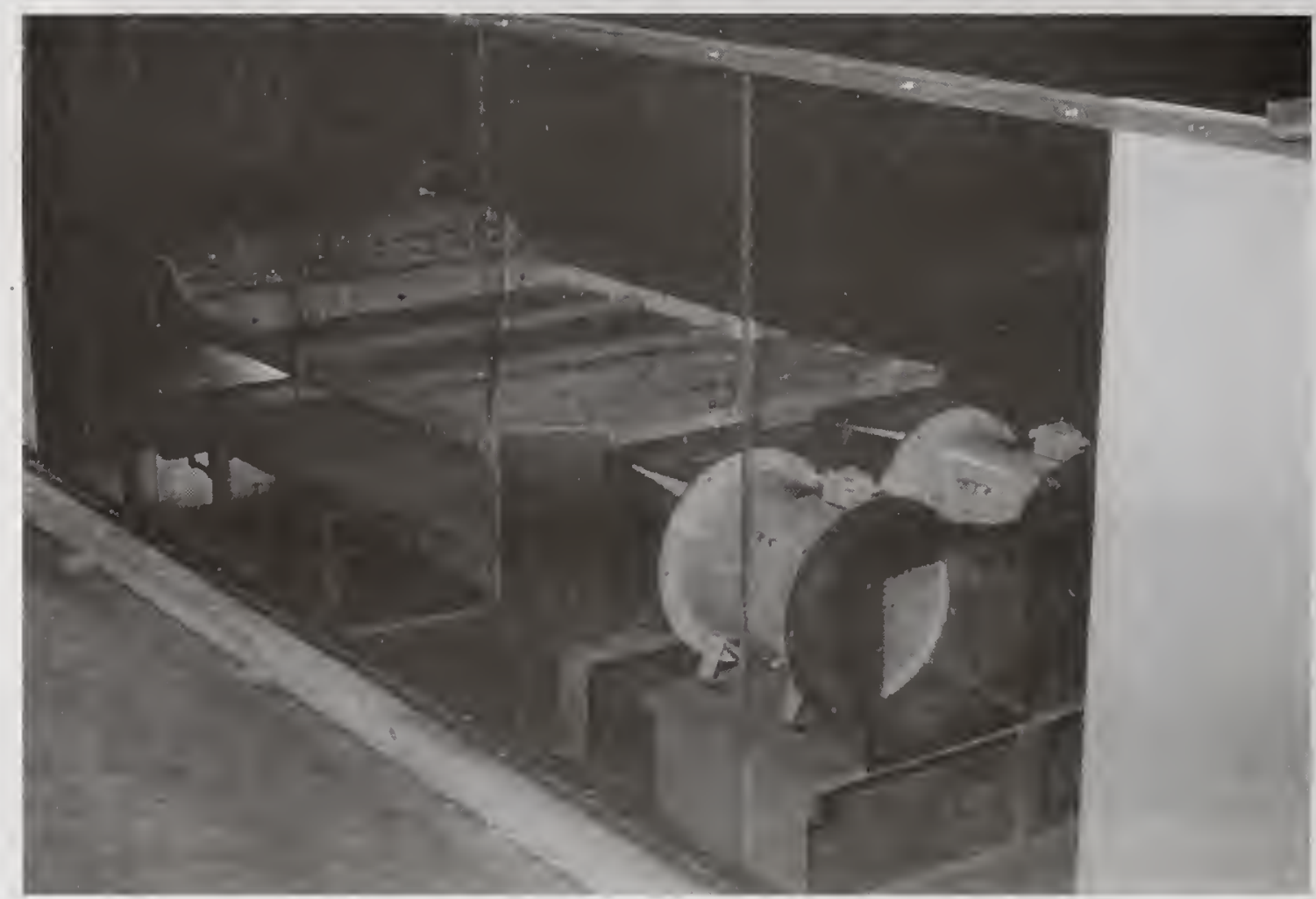

Photo 3 Pilot wind tunnel test

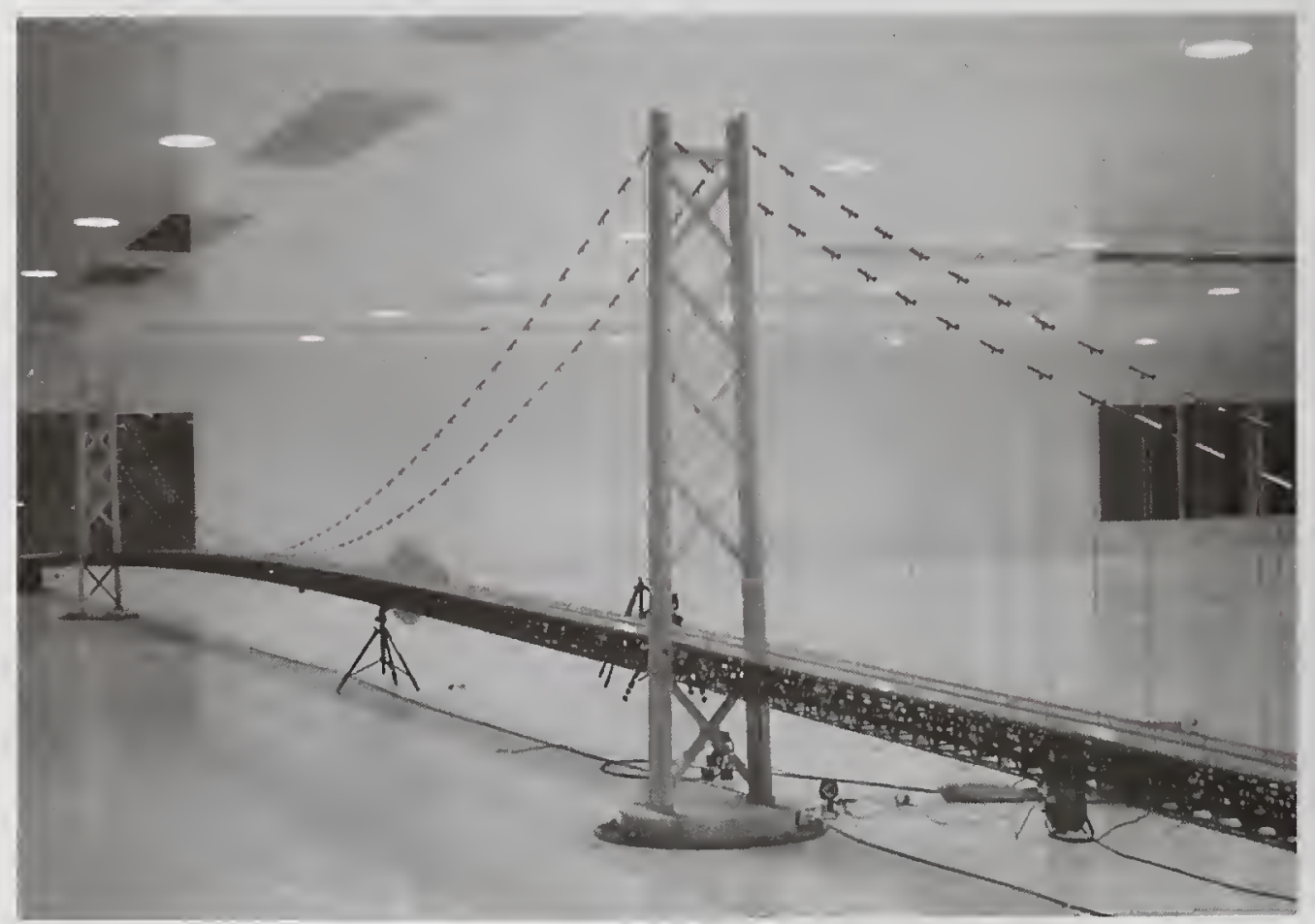

Photo 4 Full model test of the Akashi-Kaikyo Bridge 


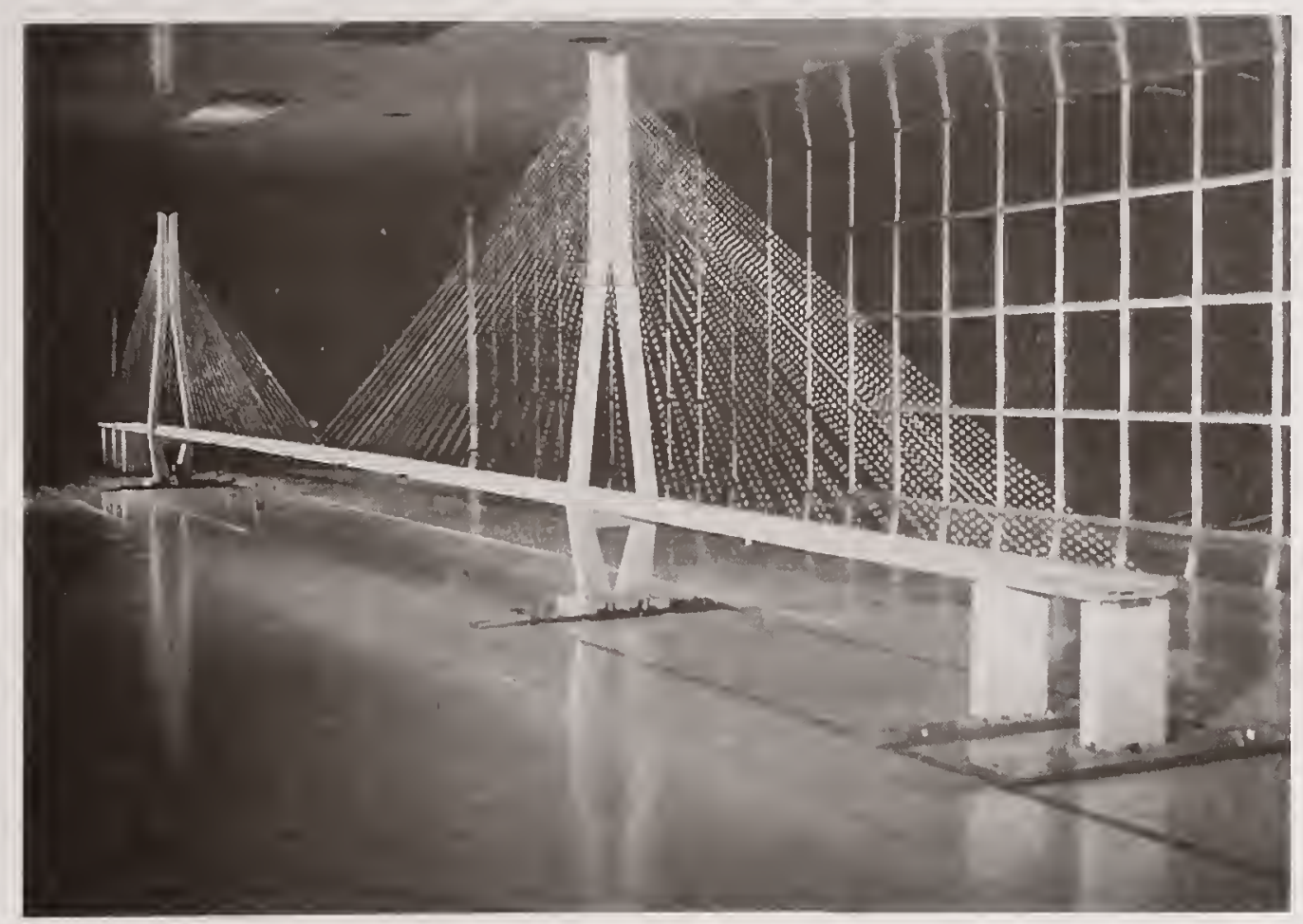

Photo 5 Model of the Tatara Bridge for the wind tunnel study in smooth flow

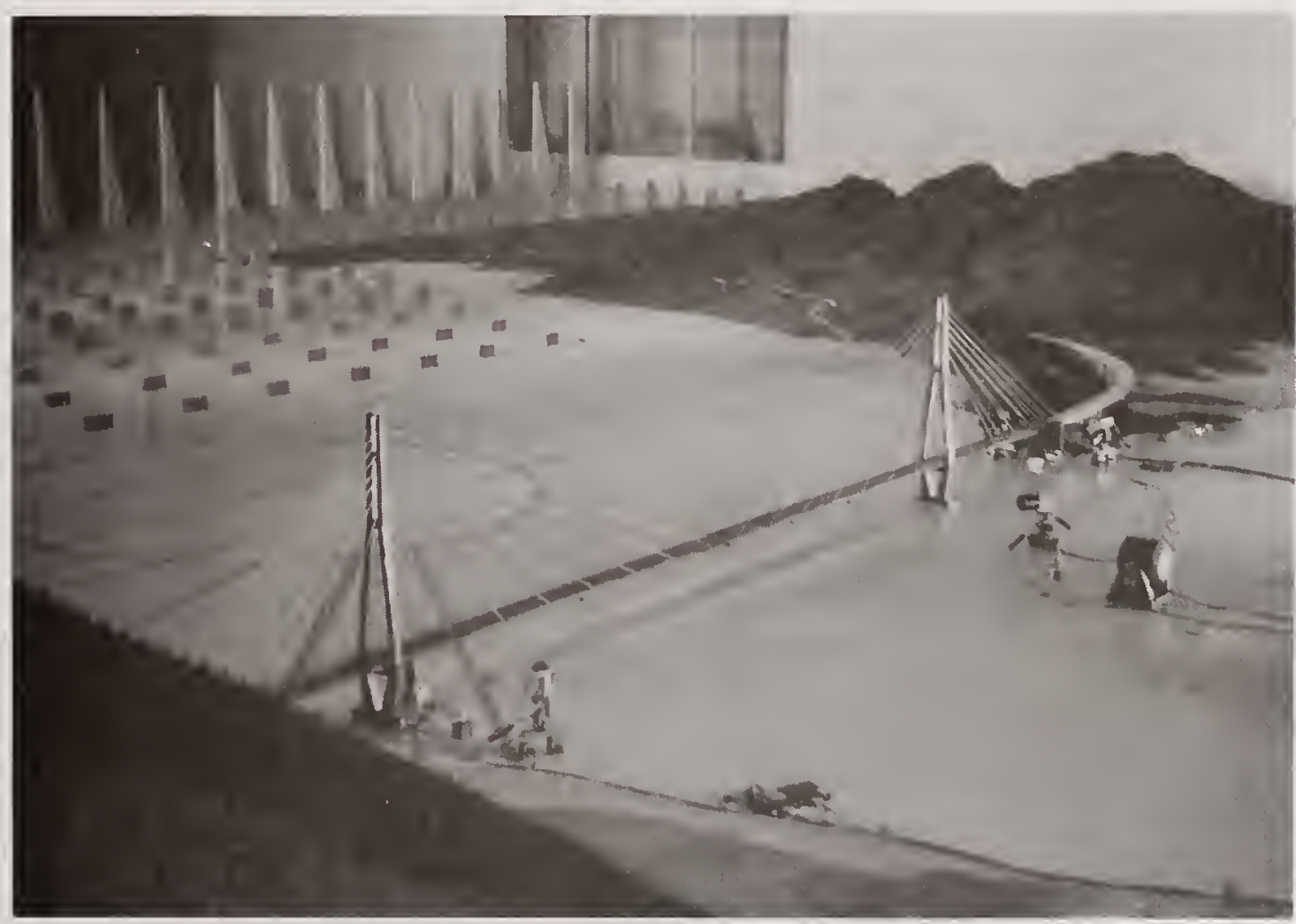

Photo 6 Model of the Tatara Bridge for the wind tunnel study in turbulent flow 


\title{
A SEISMIC RETROFITTING METHOD FOR REINFORCED CONCRETE BRIDGE PIERS AND THEIR ANAL YSIS
}

\author{
by \\ Hisanori Otuska*, Jun-ichi Hoshikuma**, and Kazuhiro Nagaya***
}

\section{ABSTRACT}

A new steel-jacketing strengthening method for enhanced flexural performance of existing reinforce concrete bridge piers was proposed in this paper. A series of large-scale specimens were cyclic-loaded, to examine the strengthening effect. Test resulsts showed that the strengthening method was effective in enhancing both the flexural strength and the ductility. Also, effects of steel-jacket details were studied based on the loadig tests. Furthermore, an analytical model for the steel-jacketing reinforced concrete piers was proposed. The flexural strength and the ductility analyzed by the model showed good agreements with the test results.

KEYWORDS: seismic retrofitting, steel jacketing, reinforced concrete bridge piers, cyclic loading test, flexural strength, ductility

\section{INTRODUCTION}

When the Hyogo-ken Nambu Earthquake hit the Hanshin and Awaji districts in the early morning of January 17,1995 , civil engineering structures, including highway bridges, were severely damaged that had never been seen in previous earthquakes. With regard to damage to highway bridges, it was noted that the piers of some bridges that had been designed in accordance with the 1964 or 1971 seismic specifications suffered severe damage; the provisions in those standards for the cut-off of longitudinal reinforcement required for piers were revised in 1980(1). The reason for the damage was that the quake's ground motion had properties that produced greater effects on highway bridges than had previously been observed. It has been estimated that severely damaged bridges received seismic forces larger than had been assumed in their design (1).

To make a bridge sufficiently resistant to earthquakes such as this one, its structure has to be made tougher by increasing the strength and ductility of the bridge as a total system (2). This concept of seismic design for a bridge also applies to the seismic retrofitting of existing bridges: it is necessary to adopt a retrofitting method that can be expected to enhance both the flexural strength and the ductility of the piers. However, when the flexural strength of piers is enhanced, the seismic forces propagated into the foundation are increased all the more. Therefore, if the calculated strength of the foundation of a bridge is smaller than the expected of its retrofitted piers, it is necessary to carry out more wide-ranging retrofiting of the bridge by retrofitting its foundation as well. On the other hand, if the ductility of the piers alone is enhanced, while their flexural strength is left as it is, this may lead to substantial plastic deformation during a major earthquake, which would cause a residual deformation that could not be repaired (3). It is therefore important to work out a retrofitting design that is capable of enhancing the flexural strength of the piers as required, within the range that can be supported by the foundation, and to make this enhancement match the improvement in the ductility.

\footnotetext{
* Head, Earthquake Engineering Division, Earthquake Disaster Prevention Department, Public Works Research Institute, Ministry of Construction

** Research Engineer, ditto

*** Assistant Research Engineer, ditto
} 
This paper proposes the steel jacketing method, with a controlled increase in flexural strength allowing well-balanced enhancement of both the flexural strength and the ductility of each pier in a reinforced concrete bridge. It also describes the results of a cyclic loading test using large-scale models constructed in order to examine the effects of enhancing the strength and ductility of bridge piers using this retrofitting method. Furthermore, the analytical method considering the confinement of concrete is checked the validness by comparing the test results.

\section{SEISMIC RETROFITTING OF REINFORCED CONCRETE PIERS USING A STEEL JACKET WITH ANCHOR BARS}

The steel jacket method, providing a controlled increase in flexural strength, involves steel plates around the reinforced concrete bridge piers, and bonding the steel jacket to the pier with epoxy resin or non-shrinkage mortar, while anchoring the jacket to the footing with anchor bars, as shown in Figure 1. This retrofitting method mainly aims to compensate for the inadequate cut-off of the longitudinal reinforcement and, at the same time, to enhance the flexural strength and ductility of the pier. The structure has several important characteristics, including the anchoring of the steel jacket to the footing with anchor bars, the vertical gap between the lower end of steel jacket and the top of the footing, and the use of H-beams fastened at the lower end of the jacket. These characteristics are described below.

First, the anchor bars play a part in enhancing the flexural strength of the pier, as well as in controlling the seismic forces propagated into the footing. This is because the increase in the flexural strength of the pier resulting from the retrofitting method can be controlled by adjusting the number and diameter of the anchor bars installed. The vertical gap between the lower end of the steel jacket and the top of the footing is provided because it is expected that, when it receives a large seismic force, the steel jacket may come into contact with the footing, which may then buckle under the unexpectedly large compressive force and receive damage. However, when the length of the vertical gap is too large, the confining effect of the jacket at the bottom of pier is reduced. The length should therefore be as small as possible.
Piers with a rectangular section also have H-beams installed around them at the lower end of the jacket. The reason for this is that, when the base of the pier suffers from a deformation with a large curvature, the jacket at the plastic hinge zone swells out, and the confining effect of the jacket is liable to be lost. When the lower end of the jacket is attached with the H-beams, however, then even under large deformations it still functions as a lateral reinforcement.

\section{CYCLIC LOADING TEST FOR MODELS OF RETROFITTED REINFORCED CONCRETE PIERS}

\section{3-1. Specimens}

The specimens used are shown in Figure 2. Their section was a square of $60 \mathrm{~cm} \times 60 \mathrm{~cm}$. The height from the base to the loading point was $3.01 \mathrm{~m}$. The shear span ratio was 5.0. As longitudinal reinforcements, SD295/D10 bars were arranged, and the ratio of longitudinal reinforcement was $1.58 \%$ (the ratio of tensile reinforcement was $0.55 \%$ ). As hoop reinforcements, SD295/D6 hoops were arranged at intervals of $20 \mathrm{~cm}$. In the specimens used in the test, the longitudinal reinforcement was not cut off at mid-height. This was because previous studies (4) had found that the steel jacket method can prevent damage to the cut-off sections of longitudinal reinforcement, thus it was decided that effect of this method in retrofitting the cut-off sections was not to be examined in this test.

When the steel jacket was applied to the specimen to be retrofitted, two steel plates with a thickness of $1.6 \mathrm{~mm}$ (SS400) were each bent into a channel -shape, and then welded into a jacket. Finally, the jacket was slipped from above over the specimen. As described above, however, a vertical gap of 5-15 $\mathrm{cm}$ was set between the lower end of steel jacket and the top of the footing (see Photo 1). In addition, H-beams $(100 \times 100 \times 6 \times 8$, SS400) were used to strengthen the lower end of the jacket. Epoxy resin was poured in between the reinforced concrete pier and the steel jacket, with a thickness of $4 \mathrm{~mm}$, to bond them.

The numbers and diameters of the anchor bars were set in such a way that the flexural strength of the 
specimen could increase by approximately $30 \%$. As described above, with this retrofitting method, any increase in the strength of the pier has to be set so that its resulting strength will not exceed that of the foundation. In this test, it was arbitrarily decided that the pier strength should be increased by about $30 \%$. It was found that, using the calculation method described later, when anchor bars equivalent to about $60 \%$ of the total strength of the steel jacket were used, the pier strength increased by approximately $30 \%$. Consequently, it was decided that twenty anchor bars, made by processing SD345 /D13 reinforcements into an M12 screw bolt (effective section area: $0.843 \mathrm{~cm}^{2}$ ), should be arranged at intervals of $12 \mathrm{~cm}$. The bars were anchored with resin anchors $55.6 \mathrm{~mm}$ outside the external edge of the concrete. The upper ends of the anchor bars were fastened to the webs of the $\mathrm{H}$-beams by double nuts, as shown in Photo 2. In this structure, the axial force produced in the anchor bars must be propagated smoothly via the H-beams to the steel jacket. In the specimens for the test, therefore, the H-beams and the steel jacket were joined with six rib plates (thickness: $6 \mathrm{~mm}$ ) per side, as shown in Figure $2 b$ and Photo 1 . The anchor bars were anchored to the footing for a length of $65 \mathrm{~cm}$.

In order to examine the retrofitting effect produced by the steel jacket, and the effect of vertical gaps of varying length between the lower end of jacket and the top of the footing, one as-built specimen (P-1) and three retrofitted specimens ( $\mathrm{P}-2$-- $\mathrm{P}-4)$ were used in this test. The vertical gap length in specimen P-2 was $10 \mathrm{~cm}$, while those of specimens P-3 and $\mathrm{P}-4$ were $5 \mathrm{~cm}$ and $15 \mathrm{~cm}$, respectively.

\section{3-2. Loading Procedure}

Photo 3 shows the way in which each specimen was loaded. While an axial force equivalent to a dead-load reaction was applied to each specimen laid down, a level load was applied to it by an actuator installed on a reaction wall. An axial force of 55 tf was used in this test. This is equivalent to a compressive stress of $15.3 \mathrm{kgf} / \mathrm{cm}^{2}$.

The yield displacement at the loading point was determined here when the longitudinal reinforcement of the base of the as-built specimen yielded, or the anchor bars of each retrofitted specimen yielded. Alternative displacements were given to the specimens by the displacement control. The loading displacement was made by a sine wave; the loading speed $3 \mathrm{~cm} / \mathrm{sec}$; and the number of loading cycles per loading step was to be three. The ultimate displacement during the test was defined here as the displacement when the strength was deteriorated to the yield strength.

\section{RETROFITTING EFFECT OF STEEL JACKET WITH ANCHOR BARS}

\section{4-1. Hysteresis loop and aggravation of damage}

Figure 3 shows the hysteresis loops of the relationships between lateral load and the displacement at the loading points of all the specimens. Figure 4 illustrates the damage to specimens P-1 and P-2 was aggravated.

In the case of P-1, the as-built specimen, based on the value for the longitudinal reinforcement strain at the base, the yield displacement was measured to be $16.0 \mathrm{~mm}$. Its peak strength was $23.1 \mathrm{tf}$. This was maintained until $4 \delta$ y was loaded, when its cover concrete started to spall off. In the stage of $5 \delta \mathrm{y}$ loading, the core concrete started to suffer damage, and the hysteresis loop began to become unstable. When even greater loads continued to be applied, damage to the core concrete was aggravated, with the level strength gradually reduced.

In the case of P-2, a retrofitted specimen, based on the yield strain of its anchor bars, the yield displacement was measured at $12.7 \mathrm{~mm}$. In comparison with $\mathrm{P}-1$, its yield displacement was smaller, because the flexural stiffness was increased by the steel jacket. Its peak strength was $31.8 \mathrm{tf}$. This was maintained until $6 \delta \mathrm{y}$ was loaded. Its anchor bars started to buckle under the load of $4 \delta$ $y$. In the stage of the $6 \delta$ y loading, seven anchor bars were broken. At the same time, the external edge of the concrete pier, in the $10 \mathrm{~cm}$ vertical gap provided at the base, began to fail due to the cyclic pressure, with the lateral strength reduced. Under the $7 \delta$ y loading, a total of ten anchor bars broke, and two longitudinal reinforcements of the pier were also broken, with the lateral strength reduced below the yield strength. Even under the final $8 \delta$ y loading, the steel jacket did not suffer from deformations such as buckling or swelling out. 


\section{4-2. Strength and ductility}

Figure 5 compares the envelope curves of the hysteresis loops in the four specimens. Table 1 compares their strength and ductility. The comparison between P-1 and P-2 shows that the peak strength and the ductility factor of the pier were enhanced by the steel jacket, with a controlled increase in flexural strength. Also, while the effect of the vertical gap length on the peak strength was only slight, the smaller the length, the larger was the ductility ratio. Based on the result of this test, it is recommended to make the vertical gap length small, at least about $5 \mathrm{~cm}$, in the case of piers with dimensions similar to these specimens.

Figure 6 shows the relationship between equivalent stiffness and lateral displacement. Equivalent stiffness was defined here as being the gradient of the straight line connecting the points of the maximum and minimum displacements in the first loading loop in each loading step. The figure shows that the equivalent stiffnesses of P-2 to P-4 under the $1 \delta \mathrm{y}$ loading were about 1.5 times greater than that of P-1. The reason for this will be that the flexural stiffnesses of the retrofitted specimens were greater than that of the as-built one, because of their increased stiffness due to the anchor bars, and because the steel jackets covering the whole height of the piers also functioned as a longitudinal reinforcement. However, the effect of the difference in the vertical gap length was not noticeable over the range of 5 to $15 \mathrm{~cm}$.

\section{4-3. Energy absorption}

Figure 7 compares the specimens with regard to accumulated energy absorption. Energy absorption in each loading step was computed here by integrating the hysteresis loop concerned. The figure shows that in the case of $\mathrm{P}-1$, the as-built specimen, from around the time of $5 \delta \mathrm{y}$, when the core concrete started to suffer damage, the energy absorption in each loading step began to decrease. In the case of $\mathrm{P}-2$ to $\mathrm{P}-4$, on the other hand, energy absorption was stable even after $5 \delta \mathrm{y}$. It was also found that the smaller the vertical gap length, the greater was the energy absorption under loads above $7 \delta$ y loading step.

Figure 8 shows effect of the retrofitting on the equivalent damping ratio. The ratio computed was based here on the hysteresis loop in the first loading in each loading step. While the ratio of P-1 was greater in the range of lateral displacement below 5 $\delta \mathrm{y}$, it began to decrease when the displacement increased beyond that. On the other hand, the equivalent damping ratios of $\mathrm{P}-2$ to $\mathrm{P}-4$ rose constantly as the lateral displacement increased, indicating that stable damping performance was obtained with the retrofitting method. It can also be seen that the damping performance of P-4, with a vertical gap length of $15 \mathrm{~cm}$, was slightly poorer than those of P-2 and P-3 after $7 \delta$ y loading step.

\section{4-4. Strain Performance}

Figure 9 compares the reinforcement and the steel jacket of P-2 with regard to the peak axial strain on the tensile side of the section at a height of $20 \mathrm{~cm}$ from the base at each loading step. Under the load for $1 \delta \mathrm{y}$, the axial strain of the jacket was $0.0838 \%$, and it had not yet yielded. Since the design had foreseen that five anchor bars on the tensile side would yield under this load, it is estimated from the yield strength (observed value: $3,916 \mathrm{kgf} / \mathrm{cm}^{2}$ ) and section area of the anchor bars that an axial strength, $\mathrm{Na}$, of the value obtained by the following formula was at work:

$$
\mathrm{Na}=3,916 \times(0.843 \times 5)=1.65 \times 10^{4} \mathrm{kgf}
$$

Assuming this axial strength to be the tensile strength propagated to the tensile side of the steel jacket, the strain produced in the jacket is computed as follows:

$$
\begin{aligned}
\varepsilon \mathrm{j} & =1.65 \times 10^{4} /(0.16 \times 60) \times 2.1 \times 10^{6} \\
& =818 \times 10^{-6}
\end{aligned}
$$

As can be seen, the strain on the jacket thus obtained agrees well with the observed value mentioned above. Consequently, judging from the strains on the anchor bars and the steel jacket under the elastic loading, it can be said that the jacket functioned effectively as a longitudinal reinforcement of a strength equivalent to that of the anchor bars. Also, because the jacket did not suffer from any visible plastic deformation, such as swelling out under the loads for $1 \delta \mathrm{y}$ or more displacements, it can be expected that the jacket will produce the proper effect of confining the concrete. The axial strain on the jacket peaked under the load 
for $6 \delta \mathrm{y}$. The displacement was equivalent to the one immediately before the anchor bars were broken, and the strength began to decrease after remaining stable near its maximum. On the other hand, Figure 10 compares P-1 and P-2 with regard to the strain of the hoop reinforcement positioned at the section at a height of $40 \mathrm{~cm}$ from the base. It can be seen from the figure that the strain produced in the hoop reinforcement of P-2 was smaller at every loading step, indicating that the jacket functioned effectively as a hoop reinforcement confining the lateral deformation of the concrete pier.

\section{ANALYSIS OF STRENGTH AND DUCTILITY OF REINFORCED CONCRETE PIERS RETROFITTED BY STEEL JACKET WITH ANCHOR BARS}

\section{5-1. Analysis Procedure}

To make a seismic design procudure, it is necessary to estimate the lateral load and displacement relation of the retrofitted pier adequately. The relation between lateral load and displacement is calculated by a method based on the moment-curvature relation described in the seismic design for reinforced concrete piers (5). In this paper, a model of analysis of the retrofitting effect based on this method is therefore used.

The test results mentioned above show that the strength and ductility of the pier are enhanced by the steel jacket with anchor bars. Specifically, the anchor bars and the jacket function as longitudinal reinforcements. Only forces equivalent to the strength of the anchor bars act on the jacket, and the jacket also functions as a hoop reinforcement to confine the concrete. On the basis of these test results, the following assumptions will be made in analyzing the strength and ductility of retrofitted reinforced concrete piers.

(1) Only the strength of the anchor bars can be counted as a effective longitudinal reinforcement by the steel jacket. Reinforcement bars are assumed to be positioned at the external edge of the concrete, as shown in Figure 11.

(2) The whole sectionl area of the jacket works as a hoop reinforcement. This effect, combined with that of the existing hoop reinforcement, can be taken into account the stress-strain curve.
(3) The vertical gap length is understood to be better as small as possible, and the steel jacket and the footing will not expected to come into contact if the pier becomes deformed, the confining strength of the jacket can be considered to be propagated into the concrete in this section. The confining effect on the gap section should be the same as that on the section covered by the jacket.

With regard to the modeling of the position of the anchor bars, there are two potential approaches. One is to assume that the anchor bars are positioned where they are actually anchored in the base (55.6 mm outside the external edge of the concrete pier, in the case of P-2); and the other is to assume that they are positioned on the external edge of the concrete pier, where the steel jacket is placed. In the former case, while the conditions in the actual structure and the analysis model correspond to one other in relation to the vertical gap section with a length from the pier base of 5 to $15 \mathrm{~cm}$, in the section covered by the jacket the flexural stiffness tends to be overestimated, because the effective height of the anchor bars is greater than it actually is. It was therefore decided that, in the design model, the anchor bars should be arranged on the external edge of the concrete pier.

In this analysis, the model of the stress-strain curve in concrete proposed by Hoshikuma et al. (6) was used, since it allows the confining effect of the hoop reinforcement to be taken into consideration. However, the strain produced when compressive stress is reduced to $80 \%$ of its peak is considered as the ultimate strain (2). This is equivalent to the strain produced when the concrete starts to spall off due to the compression.

\section{5-2. Analyzing retrofitting effect upon specimens}

To verify the method of analysis, the strength and ductility of P-2 were analyzed, and a comparison between these results and the test results is carried out. Values obtained from a materials test were used in the analysis.

The volumetric ratio of lateral reinforcement of the reinforced concrete pier, $\rho$ s, was computed by the following equation, converting the steel jacket into hoop reinforcement: 


$$
\rho s=\frac{4 A_{h}}{s \cdot d h}+\frac{4 t}{d_{j}} \cdot \frac{f_{y j}}{f_{y h}}
$$

where:

$$
\begin{aligned}
& \text { An: section area of a hoop reinforcement }\left(\mathrm{cm}^{2}\right) \\
& \text { s: spacing between hoop reinforcements }(\mathrm{cm}) \\
& \mathrm{d}^{2} \text { : effective length of hoop reinforcement }(2)(\mathrm{cm}) \\
& \mathrm{d}_{\mathrm{j}} \text { : effective length of steel jacket }(\mathrm{cm}) \\
& \mathrm{t}: \text { thickness of steel jacket }(\mathrm{cm}) \\
& \text { fyh: yield strength of hoop reinforcement }\left(\mathrm{kgf} / \mathrm{cm}^{2}\right) \\
& \mathrm{f}_{\mathrm{yj}} \text { : yield strength of steel jacket }\left(\mathrm{kgf} / \mathrm{cm}^{2}\right)
\end{aligned}
$$

In Eq. (3), the first term is the volumetric ratio of the lateral reinforcement of the pier, while the second term gives the volumetric ratio of the steel jacket as converted into hoop reinforcement. The effective length of the jacket, $\mathrm{dj}$, can be assumed here as the side length of the section of the concrete pier, in the case of structures like this, in which steel plates are placed like a jacket. Consequently, in the case of the specimens for this test, the effective length of the jacket, dj, was $60 \mathrm{~cm}$. Hence, the volumetric ratio of lateral reinforcement of $\mathrm{P}-1$, the as-built specimen, $\rho$ s, was computed to be 0.00253 . The ratio of $\mathrm{P}-2$, a retrofitted specimen, $\rho$ s, was 0.0115 . Figure 12 shows the stress-strain curve for the concrete pier obtained by using these values.

Using this stress-strain curve for the concrete, an analysis was made of the moment-curvature relation of the section, and the lateral load and displacement relation at the loading point was computed. Figure 13 compares the analysis results and the envelope curve of the loading hysteresis loop for P-1 and P-2. In the analysis, the peak strengths of $\mathrm{P}-1$ and $\mathrm{P}-2$ were computed to be 24.1 tf and 31.1 tf, respectively. These figures both agreed well with the test results. It was concluded, therefore, that the method of analysis was able to estimate the strength of the retrofitted piers with sufficient precision.

On the other hand, the ductility factors of P-1 and P-2 calculated in this analysis were 3.0 and 5.3, respectively. The corresponding test results were both higher than these analysis values. This is due to a difference in definition of ultimate stage. In the loading test, on the one hand, ultimate displacement was defined as the lateral displacement recorded when the strength was reduced to the yield strength. In the analysis, on the other hand, ultimate displacement was defined as the lateral displacement recorded when the strain of the most external edge of the concrete pier reached its ultimate strain. The ultimate displacement of P-2 obtained by the analysis method was $82.5 \mathrm{~mm}$. To compare this with the damage caused in the test when a lateral displacement of this extent was effected, the anchor bars began to buckle, reaching the stage of damage immediately before breaking, and the concrete started to spall off, with the peak strength starting to fall after having remained stable. This damage degree corresponds to the state defined as "ultimate" in the analysis. On the other hand, when P-2 was so deformed that its strength had been reduced to yield strength, the anchor bars had alrea $\delta$ y broken, and the longitudinal reinforcement was also about to break. Based on these considerations, the ultimate displacement obtained by the method had a value suitable for the design, from the points of view of residual strength, degree of difficulty of restoration, etc. It should be noted that the plastic hinge length would be different between P-1 and P-2, as shown in Figure 4. In above analysis, the ductility is calculated without taking account of the effect of the plastic hinge length, which may cause the under- or overestimate of the ultimate displacement.

\section{CONCLUSIONS}

We have proposed here a method of designing a steel jacket with anchor bars as a method of enhancing the ductility of reinforced concrete piers while controlling the increase in its strength. We carried out a lateral loading test using large models, including models retrofitted with this method. We also examined a way of analyzing the retrofitting effect, i.e., the effect of enhancing the strength and ductility with this method. The following is the summary of results of the study:

(1) The test clearly showed that the ductility of a pier can be enhanced while controlling the increase in its strength using a steel jacket with anchor bars. The pier's energy absorption and damping performance were also enhanced.

(2) It was confirmed that the jacket and hoop reinforcement were strained in such a way that the steel jacket functions effectively as a longitudinal and hoop reinforcement, with a strength equivalent to that of the anchor bars.

(3) A comparison of the three cases with a vertical gap between the lower end of jacket and the top of the base-- $5 \mathrm{~cm}, 10 \mathrm{~cm}$ and $15 \mathrm{~cm}$--showed that, while 
the peak strengths were all equal, the smaller the vertical gap length, the larger the ductility factor.

(4) A method of analyzing the retrofitting effect of this type of steel jacket with a controlled increase in flexural strength was described. It was confirmed that the strength calculated according to this method of analysis corresponded well with the observed test results. On the basis of the results of the test (number of cycles of loading: 3), the ultimate displacement obtained by this analysis is equivalent to the stage in which the anchor bars buckle, having reached the stage of damage that immediately precedes breaking. At this stage, concrete starts to spall off, and the peak strength begins to deteriorate after having remained stable for a time.

\section{REFERENCES}

1) Ministry of Construction: Report on the Damage of Highway Bridges by the Hyogo-ken Nanbu Earthquake, Committee for Investigation on the Damage of Highway Bridges Caused by the Hyogo-ken Nanbu Earthquake, 1995

2) Ministry of Construction: Guide Specifications for Reconstruction and Repair of Highway
Bridges Which Suffered Damage due to the Hyogo-ken Nambu Earthquake, Feb. 1995

3) Kazuhiko Kawashima, G.A. MacRae, Jun-ichi Hoshikuma and Kazuhiro Nagaya: Residual Displacement Response Spectrum and its Application to Evaluate Residual Displacement Developed in Reinforced Concrete Bridge Columns, 28th Joint Meeting of U.S.-Japan Panel on Wind and Seismic Effects,UJNR, May 1996

4) Kazuhiko Kawashima, Shigeki Unjo and Hiroyuki Iida: Seismic Inspection and Seismic Strengthening of Reinforced Concrete Piers at Mid-height Where Main Reinforcement is Terminated, First U.S.-Japan Workshop on Seismic Retrofit of Bridges, UJNR, Tsukuba, Dec. 1990

5) Design Specifications for Highway Bridges, V Seismic Design, Japan Road Association, Feb. 1990

6) Jun-ichi Hoshikuma, Kazuhiko Kawashima and Kazuhiro Nagaya: A Stress-Strain Model for Reinforced Concrete Bridge Piers Confined by Hoop Reinforcement, Proceedings of the Second International Workshop, Seismic Design and Retrofitting of Reinforced Concrete Bridges, New Zealand, Aug. 1994 


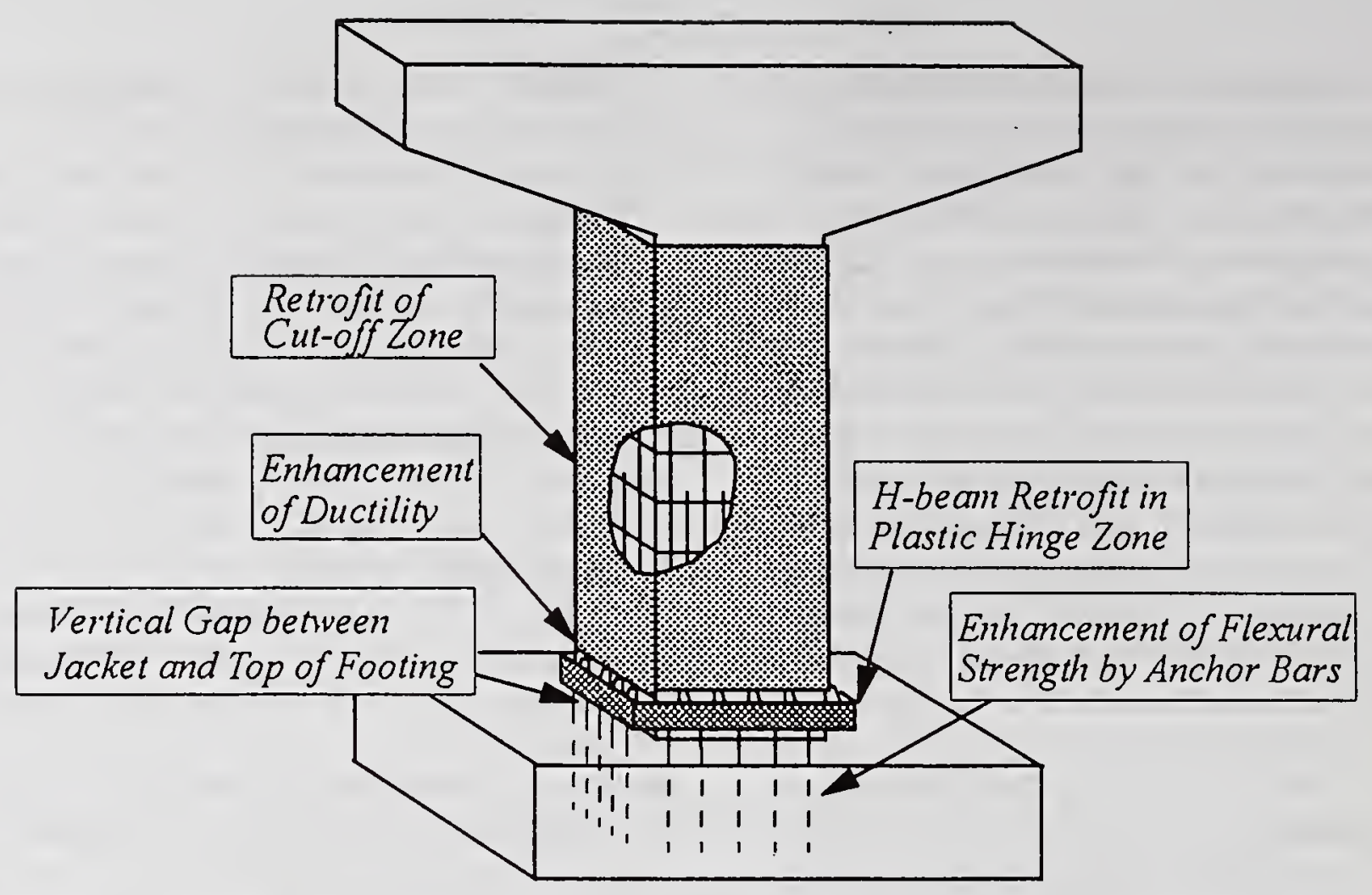

Fig. 1 Illustraion of Retrofit by Steel-Jacketing with Anchor Bars

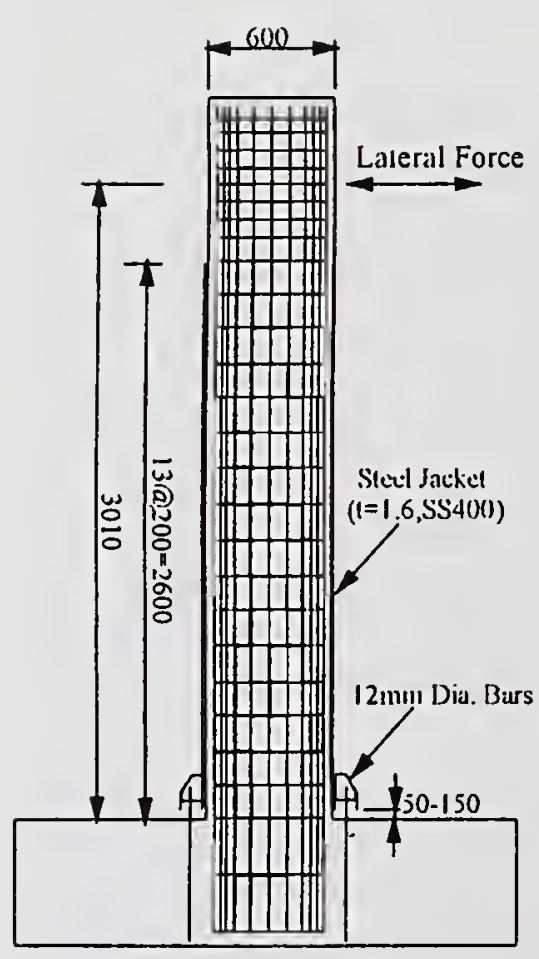

Elevation
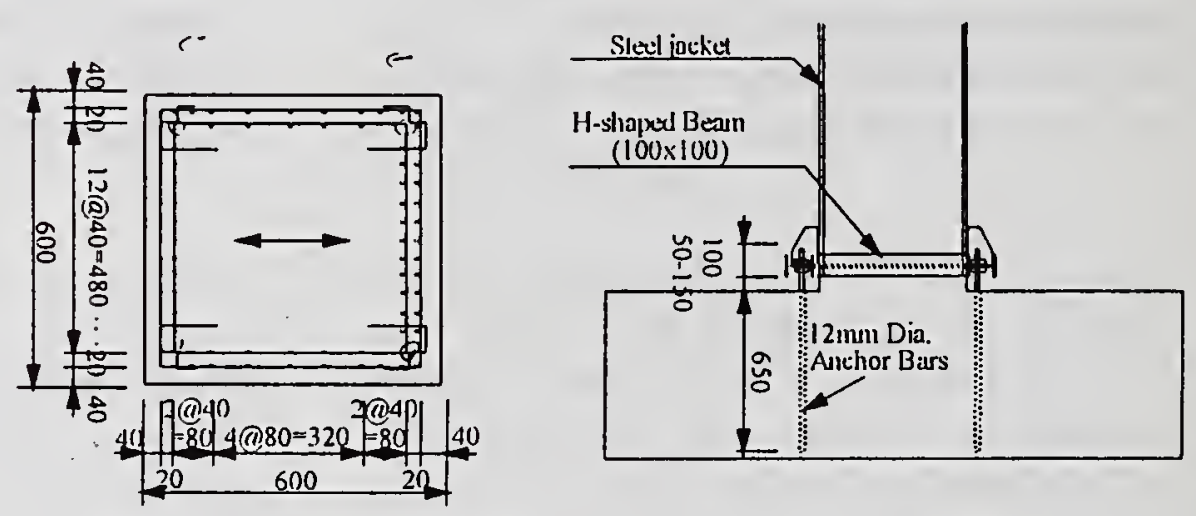

Existing Column Cross-Section

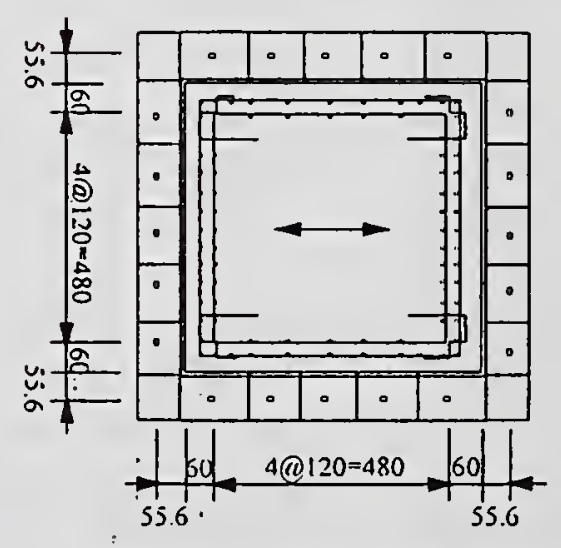

Retrofited Column Cross-Section

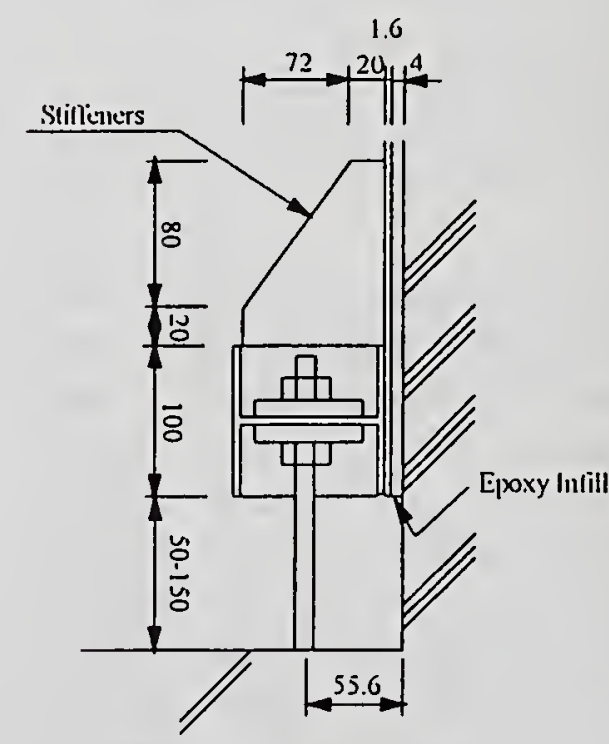

Detail of Stiffened Collar

Fig. 2 Details of Test Specimens (unit: $\mathrm{mm}$ ) 


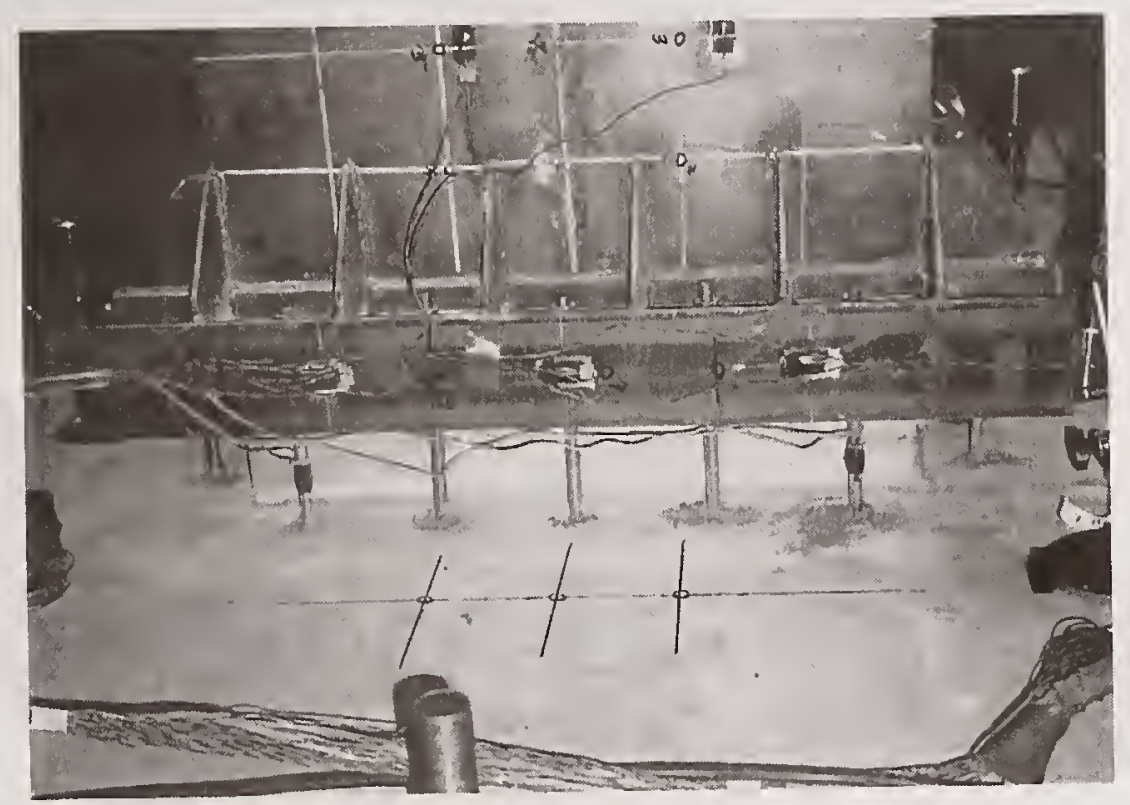

Photo 1 Detail around Base

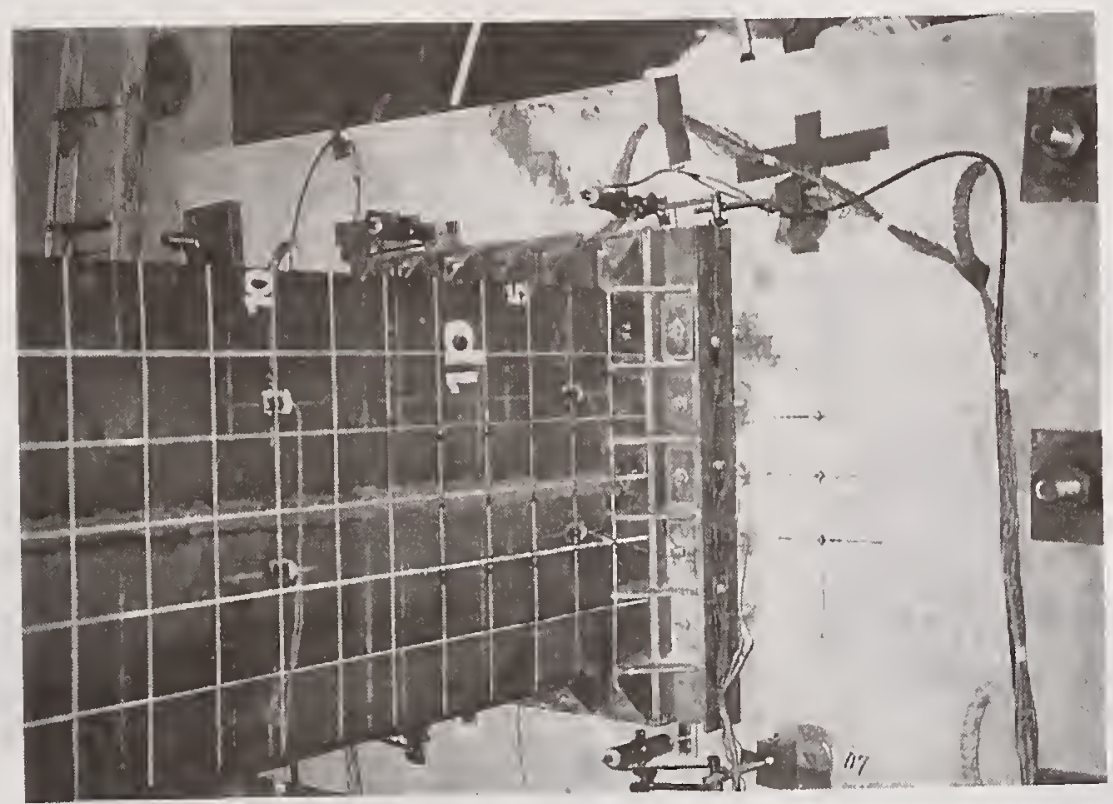

Photo 2 Steel Jacket and Anchor

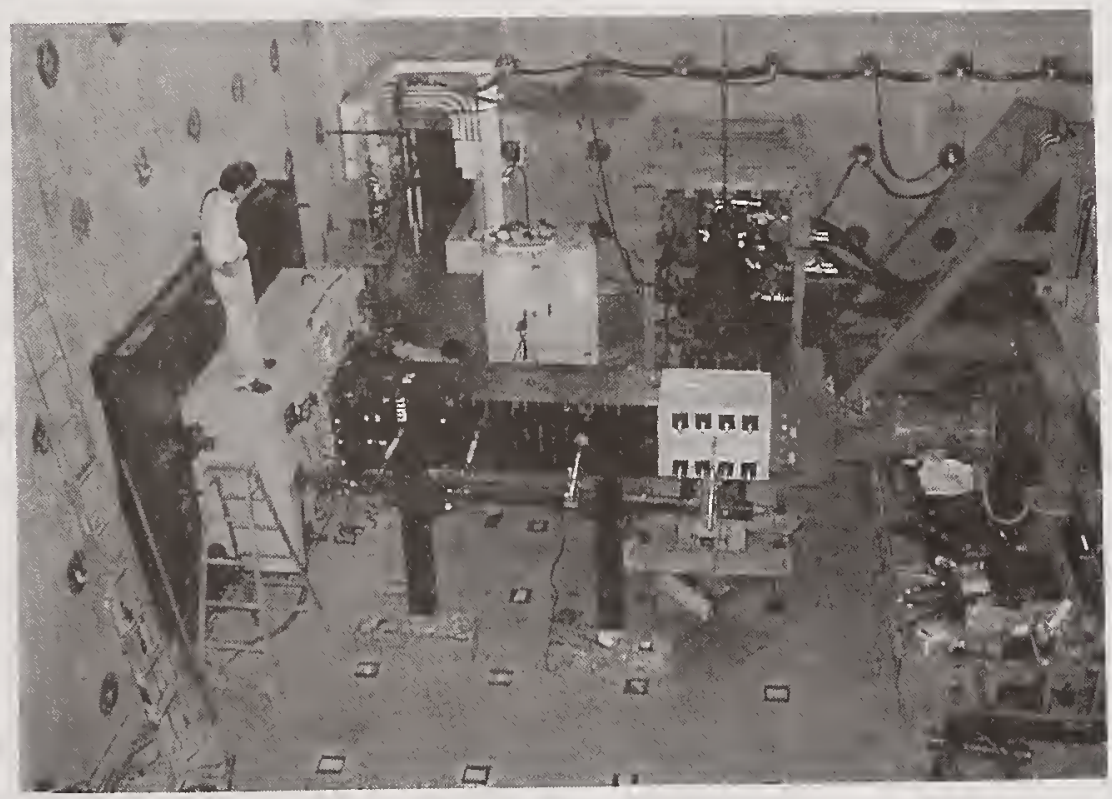

Photo 3 Set-up of Cyclic Loading Test 


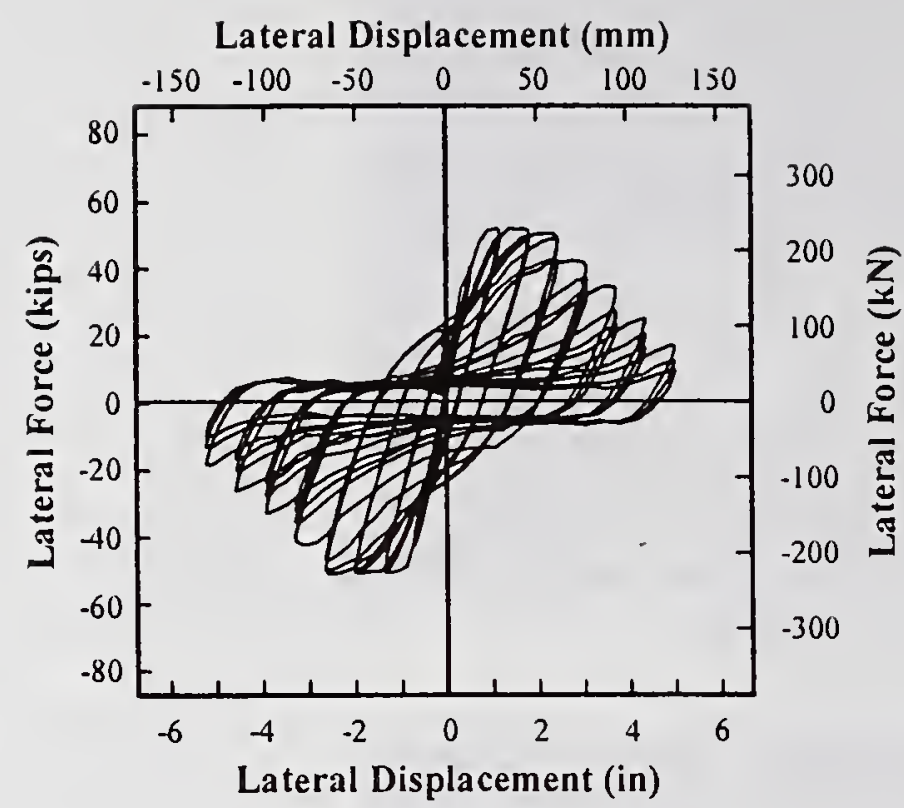

(a) P-1 Specimen

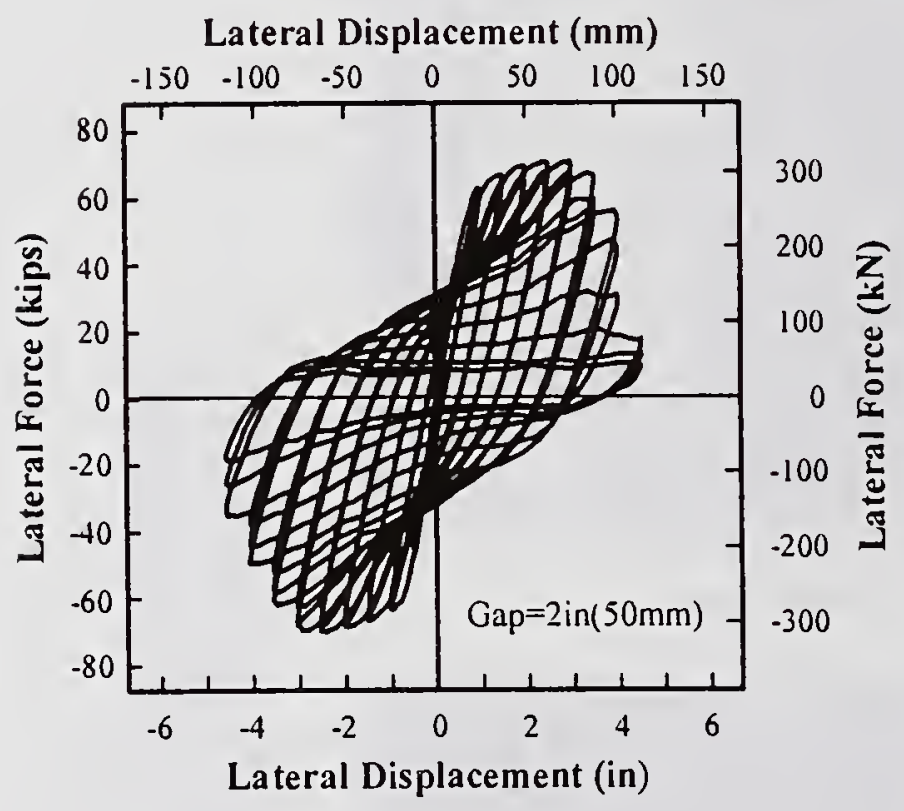

(c) P-1 Specimen

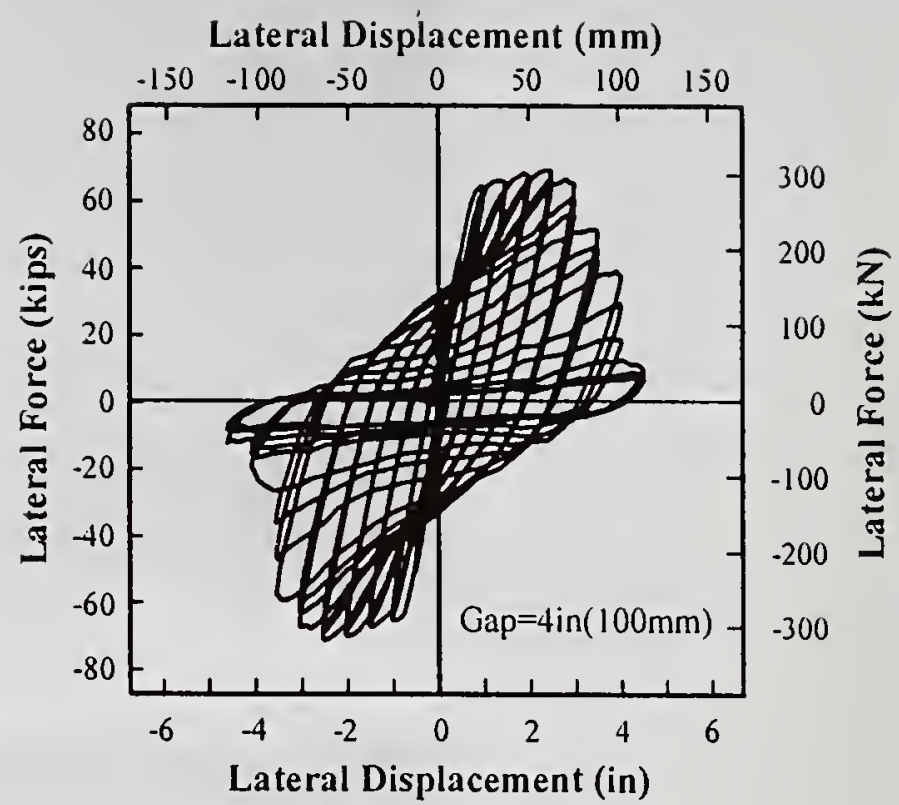

(b) P-2 Specimen

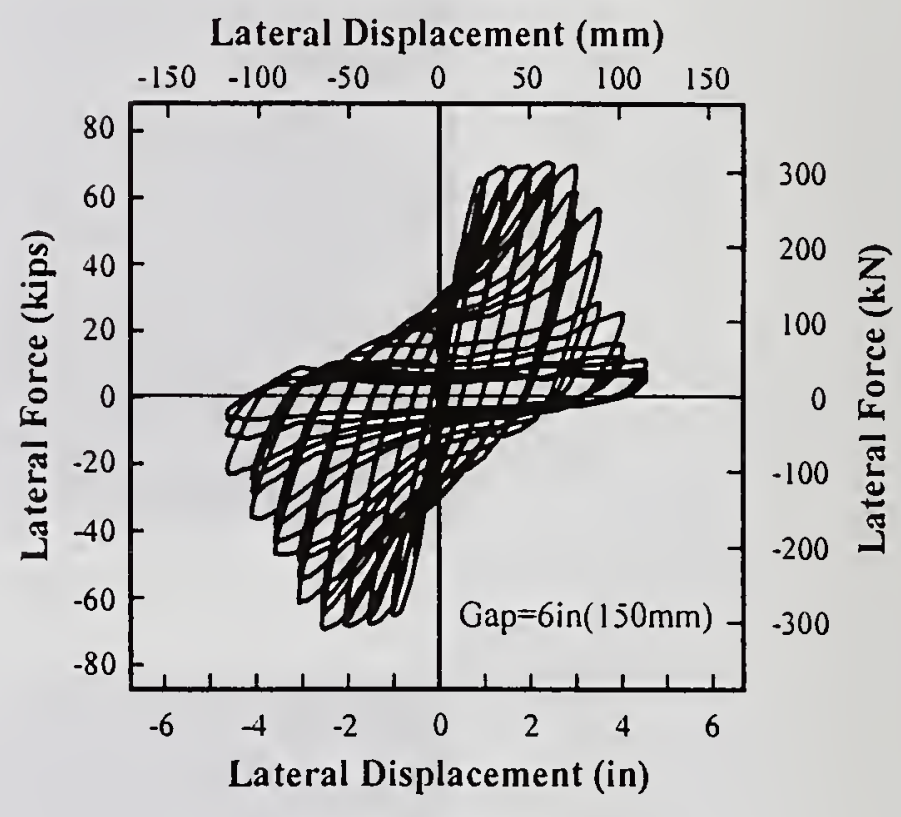

(d) P-2 Specimen

Fig. 3 Hysteresis Roop of Lateral Load and Displacement Relation 


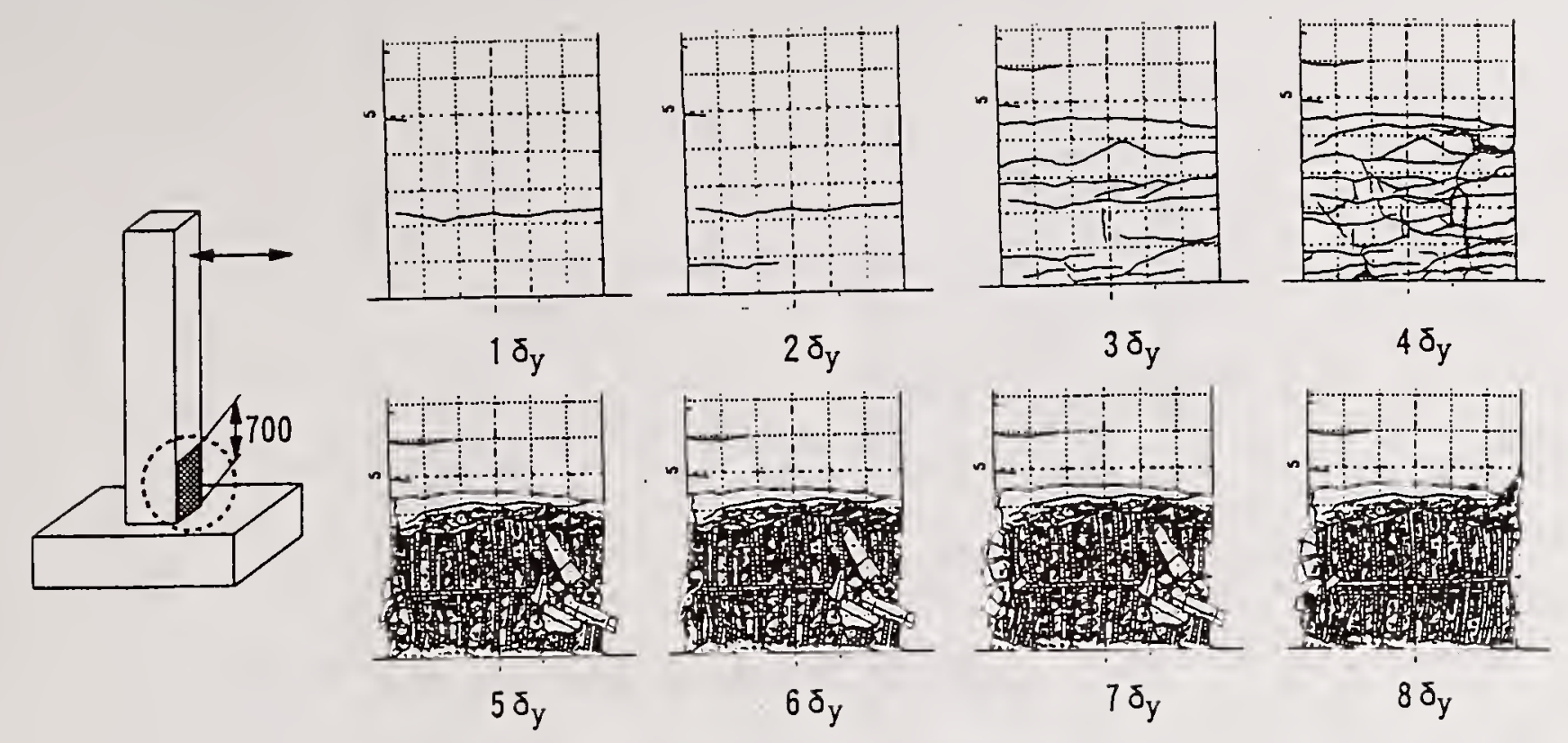

(a) P-1 Specimen
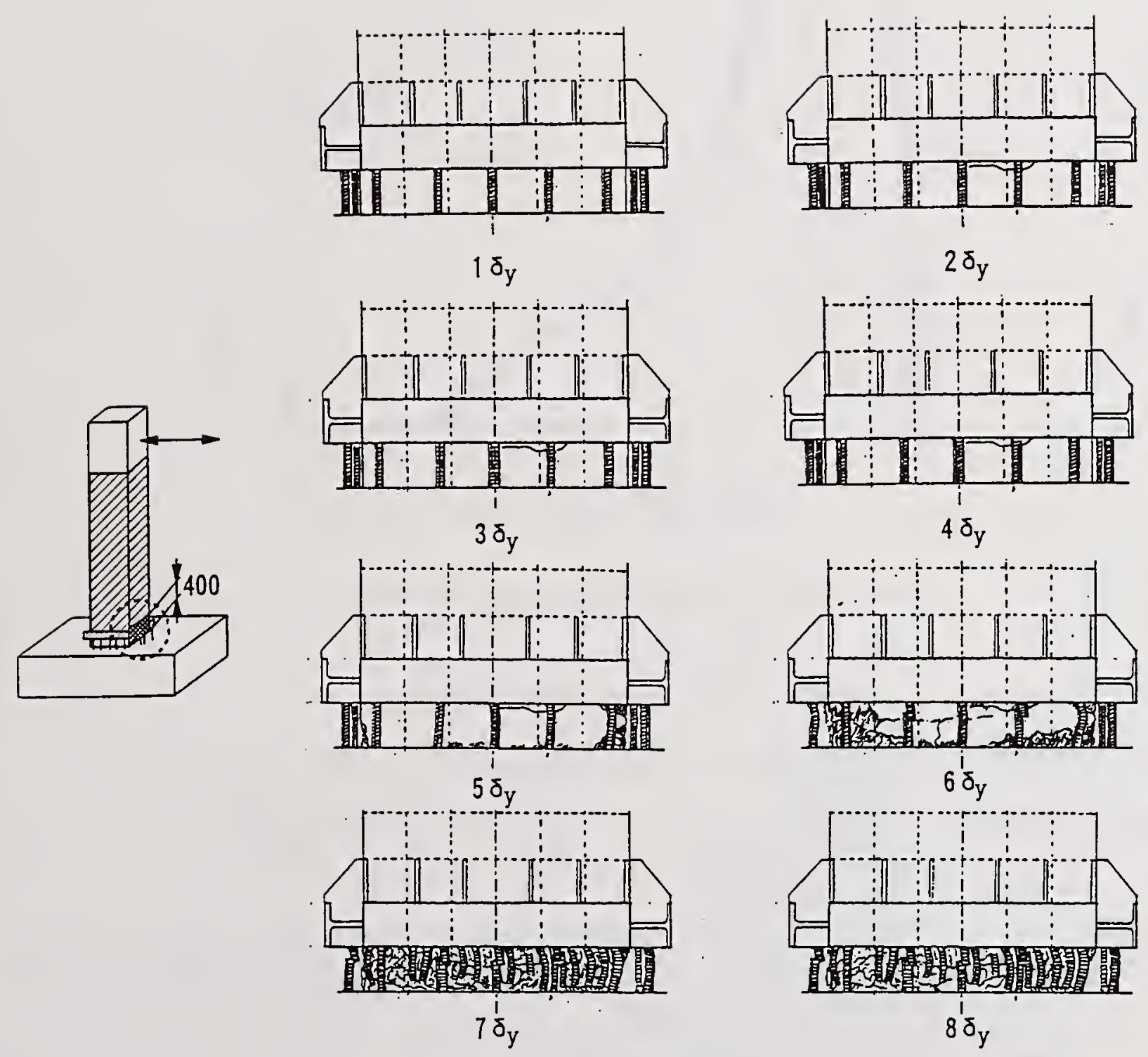

(b) P-2 Specimen

Fig.4 Damage Process Observed in Specimens 


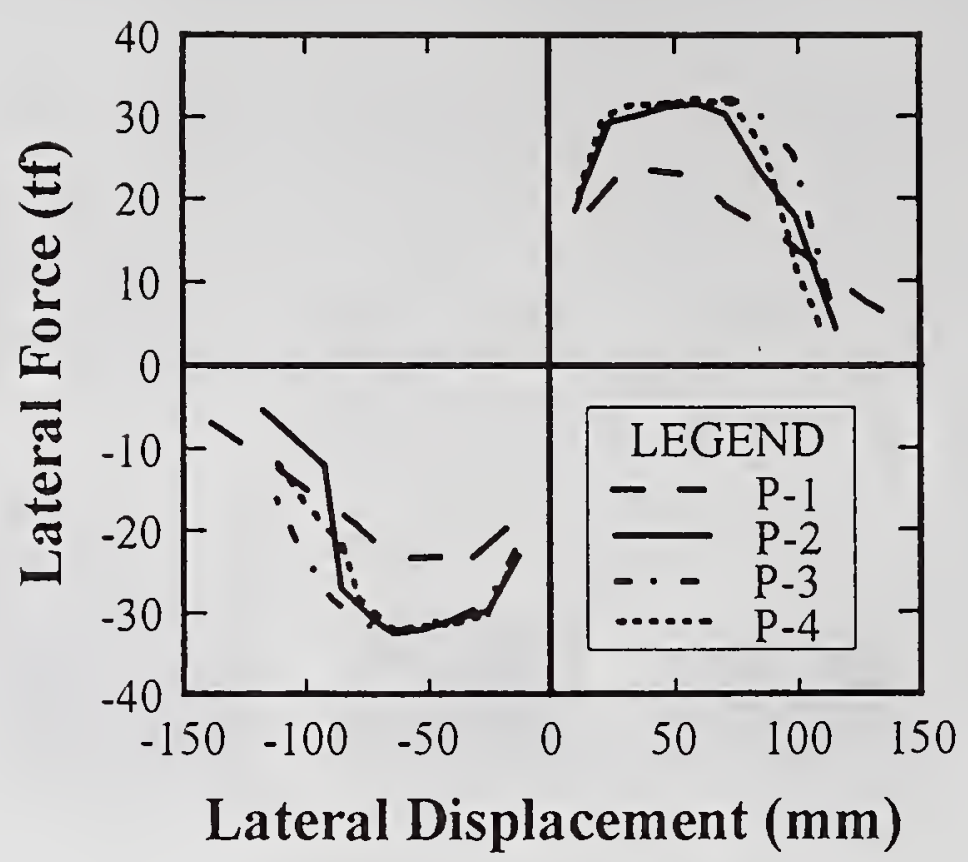

Fig. 5 Comparison of Envelope of Hysteresis Roop

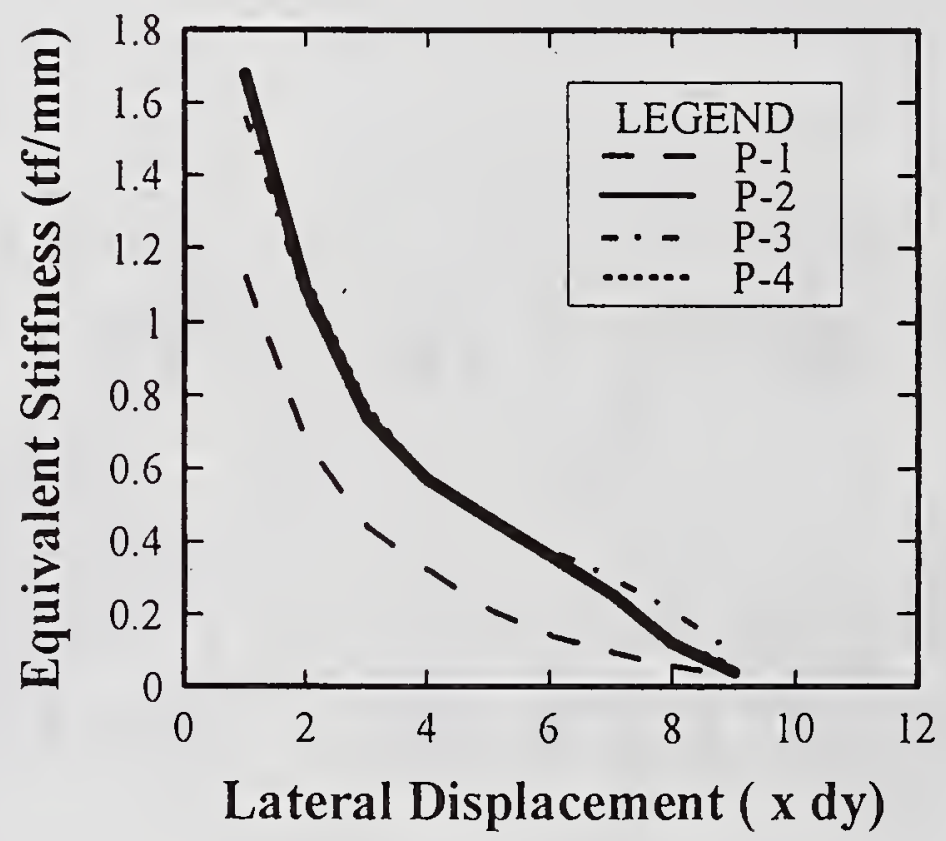

Fig. 6 Effect of Retrofit on Equivalent Stiffness

Table 1 Observed Strength and Ductility

\begin{tabular}{c|l|c|c|c|c}
\hline \hline \multicolumn{2}{c|}{ Specimen } & P-1 & P-2 & P-3 & P-4 \\
\hline \multirow{4}{*}{ Strength } & Yield Strength (tf) & 18.8 & 21.3 & 20.2 & 21.5 \\
\cline { 2 - 6 } & Peak Strength (tf) & 23.1 & 31.8 & 31.7 & 31.9 \\
\cline { 2 - 6 } & PM/Py & 1.23 & 1.49 & 1.57 & 1.48 \\
\hline \multirow{4}{*}{ Ductility } & Yield Displacement (mm) & 16.0 & 12.7 & 12.7 & 12.7 \\
\cline { 2 - 6 } & Ultimate Displacement (mm) & 87.0 & 96.5 & 110.9 & 96.0 \\
\cline { 2 - 6 } & Ductility Factor & 5.4 & 7.6 & 8.7 & 7.6 \\
\hline \hline
\end{tabular}




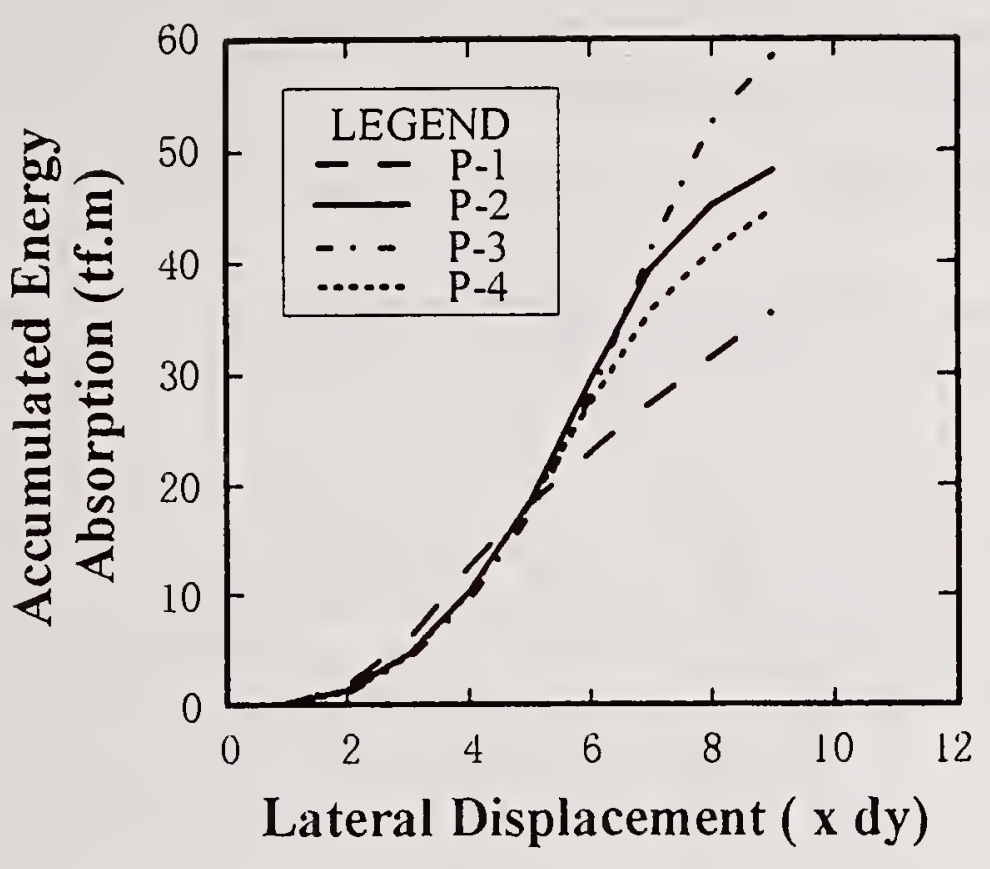

Fig. 7 Effect of Retrofit on Accumulated Energy Absorption

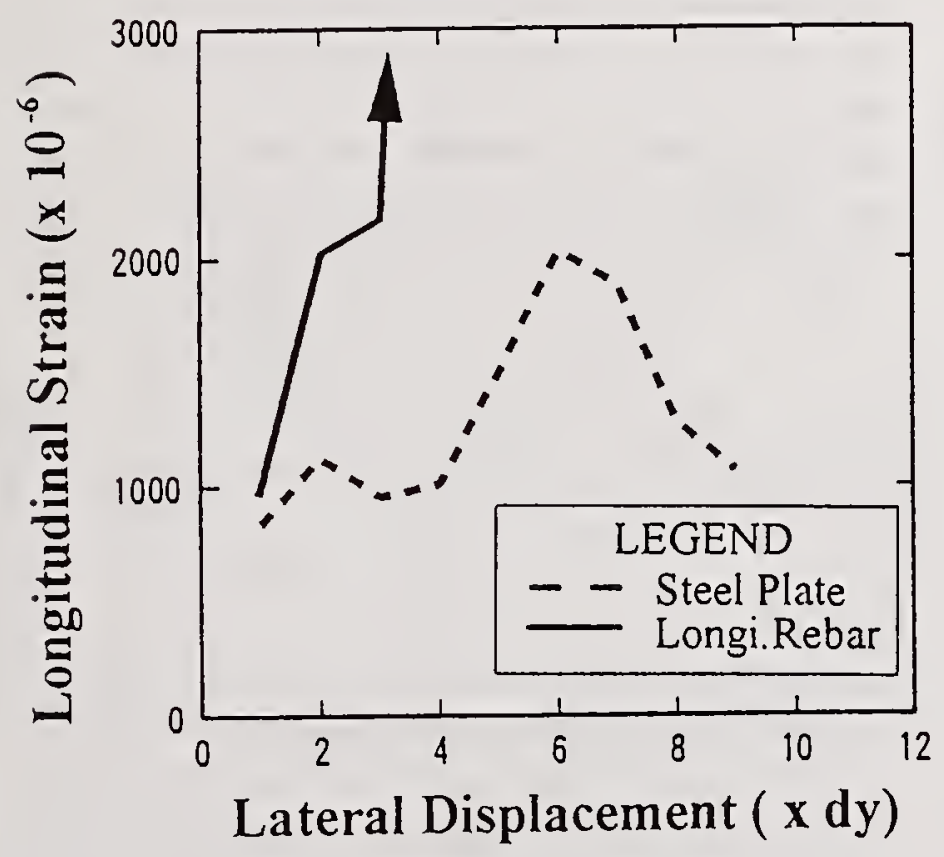

Fig. 9 Axial Strain of Longitudinal Reinforcement and Steel Plate in Specime P-2

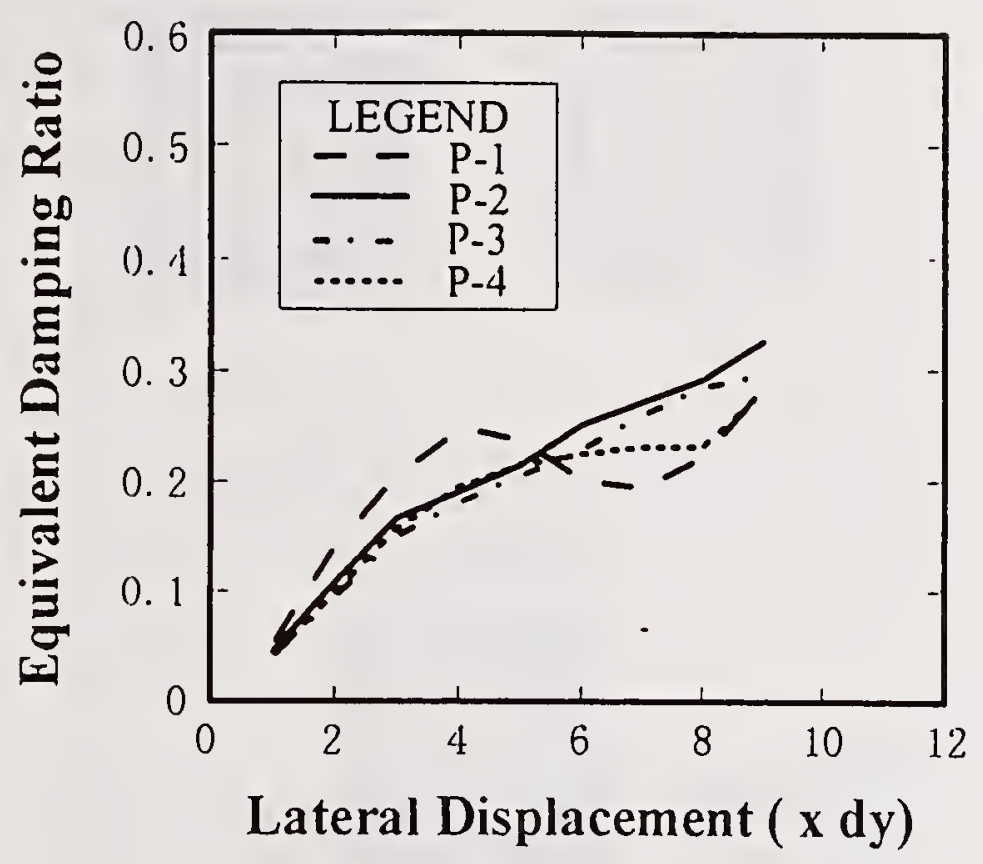

Fig. 8 Effect of Retrofit on Equivalent Damping Ratio

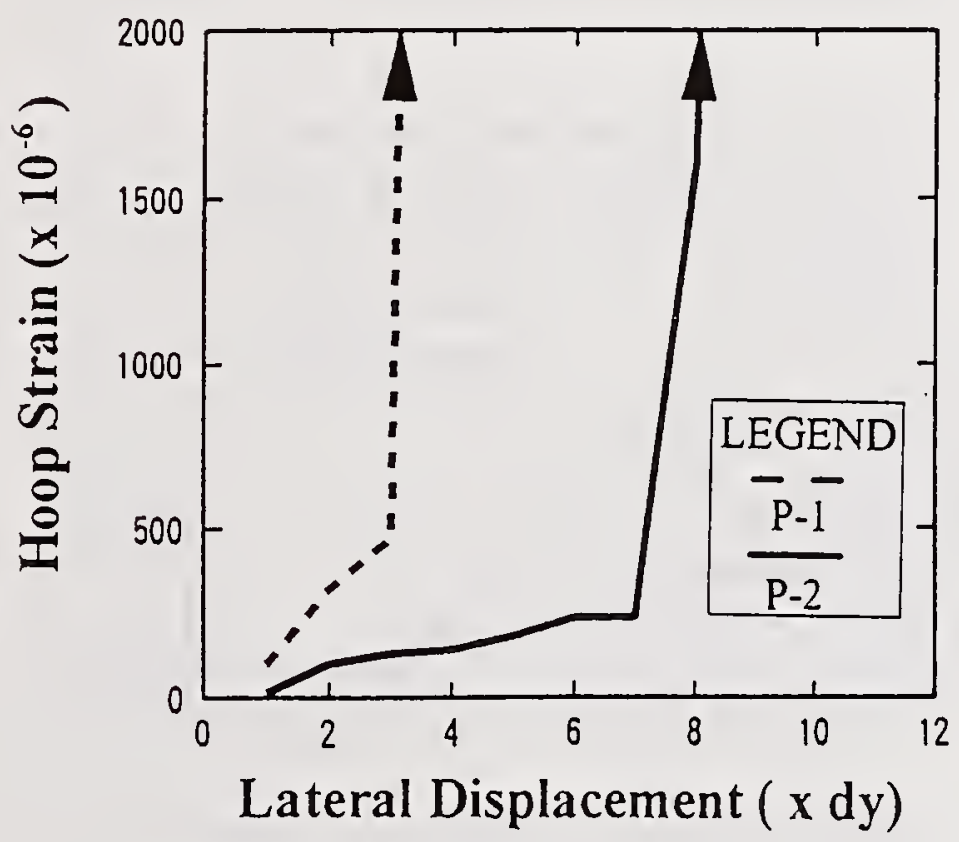

Fig. 10 Comparison of Strain of Hoop 


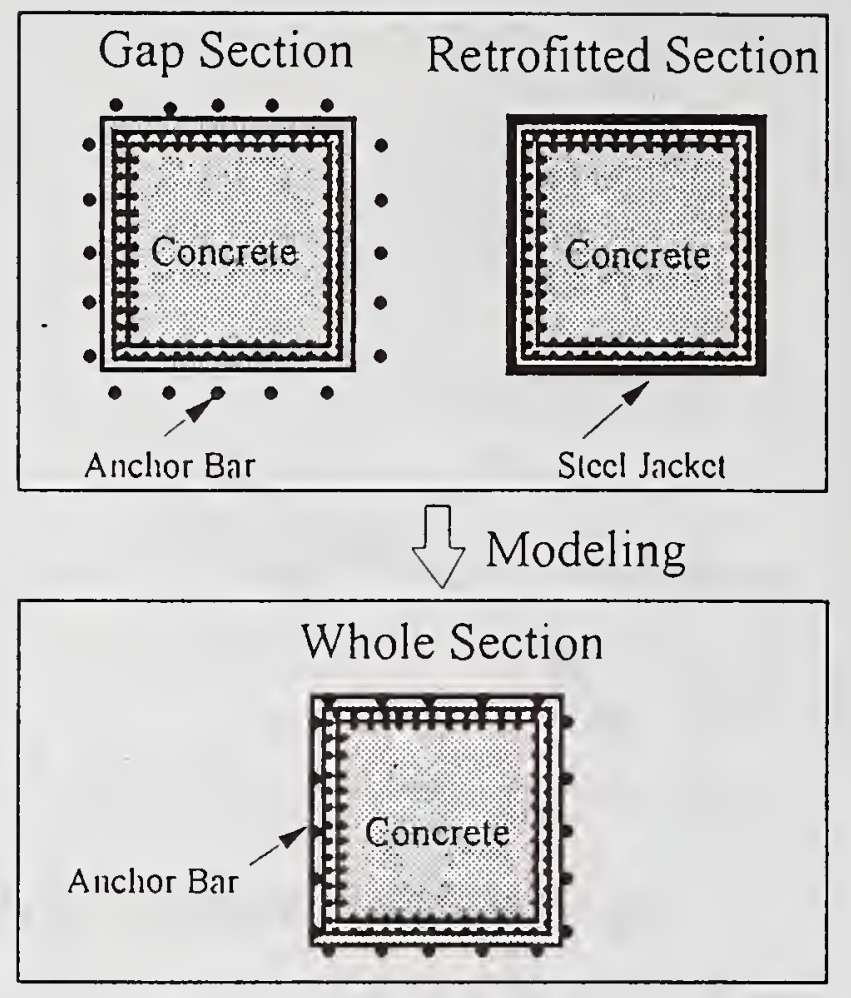

Fig. 11 Analyzing Model of Steel Jacketing with Anchor Bars

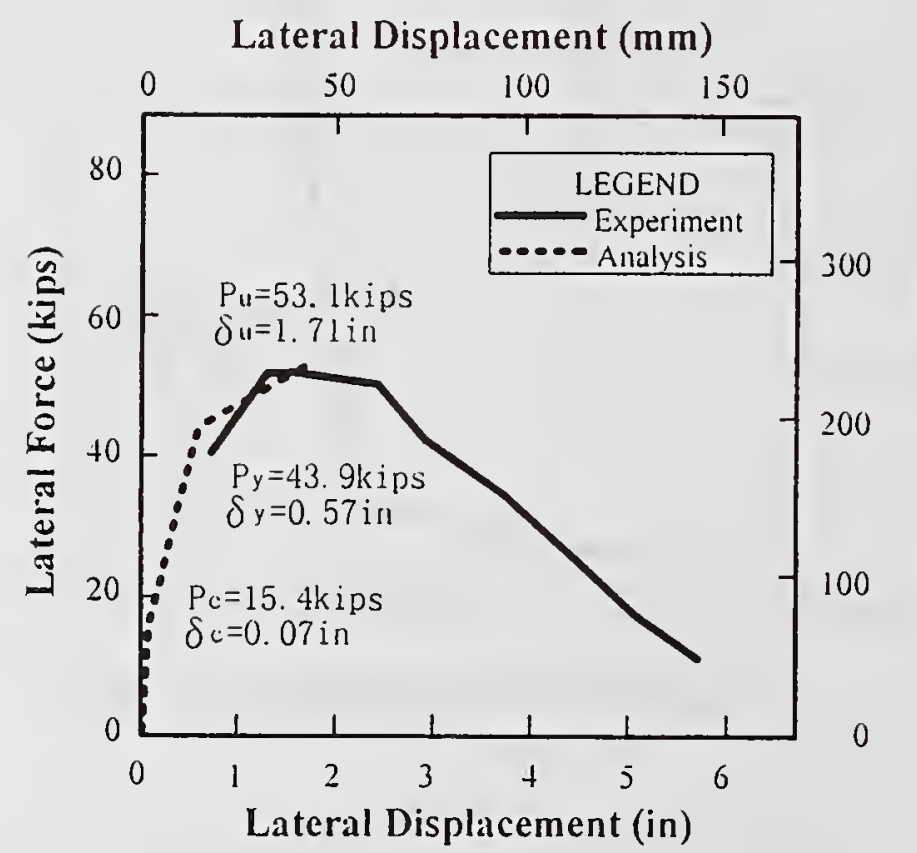

(a) P-1 Specimen

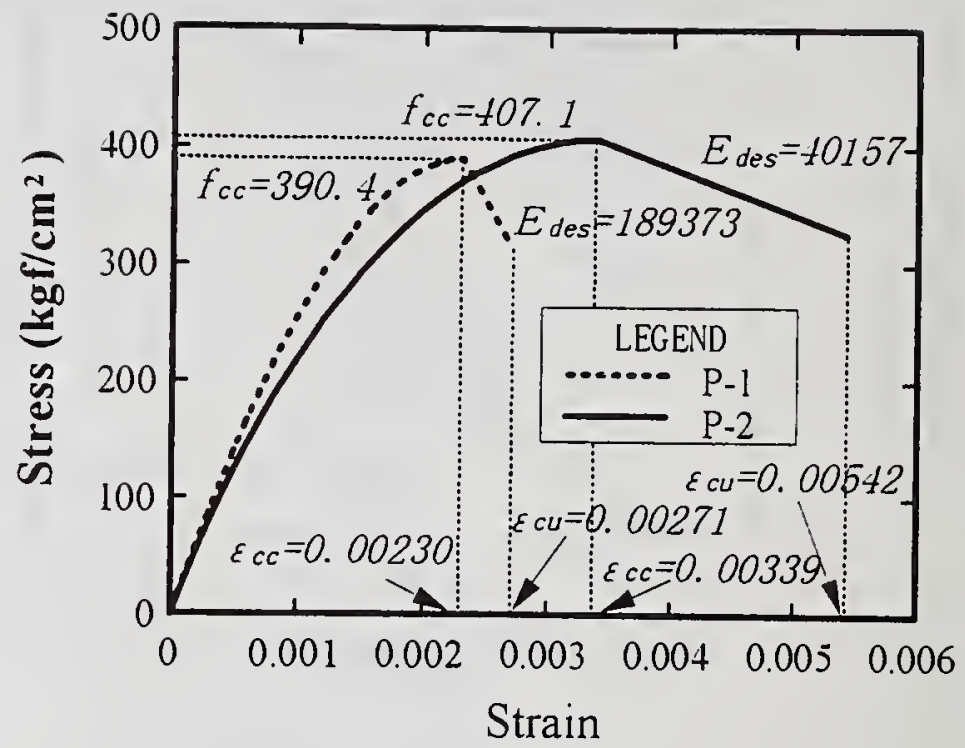

Fig. 12 Stress-strain Curve Used in Analysis

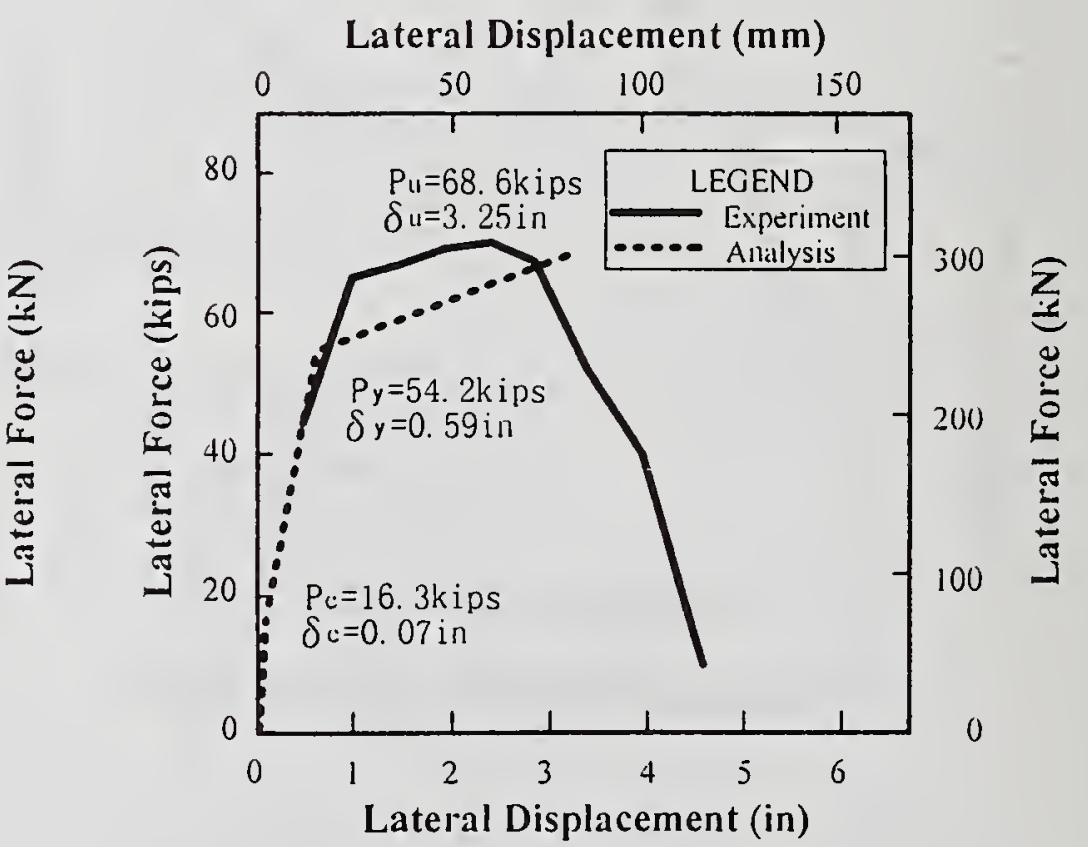

(b) P-2 Specimen

Fig. 13 Comparison of Lateral Load and Displacemetn Relation 


\title{
Experimental Study on the Bearing Capacity of Cast-in-Place Concrete Piles Damaged by the Hanshin Earthquake
}

\author{
Hiroyuki Nakajima ${ }^{1)}$, Hidenao Hayashi' ${ }^{2)}$ and Kenji Kosa ${ }^{31}$
}

\section{ABSTRACT}

To evaluate the actual behavior of pile foundations, a loading test was conducted on full-scale foundations in a box arrangement of nine cast-in-place piles. The results show that as loading was increased until the maximum jack stroke of $43 \mathrm{~cm}$ was reached, the resisting load increased constantly. After the Great Hanshin Earthquake, another loading test was conducted on actual piles whose tops had cracked during the earthquake to evaluate the degree of damage. The bending load test results allowed us to assume that the piles had been subjected to a maximum displacement of $2 \delta_{y}$. An analysis that takes the nonlinear behavior into consideration lead to the conclusion that these damaged pile tops still had the same level of rigidity and deformation capacity as sound pile foundations when considered as a complete pile foundation system. The above has clarified that the tested pile foundations possess a rigidity and deformation capacity far greater than the levels required by the specifications.

KEYWORDS: bearing capacity, cast-in-place concrete piles, ultimate behavior, load deformation

\section{INTRODUCTION}

To establish design procedures for pile foundations of bridges that can resist big earthquakes, it is necessary to understand the behavior of full-scale bridge structures during an earthquake or when they are subjected to large deformation. To evaluate the actual behavior of pile foundations in September 1993, we conducted a loading test on full-scale pile foundations in a box arrangement of nine cast-in-place piles, each having a diameter of $1,200 \mathrm{~mm}$. In March 1995 after the Great Hanshin Earthquake, another loading test was conducted on actual piles whose tops had cracked during the earthquake to evaluate the degree of damage. The measurement results from these two tests are reported here.

\section{HORIZONTAL LOAD TEST ON A FULL-SCALE MODEL OF NINE PILES"}

\subsection{Outline of the Test}

The loading test on a full-scale model was conducted in 1993 on recently-reclaimed land (around 1990) at Kishiwada Port, Osaka Prefecture. The land is a 13meter layer mainly of gravel having a maximum diameter of $300 \mathrm{~mm}$. $\mathrm{N}$ values of the experimental site ranged from 3 to 20 and the deformation coefficient obtained by the in-boring horizontal load test was around $\mathrm{E}_{b}=10 \mathrm{kgf} / \mathrm{cm}^{2}$, indicating that the ground is fairly loose. Under the reclaimed layer lies a diluvial deposit consisting of alternating cohesive and sandy soils.

The horizontal load test was conducted on both single piles and a nine-pile group (see Fig. 1 for pile arrangement). The footing of the tested pile group was $9.0 \times 9.0 \times 2.3 \mathrm{~m}$. To eliminate resistance from the surrounding soil during the test of the pile group, soil was removed from the area $10 \mathrm{~m}$ in front and $5 \mathrm{~m}$ on both sides of the footing to a depth of $2.3 \mathrm{~m}$, down to the bottom of the footing, so the test ground and the footing bottom were level. Horizontal load was applied in a single direction, multi-cycle method, $90 \mathrm{~cm}$ above the footing bottom using six hydraulic jacks, with the adjacent footing as the reaction force.

1) Section Chief, Design Section, Engineering Department, Hanshin Expressway Public Corporation

2) Section Chief, Research and Design Section, Kobe Route Reconstruction Division, Hanshin Expressway Public Corporation

3) Senior Engineer, Construction Section, Hanshin Expressway Public Corporation 


\subsection{Results of Displacement Measurement}

Figure 2 shows the relationship between the load and displacement at a point $20 \mathrm{~cm}$ above the bottom end of the footing. As loading was increased until the maximum jack stroke of $43 \mathrm{~cm}$ was reached, the resisting load also increased, attaining a maximum load of 2,050 tf. Elastic behavior was observed in the loaddisplacement relationship up to around 600 tf, but after the displacement reached about $10 \%$ of the pile diameter, the increase in displacement became steep. The logarithmic scale figure shows a bend around 800 tf, where the pile is believed to have started cracking and its rigidity began to drop.

The load-displacement curve shown in Fig. 2 was obtained by a method" that takes the non-linear behavior of foundations based on the references for application of the Restoration Specifications ${ }^{2)}$ into consideration. In the analysis, the following values were used: strength of concrete $\sigma_{\mathrm{c}}=350 \mathrm{kgf} / \mathrm{cm}^{2}$, strength of steel $\sigma_{\mathrm{s}}=3,800 \mathrm{kgf} / \mathrm{cm}^{2}$, filling layer $\mathrm{c}=0, \phi=38^{\circ}$; diluvial deposit $c=9 \mathrm{tf} / \mathrm{m}^{2}, \phi=0$; all of which were obtained from on-site tests, and correction factors for the single pile were $\alpha_{k}=1.5, \alpha_{p 1}=2.5, \alpha_{p 2}=1.25$, $\alpha_{p 3}=1.25$, with a correction factor for pile group effect of $\eta=1.0$. The ultimate load and displacement obtained by the analysis were considerably smaller than those from the tests, indicating that the analysis provides values erring on the safe side.

Figure 3 shows the measurement results of footing displacement. It can be seen from the figure that the footing rotated while lifting. This is because the rotation of the footing increased the compression force on the piles in the front row, causing them to stick in the ground while the piles in the rear row were subjected to an increasing tensile force and tended to lift. However, the front-row piles that started to settle were then braked by the resistance of the soil at the footing bottom, and eventually all the piles lifted.
2.3 Displacement Distribution on the Ground Surface and Observation Results of the Pile Tops

Figures 4 and 5 show vertical and horizontal displacements respectively on the ground around the test piles which were measured right after the load test. These values should be smaller than the actual displacement during loading. However they were determined to represent the true displacement distribution on the ground surface under the maximum load because contact displacement gauges showed nearly equal values during and after loading. Surface displacement extended over about $6 \mathrm{D}$, or 7 meters, from the piles in the front row. No distinct sliding surface was found but a $10-\mathrm{cm}$ elevation was formed just in front of the front row.

The ground around the footing was excavated about a further $1 \mathrm{~m}$ after the load test to check for cracks in the pile tops. Figure 6 shows the crack conditions in the pile tops observed from the side. Flexural cracks were found in the pile tops, a little below the bottom of the footing. They measured about $5 \mathrm{~mm}$ extending up to $80 \%$ of the cross section of the pile even after the removal of the load. This indicates that the ultimate stage of failure had been passed.

\section{LOADING TEST ON PILES DAMAGED BY THE EARTHQUAKE}

\subsection{Profile of Loaded Piles}

Loaded piles were the most severely damaged foundation piles of the Hanshin Expressway No. 3 Kobe Route in the Great Hanshin Earthquake. Visual observation and investigation using borehole cameras before the load test had revealed that the degree of damage to the 19 piles was relatively consistent with cracks of $2 \mathrm{~mm}$ in width being observed in the pile tops; but no concrete was crushed and no reinforcements were buckled.

These cracks were narrower and less damaging than those in the piles at Kishiwada test site (see Section 2). A material test was conducted by sampling three core concrete specimens and five reinforcement specimens from the pile tops. The test results were as follows: the mean concrete strength was $425 \mathrm{kgf} / \mathrm{cm}^{2}$, about 1.8 times the design strength $\left(\sigma_{\mathrm{ck}}=240 \mathrm{kgf} / \mathrm{cm}^{2}\right)$. The reinforcement specimens taken from the compressed 
section of the pile tops had a yield strength of 3,750 $\mathrm{kgf} / \mathrm{cm}^{2}$ and a fracture strength of $5,590 \mathrm{kgf} / \mathrm{cm}^{2}$, exceeding the respective reference values of 3,000 $\mathrm{kgf} / \mathrm{cm}^{2}$ and $4,500-6,100 \mathrm{kgf} / \mathrm{cm}^{2}$. Meanwhile, specimens from the cracked areas had a fracture strength of $5,400 \mathrm{kgf} / \mathrm{cm}^{2}$ which is high enough, but did not have any clear yield point. This indicates that the reinforcements had been subjected to a stress history exceeding the yield point.

\subsection{Pile Bending Test}

A pile bending test was conducted on a test specimen cut from a pile $2.8 \mathrm{~m}$ below the bottom end of the footing (Fig. 7). Two adjacent piles were used as the reaction body. A 50-tf hydraulic jack was installed between an $\mathrm{H}$-shaped steel girder laid between the two adjacent piles and the test specimen to apply a horizontal load to the point $2.5 \mathrm{~m}$ below the footing. Multi-cycle loading was applied from one direction. The specimen was loaded up to a maximum of $25 \mathrm{tf}$, equivalent to $60 \%$ of the calculated bending moment to cause the pile top section to yield. As shown in Fig. 8, the pile's horizontal displacement, curvature and load intensity were measured in the test. Figure 9 shows the load-displacement curves at the point where the load was applied. They are linear while the load is being applied and little residual displacement is observed even after load removal. This leads to the assumption that the damaged piles have not been subjected to the ultimate load. The rigidity obtained by the $M-\phi$ relationship shown in Fig. 10 is smaller than the calculated rigidity at the yield point, indicating that the reinforcement in the pile top has reached the yielding range. Calculation of the displacement based on the assumption that bending rigicity obtained from the test pile is equal to the inclination of line (A) that can be deduced by the load-deformation history rules, suggests that a maximum displacement of about $2 \delta_{y}$ was generated.

As the next step, load-deformation curves were plotted by using a method ${ }^{21}$ that takes the non-linear behavior of the foundation into consideration in order to evaluate the soundness of the entire pile foundation system that has cracked.

Here the rigidity of the damaged pile at the pile top over $1.5 \mathrm{~m}$ was reduced to the level obtained from Fig. 9. Figure 10 shows the load-displacement curves. The degree of deformation of the damaged pile foundation is slightly bigger than that of the undamaged one, but almost no decrease in ultimate strength was observed. Those piles whose rigidity had dropped due to a deformation of about $2 \delta_{y}$ led to the decrease in initial rigidity inclination and little change in strength and deformation in the ultimate state.

\subsection{Horizontal Load Test}

For the horizontal load test, the pile located in the center of the footing was cut $1.2 \mathrm{~m}$ below the footing bottom and the section below was used as a test specimen. A horizontal load was applied to the pile top. Two piles adjacent to the test pile were used as reaction piles. Because the pile was to be used for a new bridge, the maximum applied load was set to $45 \mathrm{tf}$ since it was the level where reinforcement stress in the area of maximum moment became $1,800 \mathrm{kgf} / \mathrm{cm}^{2}$ when the test pile was regarded as a pile with a free top. Figure 13 shows the load-displacement curves derived from the horizontal load test. Calculation based on these curves gives a horizontal subgrade reaction coefficient of 1.9 $\mathrm{kgf} / \mathrm{cm}^{2}$ when the horizontal displacement is $1 \%$ of the pile diameter. The horizontal subgrade reaction coefficient can be assumed to be $2.3 \mathrm{kgf} / \mathrm{cm}^{2}$ using the $\mathrm{N}$ values obtained in the standard penetration test designated in the Highway Bridge Specifications. The method used in the Highway Bridge Specifications gives mean values; when the data dispersion is taken into account, our calculated value is believed to lie approximately in the same range, and is not an abnormal value caused by the Earthquake.

\subsection{Vertical Load Test}

Using the same test pile from the horizontal load test, a vertical load test was conducted employing the footing's own weight as the reaction force. The applied load was $450 \mathrm{tf}$, the ultimate bearing capacity calculated based on the Highway Bridge Specifications. The loaddisplacement curves obtained are shown in Fig. 14, which indicates almost elastic behavior with bend. It is clear, therefore, that the load applied was below the ultimate bearing capacity. The amount of settlement was $1.3 \mathrm{~cm}$, well below the permitted level $(10 \%$ of the pile diameter $=10 \mathrm{~cm}$ ). As a result, it is obvious that the design bearing capacity specified by the Highway Bridge Specifications was obtained. 


\section{CONCLUSIONS}

To evaluate the pile behavior under an extreme deforming force, a series of load tests were conducted and the following results were obtained:

1. In the load test using a pile group (a box arrangement of nine piles), as loading was increased until the maximum jack stroke of $43 \mathrm{~cm}$ was reached, the resisting load increased constantly also. After the test, a crack $5 \mathrm{~mm}$ wide was found in the pile top section, indicating that the ultimate state had been reached.

2. Horizontal and vertical load tests were conducted with the piles that had cracked in their top section because of the earthquake. The obtained test results roughly satisfied the ultimate bearing capacity and horizontal subgrade reaction coefficient that were obtained from the Highway Bridge Specifications.

3. The bending load test results using the earthquakedamaged pile tops allowed us to assume that they had been subjected to a maximum displacement of $2 \delta_{\mathrm{y}}$. Meanwhile an analysis taking non-linear behavior into consideration lead to the conclusion that these damaged pile tops still had the same level of rigidity and deformation capacity as sound pile foundations as an entire pile foundation system.

4. All the above has clarified that the tested pile foundations possess a rigidity and deformation capacity far greater than the levels required by the specifications.

\section{ACKNOWLEDGMENTS}

We express special thanks to the members of the "Subcommittee on Substructures, Technical Research Committee of the Hanshin Expressway Public Corporation" and the "Subcommittee on Substructures, Disaster Prevention Committee of the Hanshin Expressway Public Corporation" for their kind advice in completing the load tests.

\section{REFERENCES:}

1) K. Kosa, M. Kimura, Y. Morita and K. Itoh: Full-Scale Lateral Displacement Tests on Grouped Cast-in-Place Concrete Piles, Soil and Foundations, pp. 43-46, May 1995.

2) Japan Road Association: References for Application of the Specifications for Restoration of the Highway Bridges Damaged by the Great Hanshin Earthquake (draft), June 1995. 


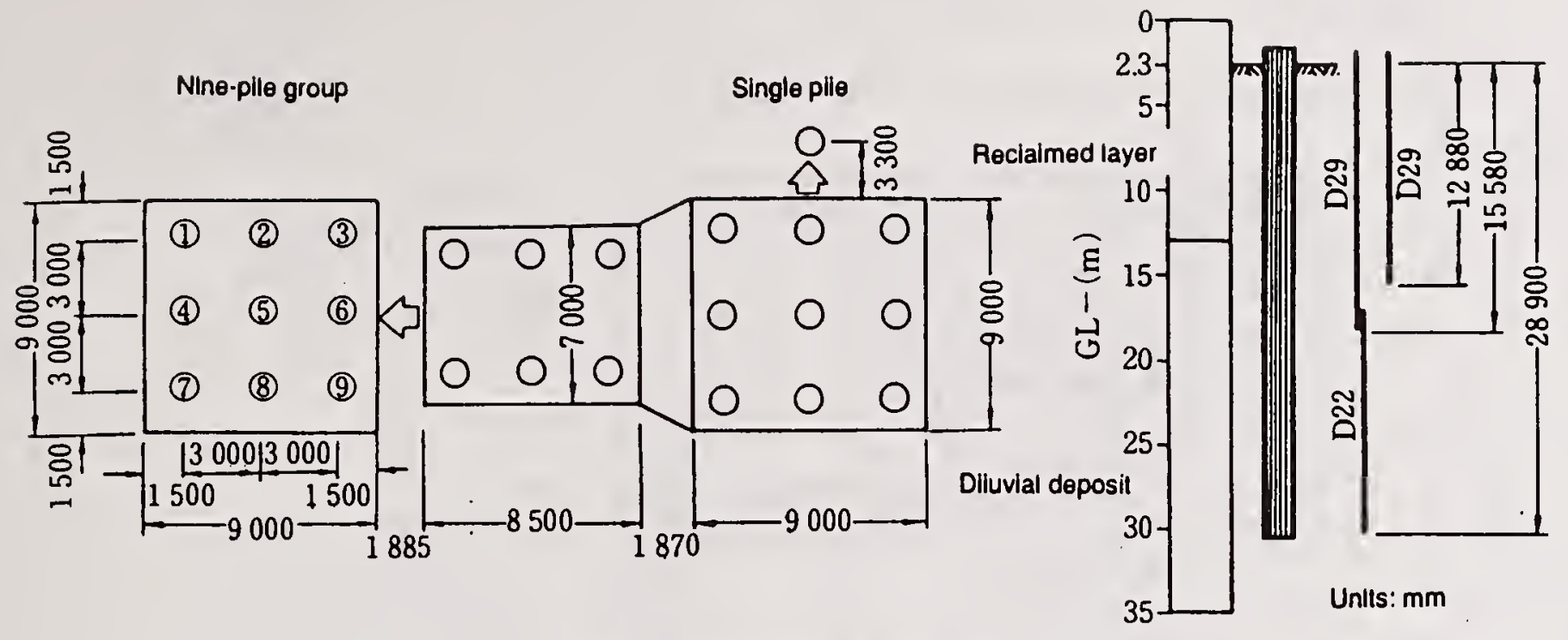

Fig. 1 Arrangement of test piles

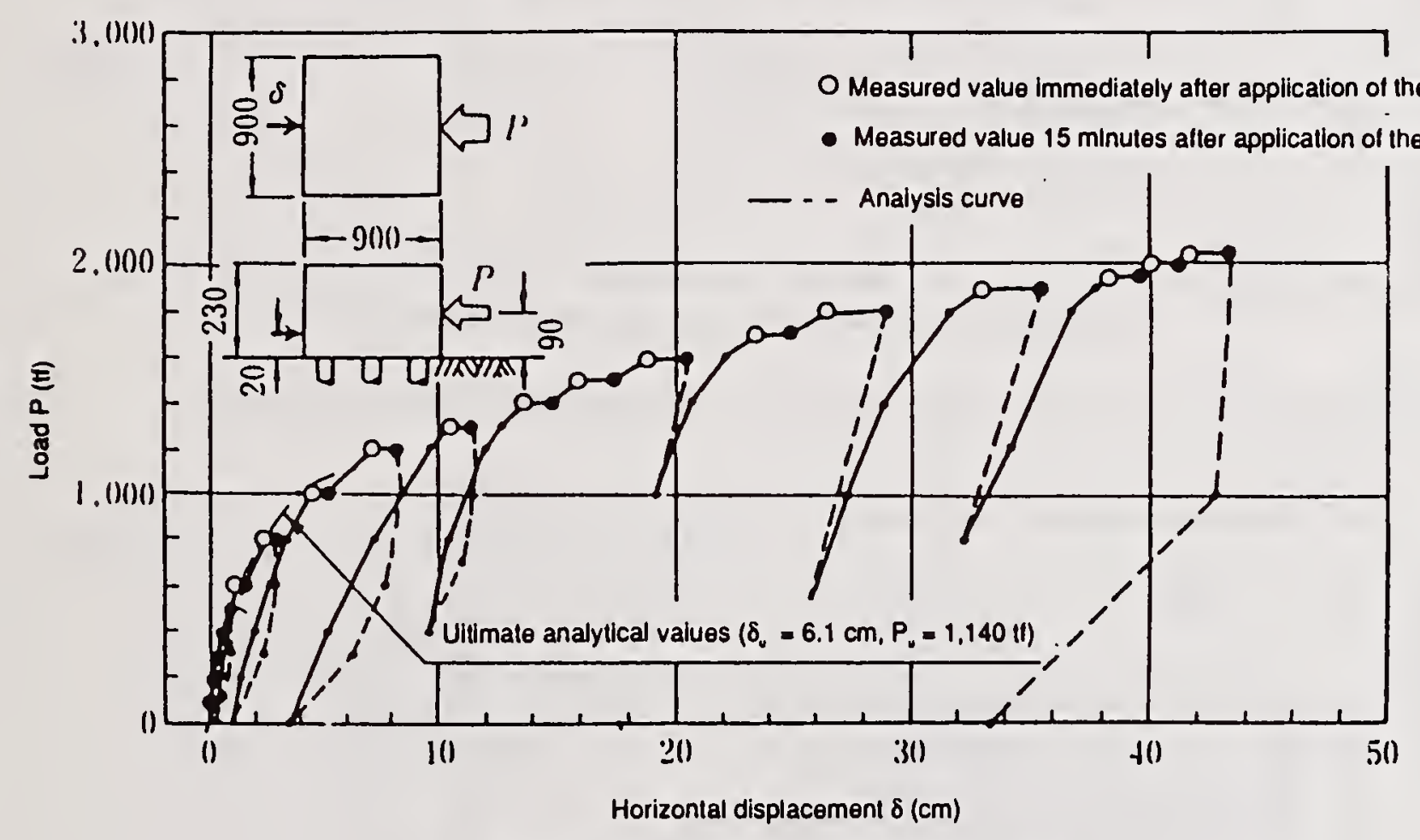

Fig. 2 Load-horizontal displacement relationship

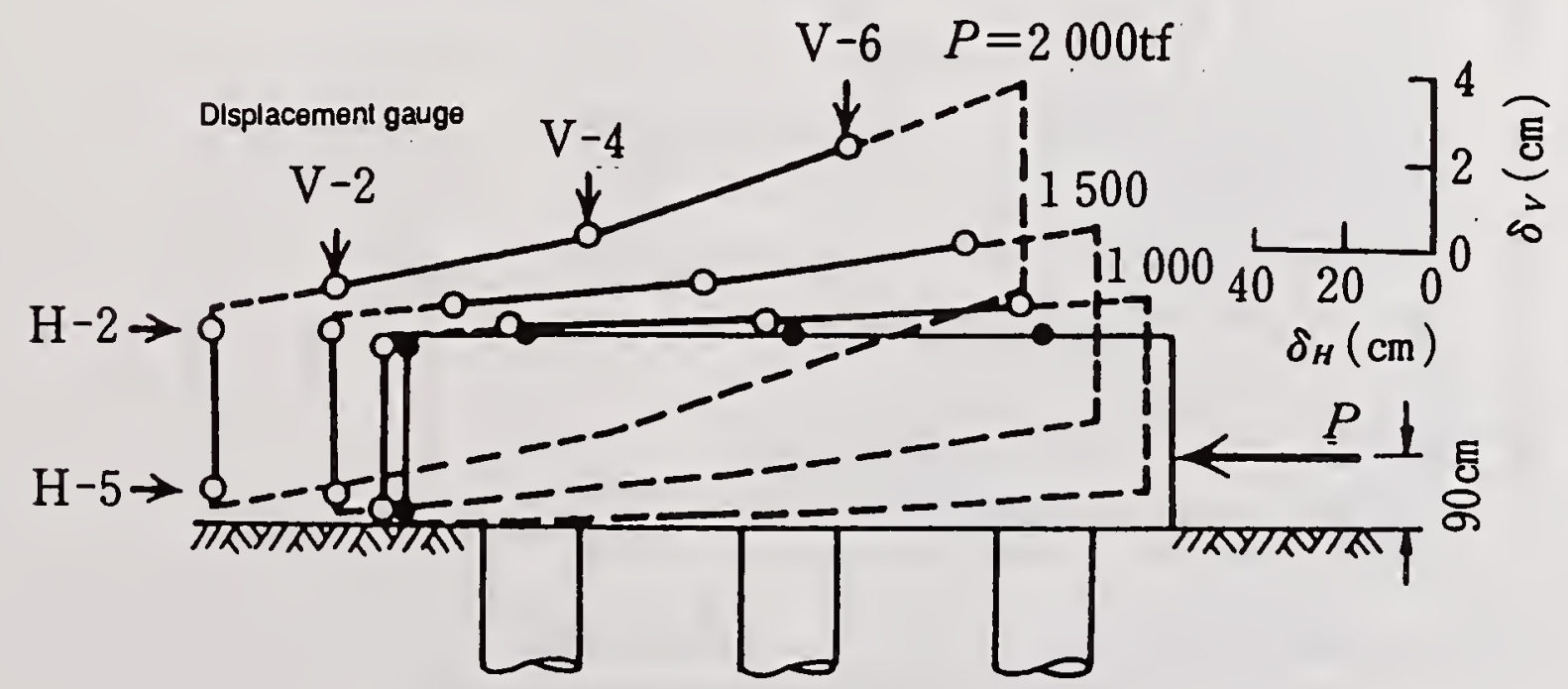

Fig. 3 Footing displacement behavior 


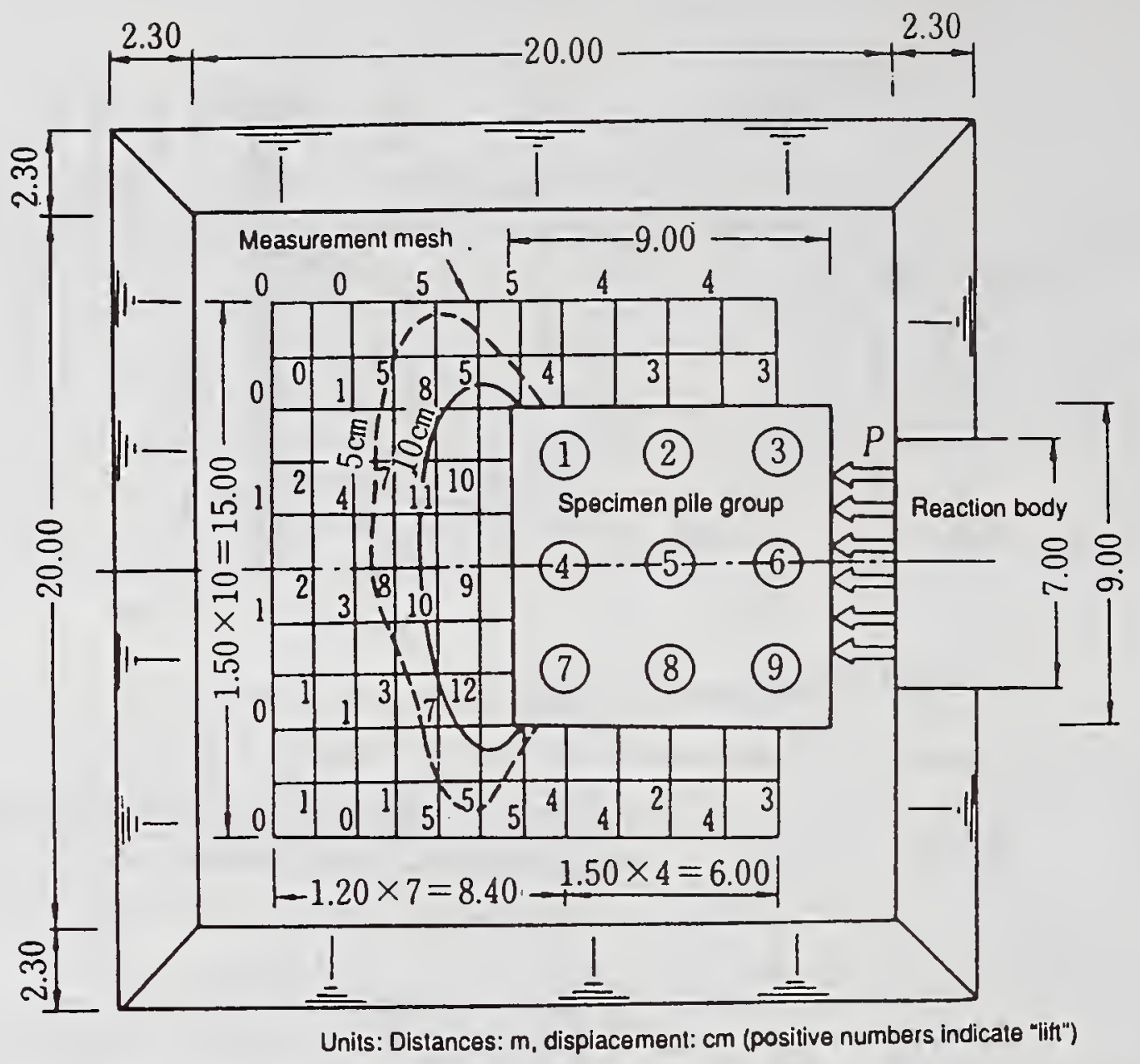

Fig. 4 Vertical displacement distribution of the ground surface measured immediately after load removal

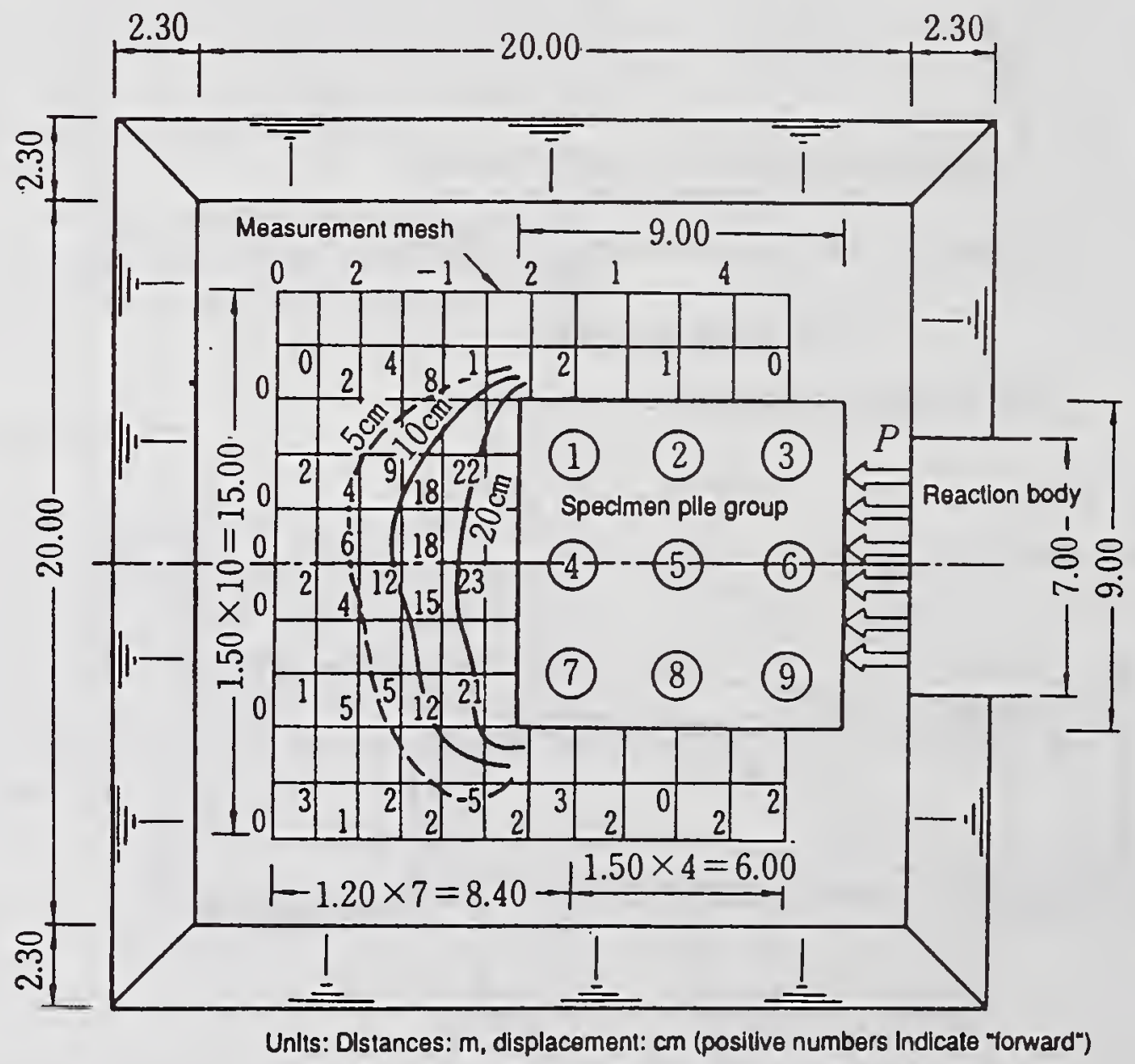

Fig. 5 Horizontal displacement distribution of the ground surface measured immediately after load removal 


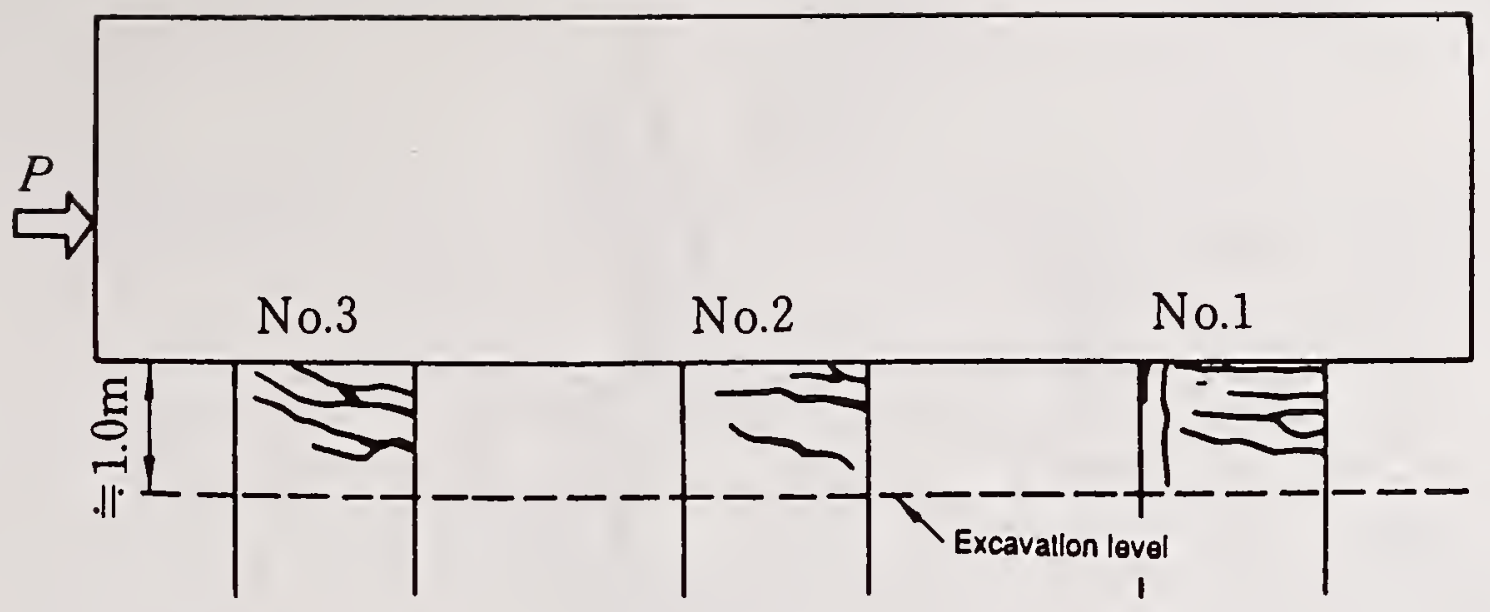

Fig. 6 Cracks in the pile tops
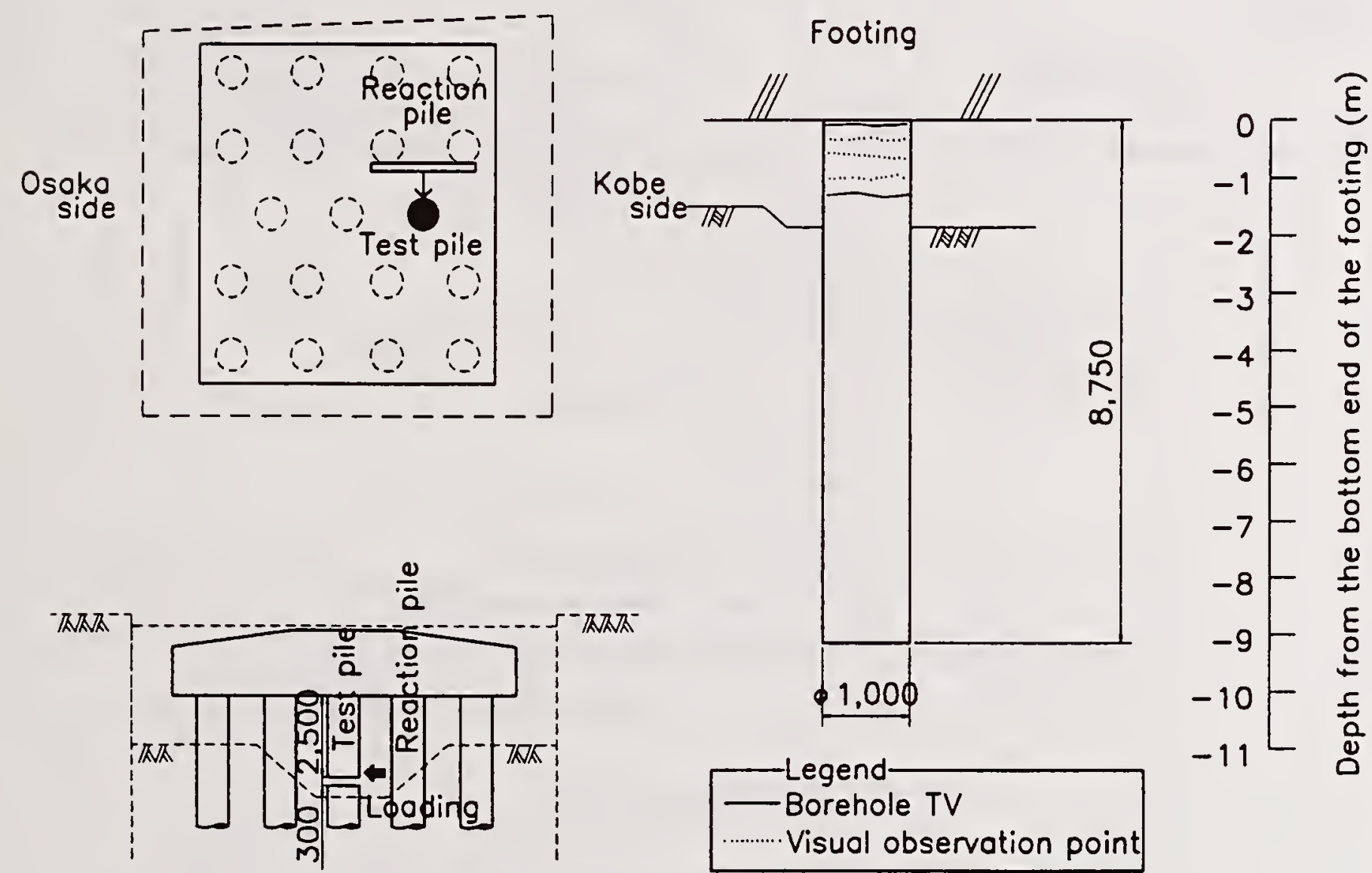

Fig. 7 Bending load test

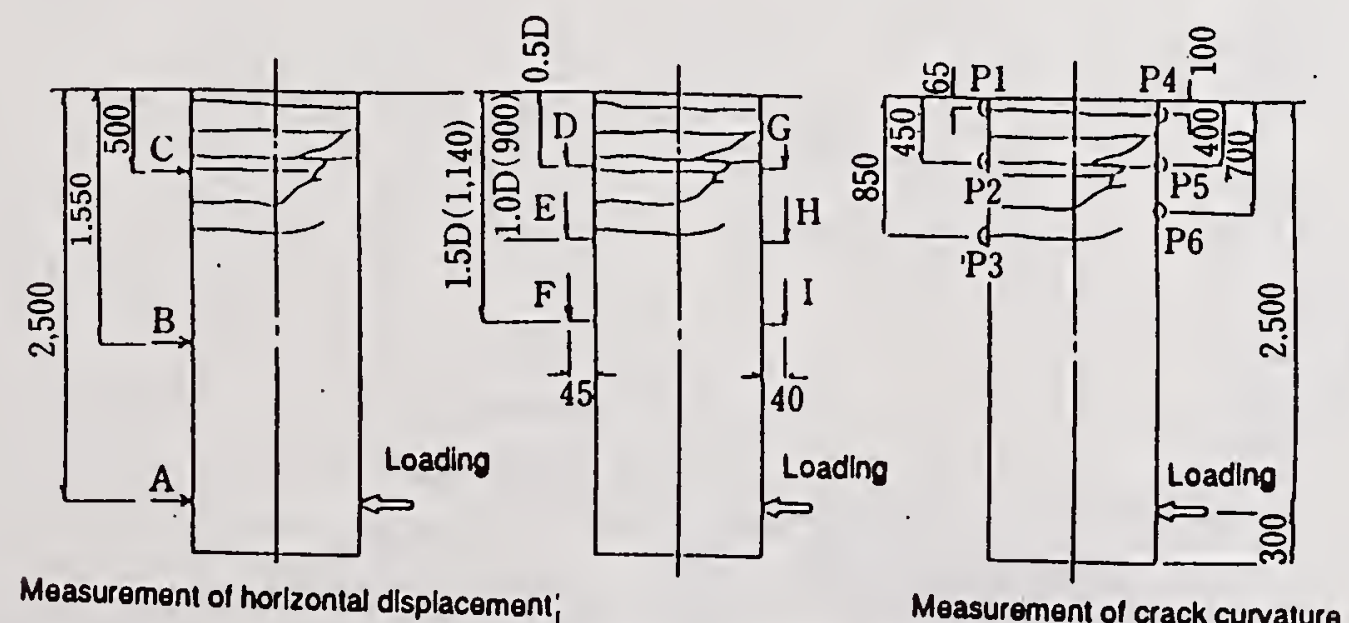

Measurement of angle of rotation and mean curvature

Fig. 8 Test pile measuring points 


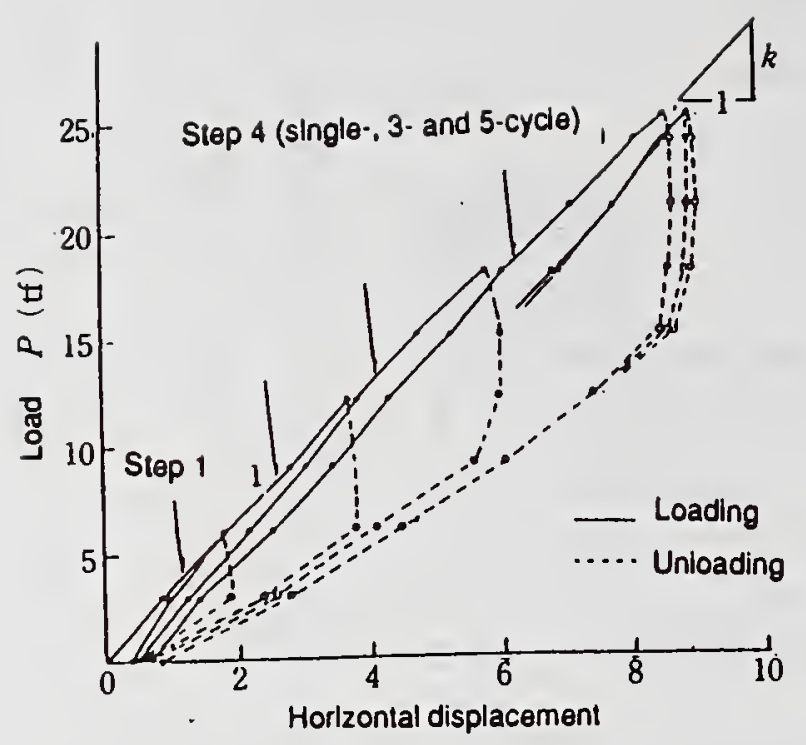

Fig. 9 Load-displacement curves of the test pile

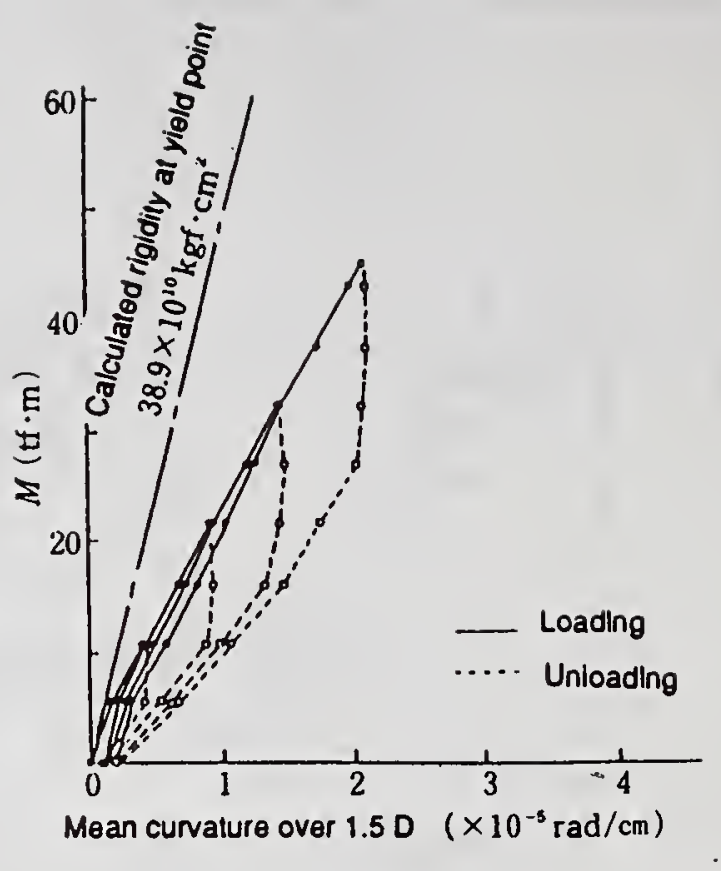

Fig. 10 Moment-mean curvature of the pile top section

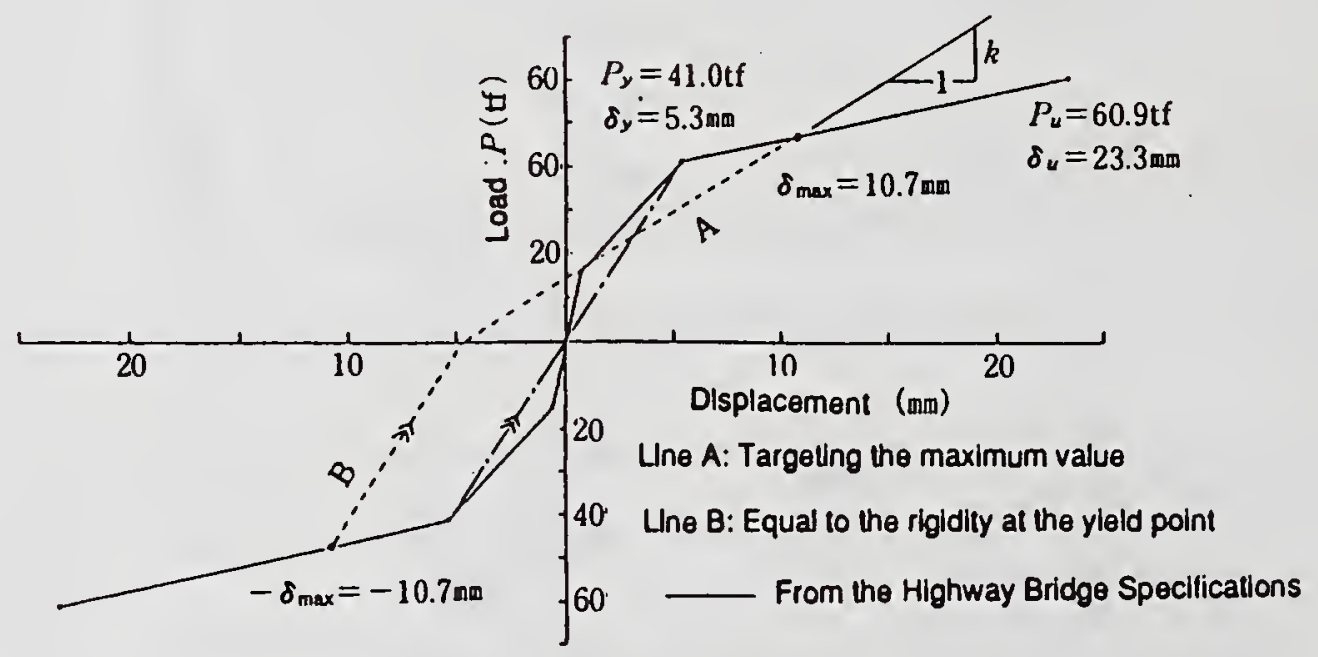

Fig. 11 Load-deformation history

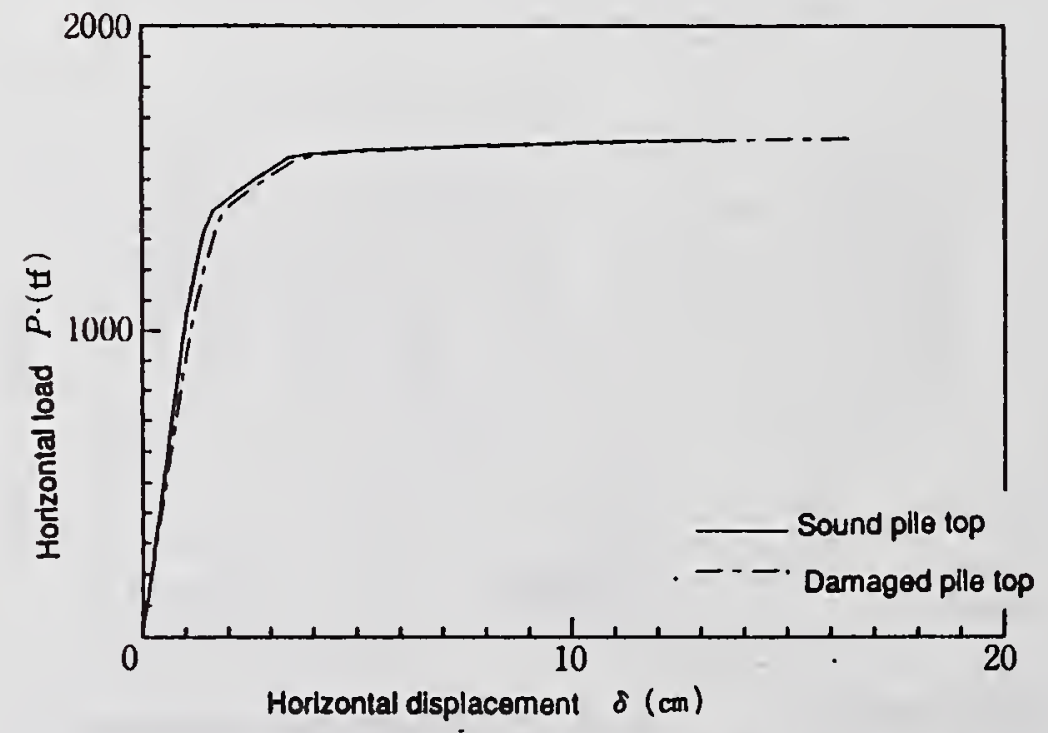

Fig. 12 Load-horizontal displacement curves 


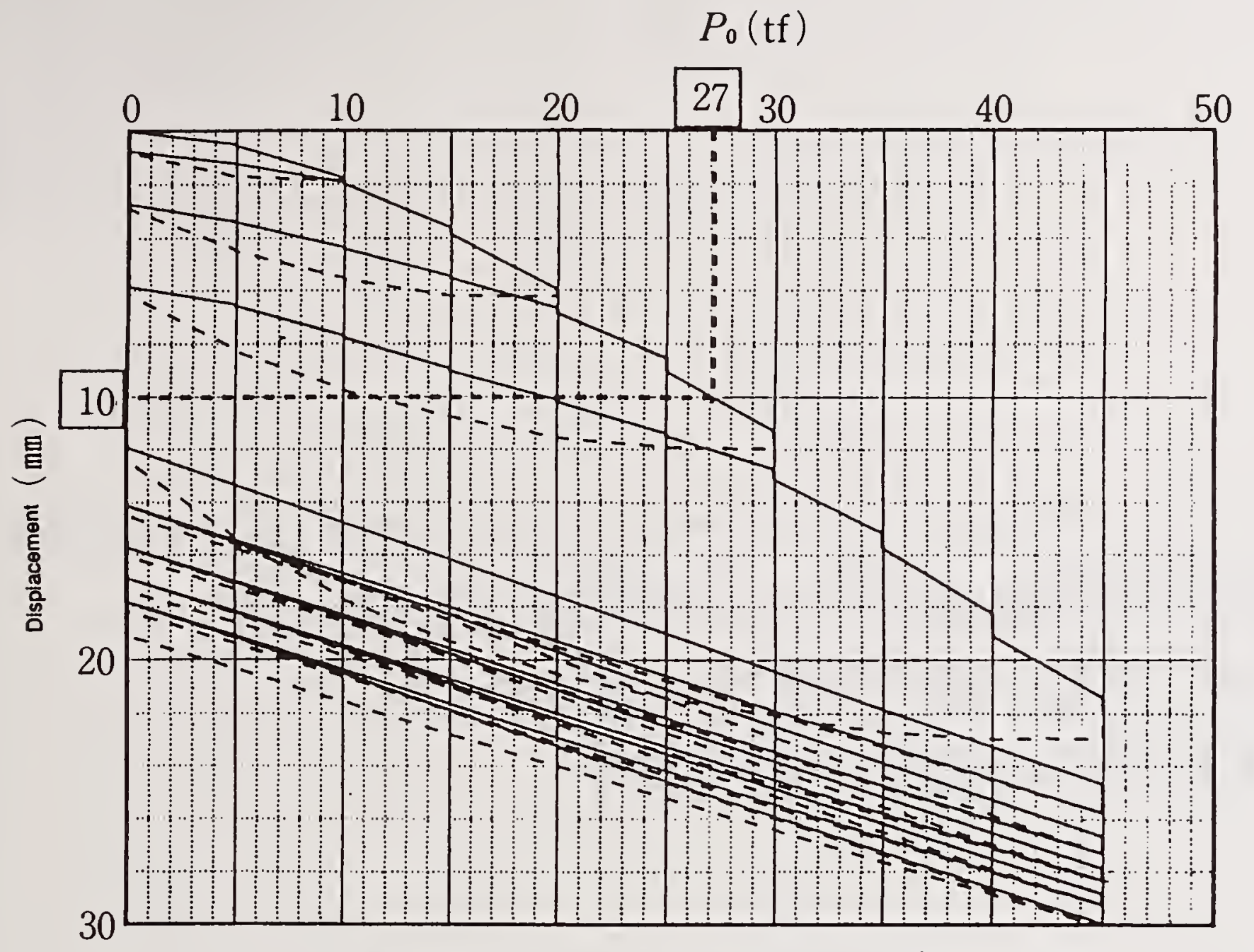

Fig. 13 Load-displacement curves (horizontal load)

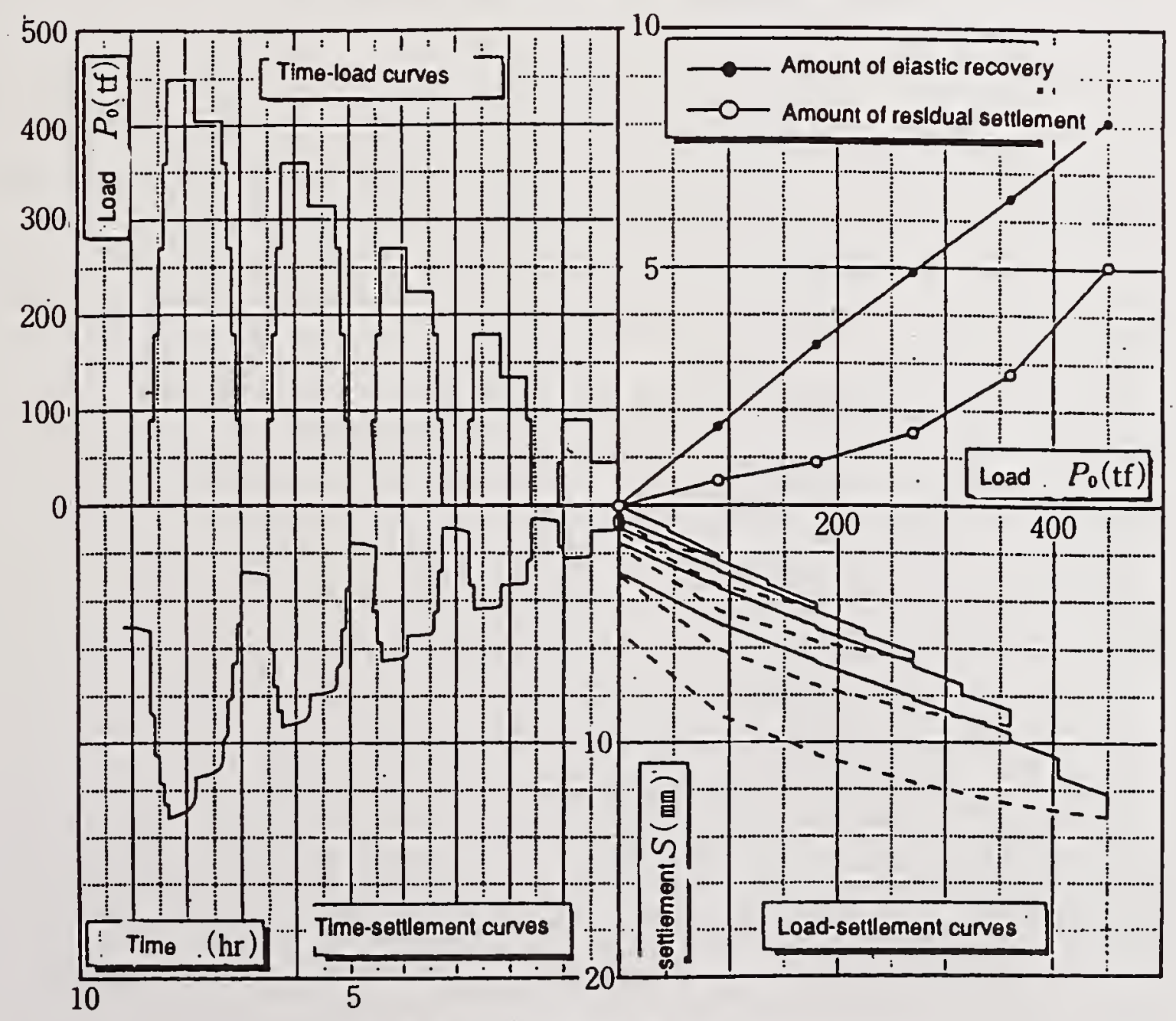

Fig. 14 Load-displacement curves (vertical load) 

MANUSCRIPTS AUTHORED FOR PANEL MEETING BUT NOT PRESENTED ORALLY 



\title{
ANALYSES OF LIQUEFACTION IN THE 1995 HYOGOKEN-NANBU EARTHQUAKE
}

\author{
by \\ Osamu MATSUO * \\ Takao SHIMAZU ** \\ Tatsuya TSUTSUMI **
}

\section{ABSTRACT}

This paper presents analysis results of field performance data on liquefaction during the 1995 Hyogoken-Nanbu earthquake. The paper contains the following: (1)Grain size distribution of soil deposits at liquefied spots in the earthquake is compiled. (2)Two case records of liquefaction of gravelly soil deposits are presented. Finally, (3)Based on the observation of liquefaction occurrence, the relationship between the standard penetration test (SPT) $\mathrm{N}$-value, soil gradation and dynamic shear stress ratio induced during earthquakes is analysed.

\section{INTRODUCTION}

The 1995 Hyogoken-Nanbu earthquake caused extensive liquefaction in a wide area of offshore reclaimed lands and natural deposits. Ground flow associated with soil liquefaction took place at waterfront in reclaimed lands as well. One of the important aspects in geotechnical engineering was liquefaction of gravelly soils in reclaimed lands. This phenomenon has attracted geotechnical engineers' interest because liquefaction of gravelly soils had been considered to be exceptional.

Another aspect was whether evaluation methods of liquefaction potential currently used in practices could well explain the performance of the ground during such a strong earthquake motion as the Hyogoken-Nanbu earthquake.

Having these geotechnical concerns, the authors reviewed liquefaction phenomena during the earthquake from a couple of viewpoints.

\section{GRAIN SIZE DISTRIBUTIONS OF LIQUEFIED SOILS}

During past decades, a number of papers have reported grain size distribution of ejected soils due to liquefaction in past earthquakes. It has been recognized, however, that soil gradation of sand boils is never identical to that of liquefied soils at depths because the liquefied soils are segregated in the course of ejection. This section summarizes grain size distributions of penetration core samples retrieved from the supposedly liquefied soil deposits.

Figure 1 shows location of borings that were performed along the Hanshin Expressways after the Hyogoken-Nanbu earthquake. The two routes of expressways shown in the figure were viaducts and a number of piers were collapsed during the earthquake. Figure 2 summarizes the grain size distributions of the subsoils at the boring locations. In the figure, mean grain size of the liquefied soils ranges from 0.1 to $1 \mathrm{~mm}$ for the Kobe Line, and from 0.3 to $10 \mathrm{~mm}$ for the Harbor Line. Fines contents are below 40-35\% for both the routes. In the Kobe Line, soil gradation of the non-liquefied soils is coarser than that of the liquefied soils.

As shown in Fig.1, the Route No.5 runs through offshore reclaimed lands. The reclaimed lands were constructed with weathered granite soil, called "Masado", that had been taken from the Rokko Mountains. The soil contains a wide range of grain size particles, from fine silt to gravel. Figure 3(a) plots the relationship of fines content and mean grain size. The relationship of Holocene alluvial sands are comparatively shown in Fig.3(b) ${ }^{1)}$. The figure demonstrates that the Masado soil contains more fines than alluvial sands with the same mean grain size.

\section{LIQUEFACTION OF GRAVELLY SOILS}

In the Hyogoken-Nanbu earthquake, liquefaction of gravelly soils in the reclaimed lands attracted geotechnical engineers' attention, because the soils called Masado with very large uniformity coefficient had been considered insusceptible to liquefaction. A couple of case records of liquefaction of gravelly soils are presented in the following. One case is for a reclaimed land and the other is for a natural deposit.

* Head, Soil Dynamics Division

Earthquake Disaster Prevention Research Center

Public Works Research Institute, Tsukuba, 305 Japan

** Researcher, ditto. 


\subsection{CASE 1: The Koshien-hama Reclaimed Land}

In the Koshien-hama reclaimed land locating offshore Nishinomiya, occurrence of sand boils was widespread and caisson-type revetments displaced seaward. Figure 4 demonstrates a boring log obtained after the quake at a site where significant amount of ejected sand was observed. As shown in the figure, a thickness from surface down to $14 \mathrm{~m}$ is composed mostly of gravelly soil, or the Masado soil.The layer below $14 \mathrm{~m}$ depth is a marine clay, the original seabed material. The thin clay layer intersecting the Masado layer was formed with dredged material during a certain period of reclamation interval.

Because the presumably liquefied Masado layer contained gravel, the large penetration test (LPT) was performed in addition to the standard penetration test (SPT). Main differences of both tests are presented in Table 1. The LPT is considered more applicable to gravelly soils than the SPT because of their difference in the shoe diameter ${ }^{2)}$. In Fig.4, the blowcounts in the Masado layer are as small as between 2 to 10 for both the tests. The correlation between the LPT and the SPT blowcounts are given in Figure 5. The LPT N-values, $\mathrm{Nd}$, are less than the SPT N-values, N. Previous studies have shown that the ratio of $\mathrm{N}$ to $\mathrm{Nd}$ is about 1.5 for sand and it is getting larger with increasing gravel content $^{2)}$. In Fig.5, however, the ratio is about 1.5 or less.

The grain size distribution of the Masado is presented in Figure 6 that was obtained by seiving large-scale undisturbed samples $(30 \mathrm{~cm}$ diameter). In the figure, volcanic gravelly soils that liquefied during the 1993 Hokkaido Nansei-oki earthquake ${ }^{31}$, and clean sands that liquefied during the 1964 Niigata earthquake ${ }^{4)}$ are also plotted for reference. It is seen in Fig.6 that mean grain size, maximum grain size and gravel content of the Masado soil are as large as $3 \mathrm{~mm}, 150 \mathrm{~mm}$ and $60 \%$, respectively. It appears in the figure that in spite of the large gravel content the SPT blowcounts are not significantly affected by the containment of gravel.

\subsection{CASE 2: Mukogawa River}

A naturally deposited sand gravel liquefied in the Mukogawa River that originates from the Rokko Mountains and flows down through Nishinomiya. Sand boils were observed in the flood plain in the extent of $120 \mathrm{~m}$ by $80 \mathrm{~m}$ area. The site is located at the eastern edge of the seismic intensity of 7 zone, the largest intensity (the Japan Meteorological Agency; JMA). An abutment and piers of the Mukogawa-shinbashi bridge locating exactly at the site had suffered displacement of a few centimeters.

Figure 7 shows the boring logs that were obtained in the liquefied area after the quake. The whole depth of $13 \mathrm{~m}$ bored are composed of sand gravel with cobbles. According to the data recorded during foundation construction of the Mukogawa-shinbashi bridge several years ago, the cobbles were as large as 150 to $300 \mathrm{~mm}$ in diameter. Grain size distribution of the sand gravel measured from the SPT core samples is demonstrated in Figure 8. It is observed that the maximum grain size is about $30 \mathrm{~mm}$, which is much smaller than the observed one during the foundation construction. Needless to say, this difference is due to the shoe diameter of $30 \mathrm{~mm}$.

In Figure 7, the SPT blow counts are 8 to 15 in the upper $4 \mathrm{~m}$ and are increasing downwards. The ground water level is $2 \mathrm{~m}$ below the ground surface. It is conceived that the soil at a depth of 2 to $4 \mathrm{~m}$ must have liquefied during the earthquake. It should be noted that there is not any impermeable soil cap over the depth that prevents the upward dissipation of excess pore-water pressure.

\section{ANALYSIS OF LIQUEFACTION AND NON-LIQUEFACTION}

\subsection{Analysis Procedures}

(1) Data used in the analysis

In order to eliminate local soil effects, past eight earthquakes in Japan including the Hyogoken-Nanbu earthquake were surveyed. The number of boring data compiled are summarized in Table 2. Among a total of 216 data, 145 are for liquefied sites and 71 for non-liquefied sites.

\section{(2) Identification of liquefaction or non-liquefaction at a site}

Judgement of liquefaction occurrence at a boring site was made primarily based on visible observation of surface features such as sand boils, cracking, or settlement. Liquefaction map compiled by Hamada, et al. ${ }^{5)}$ was used for this purpose. A site with sand boils in a nearby area was classified as "liquefied". Even at a site where sand boils were not observed, if there were ground movements or settlements, it was also considered as "liquefied".

\section{(3) Identification of liquefied depth}

For a site where liquefaction occurrence was presumed, liquefied depth must also be presumed. The depth was selected according to the following criteria:

a) below the ground water level and within $8 \mathrm{~m}$ deep 
from the ground surface,

b-1) mean grain size D 50 is larger than $0.02 \mathrm{~mm}^{3 \text { ) , }}$ or

$\mathrm{b}-2) \mathrm{D}_{50}$ is between $0.02 \mathrm{~mm}$ and $10 \mathrm{~mm}$, and fines content $\mathrm{Fc}$ is less than $35 \%$, and

c) the measured SPT $\mathrm{N}$-value is the second smallest.

In the above criterion a), the depth of $8 \mathrm{~m}$ was adopted considering that sand boils must have ejected from a relatively small depth. In the criterion b), the mean grain size D 50 of larger than $0.02 \mathrm{~mm}$ comes from an existing design manual ${ }^{4)}$. The fines content Fc of less than $35 \%$ is based also on another design manual ${ }^{6)}$. The criterion c) comes from the consideration that the smallest SPT N-value might represent locally soft layer with very limited thickness.

(4) Estimation of maximum shear stress at depth

The peak ground surface acceleration $\alpha$ smax at a boring site was at first estimated from the neighbouring strong motion records. The maximum horizontal shear stress $\tau_{\mathrm{dmax}}$ was calculated as follows.

$\tau_{\text {dmax }}=\mathrm{rd}_{\mathrm{d}} \cdot \sigma \mathrm{v} \cdot(\alpha \mathrm{smax} / \mathrm{g})$

The maximum shear stress ratio $L_{m a x}$ at depth was obtained by

$$
L_{\text {max }}=\tau_{\text {dmax }} / \sigma v^{\prime}
$$

where

$r$ d : reduction factor with depth

( $\mathrm{r} \mathrm{d}=1-0.015 \cdot \mathrm{z} ; \mathrm{z}$ : depth in meter),

$\sigma \vee, \sigma v^{\prime}:$ total and effective overburden stresses, and

g: gravitational acceleration.

\subsection{Results}

Figure 9(a) plots all the 216 data according to the criteria a), b-1) and c) as described in the above 4.1(3). Figure $9(\mathrm{~b})$ is a result obtained by employing the criterion $b-2$ ) instead of $b-1$ ). Figure $9(c)$ is a result obtained by adding to the result of Figure $9(\mathrm{~b})$ the following engineering judgements.

(a) In cases that a loose sand layer of small thickness was underlain by a dense sand deposit and accordingly the second smallest $N_{1}$-value represented the lower dense deposit, the smallest $N_{1}$-value representing the overlaying loose layer was adopted.

(b) In cases that even the second smallest $N_{1}$-value was considered to be representing a locally loose layer at a certain depth, an average $N_{1}$-value in the nearby depth was adopted. (c) In cases of "non-liquefied" sites that the ground water level was very deep or the sand deposit was capped by a thick impermeable layer, those site data were discarded, because the existence of the thick layer might have hindered the development of surface evidence.

In the figures, the horizontal axis, $N_{1}$, is given as follows $^{\text {7) }}$ :

$$
N 1=1.7 \cdot N /\left(\sigma v^{\prime}+0.7\right)
$$

where

$$
\begin{aligned}
& \mathrm{N}_{1} \text { : SPT blowcount corrected for overburden } \\
& \text { stress to } 1 \mathrm{kgf} / \mathrm{cm}^{2}, \\
& \mathrm{~N}_{\mathrm{V}} \text { : } \text { raw SPT blowcount, and } \\
& \mathrm{v}^{\prime}: \text { effective overburden stress, in } \mathrm{kgf} / \mathrm{cm}^{2} \text {. }
\end{aligned}
$$

In Figs.9, the black plots represent "liquefied" data and the open plots represent "non-liquefied" data. It appears that the two data groups are considerably well separated. The results also suggest us that soils with corrected SPT N-value of 20-25 or greater will not liquefy against such a strong ground motion as that during the Hyogoken-Nanbu earthquake.

In order to see the effect of fines content, the data were separately plotted as in Figure 10 . Lines bordering the "liquefied" plots are superimposed in the figures. The bordering lines imply the relationship between the $N_{1}$ -value and the liquefaction resistance. The terminology "liquefaction" used here may be defined as that liquefaction of subsoils may cause any surface evidence such as sand boils, cracking or settlement, as explained earlier. It is observed in the figures that at the same level of earthquake intensity as expressed by $L_{m a x}$, the bordering $N_{1}-v$ alue for sand with fines is lower than that for clean sand. This supports the view that soils with more fines are more resistant to liquefaction for the same penetration resistance ${ }^{81}$.

\section{CONCLUSIONS}

The study of liquefaction during the 1995 Hyogoken Nanbu earthquake presented in this paper may be concluded as follows.

(1) Soil gradations of subsoil materials were compiled along two expressways. It was found that mean grain size of the liquefied soils ranged from 0.1 to $10 \mathrm{~mm}$ and fines content was within $40 \%$. Non-liquefied soils were coarser than liquefied soils.

(2) Gravelly soils liquefied in a wide area of reclaimed 
lands. Liquefaction also occurred in a natural alluvial deposit. The maximum grain size of the liquefied naturally depositted sand gravel was as large as $150-300$ $\mathrm{mm}$.

(3) A total of 216 boring data, composed of 145 liquefied data and 71 non-liquefied data, was analysed in terms of the maximum shear stress ratio and the corrected SPT N-value. It was found that the corrected SPT N-values of liquefied soils were less than 20-25 and that the critical SPT N-value decreased with increasing fines content.

\section{ACKNOWLEDGEMENT}

The authors are grateful to the Hanshin Expressway Public Corporation for providing the soil gradation data. Their gratitude is also extended to the personnels concerned of Takarazuka City Government for their permission to present the boring data regarding the Mukogawa-shinbashi bridge.

\section{REFERENCES}

1) Yasuda, S.: Effects of soil gradation on liquefaction resistance, Proc. of the 38th Annual Meeting of JSCE, pp.377-378, 1983 (in Japanese).

2) The Japanese Geotechnical Society: The Geotechnical Survey Manual, 1996 (in Japanese).

3) Tanaka, Y., et al.: Liquefaction of gravelly soils during the 1993 Hokkaido Nansei-oki earthquake, 1994 (in Japanese).

4) Japan Road Association: Specifications for Highway Bridges, 1990.

5) Hamada, M., et al.: The 1995 Hyogoken-Nanbu (Kobe) Earthquake - Liquefaction, Ground Displacement and Soil Condition in Hanshin Area, Co-published by Association for Development of Earthquake Prediction, Waseda University and Japan Engineering Consultants, 1995.

6) The Japanese Architecture Society: The Design Manual for Building Foundations, pp.163-169, 1994 (in Japanese).

7) Meyerhoff, G.G.: Discussion of Session 1, Proc. 4th ICSMFE, London, Vol.3, 1957.

8) Tokimatsu, K., et al.: Empirical correlation of soil liquefaction based on SPT $\mathrm{N}$-value and fines content, Soils \& Foundations, Vol.23, No.4, pp.56-74, 1983. 
Table 1 Main Specifications of SPT and LPT ${ }^{2)}$

\begin{tabular}{|l|c|c|}
\hline & $\begin{array}{c}\text { Standard Penetration Test } \\
\text { (SPT) }\end{array}$ & $\begin{array}{c}\text { Large Penetration Test } \\
\text { (LPT) }\end{array}$ \\
\hline Tube length (mm) & 810 & 700 \\
Inner diameter of shoe (mm) & 35 & 73 \\
Outer diameter of shoe (mm) & 51 & 10.2 \\
Rod section area (cm ${ }^{2}$ ) & 5.6 & 100 \\
Mass of hammer (kg) & 63.5 & 150 \\
Falling height (cm) & 75 & 30 \\
Penetration length \\
for measuring blowcount $(\mathrm{cm})$
\end{tabular}

Table 2 Summary of Case Records Used in the Analysis

\begin{tabular}{|l|c|c|c|}
\hline \multirow{2}{*}{ Earthquake } & \multicolumn{3}{|c|}{ Number of boring data } \\
\cline { 2 - 4 } & Liquefied & Non-liquefied & Total \\
\hline Niigata (1964) & 19 & 9 & 28 \\
Tokachi-oki (1968) & 3 & 0 & 3 \\
Miyagiken-oki (1978) & 16 & 22 & 38 \\
Nihonkai-chubu (1983) & 36 & 20 & 56 \\
Chibaken Toho-oki (1987) & 1 & 1 & 2 \\
Kushiro-oki (1993) & 3 & 2 & 5 \\
Hokkaido Nansei-oki (1993) & 4 & 15 & 78 \\
Hyogoken Nanbu (1995) & 63 & 71 & 216 \\
\hline Total & 145 & & 6 \\
\hline
\end{tabular}




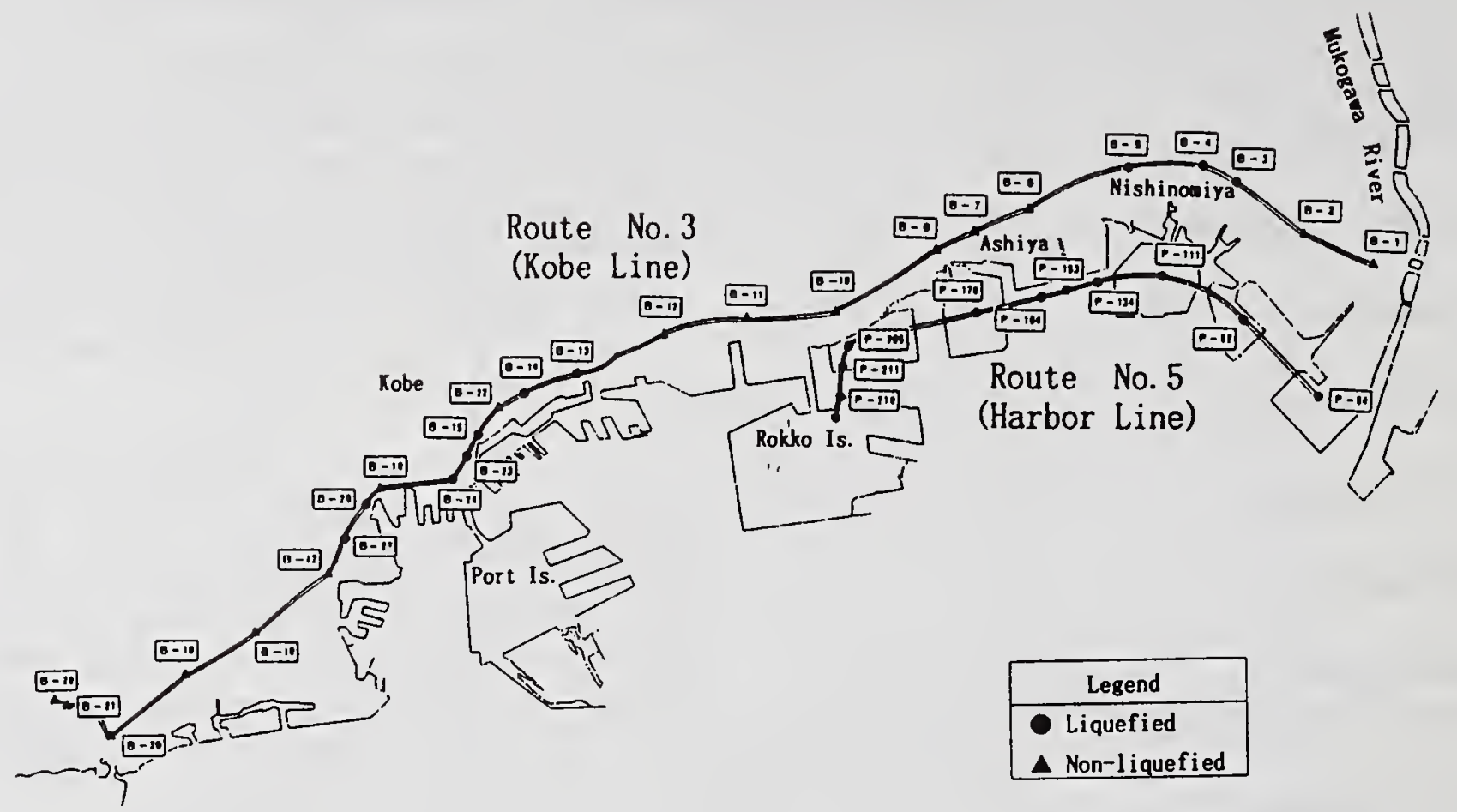

Figure 1 Location of the Borings Along the Hanshin Expressways
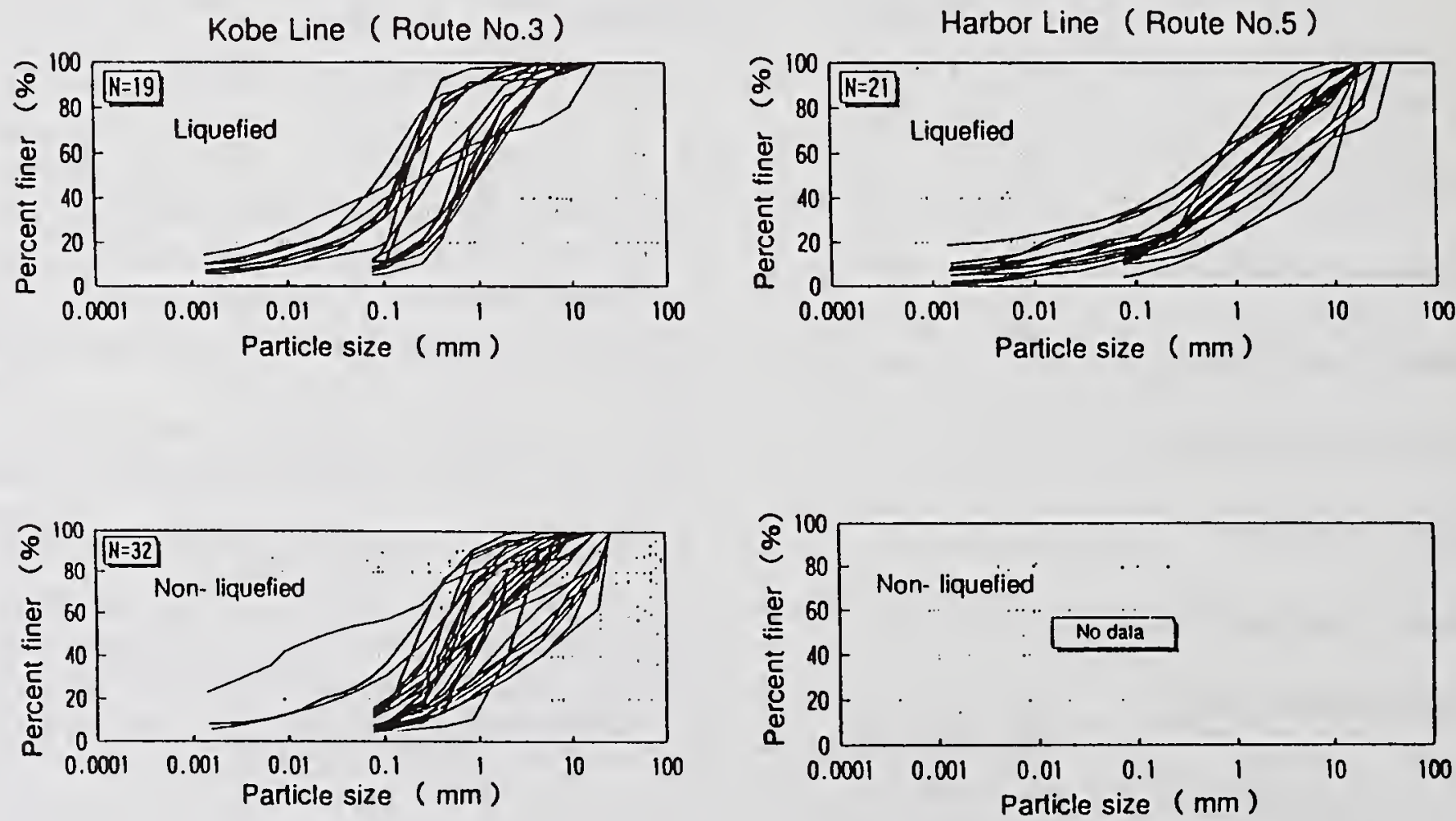

( $N$ : Number of data )

Figure 2 Grain Size Distribution of the Hanshin Expressway Subsoils 


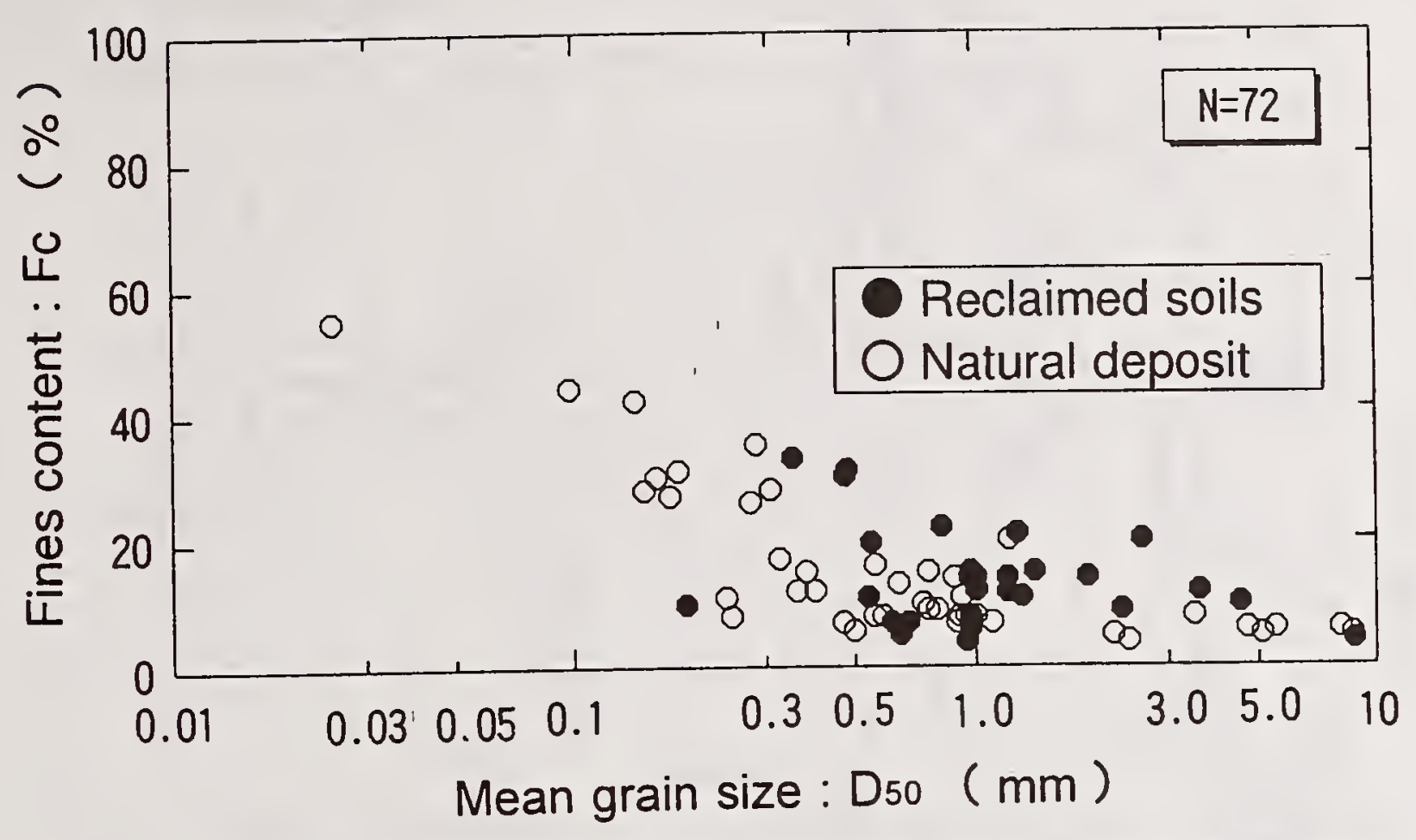

(a) Deposits in the Reclaimed Lands Along the Hanshin Expressways

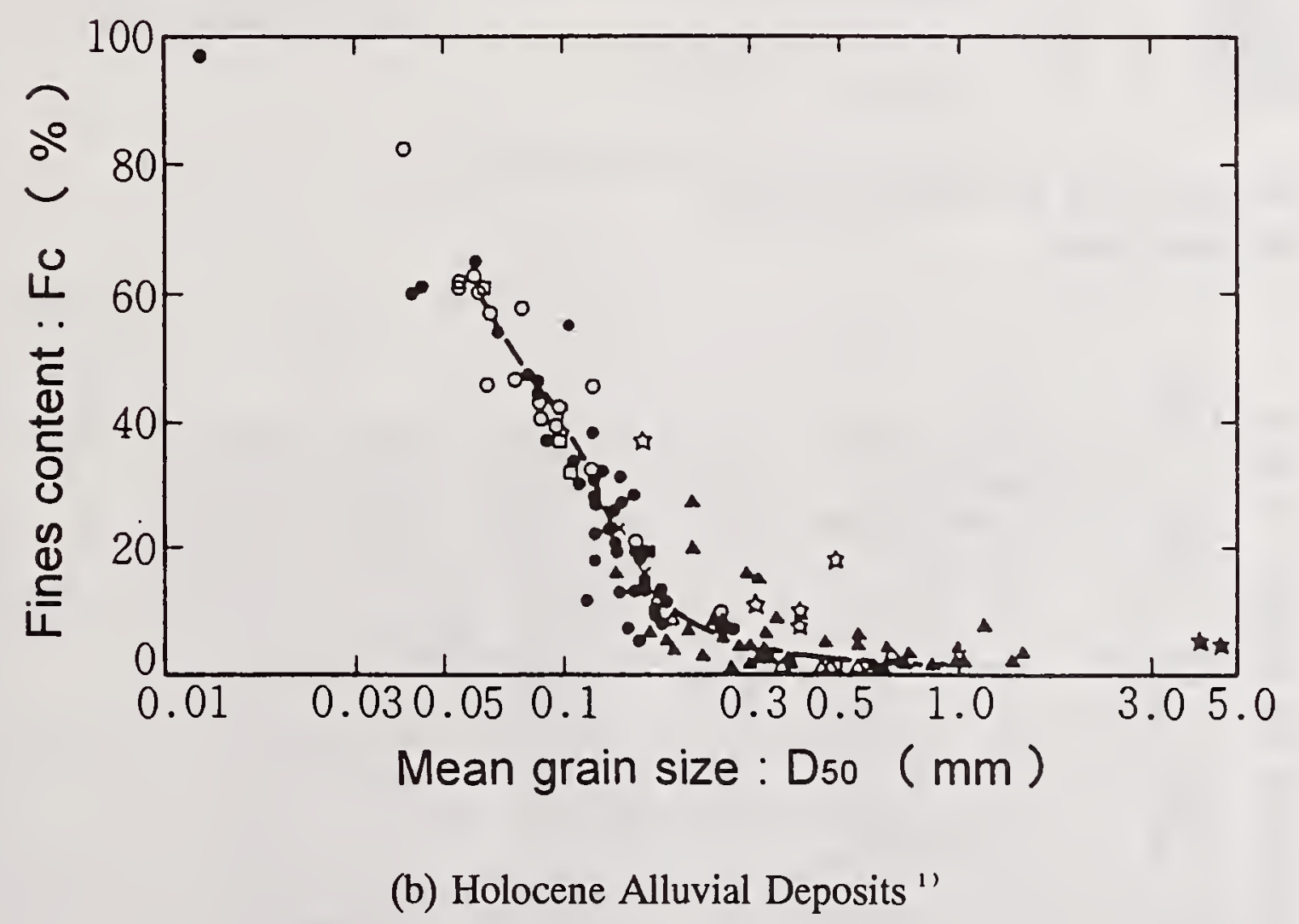

Figure 3 Correlation between Fines Content and Mean Grain Size 

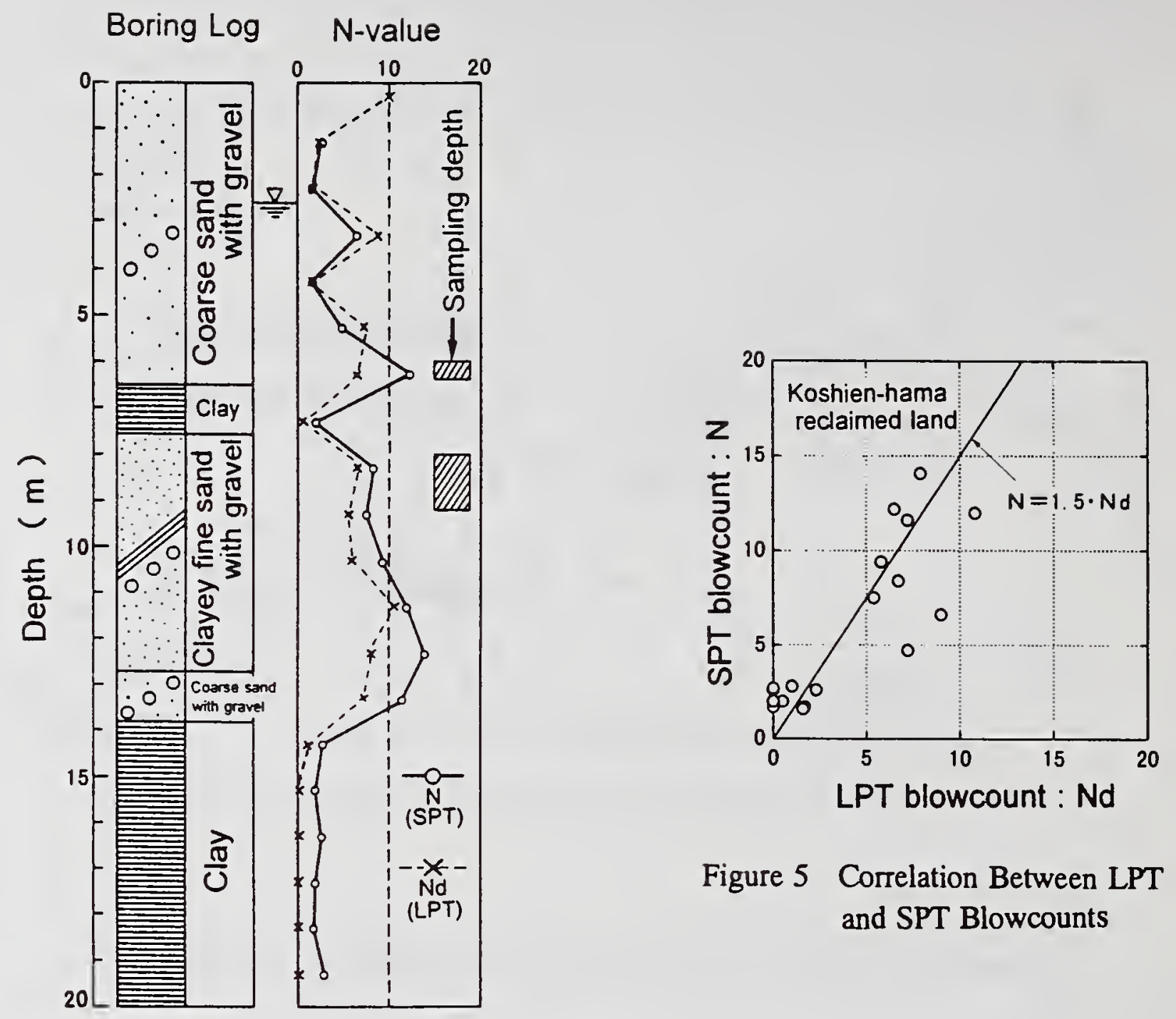

Figure 5 Correlation Between LPT and SPT Blowcounts

Figure 4 The Boring Log at the Koshien-hama Reclaimed Land

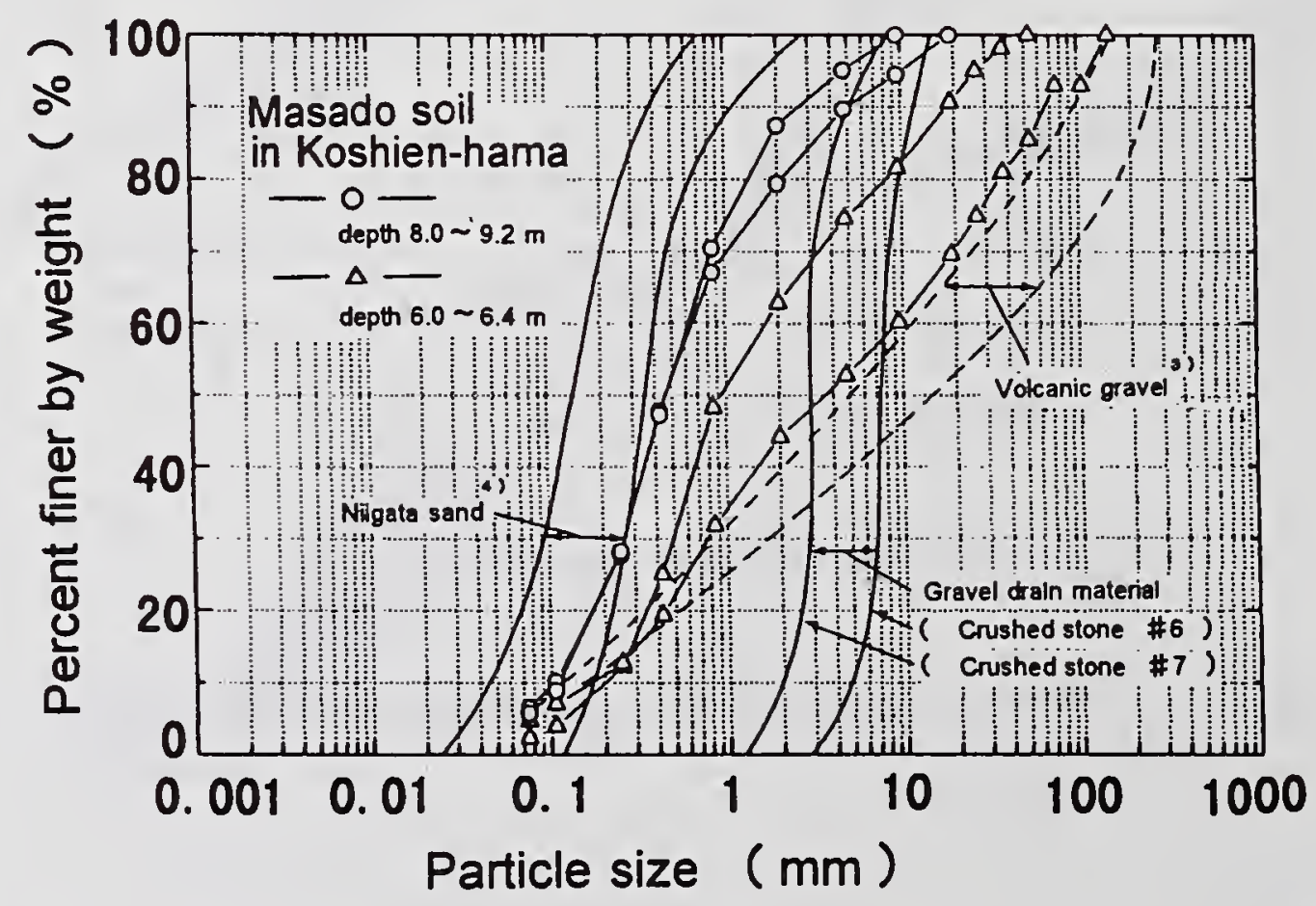

Figure 6 Grain Size Distribution of Masado Soil in the Koshien-hama Reclaimed Land 460 


\section{Boring No.B1 Boring No.B2}

Boring Log $\log _{i}$ SPT N-value Boring Log STP N-value

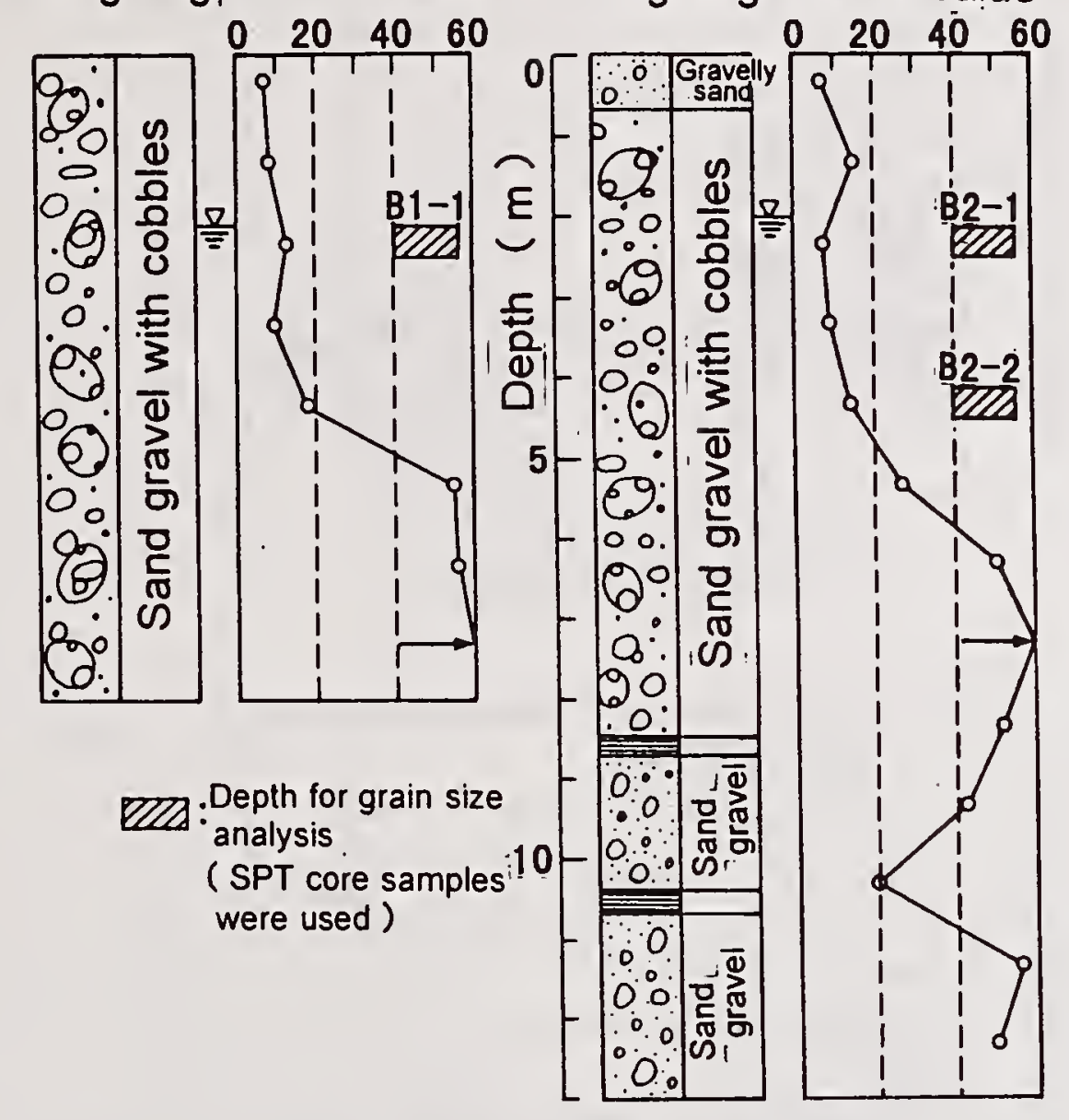

Figure 7 Boring Logs at the Mukogawa River Flood Plain

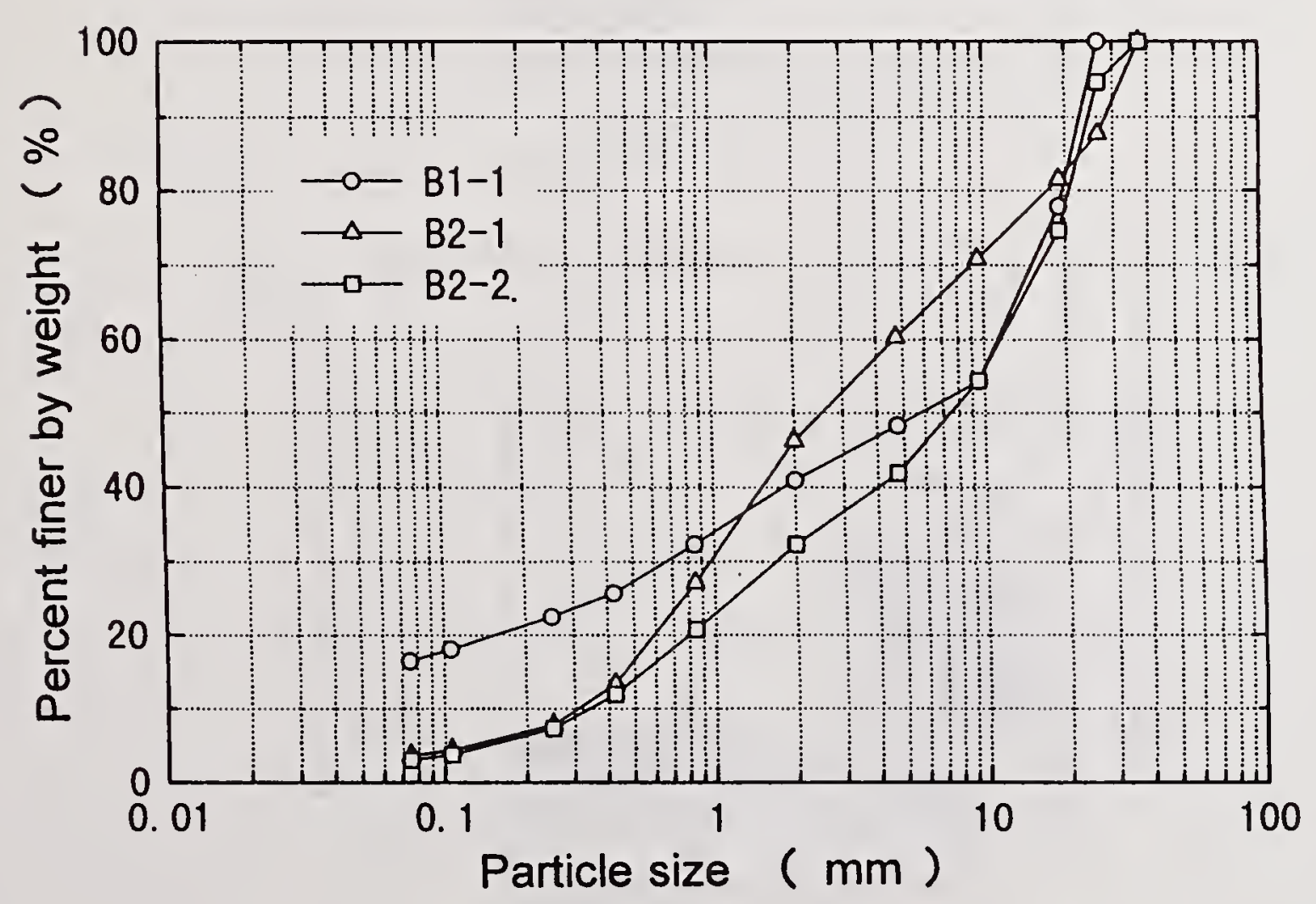

Figure 8 Grain Size Distribution of Sand Gravel at the Mukogawa River Flood Plain 
(a)

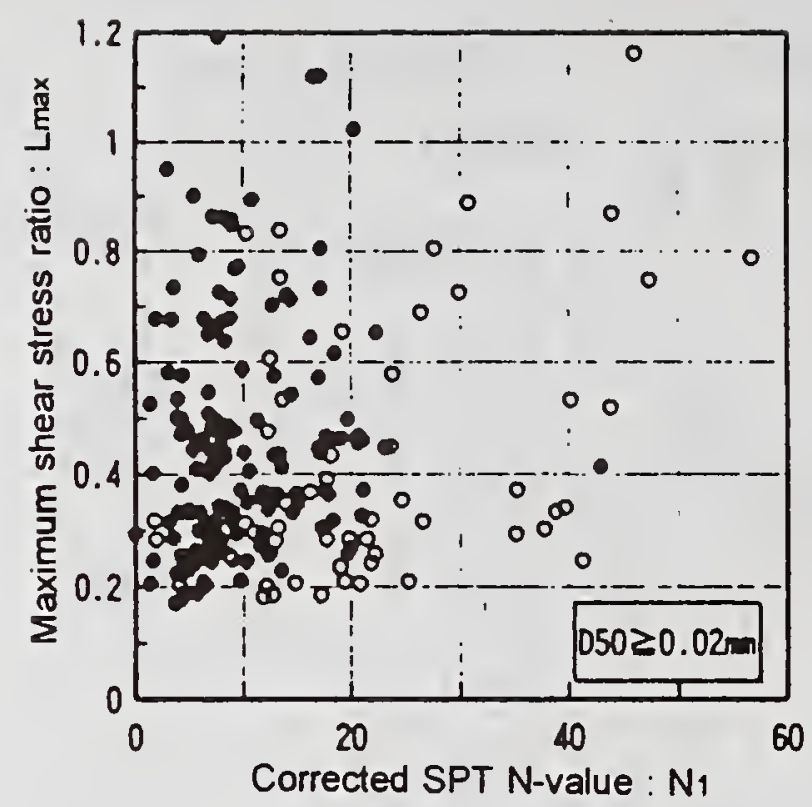

(b)

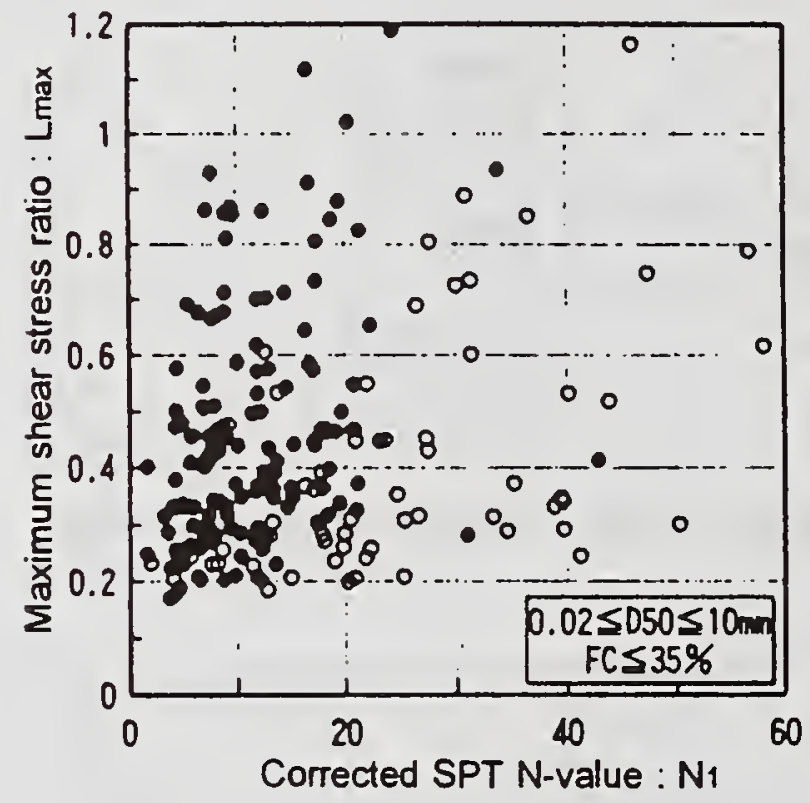

(c)

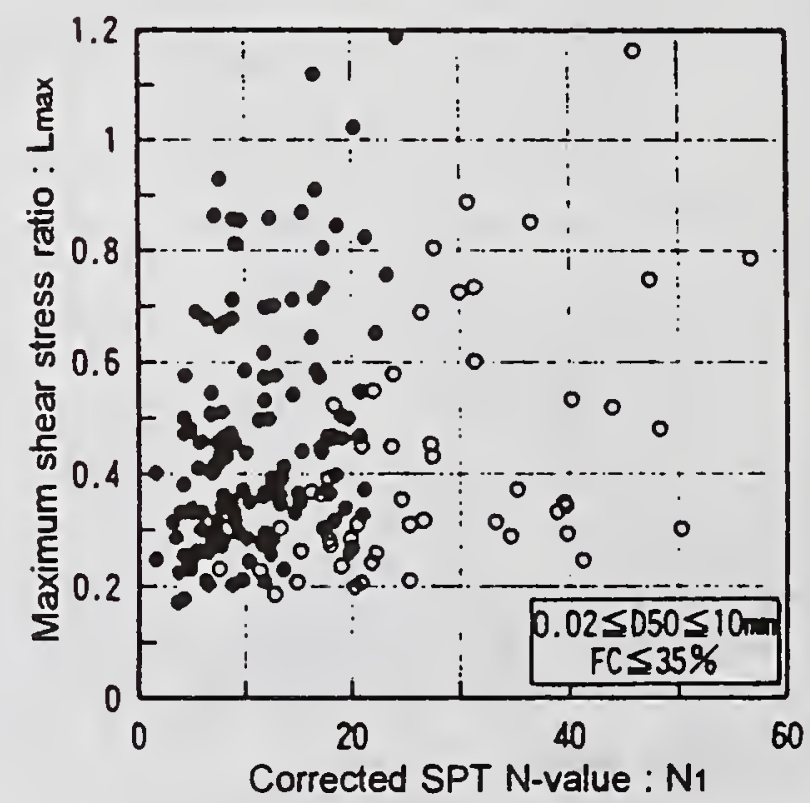

Figure 9 Plot of the Liquefied and Non-liquefied Case Records 
(a)

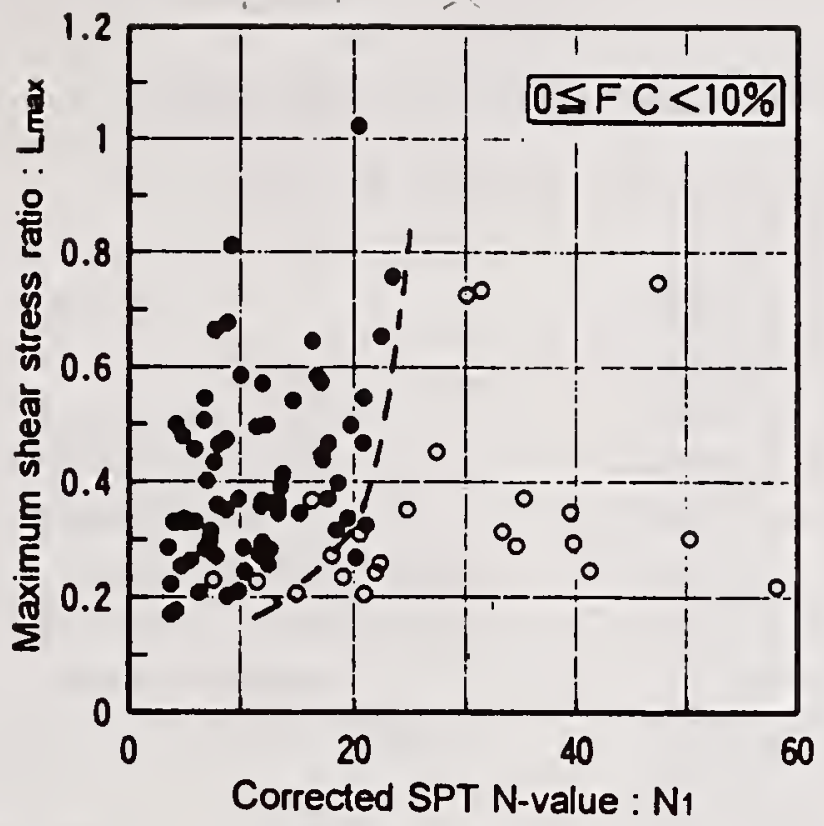

(b)

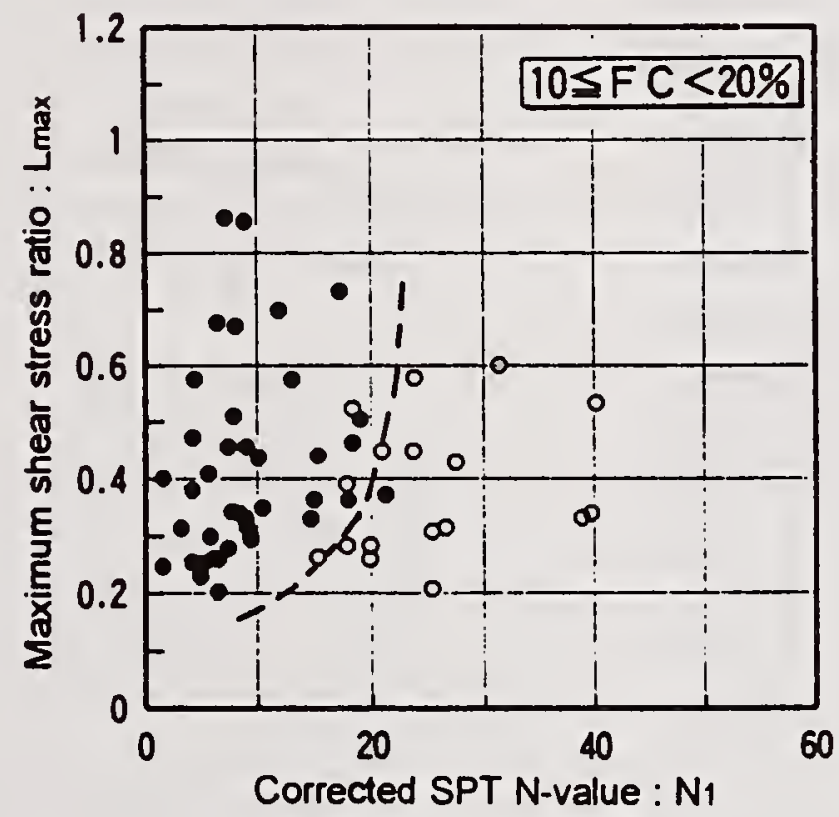

(c)

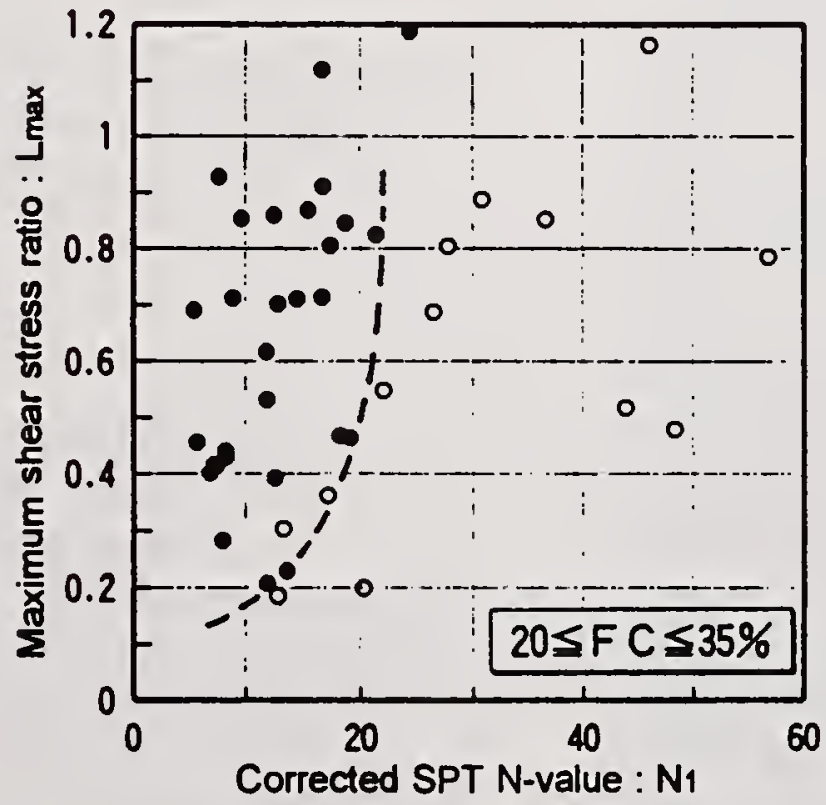

Figure 10 Plot of the Liquefied and Non-liquefied Case Records 



\title{
Photogrammetric Measurement of Three Dimensional Ground Surface Displacement Caused by the Kobe Earthquake
}

by

\author{
Hiroshi MURAKAMI and Minoru HOSHINO \\ Geographical Survey Institute, Japan
}

\begin{abstract}
The Hyogoken-Nanbu (Kobe) Earthquake in 1995 made the Nojima Fault appear on the ground in Awaji Island, Japan. The fault was a right-lateral fault with a reverse component. The maximum displacement measured on the ground along the fault was 1.7 meter in horizontal (right-lateral) and 1.3 meter in vertical direction in Nojima-Hirabayashi.

The detailed measurement of ground surface displacement around a fault has been only available as a relative movement of one side of the fault against the other. The authors succeeded in measuring three dimensional displacement of 880 points around the Nojima fault by employing air photos of before and after the earthquake.

The characteristics of the displacement are: 1) on the northwestern side of the fault, the horizontal displacement is directed toward east, but the magnitude and direction of the vertical displacement change in a complex manner; 2) most horizontal displacement on the southeastern side is more than one meter and directed toward south or southeast. In addition, large displacement can be found even in the areas beyond one kilometer from the fault line.
\end{abstract}

KEYWORDS: Awaji Island, Hyogoken-Nanbu (Kobe) Earthquake, Nojima Seismic Fault, Photogrammetric Displacement Measurement.

\section{INTRODUCTION}

The Hyogoken-Nanbu (Kobe) Earthquake (M=7.2, Epicenter: 34.36 degree N, 135.02 degree $E$, depth $=17.9 \mathrm{~km}$; Japan Meteorological Agency) occurred on January 17, 1995 and caused the Nojima Fault to appear on the ground in Awaji Island (Ohta, et al., 1995; Nakata, et al., 1995; Awata, et al., 1995; Suzuki, et al., 1995). The Geographical Survey Institute surveyed the fault on the ground just after the earthquake and found that it was a right-lateral fault with a reverse component. The maximum displacement measured on the ground along the fault was 1.7 meter in horizontal (right-lateral) and 1.3 meter in vertical directions in Nojima-Hirabayashi of Hokudancho of Hyogo Prefecture (Ohta et al., 1995). The detailed measurement of ground surface displacement around a fault has been only available as a relative movement of one side of the fault against the other. Ground surface around a fault measured in detail for a spatial large extent of an area might be useful for modeling the crustal movement of the earthquake.

The authors applied a photogrammetric approach measuring three dimensional displacement around the Nojima fault by employing air photos of before and after the earthquake. This paper describes the result of the measurement and discusses the feasibility of applying photogrammetric approach to ground surface displacement measurement caused by earthquakes (Hoshino, et al., 1996).

\section{STUDY AREA AND MEASUREMENT}

The study area covers the north eastern part of Awaji Island, Japan and encompasses an area of approximately $20 \mathrm{~km} 2,13 \mathrm{~km}$ long along the Nojima fault and $5 \mathrm{~km}$ wide (Figure 1). Air photos covering the study area of before and after the earthquake (before- and after-quake photos) were available at the scale of $1: 8,000$ and 1:5,000, respectively. The before-quake black and white photos were taken by the local government, Hokudan-cho in October, 1983 and the after-quake color photos by PASCO Corporation, Japan on the next day of the earthquake, January 18, 1995. Ground features clearly defined on the before-quake photos (e.g., road intersections, house roof tops, foot bases of electric power towers and bridges) were identified on the after-quake photos and their three dimensional coordinates measured on both 
photos to obtain the displacement vectors for each measured point. A total of 880 points were identified and measured on these photos.

The orientation parameters of before-quake photos were available as the result of aerial triangulation conducted by Hokudan-cho. The accuracies of aerial triangulation was 26 and 30 $\mathrm{cm}$ for horizontal and vertical directions, respectively. For the horizontal control of afterquake photos, thirteen horizontal GPS control points were established for this study as shown in Figure 1 by employing two existing permanent GPS control points (Takao and Toshima) which had been established by the Geographical Survey Institute (GSI) of Japan as part of their permanent GPS control point network to monitor the crustal movement. The vertical control was obtained through a level survey starting from an existing benchmark, Iwaya which had also been established by GSI (Figure 1). GSI's level survey after the earthquake revealed a $1.96 \mathrm{~cm}$ uplift of this benchmark. The aerial triangulation errors of the after-quake photos were 5 and $7 \mathrm{~cm}$ on the ground for horizontal and vertical directions, respectively. Out of the 880 points measured in this study, 545 points were selected from house roof tops, 115 from paddy fields, 102 from road intersections, and 108 from others. Not many ground features were found appropriate for measurement on the southeastern side of the fault which is covered with forests and does not have many man-made features. Some houses were severely damaged and distorted and considered inappropriate for the measurement because photogrammetric approach only allows to measure house roofs instead of ground surface itself. Houses with too much damage were plotted on "maps of houses to be dismantled" by the local governments based on the owners' requests. A total of 118 measured houses were identified in the maps, and considered to have too much distortion, and their data were removed from the measurement result.

\section{RESULT}

A part of the photogrammetric measurement result of Nojima-Hirabayashi area, where the largest relative ground surface displacement was observed, is shown in detail in Figure 2. This figure clearly shows the difference of displacement patterns between northwestern and southeastern side of the fault. The northwestern side moved eastward with subsidence and the southeastern side southward with uplift.

Figures 3 and 4 show the result of the horizontal and vertical ground surface measurement of the whole study area. The direction of horizontal displacement is not parallel to the fault line, and it is east- or northeastward on the northwestern side of the fault and south- or southeastward on the southeastern side. The vertical displacement of the southeastern side of the fault is mostly upward while the northwestern side has both downward and upward displacement areas distributed in a complex manner, especially, downward and upward displacement areas appearing alternately along the fault. These figures illustrate that the displacement is not localized along the fault line, but large displacement of more than one meter can be found even in the areas over one $\mathrm{km}$ apart from the fault line.

The significance of the photogrammetric measurement as opposed to ground survey is seen in Nashimoto where relative uplift of the northwestern side by $40 \mathrm{~cm}$ was observed on the ground (Figure 5). Figure 4 shows this area was uplifted on both side of the fault instead of only one side.

Both horizontal and vertical displacement patterns are summarized in Figure 6.

\section{DISCUSSIONS}

\subsection{Accuracy of Measured Data}

The aerial triangulation accuracy for beforeand after-quake photos were $26 \mathrm{~cm}$ for horizontal and $30 \mathrm{~cm}$ for vertical directions and $5 \mathrm{~cm}$ for horizontal and $7 \mathrm{~cm}$ for vertical directions, respectively. However, these accuracies do not include errors associated with the operator's misidentification and/or observation errors of the objects. Since there was no other independent source of direct measurement for the displacement caused by the earthquake, it was difficult to validate the total 
accuracy of the ground surface measurement conducted in this study. However, the ground survey measurement along the fault can be considered as an independent data to estimate the accuracy of the measured displacement. Four ground survey points, Nojima-Hirabayashi, Nojima-Ohkawa, Nashimoto and Ogura were selected for the accuracy estimation. As no object measured on the air photos was located exactly on the fault, the area within $15 \mathrm{~m}$ from each ground survey point encompassing both sides of the fault was considered uniformly moved and the photogrammetric measurement data within the area were used to calculate the relative displacement along the fault for horizontal and vertical directions. The difference of the relative horizontal displacement between direct ground survey and photogrammetric measurement was largest in Ogura with $58 \mathrm{~cm}$ and smallest in Nashimoto with $12 \mathrm{~cm}$. The difference of relative vertical displacement was largest in Nashimoto with $49 \mathrm{~cm}$ and smallest in Ogura with $6 \mathrm{~cm}$. The root mean square error (RMSE) of the photogrammetric measurement based on the relative ground surface displacement was $33 \mathrm{~cm}$ for both horizontal and vertical directions. Since these errors are comparable to those of aerial triangulation, the operator error is considered relatively small compared to the error introduced during the aerial triangulation.

\subsection{Feasibility of Measuring Houses}

Successful measurement of ground surface displacement caused by an earthquake heavily depends on the density of man-made features firmly fixed to the ground and clearly identifiable on both air photos before and after the earthquake. Natural features such as trees, rivers and shorelines are subject to changes over time. Unfortunately, there are not many features that satisfy these conditions. Building and house roof tops are the most clearly identifiable features on air photos, and the measurement in this study relied on their accuracy in terms of representing the ground surface displacement. As discussed above, however, it is very difficult to visually tell whether a particular house or building is heavily damaged or not from vertical air photos.
In this study, "maps of houses to be dismantled" were employed to remove damaged houses from the measurement result assuming that houses with distortion of about $30 \mathrm{~cm}$, the accuracy of the photogrammetrc measurement, should be dismantled by the owners' request. Although this assumption may not be perfect, the measurement result of houses is comparable to that of the other features, and considered usable in this study.

\section{CONCLUSIONS}

This study focused on photogrammetric measurement of the ground surface displacement caused by the Kobe earthquake and the following conclusions were derived:

i) The direction of horizontal displacement is not parallel to the fault line, and it is east- or northeastward on the northwestern side of the fault and south- or southeastward on the southeastern side of the fault;

ii) The ground surface displacement is not localized along the fault line, but large displacement of more than one meter can be found even in the areas over $1 \mathrm{~km}$ apart from the fault line; and

iii) The overall accuracy of the photogrammetric measurement was approximately $33 \mathrm{~cm}$ for both horizontal and vertical directions and small enough compared to the actual displacement of more than $1 \mathrm{~m}$ around the fault line. The photogrammetric measurement approach adopted in this study should be considered successful in detecting the ground surface displacement around the fault. However, this success depends on the magnitude of ground surface displacement and the scale and quality of air photos available for the measurement. Unfortunately, air photos of large scale are not necessarily available for the area with large ground surface displacement caused by an earthquake.

\section{ACKNOWLEDGMENTS}

The authors wish to thank Dr. Takashi Tada of GSI and Dr. Kohei Tanaka of the National Research Institute for Earth Science and 
Disaster Prevention for their suggestions and comments for this study. Hokudan-cho of Hyogo-Prefecture, Japan kindly provided valuable maps and materials used in this study. Mr. Masayoshi Maeshima and Mr. Ryozo Onozuka of GSI assisted in the data analyses. This study was funded by the Ministry of Construction, Japan as part of their Comprehensive R\&D Project program.

\section{REFERENCES}

Awta, Y. , T. Yoshida, K. Mizuno, Y. Miyati, K. Sgiyama, A .Sangawa, T. Kamai, I. Isobe, K. Okamura, E. Tukuda, F. Yoshida, H. Kamata and N. Matsuyama, 1995. Surface faults and geologic hazards with the Hyogokennanbu earthquake. Proceedings of Preliminary Research Result on Hyogoken-Nanbu Earthquake of January 17, 1995.

Ohta, Y., M. Horino and Survey Group on Disasters, Geographical Survey Institute, 1995. Notes on the Earthquake Fault on Awaji Island, Associated with the 1995 Hyogoken-nanbu Earthquake and Related Disasters. Journal of Geography, 104(1) 143-155

Suzuki, K. ,Y. Umino, M. Horino, J. Kisanuki, M. Hoshino, J. Iwahashi, H. Mizukishi, T. Nemoto, O. Nakano and G. Iida, 1995.

Geomorphological Phenomena and Damage in the Northern Part of Awaji Island Caused by the 1995 Hyogokennanbu Earthquake. GSI Journal, 83, 3451

Nakata, T. , K. Yomogida, J. Okada, T. Sakamoto, K. Asahi and N. Chida, 1995. Surface Fault Ruptures Associated with 1995 Hyogoken-Nanbu Earthquake, Journal of Geography 104(1) 127-142

Lin, A., H. Imiya, S. Uda, K. Iimura, T. Misawa, T. Yoshida, Y. Abemitsu, T. Wada and K. Kawai, 1995. Investigation of the Nojima Earthquake Fault Occurred on Awaji Island in the Southern Hyogo Prefecture Earthquake.

Hoshino, M. , H. Murakami, H. Mizukoshi and
K. Sango, 1996. Ground Surface Displacement around Nojima Fault Emerged at 1995 Hyogo-ken Nanbu Earthquake(Kobe). GEOGRAPHICAL REVIEW OF JAPAN, Vol.69(Ser.A), No.7, July1996 (in print). 


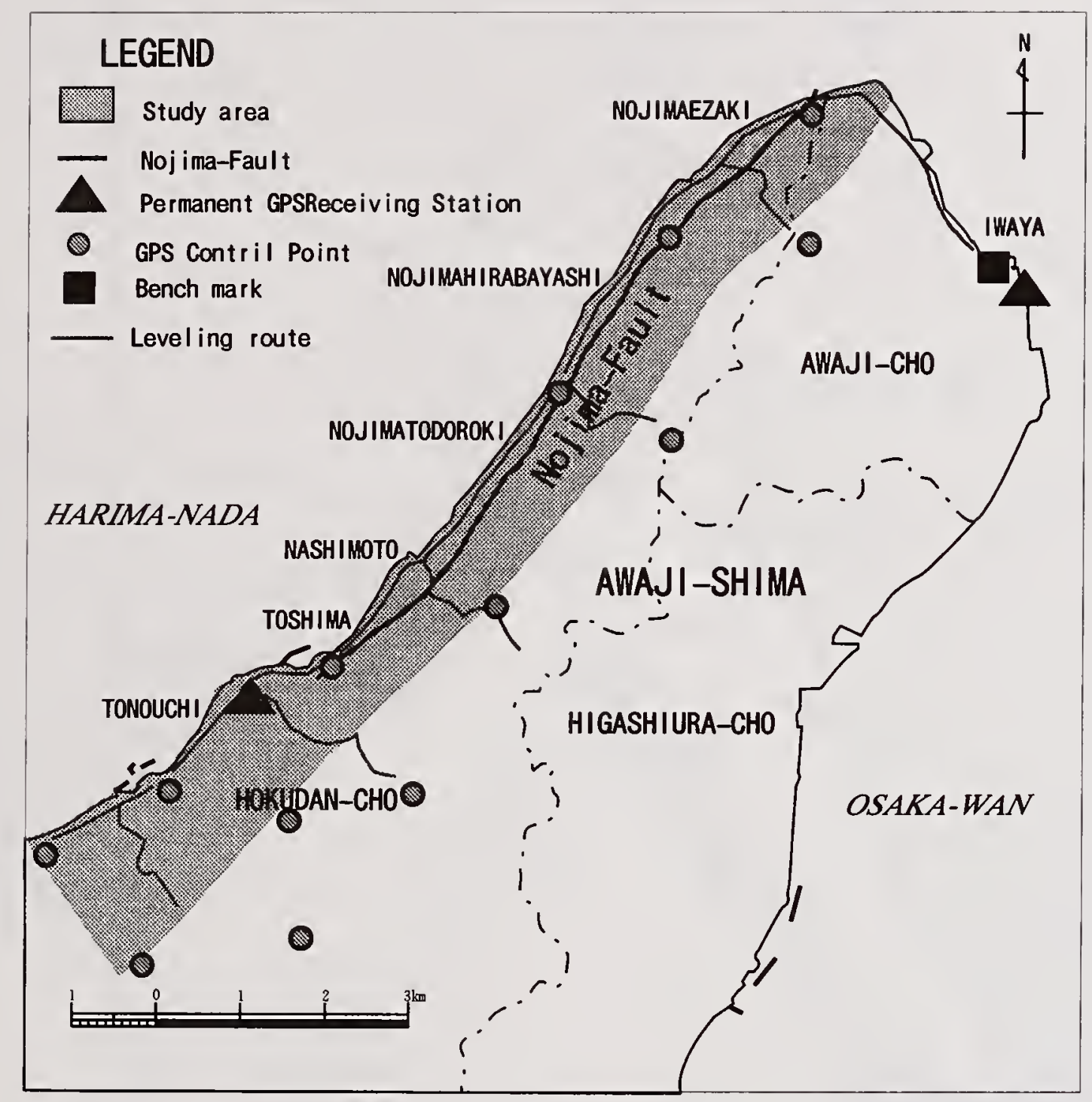

Figure 1. Study Area Control Point Distribution and Level Servey Networks. 


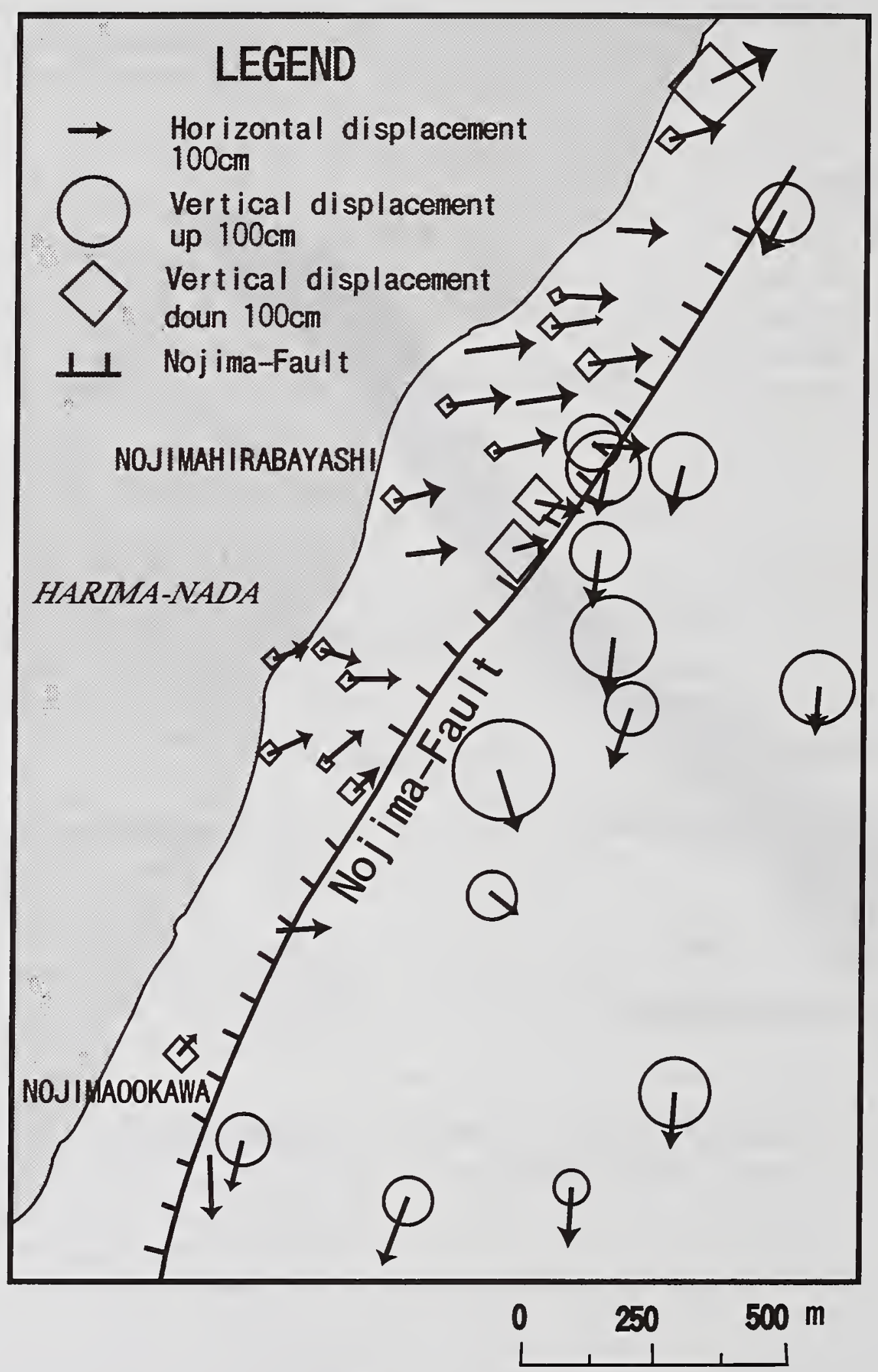

Figure 2. Ground surface displacement around Noj ima-Hi rabayashi. 


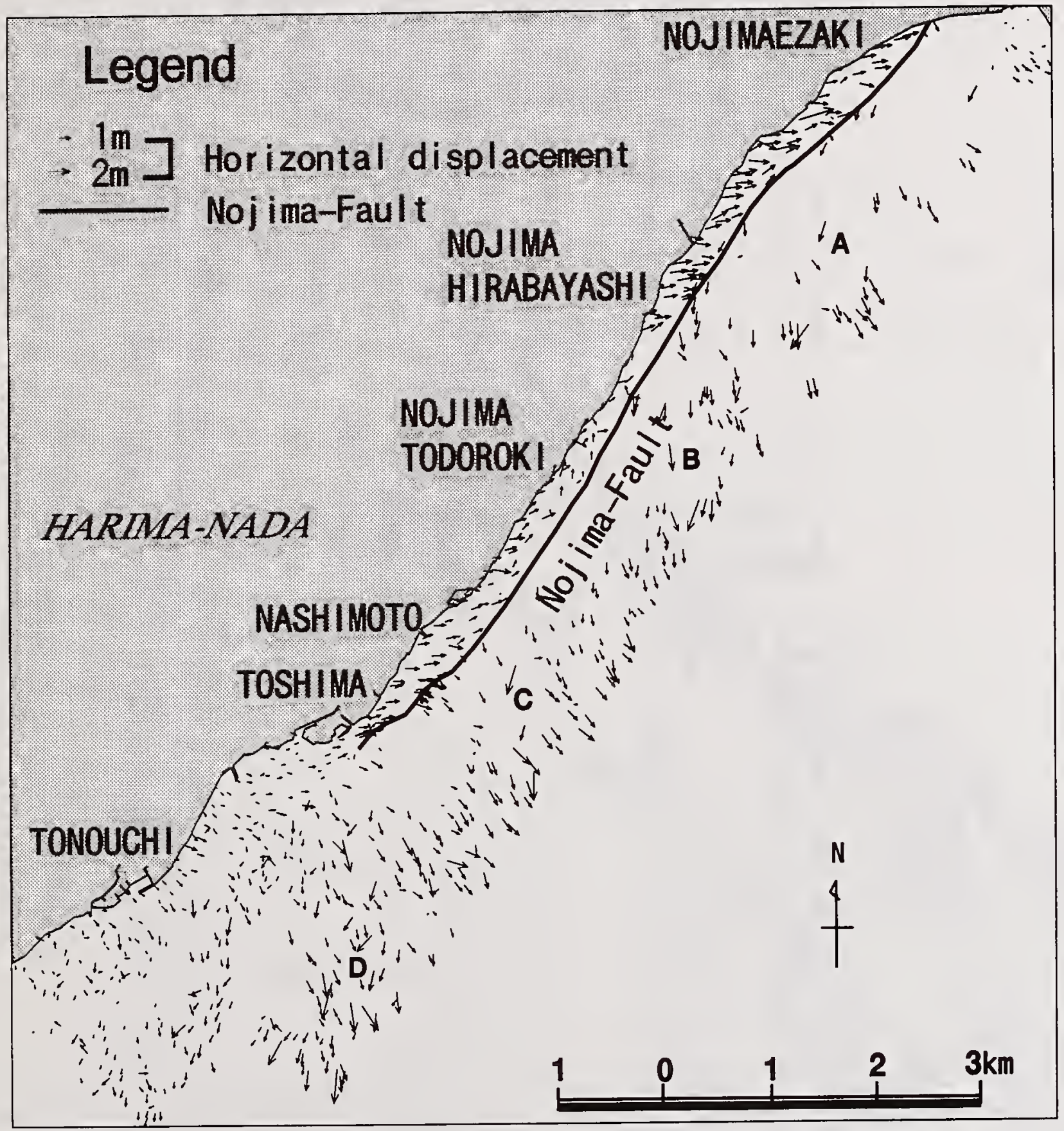

Figure 3. Distribution of horizontal displacement. 


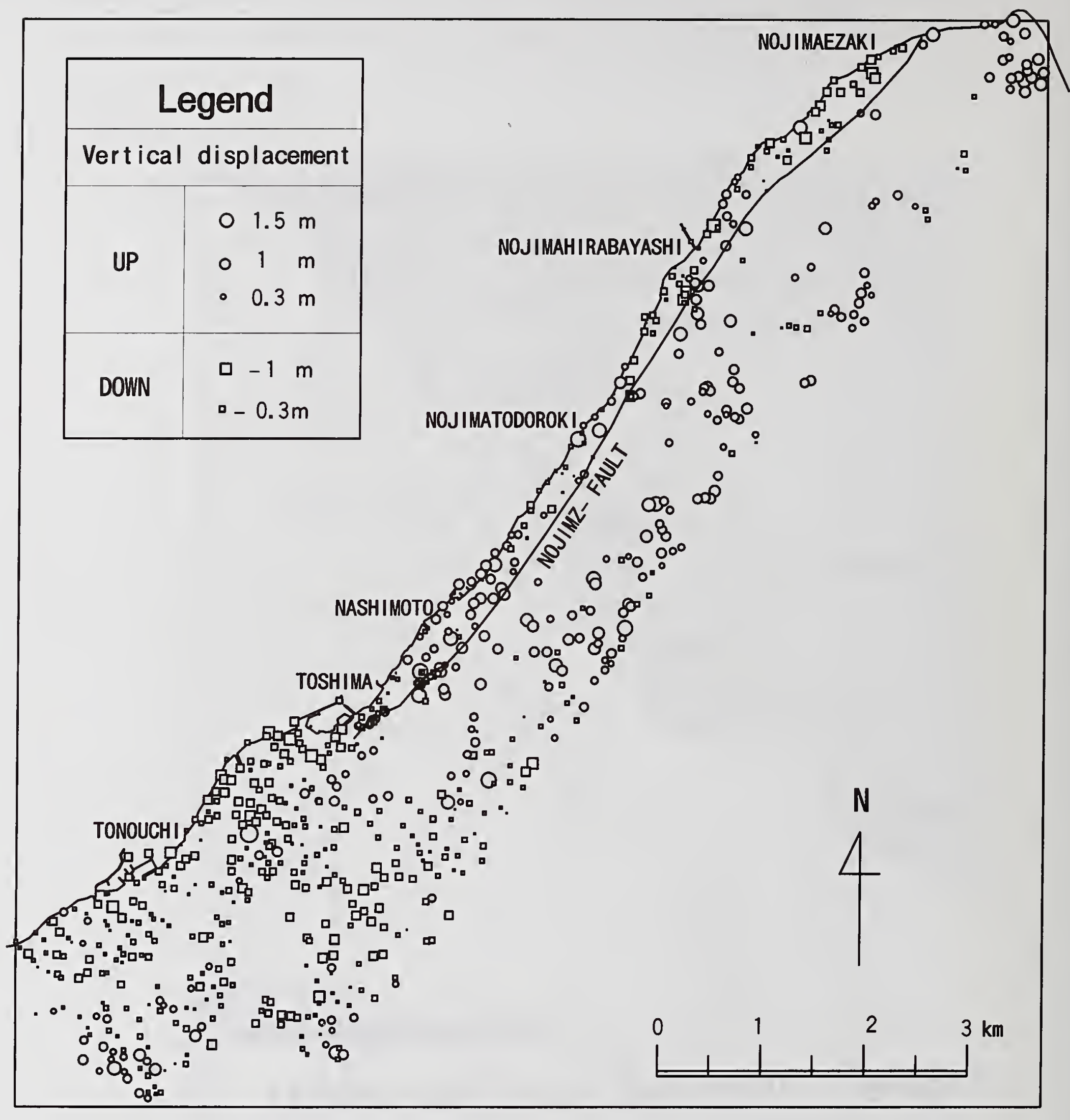

Figure 4. Distribution of Vertical displacement. 


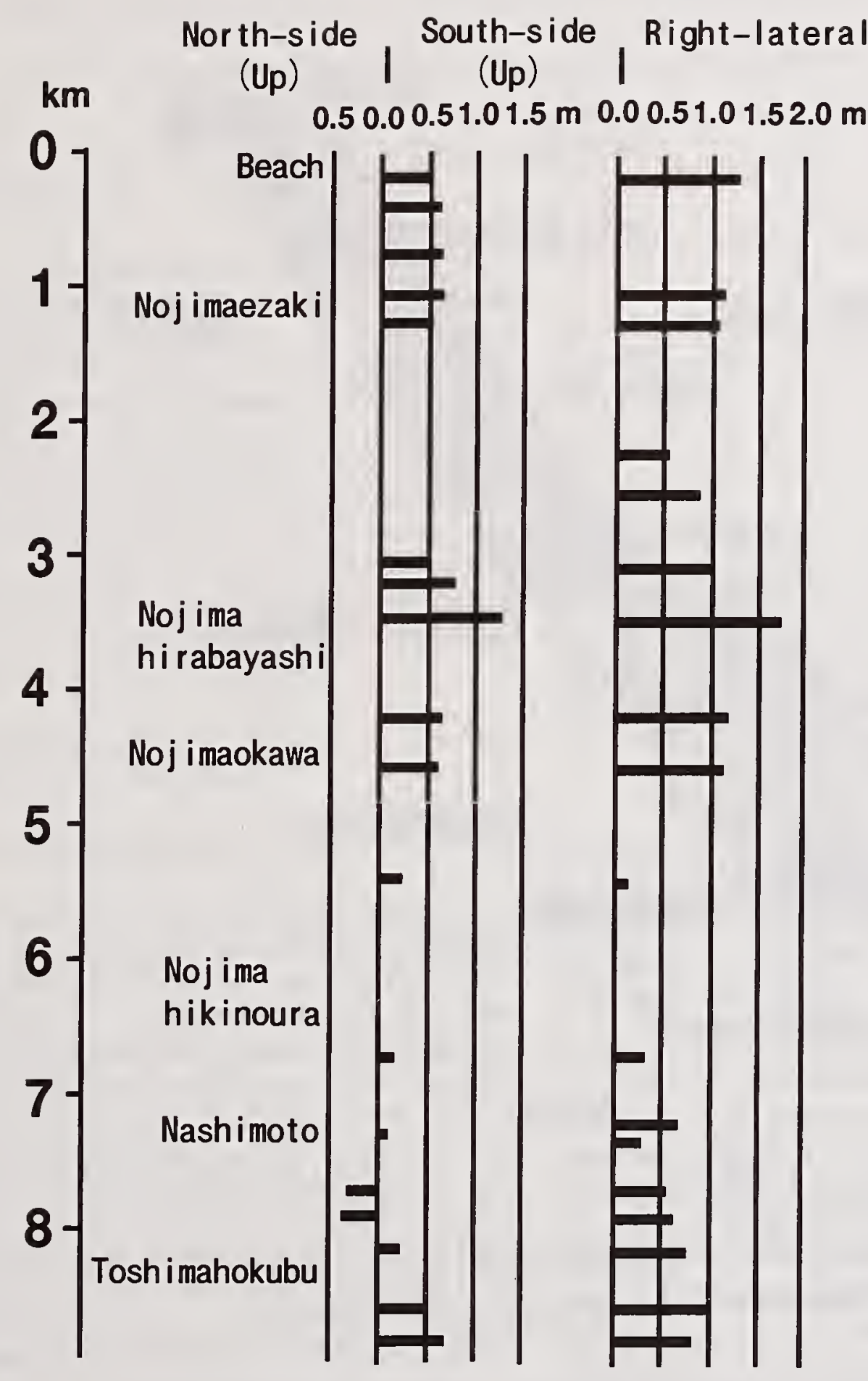

Figure 5. Displacement by ground survey. 


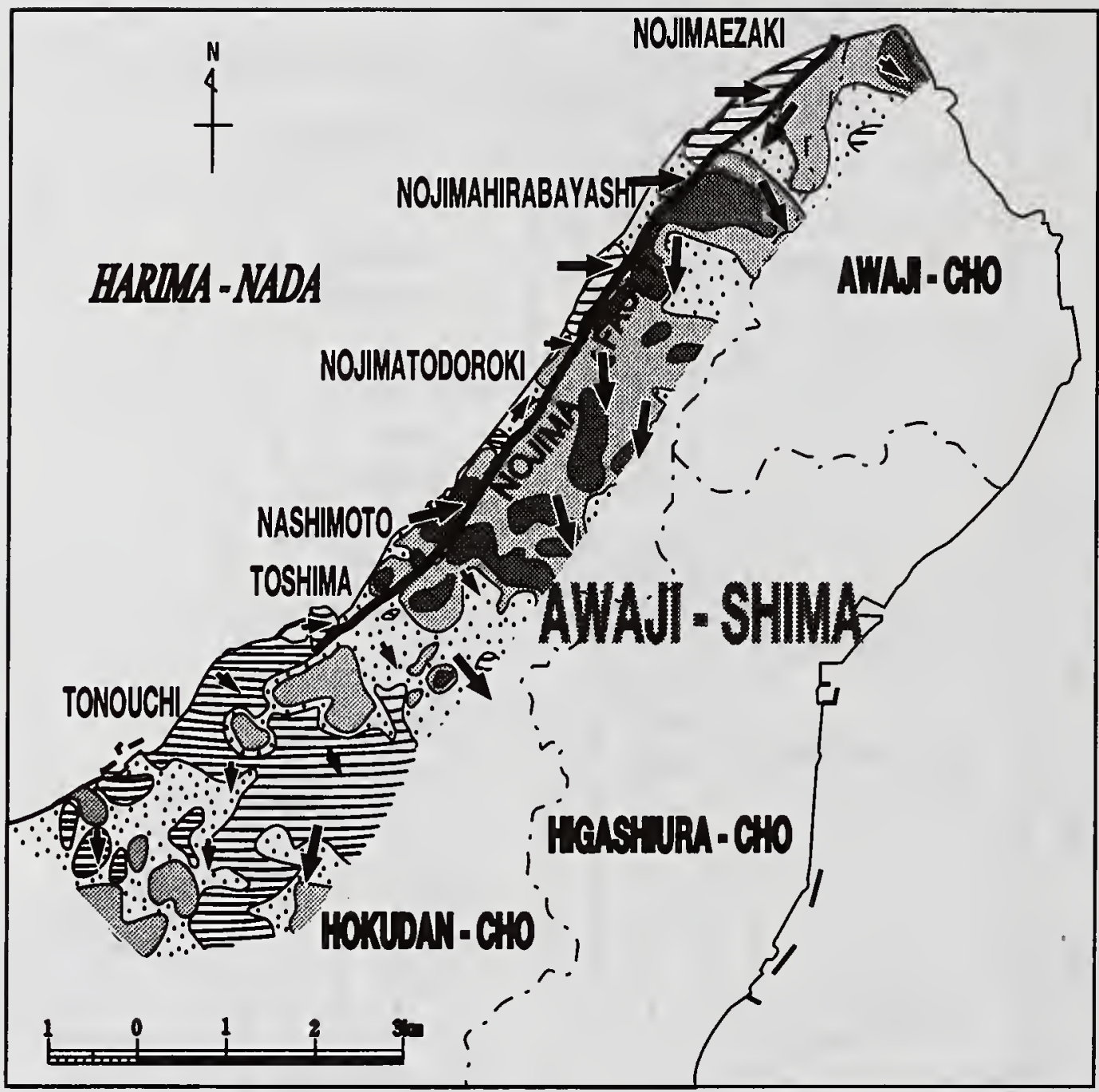

\section{Legend}

Vertical displacement

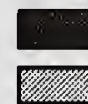

$>+0.6 \mathrm{~m}$

$\because \therefore+0.2 \mathrm{~m} \sim-0.2 \mathrm{~m}$

Area where the horlzontal displacement is more than or equal to $1 \mathrm{~m}$.

Area where the horizontal displacemen is less than $1 \mathrm{~m}$.

Figure 6. Generalized distribution of horizontal and vertical displacement. 


\title{
A Real Time System for Forecasting Storm Surges Caused by the Typhoons
}

\author{
by
}

\section{Tatsuo KONISHI *}

\begin{abstract}
A dynamical-numerical model and a new procedure for forecasting storm surges on a real time basis are proposed. The model is a traditional two-dimensional storm surge equation, on the other hand, the parameters of storm model are determined by using the geostationary meteorological satellite data for estimating radius of maximum winds of the typhoon, in addition to the forecaster's information about current and predicted positions and intensity of the typhoon. The results of hindcast and experimental forecast due to this method with application to past typhoons are shown in this paper.
\end{abstract}

KEYWORDS: storm surge; typhoon; real time forecast; model; wave set-up

\section{INTRODUCTION}

As shown in Konishi(1995a), the frequency of high storm surges in Japan has increased recently, being associated with the same tendency of the frequency of typhoons hitting in Japan. Quantitative forecast of storm surges before event is very important for disaster prevention. At present, the Japan Meteorological Agency (JMA) applies an empirical formula to the real time forecast of storm surges (JMA,1994). The method has rather good accuracy, but also has a limitation such that we can not forecast storm surges at a point where there is no storm surge record in the past. Therefore, a dynamicalnumerical model must be developed for the forecast of future storm surges.

The purpose of this paper is to propose a procedure of storm surge forecast on a real time basis and to show the results of hindcast and experimental forecast and the associated problems.

\section{STORM SURGE MODEL}

The method of numerical simulation utilized in the present study is the same as that in Konishi (1989). The two-dimensional equations of motion and continuity are expressed as

$$
\begin{aligned}
& \frac{\partial M}{\partial t}-f N=-g D \frac{\partial\left(5-\varsigma_{0}\right)}{\partial x}+\frac{\tau_{s x}}{\rho_{w}}-\frac{\tau_{b x}}{\rho_{w}} \\
& \frac{\partial N}{\partial t}+f M=-g D \frac{\partial\left(5-\varsigma_{0}\right)}{\partial y}+\frac{\tau_{s y}}{\rho_{w}}-\frac{\tau_{b y}}{\rho_{w}} \\
& \frac{\partial s}{\partial t}=-\frac{\partial M}{\partial x}-\frac{\partial N}{\partial y} \quad,(3)
\end{aligned}
$$

where the origin, $O$, is within the equilibrium level of the sea surface, Ox points east, Oy north, $\mathrm{Oz}$ is directed vertically upwards. We define $\mathrm{u}$ and $v$ as the $x$ and $y$ components of velocity and then $M$ and $N$ are the $x$ and $y$ components of volume flux given by

$$
M=\int_{-D}^{0} u d z \quad, \quad N=\int_{-D}^{0} v d z,
$$

respectively. $\quad \zeta$ is the sea surface displacement from the mean sea surface level, $D$ is the depth, $g$ is the gravity acceleration, and $f$ is the Coriolis parameter. Parameterizations of $\tau \mathrm{s} x$ and $\tau$ $\mathrm{b} \mathrm{x}$ are given as follows:

$$
\begin{aligned}
& \tau \text { s } x=\rho_{a} C d|W| W x, \\
& \tau \text {. } \mathrm{b} \mathrm{x}=\rho_{\mathrm{w}} \mathrm{Cdw}|\mathrm{V}| \mathrm{Vx} \text {, }
\end{aligned}
$$

where $\rho \mathrm{a}$ is the density of the atmosphere, $\mathrm{Cd}$ is the drag coefficient at the sea surface, $W$ is the wind velocity vector, $W_{x}$ is the $x$ component of $W, \rho \mathrm{w}$ is the density of sea water, $C d_{\mathrm{w}}$ is the drag coefficient at the sea bottom, $V$ is the mean water velocity vector, and $V_{x}$ is the $x$ component of V. $\tau_{s y}$ and $\tau_{b y}$ are parameterized in a similar way. Water head $\zeta 0$ is originated from the effect of atmospheric pressure and the relation is $\rho$ a $g \zeta 0=-(P s+P n)$. Ps and $P n$ are the surface pressure of the atmosphere and the peripheral pressure of the typhoon, respectively.

*Typhoon Research Department

Meteorological Research Institute, JMA

11, Nagamine, Tsukuba, Ibaraki, 305, Japan

Present Address: Oceanographical Division, Marine Department, JMA, 1-3-4, Otemachi, Chiyoda ku, Tokyo, 100, Japan 
Drag coefficięnts, $\mathrm{Cd}$ and $\mathrm{Cd}_{\mathrm{w}_{2}}$ are assumed to be $3.5 \times 10^{-3}$ and $2.6 \times 10^{-3}$, respectively. The values are selected from discussion of past studies, especially, Konishi and Tsuji (1995). Boundary conditions are based on Konishi (1989). On the coastal boundary, the condition of zero normal velocity is applied. As open boundary conditions, modified radiation conditions are used.

\section{TYPHOON MODEL}

In the state of the art, the accuracy of prediction of a typhoon track is not sufficient for storm surge prediction, especially for disaster prevention. Therefore, several calculations must be done to predict storm surges for the possible courses of the track. For this, we are obliged to use a parametric typhoon model in place of the results of numerical weather prediction. Fujita's formula (Fujita,1952) was supposed as the distribution of atmospheric pressure, which is given by

$$
P s=P n-\frac{\Delta P}{\sqrt{1+\left(r / r_{0}\right)^{2}}},
$$

where $\Delta P$ is the central pressure depression of a typhoon, $r$ is the distance from the center, $r_{0}$ is the parameter which is related to the radial distribution of the atmospheric pressure. Wind in the typhoon has been calculated for hindcast of storm surges by Miyazaki's formula (Miyazaki et al.,1961) written in the form,

$$
\mathrm{W}=C_{1} \cdot \mathbf{G}^{\prime}+C_{2} \cdot \mathrm{C} \cdot \exp \left(-\pi r / r_{e}\right) \text {, }
$$

where $\mathbf{G}^{\prime}$ is a wind vector, $\mathbf{C}$ is the velocity vector of the center of the typhoon and $r_{e}$ is an attenuation factor. The magnitude of $r_{e}$ is normally assigned to $500 \mathrm{~km}$ in the formula and the same value was set for $r_{e}$ in the present study. $\mathbf{G}^{\prime}$ has the same magnitude as the gradient wind vector $\mathbf{G}$ and the direction of $\mathbf{G}^{\prime}$ is turned inward of the typhoon at a certain angle from $\mathbf{G}$ to take the effect of friction between the atmosphere and the earth's surface into account. The magnitude of $\mathbf{G}$ is calculated by the equation,

$$
|\mathbf{G}|=\frac{f r}{2} \cdot\left[-1+\left\{1+\left(\frac{4}{\rho_{a} r f^{2}}\right) \frac{\partial P_{S}}{\partial r}\right\}^{1 / 2}\right]
$$

where the notations are the same as those in Section 2 and Ps is given by equation (4). There are insufficient real-time data to allow a direct analysis of the central region of most typhoons. Therefore, equation (5) is simplified and supposed to be written as

$W=C^{\prime}\left(G^{\prime}+C \cdot \exp \left(-\pi / r_{e}\right)\right)$

The inflow angle between $\mathbf{G}^{\prime}$ and $\mathbf{G}$ is supposed to be 30 degrees as in many past studies (e.g. Unoki et al., 1964). Based on these suppositions, the parameters we must determine in real time are $\mathrm{Pn}, \triangle \mathrm{P}, r_{0}$, and $C$ of equations (4) and $(7)$ and positions of the typhoon. The latter gives the typhoon velocity $\mathbf{C}$ in equation (7).

At fixed times, the forecaster in charge determines the position of the typhoon center and the intensity of the typhoon, and predicts the course and intensity change of the typhoon 12 or 24 hours later. Information on the present intensity includes central pressure, $\mathrm{Pc}$, maximum surface wind, $\mathrm{Wm}$, radius of over $50 \mathrm{kt}$ winds, $\mathrm{R50}$, and mean radius of $1000 \mathrm{hPa}, \mathrm{R} 1000$. We assign the interpolated positions between the present position and that 12 or 24 hours later to those in the numerical model. Storm surges are sensitive on the wind structure near the typhoon center. In order to include information on the structure in estimating $r_{0}$, we intend to evaluate the radius of the maximum wind, $\mathrm{Rm}$, which has not been determined in our real-time forecast system. Chubachi(1988) performed a regression analysis between the positions of maximum surface winds from aircraft reconnaissance due to the Joint Typhoon Warning Center (JTWC) at Guam and the observed cloud patterns of typhoons from the geostationary meteorological satellite "Himawari". He made three types of the regression equations for three categories of cloud patterns, EYE, CDO, and OTHERS. EYE pattern means that the eye of a typhoon is clearly found in CDO(Central Dense Overcast). CDO pattern means that no eye but CDO is found in the satellite image. OTHERS indicates that there is no eye and no organized cloud image. Good correlations, about 0.6 to 0.7 , were obtained for EYE and CDO patterns, and the regression equations of the position of maximum winds are

$$
\begin{aligned}
& \mathrm{Rm}=3.857^{*} \mathrm{E} \\
& -0.271^{*} \mathrm{Mw}+0.531^{*} \mathrm{Cus}+0.227^{*} \mathrm{Pc} \\
& -179.613 \quad \text { for EYE pattern (8) } \\
& \mathrm{Rm}=1.452^{*} \mathrm{Cuw} \\
& -0.470^{*} \mathrm{Mw} 7+0.061^{*} \mathrm{Tyn}+22.552 \\
& \text { for CDO pattern (9), }
\end{aligned}
$$

where $E$ is the length of the major axis of the eye in unit of 0.1 degrees, $M w 7$ is the maximum wind 
speed of $700 \mathrm{hPa}$ in unit of $\mathrm{kt}$, Cus and Cuw are the extensions of the convection cloud towards south and west respectively in unit of 0.1 degrees, $\mathrm{Pc}$ is the central pressure in unit of $\mathrm{hPa}, \mathrm{Tyn}$ is the latitude of the typhoon center in unit of 0.1 degrees. The Meteorological Satellite Center of the JMA determines these cloud parameters except $\mathrm{Mw} 7$ routinely at $6 \mathrm{~h}$ intervals. So we can use them for forecast of storm surges. However, no relevant data for $M w 7$ are found. The maximum wind on $700 \mathrm{hPa}$ is a little stronger than that at the surface; on the other hand the observed wind by an aircraft is weaker than the maximum wind. These have opposite tendencies to each other, and it is expected that $\mathrm{Mw} 7$ may be nearly equal to $\mathrm{Wm}$. The maximum surface wind determined by the forecaster, $\mathrm{Wm}$, is applied to Mw7. Now we can evaluate all terms in the right-hand sides of equations (8) and (9); and for the patterns of EYE and $\mathrm{CDO}, \mathrm{Rm}$ can be estimated reasonably. Using the estimation of $\mathrm{Rm}$ and the information of the forecaster with equations (4), (6), and (7), the magnitudes of $r_{0}$ and $C$ were determined in the following way. Firstly, the value of $r_{0}$ was selected, which minimizes the square error between $\mathrm{Rm}$ and the position of maximum wind calculated by equation (7) and between R1000 and the calculated one. Next, using the $r_{0}, C$ was determined by minimizing the square error between wind speeds of $\mathrm{Wm}$ and $50 \mathrm{kt}$ and the corresponding calculated values.

For the category of OTHERS, we can not obtain a proper value of $\mathrm{Rm}$, and without information on $\mathrm{Rm}$, the parameters are determined only from the forecasters' information, such as Wm, R50, and R1000. This can be validated from the following viewpoint. The state of no eye and no organized cloud, as the OTHERS pattern, means that the spatial scales of variation of wind and pressure fields become large and the position of maximum wind also becomes obscure. Therefore, it is not effective for calculations of storm surges in OTHERS patterns. In this case, we applied a recursive procedure to estimating the appropriate $r_{0}$, which is similar to Ueno(1994). The procedure described above is summarized in Fig.1

\section{RESULTS OF HINDCAST APPLIED TO TOKYO BAY}

Bay and hindcast studies were performed. Fig.2 shows the comparison of peak surges between observations and calculations of six typhoons, which caused big storm surges in Tokyo Bay in the past. This includes the results observed at ten tidal stations in and around Tokyo Bay. Rather good agreement can be found in Fig.2. The calculation simulates the observed peak surges within the accuracy of about $40 \mathrm{~cm}$.

The temporal variations of the calculated storm surges are shown in Fig. 3 for the case of Typhoon 8506(IRMA). The calculated values agree well with the observed in this figure, as well as in Fig.2, but a large seiche after the peak surge at Tokyo and some underestimation of storm surges at Minami-izu. The latter appears in all cases to some extent and improvement must be made on this point.

\section{PROBLEM 1 - EFFECT OF WAVE SETUP}

The calculation at the ports facing southerly on open cocean has the common feature of underestimation as at Minami-izu. One of the reasons is considered as the effect of wave setup proposed by Longuett-Higgins and Stewart(1962). The existence of this effect has been confirmed in the hydraulic experiments, but in situ has not, because the wave setup becomes prominent only in case of high waves (significant wave height may be greater than $4 \mathrm{~m}$ ), moreover it was difficult that the detection of the effect needs the separation of contributions by air pressure and wind stress properly from observed storm surges.

As above-mentioned method determines storm parameters objectively, the separation can be done reasonably. Konishi(1996) studied the wave setup effect with this method. He computed the storm surges at Minami-izu for six cases and subtracted the computed values from the observed storm surges, being called as SSD. SSD was compared with the wave data at Irohzaki which is very close to Minami-izu and found a good correlation between them. Though the analysis is continuing now, we will need a method in future, in which the effect of wave setup is properly incorporated for forecasting storm surges. 


\section{PROBLEM 2 - EFFECT OF MODIFICATION OF TYPHOON STRUCTURE}

We also faces on an another problem for real time forecast of storm surges. This is related to the effect of modification of typhoon structure after landing of the typhoon. Fig.4 shows the distribution of peak surges observed around the western part of Inland Sea of Japan in case of Typhoon 9119(Mireille). The simulated peak surges with the present method are also shown in the figure. The position of station number in abscissa is found in Fig.5. The experimental forecast results are shown in Fig.6, whose calculation is only based on the information at 9 o'clock on Sep.27th 1991. After about 12 hours later of the time, peak surges occurred. Computed conditions are tabulated in Table $1 . \quad$ From fig.4 the present method simulated observed peak surges with a good manner, on the other hand, the forecast cases show some overestimation especially in the eastern part of computed area. The overestimation remained, even when we use the best track and the observed central pressures for computation(Case 5 in Fig.6). The difference between Case 1 of Fig. 4 and Case 5 of Fig. 6 is due to the actual variation of radius of maximum winds. In Case 1, the closer the typhoon approaches to the analyzed area, the smaller the radius becomes, but in the forecast case(Case 5) the variation is not considered because the meteorological forecast information does not include such tendency. Detailed analysis of the event shows that it is related to the topographic convergence (see Konishi(1995b)). Thus, in order to raise the accuracy of storm surge forecast, it is important to forecast the detailed wind structure in the stormy period at forecast time.

\section{CONCLUSION}

A real time system for forecasting storm surges was developed. With the application to hindcast of past events for Tokyo Bay, the accuracy of the method is about $40 \mathrm{~cm}$ of peak surges. Hereafter, we must incorporate the effect of wave setup and consider the procedure to include the effect of typhoon modification in order to raise the accuracy of storm surge prediction.

\section{REFERENCES}

Chubachi, K., 1988: The position of maximum wind within the distance of $200 \mathrm{~km}$ from typhoon center, Document of task force in JMA for analysis of typhoon (unpublished document).

Fujita, T., 1952: "Pressure Distribution Within Typhoon", Geophysical Magazine, 23, 437451.

Japan Meteorological Agency, 1994: Tide Tables for the Year 1995, 265.

Konishi, T., 1989: "Numerical forecast of storm curges on a real time basis", Oceanographic Magazine, 39, 21-42.

Konishi, T., 1995a: "Storm surges in the western part of the Inland Sea, caused by Typhoon 9119 -analyses of tidal records, documents on flooding and field inspection", Umi to Sora (SEA AND SKY), 70,171-188 (in Japanese).

Konishi, T., 1995b: "An experimental storm surge prediction for the western part of the Inland Sea with application to Typhoon $9119^{n}$, Papers in Met. and Geophy., vol.46, 9-17.

Konishi, T. and Tsuji, Y., 1995: "Analyses of the storm surges in the western part of the Inland Sea of Japan caused by Typhoon $9119^{n}$ Continental Shelf Res., 15, 1795-1823.

Konishi, T., 1996: "A cause of storm surges observed at the ports facing on the open ocean (II)", Preprints of the Spring meeting of Japan Oceanographical Society, No.229 (in Japanese).

Longuet Higgins, M.S. and R.W. Stewart, 1962: "Radiation stress and mass transport in gravity waves, with application to 'surf beat"', Jour. of Fluid Mech., 13, 481-504.

Miyazaki, M., and T. Ueno, and S. Unoki, 1961: "The theoretical investigations of typhoon surges along the Japanese coast (1)", Oceanographical Magazine, 13 (1), 51-75.

Ueno, M. 1994: A monologue consisting of four papers on tropical cyclone motion, JMANNPD Technical Report, 32, 28-29.

Unoki, S., I. Isozaki and S. Otsuka 1964: Simulations of storm surges in Tokyo Bay, Report of the Second District Port Construction Bureau, 125pp. (in Japanese). 


\section{Satellite Center Forecast Center}

6 hourly $\begin{aligned} & \text { Determination of } \\ & \text { cloud parameters } \\ & \text { from sat. data }\end{aligned}$

Identification and forecast of typhoon positions and intensity

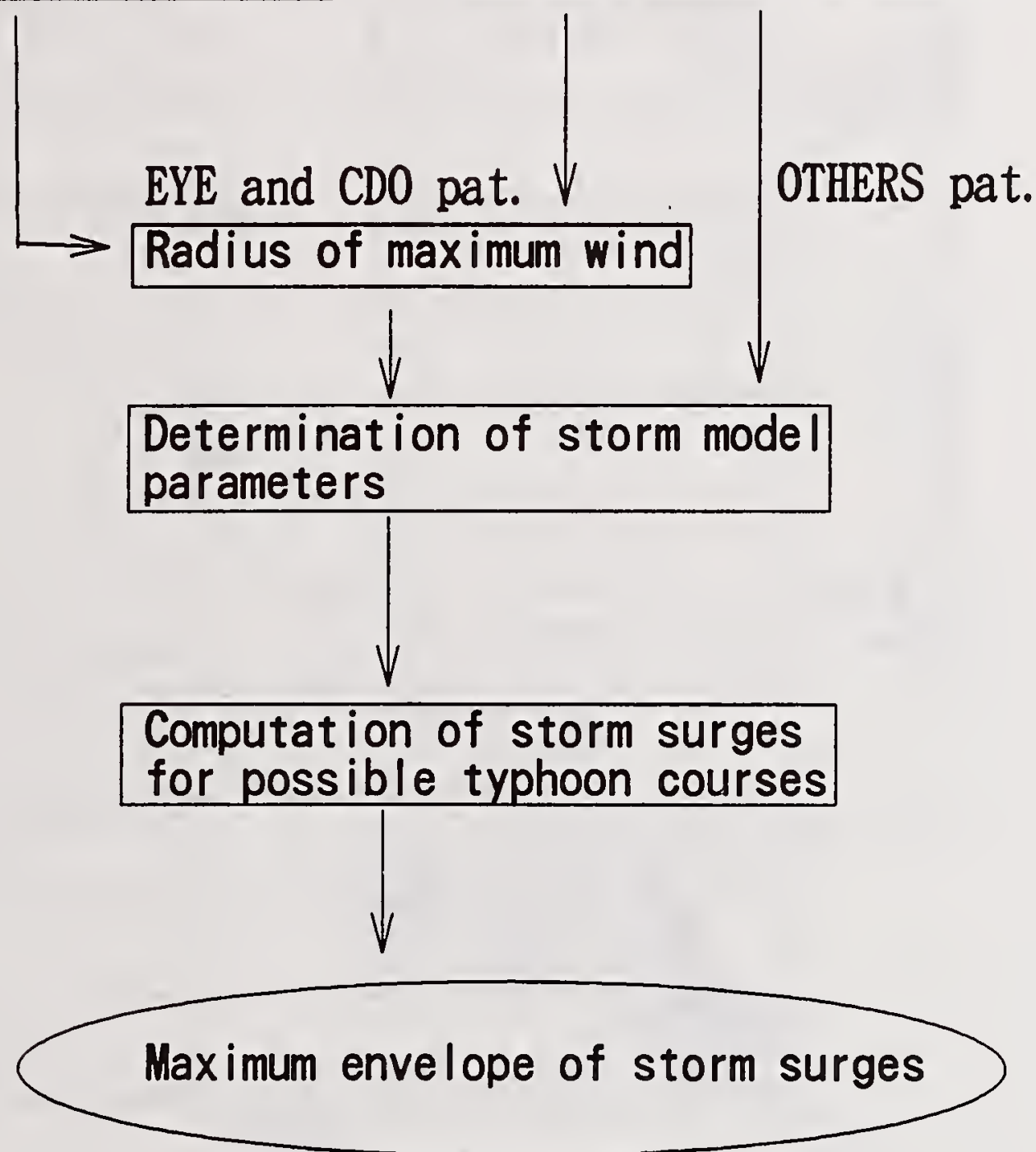

Fig.1: Forecasting procedures of storm surges (ongoing plan). 
Peak Surges (Tokyo bay)

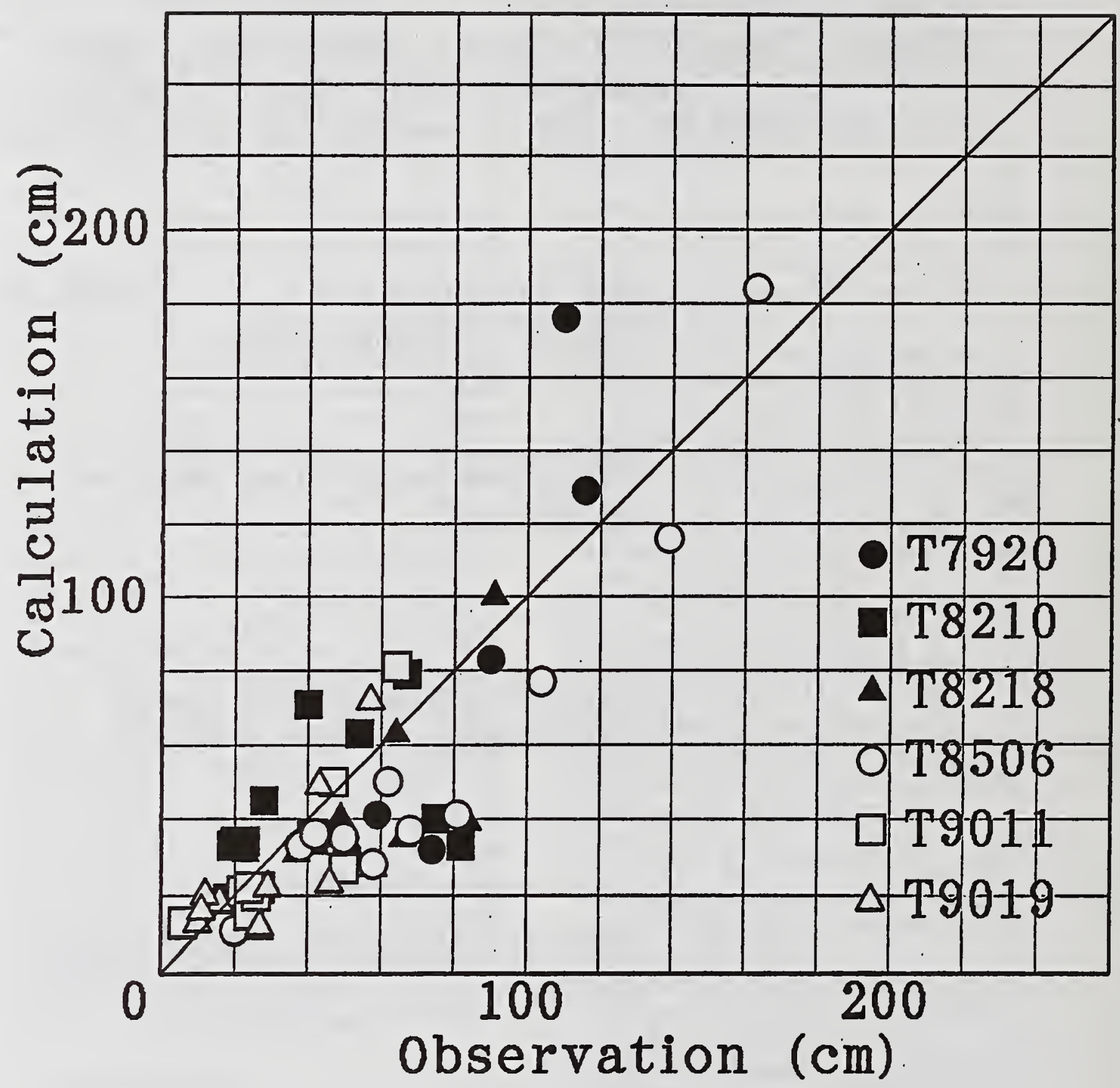

Fig.2: Comparison of peak surges between observations and calculations of six typhoons in Tokyo Bay. 

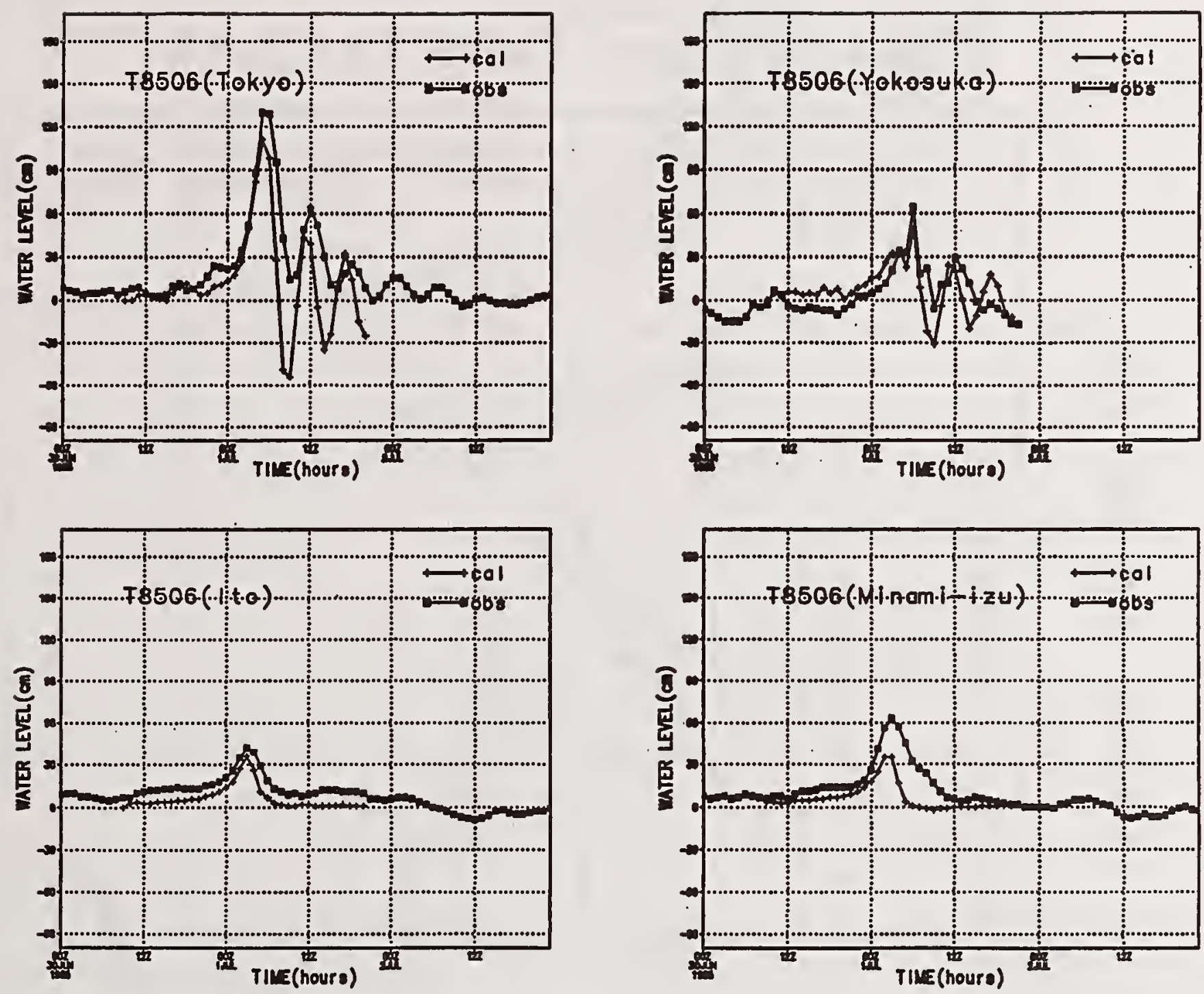

Fig.3: Temporal variations of the calculated and observed storm surges at Tokyo, Yokosuka, Ito and Minami-izu, in the case of Typhoon 8506(IRMA). 


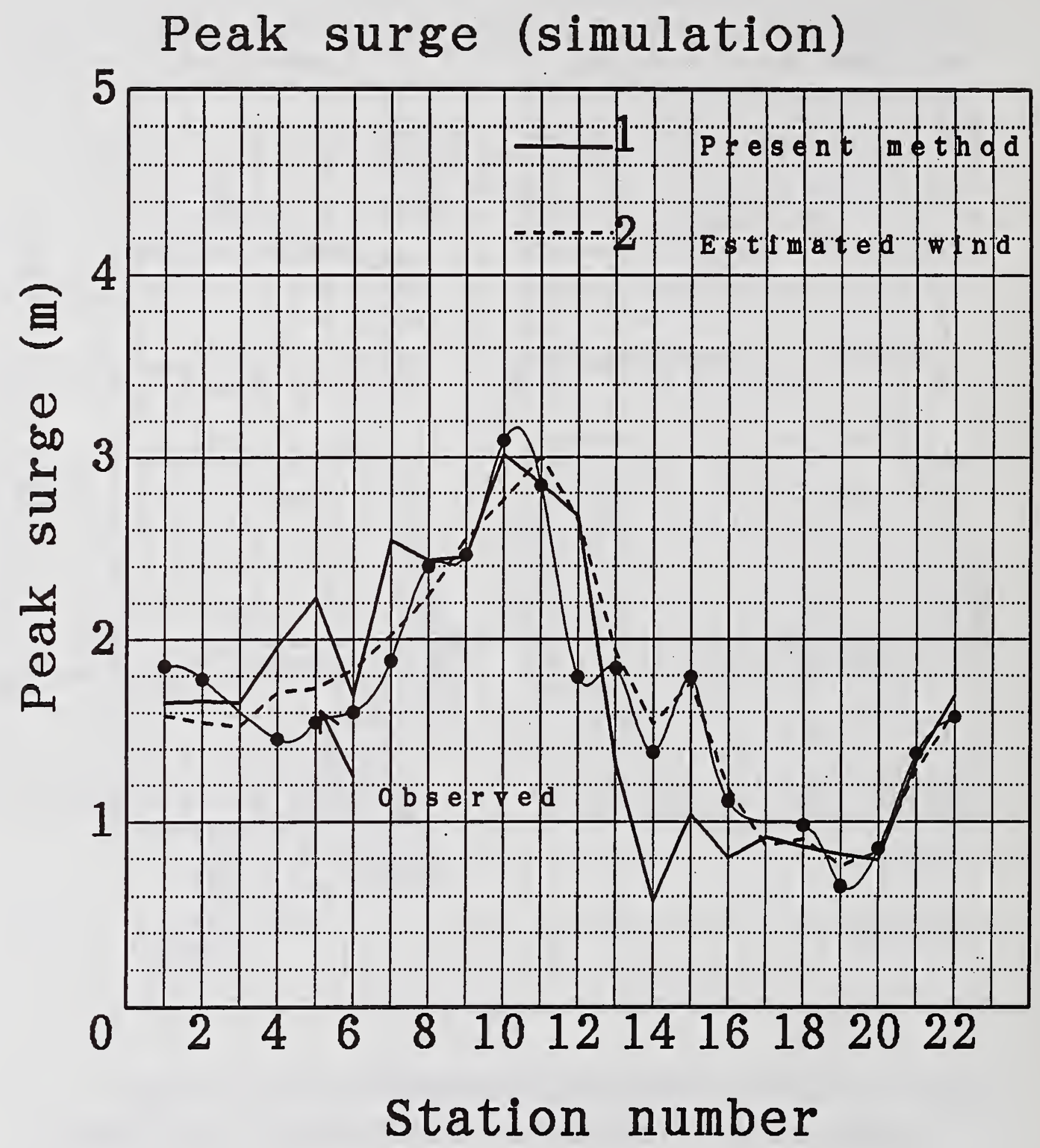

Fig.4:Comparison of simulated peak surges with those observed at the stations around the western part of the Inland Sea in the case of Typhoon 9119(Mireille). Computational conditions are given in Table 1. For the station number on the abscissa, see Fig.5. 


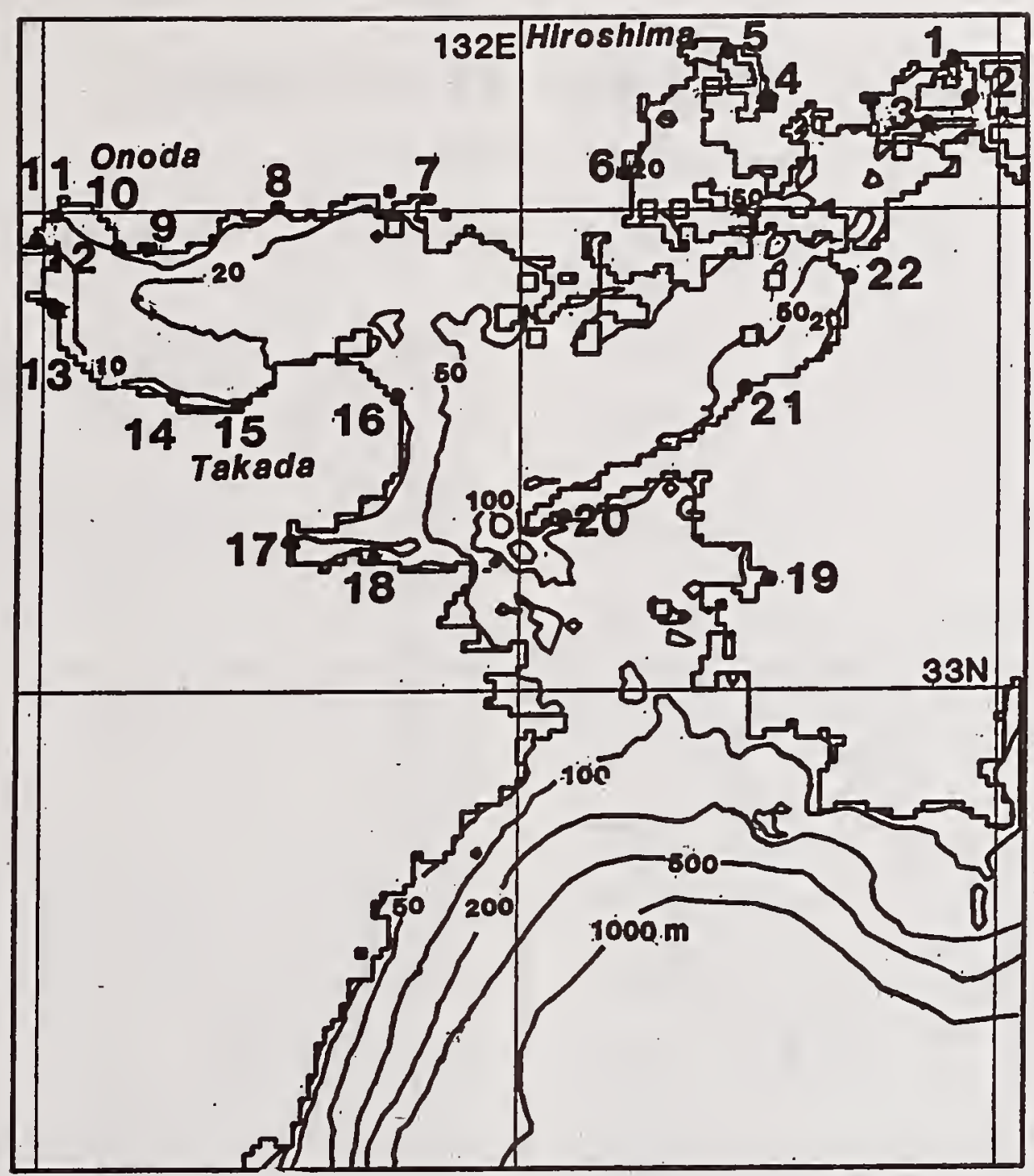

Fig.5: Domain of computation. The numeral with solid circle corresponds to the station number in Figs. 4 and 6 . Contours of the depth are drawn.

Table 1 Computational conditions of Figs. 4 and 6

\begin{tabular}{|c|ccccc|}
\hline Case & Track & $\begin{array}{c}\text { Pc } \\
(\mathrm{hPa})\end{array}$ & $\begin{array}{c}\text { ro } \\
(\mathrm{km})\end{array}$ & $\begin{array}{c}\text { C } \\
(\mathrm{C} 1, \mathrm{C} 2) \text { degree }\end{array}$ \\
\hline 1 & Best & 0bs. & Present & $\begin{array}{c}\alpha \\
\text { method }\end{array}$ \\
\hline 2 & Best & 0bs. & (Estimated wind $) *$ \\
\hline 3 & Forecast & 935 & 49 & 0.85 & 30 \\
\hline 4 & Best & 935 & 49 & 0.85 & 30 \\
\hline 5 & Best & 0bs. & 49 & 0.85 & 30 \\
\hline
\end{tabular}

(*)Estimated from tidal data, see Konishi and

Tsuji ( 1995$)$. 


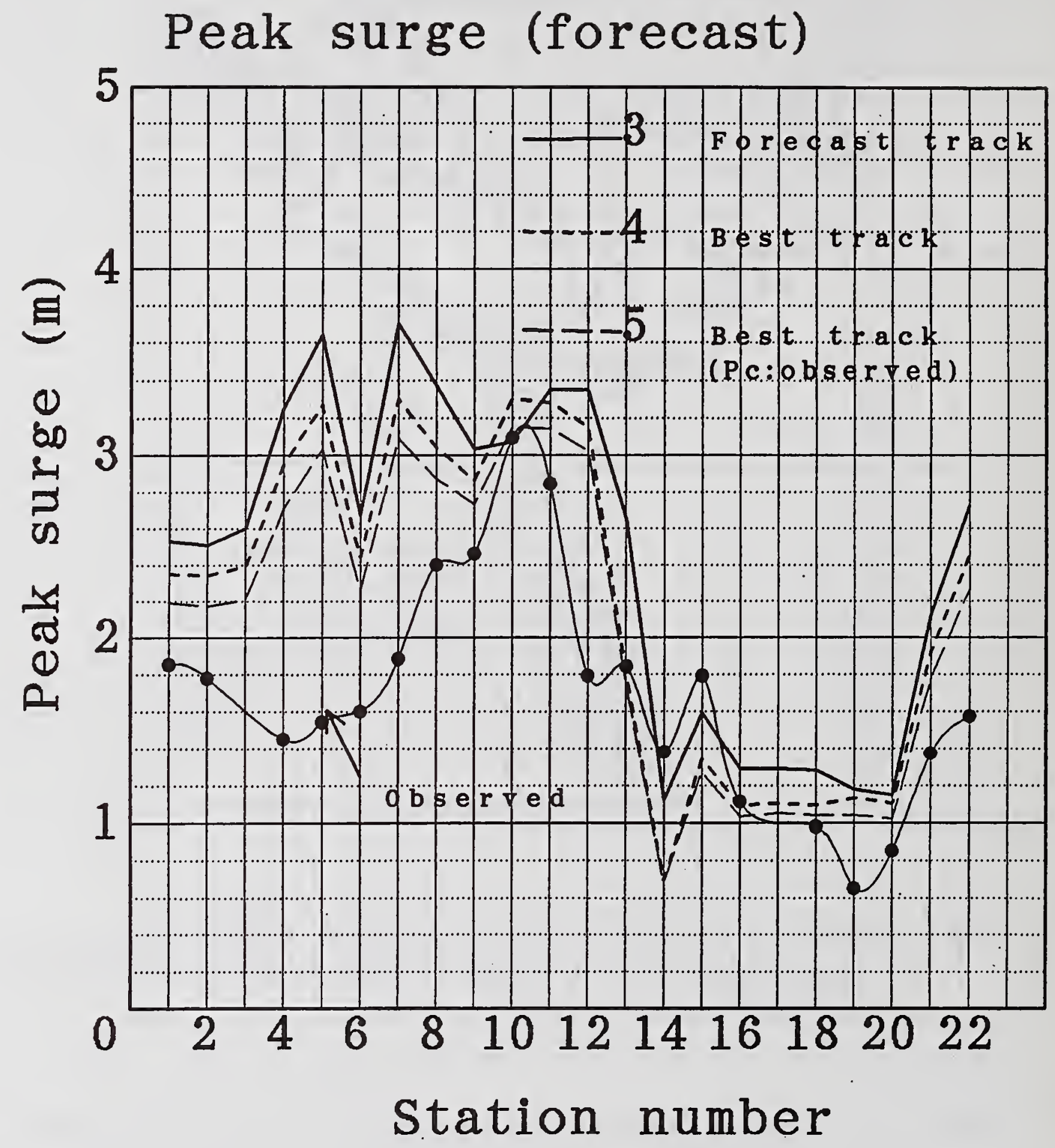

Fig.6: Same as in Fig.4, but for forecast cases. 


\section{Windborne Debris in Hurricanes and Typhoons}

by

Joseph E. Minor*

\section{ABSTRACT}

A major change is taking place in the way buildings are constructed for hurricanes and typhoons. The sustained, turbulent winds in these severe tropical cyclones carry large amounts of debris onto building facades, breaking windows and subjecting the building interior to internal pressures and rain. Concerns with occupant safety and with damage to building contents have prompted changes to building codes in the U.S. Several new code provisions require special designs for glazed openings in order to protect windows from being penetrated by windborne debris during hurricanes. Research conducted for tornado protection in schools, certain public buildings and critical facilities, including buildings in the nuclear industry, has been applied to the mitigation of damage caused by windborne debris in hurricanes. Building products, including shutters and impact resistant glazing, have been developed to protect buildings from windborne debris by rejecting debris impacts while remaining in place throughout the storm.

KEY WORDS: buildings; building codes; debris; glass; hurricane; typhoon; wind.

\section{INTRODUCTION}

It is common practice for an architect or engineer to design a building in a given community for the wind speed specified in the local building code. Using conventional methods outlined therein, this wind speed is used to develop pressures for cladding design. Implicit in this process is the assumption that if the cladding is strong enough for the pressures accompanying the largest gust in the design windstorm, it will be strong enough for pressures accompanying all of the other gusts, since these gusts will be smaller than the gust associated with the design wind speed.

Experiences with buildings in a wide range of different environments suggest that this conventional approach to defining loads and designing cladding is inadequate for tropical cyclone prone areas. Hurricanes and typhoons contain sustained, turbulent winds that generate significant amounts of windborne debris that can present a major threat to cladding, especially architectural glazing. Further, the gusty winds cause repetitive loadings that can affect glazing systems before and after impacts from debris. In building environments where these conditions can occur, breaching of the building envelope produces large internal pressures and water damage. Further, the post-breakage behavior of glass becomes an important consideration because the glass must stay in the opening following breakage to protect the envelope and not fall to the street below. Effective designs have evolved in response to new criteria for design that involve debris impact and pressure cycles representing fluctuating wind in the hurricane or typhoon.

* University of Missouri-Rolla, Rolla, Missouri, 65409-1170 USA 


\section{EXPERIENCES}

Minor and Behr (1993) summarize events over a 25 year period during which architectural glazing in buildings was broken during hurricanes. For example, architectural glazing in several tall buildings in Houston, Texas was broken by windborne debris generated by Hurricane Alicia (see Figure 1). Hurricane Andrew damaged facades in several major buildings in south Florida (see Figure 2). Failures of cladding systems during hurricanes result in damage to buildings, loss of building contents, interruption of business, hazards to people and marred images for buildings that have sustained damage.

In an example from Hurricane Andrew, the insured loss to a commercial building was US $\$ 33$ million, only US\$3 million of which was related to damage to the exterior of the building. The balance involved damage to the building interior, damage to building contents, contents replacement costs, business interruption costs and business relocation expenses.

\section{HURRICANES AND TYPHOONS}

The effects of winds in hurricanes and typhoons are especially harsh (Minor, 1984). Turbulent winds can affect a building for hours. These winds change slowly in direction as the storm approaches and passes over a building (see Figure 3). Debris can be progressively dislodged from adjacent structures, accelerated by sustained winds and impact several elevations of a building. Following impact, the building can be buffeted by cyclic wind pressures for hours before the storm moves away. This severe environment has not been recognized by building designers, building officials and product manufacturers.

\section{WINDBORNE DEBRIS}

The first suggestion that impacts from windborne debris were a likely cause for failures of architectural glazing systems during windstorms was recorded by Reed (1970). He observed that windborne debris was a significant factor in the relatively large window glass breakage rates at low elevations on high-rise buildings during the Lubbock Storm of May 11, 1970. In assessing failures of structures during windstorms, Minor, Mehta and McDonald (1972) observed that windows are traditionally designed for wind pressures, but that breakage from impacts by windborne debris is the most common failure mechanism.

In extensive wind damage surveys conducted throughout the 1970s, a pattern became apparent that proved to be common to all types of extreme wind events (Minor and Mehta, 1979). Small debris, principally roof gravel, can be carried into all elevations of building facades at velocities sufficiently large to break glass. Large debris, including framing timbers and roofing materials, can impact the building envelope near ground level with sufficient force to penetrate wall coverings and break windows. Research has defined the nature of both small and large debris in windstorms.

\subsection{Small Missiles}

Minor (1974) analyzed the window damaging mechanism during windstorms in urban areas. He identified roof gravel as the principal form of small debris that causes damage to windows in the upper floors of high-rise buildings. Field surveys of typical built-up roofs (conventional "tar and gravel") established the average roof gravel size as $0.6 \mathrm{gm}$, and an average large size of roof gravel as $5 \mathrm{gm}$. Harris (1978) defined the 
threshold of roof gravel impact velocities that cause breakage in the three basic types of window glass (annealed, heat strengthened and fully tempered). Threshold average breakage velocities for a $5 \mathrm{gm}$ steel ball representing roof gravel impacting $6 \mathrm{~mm}$ (1/4 in.) annealed, heat strengthened and fully tempered glass were reported by Harris as $10 \mathrm{~m} / \mathrm{sec}(31 \mathrm{ft} / \mathrm{sec}), 12 \mathrm{~m} / \mathrm{sec}(36 \mathrm{ft} / \mathrm{sec})$, and $20 \mathrm{~m} / \mathrm{sec}(65 \mathrm{ft} / \mathrm{sec})$, respectively. Thus, all types of glass in this common thickness can be broken by windborne roof gravel, if impact speeds are larger than about $1 / 2$ of gravel carrying wind speeds of $38 \mathrm{~m} / \mathrm{sec}(80$ $\mathrm{mph}$ ) or more.

Travel distances exceeding $30 \mathrm{~m}(>100 \mathrm{ft})$ in Hurricanes Alicia and Andrew permitted roof gravel to be accelerated to large fractions ( $1 / 2$ or more) of the $38 \mathrm{~m} / \mathrm{sec}$ ( 80 $\mathrm{mph}$ ) wind speeds estimated to have occurred at the building sites illustrated in Figures 1 and 2. Heat strengthened and fully tempered glass in windows on these buildings were broken.

\subsection{Large Missiles}

In their investigations of tornadoes, Minor, McDonald and Mehta (1978) concluded that the most prevalent type of windborne debris in residential areas is timber from wood frame houses. Individual timbers were observed to have broken windows, penetrated walls and roofs, and impaled in the ground. Additional windborne timbers were attached together as parts of failed roofing systems, timber trusses and timber walls. These observations led to the selection of a $2 \times 4$ timber weighing $7 \mathrm{~kg}$ (15 lbs) as a representative object for use in defining impact criteria for tornado shelters in schools and residences (DCPA, 1975). The ease with which this $2 \times 4$ timber, which is about $3.7 \mathrm{~m}(12 \mathrm{ft})$ long, can be propelled by a compressed air "cannon" also led to its becoming a standard for impact testing of walls, shutters and window systems.

In 1974, Tropical Cyclone Tracy devastated the City of Darwin in Australia's Northern Territory. Walker (1991) observes: "It was clearly demonstrated in the investigation of Cyclone Tracy that the two major factors contributing to the widescale damage to housing were internal pressurization of buildings following failure of windward windows, generally due to windborne debris, and fatigue failure of cladding and metal connections under the fluctuating pressures." A $4 \mathrm{~kg}(9 \mathrm{lb}$ ) $2 \times 4$ timber (about $2.7 \mathrm{~m} ; 9 \mathrm{ft}$ long) first appeared as a design missile in a building code in the Darwin Area Building Manual (1976). This design missile appears in the Australian national wind loading code (SAA, 1989), is used both editions of the South Florida Building Code $(1993,1994)$ and in Southern Building Code Congress International (SBCCI) Standard SSTD 12-94 (1994).

A $2 \times 4$ timber, $3.7 \mathrm{~m}(12 \mathrm{ft})$ in length, and travelling at $1 / 2$ of the design wind speed was advanced as one of three "large" objects recommended for use in the design of lower elevation cladding on urban buildings by Minor, et al. (1978). This recommendation was based upon field documentation conducted by the Institute for Disaster Research at Texas Tech University and research being conducted by the nuclear industry on missile impact speeds in tornadoes and other extreme windstorms. A list of large missiles for use in design is contained in Department of Energy Standard DOE-STD-1020-94 (1994).

\section{BREACHING OF THE ENVELOPE}

The building envelope must remain integral during windstorms. Breaching of the building envelope produces several harmful 
effects: internal pressure, exposure of occupants to wind and rain, damage to building contents, additional debris in the wind stream, hazardous debris falling to the street, disrupted business, and a blemished image of the building. Windborne debris has been established as a principal cause for the breaching of the building envelope during hurricanes. Failure of windward wall cladding (windows and wall coverings) or doors leads to an increase in pressure inside the building and can produce failure of the principal structural frame. As shown in Figure 4, internal pressures can effectively double forces acting to lift the roof and push side and leeward walls outward.

\section{POST-BREAKAGE BEHAVIOR}

The post-breakage behavior of architectural glazing in urban high-rise buildings is important for two reasons. First, hazards to people on urban streets below establishes the importance of keeping broken particles of glass within the window opening should breakage occur. Second, the importance of preserving the integrity of the building envelope (see discussion in 4 . above and Figure 4) reinforces the benefit of keeping broken glass in the opening should debris impact induced breakage occur. Laminated glass (two "plies" of glass joined by a plastic interlayer) offers opportunities to achieve both objectives (keeping particles within the opening and preserving the integrity of the building envelope) following breakage.

Understandings of the hurricane environment, and the concerns with public safety and property protection discussed above, have produced test protocols for cladding designs. These protocols use missile impact, followed by application of a pressure spectrum, as a basis for qualifying architectural glazing system designs for hurricanes and typhoons. Pantelides, et al.
(1994) established a test in which roof gravel weighing $2 \mathrm{gm}$ is propelled onto the window at a speed equal to the design wind speed for a specific building. Following multiple impacts, the window system is subjected to a sequence of pressure cycles to test its ability to remain in the opening following breakage. Similar test protocols are employed in SBCCI Standard SSTD 12 94 (1994) and the two editions of the South Florida Building Code $(1993,1994)$.

The post-breakage pressure spectra employed in the above test protocols were developed from a succession of three reports that contain authoritative assessments of fluctuating pressures on cladding produced by the passage of a hurricane. Jancauskas, et al. (1990) devised the basic analytical model of a tropical cyclone crossing a building site and used this model to derive cyclic pressure spectra for roof cladding. Mahendran (1993) extended this work and offered a simplified pressure spectrum for use in testing. Finally, Letchford and Norville (1994) applied these concepts to wall cladding and outlined a 18,500 cycle pressure spectrum that they recommended be used to evaluate the post-breakage behavior of glazing and external protection devices.

\section{EFFECTIVE DESIGNS}

Architects and engineers have used the design concepts and test procedures outlined above to design buildings which may be exposed to impacts from windborne debris. Further, the glazing, door and shutter industries have developed new glazing products, cladding system designs, and external protective devices (shutters) that have been tested according to criteria outlined in the new building codes and test standards.

Pantelides, et al. (1993) report that a 
laminated glass product that is anchored to the window frame with a silicone anchor bead can survive the small missile impacts and the cyclic pressure spectrum (see Figure 5). An "anchored film" design in which a polyethylene terethalate (PET) film is applied to the inner surface of monolithic glass and anchored to the window frame with a batten bar has also passed the small missile test and the cyclic pressure spectrum.

The Building Code Compliance Office in Dade County, Florida USA has approved more than 350 products that meet the South Florida Building Code debris impact requirements. Most of the approved products are shutter systems, but windows, doors, skylights, and wall coverings are included in the approved products list. An innovative new window system for residential applications is comprised of a thick layer of polyvinyl butyral (PVB) covered by a thin layer of polyethelyne terephthalate (PET) and applied to the inner surface of monolithic heat-strengthened glass (see Figure 6). Commercial size insulating glass units with both lites made of laminated glass have also passed the large missile impact test and pressure cycles prescribed by the South Florida Building Code.

\section{CONCLUSION}

Twenty years of meteorological research, building performance evaluations, wind engineering, and test method development have produced fundamental changes in the way the building envelope is designed to survive hurricanes and typhoons.. Two overlooked aspects of the windstorm environment, windborne debris and fluctuating pressures, have found their way into building codes, test standards and design practice. New impact resistant glazing products, shutter systems and architectural glazing have emerged in response to these fundamental changes in the concepts of design for hurricanes and typhoons.

\section{ACKNOWLEDGMENTS}

Support of wind engineering activities dating from 1970 by the Hazards Mitigation Section of the U.S. National Science Foundation has been instrumental in the performance of building evaluations, the conduct of basic research and the development of test methods that relate windborne debris to performance of the building envelope. The Institute for Disaster Research and the Glass Research and Testing Laboratory at Texas Tech University, and the State of Missouri through the Missouri Research Assistance Act and the University of Missouri-Rolla, have also supported these activities. The Saflex ${ }^{\circledR}$ Division of Monsanto supported debris impact related research projects at various times during this period. Participation by the above organizations in addressing the various facets of windborne debris and the building envelope are gratefully acknowledged.

\section{REFERENCES}

1. Darwin Area Building Manual, Darwin Reconstruction Commission, Darwin, NT (Australia), 1976.

2. DCPA, "Interim Guidelines for Building Occupant Protection from Tornadoes and Extreme Winds," Defense Civil Preparedness Agency, Washington, DC, 1975.

3. DOE, "Natural Phenomena Hazards Design and Evaluation Criteria for Department of Energy Facilities," DOE-STD-1020-94, U.S. Department of Energy, Washington, DC, April, 1994. 
4. Harris, P. L., "Effects of Thickness and Temper on the Resistance of Glass to Small Missile Impacts," thesis presented to Texas Tech University, Lubbock, TX in partial fulfillment of the requirements for the degree of Master of Science, 1978.

5. Jancauskas, E.D., Walker, G.R., Mahendran, M., Capitanio, C. and Prien, G.D., "Computer Simulation of the Fatigue Behaviour of Roof Cladding During the Passage of a Tropical Cyclone," Proceedings of the Twelfth Australasian Conference on the Mechanics of Structures and Materials, Queensland University of Technology, 1990, pp 327-334.

6. Letchford, C.W. and Norville, H.S., "Wind Pressure Loading Cycles for Wall Cladding During Hurricanes," J. Wind Engin. and Indus. Aerody., Vol. 53, (1994), pp 189-206.

7. Mahendran, M., "Towards an Appropriate Fatigue Loading Sequence for Roof Claddings in Cyclone Prone Regions," Queensland University of Technology, Brisbane (Australia), 1993.

8. Minor, J. E., "Analysis of the Window Damaging Mechanism in Windstorms," dissertation submitted to the graduate faculty of Texas Tech University in partial fulfillment of requirements for the Ph.D. Degree, Texas Tech University, May 1974.

9. Minor, J. E., "Window Glass Performance and Hurricane Effects," Proceedings, Specialty Conference: Hurricane Alicia: One Year Later (Galveston, TX, August 16-17,
1984), ASCE, New York, 1985, pp 151-167.

10. Minor, J. E., Beason, W.L., and Harris, P.L., "Designing for Windborne Missiles in Urban Areas," J. Structural Div., ASCE, 104 (1978) 1749-1759.

11. Minor, J. E. and Behr, R. A., "Architectural Glazing Systems in Hurricanes: Performance, Design Criteria and Designs," Proceedings. the 7th National Conference on Wind Engineering, (University of California, Los Angeles, June 27-30, 1993), UCLA, Los Angeles, 1993, pp 453-461.

12. Minor, J. E., McDonald, J. R., and Mehta, K. C., "The Tornado: An Engineering Oriented Perspective," NOAA Technical Memorandum ERL NSSL-82, National Weather Service, NOAA, Washington, DC, 1978 (reprinted as NOAA Technical Memorandum NWS SR-147, 1993).

13. Minor, J. E. and Mehta, K. C., "Wind Damage Observations and Implications," J. Structural Div., ASCE, 105 (1979) 2279-2291.

14. Minor, J. E., Mehta, K. C. and McDonald, J. R., "Failures of Structures due to Extreme Winds," J. Structural Div., ASCE, 98 (1972) 2455-2471.

15. Pantelides, C. P., Horst, A. D., and Minor, J. E., "Postbreakage Behavior of Heat Strengthened Laminated Glass under Wind Effects," $\underline{\text {. }}$ Structural Engin., ASCE, 119 (1993) 454-467. 
16. Pantelides, C. P., Horst, A. D., and Minor, J. E., "Post-breakage Behavior of Architectural Glazing in Windstorms," J. Wind Engin. and Indus. Aerody., 41-44 (1992) 24252435.

17. Reed, Jack. W., "Window Damage Study of the Lubbock Tornado," Report No. SC-TM-70-535, Sandia Laboratories, Albuquerque, August 1970.

18. SAA Loading Code Part 2: Wind Loads, AS1170.2-1989, Standards Australia, North Sydney, NSW, Australia, 1989.

19. SBCCI, "SBCCI Test Standard for Determining Impact Resistance from Windborne Debris," SSTD 12-94, Southern Building Code Congress, International, Birmingham, $\mathrm{AL}$

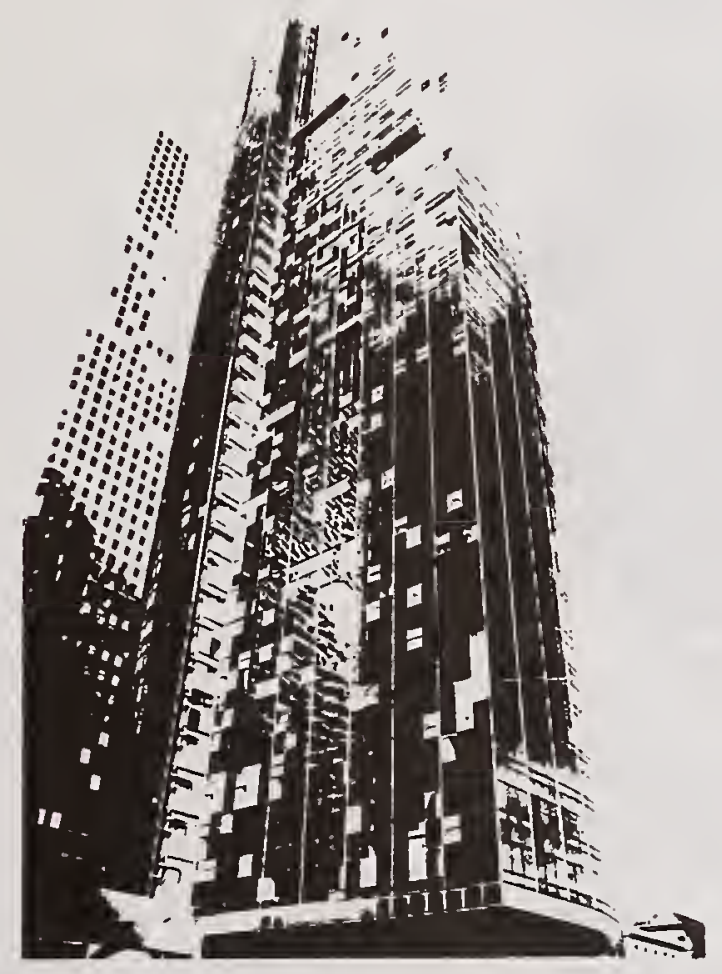

(USA), December 1994, 16 pp.

20. SFBC, "Metropolitan Dade County Edition of the South Florida Building Code," Metropolitan Dade County, Miami, Florida, adopted December 14, 1993.

21. SFBC, "Broward County Edition of the South Florida Building Code," Broward County, Ft. Lauderdale, Florida, adopted February 10, 1994.

22. Walker, G. R., "The Application of Wind Engineering Technology to the Mitigation of Damage to Housing from Tropical Cyclones - An Australian Achievement," preprint of a paper presented at International Conference on the Impact of Disasters, University of California, Los Angeles, CA (USA), July, 1991.

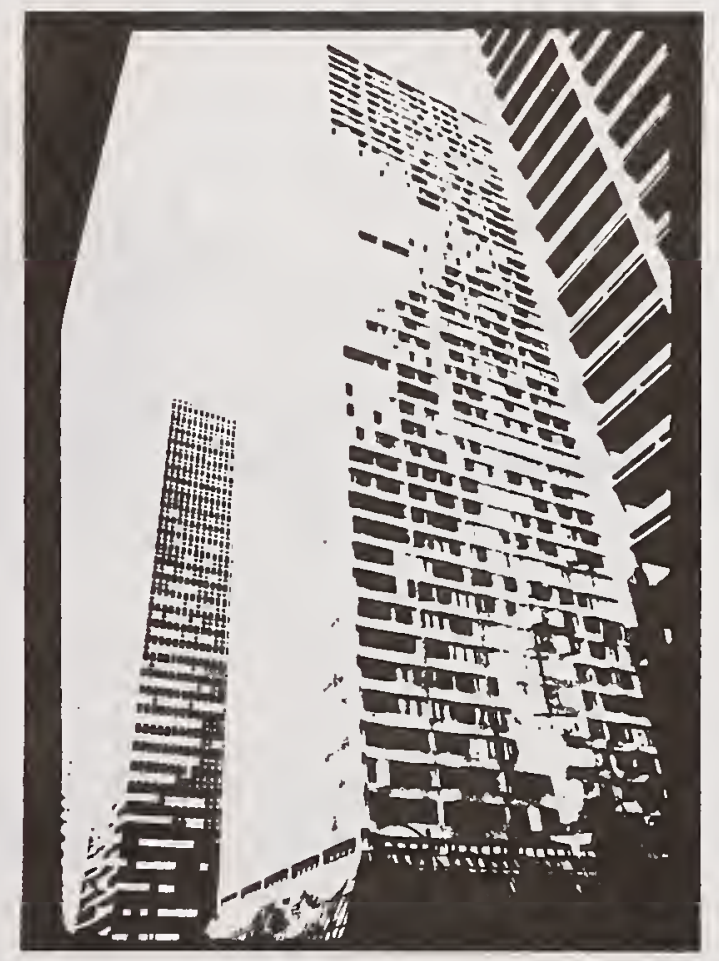

Figure 1. Window Glass Breakage in Downtown Houston, Texas Following Hurricane Alicia in August 1983 

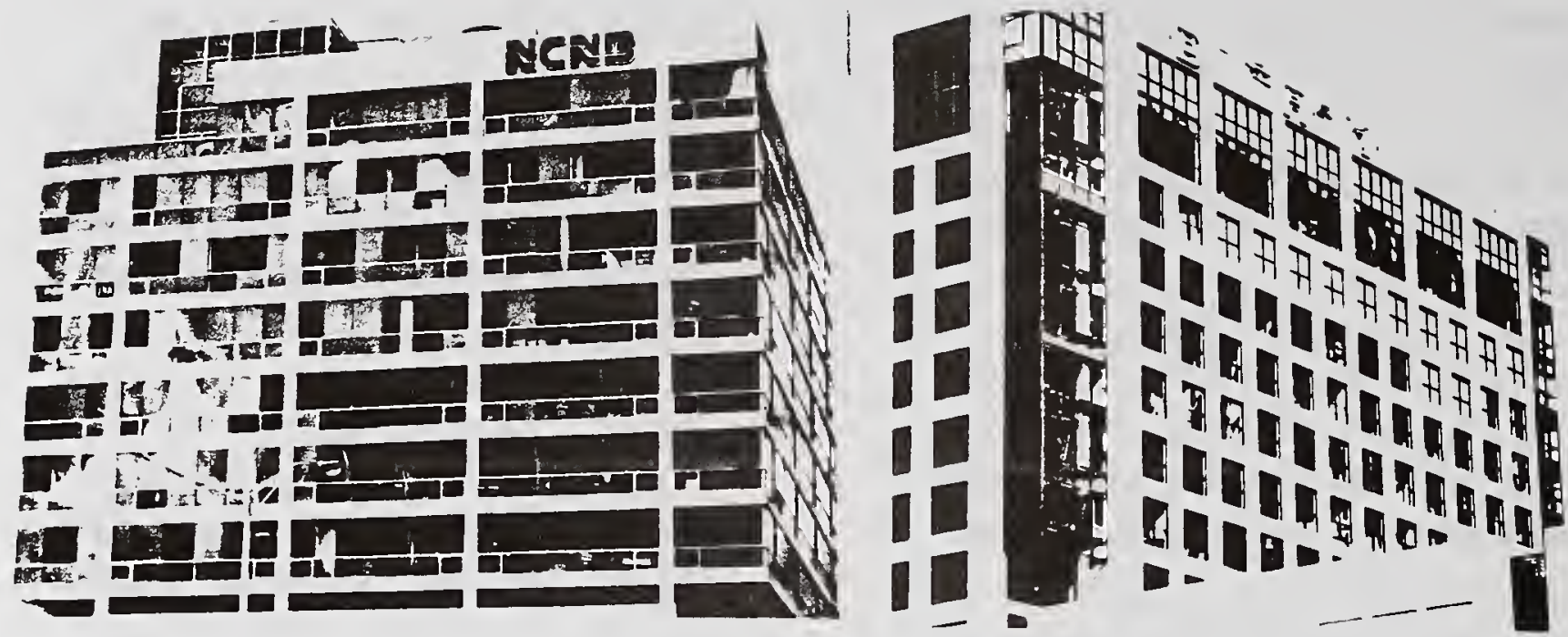

Figure 2. Window Glass Breakage in South Florida (USA) Following Hurricane Andrew in August 1992

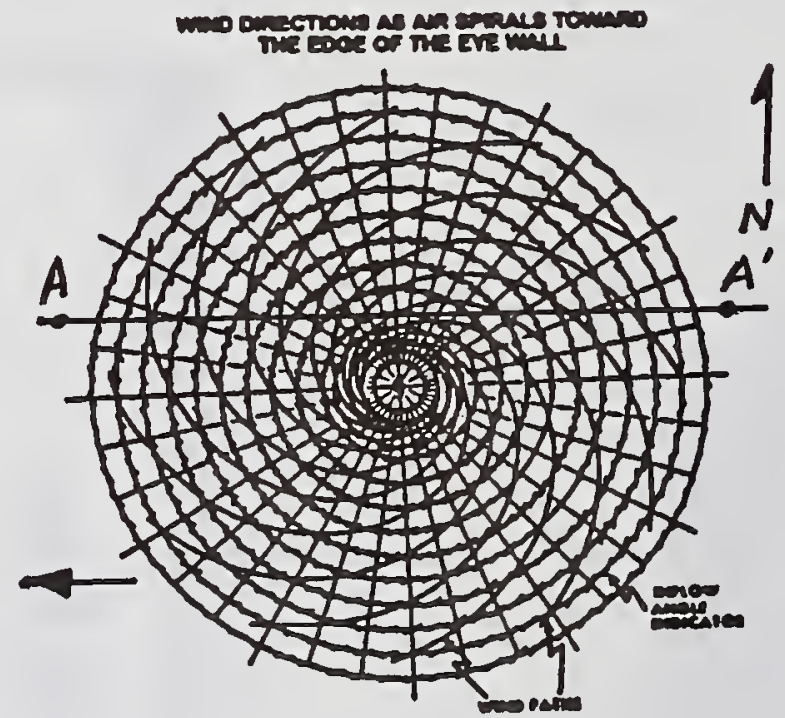

Figure 3. Hurricane Wind Field Showing Winds Spiraling Inward Toward Eye (A building at A will experience slowly changing wind directions from North to Southeast as the hurricane crosses the building from right to left.) 


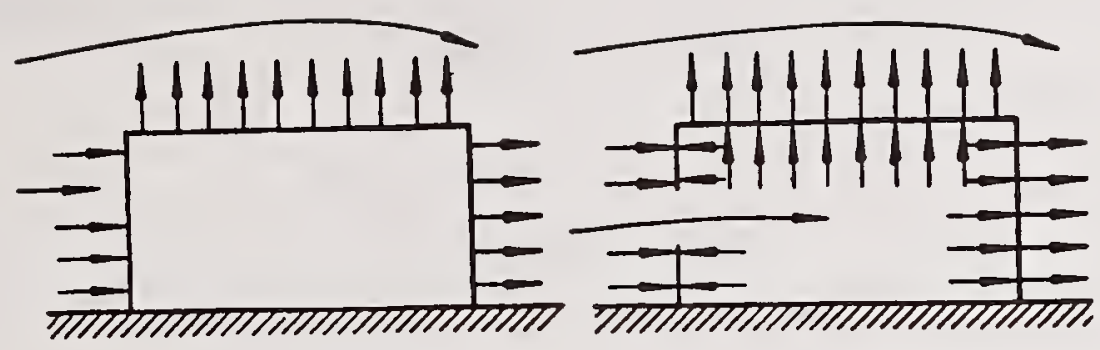

Figure 4. Breaching of the Building Envelope Results in Internal Pressures that can Double Forces Acting to Remove Roof and Push Leeward and Side Walls Outward

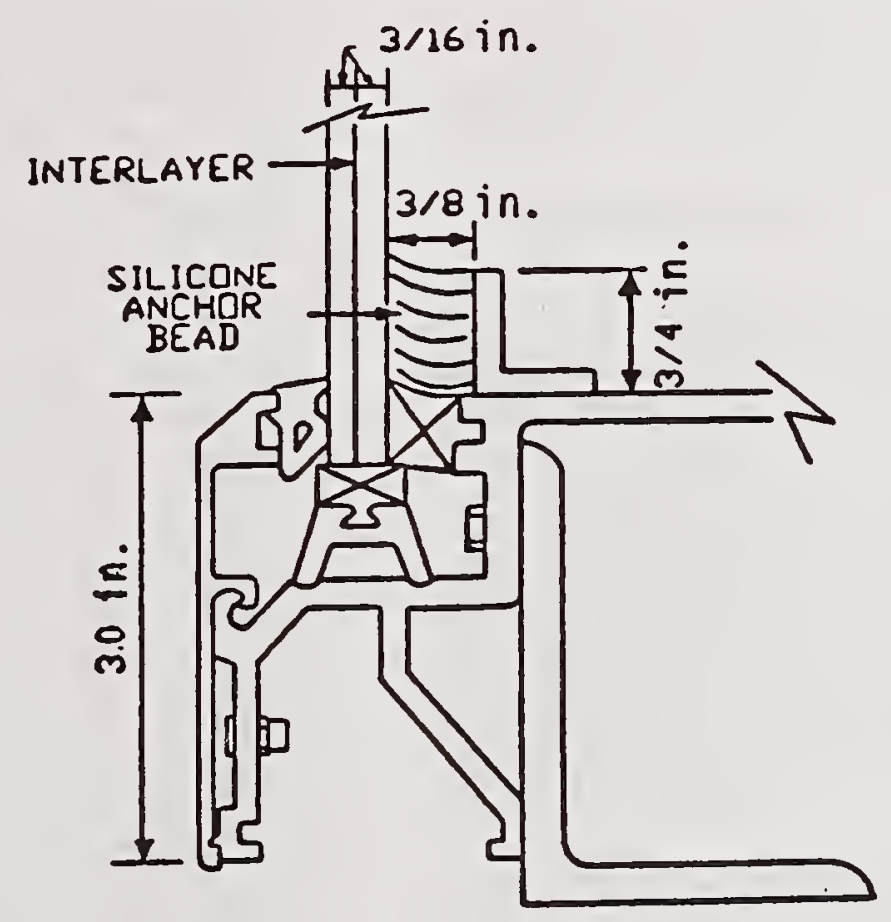

Figure 5. A Laminated Glass Unit that is Anchored to the Window Frame Will Remain in the Opening During Pressures Cycles that Follow Breakage by Windborne Debris

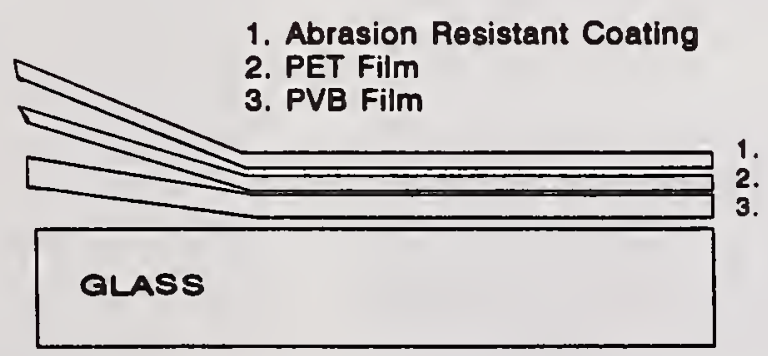

Figure 6. An Innovative Laminated Film that is Factory Applied to Monolithic Glass can Stop Impacts from Windborne Debris and Survive Pressure Cycles that Follow 



\title{
LIQUEFACTION POTENTIAL OF COARSE FOUNDATION MATERIALS: LOST CREEK DAM
}

by

\author{
Ronald A. Oaks'
}

\section{ABSTRACT}

The difficulty in using Standard Penetration Testing (SPT) in coarse grained deposits to determine the existence of potentially liquefiable soils is discussed in this document. As an alternative method of testing these coarse grained soils, a Becker Hammer Penetration Testing (BPT) program was conducted. The various details of conducting this program are discussed. In addition, the use of the Becker Hammer as a penetration testing device is compared with the SPT.

Three layers of potentially liquefiable soils have been identified in the foundation at the downstream toe of Lost Creek Dam. These layers were detected during the Field Exploration Program [1] conducted in 1991. Based on the results of this program, cross canyon continuity of potentially liquefiable layers was assumed. Due to the manner in which the overbank deposits that comprise the alluvial foundation occurred, geologists have reasoned that these liquefiable layers could extend upstream of the dam [2]. If a seismic event occurred in the area of Lost Creek Dam, these foundation soils could liquefy resulting in an upstream and/or downstream failure of the dam and catastrophic release of the reservoir.

This paper presents the geologic explorations performed to identify the layers of potentially liquefiable materials in the foundation of Lost Creek Dam. Only the foundation materials downstream of the dam were explored since exploration in the reservoir was cost prohibitive. The results of the exploration are assumed to apply to the foundation materials upstream of the embankment. The continuity of liquefiable layers (both upstream/downstream and cross canyon) is discussed for the downstream foundation.
The rationale for adjustments and results of two SPT and one Becker Hammer Penetration Test BPT exploration program(s) are presented in this paper. The results of geophysical testing conducted at this site are also presented.

KEYWORDS: site investigation; foundations; liquefaction; Standard Penetration Test; Becker Hammer.

\section{INTRODUCTION}

Lost Creek Dam is located on the western slope of the Wasatch Mountains about 12 miles northeast of Devils Slide, Utah, and 30 miles east of Ogden, shown on figure 1. The dam is situated in a relatively narrow section of Lost Creek Valley about 2,000 feet downstream from the confluence of Lost Creek and Francis Creek, where the valleys of both streams form the reservoir basin. Total reservoir capacity is 22,510 acre-feet at normal pool elevation of 6,005.0 feet. A plan view of Lost Creek Dam is shown on figure 2 .

The embankment of Lost Creek Dam is a zoned earth and rockfill structure with a crest length of 1,110 feet, a crest elevation of 6,022 feet, a crest width of 30 feet, a structural height of 248 feet, and a hydraulic height of approximately $190 \mathrm{feet}$, as shown on figure 3. The embankment was completed by the Bureau of Reclamation (Reclamation) in 1966 and contains approximately 1.8 million $\mathrm{yd}^{3}$ of earthen materials.

Appurtenant structures for Lost Creek Dam consist of an uncontrolled concrete-lined spillway located in the right abutment and an outlet works structure tunneled through bedrock adjacent to the spillway. The spillway has a design capacity of $2,455 \mathrm{ft}^{3} / \mathrm{s}$; the outlet works has a design capacity of $800 \mathrm{ft}^{3} / \mathrm{s}$ at elevation 6015.9. 


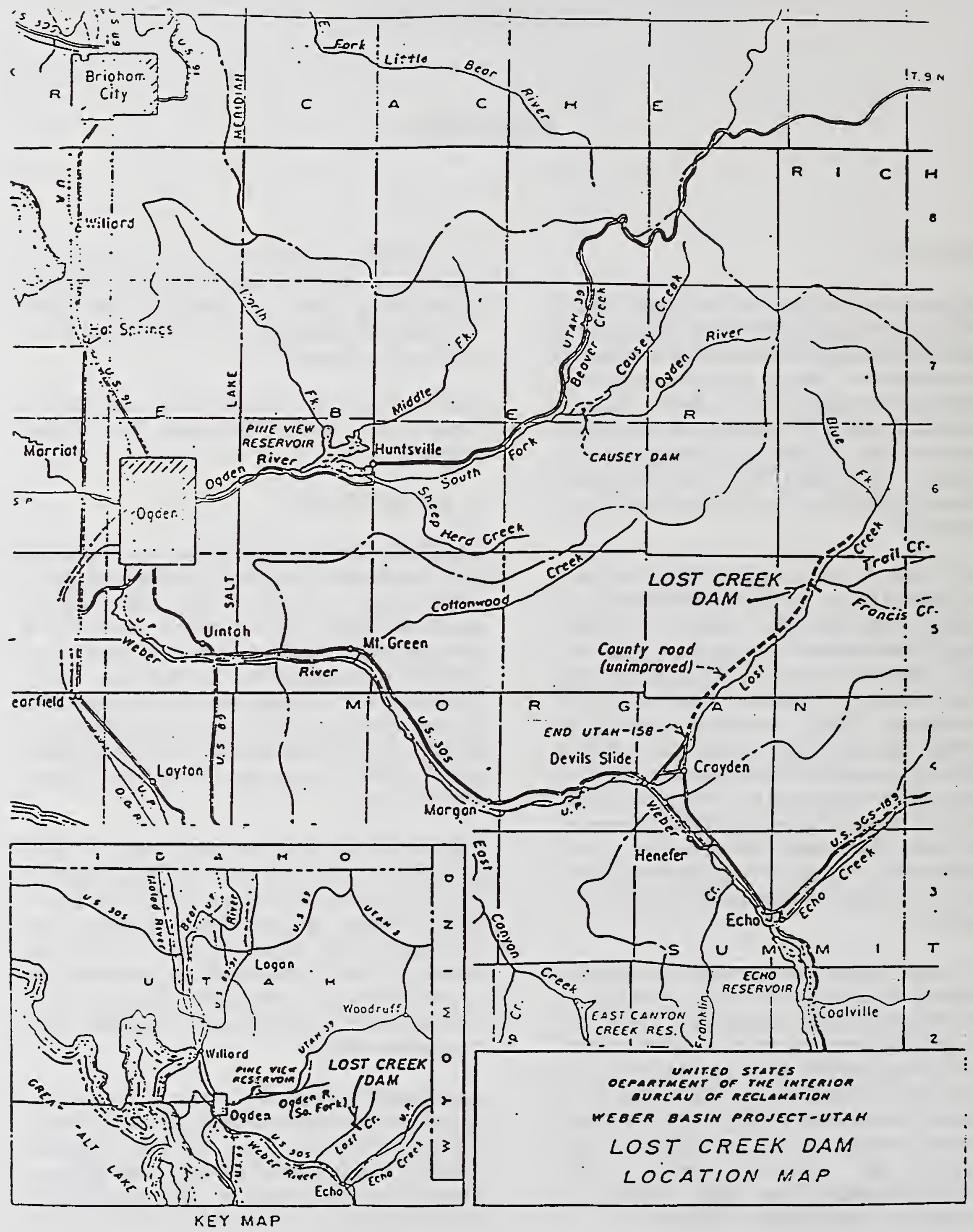

Figure 1. Location Map 


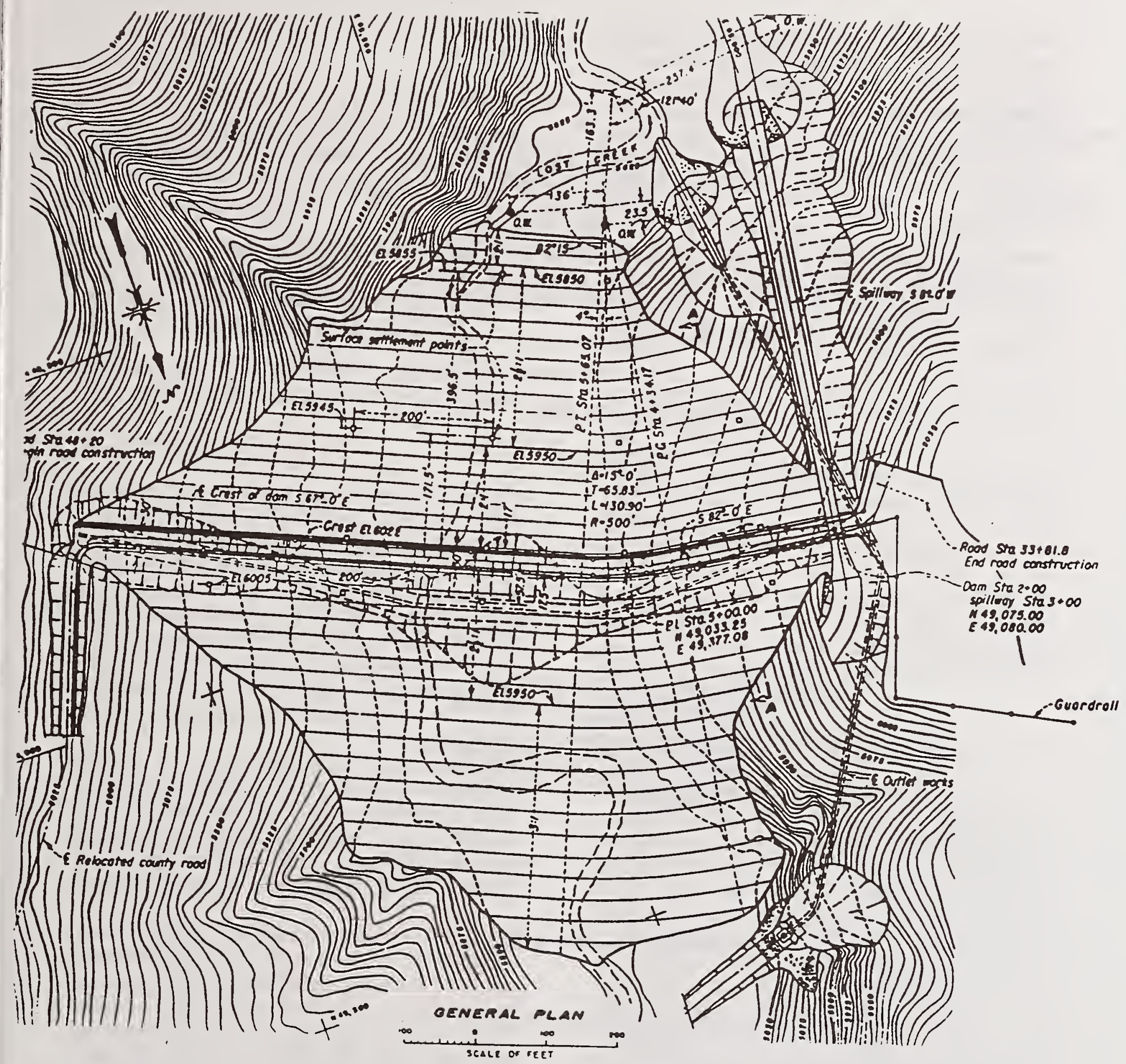

LOST CREEK DAM

Figure 2. Plan View 


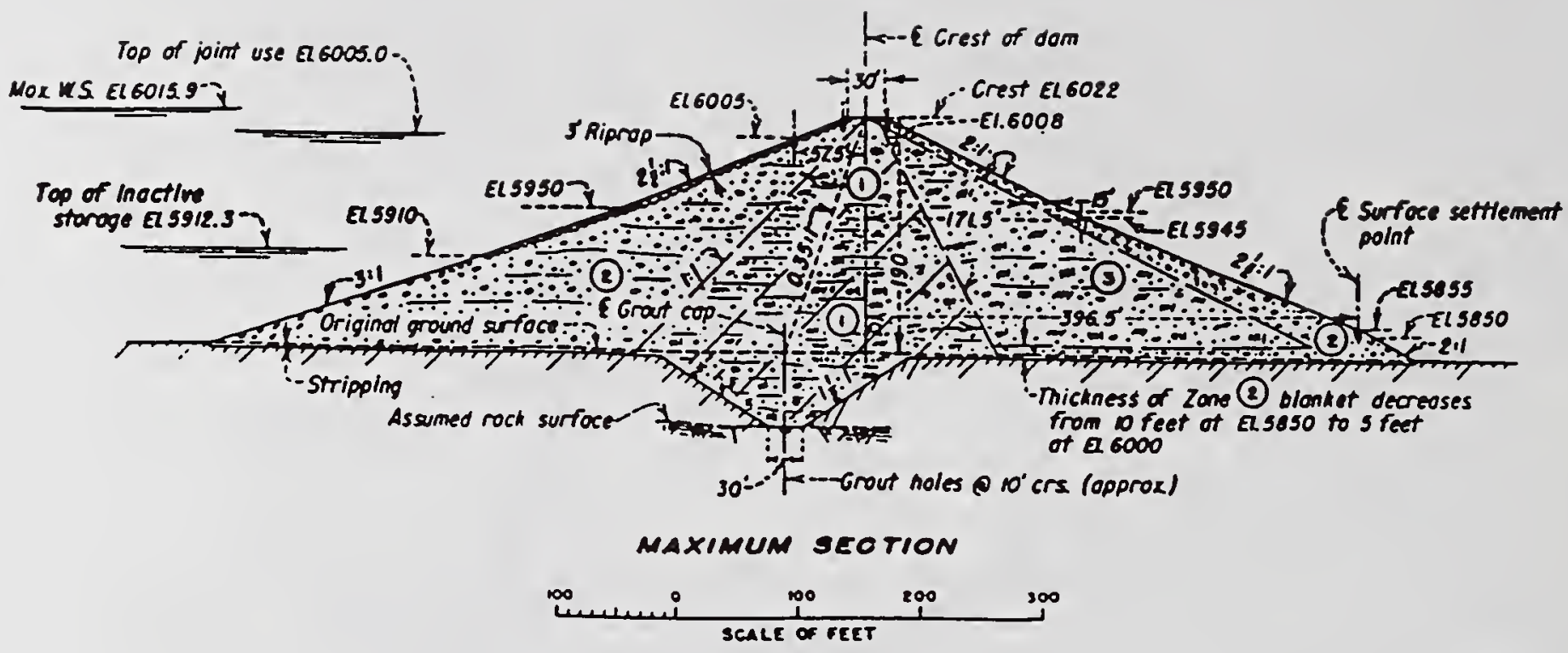

EMOANNMENT EXPLANATION

(1) Selected doy, slt, send, and grovel compocted oy tompling rollers to 6-ineh lovers

(2) Sulected sand grovel, ond cobbles, or ract frogments compocted in re-ineh lojers on crowler the troctor

(3) Miscelloneous dor. $\$ 1 t$, sond, gravel and cobbles, or roek fragments compocted in 1e-inch loyers or onsomatle tired roller

\section{LOST GREEK DAM}

Figure 3. Cross Section of Dam 


\section{GEOLOGY.}

Alluvial deposits, ranging up to 55 feet thick, are present under the shells of the dam, both upstream and downstream. These materials were removed in the dam cutoff trench excavation which extends to bedrock.

Deposits of slopewash and talus are also found beneath the abutment slopes of the dam. These deposits are generally very thin but reach a thickness of up to 20 feet.

The locations of exploration holes used to characterize the foundation are shown on figure 4.

\subsection{Foundation Materials}

A cross section of the geology at the toe of the dam is shown in figure 5. The top horizon of foundation material at the location of the 1991 exploration drill holes at the toe of the dam consists of an approximately 5-foot thick layer of fill material immediately downstream of the embankment at surface elevation 5830.0 . This material consists of angular limestone blocks ranging in size from 3 inches to 2 feet in diameter with minor amounts of sand- and gravel-sized fragments.

Beneath the 5-foot fill material layer, the first potentially liquefiable layer of alluvial material $\left(\mathrm{Qal}{ }_{1}\right)$ is encountered. At the downstream toe it extends from approximate elevation 5825 down to approximate elevation 5821. Material in this layer is classified as silty sand to sandy silt (SM, ML).

The next layer of material encountered is the alluvium (Qal) laid down by Lost Creek. It is located between approximate elevations 5821 and 5813.5. Material in this layer is classified as predominantly poorly graded gravel with silt and sand (GP, GP-GM, SP, SP-SM, SM). Based on limited SPT data and confirmed with the BPT, this layer is not considered to be liquefiable.

From approximate elevation 5813.5 to approximate elevation 5806.5 is another liquefiable layer $\mathrm{Qal}_{2}$. Material in this layer has been classified as sandy silty clay and silty sand (CL-ML, SM). As described above, this is the layer in which the lowest SPT blow counts occurred.
Beneath $\mathrm{Qal}_{2}$ is another layer of the alluvium, Qal. It occurs from approximate elevation 5806.5 down to approximate elevation 5800 . This material has been designated as predominantly poorly graded gravel with sand and cobbles (GP, GP-GM, SP). Based on limited SPT data and confirmed with the BPT, this material is not considered to be liquefiable.

From elevation 5800 to 5780 is a layer designated $\mathrm{Qal}_{3}$. Material in this layer is classified as poorly graded gravel with sand and cobbles (GP, GP-GM, SP). This material was identified as being potentially liquefiable by investigators in 1994 [2].

\section{STANDARD PENETRATION TESTS PERFORMED IN 1991.}

To determine if potentially liquefiable materials were present in the foundation below the downstream toe of Lost Creek Dam, a field exploration program was undertaken as part of Reclamation's Dam Safety process in 1991. SPT's were performed in four test holes, SPT-1 - 4, as shown on figure 4 . They were completed along the toe of the embankment using a Sprague and Henwood skid mounted, rotary drill. This work is documented in reference [1].

\subsection{Adjustments of Raw Blow Counts, SPT 1991.}

The SPT blow counts obtained were adjusted in two ways. First, raw blow counts which appeared to be increasing as the SPT sampler advanced down the hole were plotted on graph paper. An increase in blow counts as the SPT sampler is advanced indicates that a large gravel or cobble sized particle may be lodged in the sampling shoe and that this may be creating more resistance than the SPT shoe. Due to this constriction at the sampling shoe, the blow counts would be artificially high. The cumulative blow counts are therefore plotted versus the cumulative penetration in feet. The data used for this analysis were collected during the drilling program that recorded how many blows were required to advance the SPT sampler each 0.1 foot within the test interval of 1.0 foot. Once the data were plotted, a linear fit was made to that portion of the graph that shows that the blows per tenth are not increasing or are the least erratic. From this linear fit the assumed number of blows that it would have taken to drive the SPT sampler through material 


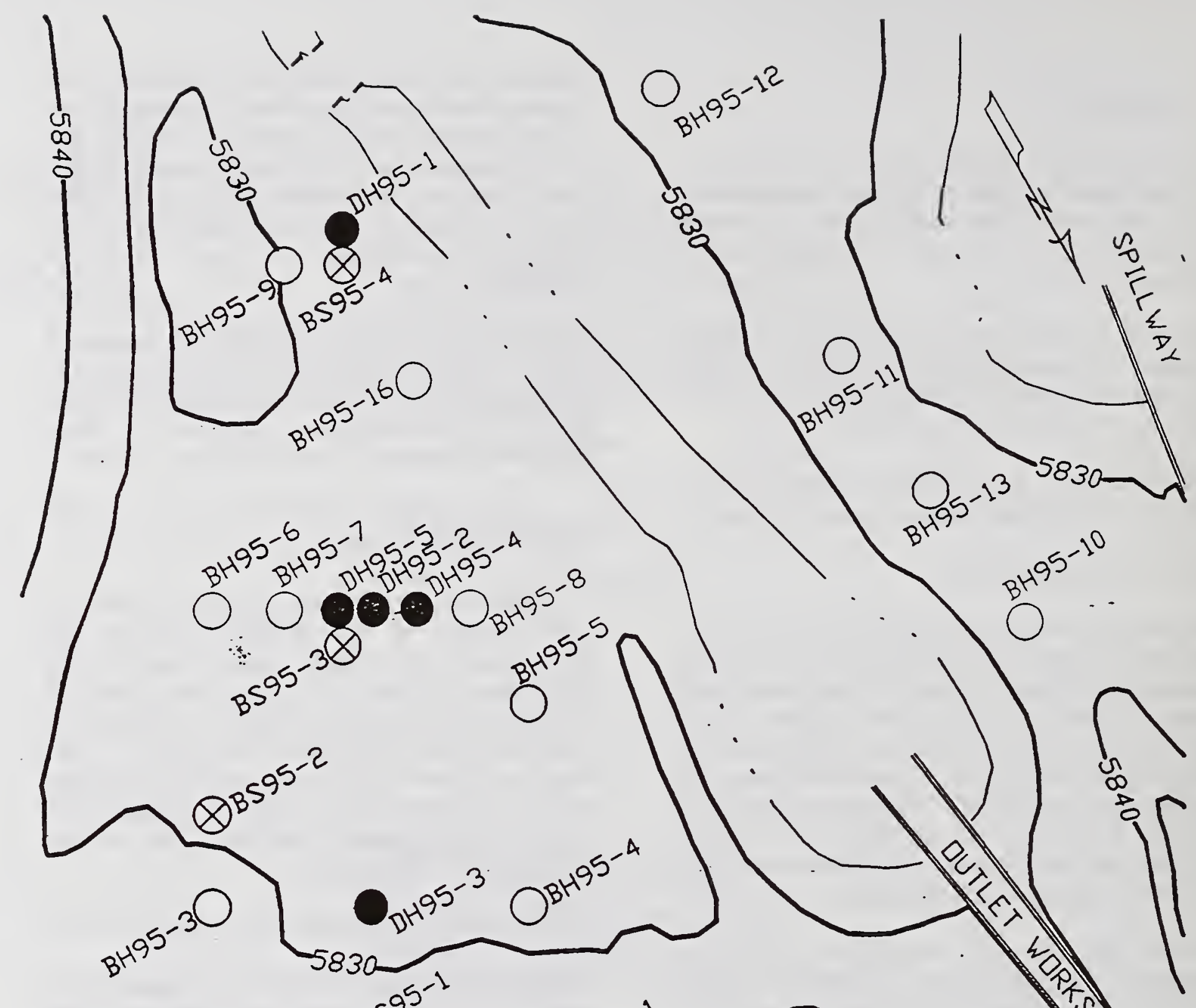

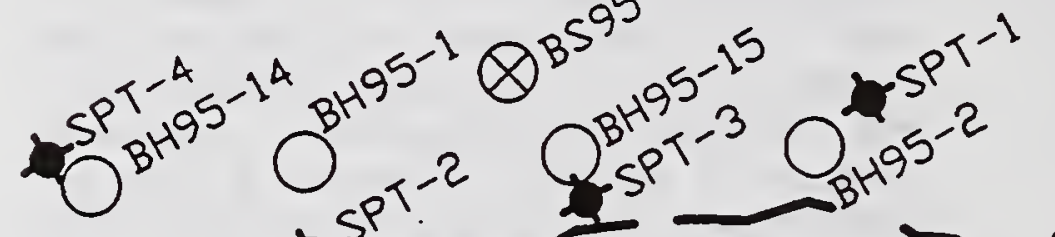

DOWNSTREAM TUE OF LOST CREEK DAM

LIMITS OF DAM-

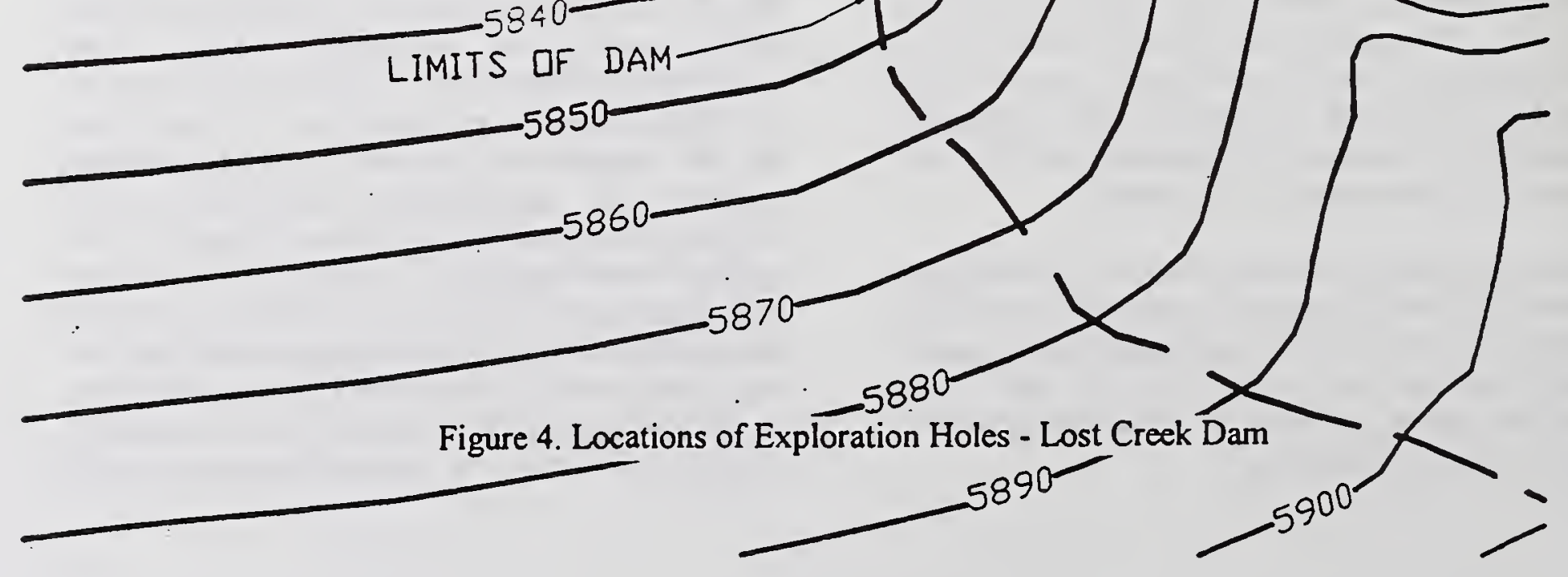




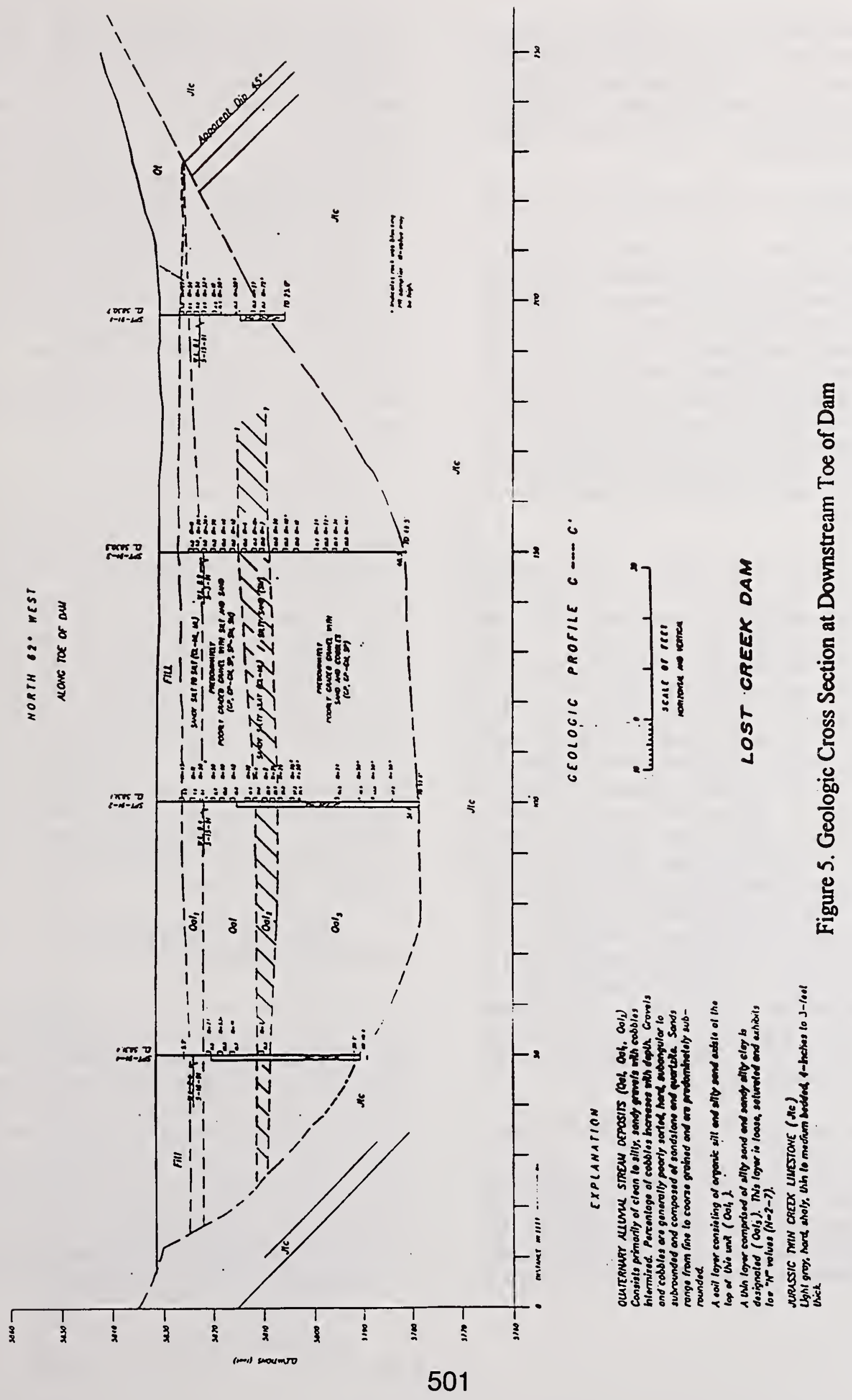


unimpeded by a large gravel or cobble sized particle can be read from the graph by following the linear fit line out to the 1.0 foot mark and reading the corresponding number of blows. The raw data and graphs used in making these adjustments can be found in reference [2].

\subsection{Adjustment to $\mathrm{N}_{1}(60)$ Blow Counts, SPT 1991.}

Once the raw blow counts requiring adjustment as described above have been evaluated, all the blow counts (those requiring adjustment for increased resistance, and those that did not) are entered into a spreadsheet and adjusted to $N_{1}(60)$ blow counts. The process for adjusting these blow counts is outlined in reference [3], and is made based on fines content and effective stress of the material being penetrated by the SPT. The spreadsheet used for performing this adjustment is documented in reference [2] and recreated, for drill hole SPT91-2, as figure 6.

Figure 6 also shows whether a ground motion acceleration $\left(A_{\max }\right)$ of $0.32 \mathrm{~g}$ - the predicted maximum acceleration associated with the Maximum Credible Earthquake (MCE) - will produce liquefaction of the materials tested [3]. This is done by multiplying $N_{1}(60)$ by $0.8 \cdot k_{\alpha} \cdot k_{o}$ to obtain a corrected blow count designated as $\mathrm{N}_{\mathrm{A}}$. The factors $k_{a}$ and $k_{b}$ correct for the initial static shear stress and the overburden stress, respectively. Values for $k_{\alpha}$ and $k_{\alpha}$ were determined as described in reference 3. This new blow count $N_{A}$ is then compared to the blow count $\left(\mathrm{N}_{R}\right)$ below which liquefaction is expected to occur. The required blow counts $\left(\mathrm{N}_{R}\right)$ are developed based on the magnitude of the earthquake, the cyclic stress ratio $\left(\tau_{\text {avg }} / \sigma_{v}{ }^{\prime}\right)$, and the fines content of the layer in which the test is being performed. Once $N_{R}$ is determined, it is compared with $\mathrm{N}_{A}$. If the $\mathrm{N}_{A}$ is less than $N$ then "Yes," that particular layer is subject to liquefaction during the MCE (see fig. 6). If the $\mathrm{N}_{\mathrm{A}}$ is greater than $N_{R}$ then "No," that particular layer is not subject to liquefaction during the MCE.

\subsection{Conclusions Related to the 1991 SPT Program.}

Based on the exploration program performed in 1991, three stratigraphic layers were identified as having potentially liquefiable materials in the foundation of the downstream toe at Lost Creek Dam. These layers have been termed $\mathrm{Qal}_{1}, \mathrm{Qal}_{2}$ and
$\mathrm{Qal}_{3}$, as discussed previously in the Geology Section. These three layers range between approximate depths of 5 to 9 feet, 16.5 to 23.5 feet and 30 feet to bedrock (a maximum of 50 feet deep), respectively, in the alluvial foundation materials downstream of the dam. Due to the large size gravel and cobble particles encountered during the drilling program and the inherent problems of testing these materials with the SPT method, additional drilling and other methods were required to define the potentially liquefiable layers. Of particular interest was the bottom layer, $\mathrm{Qal}_{3}$, in which refusal of the SPT or some indication of increasing blow counts was observed with increasing penetration for the majority of the SPT tests in this layer. The following sections of this paper present methods used to evaluate this situation and identify if these layers are indeed liquefiable.

A triggering analysis was performed in 1994 [4] for Lost Creek Dam based on information from the 1991 exploration program. This analysis was undertaken to provide information for deciding on an interim restriction to the reservoir prior to making remediations to the dam to address the seismic deficiency. Blow counts of 2 and 4 were observed in the $\mathrm{Qal}_{2}$ layer of the foundation. The $A_{\max }$ that would produce liquefaction of the $Q_{21}$ based on the blow counts above, are $0.08 \mathrm{~g}$ and $0.13 \mathrm{~g}$, respectively. The recurrence intervals for seismic events capable of producing ground motions of these magnitudes at Lost Creek Dam were determined to be approximately 79 and 188 years, respectively, showing how sensitive these potentially liquefiable materials would be to a low probability seismic event.

\section{STANDARD PENETRATION TESTS PERFORMED IN 1995.}

As a followup to the SPT's performed in 1991, a second exploration program was undertaken to further define and confirm the upstream/downstream extent of the potentially liquefiable materials at the downstream toe of the embankment. Of particular interest was the continuity of the $\mathrm{Qal}_{1}$ and $\mathrm{Qal}$ layers with the hope of obtaining additional data regarding the potentially lower layer of liquefiable material, Qal . The 1995 program used a Gus Pech II truck mounted drill rig to drill 5 holes, DH95-1 5 as shown on figure 4. SPT's were performed only in drill holes DH95-1 - 3. Drill holes DH95-4 and 


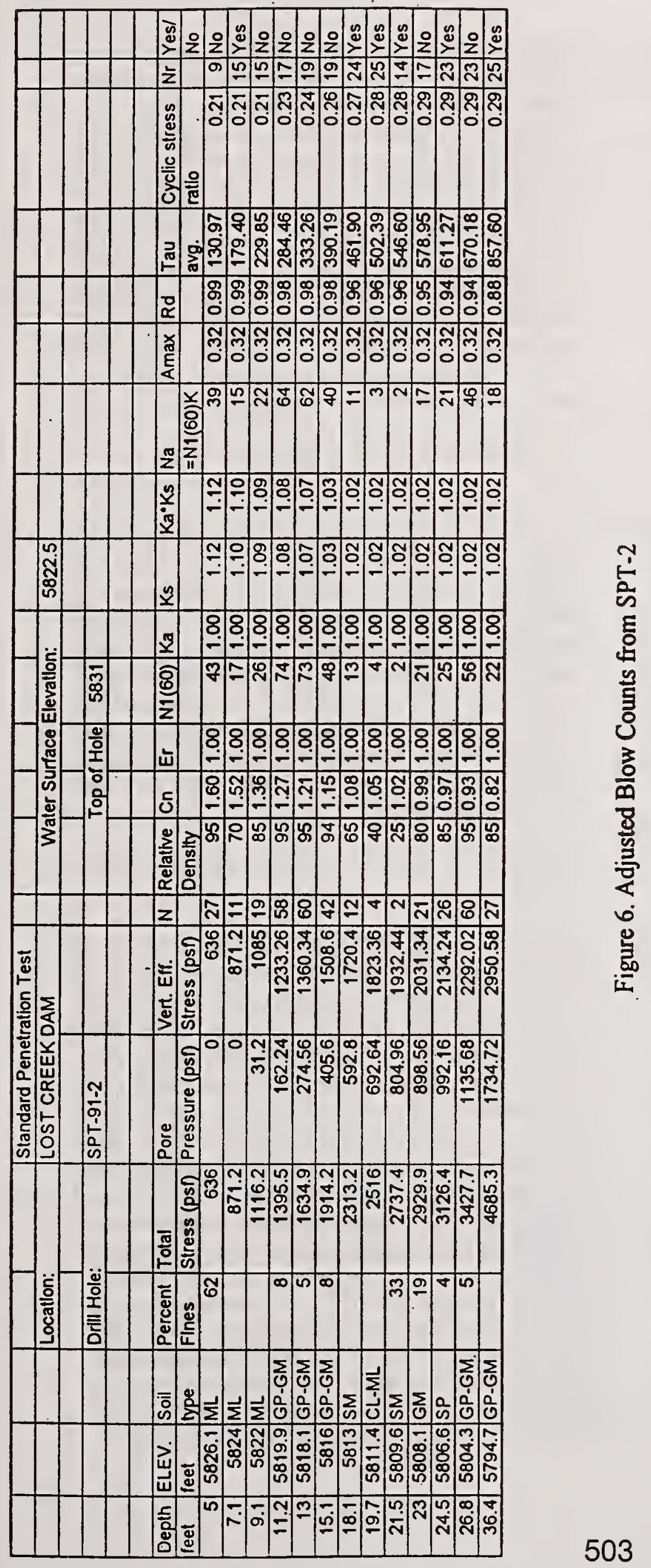


5 were used for the geophysical testing discussed in the subsequent section.

\subsection{Adjustments of Raw Blow Counts, SPT 1995.}

The raw data (penetration per blow) obtained from drill holes DH95-1 - 3 were reviewed and adjustments were made, if required, to reflect the number of blows required to advance the SPT sampler through 1 foot of soil. An example of this data, for one test interval within drill hole DH95-1 is shown on figure 7. Next, the data were adjusted in the same manner as described previously for the exploration program performed in 1991. However, instead of collecting the number of blows required to advance the SPT sampler 0.1 foot, the amount of penetration per blow was recorded. An example of the graphs used for making these adjustments, for an interval of DH95-1, is shown in figure 8.

\subsection{Adjustment to $\mathrm{N}_{1}(60)$ Blow Counts, SPT 1995.}

Since unit weights for the various layers of soil sampled during the 1991 SPT program were determined, a typical soil column was created by averaging the elevations of the stratigraphy (see fig. 4). This soil column was used to calculate the effective stress at the interval where the 1995 SPT had been performed and make an adjustment based on this stress.

Gradation lab testing was performed on materials sampled during the 1995 SPT program. The fines contents of the materials tested were used to adjust the blow counts and perform the analyses as described previously.

Liquefaction, based on an $A_{\max }$ of $0.32 \mathrm{~g}$ for the MCE, for the various materials tested was analyzed using a spreadsheet as described in the section discussing the adjustments to the 1991 exploration program.

\subsection{Conclusions Related to the 1995 SPT Program.}

Due to the nature of the material (some large size gravel and cobble particles) encountered by the SPT, there were quite a few tests where the sampler either could not penetrate or that yielded results less than satisfactory in terms of evaluating the overall strength of the material. These blow counts required a significant amount of interpretation in order to develop a value of blows per foot for certain stratigraphic intervals tested. Based on these reasons, the information obtained from this exploration program was inadequate, for determining if the lower (approximately) 30 feet of the alluvial material in the foundation was potentially liquefiable. The adjusted blow counts from this program, for drill hole DH95-1, are shown in figure 9. As indicated in the conclusions for the 1991 exploration program, a different method(s) was required in order to determine if potentially liquefiable layers within the foundation of Lost Creek Dam, and particularly the lower layer $\left(\mathrm{Qal}_{3}\right)$, were potentially liquefiable.

\section{GEOPHYSICS PERFORMED IN 1995.}

After the SPT testing was completed, all 5 holes were logged geophysically and cross hole geophysics was performed in the triplet of DH95-2, DH95-4, and DH95-5. The Bureau of Reclamation considers shear wave velocities in soils less than $800 \mathrm{ft} / \mathrm{s}$ as potentially liquefiable; 800 to $1200 \mathrm{ft} / \mathrm{s}$ likely not liquefiable, but requires some supporting evidence to rule out liquefaction; and greater than $1200 \mathrm{ft} / \mathrm{s}$, not liquefiable [3]. The results of this work are documented in reference [5] and the resulting velocity versus depth relations are reproduced in figure 10 .

\section{BECKER HAMMER TESTING PERFORMED IN 1995.}

Because the results of the SPT were inconclusive, a Becker Hammer Penetration Testing (BPT) and sampling program was undertaken in October of 1995. The Becker Hammer, when used to perform BPTs, typically uses a 6.6-inch O.D. drill casing and a tapered closed end, crowd-out bit which is driven by a diesel hammer. Blows from the Becker Hammer are recorded in a manner similar to the SPT blows. However, the Becker Hammer allows for continuous penetration tests to be conducted whereas the SPT requires a seating and clean-out interval to be included with each successive penetration test. In addition to reading the number of blows per foot for BPTs, the bounce chamber pressure resulting from the hammer striking the anvil is also recorded to determine the amount of energy imparted to the bit. Adjustments are then made to obtain the normalized BPT blow counts based on bounce chamber pressure and to 


\section{PENETRATION RESISTANCE TESTING [FORM FOR RECORDING PENETRATION-PER-BLOW DATA]}

\begin{tabular}{|l|l|}
\hline PROJECT: & Weber Basin \\
\hline FEATURE: & Lost Creek Dam \\
\hline DATE: & $4 / 8 / 95$ \\
\hline DRILL HOLE: & DH95-1 \\
\hline DRILLER: & Brad Winters \\
\hline SEATING INTERVAL: & 19.0 to 19.5 \\
\hline TESTING INTERVAL: & 19.5 to 20.5 \\
\hline
\end{tabular}

\begin{tabular}{|c|c|c|c|c|c|c|c|c|}
\hline \multicolumn{3}{|c|}{ SEATING } & \multicolumn{3}{|c|}{ TEST } & \multicolumn{3}{|c|}{ TEST } \\
\hline $\begin{array}{c}\text { Blow } \\
\text { No. }\end{array}$ & $\begin{array}{l}\text { Accum. } \\
\text { Penetr. }\end{array}$ & $\begin{array}{c}\text { Penetr. } \\
\text { per } \\
\text { Blow }\end{array}$ & $\begin{array}{c}\text { Blow } \\
\text { No. }\end{array}$ & $\begin{array}{l}\text { Accum. } \\
\text { Penetr. }\end{array}$ & $\begin{array}{c}\text { Penetr. } \\
\text { per } \\
\text { Blow }\end{array}$ & $\begin{array}{l}\text { Blow } \\
\text { No. }\end{array}$ & $\begin{array}{l}\text { Accum. } \\
\text { Penetr. }\end{array}$ & $\begin{array}{c}\text { Penetr. } \\
\text { per } \\
\text { Blow }\end{array}$ \\
\hline 1 & 0.48 & & 8 & 0.53 & 0.03 & 24 & 1.08 & 0.04 \\
\hline 2 & 0.14 & 0.06 & 9 & 0.55 & 0.02 & 25 & 1.11 & 0.03 \\
\hline 3 & 0.22 & 0.08 & 16 & 0.58 & 0.03 & 26 & 1.15 & 0.04 \\
\hline 4 & 0.3 & 0.08 & 14 & 0.61 & 0.03 & 27 & 1.19 & 0.04 \\
\hline 5 & 0.35 & 0.05 & 12 & 0.64 & 0.03 & 28 & 1.21 & 0.02 \\
\hline$\underline{6}$ & 0.48 & 0.13 & 13 & 0.69 & 0.02 & 26 & 1.23 & 0.02 \\
\hline 7 & 0.5 & 0.02 & 14 & 0.69 & 0.03 & 39 & 1.26 & 0.03 \\
\hline & & & 15 & 0.71 & 0.02 & 31 & 1.23 & 0.03 \\
\hline & & & 16 & 0.74 & 0.03 & 32 & 1.31 & 0.02 \\
\hline & & & 17 & 0.77 & 0.03 & 38 & 1.34 & 0.03 \\
\hline & & & 18 & 0.81 & 0.04 & 31 & 1.36 & 0.02 \\
\hline & & & 19 & 0.83 & 0.02 & 39 & 1.36 & 0.02 \\
\hline & & & 20 & 0.9 & 0.07 & 39 & 1.4 & 0.02 \\
\hline & & & 21 & 0.95 & 0.05 & 37 & 1.41 & 0.01 \\
\hline & & & 22 & 0.99 & 0.04 & 38 & 1.43 & 0.02 \\
\hline & & & 23 & 1.04 & 0.05 & 39 & 1.44 & 0.01 \\
\hline & & & & & & 40 & 1.46 & 0.02 \\
\hline & & & & & & 41 & 1.47 & 0.01 \\
\hline & & & & & & 42 & 1.43 & 0.02 \\
\hline & & & & & & 43 & 1.5 & 0.01 \\
\hline & & & & & & & & \\
\hline & & & & & & & & \\
\hline & & & & & & & & \\
\hline & & & & & & & & \\
\hline & & & & & & & & \\
\hline
\end{tabular}

Figure 7. Raw Data from DH95-1 


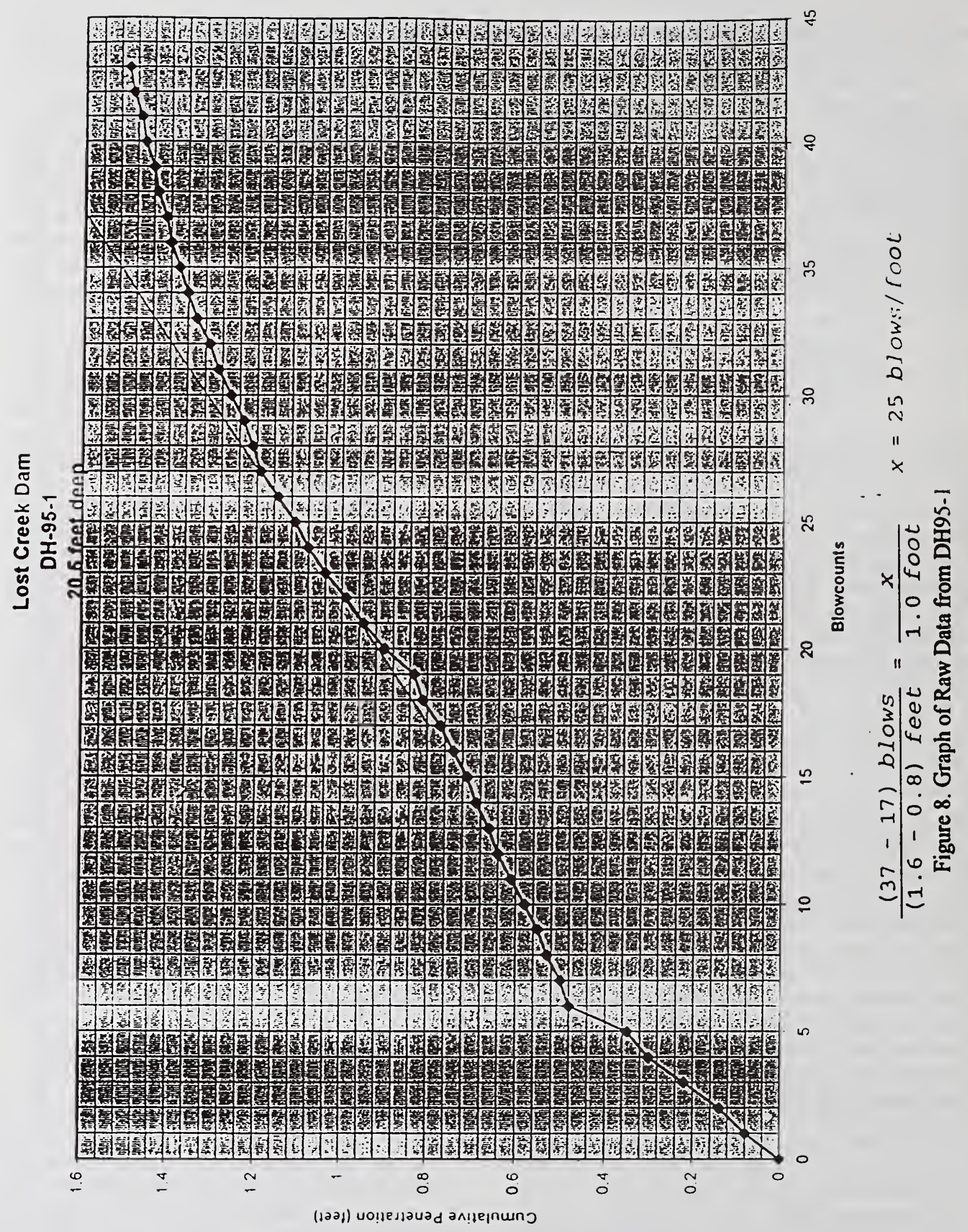




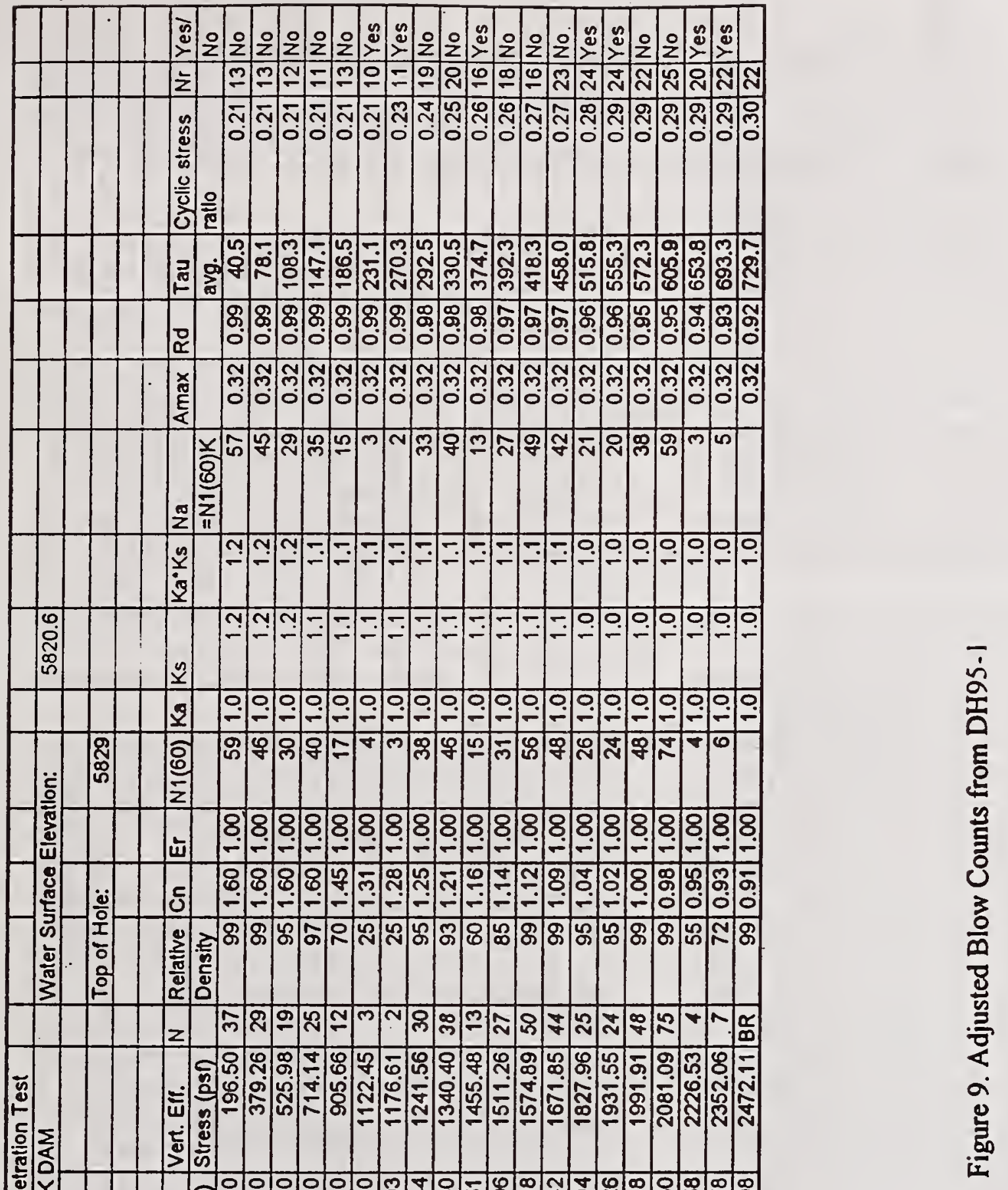

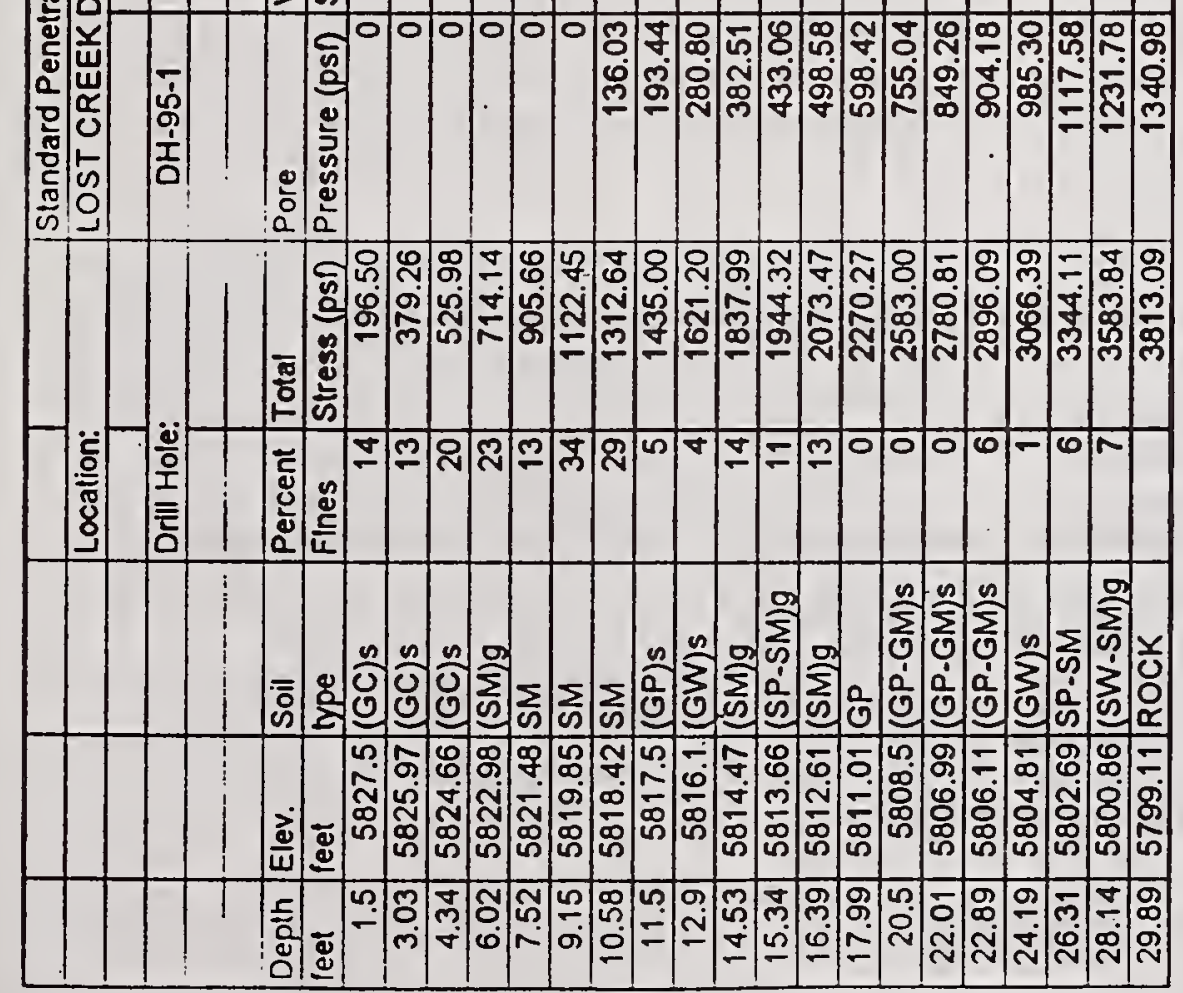


LOST CREEK DAM, UT

CROSSHOLE S-WA.VE VELOCITY PROFILE - Expanded Scale DOWNSTREAM TOE

$\mathrm{DH}-95-5 \times-2 \times-4$

S-WAVE VELOCITY $(1 t / s)$

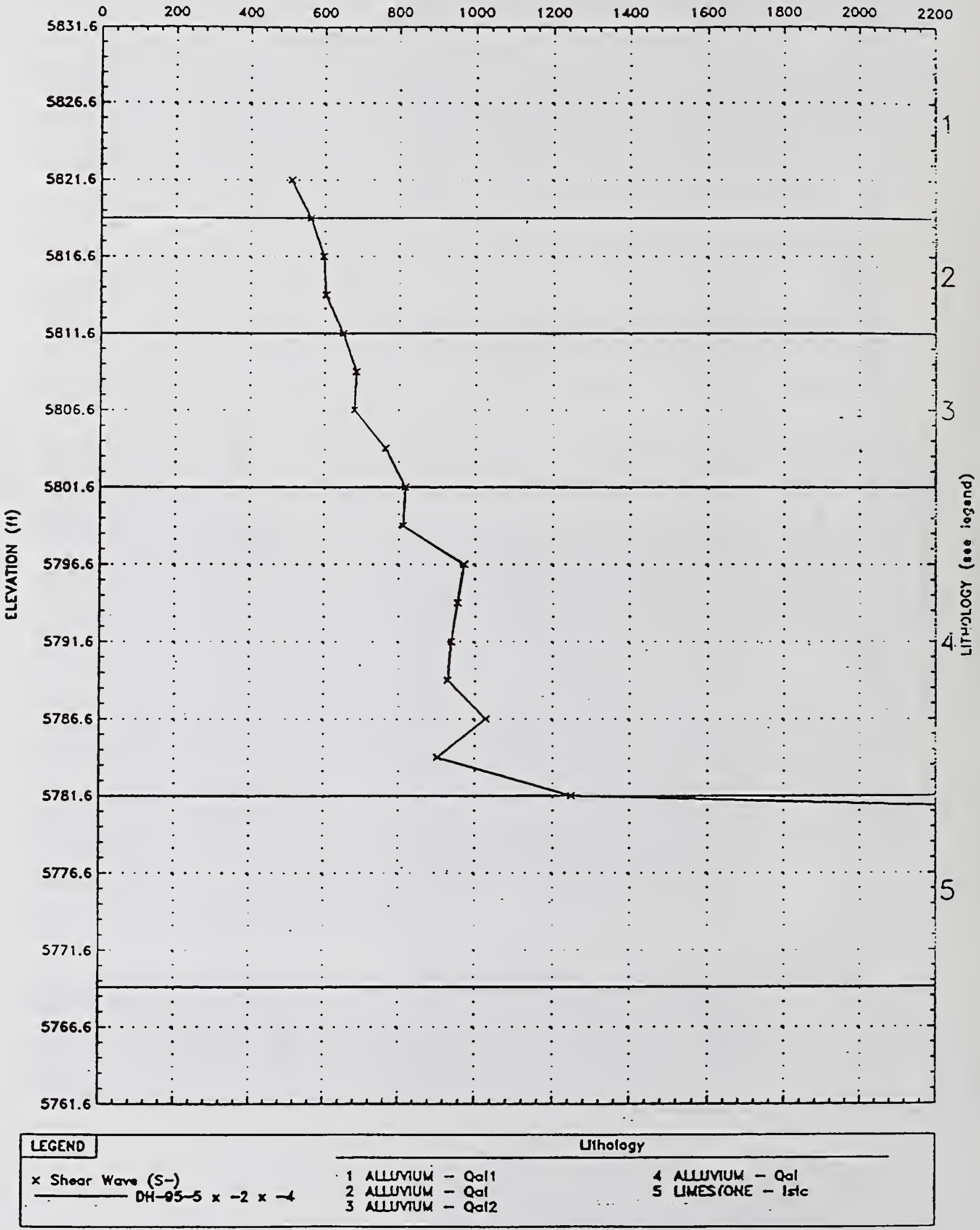

Figure 10. Geophysical Survey 
compensate for the difference in pressure due to the increase in elevation above sea level [6]. Once the BPT data have been adjusted, adjustments to correlate the data to SPT $N_{1}(60)$ blow counts can be made [6].

The blow count and bounce pressure chamber data is recorded using an automated data logger. The data logger is necessary because the blows are occurring at a rate of 1 blow about every 0.5 seconds, and it allows for the gathering of blows and bounce chamber pressures in an orderly and organized fashion. The data acquisition process is not completely automated since an operator is required to enter a "flag" into the data when the operator observes that the drill string of the BPT has been advanced one foot. The process for doing this is to mark graduated increments of 1 foot on the drill casing with chalk each time a new joint is added. Then these 1 foot increments are easily discernable by the data logger operator.

Sampling, using the Becker Hammer, is conducted using the same drill casing or pipe as is used for BPT. However, a 6.6-inch O.D., opened ended, crowd-in bit is used for sampling. Samples are obtained by advancing the bit into the material and introducing compressed air to the bit via the double walled drill pipe. The compressed air is directed between the outer and inner walls of the drill pipe to the bit and the sample is lifted and carried up through the inner annulus of the drill pipe. At this point the inner drill pipe, and thus the sample, exits to a cyclone so that the compressed air does not scatter the sample and any associated groundwater. The energy used to transport the sample is dissipated in the cyclone and the sample drops out of the bottom and is collected in a rubber tub where it is visually classified and then sampled and bagged for lab classification.

An AP-1000 Becker Hammer Drill Rig built by Drill Systems Inc. and owned and operated by Great West Drilling was used to perform BPT's in 16 holes and drill four Becker Hammer sample holes in the foundation downstream of Lost Creek Dam. The locations of the 16 penetration tests, BH95-1 16 , and four sample holes, BS95-1 - 4, are shown on figure 4.

6.1 Adjustments of Raw Blow Counts, BPT 1995.
As a check to the data logger, blow counts were also manually counted and recorded on data sheets for later comparisons to the record of the data logger. An example of this data for Becker Penetration Test Hole BH-95-8 is shown in figure 11. In addition, a pressure gauge was connected to the bounce chamber and maximum bounce chamber pressures were observed and recorded as a check against the data logger. From this data it was found that errors in the number of blow counts were introduced into the data before commencing drilling at a neu hole and when a new drill casing joint was added. These errors appeared to have been introduced into the data logger record when pressure reversals in the bounce chamber occurred during the addition of a new joint of drill casing or the lowering of the anvil back over the new joint and entire drill string.

A discussion with the designer of the data logger was held. These discussion uncovered that apparently additional errors were introduced when the diesel hammer "fires" but does not create a pressure reversal of at least $1 \mathrm{psi}$ in the bounce chamber. Errors in the blow count recorded by the data logger can also be introduced when the pressure in the bounce chamber never exceeds the 5 psi threshold pressure for counting a blow. These errors were fairly apparent due to the lower pressures observed in the data record (see fig. 11).

Manually recorded data which had a larger number of blow counts than those recorded by the data logger could be checked by looking at a detailed time related record of each individual blow. During times in the procedure when blows were recorded by the data logger in time intervals greater than .75 seconds, it was assumed that the data logger missed the number of blow counts it took to make up the time interval recorded. After making this adjustment to the data logger data, the total number of blow counts was typically in agreement with the number of blow counts that had been recorded manually.

If errors of the types described above were observed, the data was corrected to one of the manually observed blow counts or an average thereof, whichever was considered more appropriate based on the preceding and succeeding interval blow counts. 


\begin{tabular}{|c|c|c|c|c|c|c|c|c|c|c|}
\hline \multicolumn{11}{|c|}{ BH95-8 } \\
\hline & & & & & & & & & & \\
\hline Depth & Elevation $\bar{c}$ & Dalalog & Manual 1 & Manual 2 & & Datalog & Manual & & & \\
\hline & $5829.1 \mathrm{E}$ & Blow Os. & Btow Cls. & Blow Cls. & Diff. > 5 & \begin{tabular}{|l|} 
Prossure \\
\end{tabular} & Pressure & Din. > 2 & Adjust. & $N_{1}(60)$ \\
\hline 1 & 5828.1 & 122 & \begin{tabular}{|r|}
120 \\
\end{tabular} & 114 & 2 & $\begin{array}{r}7 \\
7\end{array}$ & 7 & & & 28 \\
\hline 2 & 5827.1 & 33 & 32 & 32 & & 721 & 6 & & & 15 \\
\hline 3 & 5826.1 & 5 & 11 & 13 & 182 & 5202 & 5 & & & 5 \\
\hline 4 & 5825.1 & 11 & 14 & 12 & & 5.86 & 6 & 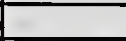 & & 8 \\
\hline 5 & 5824.1 & 21 & 21 & 21 & & 6.098 & 6 & & & 11 \\
\hline 6 & 5823.1 & 18 & 16 & 16 & & 5.596 & 6 & & & 10 \\
\hline 7 & 5822.1 & 10 & 11 & 12 & & 5.166 & 5 & & & 7 \\
\hline 8 & 5821.1 & 14 & 15 & 14 & & 5.600 & 6 & & & 8 \\
\hline 9 & 5820.1 & 20 & 22 & 22 & & 6.371 & 7 & & & 10 \\
\hline 10 & 5819.1 & 10 & 11 & 12 & & 5.717 & 6 & & & 7 \\
\hline 11 & 5818.1 & 1 & 11 & 9 & 182 & 5.056 & 4 & & $10_{p}$ & 6 \\
\hline 12 & 5817.1 & 0 & 9 & 9 & 122 & 0 & 7 & & 96 & 0 \\
\hline 13 & 5816.1 & 4 & 10 & 11 & 182 & 5.726 & 7 & & $10_{b}$ & 7 \\
\hline 14 & 5815.1 & 4 & 4 & 41 & & 8.8 & 9 & & & 14 \\
\hline 15 & 5814.1 & 52 & 52 & 51 & & 9.34 & 9 & & & 17 \\
\hline 16 & 5813.1 & 31 & 32 & 34 & & 9.44 & 9 & & & 13 \\
\hline 17 & 5812.1 & 39 & 38 & 36 & & 9.43 & 9 & & & 14 \\
\hline 18 & 5811.1 & 27 & 27 & 28 & & 9.61 & 8 & & & 11 \\
\hline 19 & 5810.1 & 22 & 23 & 24 & & 9.52 & 10 & & & 11 \\
\hline 20 & 5809.1 & 41 & 18 & 19 & 182 & 6.933 & 9 & YES & 18 & 8 \\
\hline 21 & 5808.1 & 20 & 20 & 19 & & 9.3 & 9 & & & 10 \\
\hline 22 & 5807.1 & 24 & 24 & 27 & & 9.25 & 10 & & & 10 \\
\hline 23 & 5806.1 & 29 & 29 & 30 & & 9.59 & 10 & & & 10 \\
\hline 24 & 5805.1 & 63 & 53 & 40 & 182 & 10.08 & 11 & & 40 & 15 \\
\hline 25 & 5804.1 & 60 & 53 & 46 & 122 & 10.44 & 11 & & $46 \infty$ & 15 \\
\hline 26 & 5803.1 & 26 & & 43 & 122 & 10.81 & 11 & & 43 & 17 \\
\hline 27 & 5802.1 & 8 & 45 & 39 & 182 & 10.76 & 11 & & 390 & 16 \\
\hline 28 & 5801.1 & 46 & 40 & 38 & 182 & 10.66 & 11 & & 38 & 15 \\
\hline 29 & 5800.1 & 32 & 39 & 29 & 1 & 10.3 & 11 & & & 12 \\
\hline 30 & 5799.1 & 30 & 26 & 26 & & 9.11 & 10 & & & 10 \\
\hline 31 & 5798.1 & 33 & 34 & 34 & & 10.61 & 10 & & & 14 \\
\hline 32 & 5797.1 & 43 & 4 & 4 & & 11.08 & 12 & & & 15 \\
\hline 33 & 5796.1 & 63 & 62 & 63 & & 11.41 & 12 & & & 22 \\
\hline 34 & 5795.1 & 65 & 57 & 57 & 122 & 12.25 & 13 & & & 25 \\
\hline 35 & 5794.1 & 59 & 66 & 62 & 1 & 12.44 & 13 & & & 24 \\
\hline 36 & 5793.1 & 71 & 67 & 65 & 2 & 12.88 & 13 & & & 27 \\
\hline 37 & 5792.1 & 68 & 71 & 69 & & 132 & 14 & & & 27 \\
\hline 38 & 5791:1 & 60 & 61 & 64) & & 12.52 & 13 & & & 23 \\
\hline 39 & 5790.1 & 62 & 62 & 61 & 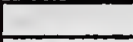 & 13.49 & 14 & & & 26 \\
\hline 40 & 5789.1 & 75 & 69 & 69 & $1 \& 2$ & 12.1 & 14 & & $69_{i}$ & 22 \\
\hline 41 & 5788.1 & 74 & 75 & 71 & & 13.11 & 14 & & & 28 \\
\hline 42 & 5787.1 & 80 & 79 & 73 & 2 & 13.66 & 14 & & & 29 \\
\hline 43 & 5786.1 & 78 & 79 & 84 & 2 & 1425 & 15 & & & 30 \\
\hline 44 & 5785.1 & 98 & 98 & 99 & & 15.18 & 16 & & & 35 \\
\hline 45 & 5784.1 & 235 & 119 & 116 & 182 & 16.07 & 17 & & $118 \ldots$ & 45 \\
\hline 46 & 5783.1 & 7 & 100 & 103 & 182 & 15.59 & 16 & & 101 os & 35 \\
\hline 47 & 5782.1 & 47 & 70 & 67 & 182 & 15.44 & 16 & & $69 \infty$ & 29 \\
\hline 48 & 5781.1 & 89 & 88 & 91 & & 16.06 & 17 & & & 35 \\
\hline 49 & 5780.1 & 139 & 140 & 141 & & 16.77 & 18 & & & 48 \\
\hline 50 & 5779.1 & 187 & 174 & 172 & 182 & 14.3 & 16 & & $173 n$ & 44 \\
\hline 51 & 5778.1 & 108 & 105 & 106 & & 14.77 & 16 & & & $30^{\circ}$ \\
\hline 52 & 5777.1 & 84 & 83 & 80 & & 15.48 & 17 & & & 31 \\
\hline 53 & 5776.1 & 104 & 107 & 110 & 2 & 16.55 & 17 & & & 40 \\
\hline 54 & 5775.1 & 146 & 147 & 145 & & 16.88 & 17 & & & 51 \\
\hline 55 & 5774.1 & 319 & 312 & 274 & 182 & 18.27 & 20 & & & 116 \\
\hline 56 & 5773.1 & 203 & 203 & 281 & 2 & 19.43 & 20 & & & 88 \\
\hline & & & & & & & & & & \\
\hline Ip - low pres & ssure revers & al bolow the & othreshold & pressure d & letected b & 6 data logg & ger & & & \\
\hline ob-operato & or blunder re & elated to the & eperation o & of the data & logger & & & & & \\
\hline nj- new joir & nt of drill cas & sing creating & g additional & blows relat & ted to the & dition of the & e casing & & & \\
\hline
\end{tabular}

Figure 11. Corrections to Raw Becker Penetration Data - Lost Creek Dam 
During the tests there were several occasions where operator blunders were made in setting the "foot mark flag" in the data logger. On some occasions this occurred because it was difficult distinguishing the foot marks on the drill casing. On other occasions the foot marker was pushed and since there is a 1 second lag before the data logger display registers that foot, it was pushed a second time resulting in an error. These errors only occurred a few times, and when they did a note was made in the manual record of what had transpired. This situation was rectified by checking the manual count and adjusting the logger data based on that count and the blow counts of the preceding and succeeding soil interval blow counts. All of the adjustments discussed above have been denoted in a sample of those tables in figure 11 based on the reason for adjustment.

\subsection{Adjustment to Normalized Blow Counts, BPT} 1995.

As discussed above, BPT blow counts are adjusted to normalized BPT blow counts to compensate for the effects of changes in bounce chamber pressures and to account for the pressure difference introduced by performing a test at an elevation other than sea level. BPT blow counts must be converted to an equivalent blow count under atmospheric pressures at sea level since all of the data related to correlating BPTs to SPT have been developed based on this condition. A spreadsheet was set up to perform this correction. An example of this spreadsheet, for test hole BH95-8, is shown in figure 12. The correction is performed based on empirical data developed by Seed and Harder [6].

\subsection{Adjustment to $\mathrm{N}_{1}(60)$ Blow Counts, BPT 1995.}

Once the correction for the difference in atmospheric pressure from sea level has been performed, the BPTs are correlated to SPTs in the spreadsheet based on procedures developed by Seed and Harder [6]. After the BPTs have been converted to SPTs the same process of adjusting blow counts as previously referenced in the discussion on SPT is used to arrive at an $N_{1}(60)$ blow count. Since the BPTs are performed with a closed end bit and yield no information regarding the material encountered, the typical soil column discussed in the 1995 SPT exploration program was used to make adjustments based on effective stress.

\subsection{Conclusions Related to the 1995 BPT Program.}

Results of the Becker Hammer BPT exploration program confirmed the existence of potentially liquefiable layers identified as $\mathrm{Qal}_{1}$ and $\mathrm{Qal}{ }_{2}$ within the foundation of Lost Creek Dam. The program also obtained credible blow counts for the layer identified as $\mathrm{Qal}_{3}$ existing in the bottom 30 feet of the alluvial foundation of Lost Creek Dam. The adjusted blow counts in the $\mathrm{Qal}_{3}$ reveal the existence of potentially liquefiable material in this layer.

Sampling with the Becker Hammer yielded continuous samples of material which were as expected based on previous sampling done during the SPT explorations. However, there was one unusual occurrence of a very clean gravel being recovered in BS95-1 at depth of 38 to 40 feet, which was not consistent with what had been sampled in the other SPT or Becker Sample holes. One drawback to sampling with the Becker Drill is that material is transported up the inner annulus of the drill string using high pressure air, and it is therefore not exactly an in-place sample and is definitely not an undisturbed sample. However, when contrasting the Becker Drill samples with SPT samples, the Becker Drill is capable of returning particles over 4 inches in maximum dimension. The SPT is restricted to sampling coarse grained material smaller than the 1.5 inch diameter opening of the sampling shoe. After discussions with the Becker Drill operator and after observing the drill sampling, it was concluded that the Becker Drill has sufficient pressure to return almost any material in a timely manner, and segregation of samples is not a concern.

\section{CONCLUSIONS.}

The results of corrected $N_{1}(60)$ blow counts from all three exploration programs (SPT 1991, SPT 1995, and BPT 1995) have been grouped together based on the close proximity to each other as shown on figure 4. These blow counts were then tabulated by elevation, as shown on figure 13. The results of this study shows that in some cases there is correlation among blow counts and in other cases there is not. Each of these holes may encounter a large gravel particle, cobble, or boulder, thus resulting in a high blow count as discussed previously. The SPTs are probably going to be more sensitive to such an occurrence, but even the BPT would probably be 


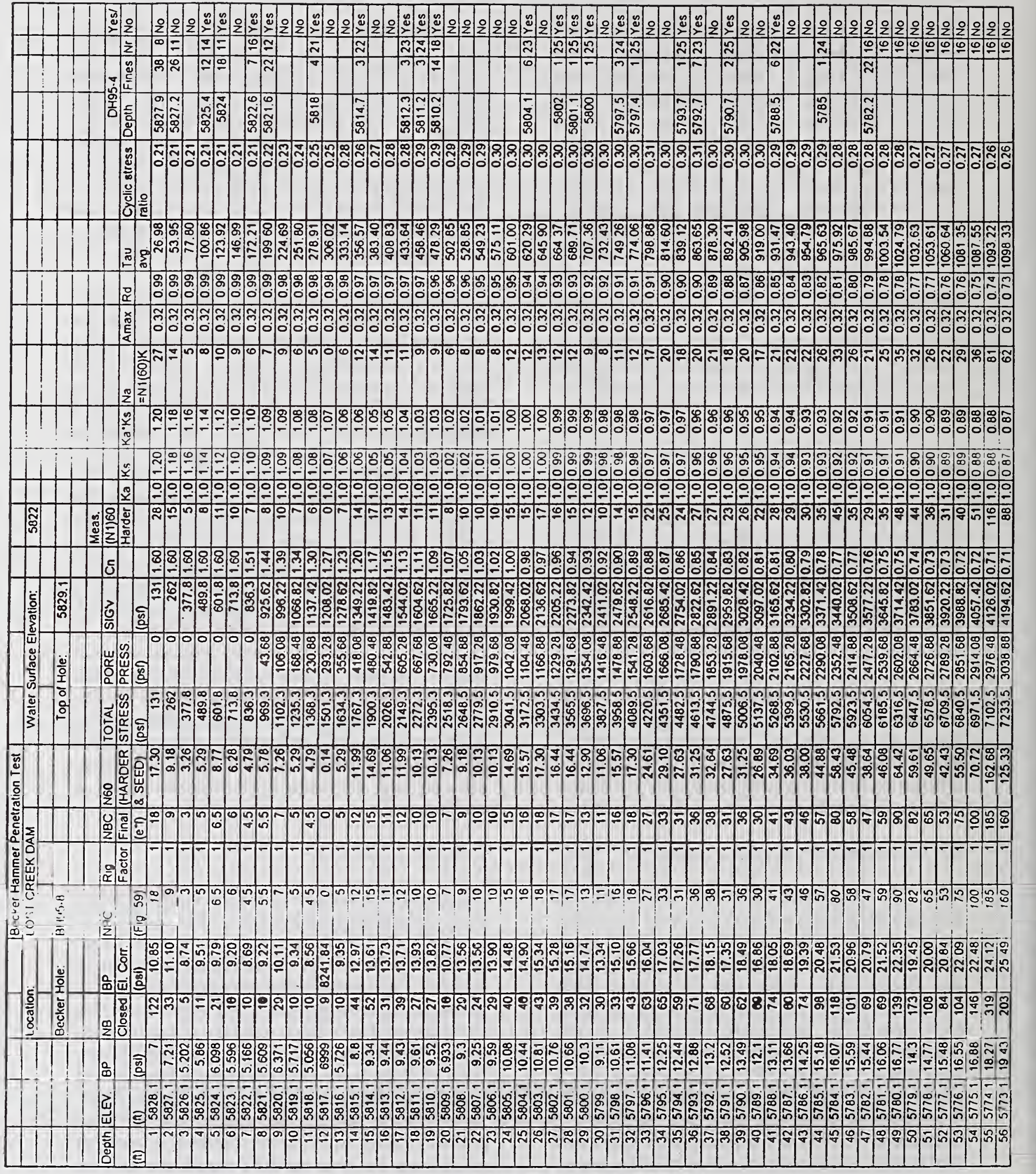

Figure 12. Adjusted Blow Counts from BPT95-8 


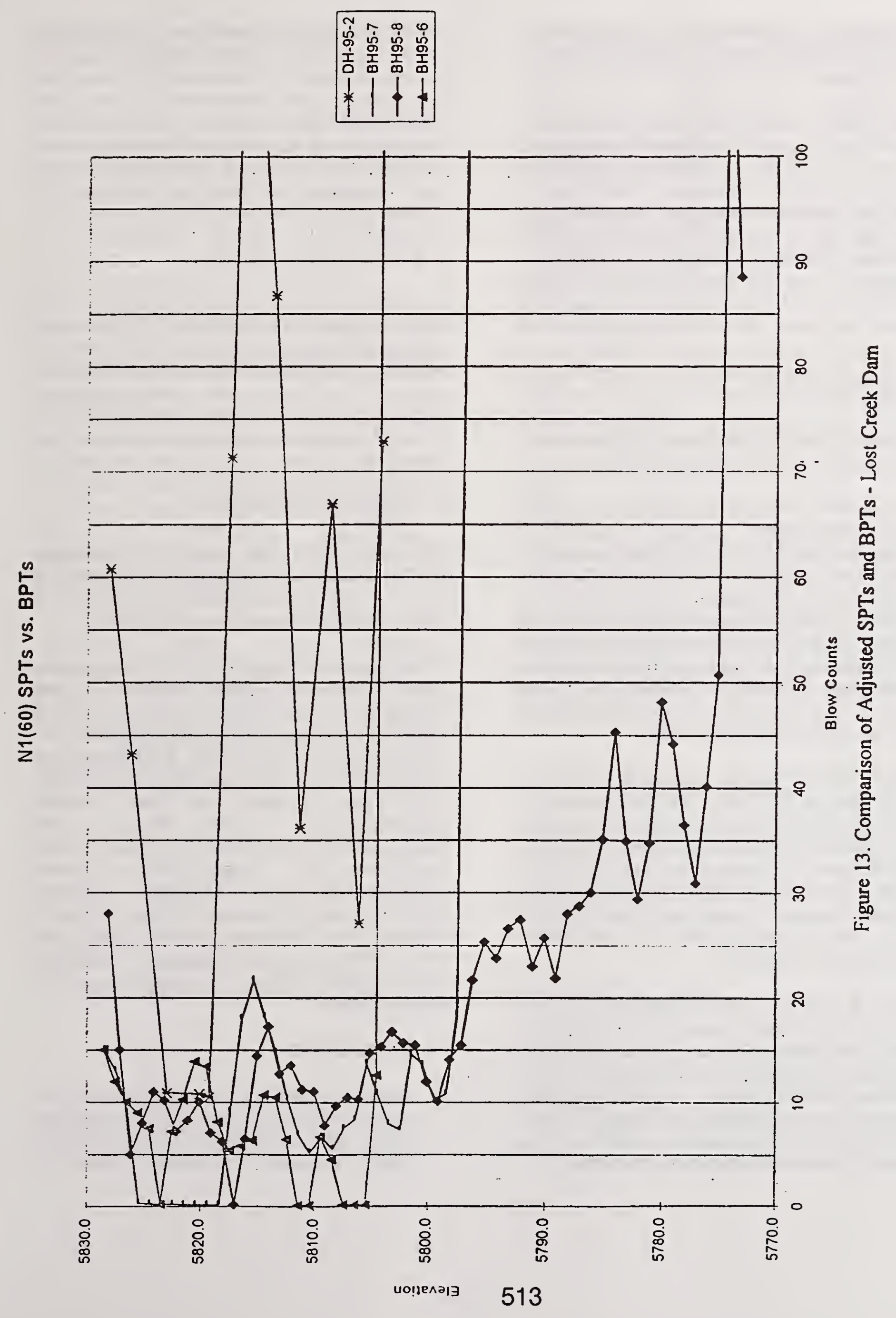


affected and not produce as low a blow count as may have been encountered at the same elevation in an SPT hole.

Based on the ease of operation and performance of the Becker Hammer at Lost Creek Dam, it appears that very valuable data was obtained related to the strengths of foundation materials. The difficulty of using the Becker Hammer is in correlating that information with the information obtained from SPT programs. The data base for relating the shear strengths of coarse grained materials to Becker Hammer blows is ever expanding and thus there appears to be more and more credence given to its use.

\subsection{BPT versus SPT}

The Becker Hammer Penetration Test has several advantages to the Standard Penetration Test.

First the BPT yields blow counts for every foot tested, whereas in order to properly perform an SPT test only one out of every 2-1/2 feet can actually be tested. This is because, for continuous testing, the procedure requires that the first six inches of soil be the seating interval, the next foot be the actual test interval, and the final foot be the clean out interval [7]. In addition, the SPT may meet refusal and then the clean out and seating intervals must be repeated thus increasing the length of interval for which one set of blow counts can be obtained.

Second, the BPT can be conducted much more rapidly than the SPT given that approximately 1 blow every 0.5 seconds can be achieved using the Becker Hammer. Because of this a testing program using the Becker can be completed in a more timely manner and economical fashion because the rig and personnel to operate the equipment are not deployed for as great a length of time as is required to perform a SPT program.

Finally, as related to the operations at Lost Creek Dam, the observation was made that the equipment used in performing BPT was less susceptible to mechanical breakdowns than the equipment used in performing the SPT programs. This is probably due to the larger size drill string of the Becker (6.6-inchoutside-diameter) as opposed to the SPT with its nominal 2.0-inch-outside-diameter drill string.
One advantage the SPT does have over the Becker, however, is that the Standard Penetration Testing is performed ahead of a cased holed. By this method the effects of wall friction as the drill string advances are quite negligible. In contrast Becker Penetration uses no casing and wall friction is a great concern. Harder and Sy have been working for several years to develop a method for compensating for this factor $[6,8]$.

\section{RECOMMENDATIONS.}

A triggering analysis as shown on figure 12 and similar analyses performed on the BPT data, yields that the foundation downstream of the dam down to bedrock is susceptible to liquefaction and should be treated. This analysis was performed using a maximum acceleration, associated with the MCE, of $0.32 \mathrm{~g}$. Methods for treating the foundation at Lost Creek Dam are discussed in references [4] and [9].

\section{ACKNOWLEDGMENTS}

The team work and spirit of cooperation demonstrated by the many people involved in this job - government, contractor, and consultants made it a challenging and rewarding project.

The author would like to thank all those who have helped make this paper possible. From Reclamation's Technical Service Center (TSC) in Denver: Tom Brown, Geotechnical Engineer;

Cletus King, Geologist; Jack Rosenfield, Civil Engineer/Instrumentation Specialist; Mike Stevens, Geotechnical Engineer; and Frank McLean, Reclamation Value Program Manager. From Reclamation's Upper Colorado Regional Office (Salt Lake City): Dan Grundvig, Regional Geologist; and Mark Vandeberg, Geologist (formerly with Reclamation's Upper Colorado Region). From Reclamation's Provo Area Office (Provo, Utah): Gary Dow, Geologist. Jim Benson of Great West Drilling: owner/operator of the Becker Hammer.

\section{REFERENCES}

1. "Results of Geologic Investigations and Data Evaluations for Lost Creek Dam - Weber Basin Project - Utah," Report Number G-480, United States Department of Interior, Bureau of 
Reclamation, Upper Colorado Region, Salt Lake City, Utah, October, 1991.

2. "GeologiclGeotechnical Technical Memorandum - Lost Creek Dam," Patty Ortiz, Technical Memorandum No. LO-3620-2, Weber Basin Project, Upper Colorado Region, Prepared by Woodward-Clyde Consultants, Denver, CO, WCC Project No. 23205, for the U. S. Bureau of Reclamation, Denve, CO, Contract No. 1425-2-CA-81-17610, Delivery Order No. 3-PD-81-17610-018, August 1993.

3. "Seismic Design Analysis," Design Standard No. 13 - Embankment Design, Chapter 13, U.S. Department of the Interior, Bureau of Reclamation, 1989.

4. "Assessment of Corrective Action Alternatives for Seismic Performance Deficiencies - Lost Creek Dam," Ronald A. Oaks, Warren J. Danos, Technical Memorandum No. LO-8314-4, Bureau of Reclamation, Geotechnical Engineering and Geology Division, Geotechnical Engineering and Embankment Dams Branch, Denver, Colorado, (DRAFT).

5. "Crosshole Seismic Wave Velocity Measurements for Soil Liquefaction Analysis Lost Creek Dam - Weber Basin Project - Utah," Ulrich Schimschal, Technical Memorandum No. D8330-95-013, U.S. Department of the Interior, Bureau of Reclamation, Technical Service Center, Denver, Colorado, July 21, 1995.
6. "Determination of Penetration Resistance for Coarse Grained Soils Using the Becker Hammer Drill," Leslie F. Harder, Jr., H. Bolton Seed, Report No. UCB/EERC-86/06, Earthquake Engineering Research Center, College of Engineering, University of Califomia, Berkeley, California, May 1986.

7. Earth Manual Part 2, Third Edition, U. S. Department of the Interior, Bureau of Reclamation, Materials Engineering Branch, Research Laboratory Services Division, Denver, Colorado, 1990.

8. Sy, Alexander, "Energy Measurements and Correlations of the Standard Penetration Test (SPT) and the Becker Penetration Test (BPT)," Ph.D. Dissertation, Supervisor: Dr. RG. Campanella, University of British Columbia, Vancouver, British Columbia, Canada, October, 1993.

9. "Technically Viable Corrective Action Alternatives for Seismic Dam Safety Deficiency - Upper Colorado Region - Weber Basin Project - Lost Creek Dam," Decision Memorandum No. DEC-LO-8314-4, Bureau of Reclamation, Geotechnical Engineering and Geology Division, Geotechnical Engineering and Embankment Dams Branch, Denver, Colorado, April 29, 1995 (DRAFT). 



\title{
U. S. Guidelines for the Seismic Rehabilitation of Buildings
}

\author{
by \\ Christopher Rojahn ${ }^{1}$ and Ugo Morelli ${ }^{2}$
}

\section{ABSTRACT}

An extensive 6-year project to prepare Guidelines for Seismic Rehabilitation of Existing Buildings is currently underway in the United States. Funded by the Federal Emergency Management Agency (FEMA) and prepared by the Applied Technology Council for the Building Seismic Safety Council, the Guidelines are intended to serve as a tool for design professionals, a reference document for building regulatory officials, and a foundation for the future development and implementation of building code provisions and standards. The Guidelines will enable users, on a voluntary basis, to rehabilitate buildings to meet specified performance levels such as Collapse Prevention, Life Safety, and Immediate Occupancy, and performance ranges such as Limited Safety and Damage Control, for specifically defined ground motion levels. The Guidelines contain significant new features, including a "Simplified Rehabilitation" method, which can be applied to certain simple, regular buildings that do not exceed specified height restrictions; a "Systematic Rehabilitation" method (the main body of the Guidelines), which can be applied to any type of building at any lucation; new Linear Static and Nonlinear Static analysis procedures; procedures for determining acceptability of existing components/elements; and procedures for incorporating emerging technologies. Seismic rehabilitation guidance is also provided for nonstructural components and systems. As of October 1995, the Guidelines were $75 \%$ complete. The expected completion date for the Guidelines project is September 1997

KEYWORDS: seismic rehabilitation; seismic retrofit; seismic strengthening; building standards; seismic performance levels.

\section{INTRODUCTION}

Model codes and standards for the seismic design of new buildings have been adopted and enforced throughout the United States for dec- ades. To date, however, only a few communities in the United States, such as the City of Los Angeles, have adopted regulations for the seismic strengthening of existing buildings. In those instances where regulations have been adopted, they have focused on one or two of the most vulnerable local building types (e.g., unreinforced masonry) and have been limited primarily to "risk reduction" measures, as opposed to higher performance levels, such as life safety. One of the primary barriers to widespread implementation of seismic strengthening/ upgrading in the United States has been the absence of consensus-backed, professionally accepted, nationally applicable standards for the seismic rehabilitation (retrofit/strengthening) of existing buildings.

In 1989, as a capstone project in a major, multiyear Federal program for mitigating earthquake hazards of existing (non-Federal) buildings, the Federal Emergency Management Agency (FEMA) initiated a two-phase effort to prepare a set of technically sound, nationally applicable guidelines for the seismic rehabilitation of buildings. Phase I, conducted by the Applied Technology Council (ATC) and completed in 1992, focused on the identification and resolution of a wide range of issues that should be considered during the actual preparation of guidelines in Phase II. The results of the Phase I project, published in FEMA Report 237, Seismic Rehabilitation of Buildings - Phase I, Issues Identification and Resolution (ATC, 1992), established the initial conceptual decisions for the Phase II guidelines writers and provided a comprehensive set of recommendations intended to guide, but not bind, the writers. Among the numerous Phase I recommendations was the recommendation that the guidelines provide per-

\footnotetext{
'Applied Technology Council, 555 Twin Dolphin Drive, Suite 550, Redwood City, California, 94065

${ }^{2}$ Federal Emergency Management Agency, 500 C Street, S.W., Washington, D.C. 20472
} 
formance based design procedures that would enable designers to achieve specific levels of building performance, such as life safety and damage control, for given levels of ground shaking.

The Phase II effort commenced in 1992 with the establishment of a five-year, \$8-million Cooperative Agreement (No. EMW-91-K-3602) between FEMA and the National Institute of Building Sciences (NIBS) for preparation of Guidelines for the Seismic Rehabilitation of Buildings (Guidelines Project). NIBS, through its Building Seismic Safety Council (BSSC), has overall management responsibility for the Guidelines Project as well as direct technical responsibility for performance of a consensus review of the Guidelines and several other specific tasks. ATC, as a subcontractor to BSSC, has responsibility for preparing the Guidelines and related companion documents and for revising the documents as appropriate following the consensus review process. The American Society of Civil Engineers (ASCE), as another subcontractor to BSSC, has responsibility for conducting Users Workshops, capturing relevant research results, and resolving issues raised (but not resolved) in Phase I.

A team of approximately 60 consultants (practitioners and researchers) from various regions of the United States have been engaged by ATC to develop the Guidelines (ATC-33 project). End users are participating in ASCEconducted "Users Workshops" at the $25 \%, 50 \%$, and $75 \%$ complete stages to evaluate and comment on the utility and user-friendliness of the Guidelines. Approximately one year prior to completion, which is scheduled for September 1997, the Guidelines will undergo a consensus review by the BSSC.

The Guidelines are based on current research knowledge and practice methods. Although no new research is being conducted to support the development process, an effort has been undertaken to identify and summarize relevant research results for use by the Guidelines writers. In addition, the new analysis methods developed in the project are being evaluated in case studies of 25 buildings damaged by the January 17, 1994 Northridge, California, earthquake.

\section{PURPOSE}

The Guidelines for Seismic Rehabilitation of Buildings (ATC, 1995) are intended to serve as a tool for design professionals, a reference document for building regulatory officials, and a foundation for the future development and implementation of building code provisions and standards. The Guidelines do not presume that rehabilitation will necessarily be mandated by a state or local code; rather, they are intended to be of use to owners and their design professionals for voluntary rehabilitation efforts.

The document is intended to be used primarily by the technical community responsible for developing and using building codes and standards and for carrying out the design and analysis of buildings. This primary user group includes architects, engineers, and building officials. Parts of the Guidelines and companion Commentary will also be useful and informative beyond the primary technical audience to building owners, government agencies, and policy makers.

The engineering expertise of a design professional (architect, engineer, code official) is a prerequisite to the appropriate use of the Guidelines, and most of the provisions of the document presume the expertise of a structural engineer experienced in building design.

The document is neither a code nor a standard. It is intended to be suitable both for voluntary use by owners and design professionals as well as for adaptation and adoption into model building codes and standards.

\section{SIGNIFICANT NEW FEATURES}

The $75 \%$ complete document contains several new features that depart significantly from previous seismic codes.

1. Criteria and methods for achieving various performance levels at various seismicity (ground shaking) levels, defined regionally in terms of recurrence intervals. Performance levels and ranges considered include: Limited Safety; Collapse Prevention; Life Safety; Damage Control; and Immediate Occupancy (see Figure 1). The combination of these parameters (performance level and ex- 
pected level of ground shaking) enable the user to seek one of the following rehabilitation objectives:

- Basic Safety Objective: Life Safety for ground shaking with a $10 \%$ probability of exceedance in 50 years and Collapse Prevention for ground shaking with a $2 \%$ probability of exceedance in 50 years.

- Limited Objectives: rehabilitation objectives less stringent than the Basic Safety Objective, such as performance levels less than life safety (Limited Safety) for ground shaking with a $10 \%$ probability of exceedance in 50 years, or Life Safety for a ground shaking with a higher than $10 \%$ (e.g., $50 \%$ ) probability of exceedance in 50 years.

- Enhanced Objectives: rehabilitation objectives that call for a higher level of performance than the Basic Safety Objective, such as Immediate Occupancy, or Damage Control, for ground shaking with a $10 \%$ probability of exceedance in 50 years, or Life Safety for ground shaking with less than $10 \%$ (e.g., $5 \%$ ) probability of exceedance in 50 years and "Collapse Prevention" for ground shaking with less than $2 \%$ probability of exceedance in 50 years.

2. Methods for "Simplified Rehabilitation", applicable to small regular buildings primarily, although not exclusively, in areas of low and moderate seismicity and specified as a function of model building type, ground shaking amplitude (seismicity level), and desired performance level (applicable to the performance levels/ranges of Limited Safety, and, in some cases, Life Safety).

3. Methods for "Systematic Rehabilitation", i.e., complete procedures for considering all elements necessary to reach a specified performance level for any building. These procedures address rehabilitation strategies, analysis proce- dures and their selection, and material acceptance criteria.

4. New methods of analysis, including (a) a new Linear Static Procedure (LSP) based on estimating maximum structural displacements, and (b) a new Nonlinear Static Procedure (NSP) (i.e., "Pushover" Analysis) that will better account for structural behavior caused by progressive yielding of structural elements.

5. Detailed procedures for determining acceptability of existing components and elements as well as designing new ones in the four major material groups: wood, concrete, steel, and masonry. These depart from standard design procedures for new buildings, which generally consider all parts of the structure to have similar characteristics.

6. Procedures for incorporating emerging technologies in the rehabilitation design, including seismic isolation and supplemental damping.

7. Criteria for seismic rehabilitation of nonstructural elements, coupled with various performance objectives and emphasizing those components important for the Basic Safety Objective. Components are divided between those that affect response and those that do not. Both prescriptive and analysis procedures are included.

\section{SCOPE}

The Guidelines can be applied to all buildings regardless of importance, occupancy, historic features, size, or other characteristics, that by some criteria are deficient in their ability to resist the effects of earthquake shaking. In addition to the direct effects of ground shaking, the document also includes consideration of the effects on buildings of local ground failure such as liquefaction. Excepted are non-building structures such as elevated tanks or billboards unless they are part of a building. Also excepted are buildings or structures covered by special codes or standards such as bridges and nuclear power plants. 
The document also applies both to the overall structural system of a building, its elements, for example, shear walls or frames, and the constituent components of elements such as a column in a frame or a boundary member in a wall. It also applies to nonstructural components of existing buildings--ceilings partitions, and mechanical/electrical systems. Rehabilitation techniques for reducing seismic demand, e.g., the introduction of isolation or damping devices, in addition to increasing strength and ductility of systems, are also included. And, although the document is not intended to address the design of new buildings, it does cover new components or elements added to existing buildings.

While the Guidelines provide detailed engineering guidance on how to conduct seismic rehabilitation analysis once the decision to rehabilitate a building has been made and while the Guidelines could be used to conduct seismic evaluations, guidance on initial decisionmaking as to whether or not to undertake a rehabilitation project is beyond the scope of the Guidelines. Secondly, the question of when the Guidelines should be applicable in a mandatory way to a remodeling or structural rehabilitation project is also beyond the scope of the document. Finally, methods of reducing seismic risk that do not physically change the building, such as reducing the number of occupants, are not covered.

Also beyond the scope of this document are recommendations regarding what Performance Level and what severity and probability of shaking should be selected for Rehabilitation of any particular building, although a risk traditionally considered acceptable in the United States is centraI to this document and is termed the Basic Safety Objective (see significant new features above). Higher and lower objectives can also be defined by the user. The Guidelines were written under the premise that greater flexibility is required in seismic rehabilitation than in the design of new buildings. Once the rehabilitation objective is established, the Guidelines provide internally consistent procedures that include analysis and design specifications necessary to meet the rehabilitation objective.

Special or new mapping of expected seismic ground shaking for the United States has not been developed for the Guidelines. Although ground shaking can be defined for any probability of occurrence, it is intended that the seismic hazard used with this document be consistent with national mapping contained in the National Earthquake Hazards Reduction Program (NEHRP) Provisions for new buildings. In the 1994 NEHRP edition (FEMA, 1995) national maps are available for ground shaking with a $10 \%$ chance of exceedance in 50 years, a $5 \%$ chance of exceedance in 50 years, and a $2 \%$ chance of exceedance in 50 years. These probabilities correspond to shaking that is expected to occur, on average, about once every 500 (or more exactly, 474 years), 1000 and 2500 years. Presently under consideration for the 1997 edition of the NEHRP Provisions for new buildings are maps that provide response spectra ordinates (at specified periods) for "Maximum Considered Earthquake" ground motions. These maps specify ground motions with a $2 \%$ probability of exceedance in 50 years that are constrained in certain regions with caps and floors developed on the basis of engineering judgment.

Also featured in the Guidelines are descriptions of damage states with relation to specific Performance Levels. These descriptions are intended to aid design professionals and owners when selecting appropriate Performance Levels for rehabilitation design and in their judgments concerning design of rehabilitation measures.

\section{CONTENTS OVERVIEW}

While the Guidelines contain information that would not be included in seismic codes for new buildings, the Guidelines are organized much like codes for new buildings (see Figure 2). Following are descriptive summaries of the contents of the $75 \%$ complete draft.

Chapter 1 provides an overview of the Guidelines, its relationship to other documents, the use of the Guidelines in the seismic rehabilitation process, and the use of the Guidelines for local or direct risk mitigation programs.

General requirements for rehabilitating existing buildings are presented in Chapter 2. The framework in which these requirements are specified is purposely broad in order to accommodate rehabilitating buildings: (1) of many different types, (2) to satisfy a broad range of performance goals, and (3) to include consid- 
eration of the variations of seismic hazards throughout the United States. Criteria for eleven general issues regarding the seismic rehabilitation of buildings are included:

- Rehabilitation (Risk Reduction) Objectives. Selection of desired performance level for given earthquake severity levels.

- Performance Levels defining the expected behavior of the building in the design earthquake(s) in terms of limiting levels of damage.

- Seismic Hazard. Determination of the design ground shaking and other site hazards, such as landsliding, liquefaction, settlement.

- As Built Characteristics. Determination of the basic construction and earthquake resistive capacity of the existing building.

- Rehabilitation Methods. Selection between simplified approaches and systematic approaches.

- Rehabilitation Strategies. Selection of a basic approach for rehabilitation, e.g., provide additional lateral load carrying elements, base isolation.

- Analysis and Design Procedures. For systematic rehabilitation approaches, selection among linear static, linear dynamic, or nonlinear methods of analysis.

- General Analysis and Design Requirements. Specification of the force actions for which given components of a building must be evaluated, and minimum design criteria for interconnection of structural components.

- Building Interaction. Guidelines for buildings that share elements with neighboring structures, and buildings with performance affected by the presence of adjacent structures.
- Quality Assurance. Guidelines for assuring that the design intent is appropriately represented by the rehabilitation construction.

- Alternative Materials and Methods. Guidelines for evaluating and designing structural components not specifically covered by other sections of the Guidelines.

Chapter 3 provides the analysis and design requirements for seismic rehabilitation of existing buildings. Four alternative analysis procedures are presented: (1) Linear Static Procedure; (2) Linear Dynamic Procedure; (3) Nonlinear Static Procedure; and (4) Nonlinear Dynamic Procedure. The limitation with regard to the use of these procedures are provided in Chapter 2. The Linear Static Procedure (LSP), which provides an approximate solution for the first mode dynamic response of a building to earthquake ground motions and uses a newly formulated equation to estimate base shear, is the preferred procedure for use with buildings of wood frame construction. Both the LSP and the Linear Dynamic Procedure (LDP), which is performed using specified ground motion criteria and accepted principles of structural dynamics, may be used for any of the recommended rehabilitation strategies except strategies incorporating the use of supplemental energy dissipation systems and some types of base isolation systems. Component actions resulting from application of the linear analysis procedures are categorized as being either force controlled or displacement controlled and compared against allowable capacities to determine acceptability. Linear analysis procedures (LSP and LDP) should not be used for buildings with highly irregular structural systems, unless the building is capable of responding to the design earthquake(s) in a nearly elastic manner and the earthquake ductility demands on the building are suitably low (guidelines for computing and evaluating the distribution of inelastic demands are provided in Chapter 2).

The Nonlinear Static Procedure (NSP) of Chapter 3 is a "push-over" analysis procedure whereby lateral loads in patterns that represent approximately the relative inertia forces generated at locations of substantial mass are applied to a two or three dimensional analytical model 
of the building. This model is deflected to displacements that are larger than the maximum displacements expected in the design earthquake, and the resulting demands are then compared with available capacities. The Nonlinear Dynamic Procedure (NDP) is performed using specified ground motion criteria, accepted principles of structural dynamics, and computer software applications (as they become available). In the NDP, the force and inelastic deformation demands in the design earthquake(s) are also computed explicitly for each component of the structure, and acceptability is based on a comparison of computed demands and available capacities at the performance level(s) of interest. The NDP should be considered for a structure in which higher mode effects are important. Nonlinear analysis procedures (NSP and NDP) may be used for any structure and any rehabilitation strategy with the following exceptions and limitations:

- When sufficient information is available on the probable strengths of materials and configurations of components (as specified in Chapter 2).

- When the NDP is used, the project should be subject to review by an independent, third-party professional engineer with substantial experience in seismic design.

Chapter 4 presents the Simplified Rehabilitation Method, which is intended for use only on a selected group of simple buildings being rehabilitated to a limited safety design objective (i.e., to a performance level less than the Basic Safety Objective). The Simplified Rehabilitation Method recognizes that the performance of certain common building types that meet specific limitations on height and regularity can be substantially improved by simply eliminating each of the deficiencies found using the NEHRP Handbook for the Seismic Evaluation of Existing Buildings (FEMA, 1992). In addition to the NEHRP Handbook deficiencies, the Guidelines define eight newly identified additional deficiencies that must be considered in the Simplified Rehabilitation Method. The design ground motion criteria in the Simplified Rehabilitation Method is the same as that specified in the NEHRP Handbook: $67 \%$ to $85 \%$ (depending on building period) of the ground motions having a less than $10 \%$ chance of exceedance in 50 years. In high seismic zones, the Simplified Rehabilitation Method is limited to buildings no taller than 2 or 3 stories, depending on building type; in moderate zones, it is limited to buildings no taller than 2 to 4 stories, depending on building type; and in low seismic zones, it is limited to buildings no taller than 2 to 6 stories, depending on building type. Moreover, in certain locations, the Simplified Rehabilitation Method can not be used on certain types of steel and concrete frame buildings with masonry infill walls and on certain types of precast concrete frame buildings.

Chapters 5 through 8 describe rehabilitation measures for components and elements, respectively, for the four major material groups: steel, concrete, masonry and wood. Included in these chapters are sections that provide (1) perspective on historical variations in material properties and connection details; (2) material properties for new and existing components; (3) evaluation methods for in-place materials; (4) attributes of typical system elements; and (5) stiffness and strength acceptance criteria for structural components, including foundation components. The acceptance criteria are expressed in terms of component demand modifiers that have been developed on the basis of available research data on the cyclic, forcedeformation relationships of materials. The demand modifiers are used in conjunction with acceptance criteria equations and specifications provided in Chapter 3.

Guidelines for the application of seismic protective systems to building rehabilitation are provided in Chapter 9. Specific guidance is provided for seismic (base) isolation systems and for passive energy dissipation systems. Additional, limited guidance is provided for other special seismic systems, including active control systems, hybrid active and passive systems, and tuned mass and liquid dampers. The guidelines in Chapter 9 recognize that seismic isolation and energy dissipation systems include a wide variety of concepts and devices. In most cases, these systems will be implemented with some additional conventional strengthening of the structure and, in all cases, require evaluation of existing building elements. Chapter 9 supplements the guidelines of other chapters with additional criteria and methods of analysis that 
are appropriate for buildings rehabilitated with seismic isolation systems and/or energy dissipation devices.

Chapter 10 provides geotechnical engineering guidance regarding building foundation and seismic-geologic sites hazards. Included are guidelines for establishing site soil characteristics and for identifying the following site geotechnical hazards: fault rupture, liquefaction, differential compaction, landslide and rock fall, and flooding. Also provided are techniques for mitigating geotechnical site hazards; criteria for establishing soil strength capacity, stiffness and soil-structure interaction parameters for making foundation design evaluations; guidance on how to estimate soil pressure on retaining walls; and criteria for enhancing foundation strength and stiffness.

Chapter 11 provides rehabilitation criteria for architectural, mechanical, and electrical components and systems that are permanently installed in buildings, including their supports and attachments. Contents introduced into buildings by owners or occupants are not within the scope of the Guidelines. This chapter contains a list of nonstructural components that are subject to the Guidelines, rehabilitation requirements related to seismic zone and the collapse prevention, life-safety and immediate occupancy performance levels; general requirements for acceptance criteria for acceleration-sensitive and deformation-sensitive components; and analysis methods. Methods for nonstructural rehabilitation, which can be accomplished through replacement, strengthening, bracing, or attachment, are provided in the Commentary.

\section{SUMMARY}

An extensive 6-year project to prepare Guidelines for Seismic Rehabilitation of Existing Buildings is currently underway in the United States. Funded by the Federal Emergency Management Agency (FEMA) and prepared by the Applied Technology Council for the Building Seismic Safety Council, the Guidelines (ATC, 1995) are intended to serve as a tool for design professionals, a reference document for building regulatory officials, and a foundation for the future development and implementation of building code provisions and standards. The Guidelines will enable users, on a voluntary basis, to rehabilitate buildings to meet specified performance levels such as Collapse Prevention, Life Safety, and Immediate Occupancy, and performance ranges such as Limited Safety and Damage Control, for specifically defined ground motion levels. The Guidelines contain significant new features, including a "Simplified Rehabilitation" method, which can be applied to certain simple, regular buildings that do not exceed specified height restrictions; a "Systematic Rehabilitation" method (the main body of the Guidelines), which can be applied to any type of building at any location; new Linear Static and Nonlinear Static analysis procedures; procedures for determining acceptability of existing components/elements; and procedures for incorporating emerging technologies. Seismic rehabilitation guidance is also provided for nonstructural components and systems.

\section{REFERENCES}

1. ATC, 1992, Seismic Rehabilitation of Buildings - Phase I, Issues Identification and Resolution, Applied Technology Council Report ATC-28, Redwood City, Calif. (published as FEMA Report 237, 1992).

2. ATC, 1995, Guidelines for Seismic Rehabilitation of Buildings $175 \%$ Complete Draft), Applied Technology Council Report ATC-33.03, Redwood City, California.

3. FEMA, 1995, NEHRP Recommended Provisions for the Development of Seismic Regulations for New Buildings, prepared by the Building Seismic Safety Council, published by FEMA, Washington, DC.

4. FEMA, 1992, NEHRP Handbook for the Seismic Evaluation of Existing Buildings, prepared by the Building Seismic Safety Council and published as FEMA Report 178, Washington, DC. 


\section{Performance Levels and Ranges}

Performance Level: the intended postearthquake condition of a building; a discrete and well-defined point on a scale measuring how much loss is caused by earthquake damage; in addition to casualties, loss may be in terms of property and operational loss.

Performance Range: a range or band of performance, rather than a discrete level.

Rehabilitation Objective: The combination of a Performance Level or Range with Seismic Demand Criteria.

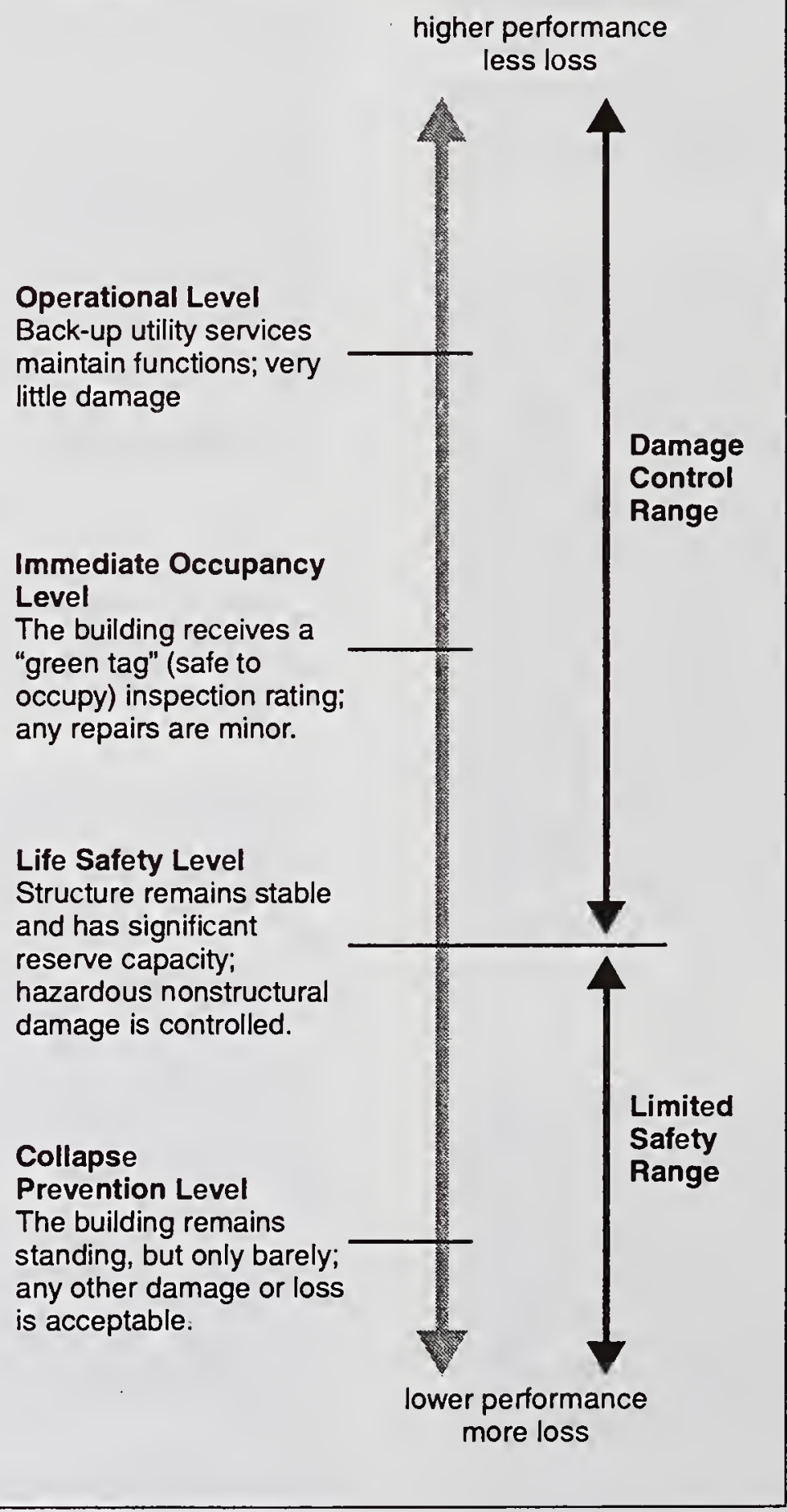

Figure 1. Performance Levels and Ranges ( $75 \%$ complete draft) 


\section{Table of Contents ( $75 \%$ complete draft)}

Preface

Page No.

1. Introduction

$\mathrm{v}$

2. General Requirements

3. Analysis and Design

4. Simplified Rehabilitation Method

5. Steel Materials and Elements

6. Concrete Materials and Elements

7. Masonry Materials and Elements

8. Wood, Light Steel Framing, and Associated Sheathings

9. Seismic Isolation and Energy Dissipation

10. Foundations and Geotechnical Hazards

11. Architectural, Mechanical, and Electrical Components and Systems

Figure 2. Guidelines Table of Contents (75\% complete draft). 



\title{
Northridge Earthquake Responses of Base-isolated \\ (USC) and Conventionally Designed (Olive View) Hospital Buildings
}

by

\author{
Mehmet K. Çelebi*
}

\section{ABSTRACT}

Recorded data during the 17 January 1994 Northridge, California earthquake $\left(\mathrm{M}_{\mathrm{s}}=6.8\right)$ from the base- isolated University of Southern California (USC) and conventionally designed Olive View Hospital (OVH) buildings indicate that they were subjected to ground motions with peak accelerations equivalent to or larger than those postulated for their design. The data reveals successes of the two different approaches of design. Both buildings performed well during the earthquake. The USC building is on rock and OVH is on alluvial deposit. The isolators of the USC building experienced non-linear displacements with peak at $3.5 \mathrm{~cm}$ that put them within $10 \%$ shear strain and effectively dissipated the energy of incoming motions attaining equivalent viscous damping of approximately $10 \%$ of the critical. The superstructure experienced reduced peakaccelerations as compared to the free-field or the foundation and did not suffer structural or contents damage. On the other hand, the conservatively designed OVH (with high lateral load resisting capability) experienced peak horizontal acceleration of $2.31 \mathrm{~g}$ at the roof compared to $0.82 \mathrm{~g}$ and $0.91 \mathrm{~g}$, respectively, at the ground floor and free-field. The OVH suffered limited non-structural damage. This stiff structure was not affected by the long duration pulses of this earthquake; however, it was affected by the resonating frequencies of the site.

In addition to Northridge data, the response of OVH, recorded during the 1987 Whittier earthquake indicates that the response characteristics of the building are significantly different for the two events -- attributable to (a) possible non-linear behaviour due to minor structural damage and (b) soil-structure effect. The study exhibits these differences for the Northridge earthquake during which the shaking was significantly stronger than that during the Whittier earthquake.

KEYWORDS: base-isolation, viscous damping, hysteretic behavior, response spectra, shear wall, peak acceleration

\section{INTRODUCTION}

Studying the responses of structures during earthquakes constitutes an important element of earthquake hazard reduction programs in order to confirm or improve methodologies for design and analyses of structures. Response records retrieved by California Division of Mines and Geology (CDMG) from (1) the base isolated USC Hospital building in Los Angeles, at $36 \mathrm{~km}$ from the epicenter, and (2) conventionally designed OVH Building in Sylmar (California), at $16 \mathrm{~km}$ from the epicenter of the $\left(\mathrm{M}_{s}=6.8\right)$ Northridge (California) earthquake of January 17, 1994 are particularly significant (Shakal, et al. 1994) because both buildings were tested with input motions having (a) peak acceleration levels equivalent to or larger than those postulated in their respective design criteria and (b) long period pulses typically generated by near-fault ground motions or surface wave motions as in the Northridge earthquake (Scientists of the USGS and SCEC, 1994). Long-period pulses result in large velocities and displacements. The effective fundamental period of an isolated structure is typically 3-5 times longer than an otherwise fixed base structure. On the other hand, the critical damping

"USGS (MS977), 345 Middlefield Rd., Menio Park, Ca. 94015 
percentages of the isolators are typically greater than $10 \%$. Even then, how base-isolated systems respond to such long-period motions has been a cause for concern. The USC records are the first set of strong-motion records from a base-isolated structure where the displacements are large enough to show that the isolators experienced non-linear displacement excursions and effectively reduced the peak accelerations and relative displacements of the superstructure. The OVH response exhibits possibly the largest peak accelerations at the input (ground) level [0.91g] and the roof level [2.31g]. The OVH building was designed in 1976 to increased level of seismic forces as a reaction to the disastrous fate of its predecessor, the original $\mathrm{OVH}$ building that was severely damaged during the $\mathrm{M}_{s}=6.4$ San Fernando (California) earthquake of February 9, 1971 and was later razed. Figure 1 shows the location of the USC hospital and the OVH building relative to the epicenter of the Northridge earthquake and significant peak accelerations recorded at select sites during that earthquake. The objective of this paper is to assess the performance of both hospital buildings during the Northridge earthquake. Response records of $\mathrm{OVH}$ building recorded at $45 \mathrm{~km}$ epicentral distance from the $\left(M_{s}=5.9\right)$ Whittier earthquake of October 1, 1987 are also included in this study as they reveal significant response characteristics of this unique building (Huang, et al., 1989). The epicenter of that earthquake is also shown in Figure 1. Further details and references are provided in Çelebi (1996a and 1996b).

\section{THE BASE-ISOLATED HOSPITAL}

The instrumentation and three dimensional view of the eight story building is seen in Figure 2. Its steel superstructure is supported by 149 isolators ( $34.6 \mathrm{~cm}$ high) on continuous concrete spread footings. The diagonally braced perimeter frames supported by 67 lead-rubber isolators (55.9 cm square) are designed to carry the lateral loads. The internal vertical load carrying columns are supported by 82 elastomeric isolators (66.0 cm square). The building is on an outcrop within $15 \mathrm{~km}$ of the Newport-Inglewood fault. It is designed for a maximum relative isolator displacement of $26 \mathrm{~cm}$ and to ATC-6 [S1] (same as UBC 1988 and 1994) spectrum with ZPA equal to $0.4 \mathrm{~g}$-- increased by $20 \%$ to account for near field effects. The maximum peak accelerations and displacements extracted from the data, summarized in Table 1 , indicate that the free-field peak in either direction is larger than that of (a) the design level, (b) above the isolators or the roof - clear evidence that the isolators were effective in dissipating the incoming vibrational energy. Response spectra (5\% damped) of horizontal free-field motions are compared in Figure 3a with the UBC (S1) design response spectra scaled to $0.48 \mathrm{~g}$. The normalized free-field response spectra (5\% damped) are compared in Figure $3 \mathrm{~b}$ with that of the shape of the design response for UBC (or ATC) S1 soil type. In general the shapes of the spectra of recorded components of motions appears to be well enveloped by the code spectrum except for some high frequency $(>1 \mathrm{~Hz})$ bands for which it is exceeded. Figures $3 \mathrm{c}$ and $\mathrm{d}$ show comparison of $5 \%$ damped response spectra for the locations at the roof, above and below isolators and free-field. It is seen that below 0.5 seconds, the free-field spectra exceeds those at the roof.

Figure 4 shows accelerations at various levels of the building in both directions, their amplitude spectra and relative accelerations and displacements of the isolators. It should be noted that the roof response increases significantly as compared to the response of the 6th floor due to change in plan above that level. In the NS direction, the maximum relative displacement is about $3.5 \mathrm{~cm}$ while in the EW direction, it is about $3.0 \mathrm{~cm}$ (at the south end). The displacements and relative displacements correspond to (a) the largest drift ratio of approximately $10 \%$ of the allowable, (b) maximum $10 \%$ shear strain (maximum relative displacement divided by the height of the isolators), (c) stiffness $K_{2}$ of the actual hysteretic curve of the isolators (Figure 5) and (d) to hysteretic damping of approximately $10 \%$ calculated by the relationship $d=\Delta(w) / 4 \pi(W)$ where $\Delta(w)$ is the actual area of the hysteresis loop at a displacement level and $W$ is the hypothetical elastic energy defined by the area 
formed by the line defined by the elastic slope at the same displacement (Hudson, 1965, Jacobsen, 1960). The level of damping, approximately 10 $\%$ and $15 \%$, for the 1 st and 2 nd modes, respectively are also extracted by system identification technique (Çelebi, 1986a). The first mode dominates the response of the building. Figure 6 shows cross-spectra, coherence function and phase angle plots of roof and 4th. floor, and relative torsional accelerations between the roof and the lower level. The family of (linear and non-linear frequencies attributed to the first and second modes seen in the cross-spectra are coherent and are in phase. The first mode frequency starts at $1 \mathrm{~Hz}$ and due to nonlinear behavior of the isolators shifts to $0.75 \mathrm{~Hz}$ in the NS direction and similarly starts with $1 \mathrm{~Hz}$ and shifts to 0.62 $\mathrm{Hz}$ in the $\mathrm{EW}$ direction. These clear peaks are indicative of the fact that distinctive instantaneous stiffnesses can be defined for the isolators as a function of the relative isolator displacements. Similarly, for the second mode, the motions are $180 \mathrm{deg}$ out of phase at around $1.5 \mathrm{~Hz}$ and shift in the frequences are also clearly identifiable for that mode.

It is important to note that the full displacement and dissipation capability of the isolators were only partially exhausted during the Northridge earthquake, suggesting that the performance of the building and its isolators will be satisfactory during future events at possibly higher acceleration and displacement levels than those recorded at the site and experienced by the structure during the Northridge earthquake and compatible with the seismicity of the area. A detailed probabilistic evaluation of the seismic hazard in Southern California and probable earthquakes for a thirty year period (1994-2024) has been recently reassessed (Working Group, 1995). Deliberations on this subject is beyond the scope of this paper.

However, it is possible to estimate the extreme situations for the building and its isolators with the known first mode frequency which starts at $1 \mathrm{~Hz}$ and then with nonlinear behavior of the isolators shifts to $0.7 \mathrm{~Hz}$ in the NS direction and similarly starts at $1 \mathrm{~Hz}$ and shifts to $.62 \mathrm{~Hz}$ in the EW direction. For this, the stiffnesses for a bilinear hysteretic curve as defined by Asher et al. $(1990,1995)$ are adopted. These stiffnesses as corresponding to 1 inch $(2.5 \mathrm{~cm})$ displacement are: $\mathrm{k}_{\mathrm{L} 1}=8.55 \mathrm{t} / \mathrm{cm}$ (for 59 ) and $9.08 \mathrm{t} / \mathrm{cm}$ (for 9 ) of the 68 lead-rubber isolators; and similarly, $\mathrm{k}_{\mathrm{L} 2}=1.98 \mathrm{t} / \mathrm{cm}$ for 59 and 2.68 $\mathrm{t} / \mathrm{cm}$ for 9 lead-rubber bearings. The stiffness of the high damping rubber (only) bearings are defined to be linear at 1 inch $(2.5 \mathrm{~cm})$ and therefore, $k_{R 1}=k_{R 2}=2.41 \mathrm{t} / \mathrm{cm}$ for 8 and 3.07 $\mathrm{t} / \mathrm{cm}$ for 73 of the 81 such bearings. To facilitate further evaluation at larger displacements, the author, based on actual hysteresis plots of prototype isolators, extended these to $k_{\mathrm{L} 3}=1$ $\mathrm{t} / \mathrm{cm}$ for all lead-rubber bearings and $\mathrm{k}_{\mathrm{R} 3}=1.75$ $\mathrm{t} / \mathrm{cm}$ for all rubber bearings. If the superstructure can be assumed to be rigid and since the mass is constant, the fundamental frequency of the system at any displacement stage can be defined by $\mathrm{f}_{1}=(0.5 / \pi)\left(\mathrm{K}_{1 \mathrm{j}} / \mathrm{M}_{1 \mathrm{j}}\right)^{0.5}$ where $\mathrm{K}_{1 \mathrm{j}}=68 \mathrm{k}_{\mathrm{Li}}+81 \mathrm{k}_{\mathrm{Ri}}$ is the total stiffness of the ( 68 lead and 81 rubber) 149 isolators. Thus, for the first mode only:

$\mathrm{K}_{11}=59(8.55)+9(9.08)+8(2.41)+73(3.07) \mathrm{t} / \mathrm{cm}$. $\mathrm{K}_{11}=830 \mathrm{t} / \mathrm{cm}$.,

$\mathrm{K}_{12}=59(1.98)+9(2.68)+8(2.41)+73(3.07)$

$\mathrm{K}_{12}=384 \mathrm{t} / \mathrm{cm}$. and,

$\mathrm{K}_{13}=68(1)+81(1.75)=210 \mathrm{t} / \mathrm{cm}$.

From these, equivalent mass units corresponding to the identified frequencies ( 1 and $.7 \mathrm{~Hz}$ of the first mode are determined): $M_{11}=21$ units (for $\mathrm{f}_{11}=1 \mathrm{~Hz}$ and $\mathrm{K}_{11}=830 \mathrm{t} / \mathrm{cm}$.) and $\mathrm{M}_{12}=19.9$ units (for $\mathrm{f}_{12}=0.7 \mathrm{~Hz}$ and $\mathrm{K}_{12}=384 \mathrm{t} / \mathrm{cm}$.). From this, an average equivalent mass is taken as $\mathrm{M}_{1 \mathrm{j}}=20$ units. Using this, the first mode frequency at large displacements can be estimated with $\mathrm{K}_{13}$. Thus, at large displacements, $\mathrm{f}_{13} \sim(0.5 / \pi)[210 / 20]^{0.5} \sim 0.46 \mathrm{~Hz}[\sim 2.2$ seconds]. At 2.2 seconds, the spectral accelerations, conservatively estimated from the free-field response spectrum (of Northridge 
earthquake with known low-frequency content) to be less than $100 \mathrm{~cm} / \mathrm{s} / \mathrm{s}$. Assuming even a higher spectral acceleration at $200 \mathrm{~cm} / \mathrm{s} / \mathrm{s}$ (at 2.2 seconds), the displacement of an isolator can then be estimated to be $d \sim S_{a} / w^{2} \sim S_{a} /(2 \pi f)^{2}$ $\sim 200 /(2 \pi[.46])^{2} \sim 24 \mathrm{~cm}$ which is within the displacement capability of the isolators and less than the moat clearance.

\section{THE OVH BUILDING}

Figure 7 shows the instrumentation and three dimensional view of the six story building and its associated free-field. The lateral force resisting system of the building is a mixed design of concrete and steel shear walls. The ground floor and second floor are typically 10 inches thick concrete shear walls that extend along several column lines. At the 3rd level, the plan of the building changes to a cross shape making a four story cruciform tower with steel shear walls surrounding the perimeter. The foundation of the building consists of spread footings and grade mat on the ground floor. The seismic design criteria of the building was based on two levels of performances defined by the design and survivability level earthquake spectra with ZPA of $0.52 \mathrm{~g}$ and $0.69 \mathrm{~g}$ respectively. The survivability earthquake is postulated for a Richter magnitude 8.5 earthquake. The two design response spectra (for $5 \%$ damping) are compared in Figure 8 with response spectra of the free-field at the OVH grounds. Also shown in the figure are the response spectra of the freefield (at epicentral distance of $45 \mathrm{~km}$ ) motions recorded during the 1987 Whittier earthquake. Peak accelerations and absolute displacements for motions recorded at the roof, ground floor, and free-field, during both events are summarized in Table 2. The maximum drift reached in the Northridge event was less than $0.2 \%$.

The building is located on an alluvial fan. Several borehole logs up to $100 \mathrm{~m}$ taken in the immediate vicinity of the building indicate that the site has approximately $3-5 \mathrm{~m}$ of dense to very dense silty sand and gravel, with underlying alluvial deposits of dense to very dense sand and silty sand with gravel and cobbles and that the depth to bedrock is between 52-92 $\mathrm{m}$ (see references in Çelebi [1986a]). The thickness of the alluvium decreases towards the hills (north of the hospital). Using three possible profiles, site transfer functions corresponding for two different depths and varying shear velocities of layered substrata are calculated based on shear wave propagation method resulting in the fundamental site frequency (period) of approximately $2-3 \mathrm{~Hz}(0.33-0.5 \mathrm{sec})$ [Figure 9].

Figure 10 shows acceleration time histories for both the Northridge and Whittier events at the roof, ground floor and the free-field and corresponding amplitude spectra and spectral ratios. In the NS direction, for lower amplitude shaking during the Whittier earthquake, the structural frequencies are $\geq 3 \mathrm{~Hz}$ and for the stronger shaking during the Nothridge earthquake, the frequency cluster is between 2-3 $\mathrm{Hz}$. In the EW direction, the lowest frequency is at $3 \mathrm{~Hz}$ (Northridge) and 3.3-3.6 Hz (Whittier). The $2 \mathrm{~Hz}(0.5 \mathrm{sec})$ is the fundamental site frequency (period) because the spectral ratio of roof/ground floor or roof/free-field motions is approximately 1 (the effect of the site frequency cancels out) or small. Therefore, two effects are occurring: (1) the frequencies (periods) at the roof are lower (higher) during the strong shaking and (2) the structural and free-field fundamental frequencies (periods) are very close to one another -- evidence that the structure was in resonance between $0.3-0.4 \mathrm{sec}(2.5-3.3 \mathrm{~Hz})$ which is also well within the site period (frequency) of $0.33-0.5 \mathrm{sec}(2-3 \mathrm{~Hz})$ calculated from the soil log. The building escapes most of the low frequency $(<2 \mathrm{~Hz})$ energy in both events.

Figure 11a,b,d,e show the coherence, phase angle and cross-spectra (Sxy) plots of the two (NS) parallel motions at the roof and two parallel (EW) motions at the roof and 4th floor of the building for both events. The frequencies (e.g., for Northridge, 3.0 and $2.5 \mathrm{~Hz}$ in the NS and 3.3 and $2.7 \mathrm{~Hz}$ in the $\mathrm{EW}$ direction) are 
close and are in phase. Therefore, the parallel motions at two wings of the cruciform tower are not torsional but can possibly be attributed to the fundamental mode of the complete structure (higher frequency) being different than that of the wing of the cruciform (lower frequency). To clarify this effect, an additional sensor should be deployed in the core of the cruciform. Figures $11 \mathrm{c}, \mathrm{f}$ are prepared to investigate rocking as a form of SSI. While for the Northridge event, rocking may have taken place in the NS direction because of unity coherence and $0^{\circ}$ degree phase angle at the fundamental mode frequency $(2.5 \mathrm{~Hz})$ that clearly peaks out in the cross-spectra, the same argument cannot be made for the EW direction motions or for the Whittier earthquake motions because they have low coherency and are not in phase at the appropriate frequencies. Therefore, more vertical sensors should be deployed on the ground floor to clarify this effect with certainty.

Damping ratios extracted from system identification procedures are $10-15 \%$ (NS) and 5-10\% (EW) for Northridge and 1-4 \% (NS) and 5-8\% (EW) for Whittier. These results are consistent with the direction and level of shaking during the Northridge or the Whittier earthquake. The high level of damping ratio assessed from stronger shaking during the Northridge earthquake may be attributed to radiation damping of the incoming motions. This is further explained elsewhere (Çelebi, 1986b).

\section{CONCLUSIONS}

Both the base-isolated USC hospital and conventionally and conservatively designed OVH building performed well during the Northridge earthquake of 17 January 1994. The USC data is the first set of data from any base-isolated building that exhibits excursions into the nonlinear range of the isolators. The drift ratios experienced by the superstructure is less than 10 $\%$ of the allowable which should explain that (a) there was no damage to the structure or its contents and (b) isolators performed well and effectively dissipated (reaching $10 \%$ hysteretic damping) the energy of motions with acceleration levels equivalent to the design level accelerations. The effective performance of the isolators also reduced the drift ratios of the building.

The OVH Building data shows that with fundamental mode period (frequencies) between 0.3-0.4 $\mathrm{sec}(2.5-3.3 \mathrm{~Hz})$ escapes the wrath of the long period pulses $(>1 \mathrm{sec}$ ) characteristic of the Northridge ground motions. The effective structural frequencies derived from the Northridge and Whittier data are different and exhibit variations attributable to non-linear effects: (a) soil-structure interaction which is more pronounced during the strong shaking of the Northridge earth quake. The building possibly experienced rocking at $2.5 \mathrm{~Hz}$ in the NS direction during the Northridge event and there is possibility that radiation damping at the foundation contributed to the response. (b) non-linear behavior due to minor structural damage during the Northridge earthquake. It is also likely that the cruciform wings responses with a different frequency than that of the overall building. Additional sensors are needed to distinguish the response of the wings and the core and to clearly verify if rocking occurs.

The designer of the building conceived a very strong and stiff structure (particularly in response to the disastrous performance of the original Olive View Hospital building during the 1971 San Fernando earthquake). However, site frequencies were not evaluated and therefore consequencies were not given proper attention in the development of the design response spectrum for the new OVMC building. The data shows that fundamental frequencies of the building are well within the influence of the site frequency $(2-3 \mathrm{~Hz})$ to cause resonance. This case study indicates that representation of site resonating frequencies need to be improved in development of design response spectra. Finally, although the performance of the OVMC may be considered to be satisfactory during the $\left(M_{s}=6.8\right)$ Northridge event when the shaking was at the postulated peak design level accelerations, it is reasonable 
to ponder; however, what the realistic ground motions would be and how the building would perform during motions generated by the postulated $M_{s}=8.5$ design level earthquake as defined by the design criteria of this building.

\section{REFERENCES}

1. Asher, J., Van Volkinburg, D., Mayes, R., Kelly, T., Sveinsson, B., and Hussain, S., 1990, Seismic Isolation of the USC University Hospital, PROC. 4th. U. S. National Conference on Earthquake Engineering, Palm Springs, Ca., May 20-24, 1990 , v. 3, pp.529538.

2. Asher, J., Hosker, S., Ewing, R., Volkinburg, D., Mayes, R., and Batton, M., 1995, Seismic performance of the base-isolated USC Hospital in the 1994 Northridge earthquake, ASME/JSME Joint PVP Confrence, Hawaii, (July 23-27, 1995), v. 319, pp. 147--154.

3. Çelebi, M. (1996a). Succesful performance of base-isolated building during the 17 January 1994 Northridge earthquake. [in print].

4. Çelebi, M. (1996b). Seismic performance of the New Olive View Hospital during the Northridge and Whittier earthquakes. submitted. ASCE Journal of Structural Division.

5. Huang, M., T.,Cao, D. Parke, and A. Shakal. (1989). Processed strong-motion data from the Whittier, California earthquake of October 1, 1987 (Part I Ground Response Records), OSMS-89-03, California Department of Conservation, Sacramento, Ca., July, 1989.
6. Hudson, D. (1965). Equivalent Viscous Friction for Hysteretic Systems with Earthquake-like excitations, PROC. III. WCEE, New Zealand.

7. Jacobsen, L. S. (1960). Damping in Composite Structures, PROC. II. WCEE, Tokyo, Japan, pp. 1029-1040.

8. Shakal, A., M. Huang, R. Darragh, T. Cao, R. Sherburne, P. Malhotra, C. Cramer, R. Sydnor, V. Graizer, G. Maldonado, C. Petersen, and J. Wampole. (1994). CSMIP strong-motion records from the Northridge, California earthquake of 17 January 1994, Report No. OSMS 94-07, California Department of Conservation, Sacramento, Ca., February 1994.

9. Scientists of the USGS and SCEC. (1994). The magnitude 6.7 Northridge, California, earthquake of 17 January 1994, Science, 266, pp. 389-397, October 21, 1994.

10. Working Group on the Probabilities of Future Large Earthquakes in Southern California, 1995, Seismic hazards in Southern California: Probable earthquakes, 1994-2024, Bull. Seism. Soc. of Am., vol. 85, no. 2, pp. 379439, April 1995. 
Table 1. Peak Accelerations and Displacements of USC Hospital

\begin{tabular}{lcccccc}
\hline \multicolumn{1}{c}{ Location } & \multicolumn{3}{c}{ Max. Peak Accel. (g) } & \multicolumn{3}{c}{ Max. Peak Displ. (cm) } \\
& NS & EW & UP & NS & EW & UP \\
\hline Roof & .21 & .19 & - & 3.9 & 5.1 & - \\
6th Fl. & .11 & .15 & - & 3.3 & 4.0 & - \\
4th Fl. & .10 & .16 & - & 3.1 & 3.3 & - \\
Above Isolators & .13 & .14 & .10 & 2.8 & 3.0 & 1.3 \\
Below Isolators & .37 & .17 & .09 & 1.7 & 2.3 & 1.4 \\
Free-Field & .49 & .22 & .12 & 2.3 & 2.5 & 1.3 \\
\hline
\end{tabular}

Table 2. Peak Acceleration and Displacements at OVH

\begin{tabular}{lcccccccc}
\hline & \multicolumn{3}{c}{ Northridge Eq. } & \multicolumn{3}{c}{ Whittier Eq. } \\
Location & \multicolumn{2}{c}{$\mathrm{NS}$} & \multicolumn{2}{c}{ EW } & \multicolumn{2}{c}{$\mathrm{NS}$} & \multicolumn{2}{c}{$\mathrm{EW}$} \\
& $\mathrm{A}(\mathrm{g})$ & $\mathrm{D}(\mathrm{cm})$ & $\mathrm{A}(\mathrm{g})$ & $\mathrm{D}(\mathrm{cm})$ & $\mathrm{A}(\mathrm{g})$ & $\mathrm{D}(\mathrm{cm})$ & $\mathrm{A}(\mathrm{g})$ & $\mathrm{D}(\mathrm{cm})$ \\
\hline Roof & 2.31 & 34.1 & 0.79 & 19.2 & 0.20 & 0.65 & 0.16 & 0.79 \\
Ground Floor & 0.82 & 28.3 & 0.42 & 18.4 & 0.06 & 0.53 & 0.06 & 0.56 \\
Free-Field & 0.91 & 32.6 & 0.61 & 15.2 & 0.06 & 0.55 & 0.05 & 0.51 \\
\hline
\end{tabular}

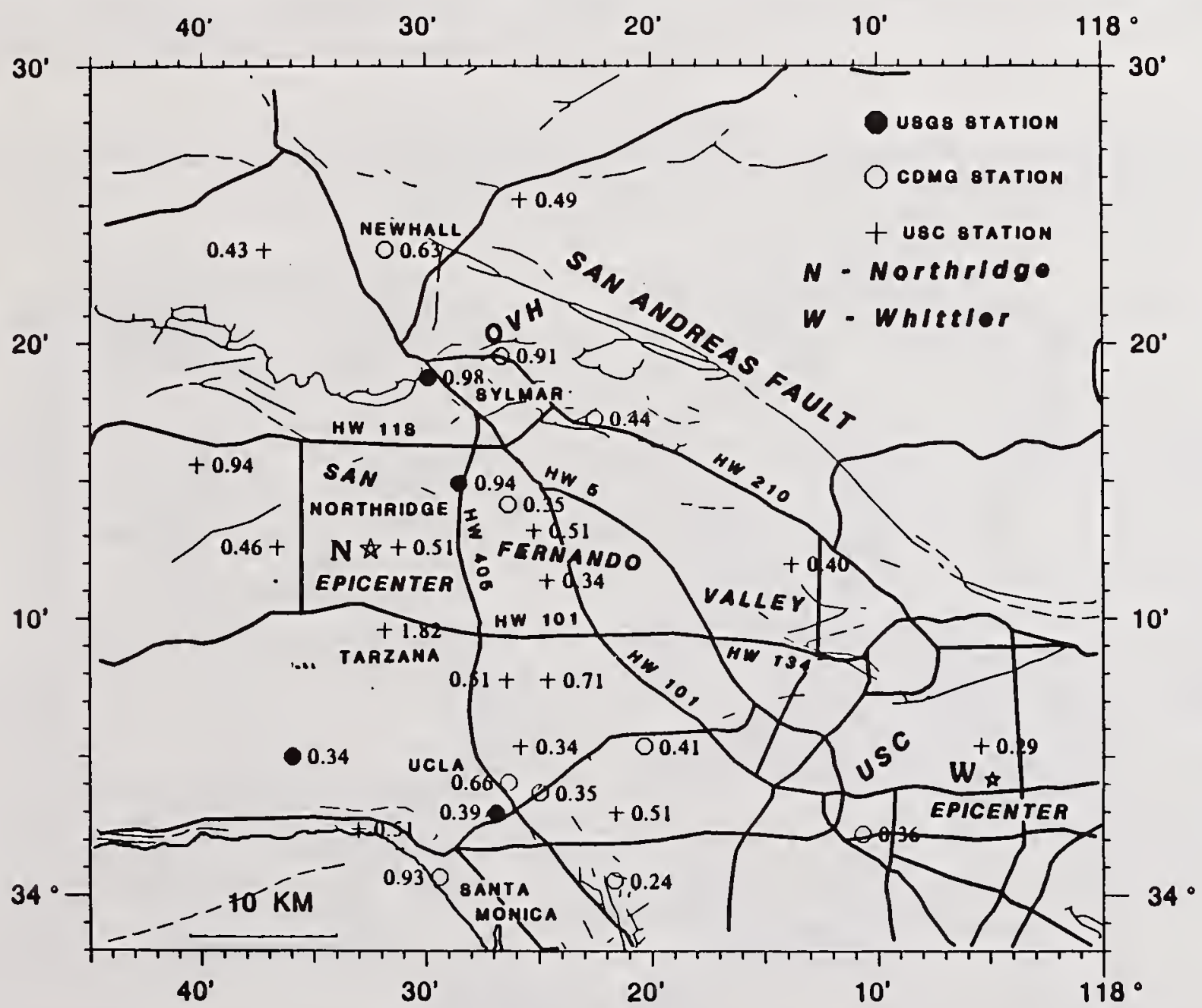

Fig. 1. Location of USC and Olive View Hospital (OVH) relative to epicenters of the Northridge and Whittier earthquakes and significant peak accelerations recorded during the Northridge earthquake. 


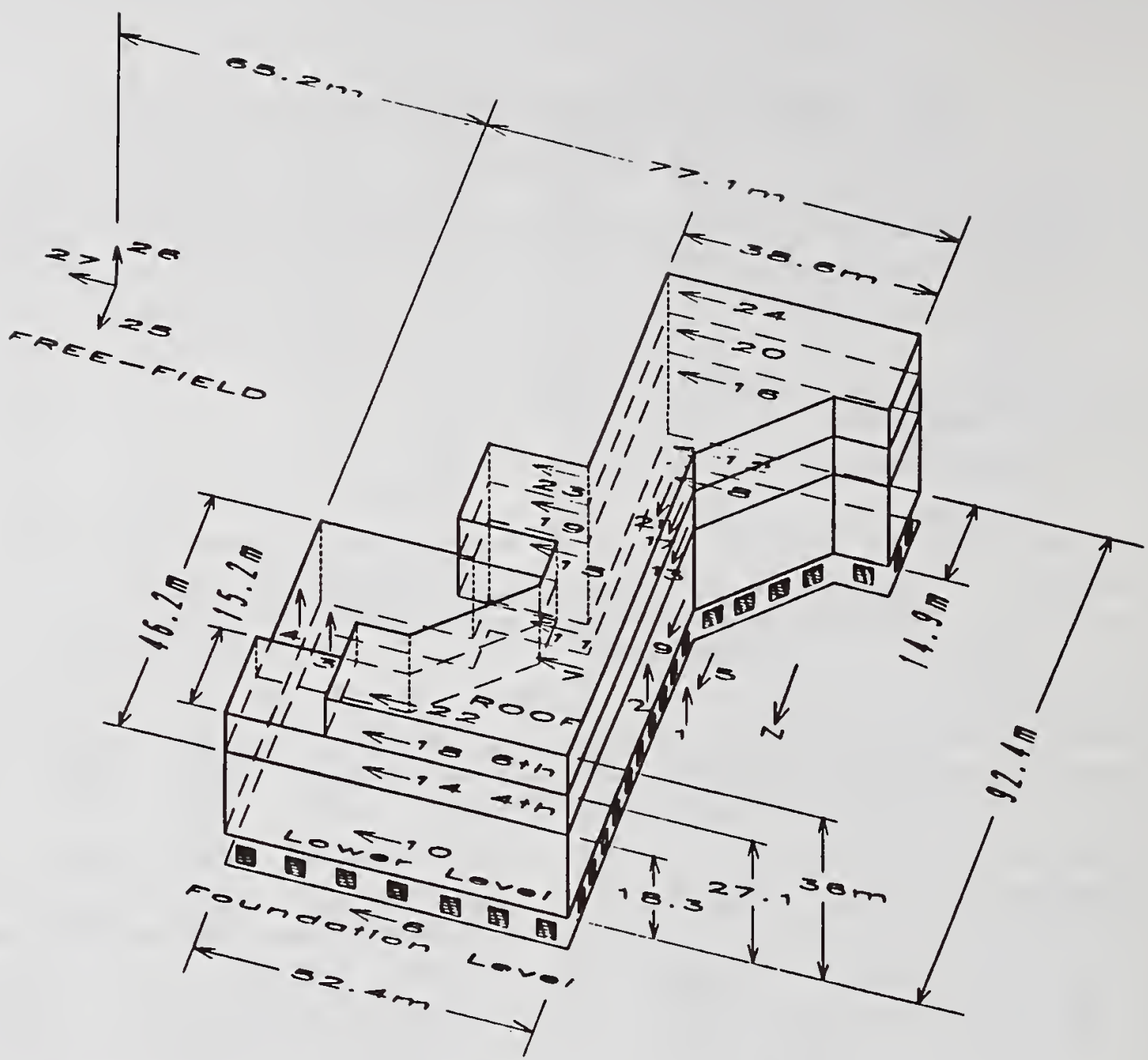

Fig. 2. General three-dimensional schematic of the USC Hospital Building showing overall dimensions, the vertical and horizontal unsymmetry and the instrumentation scheme.
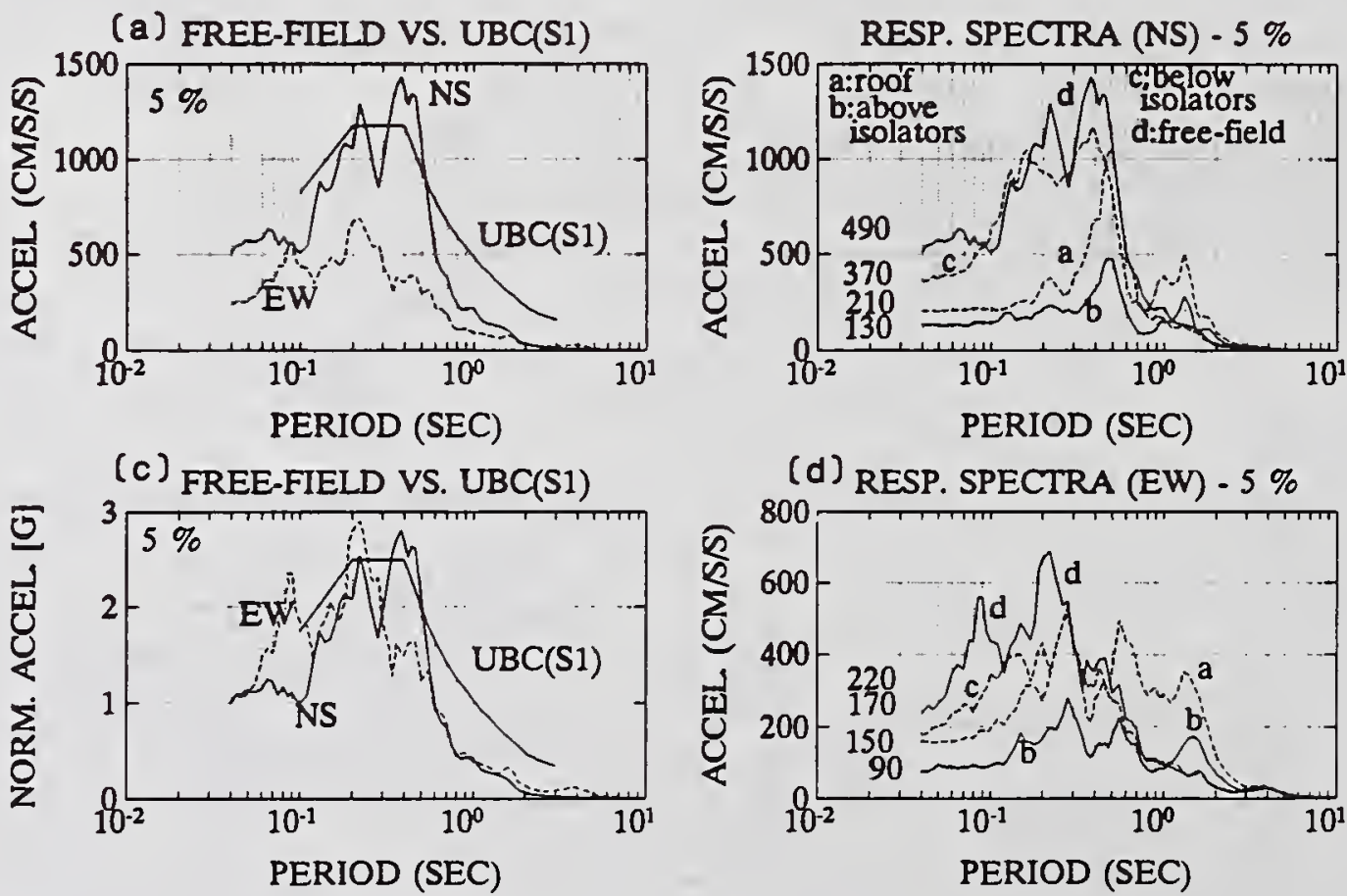

Fig. 3. Comparison of (a) free-field spectra with design response spectra, (b) normalized free-field and design response spectra and $(c, d)$ spectra of motions at different levels. 

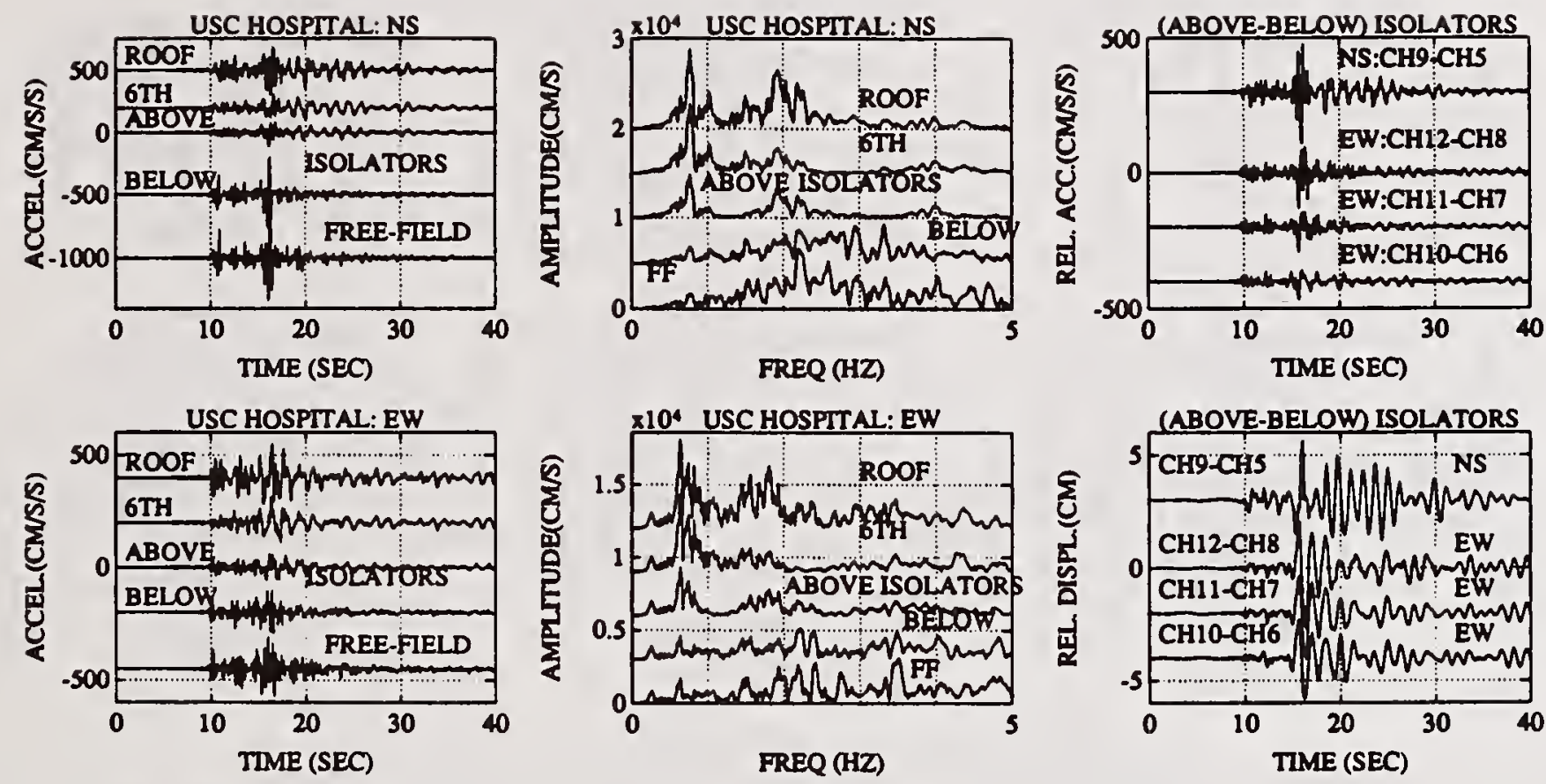

Fig. 4. (a) Accelerations and (b) displacements at various levels and (c, d) their amplitude spectra, $(e, f)$ relative accelerations and displacement of the isolators.

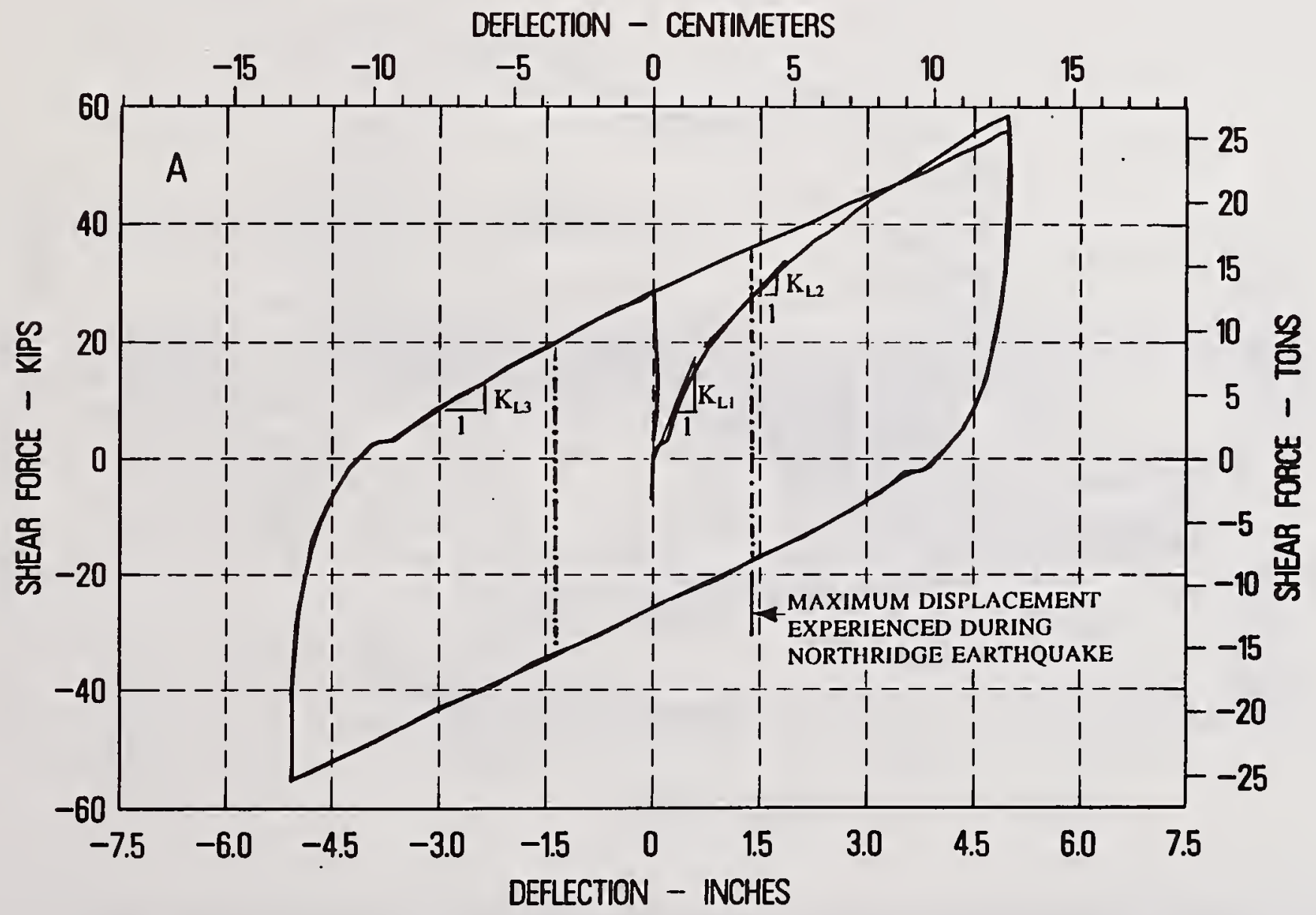

Fig. 5. Hysteresis loops from the laboratory testing of a prototype lead-rubber isolator. 

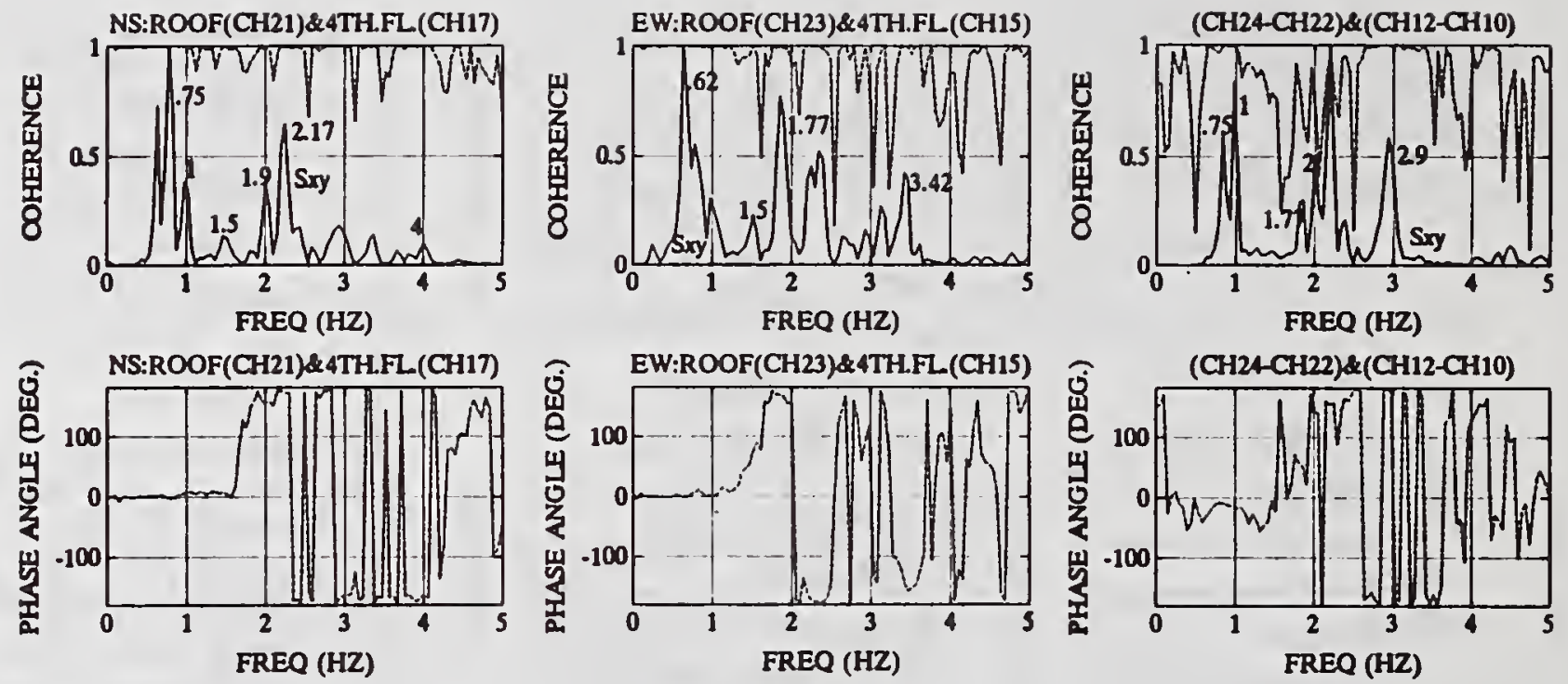

Fig. 6. Cross-spectra, coherence function and phase angle plots motions at roof and 4th floor and torsional motions at the roof and lower level.

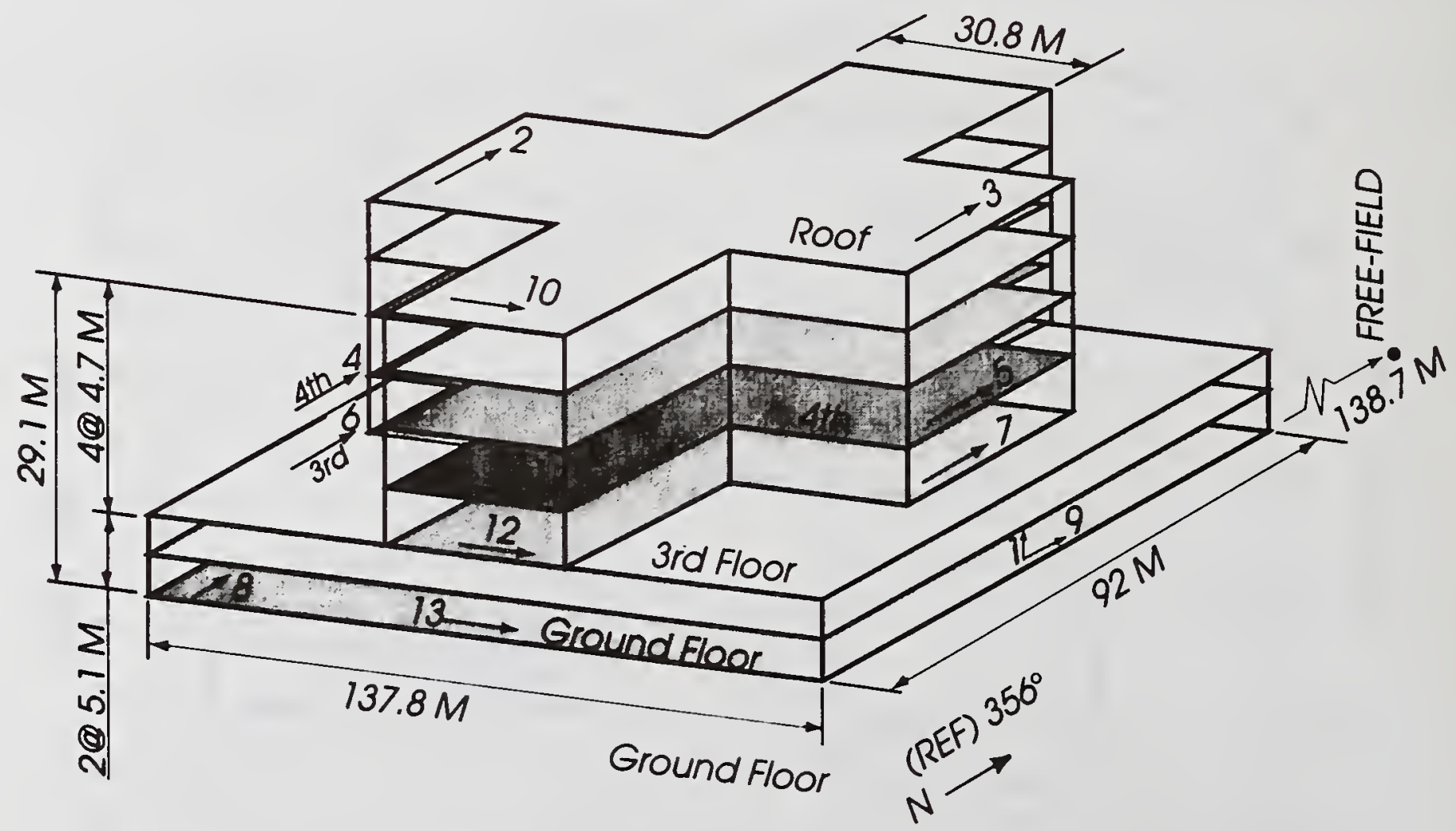

Fig. 7. General three-dimensional schematic of the Olive View Hospital (OVH) Building showing overall dimensions, the instrumentation scheme and the free-field site location. 


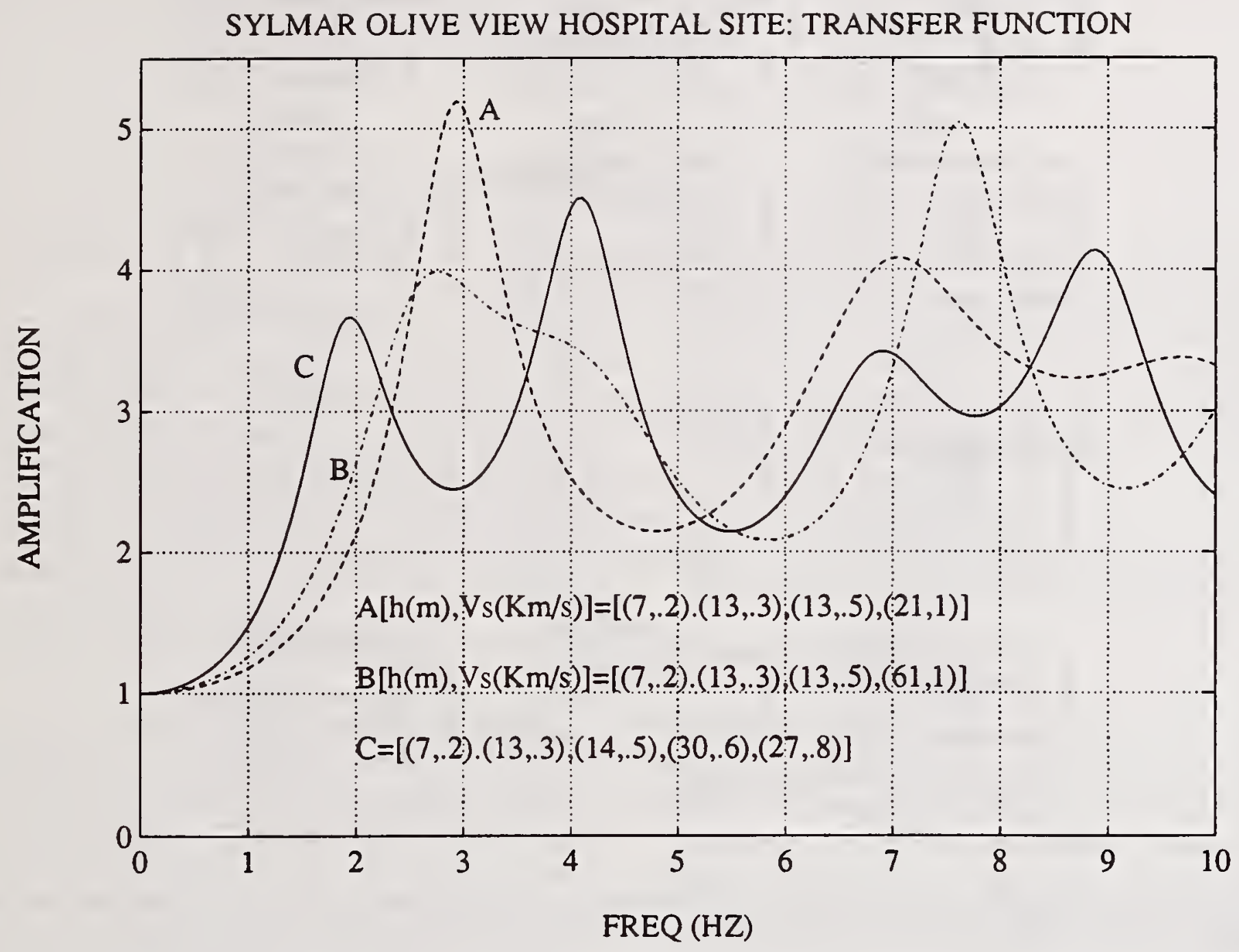

Fig. 8. Site transfer functions of OVH building site.

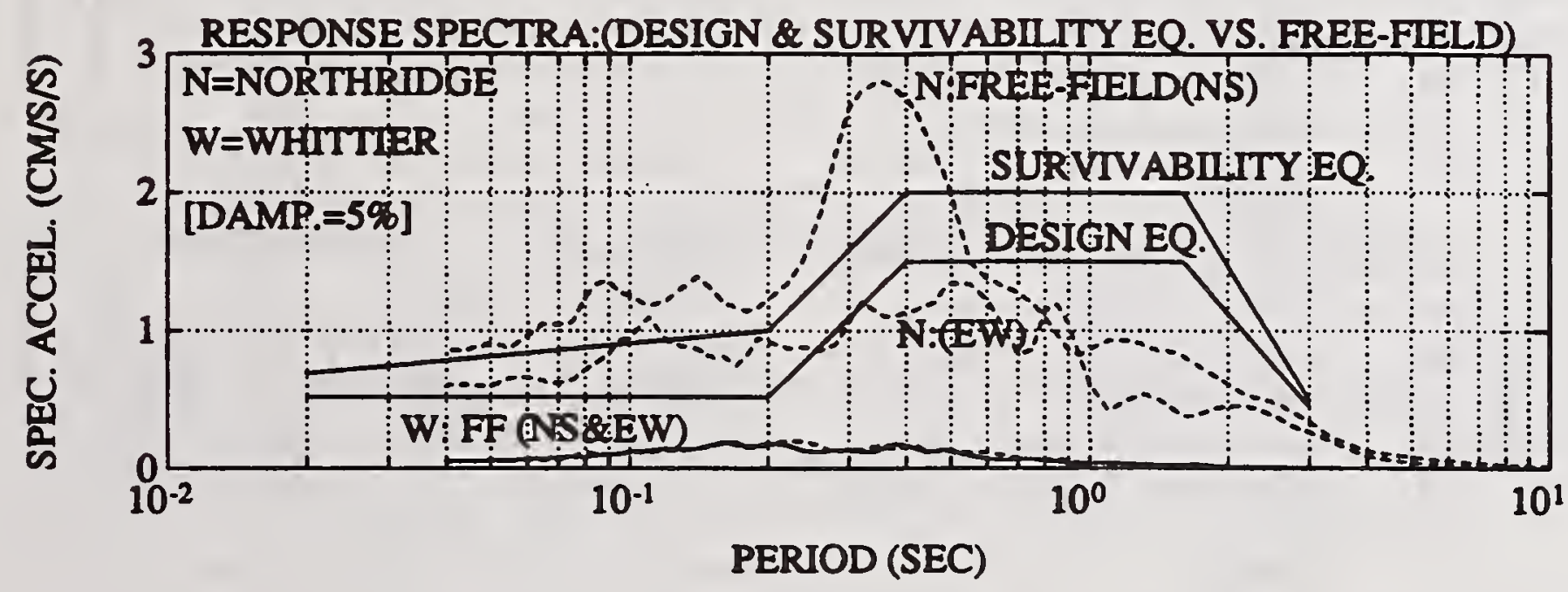

Fig. 9. Comparison of design response spectra with response spectra of free-field motions recorded at the OVH site during the Northridge and Whittier earthquakes. 

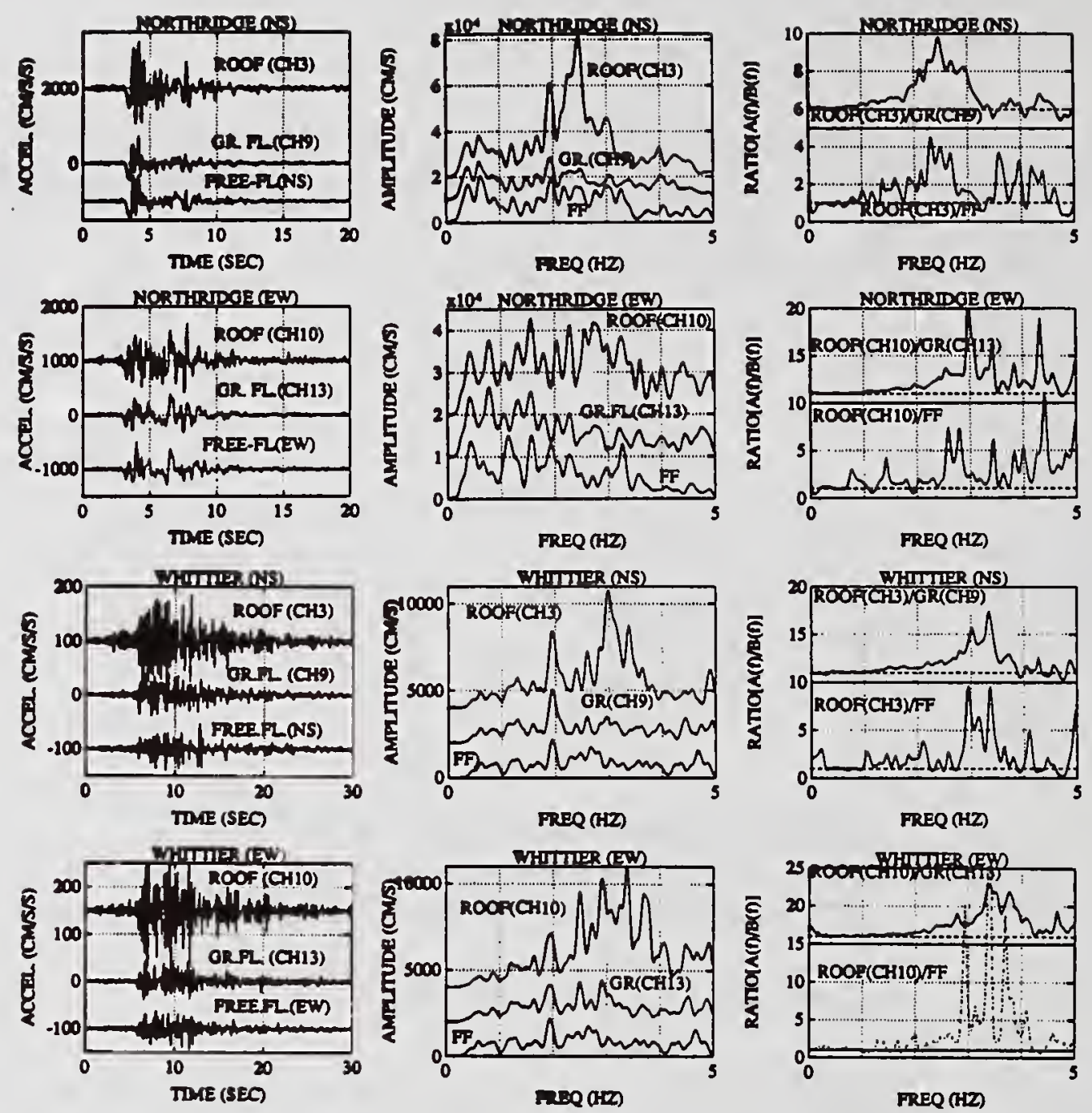

Fig. 10. Accelerations recorded during the Northridge and Whittier earthquakes at the roof, ground level and free-field and corresponding amplitude spectra and spectral ratios.
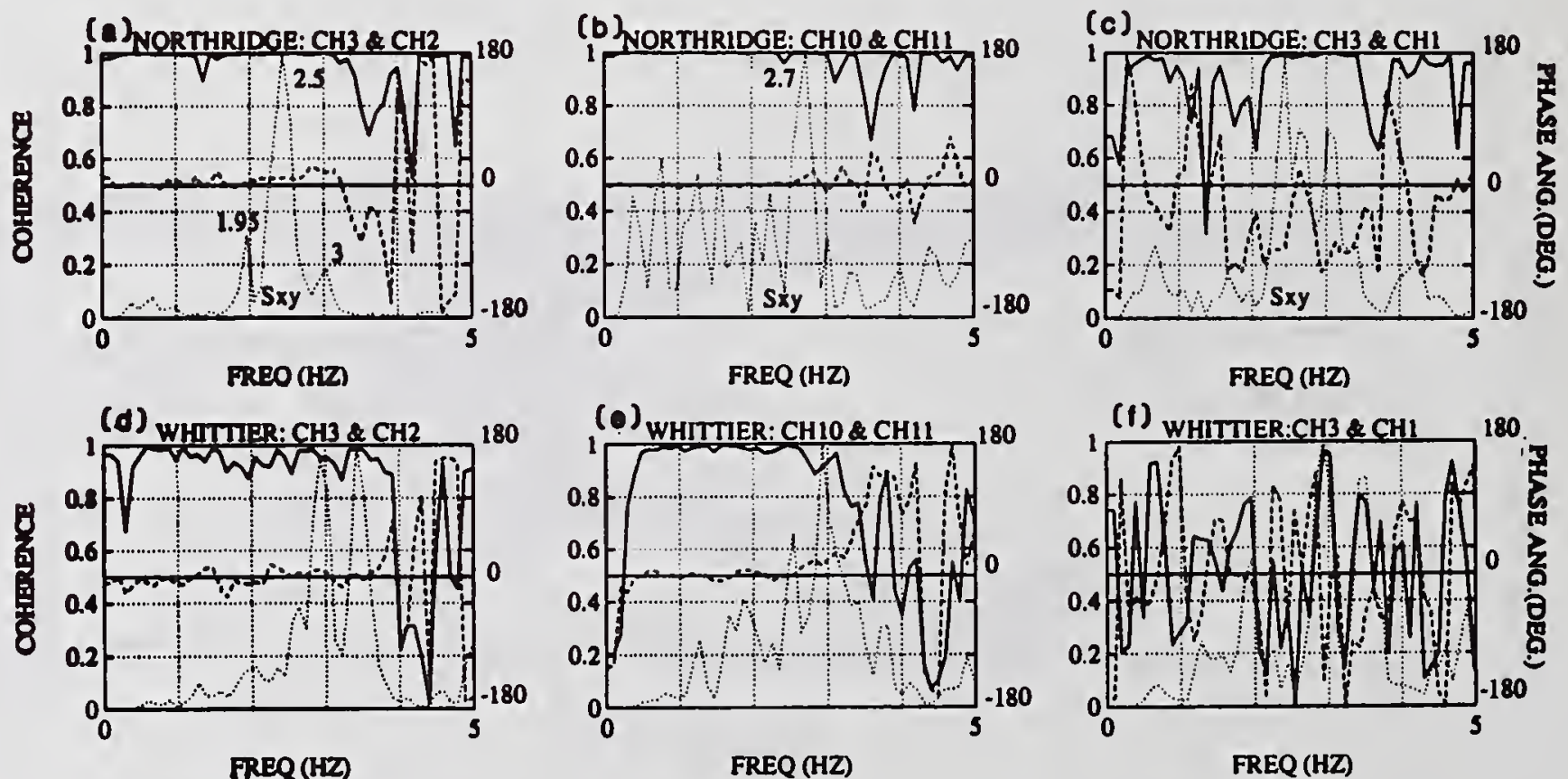

FREQ (HZ)

Fig. 11. Coherency, phase angle and cross-spectra plots of (a) parallel NS motions at the roof, (b) EW motions at the roof and 4th floor, and (c) horizontal motion at the roof and vertical motion at ground floor for the Northridge earthquake. $d, e$, and $f$ are for the Whittier earthquake. 


\title{
Recent U. S. Experience in Design and Testing of Beam-to-Column Connections for Moment-Resisting Steel Frames
}

by

\author{
Ferdinand LoRay Schwartz *
}

\begin{abstract}
This paper presents a compilation of recent reports describing emergency changes to the Uniform Building Code and resulting design information and test data for an improved design of beam-to-column connections for momentresisting steel building frames. The design of this special connection or joint was developed for construction of the U.S. Department of Energy funded Human Genome Laboratory at the Lawrence Berkeley National Laboratory.
\end{abstract}

An earthquake of 6.7 magnitude hit Northridge, California, on January 17, 1994, and a similar earthquake that devastated Kobe, Japan, exactly one year later caused serious, unexpected cracking in and around the rigidly welded joints of moment-resisting steel building frames of the strong column-weak beam design. This traditional design concept under seismic loading should result in elastic behavior of the column and plastic behavior of the connected beam. The discovery of cracks in and around beam-tocolumn joints raised the specter of these failures leading to partial or complete building collapse.

As a result of the discovery of the cracked joints, the International Conference of Building Officials adopted an emergency change to the Uniform Building Code requiring that new joint designs be verified by analysis or test to confirm meeting the required strength criteria. At the time the emergency code changes were issued, the Human Genome Laboratory was in the design phase. A new design of a Special Moment-Resisting Frame (SMRF) joint was developed and successfully tested for use as the structural lateral system for the facility. Since a number of other new designs failed similar testing, the SMRF joint represents a breakthrough in the development of beam-tocolumn joints which meet the emergency Uniform Building Code requirements. The SMRF joint is generally less complex to fabricate and erect than other new joint designs and is only slightly more expensive than the "pre-Northridge" welded joints which failed.

KEYWORDS: cracked welds; Northridge; joint design; moment-resisting; seismic; steel frames.

\section{INTRODUCTION}

On January 17, 1994, an earthquake of 6.7 magnitude hit Northridge, California, about 20 miles from Los Angeles. Mr. Donald G. Eagling describes the earthquake-induced structural failures resulting from this event in the U.S. Department of Energy's draft Seismic Safety Manual (Ref. 1) and provides considerable historical and technical data on structural design, structural failures, and the new building code requirements for ensuring resistance to earthquakes. During the Northridge event, horizontal ground accelerations of approximately $1 \mathrm{~g}$ caused major, widespread damage affecting more than 12,000 residential and commercial structures as well as highways and bridges. Classic damage, including total collapse, occurred to unreinforced masonry, non-ductile reinforced concrete, and multistory wood frame structures. Even some structures which were designed and constructed in compliance with the then current Uniform Building Code (UBC) suffered severe damage well beyond what might

* Office of Energy Research, U.S. Department of Energy, Washington, DC 20585 
be expected as a result of an earthquake of the magnitude of the Northridge event.

Inspections of beam-to-column joints after the event disclosed very serious failures in momentresisting steel frame beam-to-column joints of some structures designed to the UBC. These unexpected failures manifested themselves as significant cracking in and around the double sided, full penetration welded tee connection between the beam end and the flange of the supporting column. This "pre-Northridge" joint design is typical for steel building frames using the strong column-weak beam approach to accommodating seismic loads. The column is designed to carry the cyclic lateral loads imposed by the ground motion without exceeding the elastic limit for the column size and material. The beam, however, is supposed to deform plastically above a predetermined load to prevent over stressing or fracturing the joint or the column. In this manner the integrity of the frame is maintained, preventing collapse of a floor or the entire structure.

An earthquake of 6.8 magnitude devastated Kobe, Japan, exactly one year after the Northridge event. This earthquake destroyed about 20,000 buildings and severely damaged another 35,000. Even though the two earthquakes were of nearly equal magnitude, the much greater extent of damage in Kobe compared to Northridge was due in large part to the much higher population and building density in Kobe combined with a large number of typical wood frame residential structures. Like Northridge, however, the Kobe event caused the same unexpected cracking failures in several buildings with moment-resisting steel frames. These modern buildings were designed to the applicable building codes which are very similar to $\mathrm{UBC}$ requirements (the $\mathrm{UBC}$ is developed with international cooperation).

\section{EVALUATION, OF FAILURES}

Investigations in the aftermath of the Northridge earthquake indicated a number of potential problems in design and construction of strong column-weak beam joints including the following:

- The UBC includes both specific minimum code requirements and general (intent) provisions incorporating good engineering practices. Many newer structures were constructed under "design-build" contracts and were designed only to meet the minimum requirements of the code. Due to the competitive nature of the construction business, compliance with the general provisions of the code, which might have resulted in more conservative designs, generally was not mandated by the contracts. There is evidence that had the building designs also met the intent of the general provisions, at least some of the failures would not have occurred.

- Fractures in the welded joints of a 4-story commercial building were initially attributed to poor workmanship in welding the connections. However, review of historic test data, combined with a series of tests performed after the earthquake, indicated that even connections made with standard quality workmanship were vulnerable to this kind of damage. However, the review did highlight the importance of weld quality on the seismic performance of this kind of joint.

- Steel overstrength has become a serious problem for designing the strong column-weak beam joint, particularly when different strength steels are specified for the column and beam. In general the standard grades of steel produced exceed, but by a relatively small margin, the minimum required strength for the specified grade. The problem arises from the steel industry's practice of down grading a heat of steel if its strength properties do not meet the intended minimum. The result is that the material significantly exceeds the minimum strength of the next lower strength grade. When the design of a joint depends on its predictable inelastic behavior, the use of 
overstrength beam material may not allow plastic deformation of the beam at a low enough load to prevent excessive load being placed on the beamto-column joint.

- The observed cracking failures in and around the beam-to-column weld were brittle in nature. This could be attributed to one or a combination of several factors.

- The tendency for the heat-effected zone of a weld to be more brittle than the surrounding base metal unless sufficient preheat and careful post-heat cool-down are employed.

- Work hardening of the joint during the earthquake induced strain leading to low cycle fatigue failure.

- Typical beam-to-column joint designs with full penetration welds between the beam end and the column flange are so rigid that the cross sectional area of the weld interface cannot deform sufficiently under large bending loads to allow the joint to remain ductile.

Regardless of the cause, the standard "preNorthridge" welded beam-to-column joint used for moment-resisting steel frames exhibited a here-to-fore unnoticed and very dangerous flaw that exists in innumerable buildings throughout the world.

\section{CODE REVISIONS}

Shortly after the discovery of the unexpected steel frame joint failures in the Northridge area, the International Conference of Building Officials (ICBO), which publishes the UBC, adopted an emergency change to the code requiring that new joint designs be verified by analysis or test to confirm meeting the required strength criteria. The emergency change requires that new designs must take into consideration the effects of both overstrength and strain hardening of the beam steel which were among the suspected causes of the earthquake-damaged frame joints.
In addition, the problem is being intensively studied by the SAC, a joint venture of the Structural Engineers Association of California (SEAOC), the Applied Technology Council (ATC), and California Universities for Research in Earthquake Engineering ( $\underline{C} U R E e)$. Under emergency authorizations from the California Office of Emergency Services and the Federal Emergency Management Agency, SAC is performing research aimed at steel frame seismic damage. The results, in the form of Design Advisories and Interim Guidelines, provide assistance to both engineers and building officials pending development of new UBC provisions.

\section{IMPROVED JOINT DESIGN}

At the time that the emergency UBC changes were issued, the new Human Genome Laboratory at the Lawrence Berkeley National Laboratory was being designed and was immediately impacted by the UBC changes. Forell/Elsesser Engineers, Inc., the structural designer for the facility, undertook a study to develop and test a beam-to-column joint for the Special MomentResisting Frames (SMRF) selected as the structural lateral system for this building. The building consists of three seismically isolated modules. Details of design and testing results are provided in Lawrence Berkeley National Laboratory, Human Genome Laboratory Steel Joint Test - Technical Brief (Ref. 2). The design that evolved from this effort depends on limiting stresses in the column and panel zone to less than the elastic limit and on inelastic buckling of the beam flange away from the beam-to-column joint. It requires the use of materials of known mechanical properties, high quality welding processes, skilled crafts personnel, and diligent quality control.

\subsection{Physical Description}

The SMRF joint design is shown in Figure 1. Neither the beam flanges nor the beam web is welded directly to the column. The beam cover plates are welded to the column flange with full 
penetration groove welds.

The bottom cover plate is shop welded to the column while the top cover plate is shop welded to the beam using longitudinal fillet welds along the beam flange edges. The width of the cover plates and the column flange width are equal where the plates abut the column flange. The cover plates then taper down to a total width two inches greater than the beam flange width. The full width of the column flange at the cover plate interface distributes stress in the cover plate/column joint region as uniformly as possible. The design allows easy removal of weld tabs, facilitates inspection of the weld ends after grinding, and avoids using overhead welds.

The beam web is attached to the column using a trapezoidal web plate. The web plate is welded to the column in the shop with a full penetration, double-sided groove weld. The web plate is welded to the beam web in the field with a threesided fillet weld. The web plate is tapered to facilitate welding of the top and bottom sections of the fillet weld in the field. The beam web and web plate are predrilled in the shop to accommodate temporary bolts used to simplify field erection and to hold the beam in position for welding.

Within the column, top and bottom continuity plates are positioned on each side of the column web to align with the beam cover plates. Each of the four continuity plates is chamfered at the two inside corners to prevent contact with or welding to the column flange-web fillets. The continuity plates are welded with full penetration groove welds.

A temporary stiffener bar is welded diagonally between the under side of the bottom cover plate and the column flange during shop fabrication to prevent inadvertent stressing of the bottom cover plate groove weld during shipping and erection. This stiffener bar is removed after field erection and welding are complete.
The overall design of the beam-to-column joint offers several additional positive features over other "post-Northridge" designs as follows:

- The total cross-sectional weld area is reduced resulting in both cost reduction and the technical benefits of less heating and reduced weld shrinkage which increase reliability.

- Beam shop fabrication time is reduced by the absence of flange and web weld preparations and the need for only one weld access relief at the top of the web and top flange of the beam. The weld access relief accommodates installing and removing the backup bar for the top cover plate field weld.

- Field erection time is lessened with only one down-hand full penetration groove weld (with no interference from the beam web) for welding the top flange cover plate to the column, two fillet welds for welding the beam flange to the bottom flange cover plate, and the three-sided fillet weld for welding the web plate to the beam web.

\subsection{Design Parameters}

The SMRF joint is designed to force plastic deformation in the beam to occur away from the welded region. The length of the cover plates is approximately one nominal beam depth measured from the column centerline. However, longer cover plate lengths may be required for beams of less depth to provide sufficient length and, therefore, strength of the fillet welds between cover plates and the beam flanges. The beam is proportioned to satisfy stress and drift requirements with the additional requirement that excessive beam strength must be minimized. The column is proportioned to satisfy UBC panel zone strength requirements without using column web doubler plates.

Strong column-weak beam response is confirmed by plastic frame analysis of all possible mechanisms, accounting for the additional 
flexural demands imposed on the column by the eccentric plastic hinge location.

The design parameters and specifications used for the SMRF joint test specimens are summarized in Table 1.

\subsection{Welding Requirements}

Weld specifications stipulate special provisions for all welds used in the SMRF joint. These include:

- Detailed welding procedure specifications; welding inspection checklists; qualification of welders using high-grade materials; 100 percent ultrasonic inspection in the shop and field inspections using magnetic particle or dye penetrant techniques.

- Flux cored arc weld (FCAW) and shielded metal arc weld (SMAW) processes were subject to the following limitations:

- Charpy V-Notch toughness of weld wire of 20 foot pounds at minus $20^{\circ} \mathrm{F}$ minimum.

- Preheat requirements about $50^{\circ} \mathrm{F}$ higher than AWS D1.1.

- Post-weld control of cool-down rate if ambient temperature goes below $50^{\circ} \mathrm{F}$.

- Requirements for peening all but root and cap passes to provide stress relief.

- Grinding of all thermally cut surfaces.

- Removal of weld tabs and backup bars.

\section{PROTOTYPE JOINT TESTS}

\subsection{Test Development}

Nonlinear dynamic analysis of the building frame was used to establish the test acceptance criteria. Building frames were designed in accordance with Lawrence Berkeley National Laboratory seismic criteria which specified an allowable stress design (ASD) static base shear of 20 percent for two buildings and 28 percent for the third building. The analysis indicated that plastic beam rotations of about 0.02 radian could be expected for a Hayward seismic event, the appropriate design basis for the Berkeley area. For the buildings being designed, the total beam rotations are in the range of 120 percent to 140 percent of the maximum interstory drift. Allowing for both the limited accuracy of structural calculations and a higher than predicted seismic event, test acceptance criteria were established to achieve at least three cycles that result in plastic beam rotations of 0.03 radian, computed at the plastic hinge location.

\subsection{Specimen Material Properties}

Material properties were verified by mill certificates and by independent laboratory testing performed by Signet Testing Laboratories. The results are provided in Table 2.

\subsection{Specimen Fabrication and Testing}

Two test specimens were fabricated by The Herrick Corporation at their Stockton, California, facility. The specimens were tested at the Davis Hall Laboratory at the University of California at Berkeley. The testing arrangement and protocol were identical to the SAC test procedures.

All shop welds were made using standard shop practices. Field erection was simulated in the shop with the column vertical and the beam temporarily shored at its free end. Groove welds were made with Lincoln NR-311 FCAW wire. Fillet welds were made with Lincoln NR-232 FCAW wire. Specimens were fitted with potentiometers, strain gauges, and strain rosettes.

During preparation of Test Specimen 2, the technicians at Davis Hall Laboratory discovered a four inch long by $3 / 16$ inch deep crack in the column flange. It was located on the flange centerline starting at the bottom cover plate weld and extending downward away from the weld. The crack was discovered while grinding the area for installation of instrumentation. Signet Testing Laboratories determined that the crack was an 
acceptable defect by AWS D1.1. The testing team elected to proceed with the test without repairing the crack.

Each test specimen was installed in the test machine with the column and beam in the horizontal position to accommodate the physical design and constraints of the machine. The test arrangement is shown in Figure 2. The column flange ends were restrained from motion in the direction perpendicular to the plane of the column flanges by knife edge type supports which were placed 11 feet 6 inches apart and equidistant from the centerline of the beam. The test loads were applied to the beam flange in the direction perpendicular to the beam flanges at a distance of 12 feet from the column centerline. The test was performed by applying cyclic loads to the beam to cause deflections of from \pm 1 inch to \pm 5 inches of the beam tip at the point of load application. This simulated bending moments applied to the joint by the lateral movements of a steel frame caused by seismic events of increasing magnitude. The test steps spanned both the point of expected plastic deformation and the point of expected fracture.

\subsection{Test Results}

Both specimens met the acceptance criteria of three cycles of 0.03 radian plastic beam rotation. The general results of the tests on the two specimens are summarized in Table 3.

Specimen 1 was tested up to three cycles at \pm 5 inches of tip displacement. The permanent deformation of the beam web and flanges of Specimen 1 at the end of the five test steps is shown in Figure 3.

Specimen 2 was tested up to 10 cycles at \pm 5 inches tip displacement whereupon a beam flange fractured in the buckled region due to high strain cyclic fatigue. Also, for Specimen 2, there was evidence of minor yielding near the column crack found prior to the tests, but the crack did not appear to open or propagate during the tests.

\subsection{Cost and Other Considerations}

The cost to fabricate and erect the SMRF joint for . the Human Genome Laboratory is estimated at approximately $\$ 1000$ per joint compared to approximately $\$ 500$ per joint for a "preNorthridge" joint used in the same application. This cost differential is relatively small compared to a number of other joints designed and tested to meet the requirements of the emergency changes to the UBC.

The designer has cautioned that every potential application of the SMRF joint design, or any other advanced design, is unique and must be qualified for the specific loads and geometries for which its use is intended.

\section{CONCLUSIONS}

Brittle failures in and around the beam-to-column joints of moment-resisting steel building frames were discovered after the Northridge, California, earthquake early in 1994. As a result, requirements for the design and qualification of this type of joint have been greatly modified. The SMRF joint design has been shown by both calculation and testing to more than adequately meet the demanding requirements for resistance to the limiting earthquake-induced loading which might be expected in the Lawrence Berkeley National Laboratory area. The design offers several unique features which improve seismic performance over conventional, fully welded designs of the "pre-Northridge" concept. These include more uniform distribution of stresses in the welds connecting the beam and column, reduced fabrication and erection complexity, elimination of difficult overhead welds, and improved reliability due to reduced welding. Finally, the SMRF joint design is cost effective compared to a number of other new joint designs which are being considered for use.

\section{ACKNOWLEDGMENTS}

The author acknowledges the expertise of Mr. 
Donald G. Eagling, retired plant manager of the Lawrence Berkeley National Laboratory, whose treatise on earthquake-induced structural failures in Chapter 3 of the U.S. Department of Energy's draft Seismic Safety Manual (Ref. 1) was the source of the historical and technical data on the Northridge and Kobe earthquakes, the evaluation of the beam-to-column joint failures discovered, and implementation of the emergency building code changes described in this paper.

The author is indebted to Mr. Mark Jokerst, SE, of Forell/Elsesser Engineers, Inc., for allowing the use of the design information and test data presented in Lawrence Berkeley National Laboratory, Human Genome Laboratory Steel Joint Test - Technical Brief (Ref. 2) and for providing additional information and insight on the design, fabrication, and testing of the SMRF joint.

Finally, appreciation is extended to Mr. Ronald Levis, of Roy F. Weston, Inc., for applying his experience and knowledge of structural design to the development, editing, and production of this paper.

\section{REFERENCES}

1. Eagling, D.G. (1995). "Seismic Safety Manual, A Practical Guide for Facility Managers and Earthquake Engineers (DRAFT)." U.S. Department of Energy.

2. Jokerst, M. (1995). "Lawrence Berkeley National Laboratory, Human Genome Laboratory Steel Joint Test - Technical Brief." Forell/Elsesser Engineers, Inc., San Francisco, CA.

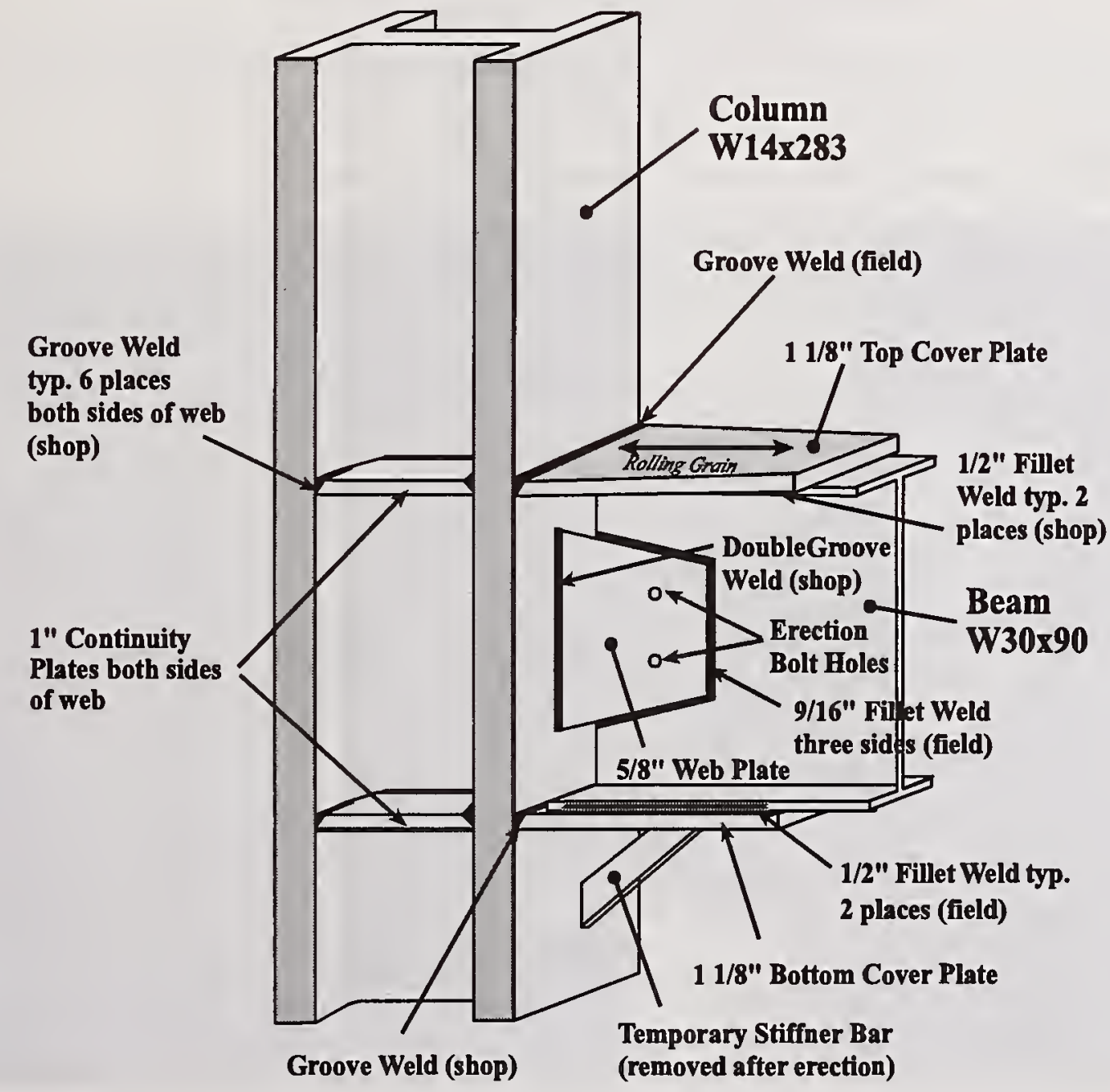

Figure 1. SMRF Joint Design 


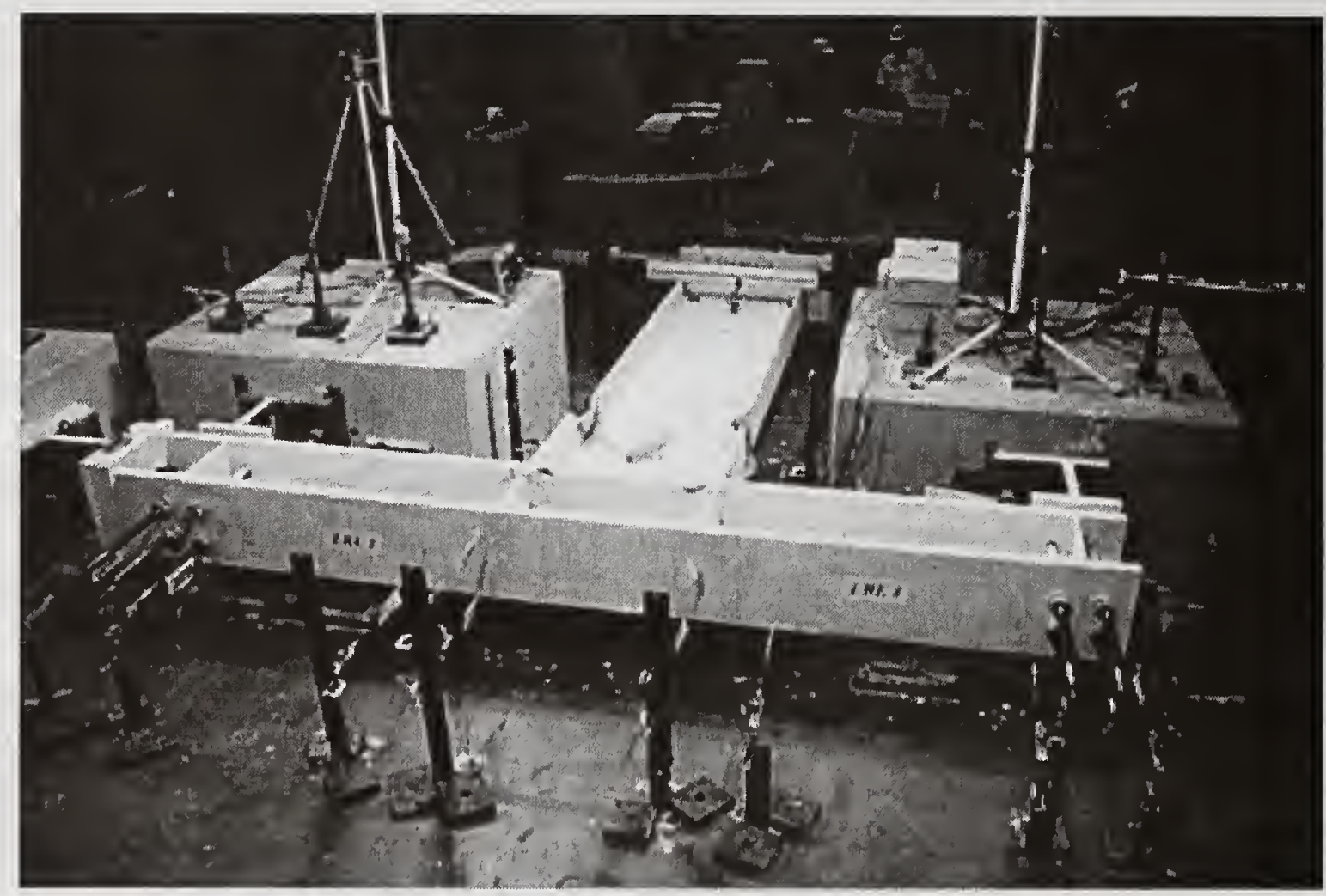

Figure 2. SMRF Test Assembly

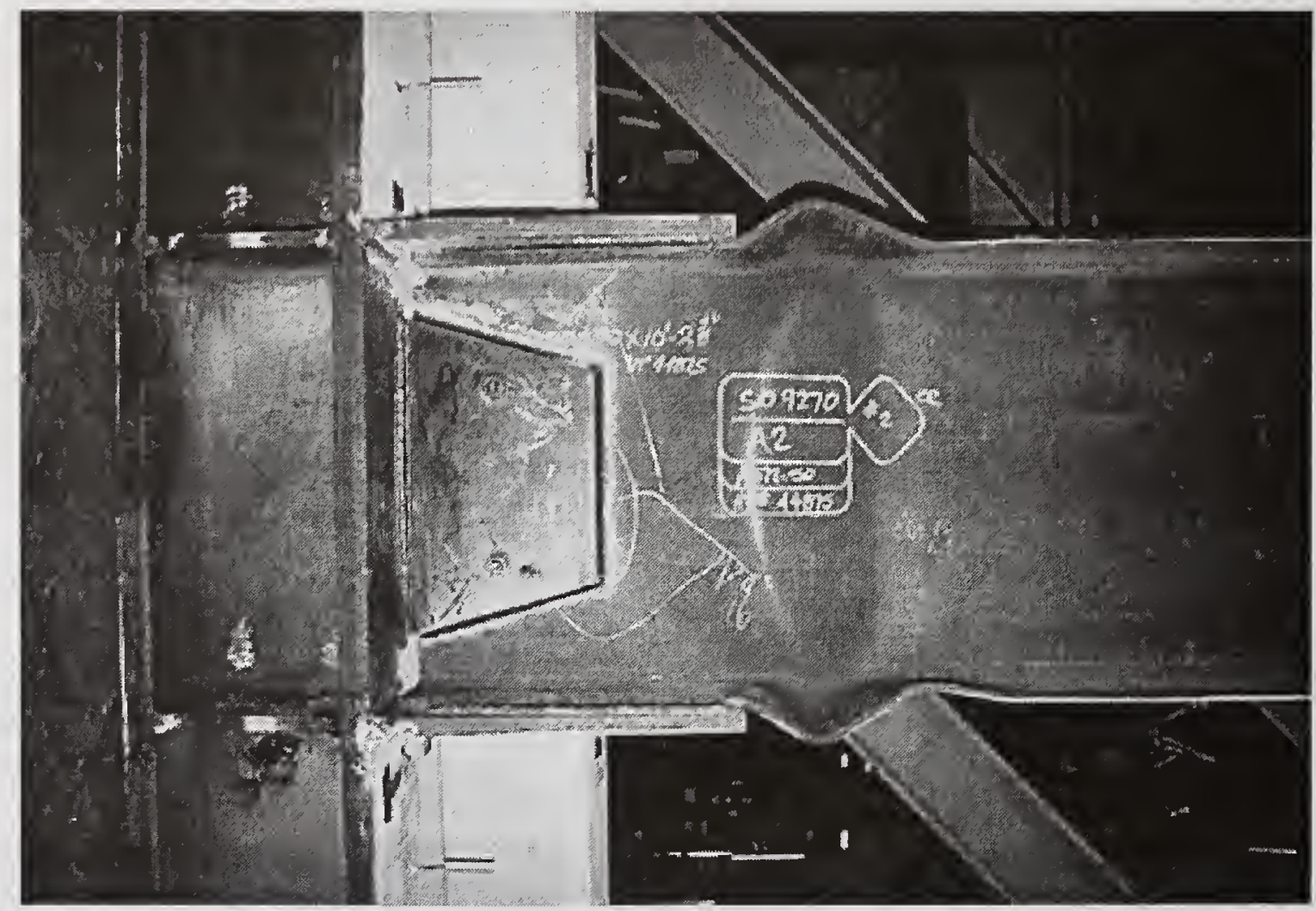

Figure 3. Permanent deformation of Test Specimen 1 at end of test 
Table 1. Test Specimen Parameters and Specifications

\begin{tabular}{||l|l||}
\hline Piece & \multicolumn{1}{|c||}{ Parameters and Specifications } \\
\hline \hline Beam & $\begin{array}{l}\text { ASTM A572 Grade 50; no limit placed on maximum yield strength. For design of the } \\
\text { connection, the mean plus one deviation of the SAC 95-01 Table A (Appendix D) data } \\
\text { (mean yield strength of 57.6 ksi and standard deviation of 5.1 ksi), plus a 10\% strain } \\
\text { hardening factor, less a 5\% web to flange strength conversion was used, yielding a total } \\
\text { effective Fy = 65.5 ksi. }\end{array}$ \\
\hline Column & $\begin{array}{l}\text { ASTM A572 Grade 50; fine grained fully killed with grain size } 6 \text { or finer; minimum } \\
\text { Charpy V-notch toughness, determined at the centerline intersection of web and flange, } \\
\text { was 20 foot pounds at 40 } \mathrm{F} \text {. In all calculations, possible material overstrength was } \\
\text { neglected. }\end{array}$ \\
\hline $\begin{array}{l}\text { Cover } \\
\text { Plates }\end{array}$ & $\begin{array}{l}\text { ASTM A572 Grade 50 with rolling grain parallel to the beam axis. Flexural stress at } \\
\text { cover plate-column interfaces = 40ksi. }\end{array}$ \\
\hline \hline
\end{tabular}

Table 2. Test Specimen Material Properties

\begin{tabular}{||c|c|c|c|c|c|c||}
\hline Piece & $\begin{array}{c}\text { Fy, } \\
\mathrm{ksi}\end{array}$ & $\begin{array}{c}\text { Fu, } \\
\mathrm{ksi}\end{array}$ & $\begin{array}{c}\text { Elongation, } \\
\%\end{array}$ & $\begin{array}{c}\text { CVN, } \\
\mathrm{ft}-\mathrm{l} b\end{array}$ & $\begin{array}{c}\text { Average } \\
\text { Grain Size }\end{array}$ & $\begin{array}{c}\text { Tested } \\
\text { by }{ }^{(2)}\end{array}$ \\
\hline \hline W30x90 Beam & 60 & 71 & 26 & & & Mill \\
\hline Web & 61.1 & 70.4 & 36.5 & & & Lab \\
\hline Flange & 50.3 & 66.1 & 41.0 & & & Lab \\
\hline \hline W14x283 Column & 51 & 70 & 29 & & & Mill \\
\hline Web & 48.5 & 67.5 & 32.5 & & & Lab \\
\hline Flange & 45.5 & 67.5 & 32.5 & $21.4 @ 40^{\circ} \mathrm{F}$ & \#6 - \#7 & Lab \\
\hline \hline Cover Plates & 61.4 & 88.2 & 22 & & & Mill \\
\hline \hline Web Plate & 61.5 & 87.5 & 28.0 & & & Lab \\
\hline \hline
\end{tabular}

NOTES

(1) Charpy V-Notch test

(2) "Mill" indicates data from mill certificate; "Lab" indicates Signet Testing Lab data 
Table 3. General Test Results

\begin{tabular}{|c|c|c||}
\hline $\begin{array}{c}\text { Tip } \\
\text { Displacement, } \\
\pm \text { inches }\end{array}$ & $\begin{array}{c}\text { Op, Plastic } \\
\text { Beam } \\
\text { Rotation, } \\
\text { radians }\end{array}$ & \multicolumn{1}{|c|}{ Description of Beam Reactions to Test Loading } \\
\hline \hline 1 & 0.000 & Very minor flaking of the paint (yield occurs at 1.1 inches). \\
\hline 2 & 0.005 & $\begin{array}{l}\text { Significant yield and plastic rotation; no buckling. Ram load peaks } \\
\text { at 148 kips. }\end{array}$ \\
\hline 3 & 0.014 & $\begin{array}{l}\text { Flange buckles before reaching } \pm 3 \text { inch displacement. Distorted } \\
\text { flanges straighten upon reversed loading. Ram load repeats up to } \\
\text { l48 kips in first cycle; subsequent ram loads show strength } \\
\text { degradation. }\end{array}$ \\
\hline 4 & 0.024 & $\begin{array}{l}\text { Flanges and web buckle; distortion remains in constant form with } \\
\text { each cycle; minor movement of flanges. Ram load diminishes to } \\
\text { yield level (105 kips). }\end{array}$ \\
\hline 5 & 0.034 & $\begin{array}{l}\text { Same behavior as 4 inch displacement test. Rotation peaks at } \theta p= \\
\text { 0.039r. Ram load decreases uniformly with each cycle. }\end{array}$ \\
\hline
\end{tabular}


APPENDIX

TASK COMMITTEE A-K REPORTS 



\section{Report of Task Committee A \\ STRONG MOTION DATA AND APPLICATIONS}

Date: $\quad 15$ May 1996

Place: $\quad$ National Institute of Standards and Technology, Gaithersburg, MD, USA

Attendees: U.S. side - Roger Borcherdt (Chairman)

Jon Ake

Ghassan Al-Chaar

David Boore

USGS

William Joyner

U.S. Bureau of Reclamation

USACERL

USGS

USGS

$\begin{array}{cl}\text { Japan side - } & \text { Takahiro Sugano (Acting Chairman) } \\ \text { Keiichi Ohtani } & \text { NHRI } \\ \text { Noriko Kamaya } & \text { JMA }\end{array}$

1. Objective and Scope of Work

To coordinate and promote sharing of strong motion earthquake data among researchers and practicing engineers, and to develop techniques and exchange information for evaluating the destructive effects of earthquake motion.

The scope of work includes:

o instrumentation

- recording, processing, and analyzing strong motion data,

o engineering characterization of ground motion,

- design applications, and

o seismic zonation.

The activities of the Task Committee include:

- regular exchange of data and publications,

o creating procedures for disseminating significant strong motion digital data with regard for the rights and expectations of (a) owner, (b) the users of data and $\odot$ the earthquake engineering community,

- planning and conducting $\mathrm{T} / \mathrm{C}$ workshops and meetings, and

- coordinating relevant research activities.

\section{Accomplishments}

Conducted an international workshop on Site Response to Strong Earthquake Motions, 16-17 January 1996, Yokosuka, Japan; conducted technical site visits relevant to the Workshop in the Hyogo ken-Nanbu area during 18-19 January 1996. The workshop was organized by Dr. Iai, PHRI with support of the Japan Science and Technology Exchange Center acting on behalf of the PHRI. More than 50 world experts discussed the response of soils under large earthquake excitation. Workshop discussions centered on the response of soils as implied by strong-motion recordings of the Northridge and Hyogo ken-Nanbu Earthquakes and recent results implied by laboratory experiments and numerical modeling results. Critical issues related to the non-linear 
behavior of soils were treated in detail. Proceedings of the workshop were prepared for publication by March 1996.

\section{Future Plans}

a. $\quad T / C$ " $A$ " recognizes the importance of understanding near source earthquake ground motions, geological effects, and structural response in support of the "Natural Disaster Reduction Initiative" of the "United States-Japan Common Agenda." Strong motion recordings obtained from past and future earthquakes provide the basic measurements essential for understanding these effects for improved earthquake resistant design and retrofit of structures needed to reduce future earthquake disasters. T/C " $A$ " in recognizing its responsibilities for "Strong-Motion Data and Applications" recommends the immediate establishment of coordinated programs for:

1) Strong-motion Instrumentation Array Design, Operation and Data Interpretation based on recent design and installation of extensive surface and borehole arrays installed by the Science and Technology Agency throughout Japan and the U.S. Geological Survey in the San Francisco Bay region and other areas.

2) Understanding Near Source Effects, especially a) near source attenuation relations for fault-normal and fault-parallel motions and b) procedures to account for source rupture types and radiation effects, including directivity, into engineering design.

3) Understanding Geological Effects; especially a) acquisition of site-condition data and analyses of corresponding strong motion data from Northridge and Hyogo ken-Nanbu earthquakes for characterizing the response of various types of geological site conditions at high levels for input rock motions for purposes of improving ground-motion amplification factors currently used in Building Code Provisions and earthquake resistant design.

4) Understanding structural response, especially coordinated efforts to facilitate interpretation of strong motion measurements in buildings for resolving important structural response problems such as those for modem steel moment frame structures.

b. $\quad T / C$ " $A$ " recognizes that extensive sets of strong-motion instrumentation installed in both countries since the Hyogo ken-Nanbu and Northridge earthquakes provide an important new resource to develop improved understanding of these important effects and responses. In preparation to fully use this important new international resource and existing resources, T/C " $A$ " recommends the development of a www (intemet) page as part of the UJNR panel page to:

- $\quad$ provide a list of participating agencies \& researchers

- $\quad$ provide internet addresses and/or hypertext links to those researchers

- list of www sites where strong motion databases are available

- $\quad$ provide a listing of recent strong motion recordings of interest and

- $\quad$ provide a list of proceedings/publications produced under the auspices of Task Committee $A$ of the UJNR.

c. $\quad T / C$ " $A$ " endorses the recommendation of $T / C$ " $B$ " conceming the importance of soilstructure interaction (SSI) as a field observation. In the U.S., USGS has initiated a project on SSI. Since the Hyogo ken-Nanbu earthquake, BRI has installed instruments 
for SSI observations in the Tolyo metropolitan area. This task committee recommends (1) exchange of information on SSI data and (2) the establishment of a coordinated program.

d. T/C " $A$ " recognizes the need for continued interaction between U.S. and Japanese researchers in the forum provided by regular workshops.

e. $\quad T / C$ " $A$ " will investigate alternative funding venues to focus on important issues such as site-response and near-source phenomena.

f. $\quad T / C$ " $A$ " in recognizing the considerable interest in proceedings of the recent workshop on "Site Response to Strong Earthquake Ground Motions" committee members will expand efforts to communicate availability of proceeding volumes through professional societies in both countries. 


\section{Report of Task Committee B \\ TESTING AND EVALUATION PROCEDURES FOR BUILDING SYSTEMS}

Date: $\quad$ 14 May 1996

Place: National Institute of Standards and Technology, Gaithersburg, MD, USA

Attendees: U.S. Side -- H. S. Lew (Chairman) NIST

Shih-Chi Liu NSF

Mehmet Celebi USGS

Erdal Safak USGS

Harish Chander DOE

Japan Side -- Keichi Ohtani (Chairman). NIED

1. Objective and Scope of Work

To develop rational test procedures and to collect performance data of dynamic response of structures through laboratory testing and prototype structures and field testing of structures insitu.

The scope of this Task Committee includes the following:

o Plans and conducts workshops and joint meetings to identify research topics and develops joint research programs.

o Coordinates research projects carried out by various laboratories in the U.S. and Japan and facilitates publication of research results and implementation of findings in codes and standards.

o Facilitates exchange of research personnel, technical information and available testing facilities.

o Develops uniform testing procedures including test loading history for case of comparison of results of tests carried out by various researchers, and for establishment of data base.

o Develops guidelines for interpretation of test results in consideration for design of structures.

o Develops methodology for evaluation and interpretation of physical test results.

\section{Accomplishments}

a. The fourth phase of the U.S. Precast Seismic Structural Systems Program (PRESSS) has been initiated in 1995 with several universities participating in the program. The fourth phase includes a full scale testing and supporting subassemblage tests and is near completion.

b. The research program on Composite and Hybrid Structures (CHS) in Japan was initiated in 1993. Experimental and analytical work is being carried out by the Building Research Institute and by several universities and construction companies. The Japan Structural Consultant Association is undertaking an application study for implementing research results into practice.

c. The research progxam on CHS in the U.S. was initiated in 1995. Dr. S. C. Goel, 
University of Michigan and Dr. Steve Mahin, University of Califomia-/Berkeley are coordinating analytical and experimental studies being carried out by several universities.

d. The second US-Japan Joint Technical Coordinating Committee (JTCC) meeting on Composite and Hybrid Structures (CHS) was held in June 1995 at Honolulu, Hawaii.

e. The U.S. Technical Coordinating Committee meeting on CHS was held in Los Angeles, California in February 1996. The second-year U.S. research program will be awarded by NSF in June 1996.

f. The JTSC-RFI (Research for Innovation) was held in Ann Arbor, Michigan in February 1996, and JTSC-CFT (concrete filled tube) was held in Chicago, Illinois in April 1996.

\section{Future Plans}

a. The third U.S.-Japan Joint Technical Coordinating Committee meeting on $\mathrm{CHS}$ will be held in November 1996 in Hong Kong.

b. $\quad T / C$ " $B$ " recognizes the importance of soil-structure interaction (SSI) as a field observation. In the U.S., USGS has initiated a project on SSI. Since the Hyogo Ken Nanbu earthquake, BRI has installed instruments for SSI observations in the Tokyo metropolitan area. This task committee recommends that (1) exchange of information on SSI data and (2) the establishment of a coordinated program. The scope of the program will be developed jointly by USGS and BRI before the 29th joint meeting in cooperation with $\mathrm{T} / \mathrm{C}$ " $\mathrm{A}$ " and $\mathrm{T} / \mathrm{C}$ " $\mathrm{H}$ ".

c. In support of the International Decade for Natural Disaster Reduction (IDNDR) Program, techniques will be explored to disseminate the findings of completed Joint Research Projects, such as masonry and precast concrete structures, to countries with high seismic risks.

d. To maximize the usefulness of research data, it is desirable to establish standards for test procedures, documentation and retrieval of test data. A joint workshop on "Load Path and Test Observation Requirements for Quasi-Dynamic and Shake Table Testing" is proposed to be held before the 29th Joint Panel Meeting to discuss this topic. 


\section{Report of Task Committee C DESIGN, EVALUATION, AND IMPROVEMENT OF STRUCTURES}

Date: $\quad 14$ May 1996

Place: National Institute of Standards and Technology, Gaithersburg, MD, USA

Attendees: U.S. side - Ken Chong (Chairman) NSF

S.C. Liu NSF

Larry Hultengren DOS

Ugo Morelli $\quad$ FEMA

Japan side .- Hisahiro Hiraishi (Chairman) BRI

\section{Objective and Scope of Work}

To develop disaster mitigation guidelines and programs that will improve the performance of new structures and the capacity of existing structures in resisting wind and seismic forces. To establish adequate evaluation of performance, each country will coordinate development of condition assessment, screening, and structural analysis and design methodologies. Enhance performance can be obtained by the intelligent renewal, repair and retrofit of existing buildings and other structures. Structures will be analyzed and instrumented, and then evaluated after disasters. Also, effective use of new advanced materials and structural systems, associated with appropriate design methods, will provide excellent structural performance in the life cycle.

The scope of work includes:

o Exchanging information, planning, and hosting workshops on new design technologies, evaluation technologies, and repair and retrofit techniques.

o Studying new materials and methods for repairing and retrofitting existing structures and for new construction.

o Developing a uniform system for screening and analyzing wind and seismic resistance capacity of structures in each country.

- Developing reliable condition assessment systems for new and existing structures.

- Evaluating masonry, precast concrete and composite/hybrid building structures: and providing documentation for post-disaster evaluation of performance.

o Coordinating research projects in the U.S. and Japan to minimize duplication and maximize benefits.

\section{Accomplishments}

a. U.S.-Japan Workshop on smart materials and structures supported by NSF was held at the University of Washington during 4-5 December 1995.

b. An NSF funded International Symposium on Civil Infrastructure Systems Research was held during 25-28 September 1995, Seoul, Korea. Researchers from U.S., Japan, Korea, and other countries participated.

c. The Third U.S.-Japan Technical Coordinating Committee meeting on Composite and Hybrid Structural Systems was held in June 1995 at Hawaii. 


\section{Future Plans}

The following are planned for $T / C$ " $C$ ":

a. The second workshop on "Structural Control and Intelligent Material Systems" is being planned in the U.S. during 1996 (co-sponsored by NSF and $T / C$ " $C$ " and " $G$ "). The workshop will be held at the University of Maryland, following the ASCE Materials Conference, November 1996.

b. Develop a reliable methodology for screening and analyzing wind and seismic resistant capacity, and advanced instrumentation technology and expert systems to provide condition assessment of existing structures.

c. Compile a database of advanced materials/systems that have potential for improving structural performance of new construction, and for use in rehabilitating and strengthening existing buildings.

d. Investigate new design methodologies based on required structural performance using advanced materials and systems.

e. Develop design guidelines for applying advanced structural and materials system to be used for composite and hybrid structures under the joint U.S.-Japan Cooperative Research Program. The fourth U.S.-Japan Technical Coordinating Committee meeting on Composite and Hybrid Structural System will be held November 1996 at Hong Kong.

f. Continue to encourage participation by private industry, consulting engineers, universities, national and local government agencies involved in instrumentation, evaluation, condition assessment, and retrofit and strengthening of existing buildings, for seismic and wind resistance.

g. In collaboration with T/C "G", to develop the next U.S.-Japan Cooperative Research Project on Smart Structural System, a working group will be formed to plan for the technical report and to develop a joint initiative within two years. The first meeting will be held in conjunction with the U.S./Japan Workshop on Smart Structures and Materials in November 1996 in Washington, D.C.

\section{Other Activities}

a. U.S. research sponsored by NSF, CORPS, FHWA, and NIST has developed reports on seismic rehabilitation and retrofit strategies, including innovative techniques for strengthening existing buildings and bridges.

b. An updated report on Civil Infrastructure Systems - Strategic Issues has been published by NSF. Work continues on development of NSF's Civil Infrastructure Systems Research Program, including strong emphasis on evaluation and improvement of structures.

c. NSF is coorporating with Japan Science and Technology Agency (STA/NISTP) on Smart Materials Research proposed by STA.

d. PWRI, BRI, NIEDC, NIST, USGS, NSF, and FHWA held a meeting during March 2829, 1996, at Stanford University to discuss opportunities for cooperation under the U.S.-Japan Common Agenda, "A New Economic Partnership for the 21 st Century".

e. Continue to encourage research in the retrofit and repair areas. 


\section{A PLAN FOR NEXT U.S.-JAPAN COOPERATIVE RESEARCH PROJECT UJNR T/C "C" \& "G"}

\section{TITLE: Development of Smart Structural Systems}

OBJECTIVE: Buildings of low-cost and high-performance can be developed by optimal use of materials in terms of their properties, cost, and availability, and by intelligent design of their components, elements and structural systems which are durable, functionally adaptive, safe under hazardous loading conditions have minimum life-cycle cost. The objective is to develop buildings and other infrastructure systems which are expected to meet the demands for high-performance, low maintenance, long service life, and possess on-line monitoring, detection, diagnosis, and control capabilities. New materials which exhibit exceptional sensoring and actuating capabilities to enable the smart structural elements and systems, shall be studied and developed. Advanced signal processing techniques and control technologies for building and infrastructure system applications are also essential to meet this objective. In this project, new structural systems are developed to have functions as follows:

1. Sensoring which sense and detect the unusual conditions.

2. Processing which diagnose the sensored data and makes judgements on the response to the unusual conditions.

3. Actuating which initiates responding actions to the unusual conditions.

OUTLINE: Development of structural systems which use high-performance and smart materials, and intelligent engineering for design and construction. These systems might employ resistance and self-control systems under unusually large external load conditions.

PRESENT

SITUATION: It is expected that new innovative structural systems use new materials such as shape memory alloys, electrorheology (ER) fluid, magnetorheological (MR) fluid, and optical fibers, etc., will be developed, in addition to the low yield point steel, viscous damper and self-repairable concrete.

\section{EXPECTED}

RESULTS: Building systems that keep the following performance will be developed:

1. Maintain the functions under unusually large external load effects.

2. Excellent habitability and durability.

3. Architecturally attractive new structural system.

\section{RECOMMENDED}

ACTIONS: To immediately commission a JTCC planning study for a 12-month period.

This study shall result in a technical report which lays out a detailed plan for a 5 -year joint U.S.-Japan research program in smart structural systems for implementation beginning in 1998. 


\section{Report of Task Committee D EARTHQUAKE ENGINEERING FOR DAMS}

Date:

14 May 1996

Place: $\quad$ National Institute of Standards and Technology, Gaithersburg, MD, USA

Attendees:

\author{
U.S. side -- William Roper (Chairman) \\ Lucian Guthrie \\ Francis McLean \\ Richard S. Olsen \\ A.G. Franklin
}

Japan side - Michio Okahara (Chairman)

Shigetoshi Kobayashi

\author{
USACE, HQ \\ USACE, HQ \\ USBUREC \\ USACE, WES \\ USACE, WES
}

PWRI

PWRC

\section{Objective and Scope of Work}

To develop technical insights into better understanding of the response of dams to seismic effects. The $\mathrm{T} / \mathrm{C}$ will plan, promote, and develop research initiatives to assist in assuring seismic safety and economical protective countermeasure against earthquake loading for these structures. Its scope of work includes:

o Methods of analysis for seismic design of dams.

Comparison of design methods and criteria between U.S. and Japan

Development of "Design Earthquake Ground Motions" for analysis and evaluation of dams.

Assessment of investigation and dynamic analysis methods as tools (modeling, calculation codes, etc.).

- Dynamic characteristics of dam construction materials.

Strength and deformation characteristics during earthquakes (concrete, soil and rock).

- Analysis of observed behavior of dams during an earthquake.

Investigation of the mechanisms of damage from earthquake loading.

Application of the analysis of the observed behavior during earthquakes to the earthquake -resistant design.

\section{Accomplishments}

a. Preliminary plans have been completed for the November 1996 Workshop.

b. Results/investigation and technical information about dam earthquake engineering were exchanged as reports and publications.

\section{Future Plans}

a. Exchange results of research/investigation and technical information about dam earthquake engineering, and feasibility of joint research and investigation is in continuous consideration.

b. Exchange visits to the institutes concerned, of scientists and engineers between U.S. and 
Japan, is to be extended for the effective communications.

c. According to progress of the activities (1) and (2), $T / C(D)$ is planning to conduct a Workshop on State-of-the-Art Review of U.S.-Japan Research on Earthquake Engineering for Dams, at the Waterways Experiment Station in Vicksburg, Mississippi. The proposed date for the workshop is 19-22 November 1996. 


\section{Report of Task Committee E DESIGN FOR WIND AND WIND HAZARD MITIGATION}

Date: $\quad 15$ May 1996

Place: $\quad$ National Institute of Standards and Technology, Gaithersburg, MD, USA

\begin{tabular}{|c|c|c|c|c|}
\hline Attendees: & U.S. side -- & $\begin{array}{l}\text { Co-Chair } \\
\text { Co-Chair }\end{array}$ & $\begin{array}{l}\text { Dr. J. E. Sabadell } \\
\text { Dr. A. W. Taylor } \\
\text { Dr. J. Golden } \\
\text { Mr. H. Bosch } \\
\text { Dr. R. Marshall } \\
\text { Dr. Joseph Minor }\end{array}$ & $\begin{array}{c}\text { NSF } \\
\text { NIST } \\
\text { NOAA } \\
\text { FHWA } \\
\text { NIST } \\
\text { University of Missouri, Rolla }\end{array}$ \\
\hline & Japan side & $\begin{array}{l}\text { Co-Chair } \\
\text { Co-Chair }\end{array}$ & $\begin{array}{l}\text { Dr. H. Okada } \\
\text { Dr. H. Sato }\end{array}$ & $\begin{array}{l}\text { BRI } \\
\text { PWRI }\end{array}$ \\
\hline
\end{tabular}

\section{Objective and Scope of Work}

To exchange technical information and to jointly plan, promote and foster research and its dissemination to improve understanding of wind and its effects on structures, establish more rational wind resistant design methods for structures, and to contribute to wind hazard mitigation.

The scope of work includes:

- Characteristics of strong wind, especially boundary layer extreme winds

o Wind effects (wind loading on and wind-induced response of structures)

- Experimental and analytical methods to predict wind and its effects

- Damage and risk assessment

o Wind hazards and wind hazard mitigation

\section{Accomplishments}

Developed T/C Goals, Objectives, and Mission Statement and identified and received approval from public and private wind related experts to serve as $\mathrm{T} / \mathrm{C}$ members. The list of U.S.-side and Japan-side members appears below:

$\begin{array}{lll}\text { U.S. side -- Co-Chair } & \text { Dr. J. E. Sabadell } & \text { NSF } \\ \text { Co-Chair } & \text { Dr. A. Taylor } & \text { NIST } \\ & \text { Dr. B. Bienkiewicz } & \text { Colorado State University } \\ & \text { Mr. H. Bosch } & \text { FHWA } \\ & \text { Dr. G. Chiu } & \text { IIPLR } \\ & \text { Dr. W. Freeborn } & \text { HUD } \\ & \text { Dr. J. Golden } & \text { NOAA } \\ & \text { Dr. A. Kareem } & \text { University of Notre Dame } \\ & \text { Dr. R. Marshall } & \text { NIST } \\ & \text { Dr. K. Mehta } & \text { Texas Tech University } \\ & \text { Dr. D. Reed } & \text { University of Washington }\end{array}$




$\begin{array}{lll} & \text { Dr. T. Reinhold } & \text { Clemson University } \\ & \text { Dr. C. Smith } & \text { MMS } \\ & \text { Dr. P. Tertell } & \text { FEMA } \\ \text { Japan side -- Co-Chair } & \text { Dr. H. Okada } & \text { BRI } \\ \text { Co-Chair } & \begin{array}{l}\text { Dr. H. Sato } \\ \text { Dr. H. Akiyama }\end{array} & \text { PWRI } \\ & \text { Honshu-Shikoku Bridge } \\ & \text { Dr. K. Kimura } & \text { Authority } \\ & \text { Dr. N. Kinoshita } & \text { MRI } \\ \text { Mr. Y. Matsuno } & \text { PWRI } \\ \text { Dr. G. Naito } & \text { National Defense Academy } \\ \text { Dr. T. Tamura } & \text { Tokyo Institute of } \\ & \text { Technology } \\ & \text { Dr. Y. Tamura } & \text { Tokyo Institute of } \\ & \text { Polytechnics } \\ & \text { Dr. Y. Uematsu } & \text { Tohoku University } \\ \text { Dr. H. Yamada } & \text { Yokohama National } \\ & \text { University } \\ \text { Dr. S. Yoshizumi } & \text { Meteorological Research } \\ & \text { Institute }\end{array}$

\section{Future Plans}

a. Exchange technical information on the following subjects:

1) Topographical effects on wind, and the use of geographic information systems (GIS) to study these effects

2) Control of wind-induced response of structures

3) Computational fluid dynamics vs. wind tunnel tests

4) Prediction of wind-induced response of full-scale structures

5) Investigation of wind hazards, including damage assessment methodologies

b. Plan and hold a joint workshop. The proposed time of the workshop is in October or November of 1997. The proposed theme of the workshop is "The Prediction and Control of Wind-induced Response." The proposed location of the workshop is in the United States. Further discussions on the time, theme and location of the workshop will take place over the next several months. 


\section{Report of Task Committee F \\ DISASTER PREVENTION METHODS FOR LIFELINE SYSTEMS}

Date: $\quad 14$ May 1996

Place: National Institute of Standards and Technology, Gaithersburg, Maryland

Attendees: $\quad$ U.S. side - Riley M. Chung (Chairman) NIST

Ron Andrus NIST

James Cooper FHWA

W. Phillip Yen FHWA

Japan side - Hisanori Ohtsuka (Act. Chair)PWRI

Noriko Kamaya Japan Meteorological Agency

Kazuhiko Kawashima Tokyo Institute of Technology

Kenji Kosa

Keiichi Tamura

Hanshin Expressway Public Corp.

Yuzo Yamaguchi

PWRI

NTT

\section{Objectives and Scope of Work}

To improve (a) the performance of lifeline systems during earthquakes and (b) engineering and other seismic countermeasures including the capability in damage estimation techniques and inspection procedures.

o Planning and conducting workshops on lifeline systems.

o $\quad$ Facilitating exchange of technical information.

o Promoting development of design guidelines and standards for lifeline systems.

\section{Accomplishments}

a. Conducted the Sixth Joint Workshop on Disaster Prevention for Lifeline Systems in

Osaka, Japan, July 18-19, 1995. The workshop addressed research and development topics in the lifeline area and gave special emphasis to lessons learned from the 1995 Hyogo-ken Nanbu (Kobe) earthquake and the 1994 Northridge earthquake. The proceedings has been printed by the Public Works Research Institute and distributed to all the workshop participants and others in the lifeline earthquake engineering community.

b. Members of this T/C have been actively involved in the planning of two major efforts between the two countries in earthquake disaster reduction. The first one is led by the STA of Japan and the OSTP of U.S. to develop a list of scientific and engineering projects for future collaboration. The second is the planning for two earthquake policy symposia, led by the State Department (through FEMA) and the Japanese Foreign Ministry. In both cases, this UJNR Panel on Wind and Seismic Effects is recognized for its excellent work in the past and recommended as the vehicle for further enhancement of the two countries' joint activities. 


\section{Future Plans}

a. Encourage collaborative research and development in the following areas:

- performance prediction and post-measurement through damage assessment of lifeline systems.

- $\quad$ systems approach to lifeline performance

- $\quad$ soil-structure interaction

- geographic information systems (GIS)

- cost-effective ground improvement techniques and other countermeasures for lifeline facilities

b. Encourage and strengthen current efforts in both countries to establish seismic design guidelines and standards for lifeline systems. Existing UJNR channels should be fully used to facilitate the exchange of relevant information concerning guidelines and standards development. Possible collaboration of joint development of guidelines and standards for lifeline systems should be pursued.

c. Hold the Seventh Joint Workshop on Disaster Prevention for Lifeline Systems in June/July 1997 in Seattle, Washington (Seattle is a sister city of Kobe). The workshop will focus on the presentations and discussions of the results of the studies completed and to be completed after the Northridge and Kobe earthquakes. 


\section{Report of Task Committee G \\ STRUCTURAL CONTROL AND INTELLIGENT MATERIAL SYSTEMS}

Date: $\quad 15$ May 1996

Place: National Institute of Standards and Technology, Gaithersburg, MD, USA

Attendees: U.S. side - Shih-Chi Liu (Chairman) NSF

Riley M. Chung NIST

H.S. Lew NIST

Ian Buckle NCEER

James Cooper FHWA

Glen Smith FHWA

Hamid Ghasemi $\quad$ FHWA

W. Phillip Yen FHWA

Japan side - Hisanori Otsuka (Chairman) PWRI

Kazuhiko Kawashima Tokyo Institute of Technology

Hisashi Okada BRI

Kenji Kosa Hanshin Expressway Public Corp.

Hisahiro Hiraishi BRI

Hiroshi Sato PWRI

\section{Objective and Scope of Work}

o develop research plans in control of equipment and structures and in high performance structural and material systems;

o implement control techniques for motion reduction or modification;

- implement use of advanced materials in actual design and construction of buildings and other infrastructure systems under seismic or wind environments;

- promote U.S.-Japan cooperation in structural control and intelligent material systems research;

o bring together governmental, academic, and industrial participants in joint pursuit of these efforts; and

- contribute to IDNDR by organizing joint research and other technical activities in structural control and intelligent material systems research based on international cooperation.

$T / C$ " $G$ " works closely with other organizations to provide the leadership in this emerging research by facilitating the exchange of technical data and information through UINR mechanisms. The scope of work includes:

- providing technical assistance, consultation and coordination of UJNR affiliated research organizations in the initiation, development, and execute their programs in research areas.

- promoting Joint government-university-industry collaborative efforts to facilitate technology transfer and practical implementation.

- sponsoring and conducting interdisciplinary workshops and meetings to identify key 
area of research and opportunities for cooperation, and to exchange new knowledge and experience in practice.

- developing promotional and demonstrative activities to stimulate public awareness and interest in this field of research.

o providing information useful for the establishment of performance standards, design and retrofit/rehabilitation of existing structures.

o promoting research in intelligent material systems, sensors, actuators, optimal control system design, and encourage laboratory and field experiments of prototype and fullscale structures.

\section{Accomplishments}

a. At BRI, performed research on structural control and intelligent material systems using self-diagnosis and self-repairable materials; work initiated April 1994.

b. At PWRI, initiated a research program on intelligent seismic structures; April 1995. This research will develop new technology using self-diagnosis materials and self-repairable materials.

c. Joint research programs for active control of bridges are being carried out through T/C "G" and "J" by EPRI, NSF, FHWA, NIST, NCEER, and UC Irvine.

d. NSF worked with STA( Japan Science and Technology Agency) on "Smart Materials" research program planning by STA.

e. A new NSF research initiative on sensors and sensoring systems for power systems and other dispersed civil infrastructure systems was issued for requesting final proposals by April 1995. EPRI and NSF are co-funding this initiative.

f. The proceedings of the 3rd U.S.-Japan Workshop on Protection Systems for Bridges were published and distributed.

\section{Future Plans}

a. Under NSF sponsorship, an U.S.-Japan workshop on "Structural Control and Intelligent Materials systems" is planned to be conducted in November 1996 in cooperation with T/C "C." The University of Maryland at College Park will host the workshop.

b. Joint research projects on innovative technologies for active and hybrid control of structures, such as bridges and buildings, will be developed by PWRI, BRI, NCEER, CUREE, and other institutions.

c. In cooperation with T/C "J" the 4th U.S.-Japan Workshop on Earthquake Protective Systems for Bridges is being scheduled for December 1996 in Japan. This workshop will be combined with the 3rd U.S.-Japan Workshop on Seismic Retrofit of Bridges, which will be held in Japan at the same time, also with T/C "J". Proposed topics for the protective systems workshop include:

- innovative protection systems and high performance material

- design methods for seismic isolated/menshin bridges

- full-scale verification of component and system performance

- comparative design studies

Proposed topics for the retrofit workshop include:

- performance criteria and risk assessment

- improved evaluation methods 
- innovative repair and retrofit methods

d. NIST will conduct a state-of-the-art review of active control systems and evaluate those available technologies for use by designers.

e. In collaboration with T/C "C", the next U.S.-Japan Cooperative Research Programs on Smart Structural Systems (CSSS) will be developed. A joint technical coordination committee (JTCC) on SSS will be established to develop a technical planning report for the joint research and to develop a joint initiative within two years. The first meeting will be held in conjunction with the U.S.-Japan Workshop on Smart Structures and Materials in November 1996 in D.C.

\section{Other Activities}

a. A joint ASME, JSME, and PVP conference on seismic base isolation was held at Honolulu, Hawaii, July 1995.

b. Under NSF sponsorship, an U.S.-Japan Workshop on Smart Materials and Structures was conducted at the University of Washington, 4-5 December 1995.

c. An U.S.-Japan Workshop on Structural Control was held in Kyoto, March 1996. The objective of this workshop, which was jointly organized by the U.S. Panel on Structural Control Research and the Japan Panel on Seismic Response Control, is to develop cooperative research in various structural control subjects and to establish a broad implementing mechanism involving academic, industrial, and governmental researchers from both sides.

d. The second International Workshop on Structural Control will be held in December 1996 in Hong Kong. The workshop will be hosted by the Hong Kong University of Science and Technology. 


\section{Report of Task Committee $\mathrm{H}$ \\ SOIL BEHAVIOR AND STABILITY DURING EARTHQUAKES}

Date: $\quad 15$ May 1996

Place: $\quad$ National Institute of Standards and Technology, Gaithersburg, MD, USA

Attendees: U.S. side - A.G. Franklin (Chairman) WES

$\begin{array}{ll}\text { F.G. McLean } & \text { U.S. Bureau of Reclamation } \\ \text { Ronald Andrus } & \text { NIST } \\ \text { R.S. Olsen } & \text { WES } \\ \text { Takeo Moriwaki } & \text { NIST (guest researcher from } \\ & \text { Hiroshima University) }\end{array}$

Japan side - Keiichi Tamura (Chairman) PWRI

Yuzo Yamaguchi NTT

1. Objective and Scope of Work

Government agencies responsible for public works must assure seismic safety and provide economical protection against earthquake hazards.

The objective of the Task Committee $(\mathrm{H})$ is to assist in meeting these needs by enhancing the availability of technology for predicting the dynamic behavior of soils, analyzing dynamic soilstructure interaction, and modifying the earthquake behavior of foundations and earth structures to assure their safe performance during earthquakes.

In accordance with the objective, the scope of work includes:

o Exchange information on technological developments and on state-of-the-art and practice related to soil behavior and stability during earthquakes.

- Exchange information and technical data relating to field performance, research, and methods of practice.

o Plan and conduct programs of cooperative research and/or workshops in coordination with the proposed or ongoing programs.

o Make othér needed efforts including exchange of researchers between U.S. and Japanese research institutions, and publication of research results and recommended practice.

\section{Accomplishments}

a. The Japanese Society of Soil Mechanics and Foundation Engineering (JSSMFE) has published in Japanese a book on Liquefaction Remediation, and has produced a draft English translation. Editing of the draft has been completed with the assistance of Panel members and it is being prepared for publication by the JSSMFE.

b. The Port and Harbour Research Institute (PHRI) has published in Japanese Handbook 
on Remedial Measures for Reclaimed Land Liquefaction, and a draft English translation has been produced by the Corps of Engineers. Review and editing of the draft has been completed by both the Japanese and U.S. sides, and it is being prepared for publication by the PHRI by the end of 1996.

c. Dr. Takeo Moriwaki and Dr. Yasushi Sasaki, of Hiroshima University, visited the Watenways Experiment Station in December, 1995, and March 1996, respectively, to exchange technical information on earthquake engineering and to view the WES research facilities, including the newly installed U.S. Army centrifuge. Dr. Sasaki also visited the sites of Sardis and Enid Dams, in Mississippi.

d. The National Research Institute for Earth Science and Disaster Prevention (NIED), the Building Research Institute (BRI), and Wayne State University (WSU), continued work in their cooperative research program "Physical and Numerical Simulation of Structural Damages Due to Liquefaction and Development of Countermeasure Techniques," planned for 1994-1998.

e. The PHRI, the Sandia National Laboratory, and the Lovelace Institutes (Albuquerque, NM) have initiated joint research on application of the Nuclear Magnetic Resonance Imaging (NMRI) method to the study of soil behavior and stability during earthquakes.

f. Dr. Takeo Moriwaki, of Hiroshima University, is a guest researcher at NIST from March 1996 to September 1996.

\section{Future Plans}

a. The JSSMFE will publish the English translation of its book on Liquefaction remediation.

b. The PHRI will publish the English translation of its Handbook on Remedial Measure for Reclaimed Land Soil Liquefaction.

c. $\quad T / C(H)$ tentatively plans to hold a workshop on the Use of Centrifuge Experiments for Research on Soil Behavior and Stability During Earthquakes in the U.S. in 1998. 


\section{Report of Task Committee I STORM SURGE AND TSUNAMIS}

Date: $\quad 15$ May 1996

Place: $\quad$ National Institute of Standards and Technology, Gaithersburg, MD, USA

Attendees: U.S. side - Michael Blackford (Chairman) NOAA Wilson Shaffer NOAA Jye Chen NOAA

Japan side - Michio Okahara (Chairman) PWRI

Shigetoshi Kobayashi PWRC

\section{Objective and Scope of Work}

The objective of this Task Committee is to mitigate damage from storm surge and tsunami through cooperative research and shared technology and information. Storm surges are considered tropical cyclones (hurricanes, typhoons). The primary cause of a tsunami is considered to be sudden sea floor deformation due to earthquakes, volcanic activity or landslides. Both hazards may cause disasters along coastal regions.

The scope of work of this $\mathrm{T} / \mathrm{C}$ is as follows:

o Exchange results of research on storm surge and tsunami occurrence, generation, propagation, and coastal effects. This includes observations on historical, current, and theoretical tsunamis. Of particular interest is the effort by U.S. and JAPAN to acquire deep ocean tsunami measurements.

o Exchange results and status of storm surge and tsunami mitigation activities including analysis of the problem, planning, warning, and engineering approaches.

o Exchange information on development of technologies such as computer programs to predict travel times, land-fall locations, inundation and run-up heights, and wave characteristics, improved instrumentation, and use of satellite communication for detection and warning.

- Facilitate dissemination through exchanges of literature, technical reports at joint meetings, special workshops, joint projects, and direct interaction among participants.

\section{Accomplishments}

a. Task Committee (I) conducted its 4th Workshop on Storm Surge and Tsunamis, Two Great Tsunamis: U.S.-Japan Anniversary Symposium, during 1-3 April 1996, in Hawaii. The Workshop was a memorial of the centennial anniversary of the June 15, 1896 great Sanriku Earthquake and tsunami in Japan and the 50th anniversary of the April 1, 1946, Aleutian earthquake and tsunami. The Proceedings of this Workshop is being prepared by the Tsunami Society for publication in their journal. The proceedings will be distributed to Task Committee Members and other interested parties when they become available 


\section{Future Plans}

The task committee will discuss, through mutual communication, plans for a 5 th Storm Surge and Tsunami Workshop in the near future. At the Task Committee meeting during the 28th Joint Meeting of U.S.-Japan Panel on Wind and Seismic Effects, a tentative date and place, Honolulu, Hawaii in 1998, was suggested by the U.S. side.

\section{Others}

a. The storm surge research community is small and incorporated into related societies and international organizations which define and stimulate work in the field. Task Committee "I" encourage these efforts.

b. Since tsunamis have been less severe in the U.S. than in Japan, the U.S. has fewer researchers in this specialty. The Task Committee, through its meetings and workshops, encourages exchanges of ideas and joint study by U.S. and Japanese investigators of tsunami events throughout the world. 


\section{Report of Task Committee on J WIND AND EARTHQUAKE ENGINEERING FOR TRANSPORTATION SYSTEMS}

Date: $\quad 15$ May 1996

Place: $\quad$ National Institute of Standards and Technology, Gaithersburg, MD, USA

Attendees: U.S. side - Mr. James Cooper (Chairman) FHWA

Dr. Philip Yen FHWA

Japan side - Dr. Hiroshi Sato (Acting Chairman) PWRI

\section{Objectives and Scope of Work}

To: (1) plan, promote, and foster research on the behavior of highway bridges when subjected to wind and seismic forces and (2) disseminate research results and provide specifications and guidelines based on the Task Committee's findings. Surface transportation systems play a vital role in the movement of goods and people. Highway bridges are especially influenced by the forces of wind and earthquakes because of their open exposure to those forces.

The scope of work includes:

o $\quad$ Focus research on highway bridges without limitation on their size and function.

o Investigate existing and new bridge designs and the behavior of whole bridge systems and/or single components of a bridge.

\section{Accomplishments}

a. $\quad$ Conducted the 11th U.S.-Japan Bridge Engineering workshop during 30-31 May 1995, Tsukuba, Japan.

b. Exchanged researchers and practitioners in Japan and the U.S. Dr. Hamid Ghasemi of FHWA was hosted by PWRI for one month investigating seismic isolation. Mr. Sentaro Takagi, Tokyo Metropolitan Government, visited FHWA and attended the FHWA Bridge Inspection course. Mr. Tomofumi Nozaki of PWRI visited Turner Fairbank Highway Research Center.

\section{Future Plans}

a. $\quad$ Conduct the 12th U.S.-Japan Bridge Engineering Workshop, October 26 through November 3, 1996, USA.

b. $\quad$ Conduct the 3rd U.S.-Japan Workshop on Seismic Retrofit of Bridges in December 1996, in Japan. The workshop will focus on practical repair methods of damaged bridges and seismic retrofit measures.

c. In cooperation with Task Committee (G), the 4th U.S.-Japan workshop on Earthquake Protective Systems for Bridges is being scheduled in December 1996, in Japan. Topics are expected to include (1) innovative protective systems; (2) design methods for seismic isolated/menshin bridges; (3) full-scale verification of component and system performance; (4) comparative design studies, and (5) smart/high performance structural materials and systems.

d. Continue to investigate and exchange technical information on improved seismic retrofit 
and strengthening procedures for highway bridges based on experimental, analytical, and field studies. This exchange should include information on maintenance of existing bridges.

e. Continue experimental research on the seismic performance of bridge piers and columns, and encourage research on seismic isolation and hybrid control of bridges in cooperation with Task Committee (G).

f. Encourage a research study on seismic, aeroelastic, and aerodynamic response of cablesupported bridges with emphasis on behavior of composite materials, cable inspection, vibration control, and corrosion protection.

g. Continue the coordinated research study to compare the seismic design criteria for bridges in Japan and the U.S. and discuss the method and analysis procedures for bridge column design. Continue information exchange on the application of the limit state design method.

h. Encourage a coordinated research study on seismic response and control, system identification techniques, nondestructive evaluation of bridge structures, use and performance of structural materials including new materials, and performance of jointless bridges. 


\section{Report of Task Committee $\mathrm{K}$ WIND AND EARTHQUAKE ENGINEERING FOR OFFSHORE AND COASTAL FACILITIES}

Data: $\quad 14$ May 1996

Place: National Institute of Standards and Technology, Gaithersburg, MD, USA

Attendees: $\quad$ U.S. side -- Dr. Charles Smith (Chairman) MMS

Mr. Michael Blackford NOAA

Dr. Wilson Shaffer NOAA

Japan side --Dr. Sugano (Acting Chairman) PHRI

\section{Objective and Scope of Work}

To develop technical insights necessary to mitigate damage to offshore and coastal facilities due to extreme wind and seismic effects. The Task Committee will plan, promote, and develop research initiatives to meet this objective, and will disseminate the results of their research for incorporation into future specification or design guidelines. Criteria for the design of offshore and coastal facilities may differ greatly from their on shore counterparts. These differences can arise due to their unique design or mass distribution, to the fluid/structure or wind/structure interaction, to the placement of foundation elements in or on soft, fully saturated soils that can be subject to large hydrodynamic pressures, and to the lack of specific environmental data or the engineering experiences developed for most onshore sites.

The scope of work includes:

o Sponsoring and conducting workshops and meetings to identify key area of research, opportunities for cooperation, and the exchange of knowledge.

- Predicting strong ground motions for offshore and coastal sites including assessing the effects of basin geometry, linear, and nonlinear local geological effects using actual seafloor response measurements.

- Determining the dynamic response and the interaction of structure/foundation/soil systems to seabed motions and/or extreme wind forces.

- Assessing the dynamic response and behavior of various operational facilities mounted on offshore and coastal structures.

o Developing assessment methodologies for seismicity and other characteristics of potential seismic sources (e.g., faults) for offshore and coastal sites about how these conditions relate to structural design criteria.

o Promoting the implementation of new research results into current design and construction processes.

o Developing research efforts to include laboratory and field programs to obtain data on the response of offshore and coastal facilities to extreme wind and seismic forces.

- Creating performance standards, design specifications, guidelines, and code recommendations for application to new construction and remedial action for existing 
facilities.

2. Accomplishments

a. Conducted two workshops on Wind and Earthquake engineering for offshore and coastal facilities.

b. Published and distributed to Task Committee members the proceedings for the second workshop.

\section{Future Plans}

a. All workshop proceedings will be published and made available to the U.S. side and Japan side T/C members; copies will be provided to both sides Secretaries-General.

b. Develop workshop agenda of the third U.S.-Japan Workshop on Wind and Earthquake Engineering for Offshore and Coastal Facilities in Japan in July1997.

c. Coordinate, where possible, ongoing research on wind and earthquake engineering for offshore and coastal facilities of interest to the members of the Task Committee. 



\section{Periodical}

Journal of Research of the National Institute of Standards and Technology-Reports NIST research and development in those disciplines of the physical and engineering sciences in which the Institute is active. These include physics, chemistry, engineering, mathematics, and computer sciences. Papers cover a broad range of subjects, with major emphasis on measurement methodology and the basic technology underlying standardization. Also included from time to time are survey articles on topics closely related to the Institute's technical and scientific programs. Issued six times a year.

\section{Nonperiodicals}

Monographs-Major contributions to the technical literature on various subjects related to the Institute's scientific and technical activities.

Handbooks-Recommended codes of engineering and industrial practice (including safety codes) developed in cooperation with interested industries, professional organizations, and regulatory bodies.

Special Publications-Include proceedings of conferences sponsored by NIST, NIST annual reports, and other special publications appropriate to this grouping such as wall charts, pocket cards, and bibliographies.

National Standard Reference Data Series-Provides quantitative data on the physical and chemical properties of materials, compiled from the world's literature and critically evaluated. Developed under a worldwide program coordinated by NIST under the authority of the National Standard Data Act (Public Law 90-396). NOTE: The Journal of Physical and Chemical Reference Data (JPCRD) is published bimonthly for NIST by the American Chemical Society (ACS) and the American Institute of Physics (AIP). Subscriptions, reprints, and supplements are available from ACS, 1155 Sixteenth St., NW, Washington, DC 20056.

Building Science Series-Disseminates technical information developed at the Institute on building materials, components, systems, and whole structures. The series presents research results, test methods, and performance criteria related to the structural and environmental functions and the durability and safety characteristics of building elements and systems.

Technical Notes-Studies or reports which are complete in themselves but restrictive in their treatment of a subject. Analogous to monographs but not so comprehensive in scope or definitive in treatment of the subject area. Often serve as a vehicle for final reports of work performed at NIST under the sponsorship of other government agencies.

Voluntary Product Standards-Developed under procedures published by the Department of Commerce in Part 10, Title 15, of the Code of Federal Regulations. The standards establish nationally recognized requirements for products, and provide all concerned interests with a basis for common understanding of the characteristics of the products. NIST administers this program in support of the efforts of private-sector standardizing organizations.

Order the following NIST publications-FIPS and NISTIRs-from the National Technical Information Service, Springfield, VA 22161.

Federal Information Processing Standards Publications (FIPS PUB)-Publications in this series collectively constitute the Federal Information Processing Standards Register. The Register serves as the official source of information in the Federal Government regarding standards issued by NIST pursuant to the Federal Property and Administrative Services Act of 1949 as amended, Public Law 89-306 (79 Stat. 1127), and as implemented by Executive Order 11717 (38 FR 12315, dated May 11, 1973) and Part 6 of Title 15 CFR (Code of Federal Regulations).

NIST Interagency Reports (NISTIR)-A special series of interim or final reports on work performed by NIST for outside sponsors (both government and nongovernment). In general, initial distribution is handled by the sponsor; public distribution is by the National Technical Information Service, Springfield, VA 22161, in paper copy or microfiche form. 


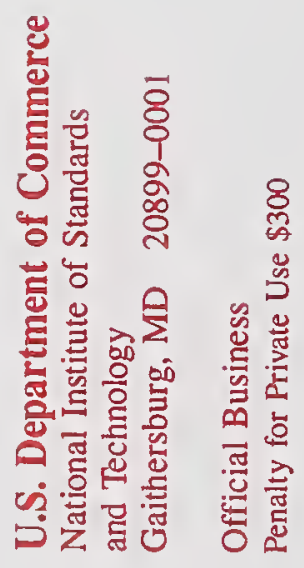

